Commission of the European Communities

\title{
DECOMMISSIONING
}

Edited by

K. PFLUGRAD, R. BISCI, B. HUBER AND E. SKUPINSKI

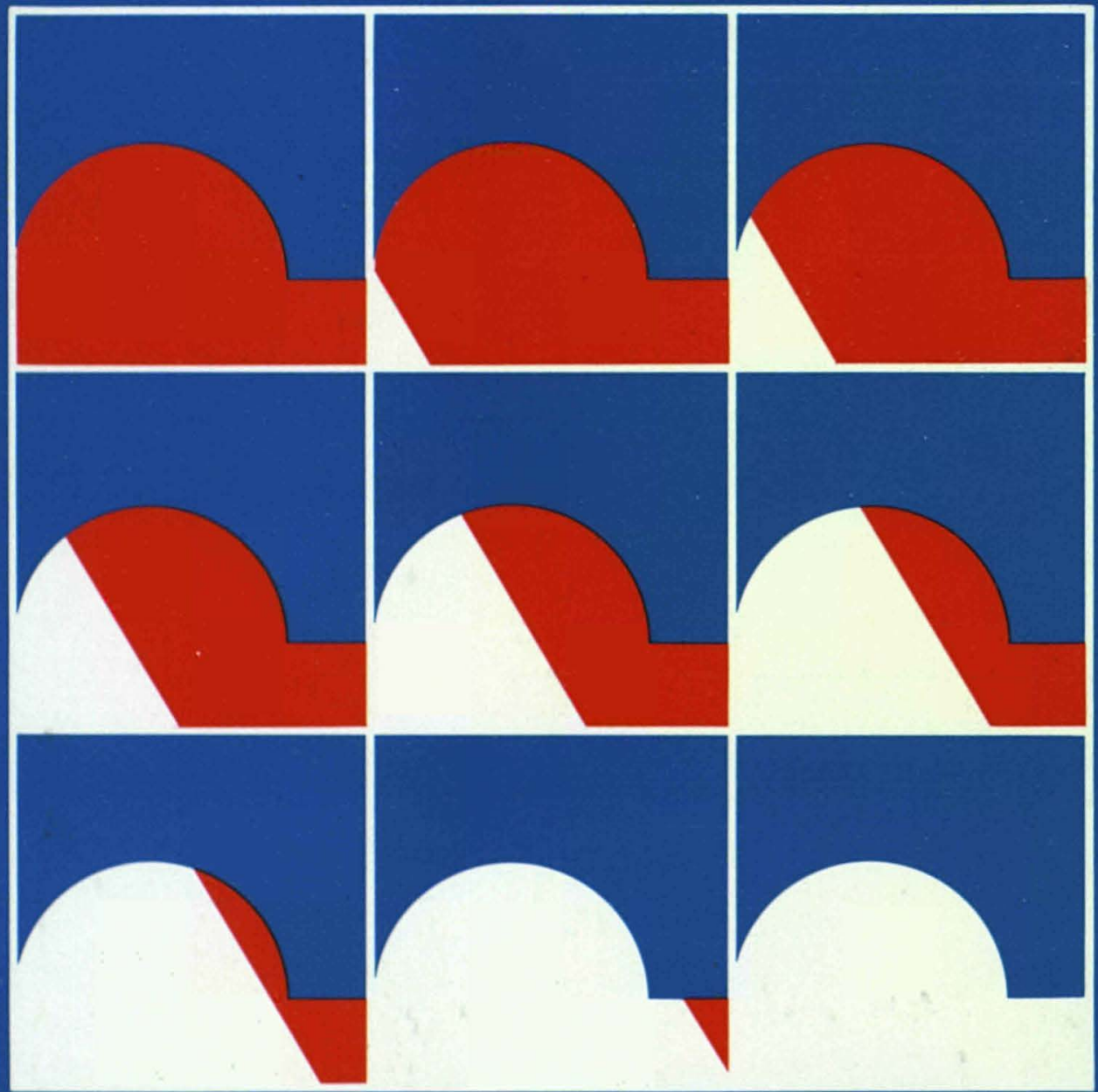

ELSEVIER APPLIED SCIENCE 



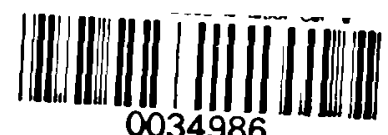



DECOMMISSIONING OF NUCLEAR INSTALLATIONS 
Proceedings of an international conference held in Brussels, Belgium, 24-27 October 1989, organised by the Commission of the European Communities, Directorate-General Science, Research and Development, Decommissioning Programme, Brussels

and F. ReY, Conference Services, Brussels

Decommissioning Programme Staff:
B. Huber (Head)
Secretariat: J. LEY
R. BISCI
J. FINLAYSON
K. Pflugrad
E. SKUPINSKI

Publication arrangements: L. EISEN (DG XIII/C, Luxembourg)

Scientific Secretary: K. Pflugrad (DG XII/D/2, Brussels)

The present Proceedings contain the full papers presented at the Conference, taking into account amendments made by the authors during or after the Conference, the discussions of the fourteen sessions and the final panel. 


\section{DECOMMISSIONING OF NUCLEAR INSTALLATIONS}

Edited by

K. PFLUGRAD

R. BISCI

B. HUBER

\section{E. SKUPINSKI}

Commission of the European Communities, Directorate-General Science, Research and Development, Brussels, Belgium

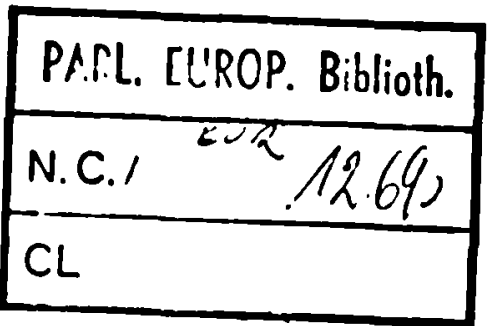

ELSEVIER APPLIED SCIE TCETRE DE DOCUMENTATION LONDON and NEW YORK

N.C.OM 94613
C.L.




\author{
ELSEVIER SCIENCE PUBLISHERS LTD \\ Crown House, Linton Road, Barking, Essex IG11 8JU, England \\ Sole Distributor in the USA and Canada \\ ELSEVIER SCIENCE PUBLISHING CO., INC. \\ 655 Avenue of the Americas, New York, NY 10010, USA \\ WITH 169 TABLES AND 366 ILLUSTRATIONS \\ (C) 1990 ECSC, EEC, EAEC, BRUSSELS AND LUXEMBOURG \\ British Library Cataloguing in Publication Data \\ Decommissioning of nuclear installations. \\ 1. Nuclear power stations. Decommissioning \& determination \\ I. Pflugrad, $\mathbf{K}$. \\ 363.179 \\ ISBN 1-85166-523-4
}

Library of Congress CIP data applied for

Publication arrangements by Commission of the European Communities, Directorate-General Telecommunications, Information Industries and Innovation, Scientific and Technical Communication Unit, Luxembourg

\title{
EUR 12690
}

\section{LEGAL NOTICE}

Neither the Commission of the European Communities nor any person acting on behalf of the Commission is responsible for the use which might be made of the following information.

No responsibility is assumed by the Publisher for any injury and/or damage to persons or property as a matter of products liability, negligence or otherwise, or from any use or operation of any methods, products, instructions or ideas contained in the material herein.

\section{Special regulations for readers in the USA}

This publication has been registered with the Copyright Clearance Center Inc. (CCC), Salem, Massachusetts. Information can be obtained from the $\mathrm{CCC}$ about conditions under which photocopies of parts of this publication may be made in the USA. All other copyright questions, including photocopying outside the USA, should be referred to the publisher.

All rights reserved. No part of this publication may be reproduced, stored in a retrieval system, or transmitted in any form or by any means, electronic, mechanical, photocopying, recording, or otherwise, without the prior written permission of the publisher. 


\section{FOREWORD}

The European Community (EC) 18 conducting research on the decomisBloning of nuclear Installations with the prime objective of developing effective technlques and procedures to ensure the protection of man and his environment against the potential hazards of nuclear 1nstallations that have been finally shut down. The results of the 1979-83 five-year programe of research on the decoumlssioning of nuclear power plants were presented at conference held on 22-24 May 1984 in Luxembourg.

The oecond, larger 1984-88 five-year programe, extended to all types of Installations of the nuclear fuel cycle, produced numerous scientific and technical achlevements, oove of which have already been tested on an Industrial scale. Great progress has in particular been achieved in the reduction of metal waste arising from decommissioning, due to advances in areas ouch as aggressive decontanination procedures and techniques for melting and recycling low-level radloactive waste metal.

From 24 to 27 October 1989, the Comm1ssion of the EC organised an International conference on the decomm18sioning of nuclear Installations. The conference, which was held 1 the Palais des Congrès at Brussels, ettracted 405 participants from 20 countries. Participants from non-member States were mainly from Japan, Swltzerland, USA, Canada, Sweden, Finland, Talwan and USSR.

The results of the 1984-88 EC programe and of selected Important profects performed outs1de the EC were presented 1n 81 papers by scientists Involved in the programe through contracts, members of the Comiseion's acientific ataff and guest speakers. Toplcs covered were as follows:

Opening Plenary Session

Aspecto relevant to decoumissioning etrategy

Design features fac1litating decommissioning

Remote operation for dismantling and decontamination

DIomantling techniques

Radloactivity measurement methods

Eatimation of wate quantit1es and the1r disposal prospects

Large transport and/or disposal contalners

Steel waste melting with a view to recycling or conditioning

Decontamination for decomisioloning purposes

Ventilation and filtration techniques for decommissioning purposes

Treatment of decommisaloning vaste

Decominesioning methodology and recycling of material

Large-acale decommlseloning operations

Panel: Decomiastoning of nuclear Installations - Achievements and future tasks

Presentations were based on a seaking time of 20 minutes. D18cussion perlode followed a ser1es of presentations in each session. The papers were aubmitted In the English language. Presentations were made In English, French, German, Italian and Spanish.

These proceedings, lesued in one volume, Include the papers presented, the saseion discussions and conclusions, and the final panel discussion.

During the OPENING PLENARY SESSION, presentatione were made by personalit1ea having high reaponsibilities in the decomiseioning of nuclear Installatione In Europe. Large-scale decomissioning operations from Ins1de and outside the EC (1ncluding JPDR and Sh1ppingport) were presented in a f Inal-day PLENARY SESSION. 
A final PANEL of personalities involved in the nuclear area in EC Member States discussed the achlevements of the 1984-88 programme, considering them to be useful to meet the future tasks in the decommissioning of nuclear Installations. As concerns future activitles, most of the Panel members recommended to pay particular attention to the collection of data on dose rates, costs, and with a view to the Single Market after 1992, to the establishment of European standardised 11mits for reuse/recycling.

As a whole, the Conference showed that, through the R\&D activities, Important advances have been made towards the demonstration that decommissioning, including the recovery of sites, is not only technically feasible, complying with safety and protection requirements, but also economically acceptable. Moreover, the collaboration of scientists has created a common understanding of the problems, which 18 propitious for the development of a consensus within the EC on the safety criteria and the policy to be adopted in the field of decommissioning. 
CONTENTS

WELCOME

S. FINZI, Commission of the European Communities,

Brussels, Belgium

OPENING PLENARY SESSION I

DECOMMISSIONING OF NUCLEAR INSTALLATIONS IN MEMBER STATES

ACHIEVEMENTS AND PROJECTS

A. CREGUT, Commissarıat à l'Energie Atomique,

Marcoule, France

A.R. GREGORY, National Power Division,

Central Electricity Generating Board, UK

LICENSING AUTHORITY EXPERIENCE AND POLICY FOR DECOMMISSIONING OF NUCLEAR INSTALLATIONS

M. LAVERIE, Director of SCSIN, Paris, France

OPERATORS' VIEW OF KEY ISSUES CONFRONTING NUCLEAR POWER

PLANT DECOMMISSIONING

J. ESSMANN, PreussenElektra, Hanover, FRG

THE COMMUNITY'S RED ACTIVITIES IN THE FIELD OF

DECOMMISSIONING. OBJECTIVES, SCOPE AND IMPLEMENTATION

B. HUBER, Commission of the European Communities,

Brussels, Belgium

SESSION II - ASPECTS RELEVANT TO DBCONISSIONING STRATBGY

STRATEGY OF NPP DECOMMISSIONING IN THE IEA NPPD MEMBER STATES

YE LARIN, V. KREMNEV, V. YELIN, S. GAVRILOV (USSR)

E. HLADKY, M. BOSANSKY, S. STRAPEC, K. SCHUBERT (Czechoslovakia)

S. NOZHAROVA, TS DELCHEVA, S. DANCHEV (Bulgaria)

DETERIORATION ASSESSMENT OF NUCLEAR POWER STATION BUILDINGS

AND LONG-TERM STABILITY AND THE LEAK TIGHTNESS OF

REACTOR CONTAINMENTS

D.C. POCOCK, Taylor Woodrow Construction Ltd.

Southall, Middlegex, UK

$H$. VAN EXEL and $R$. OBERPICHLER, Stangenberg,

Schnellenbach und Partner GmbH, Bochum, FRG

D. BEUKELMANN, R. HUTH and B. ROSE, Technischer

Uberwachungs-Verein Bayern ev, Munich, FRG

CONSEQUENCES OF SUPPRESSION OF NEGATIVE PRESSURE IN

THE KW-LINGEN CONTAINMENT

W. HARBECKE, Kernkraftwerk Lingen, Lingen, FRG

THE POTENTIAL RADIOLOGICAL CONSEQUENCES OF DEFERRING

THE FINAL DISMANTLING OF A MAGNOX NUCLEAR POWER STATION

P.B. WOOLLAM, National Power Division of the Central

Electricity Generating Board, Technology Division,

Berkeley Nuclear Laboratories, Gloucestershire, UK 
THE DECOMMISSIONING DATA BANK (DDB)

- METHODOLOGY AND APPLICATIONS -

P. PETRASCH, NIS Ingenieurgesellschaft mbH, Hanau, FRG

J. ROGER, Commissariat à l'Energie Atomique (CEA), IPSN/UDIN, Bagnols-Sur-Cèze, France

RADIOLOGICAL CRITERIA FROM UNRESTRICTED RELEASE OF MATERIALS FROM NUCLEAR INSTALLATIONS

A.M. CHAPUIS, Commissariat à l'Energie Atomique, Fontenay-aux-Roses, France

F. LUYKX, Commission of the European Communities, DG XI, Luxembourg

\section{SESSION III - DESIGN FEATURRS FACILITATING DECOMAISSIONING}

TESTING OF COBALT-FREE ALLOYS FOR VALVE APPLICATIONS

USING A SPECIAL TEST LOOP

C. BENHAMOU and $S$. COHEN, Framatome SA,

Paris-La-Défense, France

F. RUFFET, Commissariat a l'Energie Atomique,

Saclay, France

ANALYSES AND TESTING OF MODEL PRESTRESSED CONCRETE

REACTOR VESSELS WITH BUILT-IN PLANES OF WEAKNESS

P. DAWSON, A.A. PATON and C.C. FLEISCHER, Taylor Woodrow Construction Limited, Southall, Middlesex, UK

IN SITU TREATMENT OF CONCRETE SURFACES BY ORGANIC IMPREGNATION AND POLYMERIZATION

P. URSELLA and G. MORETTI, Italcementi SPA, Bergamo, Italy

V. PELLECCHIA, SNIA Techint SpA, Rome, Italy

INFLUENCE OF DESIGN FEATURES ON DECOMMISSIONING OF A LARGE FAST BREEDER REACTOR

J-L. FOURNIE, C. ALARY, D. MAIRE, N. de SEROUX and G. PEYRARD, Novatome, Lyon, France

THE RACK REMOVAL SYSTEM AS A NEW DESIGN FEATURE ADOPTED TO FACILITATE DECOMMISSIONING OF THE PROCESSING PLANT. DECONTAMINATION AND REMOTE DISMANTLING TESTS IN THE ITREC PILOT PLANT

T. CANDELIERI, A. GERARDI and G. SOFFIETTO, ENEA - Comitato Nazionale per la ricerca e per lo sviluppo dell'Energia Nucleare e delle Energie Alternative, Rotondella (Matera), Italy

DESIGN FEATURES ADOPTED TO FACILITATE DECOMMISSIONING M. DUBOURG, Framatome, Paris la Defense, France 
SESSION IV - REETB OPERATION FOR DISMANTLING AND DBCONTAYINATION

POLYJOINTED ROBOT WITH INTEGRATED LASER BEAM

J.P. ALFILLE, M. HOFMAN, Ph. GARREC, J. GONNORD

and J.P. NOEL, Commissarıat à l'Energie Atomique, IRDI-DEMT-CEN Saclay, France

INVESTIGATION OF LASER CUTTING APPLICATIONS IN DECOMMISSIONING

B. MIGLIORATI, FIAT-CIEI, Torino, Italy

G. TARRONI, ENEA-PAS-FIBI-AEROSOL, BOlogna, Italy

M. DI FINO, ENEA-TIB-FIS-TECNLAS, Roma, Italy

P. PICINI, ENEA-PAS-ISP-AMB, Roma, Italy

G. MANASSERO, FIAT-CRF, Orbassano-Torino, Italy

ADAPTATION TO TELEOPERATION OF AN EXISTING AIR-TIGHT MODULAR WORKSHOP FOR REMOTELY CONTROLLED OPERATIONS

B. GASC and M. JEANJACQUES, Technicatome,

Gif-Sur-Yvette, France

DEVELOPMENT OF MEASURING AND CONTROL SYSTEMS FOR

UNDERWATER CUTTING OF RADIOACTIVE COMPONENTS

$P$. DREWS and $K$. FUCHS, Prozessteuerung in der

Schwersstechnik, RWTH Aachen, FRG

DEVELOPMENT OF A PROTOTYPE SYSTEM FOR REMOTE UNDERWATER PLASMA ARC CUTTING AND SECONDARY EMISSION MEASUREMENTS

R. LEAUTIER, Commissariat à l'Energie Atomique, Cadarache, France

G. PILOT, Commissariat à l'Energie Atomique, Saclay, France

THE TELEMAN PROGRAMME

H.J. de NORDWALL, Commigsion of the European

Communities, Brussels. Head, TELEMan Programme

DISCUSSION

SOLID AND GASEOUS SECONDARY EMISSIONS FROM

UNDERWATER PLASMA ARC CUTTING

B. WALDIE and W.K. HARRIS, Dept. Chemical and

Process Englneering, Herlot-Watt University,

Edinburgh, UK

G. PILOT and H. LOYER, CEA, SPIN Group,

CEN Saclay, Gif-Sur-Yvette, France

IN SITU ARC-SAW CUTTING OF HEAT EXCHANGES TUBES

AND OF PIPES FROM THE INSIDE

J.P. THOME, Field Automation, Paris, France 
ELECTROCHEMICAL TECHNIQUE FOR THE SEGMENTING OF

ACTIVATED STEEL COMPONENTS

W. STANG and A. FISCHER, Kernkraftwerke Gundremmingen

Betriebsgesellschaft mbH, Gundremingen, FRG

P. POTT, AEG-Elotherm, Remscheid, FRG

ADAPTATION OF HIGH PRESSURE WATER JETS AND ABRASIVES

TO DISMANTLE NUCLEAR INSTALLATIONS

C. LORIN, R. ROUVIERE and G. PILOT,

Decommissioning Service CEN Valrho - Marcoule,

Commissariat aे l'Energie Atomique, France

SUBMERGED CUTTING OF STEEL BY ABRASIVE WATER JETS

H. HAFERKAMP, H. LOUIS and G. MEIER, Institute of

Material Science, University of Hanover, FRG

REMOVAL OF CONCRETE LAYERS FROM BIOLOGICAL SHIELDS

BY MICROWAVES

P.F. WACE and A.H. HARKER, UKAEA, Harwell Laboratory, UK

D.L. HILLS, Building Research Establishment,

Garston, Watford, UK

EXPLOSIVE TECHNIQUES FOR THE DISMANTLING OF

RADIOACTIVE CONCRETE STRUCTURES

C.C. FLEISCHER, Taylor Woodrow Construction Limited, Southall, Middlesex, UK

H.U. FREUND, Battelle-Institute, Frankfurt, FRG

DISCUSSION

SESSION VI - RADIOACTTVITY MRASUREMIENT METHODS

DEVELOPMENT OF MEASURING SYSTEMS FOR CONTAMINATION MEASUREMENTS ON REGULARLY AND IRREGULARLY SHAPED SURFACES

B. HERRMANNS, Reaktorwartungsdienst + Apparatebau GmbH, Jülich, FRG

A NEW METHOD FOR THE ANALYSIS OF SMALL PEAKS IN GAMMA RAY SPECTRA, AND A DETECTOR SYSTEM FOR MONITORING GAMMA

ACTIVITY IN LAND AREAS

A. D'EER, P. GRAY, C. KOUTSOYANNOPOULOS, D. MACMAHON

and $A$. NABOULSI, Imperial College Reactor Centre,

Ascot, UK

OPTIMIZATION OF MEASUREMENT TECHNIQUES FOR VERY LOW

LEVEL RADIOACTIVE WASTE MATERIAL

$R$. HOFFMANN and B. LEIDENBERGER, Siemens

Aktiengesellschaft, Bereich Energieerzeugung,

Erlangen, FRG

DEVELOPMENT OF SAMPLING AND ASSAY METHODS FOR WINDSCALE ADVANCED GAS COOLED REACTOR RADWASTE

F.G. BRIGHTMAN, UKAEA, Windscale Laboratory,

Seascale, Cumbria, UK 
DEVICE FOR DECISIVE MEASUREMENT OF WASTE FROM DISMANTLING OF KKN

I. AULER, F. HELK, E. NEUKÄTER and U. ZIMMERMANN, NIS Ingenieurgesellschaft mbH, Hanau, FRG

MEASUREMENT AND SORTING TECHNIQUES FOR UNRESTRICTED RECYCLING OF METAL FROM THE NUCLEAR INDUSTRY J.R. COSTES, D. DA COSTA and G. IMBARD, Decommissioning Service, CEN Valrho, Marcoule Commissariat à l'Energie Atomique, France

MEASUREMENT TECHNIQUES APPLICABLE TO RESIDUAL RADIOACTIVITY ON A DECOMMISSIONED REACTOR SITE P.B. WOOLLAM, National Power Division of the Central Electricity Generating Board, Technology Division, Berkeley Nuclear Laboratories, Gloucestershire, UK

\section{SRSSION VII - ESTIMATION OF WASTE QUANTITIES NND THEIR DISPOSAL PROSPBCTS}

INVENTORY OF GLOVE BOXES DISMANTLING OPERATIONS IN THE FUEL FABRICATION COMPLEX OF CADARACHE FROM 1986 TO 1988 A. CAILLOL, Commissariat à l'Energie Atomique, Paris, France

TESTING OF NEW TECHNIQUES IN DECOMMISSIONING OF A FUEL (U,TH) FABRICATION PLANT, ESPECIAL CONSIDERATION TO FREE RELEASE MEASUREMENT OF LOW URANIUM ACTIVITIES W. IN DER SCHMITTEN, B. SOHNIUS and E. WEHNER, NUKEM GmbH, Hanau, FRG

DEMONSTRATION OF A METHODOLOGY FOR ASSESSING SUITABLE SYSTEMS FOR MANAGEMENT OF REACTOR DECOMMISSIONING WASTES I.M. BARRACLOUGH, S.F. MOBBS and J.P. DAVIS, National Radiological Protection Board, Chilton, Didcot, Oxfordshire, UK

ANTICIPATED ASSESSMENT OF THE AMOUNT OF RADIOACTIVE WASTES ARISING FROM POOL LMBFR DISMANTLING

C. ALARY, D. MAIRE and G. PEYRARD, Novatome, Lyon, France

DECOMMISSIONING WASTE ARISINGS IN THE EUROPEAN COMMUNITY AND WESTERN EUROPE

F.H. PASSANT and R.D. WARD, CEGB, National Power

Division, Barnwood, Gloucester, UK

SITUATION AND PROSPECTS OF RADIOACTIVE WASTE DISPOSAL IN THE MEMBER STATES OF THE EUROPEAN COMMUNITY

K.H. SCHALLER and S. ORLOWSKI, Commission of the European Communities, Brussels, Belgium 
DEVELOPMENT OF A LARGE CONTAINER CAST OF LOW-LEVEL RADIOACTIVE STEEL

H. DEIPENAU, Siempelkamp Giesserei, Krefeld, FRG

K. PFLUGRAD, Commission of European Communities, Brussels, Belgium

LARGE WASTE CONTAINERS MADE OF FIBRE REINFORCED CONCRETE

C. JAOUEN, Société Générale pour les Techniques

Nouvelles, Saint Quentin en Yvelines, France

LARGE SHIELDED INDUSTRIAL PACKAGES FOR THE TRANSPORT

OF INTERMEDIATE LEVEL WASTE

M.S.T. PRICE, Winfrith Technology Centre,

Winfrith, Dorchester, Dorset, UK

DISCUSSION

\section{SESSION IX - STEET WASTE MELTING WITH A VIEN TO RECYCLING OR CONDITIONING}

MELTING OF CONTAMINATED STEEL SCRAP FROM DECOMMISSIONING

D.S. HARVEY, British Steel Technical, Swinden

Laboratories, Moorgate, Rotherham, UK

MELTING OF RADIOACTIVE METAL SCRAP FROM NUCLEAR INSTALIATIONS

M. SAPPOK, Siempelkamp Giesserei GmbH \& Co.,

Krefeld, FRG

G. LUKACS, NIS Ingenieurgesellschaft mbH, Hanau, FRG

A. ETTEMEYER and w. STANG, KGB Kernkraftwerke Gundremmingen Betriebsgesellschaft mbH, Gundremmingen, FRG

FIRST RESULTS OF THE MELTING OF RADIOACTIVE WASTE IN THE EIRAM PLANT

A. THOMA, Noell GmbH, Würzburg, FRG

MELTING OF LOW-LEVEL CONTAMINATED STEELS

S. MENON, G. HERNBORG and L. ANDERSSON,

Studsvik AB, Sweden

SEPARATION BY VAPOUR PHASE TRANSPORT OF STAINLESS STEEL CONSTITUENTS

M. ALLIBERT, Laboratoire de Thermodynamique et Physico-Chemie Métallurgiques, ENSEEG,

Saint Martin D'Heres, France

G. GIBON, G. KURKA and G. TANIS, Centre d'Etudes Nucléaires de Grenoble, Département de Métallurgie, Grenoble, France

BEHAVIOUR OF DIFFICULT TO MEASURE RADIONUCLIDES IN THE MELTING OF STEEL

E. SCHUSTER and E.W. HAAS, Siemens Aktiengesellschaft

Unternehmensbereich KWU, Erlangen, FRG 
A PROCESS FOR THE COMPLETE DECONTAMINATION OF ENTIRE SYSTEMS

W. AHLFÄNGER, Kernkraftwerk Ensland, Lingen (Ems), FRG

AGGRESSIVE CHEMICAL AND ULTRASOUND DECONTAMINATION TESTS ON SMALL VALVES, AND TUBES FROM A FEEDWATER PREHEATER, OF GARIGLIANO-BWR

F. BREGANI, ENEL, RED Division, Thermal and Nuclear

Research Centre, Milan, Italy

A. GAROFALO, ENEL, GaT Division, Special Unit for

Decommissioning, Garıgliano, Italy

DECONTAMINATION BEFORE DISMANTLING A FAST BREEDER

REACTOR PRIMARY COOLING SYSTEM

J.R. COSTES, Decommissioning Service, CEA Marcoule

P. ANTOINE, Decommissioning Service, CEA Cadarache

J.P. GAUCHON, Waste RaD Service, CEA Cadarache, France

DEVELOPMENT OF TECHNIQUES TO DECONTAMINATE THE WAGR HEAT EXCHANGERS

H. CROSSLEY and J.R. WAKEFIELD, UKAEA, Windscale

Laboratory, Seascale, Cumbria, UK

DECONTAMINATION USING CHEMICAL GELS, ELECTROLYTICAL

SWAB, ABRASIVES

G. BRUNEL, Commissariat à l'Energie Atomique, CEN Cadarache, IRDI-DERDCA-DRDD-SDFMA, France

ELECTROCHEMICAL DECONTAMINATION IN EASILY PROCESSED ELECTROLYTES

A. TURNER, Harwell Laboratory, UKAEA, Oxfordshire, UK

A. STERINGER, Kraftanlagen Aktiengesellschaft,

Heidelberg, FRG

CLOSED ELECTROPOLISHING SYSTEM FOR DECONTAMINATION

OF UNDERWATER SURFACES/

DEVELOPMENT OF VIBRATORY DECONTAMINATION WITH

ABRASIVE MEDIA

E. BENAVIDES and M. FAJARDO, Equipos Nucleares SA, Madrid, Spain

THERMAL TECHNIQUES FOR SURFACE CONCRETE DECONTAMINATION

C. MORILION, SOciété Bertin \& Cie, Tarnos, France

J.F. ROUTIER, STMI, Trappes, France

G. PILOT, CEN Saclay, France

SOME REMARKS ABOUT DECONTAMINATION

A. BERTINI, ENEL, Roma, Italy 


\section{SESSION XI - VENTILATION AND FILTRATION TECHNIQUES FOR} DECOMIISSIONING PURPOSES

VENTILATION AND FILTRATION TECHNIQUES FOR HANDLING AEROSOLS PRODUCED BY THERMAL CUTTING OPERATIONS

A. BISHOP, UKAEA, Northern Research Laboratories, Windscale, Cumbria, UK

PREFILTERING DEVICES FOR GASEOUS EFFLUENTS FROM DISMANTLING OPERATIONS

G. PILOT and M. POURPRIX, Commissariat à l'Energie

Atomique, IPSN/DPT/SPIN, CEN Saclay, France

SPREADING AND FILTERING OF RADIOACTIVE BY-PRODUCTS FROM UNDERWATER SEGMENTATION

H. STEINER, Fr.W. BACH and H. HAFERKAMP, University of Hanover, FRG

OPTIMISATION OF FILTERING SYSTEMS FOR VARIOUS CONCRETE DECONTAMINATION TECHNIQUES

W. EBELING, Salzgitter AG, Berlin, FRG

K.W. ROSE, NOELL GmbH, wïrzuurg, FRG

MEASUREMENTS OF SECONDARY EMISSIONS FROM PLASMA ARC AND LASER CUTTING IN STANDARD EXPERIMENTS

G. PILOT, R. LEAUTIER and M. NOËL, Commissariat à

l'Energie Atomique, CEN Saclay, France

H. STEINER, University of Hanover, FRG

G. TARRONI, ENEA Bologna, I taly

B. WALDIE, Heriot-Watt University, Edinburgh, UK

ANALYSIS OF RESULTS OBTAINED WITH DIFFERENT CUTTING TECHNIQUES AND ASSOCIATED FILTRATION SYSTEMS FOR THE DISMANTLING OF RADIOACTIVE METALLIC COMPONENTS

Fr.W. BACH and H. STEINER, Institut fur Werkstoffkunde, University of Hanover, FRG G. PILOT, Commissariat à l'Energie Atomique, CEN Saclay, France

E. SKUPINSKI, CEC Brussels, Belgium

SESSION XII - TREATYIENT OF DECOMNISSIONING WASTE

THE DECOMMISSIONING OF LARGE AND COMPLEX GLOVE BOX STRUCTURES IN A MIXED OXIDE FUEL FABRICATION PLANT J. DRAULANS, Belgonucleaire, Dessel, Belgium

IMMOBILIZATION OF CONTAMINATION BY THE COATING OF POLYMERS ON LARGE-SIZE WASTE PRODUCTS

C. de TASSIGNY, CEA.CENG.SPR.GARC,

Grenoble, France 
IMMOBILISATION OF ACTIVE CONCRETE DEBRIS USING SOLUBLE SODIUM SILICATES

S.P. JULL and S.N. FIELD, Taylor Woodrow

Construction, London, UK

SEPARATION OF CONTAMINATED CONCRETE

H.A.W. CORNELISSEN, NV KEMA, Arnhem, The Netherlands

CONDITIONING FOR DISPOSAL OF RADIOACTIVE GRAPHITE

BRICKS FROM REACTOR DECOMMISSIONING

J.R. COSTES, Decommissioning Service, CEA, Marcoule

C. de TASSIGNY, Radioprotection Service, CEA, Grenoble

C. KOCH, Metallurgy Department, CEA, Grenoble

H. VIDAL and A. RAYMOND, Wastes R\&D Department,

CEA, Cadarache, France

DISCUSSION

751

\section{SESSION XIII - RECYCLING OP MATERIAL AND DECOMUSSIONING METHODOLOGY}

RADIOLOGICAL IMPACT ON VERY SLIGHTLY RADIOACTIVE COPPER AND ALUMINIUM RECOVERED FROM DISMANTLED NUCLEAR FACILITIES H. GARBAY and A.M. CHAPUIS, Commissariat à l'Energie Atomique, Fontenay-aux-Roses, France

COMPARISON OF DECONTAMINATION AND MELTING WITH DIRECT DISPOSAL

K.G. JANBERG and D. RITTSCHER, GNS Gesellschaft für

Nuklear-Service mbH, Essen, FRG

KEY PARAMETERS FOR THE SAFE AND ECONOMICAL RECYCLING

OF CONTAMINATED STAINLESS STEEL

P. HEBRANT, Westinghouse European Service Center,

Nivelles, Belgium

A UTILITY VIEW OF DECOMMISSIONING A GAS-COOLED REACTOR P. MCOWAT, South of Scotland Electricity Board, Glasgow, UK

SESSION XIV - LARGE-SCALB DECONYISSIONING OPERATIONS

LARGE-SCALE APPLICATION OF SEGMENTING AND DECONTAMINATION TECHNIQUES

S. WOLFGANG and A. FISCHER, Kernkraftwerke Gundremingen Betriebsgesel lschaft mbH, Gundremingen, FRG

P. RUBIsChUNG, Nusec GmbH, Buxtehude, FRG

DECOMMISSIONING OF A MIXED OXIDE FUEL FARRICATION FACILITY S. BUCK and A. COLQUHOUN, British Nuclear Fuels plc, Sellafield, UK 


$$
\text { xvi }
$$

DISMANTLING AND DECONTAMINATION OF THE PIVER PROTOTYPE VITRIFICATION FACILITY

A. JOUAN, Commissariat à l'Energie Atomique, IRDI/SDHA, Centre d'Etudes Nucléaires de la vallée du Rhone, Bagnols-sur-Cèze, France

ADVANCES IN THE DECOMMISSIONING OF THE JPDR

K. TOMII, M. YOKOTA and T. HOSHI, Japan Atomic Energy Research Institute, Tokai-mura, Ibaraki-ken, Japan

COMPLETION OF THE SHIPPINGPORT REACTOR DECOMMISSIONING

J.J. SCHREIBER, US Department of Energy, Shippingport, Pennsylvania, USA

DISCUSSION

PANEI DISCUSSION

CLOSING ADDRESS

P TANGUY, Inspecteur Général pour la Sûreté Nucléaire

Electricité de France, Direction Générale, Paris, France 
xvii

CONFERENCE PROGRAMME COMMITTEE

A BERTINI, Ente Nazlonale per l'Energla Elettr1ca, Roma, I

H J C BOEKSCHOTEN, NV tot Keuring van Elektrotechn1ache Materialen, Arnhem, NL

A CREGUT, Commlasarlat à l'Energle Atomlque, Centre d'Etudes Nucléalres de Valrhô, Marcoule, F

A GREGORY, Central Electrlcity Generating Board, Barnwood (National Power D1v181on), Gloucester, UK

B HUBER, Comm1ssion of the European Commun1t1es, Brussels, B

F MOTTE, Studiecentrum voor Kernenergle/Centre d'Etude de l'Energle Nucléa1re, Mol, B

A URIARTE HUEDA, Centro de Invest1gaciones Energet1cas, Medloamblentales y Tecnologicas, Madrid, E

W ZIMMERMANN, Kernforschungszentrum Karlsruhe, D

Sclentific Secretary: $K$ PFLUGRAD, Commission of the European Communitles, Brussels, B.

\section{SESSION CHAIRMEN}

S FINZI, CEC

Open1ng Plenary Session I

A GREGORY, CEGB (NPD), UK

Session II

F MOTTE, SCK/CEN MOl, B

Session III

C COSTE, CEA, F

Sesion IV

W ZIMMERMANN, KfK, D

Session $\nabla$

H J C BOEKSCHOTEN, REMA, NL

Segsion VI

S ORLOWSKI, CEC

Session VII

A URIARTE HUEDA, CIEMAT, E

Session VIII

A BERTINI, ENEL, I

Session IX

M LARAIA, ENEA, I

Session $X$

J WILLIAMS, UKAEA, UK

Session XI

M CONTI, ENEA, I

Session XII

R NEIDER, BAM, D

Session XIII

A CREgut, CEA, $F$

Plenary Session XIV

P TANGUY, EdF, F

Final Panel 
ABBREVIATIONS OF ORGANISATIONS

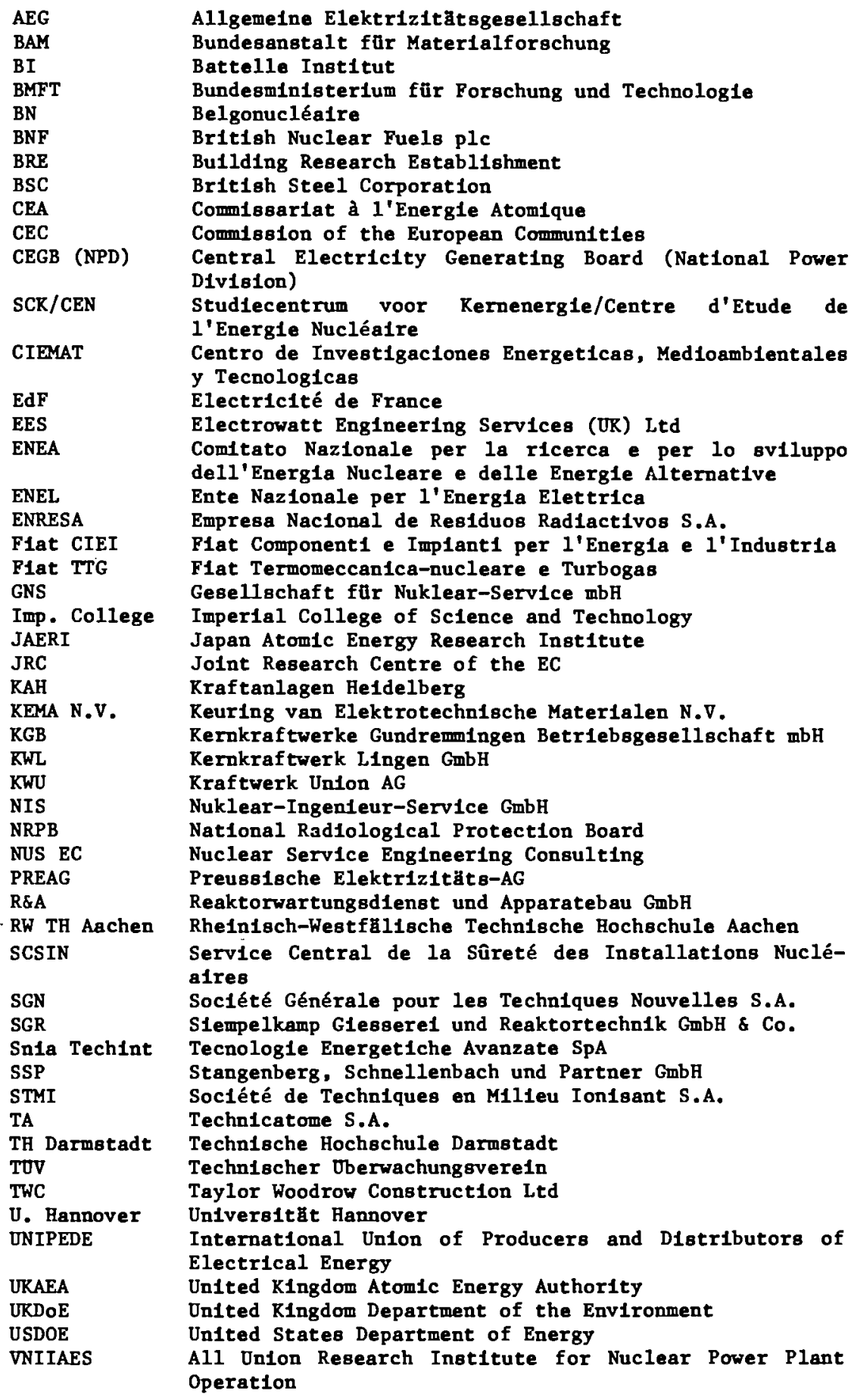




\section{WELCOME}

5. FINZI

Commission of the European Communities, Brussels, Belgium

Lad1es and gent lemen,

On behalf of Prof Paolo FASELLA, Director General for Sclence, Research and Development, I have the honour to open th1s 1989 International Conference on Decomiseioning of Nuclear Installations, and to welcome the numerous part1c1pants.

The first conference organised in this field by the Commission was held 1n May 1984, at the end of the f1rgt five-year programe of research on Decommissioning of Nuclear Power Plants, and represented a very useful step for guidance in the 1mplementation of the second five-year programme, which was completed last year, at the and of 1988. The second programe was larger than the f1rst one and the th1rd programe, which started th1s year, 18 larger st1ll. Roughly, there 18 a factor of five, in constant money, between the first and th1rd programme: th1s expansion represents in clear terms the increase in the interest of research in this fleld and the pressure of finding the best suitable solutions for the decomissioning of nuclear installations.

The present Conference should not only be a means for the presentation and discussion of the results and conclustions achieved, but should also give an opportunity to strengthen the necessary dialogue between decomisisioning experts, owners of nuclear Installations and authorities involved.

The Commission hopes that the research programme has made a useful contribution to develop safe and economic decommissioning procedures and techniques, 1mproving the protection of workers and environment. A good co-operation between research teams was effected, and this 18 already an Important achlevement, but in addition the Commission hopes to have catalysed, by th1s co-operation, the creation of a consensus on the best possible ways of accomplishing forthcoming decommissioning tasks. I would like to atress the Importance of bullding consensus on the criteria to assure safe decommissloning, which will gain harmonisation in the Community.

The new Framework Programe of research of the Community (1990-1994) that the Commission approved In July, and which will assure the continulty of the 1989-1993 programme on decomm1ssioning of nuclear 1nstallations, Indicates as main lines of approach for R\&D in the Community the so-called "prenormative" research, as woll as the development of technical demonstrations as a part of the programme 1mplementation. The new programme has preclsely these two characteristics, and we are anxlous to enrich 1ts technical content by the conclusions of the present Conference.

A Panel discussion of personalities 1nvolved in the nuclear fleld, that $I$ hope will be followed by a large debate, should provide a frultful forum for the evaluation of results and the formulation of recomendations for future tasks.

I am pleased by the wide spectrum and large number of participants that the Conference has attracted, and it 18 a special pleasure for me to welcome delegates from non-Comuntey countries.

I thank all of you for your participation and I hope that you will find the Conference useful and enjoyable. 



\title{
OPENING PLENARY SESSION I
}

\author{
CHAIRMAN: S FINZI, CEC \\ SECRETARY: K PFLUGRAD
}





\section{DECOMISSIONING OF NUCLEAR INSTALLATIONS IN MEMBER STATES ACHIEVEMENTS AND PROJECTS}

CREGUT A.

Commissarlat a l'Energle Atomlque, Marcoule, France

GREGORY A. R.

Nat lonal Power Division, Central Electricity Generating Board, UK.

\section{ABSTRACT}

Since the last International Conference arranged by the European Commision, held in Luxembourg five years ago, some Important and exciting developments in the field of decommissioning of nuclear facllities have been achleved. Knowledge and capability have been accumulated from joint research and development programmes which have been coupled with practical experience, galned from actual dismantlement of prototype reactors and other plant. Member Countrles are now in a strong position to address the task of undertaking decommissioning of the first round of commerclal nuclear power stations which having operated successfully for 20 years or more are now being taken out of service. It 18 now time to review our capability to meet this task, technically and financlally whilst taking account of waste management, regulatory requirements and public relations.

\section{INTRODUCTION}

Since the last Conference held in Luxembourg five years ago decommissioning of nuclear reactors and other facilitles has become a toplc of significant importance throughout the world and in the Community. As of now there are substantial numbers of reactors ranging from zero to two or three hundred megawatts which have been taken out of service and now awalt decommissioning. Fuel fabrication, enrichment and reprocessing plants, and research and development facilities having fulfilled their useful purposes are also awaiting decomissioning. The attached list shows the very different types of reactors and other plant that are Involved.

Th1s year, 1989, represents an 1mportant landmark with the closure of commercial nuclear power stations that have contributed valuable service to electricity production for 20 years or more. These, and some of the supporting services, have not been withdrawn from service because of technical fallure nor, 1ndeed, capability, but only because the economic case for further operation 18 no longer justifled. It may, therefore, be sald that decommisioning has arrived and will be part of the nuclear scene for a very long time to come. The questions to be addressed are, firstly, have we now sufficlent technical knowledge and experience to accept this challenge? Secondly have we confidence that the waste management services will be avallable? Next can we meet the radlologlcal protecton requirements and, lastly, have we taken sufficlent account of our long tera financial commitments? 
This review demonstrates that we are in a strong position to undertake this decomissioning task with confidence. Experience has been and continues to be, gained through the programmes of research and development that have already demonstrated in the actual decommissioning of demonstration and prototype plant and ongoing repair and maintenance of operating plant.

\section{ACHIEVEMENTS}

It is important to communicate to the general public, both
within the Community and worldwide, that decomissioning of nuclear reactors and other facilities is not an impossible problem, that has not been recognised only recently and that we are not 111 prepared to undertake the growing task ahead. On the contrary it is some 15 years since the Elk River, BWR, was dismantled but it was not the first and only such profect. So let us look back briefly on what has been achieved since then.

About that time the International Atomic Energy Agency, 1ssued a short pamphlet setting out an approach to decommissioning reactors by stages. In 1978 IAEA held a very successful symposium in Vienna which demonstrated clearly that any previous lack of knowledge on decommissioning was being made good. The number and varlety of papers showed that detalled studles, backed by practical experiment and actual projects, confirmed the earlier opinion that decommissioning was not only feasible but practicable, and the costs acceptable.

Detalled assessment of radioactive inventories of gas and water cooled reactors were presented which showed how this could impact on engineering method, waste management and 1 ts final disposal. It was noted, however, that some trace elements in steels, concrete, graphite and other materials used in reactor construction could give rise to 1sotopes sufficiently activated to inhibit the free handing and disposal of such wastes even in the longer term. An Important outcome of this symposium was to bring together a cross section of those people engaged on this important matter in many countries and has led to exchange of ideas and information coupled with collaborative participation in actual projects. This has been and will continue to be most valuable.

In April 1978 an Advisory Group of Experts convened by IAEA developed a draft code and guide for the decommissioning of land based nuclear reactor plants. It was noted, however, that since actual decommissioning experience so far had been confined to small nuclear factifties it would be premature to issue this until more experience with large nuclear power plants had been gained. It was, therefore, published as Factors Relevant to the Decommissioning of Nuclear Facilities, Safety Serles 52 (one of 13 IAEA technical documents since 1975 relating to decommissioning). This provided guidance to the steps that should be taken firstly at the time a new nuclear facility 18 in course of design and construction to take account of the ultimate need to decommission it safely and effectively. Secondly it sets out some seventeen points which IAEA 
recommend should be addressed at the actual time of plant shutdown when detalled plans to decomission are drawn up. Time has passed and in some member countries this guldance has been applied in both inteial design and actual plans to decomission.

It was a major task for the Commission to draw up and launch the f1rst 1979/83, research and development programe. The response from utflitles, research organisations and Industry in the Member States to the calls for proposals was most encouraging in terms of scope and quality and 1 t became difficult to decide who best could contribute to a well balanced programme. However, by 1983 it was confirmed that the programe was a great success which was demonstrated by the presentations to the Luxembourg Conference on Decomissioning of Nuclear Power Plants in May 1984. This led to the second, 1984/88, five year programme which was extended to include nuclear facilities more generally and the results of this are now presented here in Brussels.

In addition to these CEC Programmes it is necesary to draw attention to the benefits of exchange of information worldwide in particular with Japan and the United States, in terms of technical Information and conferences such as those organised by American - Nuclear Soclety in Sun Valley, September 1979, USDOE/NEA/OECD, Seattle 1982, and USDOE P1ttsburgh, 1987 .

The most 1mportant achievements so far relate to the practical experience gained in field trials and decomissioning of actual nuclear plants. In addition some 20 zero or low power reactors, about 70 power reactors worldwide have been taken out of service. Twenty of these, with outputs ranging from $1 \mathrm{MW}(\mathrm{e})$ to $300 \mathrm{MW}(\mathrm{e})$, are in the Community. Most have been defuelled, some have reached Stage 2 and a few have been, or are in process of being, dismantled completely. In addition to these reactors considerable progress is being made with decommissioning supporting facilities.

Thls has led to an ongoing international exchange of information through CEC and the NEA has initiated a Cooperative Programe which Includes G2 and Rapsodie (France), Nelderalchbach and Lingen (FRG), Garigliano (Italy), Eurochemlc (Belglum), WAGR and BNFL Co-precipitation Plant (UK), together with projects In USA, Canada and Japan. Thus a wealth of experlence 18 beling bullt up to address the significant decommisioning programme which is about to become a reality.

\section{PROJECTS}

This year, 1989, 1 a a very 1mportant landmark in the development of nuclear power since the first commercial plants, comisioned in the early 1960 s are now ceasing generation after 20 to 30 successful years for essentially economic reasons. Many of these are gas cooled reactors and, In particular, France and $U K$ have Indicated their Intention to phase these out of service over the next five to ten years. It will not be very long before the same fate will befall the early commerclal water reactors. It 18, therefore, necessary to address the whole task of decomissioning nuclear factlities generally as part of the ongoing requirements of nuclear based electricity generation. 
Industry must demonstrate that it can adapt the useful groundwork which has been laid down over the last decade and be able to offer a we11 Informed, well equipped and well experienced capability to undertake decomissioning of nuclear facilities within the European Community.

There are, however, three very 1mportant matters which need to be resolved to ensure smooth and successful decommissioning:

- firstly it 18 necessary to establish, as soon as practicable sultable facilities to accept disposal of large quantitles of radioactive structural steel and components, concrete, graphite and other waste materlal arising, directly or indirectly, from decommissioning operations. Detalled engineering plans cannot be finalised until the technical characteristics and regulatory requirements are finalised. Fallure to recelve this advice in good time could result in the need to provide expensive, temporary storage facllities,

- secondly it is generally accepted that it will be mandatory that suitable funds shall be established, preferably during the working lives of the various plents, to meet the ultimate costs of actual decommissioning. It is expected that these will have to be secured by central government or other approved means but, whilst it is reasonable to make allowance for future technical developments it becomes more difficult to accommodate inflation, possible changes in regulatory requirements or administrative responsibility which are likely to arise in the longer term, perhaps up to 100 years hence.

- lastly, there is an ongoing need to ensure relations with the general public are properly maintained. This is a matter of growing importance both in the context of the construction of new nuclear plants and in the longer term their decommissioning. It must be shown that the nuclear industry has definite intentions to carry out decomfssioning in a safe and sensitive manner, dispose of the waste safely and establish adequate funds to complete each and every plant as they arise.

\section{CONCLUSIONS}

Over the last decade or so the results from organised programmes of research and development backed by achievements in decomissioning radioactive facilities have shown unquestionably that the technical capability to decommission nuclear plants exists. In addition the necessary organisation and regulatory procedure are already in place so that the outcomes of future policy on national and international bases can be drawn up.

However, it should be clearly understood that although the existing means of meeting the technical requirements for Immediate or deferred dismantlement there is still ample room for 1mprovements that will reduce both occupational dose and costs.

Finally attention must continue to be paid to public relations so that confidence in the safety and economic case for construction, operation and decommissioning of nuclear power plants and their assoclated supporting services can be malntalned. 


\begin{tabular}{|c|c|c|c|c|}
\hline & SHUTDOWN POWER & REACTORS & & \\
\hline Country & Stat Ion & $\begin{array}{l}\text { Out pat } \\
\text { u(e) }\end{array}$ & Type & Source \\
\hline Belgium & Mol BR3 & 12 & PWR & $\mathbf{a}$ \\
\hline Canada & $\begin{array}{l}\text { Rolphton NPD } \\
\text { Douglas Point } \\
\text { Gent1ly } 1\end{array}$ & $\begin{array}{r}25 \\
218 \\
266\end{array}$ & $\begin{array}{l}\text { PHW } \\
\text { PHW } \\
\text { BLW }\end{array}$ & $\begin{array}{l}\mathbf{a} \\
\mathbf{a} \\
\mathbf{a}\end{array}$ \\
\hline Czechoslovak1a & Bohuntce Al & 143 & GCHWR & $\mathbf{a}$ \\
\hline France & $\begin{array}{l}\text { Marcoule G1 } \\
\text { Marcoule G2 } \\
\text { Marcoule G3 } \\
\text { Chinon Al } \\
\text { Ch1non A2 } \\
\text { Monts d'Arree EL4 } \\
\text { Saclay EL2 } \\
\text { Saclay EL3 } \\
\text { Pegase } \\
\text { Minerve } \\
\text { Rapsodie }\end{array}$ & $\begin{array}{r}2 \\
42 \\
42 \\
83 \\
210 \\
75 \\
8 \star \\
18 \star \\
35^{\star} \\
1 \star \\
40\end{array}$ & $\begin{array}{l}\text { GCR } \\
\text { GCR } \\
\text { GCR } \\
\text { GCR } \\
\text { GCR } \\
\text { GCHWR } \\
\text { HWR } \\
\text { HWR } \\
\text { LWR } \\
\text { LWR } \\
\text { FBR }\end{array}$ & $\begin{array}{l}\mathbf{a} \\
\mathbf{a} \\
\mathbf{a} \\
\mathbf{a} \\
\mathbf{a} \\
\mathbf{a} \\
\mathbf{b} \\
\mathbf{b} \\
\mathbf{b} \\
\mathbf{b} \\
\mathrm{c}\end{array}$ \\
\hline W. Germany & $\begin{array}{l}\text { Kahl VAK } \\
\text { Kahlsruhe MZFR } \\
\text { Gundremmingen KRB A } \\
\text { Lingen KWL } \\
\text { Grosswelzheim HDR } \\
\text { Neideralchbach KKN } \\
\text { Leopoldshafen FRZ } \\
\text { Otto Hahn NS }\end{array}$ & $\begin{array}{r}16 \\
58 \\
250 \\
268 \\
25 \\
106 \\
44^{\star} \\
38 \star\end{array}$ & $\begin{array}{l}\text { BWR } \\
\text { PHWR } \\
\text { BWR } \\
\text { BWR } \\
\text { BWR } \\
\text { GCHWR } \\
\text { HWR } \\
\text { PWR }\end{array}$ & $\begin{array}{l}\mathbf{a} \\
\mathbf{a} \\
\mathbf{a} \\
\mathbf{a} \\
\mathbf{a} \\
\mathbf{a} \\
\mathbf{b} \\
\mathbf{b}\end{array}$ \\
\hline Italy & $\begin{array}{l}\text { Garigliano } \\
\text { Avogadro Saluggio } \\
\text { Igpra } 1 \\
\text { Montecuccolino RB-Z } \\
\text { Latina }\end{array}$ & $\begin{array}{r}160 \\
7 \star \\
5 \star \\
10^{\star} \\
150\end{array}$ & $\begin{array}{c}\text { BWR } \\
\text { LWR } \\
\text { HWR } \\
\text { Grap/ } / H_{2} O \\
\text { GCR }\end{array}$ & $\begin{array}{l}\mathbf{a} \\
\mathbf{b} \\
\mathbf{b} \\
\mathbf{b} \\
\mathbf{c}\end{array}$ \\
\hline Japan & Toka1 JPDR & 12.5 & BWR & $\mathbf{a}$ \\
\hline Sweden & $\begin{array}{l}\text { Agesta } \\
\text { Marviken }\end{array}$ & $\begin{array}{l}12 \\
140\end{array}$ & $\begin{array}{l}\text { PHWR } \\
\text { BHWR }\end{array}$ & $\begin{array}{l}\mathbf{a} \\
\mathbf{c}\end{array}$ \\
\hline Switzerland & $\begin{array}{l}\text { DIORIT } \\
\text { Lucens CNL }\end{array}$ & $\begin{array}{l}30 * / 0 \\
8.5\end{array}$ & $\begin{array}{l}\text { HWR } \\
\text { GCHWR }\end{array}$ & $\begin{array}{l}\mathrm{b} \\
\mathbf{a}\end{array}$ \\
\hline
\end{tabular}


TABLE 1 (cont).

SHUTDOWN POWER REACTORS

Country
United
Kingdom
United
States

USSR

\section{Station}

Berkeley

Windscale AGR

Dounreay

Argonne EBWR

Vallec1tos VBWR

Shippingport

Santa Susana SRE

Dresden 1

Ind Ian Point 1

Hallam

Saxton

Hunboldt Bay

Piqua

E1k River

Carolinas CVTR

Vallec1tos EVWR

Puerto Rico Bonus

Fermi 1

Peach Bottom 1

Pathfinder

La Crosse

Three Mile Island

PM-2A

Walter Reed Reactor

$B \& \mathrm{~W}$, Lynchburg

NS Savannah

SEFOR

ASTR

GTR

PM-3A

IRL

GE EVESR

NASA Plumbrook

Westinghouse Test

Reactor

Beloyarsk 1

Chernobyl 4
Output Type Source MW(e)

$\begin{array}{rll}332 & \text { GCR } & \text { c } \\ 36 & \text { GCR } & a \\ 15 & \text { FBR } & a\end{array}$

4.5 BWR a

5 BWR a

68 LWBR a

7.5 Grap/Na a

210 BWR a

277 PWR a

$80 \mathrm{Grap} / \mathrm{Na}$ a

4.2 PWR a

65 BWR a

11.4 Organic a

23 BWR a

17 BWR a

5 BWR a

16.5 BWR a

61 FBr a

42 HTGR a

62.5 BWR a

53.3 BWR a

906 PWR a

10* PWR b

50* Homogeneous

6* - b

80* PWR b

20* FR b

$10 * \quad-\quad b$

$10 * \quad-\quad b$

9* PWR b

5* Pool b

$17 *$ BWR b

100* LWR b

60* Tank b

108 Grap/LWR a

1000 Grap/GWR a

Source: a. Nuclear Englneering International, October 1987.

b. Decomissioning of Nuclear Facilities Decontamination, Disassembly and Waste Management, IAEA 1983.

c. Other sources.

* Thermal rating 
TABLE 2

\section{REPRESENTATIVE ZERO/LOW POWER REACTORS}

\begin{tabular}{|c|c|}
\hline Country & Station \\
\hline France & $\begin{array}{l}\text { ZOE } \\
\text { Nerelde } \\
\text { Triton } \\
\text { Peggy } \\
\text { Cesar }\end{array}$ \\
\hline Italy & $\begin{array}{l}\text { Rana } \\
\text { R1tmo } \\
\text { Rospo } \\
\text { RB-1 }\end{array}$ \\
\hline Japan & $\begin{array}{l}\text { AHCF } \\
\text { OCF } \\
\text { SCF } \\
\text { MCF } \\
\text { JRR-1 } \\
\text { HTR }\end{array}$ \\
\hline United States & $\begin{array}{l}\text { EBR-1 } \\
\text { RTA } \\
\text { HTR }\end{array}$ \\
\hline United K1ngdom & $\begin{array}{l}\text { Queen Mary College (not IAEA source) } \\
\text { Dragon } \\
\text { Dounreay MTR } \\
\text { BEPo, Harwell. }\end{array}$ \\
\hline
\end{tabular}

Source: Decommissioning of Nuclear Facilities = Decontamination, D18assembly and Waste Management, IAEA 1983. 
TABLE 3

REPRESENTATIVE FUEL FABRICATION, REPROCESSING AND OTHER FACILITIES

\begin{tabular}{|c|c|}
\hline Country & Facility \\
\hline France & $\begin{array}{l}\text { ATI Reprocessing } \\
\text { ATTILA Reprocessing } \\
\text { ELAN II A and B, Fuel Fabrication } \\
\text { BT } 18 \text { Plutonium MET } \\
\text { GUEGNON Reprocessing }\end{array}$ \\
\hline W. Germany & ALKEM Fuel Fabrication \\
\hline Netherlands & $\begin{array}{l}\mathrm{MOx} \text { - Fuel P1lot Plant } \\
\mathrm{VO}_{2} \text { - Fuel Pilot Plant }\end{array}$ \\
\hline Spain & $\begin{array}{l}\text { Plutonium laboratories } \\
\text { Uranium plant } \\
\text { Uranium Oxide Fabrication Plant }\end{array}$ \\
\hline United Kingdom & $\begin{array}{l}\text { BNFL Fuel Storage Pond } \\
\text { BNFL Capenhurst Diffusion Plant } \\
\text { Site Decontamination Centre } \\
\text { Electromagnetic Separation Plant }\end{array}$ \\
\hline United Kingdom & $\begin{array}{l}\text { Niagara Falls Storage Facility } \\
\text { Montecelli UTAH } \\
\text { Argonne National Lab. Facillties } \\
\text { Hanford } 100 / 200 \text { Area Facilities } \\
\text { Oak Ridge Nat. Lab. Storage Facilities } \\
\text { Savannah River Plant } \\
\text { Battelle Columbla Lab. Facilities }\end{array}$ \\
\hline
\end{tabular}




\title{
LICENSING AUTHORITY EXPERIENCE AND POLICY FOR DECOMMISSIONING OF NUCLEAR INSTALLATIONS
}

\author{
Michel Lavérie, Director of SCSIN \\ Paris, France
}

\section{INTRODUCTION}

Under French regulations, the decommissioning of nuclear installations is covered by the same general provisions applicable to the creation, modification and operation of all nuclear installations. Indeed, it is not of a different nature than other installations (such as for example a production unit on which maintenance or modification work is carried out, or a nuclear waste temporary repository). In this discussion, we propose to describe different technical stages which, within the framework of French practice, result in the decommissioning levels as defined by the IAEA, and we shall show how the regulations establish a general framework enabling the safety authority to carry out the necessary authorization procedures.

Finally, we shall make a brief summary of the experience acquired in France with the decommissioning of nuclear reactors of different sizes and the decommissioning of fuel cycle installations.

\section{SHUTDOWN OF A NUCLEAR INSTALLATION AND DISMANTLING WORK}

The operating period of a nuclear installation is not unlimited; after around ten years for some prototype installations or after twenty to forty years for fuel cycle plants and industrial scale nuclear power plants, their operation must be ceased. This final ending of operation may take place for different reasons, the nature of which may be technical (obsolescence of equipment), economic or even safety related (undue aging of equipment, difficulty in ensuring adequate maintenance etc.). 
The reasons for shutdown are generally numerous. Experience also shows that an installation is rarely shut down for safety reasons alone but, on the other hand, the increase in the cost of the work necessary to maintain the safety level is frequently a decisive factor in deciding on shutdown for economic reasons.

When this is the case for an installation, it is up to the operating organization to propose and take suitable measures to ensure that its installation is not the source of hazards and nuisance for its staff and the environment. It is therefore necessary to carry out a certain number of technical operations on the installation to prevent contingent nuisance hazards.

From a technical point of view, it is important to draw a distinction between final shutdown and the dismantling operations of which the ultimate condition may be de-restriction of the installation (use without any specific radiological restrictions).

\subsection{Final shutdown}

Final shutdown covers the following operations:

- the radioactive materials necessary for operation, resulting from operation or in storage (new and spent nuclear fuels, fissile and fertile materials, radioactive sources and radioactive liquid effluents and waste) are removed from the installation,

- the contaminated systems are drained and flushed (without attempting to thoroughly decontaminate them). The equipment is cleaned; contaminated resins and filters are removed and, if necessary, replaced.

These operations are normally carried out with the initial operating organization's own resources. The installation remains under surveillance, the atmosphere of the zones containing the radioactivity is monitored and the remaining radiological monitoring equipment is maintained in operating condition.

On completion of final shutdown, the operating organization draws up a statement of the residual activity balance (nature and quantity of radionuclides) which will constitute one of the elements affecting the choice of the subsequent dismantling level.

\subsection{Dismantling levels}

The levels envisaged are coherent with those laid down by the IAEA (Safety series No. 52, IAEA, Vienna, 1980). 
At level 1, the final shutdown operations are supplemented by preservation of the first containment barrier (reactor vessel, process equipment, glove boxes etc.). The openings are closed and made leaktight. For example, the glove holes are fitted with caps or covers. The installation remains under surveillance. Periodic measurements and visual examinations are made to ensure that the containment systems (static containment barriers and ventilation systems) continue to operate correctly.

At level 2, with the final shutdown operations completed, the zones are decontaminated to an acceptable level and the zones in which unacceptable levels of radioactivity remain are sealed off to prevent unauthorized access.

The zone within the first containment barrier is reduced as far as possible (all easily removable parts are taken out or transferred to the zones to be sealed off). The leaktightness of this barrier is upgraded and the biological shielding is altered to completely surround it. The safety-related systems to no longer necessary are decommissioned.

Certain parts of the installation can be converted to new uses or freed subject to certain constraints, in accordance with the radioprotection regulations.

This level thus corresponds to "partial or conditional release", and may be maintained for a length of time which may vary considerably depending on the results of an ad hoc study, making allowance for the following in particular:

- requirements related to surveillance of the installation,

- maintenance of the necessary equipment,

- contingent advantages which can be drawn from the radioactive decay.

At level 3, all the materials, equipment and parts of the installation which are still highly radioactive are removed. The installation and the site are released for unrestricted use. Surveillance of the installation is no longer required.

Thus, after final shutdown of the nuclear installation, the hazards do not necessarily disappear and certain dismantling operations can even represent further hazards. The operator of a nuclear installation must therefore correctly analyse these risks after having determined a dismantling strategy. The dismantling operations corresponding to the chosen strategy must be carefully considered on a case-by-case basis making due allowance for:

- the radioactive inventory and radioactive decay. 
- the available technology,

- the waste management resulting from these operations,

- the constraints associated with surveillance of the installation at a given dismantling level,

- the cost of the different operations,

- analysis of the safety of the operations and the final state achieved.

When all these points are clarified, the operating organization can then present its proposals to the safety authority for approval.

\section{REGULATIONS AND DECOMMISSIONING}

The procedures applied for the decommissioning of an installation (and the authorization to proceed with the dismantling operations) are the same as those applicable to the creation, commissioning and significant alteration of nuclear installations. It is the decree of 11th December 1963 (modified) which covers basic nuclear installations (nuclear reactors and installations of the preparation, fabrication and transformation of radioactive substances when the total activity present exceeds the threshold corresponding to the radiotoxicity of the substances). It provides that they may only be created or substantially altered when the authorization decree has been obtained, granted after a public inquiry and signed by the prime minister.

This being the situation, let us now consider how the regulatory framework makes it possible to cope with all the different possible situations, first for the intermediate stage of final shutdown and then for decommissioning proper depending on the desired level of dismantling.

After operation is finally ceased, the first important stage concerns the final shutdown operations. This make may place within the framework of the operating licence of the installation, after approval has been received by the SCSIN. To this end, the operating organization submits a special safety analysis report - the final shutdown report - and proposes subsequent surveillance and maintenance arrangements.

For the actual dismantling, the procedure applied will depend on the final (or provisionally final) state reached after work. There are three possible cases: 
- The residual activity after the dismantling work is higher than the basic nuclear installation classitication threshold for temporary waste repositories. The installation remains classified as a basic nuclear installation and, in view of the fundamental modifications which it undergoes relative to the conditions for which its creation was licensed, a new licence, issued after a public inquiry, is necessary. This authorization covers the dismantling work and the final state, particularly the arrangements for surveillance and maintenance. It is only granted after a technical assessment of the safety of the arrangements planned by the operating organization on the basis of a specific safety analysis report which describes and analyzes the dismantling operations and the surveillance phase in the final state attained.

In practice, the first dismantling operations can be begun before

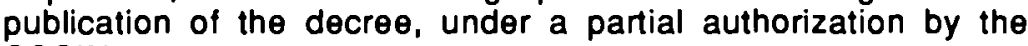
SCSIN.

- If there remain, in the installation, radioactive materials of which the total activity no longer necessitates classification as a basic nuclear installation, but is greater than the thresholds established within the framework of classified installation legislation for the protection of the environment (ICEP), the work is authorized by the SCSIN on the basis of a safety analysis report analogous to that in the preceding case. The installation in its final state shall be authorized in accordance with the procedure provided under ICEP legislation. On completion of this procedure, the installation becomes ICEP classified.

- In the last case, the level of dismantling reached (level 3) makes it possible to make the installation and the site available for use without any particular restrictions. In this case, the final state does not necessitate a special procedure. The work is authorized by the SCSIN on the basis of a safety analysis report. On its completion, and on the basis of a report accompanied by a record of the final radiological state, the installation is declassified.

It must be borne in mind that the operating organization, responsible for the safety of its installation even after final ceasing of operation, must demonstrate that the dismantling work, the final state attained and the conditions of surveillance of the installations afford an acceptable safety level. It is the role of the safety authority to make sure of this, particularly in critical examination of the operating organization's dossier and also by surveillance (inspection) at different stages of the satisfactory progress of the work.

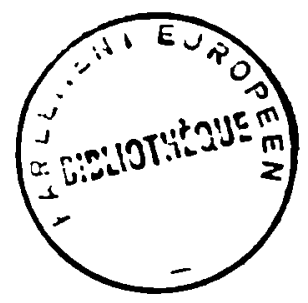




\section{EXPERIENCE ACQUIRED}

A significant number of nuclear. installations have already been declassified or are in the progress of being declassified at different levels (see Tables I and II) which has made it possible to implement the principles referred to in the preceding section.

Thus, such research reactors and pilot plants have been the subject of level 3 dismantling:

- the Peggy reactor ( $1 \mathrm{~kW}$ critical scale model of CEN Fontenayaux-Roses) which was declassified in 1976 ,

- the Minerve reactor (100 W research reactor) was declassified in 1977,

- the César reactor (Cadarache) was declassified in 1978,

- the Marius reactor (400 W power reactor of Cadarache) was declassified in 1987,

- the Attila pilot reprocessing plant (CEN Fontenay-aux-Roses) was declassified in 1985 and the plutonium metallurgy installation ("building 19" at CEN Fontenay-aux-Roses) in 1988.

For fuel cycle pilot plants, the level sought is currently total decommissioning, with the possibility of re-using the site for other purposes.

The second case (partial dismantling with decommissioning to an installation classified for environmental protection) was encountered in the dismantling and containment operations on the core structures of Zoe (925 MWe reactor, declassified in 1978) and EL3 (18 MWe reactor at Saclay, declassified in 1988).

For nuclear power reactors, the present strategy is partial dismantling with confinement of the core structures and the most radioactive materials. The planned surveillance period is of the order of thirty years before proceeding with dismantling.

The decommissioning of Chinon A1 was covered by a procedure corresponding to the first case (creation of a new basic nuclear installation).

This prototype electrical power generating reactor of natural uranium-fuelled, graphite-moderated gas-cooled technology, which served as a $70 \mathrm{MWe}$ electrical power generating unit, shutdown in 1973. Unloading of the fuel was completed in January 1974. Electricité de Frarice took the decision to keep the reactor under 
surveillance and to carry out the work necessary to ensure containment of the radioactivity still present for a long period of time.

Electricité de France submitted a corresponding request to the ministry for industry on 31st October 1979. On completion of the regulatory procedure, a decree published on 16th October 1982 in the French official gazette authorized modification of the installation to transform it to a repository for its own equipment.

Under this decree, EDF is required to present, by 16 th October 2012 at the latest, a safety analysis report concerning total or partial dismantling of the reactor. The installation remains in the basic nuclear installation class, and as such is subject to surveillance carried out by basic nuclear installation inspectors.

For Chinon A2 (a $180 \mathrm{MWe}$ electrical power reactor shut down in 1985, unloading of the fuel of which was completed in June 1986). EDF instigated the decree modification procedure on 4th March 1988.

Modification of the installation will consist of confining all the reactor Internals and dismantling the primary system and contaminated ancillary systems, which shall also be confined inside the installation.

\section{CONCLUSION}

In France, decommissioning operations are not governed by special provisions, but constitute a particular case of application of the general regulatory system covering all nuclear installations.

It will be noticed that the regulations do not lay down obligations concerning choice of techniques, both as concerns methods and timing of operations: this is the responsibility of the nuclear installation operating organizations.

The role of the nuclear safety organizations is to check, by means of technical examinations carried out at different stages of progress of the decommissioning operations, that the dismantling work and the surveillance of their installations, in their final and intermediate states, offer an acceptable level of safety.

We attach particular importance, for installations which are not immediately dismantled, to the quality of the surveillance, the periodic checks and maintenance, as well as to ensuring the availability of skilled staff and to the preservation of the technical dossiers. 


\title{
Operators' view of key issues \\ confronting nuclear power plant decommissioning
}

\author{
Eßmann, Jürgen \\ PreussenElektra \\ Haninover, Germany \\ (Prepared on behalf of the UNIPEDE Study Group on Decomissioning)
}

\begin{abstract}
SUMMARY
Within some UNIPEDE member countries the first generation of nuclear power plants are reaching, or have reached, the end of their working lives after a more than 25 -years successful operating time. In the past in the UNIPEDE countries many studies are available, which demonstrate the technical and financial feasibility of decommissioning. The more the decommissioning becomes concrete the more it is time to strike the balance and to look deeper on probable key issues, which could have an influence on realization of decommissioning. From the operators' viewpoint all relevant factors will be discussed and the key issues confronting the present plannings of decommissioning of nuclear power plant decommissioning will be identified. It will be shown that all the possible options at present can not be used because the necessary requirements have not been met so far.
\end{abstract}

\section{INTRODUCTION}

For some years the UNIPEDE member countries, which operate nuclear power plants are concerned with the problem how to manage the decommissioning of a definitive shutdown plant. Installing the UNIPEDE-Expert Group "Nucledecom" in 1976 the activities of the member countries in this field were united. The primary objective of "Nucledecom" was to examine all assessments of this topic worked out by the several member countries, to gather the results and to harmonize the statements as far as possible. As at that time didn't exist any commercial operated nuclear power plant that were going to be decommissioned, only the comparable experiences of maintenance made at home and abroad and those of companies in that line could be evaluated. In that way the technical feasibility of the decommissioning measures was able to be demonstrated and the relevant financial expenditure could be calculated, $(1,2,3)$.

The corresponding result of all assessments is that today all technical equipments are available to carry out all necessary works. For these reasons a changing of the plant design is not required in order to have a better practicability of decommissioning of a definitive shutdown plant. The opertional requirements of accessibility in service and maintenance and of conservation in availability have to be higher estimated than the not time limited decommissioning activities making of ten possible the use of processes, which are not usable from the operational viewpoint. Estimating the relevant costs it had been also proved that the expenditures of all decommissioning measures are acceptable in comparison to the construction costs $(4,5)$.

These studies are of interest in so far as the first generation of nuclear power plants after more than 25 years successful operation time are reaching, or have reached, the end of their working lives. In the 
following table I will be given a general view of the possible plants of the UNIPEDE member countries.

Table I: Commercial power plants-shutdown (selection)

\begin{tabular}{|l|l|c|l|l|}
\hline Name & Country & MWe(Gross) & Typ & $\begin{array}{l}\text { Period of } \\
\text { Operation }\end{array}$ \\
\hline KBB-A & FRG & 250 & BWR & $68-77 / 79$ \\
KWL-Lingen & FRG & 250 & BWR & $68-75$ \\
VAK-Kah1 & FRG & 16 & BWR & $60-85$ \\
AVR-Jiilich & FRG & 15 & HTGR & $66-88$ \\
MZFR-Karlsruhe & FRG & 57 & PHWR & $65-84$ \\
Chinon A1 & France & 80 & GCR & $63-73$ \\
Chinon A2 & France & 230 & GCR & $65-85$ \\
Berkeley & U.K. & 166 & GCR & $61-89$ \\
Garigliano & Italy & 160 & BWR & $64-82$ \\
BR-3 & Belgium & 12 & PWR & $62-87$ \\
\hline
\end{tabular}

It is obvious to prove and concretize all necessary technical devices in the course of the detail planning so that as well the technical placings can be given on a well calculated cost basis as the technical demands of the licensing authorities can be fulfilled. Regarding to this the key issues of today and the set limits of the objectives to permit the unrestricted use of the site, will become visible.

\section{STRATEGY FOR DECOMAISSIONING}

The uTtimate goal of alT decommissioning measures is to dismantle the plant in that way that it is possible to use the site again unrestrictively. This goal is reached through successive stages: the IAEA has identified three major stages 1,2 and $3(6)$. While Stage 1 (defueling) and Stage 3 (total dismantling) are clearly defined and generally apply to all cases, Stage 2 is dependent on plant type, national practices and industrial policies, and a number of options can be considered to establish a connection between Stage 1 and Stage 3 activities. The possible decomissioning strategies may be covered by following options:

\subsection{Option 1: Safe enclosure}

Using this option the plant is going to be essential unchanged after Stage 1 has been completed. After the disposal of all operating medium, the remaining radioactivity is in a stable condition and will be enclosed or fixed in another way. Liquid or gaseous operating medium doesn't exist any more. The nuclear plant equipments will be enclosed, protected against unauthorized persons and kept under radiological surveillance.

The goal of the "safe enclosure" is as fast as possible to enclose the remaining activity inventory without immediate plant dismantling and with less expenditure. Further on it is the goal to reduce the activity 
inventory only by natural decay during the "time of enclosure". When the measures of getting the status "safe enclosure" are finished the period of "time of enclosure" starts. The duration depends on several facts and is scheduled in different countries between thirty and hundred years.

\subsection{Option 2: Partly dismantling with safe enclosure}

On the one hand the active and inactive parts of the plant are going to be dismantled and removed and on the other hand enclosed compressedly in the remaining plant equipments. In this the active components will be partly dismantled and arranged in existed or added building in order to shield to the environment and to protect simultaneous against unauthorized persons.

In principle this option doesn't differ from the option 1. As well the natural decay will be need in order to carry out the total dismantling to a later fixed time.

\subsection{Option 3: Immediate Total Dismantling}

With this option it is assumed to remove off site all active and inactive waste materials of the controlled area of the plant direct after the end of the service life. This can be practically done only by dismantling the remaining plant and buildings so that the site may be released for reuse or with respect to the radilogical conditions as "green field" for a more general use by the public.

\subsection{Assessment of the options}

The options 1 and 3 are relatively clear to be defined. As to the intervening option 2 are various models distinguishable that are all included in the other options. For this reason this option 2 has not to be considered here so far. By economical and political reasons respectively it will become necessary, independent of the scheduled procedures, to realize the total dismantling within a short time or after a more or less extended enclosure time. In so far all the essentials in realization decommissioning on today are to be demonstrated with the options 1 and 3 .

\section{KEY ISSUES IN REALIZATION DECOMMISSIONING}

planning and realization of decommissioning have to be discussed.

\subsection{Technical Aspects}

As it has been already demonstrated in the studies, all technical devices are available to realize dismantling of a nuclear power plant by regarding all safety related requirements. This can be proven by looking on the plants in operation where at times extensive repair works have been done and some components have been exchanged. To these measures the technical expenditure were essentially higher than it will ever be necessary to a definitive shutdown plant.

The overall objective of the detail planning of the technical measures in order to select the serviceable processes, techniques and instruments, will be determined by 
- the practicability of a dose minimizing application

- the handling for decontamination

- the possibility to reuse the material

- simple operation conditions

- multi-purpose utilization

- the feasibility of remote handling (if required)

- the feasibility of automation (if required)

- the feasibility of reduce the volume

The plant are splitted up in corresponding areas and the particular working steps will be determined dependent of the demands.

\subsection{Radiological Aspects}

The exact detail planning of the decommissioning work is one requirement to meet the general demand to keep the radiation exposure to the personnel and to the public as low as reasonable achievable. In this connection the radiation exposure to the public and to the environment respectively will be of minor interest as the activity inventory of plants in this state is in a some orders of magnitude lower range than in power plants that are in operation conditions. So above all special attentions have to be given to reduce the radiation exposure to the personnel. The technical devices have to be used to meet these requirements. Looking on the relevant operational experiences it can be stated that the collective dose can be kept to such a low level that the feasibility of decomissioning will be limited in no way. Nevertheless it has to be mentioned that from the radiological point of view there are good reasons for considering the natural decay, especially of the activated components, by which, choosing the option "safe enclosure", the radiation exposure to the personnel can be reduced remarkable.

It is the objective to establish at the end of the decommissioning work the "green field" site conditions. But from the radiological point of view it has not been specified up to now what values to be achieved and in what entirety to be verified. In so $f a r$ the costs for the necessary expenditure of measurements could not be calculated.

\subsection{Waste Treatment and Repository Conception}

In the course of decomissioning a considerable amount of primary and secondary waste has to be expected. A respresentative figure of the decomissioning masses of a PWR plant is dealt with in the following table II: 
Table II: The Decommissioning Masses of a German 1.300-MWe PWR Plant (5)

\begin{tabular}{|c|c|c|c|c|}
\hline & $\begin{array}{l}\text { Complete } \\
\text { Mass } \\
(\mathrm{Mg}) \\
\end{array}$ & $\begin{array}{l}\text { Mass } \\
(\mathrm{Mg})\end{array}$ & $\begin{array}{l}\text { Radio- } \\
\text { active } \\
\text { (Mg) }\end{array}$ & $\begin{array}{l}\text { Reusable/ } \\
\text { conventional } \\
\text { dump (Mg) } \\
\end{array}$ \\
\hline $\begin{array}{l}\text { Inventory of metal- } \\
\text { lic components in the } \\
\text { controlled area } \\
\text { including: } \\
\text { - contaminated } \\
\text { - activated } \\
\text { - steel structures/ } \\
\text { liners } \\
\text { Concrete } \\
\text { Steel for rein- } \\
\text { forcement }\end{array}$ & $\begin{array}{r}10389 \\
139090 \\
5844\end{array}$ & $\begin{array}{r}6563 \\
776 \\
3050\end{array}$ & $\begin{array}{r}1411 \\
776 \\
\\
562 \\
56\end{array}$ & $\begin{array}{r}5152 \\
3050 \\
138528 \\
5788\end{array}$ \\
\hline $\begin{array}{l}\text { Complete mass } \\
\text { in the controlled } \\
\text { area }\end{array}$ & 155323 & & \multirow[t]{2}{*}{2805} & \multirow[t]{2}{*}{152518} \\
\hline $\begin{array}{l}\text { Socondary waste from } \\
\text { decommissioning }\end{array}$ & & & & \\
\hline
\end{tabular}

As it can be seen not only radioactive waste has to be expected, which has to be treated according to the regulations but also materials have to be expected as well to be storaged on dumps as to be approved for unrestricted use after a preceeding treatment.

But this treatment depends on the "de minimis" limit to be reached for unrestricted use. If extensive and expensive decontamination and radiological control is required the materials will not be decontaminated for this use but sent to a final repository. It is the fact if extremely low limits have to be reached, the quantities of controls and measurements and the quantity of materials to be finally desposed of, instead of being recycled or simply sent to a conventional waste site, would be as well multiplied extremely.

It is the fact all repositories, where ever installed, general speaking will be limited in size with reference to the mass volume to be storaged. By this reason the treatment of waste has the primary goal to reduce the waste volume so far, that only a small amount of waste has to be storaged. All treatments that can be done in this field are as well dependent on the relevant costs for the final storage packaging devices. As up to now no UNIPEDE member country - except Sweden - has laid down at what site and in which condition these waste has to be storaged, the final repositories and the waste acceptance requirements will become one of the main key issues. It is obvious that the today decommissioning 
plannings of the decommissionings works and of the time schedule will be decisively influenced on the availability of a repository.

At least the wanted feasibiltiy to reuse all metallic materials, e. g. scrapmaterial, after relevant freedecontamination in the economic cycle will be restricted by the required limiting values in so far as in the course of dismantling of a plant this measure can often not be realized by economical reasons. The necessary expenditure seems to be to high. As result it has to be feared that in the repositories those materials will be storaged as well although from the radiological point of view it is not necessary.

\subsection{Licensing Aspects}

Generally with the licensing of decommissioning - the measures and the sequences - no essential problems are to be seen. It is in any case important planning decommissioning to define clearly the decommissioning work to be done and e. g. to schedule definitely the starting point on that time when the fuels, the operating medium and the operating waste of the plant have been removed off site and by this the radioactivity has reached a range of less than $1 \%$ of that radioactivity of a plant which is in operational conditions.

Although the licensing procedures follow the national requirements and are different in the countries abroad, it seems to be nevertheless essential in any way to the procedure, to define the timely sequences and to prove the management of the decommissioning waste.

\subsection{Economical Aspects}

With reference to the financing of the decommissioning measures in that UNIPEDE countries, which have private owned utilties and operators of nuclear power plants, no problems are to be seen as the funds needed for decommissioning are accumulated over the operating time of the plant in reserves specially set up. The decommissioning costs that have been calculated on basis of relevant studies $(5,7)$ lie between $10 \%$ and $20 \%$ of the construction cost at constant price levels.

However economical aspects will become essential if, to a definitive shutdown plant, the decomissioning steps have to be decided. In case all degree of freedoms are available the procedures $c$ an be decided on the base of economic, energy economic and financial viewpoints. A long enclosure time will so be choosen in case of operating some units at the same site and the infrastructure is available in order to fulfil all neccessary measures during the enclosure time. On the other hand there may be reasons for a early further use of the site so that the complete dismantling direct after the definitive shutdown has to be realized.

Especially the last step however will be available only, if to the disposal of the radioactive waste, the limits to be reached, the repository and the relevant storage conditions have been determined and the overal costs can be fully calculated. Otherwise there is the only opportunity to choose the option "dismantling after a safe enclosure" so as it will be choosen at present in the UNIPEDE countries. 


\subsection{Public Relations}

At present no discussions in the public on decommissioning and the feasibility of realizing decommissioning work can be identified. Naturally a change is possible in case the number of power plants reaching the decommissioning stage will increase. But this will be first the fact in the next century. It has to be feared yet that in concretizing the dismantling of plants the public will inquire intensively after the repository. So the governments - which are only responsible - are demanded to meet the final requirements and to finalize the required procedures.

\section{KEY ISSUES CONFRONTING DECOMMISSIONING}

In principle the dismanting of a definitive shutdown $p l a n t$ is realizable in any way as well technical as financial. But in critical evaluation of the different aspects of decommissioning this principle will be limited in so far as within the most UNIPEDE countries it is impossible to demonstrate at what site the radioactive waste has to be stored because the repositories are not available yet. By this reason the operators have at present the only opportunity to choose the option 3 $i$. e. the safe enclosure and the later dismantling.

The reuse of all metallic radioactive materials after a relevant treatment for freedecontamination should be possible already by economical considerations. In order to realize it will be necessary to reach a common agreement on international base on what marginal conditions (limits, masses, treatment) it will be excepted. As well it should be agreed that all rubbles of the plant buildings could be reused.

But it is well known that the accepted "exemption" or "de minimis" limit is of fundamental importance in any sort of decision - making for decommissioning planning and is in so far a further key issue. This limit corresponds to the value of the specific radioactivity (becquerels per gramme or per square centimeter) below which no material, in particular scrap or waste from the dismantlement of nuclear power plants, is subjected to radiological restrictions and controls, and in other terms is considered in practice not to be any more radioactive. For example should the limit be decreased (e.g. one order of magnitude lower) the consequences on the costs and the efforts to decommission any given nuclear power plant would be enormous. The effect on overall costs and efforts increases with a decrease in the value of the limit itself; the reduction of an order of magnitude is much greater for a reduction from 1 to $0,1 \mathrm{~Bq} / \mathrm{g}$ than from 10 to $1 \mathrm{~Bq} / \mathrm{g}$. This has to keep in mind when deciding on the strategy and on the waste treatment.

At least in the future a key issue of great interest will become the requirements to be proven in connection with the stated definitive goal "green field". From the radiological point of view nobody has given a definition of the meaning "green field" to a site where a nuclear power plant has been operated for many years. In order to have the possibility to calculate the overall cost relevant to the decommissioning measures, this seems to be one key issue. At time missing these conditions the costs for verification of the "green field" couldn't be evaluated. 


\section{CONCLUSION}

It has been shown that from the theoretical point of view neither technical nor financial problems of decommissioning to be seen yet. In realizing decommissioning and the connected use of the possible options to plants which are reaching, or have reached, the end of their working life, the useable options are limited. On balance of all opportunities and of all facts - technical, economical and ecological - only restricted procedures are possible as specific key issues have not been solved so far, partly because the governments didn't make the necessary decisions.

Nevertheless from operators' view no fundamental "key issues" supposed the "de minimis" concept will be practicable - are recognizable which will jeopardize the feasibilitiy of decommissioning of a nuclear power plant neither at present nor in future. The current facts apparently confronting the detail plannings are not contradictory to this statement. These current facts necessitate however to consider the possibilities accurately and to accommodate the procedures to the realities planning decormissioning works today. But exact technical plannings and cost calculations have to be done at every time and operators are well acquainted with this method.

\section{REFERENCES}

1. P. Petrasch, G. Lukacs, J. Eßmann and G.V.P. Watzel, "New Results in Decommissioning of Nuclear Power Plants" ENC'86, Geneva, Vol.4, p. 761

2. J.D. Regan, "Decommissioning of Nuclear Stations" Nuclear Europe $10 / 1988$

3. T. Kukkola, "New Decommissioning Principles for Loviisa NPP, Nuclear Europe 10/1988

4. G.V.P. Watzel et. al

"Technik und Kosten bei der Stillegung von Kernkraftwerken nach Ende threr Einsatzdauer" VDI-Fortschrittsbericht, Reihe 15, Nr. 52 (1987)

5. J. Eßmann, G. Lukacs, "Experience and Strategy of Decommissioning NPP's in the Federal Republic of Germany" Nuclear Europe 10/1988

6. IAEA, "Factors Relevant to the Decommissioning of Land-Based Nuclear Reactor Plants", Safety Series No 52, IAEA Vienna 1980

7. CEC/NIS "Decomissioning of Light Water Reactor Nuclear Power Plants" Nuklear Ingenieur-Service (GmbH) 4/75 
THE COMMUNITY'S R\&D ACTIVITIES IN THE FIELD OF DECOMMISSIONING. OBJECTIVES, SCOPE AND IMPLEMENTATION

B. HUBER

Commission of the European Communttes, Brussels, Belglum

ABSTRACT

The European Communtty has just concluded its second five-year programme (1984-88) in the field of decommisstoning, and has started up 1 ts third programme (1989-93).

The objective of these activities is to relnforce the scientific and technological basis for the safety and protection aspects and the economic evaluation of decommissioning. Thereby, increasing emphasis Is lald on the demonstration of relevant techniques. Through the new programme, the experience to be galned from the dismantilng of the first large-scale nuclear Installations in the Communty w11l be made avallable to all Member States.

The programmes are 1mplemented mainly through shared-cost research contracts with public organisations and private companies in the Member States. The 1984-88 programme has comprised 75 contracts.

Emphasis has been laid on the exchange and dissemination of the scientific and technical results obtained. Beside this conference, this has been done through regular meetings of people working in the same area and through publication of annual progress reports of the programme and final reports of individual research contracts.

\section{INTRODUCTION}

The European Community started R\&D activities in the fleld of decommissioning ten years ago, with the 1979-83 programme on the decomisissioning of nuclear power plants. Th1s was followed by the 1984-88 programe on the decomissioning of nuclear installations, the results of which will form the main subject of the present conference. A new five-year (1989-93) programme on the decomissioning of nuclear 1nstallations is presently in the Initial stage of Implementation.

\section{OBJECTIVES}

The main objective of the R\&D activities of the Community 18 to relnforce the scientific and technical basis of decommissioning with a view to strengthening the safety and protection aspects.

Accordingly, these activities come under the heading "Nuclear Safety" In the framework programme for Community activities in the fleld of research and cechnologica1 development (1987-91).

The orfentation at safety and protection aspects determines the criterla for the selection and execution of the R\&D projects; 1mportant criteria are in particular the minimisation of occupational exposures, of effluents, and of radioactive waste arisings. The decommissioning procedures developed must, however, also be cost-effective, in order to be employed in practice.

Though it is an essentlal goal of deconmissioning, to make the sites of redundant nuclear Installations avallable for other uses, the optimum timing appears to depend on a number of factors which may vary from one nuclear installation to another, or from one country to another. The Community R\&D activities are open to different strategles, they address the requirements of early dismantling of shut-down Installations as we11 as the requirements of their long-term in situ storage. 
The Community RoD activities also have the objective of focusing the efforts deployed in the Individual Member States and of avolding unnecesoary duplication of work, through information exchange and cooperation between people working in the same area. The Integration at the level of R\&D may even catalyse a consensus on a Communtey policy in the fleld of decomisisioning.

Finally, the Community R\&D activities have the objective of demonstrating the feasibility of decommissioning procedures through pllot proJects, thereby also contributing to Improving the rellability of decomissioning cost estimates.

3. SCOPE

The scope of the Communtty R\&D activities on decomissioning has evolved from one five-year programme to another.

Whereas the first programe (1979-83) was limited to the decommisionIng of nuclear power plants, the two subsequent programmes (1984-88; 1989-93) cover nuclear installations in general.

The nature of these activities has changed, too: whereas the first progranme consisted almost exclusively of laboratory Investigations and theoretical studies, In the following programes more and more weight has been given to large-scale tests and demonstrations. So. Section C, concernIng the testing of new techniques in practice, was added in the second programe, which 18 shown in Table $I$, and four pllot dismantilng projects were included in the third programe. This trend towards larger-scale experiments, Involving radloactivity, 1s reflected by increasing expend1tures (see Figure 1).

Table I. Subjects of the $1984-88$ programme

A. Research and development projects:

- Profect $N^{\circ}$ 1: Long-term Integrity of bu1ldings and systems;

- Project $N^{\circ}$ 2: Decontamination for decommissioning purposes;

- Project $N^{0}$ 3: D1 smantling techniques;

- Profect $N^{\circ}$ 4: Treatment of Bpecific waste materlals: steel, concrete and graphite;

- Profect $N^{\circ}$ 5: Large containers for radloactive waste produced in the dismantilng of nuclear Installations;

- Project $N^{\circ}$ 6: Estimation of the quantities of radioactive wastes arlsing from decomissioning of nuclear installations in the Community;

- Profect $N^{\circ} 7$ : Influence of Installation design features on decomissioning.

B. Identification of gu1ding principles.

C. Testing of new techniques in practice, within the framework of largescale decomissioning operations. 


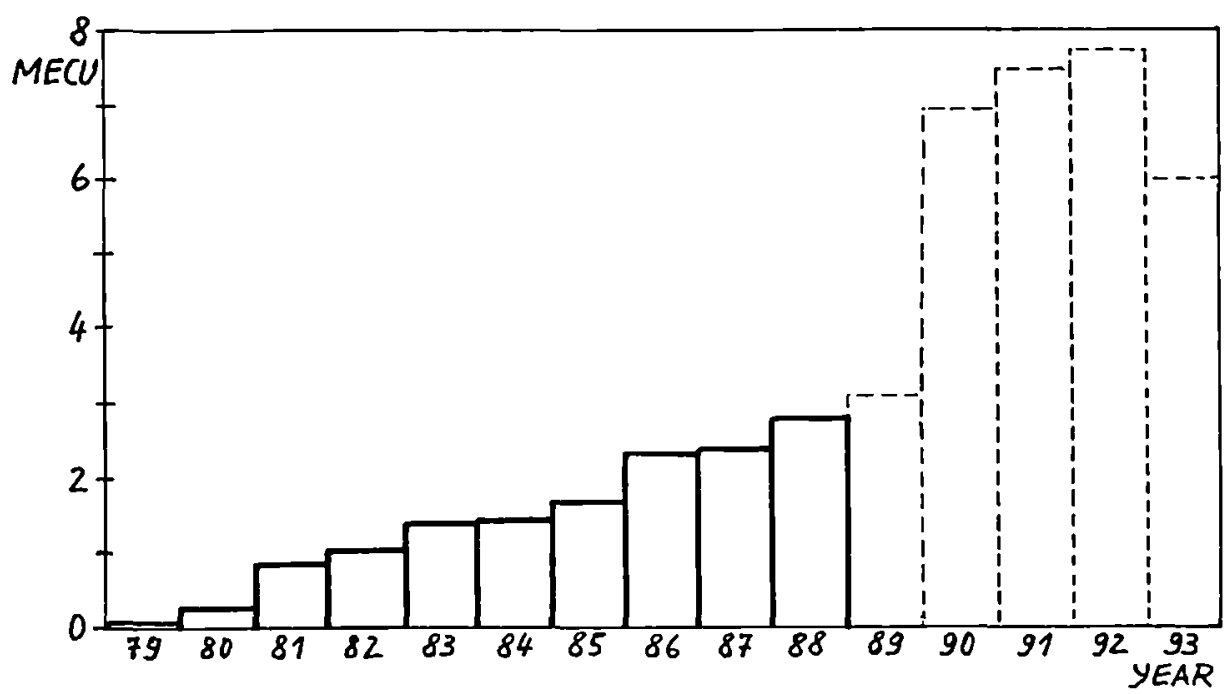

Figure 1. Community expenditures on R\&D activities in the field of decomissioning

\section{IMPLEMENTATION}

The flve-year R\&D programmes are declded by the Counc1l of the EC $/ 1 / 2 / 3 /$ on a proposal from the Commisston, who is also responsible for the Implementation. In the preparation of the programe proposal, as well as in the Implementation, the Commission is assisted by a Management and Coord1nation Advisory Comittee (CGC 6) composed of representatives of the Member States and the Comision.

The research activities in the fleld of decommissioning are mainly Implemented through shared-cost contracts with organisations and companies In the Member States. Typically, the Community is assuming $50 \%$ of the cost of a project.

At the beginning of each five-year programme, calls for research proposals were published. The proposals received are then evaluated and selected, care belng taken to avoid unnecessary duplication of work. Th1s Is a cructal phase of a programe, since it determines the detalled structure of the R\&D activities. Then, research contracts are prepared and concluded. The number of contracts was 51 and 75 in the first and the second programme, respectively. The contracts of the second programme are listed in Table II.

Research contractors working in the same programe area have met half-yearly, together with Community experts and Commisston officlals, to present their most recent work and results and to exchange information and views on the further orlentation of their activities.

The results of the research activities have also been extensively published. Annual Progress Reports were Issued during the 1mplementation period of the programe $/ 4 / 5 /$. A contract-specific final report 18 generally published upon completion of a research contract. Accordingly, the results of the 1979-83 programe are documented in 44 published final reports; as regards the 1984-88 programme, whereas some final reports are already avaflable, most are presently in print.

The results of the first five-year programme were also presented at a spectal conference, held in 1984 in Luxembourg /6/, which will now serve as a valuable reference to measure the progress achleved over the last five years. 
Table II. Contracts of the 1984-88 programme

\begin{tabular}{|c|c|c|}
\hline PROJECT & $\begin{array}{l}\text { CONTRACT } \\
\text { NUMBER }\end{array}$ & CONTRACTOR - SUBJECT OF RESEARCH \\
\hline $\begin{array}{l}\text { PROJECT } \\
N^{\circ} 1 \\
\text { LONG-TERM } \\
\text { INTEGRITY }\end{array}$ & $\begin{array}{l}\text { FIID-0030 } \\
\text { FIID-0031 } \\
\text { FIID-0032 }\end{array}$ & $\begin{array}{l}\text { Taylor Woodrow Constr. Ltd - Deterloration } \\
\text { assessment of nuclear power station bulldings } \\
\text { Zerna, Schnellenbach und Partner - Long-term sta- } \\
\text { b1lity and leak-t1ghtness of reactor contalnments } \\
\text { KW Lingen GmbH - Consequences of suppression of } \\
\text { negat Ive pressure In the KW-Lingen contalnment }\end{array}$ \\
\hline $\begin{array}{l}\text { PROJECT } \\
N^{\circ} 2 \\
\text { DECONTAM- } \\
\text { INATION } \\
\text { POR DECOM- } \\
\text { MISSIONING } \\
\text { PURPOSES }\end{array}$ & $\begin{array}{l}\text { FIID-0001 } \\
\text { FIID-0002 } \\
\text { FI ID-0003 } \\
\text { FI ID-0004 } \\
\text { FI 1D-0005 } \\
\text { FI ID-0029 } \\
\text { FI ID-0033 } \\
\text { FI 1D-0034 } \\
\text { FI 1D-0035 } \\
\text { FI 1D-0063 } \\
\text { FI1D-0065 } \\
\text { FI1D-0066 }\end{array}$ & 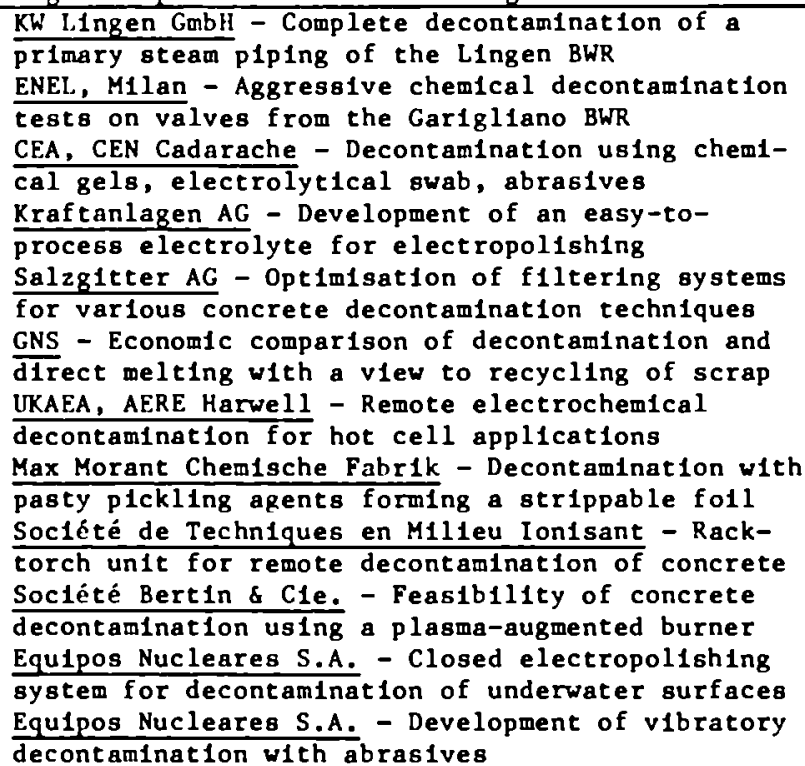 \\
\hline $\begin{array}{l}\text { PROJECT } \\
N^{\bullet} 3 \\
\text { DISMAN- } \\
\text { TLING } \\
\text { TECHNIQUES }\end{array}$ & $\begin{array}{l}\text { FIID-0006 } \\
\text { FI 1D-0007 } \\
\text { FI 1D-0008 } \\
\text { FI 1D-0009 } \\
\text { FI 1D-0010 } \\
\text { FI 1D-0011 } \\
\text { FI 1D-0012 } \\
\text { FI 1D-0013 } \\
\text { FI 1D-0014 } \\
\text { FI 1D-0036 }\end{array}$ & 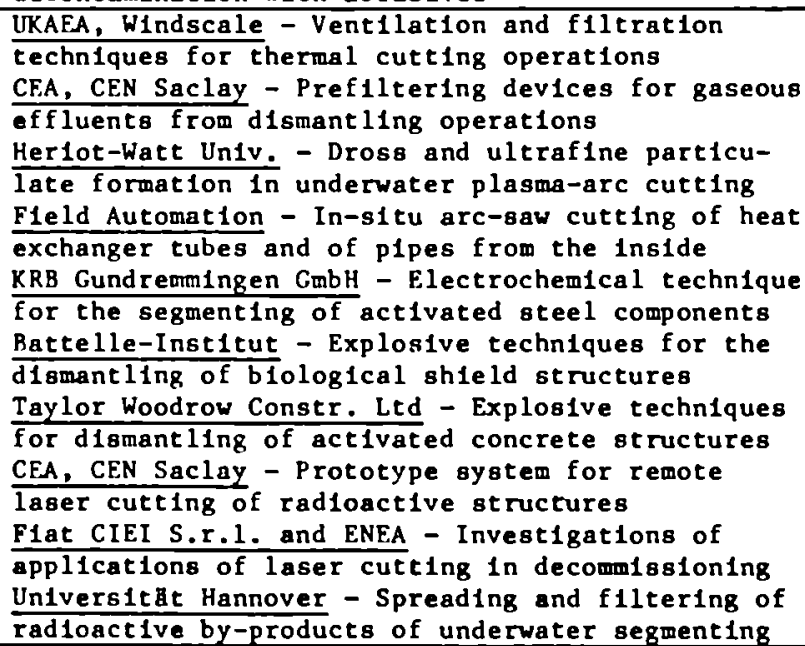 \\
\hline
\end{tabular}


Table II continued

\begin{tabular}{|c|c|c|}
\hline PROJECT & $\begin{array}{l}\text { CONTRACT } \\
\text { NUMBER }\end{array}$ & CONTRACTOR - SUBJECT OF RESĖARCH \\
\hline $\begin{array}{l}\text { PROJECT } \\
\mathrm{N}^{\circ} 3 \\
\text { continued }\end{array}$ & $\begin{array}{l}\text { FI1D-0037 } \\
\text { FI1D-0038 } \\
\text { FI1D-0039 } \\
\text { FI1D-0040 } \\
\text { FI1D-0041 } \\
\text { FI1D-0067 } \\
\text { FI1D-0069 } \\
\text { FI1D-0070 } \\
\text { FI1D-0071 } \\
\text { FI1D-0072 }\end{array}$ & 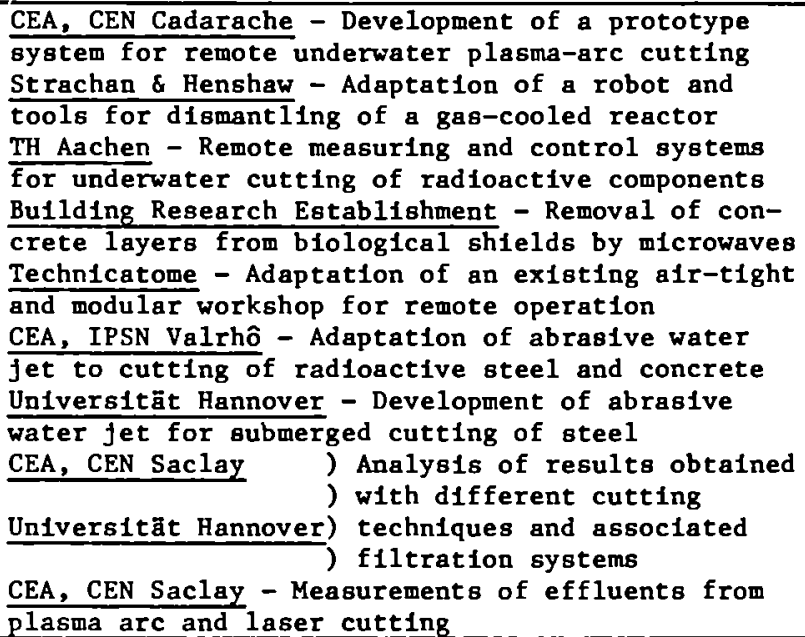 \\
\hline $\begin{array}{l}\text { PROJECT } \\
N^{\circ} 4 \\
\text { TREATMENT } \\
\text { OF } \\
\text { SPECIFIC } \\
\text { WASTE } \\
\text { MATERIALS }\end{array}$ & $\begin{array}{l}\text { FI1D-0015 } \\
\text { FI1D-0016 } \\
\text { FI1D-0017 } \\
\text { FI1D-0018 } \\
\text { FI1D-0042 } \\
\text { FI1D-0043 } \\
\text { FI1D-0044 } \\
\text { FI1D-0064 } \\
\text { FI1D-0068 }\end{array}$ & 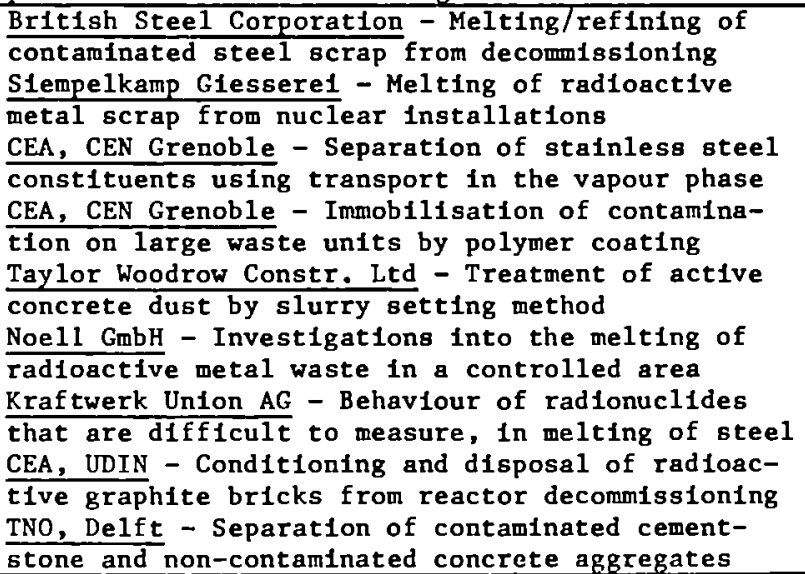 \\
\hline $\begin{array}{l}\text { PROJECT } \\
N^{\circ} 5 \\
\text { LARGE } \\
\text { WASTE } \\
\text { CONTAINERS }\end{array}$ & $\begin{array}{l}\text { FI1D-0045 } \\
\text { FI1D-0046 } \\
\text { FI1D-0047 }\end{array}$ & $\begin{array}{l}\text { UKAEA, Winfrith - Design and evaluation of large } \\
\text { contalners for reactor decommissloning waste } \\
\text { Soc. Gén. pour les Techniques Nouvelles - Large } \\
\text { waste contalners made of flbre-reinforced cement } \\
\text { Siempelkamp Giessere1 - Large waste containers } \\
\text { cast of low-level radioactive metal scrap }\end{array}$ \\
\hline $\begin{array}{l}\text { PROJECT } \\
N^{\circ} 6 \\
\text { ESTIMATION } \\
\text { OF RADIO- } \\
\text { ACTIVE } \\
\text { WASTE } \\
\text { QUANTITIES }\end{array}$ & $\begin{array}{l}\text { FIID-0019 } \\
\text { FI1D-0020 } \\
\text { FI1D-0021 } \\
\text { FI1D-0048 }\end{array}$ & $\begin{array}{l}\text { Imperial College - Computer programs for the mea- } \\
\text { surement of low-level gamma contamination } \\
\text { UKAEA, Windscale - Methods to establish the curle } \\
\text { content of waste from decommissioning } \\
\text { Reaktorwartungsdienst \& Apparatebau Gmbh - Systems } \\
\text { for contamination measurements on curved surfaces } \\
\text { Kraftwerk Union AG - Optimisation of measurement } \\
\text { techniques for very low-level radioactive material }\end{array}$ \\
\hline
\end{tabular}


Table II continued

\begin{tabular}{|c|c|c|}
\hline PROJECT & $\begin{array}{l}\text { CONTRACT } \\
\text { NUMBER }\end{array}$ & CONTRACTOR - SUBJECT OF RESEARCH \\
\hline $\begin{array}{l}\text { PROJECT } \\
N^{\circ} 6 \\
\text { continued }\end{array}$ & $\begin{array}{l}\text { PIID-0049 } \\
\text { FIID-0050 } \\
\text { FIID-0051 } \\
\text { FIID-0052 } \\
\text { FIID-0074 } \\
\text { FIID-0075 }\end{array}$ & 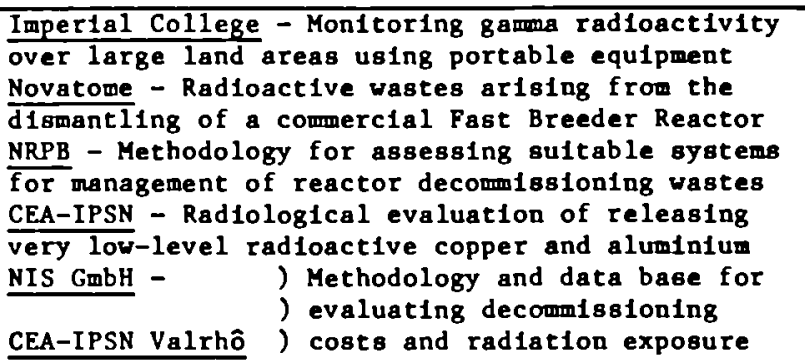 \\
\hline $\begin{array}{l}\text { PROJECT } \\
\mathrm{N}^{\bullet} 7 \\
\text { INFLUENCE } \\
\text { OF INSTAL- } \\
\text { LATION } \\
\text { DESIGN } \\
\text { FEATURES }\end{array}$ & $\begin{array}{l}\text { FIID-0022 } \\
\text { FI ID-0053 } \\
\text { FI ID-0054 } \\
\text { FI ID-0055 }\end{array}$ & 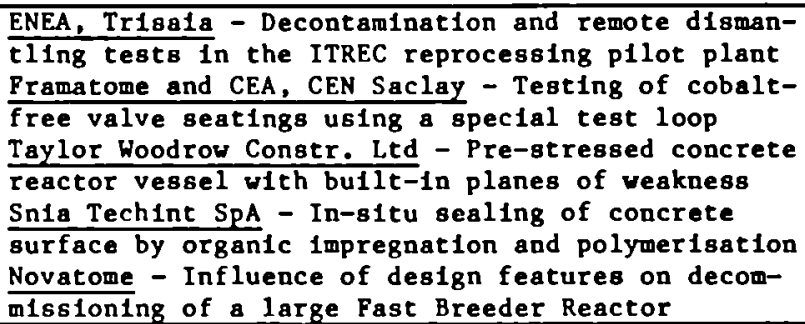 \\
\hline $\begin{array}{l}\text { SECTION B } \\
\text { GUIDING } \\
\text { PRINCIPLES }\end{array}$ & FIID-0073 & $\begin{array}{l}\text { CEA-IPSN Valrhô - Inventory of Information rele- } \\
\text { vant to the 1dentification of guiding principles }\end{array}$ \\
\hline $\begin{array}{l}\text { SECTION C } \\
\text { TESTING } \\
\text { OF NEW } \\
\text { TECHNIQUES } \\
\text { UNDER REAL } \\
\text { CONDITIONS }\end{array}$ & $\begin{array}{l}\text { FIID-0023 } \\
\text { FIID-0024 } \\
\text { FIID-0025 } \\
\text { FIID-0026 } \\
\text { FIID-0027 } \\
\text { FI ID-0028 } \\
\text { FIID-0057 } \\
\text { FI ID-0058 } \\
\text { FIID-0059 } \\
\text { FI ID-0060 } \\
\text { FI ID-0061 } \\
\text { FI ID-0062 }\end{array}$ & 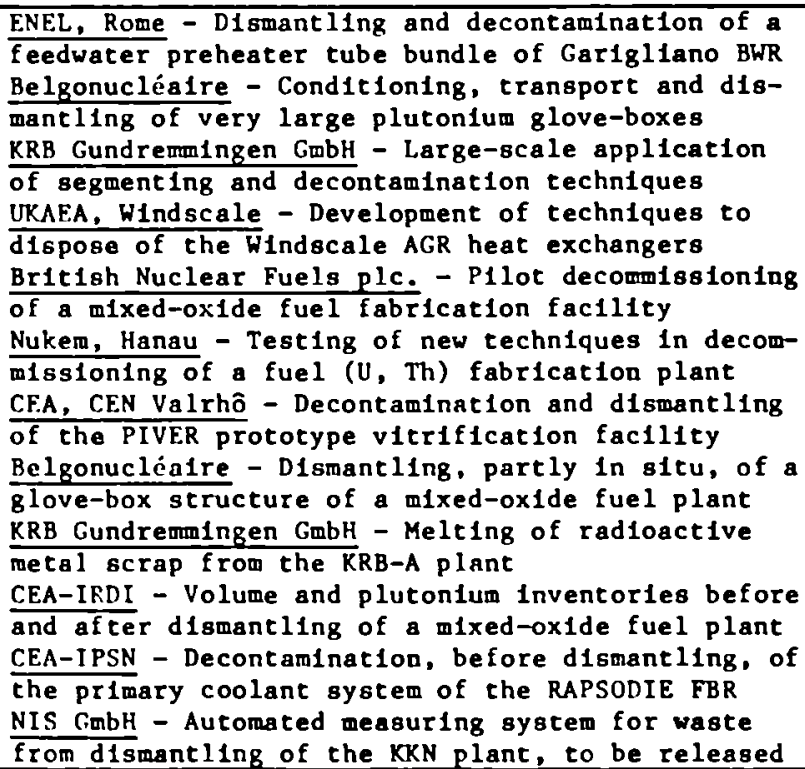 \\
\hline
\end{tabular}




\section{FOCAL POINTS}

In situ storage of Installations finally shut down

The activities in this area have been focused, on the one hand, on Inspections of selected nuclear power plants and examination of relevant materials therein, in order to determine the mode and pace of degradation. On the other hand, the measures necessary for maintaining plants in safe condition and for keeping the necessary ancillary equipment operable have been studied. These Investigations will be pursued with a steady effort, enlarging the data base and explofting the growing experience, in order to establish confidence in long-term forecasts.

\section{Decontamination for decomissloning purposes}

The work on metal decontamination has been focused on aggressive techniques, mostly using strong chemical agents or electrochemical methods. Unlike five years ago, considerable Industrial-scale experience is now avallable on decontamination of steel for unrestriated release. Moreover, methods for minimfsing secondary waste arisings have been developed, such as regeneration of the chemical agent (phosphortc ac1d) or spraying of a thin layer of gelatinous decontaminant.

\section{Dismantling techniques}

Regarding the segmentation of steel components, 1mportant R\&D subjects have been the performance assessment of various thermal cutting techniques In afr and under water, and the characterisation and retention of the cutting by-products. As regards the dismantling of concrete structures, the maln effort has been devoted to explosive techniques, Including the question of the integrity of surrounding structures which are to be preserved.

Treatment of specific waste materials arlsing in decomissioning; steel, concrete and graphite

Efforts in this area have been mainly devoted to the melting of low-level radfoactive steel scrap, which has been brought to the threshold of Industrial practice.

\section{Large contalners for radloactive waste from decommlssioning}

Recent developments concerned in particular containers made of fibrerelnforced cement and containers cast of low-radioactive steel scrap. It has- been considered that further activities in this area, which should preferably be based on the requirements of specific waste disposal factlitles, need not be supported by the new Community programe.

\section{Estimation of the quantities of radioactive waste from decommissioning}

Activities under this heading have been focused, on the one hand, on methodology studies, in particular for, evaluating strategles for the timing of dismantling installations, and for disposal or recycling of material. On the other hand, measurement systems have been developed with a view to dectding whether material from the dismantling of installations is radioactive or not.

Installation design features factlitating decomisstoning

Catalogues of design features facilitating decommissioning have been prepared for various types of Installations. In addition, selected specific design features have been developed and evaluated. The results of the studies performed over the past ten years should now be discussed with the potentlal users. 


\section{OUTLOOR}

The new five-year (1989-93) programe has been atarted with the preparation of R\&D contracts relating to the four pllot dismantling projects already Identified in the Counctl decision $/ 3 /$, 1. .:

- the Windacale Advanced Gas-cooled Reactor.

- the KRB-A Bolling Water Reactor (Gundremingen),

- the BR-3 Pressurlsed Hater Reactor (Mol),

- the AT-1 fuel reprocessing fac1lity (La Hague).

Through these projects, the experlence to be galned from the dismant $1-$ ing of the first representative large-scale nuclear installations in the Community w11 be made avallable to all Member States.

Concerning Section A, R\&D Projects, and Section C, Testing of New Techniques in Practice (other than the above-mentioned p1lot projects), a call for research proposals was published in June, with a closing date of 30 September. About 120 proposals have been submitted, many of them jolnt ly from geveral proposers, and will now be evaluated.

The new programme w1ll be characterised by a further reinforcement of cooperation across borders and, consequently, an increased integration of the Individual RGD activities.

As regards technological aspects, remote operation w1l play a greater role In the new programe. Whereas the second (1984-88) programme, as compared with the f1rst one, was distingulshed by the Introduction of a number of Industrial-scale activities, the radiation levels involved did not require the operations to be controlled remotely (an Important exception to this was the dismanting of the PIVER vitrification fac1lity). The new programe will include several dismantling projects concerning highly radiating components and requiring remote control. Moreover, the qualification and adaptation of remote-controlled semi-autonomous manipulator aystems 18 included in the programme as a Beparate R\&D area.

\section{REFERENCES}

/1/ Counc1l Dec1sion of 27 March 1979 adopting a research programe concerning the decomisstoning of nuclear power plants. OJ $N^{\circ} L 83$, 3.4 .1979$, P. 19.

/2/ Counc1l Declsion of 31 January 1984 adopting a research programme concerning the decomissioning of nuclear installations. oJ $\mathrm{N}^{\circ} \mathrm{L} 36$, 8.2.1984, P. 23.

13/ Counc1l Decision of 14 March 1989 adopting a research and technologlcal development programe in the fleld of the decommissioning of nuclear Installations. OJ $N^{\circ}$ L $98,11.4 .1989, p .33$.

14/ The Conmunity's Research and Development Programme on the Decommissioning of Nuclear Power Plants

- First Annual Progress Report (year 1980), EUR 7440, 1981.

- Second Annual Progress Report (year 1981), EUR 8343, 1983.

- Th1rd Annual Progress Report (year 1982), EUR 8963, 1984.

- Fourth Annual Progress Report (year 1983), EUR 9677, 1985.

15/ The Community's Research and Development Programme on the Decommissioning of Nuclear Installations

- First Annual Progress Report (year 1985), EUR 10740, 1986.

- Second Annual Progress Report (year 1986), EUR 11112, 1987.

- Th1rd Annual Progress Report (year 1987), EUR 11715, 1988.

- Fourth Annual Progress Report (year 1988), EUR 12338, 1989.

/6/ Schaller, R H, Huber, B (ed). Decoumissioning of nuclear power plants. Proceedings of a European Conference held in Luxembourg, 22-24 May 1984. Graham \& Trotman Ltd, London. EUR 9474 EN. 


\section{DISCUSSION}

Question: SFINZI, CEC - What are the priorities in R\&D programmes and in particular for the Community programme from the point of view of the licensing authority?

Answer: M LAVERIE, SCSIN - I attach particular importance to R\&D and other studies devoted to preparing the dismantling of major and multiple installations on an industrial scale.

Experience gained so far has been mainly with small, individual installations, frequently highly specific. We should now start preparations for major future dismantling programmes on the large reactors, and the technological procedures, guidelines and codes (such as 'de minimis' criteria, for example) should be drawn up at international level.

Question: L GILLON, SCK/CEN MOl - When do alterations to the installation require a new licence? eg change of steam generators, or removal of steam generators from a reactor after final shutdown?

Answer: M LAVERIE, SCSIN - A new licence is necessary when changes to the installation and its safety characteristics are considerable. This is not the case if the steam generators are to be replaced in a reactor by generators largely identical (this operation represents no more than major maintenance work). However, any partial dismantling programme which includes the removal of the steam generators must be duly licensed.

Question: M CONTI, ENEA - In the conclusions drawn in the paper it is stated that it is the responsibility of the plant operator to choose the time, methods and technology most suited to the task of decommissioning. In my view this freedom of choice subordinates the supervisory authority to the plant operator. It is the safety and protection of workers, the population and the environment which must be ensured, and it is therefore the responsibility of the supervisory authority to impose the action to be taken whenever the plant operator has different plans.

Answer: M LAVERIE, SCSIN - The nuclear plant operator must be made responsible in the first instance for safety. The public authorities must set the targets for safety. It is, however, for the operator to propose the technical ways and means of achieving these targets. The supervisory authority will then judge whether they are adequate and will monitor their implementation. This applies also to decommissioning. Differing approaches (in particular with regard to the time scale) may also be safe, provided that safety precautions are taken, which take account of each individual case. The operator must therefore justify and implement safety measures which may be more or less stringent, depending on the choices he makes. The licensing authority must ensure that they are respected.

Question: H L BERMANIS, United Engineer and Constructors International Since the cost of money for construction is such a large proportion of the facility cost, in cases where schedule stretchout raises the facility cost very substantially, do you still maintain that decommissioning costs are in the range of 10-208 of facility cost?

Answer: J ESSMANN, UNIPEDE - Yes, as I mentioned, the decommissioning costs of each nuclear power plant will be calculated anew once a year, taking into account inflationary aspects as well as all other technical and administrative effects influencing these costs. The figure of 108-208 of the 
facility cost is only true for power plants that are in the size range of 900-1300 Mwe. With respect to smaller power plants these figures can be much higher compared to the construction costs. Insofar as the decommissioning cost should be specified generally, eg as cost per kwh per 25 years of production, the cost $w 111$ be in the range of maximum $0.004 \mathrm{DM} / \mathrm{kWh}$.

Comment: B W EMMERSON, HM Nuclear Installations Inspectorate - I would like to stress the need to take into account future decomissioning requirements during the operating phase, to take advantage of the experience gained during the 20-30 year operating life of a NPP, for example, during shutdowns for refuelling, mantenance and, especially, for major in-plant modifications. I would advocate that from the commencement of the operation stage, the future needs of decomissioning should be addressed in order to extract the maximum experience from this period. One means of providing this experlence is to establish a decommissioning-oriented specific task-related and dose-rate-related databank. This is similar to the provision of the data needed for the successful implementation of the ALARA principle. The data would supplement the in-built design stage provisions.

Comment: MS T PRICE, UKAEA-Winfrith - relating to Mr Essmann's paper. One aspect which has not been mentioned is the large-scale effect in relative costs of decommissioning nuclear reactors. Small reactors are relatively expensive to decommission. If I compare the cost of decommissioning the $20 \mathrm{MW}(\mathrm{th})$ Dragon reactor with the cost of decommissioning a single Magnox gas-cooled reactor, the Magnox to Dragon is probably less than a factor of two. There are good reasons for this. Dragon is only about the size of two dustbins and its decommissioning is rather like 'reverse remote watchmaking'. In contrast, decommissioning of large power reactors can be effected using industrial-scale techniques with possible advantages if replication of reactor design has occurred.

Turning to financing, as Mr Essmann has said, the decommissioning of large power reactors can be charged to electricity users during reactor operation. But small research reactors lie generally in national institutes. Their decommssioning is therefore likely to be dictated by the availability of funds from central government.

The small research reactors were built in the early years of nuclear energy and hence are approaching retirement (or have been retired). We should ensure that this scale effect is made very clear so that extrapolations to large reactors by the public are not wildly pessimistic.

Comment: P FUNKE, Ministry of the Environment and Reactor Safety, Wiesbaden - Table 3 of the first presentation seems to indicate that the Alkem fuel fabrication plant has been shut down. That is not true: Alkem fuel fabrication plant at Hanau is still in operation. It may be that Table 3 refers to the Alkem plant in Karlsruhe, which was transferred to Hanau in 1970-72.

Comment: L DUSSAIWOIR, Banque Nationale de Belgique - Mr Gregory stressed that costs for dismantling could be acceptable. Mr Essmann indicated that costs may vary from 10 to 208 , even to 30 (say one to three times more) and that the real costs can only be known by dismantling a large-scale installation. On the other hand, Mr Huber reported that the area related to the influence of design features on decommissioning will not be continued under the new five-year programme. Taking into account that the amounts considered are very important, the range of 10 to 30 seems fairly wide with respect to the formation of a realistic financial provision based on calculations, especially if in future the design features to facilitate the assessment of dismantling costs are not foreseen for new installations. 
Comment: B HUBER, CEC - I would like to make a comment on the absence of an R\&D project on installation design features, from the new five-year programe (1989-93) of the EC, and a comment on the impact to be expected from further R\&D work in this area, on the cost of decommissioning.

Installation design features facilitating decomissioning have formed a subject of R\&D projects of EC programmes for the past ten years, and a number of the ideas investigated are today state-of-the-art design features. Towards the end of this period, the valuable R\&D subjects seemed to be exhausted. It appeared expedient, therefore, to draw a balance of the wealth of results accumulated, analysing them together with the installation manufacturers and operators, in order to evaluate the extent to which the proposed design features constitute real improvements, considering their impact over the whole installation life, not only the decommissioning phase. This analysis will be made under section B, 'Identification of Guiding Principles', of the new programme; it may lead to the identification of useful complementary R\&D work.

Such future R\&D work, however worthwhile, should not be expected to change the cost of decommissioning drastically ( $I$ would expect greater benefits from improved procedures for decommissioning and material management). One reason for this is that the greatest improvements with respect to early plant design (eg, plants being presently decommissioned) have already been incorporated into modern plants or are ready for incorporation into tomorrow's plants. It must also be kept in mind that design features facilitating. decommissioning usually cost an incremental investment, whose importance in relation to the benefit is increased by the necessary discounting over the time period between the expenditure (ie, time of construction of the installation) and the realisation of the benefit (ie, time of dismantling, depending on decommissioning strategy).

Question: E SKUPINSKI, CEC - Mr Essmann could you comment on the importance of reducing contamination levels from 10 to $1 \mathrm{~Bq} / \mathrm{g}$ on the costs of radwaste?

Answer: J ESSMANN, UNIPEDE - If you have to reduce the contamination levels from 10 to $1 \mathrm{~Bq} / \mathrm{g}$ you have to do more decontamination work, make more cuttings, altogether you will produce more waste packages and the necessary measurements will be very expensive.

Question: P DEJONGHE, SCK/CEN Mol - You mentioned at least two areas of uncertainty: the definitions of 'green field' and the final destination of the waste. Could you comment on the margin of uncertainty which these issues represent in your cost evaluation?

Answer: J ESSMANN, UNIPEDE - Insofar as the calculation we have done takes into consideration the 'green field' conditions, there are no uncertainties in our cost calculation.

\section{CONCLUSION}

The first session of a Conference is often the mirror of the following days. Presentations were made by four speakers, A Gregory, M Laverie, $J$ Essmann and $B$ Huber. Thanks to their having different responsibilities in their respective organisations in the frame of decommissioning nuclear installations, a lot of material for reflection and relevant questions were raised from the floor.

Licensing procedures, cost of decommissioning and impact of R\&D on decommissioning techniques were the main subjects of discussion. The liaison 
between decommssioning operations and radiation protection was also stresged.

There is a need to prepare in an adequate way the large-scale operations: until now, decommssioning and dismantling has been limited to relatively small plants and installations. This means that an effort should be made in order to extrapolate the results of the work performed by the different organisations, and to extend it to industrial installations. I think that the discussion of today, and certainly the discussions which will follow in the next few days, will contribute to the understanding between sclentists, decomissioning experts, owners of nuclear installations and involved authorities. The goal will be to approach clear ideas for a global strategy of decomissioning, and I hope this will give us the chance to make nuclear energy more undergtandable to the public and, thereby, make it more acceptable.

S FINZI, CEC 



\section{SESSION II}

\section{ASPECTS RELEVANT TO DECOMMISSIONING STRATEGY}

CHAIRMAN: A GREGORY, CEGB, UK

SECRETAR Y: E SKUPINSKI, CEC 

STRATEGY OF NPP DECOMMISSIONING IN THE IEA NPPD MEMBER STATES

YE LARIN, V. KREMNEV, V. YELIN, S. GAVRILOV (USSR)

E. HLADKY, M. BOSANSKY, S. STRAPEC, K. SCHUBERT (Czechoslovakia)

S. NOZHAROVA, TS DELCHEVA, S. DANCHEV (Bulgaria)

\begin{abstract}
Summary
Member States of the International Economic Association for Nuclear Power Plant Decommissioning (IEA NPPD) have developed a concept of closure of NPP units after final shutdown. The concept includes both extension of lifetime and decommissioning according to different options. The basis for scientific technical support of the effort is the CMEA member states' programme for closure of VVER reactor plants and the national USSR programme for NPPs with other reactor types.

Codes and standards documents have been formulated and are under development covering such areas as nuclear and radiation safety and also regarding unrestricted use of the materials of NPP units being dismantled. A Code regarding the funding of NPP decommissioning efforts has been prepared.

Pilot versions of remotely controlled manipulators to dismantle the graphite layer of Belovarskaya NPP Unit 1 have been developed; other types of manipulators for dismantling are under development. Decontamination techniques are being improved including processes of hard decontamination and remelting. Efforts are under way to decomission NPP units in the USSR and Czechoslovakia.
\end{abstract}

The CMEA countries' Comprehensive Programme of scientific and Technological progress Through the Year 2000 addresses the problems of nuclear power plant (NPP) refurbishing and dismantling following expiration of their lifetime. IEA NPPD* specialists have developed a concept of NPPU closure. NPPU closure presents a set of measures aimed at performance of work in compliance with the chosen option, i.e. NPP life extension or decommissioning following final shutdown and appropriate unit preparatory phase, as well as personnel, public and environment safety assurance.

Preparation for decomissioning and decommissioning itself are the final stages of NPUU life cycle which includes construction, commissioning and operation proper as well.

The reasong for the final shutdown of NPPU are as follows:

- explration of specified lifetime;

- an accident rendering further operation impossible;

- changes in requirements for operational reliability and safety which cannot be met with the existing construction,

- uneconomic operation.

Almost all these factors had already been taken into consideration when taking decisions on decommissioning, for example: after 20 years of

\footnotetext{
IEA NPPD International Economic Associatıon for NPP deconmissioning
} 
operation Novovoronezh NPP Unit 1 was finally shut down; or Armenia NPP, which must be decommissioned due to changes in requirements for reliability and safety.

Lead time to decommissioning of NPPU is the period when the plant operational personnel bring the unit into a nuclear safe state. In addition, this stage involves removing waste and planned maintenance of the necessary equipment and systems. Specified lead time for decommissioning is also characterized by the requirements for reducing the activity level of equipment buildings and structures due to decay of short lived nuclides (unit 'hold').

To carry out work in radiologically hazardous conditions, comprehensive R\&D/design work as well as manufacturing, testing and implementation of devices for hard decontamination and radiation resistant robotics, should be undertaken. Such issues as erection of storage facilities or repositories for waste with different activity levels, manufacture of transport containers, devices reducing the volume of dismantling wastes and their separation from materials to be reused, should be considered separately.

\section{METHODOLOGY OF STRATEGY SELECTION}

By 1989 in the USSR only 4 NPP units, 2 pilot and other commercial facilities of 1150 MWe capacity, will have been finally shut down; another unit will be shut down this year. Due to the necessity to carry out comprehensive R\&D and design work up to the year 2000, some 10-15 NPPUs including 1000 MWe units will be shut down. A sharp increase in the number of 'spent' units ( 30 years of operation) is expected early in the next century.

In Bulgaria the 'Kozlodui' plant has been in operation for 15 years already. Arrangements to extend its life following its expired specified lifetime or to start decommissioning should be made right now.

In Czechoslovakia also lifetime extension is regarded as a promising option. Besides, decommissioning of Al unit shut down in 1977 has started.

According to a preliminary assessment, the cost of NPPU dismantling involving disassembly of equipment and systems, destruction of buildings and structures of VVER 1000 unit and removal of wastes from the site, will make up 308 of NPP total cost. The total cost depends heavily on the amount of radwaste which accounts for approximately 5-20.10 $t$, on the methods of their treatment and separation from waste which can be reprocessed for restricted and unrestricted use.

In 1987-1988 in the USSR an ALL Union Scientific and Technical Programme on NPP Decommissioning was developed. It includes some work being done by IEA NPPD. The experience of IAEA and Western countries was taken into acount during the development of this programme. It is clear that uncritical use of this experience could result in the selection of an inefficient strategy of NPP decommissioning in the USSR and other countries.

In the socialist society where manpower appears in the role of aggregate manpower on a social scale, the basic criterion of strategy selection is national economic efficiency. At the same time the most part of the social and a considerable part of industrial infrastructure has been of social advantage by the expiration of NPP specified lifetime.

The main factors which determine the strategy and meet all criteria of its selection are the requirements for safety assurance, environmental, economic and socio-economic and health factors, level of technological support of decommissioning, availability and characteristics of storage facilities and repositories for waste of various activity levels, possible timescale of work. 


\section{OPTIONS OF NPP CLOSURE}

To Improve or malntain NPP performance and assure its safety, varlous measures are provided for during operation. Though these measures are not directly almed at NPPU life extension, equipment and systems service life extension by means of their repair or replacement does in some cases make it possible to choose the life extension option. On the other hand, during NPP operation requirements for nuclear, radiation and general safety can change.

The well known examples are the more stringent safety requirements imposed following the TMI and Chernobyl accidents. In the case of more stringent requirements, decommissioning, refurbishment or upgrading of NPPU should be carried out. The cholce of the option is based upon aggregate cost of work performed including economic assessment of the collective occupational dose. Figure 1 gives an example of the list of measures preceding NPP closure operations as well as the suggested timescale.

The set of measures extending the service life of some equipment components covered by a common programme can be regarded as NPPU upgrading almed at life extension provided it covers all critical components. For VVER type units the following components are regarded as critical: reactor pressure vessel, primary circuit pipelines and cables, steam generators.

Service lives of separate systems should be agreed in the programme and additional measures should be provided for if necessary. These measures may be aimed at safety improvement based on synergetic effect of reliability of separate equipment elements or redundancy of its safety systems.

The main conditions of NPP life extension is assurance of its safety. This condition is closely related to the problem of NPP equipment and system ageing and accuracy of determination of their residual service life. In some cases to extend specified lifetime standard reduction of installed capacity accompanied by reduction of equipment and structures load may seem justified. Thus even a small reduction of VVER thermal power due to appropriate protective measures allows to reduce fast neutron fluence on pressure vessel by a factor of $3-5$ and considerably extend its lifetime.

Figure 1 shows that the final option of a specific NPPU closure should be selected on a step by step basis. Using the results of a preliminary feasibility study the option for a particular NPPU is chosen. Criteria establighment 13 not included in these measures; they should be formulated by independent organizations (competent bodies) having all the necessary information and based on a comprehensive prediction of the long-term development of the nuclear power industry as a whole. The decision on Armyanskaya NPP dismantling provides an example of such a choice.

Figure 2 shows some ways of implementation of the basic option. The decision on preparing the project is made based on option comparison and feasibility study including assessment of the collective equivalent dose.

\section{LIFETIME EXTENSION}

Early in this decade most countries did not give proper consideration to NPP upgrading and refurbishment, though feasibility and engineering studies were undertaken in some. The situation has been changing lately, since the cost of NPPU life extension is estimated to be considerably lower than that of construction of replacement power facilities. At the same time the problem of NPP decommssioning will be postponed which allows to provide material and technological support and to accumulate additional funds for this purpose. 


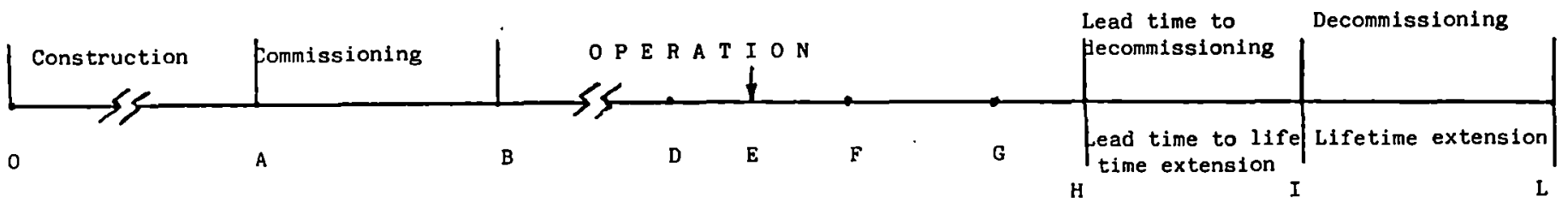

Fig. 1. NPP life cycle

O-A construction

A first critical stage

A-B comissioning

A-H operation

D start of processing data for selection of NPP closure option

$D-E$ expert feasibility study of the basic stages according to the chosen option

E establishment of criteria and selection of NPP closure option

F selection of the option

F-G development of the project according to the chosen option

G-H project updating

H final shutdown of the unit on expiration of the specified lifetime

H-I lead time to the work

I-L lifetime extension or decommissioning

For the first in the series unit with the specified lifetime of 30 years the tentative timescale is as follows:

A-D 17 years; $A-E \quad 20$ years; A-F 22 years; $A-H \quad 30$ years.

These values can vary with changing of a specified lifetime.

Time of preparation and holding can vary from several months when extending lifetime to lo years during decommissioning. L-K can vary from 10 years (immediate dismantling) to indefinite time (entombment). 


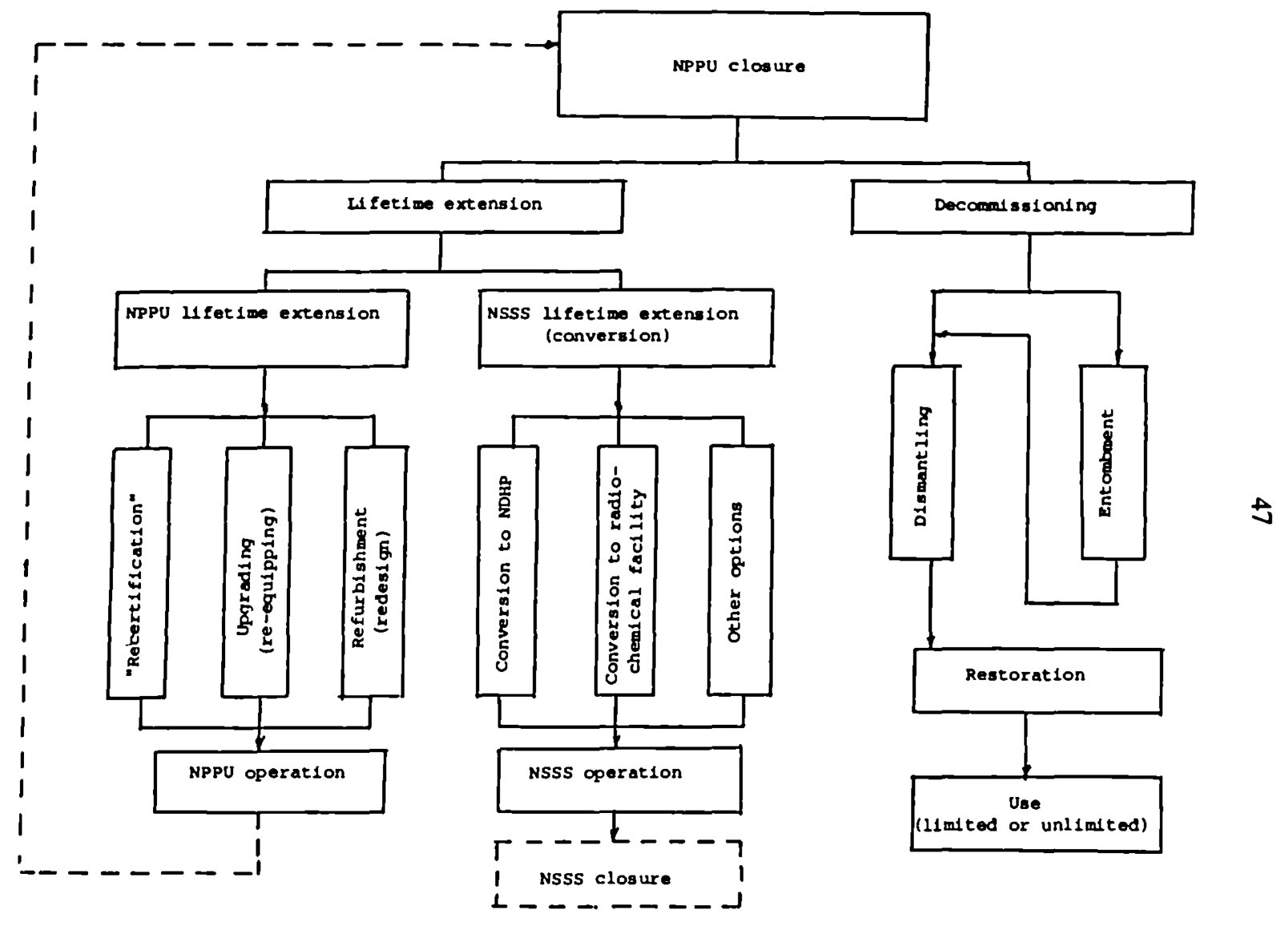

Fig. 2. Options and stages of NPPU closure 
The organization of CMEA countries participating in IEA NPPD regard the following options of NPP life extension as the most promising (Figure 2)**:

- 'Re-certification' of NPPU - an option providing for reliable operation of equipment and systems beyond their specified lifetime following detailed diagnostics, maintenance and repair;

- Upgrading - an option providing for restoration or improvement of NPPU performance within the framework of the existing NPP design;

- Refurbishment - an option providing for criterion of a new design on the basis of the unit different from the existing nuclear facility with preservation of the unit functions.

Besides the advantages mentioned NPP life extension allows a reduction in the number of NPP units and sites and improves NPP personnel living standards with the same power generation rate.

It should be pointed out however that NPPU iife extension may prove inefficient. Although in 1988 USSR specialists resolved the problem of high temperature annealing of pressure vessel components, and steam generator replacement has become almost a routine operation in Western Europe and the USA, many issues concerning NPP life extension, including accurate determination of the residual service life and replacement of large size components, remain unresolved.

Conversion is also one of the options of NPP life extension providing for the change of its functions (Figure 2). In particular, construction of large capacity nuclear reprocessing facilities seems very effective. Combined production of radiochemical materials and electricity with slightly reduced power supply could be arranged. For this purpose units to be decommissioned can be utilized as well. Some NPPs in CMEA countries, e.g. Beloyarsk and Bohunice plants, use nuclear heat to supply hot water.

Conversion of 'spent' units to nuclear district heating plants (NDHPs) and especially to nuclear power and district heating plants (NPDHPs) may prove efficient for countries with NPPs located in the vicinity of large consumers of low potential energy. Other ways of multi-purpose use of nuclear units are also possible. In the USSR the water desalination facility based on Shevchenko NPP has been in operation for a long time already.

Replacement of a nuclear reactor by a fossil-fired plant is possible. Such an approach could be used in the case of Armenia NPP for example. However, this option should be regarded as decommissioning since the nuclear island and contaminated auxiliary buildings and structures should be dismantled and the site cleaned. In any case, fossil fuel mining is tending to decrease in the European part of the USSR, also in the Urals and in most CMEA countries.

\section{NPP DECOMMISSIONING}

Decommissioning is the best studied option in CMEA countries participating in IEA NPPD.

In CMEA countries a multi-unit construction approach is used (except Obninsk and Shevchenko NPPs). Enlisting of NPP personnel for the monitoring and maintenance, as well as the general monitoring system of the mothballed Irrespective of the way of lifetime extension, the commissioned NPPU is recorded as non similar to the previous one, if the work is performed on expiration of the specified lifetime. Preparation for life extension and the extension itself are independent phases of the unit life cycle; these phases are similar to the construction phase. 
and operating units, contributes to the reduction of current monitoring and mantenance of the shut down units. The situation, however, may change if the number of NPP sites is reduced. Some rooms of the shut down unit can be used for testing and adjustment of the repair equipment and robotics used for units under operation and design. These units can be used for proving decommissioning options and 1 ifetime extension, in particular when the time is limited and personnel tralning is required. Some premises of a shut down unit can be used as storerooms or perhaps as a storage facility for wastes of this particular or operating unit.

Operation of any NPP, irrespective of how its equipment and rooms were used following final shutdown ( 1 ifetime extension included), is followed by a general dismantling stage which includes dismantling of radioactive equipment, systems, buildings and structures of the unit and structures common to the plant, as well as disposal of radwastes exceeding activity level allowing their unrestricted use. Radiation monitoring of an NPP site and protective zone can be stopped only following restoration decreasing radloactivity to the level allowing their unrestricted use. Unit mothballing for several decades is possible. It provides for the utilization of some standard systems (e.g. vent system and power supply) and continuous inspections of the unit equipment, systems and structures as well as site monitoring and safeguard.

It must be emphasized (see Figure 2) that entombment is not the final stage of decommssioning since the lifetime of artificial barriers is shorter than the time necessary for the decay of isotopes accumulated during NPP operation to the level allowing unrestricted use of buildings, Jtructures, equipment and site (fuel and operating wastes are removed during the preparatory phase of decommissioning). Entombment of nuclear reactors damaged as a result of accidents (Chernobyl in the USSR and windscale in the UK) is a separate problem. Considerable amounts of fissile materials remained inside the containment (existing or constructed). These facilities present a radiological hazard. Even after decades of holding, the activity level of these materials and structures will not allow dismantling to be undertaken without using remote devices. In windscale, for example, this work is planned to be undertaken in 30 years.

\section{CURRENT STATUS OF DECOMMISSIONING IN IEA NPPD MEMBER COUNTRIES}

In the USSR the requirements to develop decommissioning projects appeared in the Regulations in 1982. A separate issue of the 'Health Rules ... 89/79' 13 devoted to NPP decommissioning. This is the first document which determines the health rules to be met during decomissioning; requirements to decommissioning plan and provides definition of NPP closure.

IEA NPPD has developed and is developing the following documents: 1. Methodological and Codes/Standards Documents for NPPU Closure,
including:

- Terms and definitions both for NPPU closure and related areas, e.g. robotics;

- Basıc Guidelines and Programme of NPPU decommissioning;

- Guides for assurance of nuclear and radiation safety during NPPU closure;

- Standards to provide permissible activity levels of dismantled materials for their unrestricted use;

- Requirements for new NPPUs under construction from the point of view of facilitating decommissioning operations;

- Guide for the funding of NPPU decommissioning efforts. 
In addition, work on the following documents has started:

- Basic Guidelines of the Project of VVER 440 unit decommissioning;

- Guide for extension of NPPU' lifetime.

2. Engineering and Design Development, including:

- Processes and equipment for hard decontamination of components, systems, buildings and structures of NPPUs subject for decommissioning or modification (metal and concrete structures separately);

- Robotics for the dismantling of activated and highly contaminated equipment, systems and structures;

Temporary working spaces for the disassembly of equipment, systems and structures of NPPUs and for cutting, packaging and transportation within the plant site.

3. Experimental and Industrial Scale Work

- At present comprehensive engineering examination of the Novovoronezh and Armenia plant units is under way.

- In 1990 efforts will be started to prepare Armenia NPP and the first stage of Novovoronezh NPP for decommissioning.

- Examination of Beloyarsk NPP Unit 1 is in progress, including the graphite layer, to undertake complete disassembly of equipment. Experimental work is underway on hard decontamination and remelting of contaminated components of the primary circuit.

- Partial dismantling of the secondary circuit of Bohunice Al plant has been completed. Preparation for the dismantling of the nuclear island of this plant, for decontamination and remelting of contaminated components, is underway.

\section{CONCLUSION}

Implementation of the options for NPP closure described, as well as ways of NPP life extension and decommissioning, gives actual experience in the development and application of guidelines and design documentation, technology and equipment.

Selection of the option is determined by external criteria, feasibility study and the systems effect in the industry.

Considerable extension of NPPU specified lifetime will reduce the number of NPPs necessary to generate the required electricity and consequently the number of units to be decommissioned. The number of sites for new NPPs will also be reduced. Lifetime extension, however, is possible provided that NPP operation safety is assured.

The problem of NPP closure is also an ecological one.

Erection of storage facilities and repositories for the dismantled radwastes, their transportation and disposal, is a specific task.

Moreover, since the USSR is an exporter of NPPs (designs and essential equipment) it must provide for the possibility of NPP decommissioning (following an acciaent as well).

In the broad sense, NPP closure contributes to safety improvement of nuclear power as a whole.

Timely and proper selection of the basic options and their implementation allows an increase in the national economic efficiency of nuclear power and makes it safer. 
DETERIORATION ASSESSMENT OF NUCLEAR PONER STATION BUILDINGS AND LONG-TERM STABILITY AND THE LEAK TIGHTNESS OF REACTOR CONTAINMENTS

\author{
D.C. POCOCK \\ Taylor Woodrow Construction Ltd, \\ Southall, Middlesex, U.K. \\ H. VAN EXEL, R. OBERPICHLER \\ Stangenberg, Schnellenbach und Partner GmbH \\ Bochum, Germany. \\ D. BEUKELMANN, R. HUTH, B. ROSE \\ Technischer Uberwachungs-Verein Bayern e.v. \\ Munchen, Germany
}

\title{
ABSTRACT
}

Current suggestions are that complete dismantling and removal of reactors and associated bulldings and a return of sites to green field conditions may be delayed for up to about 100 years after plants cease generation. Throughout both their remaining operating life and the delay period structures are nevertheless expected to perform their intended functions efficiently. As existing power stations have been designed for comparatively shorter working lives, there is a requirement to assess the long-term performance of these structures.

\section{INTRODUCTION}

Investigations are undertaken into the likely durability and stability of reinforced concrete components of buildings and structures at nuclear power stations over the currently-envisaged period of up to 100 years for the completion of dismantling and decomissioning, as well as into the leak-tightness of the steel containments and steel liners. As sites for the studies, four UK and two German nuclear power stations are chosen, and information is also obtained from other plants in France and Italy. The main elements of reinforced concrete and the prestressed concrete structures of reactor bulldings are selected and investigated concerning their long-term performance, that is a period of about 100 years after decomissioning. A survey over the general long-term behaviour of the structural elements, and especially of their components concrete and reinforcement steel is gathered by evaluating the current knowledge in the literature. As far as the reinforcement is concerned, the corrosion mechanism is important, and surveys of available components are undertaken in this respect. Furthermore, long-term examinations of silicon sealing materials used in safety-related areas are performed. and also non-destructive ultrasonic tests on a component and calibration blocks to confirm that it is possible to detect corrosion in non-accessible areas. 


\section{REINFORCEMENT CORROSION IN CONCRETE}

\subsection{Corrosion Process}

The following sections present a concise summary of relevant details of the processes included when reinforcement corrodes in concrete. Greater attention is paid to the first stage, namely corrosion activation, which is generally the key to predicting reinforcement corrosion timescales; this is then followed by a shorter review of the second stage, corrosion propagation.

In freshly-placed concrete, reinforcement steel is protected by the high alkalinity of the surrounding cement paste, around pH 12.5-13, resulting from the cement hydration process. This causes the steel to be passivated, that is to say protected from corrosion. With time, however, this alkalinity becomes reduced as a result of the neutralising effects of carbon dioxide diffusion into the concrete from the atmosphere (carbonation). Furthermore, the ingress of corrosive salts, primarily chlorides, destroys passivation and causes corrosion even under the highly alkaline environment in concrete. The time taken for the depth of carbonation (slow) or chloride penetration (quicker) to become equal to the depth of concrete cover over the reinforcement is known as the initiation time $\left(T_{0}\right)$, as shown in Fig 2.1. In the case of carbonation the length of the initiation period is determined by how rapidly atmospheric carbon dioxide neutralises the concrete cover to $\mathrm{pH}$ values below 9 . In the case of chloride attack, initiation time $\left(T_{0}\right)$ is controlled by the mechanism of chloride transport into concrete and the time for a threshold chloride concentration to be exceeded at the depth of reinforcement.

After initiation, the rate at which the corrosion progresses is determined by the rates of the anodic and cathodic reactions, i.e. by the resistivity of concrete, the availability of moisture and oxygen, the temperature and the anode:cathode area ratio. Assuming an adequate supply of oxygen and water, corrosion proceeds for a second period ( $T_{1}$ ) until the amount of corrosion products formed is sufficient to cause cracking and eventually spalling of the concrete.

This two-stage process is shown diagramatically in Fig 2.1, together with a summary of the factors involved.

The process of corrosion occurring on reinforcement has various consequential effects, including the following:

a) One or more visible effects, such as rust-staining, cracking, spalling or delamination of the concrete surface may develop; each of these may be aesthetically undesirable.

b) Chips, fragments or lumps of concrete, collectively referred to as 'spalls'. falling from an elevated position clearly may present a safety hazard; elsewhere such pieces have been found to travel surprising distances in high winds.

c) Loss of steel by corrosion results in a reduction of cross-sectional area of reinforcement, and eventually an impairment of load-carrying capacity; 'pitting' corrosion can effectively 'chew' through a bar in a very concentrated fashion, sometimes even with little externally visible evidence that corrosion is occurring. An associated reduction in ductility increases the risk of sudden failures of bars at low deflections of members.

d) The presence of corrosion causes loss of bond between concrete and reinforcement, which, when extended over substantial lengths, can also impair capacity. 
e) Spalling of cover concrete together with substantial corrosion of links, results in an increased risk of buckling failure of compression reinforcement .

In the case of nuclear stations, generating lives of typically some 30 years were envisaged, and it would be easy to regard this timescale as the lifetime required of the structures. Compared to such a lifespan, concrete structures involved in this programe were approximately 20-30 years old when surveyed.

When considering the deterioration of concrete structures at nuclear power stations, it is also necessary to allow for the timescales associated with decomissioning. Current suggestions are that the complete dismantling and removal of reactors and associated buildings and a return of the site to green field conditions may be delayed for periods ranging from several decades to about 100 years after the plant has ceased electricity generation. The time delay is anticipated to lead to reduction in radioactivity levels and, thereby, to make the dismantling process easier.

Taken overall, therefore, the construction and generating periods of the station and the maximum decommissioning period where applicable, could represent a total lifespan of up to about 140 years. In the case of stations included in the work described here, some 110-120 years remain.

Hence the study described here aims to estimate the likely deterioration rates in reinforced concrete structures at nuclear stations, as a basis for inspection and maintenance in the future.

\subsection{Environment}

As a result of the need for convenient supplies of cooling water, many of Britain's nuclear power stations are located near or on the coastline. Therefore the buildings are exposed to coastal environments, of which the most significant feature affecting reinforced concrete durability is the airborne sea-spray carrying salt. Experience gained from studies of coastal and marine concrete structures, beginning with the 1970's 'Concrete-in-theOceans' programme, showed that the 'splash' zone of a structure i.e. just above high tide, is the most severely exposed in terms of reinforcement corrosion risk; other studies have shown that airborne salt can be blown a considerable distance inland according to prevailing winds. The severity of the environments and the effect of salt-deposition at the nuclear sites included in this project was clearly demonstrated by the fact that various cladding/glazing-fixings, pipe-hangers and other exposed steel components had required replacement.

other 'artificial' marine environments were associated with specific structures, such as cooling water inlet/outlets (CW) where very high levels of salt spray result from plant operations. Reinforcement corrosion and consequent cracking/spalling of structural concrete elements in one $\mathrm{CW}$ area inspected was the most advanced deterioration due to reinforcement corrosion observed during the project; this demonstrated the severity of that enviroment.

The relevance to this project, of concrete performance in the external environments and particularly coastal environments, is to indicate the potential threat to durability that must be designed against in decommissioning especially in respect of structures which will remain through the maximum time period.

The other main cause of reinforcement corrosion activation, carbonation, is much less likely to be significant in externally-exposed structural concrete, particularly since in northern-Europe such concrete is 
generally subject to regular wetting and drying which tends to result in very low carbonation rates. However, the following aspects of the 'indoor' environment of nuclear buildings combine to result in much more favourable conditions for concrete carbonation.

a) little or no wetting and drying (Fig. 3.1);

b) relative humidities, typically in the range 50-758 $\mathrm{RH}$ which would be regarded as favourable for carbonation (e.g. Fig. 2.2);

c) temperatures often above well ambient (e.g. up to $47.5^{\circ} \mathrm{C}$ measured in some buildings);

d) the possibility for carbon dioxide leaks, which would increase atmospheric $\mathrm{CO}_{2}$ levels, and hence accelerate the process;

Wetting of the concrete, which lowers the concrete's electrical resistivity and permits corrosion currents to flow, is rarely a limiting process in external concrete, and times to corrosion damage $\left(T_{1}\right)$ as short as 5-10 years after corrosion activation are not uncommon.

However, several measurements of concrete resistivity in the range 5-15 k-ohm-cm (i.e. able to support corrosion) were recorded on concrete subject to steam leaks, drips from pipe-joints, washing-down of floors etc. Further possibilities may exist of much increased wetting during decommissioning periods, due to such effects as condensation and progressive deterioration pipes, joints, window seals, and even facade cladding. These later effects could also result in airborne salt-spray deposition on internal concrete surfaces.

overall the environmental considerations may be sumarised as follows (refer also to Fig. 2.2):

a) The external concrete is presently exposed to coastal, saline environments conducive to chloride-induced corrosion;

b) Internal environments are conducive to carbonation of the concrete, but corrosion of reinforcement is at present unlikely to proceed at a significant rate owing to, at worst, only localised wetting;

c) The potential exist for indoor concrete, carbonated during the station's operating life, to support increased corrosion rates later in the overall service period.

\subsection{Sampling and Testing}

At stations available for the work, surveys began with planning visits for discussions with staff, selection of specific work locations and to facilitate preparation of survey specifications. As identified above, exposure and performance of the concrete were expected to differ significantly in external and internal environments, so areas of both externally and internally exposed concrete were selected.

Following preliminary visits, the surveys were performed including the following main categories of work, (Fig. 2.3).

a) visual inspection

b) non-destructive testing (N.D.T) in-situ

c) sampling and laboratory testing

Data was collected using the following N.D.T. and sampling techniques, to estimate present and future extents of corrosion.

a) Reinforcement Potentials: Non-destructive measurement of electrochemical potential of reinforcement in concrete using the 
potential-wheel technique of surface scanning, as in fig 2.4; enables the present extent of corrosion activation to be estimated.

b) Depth of cover to reinforcement: Non-destructive measurement by electromagnetic 'covermeter', to locate reinforcement and estimate Its diameter and the thickness of concrete cover

c) Chloride content profile: Measured by incrementally collecting dust drillings, and subsequent chemical analysis. The resultant profiles of chloride concentration against depth into the concrete were then mathematically analysed to obtain the parameters necessary for estimating the chloride concentrations likely to accumulate at reinforcement depth over the timescales of interest, as in Fig. 2.5 .

d) Depth of carbonation: measured by drilling or otherwise forming a shallow hole in the concrete surface and spraying a freshly fractured surface with a chemical indicator solution. Data collected were then compared with depth of cover results, and used to predict when carbonation would penetrate to reinforcement (Fig. 2.6).

e) Concrete Resistivity, measured non-destructively by wenner 4-Probe method, at each selected survey location.

f) Moisture Content, measured by analysis of incrementally collected dust drilling.

g) Laboratory tests on core samples, including water absorption and oxygen diffusivity.

\subsection{Sunmary of Results}

From surveys undertaken and the analysis of results, the following main results have emerged.

a) Whilst there was little if any reinforcement corrosion underway in internally exposed concrete, some externally exposed structures displayed various forms of cracking and spalling, either where cover was low, or in very severe local environments.

b) Chloride concentrations affecting reinforcement were generally low in internal concretes as expected. Some external concretes, however, contained appreciable concentrations of chloride; this data enabled prediction of the onset of chloride-induced corrosion.

c) Depths of carbonation were negligible in external concrete, but up to $50 \mathrm{~mm}$ in internal concrete, which was in excess of some reinforcement cover depths measured. This indicates that carbonation is likely to have penetrated to reinforcement in a percentage of the concrete and to have caused corrosion initiation. This extent of initiation is likely to increase considerably over the structures' total lifespan as a result of continuing carbonation penetration.

d) The consequent rates of corrosion propogation are likely to be high in external concretes, based on damage observations and N.D.T. results. Internal concrete may support corrosion rates of long-term significance if moisture penetration into the indoor environment is permitted to increase, which could be expected to occur with progressive ageing of the various building components. This should be taken into account in ongoing maintenance and planning of decommissioning operations. 


\section{LONG TERM STABILITY OF NUCLEAR POWER STATION BUILDINGS}

\subsection{Materlal Behaviour of Reinforced Concrete}

The single components of the composite material concrete and reinforcement have to fuifill different mechanical functions. The compressive forces are beared by the concrete and the tensile forces by the steel. To guarantee a long-term functioning of the composite material, in general the properties of both parts have to maintain. Due to the concrete this means avoiding severe deteriorations by carbonation and concrete corrosion and due to the steel avoiding severe attack by steel corrosion, as already is referred to in detail in chapter 2.

It is assumed that the concrete of the investigated plants, built in the FRG, has been manufactured according to the German standards DIN 1045 and DIN 1084. Hereby a high-quality concrete with a great strength and density is produced, based on specified requirements of the chosen concrete receipt. The base for the classification of concrete is the 28-day cube strength. On principle the strength increases till the final strength is reached. This will be obtained under the presence of sufficient humidity after some years. In the literature the increasing of strength was measured on a 30 years old structural member as example about more than $30 \%$. The development of strength is brought to an end at this time. The influence of humidity on the development of strength is shown in Figure 3.1 .

For the long-term deformation behaviour the viscous-elastic property has to be considered. Shrinkage as well as creep of the concrete have also been brought to an end during the operational state of the plant. The creepability diminishes with increasing concrete age as a result of the hardening process.

Not only the strength but also the modulus of elasticlty increases with time.

The influence of humidity on the deformation behaviour of concrete ef fects that concrete, which is under humid conditions all the time compared to a dryed out concrete has a higher creep capacity.

The durability of the composite material, in fact, is one of the most sensitive questions when looking after the long-term stability of concrete structural elements.

In general the concrete will carbonate only in the outer layer even after 100 years. It can be expected that concrete structural members will reach depths of carbonation of some centimeters after decades, see Figure 3.2:

Carbonation of concrete effects in the outer layers an increasing of its strength, the compressive as well as the tensile. Nevertheless the carbonation is important because of altering the protection for the steel from corrosion. By carbonation the steel may depassivate. If the environmental conditions will stimulate steel corrosion, this will lead to diminishing the bearing capacity of the cross section.

Structural concrete members protected against normal meteorological conditions, which means they are subjected to a more dry climate, are easier attacked by carbonation than in a molst climate. In this climate, however, electrochemical steel corrosion hardly will occur. Under such conditions deterioration of the composite material may scarcely occur. Only if the meteorological conditions often change damage of the composite material is to be suspected.

\subsection{Selection and Assessment of Structural Concrete Elements}

The research on long-term performance of structural elements of reinforced concrete and prestressed concrete of the reactor building of a nuclear power plant (NPP) is done to two different types of plants, built in 
the Federal Republic of Germany.

These are the reactor bulldings of a pressurlzed water reactor-station (PWR station) and of a bolled water reactor-station (BWR station). Both types of plant represent the actual state of technique. In the following to the PWR-reactor bullding is referred.

It 1s presumed that the plant will be correctly put out of commission after 40 years of operation. It is further presumed that the regarded reactor bullding has to fulfill its function due to stabllity even the following 100 years after decomissioning.

The main PWR structural elements which have been selected and invest1gated are the secondary containment, the reinforced concrete calotte shell bearing the steel containment, the lower part of the circle wall outside the steel contalnment and the foundation plate, see Figure 3.3. The whole reactor bullding is very bulky and 1 ts secondary containment is moreover bearing as a shell. Th1s secondary contalnment has to be investigated for it is the only structural element, which is directly exposed on 1ts outside to meteorological conditions.

In the following these selected PWR concrete structural elements are discussed according to their stability after decommissioning.

The design and the dimensioning of the secondary contalnment is moreover based upon the extraordinary loadcases due to a1rcraft 1mpact, earthquake as well as pressure waves from chemlcal reactions. After decommiss10ning the secondary containment is almost stable even with minimum reinforcement while the compressive strength of the concrete is utilized with a

range of less than 10 percent with regard to its dead load.

Extrapolation of damages due to meteorological conditions lead to eroslons of at the most a few millimeters only.

Presuming even bad environmental conditions, it is unlikely that the stability of this structural element is endangered during the whole time. It seems to be sufficlent to undertake regular visual checks. Eventually these checks will show, that 1 temlzed tests are necessary.

The lower part of the clrcle wall as well as the concrete calotte shell are deslgned for some load cases beside the operating state, e.g. earthquake, pressure test of the steel contalnment.

The mainly loaded reinforcement in the upper section of the investigated circle wall, where it is fixed in the calotte shell, is only stressed at a range of about 25 percent of the allowable stress during the operational state. In the remalning areas the circle wall is almost only subjected to compressive forces with a maximum ut1lization of about 20 percent. It can be concluded that visual checks are sufficlent enough maintaining the stability of the circle wall.

In contrary to the circle wall the reinforcement of the calotte shell will be ut1lized strongly already by dead load. The areas of highest strain are the upper radial reinforcement, these are the fixing points at the centre and at the change-over to the circle wall, as well as the radial and tangential bottom reinforcement.

Nevertheless it will be suggested to undertake routine visual checks and - dependent on this results - carbonation depth measurements. In any case damages like cracks or concrete spallings have to be repalred.

The foundation plate is designed for great extraordinary load cases, too. The reinforcement 1s ut 111 zed during the operational state locally up to about 80 percent. Monitoring the foundation plate is already handicaped by 1 ts position.

For having great reserves in stability it is obviously sufficlent making random test in great intervals. It is proposed to check the outer sealing construction once in a decade or dependent on the state in different intervals. 


\subsection{Recommendations and Monitoring}

Basing upon the general behaviour of concrete and reinforcement steel and regarding the long-term performance of these materials it can be concluded that the investigated NPPs, which have been constructed under the use of these materials with a very high quality grade and regarding strict manufacture requirements, will reach a very high life time.

Even for the proposed long period of 100 years after decommissioning it can be established, that the regarded NPPs will maintain a sufficient stablilty presuming the application of monitoring procedures.

It is recommended to apply these monitoring procedures periodically on the main structural elements, which are responsible for the stability of the buildings:

- Visual checks gaining a rough survey over the whole buildings and detecting corrosion endangered areas.

- Taking core samples as random tests of well-chosen areas, where preclse results are indispensable.

- Nondestructive tests, checking the concrete quality confirming

strength, carbonation depth and concentration of chloride. Some suitable test methods are for instance UPV-tests, percussion drilling and colourindicator tests as well as concrete cover measurements. Hence, steady deformation measurements should be applied at some relevant places.

Generally it is recommended for all inner structural concrete elements and especially for those, which are located in not accessible areas, to maintain moreover unchanged dry climatic and thus corrosion retarding conditions.

\section{LONG-TERM TIGHTNESS OF REACTOR CONTAINMENTS}

\subsection{Classification and Assessment of Damage Caused by Corrosion}

After decommissioning nuclear facilities it is essential, too, in view of contaminated or activated components, to guarantee the long-term leaktightness of the PWR steel containment or BWR steel liner and to assure integrity of important structures up to ultimate demolition of the plant. Therefore, with regard to safe enclosure over a long period, knowledge of possible long-term damage, especially as a result of corrosion at the steel containment, of possibilities of detecting such damage and of the long-term behaviour of sealing constructions is of decisive importance.

The investigations considered the reactor buildings and containments of German boiling-water and pressurized-water reactors. The investigation and assessment of the damage caused by corrosion was limited to the following areas which were classified as risk areas with regard to long-term corrosion risk:

- Mounting zone of steel containments of pressurized-water reactors (F1gure 4.1, Marking Y).

- Areas of the steel containments of pressurized-water reactors like adjoining platforms (F1gure 4.1, Marking X).

- Penetrations through the containments of pressur1zed-water reactors (Flgure 4.1, Marking 2).

- Steel liner of bolling-water reactors inside the pressure suppression pool (F1gure 4.2).

Apart from condensation water, cleaning water and reactor water were included in the considerations as corrosive medium. The results obtained for the given boundary conditions indicate that the occurrence of shallow pit corrosion and pitting corrosion has not yet been observed in detected damage cases. 
For the materials and medium conditions used here, values of between $0.09 \mathrm{~mm} / \mathrm{a}$ and $0.3 \mathrm{~mm} / \mathrm{a}$ were found in 11 terature for mass loss rates respectively erosion rates resulting from surface corrosion. Data on the corrosion velocity of shallow pit corrosion and pitting corrosion are generally not very reliable since they frequently depend on non-definable local conditions such as partly disturbed surface areas, e.g. In gaps, porosity of anticorrosive coatings etc. and cannot be described by spec1fic laws. At local points, this means that metal can be eroded quickly and that the corrosion velocity can be many times the corrosion velocity of surface corrosion.

As determined within the scope of the investigations to evaluate and classify corrosion damages, the integrity of the containment in the area of the elastic bedding (Flgure 4.3) and in other areas classified as risk areas can only be assured for the long perlod in question if design, operational, monitoring and upgrading measures are taken during operation and after decommissioning and if measures to dry the c1rculation a1r are implemented after decommissioning.

\subsection{Long-Term Behaviour of Plast1c Seals}

In the past, it was normal practice to use s1licon rubber for the seals of pipe penetrations through bullding sections or the containment as discussed here.

Within the context of this reserach project, extensive thermal aging tests were performed on 200 silicon samples (F1gure 4.4) over a period of 9000 hours at $25 \%$ compression strain. The results are given in Figure 4.5 . Comparative material tests were carried out in the as-new condition and after aging.

On the basis of the evaluation and extrapolation of the results as well as additional literature studies, it is possible to confirm that the s1licon material which is normally used to seal joints (at approx. 25\% compression and a maximum temperature load of $40{ }^{\circ} \mathrm{C}$ ) w11l have a satisfactory sealing function for many decades.

However, it is recommended that sealing points should be examined regularly, e.g. every 5 years, since the processing conditions (humldity, temperature, surface preparation etc.), which are not always constant, have a decisive influence on the life of the silicon material.

\subsection{Optimization of the Ultrasonic Testing Technique}

In order to detect possible corrosion damage in non-accessible areas such as the mounting zone of pressurized-water reactor contalnments, non-destructive tests were performed with the ultrasonic test technique.

These investigations showed that sufficiently pitted corrosion points already must exist for non-destructive tests using the ultrasonic test technique. In non-accessible areas 1t was possible to detect these corrosion points with $45^{\circ}$ angle beam search units within a range of up to 130 mm erom the upper edge of the mounting zone of the contalnment into the concrete (FIgure 4.6). 


\section{CONCLUSIONS}

Generally it is recommonded for all inner structural elements and especially those which are located in non-accessible areas to maintain unchanged carbonation- and corrosion-retarding climatic conditions. Given adequate monitoring procedures the durability and stability of the reference plants is expected to be maintained at least for 100 years after decommissioning; inspection and maintenance systems for the building components should be set up in this respect.

Based upon the general behaviour of concrete and reinforcement steel and regarding the long term performance of these materials it can be concluded that the investigated NPPs, which have been constructed from these materials with a very high quality grade and observing strict manufacturing requirements, will achieve very long lifetimes. Even for the proposed long period of 100 years after decommissioning, it can be established that the regarded NPPs will maintain a sufficient stability, presuming the application of monitoring procedures.

In view of contaminated or activated components, it is essential to guarantee leak-tightness of the steel containment or steel liner and to assure integrity of important structures up to ultimate demolition of the plant. For the 100 year period in question after decommisioning, the type and extent of corrosion damage are discussed for areas classified as potential risk areas and a combination of design, operational and maintenance measures to assure and maintain enclosure is reconmended together with monitoring and conservation.

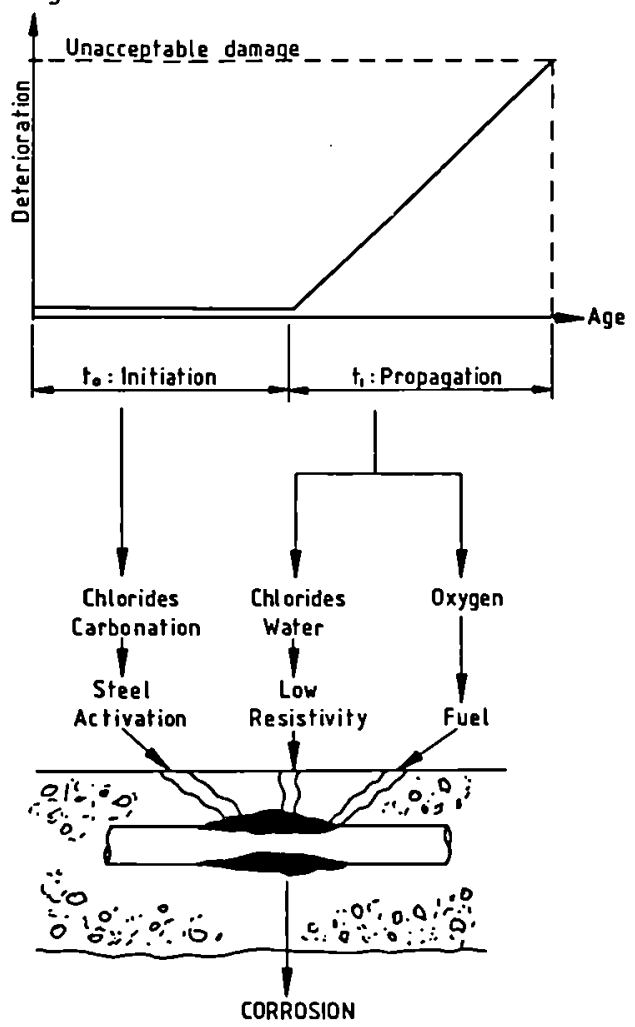

Fig 2.1 Reinforcement Corrosion Process 


\section{ENIRONMENT}

INTERNAL - VENTILATION EXTERNAL - COASTAL
WARM
DRY $(60-65 \%$ RH $)$
STEADY
CARBCNATION
MAINLEY COOLER
WEITER (90\% RH + RAIN)
VARIABLE
CHLORIDES$$
\text { (SALT - SPRAY) }
$$

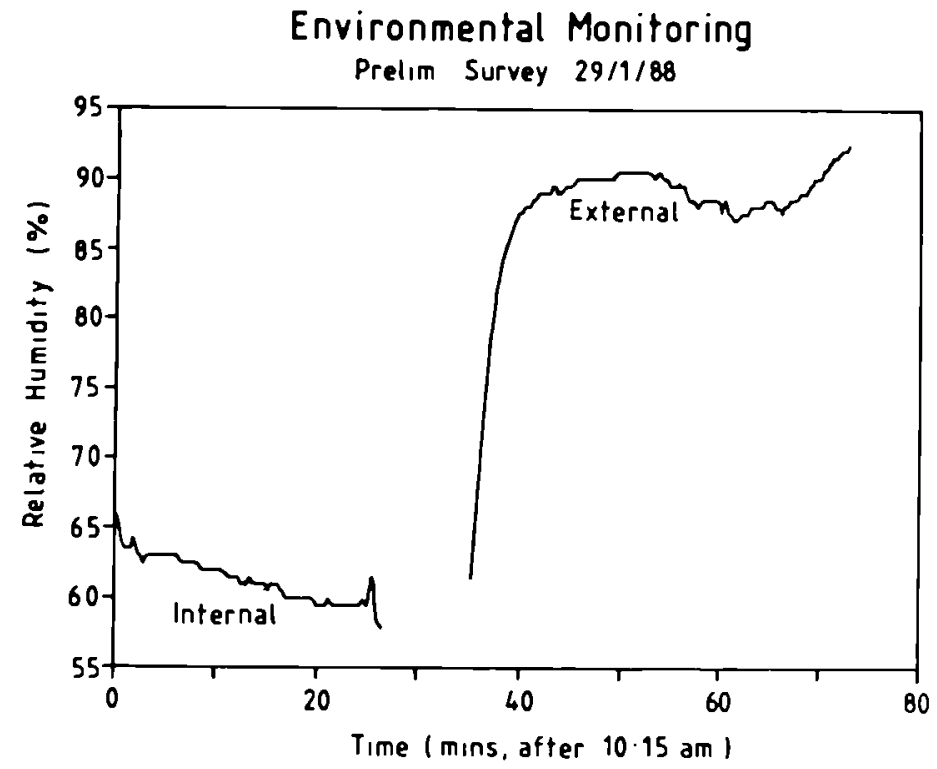

Fig 2.2 Enviromental Summary and Data Example

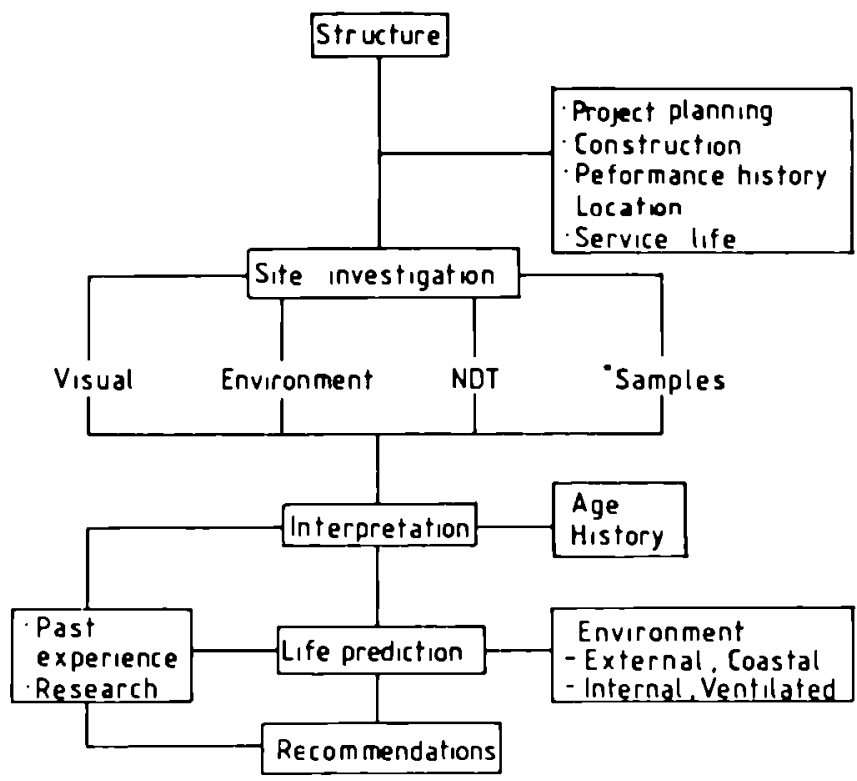

9
Fig 2.3 Survey Process 

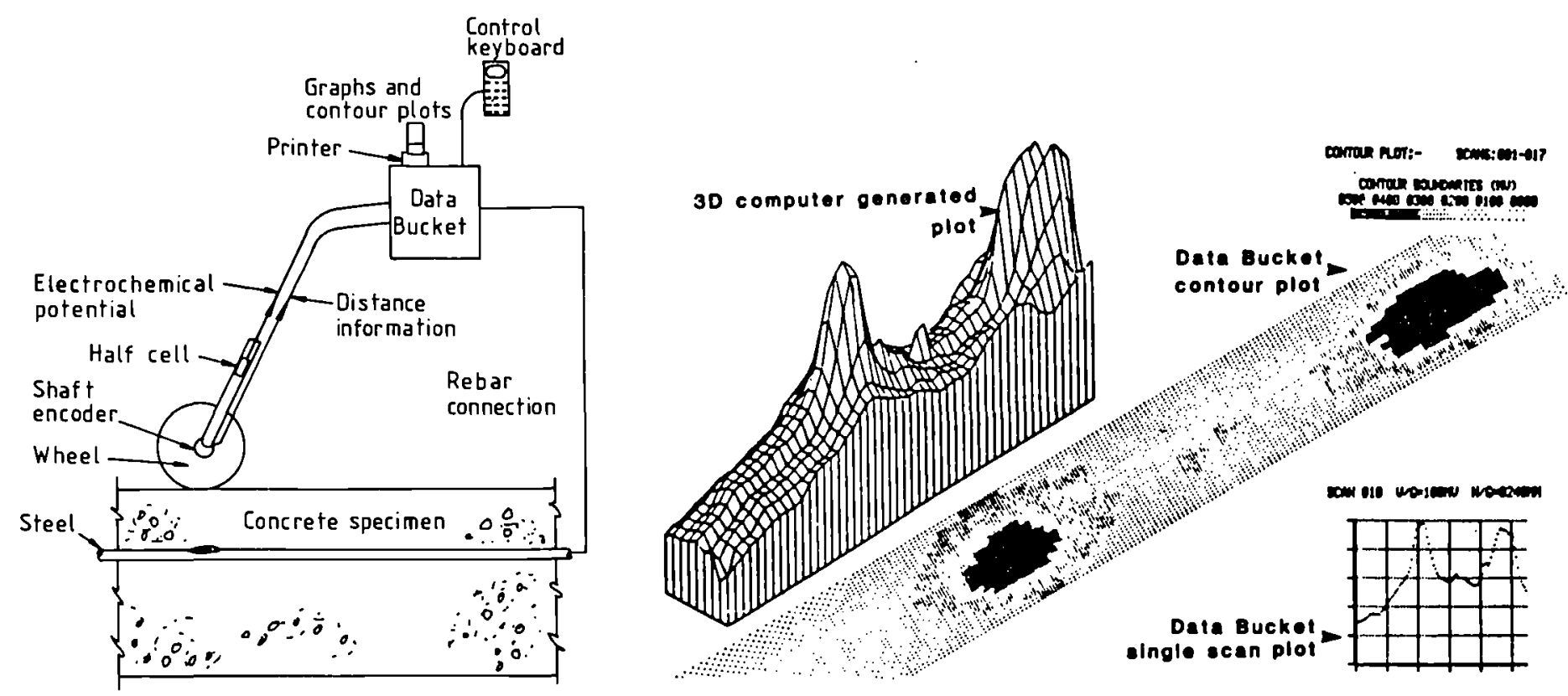

Fig 2.4 Equipment for Continuous Measurement of Reinforcement Potentials 


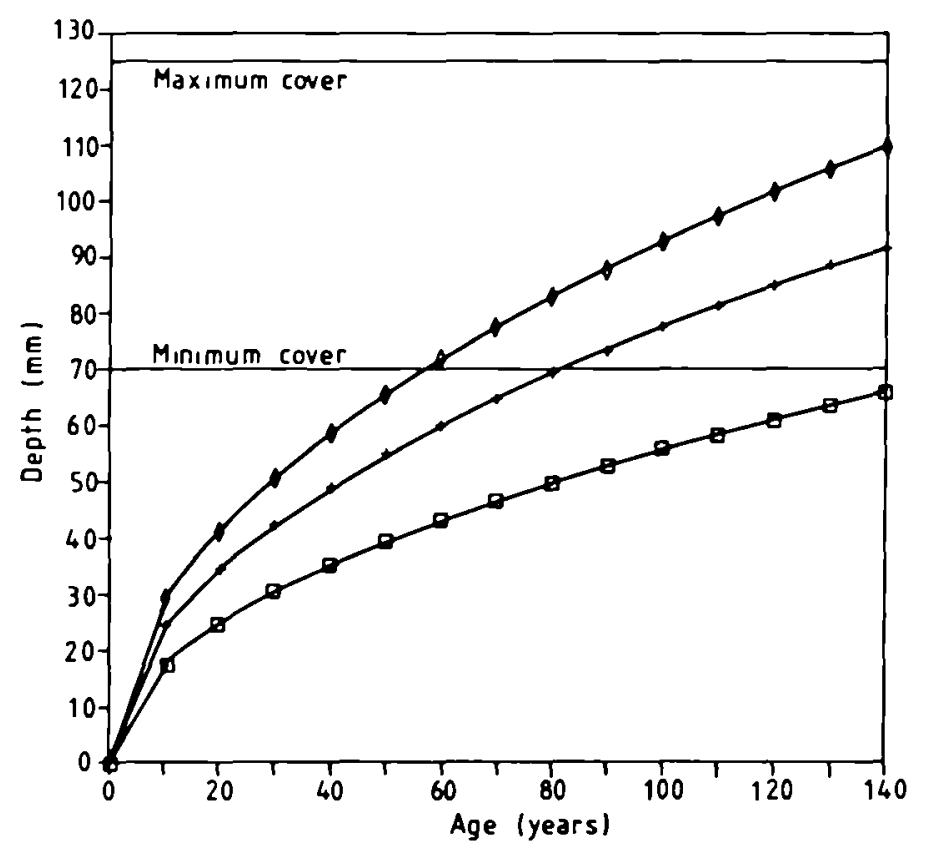

o Min carb. depth + Mean carb. depth o Max. carb. depth

\section{Location E 3}

Predicter surface level - 039 \& Ohloride ov w of smple Predicted level at Reinf.- 000 I Cnloride by w of suple

the at reinf. activation - $906 \mathrm{Yr}$ a at 0062 Chloride by wt of smople Dit fusion constant

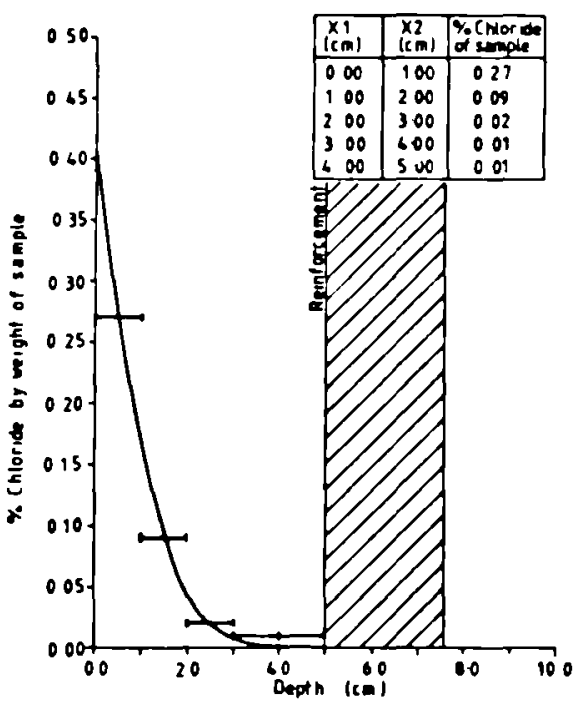

జ

Fig 2.5 Prediction of Carbonation Penetration

Fig 2.6 Prediction of Chloride Penetration 


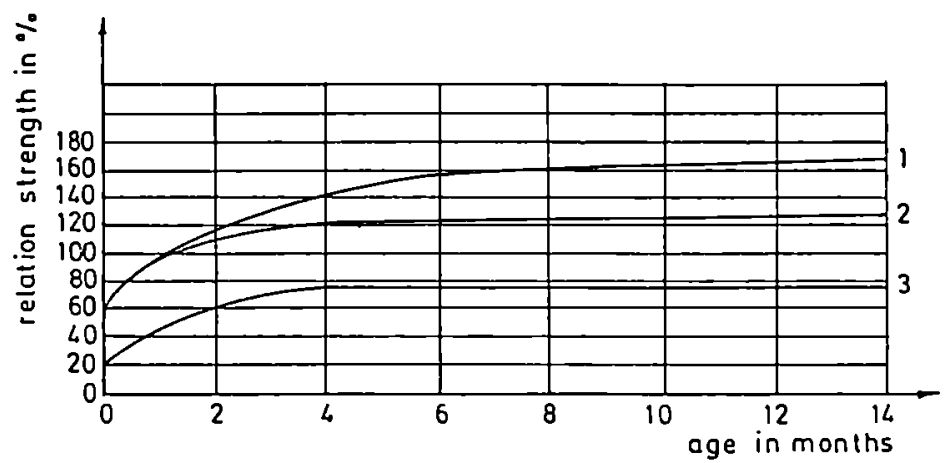

1 always humid

21 month humid, then exposed to dry air

3 always exposed to air

Figure 3.1: Influence of the humidity on the strength development of concrete

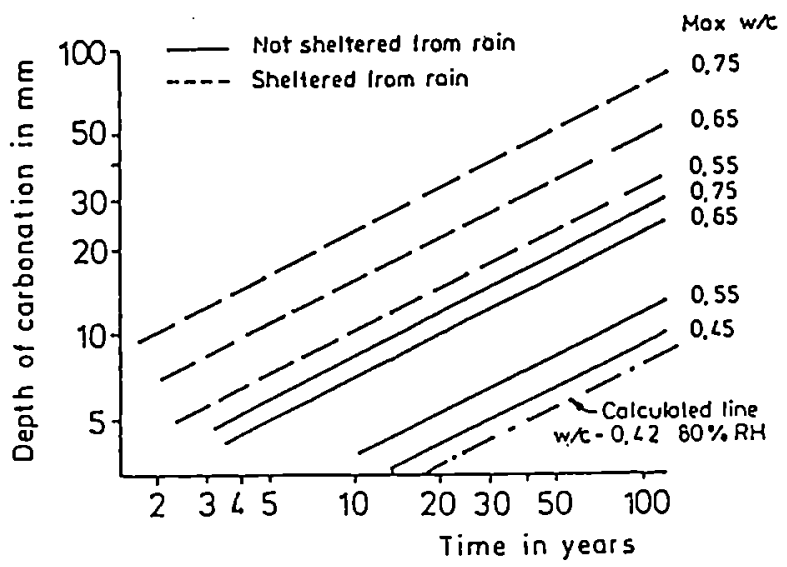

Figure 3.2: Carbonation development depending on environmental conditions and w/c-ratio 


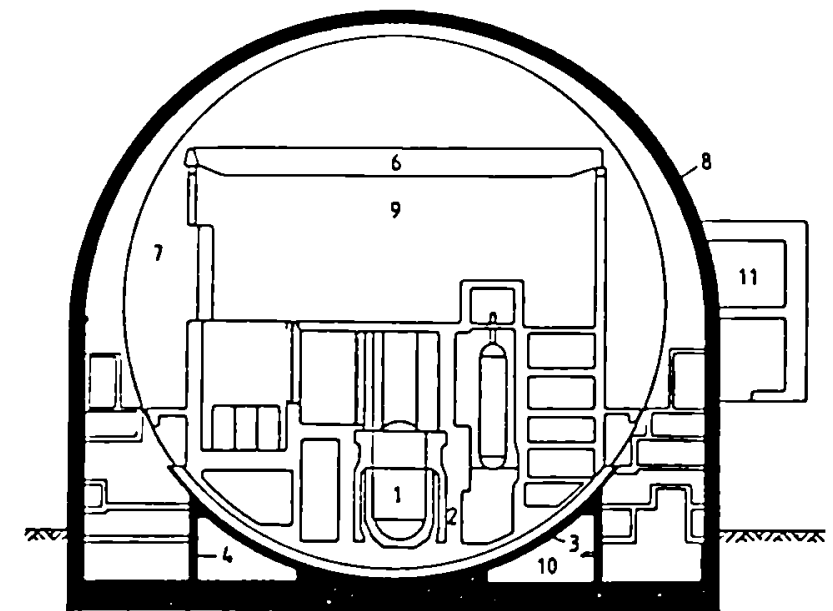

5

steel reactor pressure vessel

blological shield

3 spherical section

4 circle wall

5 roundation plate

6 reactor bullding crane

primary steel containment

8 secondary relnforced concrete containment

Inner rooms

0 annular rooms

11 steam and feed water valve compartment

F1gure 3.3: Section of a PWR station reactor bullding

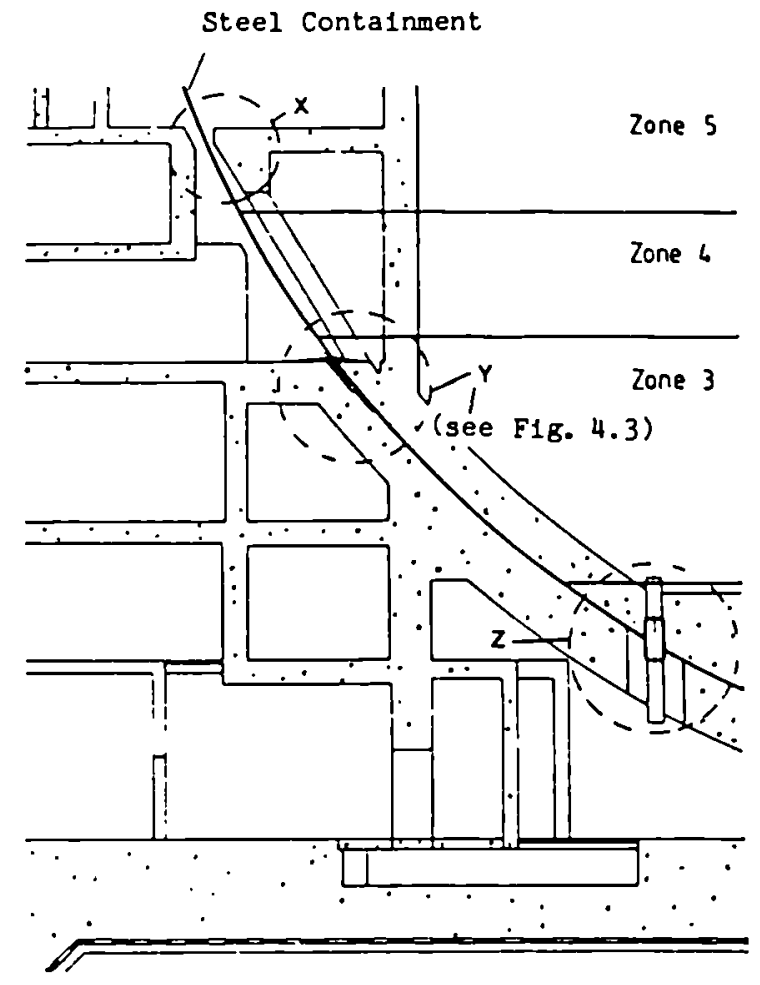

is
F1gure 4.1: Critical areas of the steel conta1nment of a PWR station in view of corrosion (Deta1l of f1gure 3.3) 


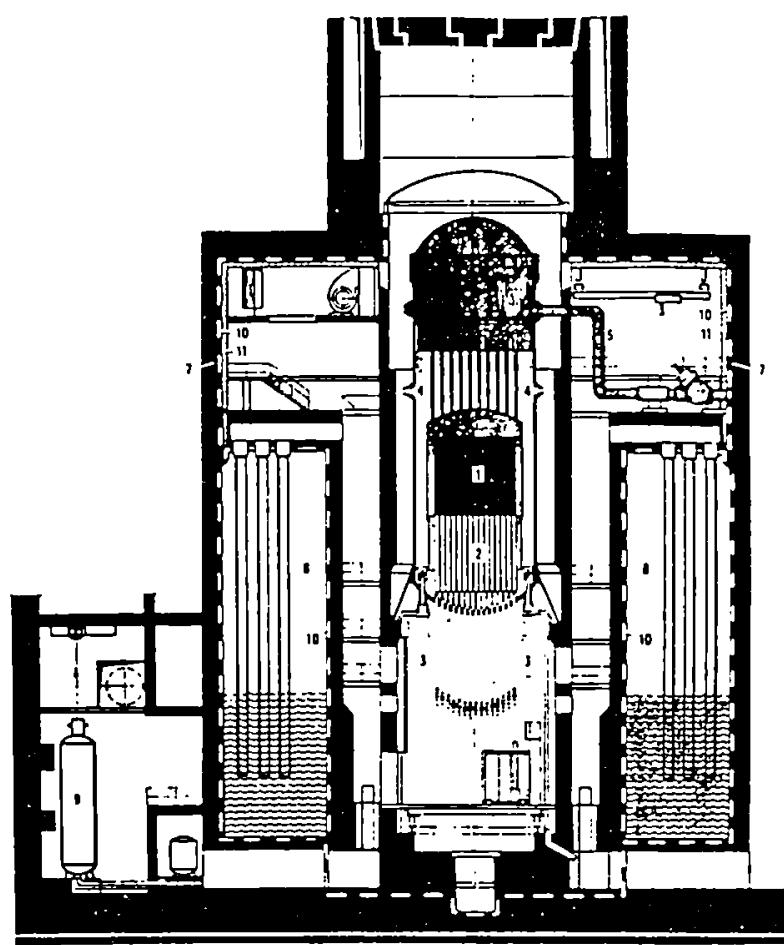

1 holetements

2 controlmember

3 reactor coolant pump

4 leed waternozzle

5 mainsteampiping

6 reactor pressure vessel

Figure 4.2: Containment with pressure suppression system of a bolling water reactor

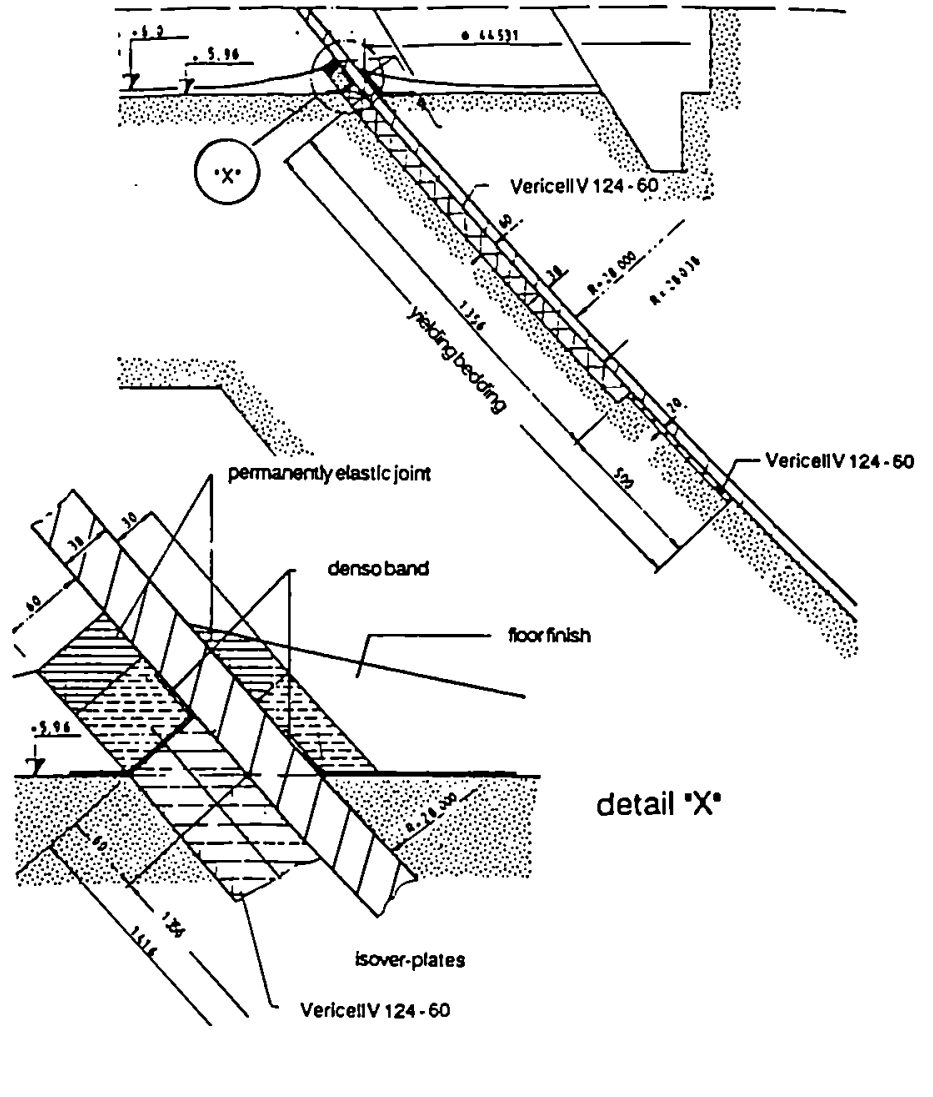

Figure 4.3: Encased bottom portion of a PWR steel containment 


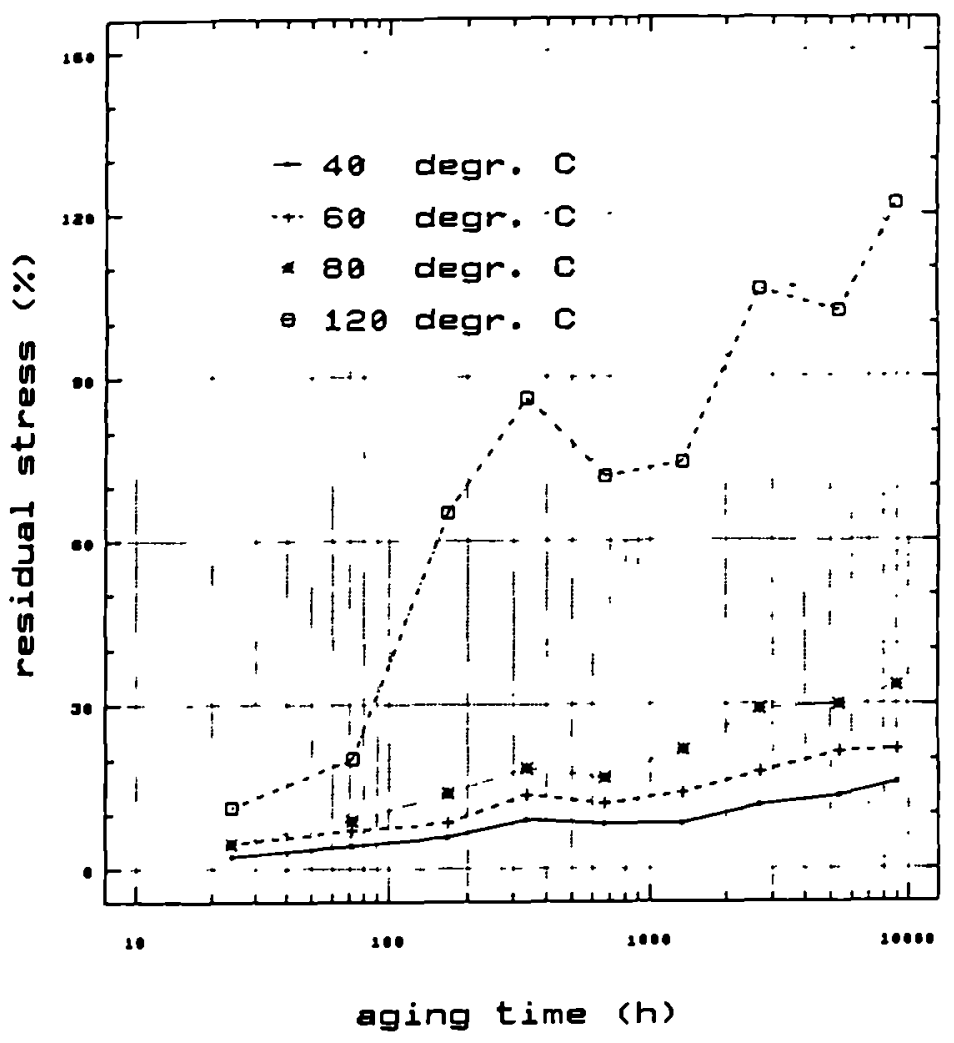

F1gure 4.5: Res1dual stress of silicon rubber after aging at several temperatures

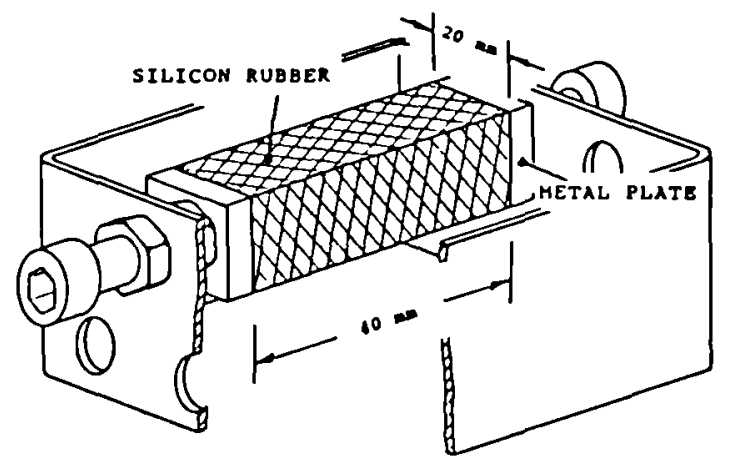

F1gure 4.4: Test arrangement of the silicon rubber samples

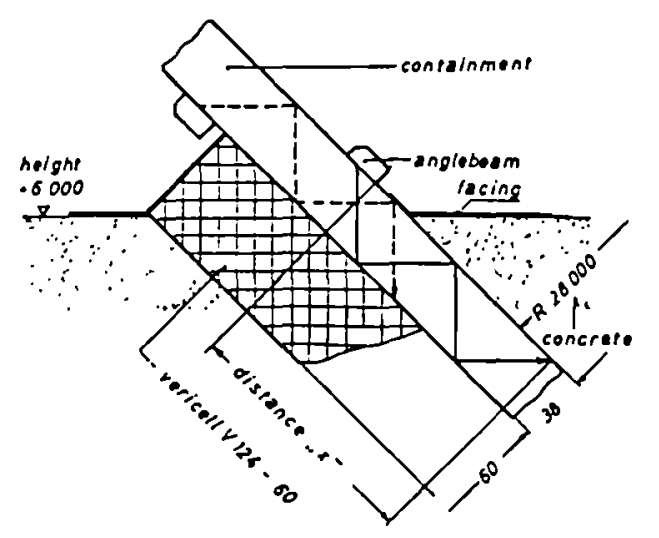

F1gure 4.6: Ultrasonic examination at the encased bottom portion of a PWR steel containment 


\title{
CONSEQUENCES OF SUPPRESSION OF NEGATIVE PRESSURE IN THE KW-LINGEN CONTAINMENT
}

\author{
Harbecke, $\mathrm{H}$. \\ Rernkraftwerk Lingen \\ D 4450 Lingen, W.-Germany
}

\begin{abstract}
Since the beginning of 1988 the status of the Lingen-Plant has been that of SE (Save Enclosure). The aim of this work is to point out the behaviour of the plant in respect to the air exchange to the environment and the global situation inside the plant.
\end{abstract}

1. INTRODUCTION

The turnkey construction of the AEG boiling-water reaktorplant KWL (Rernkraftwerk Lingen) started in 1964. The plant was operated from October 1968 till January 1977. During its lifetime the $255 \mathrm{MW}$ (net) power station produced lieg kWh of electric power. The plant was of a special design: it was fitted with two steam transformers, providing non-active secundary steam. The secundary steam was fed to a gasfired superheater and heated up to $530^{\circ} \mathrm{C}$. Therefore the turbine-hall was a non-active area.

2. TOPICS OF THE PROGRAMME

It is common practice to maintain a negative pressure in the containment of shut-down nuclear reactors to avoid a transfer of radioactivity to the outside. The objective of this investigation was to assess, from the standpoint of radiation protection of the environment, the acceptibility of suppressing the ventilation. The Lingen SE is operated with a small off-air system.

\section{TOPICS OF THE SE}

The Lingen SE includes the reactor building, the auxiliary building and the connecting building with the annulus.

Inventory of radioactive material

I. operational waste

resins

filtering powder concentrates ( $f$ ixed) other waste

II. system surfaces systems in the auxiliary build. $1.4 \mathrm{E} 10 \mathrm{~Bq}$ systems in the reactor building $2.1 \mathrm{El} 3 \mathrm{~Bq}$

III. building surfaces auxiliary building reactor building

IV. reactor pressurevessel vessel vessel internals
1.8E14 Bq

$2.2 \mathrm{E} 12 \mathrm{~Bq}$

$1.3 \mathrm{E} 12 \mathrm{~Bq}$

$2.5 \mathrm{E} 10 \mathrm{~Bq}$
$1.7 \mathrm{E08} \mathrm{Bq}$

$1.7 \mathrm{E09} \mathrm{Bq}$

2.2E15 Bq

$5.6 \mathrm{E} 15 \mathrm{~Bq}$ 


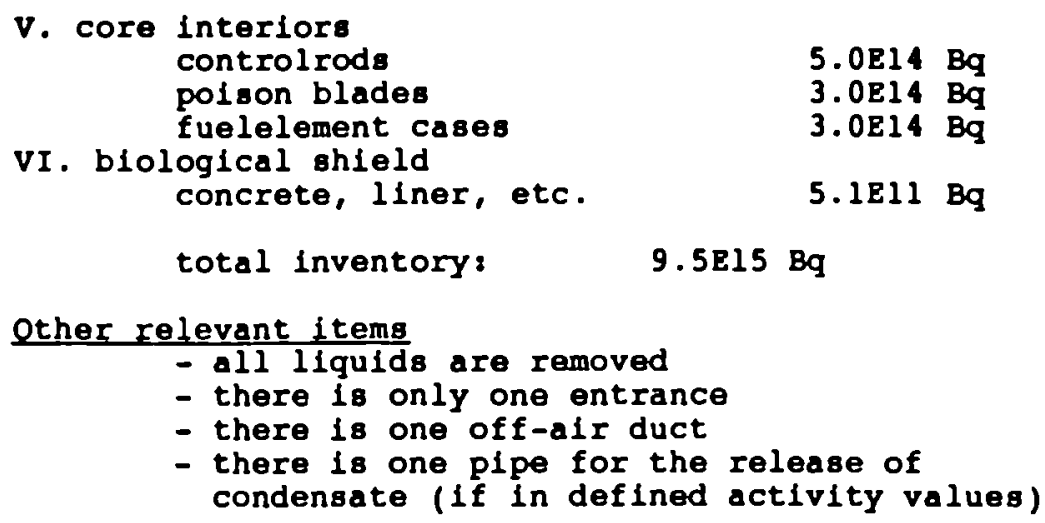

Within the SE one circulating air system with a drying system and an off-air system with a HEPA filter is in operation. The main dates are as follows:

- amount of circulated air: $2500 \mathrm{~m} \wedge 3 / \mathrm{h}$

- condensed water from the drying system is collected in tanks

- off-alr rate ca. $500 \mathrm{~m}^{\wedge} 3 / \mathrm{h}$

\section{MEASURING PROGRAMME}

Aerosol Activity

Probes of the circulating air were taken on filters and measured. The results are shown in table I.

Condensed Water

The circulating air is dryed by a cooling system. The condensed water is fed into two tanks. Probes from the water

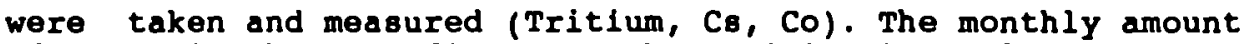
of water is shown in figure 1 , the activity in table 2 .

Temperatures and Molsture

At three levels of each bullding (top, middle and bottom) and outside the plant, readings were taken. Two examples are shown in figures 2 and 3.

Wind Velocity

Wind causes a negative pressure on the opposite side of a building. To calculate the leakages due to this effect, wind velocity is classified as a percentage of time and speed range. An example is shown in figure 4 .

Alf Leakageg

The leakage is a non-linear function of pressure difference. The function is measured every year and shown in flgure 5. It must be pointed out, that the curve includes the leakage of the total area of the SE.

\section{CALCULATIONS}

For the calculation of the air exchange to the environment some simplifications were necessary:

- It is assumed, that the leakages were spread homogenleously over the SB 
- only 50 of the leakages are on the wind-opposite front of the buildings

- the negative pressure forced by wind is calculated $p(p a)=\frac{1}{2 m v^{2}}$ with $m=1.288 \mathrm{~kg} / \mathrm{m}^{\wedge} 3$ and $v=$ wind velocity $(\mathrm{m} / \mathrm{s})$.

The calculation is done twices

a) with the negative pressure of about 10 pa due to the operation of the off-air system

b) without the negative pressure

The results are shown in figure 6 .

\section{ACTIVITY RELEASES}

With the help of the calculated leakage, the measured off-air rate and the measured activity-dates, the activity releases to the environment were calculated.

There are two facts to consider:

Air, leaving the SE via the stack is filtered. The aerosol activity is reduced by a factor of about $10 \mathrm{E} 3$ (in the calculation a factor of 500 is used) while the tritium activity is nearly unchanged (only the water content of the air is reduced because the of $f$-air stream is taken from the dry end of the circulating system).

Air, leaving the SE via leakages is unchanged.

The results of the calculation are shown in figure 7

\section{DISCUSSION OF THE RESULTS}

The activity releases to the environment are very small. They can be determined only by calculation. It was found that the aerosol releases with negative pressure (10 pa) are in the range of $10 \mathrm{E} 3$ to $10 \mathrm{e} 4 \mathrm{~Bq}$ per year. The tritium output is in the order of $10 \mathrm{Eg} \mathrm{Bg}$ per year.

Without negative pressure, the aerosol releases are higher by a factor of two, and the tritium releases are lower by a factor of two than with negative pressure.

Because of the absolute small figures it can be said the negative pressure would not be necessary in the case of KWL, that means in a plant with a small activity-level inside the SE. .

without the necessity of operating an off-air system all the time, it would perhaps be possible to run the system only when the outside atmosphere is dry, to avoid sucking wet air into the plant. It maybe that this will save having a drying system. 
Tabl- I: Aerosol Activity (Circulating syotea)

\begin{tabular}{|c|c|c|c|}
\hline \multirow{2}{*}{$\begin{array}{l}\text { Measuring } \\
\text { Period }\end{array}$} & \multicolumn{3}{|c|}{ Isotopes: } \\
\hline & $\begin{array}{l}\mathrm{Cs}-137 \\
(\mathrm{~Bq} / \mathrm{m})\end{array}$ & $\begin{array}{l}\text { Co-60 } \\
(\mathrm{Bq} / \mathrm{AOT})\end{array}$ & $\begin{array}{c}\text { Total } \beta^{\prime} / \gamma^{\prime} \\
\left.\text { ( Bq } / \mathrm{m}^{\prime}\right)\end{array}$ \\
\hline $\begin{array}{l}\text { January } \\
\text { Tobruary } \\
\text { March } \\
\text { April } \\
\text { May } \\
\text { June } \\
\text { July } \\
\text { Auguet } \\
\text { September } \\
\text { October } \\
\text { November } \\
\text { December }\end{array}$ & $\begin{array}{l}3.6 E-5 \\
0.1 E-6 \\
2.2 E-5 \\
6.0 E-5 \\
<N W G \\
\text { \&NWG } \\
<N W G \\
<N W G \\
2.4 E-5 \\
\angle N W G \\
4.3 E-5 \\
2.3 E-5\end{array}$ & $\begin{array}{l}4.7 E-5 \\
3.4 E-5 \\
2.6 E-5 \\
4.3 E-5 \\
<M W G \\
<N W G \\
\text { <NWG } \\
<N W G \\
1.3 E-5 \\
<M W G \\
<N W G \\
8.7 E-5\end{array}$ & $\begin{array}{l}3.0 E-3 \\
2.7 E-3 \\
2.2 E-3 \\
3.9 E-3 \\
4.7 E-3 \\
4.7 E-3 \\
4.9 E-3 \\
5.3 E-3 \\
5.4 E-3 \\
4.6 E-3 \\
3.5 E-3 \\
3.7 E-3\end{array}$ \\
\hline
\end{tabular}

Tabl. II: Activity of Condensate

\begin{tabular}{|c|c|c|c|}
\hline \multirow{2}{*}{$\begin{array}{l}\text { Measuring } \\
\text { Period }\end{array}$} & \multicolumn{3}{|c|}{ Isotopes: } \\
\hline & $\begin{array}{c}H-3 \\
(B q / 2)\end{array}$ & $\begin{array}{l}C 0-137 \\
(B q / 27)\end{array}$ & $\begin{array}{l}C 0-60 \\
\text { (Bq/W) }\end{array}$ \\
\hline January & $1.6 \mathrm{E} 6$ & $2.3 E 3$ & $4.8 E 3$ \\
\hline February & $2.0 \mathrm{E} 6$ & 1.184 & $6.8 \mathrm{E3}$ \\
\hline March & $1.7 \mathrm{E} 6$ & $6.1 E 3$ & $3.3 E^{3}$ \\
\hline April & $1.7 E 6$ & 7.853 & $2.5 E^{3}$ \\
\hline May & $1.5 E 6$ & $4.5 E 3$ & $3.4 E 3$ \\
\hline June & $1.6 \mathrm{E6}$ & $4.5 E 3$ & $3.4 E 3$ \\
\hline July & $1.6 E 6$ & $6.1 E 3$ & 1.084 \\
\hline Auguet & $1.8 E 6$ & $5.4 E 3$ & $2.1 E 3$ \\
\hline September & 2.106 & <NG & <NWG \\
\hline october & $2.2 E 6$ & 1.683 & $8.4 E 2$ \\
\hline Movembor & $2.6 E 6$ & $7.6 E 3$ & 2.783 \\
\hline Decenber & $2.3 E 6$ & $6.1 E 3$ & 1.283 \\
\hline
\end{tabular}

NWG - detection limit 


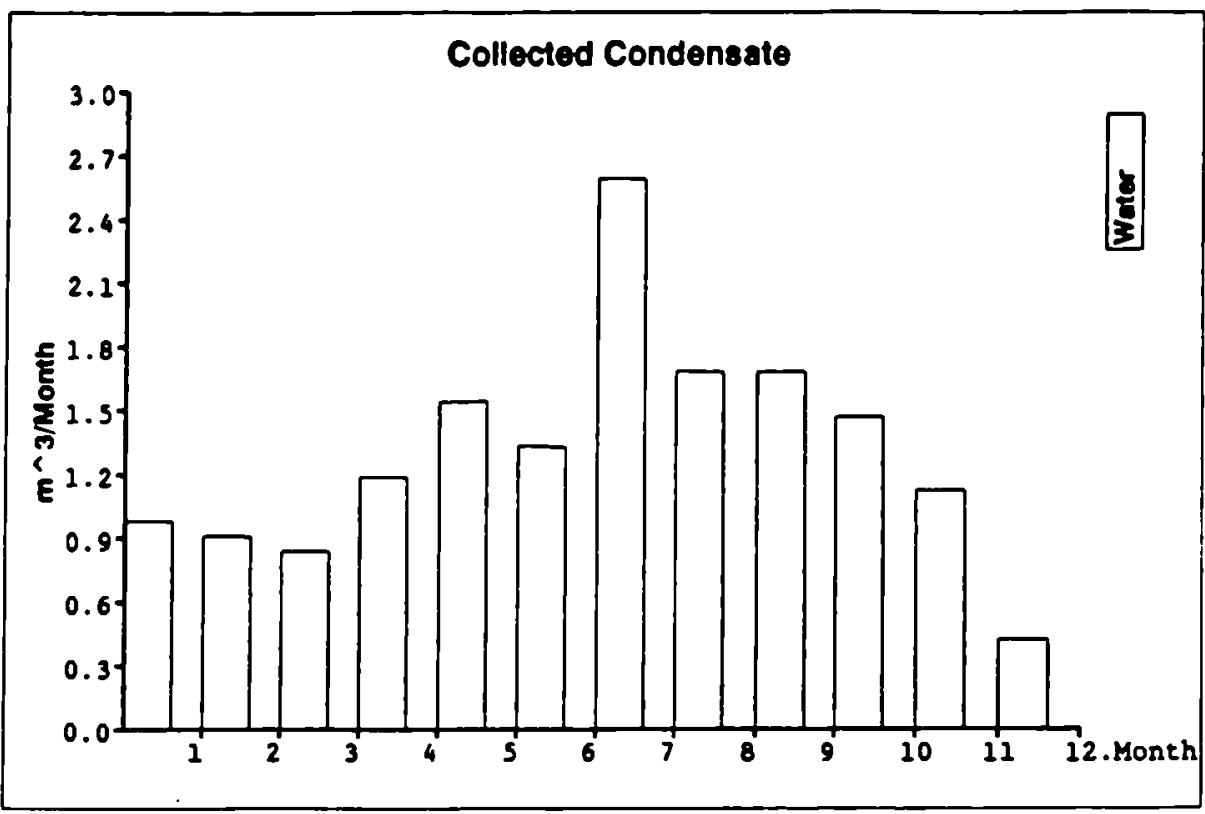

Figure 1

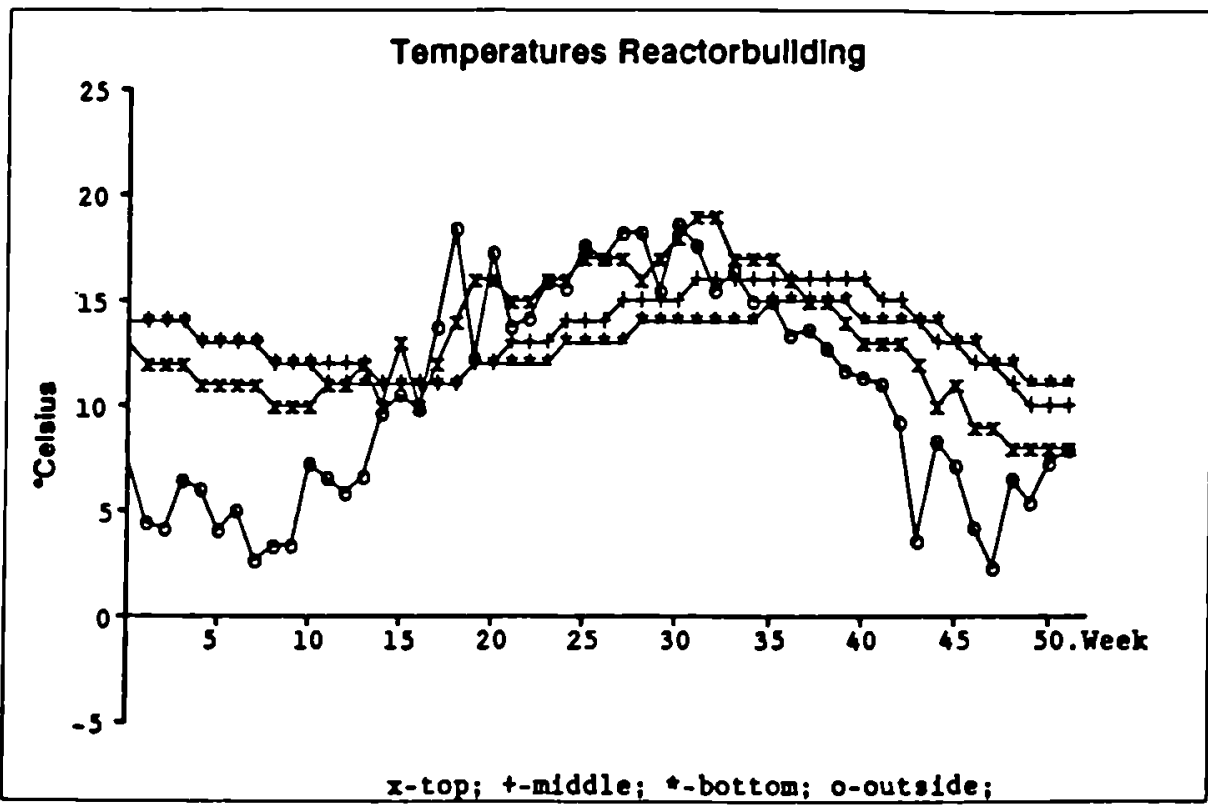

Pigure 2 


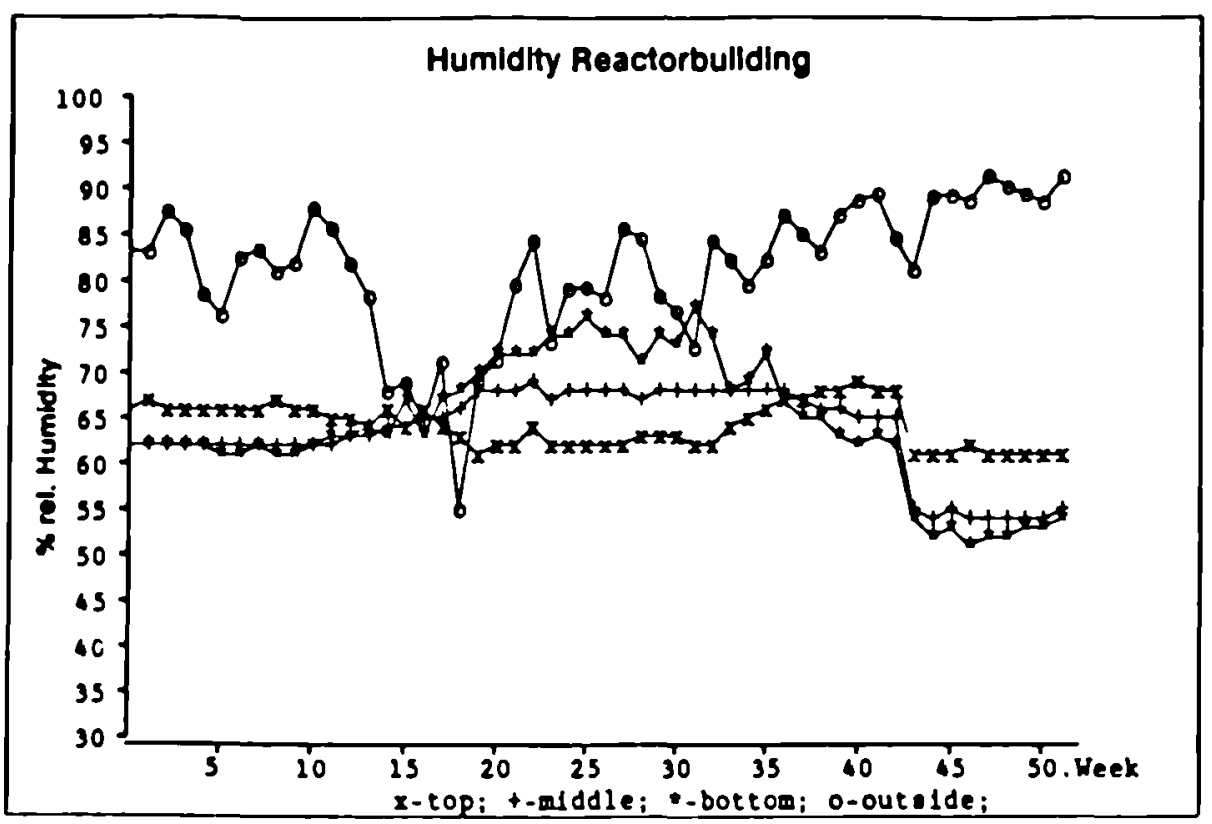

F1gure 3

Windvelocily in Percentage of Time

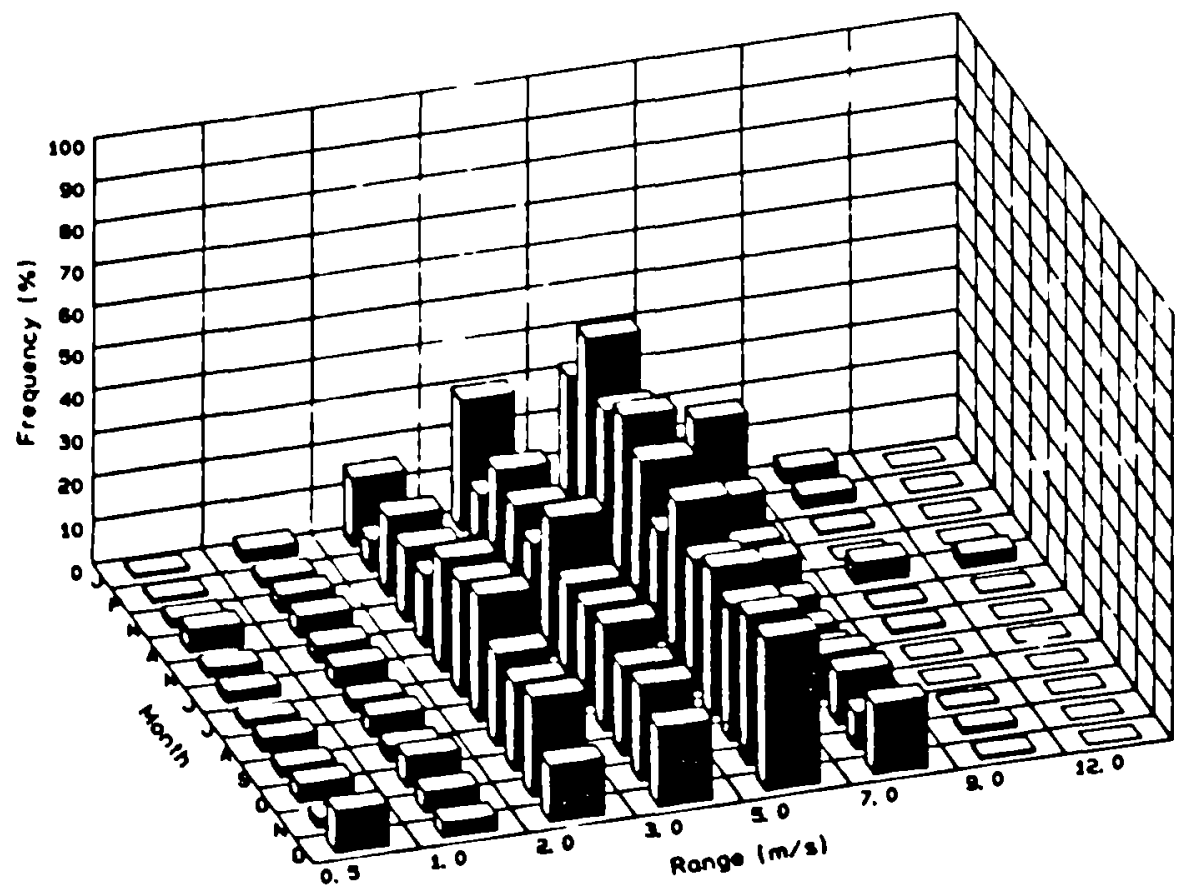

Flgure 4 

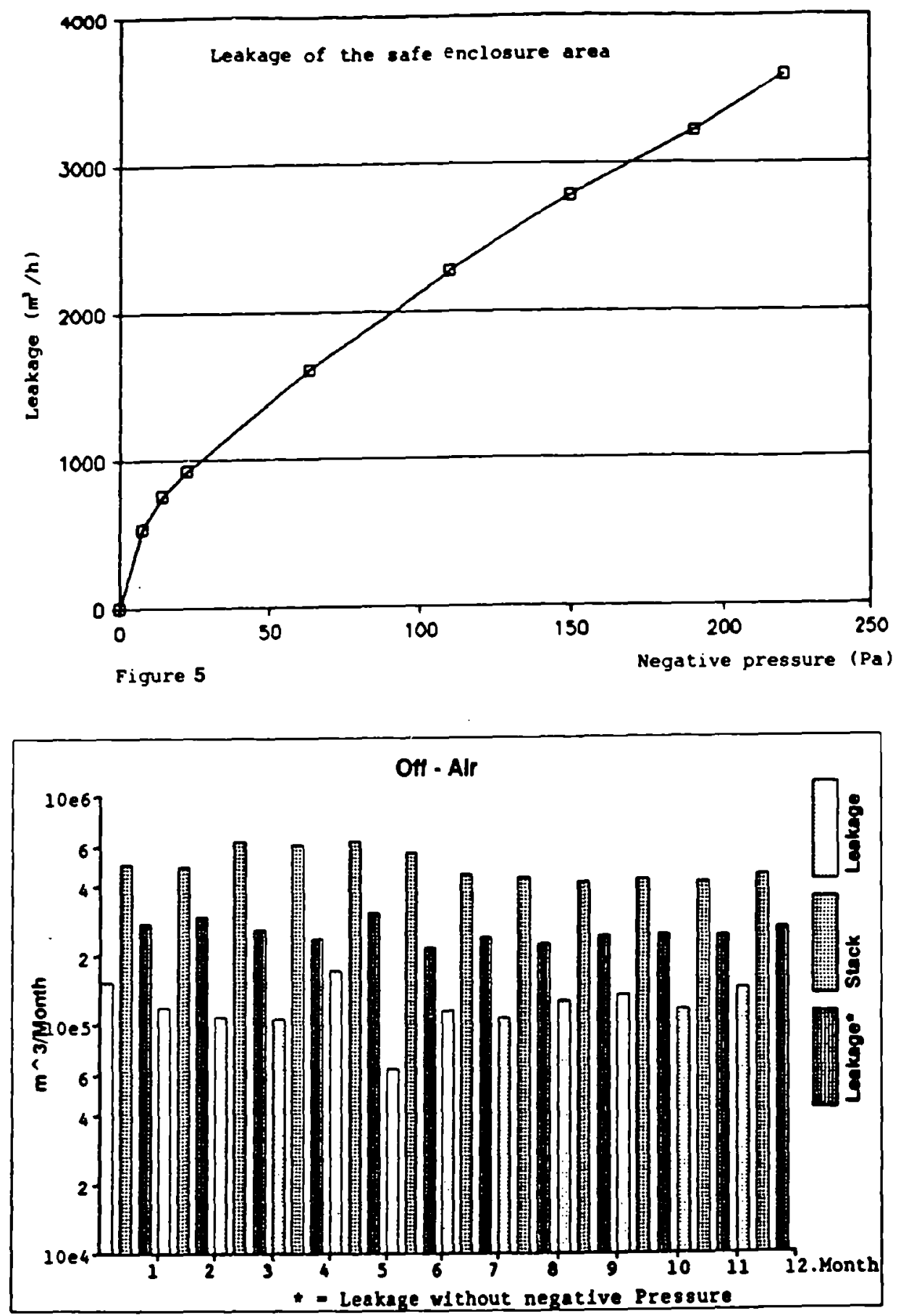

Pigure 6 


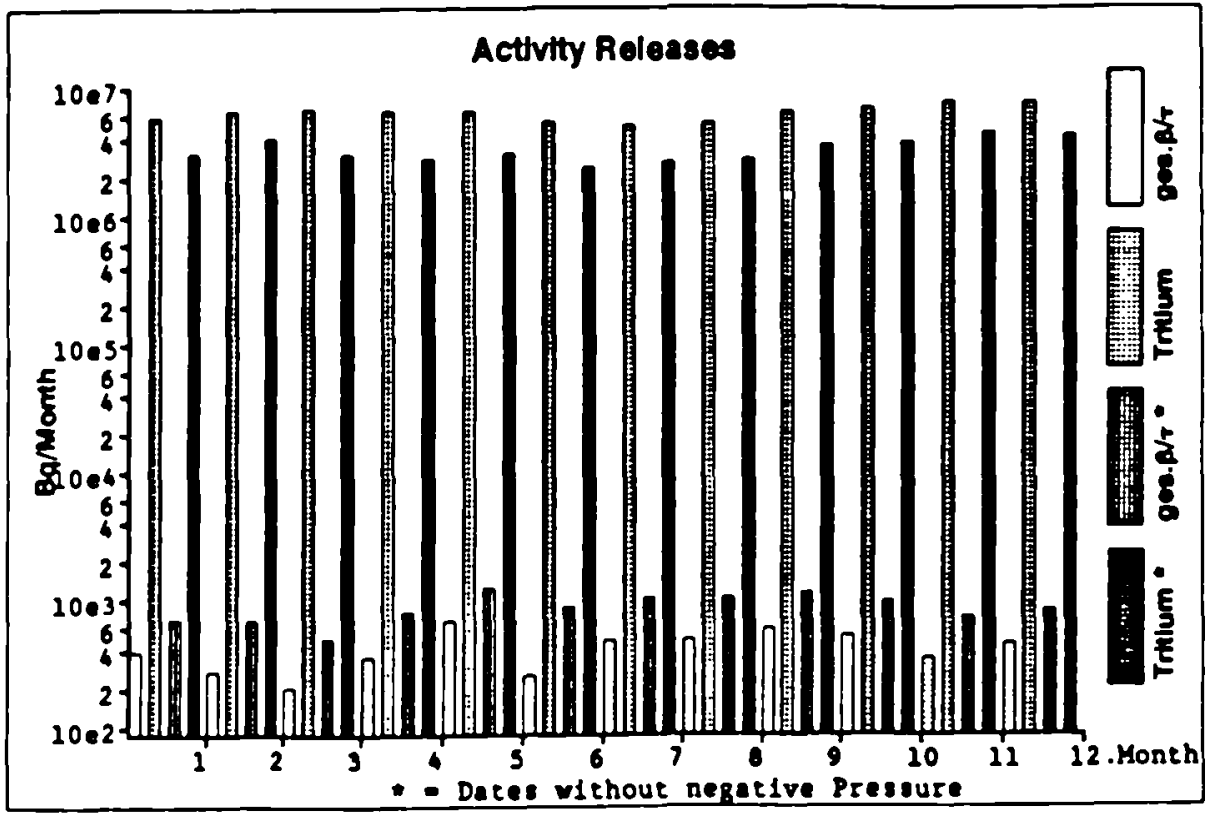

Plgura 7 
THE POTENTIAL RADIOLOGICAL CONSEQUENCES OF DEFERRING THE FINAL DISMANTLING OF A MAGNOX NUCLEAR POWER STATION

\author{
Paul B. Woollam \\ National Power Division of the Central Electricity Generating Board, \\ Technology Division, \\ Berkeley Nuclear Laboratories, \\ Gloucestershire, GL1 $39 \mathrm{~PB}$, UK.
}

\title{
ABSTRACT
}

It is proposed that final dismantilng of National Power's nuclear stations be deferred to take advantage of natural decay of residual radioactivity. A deferment of 100 to 130 years would reduce the dose commitment to dismantling staff as far as practicable and remove the need to depend on robotic systems. This in turn would lead to very significant cost savings, especially when totalled over all National Power's Magnox stations.

However, the possibility must be considered that residual radioactivity from the structure might return to man during the deferment perlod, mainly through ralnwater leakage and transport through the groundwater system but also through airborne releases. The principal objective in assessing such safety issues is to examine the engineering standards required of the residual structure: Dungeness ' $A$ ' presents a limiting case since 1 t is the only National Power nuclear site built on an aquifer from which large quantities of water are extracted for the nearby population.

This paper first determines the potential radiological consequences which might result from possible leakage of radioactive materials from the reactor structure if final dismanting were to be deferred. It then discusses any engineering constraints which these radiological consequences might impose.

\section{INTRODUCTION}

When it is no longer economic to maintaln the National Power's nuclear power stations to their current high safety standards, the reactors w1ll be safely shutdown and decommissioned. National Power is developing detafled engineering plans for the decommisstoning of its earliest nuclear plant: the. steel pressure vessel Magnox reactors. Th1s work will follow the three internationally accepted stages: the first two w111 involve defuelling the reactors and then dismantling all plant and buildings external to the $2 \mathrm{~m}$ thick relnforced concrete bioshields. Almost all of the original site would then be avallable for re-use if required. The third stage will be the dismantling of the two reactor islands, including the concrete shields, steel pressure vessels and graphite cores.

Stages 1 and 2 of decommlssioning are expected to be complete within 10 to $15 \mathrm{y}$, including a $5 \mathrm{y}$ period to defuel the reactors: this will remove 99.99\% of the radioactivity which was on site whilst the reactors were running. The timing of Stage 3, complete reactor 1sland dismantling, wi11 depend on a number of factors, including balancing the need to re-use the site against the advantages of allowing residual radioactivity in the stucture to decay.

If final dismantling is deferred, it is intended that the residual reactor bulldings would be malntained in a sealed, weathertight condition, and it is confidently expected that this can be achieved. This paper reports National Power Investigations of the potential consequences of any 
fallure in this contalnment during the deferral period using, as a

demonstration of the robustness of the radiological case for deferment, some extreme hypothetical scenarlos in which the nuclear Islands are assumed to have collapged. No Initiating event can be foreseen for such an occurrence and, clearly, this paper 18 not intended to imply that such a situation would ever be allowed to develop. On purely radiological grounds it would be most sensible to defer final dismantling for a period of up to about 130 y to take advantage of natural radloactive decay. However, again to demonstrate the robustness of the case for deferment, this investigation considers radiological consequences over a time perlod which is roughly one order of magnitude both greater and smaller than the $130 \mathrm{y}$ optimu.

If final dismantling of National Power's Magnox reactors were to be deferred, the dose comitment to dismanting staff would be reduced as far as practicable, thus complying with the spirit of the ALARP principle. Dose rates Inside a Magnox reactor, as a function of time, are shown in Figure 1. It would also reduce the need to rely on robotic systems for dismanting and the cost savings to the electricity consumers would be very significant, particularly totalling the savings over all National Power's Magnox stations. A further possible reason for deferring Stage 3 decomissioning might be that, for political rather than technical or safety reasons, no disposal routes were immediately avallable for the radioactive waste. In this eventuality the material would remain on site, within the existing secure contalnment afforded by the reinforced bloshields.

During any deferral perlod Nacional Power would remain responsible for the site and for the residual radioactive material contained within the existing shields. These have walls which are 2 m thick and 6 m thick roofs. It is easily shown that the dose equivalent rate to a person standing just outside the shield concrete, resulting from residual radioactivity in the structure, is about $10^{\rightarrow}$ of that from the local natural background. Because of the construction of the concrete shields, which are massively relnforced on both faces, it is not feasible for unauthorised access to be gained to the reactor structures without the use of very sophisticated cutting technology. For the same reason the structures would not present a worthwile target for attack by extremist groups.

However, If a decomissioned Magnox reactor were to be left for an extended period before dismantilng, the possibility that residual radioactivity from the structure might be transferred to the groundwater system mst be considered. The most likely route for radioactive materials to transport into the groundwater is rain leakage through discontinulties which might eventually form in the top shield, followed by corrosion of the radioactive structure and subsequent leakage of contaminated water through similar discontinulties in the foundation raft. The principal objective in assessing such safety 1 ssues is to examine the engineering standards required of the structure during the perlod for which final dismantling 18 deferred. The degree of containment which is necessary, and the time period over which such containment might be required, are primary inputs to the process of deciding whether it is radiologically acceptable to defer stage 3 dismantling. Dungeness in Kent presents a limlting case in such an asesment since $1 \mathrm{t}$ is the only National Power nuclear site built on an aquifer from which large quantities of drinking water are extracted for the nearby population.

National Power's Investigation set out to determine the radiation exposure which might result from the transfer of radloactive materlals from the two Magnox reactor structures to the Dungeness aquifer in the event that final dimanting were to be deferred and the reactor contalnment to fall.

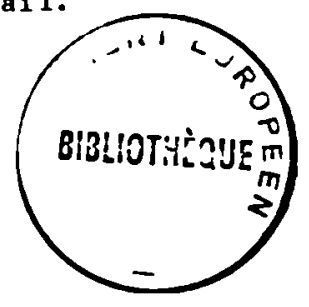


It also assesses the radiological consequences of gaseous discharges from oxidation of the graphite cores for those radioactive isotopes where atmospheric release 18 likely to be the major route by which radioactivity returns to man.

\section{BASIS OF THE ASSESSMENT}

The radioactivity Inventory of the Dungeness ' $A$ ' Magnox reactors 18 based on a series of complex neutron transport calculations (1) confirmed by measurement (2). A careful and systematic check of all 2600 known lsotopes (3) showed that nothing significant had been overlooked in determining the inventory. The long term peak dose rates inside the structure 130 y after final reactor shutdown are expected to be $3 \mu \mathrm{Sv} \mathrm{h}^{-1}$, allowing man-access in excess of $30 \mathrm{~h}^{\text {week }}{ }^{-1}$ to set up and maintain dismantling equipment. These peak dose rates occur in the interspace between the pressure vessel and the core restraint structure and come from the 1 sotopes $\mathrm{Ag}-108 \mathrm{~m}$ and $\mathrm{Nb}-94$ (see Figure 1). The total radioactive inventory of a reactor 100 y after shutdown is dominated, in simple numerical terms, by C-14 and N1-63. Both 1sotopes are betaemitters with low energy endpoints; their contribution to the whole body dose rate experienced by dismantilng workers is negligible. The only plant likely to be contaminated with actinides or fission products is the spent fuel storage pond and the radioactive effluent treatment plant. These facilities are expected to be decontaminated and dismantled during Stage 2 of decommissioning, as soon as practicable after all the fuel has been dispatched for reprocessing. Ralnwater ingress to the reactor 1sland is modelled by assuming that the water leakage rate increases linearly with time after the structure is first breached. The model has been applied to extreme situations and allows for different breaching times for both the concrete shields and the steel pressure vessel, together with different water ingress rates and, eventually, different times at which both parts of the structure finally

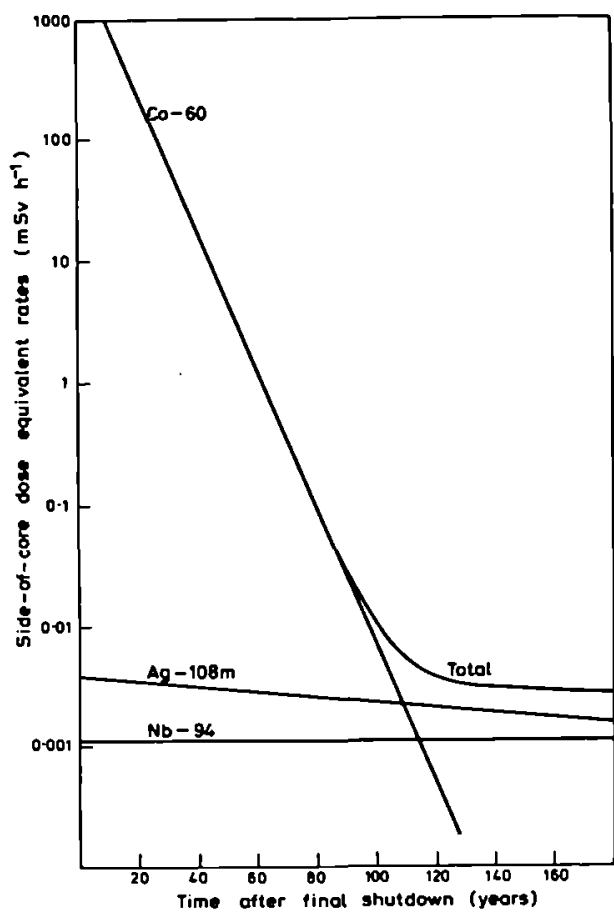

Figure 1: Reduction with time in the maximum dose rate to a dismantling engineer collapse. It also assumes that both reactor 1slands breach and collapse simultaneously. This extreme treatment of the time dependence of possible structural fallure allows an assessment to be made of the engineering standards necessary to contain the radiological consequences of rainwater ingress below particular limfts.

The release to water of many of the radionuclides present in the nuclear island structures is limited by their solubility in water (which is 
strongly dependent on the local aqueous chemlstry), and not by the bulk corrosion rate of the materials in which they were activated. For these particular radionuclides this assessment has therefore applied the concept of a solubility limited release rate. The release rates to water of three other 1sotopes ( $\mathrm{C}-14$ and $\mathrm{H}-3$, for which gaseous transfer to man $1 \mathrm{~s}$ dominant, and $\mathrm{C1}-36$, which $18 \mathrm{highly}$ soluble) are however assumed to depend on their leach rates (4): these are not solubility limited. The dominant source of these lsotopes 18 the graphite moderator.

Groundwater transport parameters used in the model to determine radioactivity transport within the aquifer are avallable from detalled hydrogeological surveys, undertaken by the Southern Water Authority $(5)$, of the aquifer on which Dungeness power station 18 sited. The nearest weli 18 about $500 \mathrm{~m}$ from the Magnox reactors and the whole $14 \mathrm{~km}^{2}$ aquifer system in 1982 supplied $2.3 \times 10^{6} \mathrm{~m}^{3} \mathrm{y}^{-1}$ to properties along the south coast of England. Figure 2 shows the location of the wells in relation to the power station. An Important parameter in groundwater radioactivity transport assessments 18 the retardation coefficlent which describes the ability of the rock medium to hold up a particular radionuclide unt 11 t has decayed. This parameter 18 critically dependent on the chemlstry of the rock and the

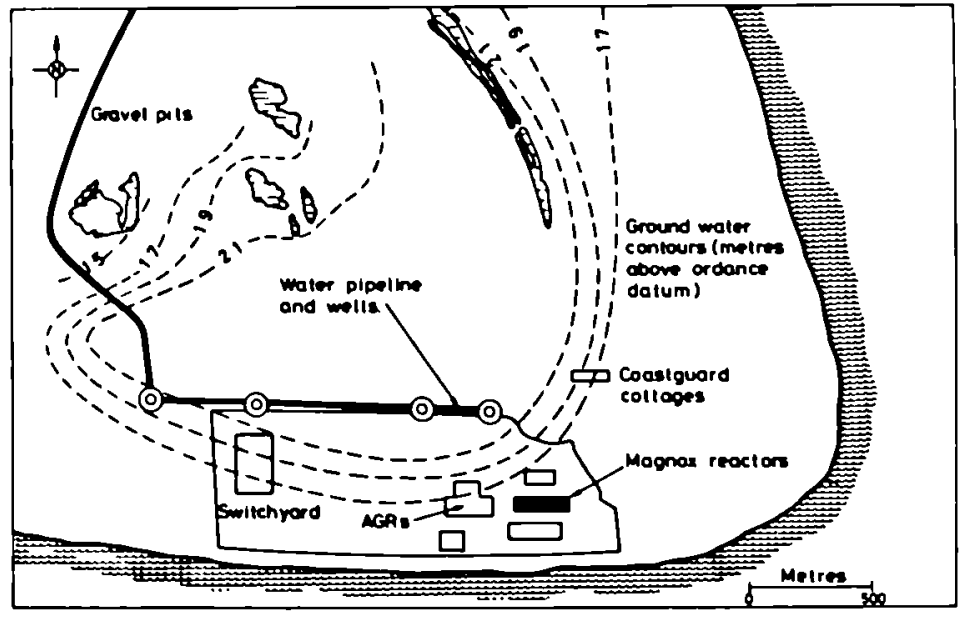

F1gure 2: The Dungeness area, showing the reactors relat 1ve to the wells and the houses

water, thus measurements have been made by National Power to determine retardation coefficients for several important lootopes under the conditions prevalling in the aquifer.

Not all of the radioactive lsotopes in the decommissioned structures have the aquifer as thelr princlpal route for returning to man. C-14 and H-3, predominatly found in the graphite, will be released to the atmosphere rather than the aquifer. A detalled methodology 18 avallable (6) for assessing the annual dose to the most exposed individual from continuous aerlal releases of these two 1sotopes. Site specific studies show that the most exposed Individuals live in ten coastguard cottages to the NNE of the Dungeness site.

Further detalls of the overall methodologies used in this work are presented elsewhere ( 7 ). 
3. RADIOLOGICAL CONSEQUENCES

Using the data outlined above, the radiological consequences of deferring Stage 3 decommissioning of Dungeness ' $A$ ' nuclear power station were determined for three basic scenarios:

1) That $15 \mathrm{y}$ after final shutdown the nuclear island concrete starts to leak at a slow rate which increases with time until the shields and vessels eventually collapse at some distant, but defined, point in the future.

11) That following Stage 2 dismantling the nuclear 1 slands will receive a treatment, or cover, of such quality that there will be no possibility of leaks over an initial extended period, taken here to be $500 \mathrm{y}$. After this time it is assumed that the degradation processes used in scenario 1 will apply, leading to eventual collapse. Comparison between the consequences of scenarios 1 and 2 will show whether it is radiologically justifiable to spend significant sums on superlative engineered protection at the start of the deferment period.

111) That the entire nuclear 1 sland, pressure vessel and core collapse completely at the end of the Stage 2 process, 15 y after final shutdown; this clearly is the maximum possible fault situation. It has been considered here even though no credible initiating event can be foreseen.

The radiological consequences of these scenarlos were assessed for a period of $1500 \mathrm{y}$ following the time when the bioshleld concrete $1 \mathrm{~s}$ first breached. It is intended that the results should be best estimates, thus all the important input data specifically apply to the Dungeness case.

\subsection{Scenario 1: Early Leakage}

Figure 3 shows the total individual dose rate to people living in the coastguard cottages and drinking the aquifer water if the bioshlelds and pressure vessels of the two reactors are breached $15 \mathrm{y}$ after shutdown and eventually collapse at times between 250 and 2000 y later. A peak dose rate of $0.5 \mu \mathrm{Sv} \mathrm{y}^{-1}$ exists for a period of $500 \mathrm{y}$ following the time when the system collapses. Outside this peak the dose rates are $0.2 \mu \mathrm{Sv} \mathrm{y}^{-1}$.

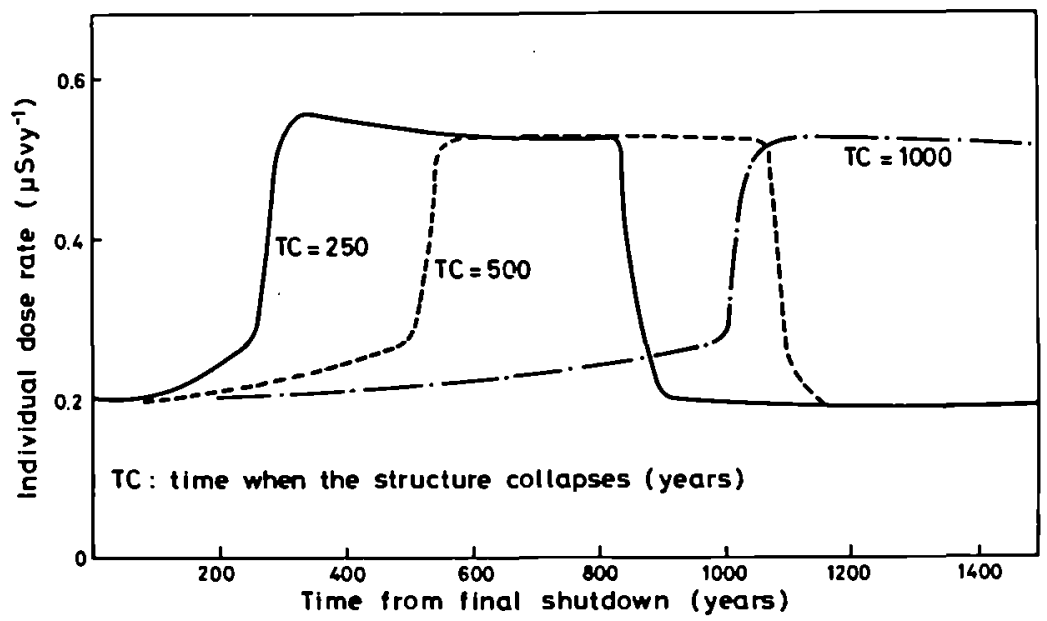

Figure 3: Variation in individual dose rate with time if rainwater starts to leak into the reactors 15 y after shutdown. 
Por the case of collapse after $500 y$, Figure 4 ghow how the dose rate depends on the various 1 sotopes leaching from the reactors. The long term dose rate of $0.2 \mu S v y^{-1}$ comes principally from $\mathrm{Cl}-36$ released to the aquifer and $\mathrm{C}-14$ relessed to the a1r: both lsotopes originate in the graphite. The peak in the dose rate curve 1 s formed by $\mathrm{Ca}-41$, again leached from the graphite at a rate limited by its solubility. Contributions from the long lived metallic s pecies N1-59, N1-63, $\mathrm{Nb}-94$ and $\mathrm{Ag}_{\mathrm{g}-108 \mathrm{~m} \text { are much }}$ lower, $11 \mathrm{mlt}$ ed by their solubilities and, for Ag-108n and $\mathrm{N1}-63$, their half lives.

\subsection{Scenar1o 2: Late Leakage \\ This ocenario 18}

Identical to scenario 1 , except that it 18 assumed that 8 ore exceptional engineering treatment has been applied to the nuclear 18 lands to prevent water 1 ingress unt 11500 y after shutdown. results show that the dose rate picture 18 very similar to the first scenario. This of courge ig not surprising, gince from the previous discussion it is clear that the dose rates are controlled by the long lived 1 sotopes $\mathrm{C}-14, \mathrm{Cl}-36$ and $\mathrm{Ca}-4 \mathrm{l}$. Over any perlod for which total and complete containment might be credible the radioactivities of these 1 sotopes w11 acarcely change.

\subsection{Scenar1o 3: Early Complete Collapse}

In the third scenario, the nuclear 18 lands are assumed to collapse completely following Stage 2 of decommissioning, thus allowing rainwater access to the entire structure $15 \mathrm{y}$ after shutdown. It 18 not possible to foresee a credible initlating event for this scenario. The resultant dose rates are shown in Figure 5, where 1 t can be seen that the peak occurs 130 y after shutdown at $0.7 \mu \mathrm{Sv} \mathrm{y}^{-1}$. The dose rate then drops slowly to the leve 1 found In the previous scenar108, $0.5 \mu \mathrm{Sv} \mathrm{y}^{-1}$, unt 11700 y after shutdown $1 \mathrm{t}$ falls to the long term level of $0.2 \mu \mathrm{Sv} y^{-1}$. The peaked form of the dose rate variation comes from the contributions, at 135 y decay, of Ni-63 0.2 $\left.\mu \mathrm{Sv} \mathrm{y}^{-1}\right)$ and $\mathrm{Ag}-108 \mathrm{~m}\left(0.02 \mu \mathrm{Sv} \mathrm{y}^{-1}\right)$ whlch have decayed before the major releases start in the previous two scenarios. It is clear that, even with the bloshields collapsing fust 15 y after shutdown, the short lived nuclides 
such as Co-60, Fe-55 and H-3 do not contribute any major Increase In dose rate to the local population.

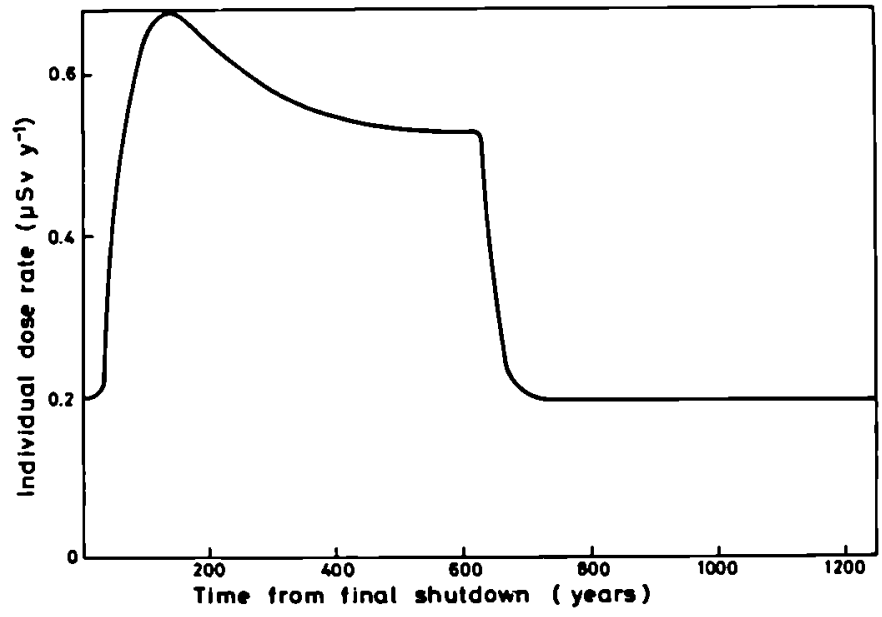

Figure 5: Variation in individual dose rate with time if the whole reactor collapses completely 15 y after shutdown.

\section{ENGINEERING CONSIDERATIONS AND UNCERTAINTIES}

The best estimate data used here lead to the very clear conclusion that the radiological consequences of deferring Stage 3 dismantling are very slight.

Considering first the release of radioactivity to the air (which is Independent of the various water ingress and structure collapse scenarios), we find resultant dose rates of $0.1 \mu \mathrm{Sv} \mathrm{y}^{-1}$, from the two Magnox reactors, to the most exposed Individual who lives in the coastguard cottages to the NNE of the power station site. This is almost entirely due to C-14 from the graphite. Release rates of $\mathrm{C}-14$ to the air are based on measurements of the transfer of this 1sotope from Dungeness moderator graphite samples to water, under a variety of chemical conditions. There is very little uncertainty on the specific activity of C-14 in moderator graphite. However, the natural $\mathrm{C}-14$ dose rate to the people 1 n the cottages 18 about 50 times higher than the dose rate from alrborne releases from the two decommissioned reactors.

If the two Magnox reactors both collapsed completely fust 15 \& after shutdown, the best estimate peak dose rate to water consumers would be $0.6 \mu \mathrm{Sv} \mathrm{y}^{-1}, 120 \mathrm{y}$ later. A siml lar collapse after 250 y decay would lead to a peak dose rate of $0.5 \mu \mathrm{Sv} \mathrm{y}^{-1}$. The peak dose rate from the decommlssioned reactors, through the aquifer route, 18 controlled by $\mathrm{Cl}-36$ and $\mathrm{Ca}-41$, both originating in the graphite cores. Ca-41 releases are solubility limited and so it is unlikely that this 1sotope could be released faster than the model predicts. It 18 assumed that $\mathrm{Cl}-36$ is released at the same rate as the bulk corrosion rate of the graphite (4). 
The bulk corrosion rate was determlned, as described earlier, by measuring the leach rate to water of C-14 from samples of 1rradiated Dungeness graphite moderator. At th1s rate $\mathrm{Cl}-36$ contributes $0.14 \mu \mathrm{Sv} \mathrm{y}^{-1}$ to the dose rate to water consumers, or some $25 \%$ of the total dose rate from the two decomint 88 ioned reactors.

From Figure 4 it can be seen that uncertainties in the parameters relating to any of the other lsotopes considered here would need to be very large to affect 8 ignificantly the outcome of this study. Indeed most of the lsotopes considered lead to dose rates far below the lowest $\left(10^{-b} \mu S v y^{-1}\right)$ shown in P1gure 4 .

All the hydrogeological parameters used in this work have been measured for the aquifer: the results presented here are best estimates based on real data. The results are relatively independent of some of the parameters, for example the ground water velocity, because the half lives of the critical 1 sotopes are so long. However, it is implicitly assumed that the water table slopes from reactor to we11: In fact in recent years this has been the case only for very limlted periods, certainly not continuously. Flgure 2 shows typical groundwater levels around the Dungeness 81 te. clearly when the slope 18 seawards no radloactivity will reach the well but, over the time periods considered here, we cannot be sure that the water table will not permanently slope, as assumed here, in the critical direction from reactor to well.

Comparison between the various scenar1os described in this report shows that there is little to be galned radiologlcally by cladding the residual nuclear bulldings or by extensive engineered sealing techniques. The pesk dose rates resulting fron collapse after a 500 y totally sealed period are the same as those following a collapee after the reactor 1 slands have leaked continuously following Stage 2 dismantling. Indeed the dose rates following a total collapse just 15 y after shutdown are only a little higher than those found following a collapse many centuries into the future. This leads to the fundamental conclusion that the very long 11 ved 1 sotopes considered here will eventually transport back to man from any engineered aurface repository or store. In the deferred Stage 3 state, the majority of the radioactivity 1 a contained within a $100 \mathrm{~mm}$ thick steel sheli inside a $2000 \mathrm{~mm}$ thick reinforced concrete structure. Th1s $1 \mathrm{~s}$ an engineering system which should be comparable, in the very long term, with near surface waste disposal sites. The radiological consequences of waste management following decommisioning will not therefore be reduced in practical terms by dismanting the reactor structurea, putting them into boxes and placing those boxes in a purpose bullt near surface repository. Thus the only requirement on the residual structures 18 that any degradation during a $130 \mathrm{y}$ period following shutdown does not result in holes sufficlently large to allow people to enter the bulldings.

The boller unita from the Magnox reactors are likely to be stored on alte during the period for which Stage 3 dismantilng 1 s deferred. Although the radiological consequences of this option have not been explicitly considered here, the resultant dose rates from leaching and radioactivity transfer to the aquifer can be compared with those from the residual nuclear bulldings. The leotoplc distribution of material in the bollers 18 broadly - Imlar to that within the structure, since this 18 its origin having been activated within the core and transferred to the bollers with the coolant 8as. It 18 expected that the boller radloactivity levels will be about 0.017 of those in the nuclear 18land, thus the contribution to the total dose rate due to water and alrborne radioactivity transport to the local population w111 also be about $0.01 \%$. The bollers are contained $1 \mathrm{n} 75 \mathrm{~mm}$ thick teel shells, In which they will be stored, so their degradation rate wil be very simllar to that of the $100 \mathrm{~mm}$ thick reactor pressure vesse 1 . 
Early intrusion into the concrete shlelds will clearly result in unacceptable dose rates; however very sophlsticated cutting techniques would be required to gain entry and, because the residual reactor structures are above ground, it cannot be argued that unintentional intrusion 18 11kely, at least for the periods for which institutional controls are effective. Unauthorised entry would lead to a situation where, $130 \mathrm{y}$ after shutdown, an Individual would need to spend 500 hours each year in the vicinity of the most active components to recelve an exposure equal to that from natural background. After about 500 y only $\mathrm{Nb}-94$ will be limportant and this time w111 rise to 1300 hours per year.

\section{SUMMARY}

The potential radiological consequences of deferring the final dismantling of the two reactors of the Dungeness 'A' Magnox power station are extremely sma11. If the concrete bloshield structures and 8 teel pressure vessels both start to leak 15 y after shutdown, at a slow but Increasing rate which leads to the eventual entize collapse of both nuclear 1slands, the peak Individual ingestion and Inhalation dose rates to the local population would be $0.5 \mu \mathrm{Sv} \mathrm{y}^{-1}$. Even $1 \mathrm{f}$ the two complete nuclear 1slands collapsed completely just 15 y after final reactor shutdown, allowing raimwater access to the entire structure, peak dose rates to the local population would be on $1 \mathrm{y} 0.7 \mu \mathrm{Sv} \mathrm{y}^{-1}$. The peak dose rate results primarily from radioactivity returned to man through the aquifer on which Dungeness power station $1 \mathrm{~s}$ built. There 18 no radiological advantage in applying extensive englneered sealing technology to the reactors at the start of the deferment perlod. Even if such technology prevented water Ingress completely for $500 \mathrm{y}$, the eventual radiological consequences when the system did leak would be the same as those from early leakage because the half lives of the isotopes involved are very long.

The gamma dose rate at the outside of the concrete shields, resulting from residual radioactivity inside the nuclear island, is estimated to be $0.02 \mu \mathrm{Sv} \mathrm{y}^{-1}, 15 \mathrm{y}$ after shutdown. There 18 therefore no radiological reason to control public access to the outside of the two residual nuclear Islands, and the only englneering constraint on the residual structures 18 that they should not degrade in such a manner that public access inside the bulldings becomes possible during the first 130 y following shutdown.

\section{ACKNOWLEDGEMENT}

Th1s paper is published with the permission of the National Power Division of the Central Electricity Generating Board.

\section{REFERENCE S}

(1) Woollam P.B. and Pugh I.G., 1979, 'Neutron Induced Activation, Waste Disposal and Radiation Levels for the Reactor Is land structure of a Decommissioned Magnox Power Station', IAEA-SM-234/10, Vienna

(2) Woollam P.B., 1978, CEGB Report RD/B/N4231

(3) Felstead L.D. and Woollam P.B., 1984, CEGB Report TPRD/B/0386/N84

(4) White I.F. et a1., 1984, 'Assessment of Management Modes for Graph1te from Reactor Decommissioning' CEC report EUR 9232

(5) Southern Water Authority, 1984, 'Jo1nt Report of the Denge Hydrogeological Study'

(6) Na1r S., 1979, CEGB Report RD/B/N4668

(7) Woollam P.B., 1987, CEGB report TPRD/B/ /087 1/RB 7 
THE DECOMAISSIONING DATA BANK (DDB)

- METHODOLOGY AND APPLICATIONS -

P. Petrasch, NIS Ingenieurgesellschaft mbH, D-6450 Hanau, FRG

J. Roger, Comissiariat l'Energie Atomique

(CEA). IPSN/UDIN

B.P. 171, 30205 Bagnols-Sur-Ceze

\section{ABSTRACT}

The objective of the work programe is to develop a concept of data bank for evaluating decomissioning cost and radiation exposure on the basis of existing data. In the first step we have defined a methodology for extrapolating experience relating to cost and occupational radiation exposure, gained in the decomissioning of specific Installations (e.g. pllot dismantling profects), to the future decommissioning of various installations. In the second step we collect existing and avallable basic data.

\section{INTRODUCTION AND OUTLINE OP TASKS}

To date a host of results has been obtained and experience gathered under the research and development projects on the decomissioning of nuclear power plants inltlated and funded by the European Community. Generally, this knowledge is passed on via publications. However, handling this information and using the data, in this form, as a basis for projectiong and extrapolations is very time-consuming. Accessibility of the data can be considerably facllitated by establishing a database. This database enables the user to $\mathrm{f}$ ind answers to specific questions within a very short tine or to get a general overview.

To take advantage of these features for evaluating the results and experience gained in deconalssioning nuclear power plants, NIS Ingenleurgesellschaft mbH (light water reactors) and the Comissarlat a l'Energie Atonique (CEA), IPSN/UDIN (gas-cooled reactors, reprocessing plants) are developing a concept for a data base.

The decomissioning of nuclear power plants constitutes a area of research in which very special questions arise. A general database conprising the entire knowledge avallable in the fleld would therefore be extremely extensive. This is why two specific areas of information were selected in developing the concept: the decommissioning cost and the radiation exposure of the personnel during the decomissioning activities. This is intended to enable a statenent on the cost to be expected and the radiation exposure to be made in advance for future decomissioning projects.

The development of this database concept began with the following questions :

- How can the decomissioning and disposal of nuclear power plants be systematized and atructured?

- What data are required for extrapolating cost and radiation exposure? 
- How can such data be collected?

- How will these data have to be processed to permit conclusions to be dram as to future decommissioning activities?

2. SYSTEMATIZATION OF DECOMMISSIONING

The structure needed to assign the information to a clear-cut system could be found by breaking down the decommissioning activities into various areas such as planning, dismantling, radiation protection and waste management.

The further subdivision must be clear-cut, but at the same time flexible; clear-cut in order to link a specific term to the associated information, and flexible in order to be able to accomodate different approaches (e.g. differences between nations).

As a result a list was finally draw up comprising 8 sections (working packages) and about 50 subgroups (see Figs. 1 and 2 ).

A more detalled structure was not useful as nuclear power plants require an approach different from reprocessing plants. National conditions governing activities in nuclear areas also play a role here.

\section{DATA RELEVANT TO DECOMMISSIONING}

The information required to extrapolate cost and radiation exposure can be divided into two large groups:

- general information providing the necessary background, including boundary conditions needed for cost determination

- special information directly related to the extrapolation process.

The first group describing general information contains the following data:

- general boundary conditions and regulations governing the decommissioning of nuclear facilities, e.g.

- national and international atomic laws and regulations

- type of final storage facility avallable

- national licensing approach

- preferred decommissioning variants

- national working conditions, e.g. daily working hours, specific conditions governing activities in controlled areas, personnel organization

- survey of the nuclear facility to be decommissioned

- type of nuclear facllity, type of nuclear power plant

- plant parameters, e.g. power output, operating time, history of operation 
- plant description, nasses, volunes, surfaces, radioactive inventory.

The second group of Information comprises the speclflcations needed for the extrapolation of decomissioning data. They provide detalled information on individual working steps and include

- speciflcation of the activities to be carried out

- number and qualification of the personnel employed

- description of the machines, equipment and devices used

- local conditions, local dose rate, spatial conditions

- working results

- manpower

- duration

- radiation exposure of personnel

- $\cos t$

A reference value $w 11$ be defined and supplied for each of the processes or working 8 teps described. A reference could be, for instance, the mass of a component. A future user would then only have to substitute a different mass value in order to extrapolate a new cost figure.

A purely mathematical treatment of the data, however, would mostly lead to results that give a wrong impression when cost and radiation dose were evaluated. In cost calculations it is Indeed possible with different information that results relating to identical activities differ, but are still correct. In this case they are based on different premises or they do not cover the same cost franework. Such problems can be avolded by describing the boundary conditions governing the cost figures, which are provided in the general information mentioned above.

In summary it can be said that the specific data about the individual working steps serve the purpose of direct mathematical extrapolation of Information. The general information serves to explain why a certain activity was performed one way rather than any other.

\section{Data collection and evaluation}

In any data collection activity one must first of all consider the avallabllity of appropriate data. In the present case there are three sources (see Fig. 3):

- actual decomissioning projects

- EC research programe

- other publications.

The scope and level of detall of decommissioning data in publications differ widely. The first step in data collection was to develop a structure in which different information could be integrated for uniform processing at a later stage. To this end a standard data set was developed which is 
shown in Pig. 4. This standard data set encompasses the following information:

- general information

- title of the event concerned and the idenfication code used for integration into the chosen decomissioning structure

- detailed description of the event

- nuclear facility concerned

- source of information

- detailed description of the technique used, the process or treatment

- information on the manpower and labour cost

- reference value to establish a basis for extrapolation, e.g. the mass of a component to be handled

- description of the individual activities forming part of the process to be carried out and their duration. If necessary, a distinction will have to be made between activities on the critical time path and activities which may be conducted in parallel.

- number and qualification of the personnel employed, indicating the respective working hours assigned to a qualification

- total manpower and determination of the specific manpower related to the reference value.

A detailed calculation of the labour cost was not done, since the costs incurred in wages are highly dependent on the respective national price and wage levels, regulations on working hours and labour law factors. The future user, however, can determine the labour cost himself on the basis of the man-hours needed and the required qualification of the personnel.

- Information on material and equipment cost, with a distinction being made between fixed and variable cost

- reference data for the cost figures (price level)

- currency

- machines, equipment and devices used, including their respective cost

- total cost and specific fixed cost related to the reference value

- consumables required or other expenditure causing variable cost, e.g. rents

- respective variable cost related to the object causing the variable cost

- total cost and specific total value related to the reference value 
- information required to determine radiation exposure

- characterization and general classification of the local dose (high, mediun, low)

- enumeration of the personnel enployed, indicating the respective individual dose rate

- addition of the relevant values to form the job dose and the relation of this dose to the reference value

- survey of the fate of the component as radioactive waste, indication of type of package for final disposal

- secondary waste produced by the decomissioning activities

- associated activities required to carry out the process concerned which, however, are assigned to another work package in order to comply with the given structure of the database.

\section{APPLICATION OF THE STANDARD DATA SET}

The atandard data set of a process or working step is designed so as to provide a comprehensive picture of the measures required. This serves the purpose of avolding a purely mathematical extrapolation which - as already pointed out - may lead to faulty results. The data set shows the user the progress of acitivities in detall, also indicating the time and associated framework activities, e.g. planning. radiation protection etc. as well as direct follow-up cost caused by secondary waste.

With each application the general information has to be regarded as the bas $1 \mathrm{~s}$ and taken into account as such.

When it comes to evaluating the influence of the general information on cost or radiation exposure, however, the future user will have to find an answer hinself. At present, while the concept is being developed, it is not possible to establish a rule governing the adaptation to general data. A case in point would be the following application:

- Pron the data set the user takes e.g. the figure of $5 \mathrm{DM} / \mathrm{kg}$ for dismantling a component

- the associated boundary condition is: Konrad repository, legal regulatlons prevalling in the Federal Republic of Germany

- the user, however, wants to enplace his component in a shallow-burial disposal facility. legal regulations prevalling in Prance.

The user will now have to determine whether he can use the cost figures without any restrictions or whether a correction is required. At present such questions cannot be answered within the database framework. The issue, however, should be clarified in future research work.

\section{SUMMARY AND CONCLUSIONS}

The concept developed by NIS Ingenleurgesellschaft mbH and the Conmissariat a l'Energle Atonique (CEA) / IPSN/UDIN makes great denands on data collection as well as on inplementation and evaluation. 
Many years of handling cost figures and cost estimates at NIS and CEA have shown that only the extrapolation of well described cost figures that have a sound basis will lead to correct values amenable to interpretation. It would therefore not be of any use to anybody, if the recently developed concept of a decommissioning database were too global and superficial in character. It is our intention to make the data we have collected available, in a useful form, to all users who may be interested.

\begin{tabular}{|ll|}
\hline & Working packages \\
\hline 1 & Project management \\
2 & Llcensing \\
3 & Operation \\
4 & Decontamination \\
5 & Dismanting \\
6 & Rediation protection \\
7 & Waste management \\
8 & Site restoration \\
\hline
\end{tabular}

Fig. 1. Decommissioning working packages

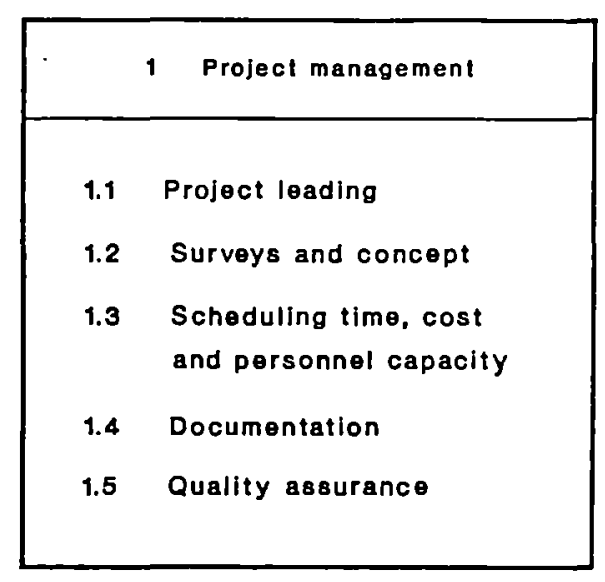

\begin{tabular}{|c|c|}
\hline & 5 Dismantiling \\
\hline 5.1 & Staff \\
\hline 5.2 & $\begin{array}{l}\text { Dismantllng non-radioactive } \\
\text { components }\end{array}$ \\
\hline 5.3 & $\begin{array}{l}\text { Dismantling radioactive } \\
\text { components }\end{array}$ \\
\hline 5.4 & Remote controlled dismantling \\
\hline 6.6 & $\begin{array}{l}\text { Removal of activated concrete } \\
\text { structures }\end{array}$ \\
\hline
\end{tabular}




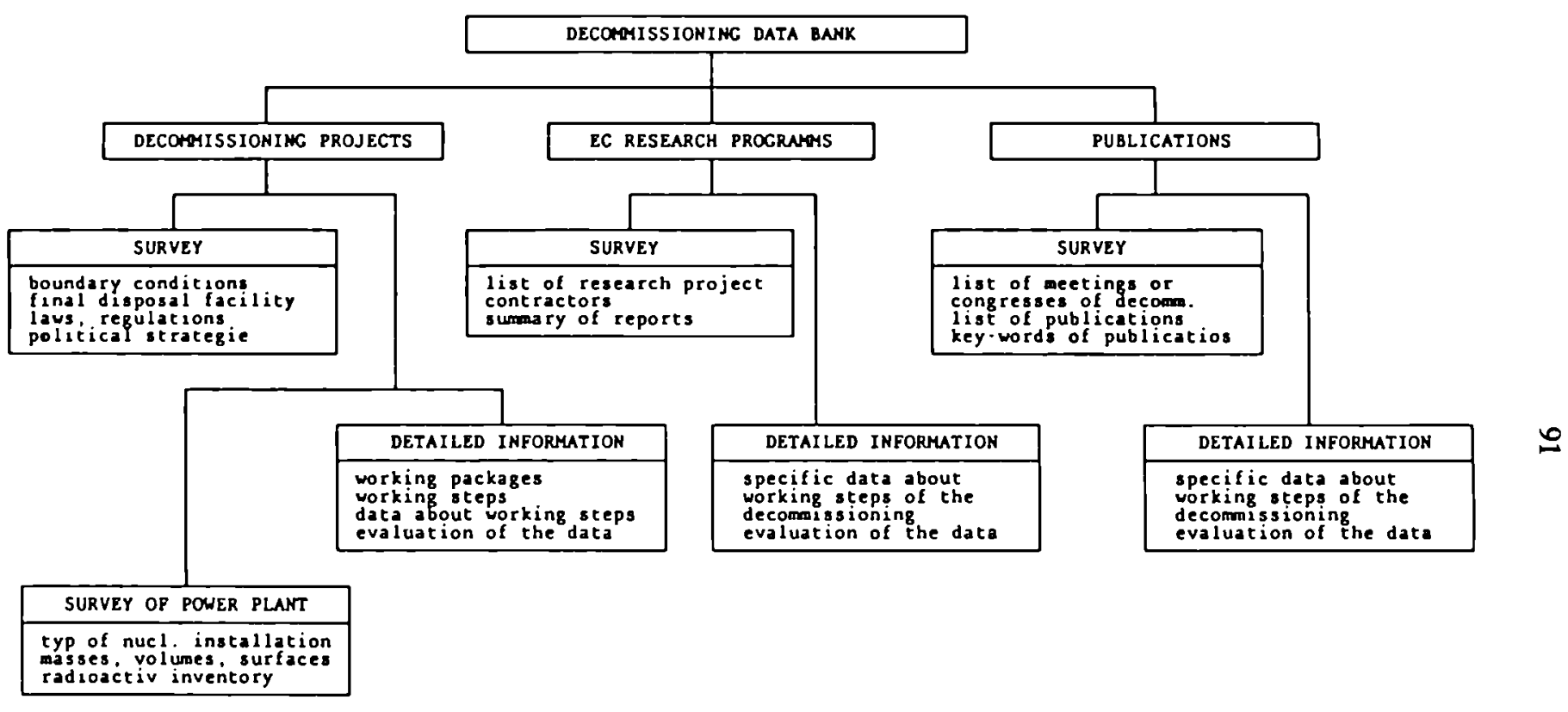

Fig. 3. Structure of the decommissioning data bank 


\begin{tabular}{|c|c|}
\hline & Standard data set \\
\hline 1 & $\begin{array}{l}\text { General Information } \\
\text { - tltle } \\
\text { - identiflcation code } \\
\text { - descrlption of event } \\
\text { - nuclear facility } \\
\text { - source of information } \\
\text { - discriptlon of the technlque }\end{array}$ \\
\hline 2 & $\begin{array}{l}\text { Reference value to establish a } \\
\text { basis for extrapolation } \\
\text { - mass, volume, wall-thlckness, } \\
\text { a. o. }\end{array}$ \\
\hline 3 & $\begin{array}{l}\text { Manpower } \\
\text { - activities and duration } \\
\text { - number of workers and } \\
\text { quallication } \\
\text { - manpower related to the } \\
\text { reference value }\end{array}$ \\
\hline 4 & $\begin{array}{l}\text { Material and equipment cost } \\
\text { - descrlption of equipment } \\
\text { - consumables required } \\
\text { - flxed and varlable cost } \\
\text { - total cost and specific cost, } \\
\text { related to the reference value }\end{array}$ \\
\hline
\end{tabular}

Fig. 4.1. Standard data set for each working step

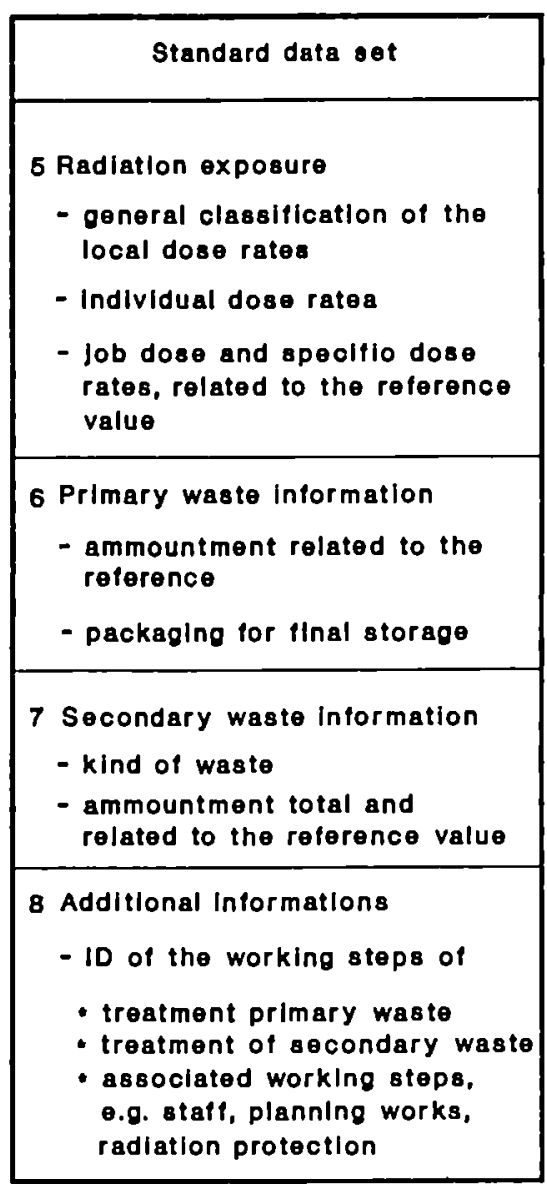

Fig. 4.2. Standard data set for each working step - continued 
RADIOLOGICAL CRITERIA FOR UNRESTRICTED RELEASE OF MATERIALS

FROM NUCLEAR INSTALI.ATIONS

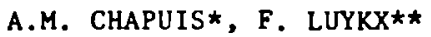

* Commissariat a l'Energie Atomique, Fontenay-aux-Roses, France

* Commission of the European Communities, DG XI, Luxembourg

\section{ABSTRACT}

It 18 widely accepted that materlals very slightly radloactive may be released to the environment without further control if this practice can be fustifled and 1 the corresponding risk to the exposed Indfulduals can be regarded as trivial. Risk levels of the order of $10^{-6}$ per year may be 80 regarded and they correspond to an annual effective dose of the order of $100 \mathrm{\mu Sv} / \mathrm{year}$.Th1s exemption level of dose, although conceptually simple, is very difficult to apply in practice in order to determine the sources and practices which may actually be exempted from regulatory control. For this reason, derived levels, expressed in activity terms, have to be set. They can be established on the basis of the characteristics of the radionuclides present and the possible exposure pathways.

There are two main routes of unrestricted release of radloactive materials, namely recycling and disposal. The option to be preferred in each case would mostly depend on the associated economic advantage that if offers.

One would expect the recycling option to be readily selected in the case of metals, the most 1mportant of which 18 steel. Disposal would normally apply to materials of little or no value such as concrete, rubble or insulating materials.

On the Initiative of the Commission of the European Communities, the Group of Experts appointed pursuant to Article 31 of the Euratom Treaty set up a Working Party to look into the problem of recycling materlals from the dismanting of nuclear installations and to propose appropriate criterla.

The criteria expressed in terms of speciflc and surface activity are directly applicable to recycling of steel scrap from nuclear power stations. A recent EC study proposes activity criterla for recycling of copper and alumintum, based on the same method.

Waste disposal may be solved on a national level and criteria are being set or proposed in some countries. An IAEA technical document provides guldance on the methods to be adopted in establishing exempt quantities for the terrestrial disposal of very low-level radioactive waste.

\section{INTRODUCTION}

At the beginning of the use of nuclear energy, classification into radioactive and non-radloactive waste was based on their or 1 in. Increase In the waste production, especially during refurbishment or dismantling of large nuclear installations, associated with the cost of their management and disposal as radloactive waste and with their value as equipment or recoverable scrap, brought to define more precisely the possible destinations of material. 
Several options may be considered : valuable material may be recycled or reused either under restrictive or unrestrictive conditions ; material may be disposed of under restrictive or unrestrictive conditions; material may be considered as radioactive waste.

The choice between these options depends on many factors (1), some of the more important considerations are the following :

- protection of individuals and population,

- availability of instrumentation for low-level activity measurements,

- availability of decontamination processes,

- industrial availability,

- costs,

- natural resources saving,

- socio-political attitudes.

This paper only deals with protection of man and proposes criteria for some applications.

\section{RADIOLOGICAL CRITERIA FOR EXEMPTION FROM REGULATORY CONTROL}

Most international organizations involved in radiation protection fleld have tackled or are dealing with the problem of exempting certain radioactive sources or practices from regulatory control.

2.1 . The ICRP approach

In 1ts publication 46 (2) on "Radiation Protection Principles for the Disposal of Solid Radioactive Waste", the ICRP states that there is a need to assign priorities so that limited resources are not wasted on trivial problems at the cost of neglecting major problems. This should be done by establishing exemption rules which could be based on a dose or risk level below which there would be no further need for radiation protection concern.

Comparatfve risk studies indicate that a probability of death of the order of $10^{-6} /$ year is generally regarded as trivial. This corresponds, applying the risk factors currently in use, to an effective dose equivalent of the order of $100 \mu \mathrm{Sv} /$ year. To guard against the possibility that many practices and sources of exposure could combine so that the total exposure of critical population groups would exceed $100 \mu \mathrm{Sv} /$ year, an exemption leve 1 of $10 \mu \mathrm{Sv} /$ year has been suggested for each practice or source.

Another criterion proposed is that the costs of the steps needed to evaluate the collective dose or for implementing additional protection measures could outwelgh any potential reduction in health detriment costs at a collective effective dose commitment of the order of 1 man. Sv per year of practice.

Eventually, a collective effective dose commitment lower than one man.Sv, made up of annual individual effective dose equivalents of less than $10 \mu \mathrm{Sv}$, is considered as an acceptable basis on which a practice or a source can be exempted.

Compliance with these two criteria is only one basis on which exemption might be granted. Sources or practices that do not comply with them could, nevertheless, be exempted from regulatory requirements if the optimization study indicates that exemption is the optimum solution. 
ICRP is currently reviewing its basic recomendations, given in Publication 26 (3), but the basic framework 18 unlikely to change very much (4). However, the dose-risk factors might change, which could influence the above dose exemption levels.

\subsection{The IAEA-NEA approach}

A joint effort by the IAEA and the NEA-OECD in 1988 resulted in a document on "Principles for the exemption of Radiation Sources and Practices from Regulatory Control" (5), which recomends a policy for exempting radiation sources and practices from regulatory control.

The two basic criteria for determining whether or not a practice can be a candidate for exemption are the following :

- Individual risks must be sufficiently low as not to warrant regulatory concern,

- radiation protection, Including the cost of regulatory control, must be optimlzed.

The first criterion has been addressed by defining a level of Individual dose that can be categorized as "trivial", and has been set at some tens of $\mu \mathrm{Sv}$ per year or less. However, because individuals may be exposed to several practices, It may be reasonable for national authorities to apportion a fraction of that upper limt to each practice and a dose level of $10 \mu \mathrm{Sv}$ per year has been suggested.

For the second criterton, if the generic study indicates that the collective dose commltment for one year of practice 1s less than about

1 man.Sv, it may be concluded that the total detriment is low enough to peralt exemption without an optimization procedure.

A practice $1 \mathrm{~s}$ defined as "a set of coordinated and continuing activities lnvolving radiation exposure which are almed at a glven purpose, or the combination of a number of similar such sets".

Comparison of the ICRP and the IAEA-NEA approach shows that although ICRP 18 perhaps less detalled in formulating its recommendations, the principles proposed for exemption and the derived dose values are nearly identical.

\section{2 . 3. The European Community Bas1c Safety Standards}

The EC Basic Safety Standards (BSS) for the health protection of the general public and workers against the dangers of lonizing radiation, laid down In EC Counc11 Directives of 15th July 1980 (6) and 3rd September 1984 (7), are mainly based on ICRP publications $n^{\circ} 26$ and $n^{\circ} 30$.

EC Directives generally bind Member States as to the results to be achleved while allowing national authortties freedom of form and means. Member States are therefore obliged to transpose the BSS Into national statutes within the prescribed perlod and to ensure their full application.

Article 2 of the BSS Directive of 1980 states that 1t "shall apply to the production, processing, handling, use, holding, storage, transport and disposal of natural and artiflclal radloactive substances and to any other activity which involves a hazard arising from lonizing radiation".

As a minimum requirement, the activities referred to in Article 2 must be reported. However, the Member States of the Communtty may go further and require prior authorization in cases decided upon by each Member State, account taken of the dangers lnvolved and other relevant considerations (Art1cle 3). 
Exemption from the requirements for reporting and prior authorization is provided in Article 4 of the Directive for activities involving, amongst others :

(a) $\ldots .$.

(b) radioactive substances of a concentration of less than $100 \mathrm{~Bq} \cdot \mathrm{g}^{-1}$ $\left(0.0027 \mu \mathrm{Ci} . \mathrm{g}_{1}^{-1}\right)$, this limit being increased to $500 \mathrm{~Bq} . \mathrm{g}^{-1}$

$\left(0.014 \mu \mathrm{Ci} . \mathrm{g}^{2}\right)$ for solid natural radioactive substances.

This article, however, dates back to the $1960^{\prime} \mathrm{s}$ and the radiological impact of these exemption levels was never assessed in detail. For this reason the Group of Experts, set up under the terms of Article 31 of the Euratom Treaty, when examining in 1985 the radiological criteria for unrestricted recycling of materials from nuclear installations, decided to convene a Working Party to look into the problem and to propose appropriate criteria.

Its report, published in 1988 (8), recommends clearance levels for steel scrap and equipment from the dismantling of nuclear power plants. Details on this report will be given below.

The Commission envisages revision of the BSS in 1990, following the publication of the new ICRP recommendations. At the same time, the Commission also intends to review Article 4 and to adapt it to the latest developments in this field.

\section{3 - DERIVED QUANTITIES}

Exemption levels cannot be expressed in terms of individual dose, since operational measurement of this parameter is not practicable. Rather, exemptions should be expressed in terms of derived quantities that are directly measurable so that compliance with the provisions of exemption can be determined.

Different scenarios leading to exposure of workers and public must be examined. The doses have to be evaluated taking into account the characteristics of the material and the expected quantities.

In the ICRP and IAEA-NEA publications, only the equivalent dose level to the general public in case of likely exposure has been recommended.

Competent national authorities must then specify the dose levels to be applied to each type of situation. These may take into account the probability of the event, the size of the critical group, the degree of conservatism of the dose evaluation, and the possibility of multiple exposure due to various practices.

For example, an occupational exposure excludes a second critical occupational exposure and the dose level may be some tens of $\mu \mathrm{Sv}$ per year ; under accidental condition with a low probability of occurrence the dose level may be $5 \mathrm{mSv} /$ year.

The principles of determination of derived quantities have been proposed, and some of the problems that may be encountered have been pointed out (9). 


\section{RECYCLING}

Some of the materials derived from refurbishment or dismantling of nuclear installations have a high economic value, thus providing a strong incentive for recycling. Th1s 18 the case for metals such as carbon steel, stainless steel, copper or alumintum. It may be the case for concrete which can be recycled for road construction when the distance between the production site and the utflization site $1 \mathrm{~s}$ short.

In the case of metal, large quantitles of scrap and 1tems circulate between various countries and the problem of recycling will have to be solved on a transnational scale.

This incited the group of experts set up under the terms of Article 31 of the Euratom Treaty to recommend exemption levels for the recycling of steel from dismantled nuclear power plants.

Th1s recommendation 18 based on a study evaluating the doses to workers and to the public under typlcal conditions for the main radionuclides found in PWR contaminants.

The doses annual to the workers are proportional to the specific activity and to the total mass of scrap treated in a year. It was assumed that 10,000 tonnes of very low-level steel from two dismantled PWRs was melted in the same steel plant, in one year. With this pessimistic assumption the dose to the workers 18 of the same order as or lower than the dose to the public for gamma emitters.

The limiting scenarios are therefore defined by exposure of the public. They are proportional to the specific activity, and depend on the partition of nuclides during melting, and on the exposure parameters (distance to the source, exposure duration, dilution during melting and manufacturing of 1 tems). These parameters were set for scenarlos dealing with carbon steel recycling. Stainless steel recycling was not studied in detall but the corresponding scenarios and parameters would lead to the same spectific activity levels.

Based on a dose level of $10 \mu \mathrm{Sv}$ per year the clearance level would be $2 \mathrm{~Bq} / \mathrm{g}$ for Co $60,4 \mathrm{~Bq} / \mathrm{s}$ for Cs $134,7 \mathrm{~Bq} / \mathrm{g}$ for Cs 137 and $11 \mathrm{~Bq} / \mathrm{s}$ for Mn 54 .

For pure beta emitters and alpha emitters the limiting scenario is Inhalation of dust by workers in the steel plant. For alpha emitters, specific activity limits seemed Inappropriate and the doses were evaluated for a surface contamination of $0.04 \mathrm{~Bq} / \mathrm{cm}^{2}$, in order to comply with IAEA regulations for the safe transport of radioactive materials. The corresponding dose was $0.4 \mu \mathrm{Sv} /$ year for $\mathrm{Pu} 239$ and Am 241 . The dose due to pure beta emitters in a usual contamination spectrum is low enough to obviate the need for a specific clearance level.

The study focused on recycling, but as the intention was to set the exemption at the boundary of nuclear installations, two scenarios corresponding to direct reuse of materlal were studied : repalr of a motor and use of a tank for water supply.

As far as possible parameters values were chosen in a realistic way and are based on industrial scale measurements. Since the preparation of the EC recommendation, these values have been refined by experiment. The improved values do not change the result. Only one problem has not yet been solved and requires further experiments and 1mproved understanding of the phenomena in order to confirm the result: 1t is the potential dose to workers due to aerosols created during the cutting of metal pleces. Further experiments will shortly provide values for the parameters needed for calculation of this dose (10). 
The recommendations from the group of experts are then :

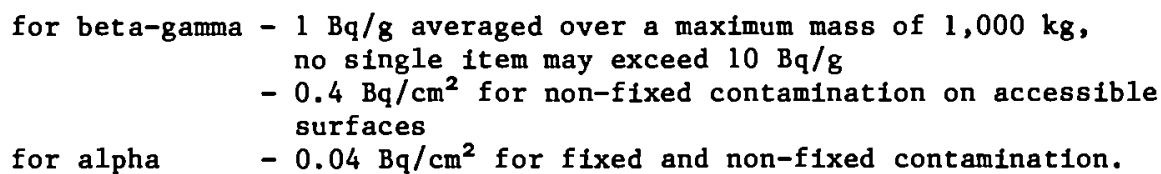

The application of these levels would result in a radiological impact on the public that is negligible from the health point of view and would avoid the inclusion of highly active items within the averaged mass. In exceptional circumstances, with very low probabilities of occurrence, the dose to the most exposed individual might be greater than those on which the evaluation is based, however the individual risk is not expected to be greater than that acceptable for the public.

Recycling of copper and alumintum has also been studied (11). The exempt mass released per year would be smaller than the mass of exempt steel, but, by the same time, the mass involved in items made with recycled metals $1 \mathrm{~s}$ generally also smaller. It appears that the limiting scenario for copper is very special use for medical purposes, and for aluminium use in ship building. In both cases the doses are proportional to the specific activity. The clearance levels would be of the same order of magnitude as those set for steel.

Besides these exemption levels, which are calculated whatever the use or destination of recycled metal, it is possible for national authorities to set specific clearance levels for particular installations depending on the characteristics of the installation and the destination of recycled metal.

\section{DISPOSAL}

Except for materlals with high economic value, the usual final destination of waste is land disposal. Three main kinds of disposal can be used :

- disposal of Inert material such as concrete, soll or rubble at a quarry or site with few or no particular specifications ;

- disposal of ordinary waste such as municipal waste at a site with requirements regarding geological characteristics, conditions of operation, monitoring and fencing;

- Disposal of industrial toxic waste at a site with more stringent Isolation conditions.

For these types of disposal, there is no need for international agreement. Disposal of very low level waste however must comply with national regulations.

The dose pathways by which disposal workers can be exposed are relatively simple and well defined and the main uncertainty lies in estimating the fraction of exempt waste in disposed waste. Landfill workers receive the highest doses which are proportional to the specific activity and to the percentage of exempt waste disposed of at the landfill.

The dose pathways by which members of the public are exposed are more complex and subject to much greater uncertainty as to whether they actually occur at all. 
An IAEA advisory group has considered the case of disposal of exempt waste in a sanitary landfill or by incineration and has proposed a methodology for determining derived quantities (12).

The example used by this group concerns a small landfill, assumes that $10 \mathrm{z}$ of the total waste are contaminated, and 18 based on a dose of $10 \mu \mathrm{Sv}$ per year.

The methods and models used by several authors are very similar to those proposed in the IAEA document $(13,14,15,16)$. However in order to take into account the Influence of the landfill size, different activity limits are proposed depending on the type or the size of the landfill $(13,14,15)$. Moreover the dose $\operatorname{lmlt}$ used for the landf111 workers 18 set by some authors to higher values (50 to $100 \mu \mathrm{Sv} /$ year) $(15,17,18)$.

The result obtained for small landf 111 and a dose limit of $10 \mu \mathrm{Sv}$ per year 18 of the order of $1 \mathrm{~Bq} .8^{-1}$ for cobalt $60(12,14)$.

\section{CONCLUSION}

Doses to workers and members of the public due to recycling or disposal of slightly radioactive waste depend on some or all of the following factors :

- spec1fic and surface activity,

- amount of radioactive material released in one year,

- fraction of radioactive material in the total amount of material,

- radiological, physical and chemical properties of material,

- characteristics of industrial plants.

Nevertheless, generic assessments may be achleved and derived limits expressed in terms of activity may be proposed, allowing the possibility of monitoring to ensure compliance with the criteria.

These derived limits are based on the dose 1 imits.

In some cases the limiting scenarios correspond to exposure of a wide group of the public for which a $10 \mu \mathrm{Hv}$ per year dose 11mit could be carried. In other cases the limiting scenarios concern individuals belonging to small critical groups (ex : occupational exposure). The probability for one of them to belong to other gmall critical groups is very low and a limit of several tens of $\mu \mathrm{Sv}$ per year could be carried.

Since large quantitles of metal scrap and items circulate between various countrles of the European Communities, the radiological problems of recycling will require to be solved on a transnational ocale. Derived 1imits may be simplifled taking into account the contaminants spectrum. In case of steel arising from the dismantling of reactor plants after normal operation, a limit of $1 \mathrm{~Bq} .8^{-1}$ for beta-gamma emitters has been recommended by the group of Experts set up under the terms of Article 31 of the Euratom Treaty. This value may be averaged over not more than one metric tonne. To avold the inclusion of highly active items within the averaged mass thefe 1s on additional requirement that no single item exceeds 10 Bq.8 ${ }^{-}$. Furthermore clearance levels have been specifled for surface activity.

The case of disposal may be solved on a national scale taking into account the national practices and regulations. It seems that different activity limits may be set for different types or sizes of landfill. For ordinary small sized landfilis the activity limit for cobalt 60 seems to be of the order of 1 to $10 \mathrm{~Bq} \cdot \mathrm{g}^{-1}$. 


\section{REFERENCES}

1. IAEA Technical reports; Factors relevant to the recycling or reuse of components arising from the decommissioning and refurbishment of nuclear facilities; Technical report series $n^{\circ} 293$, IAEA, Vienna 1988

2. Radiation protection principles for the disposal of solid radioactive waste; ICRP Publication 46, Annals of the ICRP, Vo1.15 n 4, 1985 Pergamon Press

3. Recommendations of the International Commission on Radiological Protection; ICRP Publication 26, Annals of the ICRP, Vol.1, $\mathrm{n}^{\circ} 3$, 1977

4. G.A.M. Webb ; International Commission on Radiological Protection Guidelines ; Workshop on Rules for Exemption from Regulatory Contro1, Washington, 1988, NUREG/CP-0101

5. IAEA Safety Guides; Principles for the exemption of radiation sources and practices from regulatory control; Safety Series $n^{\circ} 89$, IAEA, Vienna 1988

6. Council Directive of 15.07 .80 amending the Directives laying down the Basic Safety Standards for the health protection of the general public and workers against the dangers of lonizing radiation (Official Journal of the European Communities, L 246 of 17.08.1980) EUR 7330, Luxembourg

7. Council Directive of 03.09.1984 amending Directive 80/836 Euratom as regards the Basic Safety Standards for the health protection of the general public and workers against the dangers of ionizing radiation (Official Journal of the European Communities L 265 of 05.10.1984), EUR 9728, Luxembourg

8. Commission of the European Communities; Radiological protection criteria for the recycling of materials from the dismantling of nuclear installations; Radiation Protection $n^{\circ} 43$; Luxembourg 1988

9. A.M. CHAPUIS; Principles for determining derived limits for the exemption of objects and materials; Workshop on rules for exemption from regulatory control, Washington, 1988, NUREG/CP 0101

10. G. PILOT; Measurements of effluents from plasma arc and laser cutting; International Conference on the Decommissioning of Nuclear Installations ; Brusse1, 24-27 0ctober 1989

11. H. GARBAY, A.M. CHAPUIS ; Radlological evaluation of releasing very low level radioactive copper and aluminium from nuclear control ; International Conference on the Decommissioning of Nuclear Installations; Brussels, 24-27 October 1989

12. IAEA Technical document ; Exemption of radiation sources and practices from regulatory control; Application of the principles to low-level radioactive waste disposal in the terrestrial environment ; IAEA-TECDOC-401, Vienna 1987

13. T.J.SUMERIING, B. SWEENEY ; A review of the justification for exemption orders and for other low-level radioactive waste disposal practices; ANS Report n ${ }^{\circ} 683-1,1987$; DOE Report DOE/RW/87.069, Department of Environment, UK 
14. Private communication from Institut für Strahlenhyglene des Bundesgesundheltsamtes, Neuherberg, Federal Republic of Germany

15. A.M. CHAPUIS, Ph. GUETAT, Ph. RENAUd ; Propositions pour l'acceptation de déchets de très falble activité dans des décharges contrôlées ; CEA, IPSN/SEPD 89-10, 1989

16. S.M. NEUDER, W.E KENNEDY ; Onsite disposal of radioactive waste, NUREG-1101, Vol.2, 1987

17. Exigences préalables de radioprotection pour exempter certaines matières radioactives de permis après le transfert pour évacuation Projet de réglementation ; Canada

18. Proposed Rules for the policy statement on exemptions from regulatory control ; USNRC ; 10 CFR Ch.1, Federal Reglster 53, 238, Dec.12, 1988 


\section{DISCUSSION}

Question: A R GREGORY, CEGB (NPD) - Mr Larin, what are the large-scale works undertaken in the USSR and where do you dispose of the waste?

Answer: Y LARIN", VNIIAES - No work on a large scale has been done, but there has been pilot work at Beloyarsk (Unat/Graphite). On-site interim storage is used. Present work aims at defining procedures and development of techniques to face major dismantling tasks.

Question: P DE JONGHE, SCK/CEN Mol - I thank you for speaking about the accident at chernobyl. Can you now set the objectives with regard to the degree of decontamination or residual contamination of the terrain in the environment ( $30 \mathrm{~km}$ zone) of Chernobyl?

Answer: Y LARIN*, VNIIAES - Our policy so far has been to contain the contamination and to prevent it from spreading. Really thorough decontamination has not yet been envisaged for economic reasons and because of the fact that any human residence is prohibited within a radius of $30 \mathrm{~km}$. It is not foreseen for the time being to allow populations return to the area to live there on a continuous basis.

Question: H J C BOEKSCHOTEN, KEMA - Does the radon originate from the reactor building or from outside?

Answer: W HARBECKE, KWL - Before commissioning we found radon in the containment as well.

Question: A R GREGORY, CEGB - Does the selection of a coastal or an inland site show any difference in the measurements?

Answer: C FLEISCHER, TWC - Previous work carried out in the phase 1 programme did not show any wide variations, although stations were selected from coastal as well as inland sites.

Question: R NEIDER, BAM - Why do you differentiate between the beta-gamma surface contamination where only non-fixed contamination is counted, while for alpha contamination you take the whole contamination? I think that in both cases the total contamination should be taken into account because this figure is measured in practice.

Answer: A M CHAPUIS, CEA - Recycling in the nuclear field is a good solution and may be used for activities above the limits for unrestricted release. It seems that the possibilities in the nuclear field could be too low to use all the scrap coming from the dismantled installations (especially in France when the reactor dismantlings will occur).

For beta-gamma surface contamination, the mass activity limit covers the total surface contamination. The non-fixed surface contamination has, however, to be taken into account in specific scenarios such as contact contamination during handling.

For alpha emitters mass activity was not set because it is not measurable. The study does not intend to set surface activity limits based on the dose to the public. It was assumed that steel scrap suitable for unrestricted release would be transported as non-radioactive material and the corresponding limits have been used.

Translation from Russian by D de Heering, Belgonucléaire 
Comment: R NEIDER, BAM - When exemption limits for recycling materials from nuclear power plants are discussed it should be requested that, as far as possible, this material should be recycled within the nuclear field. In this way the general population will not come into contact with this activity.

Question: J ESSMANN, Preussenelektra - Mr Petrasch, from your comments I gather that your databank contains only data relating to decomissioning or some aspect of decommissioning. Why do you not plan to include data on the replacement of large items of equipment, which relate to the operation of nuclear power stations? Such data are often very informative from the point of view of technical complexity and radiation protection measures.

Answer: P PETRASCH, NIS - The final illustration shows three ways in which the requisite data can be acquired. The third option, shown as general 'Publications', includes, of course, the point to which you referred.

Question: D VANDE PUTTE, Electrowatt - You showed us the results of radiological risk calculation but have you approached companies to find out whether they would take the economic risk of using recycled steels?

Answer: A M CHAPUIS, CEA - Car constructors have not been contacted. However, a steel plant owner who recycled steel scrap from a French reactor was so pleased that he melted some commemorative items.

Question: P FUNKE, Ministry of the Environment and Reactor Safety, Wiesbaden - Are there plans to extend the databank to include fuel element manufacturing and would this serve any purpose?

Answer: P PETRASCH, NIS - The initial design work was centred on nuclear power stations and reprocessing plants. There is no reason why in the future data on the shutdown of fuel element manufacturing installations should not also be covered.

Comment: $K$ PFLUGRAD, CEC - the CEC has started a one-year study related to a databank on dose rates and costs in decommissioning nuclear power plants. Th1s 18 a start and there is no reason that other installations from the nuclear fuel cycle should not be included in possible future studies.

Question: H J C BOEKSCHOTEN, KEMA - For the release of radioactlvity from Magnox power stations $\mathrm{C}-14, \mathrm{Cl}-36$ and $\mathrm{Ca}-4 \mathrm{l}$ are the important nuclides. They originate from the graphite. What will the important nuclides from LWRs be?

Answer: P B WOOLLAM, CEGB (NPD) - The long-lived isotopes which originate in steels, such as $\mathrm{N}_{1}-59$ and $\mathrm{Nb}_{-94}$, will control doses under the circumstances I discussed. However, such metallic isotopes are held up in the groundwater system to such an extent that, even with their long half-lives, they will tend to have decayed before they can be released to the water consumer.

Question: $P$ B WOOLLAM, CEGB - How did the CEC derive an averaging mass of $1000 \mathrm{~kg}$ for the 'de minimis' limit? Would it be possible to make this averaging mass larger?

Answer: A M CHAPUIS, CEA - It was based on the mass used for the sea dumping. Averaging on a larger mass could be possible, for example on the mass corresponding to the truck load. 
CONCLUSION

This session was very well attended and the presentations mostly satisfactory in terms of both content and visual aids. There was, however, an apparent reluctance to contribute to the discussion from the floor despite adequate time being available.

Mr Larin reviewed the preparation being undertaken by IEA/NPPD Member states to build up plans and procedures for decommissioning nuclear facilities. However, apart from the magnificent successful efforts to contain the Chernobyl residual reactor structure within a concrete sarcophagus, little other work has been undertaken until now. The second paper, Mr Pocock et al, dealt in a workmanlike manner with the long-term stability and leak tightness of a reactor containment structure. It was confirmed that no significant differences between coastal and inland sites had been identified. The last paper in this group, by Mr Harbecke, drew attention to the possibility of suppressing negative pressure within the containment of shutdown nuclear reactors without significant transfer of radioactive aerosols to the outside. The benefits which could accrue must be considered in relation to individual reactor characteristics.

Mr Woollam outlined the consequences of deferring dismantlement of the residual Magnox structures for 100 to 130 years, in relation to radioactivity transport through the groundwater system. This draws attention to the inherent safety of leaving these reactors, provided reasonable attention is paid to maintenance.

Mr Petrasch described his work on the development of a databank for cost on a radiation exposure evaluation which will be in a useful form and applicable to decommissioning studies. The CEC has now started a one-year study which could lead to future studies on fuel cycle and reprocessing plants.

The final contribution from Mme Chapuis was presented in her customary polished style and was directed to the criteria for recycling of metals, in particular steel, and disposal of concrete rubble. This led to a discussion centred on radiological limits for reuse, costs and transport of such materials within the Community and the satisfactory conclusion of Session II.

A R GREGORY, CEGB (NPD) 
SESSION III

DESIGN FEATURES FACILITATING DECOMMISSIONING

CHAIRMAN: F MOTTE, SCK/CEN, B

SECRETARY: R BISCI, CEC 

TESTING OF COBALT-FREE ALLOYS FOR VALVE APPLICATIONS USING A SPECIAL TEST LOOP

\author{
BENHAMOU C., COHEN $S$. \\ Framatome S.A., Paris-La-Défense, France \\ RUFFET $\mathbf{P}$.
}

Comissariat l'Energie Atonique, Saclay, France

\begin{abstract}
Considering that use of Cobalt alloys should be avoided as $f$ ar as possible in PUR conponents a progranne ained at establishing the performance of Cobalt free alloys has been perforned for valve applications where Cobalt alloys are mainly used. Referring to past work two types of Cobalt free alloys were selected : Ni-Cr-B-Si and $\mathrm{Ni}-\mathrm{Cr}-\mathrm{Fe}$ alloys. Cobalt free valves behaviour has been evaluated comparatively with Cobalt valves by implementation of a progranme in a special PUR test loop. At the issue of the loop tests programme which included Endurance. Thermal shock and Erosion tests Cobalt free alloys candidate to replace Cobalt alloys are proposed in relation with valve type.
\end{abstract}

\title{
1. INTRODUCTION
}

The radiation level around the components of Pressurized Water Reactors (PWR) particularly governs the radiation exposure of the vorkers during the periodic maintenance operations, as well as during decomaissioning operations. Since the activation product cobalt 60 is one of the main contributions to this exposure, the use of Cobalt alloys in the primary circuit should be avoided as far as possible.

The alloys likely to replace Cobalt alloys mainly used in nuclear valves e.g RCo-Cr-A and RCo-Cr-B (Trade-mark Stellite grade 6 and 12 respectively) as required in aus 5-13 (American Velding Society) specification or in French RCC-M code (Design and construction rules for mechanical components of PYR Nuclear Islands) Section IV $s$ S 8000, wust comply with the following criteria :

- good reldability

- hardness equivalent to that of Cobalt alloys

- resistance to corrosion, friction and wear equivalent to that of Cobalt alloys.

Referring to past vork [1] [2] [3], Franatone, jointly with CEA (Comnissariat l'Bnergie Atomique), assessed a nunber of hard Cobalt free alloys considered as pronising; two of then were selected : Ni-Cr-B-Si (Trade mark Colnonoy) and $\mathrm{Ni}-\mathrm{Cr}-\mathrm{Fe}$ (Trade mark Cenium) alloys.

The work bere presented, partially sponsored by the Comission of the European Comnunities, aims at establishing the performances of these two alloys, conparatively to Cobalt alloys, on selected ralres nounted on a special CEA loop, operated in conditions as close as possible to PUR working conditions.

The work programme was driven as follows, considering that for a first evaluation are concerned essentially valve types which are the nost numerous used in nuclear plants :

- Basic study including design of selected valves and specification of Cobalt-free alloys and relding processes applicable for deposition,

- Comissionning of valves vith Cobalt and Cobalt free alloys,

- Inplenentation of the selected hardfaced valves in the CEA test loop. 
2. BASIC STUDY

- Selection of Materials

Screening work, conducted over the past several years by Framatome and

CEA (1) (2) (3) on Cobalt-free hardfacing alloys which could replace the Cobalt base alloys, have covered evaluation of mechanical and physical properties, weldability, wear and galling resistance and resistance to corrosion in a PUR coolant environment.

Table I gives the chemical composition of cobalt-free alloys selected with respect to the above criteria by comparison to Cobalt alloys.

- Selection of valves

Figures 1,2 and 3 shows a representative schema of selected valves which are respectively globe valve, valve body with bonnet and swing check valve.

Hardfacing deposits and integral products (cast or forged) concerned with cobalt base alloys were identified.

\section{COMISSIONNING OF VALVES}

Close contacts were promoted with valve suppliers for the manufacturing of valves to be tested on CEA loop; this rork included the following items :

- verification of documents in association with the supply e.g. plans, procurement specifications of materials, manufacturing process, qualification of welding processes, laboratory reports about Cobalt-free alloys, manufacturing report,

- special follow of hardfacing deposit performance,

- hydrotest and water tighness control of the valves,

- assembly conditions of the valves on the branch test of the loop.

This last item was deeply discussed with loop operator, CEA.

The whole detailed valve supply, delivered to CEA loop test facilities is summarized table II with respect to hard alloy and velding process selection.

Referring to problems met in performing the hardfacing deposits special investigation of velding procedures was necessary to be completed by the valve supplier for manufacturing successfully the valves with Colmonoy 4-26 and Cenium 36 .

All the above tests associated to the valve supply have been finally carried out without any problem.

\section{IMPLEMENTATION OF VALVES IN THE LOOP}

The test programme principles of the valves mounted on CEA Doubleau loop have been assessed with respect to PUR working conditions. The behaviour of cobalt free alloys are evaluated comparatively to cobalt alloys by testing successively the valves with stellite, the valves with Colmonoy and the valves with Cenium.

Figure 5 gives a schematic representation of the loop with its test branch; respective location of the three different valves on the test branch is indicated figure 4.

The detailed loop test procedure included for each serie of valves (same hardalloy) Endurance tests, Thermal shock tests and Erosion tests.

- Endurance tests

Endurance tests consists of 1500 cycles of valves opening and closing according to the sequence described figure 4 for one cycle. The globe valve is fitted with an electric actuator for remote automatic monitoring of opening and closing; at every cycle the electro-valve (E.V. figure 4) is opened for reducing the pressure downstream from the globe valve being in closed position ; consequently subsequent opening of the globe valve happens under a high differential pressure (150 bars) as met in 
the nost severe PUR working conditions.

- Thermal shock tests

The principle of thermal shock tests is described figure 5 for one cycle (hot shock + cold shock); 40 cycles are planned in the prograne, 20 with $\Delta \theta=100^{\circ} \mathrm{C}$ and 20 with $\Delta \theta=250^{\circ} \mathrm{C}$, the globe value being in opened position during the tests.

- Erosion tests

In connection with erosion loop tests at 70 and $320^{\circ} \mathrm{C}$ special globe value front disks with calibrated machined orifices have been designed experimentally and manufactured by the valve supplier.

The globe valve is kept closed during the ten hours which lasts the test; Erosion conditions between disk and seat results from the bigh velocity of fluld through the orifice. Liquid phase is achieved in the orifice by keeping the donnstream pressure above the saturated pressure of water at the test temperature.

- Valves behaviour evaluation

As regards the behaviour of valves during the loop tests non destructive examinations are performed for evaluation :

- hydrotest of the branch before Endurance, Thermal shock and Erosion tests,

- visual and dye penetrant examination of hardfaced surfaces after each category of tests,

- control of strength transmitted to the stem by the actuator every 100 cycles during endurance tests,

- water-tightness control of valves after $0,500,1000,1500$ cycles for endurance tests, and after 0,20 cycles $\Delta \theta=100^{\circ} \mathrm{C}$ and 20 cycles $\Delta \theta=250^{\circ} \mathrm{C}$ for thernal shock tests,

- flow rate control during erosion tests and leakage measurements of values before and after erosion tests at 70 and $320^{\circ} \mathrm{C}$.

\section{RESULTS AND DISCUSSION}

The full loop test programme has been achieved on the branches fitted with stellite and Colmonoy valves; the Cenium valves have only been submitted to endurance tests; the rest of the programme is in progress on these last valves.

- Visual and dye penetrant examinations of hardfaced surface.

Cracking of hardfaced surfaces vere observed on :

- stellite grade 6 of the 2" globe valve seat after the thernal shock tests $\Delta \theta=250^{\circ} \mathrm{C}$

- Colmonoy 4 of the 2" globe valve and body valve seats after the theral shock tests $\Delta \theta=250^{\circ} \mathrm{C}$

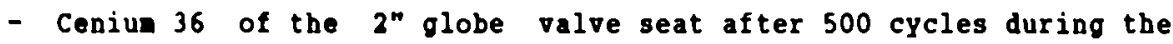
endurance tests.

No cracking was observed on the other bardfaced surfaces either of the globe values or on the swing check valves.

- Water tightness control of valves

rigures 6 and 7 give, at different steps of loop tests perforance, the variation of leakage neasured respectively on valves with stellite and valves with Colnonoy alloys. In accordance with cracking revealed by visual and dye penetrant examinations valve leakage increases significantly after the thernal shock tests related to high differential teaperature $(\Delta \theta=$ $\left.250^{\circ} \mathrm{C}\right): 400 \mathrm{~cm}^{3} / \mathrm{h}$ instead of $1 \mathrm{~cm}^{3} / \mathrm{h}$ for the globe valve with stellite and $10380 \mathrm{cs} / \mathrm{h}(10.4 \mathrm{l} / \mathrm{h})$ instead of $5 \mathrm{ca} / \mathrm{b}$ for the globe valve with Colnonoy.

Taking into account the above leakage, special disk with calibrated orifice designed for erosion tests was finally only used on the globe valve with stellite; the corresponding induced leakage was brought fron $0.4 \mathrm{l} / \mathrm{h}$ 
to $37 \mathrm{l} / \mathrm{h}$.

The erosion tests driven at 70 and $320^{\circ} \mathrm{C}$ did not show any behaviour difference between stellite and Colmonoy valves; the relatively slight leakage increase of these two valves were equivalent after erosion tests. Concerning the swing check valve the behaviour of cobalt free alloys is comparable to that of cobalt alloys.

- Discussion

For discussion it is obvious now that evaluation of cobalt free alloys must be specifically related to a type of valve e.g. its size, design and velding process to be used : problems are particularly severe in small bore valves, as the globe valve tested, where access to the seating area is restricted ; weld deposits are generally manually applied in these area using Oxyfuel or Tungsten Inert Gas (TIG) techniques; these are highly skilled surfacing operations and necessarily expensive and slor; strong need exists in developping the application of automatic advanced arc surfacing techniques to small bore components.

Nevertheless main features gained from the loop test programme can be summarized as follows in relation with the valve type :

- 2" globe valve

- high sensitivity of Cenium 36 alloy to endurance tests,

- slight sensitivity of stellite grade 6 and increased sensitivity of Colmonoy 4 to high differential thermal shock tests,

- equivalent behaviour of stellıte grade 6 and Colmonoy 4 to erosion tests. - 3" swing check valve

Equivalent good behaviour of Colmonoy 4-26 and Cenium Z 20 when compared to stellite grade 6 .

For integral parts as slide rings used in these two valve types no behaviour problem was met with proposed Cobalt free alloys : Nitronic 60 and Cenium Z 20698.

\section{CONCLUSION}

Considering that use of cobalt alloys should be avoided as far as possible in PWR components a programme aimed at establishing the performance of Cobalt-free alloys has been performed for valve application using a special test loop. Referring to past work two types of cobalt free alloy were selected : Colmonoy and Cenium alloys.

at the issue of the loop tests programme which included Endurance, Thermal shock and Erosion tests, candidate to replace cobalt alloy can be proposed in relation with valve type; Colmonoy 4-26 and Cenium Z 20 deposited by plasma are process have be found convenient for use in 3" swing check valves ; for integral part acting as guide ring Nitronic 60 and Cenium Z 20/698 were tested sucessfully.

Looking at small bore components as $2 "$ globe valve, to day no solution cas be proposed ; Introduction of Cobalt free alloys is dependent of the development of automatic advanced arc surfacing techniques applied to small bore components.

\section{REFERENCES}

(1) LELONG C., BENHAMOU C., MOULIN P. Propriétés des alliages Cenium materiaux durs pour frottement sans Cobalt. Colloque International sur les Matériaux durs pour frottement dans les Réacteurs Nucléaires. Avignon 25-26 septembre 1980.

(2) FRAMATOME Presentations at Cobalt Replacement EPRI Workshop EPRI RP 1935 Workshop Proceedings. Palo Alto, October 13-15, 1982.

(3) FRAMATOME Presentations at PUR Radiation Control EPRI Norkshop EPRI Workshop Proceedings not referenced - Washington D.C.,May 1-2,1984. 
Table I : Chenical Composition of selected hard alloys

\begin{tabular}{|c|c|c|c|c|c|c|c|c|c|c|c|c|c|c|}
\hline Specification & $\begin{array}{l}\text { Alloy desiomation } \\
\text { and/oc trade mark }\end{array}$ & C & $a$ & 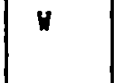 & $\mathbf{M i}$ & $\mathbf{1 0}$ & m & Si & Pe & $\mathbf{v}$ & B & $\boldsymbol{x}$ & $\infty$ & Fan \\
\hline \multirow{2}{*}{$\begin{array}{l}R 0 C-n / S 8000 \\
\text { or } \\
\text { nis } 5-13\end{array}$} & RCo-Cr-N/stellite $G .6$ & $0.9 / 1.4$ & $26 / 32$ & $3.0 / 6.0$ & $\leq 3.0$ & $\leq 1.0$ & $\leq 1.0$ & $\leq 2.0$ & $\leq 3.0$ & - & - & - & Bal & \multirow{7}{*}{$\begin{array}{l}\text { Rods a Ponders } \\
\text { for } \\
\text { Bardfacing } \\
\text { deposits }\end{array}$} \\
\hline & $\mathrm{RCO}-\mathrm{Cr}-\mathrm{B} / \mathrm{stell}$ ite $G .12$ & $1.2 / 1.7$ & $26 / 32$ & $7.0 / 9.5$ & $\leq 3.0$ & $\leq 1.0$ & $\leq 1.0$ & $\leq 2.0$ & 53.0 & - & - & - & Bal & \\
\hline \multirow{2}{*}{ AUS 5-13 } & Peti-Cr-NColeanoy 4 & $0.3 / 0.6$ & $8.0 / 14.0$ & - & $\mathrm{Bal}$ & - & - & $\begin{array}{l}1.25 / \\
3.25\end{array}$ & $\begin{array}{l}1.25 / \\
3.25\end{array}$ & - & $\begin{array}{l}2.00 / \\
3.00\end{array}$ & - & - & \\
\hline & Rrti-Cr-B/Colmanoy 5 & $0.4 / 0.8$ & $10.0 / 16.0$ & - & $\mathrm{Bal}$ & - & - & $\begin{array}{l}3.00 / \\
5.00\end{array}$ & $\begin{array}{l}3.00 \prime \\
5.00\end{array}$ & - & $\begin{array}{l}2.00 / \\
4.00\end{array}$ & - & - & \\
\hline \multirow{4}{*}{$\begin{array}{l}\text { Typical } \\
\text { couposition } \\
\text { from } \\
\text { sppplier }\end{array}$} & Colmanoy $4-26$ & $0.3 / 0.6$ & $\simeq 26$ & - & Bal & - & - & \begin{tabular}{|l|}
$1.25 /$ \\
3.25
\end{tabular} & $\begin{array}{l}1.25 / \\
3.25\end{array}$ & - & $\mid 1.5 / 3.0$ & & & \\
\hline & Ceniun 36 & $1.1 / 1.2$ & 25.0 & 4.0 & 34.0 & 8.0 & 0.5 & 0.85 & Bal & 0.5 & - & - & - & \\
\hline & Ceniun 220 & $0.2 / 0.5$ & $22 / 30$ & $1.0 / 4.0$ & $15 / 25$ & $6.0 / 10.0$ & 52.0 & $\leq 2.0$ & Bal & 1.0 & - & - & - & \\
\hline & Ceniun $220-698$ & $1.3 / 1.7$ & $22 / 30$ & $1.0 / 4.0$ & $15 / 25$ & $6.0 / 12.0$ & $\leq 2.0$ & $\leq 2.0$ & $\mathrm{Bal}$ & 1.0 & - & - & - & Cast \\
\hline $\begin{array}{c}\text { ASTM A } 276 / \\
\text { A } 479\end{array}$ & Mitranic 60 & $\leq 0.10$ & $16.0 / 18.0$ & - & $\begin{array}{l}8.00 / \\
9.00\end{array}$ & - & $\begin{array}{l}7.00 / \\
9.00\end{array}$ & $3.5 / 4.5$ & Bal & - & - & $\begin{array}{l}0.08 / \\
0.18\end{array}$ & - & Fanoed \\
\hline
\end{tabular}


Table II : Composition of the loop test branches with Cobalt base alloys and Cobalt free alloys

- Stellite Branch (Reference)

\begin{tabular}{|c|c|c|c|c|}
\hline $\begin{array}{c}\text { VALVE } \\
\text { DESIGNATION }\end{array}$ & $\begin{array}{l}\text { UELDING } \\
\text { PROCESS }\end{array}$ & $\begin{array}{l}\text { HARDFACING } \\
\text { DEPOSIT ON } \\
\text { BODY SEAT }\end{array}$ & $\begin{array}{c}\text { HARDFACING } \\
\text { DEPOSIT ON } \\
\text { DISK }\end{array}$ & $\begin{array}{c}\text { INTEGRAL } \\
\text { RING }\end{array}$ \\
\hline $\begin{array}{c}\text { 2" BODY } \\
\text { WITH BONNET (1) }\end{array}$ & OX - AC & $\begin{array}{l}\text { STELLITE } \\
\text { GRADE 6 }\end{array}$ & - & - \\
\hline $\begin{array}{c}\text { 2" GLOBE } \\
\text { VALVE (1) }\end{array}$ & OX - AC & $\begin{array}{l}\text { STELLITE } \\
\text { GRADE 6 }\end{array}$ & $\begin{array}{l}\text { STELLITE } \\
\text { GRADE 12 }\end{array}$ & $\begin{array}{c}\text { VIRIUM 16 } \\
\text { (CAST STELLITE } \\
\text { GRADE 6) }\end{array}$ \\
\hline 3" SHING (2) & PLASHA & $\begin{array}{l}\text { STELLITE } \\
\text { GRADE 6 }\end{array}$ & $\begin{array}{l}\text { STELLITE } \\
\text { GRADE 6 }\end{array}$ & $\begin{array}{l}\text { STELLITE } \\
\text { GRE 6 6 }\end{array}$ \\
\hline
\end{tabular}

- Colmonoy Branch

\begin{tabular}{|c|c|c|c|c|}
\hline $\begin{array}{c}\text { VALVE } \\
\text { DESIGNATION }\end{array}$ & $\begin{array}{c}\text { UELDING } \\
\text { PROCESS }\end{array}$ & $\begin{array}{c}\text { HARDFACING } \\
\text { DEPOSIT ON } \\
\text { BODY SEAT }\end{array}$ & $\begin{array}{c}\text { HARDFACING } \\
\text { DEPOSIT ON } \\
\text { DISK }\end{array}$ & $\begin{array}{c}\text { INTEGRAL } \\
\text { RING }\end{array}$ \\
\hline $\begin{array}{c}\text { 2" BODY BONNET (1) } \\
\text { 2" GLOBE } \\
\text { VALVE (1) }\end{array}$ & TIG & COLMONOY 4 & - & - \\
\hline $\begin{array}{c}\text { 3" SUING } \\
\text { CBECR VALVE (2) }\end{array}$ & PLASKA & COLMONOY 4-26 & $\begin{array}{c}\text { COLOMONOY } \\
4-26\end{array}$ & $\begin{array}{c}\text { NITRONIC 60 } \\
\text { (FORGED) }\end{array}$ \\
\hline
\end{tabular}

- Cenium Branch

\begin{tabular}{|c|c|c|c|c|}
\hline $\begin{array}{c}\text { VALVE } \\
\text { DESIGNATION }\end{array}$ & $\begin{array}{l}\text { WELDING } \\
\text { PROCESS }\end{array}$ & $\begin{array}{l}\text { HARDFACING } \\
\text { DEPOSIT ON } \\
\text { BODY SEAT }\end{array}$ & $\begin{array}{c}\text { HARDFACING } \\
\text { DEPOSIT ON } \\
\text { DISK }\end{array}$ & $\begin{array}{l}\text { INTEGRAL } \\
\text { RING }\end{array}$ \\
\hline $\begin{array}{l}2^{\prime \prime} \text { BODY } \\
\text { UITH BONNET (1) }\end{array}$ & $O X-A C$ & CENIUM 36 & - & - \\
\hline $\begin{array}{l}2 " \text { GLOBE } \\
\text { VALVE (1) }\end{array}$ & $\begin{array}{c}O X-A C \\
T I G\end{array}$ & $\begin{array}{c}\text { CENIUM } 36 \\
-\end{array}$ & $\begin{array}{c}- \\
\text { CENIUM } \\
Z \quad 20 / 698\end{array}$ & $\begin{array}{c}\text { CENIUH } \\
220 / 698 \\
\text { (CAST) }\end{array}$ \\
\hline $\begin{aligned} & 3 " \text { SUING } \\
& \text { CHECK VALVE (2) }\end{aligned}$ & PLASKa & CENIUM Z 20 & CENIUK $\mathrm{Z} 20$ & $\begin{array}{c}\text { CENIUK } \\
220 / 698 \\
\text { (CAST) }\end{array}$ \\
\hline
\end{tabular}

Valve supplier : (1) SEREG (now SCHLUKBERGER Industries)/LYON-FRANCE

(2) VELAN-RATEAU/LA BAULE-FRANCE 
FIGURE 1 : GLOBE VALVE
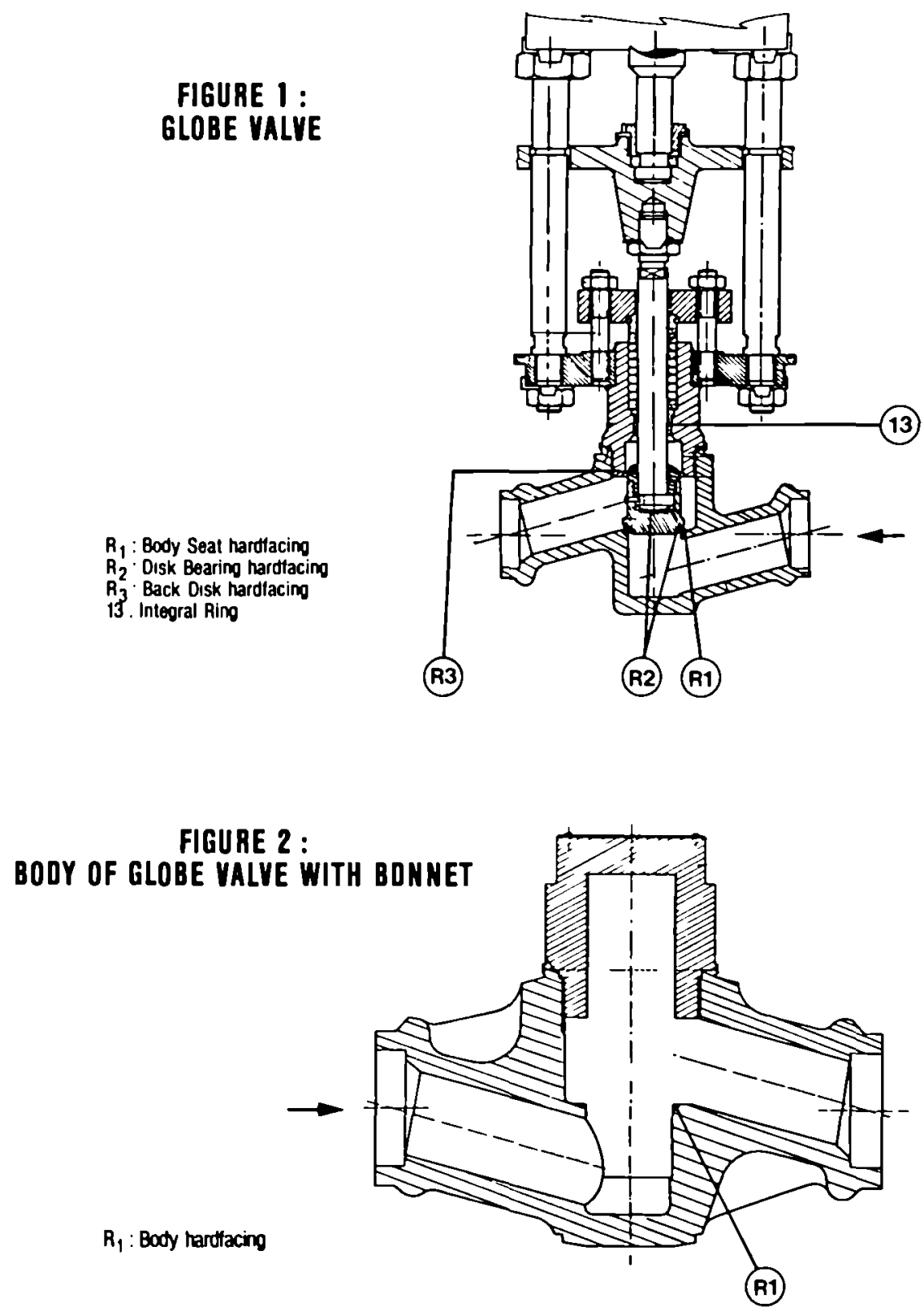
(3)
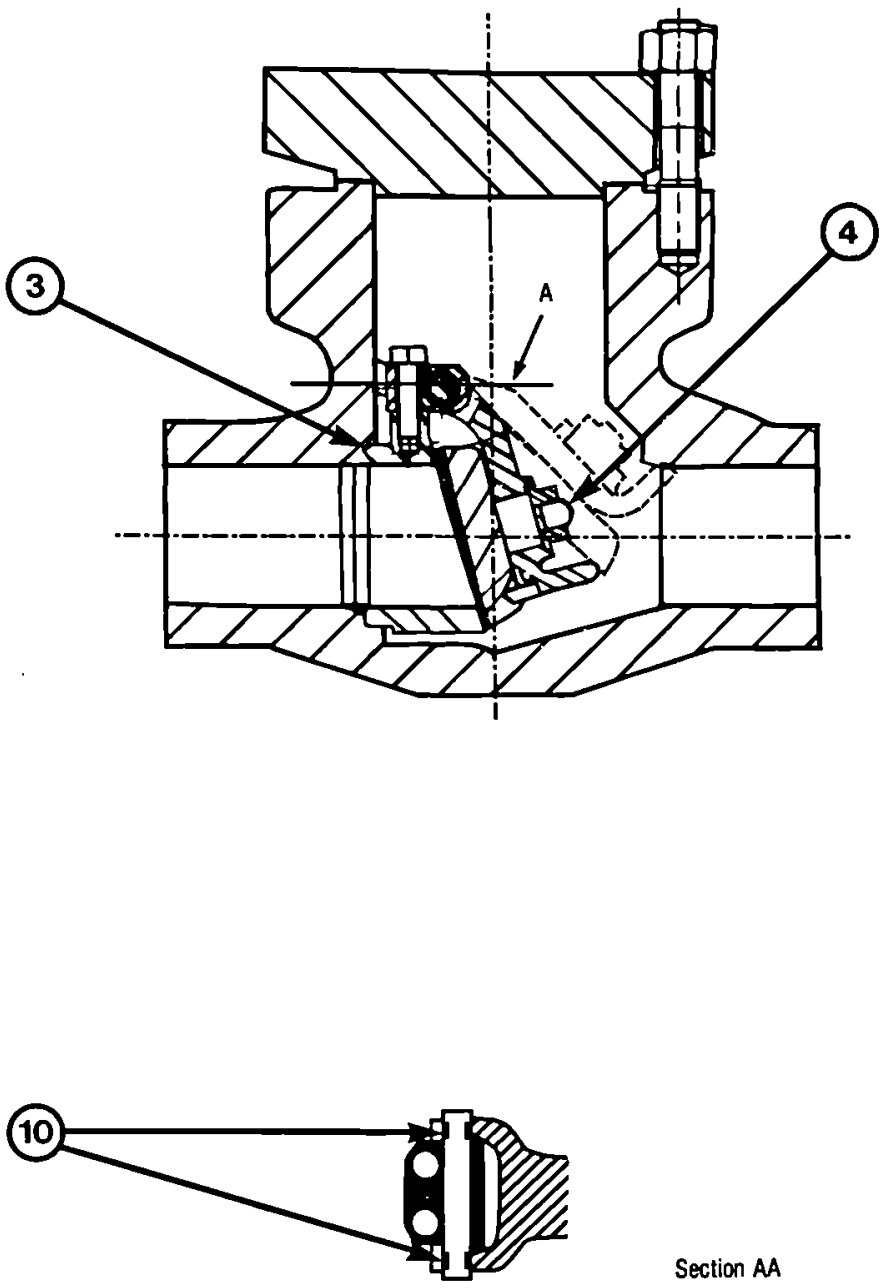

Section AA

\author{
$3:$ Seat with hardfaced bearing face \\ 4 : Disk with hardfaced bearing face \\ 10 : Integral Ring
}

FIGURE 3 : SWING CHECK VALVE 


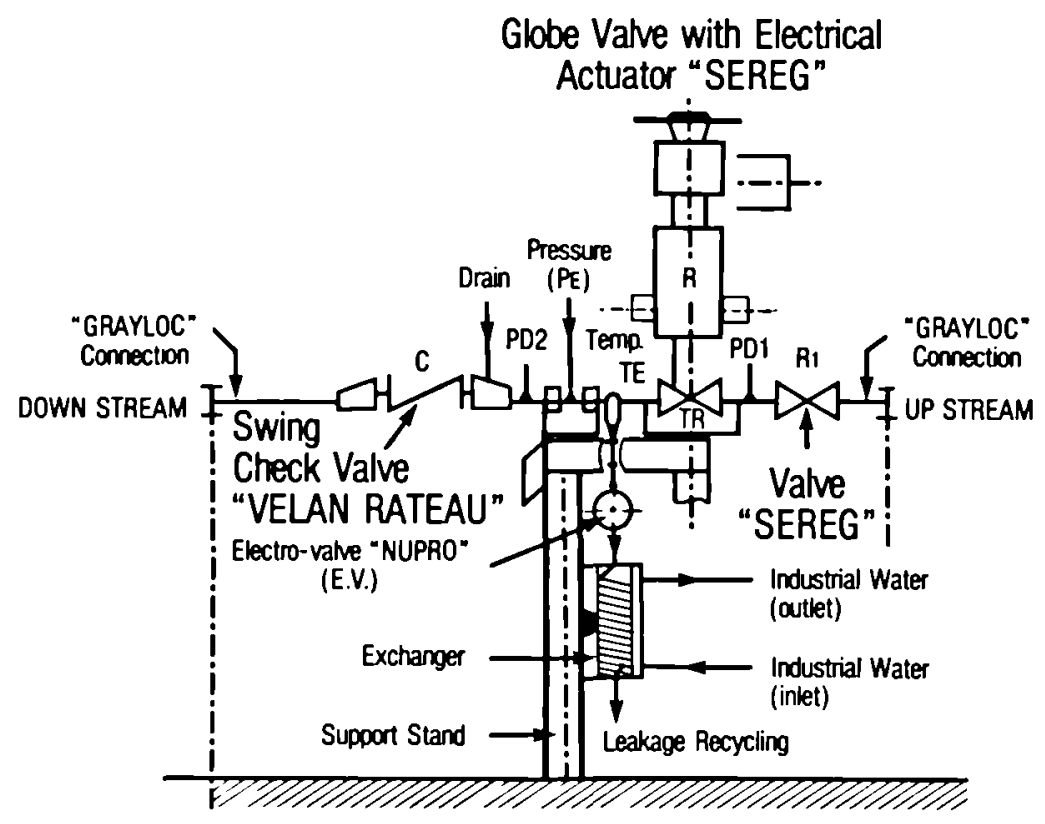

\begin{tabular}{|c|c|c|l|}
\hline $\begin{array}{c}\text { Globe } \\
R\end{array}$ & $\begin{array}{c}\text { Swing } \\
C\end{array}$ & $\begin{array}{c}\text { Electro-valve } \\
E_{V}\end{array}$ & \multicolumn{1}{|c|}{ PHASE } \\
\hline 0 & 0 & $C$ & Flowrate in $\mathrm{R}, \mathrm{C}\left(320^{\circ} \mathrm{C}\right.$ - 150 bars $)$ \\
\hline $\mathrm{C}$ & $\mathrm{C}$ & $\mathrm{C}$ & R closing without $\triangle \mathrm{P}$-No Flowrate \\
\hline $\mathrm{C}$ & $\mathrm{C}$ & 0 & $\begin{array}{l}\text { Depressurization between } \mathrm{R} \text { and } \mathrm{C} \text {. } \\
\mathrm{P} \leqslant 5 \text { bars }\end{array}$ \\
\hline $\mathrm{C}$ & $\mathrm{C}$ & $\mathrm{C}$ & Electro-valve closing \\
\hline 0 & 0 & $\mathrm{C}$ & $\mathrm{R}$ opening with $\triangle \mathrm{P}=150$ bars \\
\hline
\end{tabular}

$0:$ Opened $-C:$ Closed

FIGURE 4:

TEST BRANCH DESIGN AND PRINCIPLES OF ENDURANCE TESTS 


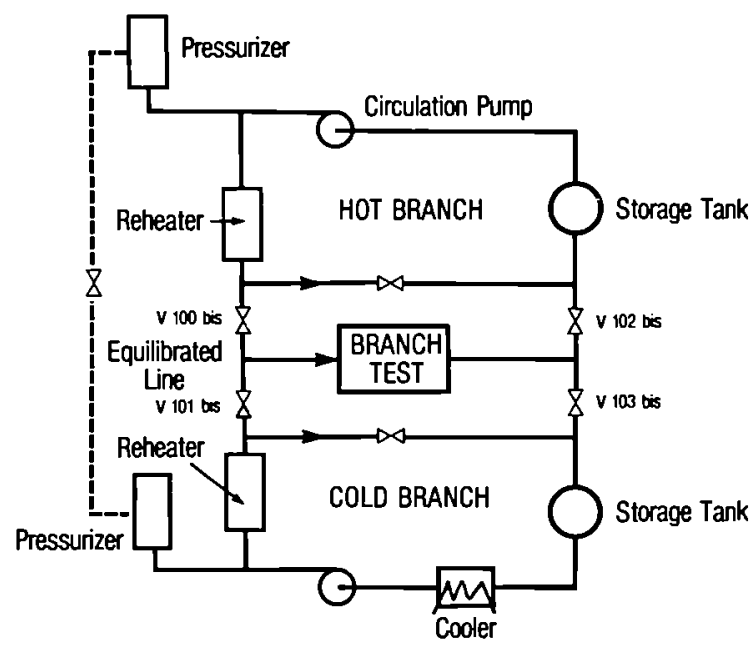

\begin{tabular}{|c|c|c|c|l|}
\hline \multicolumn{2}{|c|}{ HOT BRANCH } & \multicolumn{2}{c|}{ COLD BRANCH } & \multicolumn{2}{c|}{$\begin{array}{c}\text { PHASE } \\
\text { V100 bis }\end{array}$} & V102 bis & V101 bis & V103 bis & (0:0pened - C: Closed $)$ \\
\hline 0 & 0 & C & C & Hot Shock \\
\hline C & C & 0 & 0 & Cold Shock \\
\hline
\end{tabular}

Nota : R valve will be kept in opened position during these tests

FIGURE 5 :

\author{
LOCATION OF BRANCH TEST ON LOOP \\ AND PRINCIPLES OF THERMAL SHOCK TESTS
}




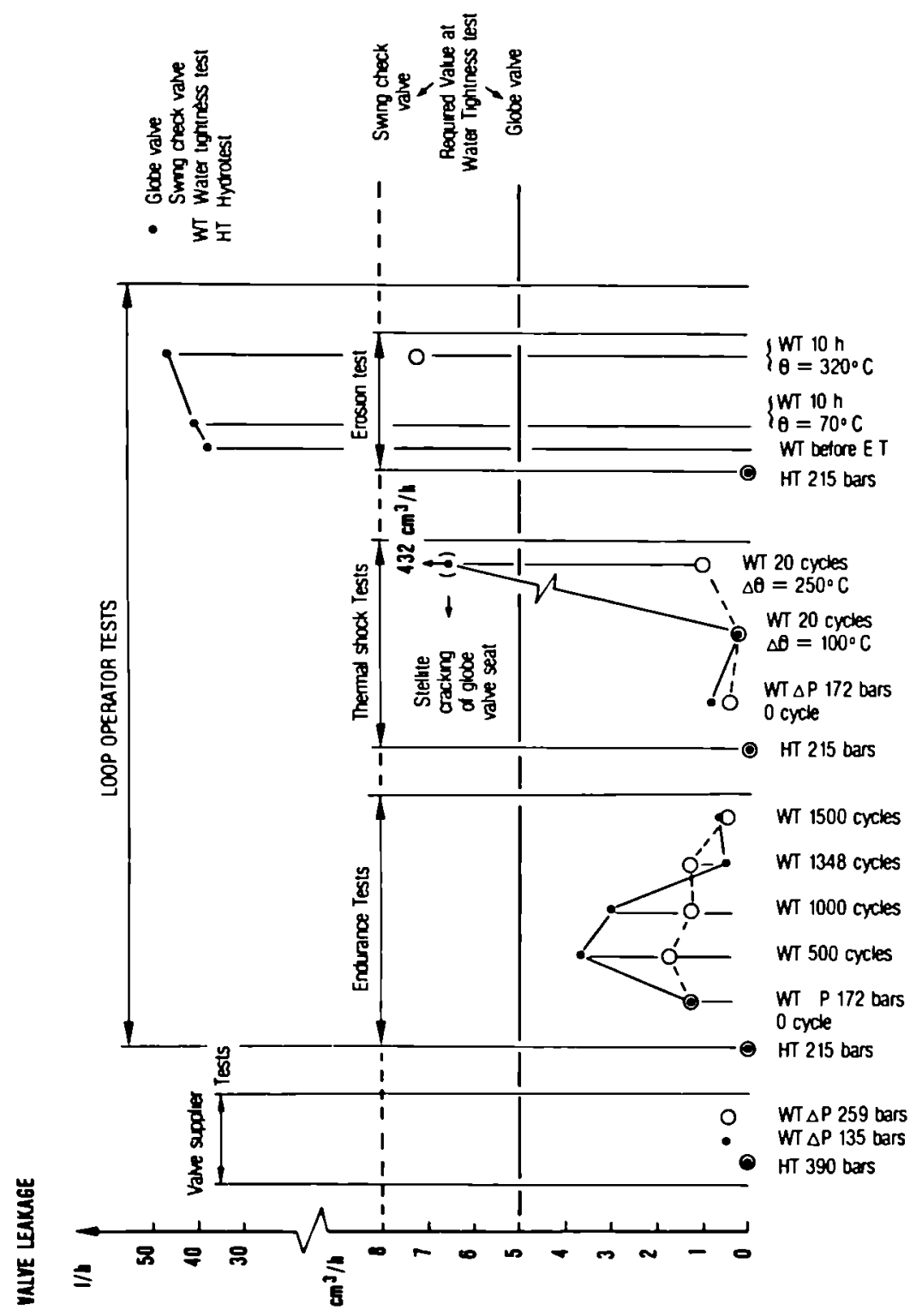

FIGURE 6 :

HYDROTEST AND WATER-TIGHTNESS CONTROL OF VALYES WITH STELLITE DURING LOOP TESTS 


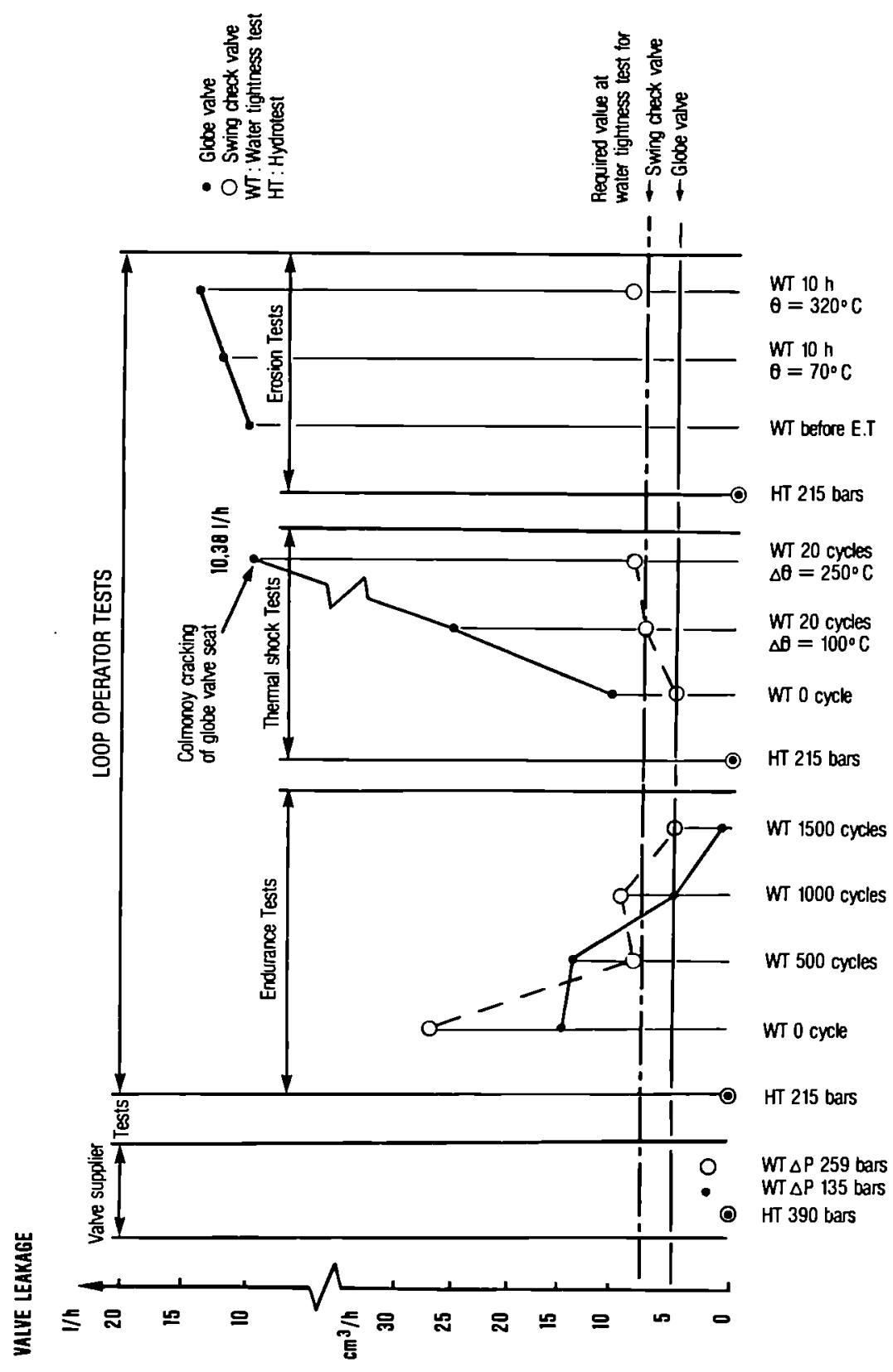

FIGURE 7 :

HYDROTEST AND WATER TIGHTNESS CONTROL OF VALVES WITH COLMONOY DURING LOOP TESTS 


\author{
ANALYSES AND TESTING OP MODEL \\ PRESTRESSED CONCRETE REACTOR VESSELS \\ WITH BUILT-IN PLANES OF WEAKNESS
DAWSON P., PATON, A.A., FLEISCHER, C.C.
Taylor Woodrow Congtruction Limited,
Taywood House, 345, Ru1slip Road,
Southa11, Middlesex, UB1 2QX.
U.R.

\begin{abstract}
Th1s paper describes the design, construction, analyses and testing of two small scale, single cavity prestressed concrete reactor vessel mode1s, one without planes of weakness and one with planes of weakness Immediately behind the cavity liner. Th1s work was carried out to extend a previous study which had suggested the likely feasibility of constructing regions of prestressed concrete reactor vessels and blological shields, which become activated, using easily removable blocks, separated by a sultable membrane. The paper describes the results obtalned and concludes that the planes of weakness concept could offer a means of factlitating the dismantling of activated reglons of prestressed concrete reactor vessels, blological shields and simflar types of structure.
\end{abstract}

\title{
1. INTRODUCTION
}

In a study undertaken by Taylor Woodrow Construction Ltd (TWC) in the first five year (1979-1983) research programe sponsored by the Commission of the European Communtties (CEC), one feature proposed as an ald to decommissioning prestressed concrete reactor vessels (PCRV) and other simflar structures was the construction of the inner zone of concrete Imediately behind the 11ner, where activation would normally be expected to occur, as a blockwork matrlx, each block being separated from 1 ts nelghbours by a thin membrane. The study suggested that the planes of weakness so formed would have no significant effect on the performance or integrity of the PCRV and recommended further, more detalled work be done. The work of the f1rst study is described in Euro Report Ref. EUR 9399 EN (1).

A second study was therefore undertaken as part of the CEC's second five year (1984-1988) programme and this is fully described in a report submitted by TWC to the CEC in March 1989. The second study comprised the design, construction, analyses and testing of two small scale, single cavity PCRV, one whthout and one with planes of weakness behind the cavity liner. The approach adopted for the study was to review the prevlous analyses to 1dentify key aspects to be taken into account for the design, construction and testing of the models and complement this wh a comparative analytical study.

The paper outlines the work carried out in the second study, describes the key results and presents the conclusions drawn.

\section{DESIGN OF THE MODELS}

Overall, the models were designed as simple, single cavity PCRV, to acale of approximately 1/20th with respect to the Hartlepool and Heysham 1 Advanced Gas-Cooled Reactor vessels currently operating in the U.K. The Internal cavity of each model was 1 ined using a $0.9 \mathrm{~mm}$ 
thick mild steel liner whose external surface embodied tangs which were anchored into an externally applied grout screed, $13 \mathrm{~mm}$ thick. This screed was also provided to offer some support to the liner during the concreting operations.

Detalls relating to key features of the design are described below and fllustrated in Figures 1,2 and 3.

\section{(a) Hoop prestress}

The hoop prestress consisted of 17 hoop tendons, each consisting of two, $8 \mathrm{~mm}$ diameter plastic coated strands, each encircling the vessel once, Just below the concrete surface, and anchored in diametrically opposite buttresses. In calculating the forces in the hoop tendons, a friction coefficlent of 0.08 was assumed between the strand and its plastic coating and this value was verifled by tests carrled during the stressing operations which indicated a probable friction coefficient of 0.085 .

In order to allow for the bending stresses induced in the strand as it curved around the model, the jacking load was limited to that corresponding to $58 \%$ of the Characteristic Strength of the strand to ensure that the overall stress in the strand never exceeded a value corresponding to $80 \%$ of the Characterfstic. This gave a jacking load of $41 \mathrm{KN}$. Each hoop strand was anchored at both ends in barrel and wedge anchors and was designed to be stressed at both ends with subsequent shimming after lock-off to recover wedge pull-1n.

(b) Vertical prestress

The vertical prestress conslsted of 18 plastic coated strands, each $8 \mathrm{~mm}$ in diameter, anchored at the top and bottom cap surfaces in barrel and wedge anchors. The specifled jacking load was 56KN, corresponding to $80 \%$ of the Characteristlc Strength of the strand, and the strand was stressed and shimmed at the top anchorage only, the bottom one being inaccessible to the fack.

(c) Planes of Weakness

The planes of weakness blocks were formed from $75 \mathrm{~mm}$ square plastic electrical conduit cut 1 nto $37 \frac{1}{\mathrm{~mm}}$ lengths for the base blocks and $75 \mathrm{~mm}$ lengths for the wall blorks. This conduit has one removable side which enabled the sections for the wall blocks to be deformed to make a circle around the liner. Two layers of blocks were provided below the bottom plate of the liner and one layer around the wall.

The Design Pressure for the models, compatible with the above structural detalls, was $1.9 \mathrm{MN} / \mathrm{sq} \cdot \mathrm{m}$ and the calculated Factor of Safety was 1.7 .

\section{ANALYSES OF THE MODELS}

Analyses of the models were carried out using the computer program ADINA (Automatic Dynamic Incremental Non-Linear Analysis) -TW version. The program is designed such that it can perform a linear analysis and then follow this with a non-linear analysis requiring only a relatively few Input changes, and was particularly sulted to the analyses of the PCRV models.

The analytical grid used for the analyses is shown in Figure 4 which also shows the points at which graphical output from the analyses has been obtained. These points, and the vertical and horizontal sections at which stress profile plots have been produced, were 
compatible with the locations of the internal and external instrumentation so that the analytical plots could be used directly for monftoring the behaviour of the models during their pressure tests.

The broad result of the analyses was to suggest that both models, when tested, should behave very similarly, with linear behaviour up to approximately $2.50 \mathrm{mN} / \mathrm{sq} . \mathrm{m}(1.32 \times$ design pressure) and an ultimate load capacity of approximately $4.75 \mathrm{MN} / \mathrm{sq} . \mathrm{m}(2.50 \times$ design pressure). Th1s is Illustrated In Figure 5 which, for each model, shows the analytically predicted vertical deflection at the centre of the top cap for Increasing pressure.

4. CONSTRUCTION OF THE MODELS

For the model with planes of weakness, the basic construction sequence was:

- Place concrete In centre area of base with base relnforcement.

- Construct planes of weakness blocks on base.

- Place liner with 1ts pre-applied screed.

- Construct planes of weakness blocks around liner.

- FIx remainder of reinforcement, hoop prestressing strands, and ducts for vertical prestressing strands.

- Place concrete in walls, up to liner top plate level.

- Place concrete in top cap and to top of walls.

- Pit vertical prestressing strands.

- Apply prestress.

The construction sequence for the model without planes of weakness was olmilar, with the planes of weakness related activities omitted. Construction of the model without planes of weakness preceded construction of that with planes of weakness by approximately two weeks. Steps were taken to ensure that, within practical limitations, this time interval was maintained between key events in the construction and testing of the two models so that, when tested, each would be essentially the same age and in the same condition.

It had always been recognised that, for prestressing strands as short as those in the models, wedge pull-in at lock-off would cause a significant loss in anchorage load and it would therefore be necessary to shim the stressed anchorages after lock-off to recover those losses. Following some preliminary tests to estimate the loss in anchorage load due to pull-in at lock-off te was declded to shim as many as possible of the hoop anchorages by $2 \mathrm{~mm}$ and as many as posstble of the top vertical anchorages by $4 \mathrm{~mm}$ or, where not possible, by $2 \mathrm{~mm}$. In practice, for the two models taken together, 8 vertical anchorages accepted $4 \mathrm{~mm}$ shims, and the remainder of the vertical anchorages and all but 10 hoop anchorages accepted $2 \mathrm{~mm}$ shims. Following the shimming exerclse a series of anchorage lift-of tests were undertaken and these suggested that, compared to the design assumptions, the respective levels of hoop and vertical prestress were approximately $25 \pi$ and $15 \pi$ less than intended.

\section{PRESSURE TESTING OF THE MODELS}

The two models were instrumented in an Identical manner, each with 24 electrical resistance strain gauges and 22 deflection transducers. Data from the instrumentation were collected by a data logging system and processed to glve output in microstrain and $\mu \mathrm{m}$.

Hydraulic water pressure was applied to the models by a combination of a1r driven pumps, with a Standard Test Gauge connected 
Into the hydraulic supply line to monftor the pressure during testing of the models.

Following a preliminary pressurisation to $0.25 \times$ design pressure, to check instruments and equipment, the main pressure test on each model consisted of three pressure cycles to design pressure (1.9MN/sq.m) followed by one cycled to $1.5 x$ design pressure $(2.85 \mathrm{~m} / \mathrm{sq} . \mathrm{m})$. For each cycle to design pressure, the instrumentation was read at $0,1.90,2.24,2.59$ and $2.85 \mathrm{MN} / \mathrm{sq} . \mathrm{m}$, and again on return to zero. At each pressure hold several instrument scans were taken and selected Instrumentation data plotted to verify satisfactory behaviour of the model prior to proceeding to the next pressure hold.

After the first cycle to design pressure of the model without weak planes two damp patches were observed on the upper surface of the top cap almost directly above the liner haunch. During and after the overload test simflar patches were observed, together with several damp spots and water runs on the outside vertical surface. It was deduced that the liner of this model had ruptured during the first pressure cycle, that the concrete had subsequently cracked and that water leakage had occurred. The behaviour of the instrumentation assoclated with the top cap of this model supported that deduction.

\section{RESULTS}

For each model, averaged results for each pressure cycle were plotted on the approprlate predicted analytical plots. The plots prepared comprised:

(a) Pressure against radial and vertical deflectlons. (Measured and predicted)

(b) Pressure against radial, vertical and hoop strains. (Measured and predicted)

(c) Varlations in radial, vertical and hoop stresses at varlous sections through the models. (Predicted only)

(d) The deformed shape of the models at prestress only, prestress + design pressure. (Predicted only)

Altogether, 140 plots were produced for the two models and all of them are presented in the study report. Clearly, within the 11mits of this paper 1t is possible only to present a fragment of them and those shown in Figures 5 and 6 have been chosen to 1llustrate the conclusions given in Section 7 of the paper.

In assessing the results and forming conclusions from them, it is necessary to bear in mind, firstly, the unavoldable differences between the two models as built and as analysed, and, secondly, the small magnitude of the deflections being measured during the tests. In respect of the differences, whereas the analyses assumed a concrete $E$ value of $32 \mathrm{GPa}$, the actual $\mathrm{E}$ values achleved ranged from $33 \mathrm{GPa}$ to $38 \mathrm{GPa}$, thus making the models a little stiffer than predicted. Also, with the actual level of prestress being less than that used in the analyses, cracking during the overload test was to be expected earlier than predicted. In respect of magnitude of measured and predicted deflections, the values were, at maximum, less than $1 \mathrm{~mm}$.

There is not, within this paper, sufficlent time nor space to comment fully on all the results that have been obtained but those results which have had an influence on the conclusions drawn are Identified in Section 7 below. 


\section{CONCLUSIONS}

On the basis of the results obtalned from the study, the following conclusions have been drawn.

(a) The analyges indicate that the planes of weakness configuration assumed in the study has no significant effect on the structural behaviour of the PCRV.

(b) The behaviour of the top cap of the model with planes of weakness agreed with analytical predictions, as shown by Figure 5 which shows the plots of predicted and measured vertical deflection near the centre of the top cap of this model.

(c) The behavlour of the top cap of the model without planes of weakness did not agree with analytical predictions. It is belleved that this was due to the existence of pressurised cracks in the concrete following rupture of the liner, as postulated in Section 5 of this paper.

(d) The behaviour of the botton cap of the model without planes of weakness agreed with analytical predictions, with a plot of predicted and measured vertical deflection at the centre of the bottom cap olmilar to an inverted version of Figure 5 .

(e) The behaviour of the bottom cap of the model with planes of weakness did not agree with predictions. It 18 believed that this unexpected behaviour may have been due to a mismatch between the physical and analytical modelling of the materfal used to form the weakness planes. It reflects the non-representative scaling of the th1ckness of the material which would be used in a full size structure, and Indicates the need to keep this material as thin as possible.

(f) The barrel regions of both PCRV models behaved similarly and essentially as predicted by the analyses. Figure 6 shows a typical plot of radial deflection of the barrel of one of the models.

In general, the analyses confirm the findings of the previous study in that the planes of weakness appear to have no significant effect on the behaviour or integrity of the PCRV. Furthermore, the corresponding reglons of the models unaffected either by the water leakage or by the scallng effect of the weakness plane material behaved in an essentially simllar manner. To this extent, therefore, the model tests appear to support the analytical results.

The overall conclusion, therefore, 18 that the planes of weakness feature could provide an acceptable means of facilitating the dismantilng of the activated regions of concrete in PCRV, blological shields and similar structures.

\section{REFERENCES}

1. A.A. Paton, P. Benwe11, T.F. Irwin and I. Hunter, Civil Englneering Design for Decommissioning of Nuclear Installations, published by Graham \& Trotman Ltd. on behalf of the Commission of the European Communit1es, Report Ref. EUR $9399 \mathrm{EN}, 1984$. 


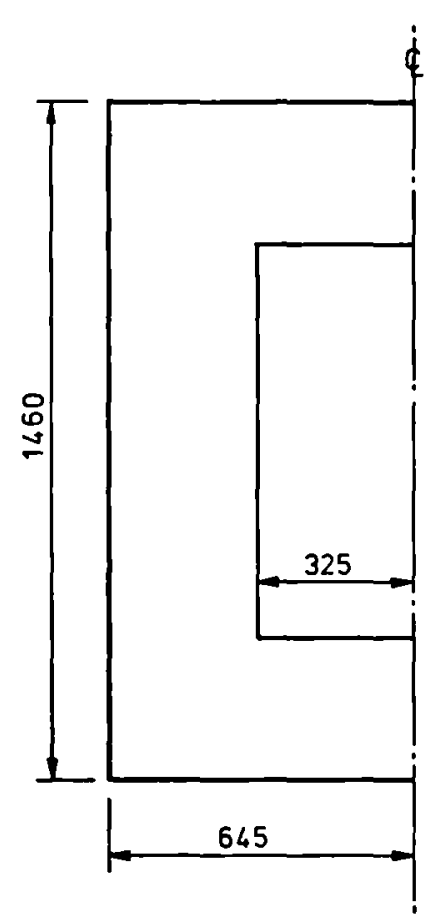

Half section through model without planes

of weakness

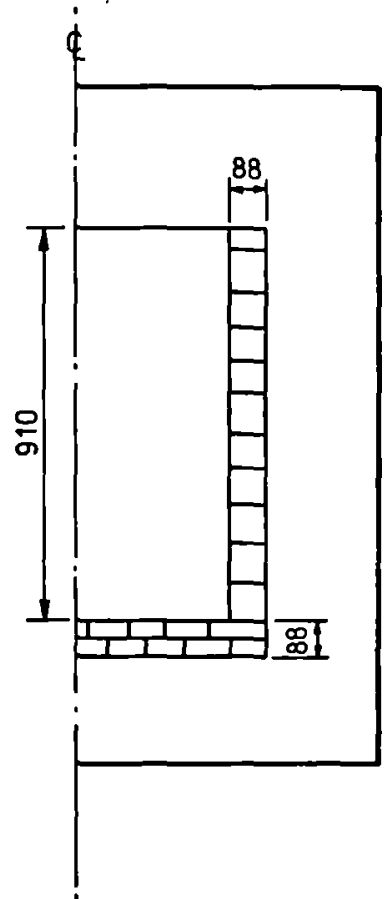

Half section through model with planes of weakness

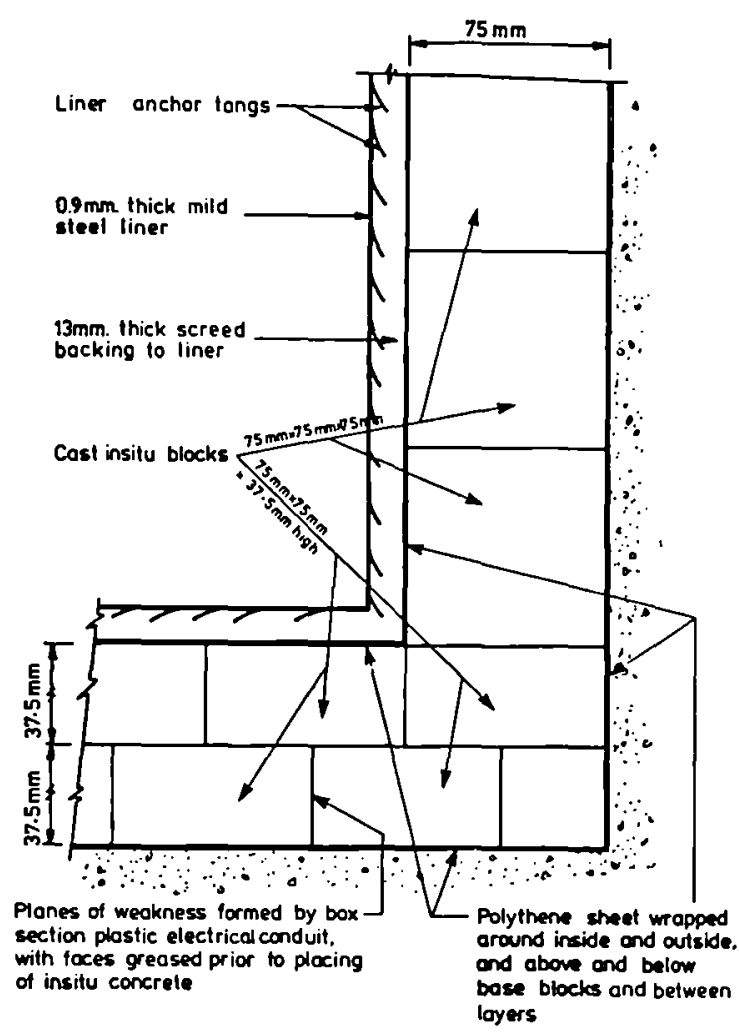

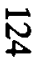
formation, liner and screed 


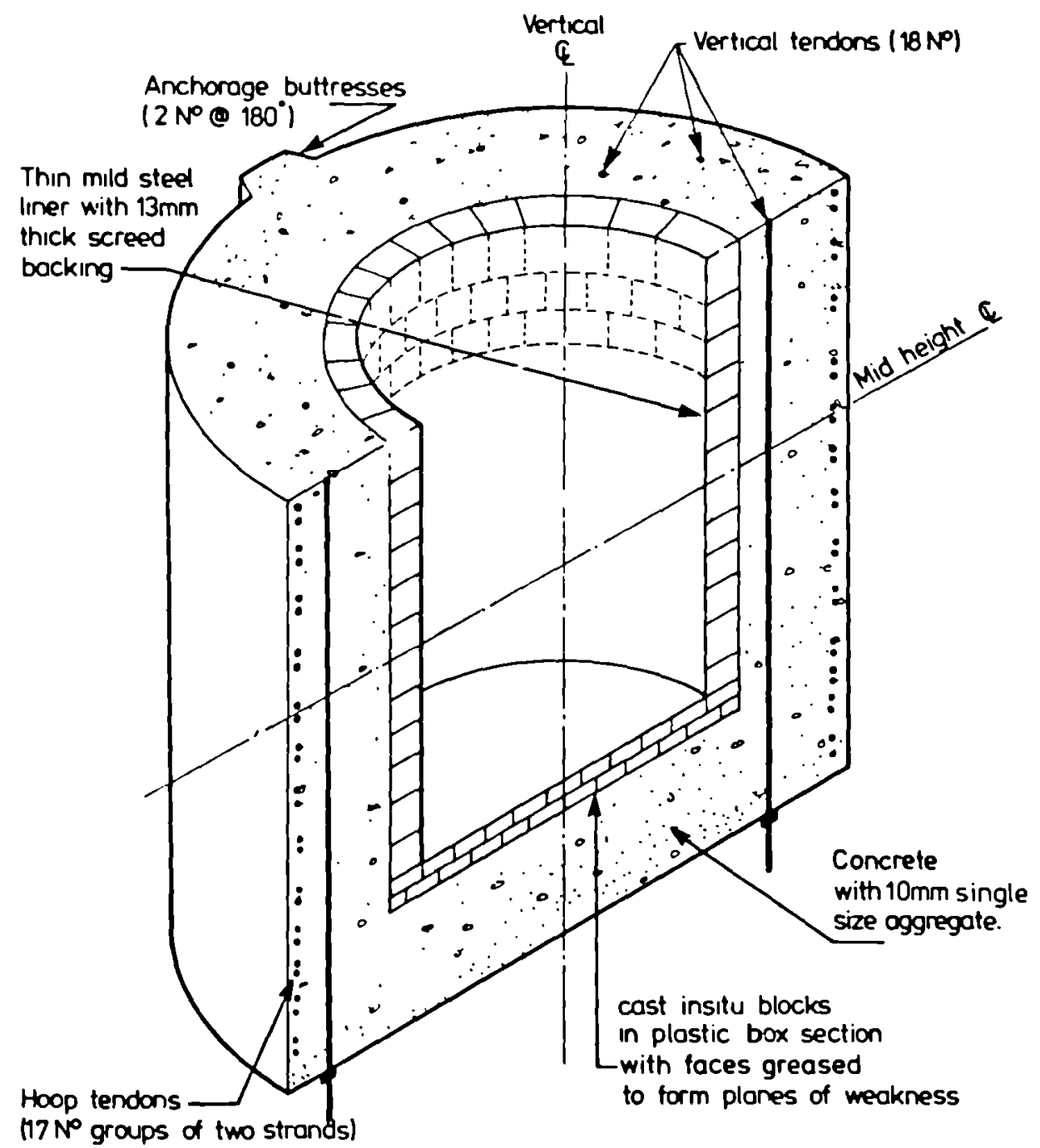

Figure 3: Cut away view of model with planes of weakness 


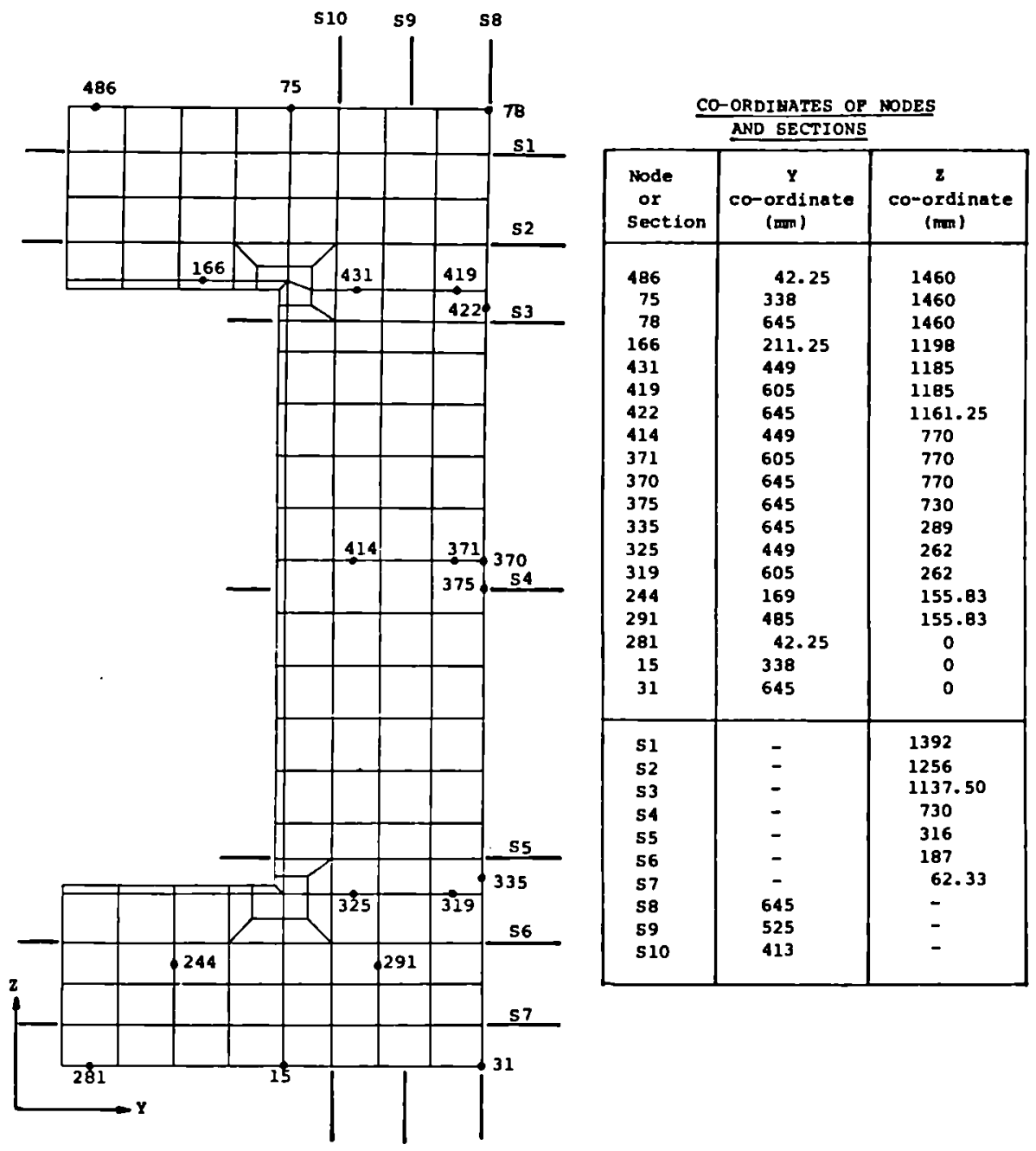

Figure 4: Analytical grid, showing location of nodes and sections corresponding to plots of analytical results 


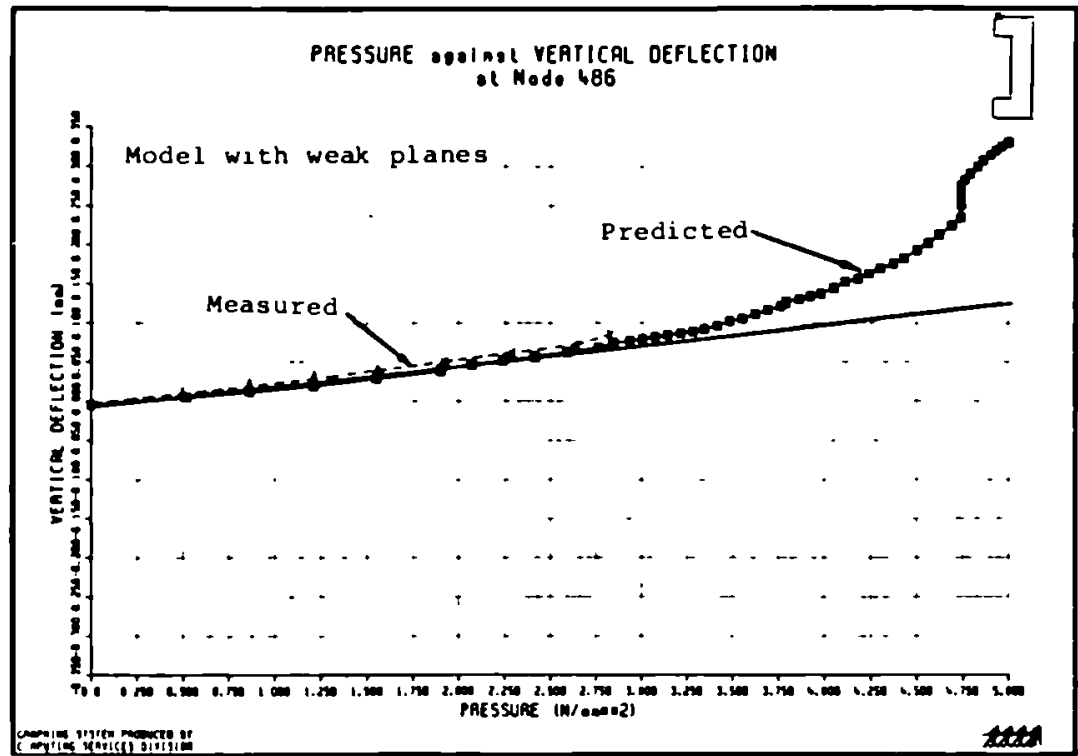

Figure 5

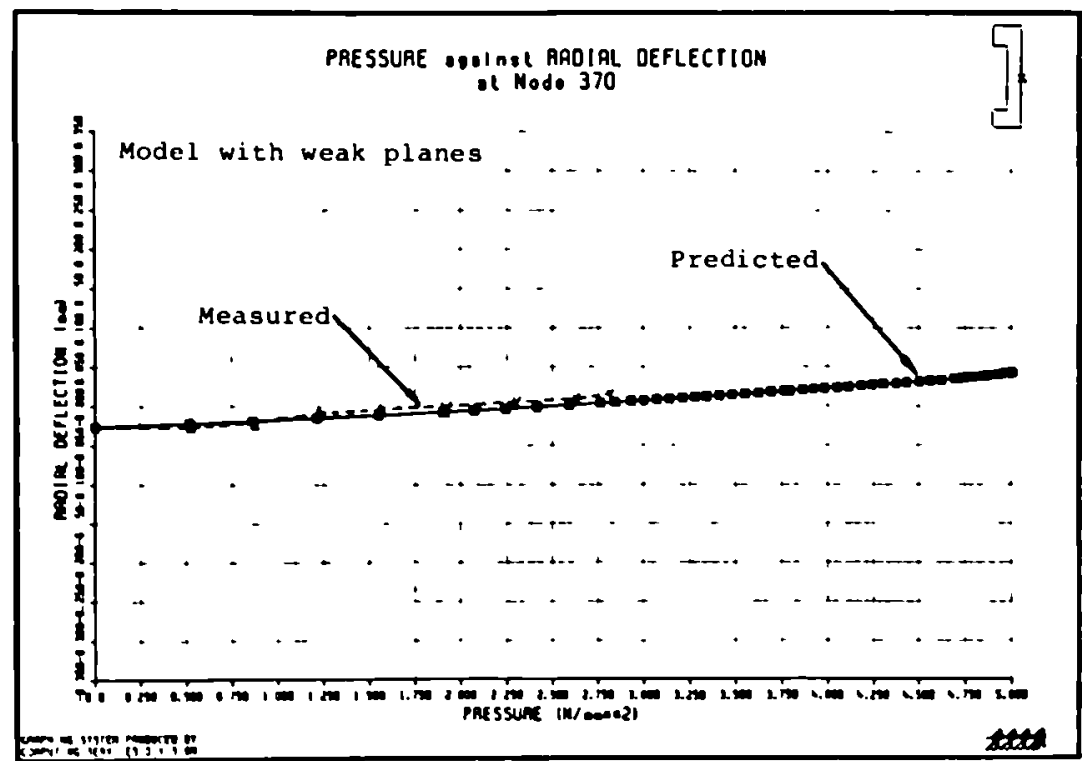

Figure 6 
$\frac{\text { IN SITU TREATMENT OF CONCRETE SURFACES BY ORGANIC }}{\text { IMPREGNATION AND POLYMERIZATION }}$

P. URSELLA and G. MORETTI

Italcementi SpA, Bergamo, Italy

V. PELLECCHIA

SNIA Techint SpA, Rome, Italy

Summary

The impregnation by resins of concrete structures is a process well known as PIC (Polymer Impregnated Concrete). This process improves the physical-chemical features of concrete matrixes in order to extend their durability when severe environmental conditions may occur. The main objective of this research contract has been the verification of a proper impregnation 'in situ' of existing concrete surfaces, of any laying in the space, by means of a prototype machine, expressly designed and implemented, and verification of the increase of mechanical resistance, leach resistance, durability of treated material. In a nuclear facility this goal is very important in relation to the long term integrity of concrete structures during operating lifetime and, in particular, after final shutdown.

\section{INTRODUCTION}

The research contract was subdivided into two main steps: the first was devoted to the design, manufacturing, preliminary testing and setting up of a special prototype mobile unit for 'in situ' treatment of concrete surfaces by organic impregnation and polymerization. The second was relevant to the project and implementation of a reinforced concrete walling unit, treatment of some sectors of this unit, and characterization of the concrete structure after impregnation. SNIA Techint were responsible for the activities involved in the first step, while Italcementi took care of the second one.

\section{RESEARCH CARRIED OUT}

\subsection{Design, Implementation and Setting Up of Prototype Unit}

The input data for developing the design of prototype were obtained through preliminary laboratory tests designed to optimize the process parameters with a view to obtaining the desired depth and degree of impregnation. Several series of tests on $4 \times 4 \times 16 \mathrm{~cm}$ concrete samples were performed in a special working chamber at various temperatures and pressures.

The main service requirements for the prototype machine were stated as follows: capability of a tight coupling of the working chamber, by vacuum action, to the concrete area to be treated during degassing and/or monomer injection phases; capability to assure such coupling in all directions for treatment of concrete floors, walls or ceilings; seals capability to withstand the chemical attack arising from injected monomers.

A simplified scheme of the operative principle of the impregnation chamber is shown in Figure 1. The impregnation prototype device was designed, manufactured and then fitted on a specially modified fork lift truck as shown in Figure 2. The main operating features of the unit are: 
- Impregnation area for each cycle $(1.8 \mathrm{~m} \cdot 0.75 \mathrm{~m})$.

$$
\begin{aligned}
& 1.35 \mathrm{~m}^{2} \\
& 5 \div 300{ }^{\circ} \mathrm{C} \\
& 5 \div 60{ }^{\circ} \mathrm{C} / \mathrm{h} \\
& 10 \mathrm{kPa} \\
& 25 \mathrm{kPa} \\
& 7 \mathrm{~kW} \\
& 6 \mathrm{~kW}
\end{aligned}
$$

- maximum power demand during thermopolymerization attraction strength developed by the vacuum annulus under $50 \mathrm{kPa}$ depressure

$3.2 \mathrm{kN}$

- thrust inside impregnation chamber created by monomer injection at about $20 \mathrm{kPa}$ overpressure

Preliminary tests were carried out at the workshop; after a proper setting up, the prototype unit satisfactorily performed all operations, attalning or even exceeding the targets established in the project. The unit was then shipped to the Italcementi laboratories to start the experimental research work.

\subsection{Project and Manufacture of a Concrete Walling Unit}

In order to carry out the investigation programme, a concrete structure was designed and implemented, the size and shape of which was representative of an actual concrete unit. A schematic outline of this structure, consisting of vertical and horizontal elements, is shown in Figure 3. The vertical portion was $0.30 \mathrm{~m}$ thick, $8.0 \mathrm{~m}$ long and $3.50 \mathrm{~m} \mathrm{high}$. The concrete was reinforced by means of square-mesh nets formed by $0.02 \mathrm{~m}$ diameter rods with improved adherence. At the project stage, it had been decided that half of the structure should be made of ordinary concrete and the remainder of high density baritic concrete.

The baritic aggregate used to manufacture the heavy concrete was made up of a single fraction having a minumum diameter of $25 \mathrm{~mm}$ and an absolute density which turned out to be $4200 \mathrm{~kg} / \mathrm{m}^{3}$, as provided for by UNI (1). The chemlcal analysis showed a high BaSO 4 content (93.598) along with the presence of $\mathrm{CaO}$ (3.038) and $\mathrm{SiO}_{2}$ (2.468). Ordinary concrete was prepared with sand and river gravel of a siliceous nature and using elght different fractions to obtain a grain size curve with maximum diameter of $22 \mathrm{~mm}$. The characteristics of the mixes and the physical and chemical properties of both heavy and ordinary concrete, as received and after laboratory impregnation, are given in Table I. On carryıng out impregnations, according to laboratory procedures, we could prove that these concretes absorbed a relatively small amount of monomers, 1.e. $2.5 \div 3.5$ by welght. The mechanical compressive strength was measured on 100 mn edge cubes. The modulus of elasticity and Polsson's ratio were measured on four cylinders for each type of concrete (normal and PIC) in conformlty with guidelines of UNI (2). The thermal conductivity coefficient was measured on two couples of $0.07 \times 0.65 \times 0.65 \mathrm{~m}$ plates, by the method of a hot plate equipped with a guard ring (3).

\subsection{Impregnation and Polymerization of some Sectors of the Concrete Walling Unit}

Eight segments were taken from the concrete unit and treated by means of the experimental equipment set up by SNIA Techint. Two cycles of treatment were proved: one called 'short' treatment, the other 'extended'. The phases and the times required by each treatment phase are shown in Table II. During the structure desiccation process a temperature control was 
carried out by means of three thermo-resistors Pt-100 placed into three holes which were located at the centre of the area involved in the treatment, at a depth of $35.0,55.0$ and $100.0 \mathrm{~mm}$ respectively. The temperature trends as a function of time and related to the extended cycle are shown in Figures 4 and 5 . Is is clear that the temperatures measured on the portion of the structure that were built out of baritic concrete are significantly different from those obtained on normal concrete. The different thermal conductivity of the material, $1.4 \mathrm{w} / \mathrm{m} /{ }^{\circ} \mathrm{C}$ of baritic concrete against $2.2 \mathrm{~W} / \mathrm{m} /{ }^{\circ} \mathrm{C}$ of normal concrete, has a considerable effect on temperature profiles. Upon completion of heating, heavy concrete had gone up to a temperature of $120^{\circ} \mathrm{C}$ at a depth of $3.5 \mathrm{~cm}$ under the 'short' treatment and $150^{\circ} \mathrm{C}$ under the 'extended' treatment. At the same depths and during the same periods temperatures were $15^{\circ} \mathrm{C}$ lower in ordinary concrete.

As far as hot water polymerization is concerned, two procedures were tested: in the former water was heated in the machine boiler and allowed to circulate via the pump; in the latter, water was heated via the resistors fitted to the impregnation chamber itself, starting off with hot water and without resorting to circulation.

\subsection{Characterization of Concrete Structure after Impregnation}

After polymerization, the following samples were collected via coring from each of the treated segments: cores measuring 50, 100 and $150 \mathrm{~mm}$ in diameter. The cores with a $50 \mathrm{~mm}$ diameter were cut by means of a diamond bladed saw into $10 \mathrm{~mm}$ thick sections, and from each of these the samples to be used for both differential thermal analysis and pore size analysis were cut out. Two cylindrical $20 \mathrm{~mm}$ thick specimens were sliced from the $100 \mathrm{~mm}$ diameter cores for the purpose of measuring water absorption by capillary upstarting and of determining the porosity accessible to water. Specimens were collected from the $150 \mathrm{~mm}$ diameter cores in order to evaluate their resistance to sliding friction by means of an Amsler tribometer and to subject them to leaching tests.

\section{RESULTS}

The differential thermal analysis performed both via Differential Scanner Calorimetry (DSC) and according to a simplified procedure, made it possible to determine the polymer content of concrete at different depths. The determinations of capillary absorption, whose results are summarised on the diagrams in Figures 6 and 7, stress the effect of impregnation. The rate of absorption by capillarity in impregnated concrete was much slower than in normal concrete: ordinary concrete achieved a steady state soon after 24 hours, whereas impregnated concrete did not, even after 320 hours. Moreover, on conclusion of the test, the quantity of water absorbed by impregnated concretes turned out to be about 508 lower than that of ordinary concretes. Table III shows the results of the water absorption test under vacuum, performed according to UNI (4). The values relating to resistance to wear, whose results are given in Table III, show that impregnation has a weak effect on concrete made of silico-calcareous aggregates, while it boosts resistance to wear of baritic concrete by around 15\%. The extended treatment, whose results are shown in the diagrams in Figures 8 and 9, boosted both the percentage of absorbed resins and the concrete depth involved in the treatment. In the outer $8 \mathrm{~cm}$ the percentage of resin was up to $3.5 \mathrm{wt}$; moreover impregnation and polymerization involved the concrete up to a depth exceeding $60 \mathrm{~mm}$. The pore size analysis showed that, up to approximately $45 \mathrm{~mm}$, that is the area which had been involved in the 
treatment to a greater extent, porosity was three times lower with respect to concrete as received.

Leaching tests were carried out in accordance with UNI provisions (5). In this case we started analysing the leaching solutions at preset ages comprised between one and 60 days, in order to find the main constituents of the cementitious matrix: Na, K, Si, Ca and $\mathrm{Mg}$. Three leaching solutions were prepared: a solution with $\mathrm{pH} 7.0$ (distilled water), a buffer solution with a $\mathrm{pH}$ of 5.7 (glycine) and a buffer solution with a pH of 2.3 (glycine sulphate). Two testing temperatures were used: $20^{\circ} \mathrm{C}$ and $40^{\circ} \mathrm{C}$. The results of the analytical determinations (expressed in $\mathrm{mg} / \mathrm{l}$ per day) indicate an asymptotic decrease in the rate at which ions concentrate in the leaching solutions. In particular, it was found that there existed no significant differences between the behaviour of baritic concretes and that of siliceous ones. This fact leads us to suppose that ions contained in the solutions mainly come from the cementitious matrix. As compared to the behaviour of concretes as received, the PIC behaviour is greatly different due to ions of alkaline elements $(\mathrm{Na}, \mathrm{K})$, whereas it is not in the case of $\mathrm{Ca}$, $\mathrm{Mg}$, and $\mathrm{Si}$. As an example, Figures 10 and 11 reproduce the diagrams relating to baritic concrete, either impregnated or not.

\section{CONCLUSIONS}

The main purpose of the research programme, that is the implementation of a system for the 'in situ' impregnation of concrete, has been fulfilled. The periods needed by the impregnation treatment turned out to be longer than those required for laboratory tests or for impregnated prefabricated structures, made of ordinary concrete.

'In situ' treatment, even if carried out on a compacted, nuclear grade concrete, reached an approximate $6 \mathrm{~cm}$ depth. The content in polymers of an impregnated concrete usually amounts to about 58 by weight, whereas in the concretes under testing it amounts to a figure ranging between 38 and 3.58 by weight, owing to their reduced porosity. When investigated by means of such mechanical tests as compressive strength, resistance to wear, modulus of elasticity or by means of physical and chemical determinations (pore size distribution, water absorption, leaching test), the improvement of concrete characteristıcs justifies both impregnation and polymerization processes.

This treatment prevents leaching solutions from entering the inner part of the cementitious paste, while preserving it from the attack of external aggressive or contaminant agents.

\section{REFERENCES UNI (*)}

(1) UNI 8520 - Section 13 - Aggregates for use in concretes. Determination of density and water absorption of fine aggregates.

(2) UNI 6556 - Tests of concretes. Determination of static modulus of elasticity in compression.

(3) UNI 7745 - Insulating materials. Determination of thermal conductivity by means of the guarded hot plate method.

(4) UNI 6394 - Section 2 - Density of concrete. Determination on hardened concrete.

(5) UNI $\mathbf{8 7 9 8}$ - Radioactive waste solidification products. Long term leach test.

(*) UNI - Ente Nazionale Italiano di Unificazione. 
TABLE I: Physical and chemical properties of ordinary and barytic concretes, prior to and after impregnation

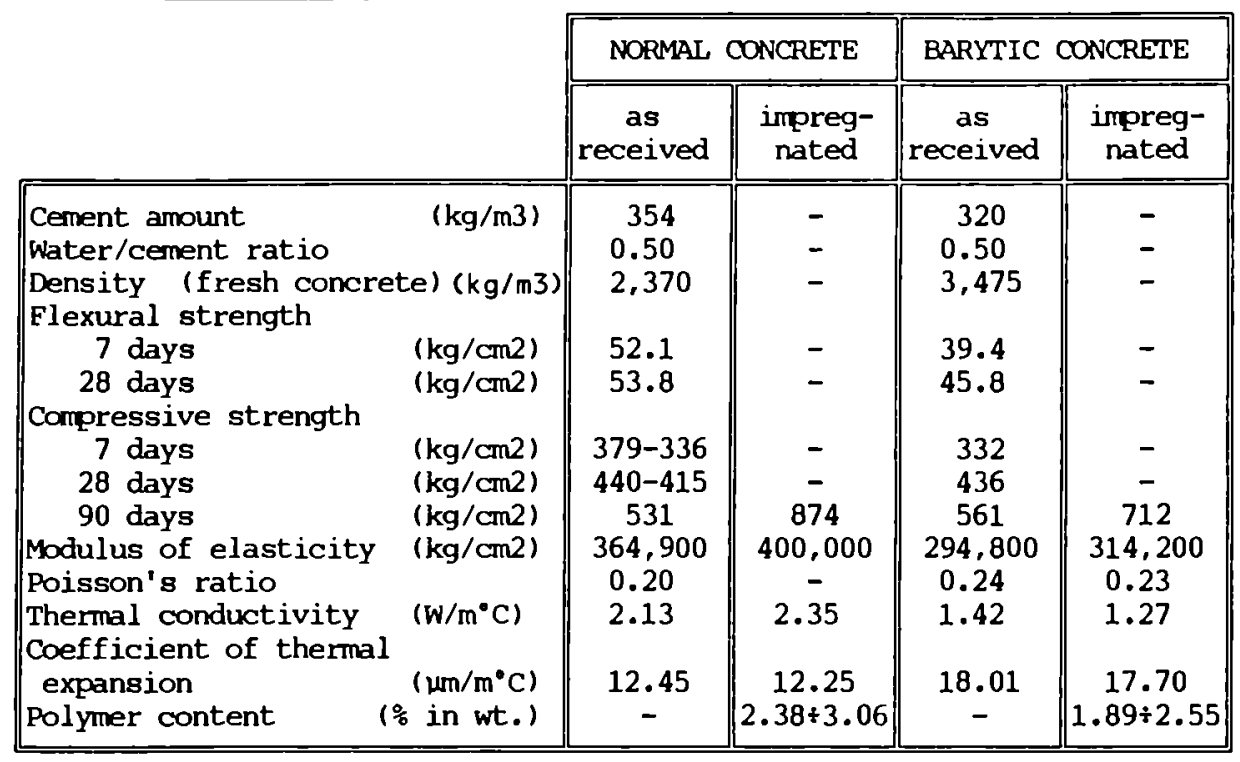

TABLE II: Impregnation and polymerisation: times required for the different phases and the two different treatments employed

\begin{tabular}{|c|c|c|}
\hline \multirow{2}{*}{ PROCESS PHASE } & \multicolumn{2}{|c|}{ TIME (hs) } \\
\hline & "SHORT" TREATMENT & "EXTENDED"TRFATMENT \\
\hline $\begin{array}{l}\text { Heating up to } 110^{\circ} \mathrm{C} \\
\text { Heating up to } 160^{\circ} \mathrm{C} \\
\text { Natural cooling } \\
\text { Degassing } \\
\text { Impregnation with monomer } \\
\text { (pressure at } 0.2 \text { atm) } \\
\text { Polymerisation with } \mathrm{H} 2 \mathrm{O} \text { at } \mathrm{H} 2 \mathrm{O}\end{array}$ & $\begin{array}{r}4 \\
6 \\
14 \\
1 \\
5 \\
4\end{array}$ & $\begin{array}{r}8 \\
8 \\
12 \\
1 \\
10 \\
6\end{array}$ \\
\hline
\end{tabular}

TABLE III: Absolute density, porosity accessible to water, and wear due to sliding friction

\begin{tabular}{|c|c|c|c|}
\hline & $\begin{array}{l}\text { DENSITY } \\
\mathrm{kg} / \mathrm{m} 3\end{array}$ & $\begin{array}{l}\text { POROSITY } \\
\text { volume } \%\end{array}$ & $\begin{array}{l}\text { WEAR DUE TO } \\
\text { SLIDING } \\
\text { ERICTION } \\
\mathrm{mm} / 1000 \mathrm{~m}\end{array}$ \\
\hline $\begin{array}{l}\text { BARYTIC CONCRETE } \\
\text { External surface } \\
\text { At } 16 \mathrm{~cm} \text { depth }\end{array}$ & $\begin{array}{l}3464 \\
3491\end{array}$ & $\begin{array}{r}6.93 \\
10.20\end{array}$ & $\begin{array}{l}10.60 \\
14.56\end{array}$ \\
\hline $\begin{array}{l}\text { NORMAL CONCRETE } \\
\text { External surface } \\
\text { At } 16 \text { con depth }\end{array}$ & $\begin{array}{l}2358 \\
2316\end{array}$ & $\begin{array}{r}7.87 \\
10.02\end{array}$ & $\begin{array}{l}6.25 \\
6.67\end{array}$ \\
\hline
\end{tabular}




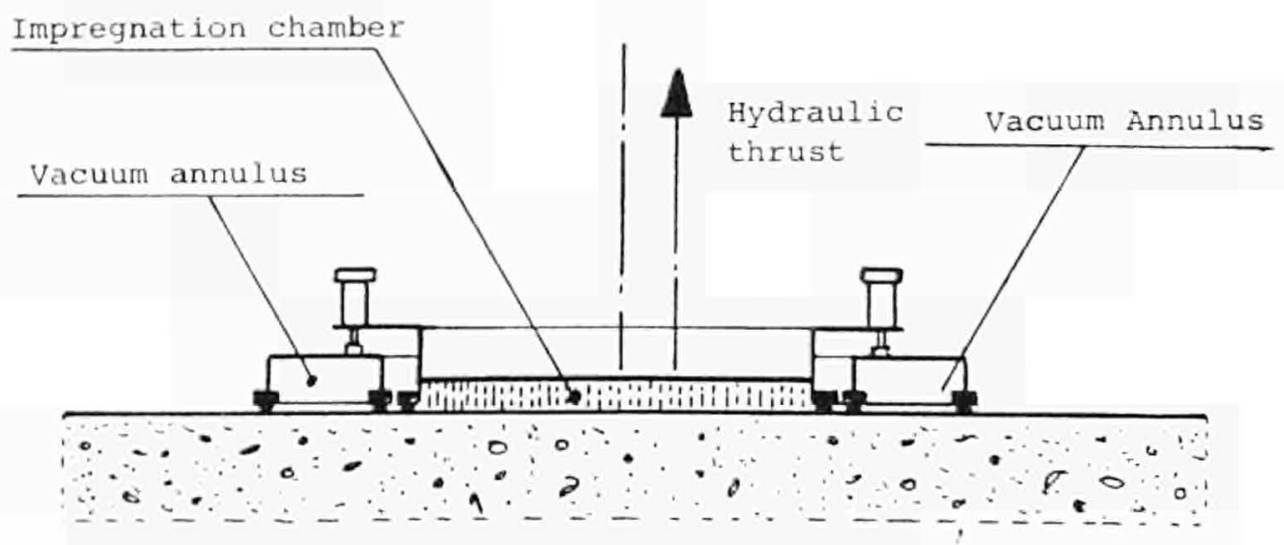

Figure 1: Scheme of impregnation principle

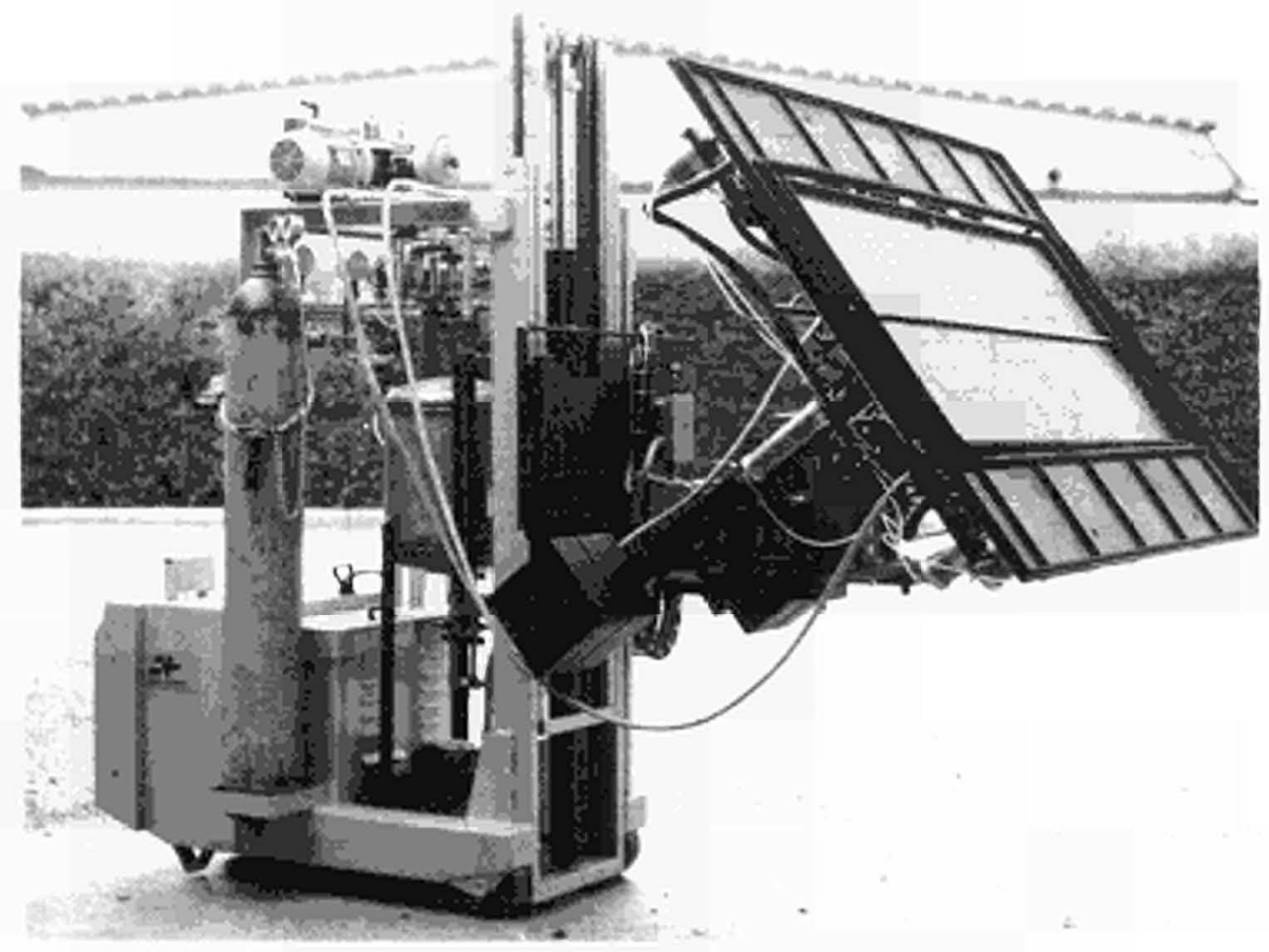

Figure 2: Prototype impregnation unit 


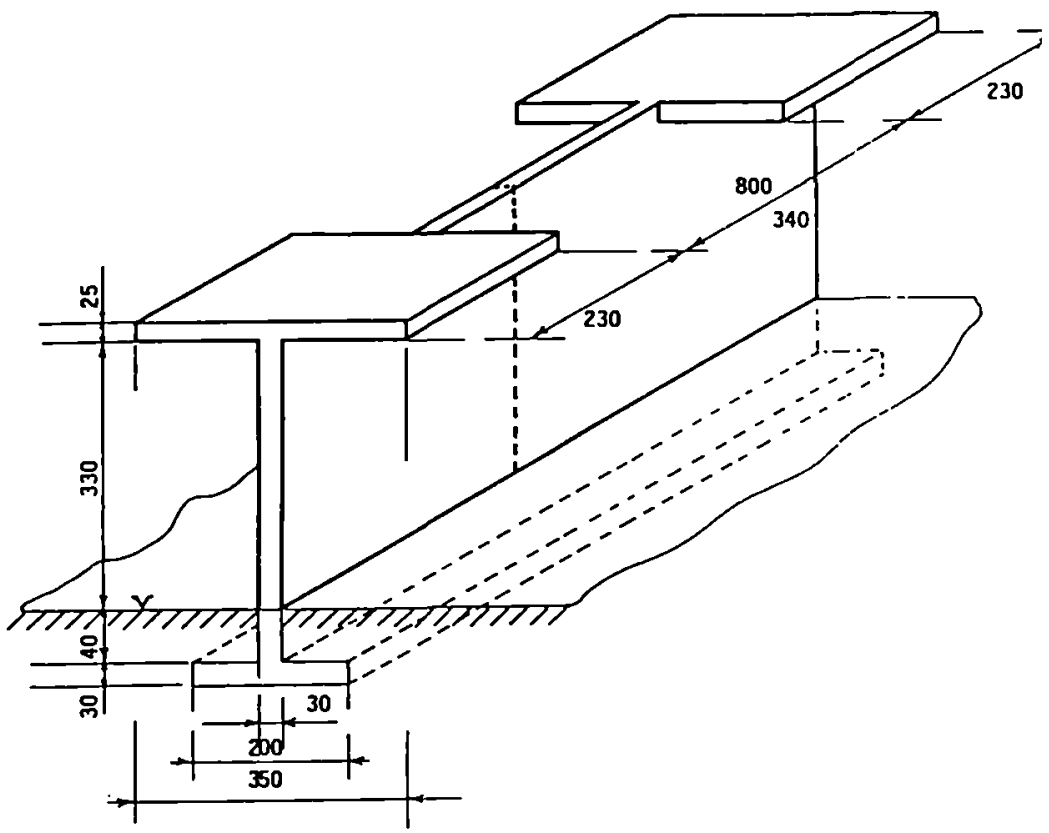

Figure 3: Axonometric sketch of the structure manufacture for in-situ impregnation tests (dimensions in $\mathrm{cm}$ )

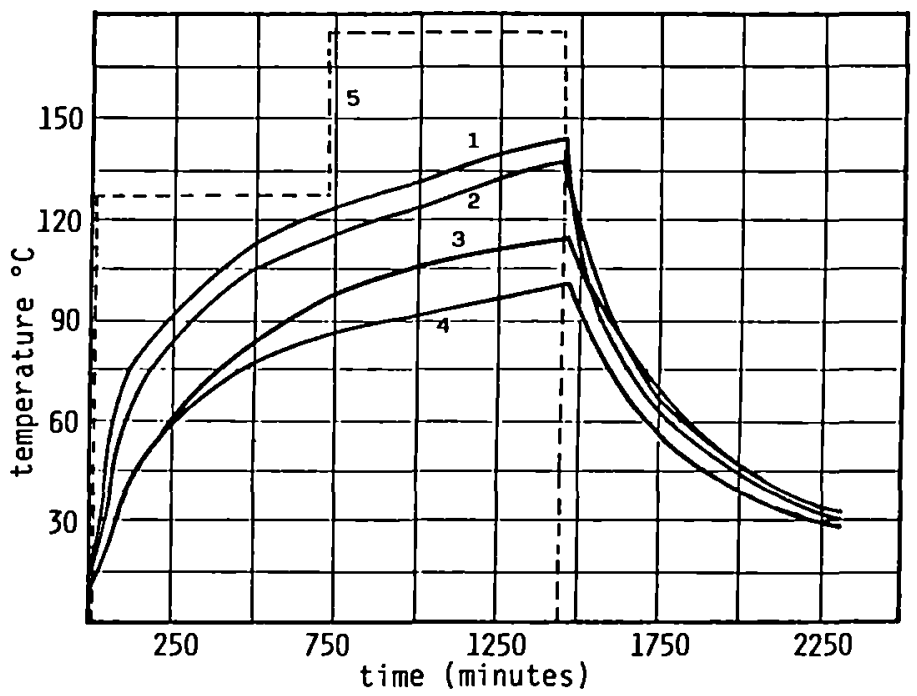

Figure 4: Trend of temperatures detected during the prolonged heating of normal concrete

1 - probe at $35 \mathrm{~mm}$ depth

3 - probe at $100 \mathrm{~mm}$ depth

$200 \mathrm{~mm}$ apart from the edge of
temperature on thermoregulator

2 - probe at $55 \mathrm{~mm}$ depth

4 - probe at $100 \mathrm{~mm}$ depth and the heating plate 5 - preset 


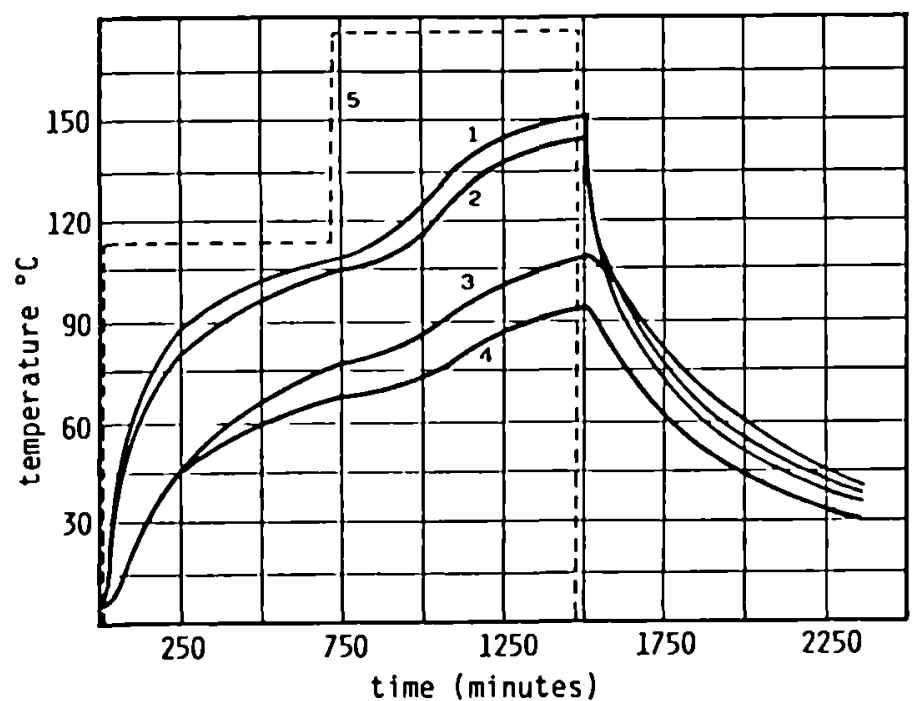

Figure 5: Trend of temperatures detected during the prolonged heating of barytic concrete

1 - probe at 35 depth

2 - probe at $55 \mathrm{~mm}$ depth

3 - probe at $100 \mathrm{~mm}$ depth

4 - probe at $100 \mathrm{~mm}$ depth and

$200 \mathrm{~mm}$ apart from the edge of the heating plate 5 - preset

temperature on thermoregulator

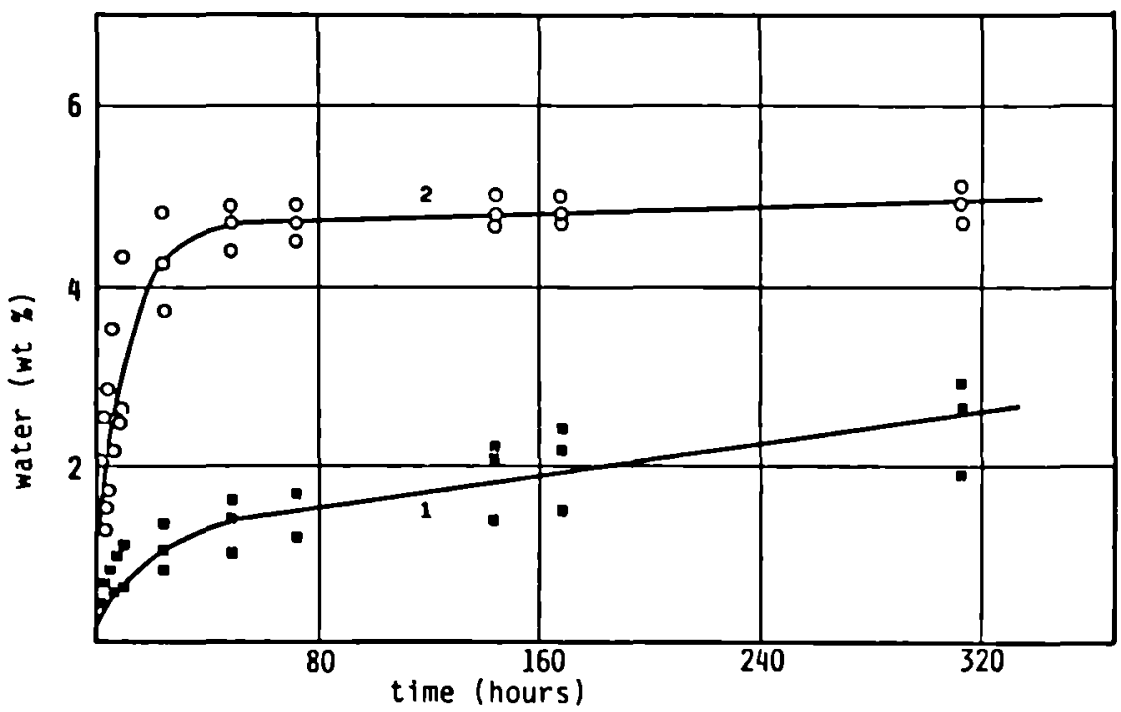

Figure 6: Trend of vater quantity absorbed by capillarity on ordi nary concrete specimens

1 - impregnated concrete

2 - concrete as recelved 


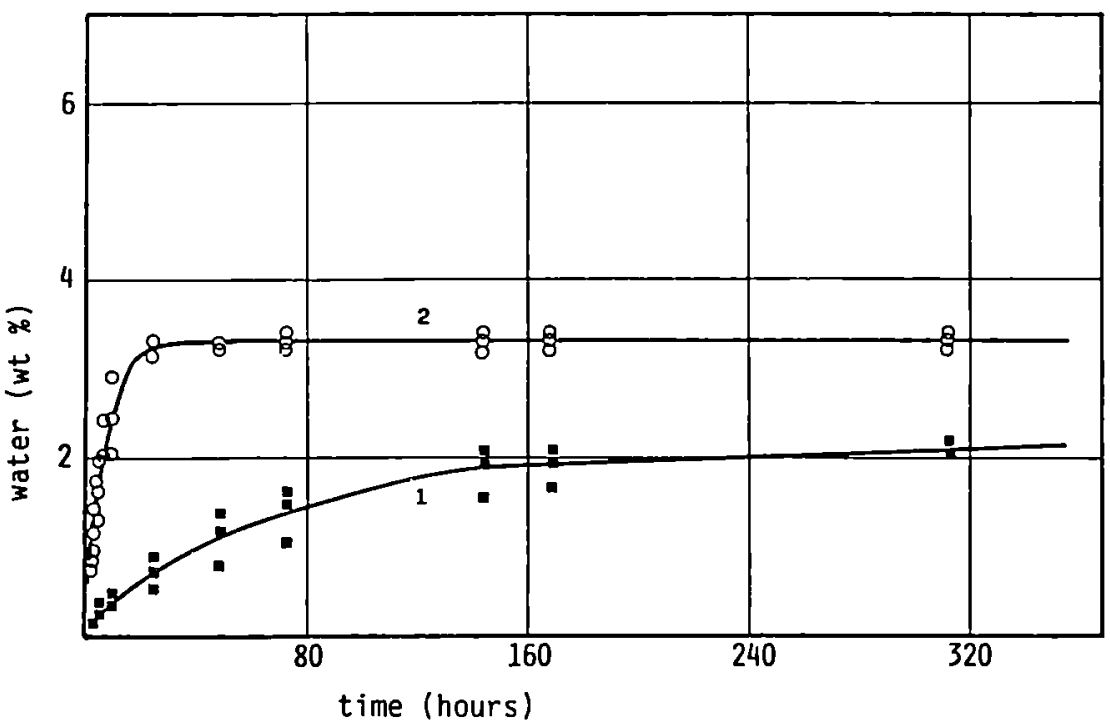

Figure 7: Trend of water quantity absorbed by capillarity on barytic concrete specimens

1 - impregnated concrete 2 - concrete as received

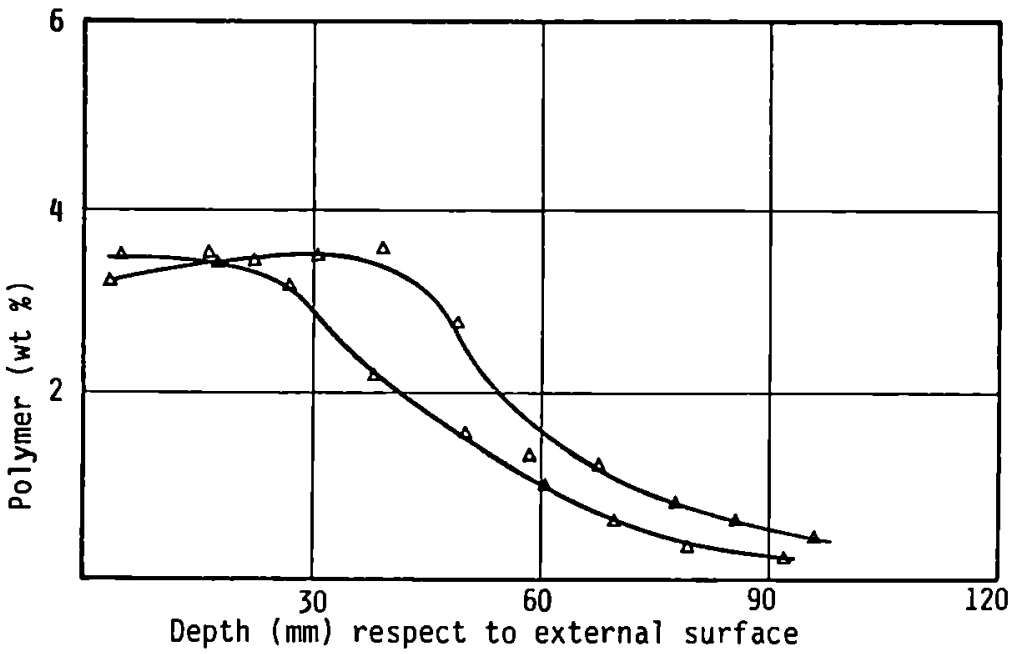

Figure 8: Ordinary concrete: trend of polymer content versus depth (the curves refer to two specimens collected from the same sector) 


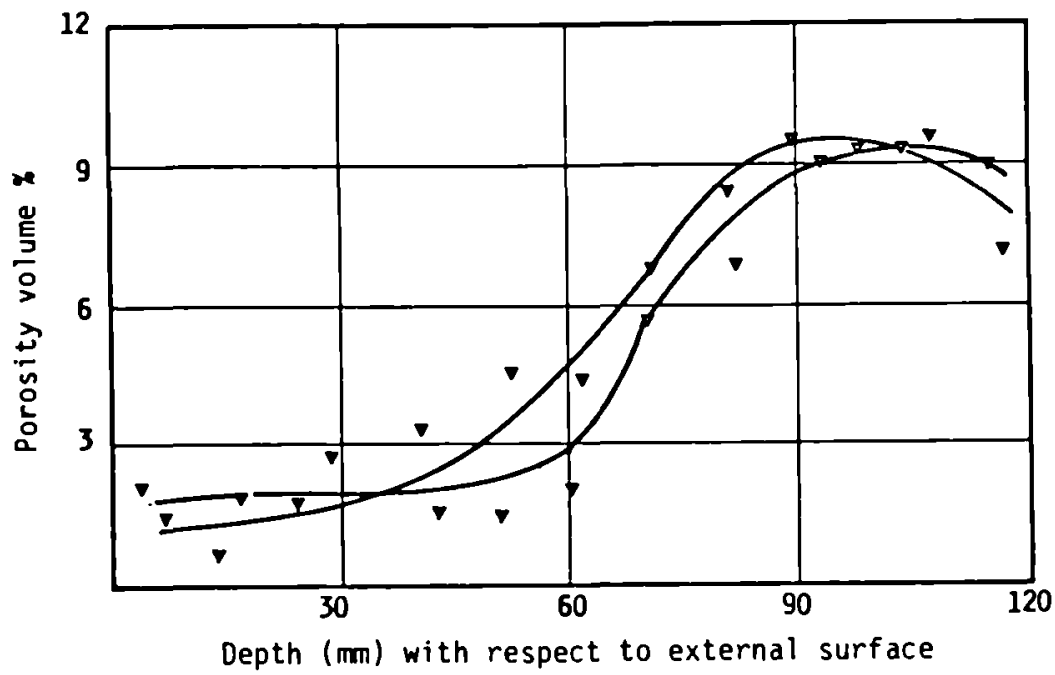

Figure 9: Ordinary concrete: trend of porosity versus depth (the curves refer to two specimens collected from the same sector)

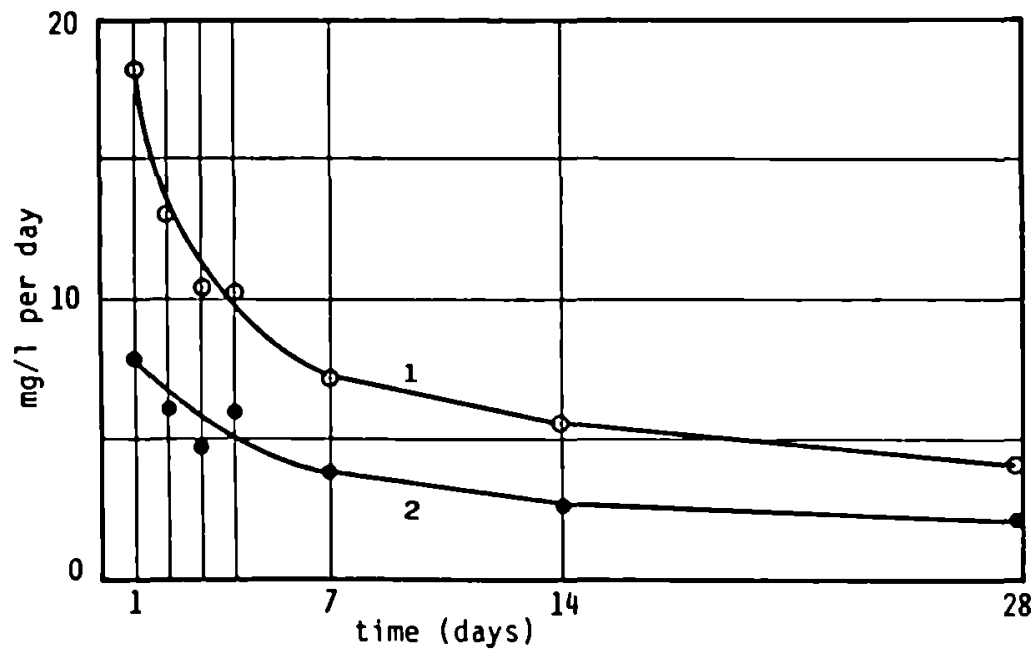

Figure 10:Baryt1c concrete: trend of the concentration of Na lons under solution as a function of time (leaching agent used: glycine, testing temperature: $\left.40^{\circ} \mathrm{C}\right) \quad 1$ - concrete as received 2 - in pregnated concrete 


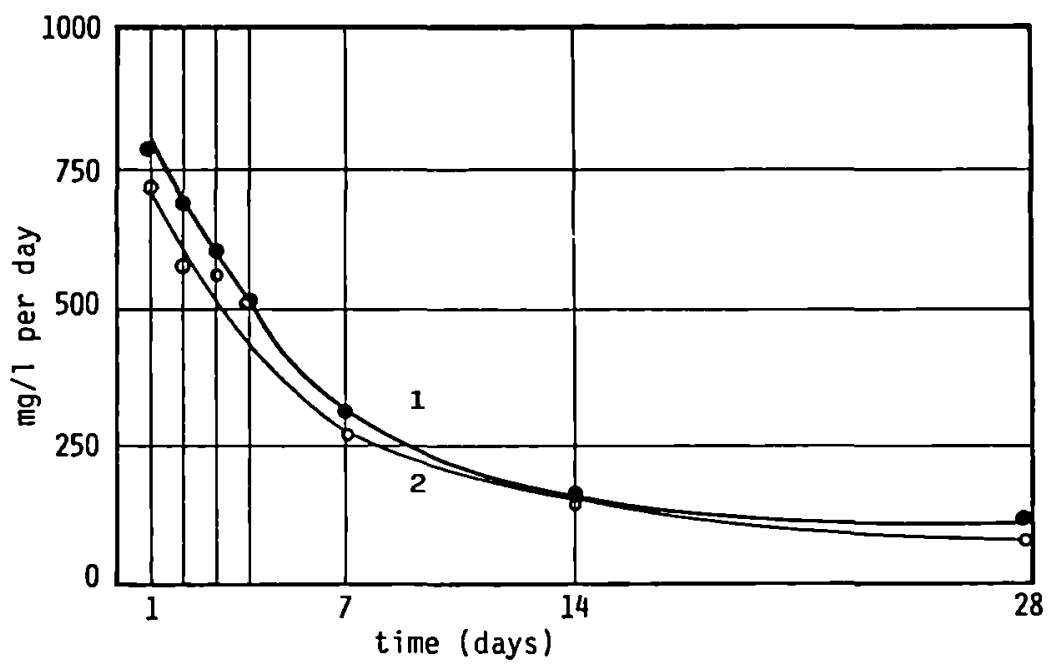

Figure 11: Barytic concrete: trend of the concentrations of Ca ions under solution as a function of time (leaching agent used: glycine sulphate; testing temperature: $40^{\circ} \mathrm{C}$ )

1 - concrete as received

2 - impregnated concrete 


\title{
INFLUENCE OF DESIGN FEATURES ON DECOMMISSIONING OF A LARGE FAST BREEDER REACTOR \\ EQURNIE J-I. , ALARY C. , MAIRE D. , de SEROUX N. , PEYRARD G. Novatome, Lyon, France
}

\begin{abstract}
The evolution of FBR design in Europe shows that pool-type design will become the reference design for future FBR and the projected European Fast Reactor (EFR) is based on this concept. The identification of design features shows that the main contributors of the sodium and structures activity are the Co60 for gamma radiation source and low decay, $\mathrm{Ni63}, \mathrm{Nb} 94$ and $\mathrm{Ni} 59$ for long time decay. So, the technical benefits of a Co content reduction are interesting for the high activated structures and for diagrid thimbles coating and we made proposals to lower Co content in steels or alloys and to substitute coatings. We identify measures which must facilitate both the sodium draining and the reactor block and internals cleaning : all which improve the gravity draining and the downing of the sodium flow make easier the penetration of cleaning products. The features, connected with the dismantling of the very activated internals structures, of the roof and of the lay-out, are mentionned.
\end{abstract}

\section{1- DESIGN FEATURES OF A LARGE FAST BREEDER REACTOR (FBR)}

The general structure of a fast breeder reactor always includes 3 main systems: the primary sodium system, removing the heat produced in the core (this sodium is activated by neutrons), the secondary sodium system, non-radioactive, and the third steam-water system. Two design solutions are then possible : either the primary system is entirely contained in a large vessel (pool-type), or the vessel only contains the core (loop-type). Most large FBR are designed on pool-type (figure1), and all European studies used this concept after the SPX1 construction (SPX2 in France, CDFR in the UK, SNR2 in Germany). So the projected European Fast Reactor (EFR) will be a pool-type NSSS.

For these pool-type reactors, all the activated or contaminated components are enclosed in a single vessel. Figure 2 shows the SPX1 reactor block. 


\section{IDENTIFICATION OF THE MAIN FEATURES DETERMINANT TO DECOM- MISSIONING}

This design leads to relative positions of the core, of the internal structures and of the removable components (pumps, exchangers) such as the far components and strutures are very little activated, and particularly, the vessel vault concrete is not active.

Only components which are in the main vessel, will be activated or contaminated. Also , a calculation of the activation and contamination by corrosion and fission products was achieved. The calculation was executed for the Superphénix 2 reactor from codes (Corona , C ANIS N) validated by the tests and the working experience of the reactors Phenix and Superphénix 1. The hypotheses of the calculation are the dimensions and specifications used for the Superphénix 2 project : Co content of $0,2 \%$ for the stainless steels (1800t), and of $1 \%$ for the Inconel 718 (5t).

A radioactive products balance shows (Table I): -the primary sodium contains Na22 (activation), -the components near the core are very activated (essentially Co60), -the diagrid stellite is the most important source of the structures, -the sodium and the structures are contaminated by the fission products (Cs 137) and the corrosion products (Mn54 et Co60) but not really by the actinides .

Table I: Radioactive sources balance just after the reactor shutdown (SPX2)

\begin{tabular}{|c|c|c|c|c|c|}
\hline COMPONENTS & $\begin{array}{l}\text { WEIGHT } \\
\text { (t) } \times \mathrm{nb}\end{array}$ & \begin{tabular}{|l|}
$\emptyset \times H$ \\
$(\mathrm{~m}) \times(\mathrm{m})$ \\
\end{tabular} & $\begin{array}{c}\text { TYPE } \\
*\end{array}$ & 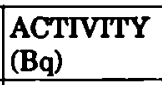 & \begin{tabular}{|l|}
$\begin{array}{l}\text { DOSE RATE } \\
\text { (Sv/h) }\end{array}$ \\
\end{tabular} \\
\hline SODIUM & 2800 & & ACT(Na22) & $1.6 \mathrm{E}+6 / \mathrm{g}$ & \\
\hline PRIMARY PUMP & $100 \times 4$ & $2.2 \times 15$ & PC(Mn54) & $1.8 \mathrm{E}+12$ & 0.04 at $0.5 \mathrm{~m}$ \\
\hline EXCHANGERS (IHX) & $70 \times 8$ & $3 \times 17$ & $P C(M n 54)$ & $3.7 \mathrm{E}+12$ & 0.06 at $0.3 \mathrm{~m}$ \\
\hline LOAD MACHINE & 20 & $2.2 \times 16$ & ACT(Co60) & $1 E+5 / g$ & 0.04 contact \\
\hline ROD MECHANISM & $1.5 \times 33$ & $0.3 \times 10$ & ACT(Ag110m) & $1.5 \mathrm{E}+8 / \mathrm{g}$ & 90 contact \\
\hline MAIN VESSEL & 360 & $20 \times 16$ & ACT $\left(C_{060}\right)$ & $8 \alpha_{\mathrm{g}}$ & $2 \mathrm{E}-5$ contact \\
\hline INNER VESSEL & 200 & $19 \times 10$ & ACT(Co60) & $4 E+3 / g$ & 0.18 contact \\
\hline ROOF SLAB & 1100 & $20 \times 2.5$ & PF(Cs137) & $3 \mathrm{E}+3 / \mathrm{cm}^{2}$ & \\
\hline ROTATING PLUGS & 800 & $10 \times 3.3$ & PF(Cs137) & $3 \mathrm{E}+3 / \mathrm{cm}^{2}$ & \\
\hline ACS & 150 & $4.5 \times 9$ & ACT $\left(\mathrm{Co60}_{0}\right)$ & $3 E+6 / g$ & 0.75 contact \\
\hline \multirow[t]{2}{*}{ DIAGRID } & 150 & $7 \times 1$ & ACT $\left(C_{060}\right)$ & $7 \mathrm{E}+9 / \mathrm{g}$ & 1000 contact plate \\
\hline & & & ACT(Co60) & $4 \mathrm{E}+12 \mathrm{~Bq} / \mathrm{g}$ & stellite \\
\hline STRONGBACK & 200 & $13 \times 3$ & ACT(Co60) & $1.5 \mathrm{E}+7 / \mathrm{g}$ & 3 contact \\
\hline
\end{tabular}

*:ACT: activation PF : fission products PC: corrosion products

$1 \mathrm{Ci}=3.7 \mathrm{E} 10 \mathrm{~Bq}$ 


\section{Radioactive source decay:}

Complementary calculations have been done for decay time between 0 and 200 years, and they take into account the long half-life radionuclides. The main contributors are the $\mathrm{Co} 60$ for gamma radiation source (first 80 years), $\mathrm{Ni} 63, \mathrm{Nb} 94$ and $\mathrm{Ni}$ 59 for long time decay.

The figures 3 and 4 show the results for the diagrid and the lower part of the main vessel: the activation level decreases from the most activated structure (the diagrid) to the external structures (vessels, slab, concrete) which are protected during the $\mathbf{4 0}$ years in operation by neutron shields and the sodium surrounding the core. The concrete of the pit is not activated : a pool-type fast breeder reactor is not producing activated concrete wastes.

For internal structures, from the previous figures, we deduce a decay type curve, with characteristic inflexion points : the first one for a 25 to 30 years till the cobalt part becomes inferior to the nickel 63 part, the second one for a 80 to 100 years till the Nb94 part becomes superior to the Co60 part (cf figure 5).

\section{Decommissioning of a large FBR}

A Superphenix 1 study (ref [2]) showed that it is possible to decommission this reactor up to each of the 3 levels defined by the IAEA. Applied to the Superphenix 2 reactor , and taking into account the previous results, we can consider the following cases :

- level 1 : after the final shutdown, only roof components (pumps, IHX, control rod mechanism,..) will be removed, primary and secondary sodium loops being drained . Internals and other components, which were in sodium, could be dismantled after about 30 years.

- level 2 : after the final shutdown, dismantling of all nuclear components except internal structures in the reactor block. Buildings (except reactor building) are dismantled. The reactor block and structures could be dismantled after about 100 years.

- level 3 : after the final shutdown, all structures could be dismantled.

\section{3- REDUCTION OF COBALT CONTENT IN STEELS AND ALLOYS :}

Technical benefits of the Co content reduction are interesting for high activated structures, either on decommissioning (reduction of dose rate , activity, wastes,.), or on plant maintenance by reduction of biological shields thickness (handling flask , hot cells,..), by components maintenability improvement and by in-service inspection improvement. 
The cobalt content in stainless steels (SS) or Inconel depends firstly on the cobalt content of the nickel iron used in SS, then on smelted alloys percentage, on scrap and finally on the hearth furnace type .

SS: from an initial specification of $0,2 \%$, the costs increasing due to the Co content reduction on provisioning is:

$0,2 \%$ to $0,1 \%$ of Co content : 0 or some $\%$

$0,2 \%$ to $0,05 \%$ of Co content : $\sim 10 \%$

$0,2 \%$ to $0,01 \%$ of Co content : no values.

Inconeli from an initial specification of $1 \%$, the costs increasing due to Co content reduction on provisioning is :

$1 \%$ to $0,1 \%$ of Co content : $\sim 10 \%$

$1 \%$ to $0,05 \%$ of Co content : $\sim 30 \%$ or more.

Proposals are given in table hereafter :

Table II: Proposals for cobalt content specifications (SS: INC)

\begin{tabular}{|l|l|l|}
\hline COMPONENTS & INITLAL SPEC & PROPOSAL \\
\hline MAIN \& SAFETY VESSELS & SS: $0,2 \%$ & $0,2 \%$ \\
INTERNALS STRUCTURES(DIAGRID, ..) & SS: $0,2 \%$ & $0,05 \%$ \\
ACS LOWER PART & SS: $0,2 \%$ & $0,05 \%$ \\
ACS UPPER PART & SS: $0,2 \%$ & $0,2 \%$ \\
INNER VESSEL & SS: $0,2 \%$ & $0,1 \%$ \\
REMOVABLE COMPONENTS ON ACS (LOWER) & SS: $0,2 \%$ INC:1\% & $0,05 \%$ \\
REMOVABLE COMPONENTS ON ACS (UPPER) & SS: $0,2 \%$ & $0,05 \%$ \\
PARTICULAR BOLT STEEL & no specification & $0,2 \%$ \\
\hline
\end{tabular}

\section{4- SUBSTITUTION OF COBALT COATINGS}

The base cobalt hard-facing ("stellite"), on diagrid thimbles , is the main activation source of the reactor block (see table I). A 100 years waiting does not suffice to obtain a complete decay of this hard-facing ( $1 \mathrm{MBq} / \mathrm{g})$. So , one of the important recommendations is the substitution of this coating by a cobalt-free coating or the application of a surface treatment .

The choice criteria of a new material or surface treatment are at first its qualities of friction in sodium at high temperature, its cost and its activation under the neutronic flux. Selection tests show that some substitute hard-facing ( nitrure coating, "aluminiures") or shoot-peened materials seem to have good friction characteristics (see ref [3] \& [4]).

A comparative cost of the use of selected materials or coatings is given in the 
table III hereafter.

Table III. Hard-facing comparative costs : "stellite" and substitutes

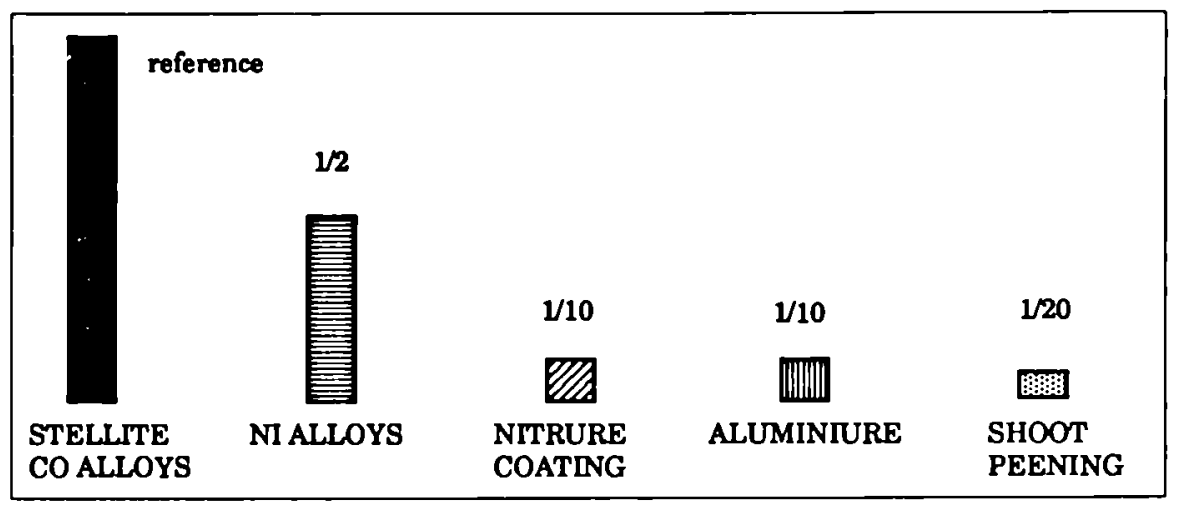

This hard-facing activation has been calculated, in comparison to cobalt coating. It' 8 equivalent to the SS base metal as shown in figure 6 for the nitrure coating. The essential measure to take into account is the cobalt base hard-facing suppression replaced by a qualified substitute hard-facing, particularly by undertaking some tests to know the influence of activation on friction characteristics .

\section{5- BLOCK REACTOR DRAINING AND CLEANING}

One of the FBR principal characteristics is their cooling by liquid sodium, and this coolant fluid gives particular constraints for the decommissioning , particularly for the draining and the cleaning of the reactor block .

The elimination of the sodium adhering to the metallic surfaces can be realized during the decommissioning by a water washing , perfectly controled for the small thicknesses, but which does not suit for big retentions. These retentions must be avoided by preventive design. The measures, which must facilitate both the sodium draining , and the reactor block and internals cleaning , are converging : all which improve the gravity draining and the downing of the sodium flow make easier the penetration of cleaning products. These measures concern at first, all the diagrid and the core support structure taking into account simple technical improvements to solve important difficulties: for example to foresee the drillings and a hollow thimble needed for the draining device .

In the case of a long delay, it could be interesting to change the sodium in a stable compound, by example in carbonate, before its ultimate removal.

The primary sodium purification in cesium ( $C s$ 137) during the reactor draining is recommended whatever its outcome. 


\section{6- INTERNAL AND SLAB STRUCTURE CONCEPT}

The features connected with the dismantling of these very activated internals structures are ticklish to treat, because they are connected to their design. But we propose several measures such as :

- to pursue the components weight reduction,

- to maintain at the design stage the provision for removing some components (ACS, neutron shield assemblies,...),

- to study the possibility of removing some others like the roof and the rotating plugs.

\section{7- GENERAL LAYOUT}

Several improvements , connected to the handling means, the packing and the conditionning area of the reactor block structures , are proposed, particularly:

- to have an handling multipurpose device available for decommissioning,

- to foresee the possibility of future use of some equipment operation (cells and storage fuel pool ) by fitting up their access.

\section{8- CONCLUSION}

The examination of the FBR design characteristic influence on their decommissioning allowed us to verify that a fast reactor, in spite of a few specific problems (sodium, diagrid), should not give more problems for its decommissioning than a thermal reactor. Nevertheless the acquired experience or to be acquired during a fast reactor decommissioning at final shutdown (Rapsodie,..) will have to be exploited so as to get the experimental data for the future commercial pool-type reactors.

These measures can be important for decommissioning as well as for some exploitation operations and the acquired benefit is more especially quickly appreciated as it decreases the exploitation costs , without waiting some further decommissioning operations.

The identified measures must, in their principle, be studied and adapted if necessary during the studies of the European Fast Reactor, EFR .

\section{References:}

[1] A. CREGUT et al : OCDE Meeting 17 au 19 Mars 1980 Paris p.15-21

[2] A. CREGUT et al : IAEA SM 243/33 13 au 17 Novembre 1978 Vienna p. 187-202

[3] J. DAVIOT et al : LIMET 88 Avignon ; paper 503

[4] A. PIREAU Rapport Belgonucléaire RAP-049- for the CEC (GT"codes et normes") 


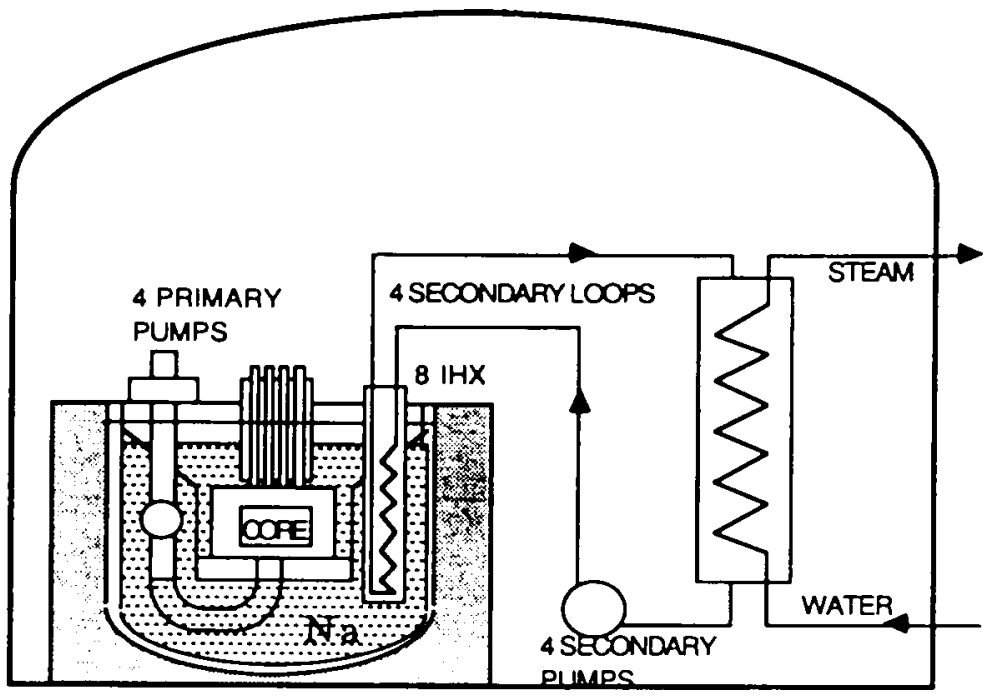

Figure 1 : Principle of a fast breeder pool-type reactor

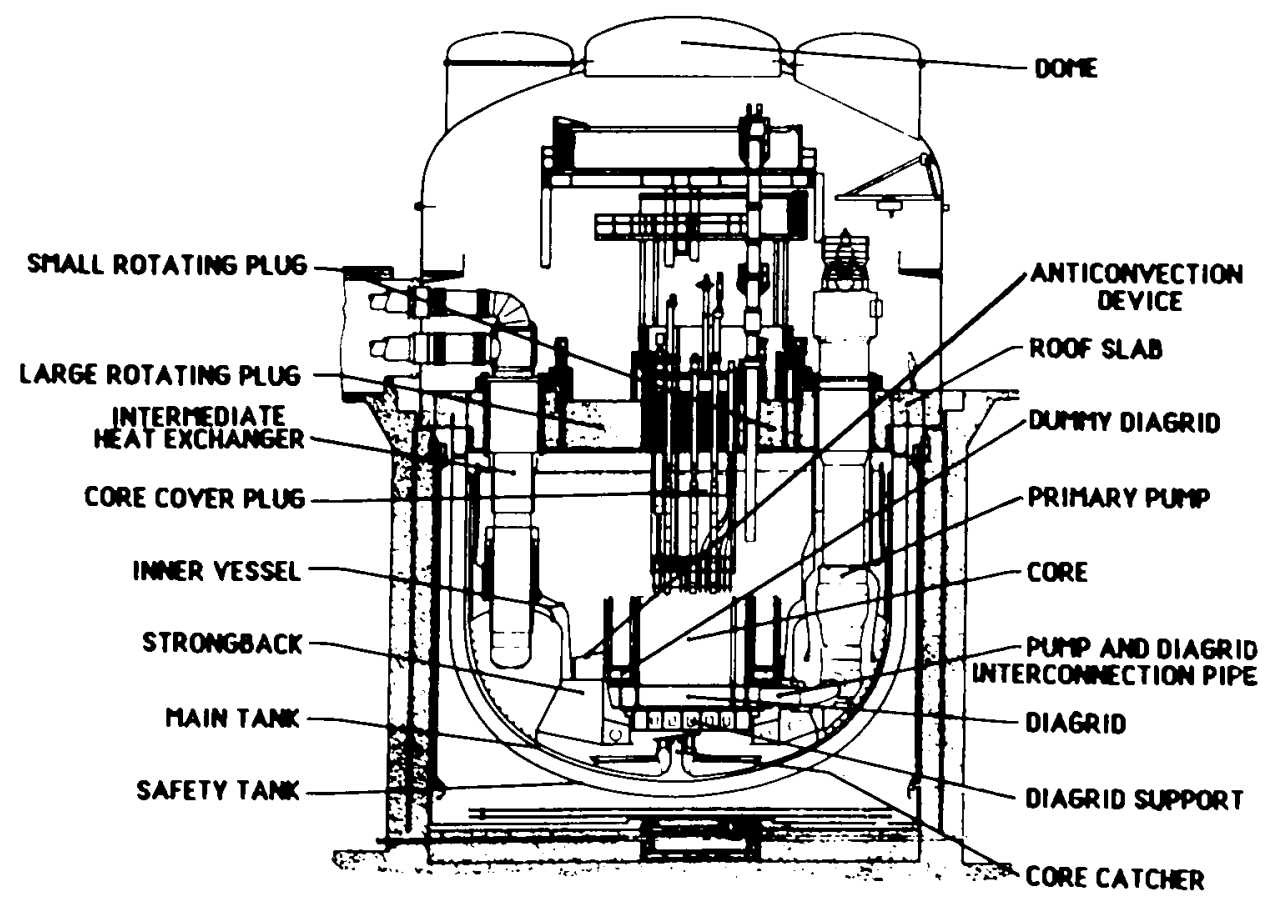

Figure 2 : SPX1 reactor block 


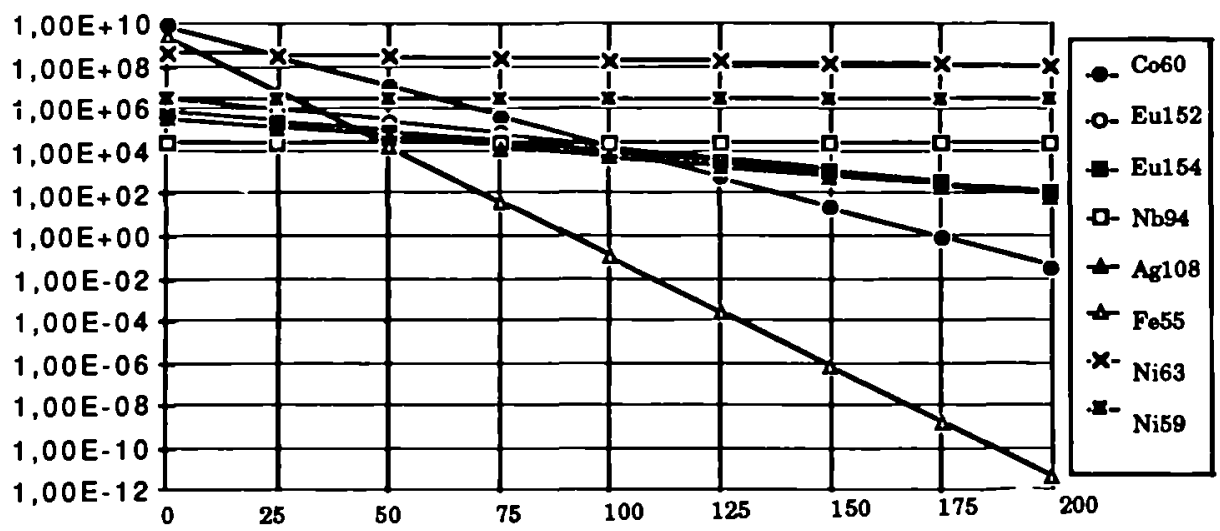

Figure 3 : Diagrid activity $\left(\mathrm{Bq} / \mathrm{cm}^{3}\right)$

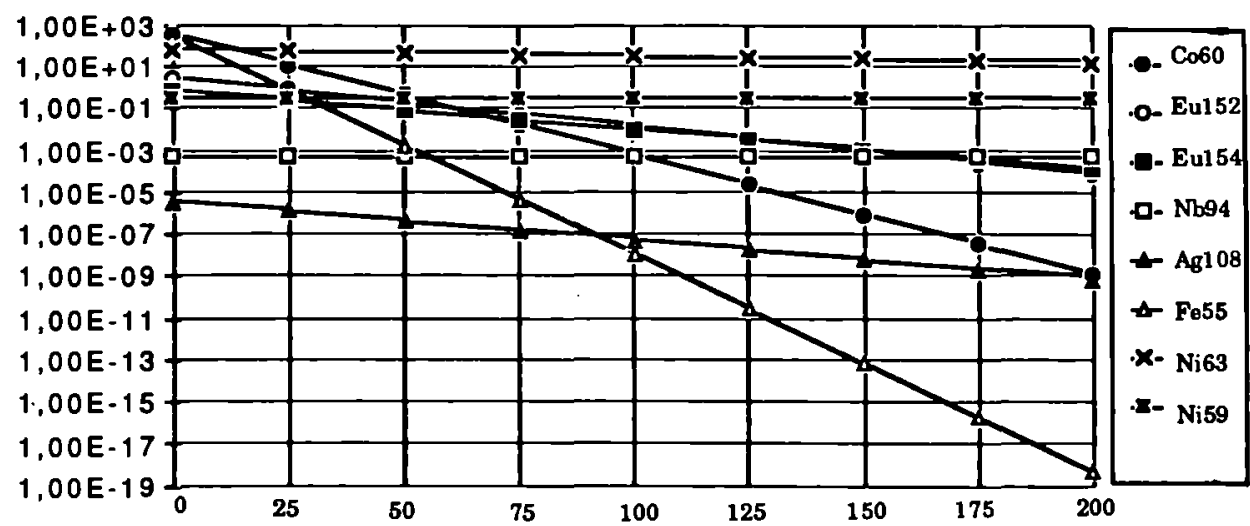

Figure 4 : Main vessel activity $\left(\mathrm{Bq} / \mathrm{cm}^{3}\right)$ 


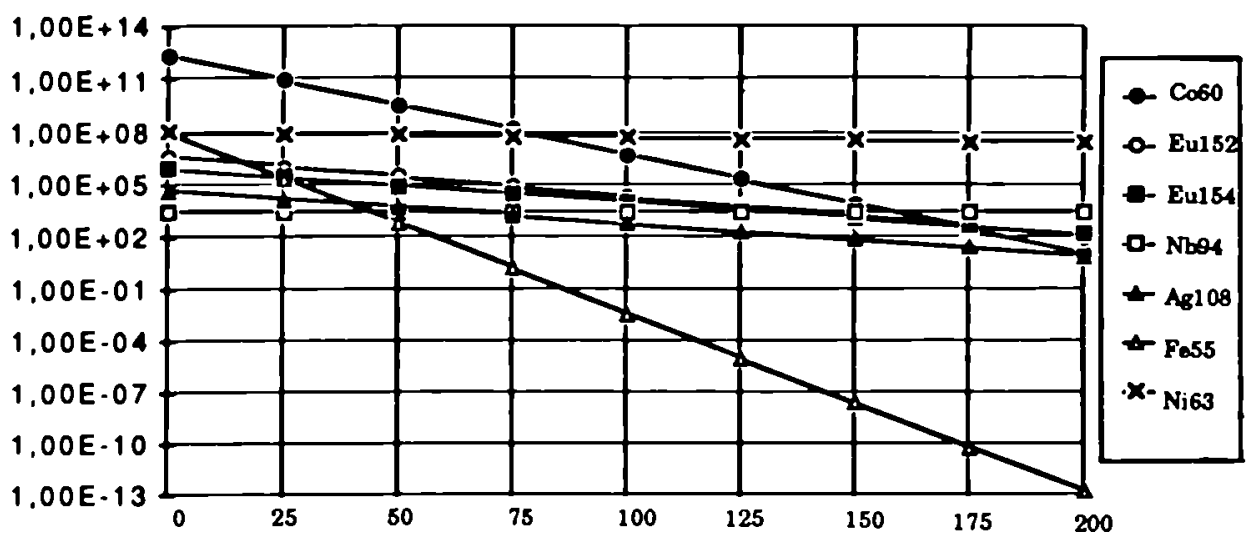

Figure 5 : Stellite activity $\left(\mathrm{Bq} / \mathrm{cm}^{3}\right)$

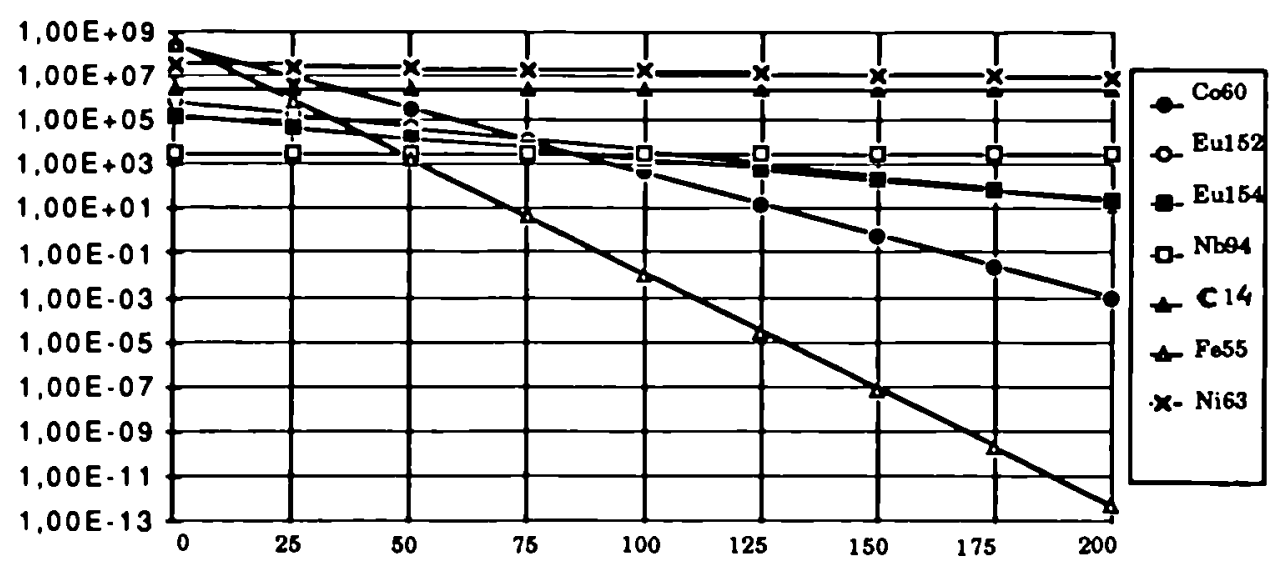

Figure 6 : Nitrure coating activity $\left(\mathrm{Bq} / \mathrm{cm}^{3}\right)$ 


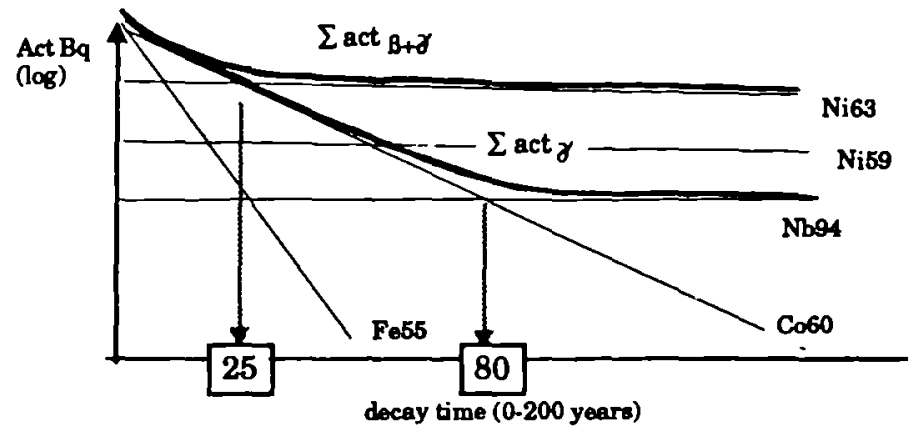

Figure $7: \sum$ act $_{\beta+\gamma}$ and $\sum$ act $_{\gamma}\left(\mathrm{Bq} / \mathrm{cm}^{3}\right)$ 
THE RACK REMOVAL SYSTEM AS A NEW DESIGN FEATURE ADOPTED TO FACILITATE DECOMISSIONING OF THE REPROCESSING PLANT. DECONTAMINATION AND REMOTE DISMANTLING TESTS IN THE ITREC PILOT PLANT.

CANDELIERI T., GERARDI A., SOFFIETTO G.

ENEA - Comitato Nazionale per la ricerca e per lo sviluppo dell'Energia Nucleare e delle Energie Alternative Rotondella (Matera), Italy

\section{ABSTRACT}

The scope of this research is to evaluate the advantages of the Rack Removal System in the dismantling of reprocessing installations. The objective of this work is to verify experimentally the possibility of the decontamination of any particular module and the capability of the remote dismantling of components installed in the mobile rack. In particular, the main objective is to develop remotely operated equipment for the dismantling of centrifugal contactors.

The equipment's decontamination, wich represents the most important preliminary phase of the decommissioning operation, allowed to obtain low level radioactivity.

A supporting program has been performed in order to define data project and design of the remote dismantling machine.

On the basis of tecnological cold test results it has been optimized the project of the dismantling machine's construction. Positive results obtained during the hot dismantling operations on the Rack 6 bis attested the effectiveness of the Rack Removal System as an original design which provides an easier decommissioning of reprocessing plants.

\section{INTRODUCTION}

The ITREC is a multipurpose pilot plant; it started in hot operation in July 1975, with the reprocessing of Elk River Reactor Th-U spent fuel elements.

The main characteristic wich differentiates the ITREC plant from other reprocessing plants is its modular units, the mobile racks, in which all equipment for the main chemical process is installed. Such an arrangement provides for the remote-controlled removal of the individual mobile units during maintenance and/or modification work. This original design of the ITREC pilot plant, based on the RACK REMOVAL SYSTEM, facilitates also the decomissioning operations.In fact this system permits the remote transfer of the process equipment, installed on the mobile rack, from the Hot Cell to the Decontamination Cell. Herein is done the internal and external decontanination of the equipent in order 
to reduce the radioactive level for a safe access of the personnel during the dismantling operations.

The aim of the present research consists in the development of remotely-operated equipment in order to dismantle the centrifugal contactors installed on the Rack 6 bis (see Fig. 1).

\section{PROGRESS AND RESULTS}

\subsection{Decontamination Operations}

The decontamination operations have involved the Rack 6 and the Rack 6 bis. These Racks, including the evaporator of the law flow and the first stage mixer-settler extraction battery, represent the most difficult section (of the ITREC plant) to decontaminate; in this occasion a total decontamination of the plant reprosessing section was also performed in order to verify the efficiency of the washing system used and the possibility of access to the Hot Cell.

The deconteminating solutions used are storaged in the High Level waste tanks of the plant until their solidification.

The need to avoid the introduction into the storage vessels of ions wich may upset the subsequent solidification-vetrification process and, still more important, the need to ensure compatibility of these solutions with plant material (AISI-304L) for a long storage, has led to the exclusion of all commercial decontaminating agents whose efficiency is based essentially on the combined action of high oxidant substances with high complexing power, which are highly corrosive.

The decontamination procedure, using firstly $\mathrm{HNO}_{3}=12 \mathrm{M}$ and successively less concentrated solutions till a final washing with demineralized water, certainly takes more time than a procedure with more active decontaminants; however, no problems about materials' compatibility and future treatment and conditioning of waste have arisen.

The evaporator and the tanks with heating jackets were decontaminated in two consecutive cycles ( $\mathrm{HNO}_{3}$ conc) maintaining the decontamination solution for $10 \mathrm{~h}$ at boiling temperature and emptying completely the tanks at every cycle: finally, a double washing with demineralized water was done.

For the decontamination of the mixer-settlers extraction battery the flowsheet of Thorex process was used, substituting, to the normal feed a $\mathrm{HNO}_{3}=6 \mathrm{M}$ solution and finally washing with the demineralized water. In the absence of in-line control the decontamination levels subsequently achieved were checked by sampling in the H.L.w. accountability tank (1AW flow); the gross gamma are shown in Tab. 1.

The dose values found in plug rooms of Rack $N^{0} 6$ were sufficiently low to enable the disconnection of the rack and its transfer to the Decontamination Cell.

Decontamination of the mixer-settlers battery and of Rack N.6 was completed in the Decontamination Cell by successive washing with: $\mathrm{Na}_{2} \mathrm{CO}_{3}$ at 20\%; $\operatorname{COO}\left(\mathrm{NH}_{4}\right)_{2}=0,3 \mathrm{M}+\mathrm{EDTA}=0,18 \mathrm{M}$; $\mathrm{HNO}_{3}=6 \mathrm{M}$, using for every washing 1001 . 4 of solution introduced in the first stage of the battery 
and subsequently in the other equipment.

At the final stage all equipment has been first flushed with denineralized water $(50 \mathrm{~h})$ to eliminate acidity in the piping and then flushed with steam and air to dry it.

Finally the rack was spray-washed externally with demineralized water within the Decontamination Cell.

\section{Decontamination Procedures}

\section{Decontamination Procedure of Rack No. 6 in Hot Cell}

Vessels with heating system (Evaporator, etc.):

- Vessels filling - at operative volume - with $\mathrm{HNO}_{3}$ 12M

- Heating at bolling point for $10 \mathrm{~h}$.

- Total emptying of solution

- Repeat the above three operations

- Two washings with demineralized water (vessels filling at operative volume)

After these operations the radioactivity concentration is $\leqslant 10^{-3}$ MBq/l (verified by sampling and analysis).

Vessels without heating system:

- Vessels filling - at operative volume - with $\mathrm{HNO}_{3} \quad 12 \mathrm{M}$

- Homogenizing for $1 \mathrm{~h}$.

- Total emptying of solution

- Repeat the operations N.1, N.2 and N.3

After these operations the radioactivity concentration is $\leqslant 10^{-3}$

$M B q / 1$ (verified by sampling and analysis).

Connection pipes:

- All connection pipes are decontaminated by flushing the decontaminating solutions during its transfer between two vessels and maintaining the steam flow for more 10 minutes.

Mixer-Settlers Battery:

- The decontanination of the mixer-settlers battery is done by feeding for 50 hours the normal flow sheet solutions with exception of the $1 \mathrm{AF}$ stream which is substituted by $\mathrm{HNO}_{3}=6 \mathrm{M}$ solution.

- The decontamination level is verified by analyzing samples of the effluent collected in the vessel.

- The final value reached in the $1 \mathrm{Aw}$ collecting vessel is $10 \mathrm{MBq} / 1$.

Transfer Operation of the Racks from Hot Cell to the Decontamination Cell

- Complete empting of the equipment and pipes

- Internal washing, when possible, of the equipment and pipes

- External washing of the terminal boxes, connectors and metal surfaces 
inside the double wall

- Disconnecting the pipe connectors on the three terminal boxes

- Releasing the lock wich fastens the rack to the first steel wall

- Traversing the truck to the rack loading position

- Moving the rack from its working position onto the truck

- Moving the truck to the door leading from the hot cell to the decontamination cell

- Transferring the rack from the truck to the interior of the decontamination cell

- External decontamination of the rack and internal decontamination of the chemical equipment, pipes and accessories by suitable decontaminating solutions

- Transfer of the decontaninated rack from the decontamination cells to the corridor area through the ceiling trap door.

Decontamination Procedure of Mixer-Settlers Battery in Decontamination Cell

- The radiation exposure level was measured in different points of the Rack. The maximum value noticed was about $4.10 \mathrm{mC} / \mathrm{kgh}(16 \mathrm{R} / \mathrm{h})$.

- The decontamination of mixer-settlers battery has been completed in the decontamination cell by further washings with 1001 . each of the following solutions:

$$
\begin{aligned}
& \text { lst }-\mathrm{Na}_{2} \mathrm{CO}_{3} \text { at } 20 \% \\
& \text { 2nd }-\mathrm{COO}\left(\mathrm{NH}_{4}\right)_{2}=0,3 \mathrm{M}+\mathrm{EDTA}=0,18 \mathrm{M} \\
& \text { 3rd }-\mathrm{HNO}_{3}=6 \mathrm{M}
\end{aligned}
$$

- Final washing for a time of $50 \mathrm{~h}$. with the 2001 . total volume of demineralized water.

- Flushing by steam and air.

- Remote external washing by $\mathrm{HNO}_{3} \mathrm{O}, 1 \mathrm{M}$ solution (300 1.).

- After these washing operations the maximum value of radiation exposure was $1.03 \mathrm{mC} / \mathrm{kgh}(4 \mathrm{R} / \mathrm{h})$.

Decontamination Procedure of the Rack 6 bis

The Rack N. 6 bis, equipped with the centrifugal contactors (1st cycle) extraction battery has been utilized for a preliminary nuclear hot tests.

In order to perform the remote dismantling tests on the Rack 6 bis, it has been decontaminated with the same modes utilized for the Rack No. 6 as previously described. 
After the cycles of internal and external decontanination the radioactivity level surveyed was not superior to $2,5, \mathrm{uC} / \mathrm{Kgh}$. Data vere reported in Tab. 2 with reference points in Fig. 1.

The Rack 6 bis was disconnected from the three plugs and transferred to the Decontanination Cell by the Rack Rewoval System.

\subsection{Design and construction of cutting equipment for dismantling the centrifugal contactors}

The preliminary design of the cutting equipment for dismantling the centrifugal contactor has been conceived taking in account the following constraints :

- clearance of the plant (ceiling trap door)

- layout of the Rack 6 bis

- facilities installed into the cell.

The main feature of the dismantling machine was to remotely operate for cutting connection tubes of the centrifugal contactor and to unscrew the two anchor bolts.

The remotely removal of the centrifugal contactor was done by a special grapple purposely designed and moved by the 10 ton bridge crane installed in the upper area (corridor) of the cell moved through the ceilling trap door.

In the preliminary R\&D design was adopted the rotary disk cutter system but its negative laboratory's test results suggested the opportunity to substitute it with shear techniques. The main reasons for having chosen this technique were:

- the restricted clearance avallable near the contactor prevented the access of the rotary cutting tools,

- the significant formation and spread of radioactive swarfs during the sawing operation;

The machine final design is equipped with a control consolle (master) (Fig.2) and a cutting operative unit (slave) (Fig. 3).

The dismantling machine has been conceived to operate inside the decontanination cell of the ITREC Plant behind walls using shielding window. mechanical manipulators and close circuit television to visualize the processing procedures.

The main 1 tems of the dismantling device equipment are indicated as followa:

- Frame structure along with the guiding rail supporting the cutting operative unit (3) wich is moved to face each of the 16 centrifugal contactorg installed on the Rack 6 bis.

- Cutting operative unit (Fig. 3) constituted by:

hydraulic pistons driving horizontally and vertically the shears;

-pneumatic screwers for bolts removing;

-electrical motor reducer for cutting unit motion on the rail;

-electrical motor reducer for vertical adjustment of the shears and 8crewers:

-compressed air buffer tank for shear force regulation;

-CCTV cameras. 
The cutting unit is remotely operated by a control consolle located outside the decontamination cell close to the shielded window through wich the operators follow directly the work (Fig. 2).

Television is used as an auxiliary viewing system to help performance handling tasks in hard-to-see places. The television system consists of two cameras with zoom installed on the dismantling device and monitor located on the control consolle. With this system, the capability is available for doing close alignments work as well as general surveillance.

\section{Remote dismantling operation}

As a conseguence of the highest radioactive level checked on the centrifugal contactor No. 6 (ref. point 14 - Fig.1-Tab. 2) it was decided its removal.

Following is described the removal operative sequence:

- Transferring the dismantling machine from the corridor to the decontamination cell. Facing and alignement with Rack 6 bis has assured with interconnecting clamps and mechanical safety interlocks.

- Supplying the electric and pneumatic service line. Control board's instrumentation is now actuated.

- Positioning of the operative unit in front of the Centrifugal contactor No. 6. The two electric drives provide its motion; encoders display assures correct position coordinates of the shears according to the runway indicated in the following sketch. CCTV monitors permit to follow the approach and successive operational sequence.

- Cutting of the connection's tube in accordance with operative procedures worked out during the previous cold tests. Oil pressure changing also confirms that the cutting action has been completed.

- Grappling of the centrifugal contactor prong (a specific pneumatic grapple has been designed and constructed for this handling operation, see Fig. 5).

- Positioning of the operative unit for anchor bolts unscrewing operation.

- Operating the pneumatic unscrewer and removing the two anchor bolts (Fig. 5).

- Lifting the removed component from the shaft coupling system (Fig. 6).

- Transfer the removed component into the shielding container (Fig. 7).

- Transfer the shielding container to the waste area of the ITREC Plant for eventual storage.

\section{CONCLUSIONS}

The main purpose of the present research is to demonstrate how the project philosophy of a nuclear reprocessing plant, based on the Rack Removal System, can facilitate final decommissioning operations.

A further contribute to facilitate the plant decommissioning is certainly due to and adequate engineering solution of connection tubes outline among the installed equipments on each mobile unit (racks). 


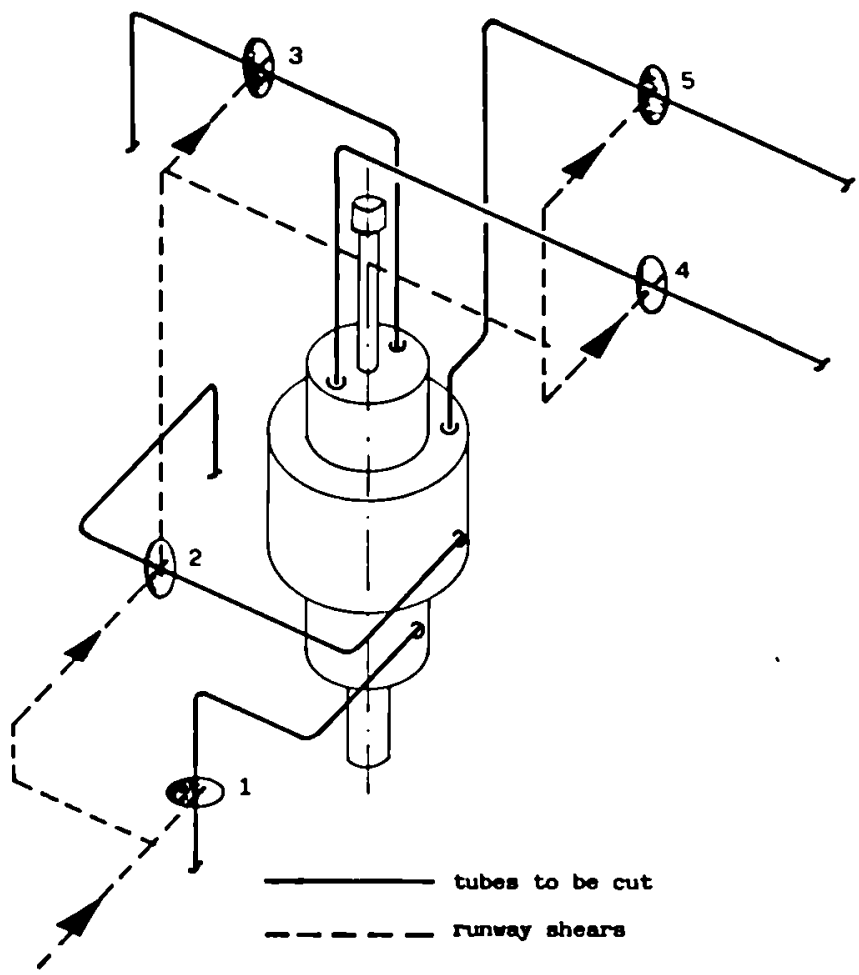

The Rack 6 bis, on which were carried out the remote dismantling tests, has been realized on the basis of these two design criteria.

The experimental results obtained by these tests confirm aubstantially the objectives of the present research program.

Furthermore the results demonstrate the remote dismantling feasibility of plant equipment previously arranged according to the above mentioned criteria. In fact in the reprocessing plants some components (as axer-settlers battery) due to their complex geometry are not easy to decontaminate and therefore represent a source of radioactivity irradiation.

The possibility of the remote removal of these components facilitates the final decomissioning operations reducing the man-rem dose at reasonable costs.

In this research progran dismantling operations were carried out by echanical cutting techniques (shears) but other cutting techniques could be adopted (rotary disk cutter, plasma arc, laser) wen these will have reached adeguate reliability in decomissioning application.

The ultimate goal of the R\&D in decommissioning is to produce an integral system constituted by advanced teleoperated robots associated with one of the cutting techniques above mentioned. 
Tab. 1 EXPOSURE INTENSITY OF RACK 6 bis IN THE DECONTAMINATION CELL

\begin{tabular}{|c|c|c|c|c|c|c|c|c|c|c|}
\hline \multirow[t]{2}{*}{$\begin{array}{c}\text { Reference } \\
\text { point }\end{array}$} & \multicolumn{2}{|c|}{$\begin{array}{l}\text { Ist measurement after } \\
\text { removal in the } \\
\text { decontamination cell }\end{array}$} & \multicolumn{2}{|c|}{$\begin{array}{l}\text { 2nd measurement after } \\
\text { washing with } \\
\mathrm{Na}_{2} \mathrm{CO}_{3} 20 \%\end{array}$} & \multicolumn{2}{|c|}{$\begin{array}{l}\text { 3rd measurement after } \\
\text { washing with } \\
\mathrm{COO}\left(\mathrm{NH}_{4}\right)_{2}+\mathrm{EDTA}\end{array}$} & \multicolumn{2}{|c|}{$\begin{array}{l}\text { 4th measurement after } \\
\text { washing with } H N Q_{B} 6 M \\
\text { and demineralized water } \\
\end{array}$} & \multicolumn{2}{|c|}{$\begin{array}{l}\text { 5th measurement after } \\
\text { external washing } \\
\text { and air drying }\end{array}$} \\
\hline & $\begin{array}{c}\text { Extemal side } \\
\text { (uC/Kgh) }\end{array}$ & $\begin{array}{c}\text { Internal side } \\
(\omega \mathrm{C} / \mathrm{Kgh})\end{array}$ & $\begin{array}{c}\text { Extemal side } \\
(\mu \mathrm{C} / \mathrm{Kgh})\end{array}$ & $\begin{array}{c}\text { Intemal side } \\
\text { (uC/Kgh) }\end{array}$ & $\begin{array}{c}\text { External side } \\
(\mathrm{uC} / \mathrm{Kgh})\end{array}$ & $\begin{array}{c}\text { Internal side } \\
(\mathrm{\omega} / \mathrm{Kgh})\end{array}$ & $\begin{array}{c}\text { Extemal side } \\
(\mathrm{uC} / \mathrm{Kgh})\end{array}$ & $\begin{array}{l}\text { Internal side } \\
(\mu \mathrm{C} / \mathrm{Kgh})\end{array}$ & \begin{tabular}{|c|} 
Extemal side \\
$(\omega \mathrm{C} / \mathrm{Kgh})$
\end{tabular} & $\begin{array}{l}\text { Internal side } \\
(\mu \mathrm{C} / \mathrm{Kgh})\end{array}$ \\
\hline 1 & 1.6 & 1.5 & 0.8 & 0.9 & 0.4 & 0.6 & 0.13 & 0.51 & 0.12 & 0.41 \\
\hline 2 & 23.5 & 26.4 & 18.72 & 19.2 & 9.8 & 10.3 & 2.06 & 2.6 & 1.6 & 2.16 \\
\hline 3 & 3.9 & 2.7 & 1.5 & 1.05 & 1.3 & 0.51 & 0.9 & 0.4 & 0.6 & 0.4 \\
\hline 4 & 3.9 & 4.42 & 1.82 & 3.12 & 0.9 & 1.3 & 0.51 & 0.51 & 0.41 & 0.25 \\
\hline 5 & 3.12 & 2.5 & 1.5 & 2.06 & 1.23 & 0.51 & 0.4 & 0.51 & 0.3 & 0.42 \\
\hline 6 & 9.05 & 9.80 & 3.9 & 3.4 & 2.6 & 2.6 & 2.06 & 2.06 & 1.3 & 1.3 \\
\hline 7 & 9.4 & 12.1 & 3.12 & 3.12 & 2.06 & 2.20 & 2.06 & 1.82 & 1.82 & 1.3 \\
\hline 8 & 10.7 & 11.1 & 7.6 & 8.2 & 4.7 & 5.0 & 1.3 & 1.5 & 1.3 & 1.5 \\
\hline $\mathbf{9}$ & 5.4 & 3.35 & 4.42 & 2.7 & 2.75 & 2.2 & 0.6 & 0.6 & 0.6 & 0.6 \\
\hline 10 & 3.0 & 3.4 & 2.06 & 2.01 & 1.0 & 0.6 & 0.25 & 0.5 & 0.25 & 0.5 \\
\hline 11 & 3.0 & 3.10 & 1.82 & 2.25 & 0.9 & 0.95 & 0.25 & 0.25 & 0.15 & 0.25 \\
\hline 12 & 2.8 & 2.7 & 1.7 & 1.6 & 1.4 & 1.20 & 0.25 & 0.15 & 0.25 & 0.15 \\
\hline 13 & 2.7 & 2.8 & 2.09 & 2.09 & 1.22 & 1.21 & 0.18 & 0.15 & 0.15 & 0.15 \\
\hline 14 & 24.2 & 31.3 & 9.2 & 21.5 & 6.7 & 9.7 & 2.3 & 2.6 & 2.11 & 2.5 \\
\hline 15 & 2.7 & 2.6 & 2.09 & 2.02 & 1.19 & 1.20 & 0.6 & 0.4 & 0.4 & 0.25 \\
\hline 16 & 2.6 & 2.8 & 2.05 & 2.01 & 0.7 & 1.10 & 0.6 & 0.15 & 0.4 & 0.15 \\
\hline
\end{tabular}




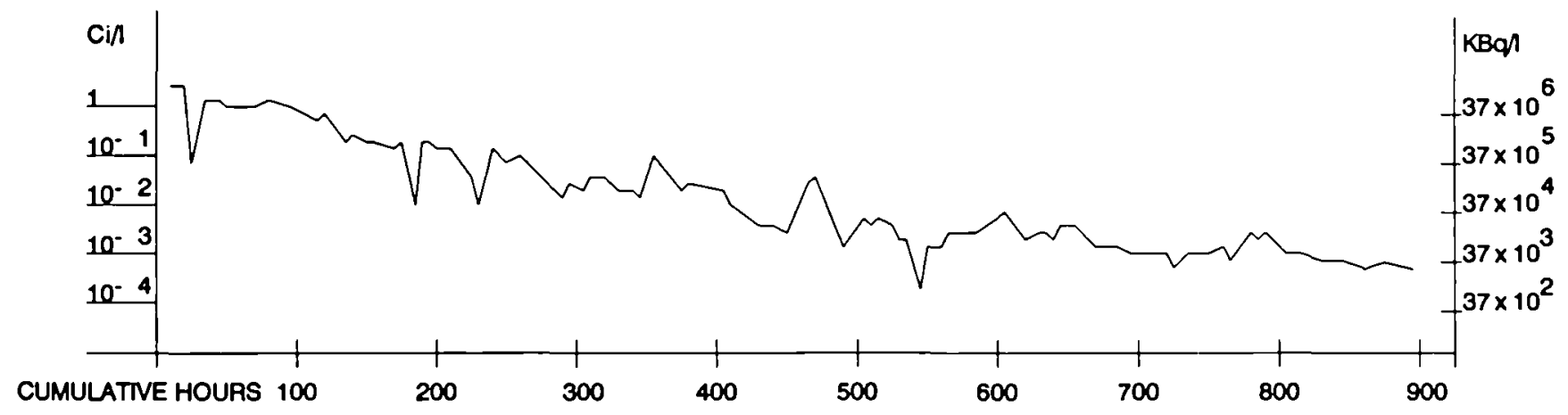

Tab. 2 Gross $Y$ values in 1AW flow during washing in decontamination operation 


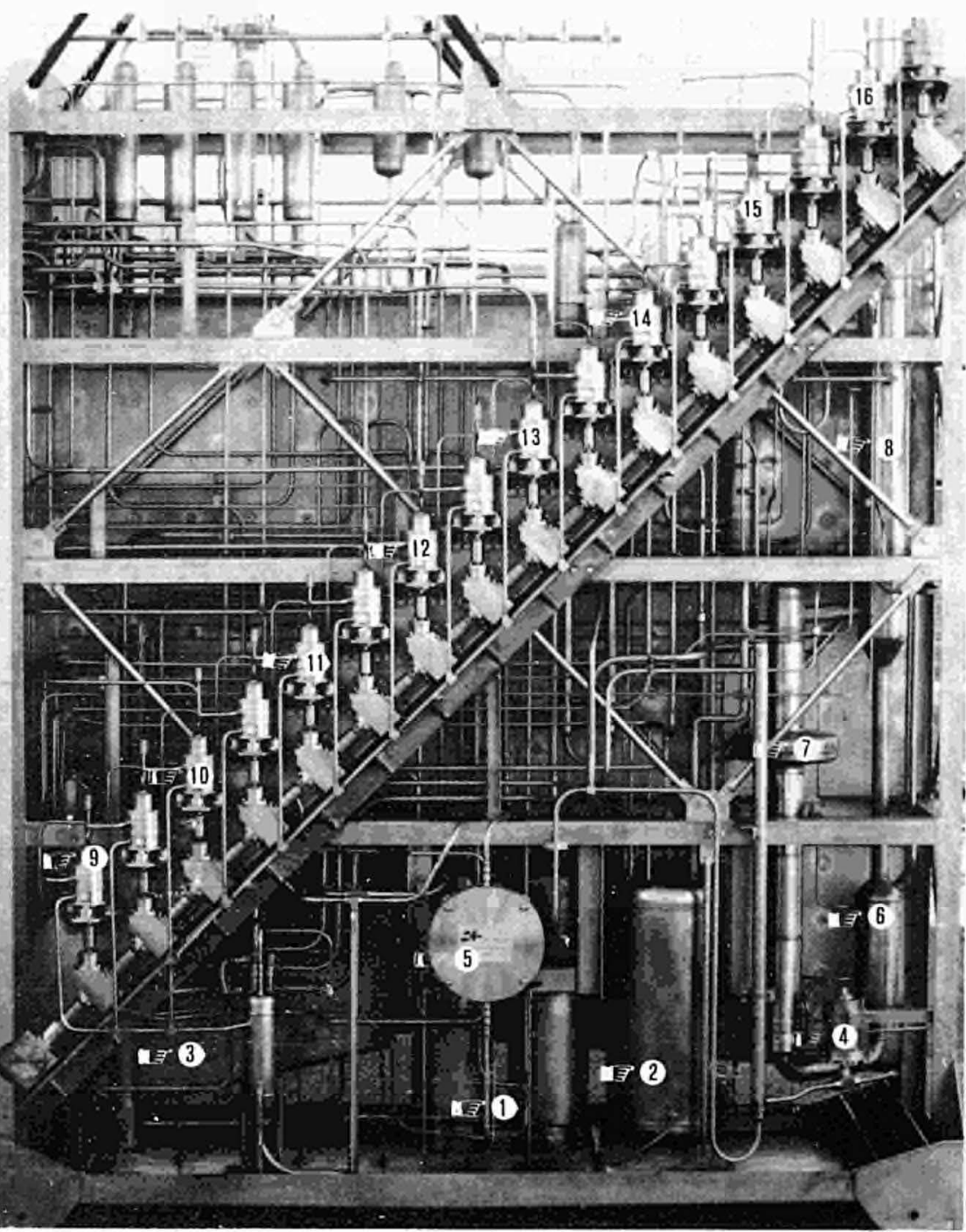

Fig. 1. Rack 6 bis - Measuring points radiation exposure intensity 


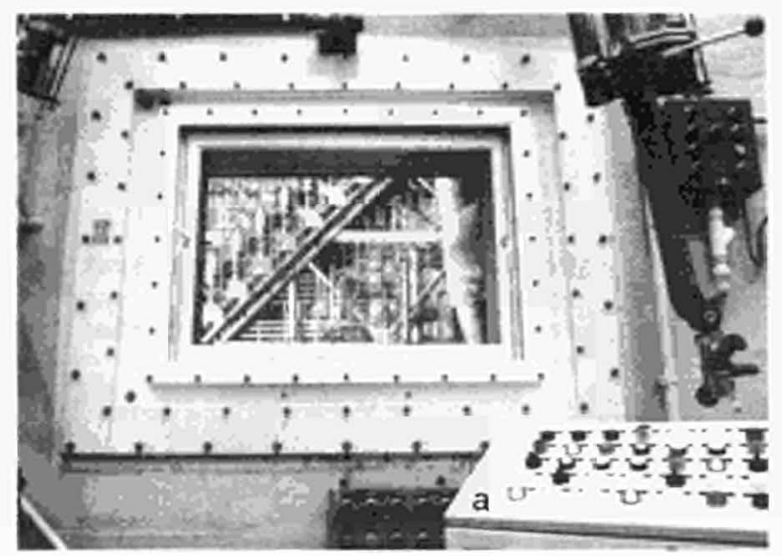

Fig. 2 .

Operative area of the

decontamination cell where with the control console (a) the dismantling operation on the rack 6 bis, visible through the shielding window, is being carried out

Fig. 3.

Operative unit of the dismantling device. Visible are the shears (b); the anchor bolt unscrewers (0); the upper TV camera
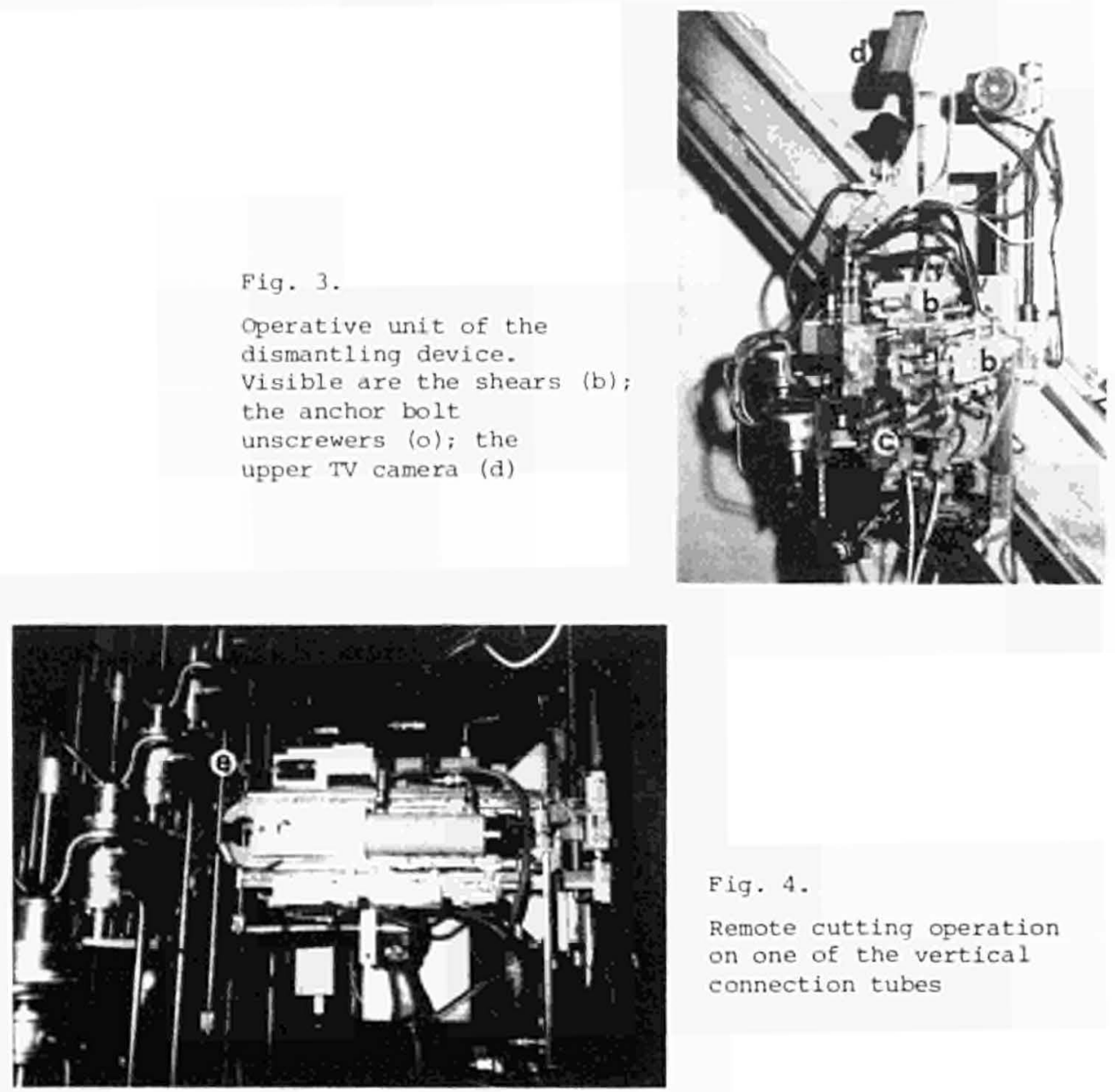

Fig. 4 .

Remote cutting operation on one of the vertical connection tubes 


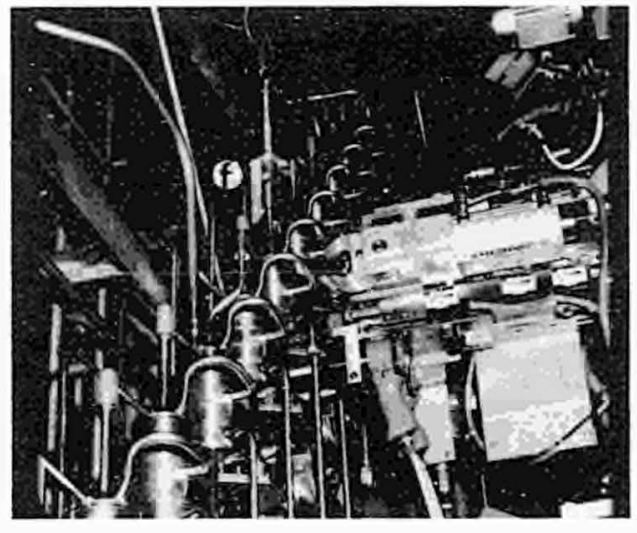

Fig. 5.

Unscrewing anchor bolts operation - the grapple (f) is positioned for grasping the prong of the centrifugal contactors

Fig. 6.

Lifting of the centrifugal contactors from the shaft coupling system

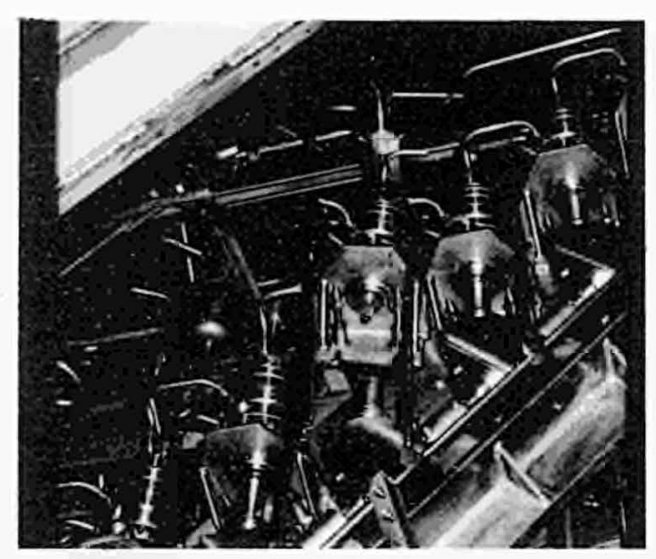

Fig. 7.

Transfer of the removed component into the shielding container 


\title{
DESIGN FEATURES ADOPTED TO FACILITATE DECOMMISSIONING
}

\author{
DUBOURG $M$. \\ Framatome, Paris la Défense, France
}

\begin{abstract}
By analyzing the design of both 900,1300 MWe and future 1450 MWe PWR units, it appears that the design improvements taken into account for reducing occupational dose exposure of maintenance personnel and the development of automated tools for performing maintenance and repairs of major components, contribute to facilitate future dismantling and decommissionning operations.
\end{abstract}

\section{EVALUATION OF ACTIVITY AND RADWASTE VOLUMES}

Several evaluations of activity and radwaste volume have been made for 1 ight water reactors. For a 1300 MWe PWR the total activity at the end of its operational life is about 4 millions curies and mainly due to the Cobalt 60 activity.

$90 x$ of this total amount is localized in the metallic structures surrounding the core (core baffles or core shroud).

After 40 years of cooling period the total activity decreases down to 300.000 curies due to the decrease of Cobalt 60. (See figure 1).

However other radionucleides such as $\mathrm{Ni} 63,92$ years of half-life, $\mathrm{Nb} 94,20.000$ years of half-life, and $\mathrm{Ni} 59,80.000$ years of half-life tend to level the remaining activity in the highly irradiated structures of reactors internals made of austenitic stainless steel.

The table I gives a typical breakdown of volumes of irradiated metallic wastes for a BWR and a PWR and shows the favourable position of PWR's compared to BWR's and their relative evolution versus the cooling time after plant shutdown.

The total amount of contaminated structures including concrete of a PWR is estimated to 14,000 tons, the total amount on which 6,000 tons could be recovered of an unrestricted release after decontamination.

\section{DESIGN FEATURES TO FACILITATE DECOMMISSIONING}

The examples given in this paper, illustrate the type of work and the features taken at the design stage which could facilitate the future dismantling operations of nuclear power plants.

More generally speaking, we believe that critical analysis and improvements in operating and maintenance conditions contribute to reduce difficulties of future dismantling operations.

\subsection{Reducing Activity}

The overall activity at the time of dismantling results essentially from the activation of irradiated structures during reactor operation and from the deposition of activated cruds on the internal surfaces of plant components at the end of the plant life. 
In order to reduce such activation and contamination a strict control of materials submitted to neutron flux is performed and residual elements such as Cobalt 59 or other tracing long 1 ife radioelements are strictly limited.

Cobalt 59 content is restricted as follows :

- Reactor vessel shell base material

- Reactor vessel stainless steel cladding

- Reactor internals material

- Steam generator Inconel 600 tube bundle mat. : $s .10 \%$

- Steam generator Inconel 690 tube bundle mat. : s .035 $z$

+ N4 plant ( 1400 MWe)

For the manufacturing of reactor internals, stabilized stainless steel materials which contain tracing elements such as Niobium, the irradiation of which produces long lived radioelements are strictly prohibited.

Figure 2 shows the activation of reactor internals core baffle and the major contribution of Cobalt and Nickel in the short term range.

On long term, see figure 3, the major contribution is due to $X$ emitters such as $\mathrm{Ni} 59$ but also to $\gamma$ emitters such as $\mathrm{Nb} 94$ which is a tracing element in the stainless steel.

In fuel assemblies, Cobalt 58 ( 71 days of half-1ive) is produced by activation of Inconel grids. In the FRAMATOME developed Advanced Fuel Assemblies AFA, Inconel grids are replaced by Zircaloy grids with Inconel clip springs. Activity calculations show potential reductions of dose field about $30 \%$.

In addition, investigations are underway to find an alternative to stellite (55-60 $\mathrm{z}$ Cobalt) in valve parts directly in contact with the primary coolant.

In particular, studies and tests are being carried out on the use of Nickel base alloys such as Colmonoy (77 z Ni, 11,5 z Cr) or AISI $440 \mathrm{C}$ martensitic stainless steel and Cobalt free thin hard faced coating of critical components, such as Control Rod Drive Mechanism grippers and cves valves.

\subsection{Practical measures and decontamination}

Some practical measures have been taken at the design stage and during operation for minimizing the residual contamination of surfaces : These measures include :

- Primary coolant coordonate B/Li chemistry.

- Specifications for surface conditions of steam generator materials and mainly the electropolishing of steam generator channel heads. Dose field reduction of 4 could be obtained on the contamination of channel heads by major radionucleides after electropolishing.

- Large purification flow capability during plant shutdown for entrapping activity.

- Periodical decontamination of steam generator channel heads or isolated components to facilitate inspection and maintenance work.

Dilute chemical decontamination processes with the regeneration of reagents on ion exchange resins are widely used for the steam generator replacement on PWR's or for the replacement or the repair of recirculation piping on BWR's.

Two major processes are in competition : the AECL CANDECON and the CEGB LOMI process with their respective advantages and inconvenients.

With its mobile decontamination unit mounted on mobile trailers, FRAMATOME in 1986 performed the decontamination of the replaced recirculation loops of Muhleberg and an equivalent of 200 to 250 man rem was 
saved by the personnel involved in the replacement and dismantling of the two recirculation loops of the Muhleberg plant (see photograph).

\subsection{Large component replacement}

The possible replacement of large components such as steam generators, reactor primary coolant pumps and all the main components are taken into account at the design stage.

In the past, the removal of large irradiated stainless steel components such as reactor neutron thermal shield was carried out on the first generation of commercial PWR ie : the CHOOZ and TRINO reactors ( 300 MWe) at their beginning of their operating 1 ife, or the NOVOVORONEJH unit 1 (russian PWR of 210 MWe) at the end of its operating 1 ife.

Development of underwater segmenting techniques based on electroerosion was carried out for such purpose of TS removal.

More recently the development of all the necessary tooling and procedures was performed for the removal of corrosion damaged steam generators of PWR plant.

In Europe the lst operation was carried out at the OBRIGHEIM PWR plant in Federal Republic of Germany.

From our side FRAMATOME has made a large extensive research program including development of decontamination process and the construction and full scale testing of automated tooling.

The development program includes the following technical subjects:

- Soft chemical decontamination process of the lower part of the steam generator to be replaced and the associated portions of primary pipings.

- Proper selection of a primary piping sectioning technique based on a thermal process (Plasma) or on a mechanical cutting process. device.

- Bevelling of the primary piping by using a single point machining

- Automatic welding process with video follow up of the welding junction between the new steam generator and the existing primary piping.

In addition to the technical research and demonstration, operational research is also performed in order to reduce man rem exposure and to shorten the execution time of steam generator replacement.

\subsection{Plant lay-out design}

Several features of the plant lay-out design have been defined to facilitate plant operation and consequently plant dismanting, these features include :

- Isolation between active and non active areas in nuclear buildings where active and non active zones are existing.

- Shortening of the piping lay-out of primary and auxillary systems of the 1300 MWe plant. In addition some efforts were devoted for minimizing the number of valves.

- Erection of monorails and hoists for facilitating the replacement of components such as the RHR pump motors, or heavy valves or man hole covers of steam generators.

- Collection of the floor drains has been carefully review for avoiding stagnation or spillage of active waters.

- Implementation of a neutronic protection liner of the reactor vessel concrete well for 1 imiting and reducing the activation of concrete and iron structures.

This modification has been included in the new $\mathrm{N}_{4}$ type reactor design ( 1400 MWe). 


\subsection{Updating of documentation}

The dismantling of active areas of a nuclear power plant must lead to a minimal collective exposure dose for the operating personnel. For carefully planning, the work in hostile environment, it is absolutely necessary to collect and to update all information related to the plant design (drawings, material specifications, various modification and implementation ...) and also information related to the plant operating performance during the plant life.

The development of computerized data based techniques can solve the problem of keeping and updating all necessary information for performing dismantling and decommissioning.

\section{CONCLUSIONS}

The experience gained by NSSS vendors over the past 25 years in the design and construction of 1 ight water reactors combined with the expertise gained by the personnel involved in the design of the first nuclear power plants have contributed to develop skills, equipments and capabilities for complete or partial dismantling shutdown.

The choice of materials having low content of tracing materials such as : Cobalt, Niobium are of a prime importance for the design of structures submitted to neutron fluxes or in close contact with the primary coolant such as steam generator tube bundle.

It seems however that additional efforts have to be devoted for improving the cost of dismantling operations and also for minimizing the volumes of radwastes arising from decommissioning.

In that respect, the waste volume reduction technologies such as : incineration, calcination, encapsulation combined with the retrieval of materials and the recycling of contaminated components for a possible re-use in the nuclear industry are of major interest.

In fact the retrieval of high valuable materials and the recycling of large contaminated equipment using appropriate decontamination and segmentation techniques could solve the problem of radwaste storage generated by dismantling operations.

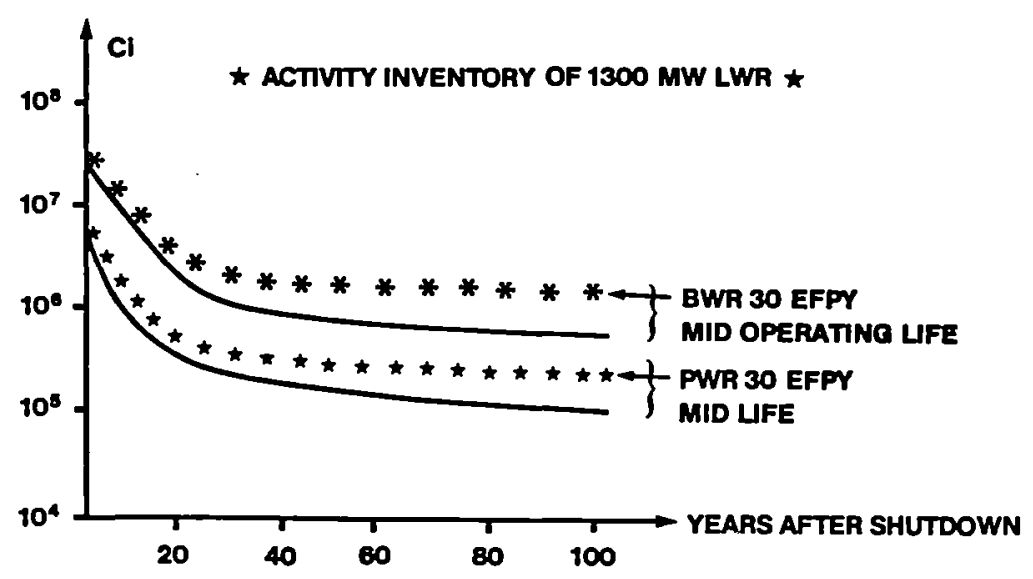

Figure 1 


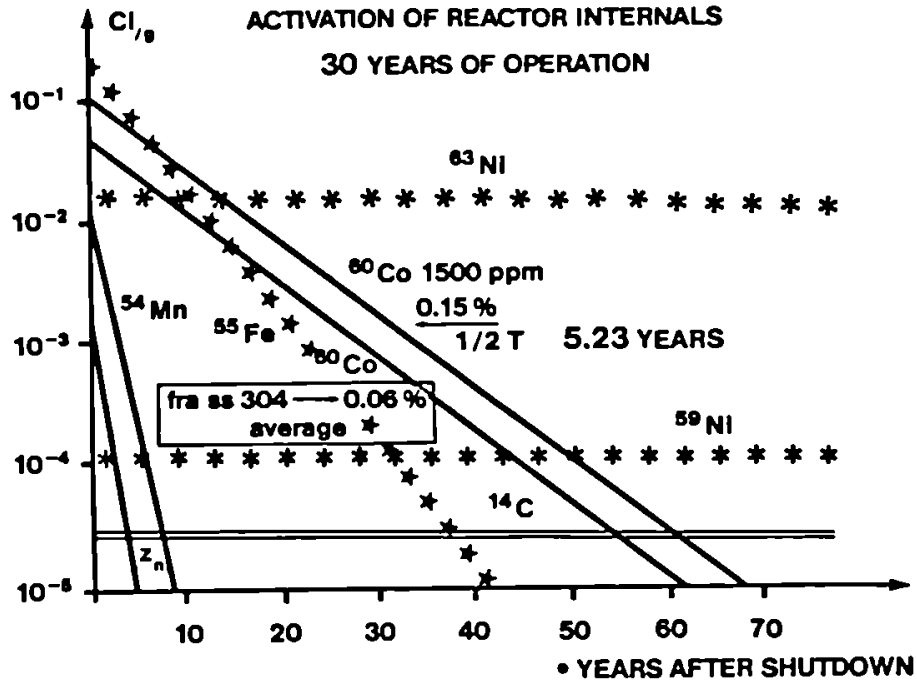

Figure 2

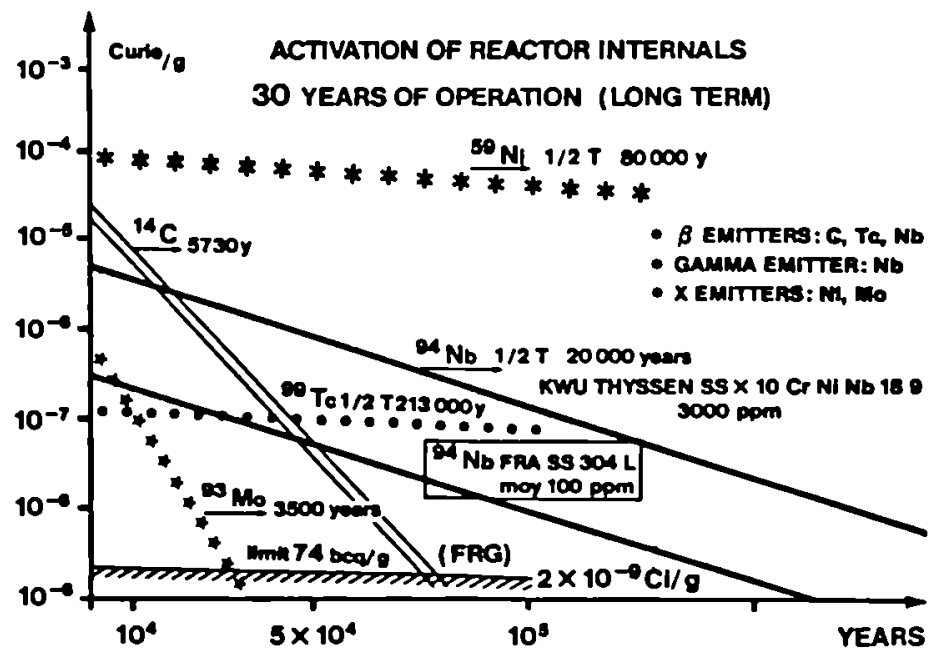

Figure 3 


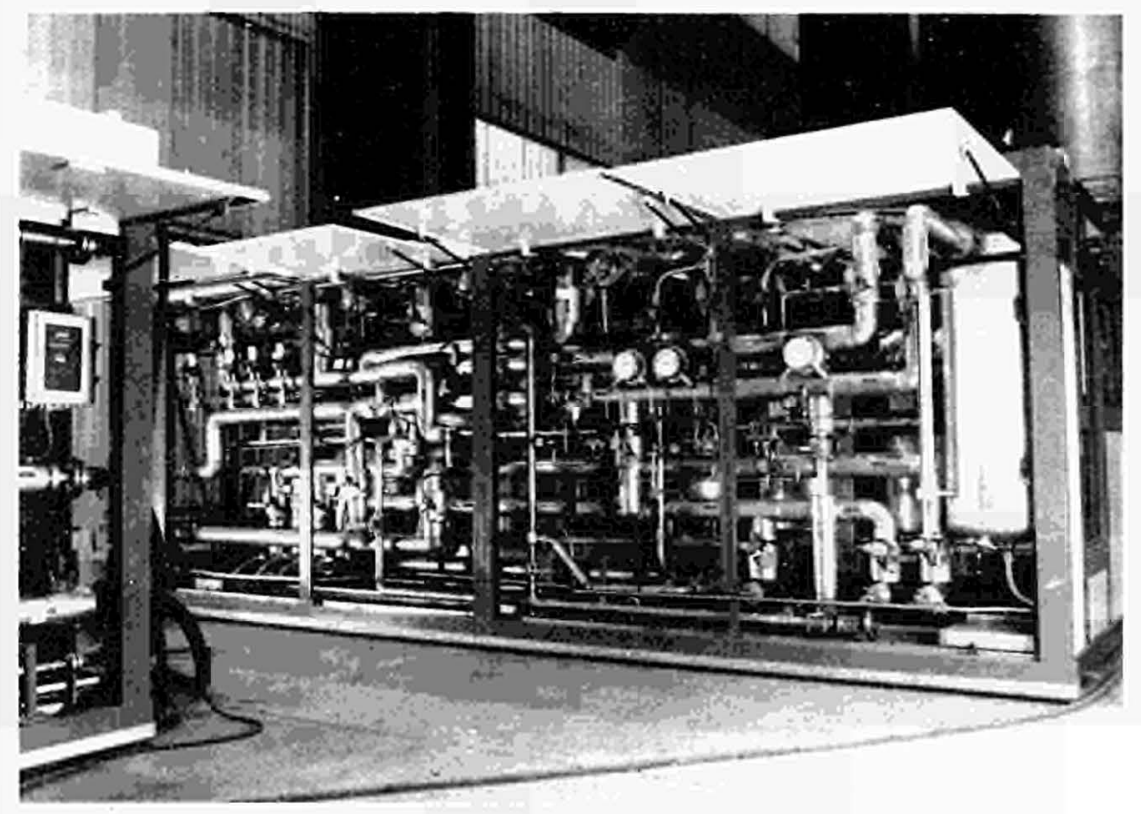

Figure 4. Decontamination skid

TYPICAL BREAKDOWN OF LWR METALLIC WASTES

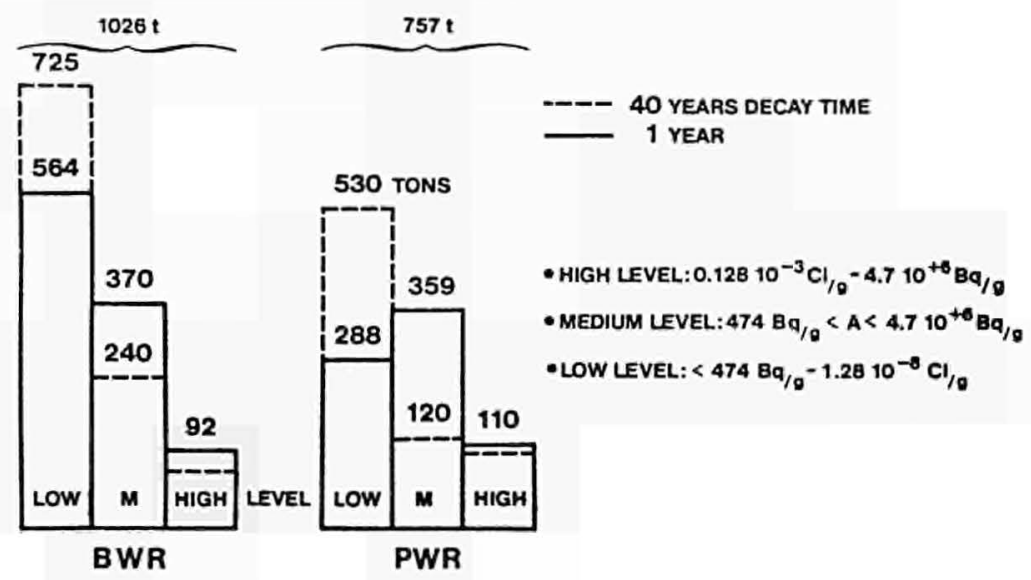

Table I 


\section{DISCUSSION}

Question: F MOTTE, SCK/CEN Mol - Cobalt is also present as a trace element associated to nickel and, therefore, the erosion-corrosion products of the whole primary loop contain Co-60, even in the absence of the cobalt alloys. My question is: in a commercial PWR, what is the relative importance of these two sources of co-60: cobalt alloys on the one side, main constituent materlal (stainless steel and other nickel alloys) on the other?

Answer: M DUBOURG, Framatome - The problem of hard-faced materials on the valves is erosion and wear initiated by malfunctioning. Particles from the hard-faced side, which is Stellite (55 cobalt), are then transported in the primary coolant and become activated. An example of importance has been shown on the Fessenheim reactor where erosion occurred on some valves of the primary coolant system and initiated high dose rates during at least one or two fuel cycles. There is considerable interest in replacing cobalt-based alloys on critical valves either by nickel-based or other low-cobalt alloys.

Answer: C BENhAMOU, Framatome - Different materials contribute to Co-60 contamination as follows:

708 - steam generator tubes of Inconel 600 (nickel-based alloy)

20 - reactor internals and piping of stainless steels

108 - end valves where cobalt-based alloys such as Stellite grade 6 and 13 are deposited.

Question: F MOTTE, SCK/CEN Mol - As you know, in the now so-called first generation PWR plants, the reactor vessel was surrounded by a thick neutron shield tank, in which most of the escaping neutrons were slowed down and captured. The surrounding concrete was hardly activated. In your most recent desıgn, the 1400 MWe unit called N4, I notice a return to a neutron shield if not a neutron shield tank. Could you give some more details on this neutron shield?

Answer: M DUBOURG, Framatome - The shielding of the reactor on the N4 plant is by a neutron protection liner which incorporates hydrogenated products and absorbants to reduce the amount of activated concrete. The aim of this liner corresponds to the first original design of neutron shield tanks (BR3 and $(\mathrm{HOOZ}$ ) but takes into account new regulations for the loads.

\section{CONCLUSION}

I would like to conclude that this session has given, at least partly, answers to the following issues:

- how to bulld but also how to operate an installation to facllitate its dismantling at the end of its active life, producing a minimum amount of waste;

- on an interesting field for apparently modest but productive innovations, not very spectacular but quite important;

on a long-term effect - ten years in the community programme - which will certainly bring the related technology to maturity;

- on one of the ways for the nuclear industry to save at least man-rem and most probably money.

Personally, I disagree with the point of view expressed this morning during the plenary session that the money saved during decommssioning will 
mostly be counterbalanced by an increase of the investment costs related to the design features facilitating decommissioning; part of my argument is based on the fact that the features facilitating decomissioning are also, in many cases, facilitating the operation; Mr Fournie made some references to this point in his presentation.

F MOTTE, SCK/CEN Mol 


\title{
SESSION IV
}

\section{REMOTE OPERATION FOR DISMANTLING AND} DECONTAMINATION

\author{
CHAIRMAN: G COSTE, CEA, F \\ SECRETARY: E SKUPINSKI, CEC
}



POLYJOINTED ROBOT WITH INTEGRATED LASER BEAM

\author{
J.P. Alfille, M. hofmAN, Ph. GARREC, J. GONNORD and J.P. NOEL \\ Commissarlat à l'Energie Atomique \\ IRDI-DEMT-CEN SACLAY
}

\begin{abstract}
Summary
Full details are given of the project for a robot laser beam to be used as a cutting tool in decomissioning work in hot cells. Results obtalned with the complete system, i.e. robot plus industrial $\mathrm{CO}_{2}$ laser, are described, also the potential for laser cutting in a non-active working environment.
\end{abstract}

\title{
1. INTRODUCTION
}

The potential of the laser system became apparent at an early stage in the field of remote cutting, particularly in industry. Lasers are now zufficiently reliable for industrial use.

Further studies in our laboratory on manipulating laser beams and transmitting power beams over significant distances led to the concept of using a robot for cutting operations in a hostile environment.

The ROLD (decomissioning laser robot) is the result of these studies. It combines a jointed arm with a power laser. The laser beam travels through the arm structure, which is designed to fit into a standard 250 mm hot-cell orifice. An RGD programme to evaluate the laser process in decommissioning applications was launched (UDIN/Dg D) and completed with joint funding by the CEC (DG XII, Section A3).

\section{DESCRIPTION OF THE LASER ROBOT}

\subsection{Design Features}

\subsubsection{Beam transmission}

The beam is transmitted inside the arm via a series of mechanical/ optical joint assemblies, each consisting of two plane mirrors set at $45^{\circ}$.

Principle: The entry beam is reflected off mirror Ml at $45^{\circ}$ to mirror M2, which is parallel to $\mathrm{Ml}$. This forms a sort of periscope. The beam is thus constantly aligned with the mechanical axis, so the system can rotate freely (Figure 1).

\subsubsection{Mechanical structure}

There are five joints, since on this type of robot a sixth axis, which is the usual number on manipulating robots, is not required because the focal spot revolves symmetrically. The complete arm thus comprises a carrier with three joints (to position the effector) and a 'hand' with only two joints (to guide the effector). The axes of the hand are concurrent so as to 


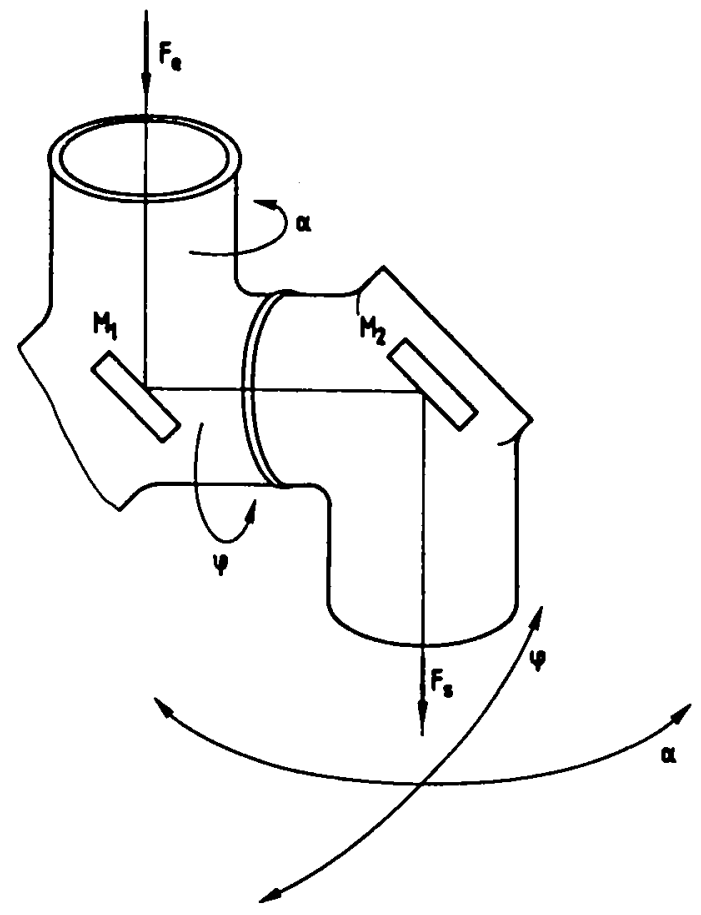

Fig. 1. Principal of mechanical/ optical joint assembly

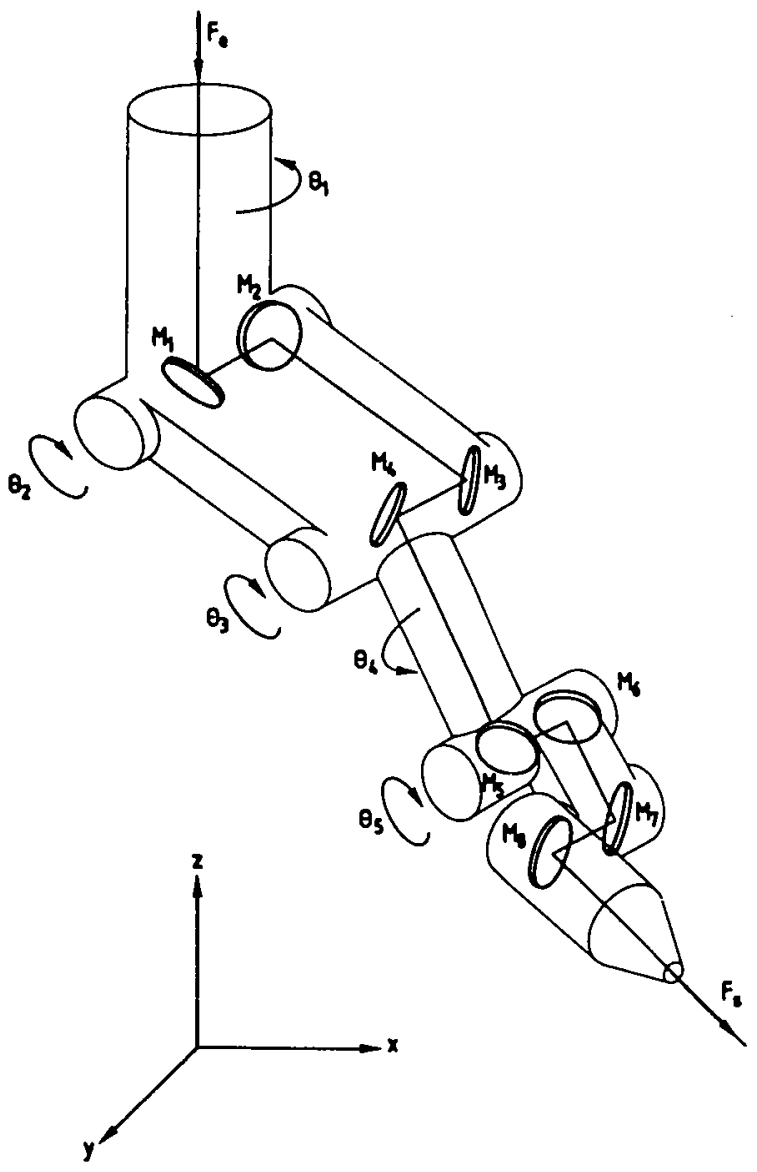

Fig. 2. Kinematic chain for ROLD robot

กับ 


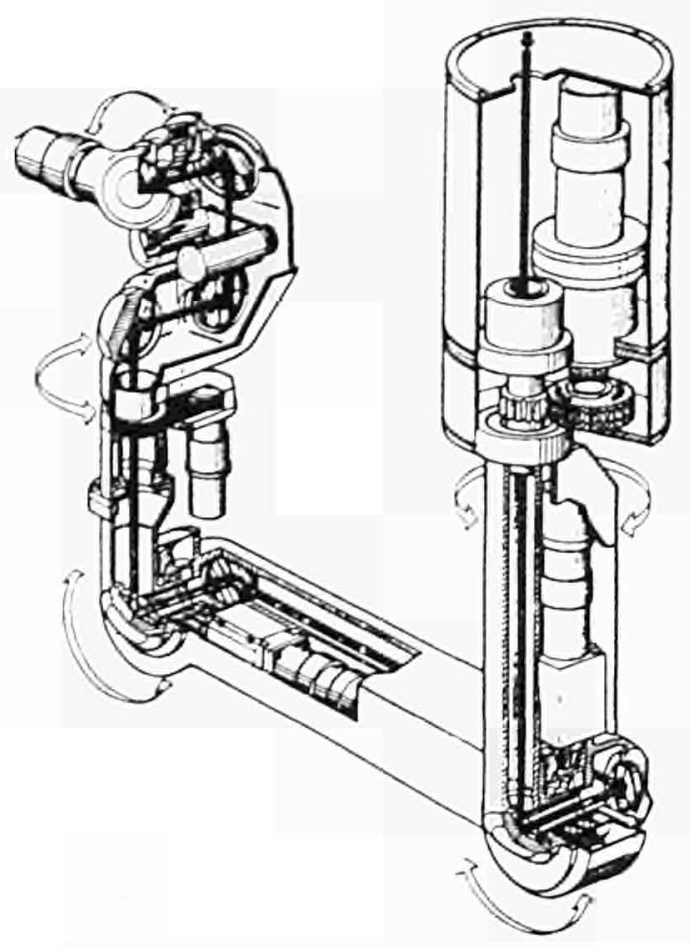

Fig. 3. Cut-away view of arm

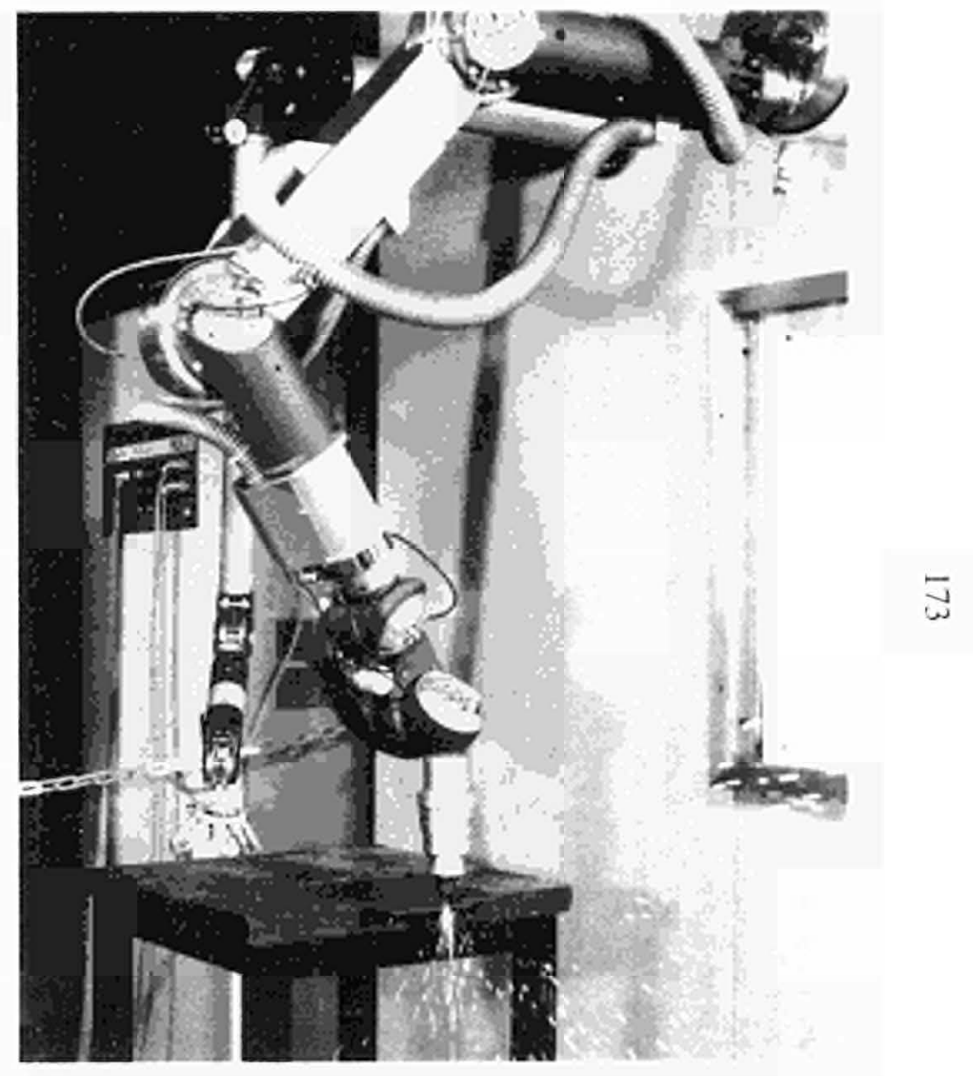

Fig. 4. A prototype of the arm 
simplify the calculations for converting the coordinates. The time required to carry out this calculation is $32 \mathrm{~ms}$. The layout of the arm joints is shown in Figure 2.

All the components of the jointed structure are made of cast aluminium alloy. The beam travels inside the arm in a compartment separated from the activators. These are completely integrated into the arm. Figure 3 shows the internal layout of the components and the path followed by the laser beam.

\subsection{Specifications}

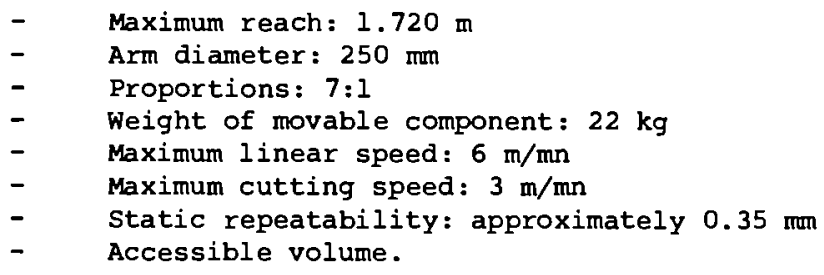

For this type of robot a distinction must be made between the concepts of accessible geometrical point and what is feasible in practice. To give an idea of the practical potential of the robot we must look at all the feasible tasks within the locus of the accessible points.

- Maximum laser power: $2000 \mathrm{~W}$

- Maximum beam diameter: $30 \mathrm{~mm}$

- Standard focal length: $127 \mathrm{~mm}$

- Demountable end nozzle

- Ratchet mirror holders with automatic repositioning.

\subsection{Activators and Sensors}

Each axis is governed by a d.c. geared motor and a transmission appropriate to the particular configuration of the axis: gear train, bevel gears or notched belt. shaft.

Speed is measured by a tachometric dynamo driven directly by the drive

The position is measured by a pancake resolver. These sensors allow the beam to pass freely through the centre of the joint and their high precision ensures absolute coding.

Figure 4 shows the complete apparatus.

\section{$2.4 \quad$ Programming}

Programming is carried out by point by point learning using a control box with push buttons. The programmable parameters of the laser cutting process are:

- Type of interpolation: articular, cartesian or nozzle location

- Linear speed of nozzle movement

- Opening of laser shutter

- Laser power

- Opening the assisting gas valves.

These functions are carried out by means of a control system using two INTEL 8086 microprocessors, as illustrated in Figure 5. 


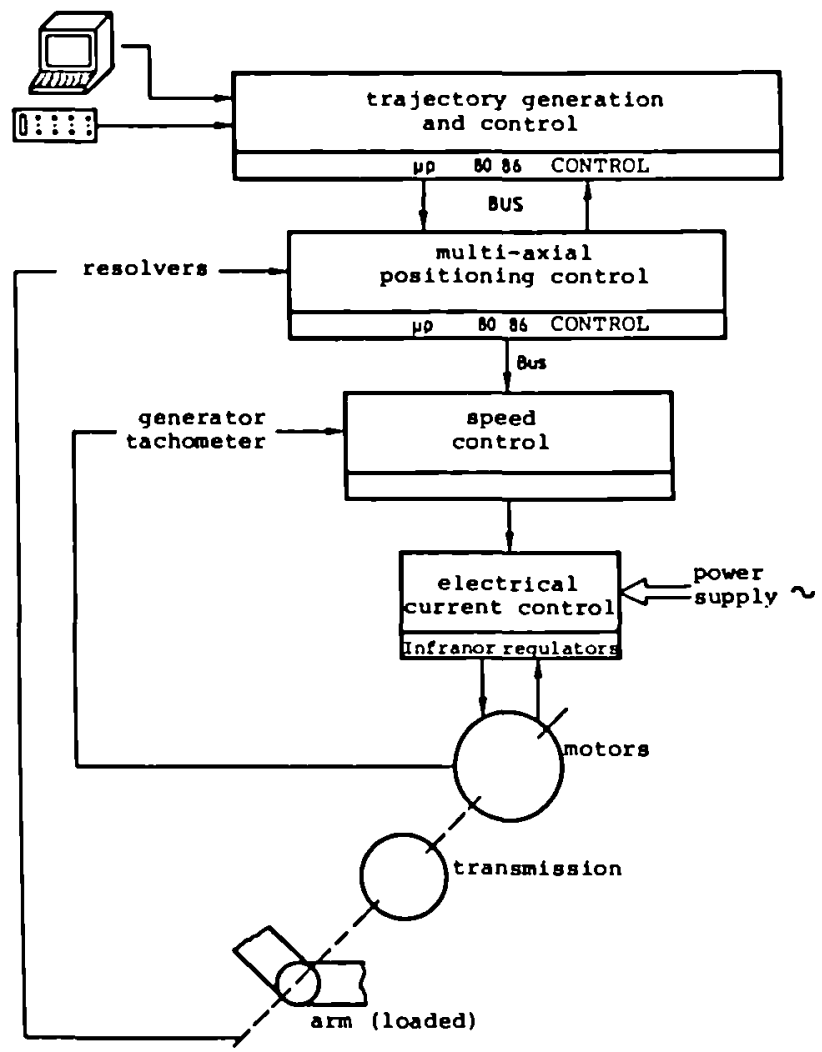

Fig. 5. Control system

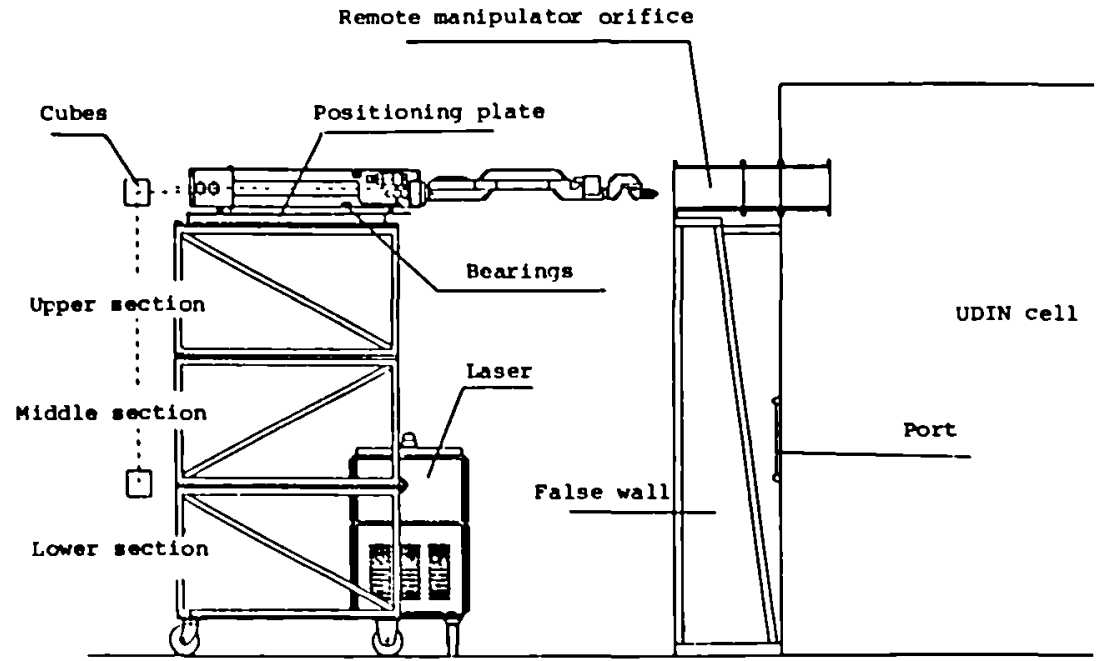

F1g. 6. ROLD system in operation 


\section{EXPERIMENTS IN THE NON-ACTIVE WORKPLACE}

\subsection{ROLD System}

The arm was combined with an industrial $\mathrm{CO}_{2}$ laser and the accessories required for its complete installation in a working configuration.

This is the RoID system, which comprises:

- A laser robot

- A power laser (ROFIN SINAR RS 1200)

This laser has been modified externally to make it suitable for the workplace. It is mounted on a metal frame which:

* can be fitted with a sling for handling on the gantry and transport by lorry,

* can easily be moved by hand because the frame is fitted with four castors .

* can be locked in any position by its four bolts.

A framework for inserting the robot which also forms a structure for the beam guidance optics. This apparatus provides access to the usual height of the orifices of remote handling equipment (e.g. in the trial installation the robot has to work at a height of $3.05 \mathrm{~m}$ ). The framework consists of a number of removable sections, so that the robot can be transported easily. Figure 6 illustrates the ROLD system.

\subsection{Cutting Tests in the UDIN Facilities (CEN de Fontenay-aux-Roses)}

\subsubsection{General remarks}

Feasibility tests were carried out in a mock-up of a hot cell belonging to UDIN. This facility, which is situated in the centre d'Etudes Nucléaires de Fontenay-aux-Roses, was used for carrying out cutting work in non-active conditions to test the processes and tools under nuclear workshop conditions. We chose a set of typical components, such as:

- mild or stainless steel piping 10-300 $\mathrm{mm}$ in diameter. The thickness of these pipes varies from 1 to $6 \mathrm{~mm}$.

- steel structural components, sectional type, 3-6 mm thick.

\subsubsection{Laser cutting process}

Laser cutting is a technique for thermal cutting of materials by local fusion as opposed to other methods of mechanical cutting.

This cutting process combines the thermal action of the focussed laser beam with the mechanical effect of a jet of gas applied to the fusion zone. The movement of the tool or beam at a constant distance from the focal point gives a continuous cut.

The cutting capacity (thickness and speed) depends on the system, the power of the laser source, the dynamic quality of the cutting machine, the volume of work and flexibility.

In decommissioning operations the quality of the cut is considered secondary, but it should be noted nevertheless that a poor cut produces significantly more harmful products (aerosols). 


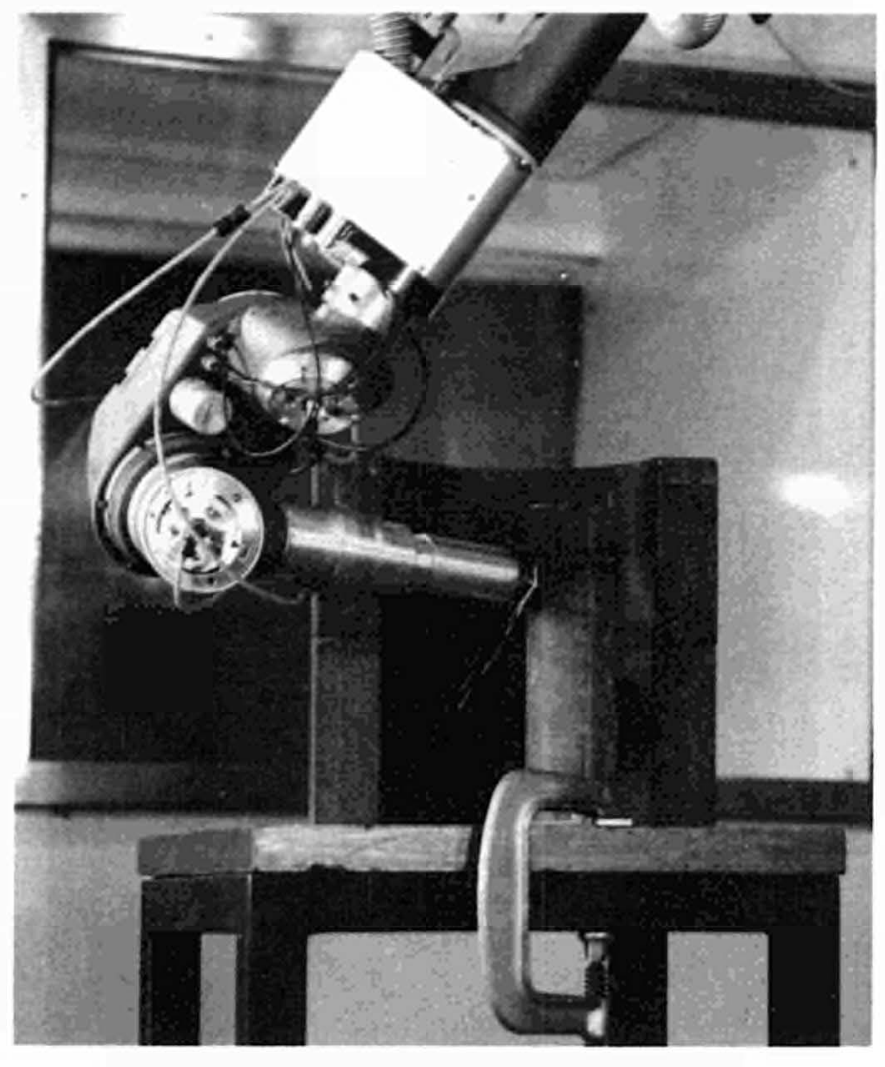

Fig. 7. Cutting a large diameter pipe - first stage

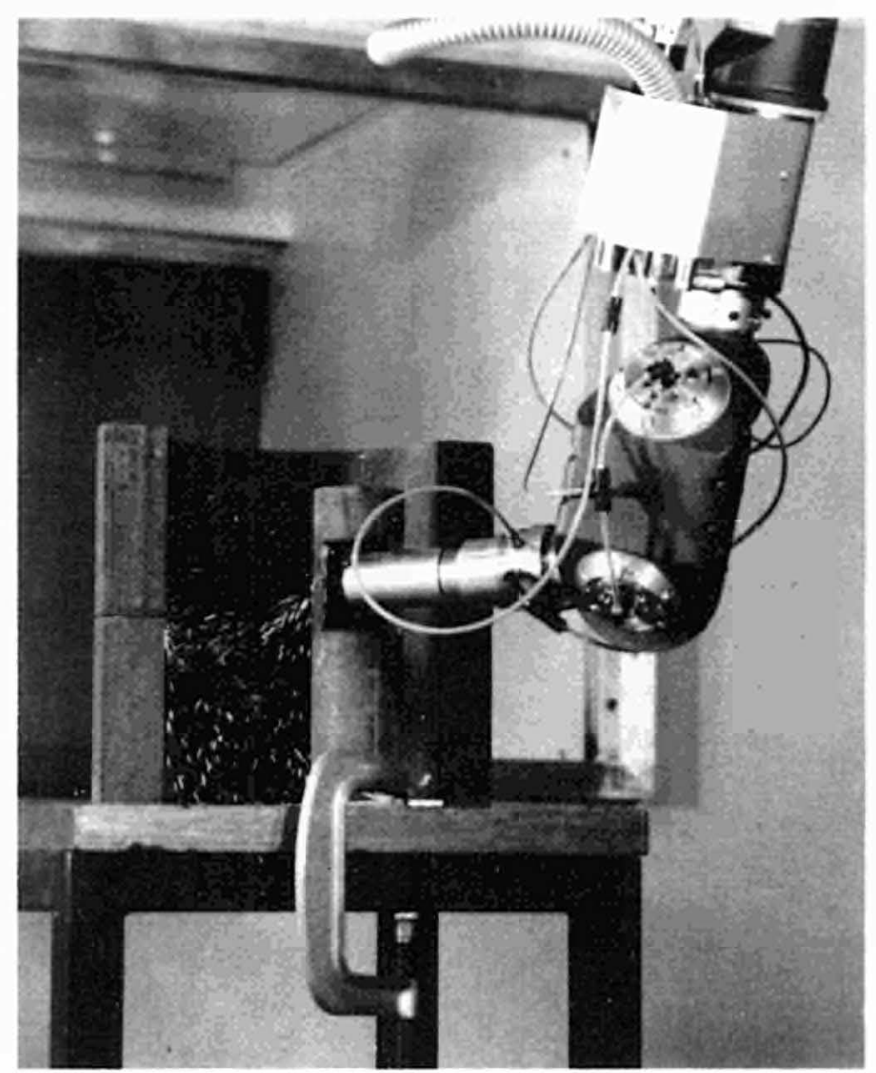

క
Fig. 8. Cutting a large diameter pipe - second stage 


\subsubsection{Methodology}

Two-stage cutting method (for pipes over $35 \mathrm{~mm}$ in diameter)

The programming is done in two stages - the first to make an opening large enough for the nozzle to penetrate inside the pipe, and the second to complete the cut on the internal face of the pipe. This trial is illustrated in Figures 7 and 8 . Figure 9 shows the cutting of a cluster of tubes near a wall using the same method.

\section{Direct cutting of pipes}

This method obviously reduces the programming time. We cut small diameter pipes (up to $35 \mathrm{~mm}$ ) in both mild steel and stainless steel. Figure 10 shows the cut pipes.

\subsubsection{Test conditions}

The test parameters were:

$\begin{array}{ll}\text { Laser power } & 400 \mathrm{~W} \\ \text { Cutting speed } & 0.2 \mathrm{~m} / \mathrm{min} \\ \text { Oxygen gas cutting } & 501 / \mathrm{min} \\ \text { Tube diameter } & 1.3 \mathrm{~mm} \\ \text { Distance between nozzle and workpiece } & 2 \mathrm{~mm} \\ \text { Focal length (Zn-Se lens) } & 127 \mathrm{~mm} \\ \text { Beam diameter } & 12 \mathrm{~mm}\end{array}$

\subsubsection{Quality of cut}

The photograph of a sample in Figure 11 shows the quality of cut obtained: a roughness $\mathrm{Ra}$ of the order of 10 with a kerf width of $0.5 \mathrm{~mm}$ (pipe $6 \mathrm{~mm}$ thick).

\subsubsection{Capabilities of the ROLD tool}

The cutting capacity of the ROLD system was evaluated. This is a function of the power of the laser source used in the robot. Under present conditions ( $1400 \mathrm{~W}$ ), the maximum thicknesses are $40 \mathrm{~mm}$ in mild steel and $20 \mathrm{~mm}$ in alloy steel. Up to these limits the quality of cut is acceptable.

If a lower quality of cut is accepted these limits may be extended to $70 \mathrm{~mm}$ for mild steel and $40 \mathrm{~mm}$ for alloy steel; a lower cutting speed significantly increased aerosol production.

\section{CONCLUSIONS}

A flexible system of cutting by laser beam has been produced and put into service.

This system showed during demonstration trials that it was suitable for cutting a large number of components of three-dimensional structures (in steel, alloy steel and various other materials).

Certain limitations, arising from the actual principle of a robot arm on a fixed base, became apparant, viz:

- Difficulty of achieving certain trajectories required for cutting.

- The system of teaching point by point was a constraint for work in a cell.

With regard to the second limitation, the use of a computer simulator which can plot trajectories and give advance warning of limits of use and 


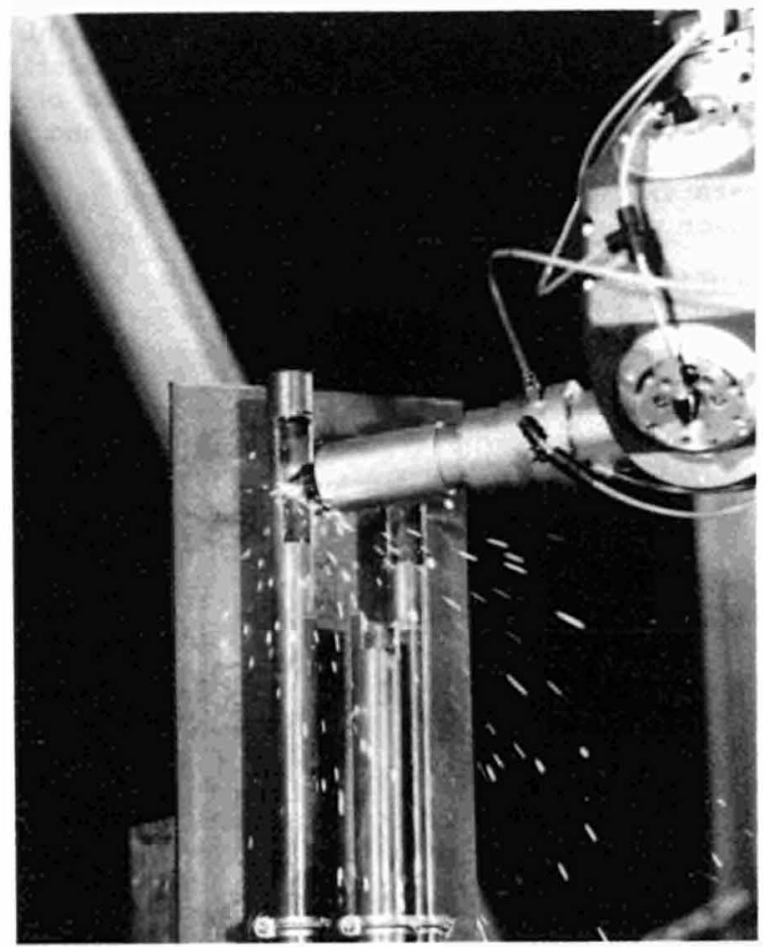

Fig. 9. Cutting a cluster of pipes close to a wall

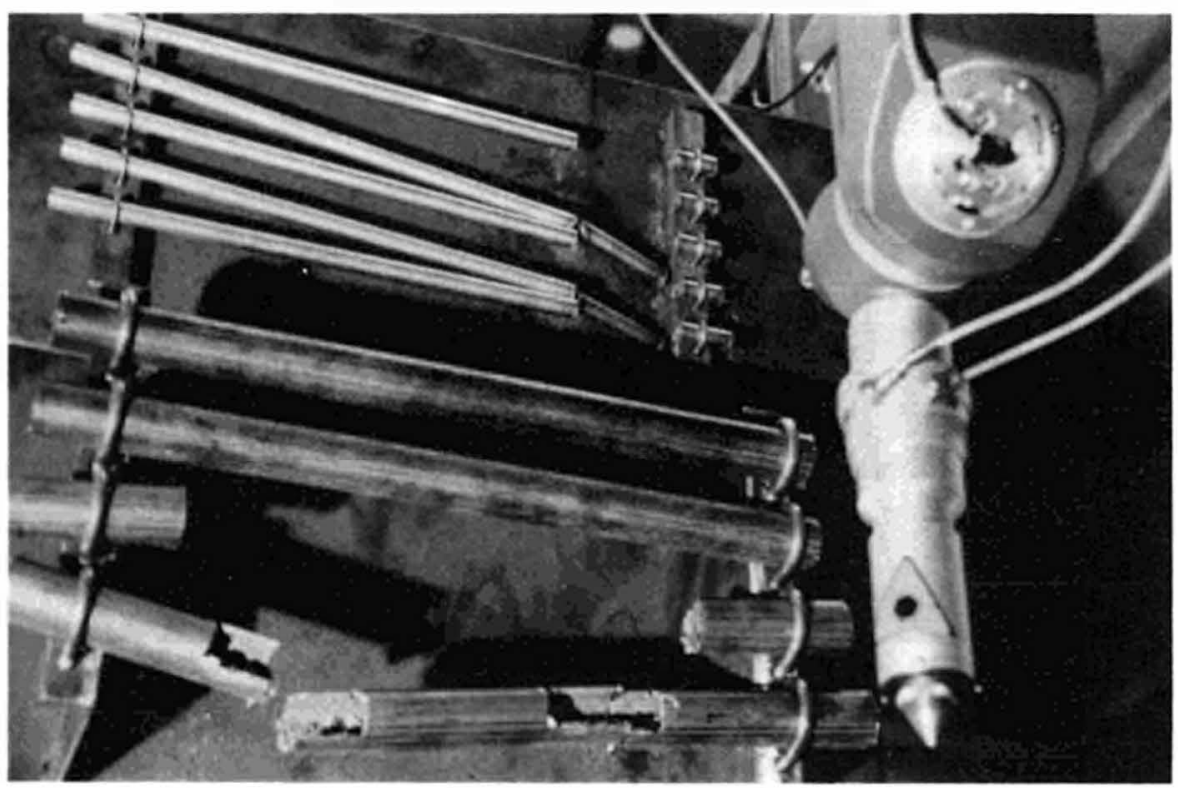

Fig. 10. Cutting a rack of pipes close to a wall 
the development of offline teaching methods, should enable us to make this tool more flexible in use. This system comprises a geometrical command model corresponding to that of the ROLD robot. The position of the sample to be cut is specified in the viewfinder of the simulator and the programe can then calculate the approach and cutting trajectories.

Developments in hand concern integrating these improvements and using a 3D optical sensor which can input information on the environment.
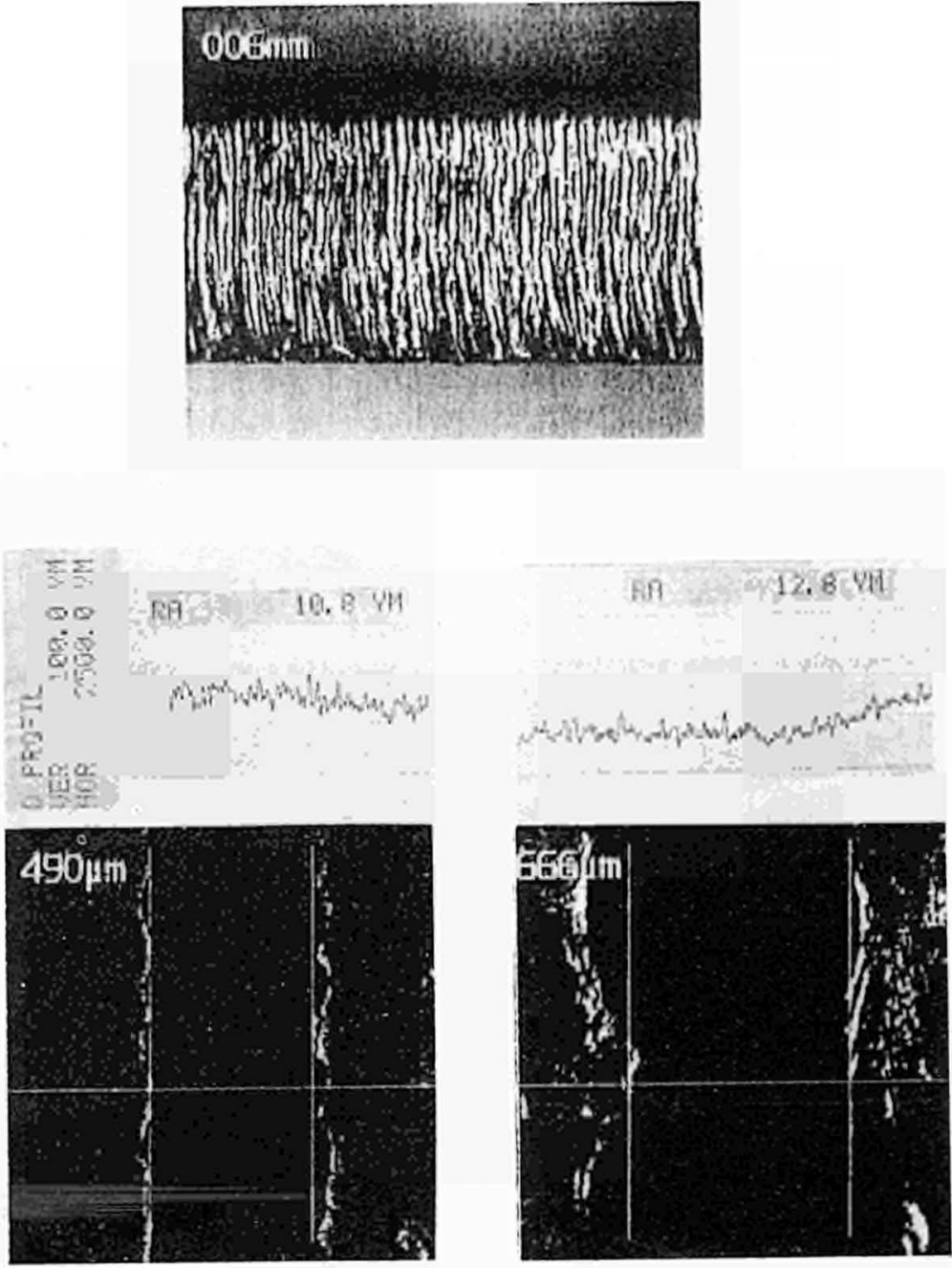

Fig. 11. Quality of cut 


\title{
INVESTIGATION OF LASER CUTTING APPLICATIONS
}

\author{
IN DECOMMISSIONING
}

\author{
B. MIGLIORATI*, G. TARRONI", M. DI FINO“, P. PICINI“", G. MANASSERO** \\ - FIAT-CIEI, Via Cuneo 20, I-10152 Torino Italy \\ " ENEA-PAS-FIBI-AEROSOL, V.le G.B.Ercolani 8, I-40138 Bologna Italy \\ - ENEA-TIB-FIS-TECNLAS, Via E. Fermi 27, I-00044 Frascati - Roma Italy \\ “ ENEA-PAS-ISP-AMB, CP 2400, I-00100 Roma Italy \\ * FlAT-CRF, Strada Torino 50, I-10043 Orbassano-Torino Italy
}

\begin{abstract}
SUMMARY
The aim of this work, performed on an experimental basis in a frame of strict collaboration between industry and public research laboratories and supported by a CEC contract, was to bring out the items for better evaluation of laser beam application possibilities in dismantling nuclear power plants. The main topics of the research have been: 1) Study and definition of the relevant basic parameters ruling the aerosol generation rate and behaviour in terms of physical and chemical characteristics; 2) Study of the feasibility of local abatement of the aerosol produced and of the pressure drop in HEPA filters; 3) Study of the long distance transmission of laser beam power with evaluation of the power loss and of the beam characteristic modifications; 4) Study of laser beam technique application in dismantling the Garigliano power plant steam drum in order to better evidence the feasibility of the use of this technique and the problems still to be solved.
\end{abstract}

\section{INTRODUCTION}

The general aim of the work carried out in the frame of the CEC contract FIl-D0014-I(TT) was to obtain a more complete evaluation of the possibility of using the laser beam cutting technique in dismantling nuclear power plants. The specific objectives of the research were: 1) to obtain better knowledge about the aerosol produced, also with the aim of investigating the possibilities of their abatement and filtration; 2) to study systems for transmission of the laser beam over long distances in order to give more concrete motivations for the eventual use of this cutting technique as a dismantling method; 3 ) to study the possibility of practical utilization of laser beam cutting for dismantling a real complex system.

To obtain these goals, the activities were subdivided from the beginning between laboratories belonging both to private industry (FIAT) and to the public administration (ENEA). The groups involved were: 1) Laboratory of Aerosol Physics and Toxicology, Department of Environmental Protection and Human Health (ENEA-PAS-FIBI-AEROSOL), which performed all the measurements (sampling, analysis and data treatment) relative to aerosol and slag produced in laser beam cutting. This work has been performed in a facility specifically designed for aerosol measurements and equipped with a $2 \mathrm{~kW}$ laser source; 2) Laboratory of Laser Technology, Department of Basic Intersectorial Technology (ENEA-TIB-FIS-TECNLAS), which was mainly involved in the set-up of the $2 \mathrm{~kW}$ power cutting facility and exhausting line; 3) Laboratory of Experimental Engineering, Department of Environmental Protection and Human Health (ENEA-PAS-ISP-AMB), with the task of studying the behaviour of HEPA filters challenging the aerosol produced during high temperature cuttings; 4) FIAT-CRF (Torino), that studied the more efficacious methods for transmitting laser beam power over long distances using a $5 \mathrm{~kW}$ laser source; 5) FIAT-CIEI (Torino), with the task of studying the engineering problems related to dismantling one specific component of the Garigliano nuclear power plant, by taking into account the results obtained in the course of the programmed experiences. 


\section{AEROSOL CHARACTERIZATION AND EFFLUENT PRODUCTION RATE}

\subsection{Particle Morphology and Granulometry}

The aerosol produced in cutting steel by means of laser beam was composed of two types of particle: very fine particles, having dimensions of some hundredths of micrometer which, because of coagulation, very rapidly form chain-like aggregates of some tenths of micrometer, and spherical compact particles of diameter greater than a few micrometers having a density of about $5 \mathrm{~g} / \mathrm{cm}^{3}$, easily capturable by inertial or electrostatic abatement systems. The origin of these two types of particles is also different: the aggregates are due to coagulation of particles produced by condensation of vaporized material; the spherical and compact particles are probably formed by material expelled in liquid form during the cutting process. The amount of the compact particles constituting the 2 nd mode in the granulometric spectra greatly depends on the sampling modality and the sampling point.

The results, in terms of mass percentage in the main granulometric fraction,as obtained in our facility, show a mass fraction greater than $60 \%$ collected in the back-up filter of the used impactor (particle diameter $<0.5 \mu \mathrm{m}$ ). The fraction of particles greater than $3.5 \mu \mathrm{m}$, imputable to compact particles of the 2 nd mode contains, on average, a mass lower than $7 \%$. It is therefore possible to affirm that the value of aerosol production per unit length of cutting as reported in the following, has to be considered for more than $93 \%$ in mass, as attributable to chain-like aggregates of very fine particles (lst mode of the spectrum).

A parameter useful to investigate the dimensional variations of the particles in the various experimental situations is the diameter of average mass $\left(D_{m e}\right)$, defined $(1)$ as the diameter of the spherical particle having the mean mass of the particles and the same density. The values of $D_{\text {me }}$ were obtained by simultaneous measurements of particle number concentration (by CNC) and aerosol mass concentration (by total filters) and are therefore mainly connected to the spectral fraction composed of aggregates. As the actual aggregate density is unknown, admitting that it could be defined for this type of particle, an arbitrary value of $1 \mathrm{~g} / \mathrm{cm}^{3}$ was assumed for calculations. Figure 1 presents the $D_{m e}$ trend as a function of the aerosol production rate, $\mathrm{p}(\mathrm{g} / \mathrm{min})$, obtained by cutting stainless steel by Oxygen, Air and Nitrogen and carbon steel by Oxygen. As can be observed, good correlation exists between $\mathrm{D}_{\mathrm{me}}$ and production rate p. The data best fit by the least square method shows that they are well interpolated by the function:

$$
D_{m e}=H * p^{1 / 3} \quad \text { with } H=0.274
$$

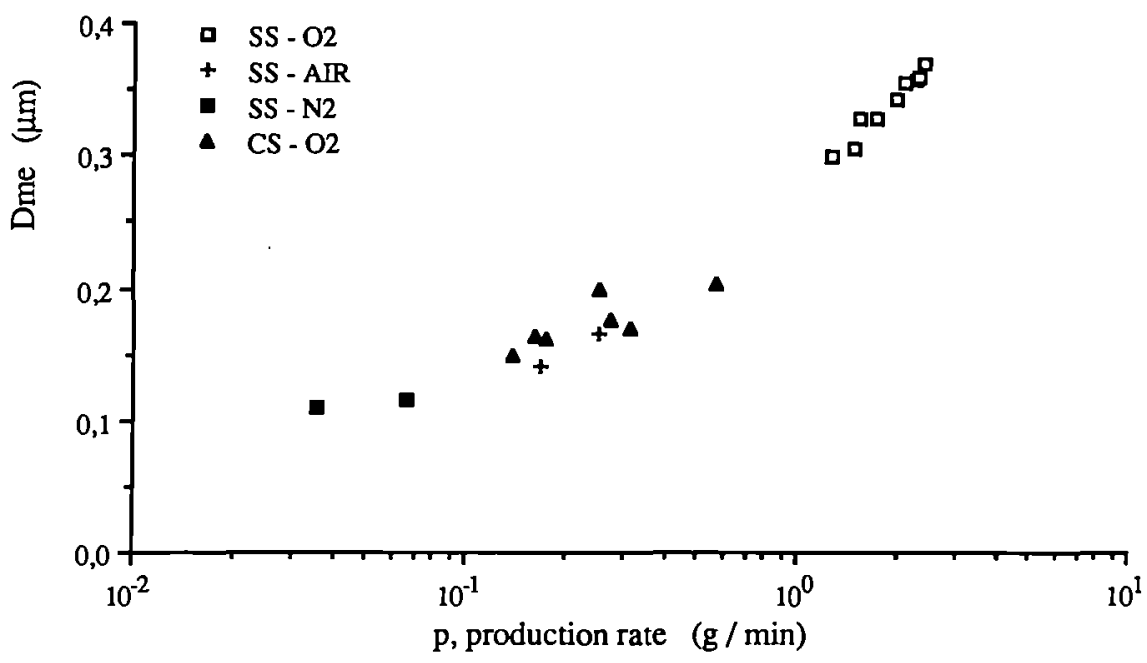

Figure 1. Diameter of average mass $\left(D_{m e}\right)$ as a function of the aerosol production rate. 
Some tests were carried out with the aim of investigating the size modifications due to coagulation for a highly concentrated aerosol. The results obtained show an increase of the Mass Median Aerodynamic Diameter (MMAD) from about $0.4 \mu \mathrm{m}$ (at the end of the cutting) to $1.6 \mu \mathrm{m}$ in 12 minutes.

It is thus possible to affirm that the measured aerosol size distribution of the aggregates depends on concentration at the source (generation rate), on the aerosol life time and the concentration at which it is maintained.

\subsection{Aerosol Production and Slag}

A series of tests was carried out to investigate the effect of the various parameters on the mass of aerosol and slag produced per unit length of cutting. The parameters considered in the tests were: laser power, type and pressure of the assistant gas, cutting velocity, plate thickness. The cutting performed on AISI 304 stainless steel plates furnished well-reproducible data: with the same parameters, aerosol production variability was of the order of $10 \%$ and that of the mass lost by the plate of the order of $15 \%$. In the case of the carbon steel the cutting was much more irregular (probably because of the strong reaction with the Oxygen) and the data variability was of the order of $30-40 \%$.

The values of aerosol production and mass removed from the plate per unit length of cutting showed no significant trend with the laser power (in the range $1000+1900 \mathrm{~W}$ ) nor with the assistant gas (Oxygen) pressure $(20+300 \mathrm{kPa})$.

The effect of the cutting velocity (Figure 2) depends on plate thickness. A reduction in the amount of aerosol produced resulted when increasing the cutting velocity, more pronounced with thicker plates. The value of the removed mass also decreases when the velocity increases, with a gradient that depends on plate thickness.

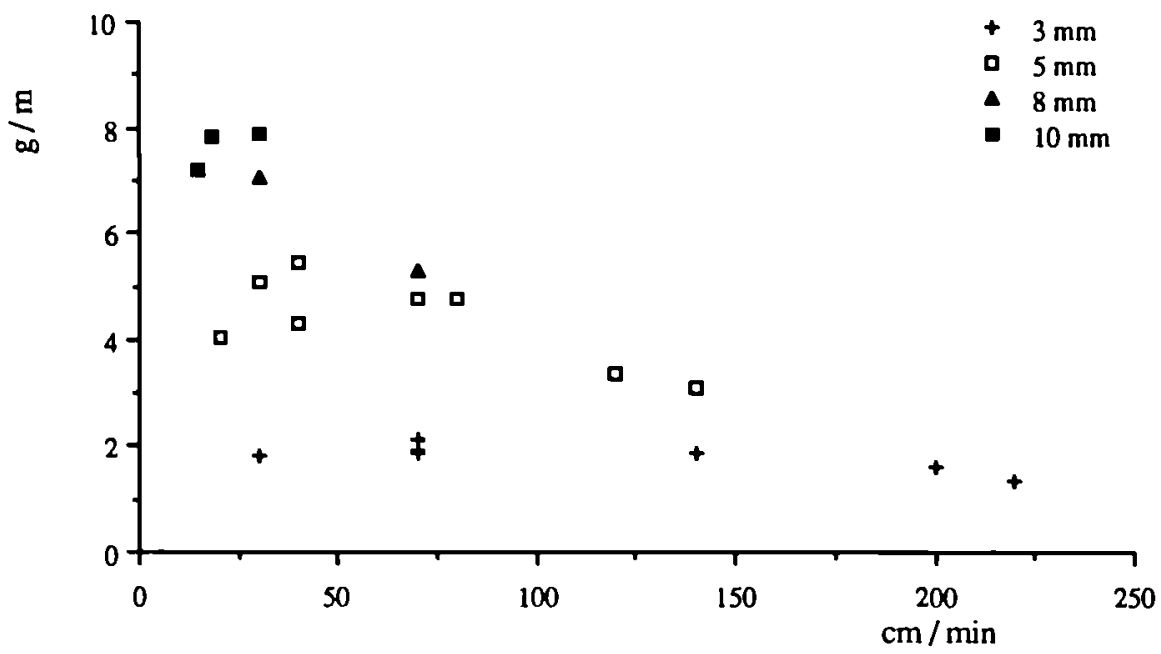

Figure 2. Mass of aerosol produced per unit length of cutting versus cutting velocity.

The mass of aerosol produced and the mass removed from the plate per unit length of cutting as a function of plate thickness, have been tested for different cutting velocities. The increase of aerosol production with plate thickness is progressively less pronounced with increasing cutting velocity. In addition, at the same cutting velocity, the increase of aerosol production is progressively less pronounced when increasing plate thickness. The values of mass removed show a less definite trend as a function of the various cutting velocities, but show an evident increase with increasing plate thickness.

One of the factors that most influences the production of effluents is the type of assistant gas. By using Air or Nitrogen instead of Oxygen it is possible to obtain on average a reduction 
of a factor of about 7 in aerosol production. It must nevertheless be noted that cutting efficacy, by maintaining the other parameters constant, decreases progressively from Oxygen to Air to Nitrogen; for example, it was not possible to cut the $5 \mathrm{~mm}$ plate with Nitrogen. Also the values of the mass removed from the plate decrease when cutting by Air instead of Oxygen: on average, the reduction obtained was of the order of a factor of $1.5+2.5$.

In the case of carbon steel the investigation was less systematic with respect to stainless steel, also because the already mentioned lower reproducibility of data made it difficult to show the effect of the various parameters. The mass of aerosol produced per unit length of cutting is systematically lower in the case of carbon steel than stainless steel; precisely, by a factor from 1.2 to 3.2 in the case of cutting by Oxygen and about 2.6 in the case of cutting by Air. The mass removed from the plate, even if with great variability of data resulted, instead, greater in the case of cutting carbon steel plates, on average by a factor of 2 . Finally, it must be observed that the cutting efficacy decrease from Oxygen to Air to Nitrogen is much more pronounced for carbon steel than for stainless steel.

\subsection{Aerosol Elemental Composition}

The elemental composition was determined by two methods: Atomic Absorption Spectroscopy (AAS) and Energy Dispersive X-Ray Analysis (EDAX).

The composition of the compact particles,as derived from EDAX analyses, even if data indicates a certain variability, is not far from that of the bulk material. The elemental composition of aggregates is, instead, significantly different in comparison with the bulk (AISI 304 SS) material. It is possible to note in fact an increase of a factor of about 2 in the $\mathrm{Ni}$ content and an analogous decrease in the Cr content.

The AAS analysis concerning the particulate collected in the impactor stages furmished very inconstant data, except those relative to the back-up filter (fine fraction of the particulate). The variability can be justified by the fact that often the mass collected was very scarce. In spite of a certain variability, the data indicate, for the particle fine fraction, an enrichment in the $\mathrm{Ni}$ content from $9.3 \%$ in the bulk material to $17 \div 25 \%$ in the aerosol, and a reduction in the $\mathrm{Cr}$ from $19.3 \%$ in the bulk material to $9+15 \%$ in the aerosol. These results are in good agreement with those obtained by means of EDAX analyses on the particle fine fractions.

The ratio between the sum of metals determined by AAS and the total mass obtained by weighing the sample, varies between 0.52 and 0.65 and is then systematically lower than the value (for oxides) of the stoichiometric ratio between the mass of metals and total mass $(0.70$ for $\mathrm{Fe}_{2} \mathrm{O}_{3}, 0.68$ for $\mathrm{Cr}_{2} \mathrm{O}_{3}, 0.75$ for $\mathrm{NiO}$ ). No valid explanation was found for this discrepancy.

The analyses on samples collected during the cutting tests performed by using Nitrogen and Air as assistant gases furnished less reliable quantitative values, because of the exiguity of the collected mass. Notwithstanding this, both the analyses by AAS and EDAX showed the same tendencies towards an enrichment in the $\mathrm{Ni}$ content and a reduction in the $\mathrm{Cr}$ content.

These data therefore suggest the conclusion that the aerosol fraction composed of compact particles of larger size remains substantially of the same composition as the bulk material, while that composed of aggregates of fine particles has a marked variation. The two spectral modes are then different, not only for particle morphology, but also as to their content in elements.

\subsection{Effect of Local Aspiration on the Aerosol Concentration in the Cutting Box}

The elevated aerosol concentration in the area where the cutting occurs causes contamination on surfaces exposed to the effluents. A series of tests was therefore performed to investigate the possibility of reducing the aerosol concentration in the cutting environment by using a system of local aerosol aspiration close to the source. The tests indicated the great advantages obtainable by using a strongly localized aspiration system when cutting larger size plates and whenever it is possible to realize almost complete containment: in fact a reduction of more than two orders of magnitude in aerosol concentration has been obtained. In cutting small pieces, one can obtain a considerable advantage by using local aspiration even without total containment: in fact, a reduction of a factor of about 5 can be obtained when a suitable flowrate is adopted. An indication of the critical importance of the flowrate was obtained. 


\section{PRESSURE DROP ACROSS HEPA FILTERS}

To evaluate the pressure drop across HEPA filters loaded by the aerosol arising from a high temperature metal cutting process, the fumes produced by the plasma torch cutting of AISI 304 stainless steel plates were used. The most reliable data refer to tests carried out with the following parameters: cutting power, $15 \mathrm{~kW}$; plasma torch nozzle, $2.5 \mathrm{~mm}$; plate thickness, $20 \mathrm{~mm}$; cutting gas flow rate, $32 \mathrm{1} / \mathrm{m}$; cutting velocity, $275 \mathrm{~cm} / \mathrm{min}$; exhaust flow rate, $1810 \mathrm{~m}^{3} / \mathrm{h}$.

The aerosol production per unit length of cutting was $(1.7 \pm 0.3) \mathrm{g} / \mathrm{m}$, the aerosol concentration in the ventilation channel $(16 \pm 3) \mathrm{mg} / \mathrm{m}^{3}$ and the mass removed from the plate per unit length of cutting $(600 \pm 25) \mathrm{g} / \mathrm{m}$.

The main results obtained are: 1) the pressure drop across HEPA filters vs the mass loaded is linear; 2) this particular kind of aerosol (aggregates of fine particles) shows a strong tendency to clog the HEPA filters. In fact, the mean value of the pressure drop across HEPA filter vs mass loaded resulted equal to $16 \mathrm{~Pa} / \mathrm{g}$ that is about five times greater than that caused by compact particles; 3) the efficiency of the tested HEPA filters does not show valuable variation even with high pressure drops; 4) in all the tests performed the HEPA filter pressure drops measured at the end of a cut $\left(\Delta \mathrm{P}_{\mathrm{fin}}(\mathrm{n})\right)$ were always greater than that measured on the same filter at the beginning of the subsequent one $\left(\Delta \mathrm{P}_{\text {in }}(n+1)\right)$ (see Figure 3$)$ notwithstanding the mass loaded on the filter, the temperature, relative humidity and the flow rate of the exhausts were the same. The mean value of this unexpected decrease is about $13+15 \%$ of the $\Delta P$ value.

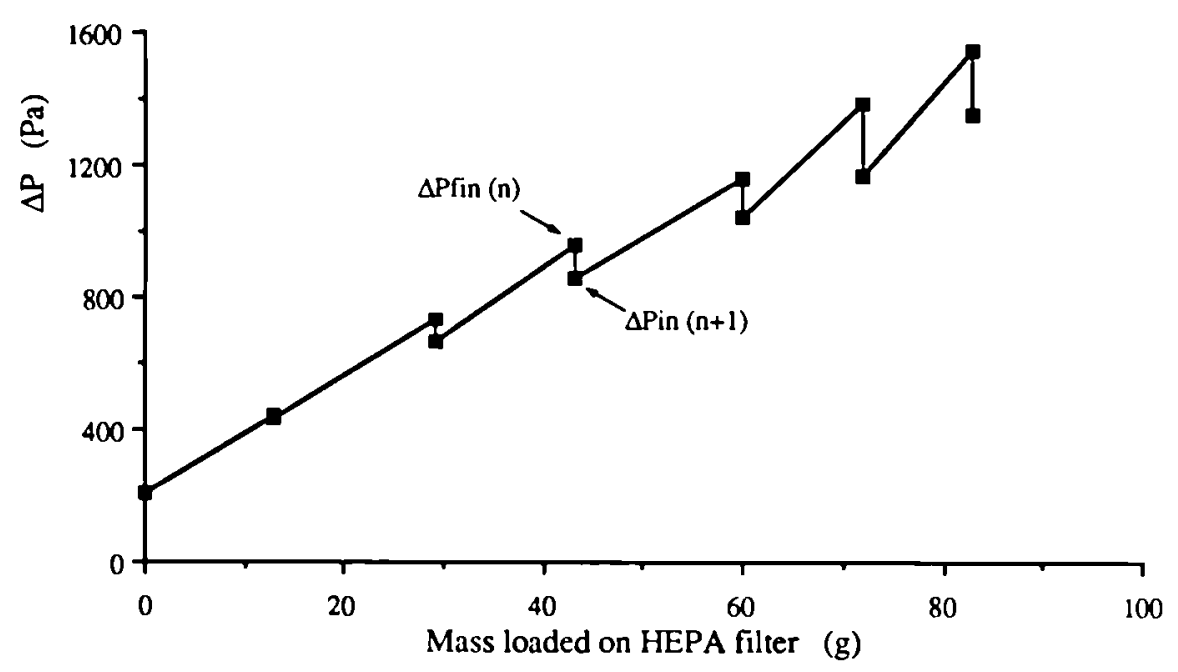

Figure 3. Pressure drop $(\Delta \mathrm{P})$ versus mass collected in 6 consecutive cuts.

\section{LASER BEAM PROPAGATION AND CONTROL}

\subsection{Laser beam transmission and remote focalization}

One of the objectives of the research was to verify the utilization of the laser beam at long distance from the source and, mainly, to have a uniform process result in a large working area. This requires a laser beam collimated in the selected range of distances between 5 and $30 \mathrm{~m}$ from the source. To describe the beam quality of a high power laser it is necessary to know three parameters which can, for example, be the order $\mathrm{N}$ of the oscillating mode in the cavity, the position and dimension of the minimum diameter of the fundamental mode. By a theoretical 
and experimental procedure it is possible to calculate the characteristics of the corrective mirrors and of the laser beam along the optical path.

In the case of the $5 \mathrm{~kW}$ Spectra Physics source using a divergent mirror (focal length $1900 \mathrm{~mm}$ ), $3 \mathrm{~m}$ from the output window, and a converging mirror (focal length $2750 \mathrm{~mm}$ ), placed $1 \mathrm{~m}$ from the divergent one, a collimated beam of about $50 \mathrm{~mm}$ in diameter has been obtained all along the working range (Figure 4).

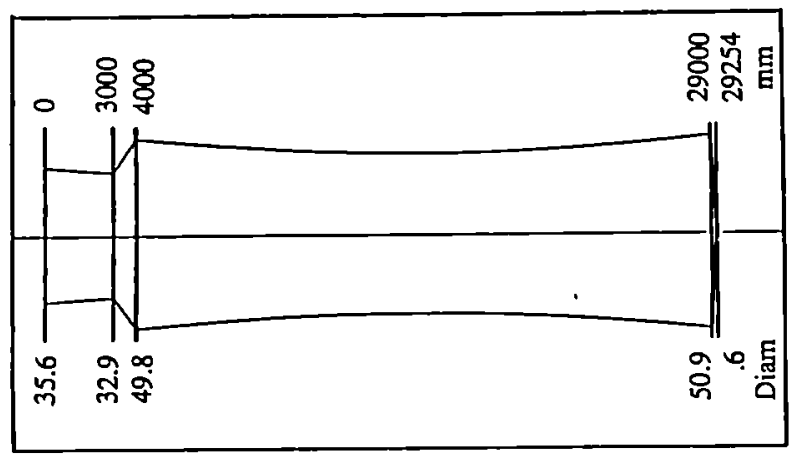

Wave length: $10.6 \mu \mathrm{m} \quad$ Multimode coefficient: $2.63 \quad$ Focal length: 10 "

$\begin{array}{cccccc} & \begin{array}{c}\text { Focal lens } \\ (\mathrm{mm})\end{array} & \begin{array}{c}\text { Lens position } \\ (\mathrm{mm})\end{array} & \begin{array}{c}\text { Beam diameter } \\ (\mathrm{mm})\end{array} & \begin{array}{c}\text { Waist diameter } \\ (\mathrm{mm})\end{array} & \begin{array}{c}\text { Waist position } \\ (\mathrm{mm})\end{array} \\ 1 & -1900 & 3000 & 32.9 & & \\ 2 & 2750 & 4000 & 49.8 & 32.3 & 5200 \\ 3 & 254 & 29000 & 50.9 & 5.5 & 1091 \\ 4 & & 29254 & .6 & 42.0 & 16022 \\ & & & & .5 & 29256\end{array}$

Figure 4. Laser beam characteristics at $30 \mathrm{~m}$ from the source (S.P. 975) computed using the propagation parameters as input for numerical program.

\subsection{Experimental set-up and cutting tests}

In order to verify the theoretical calculation on the laser beam propagation and, afterwards, to carry out some cutting tests it was necessary to design and build the opticalmechanical structures necessary for the experimental checks.

The optical system used is shown in Figure 5.

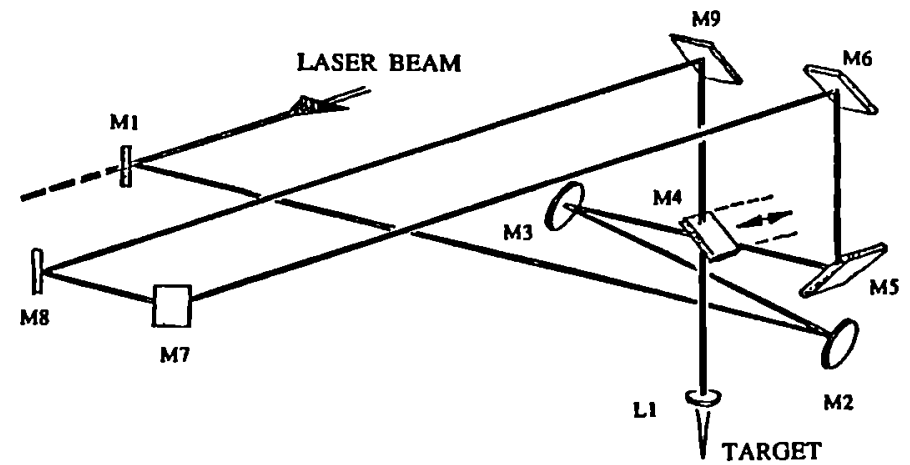

Figure 5. Optical system set up for the propagation and focalization of a laser beam. 
The laser beam, intercepted by a mirror, M1, enters the working station where mirrors M2 and M3 (which form the collimator telescope) are provided. If mirror M4 intercepts the beam, the focal plane position is about $5 \mathrm{~m}$ from the output window of the source. Otherwise the laser beam is directed by the plane mirrors M5, M6, M7, M8 and M9 and, after a path of about $30 \mathrm{~m}$, reaches the working plane.

The cutting tests have been performed both with transmissive (lens) and reflective (mirror) devices as focalizing elements. In Table I the most significant cutting results, mainly obtained with a focal length of 20 inches, are summarized. The assistant gas (Oxygen) was utilized at $800 \mathrm{kPa}$ with about $5000 \mathrm{l} / \mathrm{h}$ flow rate; the laser power was $4 \mathrm{~kW}$.

Table I. Laser cutting of mild steel Fe $42 \mathrm{C}$ and AISI 304 stainless steel with the S.P. 975 source. Main results.

\begin{tabular}{|c|c|c|c|l|}
\hline $\begin{array}{c}\text { Test } \\
\text { number }\end{array}$ & Material & $\begin{array}{c}\text { Sample } \\
\text { thickness } \\
\text { (mm) }\end{array}$ & $\begin{array}{c}\text { Cutting } \\
\text { speed } \\
\text { (cm/min) }\end{array}$ & Notes \\
\hline 1 & Fe 42 C & 15 & 30 & Good cut without attached slag \\
2 & Fe 42 C & 15 & 50 & Cut with some attached slag on the bottom \\
3 & AISI 304 & 15 & 30 & Good cut \\
4 & AISI 304 & 15 & 50 & Complete cut only every now and then \\
5 & Fe 42 C & 30 & 20 & Good cut \\
6 & Fe 42 C & 30 & 25 & Cut with some attached slag on the bottom \\
7 & AISI 304 & 30 & 20 & Cut with some attached slag on the bottom \\
8 & AISI 304 & 30 & 25 & Not complete cut \\
9 & Fe 42 C + & $30+5$ & 15 & Cut with some attached slag on the bottom \\
\hline
\end{tabular}

\subsection{Discussion}

In order to predict the laser cutting capability at long distance it is necessary to know the optical characteristics of the beam. The propagation parameters can be obtained by a theoreticalexperimental procedure and the relative numerical program.

Several high thickness laser cutting tests have been carried out on metallic materials. The values of the process parameters are valid if associated with the specific laser source utilized in the research and might be improved with beams having an energy distribution closer to the fundamental mode.

The thicknesses involved in the dismantling of components of a Nuclear Power Plant require at least a $10 \mathrm{~kW}$ laser source at the output window, metallic optics with a small absorption coefficient and a good system for feeding the assistance gas to the interaction zone.

\section{STUDY OF APPLICATION OF THE LASER TECHNIQUE TO THE DISMANTLING OF ONE SPECIFIC NUCLEAR COMPONENT}

\subsection{Main lines of the study}

The results of the research programme pointed out that the laser technique can be attractive if the dismantling activity concems nuclear components characterized by high radiation fields and reduced operating space. Consequently the applicability study has been referred to the Garigliano "steam drum", which represents the above-mentioned conditions very well.

It is a steam demister (Figure 6) located above the reactor vessel and composed of a cylindrical, horizontal axis tank, with $2134 \mathrm{~mm}$ inside diameter and $19965 \mathrm{~mm}$ length, made of carbon steel clad inside with a stainless steel layer. The tank contains various stainless steel components (filters, moist separators, manifolds), installed closely to one another.

The "steam drum" is considerably contaminated and its eventual demolition in such conditions would involve large radiation doses to the personnel. 


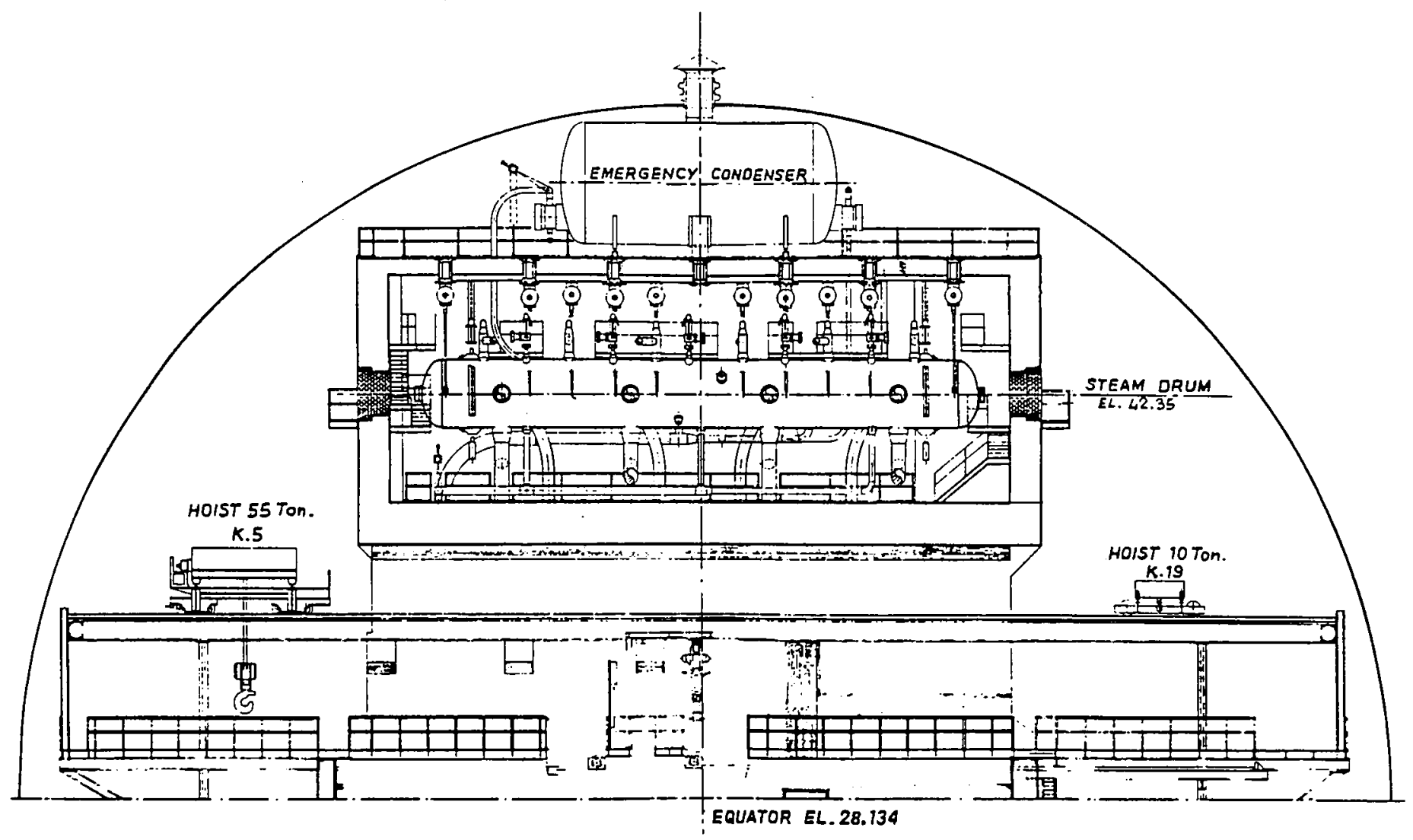

Figure 6. Steam drum. 
The applicability study includes a detailed consideration of the component through its manufacturing drawings, a preliminary study of the facilities required for the dismantling (including the laser, appropriate robots, hoisting devices, auxiliary equipment) and the most suitable dismantling operation and procedure.

\subsection{Main facilities}

The laser set (Figure 7) composed of an electric switchboard, cooling system, laser generator and optical module, will have a power (on the beam) of $10 \mathrm{~kW}$.

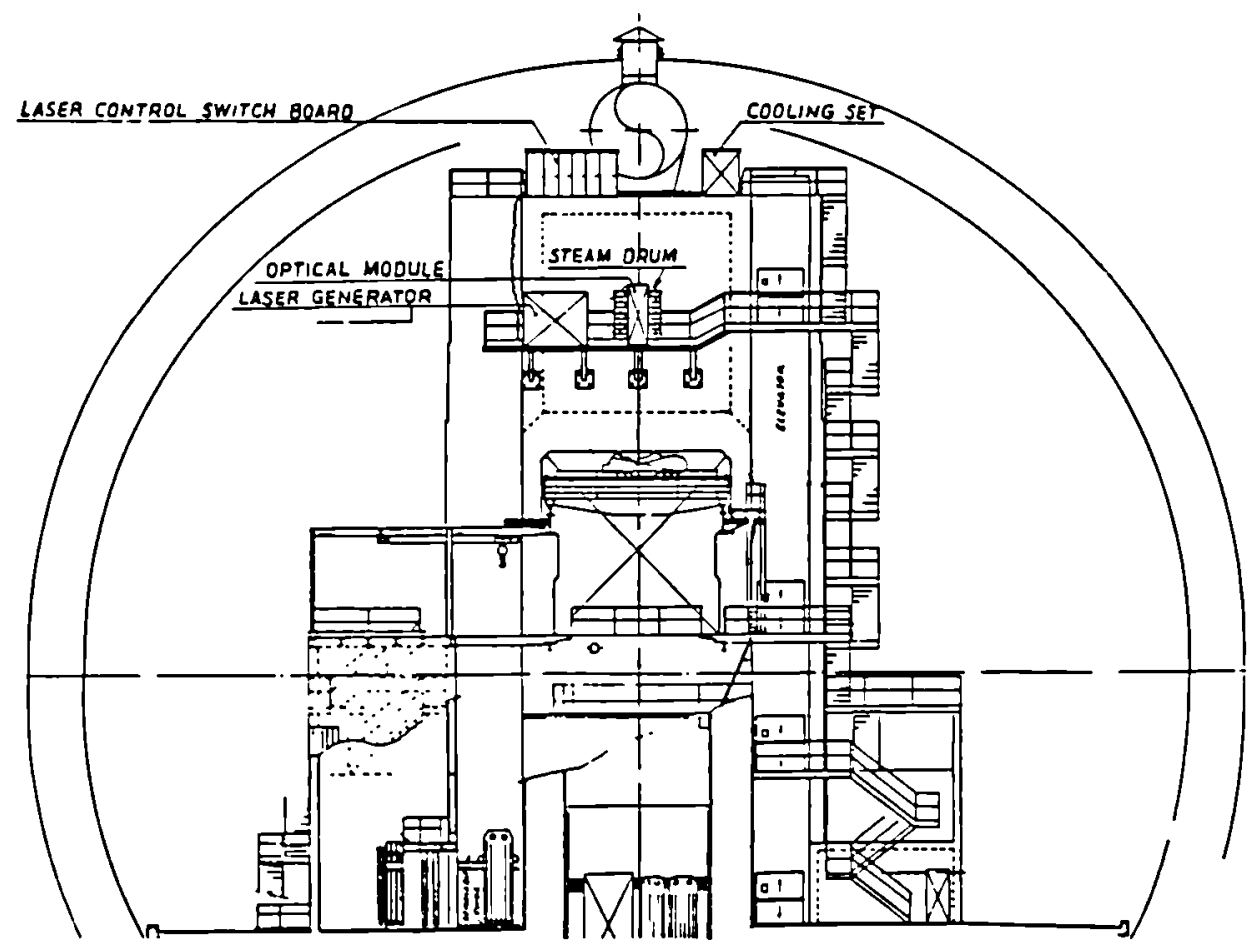

Figure 7. Laser set location.

The robot for cutting and removal of the steam drum's inner parts (Figure 8) will have the following characteristics:

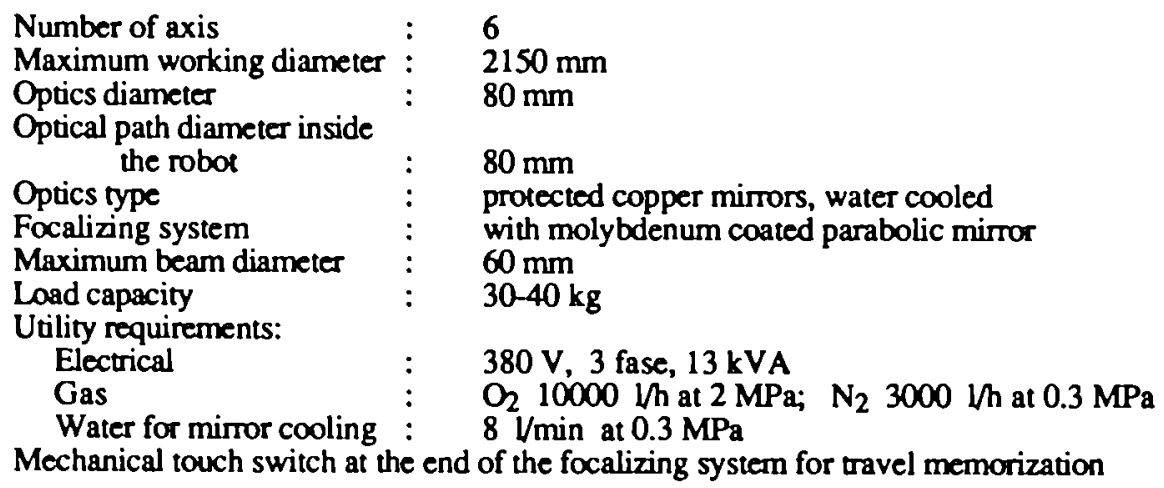




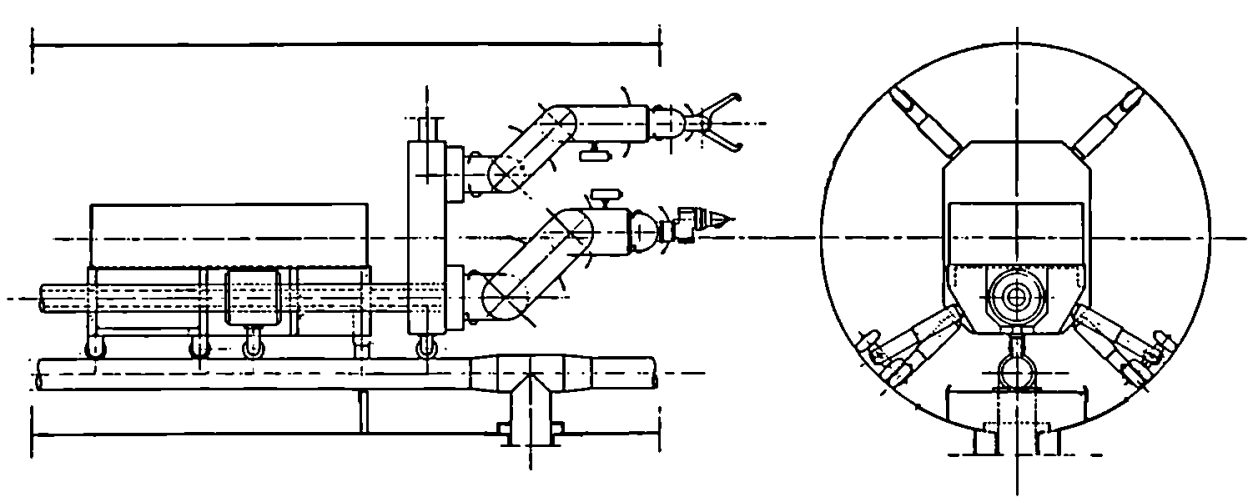

Figure 8. Laser robot for cutting and removal of the "steam drum" inner parts.

Proper ventilation systems will be installed to maintain the working room slightly under pressure with respect to the outside ambient. Furthermore, during cutting, suitable aerosol local abatement systems will be provided in order to reduce contamination propagation.

\subsection{Dismantling operation and procedure}

All the steam drum's dismantling operations should be remotely actuated by operators located outside the cutting room.

Access to this room should be required only for the preliminary activities (steam drum decontamination and isolation), for area preparation (working room confinement and installation of the facilities), maintenance or adjustment of the apparatus and in the case of possible equipment repair.

\section{CONCLUSION}

As a general conclusion, one can affirm that the possibility of using the laser beam in long distance steel cutting has been proved; for samples thicker than some centimeters some improvement must be carried out in the cutting facility. The aerosol produced, even if well characterized as one of the main aims of the research program, still presents problems of abatement and filtration. These problems, on the other hand common to other high temperature cutting methods in atmosphere, need further investigation.

\section{RFERENCES}

1) P.C.Reist. Introduction to Aerosol Science. Macmillan Publ.Co., New York, 1984.

2) Handbook of Chemistry and Physics. CRC Press, Cleveland (USA), 1970.

3) B. Migliorati and P. Gay. Advanced Cutting Technique: Laser Beam Cutting. Proc. European Conf., May 1984, EUR 9474, 1984. 
ADAPTATION TO TELEOPERATION OF AN EXISTING AIR-TIGHT
MODULAR WORKSHOP FOR REMOTELY CONTROLLED OPERATIONS

GASC Bernard

JEANJACQUES Michel

TECHNICATOME, BP $N^{*} 17$ - 91192 GIF SUR YVETTE (FRANCE)

\begin{abstract}
The purpose of the research program is to extend the capabilities of an existing air-tight modular workshop dedicated to the treatment of alpha contamined materials to other beta-garma contaminated materials. In this connection, new elements have been developed and tested in a modular workshop used as testing facility as operations previously carried out by operators wearing ventilated suits should be from now on controlled by teleoperation from outside of the workshop. The test results enabled qualifying dedicated materials, which enlarged to some extent the field of applications of the air-tight modular workshop.
\end{abstract}

\title{
1 INTRODUCTION
}

The CEA in connection with TECHNICATOME has developed a tight modular workshop for dismantling the ATl plant facilities in LA HAGUE. This workshop, constructed of re-usable stainless steel panels assembled by bolting, provides a tight and decontaminable working zone compatible with any $k$ ind of buldling configuration. The operators wearing ventilated sults may work on alpha-contaminated materials under the best safety conditions.

For the purpose of extending the workshop working capabilities, this research program covers the implementation of special modular components for teleoperation as in a conventional cell.

The following components were designed and constructed for their easy adaptation with the existing modular system :

- manipulator holder panel,

- swivelling hatch panel,

- wall equipment sealed transfer device,

- modular biological protection.

With prior tests and trials carried out in a workshop in operation such components are now being qualified for remotely controlled treatment of beta and gamma-contaminated materials in tight modular workshop, for compliance with a protection standard of up to $100 \mathrm{~mm}$ thick lead.

\section{DESCRIPTION OF THE EXISTING MODULAR HORKSHOP}

\section{1 objectives}

The workshop is devoted to contaminating operations or 'nuclear cleanliness operations' to be performed with safe and tight containment. It is adaptable to the dimensions of the premises and materials to be treated and may be connected with an existing containment. All the ele- 
ments are made of fabricated $Z 2$ CN 1810 (304 L) stainless steel sheets so as to be easily decontaminable and re-usable. All the elements are easily and quickly assembled.

The operators may work in the workshop with ventilated suits, owing to a SCALHENE airlock.

\subsection{Design}

The modular workshop walls are composed of standardized square and/or rectangular panels, 1.5 to $2 \mathrm{~mm}$ thick; the edges being folded to the outside provide stiffness of the walls and tightness by means of bolteddown compression seal. The inner surface is plane and smooth.

Volumes are provided by panels assembled by angle pieces and secured to the groundfloor and to the building walls by modular hoops.

Allowable negative pressure in the whole workshop: $300 \mathrm{~Pa}$ for $2 \mathrm{~mm}$ thick panels, this value being slightly superior to that prescribed for zones classified 3 and 4 , respectively $140 \mathrm{~Pa}$ and $220 \mathrm{~Pa}$.

\subsection{Details on Existing Elements}

\subsubsection{Panels and Volumes}

- standard panels :

-Dimensions: $0.4 \times 0.4 \mathrm{~m} ; 0.4 \times 0.8 \mathrm{~m} ; 0.4 \times 1.6 \mathrm{~m}$

$$
0.8 \times 0.8 \mathrm{~m} ; 0.8 \times 1.6 \mathrm{~m}
$$

- groundfloor hoops and angle pieces :

- Dimensions : 0.4 to $2.4 \mathrm{~m}$ in length

- gussetted angle irons

- dual-wall panels used for partitions (same dimensions)

\subsubsection{Penetrations and Passage ways}

- for the personnal :

- without ventilated suits : various tight doors

- with ventilated suits : SCALHENE airlock, push-type door

- for the equipment :

- single or double doors of various dimensions,

- guillotine type doors $(3.2 \times 2.4 \mathrm{~m})$,

- equipment and waste drum airlock,

- frame panels $(1.6 \times 1.6 \mathrm{~m})$, opening of $1.2 \times 1.2 \mathrm{~m}$; a plate is attached to the frame with screw-clamps; a flat gasket provides tightness.

- for utilities :

- frame panels with penetration plates, with optional equipment,

- special panels for tingt penetrations for cables and pipes,

. ventilation panel.

- for vision and lighting :

- frame panels with transparent plates,

- frame panel for lighting $(0.8 \times 1.6 \mathrm{~m})$. 


\subsubsection{Assistance to Handling}

The workshop may be equipped, if need be, with special panels providing a rolling path for a (motorized or not) handling beam. Theses modular panels ( $0.4 \mathrm{~m}$ in width) fitted in the vertical walls are decontaminable. Stress pick-up is ensured by a set of external beams in compatibility with biological shielding, if necessary.

\subsection{Expertise Gained}

Apart from the large facility constructed in La Hague (see Figure 1), other modular workshop have been set up as yet such as :

- the pipe cutting workshop installed in Marcoule for dismantling G2;

- the containment enclosure of an underwater cutting workshop in Cadarache;

- the teleoperation inactive testing cell of the qualification station for dismantling equipment of IPSN/UDIN in Fontenay-aux-Roses. All the operators of such workshops are fully satisfied of their advantages :

- easy assembly and adaptation,

- good standard of tightness, and appropriate mechanical strength,

- easy cleansing and decontamination.

\section{PROGRAM FOR EXTENSION TO TELEOPERATION}

The above described modular workshop allows to work in a zone isolated from the environment under excellent safety conditions. It is well adapted to any intervention on alpha-contaminated materials.

Should the concerned materials be irradiating, teleoperation in necessary using appropriate blological shielding. In this regard, the EEC, CEA and TECHNICATOME have jointly worked out a project devoted to teleoperation with prior development of the following items :

- a system for telemanipulator holder;

- a system for motorized opening making it easier to gain access to the equipment;

- a device for tight transfer of the removable wall equipments;

- a modular system for biological shielding.

The extension program already completed covered firstly, the design and construction of the components of the above mentioned systems, and secondly their assembly and testing on a cell made of modular panels. This cell dedicated to testing the dismantling tools in inactive conditions and for teleoperation comes under the testing facilities of the dismantling equipment qualification station of CEA/IPSN/UDIN set up in Fontenay-auxRoses.

Note that the design and construction of such elements had to comply with the general plant design : modularity, easy assembly and decontamination, low cost.

\section{PROGRAMM PERFORMANCE AND RESULTS}

\subsection{Telemanipulator-holder System}

The system should be designed to accomodate two tight telemanipulator-holder sleeves (standard dia. $254 \mathrm{~mm}$ ) fulfilling the same functions as in conventional cells. 


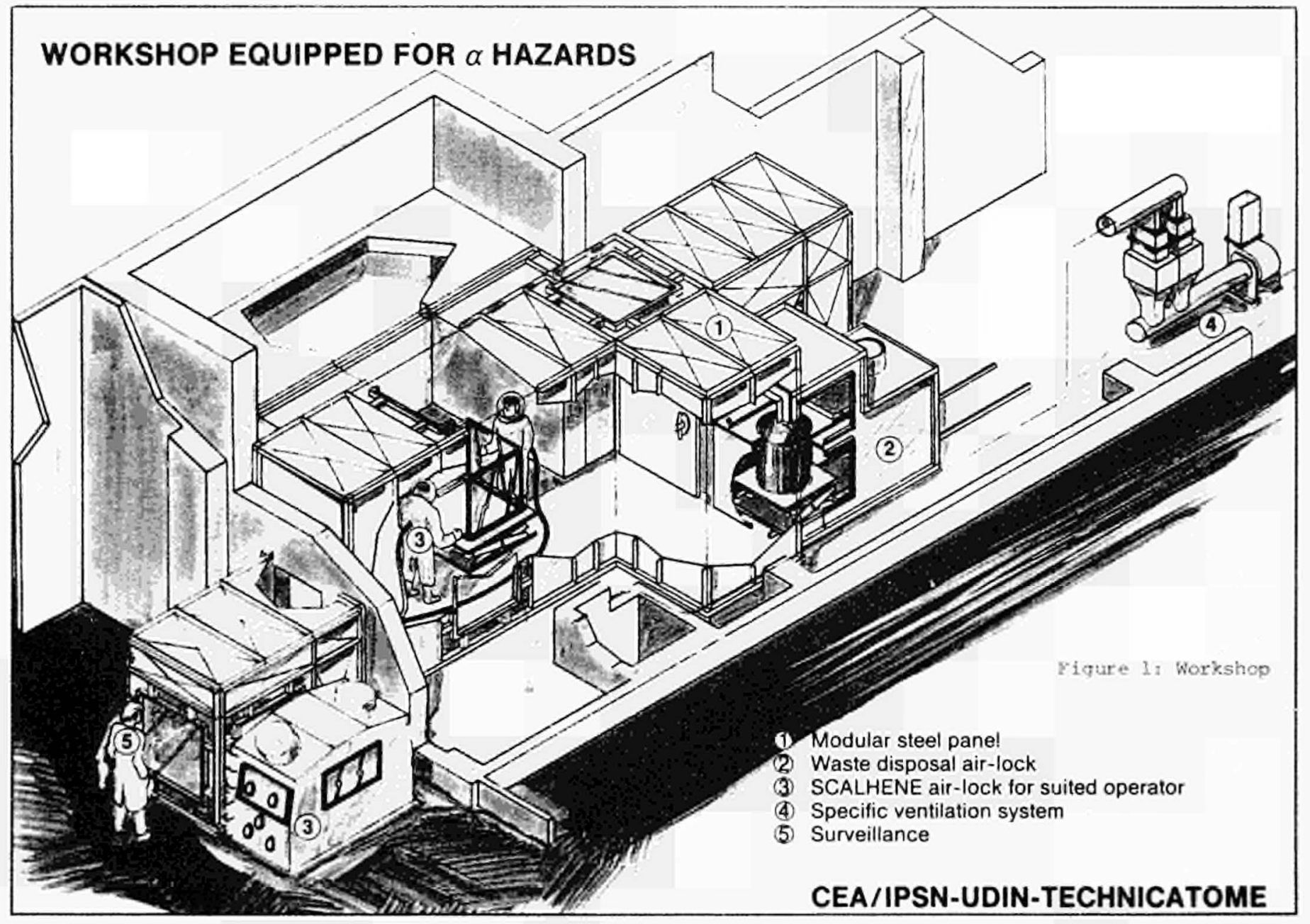


The solution resulted in constructing a telemanipulator panel including the following elements starting from groundfloor :

- a standard pane1 : $0.8 \times 1.6 \mathrm{~m}$,

- a vision frame panel : $1.6 \times 1.6 \mathrm{~m}$,

- a telemanipulator holder panel,

- angle brackets and split-fittings for stress pick-up (see Figure 2).

The telemanipulator holder panel $(0.8 \times 1.6 \mathrm{~m})$ is provided with two apertures of same standard diameter as the sleeves. The structure supporting the sleeves comprises a grooved plate fitted with supporting lugs which will be screwed on split-fittings bolted in turn on angle brackets.

All vertical loads and momentums from the telemanipulators are thus picked up by angle brackets with no strain on the cell panels.

The workshop may be equipped with all the telemanipulators currently used in nuclear plants owing to a set of sleeve extending tubes.

For testing the system mechanical strength, the sleeve free end displacement was measured under vertical stress. The moment applied onto the supporting plate (up to $3000 \mathrm{~N} . \mathrm{m}$ ) is transmitted to the support angle brackets via support lugs and split-fittings.

The system behaviour remained elastic within the normal use conditions of the telemanipulators. No difficulty was encountered in installing and operating the telemanipulators.

\subsection{Motorized Opening System}

The system should be designed for easy transfer of components to be dismantled from the outside into the worshop using conventional hoisting equipment. In the solutions opted for a motorized swivelling or sliding hatch is fitted on a standard frame panel $(1.6 \times 1.6 \mathrm{~m})$. In closed position the hatches must provide the same containment and tightness standard as in the whole workshop.

- Swivelling hatch panel

The final version is shown in Figure 3. It comprises frame panel (1.6 $\times 1.6 \mathrm{~m}$ ) with flat joint, forming part of the workshop roof; the hatch relies on the standard frame panel by means of four pneumatic snap-fasteners. The joint release movement and rotation are ensured by two ball thrust bearings and a pneumatic jack mounted on a plate fitted on the frame panel.

When open, the hatch is in the vertical position and gives free access to the complete frame panel aperture $(1.2 \times 1.2 \mathrm{~m})$.

- Sliding hatch panel

As above, the hatch is designed to be installed on a standard frame panel $(1.6 \times 1.6 \mathrm{~m})$ included in the workshop. The structure supporting the hatch slides along two sliding guides made of $U$-shaped pieces owing to spring-type handling balls. Translation is provided by pneumatic jack.

When the plug is put in position above the aperture, it is pushed onto the frame-panel joint by four small pneumatic jacks. In this case, the tightness and interlocking functions are likewise independent from the opening/closing function. 


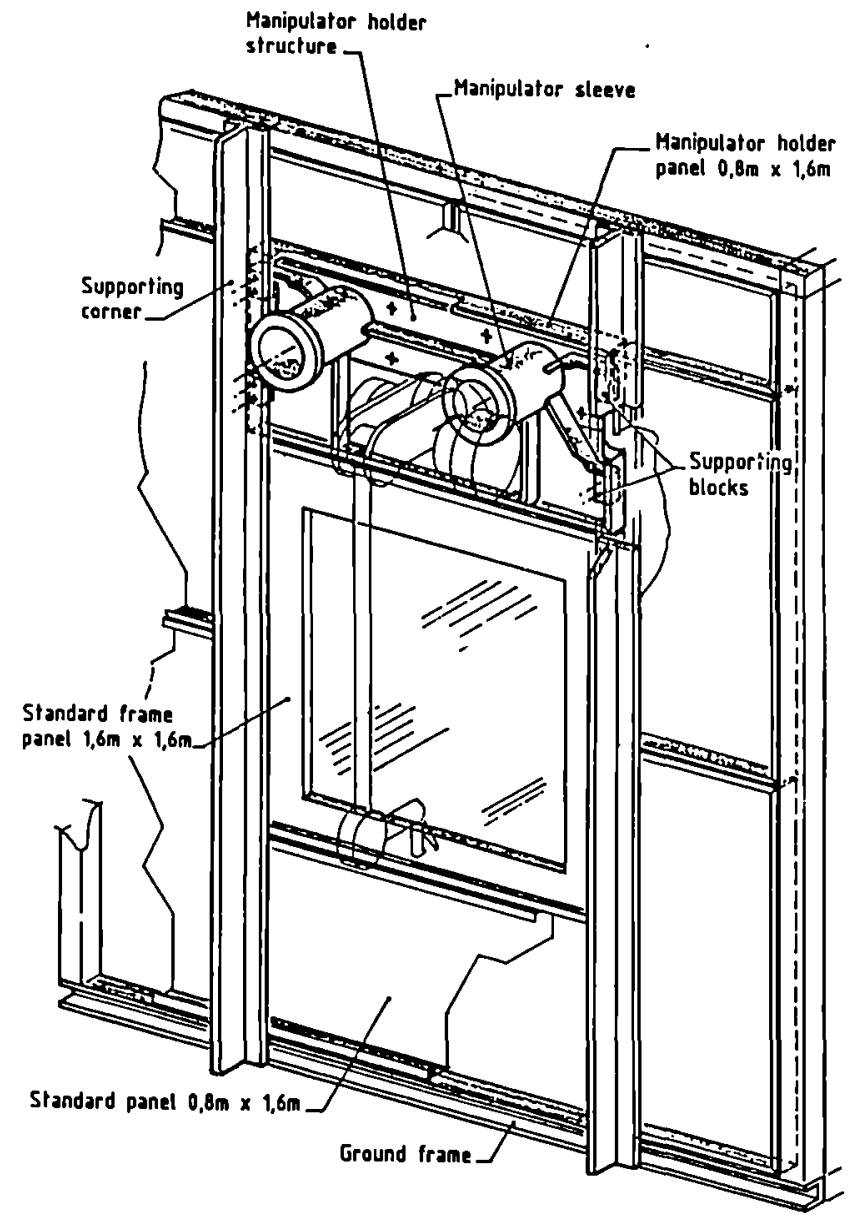

Figure 2: Telemanipulator holder structure

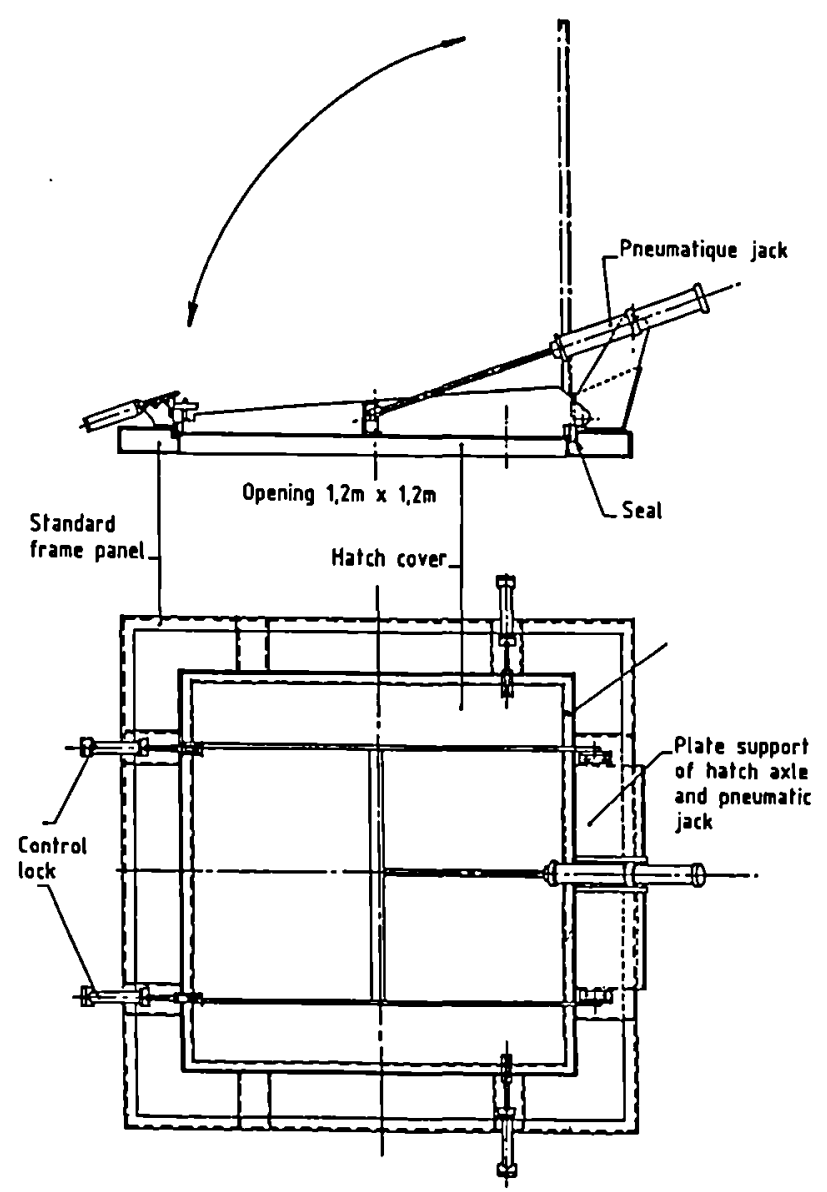

‡ั

Figure 3: Swivelling hatch panel 


\subsection{Tight Transfer System for Removable Wall Equipment}

This system should support wall-type equipment such as camera sets, sensors, etc. while enabling maintenance without any rupture in containment owing to equipment transfer in glove-box.

The solution opted for comprises a connection channel developed by LA CALHENE Cy together with interfaces and accessories for assembly on the modular workshop. Note that the purpose of the connection channel is to ensure tight liaisons between containment enclosures, and the ir disconnection, while keeping with tightness functions.

The 'cell door flange' (mark 1) as shown in Figure 4 is screwed up on the first enclosure wall aperture owing to screwing ring acting as counterflange. The channel bellows flange (mark 6 ) is bolted on flange (mark 14) welded on the second enclosure wall. The channel end is fitted with a 'container flange' plugged with a container door which is the same as that of the LA CALHENE type waste storage container.

Connection is performed as follows :

- channel berthing with cell flange,

- release of channel bellows,

- locking of the 'container flange' by rotating on the cell flange; this manoeurre results in the automatic locking of the two doors one after the other (which explains the designation of the so-called dual-door),

- unlocking of the dual door and removal in the corresponding enclosure.

The efficency of the system originates from the bellows flexibility which allows for some deviation in alignment for connecting and disconnecting with no need for moving the enclosures.

A mounting interface was developed to benefit from the various possibilities for using the connection channel ; it relates to a frame panel $(0.8 \times 0.8 \mathrm{~m}$ with $0.55 \times 0.55 \mathrm{~m}$ aperture) on which supporting plates may be fitted with screw-clamps. On the bellows side, the channel is assembled by means of a plate on which is welded the corresponding flange; the cell door flange is mounted by means of a plate pierced for the adequate aperture.

The wall equipment is supported by a container door fitted with a flat-bottom cylinder as shown in Figure 5 . This device may be transferred into a glove-box equipped with cell door in keeping with containment and without any risk of contamination of the door external walls owing to the dual-door principle.

The frame-panel unit mounted on modular workshop, the interface plate, the connection channel and glove-box and/or tight enclosure fitted with cell door flange are used to provide a temporary or durable connection between both enclosures for transferring equipment with dimensions compatible with the channel size. Moreover, provision of the cell door flange on the workshop, enables berthing of the LA CALHENE type waste storage container as shown in Figure 5.

To conclude, the above described system is qualified for supporting removable wall equipment and subsequent tight transfer in glove-box, for transferring equipment from the modular workshop towards containment 

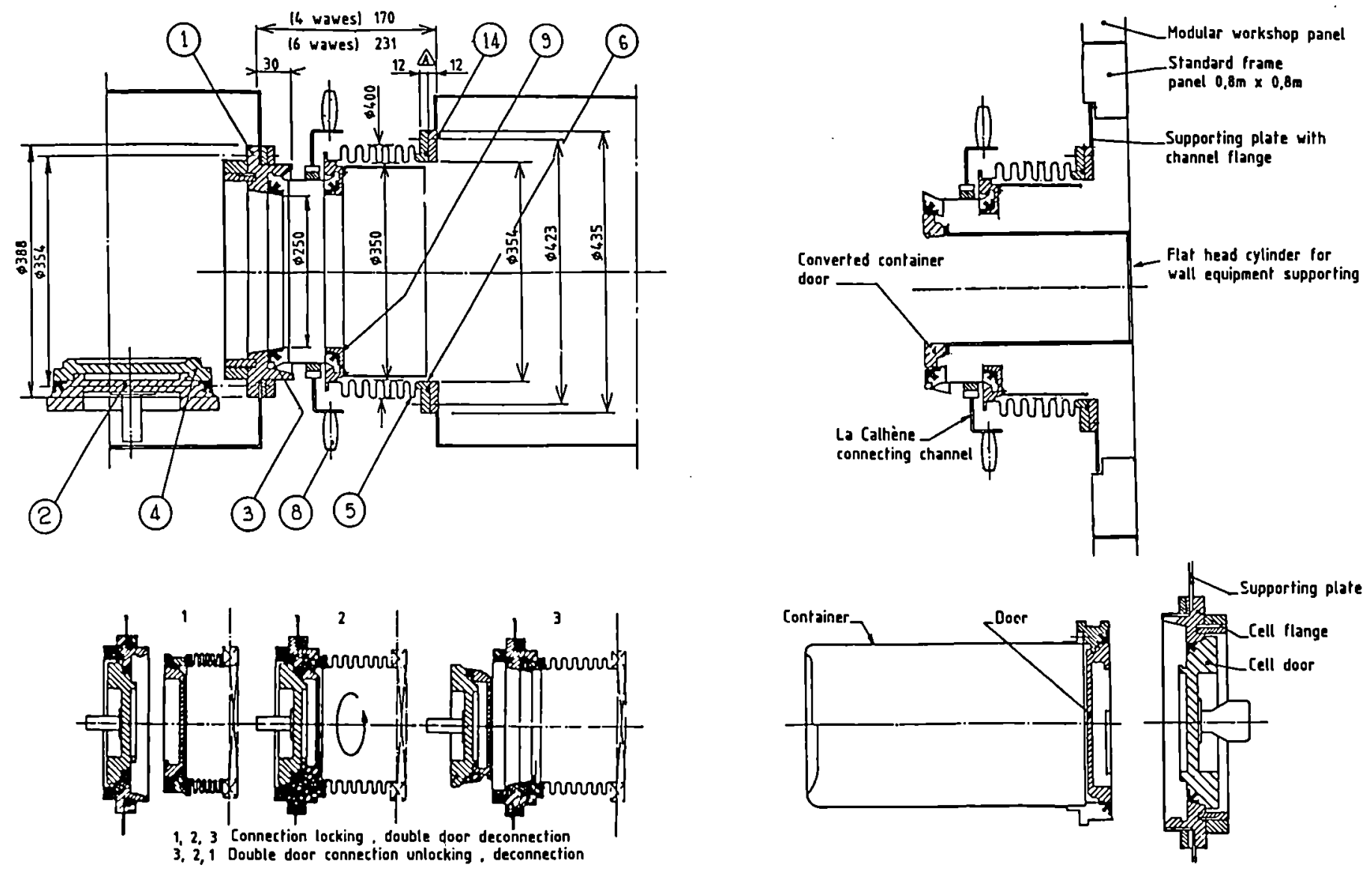

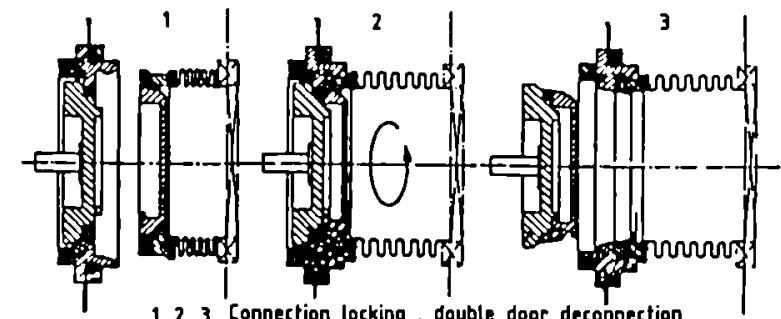

1, 2, 3 Connection locking double door deconnection
3. 2,1 Double door connection unlocking, deconnection

Figure 4: Sketch and principle of tight transfer of La Calhène connecting channel
Figure 5: Examples of connecting channel utilization

- supporting of removable wall equipment

- waste evacuation with La Calhène container 
enclosures such as: existing cell, other worskhops or glove-boxes or vice-versa.

\subsection{Biological Shielding System}

The modular worshop is well adapted to handling of alpha-contaminated materials with no need for additional protection. Nevertheless, it may be necessary to resort to additional protections for the treatment of betagamma contaminated materials.

This being the case, option was made for providing a protection by heaping up $25 \mathrm{~mm}$ thick lead plates up to $100 \mathrm{~mm}$ in height, appropriately attached from outside.

The design opted for features the following as shown in Figure 6 :

- $25 \mathrm{~mm}$ thick lead plates $(0.8 \times 0.8 \mathrm{~m}$ and $0.8 \times 0.4 \mathrm{~m})$ with two inserts on either edge for handling purposes.

- offset assembly of a plate layer with respect to the other so as to

eliminate radiation leacks at the joints;

- modular structure including vertical T-shaped pieces bolted on the panel edges at $0.8 \mathrm{~m}$ intervals, for securing the lead plates. For adaptation purposes, each T-schaped piece is composed of a screwed steel plate (section : $60 \times 10 \mathrm{~mm}$ ) with welded struds for panel attachment and a steel T-shaped piece base (section $20 \times 50$ or $20 \times$ 75 or $20 \times 100 \mathrm{~mm}$ ) depending on the selected lead thickness.

- The lead panels are placed between the T-shaped pieces and held in position by lead plate strips screwed on the angle bracket bases.

- The lead plates are vertically relying on each other so that the weight is directly picked up by the ground.

This system has been tested as a complete unit mounted in the cell of the workshop set up in Fontenay-aux-Roses (dimensions : $0.8 \times 3.76 \mathrm{~m}$ and thickness : $2 \times 25 \mathrm{~mm}$ ).

No specific difficulty was noted in assembling the T-shaped pieces or in handling the lead plates. Therefore qualification of the biological shielding was obtained for its integration in the tight modular workshop.

\section{CONCLUSIONS}

The new components incorporated in the modular workshop allow for its utilization in the teleoperation mode owing to the following functions :

- supporting of standard telemanipulators (dia. $254 \mathrm{~mm}$ ),

- tight access to equipment via motorized hatches mounted on frame panels,

- tight transfer of equipment items of dia. less than $250 \mathrm{~mm}$ towards another tight enclosure or vice-versa,

- support of removable wall equipment and tight transfer in glovebox,

- modular biological shielding of the workshop : up to $100 \mathrm{~mm}$ of lead may be added up to the existing standard and special panels; these are now qualified for working in teleoperation mode. 


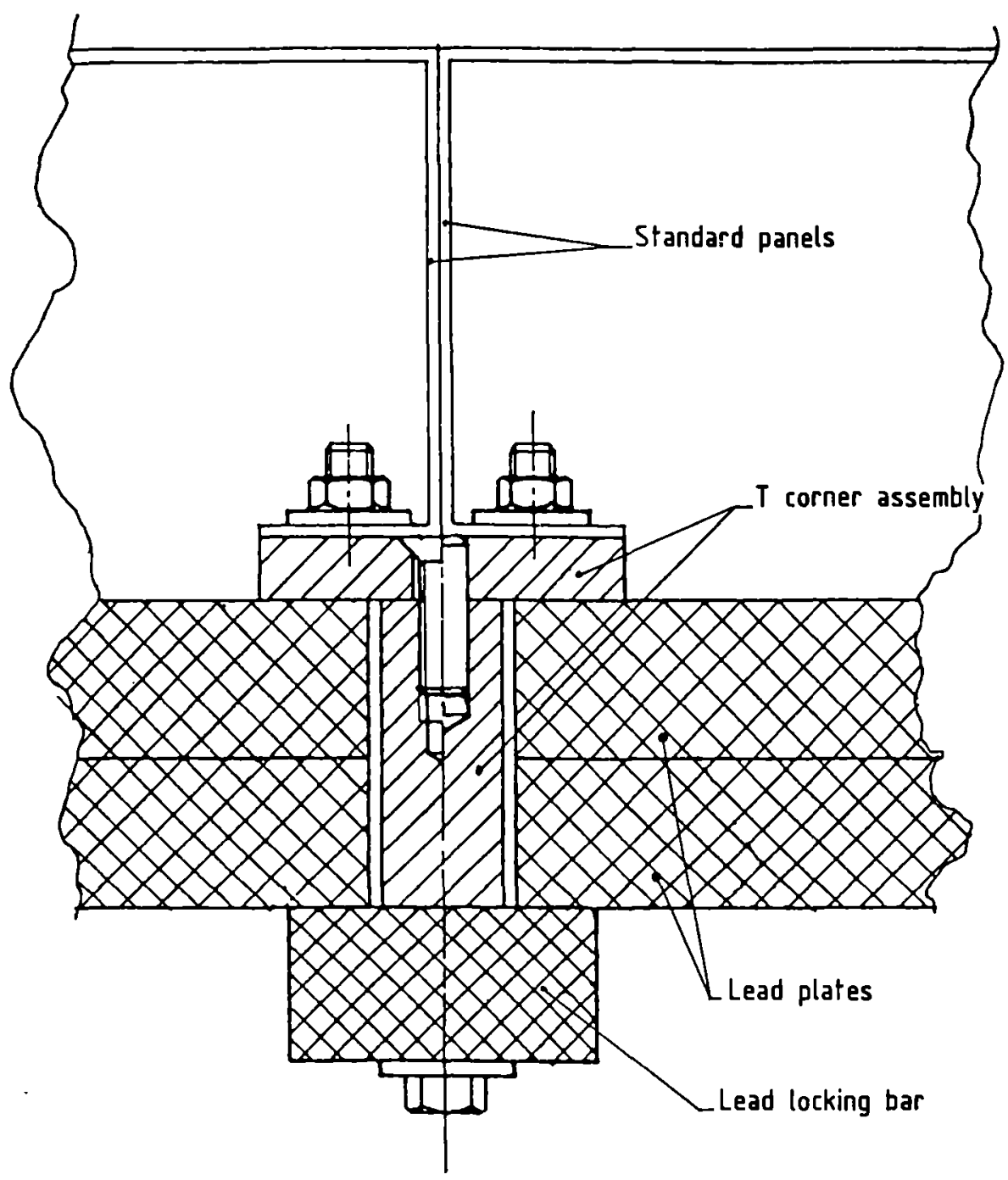

figure 6: Cross section of the $50 \mathrm{~mm}$ thick lead biological protection 
DEVELOPMENT OF MEASURING AND CONTROL SYSTEMS FOR UNDERWATER CUTTING OF RADIOACTIVE COMPONENTS

P. DREWS and $K$. FUCHS

Prozessteuerung in der Schweisstechnik, RWTH Aachen, FRG

\section{Summary}

The underwater dismantling of nuclear power plants has to be remotely controlled with simultaneous optical control by underwater cameras. It is this optical control in particular that leads to problems as, for example, abrasive wheel cutting is subjected to a wide range of interferences so that a minimum of contrast and blurred contours of camera images must be accounted for. This paper describes a new image processing system that has been developed in addition to the use of a modified underwater TV camera for optical cutting process control (plasma and abrasıve wheel cutting). Workpiece recognition is performed through the comparison of actually measured objects with pre-trained reference patterns allowing the determination of object location and orientation, the data of which are then supplied to the handling controller.

A completely satisfactory prototype system has been built, which is capable of performing image analysis (workpiece recognition, workpiece position, etc.) as well as the control of a handling system with an inductive sensor (distance detection, edge recognition and distance control). With an additional camera the operator has the means of visual process observation. The overall functioning of the system has been tested and demonstrated with a four-axes handling system.

\section{CAMERA FOR HORKPIECE RECOGNITION}

A new lmage processing system with a solid-state camera has been developed, built and adapted to workpiece recognition tasks with special consideration of the rough work conditions typical of cutting procedures. The camera system is thus suitable for extreme conditions like cutting under water.

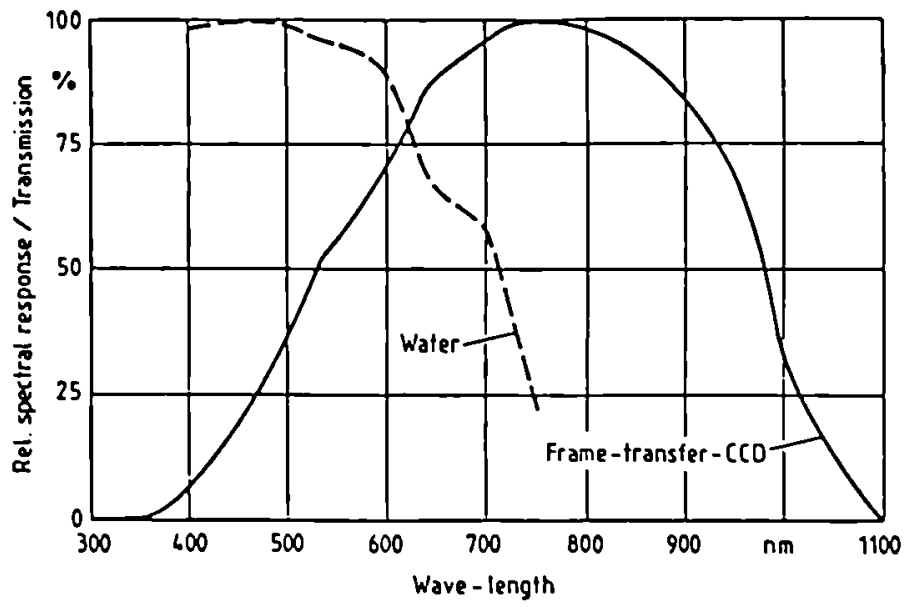

Fig. 1. Spectral response of the solid-state camera 
Figure 1 shows the spectral response of the solid-state camera and also illustrates the spectral transmission course of water in comparison with the spectral sensibility of the solid-state camera. The overlapping of the curves leads to a range of wave length of only 500-700 nm to illuminate a given scene. The use of halogen reflector lights is therefore a reasonable means.

For image pick-up, the semiconductor camera uses an image matrix of 128 * 128 pixels with $60 \mathrm{~nm}$ a distance. The controller of the camera provides a number of signals for surveillance and control of the camera functions. It is possible to adjust the pixel scanning frequency within a range of $0.25 \mathrm{MHz}$ up to $5 \mathrm{MHz}$ corresponding to an image frequency of up to 260 images/sec. The camera computer is fitted with two image storages to which optional access through reading and writing is possible. In the image storages, the binary as well as the grey-scale value are simultaneously stored. The internal arrangement of any image storage allows simultaneous reading and writing access of the processor to the contents of the image storage while the camera's writing is in progress. Figure 2 presents the block diagram of the camera system processing the image.

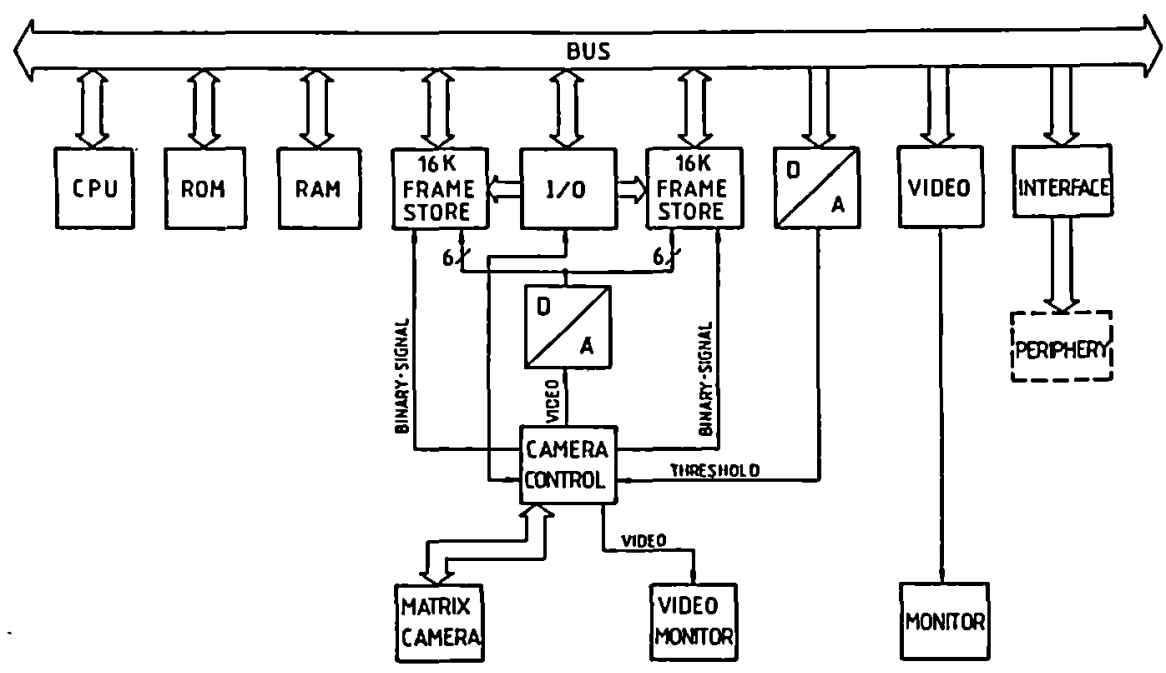

Fig. 2. Block diagram of camera system for workpiece recognition

Communication with the handling system is intended to be performed by parallel interfaces. By sending the command 'start measuring' to the camera system via handling system control, synchronization and initiation of a measuring cycle is effected. After measuring, information on location of object, orientation and measuring errors is available to parallel ports for further processing.

\section{DESIGN AND ASSEMBLY OF AN OPTICAL CAMERA SYSTEM WITH SIGNAL PROCESSING AND EVALUATION THROUGH MICROCOMPUTER CONTROL}

Any image is presented to the computer as a digital matrix of greyscales. The job of an image processing system is to break the images up into segments, to attach internal patterns to these segments and so provide a description of the objects involved in a given scene together with their 
locations. For the retrieval of this information, problems arising in information pre-processing, information reduction, segmentation, feature extraction, representation and analysis, need to be tackled and solved.

\subsection{Image Pick-Up and Pre-Procession for Interference Reduction}

Image break-up starts off with the synchronous reading and storage of grey-scale image consisting of 64 grey-scales. It is important at the stage of taking the picture that the overall illumination and photographic conditions be selected in a way that the objects to be recognized and measured stand out clearly against the background.

The original image is stored in the first of two image memories. Any further activities, such as, for example, filtering processes, and the storing of intermediate results, are effected in the second image storage so as to allow the original image to be always available for comparison with other images.

The task of image pre-processing is the reduction of interferences (such as dust, etc.) and their impact on the amount of information of interest. For the elimination of fauls caused by the device itself due to defects within the camera system or within the optical system, it is suitable to generate one reference image of the original image.

For the reduction of locationally closely confined interferences, lowpass filtering and weighted average filtering show good results. In order to keep the time consumption for calculation processes within a reasonable limitation, operationg like these should be restricted to small window sizes of, for example, $3 * 3$ dots. The median filter represents an effective, even if time-consuming operation. This operation, as line-orientated filter, eliminates even strong interferences. This method allows any number of interferences of a width smaller than half the filter to be eliminated.

As mentioned above, the workpieces must stand out against the background through a significant change of light intensity. The transitions of light intensity thus given at the edges of the object, whose steepness varies in relation to the photographic conditions, are emphasized in a further pre-processing stage. This permits the segmentation into significant partial areas by applying the filter operation to the entire image. This $3 \star 3$ operation combines low-pass filtering in horizontal and vertical directions and subsequently determines the local difference. With these differences, changes of intensity in lines and in columns are copied as local intensity maxima. As a consequence of the combined low-pass filtering, the result is resistant against random noise which must be paid for with slightly wider contours.

\section{1 .1 Segmentation and reduction of information}

Up to this stage, all operations have been applied to the entire contents of the image. The task of the following image processing is the reduction of this great amount of information to only the relevant information. This is effected by an edge tracking algorithm generating thin, binary contours of the object from the gradient image generated by the sobel operation. Starting from suitable initial points (e.g. points with high gradient value), paths which meet as closely as possible predefined criteria are sequentially generated. With the implemented procedure, starting from the actual edge and its initial direction, any path that can be generated by a change of direction of $0^{\circ},+45^{\circ}$ or $-45^{\circ}$ is investigated into three directions up to a depth of three image pixels. For the appraisal of the respective direction, the total of all gradient values of the nine paths are drawn on. By starting from the actual point the next contour point is 
defined as that which is located in the direction of the maximal evaluation figure. The contour points so determined are stored in a reference list for further procession.

With the implemented algorithm those contour points are marked by flags in the image memory which are reset at the beginning of contour tracking. Before a new contour point is included in the reference list on contour tracking, the flag of this image pixel is tested. If this flag indicates that this image pixel has not yet been marked as contour point, it is included in the list as a new contour point. Otherwise, contour tracking is stopped since a contour point already specified has been reached. A contour is completed if start and end point are the same.

\subsubsection{Specification of characteristic features}

After extraction of the contour, the contour must then be examined as to which features are typical of the workpiece. Since only completed contours are admitted, this line encompasses a piane whose centre of gravity can be specified. Furthermore, the perimeter is calculated in addition to the contour length already determined. Plane and perimeter are set off to the so-called shape factor, being thus an additional characteristic feature of the workpiece. The radius function is a further characteristic feature designating the workpiece. The distance between contour and centre of gravity is calculated and stored as radius function. In developing the radius function, the following special issues must be taken into account. Depending on the respective course of the contour, the centre of gravity can be located outside the completed contour line. This is why no distance value can be determined for some angles. In cases like these, the zero distance value j.s attached to the respective angles. On the other hand, several contour points can belong to part of one angle. In this case, the maximal distance value is assigned to the respective angle. The course of the radius function specified in this way is a characteristic feature which can, on the one hand, serve to distinguish between different workpieces and, on the other hand, allows the determination of the location of a recognized workpiece. Figure 3 clearly illustrates the course of the radius function of a square object.

Radius

RADIUS FUNCTION

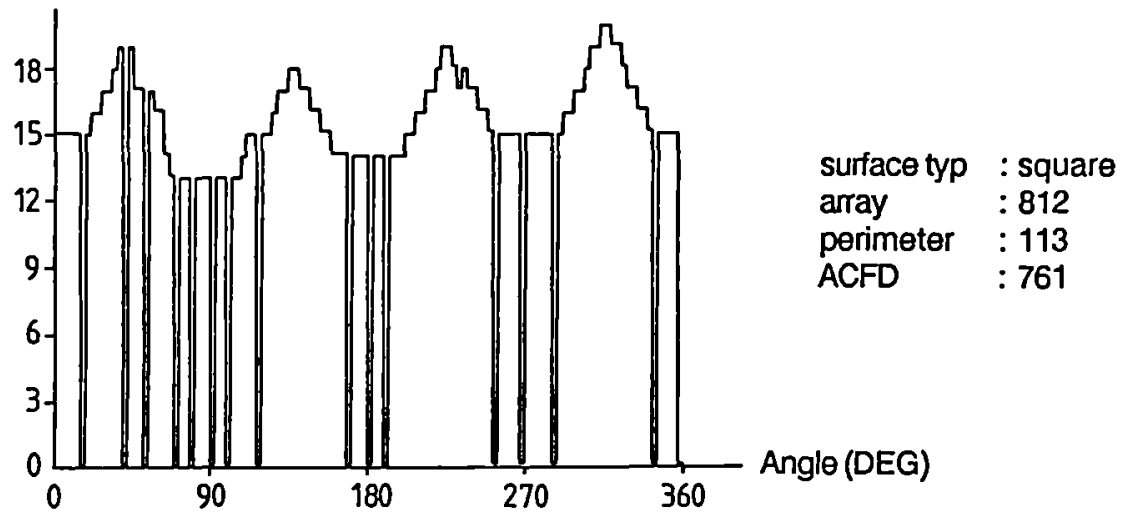

Fig. 3. Typical course of the radius function of a square object 
In order to assign a feature-describing numerical value to the course of the radius function typical of the workpiece, a correlation algorithm has been developed and 1 mplemented:

$$
\operatorname{ACFD}_{v}=\left(\sum_{1=0}^{m-1}\left|v_{(i)}-v((r+i) \bmod m)\right| ; 0 \leq r \leq \underset{m \in N}{m-1}\right)
$$

The maximal value of the ACFD serves as a geometric feature for the detection of a workpiece. Figure 4 illustrates the course of the ACFD of the above square object.

Total of

Difference DIFFERENCE FUNCTION

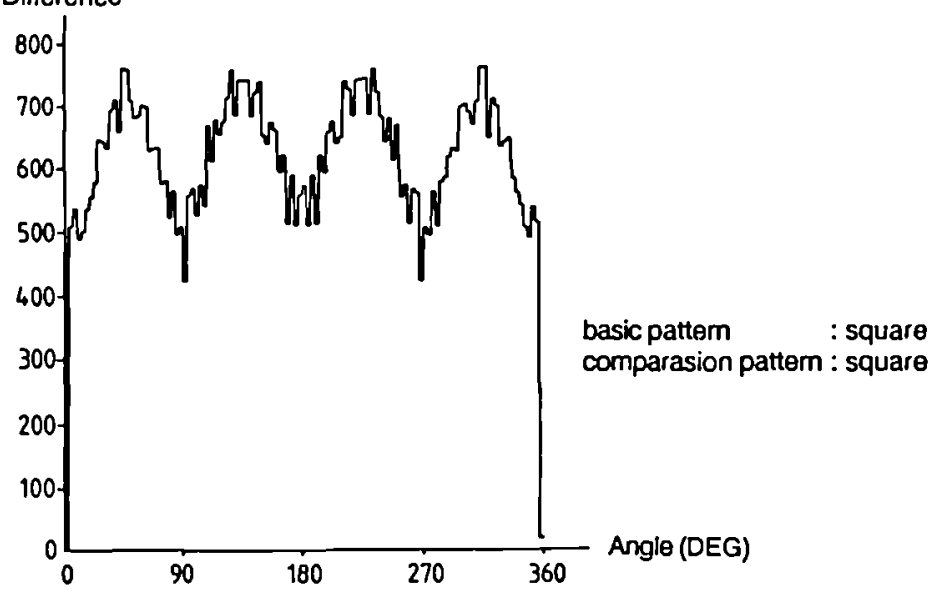

Fig. 4. Auto-correlated function of differences of a square object

Purthermore, this correlation function also serves to determine the orientation of an object recognized in relation to the reference position taught. For this purpose, the radius function of the actual workpiece to be measured is correlated to the radius function of the predefined reference pattern following the above rule. Highest agreement between the reference pattern and the actual pattern is given wherever this correlation function has the absolute minimum. The location of this minimum specifies the deviation of the actual object from the predefined reference position.

\section{1 .3 Object recognition and measurement}

At present, the existing system allows teaching of up to 15 objects each under a different object name as a pattern together with the features plane, perimeter, auto-correlation value and radius function, their storage and their simultaneous availability to be worked with.

In order to compare an actual workpiece with the stored patterns and thereby to recognize the object, a three-dimensional feature vector of the object to be recognized is developed. This vector indicates a certain point in the feature area and is compared with the feature vectors of all the patterns stored. This is achieved by calculating the respective distance botween the actual point from the characterized area and point taken from the pattern. From the amount of patterns the nearest one to the feature 
point of the object actually to be recognized is selected. The absolute value of the minimal distance value has been chosen as a further criterion with the help of which it is decided whether the actual object does exist in the form of a pattern at all and can therefore be recognized. If this distance value exceeds a programmable value, the object is considered not recognized. This indicates, on the one hand, that the object is not known to the system or, on the other hand, that pick-up conditions have decisively changed so that reliable recognition of the object is no longer possible. If the object has been recognized, its orientation is calculated in relation to the adapted orientation. Then the name of the object, location of centre of gravity and orientation, are issued.

with the coupled sensor-handling system, in which the camera is rigidly mounted above the operating range of the handling system for correction of tool movements, camera coordinates must be transformed into the coordination system of the handling system.

\subsection{Work Phase}

During the work phase, the control unit of the handling system sends a request signal to the camera computer. This signal initiates a full image processing cycle. After object measuring is finished, the camera computer supplies the actual information on the type of object, location of object and orientation over to the handling control. The control unit of the handling system uses this information to call up the object-specific motion program, to correct it in accordance with the actual data in terms of location of object and orientation and to start the process.

Figure 5 finally presents the design of the overall system which has been developed to show arrangement of some of the individual components and sensors in cooperative function.

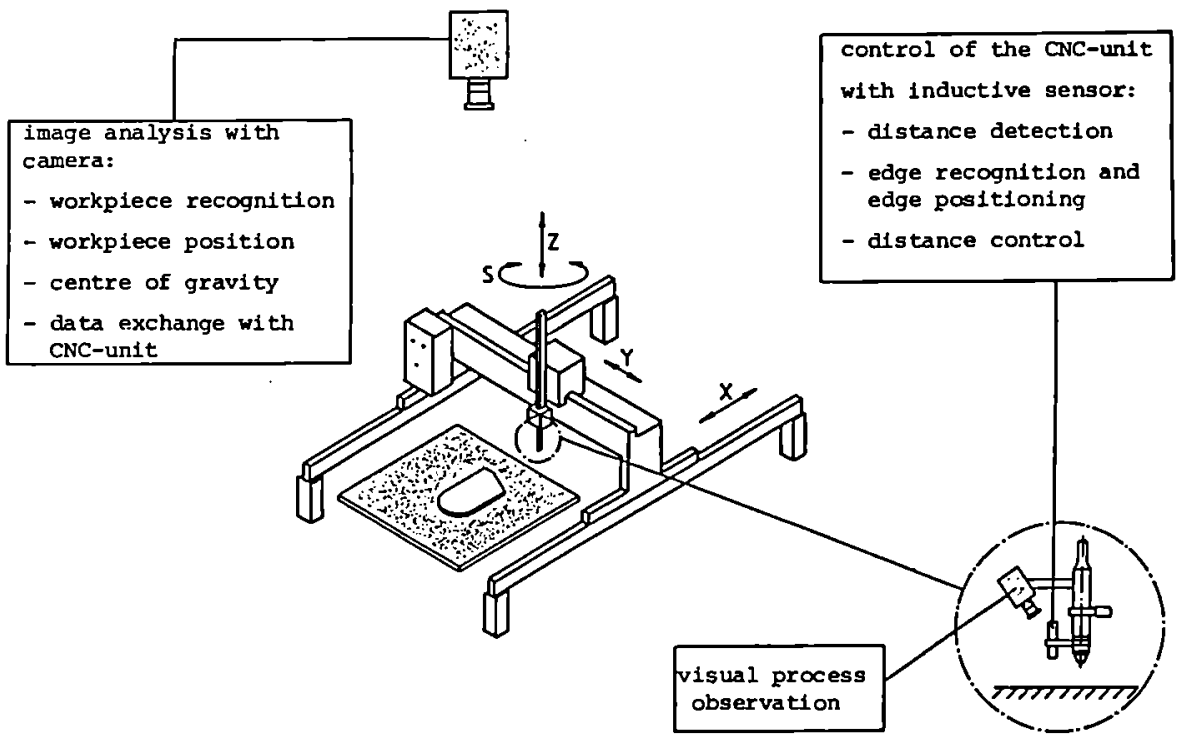

Fig. 5. Camera-controlled cutting of components 


\section{CONCLUSIONS}

A system like the one described above allows the workpiece position under water to be measured in three dimensions by means of a camera system. In addition to this, the possibility exists to adapt handling movements on the basis of the camera information supplied. Fine positioning is performed with the help of additional inductive and optical sensors. The overall operation of the system was tested and demonstrated with a four-axes handling system, leading to the conclusion that the decommissioning of nuclear components under water is definitely possible, provided that the ambient water is clean and that components stand clearly out against the background. 


\title{
DEVELOPMENT OF A PROTOTYPE SYSTEM FOR REMOTE UNDERWATER PLASMA ARC CUTTING AND \\ SECONDARY EMISSION MEASUREMENTS
}

\author{
LEAUTIER Robert \\ Commissariat a l'Energie Atomique, Cadarache, France \\ PILOT GUY \\ Commissariat a l'Energie Atomique, Saclay, France
}

\section{ABSTRACT}

An account of the dismantling of nuclear installations by plasma arc cutting is given by the authors in this conference paper.

These research and development tests of the plasma arc tool are relative to its use under variable conditions (working parameters, remote piloting, cutting environment, radioactive or non-radioactive materials, maintenance) with an assessment of the secondary emissions (gases and aerosols). The nature and concentration of the different gases and aerosols as well as the size distribution of the latter are defined. The balance of the solid secondary emissions is also carried out for certain tests.

1. INTRODUCTION

Research testing relative to dismantling by underwater plasma arc cutting was carried out in the realistic environment of the Pegase reactor hot workshop at Cadarache in close cooperation between the service support Technique (Technical service) and the service de protection des Installations nucléaires (Nuclear Protection service) of Saclay.

This research was done keeping in mind the problem of the "dismantler", and therefore, the following main objectives :

- simplicity, robustness

- remote maintenance of the tool

- semi- industrial character with mockups from real installations

- analysis of harmful emissions

Plasma arc cutting has certain advantages such as low tool reactions during cutting, reduced size of the torch, high cutting speed ( $6 \mathrm{~cm}$ per min for $1000 \mathrm{~mm}$ thickness) (see figure 1). This process requires :

- electricity (200 kw for $100 \mathrm{~mm}$ thickness), gas for plasma, and water for cooling

- the remote control of the tool, 
and generates secondary emissions such as slags, gases, and aerosols

2. THE TOOL : ITS IMPROVEMENT, CONTROL, ENVIRONMENT

Presently available torches, for working in air required considerable modification for remote work underwater.

- Preliminary tests showed that it was essential to maintain a constant distance between the torch and the work piece.

- A mechanical system using ball bearings was therefore adapted (see figure 2).

Numerous tests with different gases such as argon, hydrogen, nitrogen or their mixture were carried out.

Argon has a low ionisation potential and thus enables correct arc control to be maintained.

Nitrogen has high enthalpy and molecular mass. However it generates nitrous by-products which may affect the environment.

Hydrogen makes cutting easier, but is not acceptable for safety reasons.

- The main wearing factor is the forming of parasite arcs on the torch nozzle. The nozzle is now protected by a ceramic sheath against slags.

- Tool control is ensured by a motorized system (see figure 3) associated with a pneumatic spring and inductive sensor system (see figure 4). The edge of the plate is defined by the pilot arc.

The torch system is nuclearized (see figures 5 and 6) in order to facilitate remote changing of main wearing parts (tuyere, electrode and torch body).

These parts are removed using simple tools and replaced by axial interlocking (see figure 7).

- The working environment is equipped with a 3.2 cubic meter modular containment in stainless steel.

This containment is placed above a 1.5 meter diameter, 3 meter deep cutting tank (see figure 8).

The containment has a ventilation circuit, connected to the main bulding. Ventilation system, with a HEPA filter upstream and an electrostatic filter downstream.

The circuit is equipped for measuring gases and aerosols (see figure 9 ).

The air inlet and outlet in the containment are placed so as to prevent the spreading of gases and aerosols.

Standard operating conditions are :

a ventilation flow of $1000 \mathrm{~m} 3 / \mathrm{h}$, a negative pressure of $10 \mathrm{~mm}$ water column. 
3. SECONDARY EMISSIONS

The secondary emissions are mostly constituted by the following elements

- sedimented dross

- attached slag

- suspended particles (taking account of soluble element)

- gases and aerosols in the air and drawn off in the ventilation circuit.

As an example, following the cutting of a stainless steel plate $900 \mathrm{~mm}$ long and 40 or $20 \mathrm{~mm}$ thick, the conductivity of the water increases from $3.5 \mu \mathrm{S}$ to $30 \mu \mathrm{S}$ (see table I)

3.1 STUDY OF THE GASES

After studying the composition of the gaseous products with pure argon at their source, the cutting of a plate, $70 \mathrm{~mm}$ thick and $1500 \mathrm{~mm}$ long, results in a hydrogen emission of 14 to 20 \& in volume at the source.

A dilution flow of $1000 \mathrm{~m} 3 / \mathrm{h}$ is then necessary so as not to exceed the threshold of 1 if in the exhaust duct

Moreover, nitrogen oxyde is produced to a level of 15 ppm with pure argon and of a 1 to 2 with an argonnitrogen mixture.

The ozone concentration is negligible.

The gaseous balance for the same conditions is given in table II.

3.2 STUDY OF THE AEROSOLS

A diagram concerning aerosols is given in figure 9.They have a normal log size distribution centered towards a mean diameter of $0.1 \mu \mathrm{m}$ (see figure 10). The mass concentrations in the exhaust duct are 20 to 40 times lower than for an underwater cutting (see figure 10).

The elementary chemical composition of the aerosols compared to the composition of the cut steel shows a slight enrichment in chromium (lower than 2) and a high enrichment in manganese (higher than 30).

\section{RADIOACTIVE BALANCE}

After cutting radioactive plates only the cesium radioactive balance has been established. This radioactive element is one of the most commonly encountered in the dismantling of nuclear installations.

Numerous samplings, of filters, solutions, rubbings, for example carried out during the cutting of contaminated and activated plates $(0,7 \mathrm{~Bq} \mathrm{~g}-1$ and $1900 \mathrm{~Bq} \mathrm{~g}-1)$ enable the following results and conclusions to be obtained :

- The aerosol concentration in the exhaust duct, with a flowrate of $1000 \mathrm{~m} 3 \mathrm{~h}-1$ varies from 1 to $4 \mathrm{mg} \mathrm{m}-3$, and the 137 Cs volumic activity varies from 380 to $900 \mathrm{Bqm}-3$. 
- The mass median aerodynamic diameter of the aerosols is about $0.2 \mu \mathrm{m}$ (see figure 11)

- Sedimented dross and aerosols represent respectively 85 and 0.1 of the removed mass.

The radioactive analysis clearly shows :

- A two-fold explanation of the water activity : nonfixed activity transfer on the whole work piece after immersion, and activity transfer from the cut part.

- Important cesium enrichment in the aerosols. The $137 \mathrm{Cs} / 60$ co ratio in the plate before cutting and in the aerosols leads to an enrichment factor over 10.

- As for the $60 \mathrm{Co}, 137 \mathrm{Cs}, 54 \mathrm{Mn}$ radioisotopes involved, the efficiency of the electrostatic filter used is greater than 90 . This type of prefilter ensures the protection of the HEPA filter.

raking into account the different epuration and dilution systems of our installation a radioactive balance was carried out showing global activity distribution (see Eigure 12)

The volumic activity along the ventilation system (see figure 13) is given for a work piece contaminated mainly with $137 \mathrm{cs}$, and for which most of the activity was not fixed.

Table I

mass distribution of the secondary elements (thickness of the workplece : $20 \mathrm{~mm}$ )

\begin{tabular}{|c|c|c|c|c|c|}
\hline conornons & $\begin{array}{c}\text { mass loss } \\
\text { of the } \\
\text { workplece } \\
(g \mathrm{~m}-1)\end{array}$ & $\begin{array}{c}\text { (1) } \\
\text { arteched } \\
\text { slag } \\
(\%)\end{array}$ & $\begin{array}{c}\text { (2) } \\
\text { sedimented } \\
\text { drosse } \\
(x)\end{array}$ & $\begin{array}{c}\text { (3) } \\
\text { ouspended } \\
\text { perticles } \\
\text { (x) }\end{array}$ & $\begin{array}{c}\text { (4) } \\
\text { aerosots } \\
(x)\end{array}$ \\
\hline $\begin{array}{l}\text { UNDER } \\
\text { WATER }\end{array}$ & 1248 & 6.7 & 92.9 & .49 & .0059 \\
\hline IN NR & 1308 & 5.7 & 84.1 & & .194 \\
\hline
\end{tabular}

- Porcentages in revation to total (1)+(2)+(3)+()

Table \|

gaseous repartition (I/min)

Plasma gas : pure eron

Thicknoses: $70 \mathrm{~mm}$

Length : $1500 \mathrm{~mm}$

\begin{tabular}{|c|c|c|c|c|c|c|c|}
\hline$A$ & $H_{2}$ & $\mathrm{O}_{2}$ & $\mathrm{NO}$ & $\mathrm{NO}_{2}$ & $\mathrm{O}_{3}$ & $\begin{array}{c}\text { water } \\
\text { steam } \\
\text { and } \\
\text { othere }\end{array}$ & tots \\
\hline 170 & 50 & 5 & $4.20-0$ & $4.610-4$ & $2.50-7$ & 22 & 247 \\
\hline
\end{tabular}




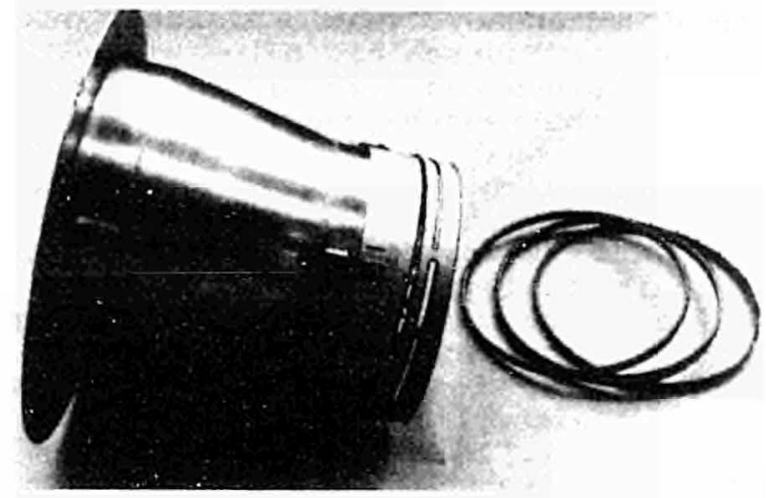

horizontal connection on vessel

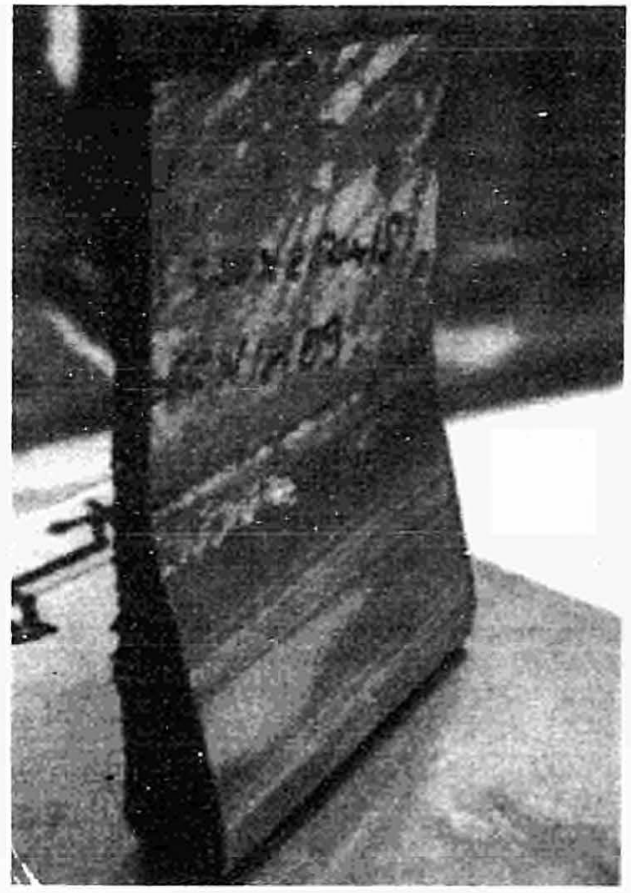

vessel wall with variable thickness

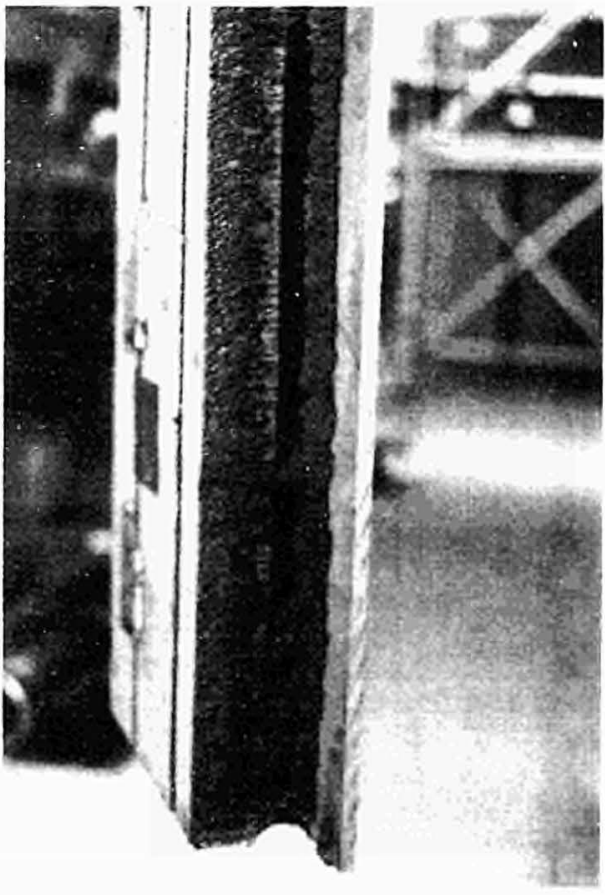

plate : thickness $70 \mathrm{~mm}$ - length $1500 \mathrm{~mm}$

Figure 1: examples of pieces cut by plasma torch 


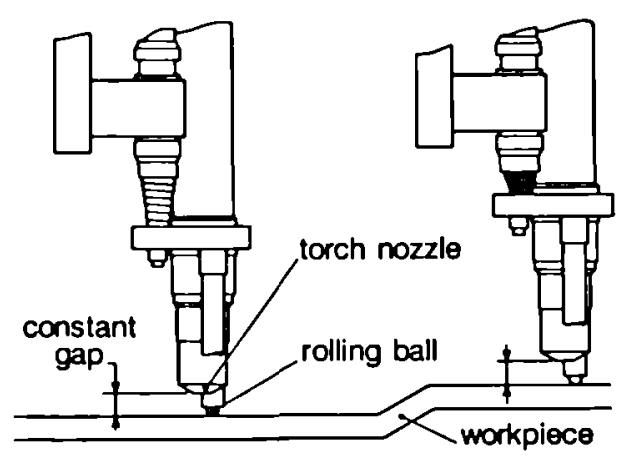

Figure 2 : workpiece / torch gap
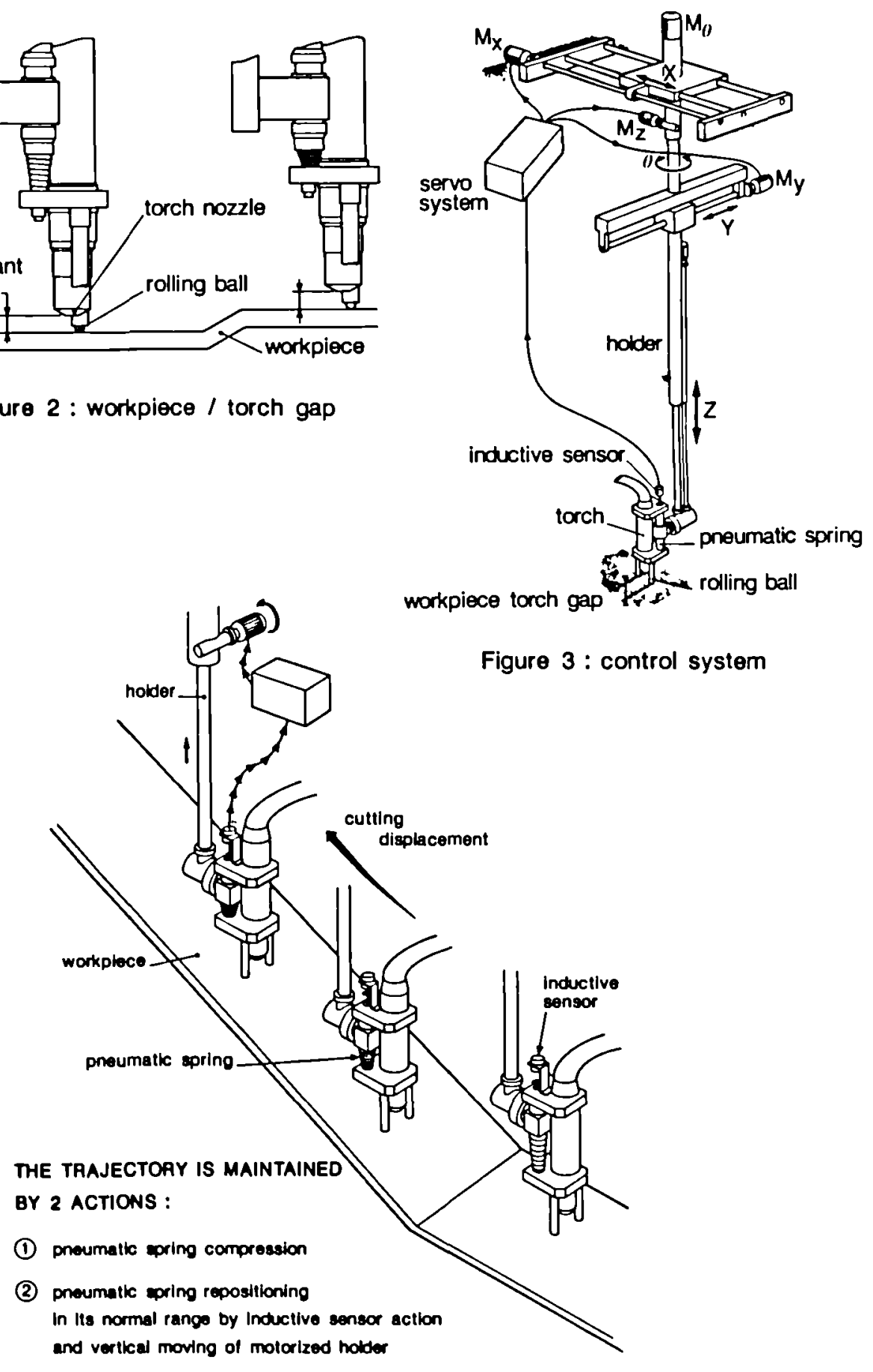

Figure 3 : control system

Figure 4 : pneumatic spring and inductive sensor system 


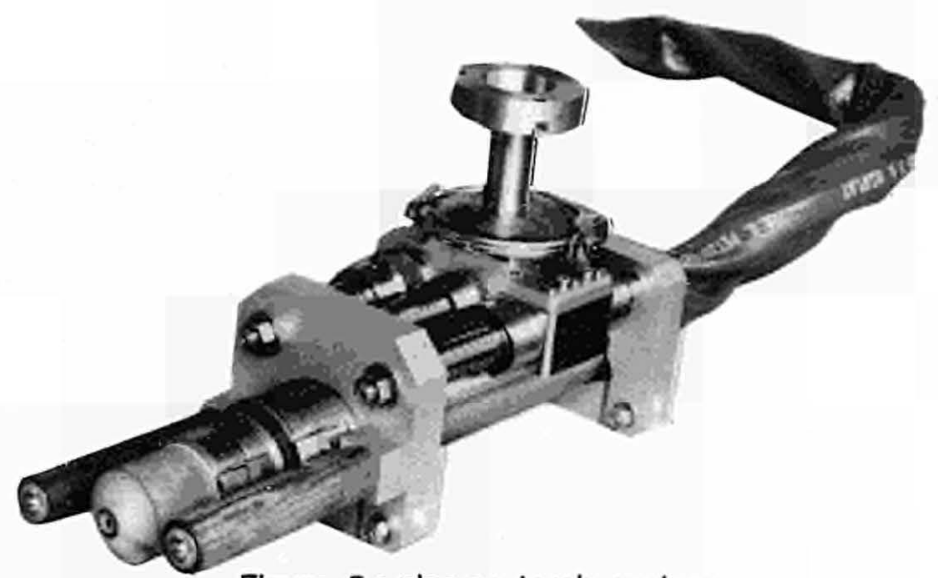

Figure 5 : plasma torch system

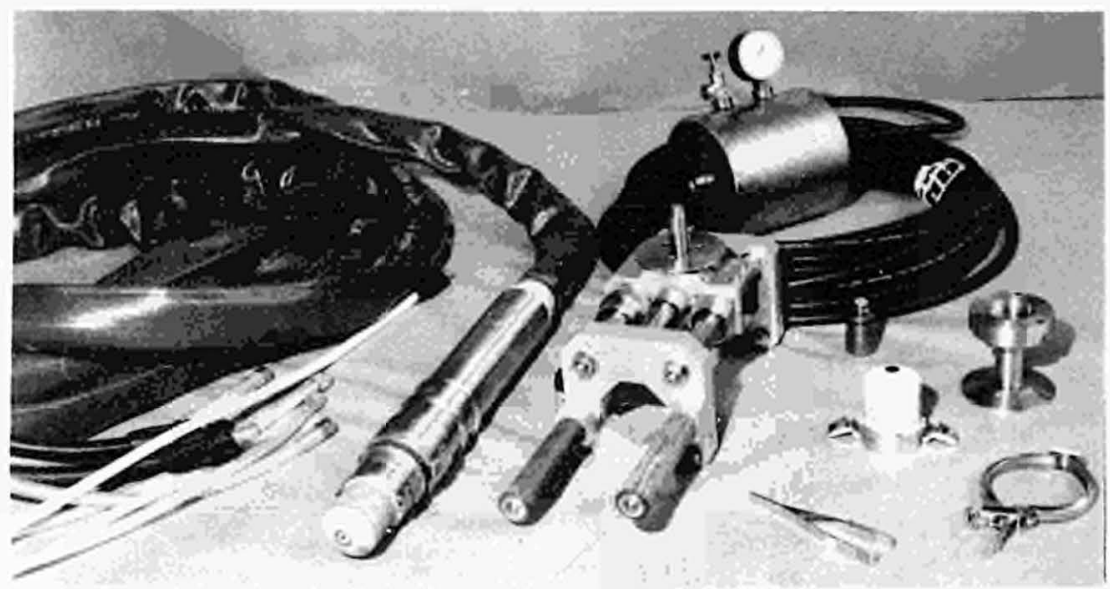

Figure 6 : plasma torch system

Figure 7 : wearing parts removed using simple tools and replaced by simple axial interlocking

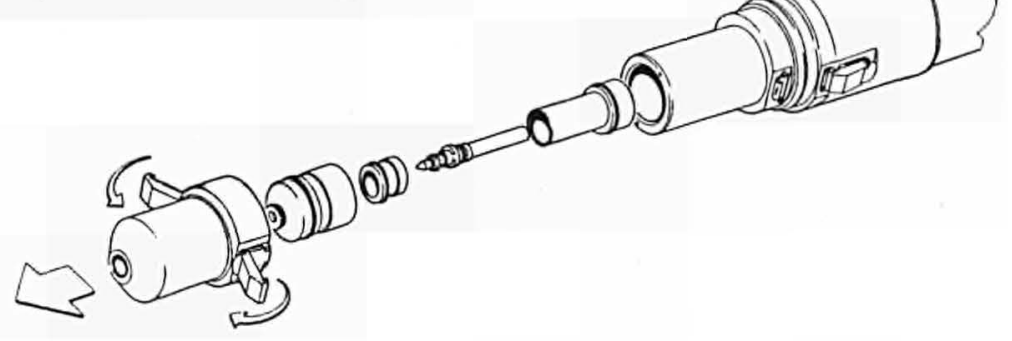




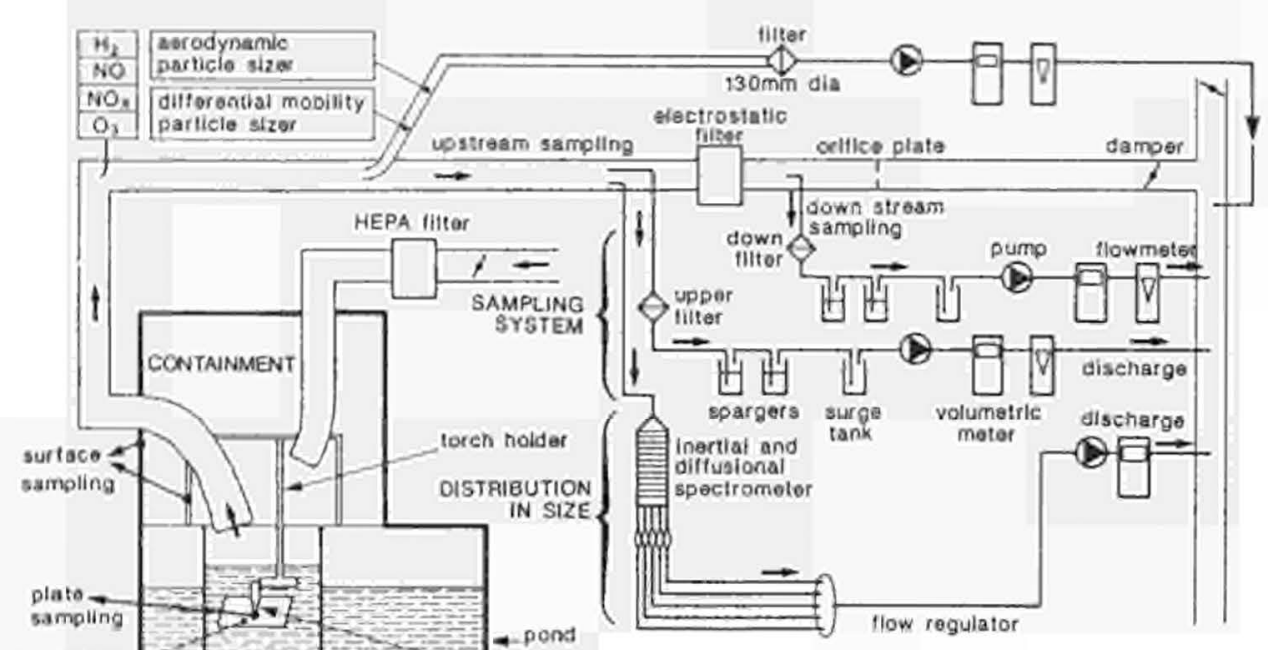

Figure 9:

diagram of the experimental installation for the aerosol measurements

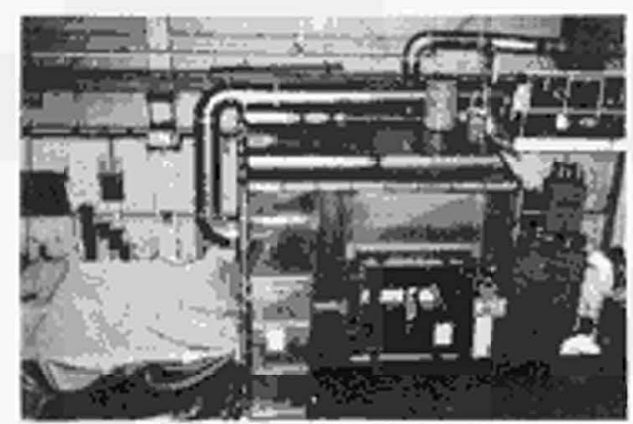

Figure 8 : containment

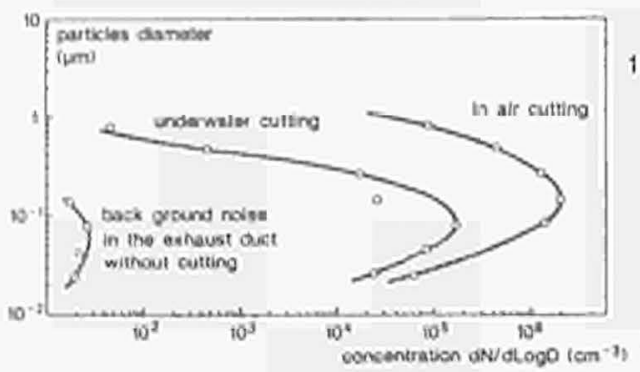

Figure 10: size distribution in the exhaust duct in air and underwater cutting

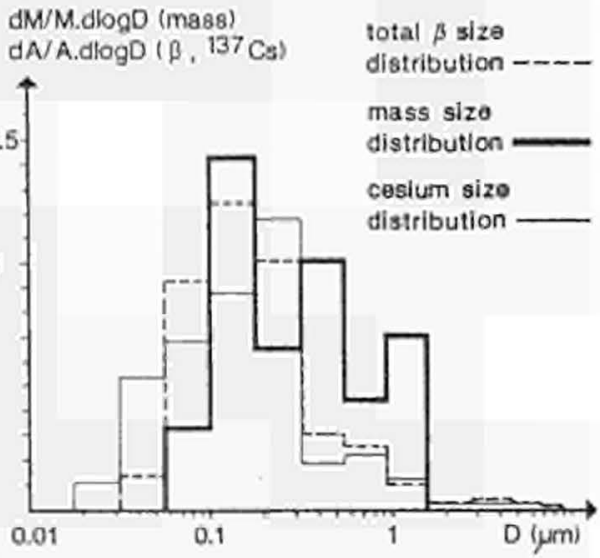

Figure 11: size distribution 


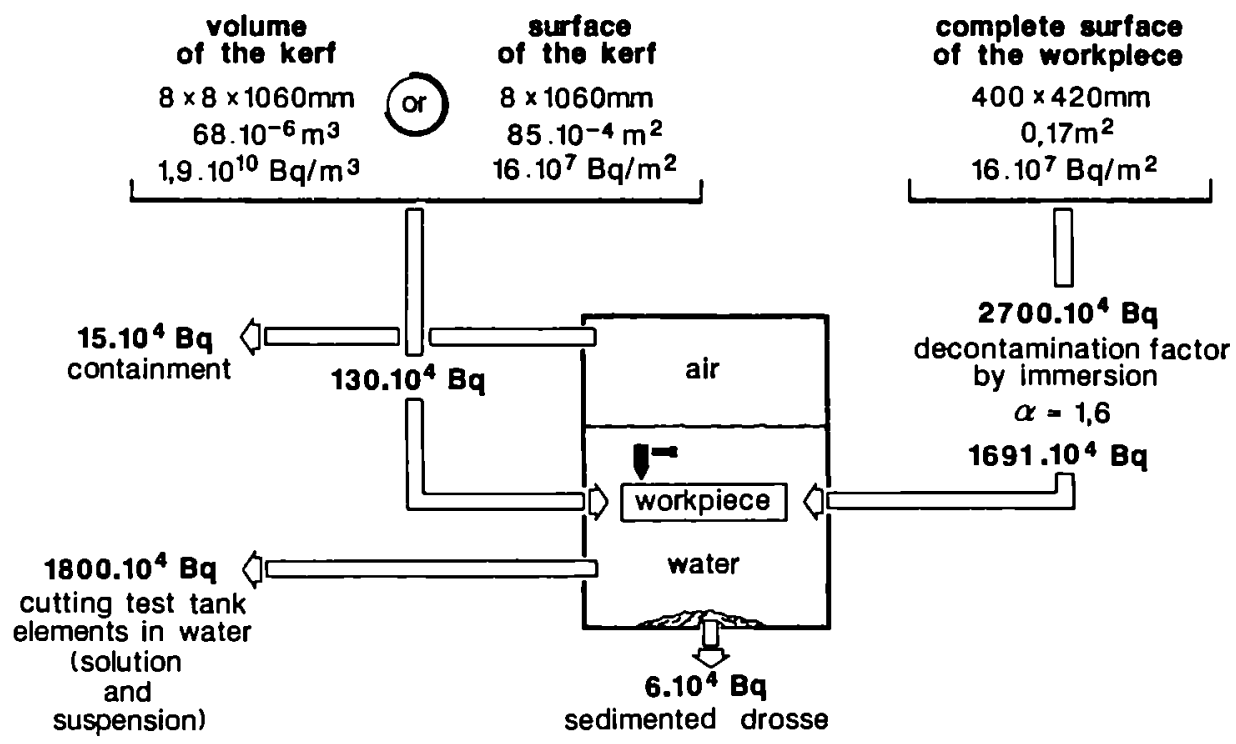

Figure 12 : cutting of a contaminated workpiece - 137 cesium case global distribution of the activity

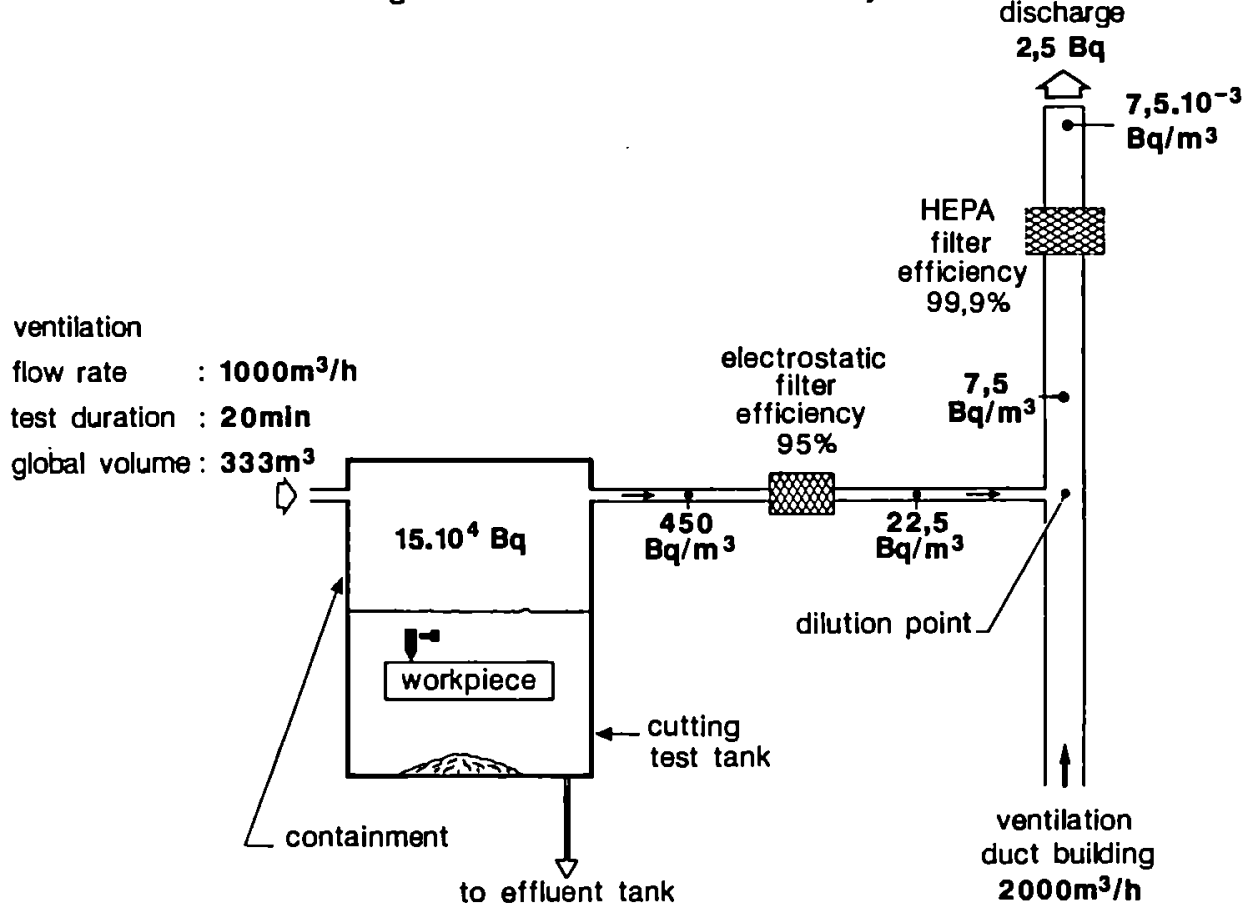

Figure 13 : cutting of a contaminated workpiece - 137 cesium case global distribution of the activity concentration in the ventilation system 


\title{
THE TELEMN PROGRAMTE
}

\author{
H.J. de Nordwall \\ Comission of the European Comunities. Brussels \\ Head, TELEMAN Programe
}

\section{ABSTRACT}

The TELEMAN programe is a five year cost-shared research programme covering remote handling in hazardous and disordered nuclear environents.

TELEMAN's technical objective is to strengthen the scientific and engineering bases upon which the design of teleoperators for use throughout the nuclear industry rests. This will be done by providing new solutions to problems of manipulation, material transport and mobile surveillance in nuclear environments and by demonstrating their feasibility.

The Commission's motivations lie in the potential teleoperators have to improve the separation of workers from radioactive equipment. The same technology will also enable plant operators and public authorities to deal more effectively with nuclear accidents. Finally, gains in productivity. particularly in the repair and maintenance area can be expected.

Community support is justified by the cost of the reliability and autonomy required for the nuclear teleoperator, the need to rationalise $R$ D investment in an area of increasing industrial potential and a common interest in coherent responses to emergencies.

\section{INTRODUCTION}

Remote handling has always been an important part of nuclear technology characterised by the exercise of considerable mechanical engineering ingenuity under trying conditions and an endless debate between the advocates of simplicity and automation. Simplicity of ten meant man providing power, control and tactics; automation meant a dedicated systes. not unlike a production line, whose maintenance became a nightmare, and is still perceived as such by some engineers. The electronic revolution has given us new options : computer assisted teleoperation in which man shares the functions of control with a machine potentially able to work faster and longer than the human hot cell operator ; relief from the drudgery of repetitive operations : 
machines able to maintain machines and the transfer of complexity from operator to a control system with which he can communicate in something approaching his own language. Tactics for the moment, remain a human function, but one can forsee a time when intelligent machines will plan and execute operations and supervise the human operator.

That the new technology came at a time when nuclear research was becoming difficult to fund in some countries was an additional bonus to those institutions already seeking a broader role in the research and industry of their countries; that the robot jumped from science fiction into industry when it did was because of the dramatic reduction in the cost and size of the electronics associated with sensing, control and comunications rather than advances in engineering, though robots will only play an important part in our lives if engineering development proceeds in parallel. From the nuclear side utilities were under pressure to reduce radiation doses during inspection and waintenance and perform new inspections to extend the working lives of their plant. Then came the Three Mile Is land and Chernobyl accidents.

The Commission, like other organisations charged with nuclear industry promotion, could not ignore a technological opportunity that promised simultaneous gains in performance, reliability, plant surveillance, operator exposure and cost. It therefore mounted a series of studies with the following objectives :

- To investigate the likely evolution of the nuclear market and teleoperators in the light of anticipated developments in both robotics and nuclear technologies.

- To analyse the functions required of robots and teleoperators to meet currently perceived nuclear needs.

- To suggest appropriate lines of development.

- To provide a basis from which any future Comission activities could be launched.

In addition those working units of the commission who needed teleoperators to meet other obligations, such as fusion development, have sought out firms willing and able to meet their needs.

\section{NUCLEAR REQUIREMENTS}

The range of radiation fields experienced in the nuclear industry makes it convenient to consider three classes of application :

- applications in which a reduction of doses to the nuclear workers is achieved by avoiding many small exposures to radiation,

- applications where several men or teams of men are needed to avoid individual dose limits being exceeded.

- applications in which man acces in inconceivable.

In all of these categories contamination can make removal of a machine from the workplace, for example for repair, slow and expensive. 
The Jobs performed in the first group are of ten repetitive and precisely defined. Monitoring and washing transport casks is not too dissinilar from paint spraying. The packaging of nuclear fuel or waste has much in common with packaging and warehousing technology found elsewhere and industrial robots have been successfully adapted to a number of such tasks. Contanination control is achieved using flexible gaiters and clean air flows through the robot into the workplace. In automated fuel transfers linear wotors in which the stator renains outside contaiment have been used.

The second group includes jobs with an element of unpredictability.

Searches for the causes of observed abnornalities, maintenance, and the repair of plant situated within closed containment can all require machines that can be configured in different ways, possess considerable dexterity and are capable of movement within their working environments.

This lack of definition simultaneously creates enthusiasm for new technology and suspicion on the part of potential users about the cost benefit equation.

An even greater degree of flexibility is likely to be required of machines intended for use in the completely inaccessible environments found in reprocessing. irradiated fuel handling, fusion and severe accident magenent. All inspection, maintenance and repair tasks, forseen and unforseen must be executed in ways that meet stringent requirements for remote repairability and reliability over a long period. When the time required to gain needed confidence in such unfaniliar technology is added to its development tine, it is hardly surprising that the gestation period is long.

TELEMAN addresses the two latter groups of applications, those characterised by a demand for flexibility and by uncertainty. The combination of uncertainty and concern about danage to the plant as a result of collision or incorrect execution of a Job forces one towards teleoperation in which man remains in the control loop.

Complexity, difficult comunications, poor vision and the shortconings of man as a controller of processes with many degrees of freedom have led to the concept of computer assisted teleoperation where the operator can call up a number of autonomous functional packages to execute specific jobs.

The computer can in turn, given suitable inputs from sensors or position encoders, help the operator to avoid collisions, illegal or dangerous actions. Robots and telemanipulators currently under develoment are being given artificial intelligence to raise the level of man-machine comunication and hence further relieve the operator from problens arising from complexity.

In any case artificial intelligence is an essential component of autonomy. The extent to which nuclear users will embrace autonony, even in the context of a systea supervised by a human operator.

reaains to be seen. At present the human operator is being asked to cover for some of the fundanental problems associated with intelligent uachines namely the licensing of inference engines and the acceptability of recursive programe generation. clearly both operator and wachine are growing in intellectual stature. 
Examination of the technology required for damage assessment or control will continue with a view to including this type of machine in a later programe.

\section{PROGRAMME STRUCTURE AND CONTENT}

TELEMAN will address basic problems associated with remote operations using computer assisted teleoperators with increasing degrees of autonomy, questions relating to teleoperation in nuclear environments and the integration of the disciplines that make up robotics.

To serve the maxinum number of nuclear industry users and entrepreneurs and minimise the risks associated with a rapidly evolving market. TELEMAN will invest most of its resources in the provision of generic building blocks for incorporation in a variety of specialised machines. These sub-system technologies in turn could then be used by industry in ways that cannot all be forseen today.

TELEMAN will demonstrate its research products by incorporating them into research machines that exist or are under development in the laboratories of its contractors. In the context of TELEMAN, research machines will serve as devices for the integration of technologies and technologists. Analysis of the behaviour of research machines will show how machines will need to evolve to meet commercial demands and thus lay the groundwork for product development and demonstration programmes to be executed outside TELEMAN by industry in a competitive environment. It is accepted that advanced teleoperator development requires a step between development of sub-system technology and the production of an industrial prototype as well as frequent interaction between constituent disciplines. Research machine construction therefore needs a multi-disciplinary environment.

Finally provision will be made for evaluation of the products of TELEMAN by users. This will include reliability assessments and mission simulations. Studies of issues of general interest such as what is needed for a minimum effective response to a major accident or the assessment of new technology as a prelude to its inclusion in the programme will also be made.

\subsection{Component and Sub-system Development}

Examination of the machine functions required for a wide range of teleoperator applications showed that there is a recurring need for a relatively small number of basic technologies and, in this area, there is a high degree of complementarity with ESPRIT. Key topics are those connected with perception of surroundings, intelligent job or route planning and decision making, power transmission, locomotion,

manipulation, control and comanication. One should therefore expect TELEMAN to utilise in the nuclear industry, where possible, mainstream robotic developments. In general control equipment will be rather independent of the mission to be undertaken whereas sensors. comunications and locomotion tend to be rather job specific. 


\subsection{Environmental Tolerance}

Teleoperators to work in nuclear environments will need to tolerate radiation, heat, corrosive chemicals, water, stean, dust, electromagnetic interference, vibration and decontanination. TELEMAN will provide design methods and data on environental tolerance and failure modes.

This will require the development of circuit elements, electronic systems, sensors and materials resistant to these threats and having known and understood fallure modes. In addition means to mitor damage to the machine so that it may remove itself from the threat will be needed.

Avallable and emerging electronic hardware will need to be ruggedised to make it applicable where radiation fields and temperatures are high. Finally, the desire to cope with disorder leads naturally to a need for devices to nonitor mechanical stability and stress and provision must be made for rescue or repair of stranded machines.

\subsection{Research Machine Projects}

Research machines are experimental machines that precede prototypes. Their purpose is to demonstrate the integration of the disciplines of informatics, engineering, ergonomics and psychology involved in teleoperator construction into neat serviceable packages. They also serve as test-beds for novel components or control systems and essential alds for the training of engineers in teleoperation and robotics.

It has been agreed in consultation with the TELEMAN Users group that the programe should be focussed on the following classes of teleoperator :

1) Improved light, mobile machines that can be used to collect information, relay signals, provide alternative viewpoints or serve as an extra hand.

(i) More robust, mobile machines for maintenance, repair, post accident intervention or decomissioning. This includes manipulators attached to gantrys and teleoperated cranes.

(ii) Improved long reach devices able to work through restricted apertures in a containment boundary.

Several test-beds and demonstrators amenable to modification already exist.

\subsection{Product Evaluation}

This task has three objectives :

- To involve end-users of teleoperators in TELEMAN by inviting the to test and evaluate concepts developed in the laboratory.

- Monitoring of developments capable of influencing trends in teleoperator development. 
- Monitoring the status of tools for the assessment of performance, reliability and user-friendliness.

\section{RELATIONSHIP TO OTHER CEC PROGRAMMES}

Important non-nuclear creators of technology useful for nuclear remote handling are to be found in the ESPRIT and BRITE programmes. The fusion and decommissioning programmes are important users as well as active builders of specialised teleoperators.

However, while reading the descriptions that follow of what could be available from ESPRIT and BRITE, one must bear in mind that their goals differ fron those of TELEMAN. The relative priorities of safety and productivity are reversed and nuclear environments can make maintenance and recovery of vehicles extremely expensive and even dangerous if adequate attention is not paid to fault tolerance. That said, even a modest transfer of technology from these programmes would be significant for TELEMAN.

\subsection{ESPRIT Input}

Relevant ESPRIT I projects can be found in the Computer Integrated Manufacturing, Advanced Information and Sof tware Technology subprogrammes. The Computer Integrated Manufacturing Programme is essentially an application driven activity. It covers standards, job planning, the design of material transfer tools, some of which are based upon industrial robots and others on more specialised manipulators, sensor integrated control systems, CAD-robot interfaces, robot programming, communications and machine identification transponders that could perhaps be used in robot recovery systems. The list of potentially interesting projects has been discussed with ESPRIT managers. The information available to those dealing with TELEMAN in the Commission includes status reports, budgets, evaluations of how well members of the groups collaborated, the quality of contractors, the availability of usable products, and the existence of proposals for ESPRIT II. This would also benefit TELELMAN contractors.

The Advanced Information Processing and Software (AIPS) projects are more technology driven and therefore usually further from the marketplace. Some of the more interesting projects are algorithms and dialogue controllers for speech driven processes, systems for fault diagnosis in communications networks, expert system builders, data bases for use with real time process control using knowledge based systems, image analysis (including moving images), mapping and real time navigation, decision making control, low cost high performance multiprocessor computers, software reliability, re-usable sof tware modules and environments to accomodate them.

Arrangements aimed at exploiting ongoing work in TELEMAN have been studied.

The Commission's investment in these project is some $80 \mathrm{MECU}$ to date.

A list of ESPRIT II projects cannot be given yet since many are still being negotiated. CIM is expected to expand into process control, and more emphasis will be given to material handling arms with a long reach and robot vehicles for use in factory environments. 
Existing activities in vision sensor data fusion will continue in the direction of the further development of devices to inspect machined parts e.g. by combining canera inages with CAD data.

Two vehicle developments are under consideration, one as a test-bed for control sof tware, the other for use in the logging industry.

TELEMAN can undoubtedly benefit from close liaison with these projects, in which the comission expects to invest sose $35 \mathrm{MECU}$.

A number of the projects concerned with generic problens in real time computing, artificial intelligence and environsental perception are expected to continue.

\subsection{Basic Research in Industrial Technologies (BRITE)}

TELEMAN expects to benefit fro BRITE investment in high strength plastics and composites. Interesting products include thermosetting sheet material for the preparation of moulded composite structures. techniques for producing complex three dimensional shapes from reinforced plastics and improved polyimides for service at $250-350^{\circ} \mathrm{C}$.

\subsection{Decommissioning and Fusion}

Organisations engaged in deconnissioning and the fusion programe itself are markets for teleoperators. The decomissioning programe has a budget of $18 \mathrm{MECU}$. JET and NET rather more, to adapt existing technology to their needs.

Both JET and the Decomissioning Programme finance important demonstrations of current technology and these demonstrations can be seen as important test-beds for new technology. Analys is of the performance of their tools will serve to define future needs in a practical way. JET, and to a lesser extent decomissioning, have had to engage in the development of new technolgy because what was avallable could not do the job. Other users of teleoperators such as CECB and EdF have also chosen to develop a significant part of the new technology needed in-house.

It is to be hoped that decomissioning contractors will exploit TELEMAN to develop generic technology required for the next generation of tools. Users of the types of machine that have emerged as foci for the TELEMAN prograne can readily be envisaged in Decomissioning and Fusion. In addition at least one civil engineering company has perceived the potential of intelligent cranes outside the nuclear industry.

Two classes of teleoperator not catered for are large automatic guided vehicles for carting away rubbish prior to packaging and vehicles designed to deliver the large tools required for disaster management to their workplaces the at site of a major accident. Public money is however being spent on development of teleoperated wilitary vehicles for example for the movement of men and supplies. 


\section{IMPLEMENTATION}

TELEMAN is managed by CGC 5 sitting in a special configuration, which is designed to reflect all nuclear interests. The chairman of the TELEMAN Users Group in an ex-officio member of CGC-5 T.

Preference will be given to projects in which industry, research organisations and universities collaborate and participants come from more than one Member State. The Commission will contribute up to $50 \%$ of approved research costs.

In cases where work, supported by national funds or entirely privately funded is already going on, the Commission's role may be limited to simply organising co-ordination and providing some community funding to cover the cost of collaboration. However, in certain cases where it is clear that strategically important work requires a common approach, the comission could, in consultation with the CGC. consider organising concerted actions.

Provision for training or mobility grants specifically linked to the objectives of the programe are envisaged. These grants enable students and researchers to take advantage of facilities elsewhere in the Community to carry out the practical work for an advanced degree or to gain first hand experience of a technique.

TELEMAN was finally adopted on the $18 \mathrm{July} 1989$. A first call for proposals was published on the 22nd. September. Proposals should reach the Commission by the 30 th. November. 


\section{DISCUSSION}

Question: J WILLIAMS, UXAEA-harwell - how do the economics of using a laser to dismantle items compare with other methods of dismantling, eg plasma cutting?

Answer: B MIGLIORATI, FIAT - The economic evaluation of the laser must be carried out after definition of the component to be dismantled and after detalled design. Our programme is not yet at a stage to make such an evaluation.

Answer: P GARREC, CEA-Saclay - The robot itself does not raise special comments on its cost. It is a very simple arm, since no effort is applied on 1ts structure. The expendables of the robot are the lenses and the mirrors. They have to be replaced regularly. We have not compared the laser technique with other dismantling techniques.

Question: A ETTEMEYER - Is there any experience with underwater laser cuttıng?

Answer: P GARREC, CEA-Scalay - We have already practised this type of cutting in our laboratory. Please contact us to visit the laboratory to discusg the technique further.

Question: G COSTE, CEA-FAR - What about improving the performance in laser cutting, in particular to cut pipes of about 2 or 3 inches in diameter?

Answer: P GARREC, CEA-Saclay - The laser power can easily be raised to 2 or even $3 \mathrm{~kW}$ without inconvenience for this type of robot. The intervals of replacement of the expendables may be reduced proportionately. However, at this time we are able to cut mild steel pipes of 1.5 inch diameter with an effective power of about $800 \mathrm{w}$. Two- or three-inch pipes could certainly be cut with an optımised gas jet. The man problem is to expel the fused steel with the same rate of power.

Question: E SKUPINSKI, CEC - what is the present status of development of automatic trajectory teaching with the aid of a three-dimension laser camera?

Answer: J GONNORD, CEA-Saclay - The feasibility of the use of a threedimension camera to replace the teaching phase has been demonstrated. The lmage of the work space (field depth 80 to $200 \mathrm{~cm}$ ) is reconstructed on the operator screen using a simple man-machine interface. The operator indicates on the screen the desired trajectory with the aid of an electronic mouse. The PC then computes the actual trajectory points.

The main problem comes from the fact that the uncertainty on the coordinates $(X, Y, Z)$ given by the camera is either very low (less than $1 \mathrm{~mm})$ or infinite, in the case of reflective discontinuity. The software is now able to decide if a point is good or not in more than 90 of the bad cases from intensity data which are also returned by the camera. Information given by the operator may also be used.

Question: G COSTE, CEA-FAR - What about 'normalisation' of different measurements done in varıous European countries (Hannover, windscale, etc)?

Answer: G PILOT, CEA-Saclay - In the framework of standard cutting experiments using a plasma torch, the same measurement rig for secondary 
emissions has been used in order to eliminate the discrepancies arising from the use of different measuring devices. The contractors involved in the standard plasma cutting experiments were: University of Hanover, Heriot Watt University of Edinburgh and CEA-Cadarache. These measurements were done by CEA-Saclay within the framework of a contract under the 1984-88 EC programme entitled 'Measurements of secondary emissions from plasma arc and laser cutting in standard experiments'. All results are presented in our paper, but we can say now that the differences we found result mainly from the different scales of the facilities and sometimes from certain particularities in the cutting parameters.

Question: I GILLON, SCK/CEN Mol - Could you please specify the type of metals which can be cut by the plasma arc method?

Answer: R LEAUTIER, CEA-Cadarache - The plasma arc torch can handle such metals as stainless steel (including claddings), carbon steel and aluminium.

Question: G COSTE, CEA-FAR - What is your view about improving the performance of underwater plasma arc cutting, especially for cutting in PWRs (vessel thickness of about $250 \mathrm{~mm}$ )?

Answer: R LEAUTIER, CEA-Cadarache - It is apparently physically possible to obtain underwater plasma arc cuts up to a thickness of $120-150 \mathrm{~mm}$. Our colleagues at the University of Hanover are developing a plasma arc cutter and a tool based on an electric arc with consumable electrode assisted by water jet for cuts of about $200 \mathrm{~mm}$. Under the EC programme we intend to test these tools, as well as the pilot systems developed by the University of Aachen, in a nuclear installation at Cadarache. The secondary effects associated with these processes will also be evaluated.

\section{CONCLUSION}

The main items in this session were robots for laser cutting, systems for underwater plasma cutting, and control systems for underwater cutting. From the papers presented and the subsequent discussion, the following conclusions can be drawn:

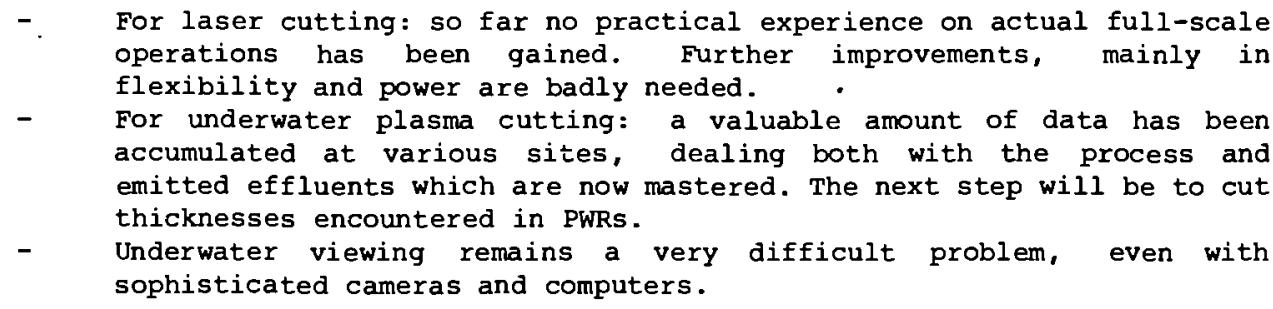

G COSTE, CEA 


\section{SESSION V \\ DISMANTLING TECHNIQUES}

CHAIRMAN: W ZIMMERMAN, KFK, D

SECRETARY: E SKUPINSKI, CEC 


$$
\text { - }
$$




\title{
Underwater Cutting Technigues Developments
}

\author{
Friedrich-wilhelm Bach \\ University of Hanover \\ Institute of Material Science \\ Federal Republic of Germany
}

\section{Abstract:}

The primary circuit structures of different nuclear powerplants are constructed out of stainless steels, ferritic steels, plated ferritic steels and alloys of aluminium.

According to the level of the specific radiation of these structures, it is necessary for dismantling to work with remote controlled cutting techniques. The most successful way to protect the working crew against exposure of radiation is to operate underwater in different depths.

The following thermal cutting processes are more or less developed to work under water:

For ferritic steels only

- flame cutting.

For ferritic steels, stainless steels, cladded steels and aluminium alloys

- oxy-arc-cutting

- arc-waterfet-cutting with a consumable electrode

- arc-saw-cutting

- plasma-arc-cutting and

- plasma-arc-saw.

The flame cutting is a burning process, all the other processes are melt-cutting processes.

To cut higher wall thicknesses of stainless steel plated ferritic steel up to $100 \mathrm{~mm}$, the combination of arc-waterjet-flame-cutting and plasma-arc-flame-cutting is possible, but up to now not really developed.

This paper explains the different techniques, giving a short introduction of the theory, a discussion of the possibilities with the advantages and disadvantages of these processes giving a view into the further research work on this interesting field.

\section{Flame cutting:}

\section{Theory:}

The flame cutting technique uses a torch assembly carrying a flowing mixture of fuel gas and oxygen which is ignited at the nozzle of the torch. After reaching the ignition temperature of 
the metal (about $800^{\circ} \mathrm{C}$ ) by preheating flames, the main oxygen jet is turned on and the heated metal is burned away.

Up to a water depth of $7 \mathrm{~m}$, the fuel gas can be acetylene. Danger is given when the pressure increases - acetylene can explode. The flame cutting process is limited to cut ferrous metals like mild steel. This depends on the physical limits: the melting temperature of the material must be lower than the ignition temperature, the melting point of the oxides must be lower than the melting point of the material, the burning process has to be exothermic.

In a higher water depth only pressure resistant fuel gases like hydrogen or MAPP are possible.

Advantages and limits:

The advantages of this process are:

- a well known technique (from cutting in atmosphere), but it is neccessary to adapt a special nozzle chamber to build up a dry atmosphere,

- the high cutting speed rate,

- small kerf,

- high cutting thickness and

- life time of the torch.

The results are similar to cutting in atmosphere.

The disadvantages are only the limitation to cut ferrous metals like mild steel and a relatively accurate setting of the distance nozzle - workpiece. In relationship to the plasma arc-cutting techniques there is a higher secundary waste by ferritic oxides.

\section{Ooxy-arc-cutting:}

\section{Theeㅡㅁㅗy:}

The oxy-arc-cutting works with a hollow stick electrode, covered by plastics, and an oxygen-jet. After touching the material, an arc is established, the material melts and the kinetic energy of the oxygen-jet throws out the material and forms a kerf. It is important to $\mathrm{fix}$ an angle of about 60 degrees to the workpiece for a proper process. The stick electrode is a consumable electrode.

\section{Report:}

Thermal cutting processes which are useful for dismantling techniques are divided in two parts, depending on the input of energy:

- Flame processes

- Arc processes 


\section{THERMAL CUTTING - OVERVIEW}

THERMAL CUTTING

FLAME PROCESSES

- Flame cutting

- Oxygen lance cutting

ARC PROCESSES

Oxyarc cutting

- Arcsaw cutting

- Arc waterjet cutting

- Plasmaarc cutting

Plasmasaw cutting

Figure 1: Thermal cutting techniques

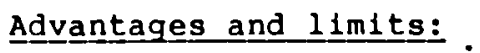

The advantages of this process are:

A simple and cheap process, excellent for gouching, no influence of water depth.

The disadvantages are:

A discontinuous process, the electrode has to be changed after burning, a high secundary waste. It is necessary to develop this process as a remote controlled process.

\section{Arc-saw-cutting:}

Theory:

The arc saw is developed in the USA and in Japan. It is a circular, toothless metalilic blade which can be used to cut any conducting metal without contacting the workpiece. The blade rotation (300-1800 rev/min) assists the cooling of the blade and the removal of the molten metal from the kerf of the cutting zone.

The cutting action is obtained by means of a high current electric arc between the rotating blade and the material being cut. 


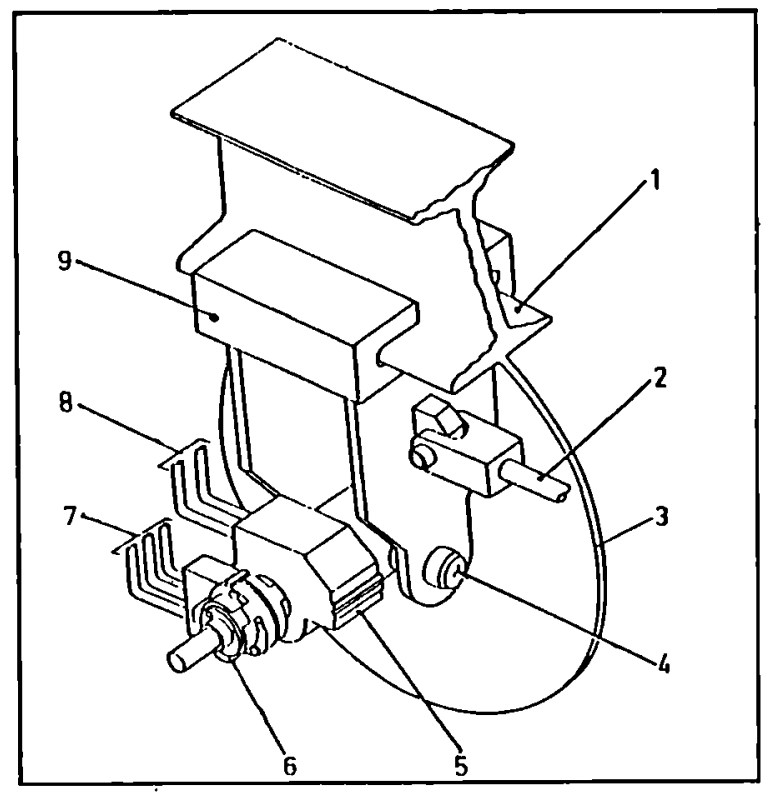

1 Radial Support Arm

2 Horizontal Drive Rod

3 Blade

4 Pivot Shaft

5 Hydraulic Drive Motor

6 High Amperage Commutator

7 Power supply

8 Hydraulic Drive Line

9 Radial Carriage

Figure 2: Arc saw-schematic view

\section{ARC SAW \\ CUTTING PARAMETERS}

SUPPLY UNIT

SAW BLADE

max. cutting thickness

max. current

voltage

weight diam. [mm] $\quad 178 \quad 305 \quad 406$

diam. [mm] $762 \quad 1270 \quad 1829$

$\begin{array}{llll}\text { [mm] } \quad 229 & 381 & 762\end{array}$

[A] 60001500025000

$\begin{array}{llll}\text { [V] } & 25 & 25 & 25\end{array}$

$\begin{array}{llll}\text { [kg] } & 181 & 530 & 1238\end{array}$

Figure 3: Arc saw - cutting results 
Advantages and limits:

The advantages of this process are:

- cutting of high wall thicknesses $(1 / 3$ of diameter of the blade) with high speed, small kerf and the possibility of cutting tubes.

The disadvantages are:

- the heavy weight, the high pretensions to the remote controlled system, the high costs and to cut only in one direction. Up to now there is the problem for cutting underwater that the blade can get stuck in the kerf by particles.

\section{Arcc-waterjet-cutting:}

\section{Theoory:}

The arc-waterfet-cutting or consumable electrode cutting with waterjet works with a consumable copper covered steel or stainless steel electrode and a surrounding waterjet. The electrode wire touches the material and starts an arc. The electrode and the material melt. The water fet (10-20 bar) removes the molten material and a kerf is formed. It is a continuous short circuit process.

\section{Advantantages and limits:}

The advantages of this process are:

- the torch is relatively simple,

- builds small,

- high cutting speed,

- small kerf,

- high wall thickness,

- no influence of water depth.

The process allows whole piercing and gauching and to cut tubes and bundles of tubes.

The disadvantage is, that the material of the consumable electrodes gets into secundary waste. Up to now there has been some research work to do, to exclude damages by bypass arcs and to increase the maximum of wall thickness.

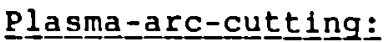

\section{Theeㅡㅁㅗ:}

A gas which is dissociated and lonized is called plasma. To transfer a gas into this high energetic level, it is given into an electric arc and constricted by the magnetic and thermal pinch effects. The plasma gas, which leaves the nozzle has a temperature of about $8000^{\circ} \mathrm{C}$. It touches the material surface and transfers the energy by recombination. The high kinetic energy blows the molten material away. For cutting only transferred arcs are possible. 


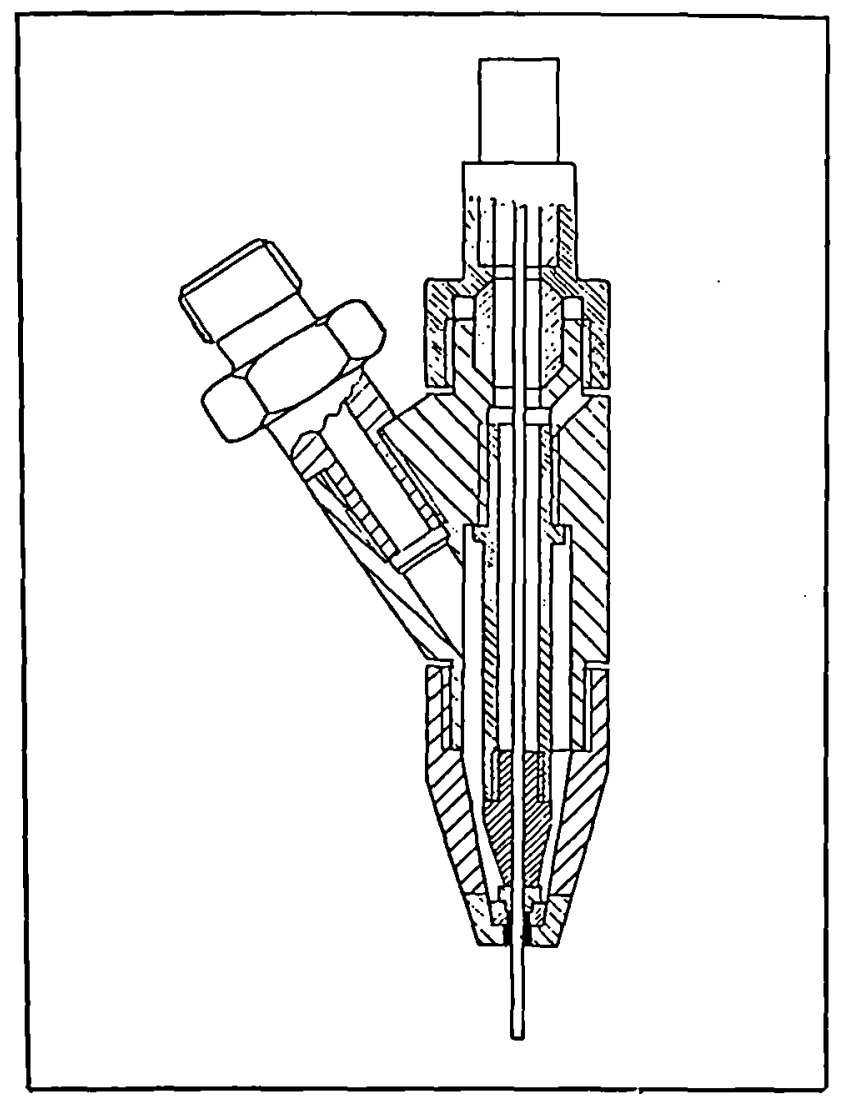

Figure 4: Consumable electrode cutting with waterjet - (Bchematic) (1)

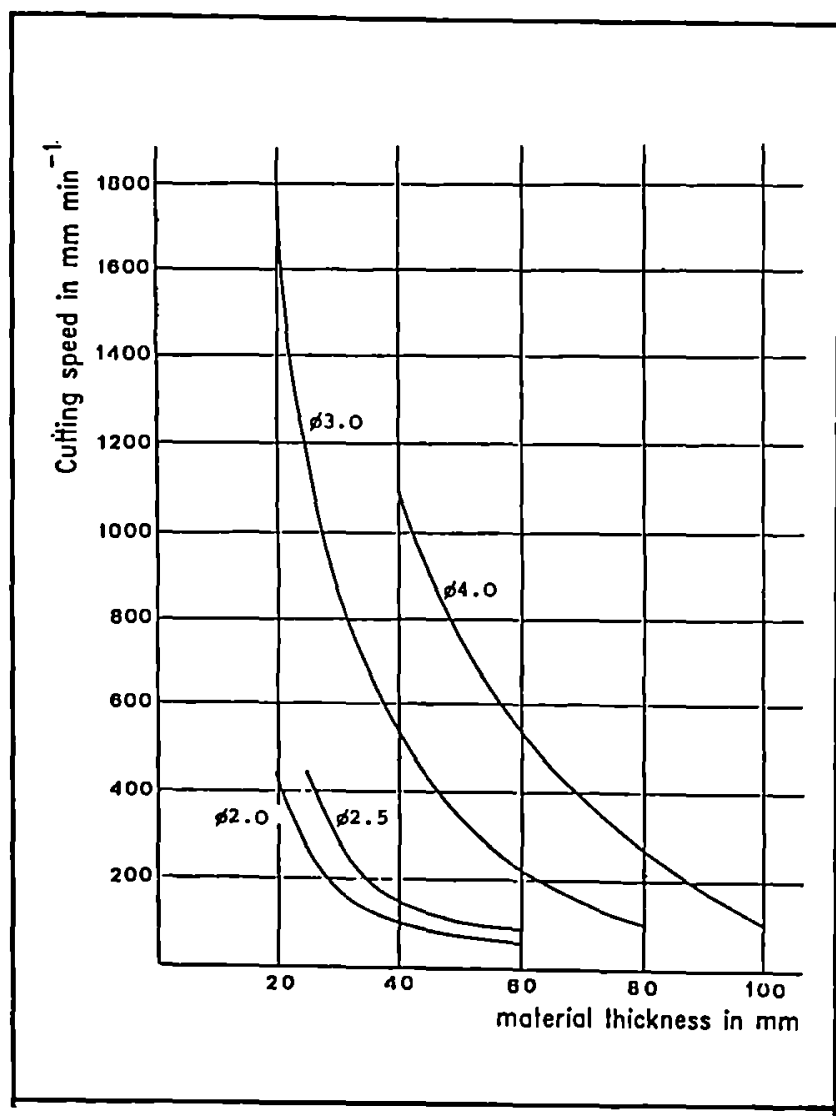

$\underset{+}{\mathbb{W}}$ with waterjet - cutting characteristics

The today given maximum of wall thickness is about $100 \mathrm{~mm}$ stainless steel 


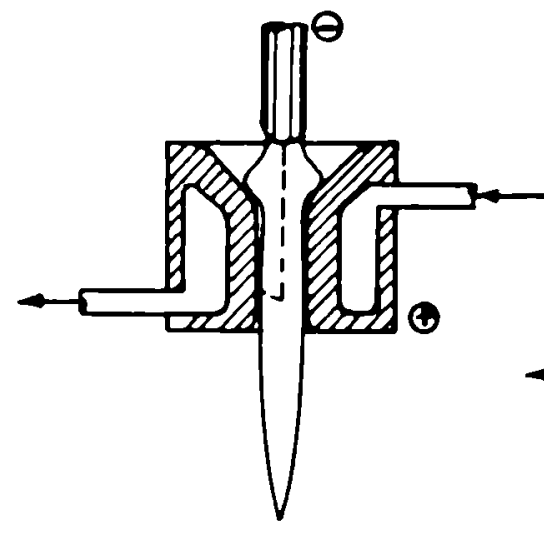

non transferred arc

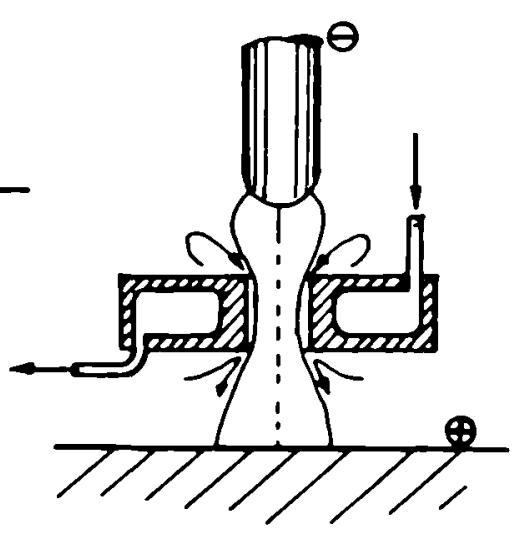

transferred arc

Figure 6: Plasma arc cutting - schematic

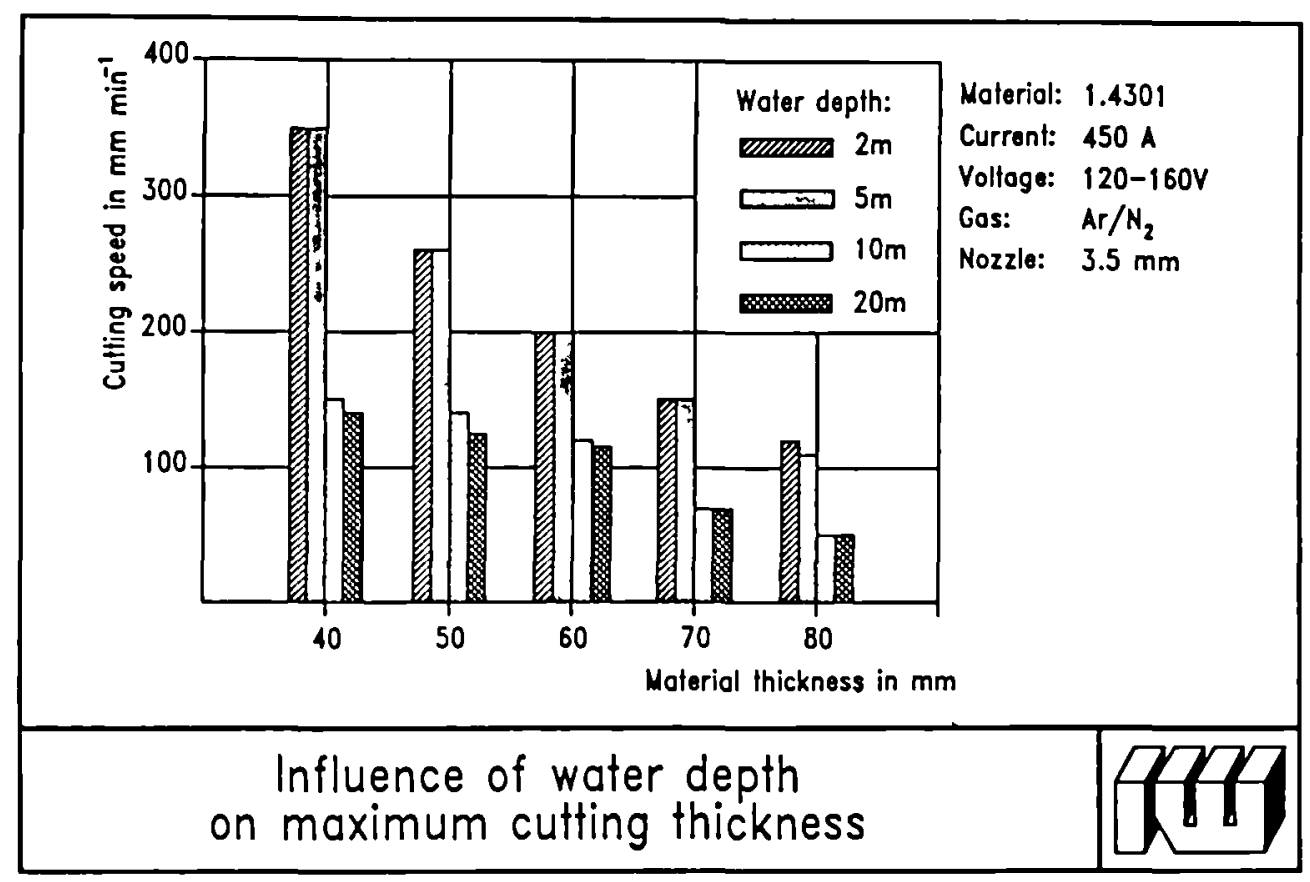

Figure 7: Plasma arc cutting 


\section{Advantages and limits:}

The advantages of this process are:

- high speed rate,

- small kerfs,

- excellent feasibility of remote operation,

- high life time of electrodes and nozzles,

- few secundary waste.

The disadvantage is the decreasing wall thickness by increasing water depth.

\section{Plasma arc-saw:}

The plasma arc-saw-prototype is a result of a research work sponsored by the German government. The idea was to build plasma torches which are smaller than the cut kerf - we called them, diving torches.

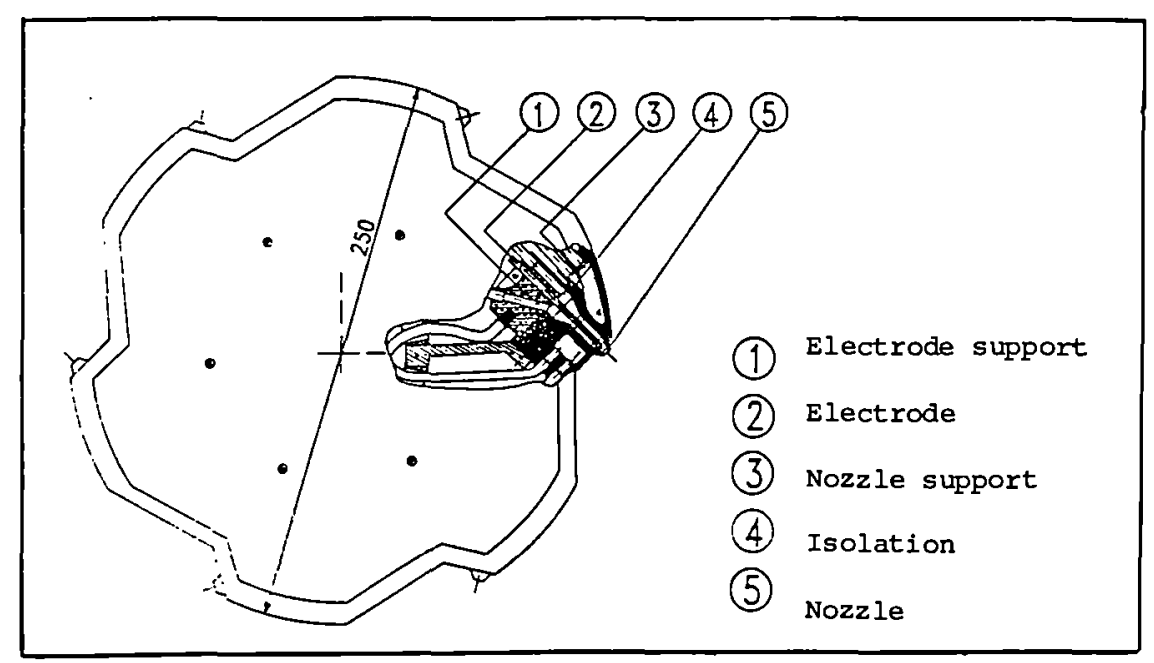

Figure 8: Plasma saw - schematic [2]

Twelve special developed plasma torches are fixed on the periphery of a rotating blade. The direction of the plasma-jets changes from one torch to the other with an angle of about $30^{\circ}$. It is possible to cut a kerf of about $14 \mathrm{~mm}$, while the thickness of the blade is about $10 \mathrm{~mm}$. The blade rotates about one to three times per minute.

Today it is possible to cut steel constructions up to $300 \mathrm{~mm}$ thickness.

It is also possible to cut tubes and bundle tubes. 

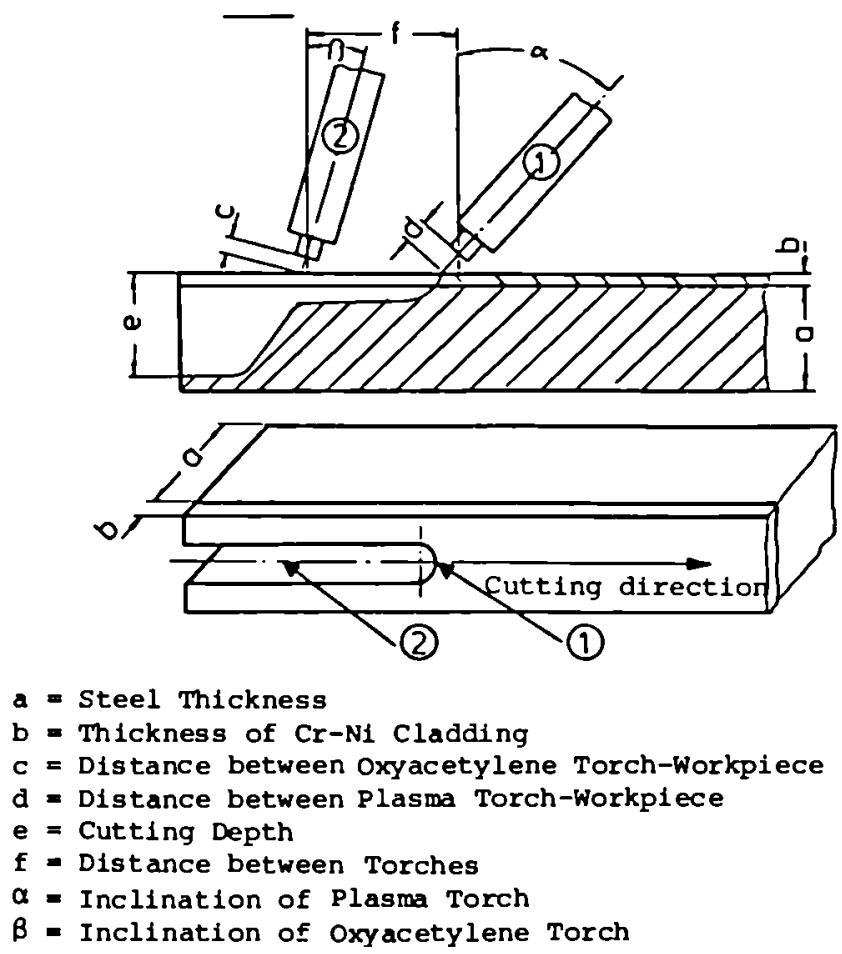

Pigure 9: Combination of plasma arc and flame cutting [3]

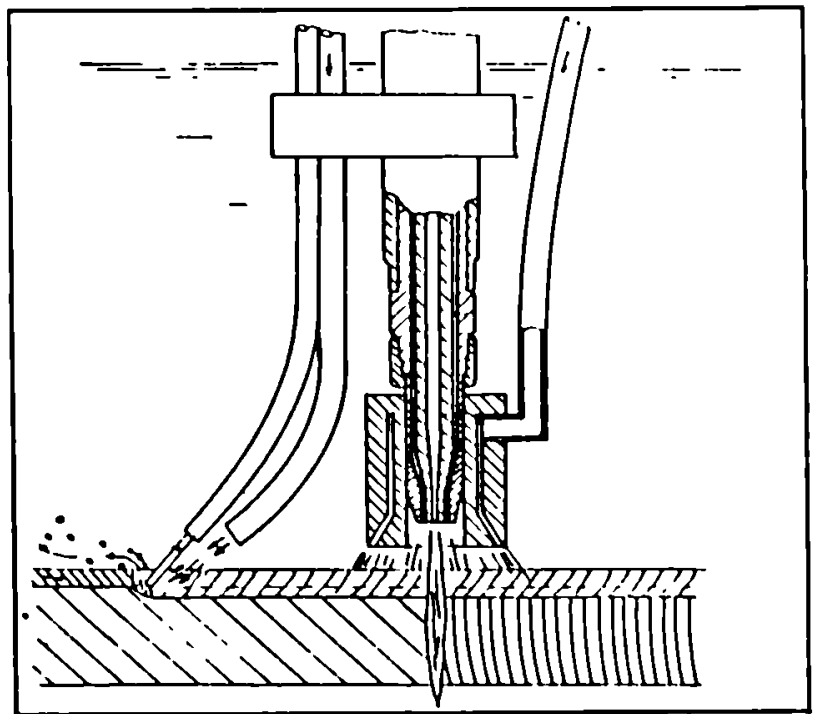

Pigure 10: Combination of consurable electrode and flame cutting [4] 
The advantage of this technique is:

The wall thickness depends like the arc saw only on the diameter of the blade, excellent feasibility of remote controlled operation, low secundary waste depending of low energy input, possibility to cut kerfs without cutting through the material.

The disadvantage is that up to now the plasma arc saw works only in the gravity position. Vertical cutting may be possible with further development.

\section{Conclusions:}

1. Knowing the state of the art and add some developments it is possible today to solve a lot of problems of dismantling by thermal cutting processes.

Therefore it is necessary to have a qualified remote control, optical and electrical sensor systems and technigues to collect and filter the effluents in the atmosphere and in water.

2. For higher wall thickinesses than given in this report, depending on the physics, the different torches have to be developed further.

3. A way for the future is to combine different systems - such as stainless steel plated ferritic steel - the plasma arc and flame cutting systems; (Figure 9), the arc-water-jet-flame cutting (Figure 10 ) as well as to combine thermal and mechanical cutting processes.

\section{References}

1 Hamasaki, M.; Tateiwa, F.; Katamura, M.; Ogawa, Y. Underwater cutting using a consumable electrode water jet technique

Journal of the Japan Welding Society 46 (1977) 5, pp. 264-270

2 Bach, Fr.-W.; Jaeger, M.

Entwicklung einer Plasmaschneidtechnologie nach dem "Sägeprinzip" zum Zerteilen nuklearer Komponenten großer Wandstärken BMFT-Forschungsbericht, $02 \mathrm{~S} 7287$

3 Bach, Fr.-W.; Bisci, R.; Boedeker, B.; Klare, J.; Piana, F. Dismantling techniques for steel components

Proc. of a European Conference Decommissioning of nuclear power plants, 22.-24.5.1984

EUR 9474

4 Hamasaki, M.; Murao, Y.; Tateiwa, F. Fundamental underwater cutting method experiment as a dismantling tool for a commercial atomic reactor vessel

Nuclear technology 59 (1982)1, pp. 99-103 


\section{SOLID AND GASEOUS SECONDARY EMISSIONS FROM UNDERWATER PLASMA ARC CUTTING}

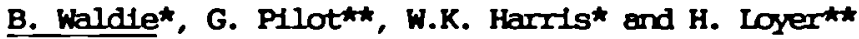

*Dept. Chemical and Process Engineering, Herlot-Watt Untversity, Edinburgh EHI4 AAS, Sootland

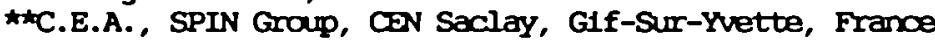

\section{ARSTRACT}

Solld and gaseous enissions from underwater plasma-arc arting of non-actlve stainless steel have been studiled. The influenos of water depths up to $9.55 \mathrm{~m}$ was investigated. Argan/nitrogen plasma gas was used in prefiltered and detanised water. The distributtion of secondary solid wastes was measured, sedimented dross being the major one, > 908 wt. of total soltds collected. Aercosol particles camprised 0.025 \& wt or less, decreasing with water depth. Attached slag increases with depth at constant plasma conditions. Measurements of elemental metal contents of aerosols and fine suspended particles showed mass enhanoement by chemical reaction and enrichment in manganese, a more volatile constituent of stainless steel. Aerceol size distributions measired with an inertial impaction/diffusion spectrometer gave mean sizes of 0.16 to 0.23 microns, there being no systematic varlation with water depth. Gaseous enissions comprised mainly plasma gases plus $\mathrm{H}_{3}$ and NO. Conoentrations and evolution rates varied with depth, $\mathrm{H}_{2}$ due probably to differences in plasma power and No die to absorption. The latter phenomenon made the water acidic.

\section{INIROOUCTION}

For safe and rellable application of underwater plasma cutting in decomissioning of ruclear installations, data is needed on the yields and characterlistics of secondary emissions. These emissions coarr in the effluent gas and in the water. Emissions in the gas comprise aerosol particles and any gases formed by chemical reactions in the underwater plasma auting process. Potential enissions in the water Include dross particles projected from the arting zone into the water and arrosol particles captured by the water. Some molten material may solldify as attached slag on the rear face of the metal being art. Previous reports on enissions were mainly for firod water depths and the influemes of depth, espectally on eerosol enissions, is of Interest, for example in establisiting an optimum depth.

In this foint study, instrumentation techniques developed by C.E.A. Saclay (1) for characterization of aerosol particles and gaseous emissions were applied on the underwater plasma outting facility at Herlot-hatt University, Edinburgh. The arting facility had been desigred (2) in a related project, to study the effects of depth on secondary solld emissions from plasma arc auting at depths to 10 metres. The main objectives of this project were:-

to establish a balance for the distribution of all secondary solld wastes 1.e. attached slag, sedimented dross, suspended finer dross particles and aerosols.

- to characterize the eerosols evolved as a function of water depthcharacteristics to be measured include concentration, size distribution and chemical composition.

- to determine the concentrations and quantities of gases evalved, principally $\mathrm{O}_{2}, \mathrm{O}_{3}, \mathrm{H}_{2}, \mathrm{NO}$ and $\mathrm{NO}_{x}$. 


\section{EXPERTMENTAL}

\subsection{Plasma outting Iig}

A schematic diagram of the overall rig with the deep water colum, sampling equipment and instrumentation is shown in Figure 1 . The cylindrical colum of $0.6 \mathrm{~m}$ diameter can be filled with water to give immersion water depths up to $10 \mathrm{~m}(2)$. Cutting was in the nommal gravity position, the torch being stationary and the workplece moved horizontally by an external variable speed drive. A tray under the workpiece, and moving with it, ollects most of the sedimented dross. Good acoess is provided to allow remaining sedimented dross to be collected after each run.

A commercial plasma torch, modifled for use at 10 metres water and fitted with a $2 \mathrm{~mm}$ diameter mozzle was employed. Plasma gas was a 608 Angan/ 408 Nitrogen mixture. Workpleces were of $37 \mathrm{~mm}$ thick grade 304 stainless steel. Relatively low autting speeds, $45 \mathrm{~mm} / \mathrm{min}+13 \%$, were used to increase the time for on-line particle size analysis instruments. Plasma current was 200 emps except for the $9.55 \mathrm{~m}$ depth run where 230 amps was used to ensure cutting. Water was delonised and prefiltered through a membrane filter ( 0.45 micron), a fresh change being used for each run.

2.2 Analytical instruments and techniques

Aerosol particle and gas samples were drawn fram a $125 \mathrm{~mm}$ diameter straight stainless steel exhaust duct (1). This was connected (Figure 1) to the oolum at positions dependent on water depth to minimise the time lag to the sample points. Dry filtered orygen free nitrogen at 80 $\mathrm{m}^{3} / \mathrm{hr}$ was mixed with the plasma effluent stream at the duct inlet. This diluent prevented condensation in the duct and helped ensure hamogeneity. Use of nitrogen also prevented formation of potential explosive mixtures from hydrogen evolution. Samples were drawn through selected sizes of nozzles at controlled flows to ensure isokinetic sampling. Total yields of particles and gases are calculated from the ratio of the measured total flow and sample flow rates.

Total aerosol mass concentrations were measured by filtration and welghing. The fibreglass filters, 47 and $130 \mathrm{~mm}$ diameter, have collection efficiencies of $>99.998$ for particles $>0.3$ micron.

Three methods of aerosol particle size analysis were studied:- a commerctal Differential Mobility Size Analyser (D.M.P.S.) sampling onIine, a prototype inertial/diffusional spectrometer (SDI 2000), and finally batch bag sampling with subsequent analysis by D.M.P.S. The inertial/diffusional spectrometer proved most suitable but requires precise weighing and ideally chemical analysis of very small deposits. Rum times were too short to allow a full size scan with the D.M.P.S. instrument and bag sampling is prone to coagulation effects.

Gas analysis involved a range of commercial instruments suited to expected individual components (FIgure 1). For example NO and $\mathrm{NO}_{\text {, were }}$ measured by chent-luminescence and hydrogen by thermal conductivit ty.

Mass concentration of fine particles remaining in suspension in the water after a aut was measured by filtration of several 25 or 501 samples through cellulose acetate membrane filters. A dissolution and centrifuging technique (2) is used to avoid problems with variations in moisture content of membranes. Dispersed dross in the tray and in the vessel base were combined, dried, weighed and sieved. Aerosol particles and fine suspended particles were analysed for elemental metal content by X-ray fluorescence or incuction coupled plasma spectrosoopy. 


\section{RESULTS AND DISOUSSION}

\subsection{Overall yield and distribution of solld entssions}

Data on mass 1089 from the workplece and consequent distribution of soltd emissions are summartsed in Table 1. Sedimented dross is the major solid entsestan at more than 908 of the total. Size distributions of sedimented droses (Flgure 2) show no trend with water depth. The apperently wide varlation in size distributions can arlse from small changes in the number of large (>20 mm) plecos. There is some evidence of increase in attached slag with depth to $3.55 \mathrm{~m}$, probably due to reduced plesma veloctities with increased pressure. This was counteracted at $9.55 \mathrm{~m}$ by ratsing the gas flow rate and arrent.

The increase in suspended particles with depth is probably due to the greater meen sedimentation distance, suspended particles being those which have not sedimented out some 5-10 minutes after a art. The Increase is much greater than can be acoounted for by improved eerosol capture. At $9.55 \mathrm{~m}$, the higher arrent may also have contributed.

As shown in Table I, the total mass collected was higher, by 6-198, than the mase lose from the workptece. Some of this gain will be due to corldation and perhaps other reactions. There was definite evidence of reaction of the suspended particles, their mass being approximately twice their total elemental metal content. Materlals were dried as much as possible but oocluded water in the dross and slag may also acoount for scme of the observed mass gain.

3.2 Aerceol particles

These represented not more than 0.0258 wt. of total solid enissians. A reduction by a factor of about 5 is achieved in aerosol emission by increasing the water depth from 0.08 to $9.55 \mathrm{~m}$ (Flgure 3). Most ooars in the first $3.55 \mathrm{~m}$. Of course even slight immersion gives a large recuction compared to cutting in air - a factor of at least 20 was observed here at $0.08 \mathrm{~m}$ compared to a preliminary art in air. Regarding the dininishing effect of water depth, ane postulate is that the more readily separated larger and smaller sizes of particles are removed in the initial water layer. The intenmediate sizes, which are less readily separated by elther diffuston or inertlal mechantsms, are then more likely to pass through the upper water layers. This postulated effect would also support qualltatively the absence of any trend of meen particle size with depth (Table II). The order of mean perticle size is similar to that reported by Bach et al (4) using a different instrument. Here the wide slze range capability of the Inertial/diffusion instrument gives more detafled size distribution data (Flgure 4). Whilst the dominant mode is around 0.2 microns there are some particles up to about $8 \mathrm{micrans}$ in size. These sizes are all based on the simplifying assumption of spherical particles. For small sample masses detalled distributions as exemplified in Figure 4 necossitate elemental analysis of deposits from the SDI 2000 instrument. $\mathrm{Fe}$, the dominant spectes analysed was taken as representative. Measumement of the masses of deposits by weighing gave anly the four or five dominant size classes in a distribution.

Motal element analysis of aerosol particles was also useful in showing total mass enhanoenent by reaction and enrictment by more valatile constituents in the stainless steel workpiece. Total aerosol mass was nearly twice the total elemental metal content (Table III) signifying extensive reaction, e.g. oxidation, nitriding, after metal voporization. This enhanoement is greater than can be explained by formation of oxides such as $\mathrm{Fe}_{2} \mathrm{O}_{3}, \mathrm{Fe}_{3} \mathrm{O}_{4}$ ar common nitrides. It also 
coars in aerosols from a cut in air and, as noted previously, in suspended particles.

Substantial enrictment in manganese is seen in aerosols from all cuts (Table IV). The $\mathrm{M} / \mathrm{Fe}$ ratio is an order of magnitude or more higher than for the parent steel. This is presumably due to the higher volatility of manganese whose atmospheric boiling point is some 300$600^{\circ} \mathrm{K}$ lower than those of other oonstituents. There is also less emphatic evidence of enrictment in $C r$ which has a lower boiling point than $\mathrm{Ni}$ or $\mathrm{Fe}$. The apparent enrictment in oopper is most likely due to copper losses from the torch nozzle. The possibilitiles of aerosol enrichment is of interest if the more active constituents are also more volatile. Hayashi et al. (4) found proportions of $\mathrm{Fe}, \mathrm{Ni}$ and $\mathrm{Cr}$ to be similar to those in the parent stainless steel but did not analyze for manganese.

\subsection{Gas evolution and water quality}

The matn gases evalved, bestdes argan and nitrogen, were $\mathrm{H}_{2}$ and $\mathrm{NO}$. Yields of $\mathrm{O}_{3}, \mathrm{NO}_{\mathrm{x}}$ and $\mathrm{O}_{2}$ were much smaller. $\mathrm{O}_{3}$ and $\mathrm{NO}_{x}$ concentrations in the effluent ${ }^{x}$ gas with $\mathrm{N}_{2}$ dilution were $3_{<} 0.02 x^{x}$ and $<0.6$ ppm respectively and $\mathrm{O}_{2}$ was negligible. These $\mathrm{O}_{3}$ and $\mathrm{NO}_{4}$ concentrations correspand to $<0.4^{2}$ and $<12 \mathrm{ppm}$ in the plasma effluent before dilution.

Variations in $\mathrm{H}_{3}$ and $\mathrm{NO}$ concentrations in diluted effluent gas over the four runs are shown in Figures 4 and 5 . Taking mean values of $\mathrm{H}_{3}$ and NO concentrations over the near steady state parts of Figures 4 and 5 and the appropriate dilution factors allows flow rates of gases leaving the water to be calculated (Table V). Allowanoe is made for conversion of some $\mathrm{N}_{2}$ to $\mathrm{NO}$ and saturation with water is assumed. NO concentrations and flow rates decrease systematically with depth due to absorption, probably preoeded by oxidation (5).

Differences in mean hydrogen evolution over the four rums are most likely due to differences in plasma power $(5,6)$, $44 \mathrm{kw}$ being used at $9.55 \mathrm{~m}$ compared to an average of $29 \mathrm{kw}$ at the other three depths. In an earlier study of argan plasma cutting of carbon steel (6), H, evolution rate increased with plasma power. Present mean ylelds per $k w, 0.35$ and $0.366 \mathrm{l} / \mathrm{min}$ are somentat higher than previously. As in that study, $\mathrm{H}$ concentrations appear sufficient for explosive mixtures to form of initial dilution with air if potential suppression effects of water vapour are neglected.

The $\mathrm{pH}$ of the water decreases significantly over a run and conductivity rises correspondingly (Table VI). This acidity is presumably due to absorption of oxides of nitrogen $(5,7)$. A practical implication is the potential for dissolving some solid materials thus complicating any subsequent separation from water. The extent of acidity development will depend on the degree of contacting of gas and water and oould therefore be less in a larger vessel.

\section{concuusians}

Solid entssions from underwater argon/nitrogen plasma arc cutting are predominantly in the form of sedimented dross, > 908 mass of total mass. Finer suspended particles in water and aerosol particles represent less than 1.48 and 0.0258 mass respectively. The other solld, attached slag, increases somewhat with water depth at constant plasma conditions due probably to reduoed plasma velocities. Aerosol yield decreases by a factor of about 5 over the depth range 0.08 to $9.55 \mathrm{~m}$, mainly in the first $3.55 \mathrm{~m}$.

Mean aerosol particle sizes as measured with a inertial impaction/diffusion instrument lay in the range 0.16 to 0.23 micrans. 
There was no trend with water depth. Comparison of elemental metal content and total mass shows that aerosol particles and fine suspended particles have undergone appreciable reaction. Also aerosol particles are substantially enriched in manganese compared to the parent stainless steel, presumably due to the higher valatility of manganese.

The matn gases evolved, besides the plasma gases, are $\mathrm{H}_{2}$ and $\mathrm{NO}$. Conoentrations of $\mathrm{O}_{2}, \mathrm{O}_{3}$ and $\mathrm{NO}_{4}$ are much lower. $\mathrm{H}_{2}$ yleld can increase with depth, probably due to the higher plasma power used in the deepest water, $9.55 \mathrm{~m}$. No evolution decreases systematically with depth due to aboorption of nitrogen oxides. This causes the initially detontsed water to become apprectably acidic.

\section{REFERENCFS}

1. Antolne, P., Le Garreres, J., P1lot, G. and Parprly, M. Proc. Spectrum '86, Nlagara Falls (N.Y.), Sept. 14-18, (1986).

2. Waldie, B. Ammal Report, Project FIlD-008, in 3rd Amual Progress Report (Year 1987), C.E.C. R and D Programme on Deocmissioning of Nuclear Installations, p. 82 C.E.C., Luxembourg (1988)

3. Bach, F.W., Biscl, R. Boedeleer, B., Knadestedt, H.G. and Plana, F. Proc. C.E.C. Canf. Decomilssioning of Nuclear Power Plants, Luxembourg, 229 (1984).

4. Hayashi, $K$. et al. ISFIKAWAJIMA-HARIDA ENG. REV., 22(1), 35, (1982).

5. Waldie, B., Pilot, G., Harris, W.K. and Lower, H. Submitted 9th International Symposium on Plasma Chemistry, ISPC9, September, 1989.

6. Ryan, E.J. and waldie, B. Proc. ISPC 5, Edinburgh, Vol.1, 242(1981).

7. Waldie, B. Anmal Repart, Project FI1D-008, in 2nd Anmual Progress Report (Year 1986), C.E.C. $R$ and D Programme on Decommissioning of Nuclear Installations, p. 57 C.E.C., Luxembourg (1987)

Table I Workpiece mass loss and distribution of ollected solid entssions

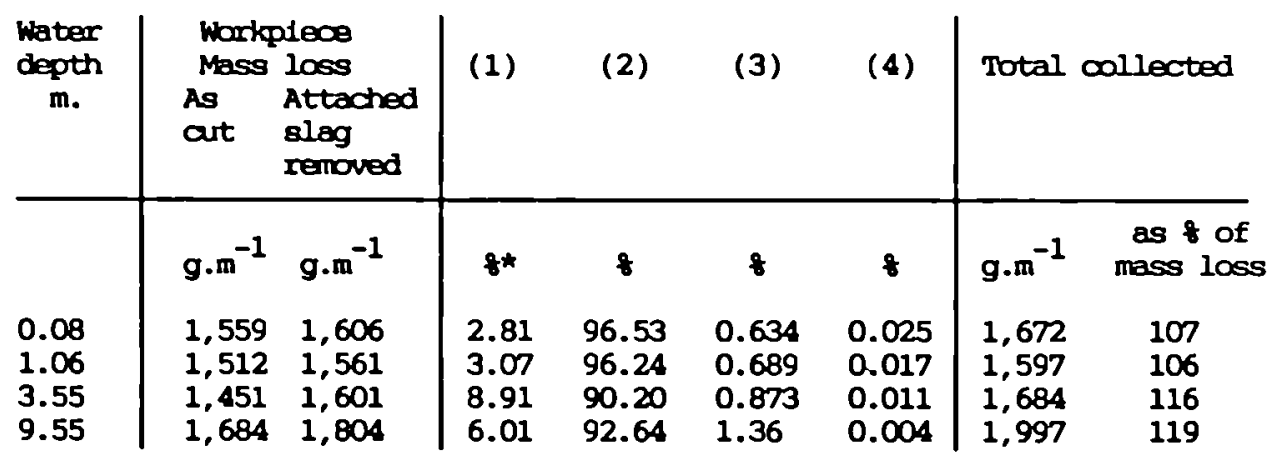

- As percontago of total $(1+2+3+4)$ collected
(1) Attached slag
(3) Suspended particles
(2) Sedimented dross
(4) Aerosol particles 
Table II. Aerosol particle size data from SDI 2000 instrument

Water
Depth
$m$

$\begin{array}{lcc}0.08 & \text { heighing } & \text { Analysis } \\ 1.06 & 0.198 & 0.229 \\ 3.55 & 0.158 & 0.161 \\ 9.55 & 0.191 & 0.187 \\ & 0.200 & 0.183\end{array}$

Table III. Comparisan of total mass and elemental metal content of aerosol filter deposit

aut

water depth,

m

$\begin{array}{rl}\text { (Air) } & 2.21 \\ 0.08 & 1.73 \\ 1.06 & 1.97 \\ 3.55 & 1.96 \\ 9.55 & 1.86\end{array}$

Mean of

underwater arts $\quad 1.88$

Table IV. Ratios of elemental metal contents

of aerosol particles on $130 \phi \mathrm{mm}$ filters

Air Out

$$
0.08 \quad 1.06 \quad 3.55 \quad 9.55
$$

304

$\begin{array}{lllllll}\mathrm{Cr} / \mathrm{Fe} & 0.307 & 0.247 & 0.354 & 0.368 & 0.299 & 0.252 \\ \mathrm{~N} 1 / \mathrm{Fe} & 0.085 & 0.107 & 0.170 & 0.159 & 0.148 & 0.125 \\ \mathrm{Mn} / \mathrm{Fe} & 0.365 & 0.287 & 0.338 & 0.263 & 0.219 & 0.025 \\ \mathrm{C} / \mathrm{Fe} & 0.029 & 0.189 & 0.127 & 0.080 & 0.082 & 0.006\end{array}$

Table V. Calculated flow rates of plasma gas effluent stream before dilution with Nitrogen

\begin{tabular}{|c|c|c|c|}
\hline 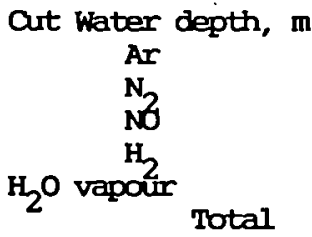 & $\begin{array}{r}0.08 \\
28.1 \\
18.4 \\
0.9 \\
8.9 \\
2 \\
58.3\end{array}$ & $\begin{array}{r}1.06 \\
28.1 \\
18.4 \\
0.8 \\
11.2 \\
\frac{2}{60.5}\end{array}$ & $\begin{array}{r}3.55 \\
28.1 \\
18.4 \\
0.7 \\
10.3 \\
\frac{2}{59.5}\end{array}$ \\
\hline
\end{tabular}

Note:- Flow rates of $\mathrm{NO}_{2}, \mathrm{O}_{3}$ and $\mathrm{O}_{2}$ are $<10^{-3} 1$.min ${ }^{-1}$ for all arts. 
Table VI. Electrical conchuctivity and pH of water before and after outting

\begin{tabular}{|c|c|c|c|c|}
\hline \multirow{2}{*}{$\begin{array}{l}\text { Ort water } \\
\text { depth } \\
\text { m }\end{array}$} & \multicolumn{2}{|c|}{$\begin{array}{c}\text { Electrical conpuctivity } \\
\text { us } \mathrm{cm}\end{array}$} & \multicolumn{2}{|c|}{ PH } \\
\hline & Before & After & Before & After \\
\hline $\begin{array}{l}0.08 \\
1.06 \\
3.55 \\
9.55\end{array}$ & $\begin{array}{l}4.6 \\
4.7 \\
5.7 \\
3.8\end{array}$ & $\begin{array}{l}37.5 \\
24.4 \\
36.3 \\
25.8\end{array}$ & $\begin{array}{l}7.5 \\
7.5 \\
7.3 \\
7.4\end{array}$ & $\begin{array}{l}4.3 \\
4.6 \\
4.2 \\
4.2\end{array}$ \\
\hline
\end{tabular}

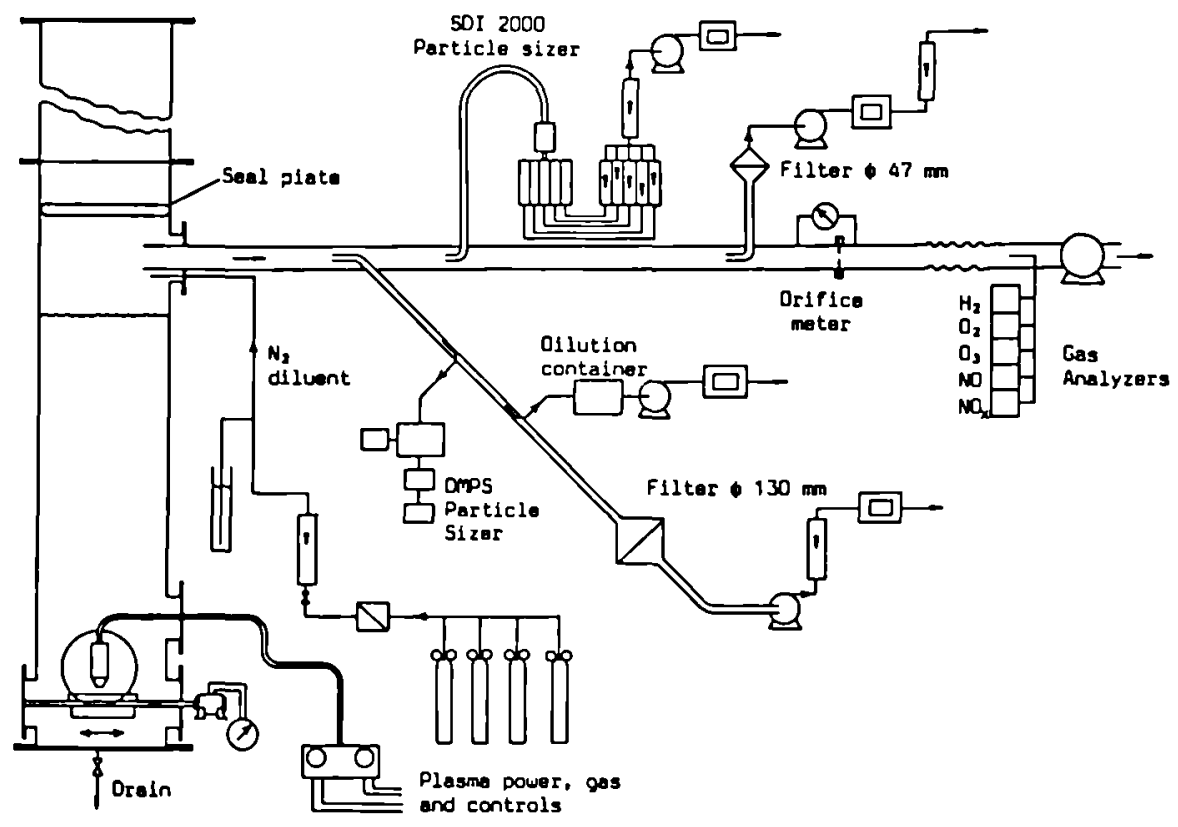

Figure 1. Schematic of experimental rig 


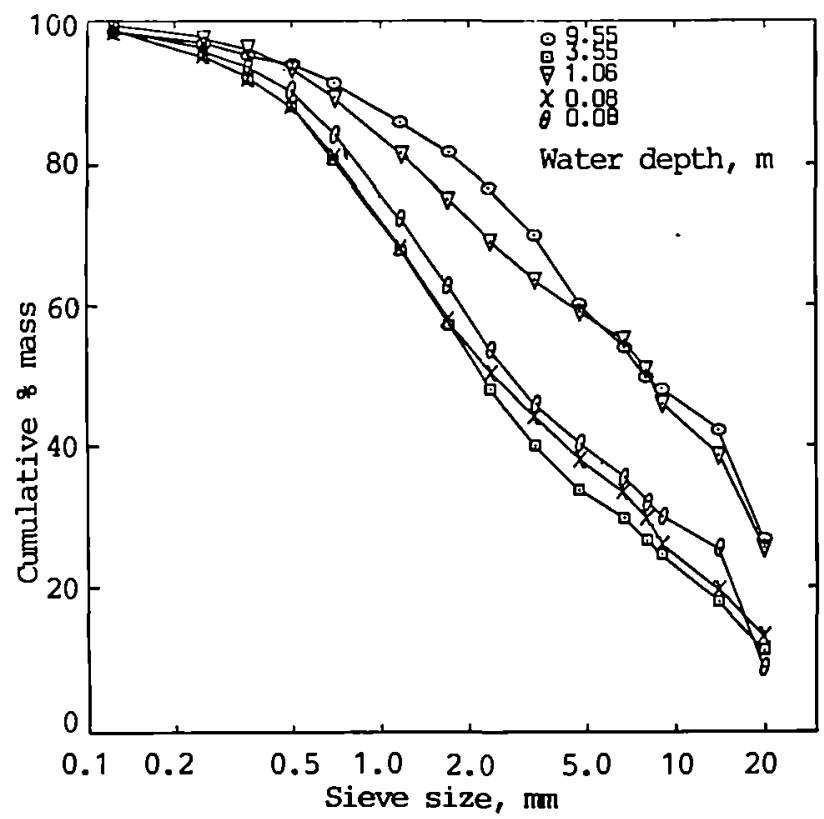

Figure 2. Size distribution of sedimented dross particles at different water depths.

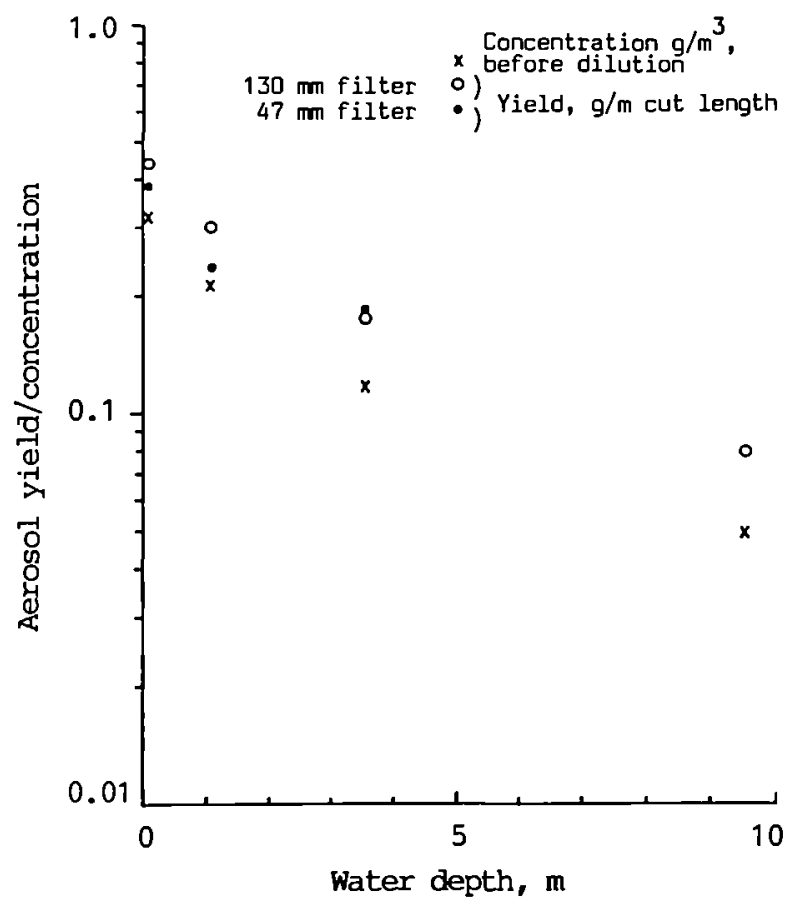

Figure 3. Effect of cut water depth on aerosol yield and concentration 


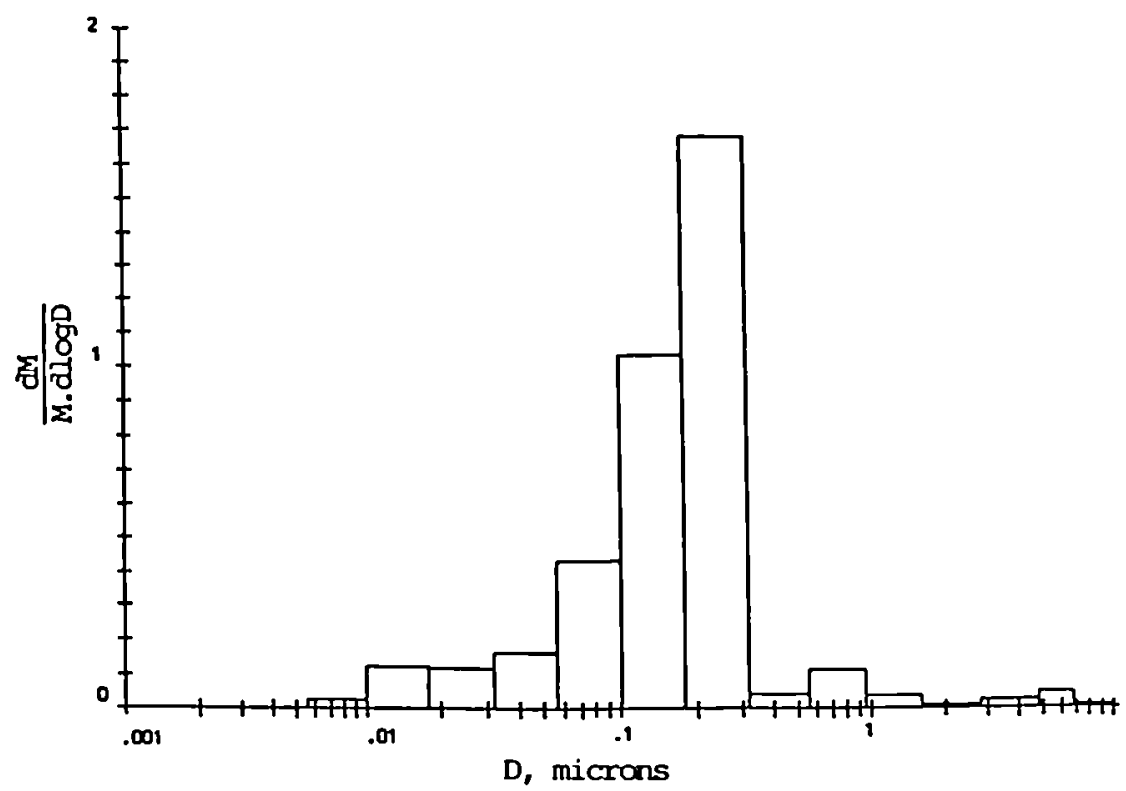

Figure 4. Aerosol size distribution from SDI 2000 instrument based on chemical analysis for $\mathrm{Fe}$. Out in $1.06 \mathrm{~m}$ water

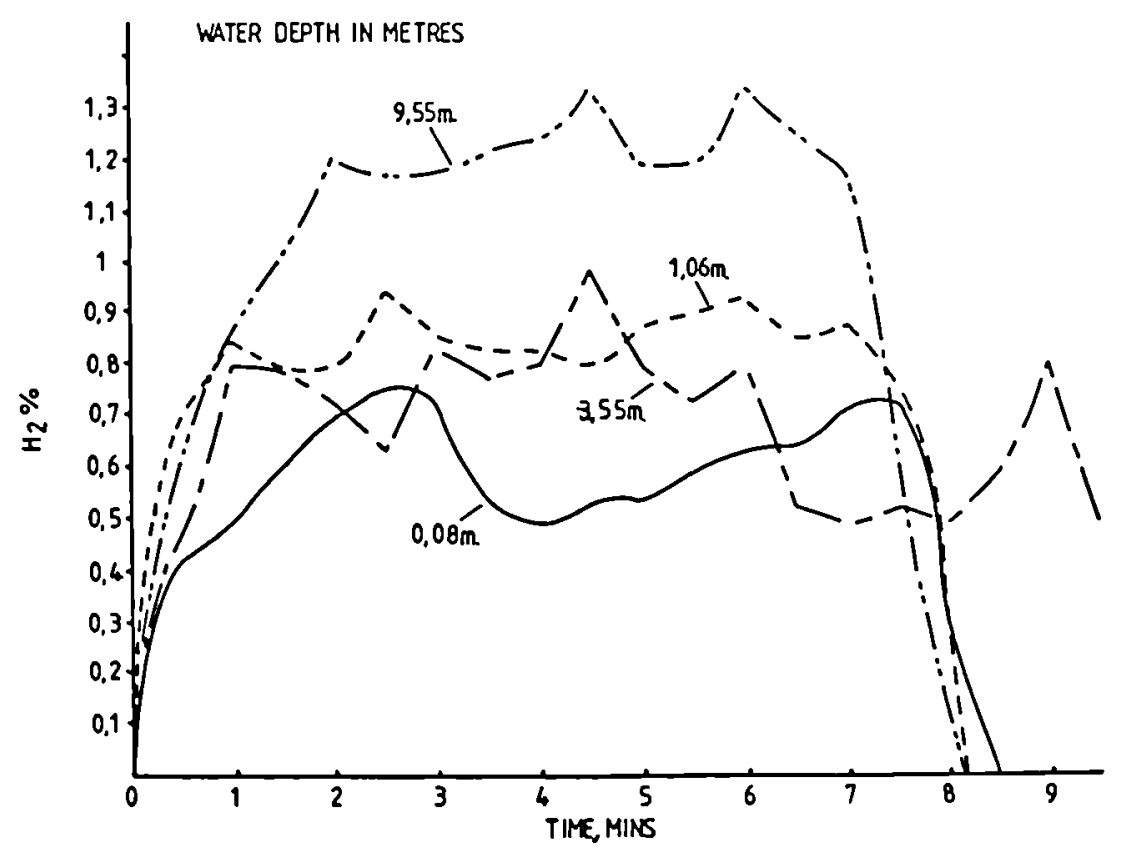

Figure 5. $\mathrm{H}_{2}$ concentration profiles in diluted effluent gas 


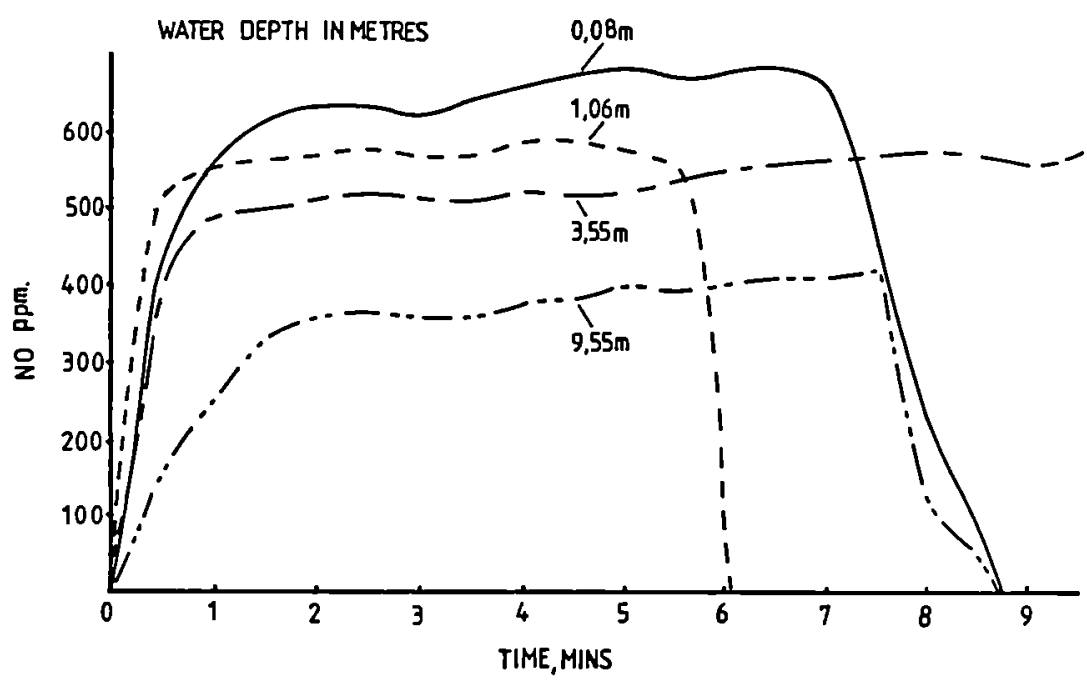

Figure 6. No concentration profiles in diluted effluent gas 
IN SITU ARC-SAW CUTTING OF HEAT EXCHANGER TUBES AND OF PIPES FROM THE INSIDE

J.P. THOME

FIELD AUTOMATION

\section{ABSTRACT}

Th1s study has provided a demonstration of the rellability of the electric arc-saw cutting process applied to the cutting of low diameter and thin tubes from the inside.

Conversaly this process is not applicable to the cutting of thick manifolds from the Inside, owing to the redundant dimensional restrictions on the sizing of the cutting head and the size of 1ts supply cord (11mited to 600 amps).

The arc-saw cutting process has been studied for application on three different types of cutting tools:

- Tranversal cutcing parameters for Steam Generator tubes (Stainless Steel $0 . D .22 \times 1 \mathrm{~mm}$ and Inconel $6000 . \mathrm{D} .22,2 \times 1,27 \mathrm{~mm}):$ Intens1ty $50 / 60 \mathrm{amps}$, orbital rotation $1,000 / 1,500 \mathrm{rpm}$, cutting time $90 / 100 \mathrm{sec}$. The Molybdenum electrode wearing allows only two successive cuts. A flexible tool and a representative bench for SG tubular plate simulation have been realized.

- Longltudinal cutting parameters for Steam Generator tubes (Stalnless Steel 0.D.22x/m): cutting speed $12 \mathrm{~mm} / 8$, Intensity 50 amps, electrode rotation: 1,750 rpm. The wearing of the Molybdenum electrode 18 negligeable.

- Internal cuts of Stainless Steel thick tubes: out of the experimental datas, a formula has been elaborated which relates the cutting speed to the maximum Intensity avallable and to the geometrical parameters. According to this formula, it appears that a $0 . D .240 \times 6 \mathrm{~mm}$ tube may need more than a 1600 amps supply to be cut in a 15 minutes industrial time.

Th1s process 18 therefore not applicable, owing to redundant dimensional restrictions of the cutting head supply cord.

\section{INTRODUCTION}

The principle of underwater metal cutting by electric arc-saw presents some simflarities with the arc gouging process and electrode arc cutting. Besides its numerous other advantages as high precision work and small production of cutting waste, this method 18 especially appropriate for telemantpulation by robots; particularly because of small induced vibrations and cutting forces involved in this process, and by the possibility to use small size cutting discs allowing for high accessibility to complex areas.

Th1s work was mainly almed at an adaptation of this procedure to In-situ cutting by robots, especially inside of tubes and pipes, with a special objective to dismantle steam generators and other heat exchangers in nuclear installations.

Th1s development comprised design studies for apparatus to be adapted on special crawler or robot arm, laboratory studies of the cutting parameters, miniaturization of cutting heads for their introduction into small diameter ducts. 
2. ARC-SAW TRANSVERSAL CUTTING OF STEAM GENERATOR TUBES

We have basically centered ourselves on the development of tools compatible with thefr use on tubular plate perfphery (fexcfble tool concept), in automatic mode.

The advantage of this process lies in the fact that it offers:

a) Effort-free, speedy cutting providing for the design of simple and compact tools, mounted on flextble cords so.as to access all tubes of a SG tubular plate, despite the spherical shape of the SG water plenum.

b) The simplicity of monitoring-control (servoed to the measurement of the current delivered), compatible with "standard" remote manfpulation.

c) The possibility of accessing into low diameter tubes (from I.D.16mm). d) The quality of the transversal cuts whereby tubes can be handled (internal decontamination, plugging) without having recourse to an additional machining phase (trimming of the cutting plane) generating contamfnated chfppings.

The transversal cutting tool is featured by the following points:

a) It possesses a fixed electrode, which is not rotated around itself, handled at the end of a flexible rod.

b) The "plunging" and "advance" movements of the electrode are monftored by the axfal movement of an isolating envelope part rotating around itself.

c) A translation movement is thus imparted to the end of the flextble-holder rod, along a cfrcular or helfcal route.

The results obtained on the test bench lead to the following observations:

- The average wear on the electrode increases with the rotation speed and the cutting time.

- The quantity of input energy is minimum whatever the cutting time, for a rotation speed of approximately $2,000 \mathrm{rpm}$.

- The wear of the electrode is maximum for all rotation speed, between 15 and 25 amps.

- The electrode should be continuously washed with cooling water. The minimum flow rate at the end of cutting is approximatly 2.41 fters $/ \mathrm{mn}$.

- Check (figure 1) that the cutting involves no deformation of the tube, nor presence of dross on the joint plane.

A prototype of the flexfble transversal cutting tool has been produced, together with a new operating bench representing the real use configuration under tubular plate (figure 2).

During the tests on this prototype, we have observed an improvement of the cutting conditions:

- The appearance of the cut is regular, with no deformation of the tube on the cutting plane, and without chippings (fines being recovered in the cooling water).

- Possibflity of making two cuts with a single Mo electrode, using a low power, hence small generator.

Nota: the wear ratio (Rus = volume machined/volume worn) of the electrode could be still further increased by choosing other materials, for example thorlated tungsten used for TIG welding electrodes.

- The monitoring-control of the tool is relatively simple to perform (monitoring of the rotation speed/off-centering travel/generator). 
The parameters to be used with this prototype tool are:

- generator providing 100 amps with 20 Volts;

- dia. 15x1m Molybdenum electrode;

- cutting speed of $1,500 \mathrm{rpm}$;

- cutting time $100 \mathrm{sec}$. (whence an average current of 50 amps);

- cooling fluid flow rate of $2.51 / \mathrm{mn}$.

\section{ARC-SAW LONGITUDINAL CUTTING OF STEAM GENERATOR TUBES}

This cutting has been specifically designed for removing the ends of steam generator (SG) tubes. This removal 18 necessary when the tubular plate is to be decontaminated (SG decommissioning), or a tube end extracted in view of examining or replacing by a sound section (SG maintenance).

In fact, the very considerable forces to be developed to extract an expanded tube over the whole thickness of the tubular plate (around 550mm) Involves equipment of respectable size, with all the drawbacks latent in such a "forced" extraction system.

Longitudinal cutting by arc-saw obtains cuts of controlled depth in the thickness of the side of the tube, all along a generatrix, without risking touching the tubular plate (In the opposite case there would be a risk of causing the tube to be welded to the plate).

The cut 18 made progressively from the Inner face of the tubular plate, with a mechanically constant pre-set depth, which avold touching the tubular plate's bore, even when the inside diameter of the tube 18 not uniform.

The effect of these grooves is to release the tube's expansion stresses and thus facilitate 1 ts extraction by reducing the forces required from several tons to an anticipated few dozen kilos.

With the reduction in the extraction forces, it is thus possible to design more compact extraction tools therefore sulted to an application in the peripheral area of SG water plenum.

The mechanical driven cutting head is featured by the fitting of the following components:

a) A rigid rectilinear head containing the rotary electrode on a rotating electrical commutator, a transmission, mechanical pressors and a pre-set stop to monitor the cutting depth, and a cut follow-on to provide for a rectilinear cut.

b) A flexible cord linked to this rigid head, comprising a flexible mechanical transmission and a power supply, also conveying the cooling water to the electrode.

An Inttial series of tests, with a single dia.20xlmm Mo electrode, obtained a cut $1,060 \mathrm{~mm}$ long. Further tests have shown, as from the recording of the varlous parameters, the following observations:

- The wear of the electrode decreases as from a cutting speed above $8 \mathrm{~mm} / \mathrm{s}$, and increases with the cutting time.

- The average current increases with the cutting speed.

- The electrode torque 18 very considerable, which 1mproves the cutting performances.

- The wear of a Mo electrode, measured over a lenght equivalent to two cuts (550rm each) across the tubular plate, is negliglble.

- The monitoring/control of the tool is relatively simple to perform, as long as the electrode's rotation speed is controlled. 
The mechanical driven cutting head has therefore proved fully satisfactory throughout the tests. It appears to be fully adapted, as to its design, to Industrial use, with minor improvements.

The cutting parameters adopted are the following:

- D1a.20xlmm Molybdenum electrode.

- Rotation speed 1,750 rpm.

- Advance speed $>12 \mathrm{~mm} / \mathrm{s}$.

- Average current 50 amps.

- The cooling water should wash the electrode continuously.

- Cutting time for a $550 \mathrm{~mm}$ long kerf: 46 seconds.

We have also tested a turbine driven cutting head consisting of using the electrode cooling water to drive 1 ts rotation, with a view to extreme simplification of the tool mechanism.

Although the general performance of this head does not differ from the one above, it is however not possible to achleve an advance speed greater than $6 \mathrm{~mm} / \mathrm{s}$. Beyond this speed, the mechanical friction of the electrode on the test tube becomes too great for the torque applied, which causes it to slow down and to stick.

To conclude, this experimental process does not appear to be suited to industrial use:

- The torque applied to the electrode remains insufficient to accelerate the cutting speed beyond $6 \mathrm{~mm} / \mathrm{s}$.

- Thus, the wear of the Mo electrode remains too great to make a $550 \mathrm{~mm}$ long cut at constant depth.

- It is not technically easy to integrate a system measuring the rotation of the turbine on the tool, which is indispensable to the monitoring/control of the tool.

The appearance of the cuts, made both with the mechanical and the turbine heads, are Identical, with an agglomeration of dross on the lips of the cut (figure 3 ).

4. ARC-SAW TRANSVERSAL CUTTING OF THICK, LARGE DIAMETER TUBES

In an Initial phase and simultaneous to tests, a study has been performed on a vector with cutting disc on board, its movements inside pipes with a diameter greater than $200 \mathrm{~mm}$ being self-propelled. The specifications relevant to this vector are:

a) Autonomy of movement.

b) Crossing of ascendant verticals.

c) Possible action in pipes of varlable Inside diameter (between 245 and $315 \mathrm{~mm}$ I.D.).

d) Crossing of bins (min. curvature radius $>4 x d i a$. ).

e) Cutting of thick walls, approximately $20 \mathrm{~mm}$.

Th1s "push-pull" crawler type vector, as shown on figure 4, consists of a work trolley, with an arc-saw cutting head on board, and a tall-end trolley linked to the one above by a coupling-actuator.

Each trolley consists of two modules coupled together, which provide for the centering, rolling and clamping in the pipe.

The actuator provides the alternative movement of a trolley in relation to the other by alternating action of the module clamps, which creates the advance of the vector. 
The two modules of the work trolley are coupled by an equipment which provide for the rotation and radial off-centering in the pipe of the arc-saw cutting head on board.

The tests performed within the scope of this contract were designed to determine the best machining parameters, whilst remaining within the context of a cutting process with low current, approximately 100 amps.

They concern the cutting of $0 . D$. $190 \times 6 \mathrm{~mm}$ and $0 . D$. $236 \times 6 \mathrm{~mm}$ Stainless Steel pipes samples, $22 \mathrm{~mm} d \mathrm{da}$. bars, and finally 0.D. $89 \times 4 \mathrm{~mm}$ SS tubes.

The electrodes employed were made of copper, steel and Molybdenum with different diameters and thicknesses.

The cutting procedure consists in spiral machining, obtaining a given penetration into the material (plunging) in correlation with the scrolling speed ( $V d$ ) of the electrode in the tube (internal rotation of the cutting head Inside the pipe).

In fact, so as to simplify the test bench, It substitutes the rotation of the tube sample itself for the rotation of the cutting head.

The results obtained during the tests have enabled us to establish and check the validity of an empirical formula whereby the scrolling speed Vd to be used can be estimated.

It can be stated as follows:

$V d=I 11 m * \mathrm{Cu} / \mathrm{Se}$

- The Vd parameter (scrolling speed in front of the electrode) 1s generally the determining parameter for the feasibility of the cut. In fact, if this value is too low, the cutting time becomes too high to justify cutting by electric arc as compared to other existing processes (milling, grinding, plasma, ...)

- The Illm parameter describes the limft current avallable on the generator.

- The $\mathrm{Cu}$ coefficlent, determined experimentally as being the ratio of the volume machined to the quantity of energy required for machining, has a value of $0,06 \mathrm{~mm}^{3} / \mathrm{A} .8$. In the case of SS tubes with dia. greater than $50 \mathrm{~mm}$.

- The electrical arc surface of the electrode (Se) corresponds to 1 ts "active" surface during machining, this value depending on the type of machining performed. The formula is stated as follows: Se - Larc * $e$ * $\mathrm{K}$ Se 18 only a fraction of the electrode surface Involved in the cutting, which 18 determined by the length of arc in contact (Larc), the thickness of the electrode (e), and the application of a $K$ efficiency ratio determined experimentally for each type of cut ( In the case of a thick tube, $K=0,5$ ). Larc $=2 \star r \star A C O S\left(-\left(R^{2}-r^{2}-D_{E L T A}{ }^{2}\right) / 2 \star D E L T A * r\right.$ I 18 the radius of the electrode $R$ is the radius of the tube DELTA 18 the distance between the two: $R-r+$ pass depth ACOS is the arc cosine function.

Example: In order to cut an $0 . D .89 \times 4 \mathrm{~mm}$ SS shroud In an "Industrial" time of 300 seconds ( $1 . e$. Vd $=0,85 \mathrm{~mm} / \mathrm{s}$ ), with an Mo dia. 40x1,5mm electrode, th1s would require: I11m $=0,85 * 25,8 / 0,06=366$ amps. 
According to this empirical formula, it can be seen that the only ways of Increasing the cutting speed (Vd) consist in:

- Increasing the value of the $\mathrm{Cu}$ coefficient by reducing the energy consumption.

- Reducing the arc section se of the electrode by reducing its diameter, but taking into account the electrode's wear factor.

- Increasing the limit current avallable on the generator.

To conclude, the test results and the application of the above formula have enabled us to produce two curves, illustrating the different machining parameter cholces (figure 5). These curves apply to the case the cutting of an I.D. $81 \mathrm{~mm}$ SS tube, with a 100 amps/20V generator, and with $1,5 \mathrm{~mm}$ thick electrodes (figure $5 \mathrm{a}$ ) or $1 \mathrm{~mm}$ thick electrodes (figure 5b).

For example, the application of these curves to the cutting of an $0 . D$. $93 \times 6 \mathrm{~mm}$ shroud determines the generator required, contingent on a minimum cutting speed of $0,85 \mathrm{~mm} / \mathrm{s}$ :

According to curve $5 \mathrm{a}$, a dia. $10 \mathrm{xl}, 5 \mathrm{~mm}$ electrode provides a maximum speed of $0,19 \mathrm{~mm} / \mathrm{s}$; it is therefore necessary to multiply this speed by the ratio $0,85 / 0,19=4,47$.

As the speed is in direct proportion to the limit current, this latter simply has to be increased to a value of $100 \star 4,47$, i.e. 450 amps approx.

Within the scope of this contract, the arc-saw cutting head on board of the "crawler" vector, thus the test bench drive motor, had been designed for a maximum current of 600 amps (in view of the maximum foresceable size of the cords supplying the vector). But according to the test made, it is not possible to perform cuts on thick pipes in "industrial" times with too low powered generators.

The formula calculating Vd demonstrates that it would be necessary to have more than 1,600 amps available to obtain the cutting of an $0 . D$. $240 \times 6$ m tube in 15 minutes, with a dia. $90 \times 2 \mathrm{~mm}$ electrode.

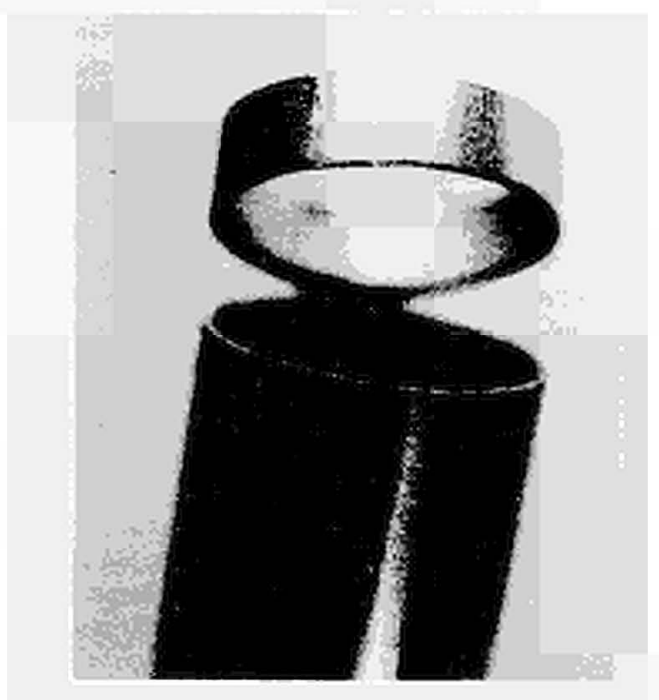

Figure 1: SG tube transversal cutting aspect 

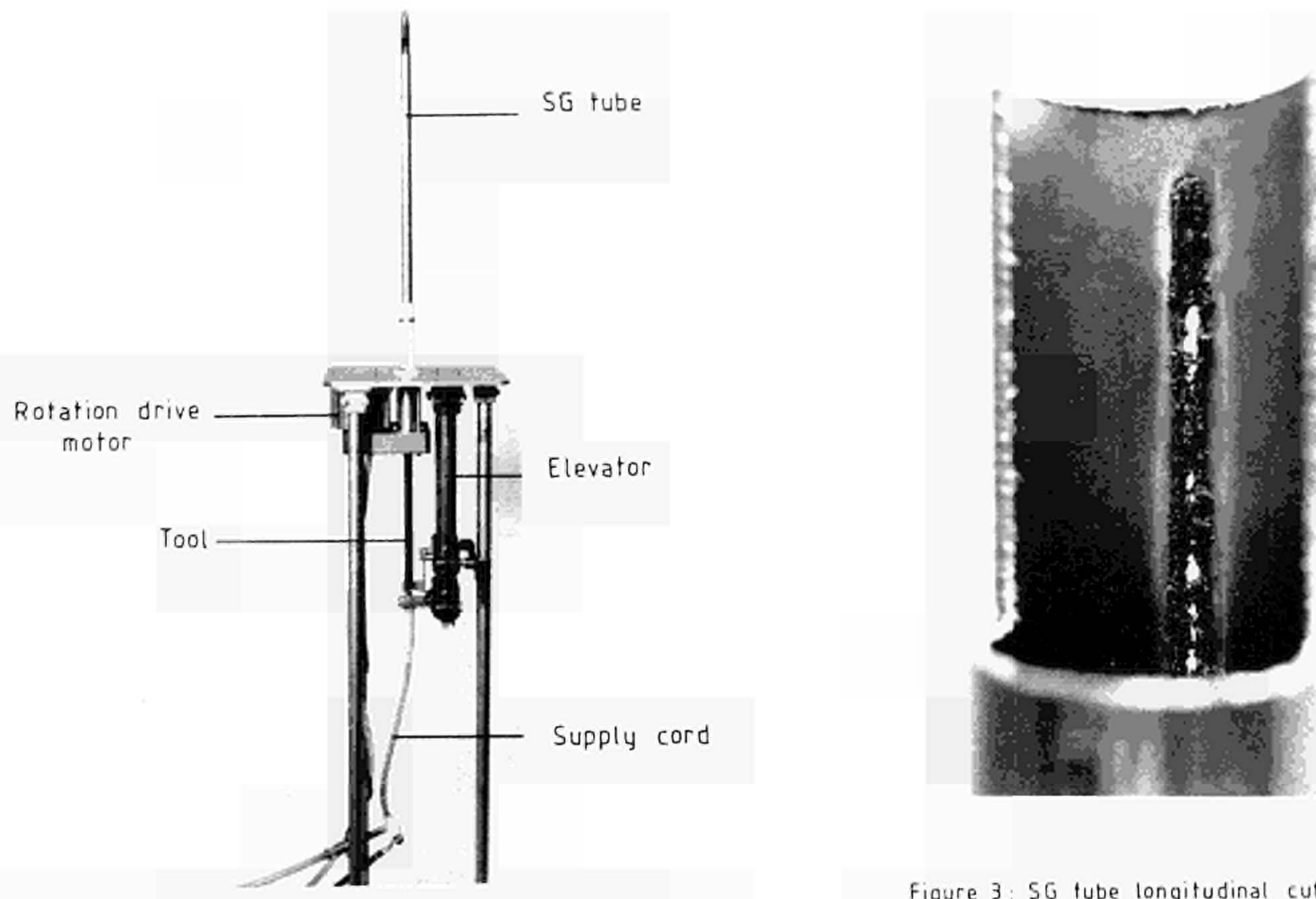

Fiqure 2: Transversal cutting flexible tool on test bench 

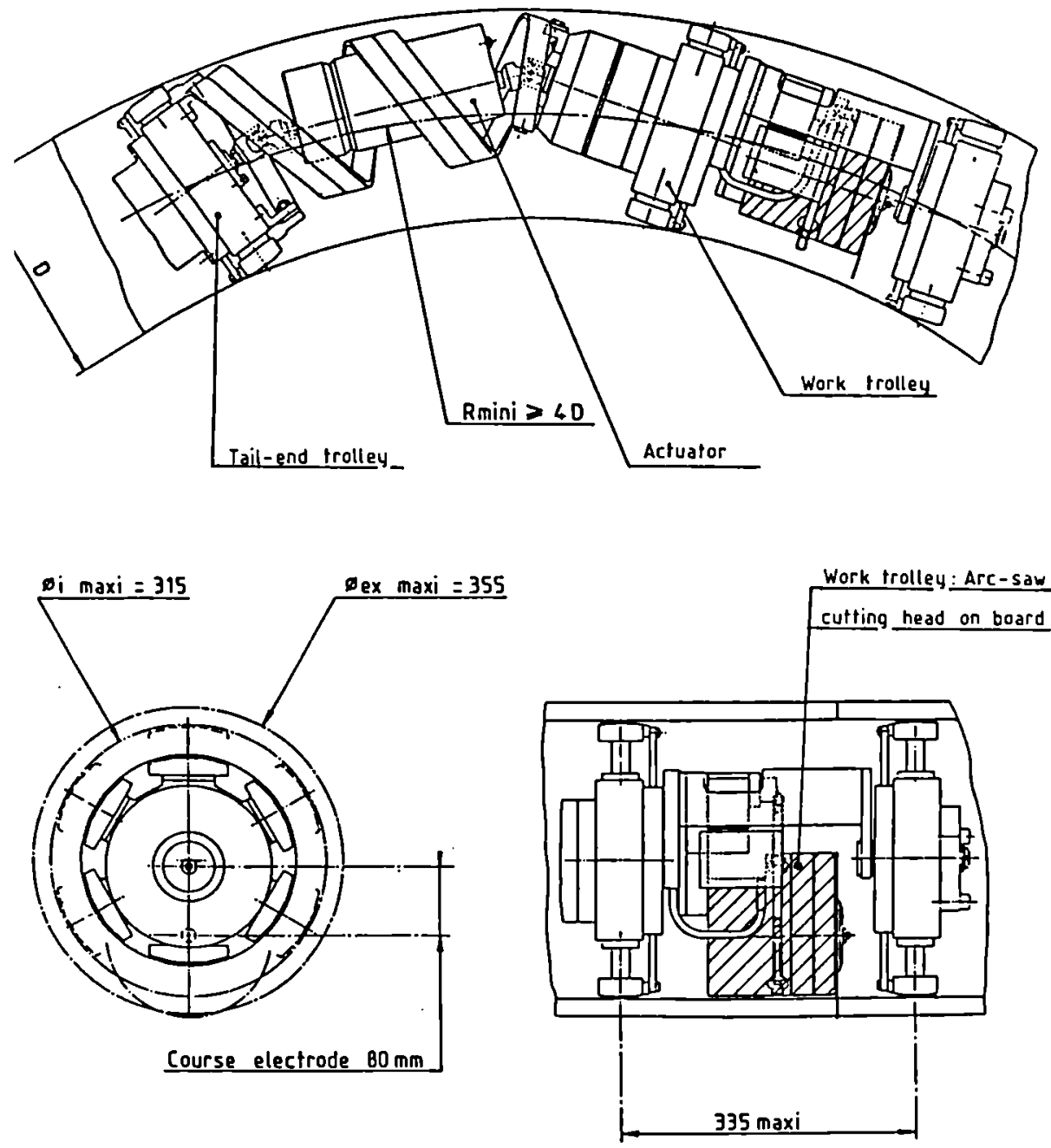

Figure 4: "Push-pull" crawler vector 
Fig 5 a

$1.5 \mathrm{~mm}$ thick

$V d=f($ pass depth)

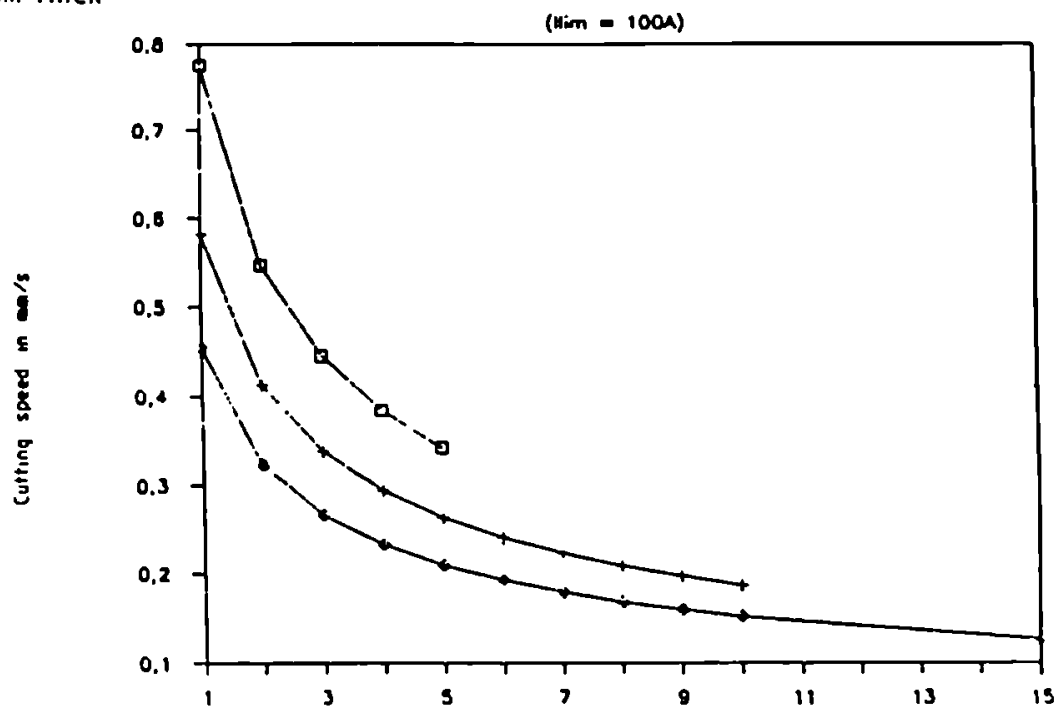

Pass dapth $n$ min

- 0.0. 1. c. : $20 \mathrm{~mm}$ o dio. ele. : $40 \mathrm{~mm}+$ Do. elec. : $30 \mathrm{~mm}$

Fig. 5b

$1 \mathrm{~mm}$ thick

$V d=f($ pass depth)

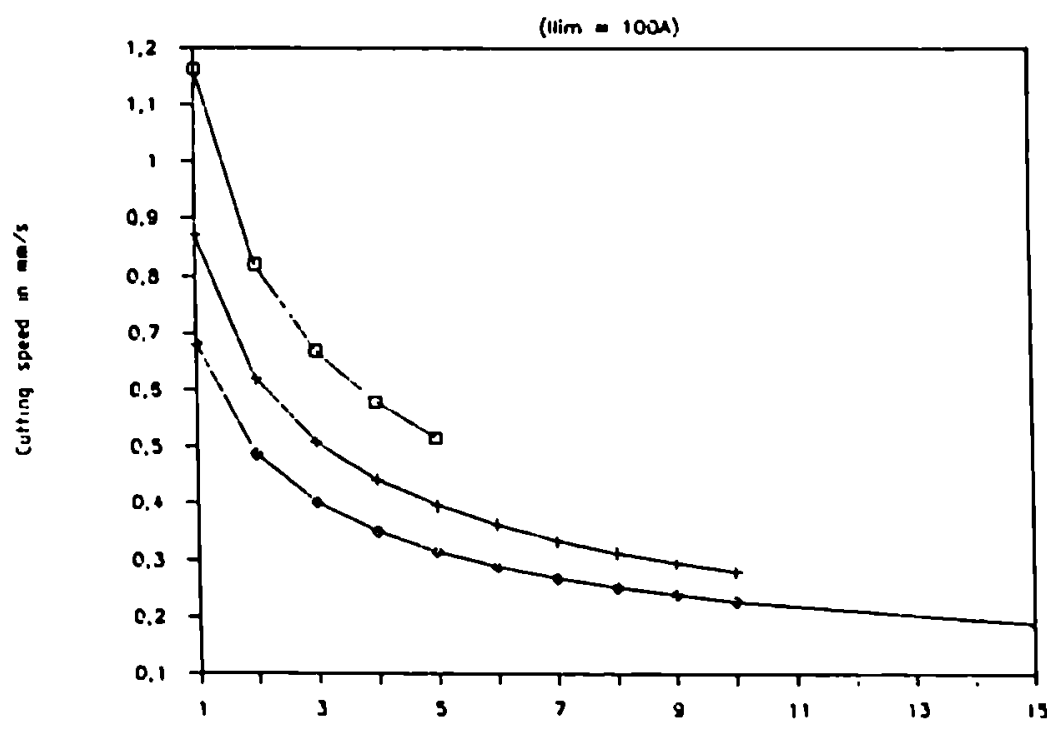

D 0.0. . elec. . $20 \mathrm{~mm}$

Pass depth $n$ an

- Cio. alec. : $30 \mathrm{~mm}$

- dia elec. : $40 \mathrm{~mm}$

Figure 5: Experimental results (thick tubes cutting) 
ELECTROCHEMICAL TECHNIQUE FOR THE SEGMENTING OF ACTIVATED STEEL COMPONENTS

\author{
Stang Wolfgang, Fischer Alfred \\ Kernkraftwerke Gundremmingen Betriebsgesellschaft mbH \\ Gundremmingen, F.R.G. \\ Pott Paul \\ AEG-Elotherm, Remscheid, F.R.G.
}

\begin{abstract}
Electrochemical machining (ECM) is well known in non nuclear metal working i.e. for special manufacturing tasks. In the nuclear power plant KRB unit A electrochemical decontamination has been introduced for decommissioning. Therefore it was obvious to examine ECM technique for the potential of cutting thick walls of activated steel. Three different methods (atatic, step by step and dynamic cathode movement) have been tested on non irradiated samples of the reactor pressure wall (22NiMoCr37 with stainless cladding). The best test results could be achieved by a stepwise moving cathode. On the test facility a $143 \mathrm{~mm}$ thick sample has been cut through within 750 min by an abrasion efficiency of $0,9 \mathrm{~mm} / \mathrm{Am}^{\circ} \mathrm{min}$. The dissolved material out of the $8 \mathrm{~mm}$ gap was converted to approximately the double amount of waste in form of dry metal salt.
\end{abstract}

\title{
1. INTRODUCTION
}

Cutting the neutron activated wall of the reactor pressure vessel (RPV) is one of the most difficult tasks by dismantling light water reactors. Adverse circumstances like wall thickness between 120 and $250 \mathrm{~mm}$, difficult accessibility, high radiation, stainless inside cladding etc. conplicate this job. The competing technologies are thermal or explosive cutting, sawing, milling, grinding. General problems rise up by under water application, use of remote control and handling of the dismantled pieces. Therefore it is obvious that the isolated evaluation of a cutting technique by simple characteristics like cutting speed, gap width, waste volume etc. can be only a firat approach of an optimization. Nevertheless these qualities of a new technique have to be studied to estimate the applicability. For this reason KRB and AEG-Elotherm decided to exchange their spezific experiences and to examine the ability of the ECM-technique by cutting thick plates of non-activated ateel.

\section{PRINCIPLE OF ECM-TECHNIQUE}

If two metallic electrodes connected with direct current (DC) are immerged in a hydrated electrolyte solution, then an electrical current flows. A transport of electric charges by dissociated ions between the cathode and anode occurs ( $f$ ig. 1).

This process detected by Faraday is used for ECM-technique and electrochemical decontamination (fig. 2). 


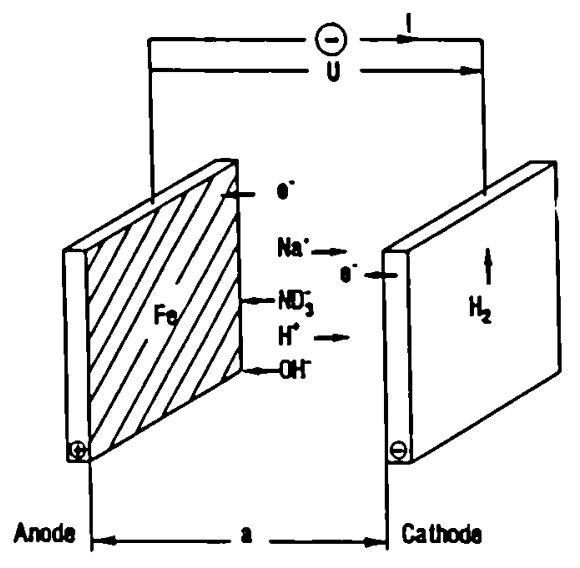

Fq 1 Faraday Process

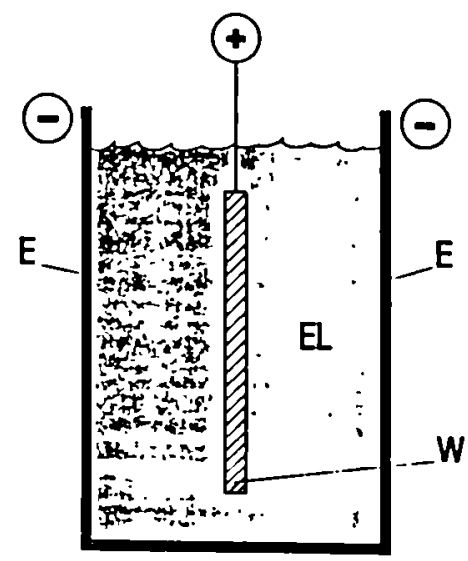

Fio 2 Electrochemical Decontamination

In the case of ECM ( $f i_{g}$. 3) a negative shaped electrode (E) is used as cathode of a DC-generator (G). It moves with a controlled velocity (V) towarde the working piece (W). The electrolyte (EL) and the DC-source cause a dissolution of the aurface material opposite to the electrode. In this way a gap near and around the electrode is produced. The diseolved terial precipitates as metal hydroxide or metaloride in the electrolyte.

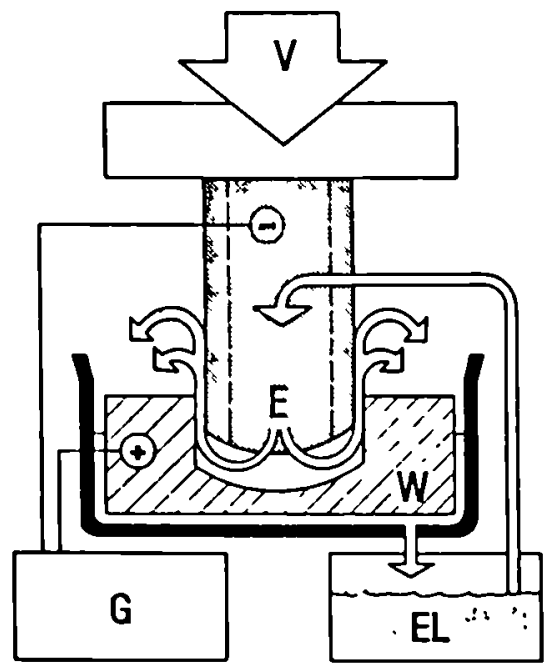

Fig 3 ECM - Technique 
3. APPLICATION OF ECM FOR RPV-DISMANTLING

The RPV of a light water reactor consists out of ferritic steel with stainless steel cladding inside. The wall thickness ranges between 120 and $250 \mathrm{~mm}$ including the cladding of approx. $7 \mathrm{~mm}$. During nuclear operation the vessel wall cloge to the core is highly activated by neutrons (in KRB A up to $5^{\circ} 10^{5} \mathrm{~Bq} / \mathrm{g}$ ). Dismantling therefore has to be realized carefully by remote techniques to reduce personal dose. But also the spread of kerf material has to be eliminated. The shielding effect of water can be used as long as the vessel is filled. Before complete cutting either an additional vessel outside has to be installed or the water must be drained. ECM-technique can be used in both ways.

There are different possibilities for RPV-segmenting (fig. 4) i.e. cutting rings, stripes or blocks.
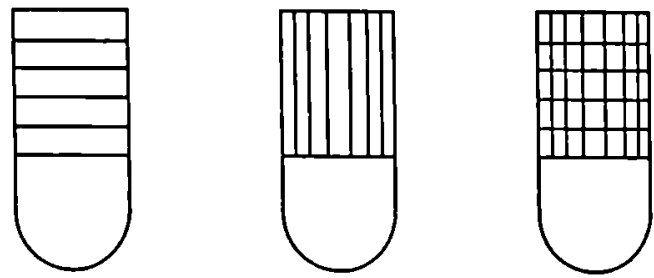

Fin. 4 RPV - Sequentung techniques

Small blocks can be directly packaged in waste containers whereas rings or stripes have to be moved into the fuel storage pool and segmented afterwards. The special effort for ECM might be reasonable only in the high irradiated areas of the RPV. Other portions can be cut by thermal methods with less effort.

\section{TEST FACILITY AND EXPERIMENTS}

It was decided to test the basic efficiency of ECM on non irradiated RPV samples (fig. 5).

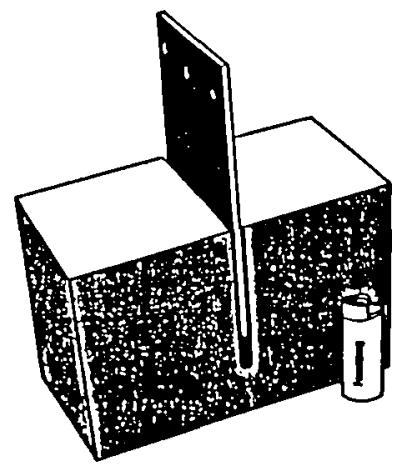

Fig. 5 RPV - Samplo

The samples $(210 \times 107 \times 143 \mathrm{~mm})$ consisting of 22NiMoCr37 were cladded with a CrNi-alloy $(1.4556)$. 
For the cutting tests a sinking machine SMV-1-50 of AEG Elotherm vas used $(f 1 g, 6)$.

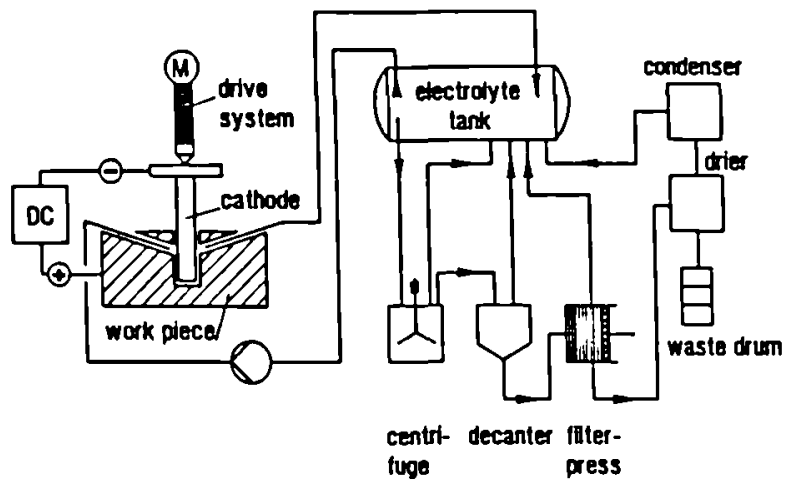

Fig. 6 ECM Test Faciilty

This machine consists of a sinking-facility and a closed cycle for electroljte treatment. The cathode can be moved vertically and is rinsed by the electrolyte $\left(10 \% \mathrm{NaNO}_{3}\right)$. The electrolyte solution is pumped to the cathode on one side and to a regeneration facility on the other side. There the iron sludge is extracted by a filterpress and afterwards dried.

The voltage was limited to $10 \mathrm{~V}$ to achieve a smallest gap between cathode and the sample (anode). The temperature of the electrolyte was stabilized at $30{ }^{\circ} \mathrm{C}$, the pressure of the pump at 3 bars and the pHvalue at 8.5 . Three different moving methodes were tested:

- static cathode

- stepwise moving cathode

- continuously moving cathode.

\subsection{STATIC CATHODE}

The first tests rere executed with a static cathode in a position of $0.3 \mathrm{~mm}$ to the rorkpiece at the beginning. During the cutting process the gap increased and the electric current decreased.

The experiment came to on end after penetrating the stainless steel cladding of $7 \mathrm{~mm}$ wen the bese material vas reached because of pessivation effects (fig. 7).

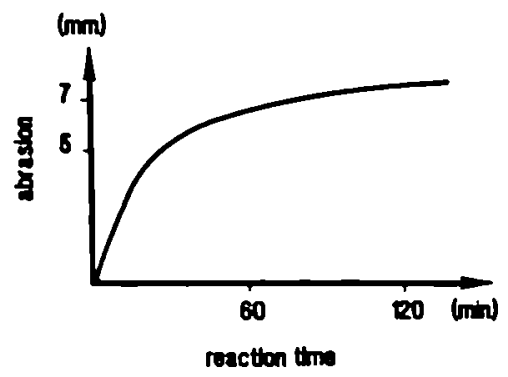

Fig 7 Test resutts of static cathode 


\subsection{STEPWISE MOVING CATHODE}

During these tests the cathode was driven forward in regular time intervals of $60 \mathrm{~s}$ by constant steps of $0,2 \mathrm{~mm}$. The step by step procedure demonstrated, that it was possible to cut the sample completely by a simple methode and within a reasonable time of 750 min (fig. 8). The bending atiffness of the cathode produced the only problem. The pressure difference of the electrolyte caused a bending of the cathode resulting in a short circuit between the cathode and the working piece. This problem was solved by the use of ceramic spacer blocks.
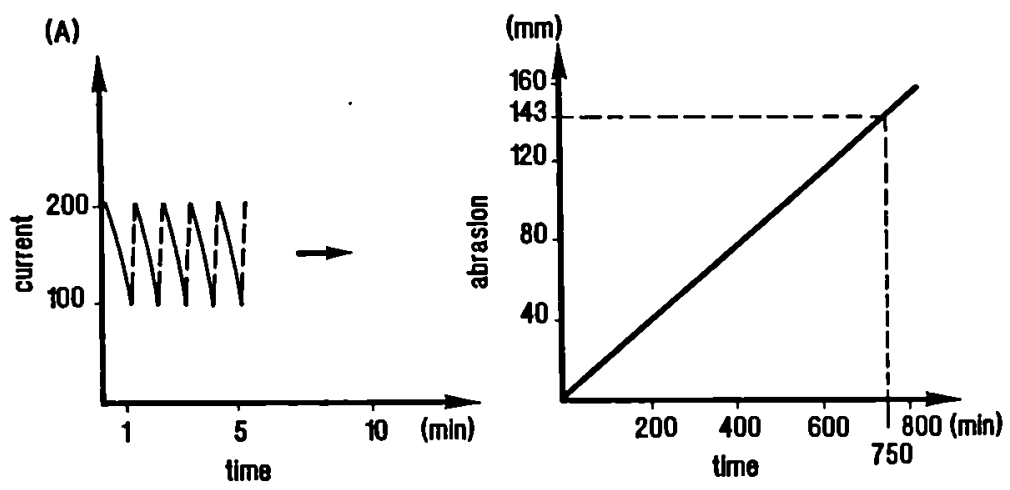

Flg. 8 Test results of stepwise moving cathode

\subsection{CONTINUOUSLY MOVING CATHODE}

In the third test serie the cathode was driven continuously by a velocity of $0,2 \mathrm{~mm} / \mathrm{min}$ and the electrical power had to be controlled automatically. With optimized parameters the cutting speed was higher than with the stepwise moving cathode (fig. 9). On the other hand this technique was very sensitive to changes of electrolyte pressure and voltage. Without interruption the time for complete cutting through was 715 min.
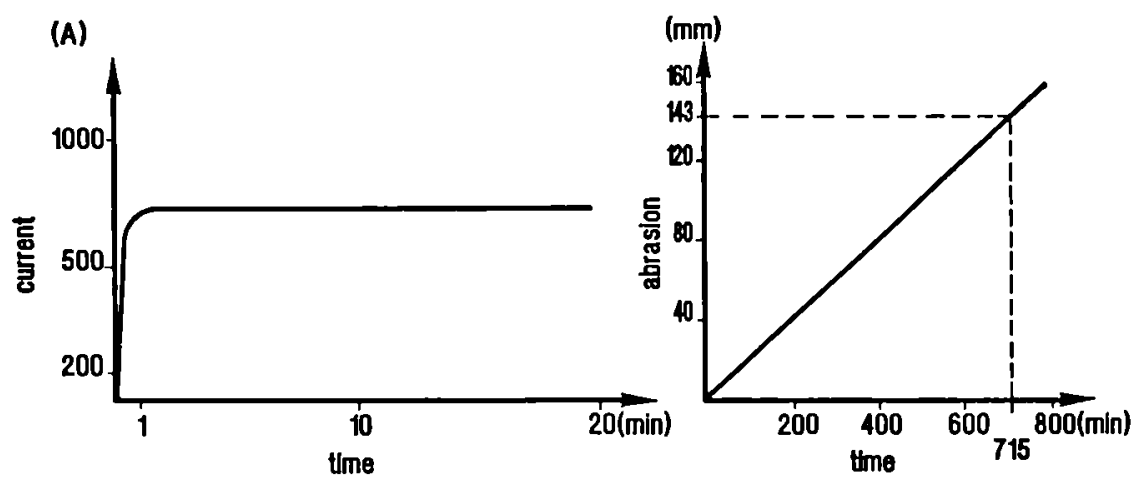

Fig. 9 Test results of continous moving cathode 


\subsection{WASTE TREATKENT} equation

The electrolyte procese is described by the following chemical

$$
\begin{aligned}
& 5 \mathrm{NaNO}_{3}+16 \mathrm{H}_{2} \mathrm{O}+11 \mathrm{Pe} \longrightarrow \\
& 11 \mathrm{Fe}(\mathrm{OH})_{2}+4 \mathrm{NaOH}+\mathrm{NaNO}_{2}+\mathrm{NH}_{2} \mathrm{OH}+\mathrm{NH}_{3}+2 \mathrm{NO}
\end{aligned}
$$

The iron hydroride sludge precipitates in the solution. The sodium hydroxide - nitride and hydroxylamin don't disturb the procese. The gaseous products ammonia and nitric oxide have to be sucked of $f$ and filtered before venting.

The diseolved material is concentrated in the fron hydroxide sludge which can be preseed and dried for volume reduction. The quantity of waste arising by this procese is appror. the double amount of the material which can been dissolved.

\section{CONCLUSION}

The ECM-technique is suitable for cutting thick oteel plates especially the activated areas of the reactor pressure vessel of a light water reactor. The relative low cutting velocity is acceptable for this epecial dismentling task. The executed experiments demonstrated the good functioning of eeneltive parameters like cathode tracking, cathode stiffnese, flow of the electrolyte. are

Comparing with other cutting techniques the main advantages of ECM

- lor tool forces

- closed raste cycle

- exact cutting geometry (important for cutting without break through).

It seems that the method has reached the final in the competition with thermal and mechanical dismantling techniques. 


\author{
ADAPTATION OF HIGH PRESSURE WATER \\ JETS AND ABRASIVES TO DISMANTLE \\ NUCLEAR INSTALLATIONS \\ C.LORIN - R. ROUVIERE - G. PILOT \\ Decomissioning Service \\ CEN VALRHO - Marcoule \\ Commissartat a l'Energie Atomique (France)
}

\title{
1 OBJECTIVE
}

The application of cutting processes by water jets and abrasives during the dismantling of nuclear installations, needs adaptations, an evaluation of produced nuisances and the inspection of 1 ts possibilities.

The work applied this cutting process to different samples of steel and concrete with telemanipulators.

\section{THE TESTING CELL AND THE USED EQUIPMENT}

The cell ventilated and tight, was built in modular panels. The volume of which is about $30 \mathrm{~m} 3$, authorizes the enclosure of all the produced effluents, to guide the gaseous effluents towards an extraction line equipped with measuring apparatus, and to protect the operators from all incidents generated by the equipment.

The principal window of this cell was equipped with a windscreen washer and wiper to allow a good direct view inside, and also another window located - on a perpendicular wall, was equipped with a CCD colour camera.

This cell encloses the equipment of the cutting system composed of :

- The head or lance rested on a carriage

- A distribution system for abrasives

- A operating station

It is put in a water tank built of stainless steel, having the capacity of the about 1 cubic meter and fitted with pump and agitator to do the analysis of effluents.

\section{THE FIRST OPERATING UTILISATION}

To bring this equipment into operation with water and abrasive jets under high-pressure, poses a lot of problems due to :

- the lack of knowledge of the equipment

- some defects of our testing installation 
- the Inexperience of operators

- some defects of a new basic apparatus.

In order to resolve these first disadvantages, it has been necessary to add complementary equipment :

- The measure of static high pressure at the output of generator.

- The measure of water flow through the cutting head.

- The measure of jet setting with a by pass of feed pump of generator.

\section{TESTS AND ANALYSIS OF CUTTING PARAMETERS}

\subsection{GENERAL}

They had for objectives to characterise the operating conditions of this apparatus automatically : it is, in particular, necessary to adjust the jet power to the thickness of the cut piece in order to avold the excessive loss of energy, and to reduce the produced wastes. The manufacturer of this equipment proposed numerical values for five parameters, following the thickness of concrete or steel to cut, with a pressure of 2400 bars, which are :

- The sapphire diameter

- The granulometry of abrasive

- The abrasive flow

- The diameter of diaphram

- The diameter of accelaration tube

\subsection{PARTICULAR RESULTS}

The study of these parameters shows :

1) For the water flow as a function of sapphire diameter.

The results are show on Table I : when the sapphire diameter is growing from $0.457 \mathrm{~mm}$ to $0.813 \mathrm{~mm}$, the flow is decreasing about $12 \%$, because of the high increase of pressure inside the tube, the loss of power is about $35 \%$.

2) For the abrasive granulometry .

This is given by the manufacturer with the indication of minimal and maximal diameters.

3) Variations of abrasive flow as a function of orifice diameter .

The results are shown in table II : the abrasive flow is dependent on used types and of the granulometry : if the granulometry increases the flow decreases.

4) Acceleration tube and sapphire diameter.

In this tube, the abrasive particles are accelerated under the action a of water jet with the speed of 450 meters/s. Its diameter must be chosen, 
following our test, in the strip shown on the Figure "1".

\section{THE CUTTING OF STEELS}

\section{1) Material of tests}

Materials used were mild and stainless steel samples respectivly 500 x 400 $\mathrm{mm}$ with a thickness of 10 and $30 \mathrm{~mm}$, and $500 \times 400 \mathrm{~mm}$ with a thickness of 60 and $100 \mathrm{~mm}$, for at first, a nominal test with the parameters given by the manufacturer and after for complementary tests, in CEA Station, in which only one parameter changes during each test.

2) Results (See table III)

- The cutting speed is the same for stainless or mild steels.

- The cutting speed is constant for a distance of 1 to 20 mm between the injector and the material.

- The optimum for the ratio abrasive flow/water flow is included between 20 and $30 \%$ according to the cut thickness, but this percentage must be improved to reduce the wastes.

- The quality of the abrasive is important in relation to the cutting performance : tests have been made with the "garnet" or the "grenal" which have the same composition, and with "Projamine", "Rugos", "Sable du Ventoux". The first is the best and it is used henceforth for all the tests:

- The abrasive flow is dependent on the granulometry.

\section{THE CUTTING OF CONCRETE}

\section{1) Material of tests}

The samples of reinforced concrete have been manufactured in our workshops $(500 \mathrm{~mm} \times 500 \mathrm{~mm}$ with a thickness of 100,200 and $500 \mathrm{~mm})$ with different types of steel reinforcement.

The drying time of these samples are included, between fifty and one hundred and twenty days, corresponding to the time between the beginning and the end of all tests.

\section{2) Results (See table IV)}

There is a considerable dispersion of performance about the speed ( 12,4 $\mathrm{mm} / \mathrm{mn}$ and $80 \mathrm{~mm} / \mathrm{mn}$ ) for the concrete samples of two hundred millimetres of thickness. Three reasons can explain this result.

- The heterogeneity of the drying time between the beginning and the end of the tests (three months) : it has been observed by the technicians that, at the beginning, the aggregate, included inside the new concrete, is not cut out,but is taking of $f$, unbroken, from the concrete, and, at the end the aggregate is cut in two parts during the cutting of old reinforced concrete.

The drying of the reinforced concrete over a long period, is, therefore, very important to obtain a good cohesion of this material, and consequently 
to realise a good cutting.

- The tubes of acceleration of abrasives are wear out very quickly, (the manufacturer provides four hours for their mean life time). and, the present results are much dependant on the durability of the inner surface tubes, for a type test, as well as on the precision of coaxiality control between this tube and the water jet.

- As it is impossible for the operators to have a general view of the cutting field during this work, all the steels inside the concrete are not always all cut, and, in fact, it is not possible to compare the cutting speeds precisely.

Added to this basic observation, we can observe, with reference to the cutting of steels the following :

- a similar effect for the parameter "sample nozzle distance" : there is not an influence for the cutting speed for a movement between 1 and twenty millimetres, but the larger the distance is, the brooder the hole is ;

- the effluents produced during the cutting of concrete are more important than for the cutting of the steels ; particularly it is developped a fog. very loaded with small particles, which are deposited on the walls, and on the windows of the cell in which this equipment was used. This fog obstructs the view inside the cell, for the workers, during this operation.

- During the cutting operation, pieces of aggregate have the possibility to go in all the directions, which is very dangerous for the environement (telemanipulators, windows, cameras, ...).

This phenomenon is more important with a concrete which is not dry enough

\section{ADAPTATION TO THE TELEOPERATION}

1) Design and Manufacturing of all components necessary, for a work with telemanipulators.

To work in a cell, the water jet cutting apparutus must be coupled with an electronic remote manipulator "MA $23 \mathrm{M}^{\prime}$, using special devices :

- a special rest of slave arm

- a piece to grasp the cutting hose nozzle with the remote manipulator

- several spiral hose pipes for high pressure (2.800 bar)

- special connections with the remote manipulator.

- The slave arm of the telemanipulator was bound, with a special support, in order to have access to all the samples, in all their dimensions. Owing also to this support, it was possible, to put the equipment inside a special device, to change the head of this material. This operation is very easy to make in a cell with a telemanipulator.

2) Study and realisation of components used in teleoperation maintenance .

The maintenance operations concern the injector and relate to :

- mounting and dismantling of special high pressure connections with the remote manipulator : 
- mounting of acceleration tube and adjusting of jet.

The first operation is executed in a cell with special apparatus realised by CEA. It consists of a cradle with two positions for the cutting hose nozzles, and an apparatus for the guiding, the mounting and dismantling of special connections.

The two other operations are carried out in a special glove box or outside.

\section{3) Lance dismantling tests .}

Because of the wear of the nozzle for the acceleration of abrasives, it is necessary to replace it, and this operation has been carried out inside the cell with a telemanipulator without particular problems.

\section{CUTTING AND TELEDISMANTLING TESTS WITH A REMOTE MANIPULATOR}

1) A preliminary test to cut some centimetres of steel has been carried out on a sheet of $10 \mathrm{~mm}$ of thickness, and also the special apparatus for the mounting and dismantling operations has been tried out in a cell.

The result of tests are shown on table IV with cutting of stainless steel (thickness $10 \mathrm{~mm}$ at $60 \mathrm{~mm}$ ) and concretes (thickness 100 at $300 \mathrm{~mm}$ ) using several types of abrasives and differents diameters of the nozzle $(0,46 \mathrm{~mm}$ $-0,81 \mathrm{~mm})$.

The dispersion of performances, is due at the method of work : the teleoperation cutting is not very easy and the operator cannot realise a correct cut.

2) Nevertheless, it is possible to extract the following conclusions of all these tests :

- the reaction of the tool on the telemanipulator with stress back is not very high, but stays entirely compatible with the equipment and with the operator (it is about 10 to $15 \mathrm{daN}$ ) which proves the good choice of helicoidal hosepipes to resolve this problem.

- The viewing means, used to follow the work in the cell, must be judiciously selected and arranged to be sure to make a good cutting :

1. In indirect seeing, it is necessary to use two cameras, located inside two tight boxes, with windows (with windscreen washer and wiper): these boxes are put in two perpendicular plans and should be able to look at the same place with the possibility to increase the near field (electric zoom). An amelioration could be brought with a stereoscopic vision :

- during all the operation, it is necessary to suck off the dust water fog in a continous way, at its generation, but in the opposite direction to the vision : 
- the protection of the part opposite to the cutting will be very difficult to obtain in the most configurations and that is why it can be considered that there are two possibilities for industrial use to-day :

- the underwater cutting

- the cutting with an equipment in a fixed position

- the recovery of liquid and solid effluents produced in large quantities $1 s$ also a difficult problem which must be studied for each case :

- an efficient futur dismantling equipment should take place elther with the aid of a computer (TAO, treatment helped by computer). Or with a robot, by defining and recording preliminarly lines of cutting.

The new robot telemanipulator RD500, realised by CEA and now tested in our workshops, will in the future be qualified to resolve such type of work.

\section{3) Functional test .}

A functional cutting test for tubes (diameter $1^{\prime \prime}$ and $1^{\prime \prime}$ ) and also for a shaped piece $(160 \mathrm{~mm} \times 65 \mathrm{~mm})$ have been made with the following parameters.

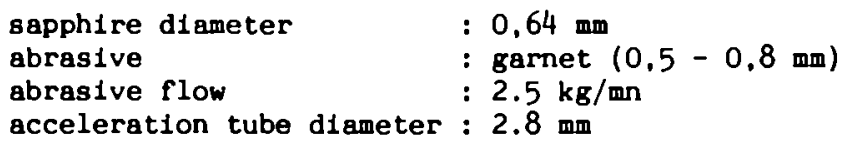

The direct cutting, above the tank with a depth a water of $50 \mathrm{~cm}$, has managed to drill the tank bottom before the end of cutting. A concrete slab of $100 \mathrm{~mm}$ thickness has been placed between the shaped piece and the water at a distance of $100 \mathrm{~mm}$, and had two advantages, to protect the material behind the water abrasive jet, and to simulate the cutting of tubes before a reinforced concrete. This slab was damaged and drilled during this operation.

In conclusion, this functional test shows that the telemanipulation of water jets with abrasives, is not yet an industrial process, because following fondamental problems are not solved :

- the protection behind the jet

- the development of viewing means

- the ald of a computer (TAO) or the work in a robot way

\section{RECOVERY OF GENERATED WASTES}

1) At the beginning, the first cutting tests were carried out in a vinyl cell which prevented the dispersion of wastes, but did not allow easy recovery.

Actually. all the test apparatus is mounted in a tight inactive cell with the remote manipulator in the CEA homologation STATION created to test all decommissioning equipment. This cell is equiped with a dripping pan and with a pump to collect the liquid and solid wastes. It is also equipment with a ventilation system with filters and aerosol traps for making aerosol 
measurements.

The collection of the wastes is difficult because the abrasive density is high (about 4), the granulometry is low and the steel particles are very small.

With short tests about 6 minutes for samples of $10 \mathrm{mn}$ and 30 minutes for samples of $100 \mathrm{~mm}$, it is possible to collect the wastes by manual work : for the liquids, a pump is used, for the solids, mechanical means are used.

\section{2) Measurement of secondary emissions .}

\section{Objectives}

The objectives of this work were as follows :

- Balance of all secondary emissions (solid and liquid) produced by the cutting of stainless steel, mild steel and concrete samples.

- Caracterisation of aerosols in the exhaust duct and of the abrasives (before and after cutting).

Experimental rig (Figure 2) .

The experiments took place in a $32 \mathrm{~m}^{3}$ cell and the samples to cut were put over a tank, partially filled with water, which collected the wastes by sedimentation. An exhaust duct was connected to this cell in order to maintain a $300 \mathrm{~m}^{3} \mathrm{~h}-1$ ventilation.

The ventilation circuit is composed of a demister (for trapping the big droplets), an electrostatic precipitator (prefilter) and HEPA filters.

Isokinetic sampling to a variety of instruments is done through probes inserted into the exhaust duct (Figure 2) :

- sampling filters (F1, F2, F3)

- impactors (A1, A2)

- dryers (B11, B12, B13, B21, B22, B23)

in order to measure the aerosol concentration and size distribution and the water vapour concentration.

The abrasives arc collected at the bottom of the tank and their size distribution is determined by sieving.

The working cutting parameters for each experiment are given in table VI.

\section{$\underline{\text { RESULTS }}$}

The balance of secondary emissions is expressed in table VII for each experiment. Globally, with the defined working conditions, we can deduct that : 
- $10^{6}$ to $10^{-5}$ of the total solid mass and about $10^{-2}$ of the water mass are drawn into the exhaust duct of the cell ventilation. The air of this circuit can be oversaturated.

The mass mean aerosol diameter is about $3 \mu \mathrm{m}$.

- 0.2 to $1.3 \%$ of total solid mass is deposited on the walls of the cell.

- The used cleaning devices (demister and electrostatic precipitator) have a small efficiency for the liquid mass drawn into the ventilation circuit. That means that the water is mainly in vapour phase

- The sedimented solid mass composed at $98 \%$ by abrasives has after cuttinga mass mean diameter inferior to $80 \mu$ mew abrasives have a diameter comprised betwen 500 and $800 \mu \mathrm{m}$ ) and after the test $85 \%$ of abrasive particles are broken. To recycle abrasives does not appear, at first sight, to be profitable.

\section{CONCLUSION}

The work on the cutting process by water and abrasives jets for the dismantling of nuclear installations has been realised in connection between the Hanover University and CEA ; the first making basic studies for the application on steel samples under water, the second operating in air automatically for the cutting of large samples of concrete and steel.

The two partners are in good agreement on the result for the cutting performance : there is an optimum for the proportion of water and abrasive, mass flow and the best way is to use a nozzle with a hole of $0.46 \mathrm{~mm}$ diameter and high pressure to obtain a good efficiency and also a mimimum waste generation.

Actually the water abrasive jet equipment, used to cut steels, and reinforced concretes is operational and all needed work techniques are being perfected, but work remains still to do for using this tool in remote operation.

TABLE I : FLOW PRESSURE DROP CONNECTIONS

\begin{tabular}{|c|c|c|c|c|c|}
\hline $\begin{array}{l}\text { SAPPHIRE } \\
\text { DIAMETER } \\
\text { (mm) }\end{array}$ & $\begin{array}{l}\text { SAPPHIRE } \\
\text { DIAMETER } \\
(\text { Inch })\end{array}$ & $\begin{array}{c}\text { THEORETICAL } \\
\text { FLOW } \\
(1 / \mathrm{mn})\end{array}$ & $\begin{array}{l}\text { CALCULATED } \\
\text { FLOW } \\
(1 / \mathrm{mn})\end{array}$ & $\begin{array}{l}\text { DIFFERENCE } \\
(x)\end{array}$ & $\begin{array}{l}\text { PRESSURE } \\
\text { INSIDE } \\
\text { TUBES } \\
\text { (bar) }\end{array}$ \\
\hline $\begin{array}{l}0.457 \\
0.635 \\
0.762 \\
0.813\end{array}$ & $\begin{array}{l}0.018 \\
0.025 \\
0.030 \\
0.032\end{array}$ & $\begin{array}{l}4.79 \\
9.23 \\
13.2 \\
15.10\end{array}$ & $\begin{array}{r}4.71 \\
8.74 \\
12.0 \\
13.25\end{array}$ & $\begin{array}{l}1.7 \\
5.3 \\
9.8 \\
11.9\end{array}$ & $\begin{array}{r}83 \\
242 \\
507 \\
599\end{array}$ \\
\hline
\end{tabular}




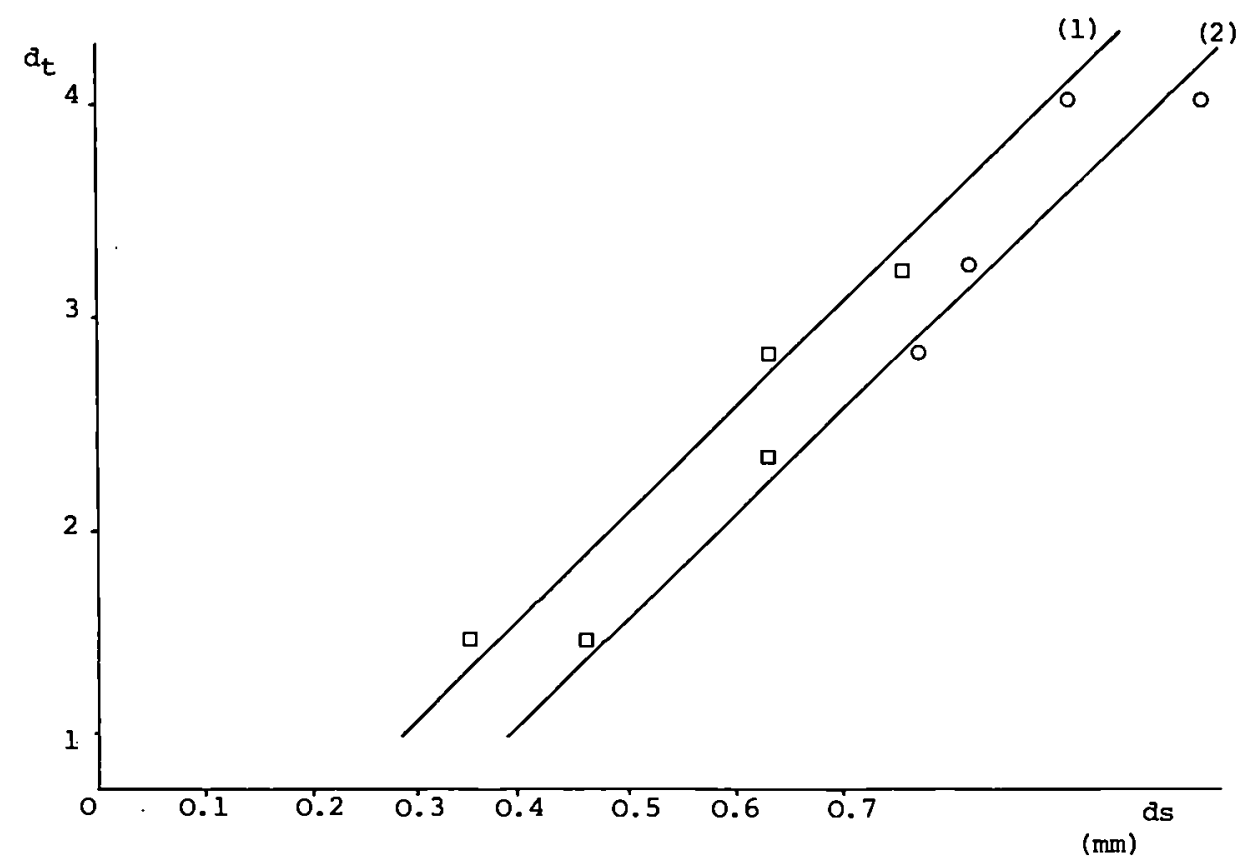

FIGURE 1 : Diameter of acceleration tube $d_{t}$ according to the sapphire hole ds. (mm)

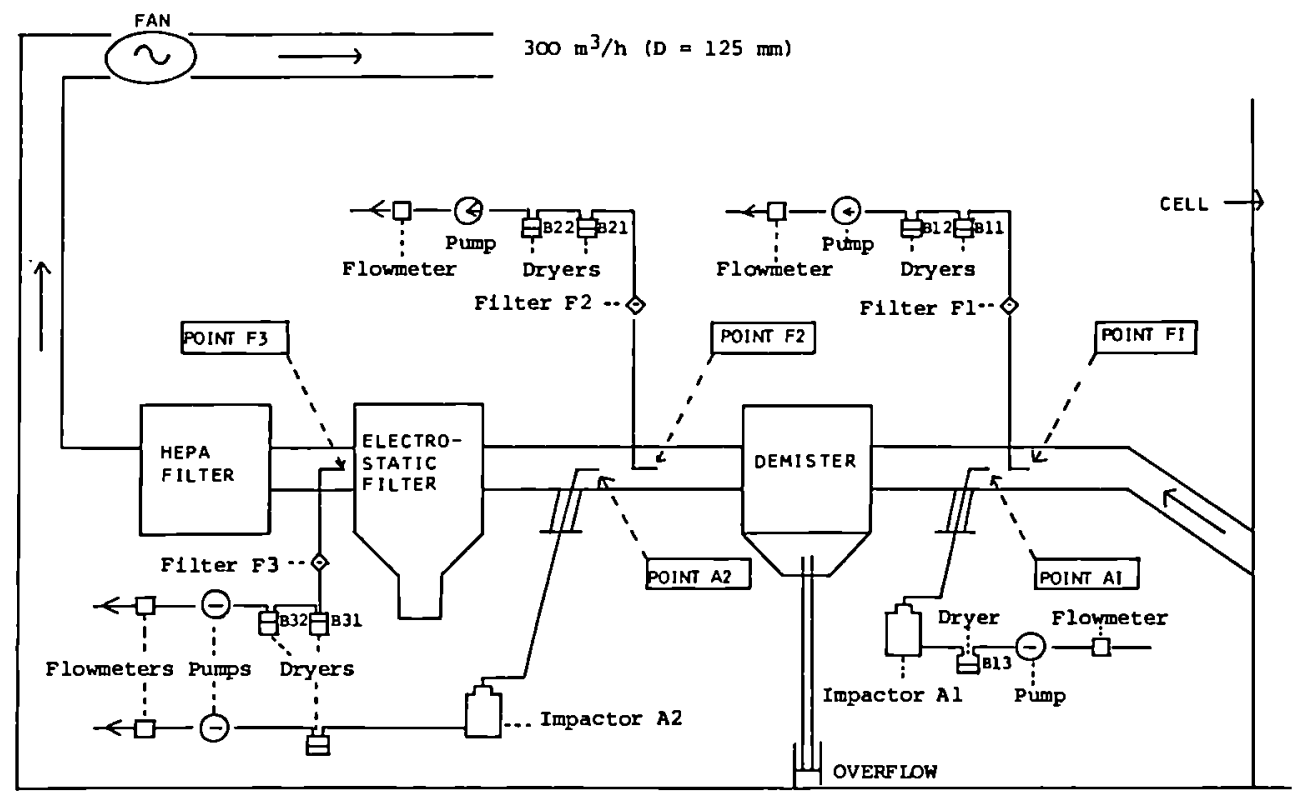

FIGURE 2 : Diagram of the ventilation system and of the associated samplings 
TABLE II : ABRASIVE FLON MCCORDING TO THB BOLB DIAHETER

\begin{tabular}{|c|c|c|c|c|c|c|c|}
\hline $\begin{array}{l}\text { DIAPHRAGM } \\
\text { NUMBER }\end{array}$ & DIAMETER & $\begin{array}{c}\text { Grenal : Gra } \\
\text { PERIOD } \\
\text { JAN/JUN }\end{array}$ & $\begin{array}{l}\text { low abrasive } \\
\text { lometry: } \\
\text { PERIOD } \\
\text { JULY/DEC }\end{array}$ & MEAN VALUE & $\begin{array}{c}(\mathrm{kg} \mathrm{mn}) \\
\text { Garnet : Grd } \\
\text { PERIOD } \\
\text { JAN/JUN }\end{array}$ & $\begin{array}{l}\text { PERIOD } \\
\text { JULY/DEC }\end{array}$ & MEAN VALUE \\
\hline 12 & 4,8 & 0.275 & - & 0.275 & & & \\
\hline 14 & 5.6 & 0.475 & - & 0,475 & & & \\
\hline 15 & 6 & 0.55 & - & 0.55 & & & \\
\hline 16 & 6.4 & 0.725 & _ & 0.725 & & & \\
\hline 20 & 8 & $1,17(6)$ & 1.1 (1) & 1,16 & & & \\
\hline 23 & 9.2 & $1,78(14)$ & 1.8 (1) & 1.78 & & & \\
\hline 24 & 9.6 & - & - & - & - & $1.65(3)$ & 1,65 \\
\hline 25 & 10 & $2.3(3)$ & - & 2,3 & & & \\
\hline 27 & 10.8 & $2,7(6)$ & $2.7 \quad(2)$ & 2,7 & & & \\
\hline 28 & 11,2 & & & & 2,6 & - & 2.6 \\
\hline 29 & 11.6 & & & & 2.9 (1) & $2.73(9)$ & 2.75 \\
\hline 30 & 12 & & & & 3.28 & - & 3.28 \\
\hline 31 & 12,4 & & & & $3.425(8)$ & $3.433(3)$ & 3.43 \\
\hline 33 & 13.2 & & & & $3.45(2) \|$ & $4 \quad(4)$ & 3.82 \\
\hline
\end{tabular}


TABLE III : RESULTS OF TBSTS STAINLESS STREL SAMPLES

\begin{tabular}{|c|c|c|c|c|c|c|c|c|c|c|c|c|c|c|c|}
\hline $\begin{array}{l}\text { hober } \\
\text { and date } \\
\text { of the } \\
\text { teet }\end{array}$ & $\begin{array}{c}\text { Thichones: } \\
\text { m }\end{array}$ & $\begin{array}{c}\text { Duration } \\
\text { of the teet } \\
-\end{array}$ & Sepphire & $\underset{1}{\text { Volues }}$ & $\begin{array}{l}\text { Flow } \\
\text { 1/m }\end{array}$ & Type & $\underset{\text { Crenulo- }}{\text { aetry }}$ & $\begin{array}{l}\text { Dle- } \\
\text { phrage }\end{array}$ & Flow & $\frac{{ }^{x}}{\text { Abreslive }}$ & $\begin{array}{c}\text { D } \\
\text { Tube } \\
-\end{array}$ & $\begin{array}{c}\text { Distance } \\
\text { tube/plece } \\
-\end{array}$ & $\begin{array}{c}\text { Cut } \\
\text { length } \\
-\end{array}$ & $\begin{array}{l}\text { Speed } \\
-\end{array}$ & $\begin{array}{l}\text { Breadth } \\
\text { between } \\
\text { grooves } \\
\text { m }\end{array}$ \\
\hline$\underset{23 / 03 / 88}{\operatorname{Mn} 2}$ & 10 & $\begin{array}{l}2 \cdot 10^{\prime \prime} \\
2,5= \\
2 !\end{array}$ & 0.46 & $\begin{array}{c}11 \\
10.5 \\
10\end{array}$ & 5 & Grenal & $\begin{array}{c}0.25=0.6 \\
n\end{array}$ & 20 & 1.15 & $\begin{array}{l}23 \\
23 \\
23\end{array}$ & 1.5 & : & $\begin{array}{l}488 \\
496 \\
489\end{array}$ & $\begin{array}{l}225 \\
238 \\
245\end{array}$ & $\begin{array}{l}2 \\
2 \\
2\end{array}$ \\
\hline $\begin{array}{l}1 / 30 / 03 / 88 \\
2 / 30 / 03 / 88 \\
3 / 30 / 03 / 88 \\
4 / 30 / 03 / 88 \\
5 / 30 / 303 / 88 \\
6 / 30 / 03 / 88\end{array}$ & $\begin{array}{l}10 \\
:\end{array}$ & $\begin{array}{l}2, \\
2, \\
2, \\
2 ! \\
2, \\
2,\end{array}$ & $\begin{array}{c}0,36 \\
\vdots \\
\vdots\end{array}$ & $\begin{array}{l}6.5 \\
7 \\
6.5 \\
6 \\
6.5 \\
6.5\end{array}$ & $\begin{array}{l}3.25 \\
3.5 \\
3.25 \\
3 \\
3.25 \\
3.25\end{array}$ & $\begin{array}{c}\text { Grenal } \\
\vdots \\
\vdots\end{array}$ & $\begin{array}{c}0.25=0.6 \\
\vdots \\
\vdots\end{array}$ & $\begin{array}{l}16 \\
16 \\
15 \\
14 \\
14 \\
12\end{array}$ & $\begin{array}{l}0.75 \\
0.7 \\
0.55 \\
0.475 \\
0.475 \\
0.275\end{array}$ & $\begin{array}{l}23 \\
20 \\
17 \\
16 \\
15 \\
8.5\end{array}$ & 1.5 & $:$ & $\begin{array}{l}313 \\
297 \\
252 \\
244 \\
232 \\
169\end{array}$ & $\begin{array}{l}156.5 \\
148.5 \\
126 \\
122 \\
116 \\
84.5\end{array}$ & $\begin{array}{l}1.9 \\
1.9 \\
1.9\end{array}$ \\
\hline$\underset{02 / 06 / 80}{M 45}$ & 30 & $\begin{array}{c}5 \cdot 30^{*} \\
10^{\circ} \\
10^{\circ}\end{array}$ & 0.64 & $\begin{array}{c}49.5 \\
48.5 \\
49\end{array}$ & $\begin{array}{l}99 \\
8.8\end{array}$ & Orene1 & $\begin{array}{c}0.25: 0.6 \\
:\end{array}$ & 23 & $\begin{array}{l}1.85 \\
1.76 \\
1.76\end{array}$ & $\begin{array}{l}20.5 \\
20 \\
20\end{array}$ & $i^{2}$ & ! & $\begin{array}{l}488 \\
483 \\
481\end{array}$ & $\begin{array}{l}89 \\
88 \\
87\end{array}$ & $\begin{array}{l}2.8 \\
3 \\
3.2\end{array}$ \\
\hline$\underset{23 / 03 / 88}{\text { Hns }}$ & :30 & $\begin{array}{l}4.50^{\prime \prime} \\
4 \cdot 50^{\prime \prime} \\
5\end{array}$ & 0,64 & $\begin{array}{c}43 \\
42.5 \\
43.5\end{array}$ & $\begin{array}{l}8.9 \\
8.8 \\
8.7\end{array}$ & $\begin{array}{c}\text { Grenal } \\
:\end{array}$ & $\begin{array}{c}0.25=0.6 \\
:\end{array}$ & 23 & $\begin{array}{l}1.8 \\
1.8 \\
1.8\end{array}$ & $\begin{array}{l}20 \\
22 \\
20.7\end{array}$ & 2.3 & 10 & $\begin{array}{l}485 \\
496 \\
493\end{array}$ & $\begin{array}{r}100 \\
103 \\
99\end{array}$ & $\begin{array}{l}3 \\
3 \\
3\end{array}$ \\
\hline $\operatorname{mu}_{23 / 03 / 88}$ & 30 & $\begin{array}{l}4.50^{\circ} \\
4.50^{\circ} \\
4.55^{\circ}\end{array}$ & $\begin{array}{l}0.64 \\
43.5 \\
43.5\end{array}$ & $\begin{array}{l}42.5 \\
43.5 \\
43.5\end{array}$ & $\begin{array}{l}8.8 \\
9 \\
8.7\end{array}$ & Grenal & $0.25=0.6$ & 23 & $\begin{array}{l}1.8 \\
1.8 \\
1.8\end{array}$ & $\begin{array}{l}22 \\
20 \\
20.7\end{array}$ & 2,3 & 10 & $\begin{array}{l}490 \\
493 \\
495\end{array}$ & $\begin{array}{l}101 \\
102 \\
101\end{array}$ & 4.5 \\
\hline
\end{tabular}


TABLB IV : CUITIKG CONDITIONS FOR TBSTS WITH SBCONDARY EAISSIONS

\begin{tabular}{|c|c|c|c|c|c|c|c|c|c|c|}
\hline \multirow[b]{2}{*}{$\begin{array}{l}\text { Test nuaber } \\
\text { UDIN }\end{array}$} & \multirow[b]{2}{*}{ Sanplo } & \multirow[b]{2}{*}{$\begin{array}{c}\text { Thickness } \\
\text { in }\end{array}$} & \multirow[b]{2}{*}{$\begin{array}{c}\text { Cutting } \\
\text { Type }\end{array}$} & \multicolumn{3}{|c|}{ ABRASIVE } & \multirow[b]{2}{*}{$\begin{array}{c}\text { Sapphire } \\
\mathbf{m}\end{array}$} & \multicolumn{2}{|c|}{$\begin{array}{l}\text { FOCALISATION } \\
\text { TUBE }\end{array}$} & \multirow[b]{2}{*}{$\begin{array}{l}\text { Distance } \\
\text { tube/piece }\end{array}$} \\
\hline & & & & Kind & Granulonetry & $\begin{array}{c}\text { Diaphrage } \\
0\end{array}$ & & Length & 0 & \\
\hline HA3 & nild steel & 30 & autonat. & grenal & $0.25-06$ & 9.2 & 0.64 & 76 & 2.3 & 1 \\
\hline HA5 & $\begin{array}{c}\text { stainless } \\
\text { steel }\end{array}$ & 30 & " & 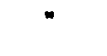 & $0.25-06$ & 9.2 & 0.64 & 76 & 2.3 & 1 \\
\hline HA17 & nild steel & 100 & 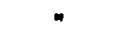 & garnet & $0.5-0.8$ & 12.0 & 0.76 & 76 & 3.2 & 1 \\
\hline HA19 & stainless & 100 & $n$ & $n$ & $0.5-0.8$ & 12,4 & 0.76 & 76 & 3.2 & 1 \\
\hline HA32 & concrete & 250 & $n$ & " & $0.5-0.8$ & 13.2 & 0.81 & 76 & 3.2 & 1 \\
\hline HT1 & $\begin{array}{l}\text { stainless } \\
\text { steel }\end{array}$ & 10 & telema. & Grenal & $0.25-0.6$ & 8 & 0.46 & 76 & 1.5 & $1+5$ \\
\hline HT2 & $\begin{array}{l}\text { stainless } \\
\text { steel }\end{array}$ & 30 & - & " & $0.25-0.6$ & 9.2 & 0.64 & 76 & 2.3 & env 10 \\
\hline$H T 4$ & reinforced & 100 & " & garnet & $0.5-0.8$ & 9.6 & 0.64 & 76 & 2.3 & $1 \cdot 10$ \\
\hline HA23 & reinforced & 200 & automat. & " & $0.5-0.8$ & 11.6 & 0.76 & 76 & 2.8 & 1 \\
\hline conpl.1 & $\begin{array}{c}\text { stainless } \\
\text { stoel }\end{array}$ & 100 & $\cdots$ & $n$ & $0.5-0.8$ & 12,4 & 0.76 & 76 & 3.2 & 1 \\
\hline compl. 2 & stainless & 100 & 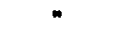 & $"$ & $0.5-0.8$ & 12.4 & 0.76 & 76 & 3.2 & 1 \\
\hline cospl.2' & stainless & 100 & $n$ & " & $0.5-0.8$ & 12.4 & 0.76 & 76 & 3.2 & 1 \\
\hline
\end{tabular}


TABLE $\mathrm{V}$ : RESULTS OF TELEMANIPULATION TBSTS

\begin{tabular}{|c|c|c|c|c|c|c|c|c|c|c|c|c|c|c|c|}
\hline Muber & & & & WATER & & & ABRASIVE & & & & & & & & \\
\hline $\begin{array}{l}\text { of the } \\
\text { toet }\end{array}$ & $\begin{array}{c}\text { Thictoreas } \\
-\end{array}$ & $\begin{array}{l}\text { Duration } \\
\text { of the teat } \\
\text {. }\end{array}$ & Sopphire & $\begin{array}{l}\text { Volumo } \\
1\end{array}$ & $\begin{array}{l}\text { Flow } \\
\text { 1/m }\end{array}$ & Type & $\begin{array}{c}\text { Orenulo- } \\
\text { notry }\end{array}$ & $\begin{array}{l}\text { D1a- } \\
\text { phragu }\end{array}$ & Flow & $\frac{\text { Abrasive }}{\text { Water }}$ & Tube & $\begin{array}{c}\text { tube/plece } \\
-\end{array}$ & $\begin{array}{c}\text { 2ength } \\
-\end{array}$ & $\begin{array}{l}\text { Speed } \\
-\end{array}$ & $\begin{array}{l}\text { botween } \\
\text { croover } \\
\text { - }\end{array}$ \\
\hline $\begin{array}{c}\text { kT1 } \\
05 / 09 / 88\end{array}$ & $\begin{array}{l}\text { Staninleas } \\
\text { oteel } 10\end{array}$ & $20^{\circ}$ & 0.46 & 61 & 3.05 & Orenal & $0.25-0.6$ & 20 & 1.1 & 36 & 1.5 & 1.5 & $<200$ & $<10$ & (4) \\
\hline$\underset{06 / 09 / 80}{\operatorname{kT2}}$ & $\begin{array}{l}\text { Steinlease } \\
=\tan 1\end{array}$ & $23^{\circ}$ & 0.64 & 203 & 8.8 & Grenal & $0.25-0.6$ & 23 & 1.8 & 20 & 2.3 & $\begin{array}{c}\text { environ } 10 \\
\text { (1) }\end{array}$ & $<100$ & $\operatorname{mon}_{\text {signt- }}$ & 5 \\
\hline $\begin{array}{c}11 T 3 \\
08 / 09 / 88\end{array}$ & $\begin{array}{l}\text { St.eteel } 60 \\
\text { et. teel } 60\end{array}$ & $\begin{array}{l}10^{\circ} \\
10^{\circ}\end{array}$ & $\begin{array}{l}0.64 \\
0.64\end{array}$ & 94.5 & 9.45 & Grenal & $0.25=0.6$ & 27 & $\begin{array}{l}2.67 \\
2.74\end{array}$ & 29 & $\begin{array}{l}2,8 \\
2,8\end{array}$ & $?$ (2) & $<50$ & & \\
\hline$\underset{07 / 09 / 88}{174}$ & $\begin{array}{l}\text { Renforeed } \\
\text { concre tel } 100\end{array}$ & $20^{\circ}$ & 0.64 & - & - & Garnet & $0,5-0,8$ & 24 & 1.6 & - & 2,3 & 1.10 & env. 400 & 20 & \\
\hline $\begin{array}{c}\text { TT5 } \\
08 / 09 / 88\end{array}$ & $\begin{array}{l}\text { Renforeed } \\
\text { concretezoo }\end{array}$ & $\begin{array}{l}10^{\circ} \\
10^{\circ}\end{array}$ & $\begin{array}{l}0.76 \\
0.76\end{array}$ & $\begin{array}{l}116.5 \\
118\end{array}$ & $\begin{array}{l}11.65 \\
11.8\end{array}$ & Garnet & $0.5=0.8$ & 29 & $\begin{array}{l}2.94 \\
2.9\end{array}$ & $\begin{array}{l}25 \\
24.5\end{array}$ & $\begin{array}{l}2.8 \\
2.8\end{array}$ & $?$ & $<200$ & then & 10 \\
\hline $\begin{array}{c}\text { kT6 } \\
09 / 09 / 88\end{array}$ & \begin{tabular}{|l|} 
Renforced \\
concrete 300
\end{tabular} & $\begin{array}{l}10^{\circ} \\
10^{\circ}\end{array}$ & $\begin{array}{l}0.81 \\
0.81\end{array}$ & $135^{-}$ & 13.5 & Garnet & $0.5=0.8$ & $\begin{array}{l}33 \\
33\end{array}$ & 4.05 & 30 & $\begin{array}{l}3.2 \\
3.2\end{array}$ & $1: 10$ & < 100 & picatif & \\
\hline
\end{tabular}


TABLE VI : CUTTING CONDITIONS FOR TESTS WITE SBCONDARY EUISSIONS

\begin{tabular}{|c|c|c|c|c|c|c|c|c|c|c|}
\hline \multirow[b]{2}{*}{$\begin{array}{l}\text { Test nuaber } \\
\text { UDIN }\end{array}$} & \multirow[b]{2}{*}{ Semple } & \multirow[b]{2}{*}{ Thickness } & \multirow[b]{2}{*}{$\begin{array}{c}\text { Cutting } \\
\text { Type }\end{array}$} & \multicolumn{3}{|c|}{ ABRASIVE } & \multirow[b]{2}{*}{$\begin{array}{c}\emptyset \\
\text { Sepphire } \\
\mathbf{m}\end{array}$} & \multicolumn{2}{|c|}{$\begin{array}{l}\text { FOCALISATION } \\
\text { TUBE }\end{array}$} & \multirow[b]{2}{*}{$\begin{array}{c}\text { Distance } \\
\text { tube/piece } \\
\text { ad }\end{array}$} \\
\hline & & & & Kind & $\begin{array}{c}\text { Granulooetry } \\
\text { ex }\end{array}$ & $\begin{array}{c}\text { Diaphragu } \\
\text { no }\end{array}$ & & 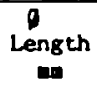 & $a$ & \\
\hline HA3 & nild steel & 30 & eutomat. & grenal & $0.25-06$ & 9.2 & 0.64 & 76 & 2.3 & 1 \\
\hline HA5 & stainless & 30 & * & " & $0.25-06$ & 9.2 & 0.64 & 76 & 2.3 & 1 \\
\hline M17 & ndld steel & 100 & * & garnet & $0.5-0.8$ & 12,0 & 0.76 & 76 & 3.2 & 1 \\
\hline HA19 & stainless & 100 & " & “ & $0.5-0.8$ & 12,4 & 0.76 & 76 & 3.2 & 1 \\
\hline MA32 & $\begin{array}{l}\text { steel } \\
\text { concrete }\end{array}$ & 250 & " & - & $0.5-0.8$ & 13.2 & 0.81 & 76 & 3.2 & 1 \\
\hline HTI & $\begin{array}{l}\text { stainless } \\
\text { steel }\end{array}$ & 10 & telema. & grenal & $0.25-0.6$ & 8 & 0.46 & 76 & 1.5 & 1.5 \\
\hline $\operatorname{HT} 2$ & $\begin{array}{l}\text { stainless } \\
\text { steel }\end{array}$ & 30 & $"$ & & $0.25-0.6$ & 9.2 & 0.64 & 76 & 2.3 & env 10 \\
\hline $15 T^{4}$ & $\begin{array}{l}\text { reinforced } \\
\text { concrete }\end{array}$ & 100 & $n$ & garnet & $0.5-0.8$ & 9.6 & 0.64 & 76 & 2.3 & $1 \cdot 10$ \\
\hline $\operatorname{HA23}$ & reinforced & 200 & automat. & $n$ & $0.5-0.8$ & 11.6 & 0.76 & 76 & 2,8 & 1 \\
\hline coepl.1 & stainless & 100 & 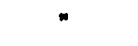 & " & $0.5-0.8$ & 12,4 & 0.76 & 76 & 3.2 & 1 \\
\hline $\operatorname{cospl} .2$ & stainless & 100 & $n$ & $n$ & $0.5-0.8$ & 12,4 & 0.76 & 76 & 3.2 & 1 \\
\hline conpl. $2^{\prime}$ & atainless & 100 & $n$ & $n$ & $0.5-0.8$ & 12,4 & 0.76 & 76 & 3.2 & 1 \\
\hline
\end{tabular}


TABLE VII : EVALUATION OF SBCONDARY EMISSIONS

\begin{tabular}{|c|c|c|c|c|c|c|c|c|c|c|c|c|}
\hline Number test & $\underset{\text { HA3 }}{2}$ & $\stackrel{3}{H A 3}$ & $\begin{array}{c}4 \\
\text { HA5 }\end{array}$ & $\begin{array}{c}6 \\
\text { HA19 }\end{array}$ & $\begin{array}{c}7 \\
\text { HA17 }\end{array}$ & $\begin{array}{c}8 \\
\text { HA32 }\end{array}$ & $\begin{array}{l}10 \\
\text { HT1 }\end{array}$ & $\begin{array}{l}11 \\
\text { HT2 }\end{array}$ & $\begin{array}{l}12 \\
H T 4\end{array}$ & $\begin{array}{c}14 \\
\text { compl } 1.1\end{array}$ & $\begin{array}{c}15 / 17 \\
\text { cosp. } 2 / 2\end{array}$ & $\begin{array}{c}16 \\
\text { HA23 }\end{array}$ \\
\hline Abrasive & & Grenal & & & Gamet & & & & & & Gar & \\
\hline $\begin{array}{l}\text { Material } \\
\text { thickness (m) } \\
\text { length (m) }\end{array}$ & $\begin{array}{c}\text { Muld } \\
\text { Steel } 30 \\
1.00\end{array}$ & $\begin{array}{l}\text { Mild } \\
\text { Stee1 } 30 \\
1.00\end{array}$ & $\begin{array}{c}\text { Stain1ess } \\
\text { Stee1 } 30 \\
1.45\end{array}$ & $\begin{array}{l}\text { Stainless } \\
\text { Steel } 100 \\
0.68\end{array}$ & $\begin{array}{l}\text { Mi1d } \\
\text { Steel } 100 \\
0.62\end{array}$ & $\begin{array}{l}\text { Reinfor- } \\
\text { ced 250 } \\
0.32\end{array}$ & $\begin{array}{l}\text { Stainless } \\
\text { Steel } 10 \\
-\end{array}$ & $\begin{array}{l}\text { Stainless } \\
\text { Steel } 30 \\
-\end{array}$ & $\begin{array}{l}\text { Reinfor- } \\
\text { ced } 100 \\
-\end{array}$ & $\begin{array}{l}\text { Stainless } \\
\text { Stee1 } 100 \\
1.78\end{array}$ & $\begin{array}{l}\text { Stainless } \\
\text { Steel } 100 \\
0,14 /, 117\end{array}$ & $\begin{array}{l}\text { Reinfor- } \\
\text { ced } 200 \\
1,15\end{array}$ \\
\hline Samp1ing/min & 22.67 & 23.10 & 22.48 & 29.53 & 35.08 & 30,15 & 22 & 20 & 20 & 76 & $5 / 5$ & 30 \\
\hline $\begin{array}{l}\text { Abrasive Used } \\
\text { mass }(\mathrm{g})\end{array}$ & 20960 & 32050 & 29600 & 83900 & 99440 & 106000 & 22500 & 42000 & 31600 & 213200 & $\begin{array}{l}16650 / \\
17700\end{array}$ & 45500 \\
\hline $\begin{array}{l}\text { Removed mass } \\
\text { naterial }(\mathrm{g})\end{array}$ & 468 & 523 & 764 & 1636 & 1538 & 2985 & 112 & - & - & 3718 & $340 / 274$ & - \\
\hline $\begin{array}{c}\text { Total solid } \\
\text { mass }\end{array}$ & 21428 & 32573 & 30364 & 85536 & 100978 & 108985 & 22612 & - & - & 216918 & $\begin{array}{l}16990 / \\
17974\end{array}$ & - \\
\hline $\begin{array}{l}\text { Total mass } \\
\text { on the walls }\end{array}$ & & $\begin{array}{c}699 \\
(1.3)\end{array}$ & $\begin{array}{c}53 \\
(0.2)\end{array}$ & $\begin{array}{c}792 \\
(0,9)\end{array}$ & $\begin{array}{c}192 \\
(0.2)\end{array}$ & $\begin{array}{c}887 \\
(0,8)\end{array}$ & - & - & - & - & - & - \\
\hline $\begin{array}{c}\text { Aerosol mass } \\
\text { (8) }\end{array}$ & $\begin{array}{r}0.2 \\
(10-3)\end{array}$ & $\begin{array}{l}<0,03 \\
(<10-4)\end{array}$ & $\begin{array}{r}0,034 \\
(10-4)\end{array}$ & $\begin{array}{r}0.088 \\
(10-4)\end{array}$ & $(<0.035)$ & $\begin{array}{l}<0.045 \\
\left(<4.10^{-5}\right)\end{array}$ & $\begin{array}{c}0.2 \\
\left(8.8 .10^{-4}\right.\end{array}$ & $\left\{\begin{array}{c}<0.085 \\
\left(=2.10^{-4}\right)\end{array}\right.$ & $(=4.135-4)$ & $\begin{array}{c}0,38 \\
=1,8 \cdot 10^{-4}\end{array}$ & - & $\begin{array}{c}0,13 \\
\left(=3.10^{-4}\right.\end{array}$ \\
\hline $\begin{array}{l}\text { Aerosol } \\
\text { cut mass }\end{array}$ & 0,2 & $<0.03$ & 0.023 & 0.129 & $<0.06$ & $(0.14)$ & - & $\begin{array}{c}- \\
-\end{array}$ & - & 0,21 & - & 0,11 \\
\hline $\begin{array}{l}\text { Used water } \\
\text { mass }\end{array}$ & 106500 & 151400 & 147000 & 313000 & 368000 & 391000 & 61000 & 203000 & 245000 & 756000 & 64200 & 253200 \\
\hline $\begin{array}{l}\text { Water mass } \\
\text { In the } \\
\text { ventilation }\end{array}$ & $\begin{array}{l}1003 \\
(0.9)\end{array}$ & $\begin{array}{l}1162 \\
(0,8)\end{array}$ & $\begin{array}{l}1223 \\
(0,8)\end{array}$ & $\begin{array}{l}2444 \\
(0,8)\end{array}$ & $\begin{array}{c}2726 \\
(0.75)\end{array}$ & $\begin{array}{l}4598 \\
(1,2)\end{array}$ & $\begin{array}{l}1200 \\
(2,0)\end{array}$ & $\begin{array}{l}1764 \\
(0.9)\end{array}$ & $\begin{array}{l}1858 \\
(0.9)\end{array}$ & $\begin{array}{l}7117 \\
(0,9)\end{array}$ & $\begin{array}{c}120 \\
(0,2)\end{array}$ & $\begin{array}{l}1922 \\
(0,8)\end{array}$ \\
\hline
\end{tabular}


SUBMERGED CUITING OF STEEL BY ABRASIVE WATER JETS

Haferkamp, H.; Louis, H. and G. Meier;

Institute of material science, University of Hanover, Germany

\section{ABSTRACT}

A special cutting head for underwater use was designed and built. Tests were carried out to find out useful parameters for submerged cutting. With regard to the production of secondary waste the abrasive flow rate had to be minimized. It seems to be useful to realize this demand by using a small water jet nozzle ( up to $0.4 \mathrm{~mm}$ diameter) and a high pressure (up to 4000 bar) with an optimal abrasive flow rate of about $5 \mathrm{~g} / \mathrm{s}$.

In case of a higher ambient pressure a decrease of the cutting performance was measured. But this decrease is not important regarding decomissioning because the ambient pressure is less than 2 bar.

An air mantle nozzle was adapted to the cutting head to improve the working distance under water. The air mantle surrounding the abrasive jet lowers the friction between jet and surrounding water and increases the cutting efficiency in case of greater working distances.

\section{INTRODUCTION}

Different methods like laser or plasma cutting are well known today for decomissioning nuclear facilities. But most of these methods are thermal techniques and cause gas bubbles and reaction products.

An alternative non-thermal method is the abrasive water jet cutting technique: Small mineral particles accelerated in a high speed water jet, are able to cut any kind of material. Advantages of this technique are:

- non-contacting process

- no thermal induced gas bubbles

- no chemical reaction products

- small cutting forces (for the manipulator)

- small kerfs (small amount of radioactive waste)

However, regarding the minimization of secondary waste it is necessary to reduce the added abrasives and to reach a high cutting performance.

The work was aimed at the optimization of this technique for submerged application. Relevant parameters as pressure, flow rates of water and abrasives, abrasive material and traverse rate were considered.

\section{ABRASIVE JET GENERATION}

\subsection{Pressure generation}

Two different working principles of high pressure pumps are available to generate an abrasive jet. On one hand slowly working pressure intensifiers are used. These intensifier pumps are normally double-ended pistons utilizing differential areas to multiply pressure provided by a standard variable displacement hydraulic pump. With a commercial available intensi- 
fier pump pressures up to 4000 bar are achievable, but at a comparatively low level of flow rate of 2 to $41 / \mathrm{min}$. Up to three intensifiers are mounted in one pumping set.

Direct driven plunger pumps give an alternative to pressure intensifiers. These pumps, which are known from water jet cleaning technique, normally work at a lower pressure level, but with a higher flow rate than intensifier pumps.

\section{$\underline{2.2}$ Jet generation}

For generating the abrasive jet two possibilities are applicable (1) which are related to the operating characteristics of the pump (fig. 1).

Because of the higher flow rates and the lower working pressure, adding of the abrasives in the pressure hose is only possible by using plunger pumps. In this case the diameter of the nozzle, which forms the abrasives jet, is large enough to let the abrasives pass through. First experiments with a low pressure abrasive jetting system have been published in 1986 (2). Steel samples of $13 \mathrm{~mm}$ thickness had been cut with a $10.4 \mathrm{MPa}$ jet at a traverse rate of $51 \mathrm{~mm} / \mathrm{min}$. The advantages of this single nozzle arrangement are the lower dissipation of energy for mixing water and abrasives and the lower nozzle wear. But on the other hand a pressure vessel for the abrasives is necessary and the water and abrasive flow rates are quite high.

In most cases of today's application the abrasive water jet is formed in a special mixing head. First a plain water jet is formed and the abrasives are added afterwards in a hard metal or ceramic mixing nozzle. For this two nozzle arrangement plunger-pumps are applicable as well as intensifier-pumps (fig. 1). Depending on the pressure level and the flow rate sapphire nozzles with an outlet diameter up to $1 \mathrm{~mm}$ or larger metallic nozzles are used to generate the water jet, which accelerates the abrasive particles.

With regard to the demand of minimization of secondary waste in case of decommissioning only the two-nozzle-arrangement with a mixing head and small water nozzles is usable, because the flow rates of water and abrasives are quite small in this case.

\subsection{Design of the abrasive mixing head}

The mixing head works according to the principle of water-jet pump, what means that the high speed water jet generates a suction pressure in the suction port, which produces a pneumatic transport of the abrasives into the mixing head.

For all the cutting tests a self-designed abrasive cutting head was used. Based on first investigations published in (3) a modified cutting head was built (figure 2 - with adapted air mantle nozzle). In the tests a 0.25 mn-water jet nozzle and a 1.2 mm-focusing nozzle were used. Conical adapters were designed to fix focusing nozzles of different geometries at 
the cutting head. To adjust the achsis of the focusing nozzle on the high speed water jet a ball joint was created. So the focusing nozzle is within small angles movable around the water jet nozzle. In case of not adjusting the cutting head the irregular wear in the focusing nozzle increases rapidly and cutting efficiency decreases because of friction loss. After adjusting, the movable part of the abrasive cutting head is fixed by adjusting screws.

\section{EXPERIMENTAL SETUP}

Different tests were carried out under water in a water basin and in a special pressure chamber to simulate a higher ambient pressure.

For the cutting tests an intensifier pump was used, the maximum pressure is 4000 bar with a maximum flow rate of water of $2.51 / \mathrm{min}$. The cutting head was moved across the sample by a special traverse mechanism which allows to realize traverse rates between 2 and $8000 \mathrm{~mm} / \mathrm{min}$.

For adjusting and controlling the abrasive feed rate an abrasive feed system was designed which ensures the adjustment of very small flow rates to minimize secondary waste (4). To add the abrasives the suction pressure produced by the abrasive cutting head is used. The suction pressure can be reduced by a vacuum governor and the addition of compressed air. The resulting air stream transports the abrasive particles. They run out of the storage tank through an orifice plate which is used for the setting of the flow rate. The orifice plate is changeable to realize different flow rates.

Another possibility to dose the abrasives is the use of a vibration feeder. The amplitude of vibration is adjustible and so the mass flow of the abrasives. The transport is realized by air stream, too.

\section{CUTTING RESULTS}

All the cutting tests were carried out under water. The abrasive material was garnet, mesh 40 - 60. In all diagrams an average depth of kerf is given.

The used focusing nozzle were out of tungsten carbide or boron carbide, for all standard tests pressure was 2400 bar, nozzle diameter was $0.25 \mathrm{~mm}$ and the diameter of the focusing nozzle was $1.2 \mathrm{~mm}$. A lot of focusing nozzles were used with the same state of wear to eliminate the influence of different diameters because of wear.

For the cutting experiments samples of steel (ferritic steel: A 42 (1.0425); austenitic steel: $\mathrm{X} 2 \mathrm{CrNi} 8 \mathrm{9}(1.4306)$ ) and aluminum alloy (AlMgSi 0.5 ) were used. All the samples were not cut through but notched to measure and compare the depth of kerf.

\subsection{Effects of pressure and traverse rate on depth of cut}

Some tests were carried out to indicate the influences of the water pressure and the traverse rate on the cutting efficiency. The results are given in figure 3. 
Increasing the pressure up to 3000 bar the depth of kerf grows linear with the pressure (in steel as well as in aluminum or ceramics).

Doubling the traverse rate causes halving in depth of kerf. This effect is also existing at very low traverse rates: cutting ferritic steel with a traverse rate of $10 \mathrm{~mm} / \mathrm{min}$ effects a depth of cut of $75-80 \mathrm{~mm}$.

\subsection{Effect of different abrasives}

To show the influence of the properties of the abrasives different types of abrasive particles were tested. The results are given in figure 4 . All kinds of garnet with different grain sizes (Minersiv: $0.25-0.60 \mathrm{~mm}$; Elvers: $0.50-0.80 \mathrm{~mm}$ ) produce nearly the same depth of kerf. So the influence of the particle does not seem to be very important.

Looking at the results of glass particles, the influence of the particle shape is obviously high. Glass balls are not able to kerf as deep as glass sand because the balls have no sharp edges to cut.

The results in figure 4 show additionally that it is possible to cut with quartz sand. The depth of kerf is quite high and when using under water there is no danger of silicosis.

\subsection{Effect of the geometry of the focusing nozzle}

Figure 5 shows the effect of the the geometry of the focusing nozzle on the depth of kerf. All tests were carried out under the same standard conditions with a water jet nozzle produced by Seitz-Comadur (model 10). The influence of the length of the focusing nozzle is, within dispersion, not important, but it is useful to take nozzles longer than $20 \mathrm{~mm}$.

In opposite the influence of the diameter is very high. If the hole is smaller than about $0.9 \mathrm{~mm}$ water and abrasive particles are not able to pass without high friction loss. If it is larger than $1.5 \mathrm{~mm}$ (using 2400 bar and a water jet nozzle with a diameter of $0.25 \mathrm{~mm}$ ) there is no sufficient acceleration of the particles inside the focusing nozzle.

Due to the wear inside the focusing nozzle during the cutting process it is useful to start cutting with the smallest possible diameter to reach a long tool life. Starting cutting with a nozzle diameter of about $1.2 \mathrm{~mm}$ and changing the focusing nozzle when reaching $1.5 \mathrm{~mm}$ means a tool life of about 5 hours using standard conditions. Different kinds of abrasives cause different wear rates. Regarding this it is useful to take garnet or quartz sand (see figure 4). Abrasives like korundum or silica carbide are too hard, so they produce a high rate of wear.

\subsection{Effect of abrasive flow rate on depth of cut}

cutting contaminated material results problems in subsequent waste treatment. Not only the particles of the cut structure but also the cutting material like water and abrasives have to be treated. These demands result in the amounts of water and abrasives having to be minimized.

The water flow rate can be reduced by using a small nozzle. Also the 
flow rate of abrasives has to be optimized to reach a good cutting efficiency by producing a minimal secondary waste.

Figure 6 (left side) gives the results of cutting tests carried out on ferritic and austenitic steel. Both materials show the same behaviour: The depth of cut reaches a maximum level when using a specific flow rate of abrasives; increasing this flow rate causes a reduction in depth of kerf. The optimum value of abrasive flow is about $6 \mathrm{~g} / \mathrm{s}$ in case of using $2400 \mathrm{bar}$ and a nozzle of $0.25 \mathrm{~mm}$ diameter. The abrasive-water mass-ratio amounts to 0.17 .

But one has to notice that when cutting through the optimal abrasive flow rate is higher than in case of notching the samples (see figure 6 , right side).

An increasing abrasive flow rate does not produce a decrease in critical traverse rate, because all particles are able to flow out of the groove quite easily. In case of notching the sample an increasing amount of abrasives effects an obstruction of the kerf and a decrease in kerfing depth.

\subsection{Effect of nozzle sample distance on depth of cut}

In case of using the method of abrasive water jet cutting for dismantling contaminated structures the aspect of remote-controlled operation is quite important. To lower the demands in handling and positioning accuracy it is necessary to increase the working distance of the abrasive jet.

In case of cutting submerged the energy loss is much higher than in air because of friction between the abrasive jet and the surrounding water.

The maximum depth of cut reaches in case of submerged cutting only 60-70 \& of the possible depth in air. Increasing the working distance under water the depth of ker $f$ decreases faster than in air.

Some investigations were done on ferritic steel to influence the working distance by the length of the focusing nozzle. When using short distances the influence of the length is not very important (figure 5), but increasing the stand-off distance the depth of cut decreases faster in case of cutting with a short focusing nozzle $(20 \mathrm{~mm})$ than a long one $(50 \mathrm{~mm})$.

These results point out the importance of chosing the right focusing nozzle. Another method to increase the possible stand-off distance is described in (5). This method to increase the working distance was developed further for application in case of abrasive cutting under water. An air mantle nozzle was designed and tested. The setup is shown in figure 2.

For first cutting tests a tungsten carbide nozzle with an inner diameter of $3 \mathrm{~mm}$ was used. The air mantle was built up by primed air. The addition of compressed air didn't increase the depth of cut. The results of these tests are given in figure 7.

Different nozzles to form the air mantle were tested. All nozzles were out of tungsten carbide because of the high rate of wear. The results show that it is useful to adapt a short nozzle with quite a large diameter (about 3 mon when using standard cutting conditions). 


\subsection{Effect of the ambient pressure on the behaviour of the cutting head}

For remote-controlled operation under water the influence of the water depth on the reliability of the abrasive mixing process has to be tested. A pressure chamber was built up to realize a higher ambient pressure. In first tests the suction pressure produced by the water jet was measured in case of different ambient pressures.

These tests have shown that even at higher ambient pressure it is possible to produce a low absolute pressure inside the mixing head when using the suitable diameter of focusing nozzle (6). This suction pressure ensures to feed the abrasives.

The results of cutting tests are given in figure 8 . Hyperbaric cutting in air effects no decrease in kerfing depth up to 6 bar absolute ambient pressure. Cutting under water causes a decrease in kerfing depth when increasing the water depth up to $50 \mathrm{~m}$. But for decomissioning this fact is not very important because the maximum water depth to cut in is about 10 $15 \mathrm{~m}$ only (4).

\section{DISCUSSION AND OUTLOOK}

The cutting tests have shown the possibility to cut austenitic and ferritic steel under water using small amounts of water and abrasives. The cutting depth depends on the abrasive flow rate and a plain optimum in flow rate is existing when notching the samples. The working distance of the abrasive water jet can be increased by using a longer focusing nozzle. In addition it is possible to increase the working distance by air coating of the jet.

Tests carried out in a pressure chamber have shown that the cutting head also in case of a higher ambient pressure produces a sufficient suction pressure.

All the results showed the possibility to cut contaminated material by abrasive water jets. The results given in figure 9 show that it could be -meaningful to use smaller nozzles because of the cutting efficiency. The tests were carried out in co-operation with the CEC-contract FIlD-0067 (CEA). In all tests the mass-ratio of water to abrasive was about $5: 1$.

In case of using small nozzles the kerf area rate (velocity of formation of the kerf) is increasing linear with the water flow rate and with the abrasive flow rate. However, when reaching an optimum water flow rate of about $6 \mathrm{l} / \mathrm{min}$ (nozzle diameter $0.46 \mathrm{~mm}$ ) the kerf area rate decreases when increasing the nozzle diameter further on. This fact means that the use of more abrasive material and more water - both means an increasing amount of waste - does not produce a deeper kerf or a higher traverse rate. Regarding this it is suitable to use nozzles up to a diameter of $0.46 \mathrm{~mm}$, but a pressure as high as possible to reach a good cutting efficiency while producing a minimum of secondary waste.

Additionally there is a possibility to cut material with thicknesses of more than the maximum kerfing depth with such small amounts of water and 
abrasives by an abrasive keyhole saw. An oscillating abrasive jet according to (7) is combined with a traverse mechanism like a keyhole saw to produce a kerf which is wide enough to allow the cutting head to enter this kerf (figure 10). It seems possible to design such an arrangement for a width of kerf of about 12 - $15 \mathrm{~mm}$. For straight-line cutting the thickness of material to be cut is nearly unlimited.

\section{REFERENCES}

1. Blickwedel, H. ; Haferkamp; H. and H. Louis:

"Abrasive Jet Cleaning and Cutting for Underwater Use".

In: Proc. of the 2. International GUSI-Symposium - Underwater Technology (Geesthacht, Germany, 1987) GKSS-Forschungszentrum Geesthacht GmbH, Geesthacht, Germany, 1987

2. Fairhurst, R.M.; Heron, R.A. and D.H. Saunders:

"'Diajet' - a new abrasive water jet cutting technique".

In: Proc. of the 8th International Symposium on Jet Cutting Technology (Durham, England, Sept 1986) BHRA, The Fluid Engineering Centre, Cranfield, England, 1986

3. Blickwedel, H.; Decker, B.; Haferkamp, H. and H. Louis:

"Submerged Cutting with Abrasive Water Jets".

In: Proc. of the 8th International Symposium on Jet cutting Technology (Durham, England, Sept 1986) BHRA, The Fluid Engineering Centre, Cranfield, England, 1986

4. Louis, H.:

"Development of abrasive water jet for submerged cutting of steel".

The Community's research and development programme on decommissioning of nuclear installations

3. annual progress report 1987, Commission of the European Communities, Luxembourg, 1988

5. Gelfort, E.; Mischke, J.; Blickwedel, H. and H. Haferkamp:

"Submerged Cutting of Nuclear Fuel Elements by High Speed water Jets". In: Proc. of the 8th International Symposium on Jet Cutting Technology (Durham, England, Sept 1986) BHRA, The Fluid Engineering Centre, Cranfield, England, 1986

6. Haferkamp, H.; Louis, H. und G. Meier:

"Submerged cutting of contaminated material by abrasive water jets under the protection of water shield".

In: Proc. of the 9th International Symposium on Jet cutting Technology (Sendai, Japan, Oct 1988) BHRA, The Fluid Engineering Centre, Cranfield, England, 1986

7. Hashish, M.:

"Aspects of abrasive water jet performance optimization".

In: Proc. of the 8th International Symposium on Jet cutting Technology (Durham, England, Sept 1986) BHRA, The Fluid Engineering Centre, Cranfield, England, 1986 


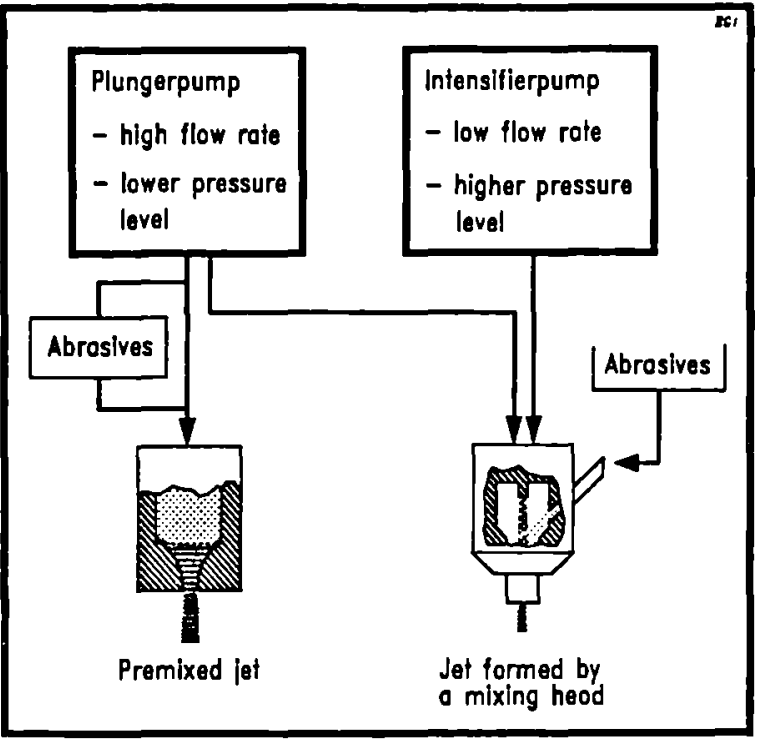

Figure 1: Mixing arrangements to form abrasive jets

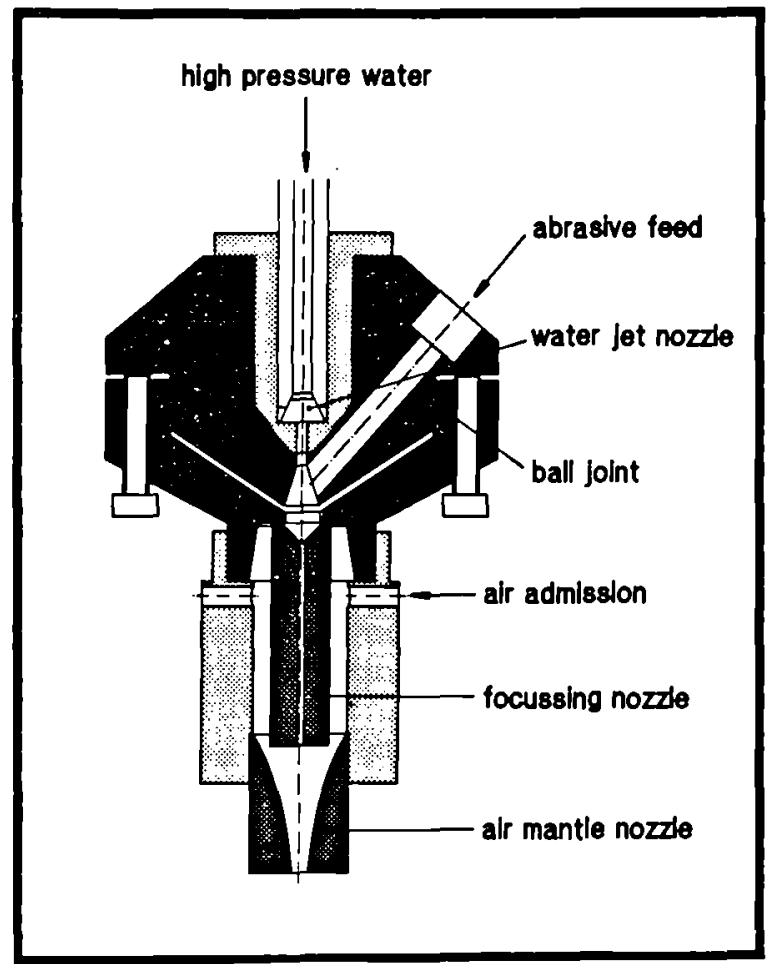

Figure 2: Abrasive cutting head with adapted air mantle nozzle 

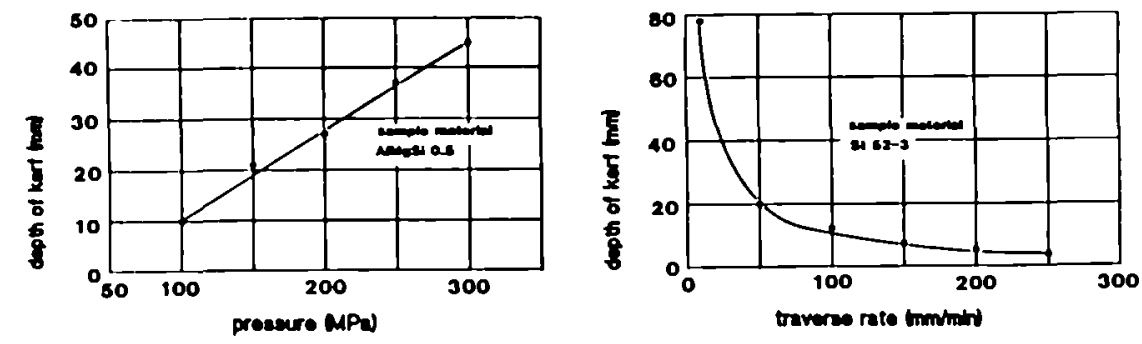

Stenderd paramotere nozde dameter: $d=0.25 \mathrm{~mm}$ focus diamoter: $D=1.2 \mathrm{~mm}$

punding preacure: $p=300 \mathrm{MP}$ nozdoreanple distuncer $=2 \mathrm{~mm}$ focue kngth: $L=50 \mathrm{~mm}$ abraster: Mherak $0.4 \mathrm{~mm}$ abraatre fout $\dot{M}=5$ os surounding mechere water

Figure 3: Effect of pumping pressure and traverse rate on depth of kerf

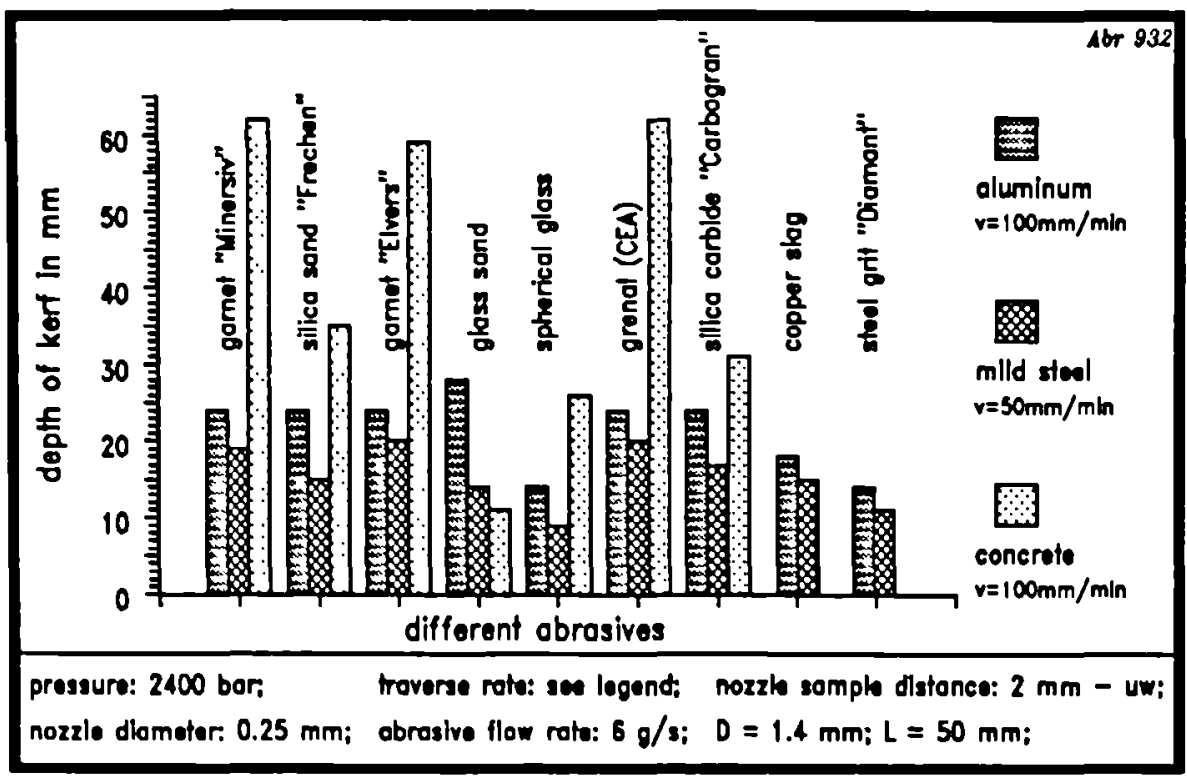

Figure 4: Effect of abrasive material on depth of kerf 


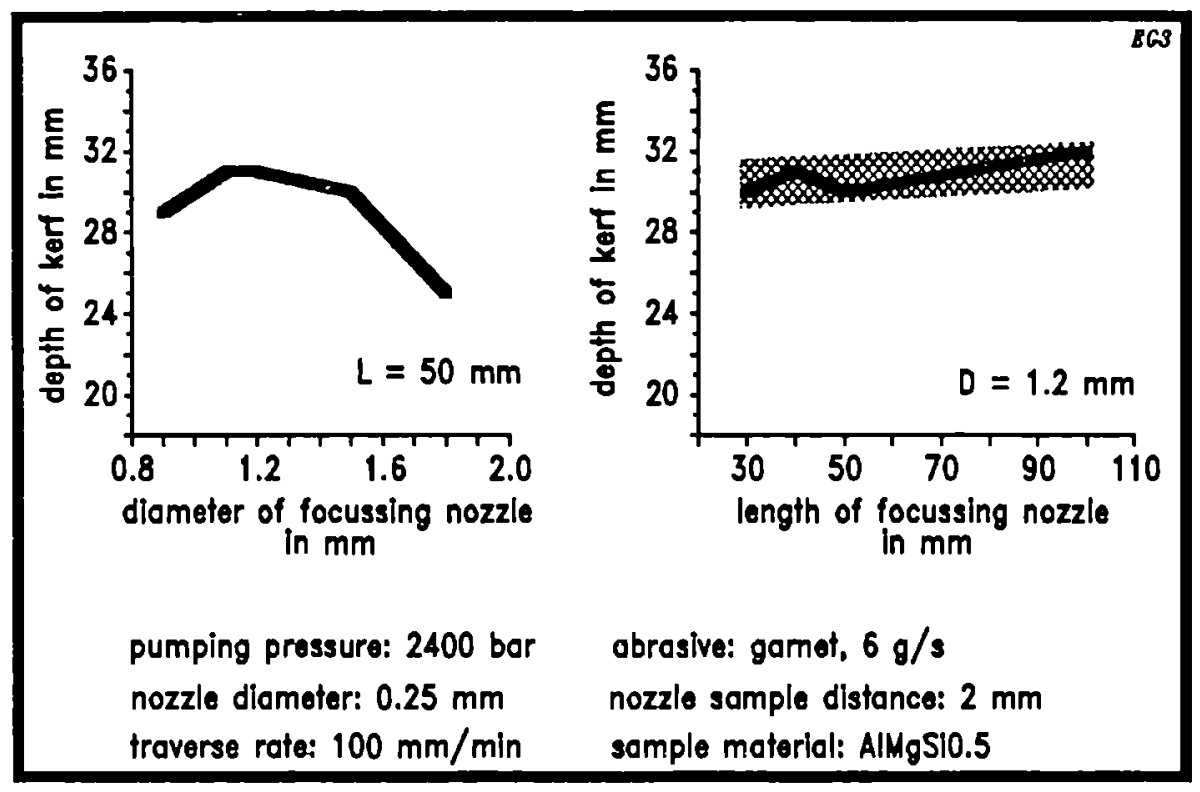

Figure 5: Effect of focus geometry on depth of kerf

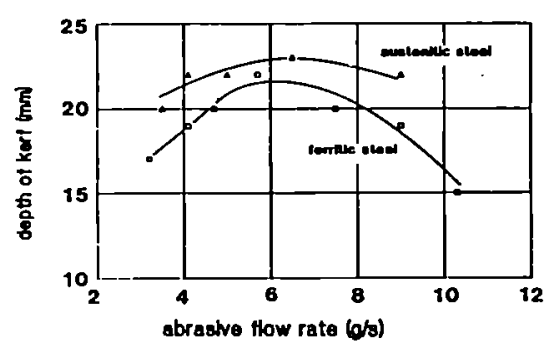

nozde dlanoter: $d=0.25 \mathrm{~mm}$ focus dlaneter: $D=12 \mathrm{~mm}$ focus length: $L=50 \mathrm{~mm}$ pumplng pressure: $p=240 \mathrm{MPa}$ nozde sample dlstance: $8=2 \mathrm{~mm}$ abrasive: Mineratv 0.4 aurrounding modim water

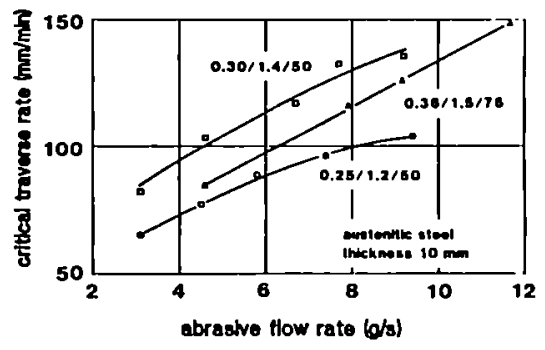

nozde dlam./tocus dlam/focus length: see dlagram

nozde sample distance: $s=5 \mathrm{~mm}$ abrastve: Grenal ourrounding mediun: alr

Figure 6: Comparison of cutting and kerfing results 


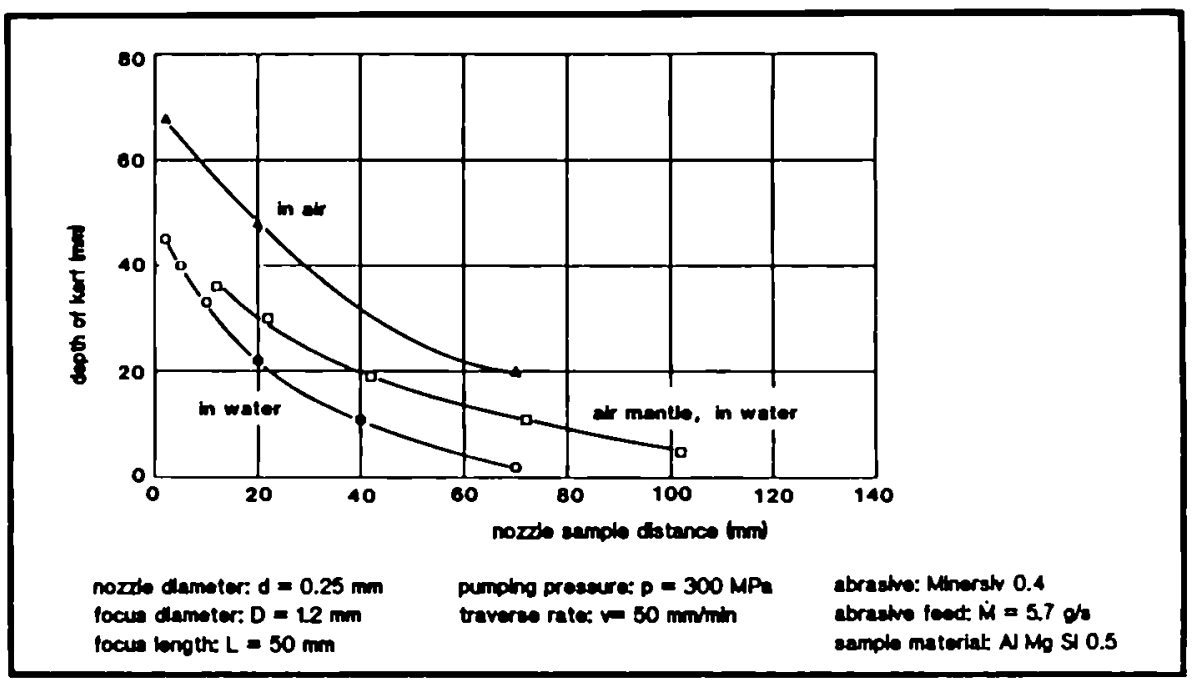

Figure 7: Effect of surrounding medium on cutting efficiency

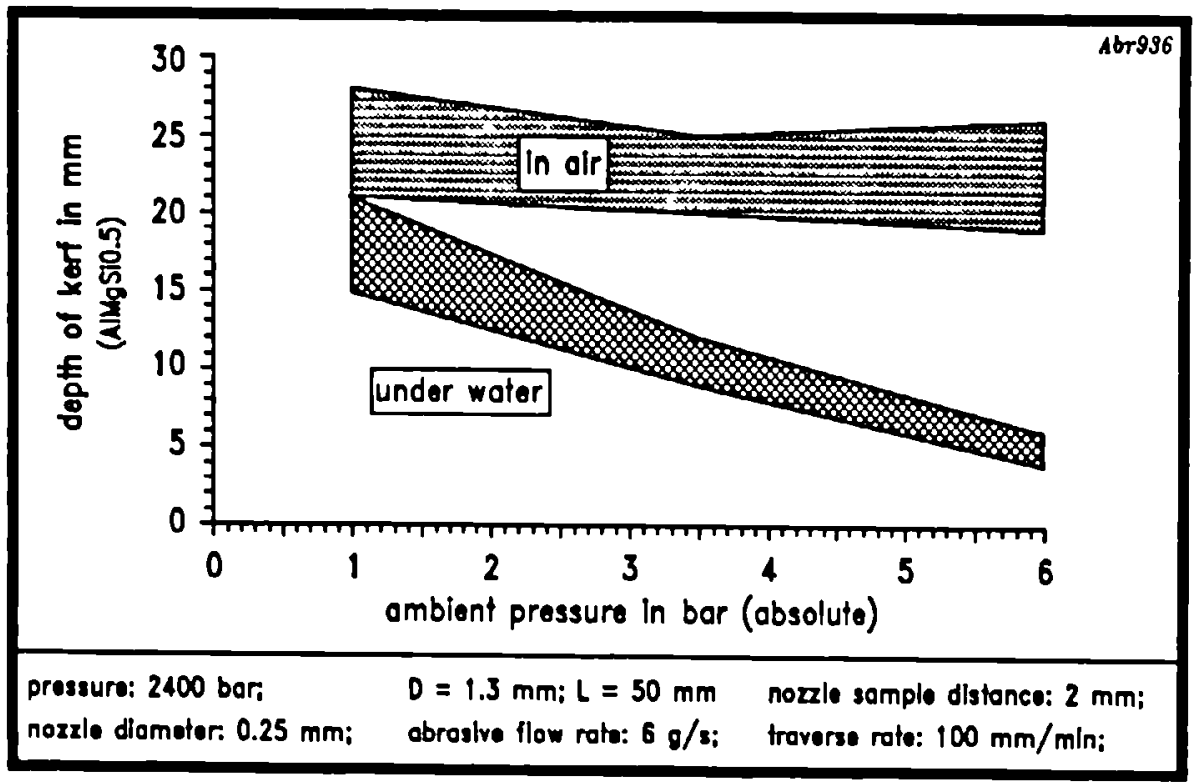

Figure 8: Effect of ambient pressure on depth of kerf 


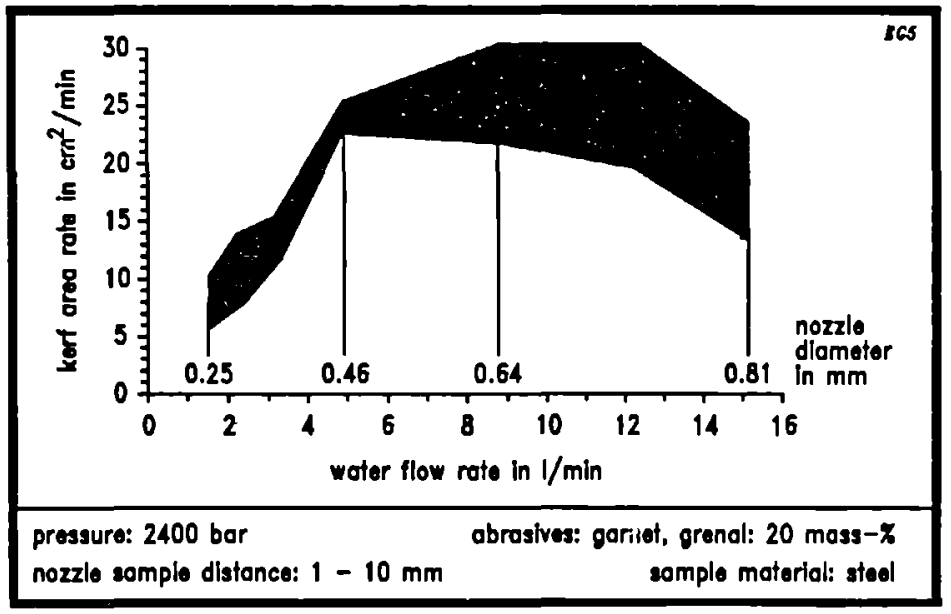

Figure 9: Effect of flow rate on cutting efficiency

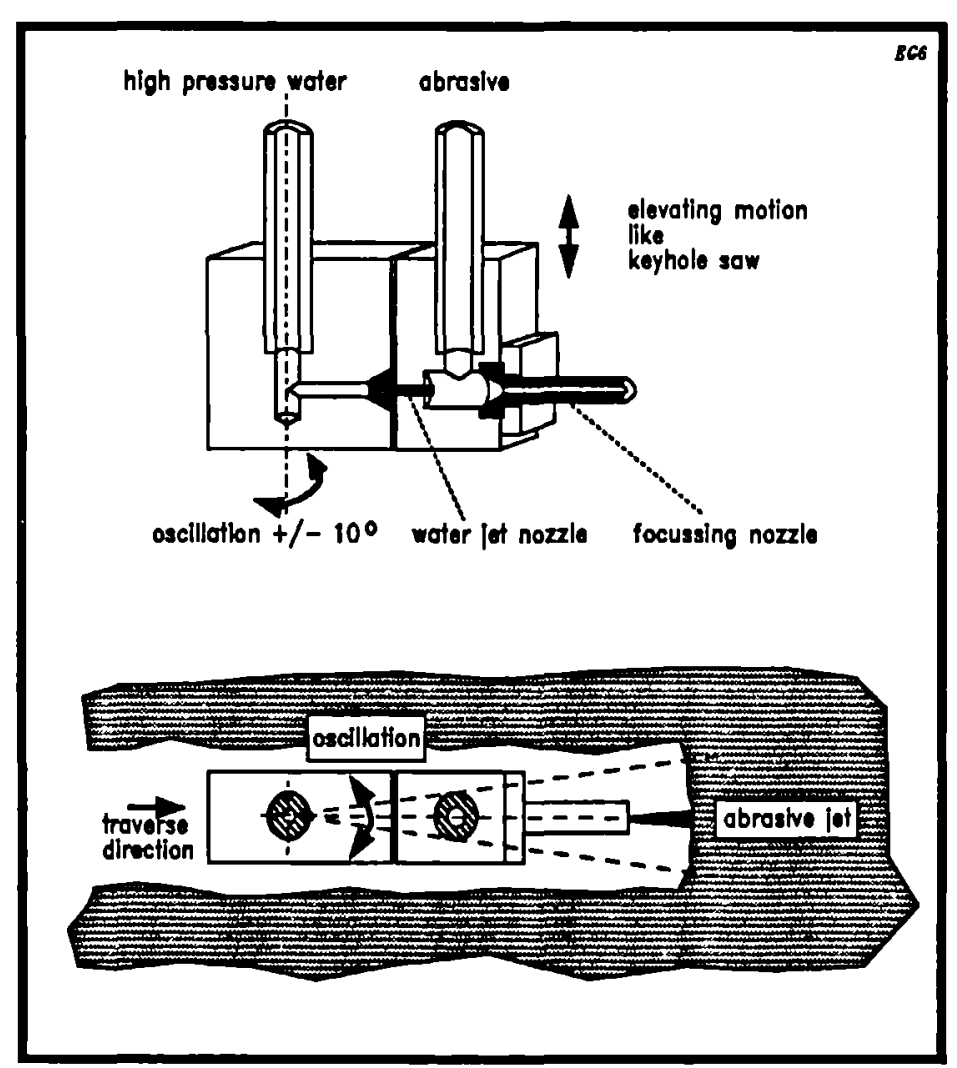

Figure 10: Abrasive keyhole saw 
REMOVAL OP CONCRETE LAYERS FROM

BIOLOGICAL SHIELDS BY MICROWAVES

WACE P.F., HARKER A.H.

UK Atomic Energy Authority, Harwell Laboratory, UK.

HILLS D.L.

Building Research Establishment, Garston, Watford, UK.

\section{ABSTRACT}

A comprehensive literature review has been carried out, to provide information for an experimental programe and equipment design. Mathematical modelling of the microwave and power fields in a concrete block, both steel reinforced and unreinforced, subjected to microwave attack at two frequencies, has been carried out and estimates of the likely temperature rise with time obtained.

A method of launching microwaves into concrete has been established from theoretical considerations and from the findings of the literature review. Equipment for laboratory trials has been designed and assembled using an $896 \mathrm{MHz}, 25 \mathrm{~kW}$ microwave generator. Reinforced concrete blocks, $0.6 \mathrm{~m}$ in dimension and representing the concrete in a Magnox reactor biological shield, have been attacked at different power levels and the surface removed to the depth of the reinforcing steel (100 rm).

Outline proposals for the design of a remotely operated prototype microwave machine for stripping the surface of large concrete test panels have been prepared.

\section{INTRODUCTION}

In January 1987, a feasibility study was initiated to examine the cracking of concrete by microwave energy, a technique pioneered by the Building Research Establishnent (BRE) in 1965 (I). Interest in the subject has revived recently, owing to its potential for demolishing radioactive concrete with minimal human intervention or dust production.

Previous studies of the method had experienced difficulties with reflection of the microwave power back to the magnetron and had been largely confined to plain concrete, leaving some doubt as to whether reinforced material could be successfully attacked. Consequently, the objectives of the present study were to: (a) conduct a literature search, (b) derive a mathematical model of the microwave field and temperature distribution. (c) devise suitable microwave beam launching techniques, (d) undertake high power trials, (e) envisage the design of remotely operated equipment.

This paper gives a brief outline of the findings related to all these topics. The apparatus employed is illustrated in Figure 1.

\section{LITERATURE REVIEW}

References relating to the subject fall into three main experimental areqg; fijsuring/crgfking of copfrete in the UK $(1) .(2)$; road repairs in USA $(3),\{4)^{\text {. France }}$ and USSR ; and general ffegfuring/spalling of rock and concrete in Japan $(9),(8)$, USSR $(9)$ and France $(10)$. Table I below shows the rates of treatment achieved by the microwave process in these operations. 
Table I

Comparative Treatment Rates in Microwave Applications

\begin{tabular}{|l|c|}
\hline \multicolumn{1}{|c|}{ Process } & $\begin{array}{c}\text { Treatment } \\
\text { Rate } \\
\text { l/kWh }\end{array}$ \\
\hline $\begin{array}{l}\text { Single-line cracking (1), (2) } \\
\text { levering up of slabs } \\
\text { Curing of polyester/cement road patches (3) }\end{array}$ & 300 \\
Refurbishing of asphaltic aggregate (5) \\
$\begin{array}{l}\text { In-situ asphalt road surface recycling } \\
\text { Microwave demolitign of unreinforced horizontal } \\
\text { concrete surfaces }\end{array}$ & 25 \\
\hline
\end{tabular}

While the numbers in Table I have been derived from brief references to material removal rates and are very approximate, they nevertheless show a clear gradation that makes physical sense. Thus the economy of power consumption effected in the early BRE work, by merely cracking the concrete into removable slabs, makes such a procedure about two orders of magnitude more efficient than comparable operations. The $25 \mathrm{l} / \mathrm{kWh}$ efficiency achieved in the curing process is to be expected owing to the deliberate selection of rapidly-reacting polymer blends. Conversely, the drop to 7 and $3 \mathrm{\ell} / \mathrm{kWh}$ for asphalt treatments may be taken to illustrate the comparatively low loss factor of this material, and the effect of using lossy aggregate ${ }^{(5)}$. These numbers thus provide an illuminating context for the efficiency figure of only $1 \mathrm{l} / \mathrm{kWh}$ for demolition of unreinforced concrete ${ }^{(8)}$, which is now seen to be entirely reasonable for a high strength material of rather unfavourable loss factor.

The principal conclusions of the review are:

a) Microwave demolition of concrete has been demonstrated on several occasions since 1964 and is clearly feasible.

b) Nearly all reported demonstrations relate to plain concrete. The little information available on either reinforced or very dense concretes indicates that both reinforcement and higher density may make the disintegration of reinforced shielding considerably more difficult than for plain concrete.

c) Disintegration of concrete under microwave attack is generally agreed to be due mainly to internal tensile stresses created by the generation of steam from the water present in a relatively impermeable mediun that hinders its egress. Thermal stresses also contribute to the process. d) Attack takes place primarily over the outer $100 \mathrm{~mm}$, which is convenient for stripping off surface layers. This depth of attack will vary with the type of concrete in question, the frequency of the microwaves, the presence of reflections from reinforcement, the rate of traverse of the applicator and the applicator/concrete air gap. e) Demolition rates of about $1 \mathrm{l} / \mathrm{kWh}$ of applied energy have been recorded for plain concretes, and the context provided by other applications such as road repairing is consistent with these findings. 
f) Power costs at demolition rates of about $1 \mathrm{l} / \mathrm{khth}$ (applied) are thought to be only a modest fraction of total costs.

3. THEORETICAL ANALYSIS - POWER, FREQUENCY AND REINFORCEMENT

The microwave field and associated thermal power in a $0.6 \mathrm{~m}$ cubic concrete block have been evaluated using electromagnetic theory for a plane incident wave. Both steel reinforced and unreinforced concrete have been examined, at microwave frequencies of $896 \mathrm{MHz}$ and $2450 \mathrm{MHz}$.

The analysis indicates that, for unreinforced concrete, the maximum internal temperatures occur in the first few centimetres below the surface and the temperature profile consists of a series of hot spots, corresponding to the standing wave pattern, which decrease exponentially in magnitude with depth. Over a short period of time, before significant thermal diffusion occurs, the temperature increases approxinately linearly with time and also with power. Near-surface power absorption at $2450 \mathrm{MHz}$ is nearly three times as great as at $896 \mathrm{MHz}$.

Extension of this analysis to examine the effects of steel reinforcement at $100 \mathrm{~mm}$ below the surface revealed that reflection from the steel would greatly increase the deposited power density in the concrete cover. Thus, in Figure $2(a)$ the background pattern shows the exponentially-decaying peaks set up by the standing waves generated in the block as a whole, while the greatly enhanced near-surface peaks illustrate the reflected power density in the cover due to the presence of the reinforcement. Concrete removal would be greatly enhanced by this effect, provided reflections back to the generator were avoided.

For example, Figure 2(b) shows that a temperature of $250^{\circ} \mathrm{C}$ is obtained at 50 depth after 4 minutes at $896 \mathrm{MHz}$ and $20 \mathrm{~kW}$. The same power at $2450 \mathrm{MHz}$ is predicted (not shown) to give this temperature after less than 2 minutes. Such comparisons are also affected by the input power density, because the exponential decay (Figure 2(a)) implies that heat losses from the face become relatively less important at high inputs. These comparisons are also affected by the local high peaks in power absorption (Figure $2(a)$ ) due to reflection from the reinforcement. The predictions are thus a helpful guide, but need further development to attain fully quantitative status.

\section{LAUNCHING TECHNIQUE}

Reflection of power from the initially smooth face of the concrete and, later, from the jagged edges of the excavation, has been a problem for all operators. To minimise this effect, a leaky waveguide applicator or an oblique beam was considered essential to the success of the scheduled tests. The latter option was chosen after a calculation of the refractive index of concrete had shown that a beam obliquity of $45^{\circ}$ should give a practical compromise between the requirements of refraction and reflection at the concrete surface, the propagation of microwaves within the test cavity, and the clearing of debris. The waveguide was fitted with a bolt-on termination for alternative horns.

Examination of horn configurations led to the choice initially of a square end to the waveguide rather than an oblique end or a horn of varying geometry. This provided as concentrated a plane vave as possible. From the literature it has been found that power reaching the concrete from the horn decreases rapidly with the stand-off distance so that a fairly close spacing of about $5 \mathrm{~cm}$, consistent with practical manoeuvring of the concrete block, was chosen. The maximum power density, calculated at the obliquely attacked concrete surface, was about $20 \mathrm{~kW} / \mathrm{m}^{2}$ per $\mathrm{kH}$ of 
applied power, which is at least as great as that used in most of the experiments described in the literature.

Some propagation of microwaves between the cavity wall and the concrete face, assisted by reflections from the floor, was anticipated; but this was expected to constitute a second-order effect.

\section{LABORATORY TRIALS}

The equipment consisted of a variable-power $25 \mathrm{~kW}, 896 \mathrm{MHz}$ generator which launched microwaves into a $248 \times 124 \mathrm{~mm}$ rigid rectangular waveguide approximately $3 \% \mathrm{~m}$ long, leading to a microwave cavity fabricated from a steel box of approximately $1.5 \mathrm{~m}$ in each dimension which enclosed the concrete block under test. The waveguide was arranged in a series of bends to provide a downward oblique attack on a vertical face of the concrete and its length was set to provide primary tuning of the load and generator impedances. Second-order tuning was via a 4-stub tuner close to the steel box cavity. The generator was protected against power reflection by a circulator mounted on its launch guide. The concrete test blocks were of $0.6 \mathrm{~m}$ dimension and the mix composition and steel reinforcement were representative of those in a Magnox reactor biological shield. Details are given in Table II. The blocks were stored in a warm, dry environment for seven months prior to testing, at which time the evaporable water content in the surface layer was $2 \%$ to $3 \mathrm{wt} \%$.

Table II

Composition of Concrete Blocks

\begin{tabular}{|c|c|c|c|c|c|c|}
\hline \multirow{2}{*}{$\begin{array}{l}\text { Block } \\
\text { No }\end{array}$} & \multicolumn{2}{|c|}{ Mix Composition } & \multirow{2}{*}{$\begin{array}{l}\text { Water/ } \\
\text { Cement } \\
\text { Ratio }\end{array}$} & \multirow{2}{*}{$\begin{array}{l}\text { Slump* } \\
\mathrm{mm}\end{array}$} & \multicolumn{2}{|c|}{28 day } \\
\hline & Constituent & $\begin{array}{l}\text { Proportion } \\
\text { by Weight }\end{array}$ & & & $\begin{array}{l}\text { Strength } \\
\mathrm{N} / \mathrm{mm}^{2}\end{array}$ & $\begin{array}{c}\text { Density } \\
\mathrm{kg} / \mathrm{m}^{3}\end{array}$ \\
\hline 1 & $\begin{array}{l}\text { Portland cement } \\
20-10^{+} \text {limestone } \\
10-5^{+} \text {limestone } \\
5-0^{+} \text {sand }\end{array}$ & $\begin{array}{l}1.00 \\
2.04 \\
1.06 \\
1.53\end{array}$ & 0.48 & 100 & 54.6 & 2420 \\
\hline 2 & $\begin{array}{l}\text { Superplasticising } \\
\text { admixture } 0.3 \% \text { of } \\
\text { cement weight }\end{array}$ & & 0.44 & 10 & 63.6 & 2455 \\
\hline $\begin{array}{l}\text { Stee } \\
\begin{aligned} \\
* \quad S \\
\\
\quad \mathrm{ar} \\
\\
+\quad \mathrm{Pz}\end{aligned}\end{array}$ & $\begin{array}{l}\text { reinforcement: } 25 \\
\text { ve } \\
\text { Co } \\
\text { ump is a measure } 0 \\
\text { d was measured in } \\
\text { irt } 102 \text { : } 1983 \\
\text { irticle size range }\end{array}$ & $\begin{array}{l}\text { min diameter } \\
\text { tically, } 15 \\
\text { dcrete cover } \\
\text { the workab } \\
\text { iccordance } \\
\text { f aggregate }\end{array}$ & $\begin{array}{l}\text { bars on } \\
\text { mm cen } \\
100 \mathrm{~mm} \\
\text { lity of } \\
\text { th Brit } \\
\text { measur }\end{array}$ & $\begin{array}{l}250 \mathrm{~mm} \\
\text { res hor } \\
\text { =hick. } \\
\text { freshly } \\
\text { ish Stan } \\
\text { d in mo }\end{array}$ & $\begin{array}{l}\text { entres } \\
\text { zontally. } \\
\text { mixed con } \\
\text { ard BS188 }\end{array}$ & herete \\
\hline
\end{tabular}

Four reinforced faces on two concrete test blocks were subjected to a total of five microwave attack tests at different power levels. Table III gives all the results. Concrete spalled from the surface at rates and 
Tale III

Experimsital Results

\begin{tabular}{|c|c|c|c|c|c|}
\hline Exorlimat Mber & 1 & 2 & 3 & 4 & 5 \\
\hline abjectivo & Comissian generator & $\begin{array}{l}\text { Vertical } \\
\text { traverse } \\
\text { ax. paner }\end{array}$ & 15 bo ren face & Do k t rew face & 25 k t rey foos \\
\hline Matn Reoult & 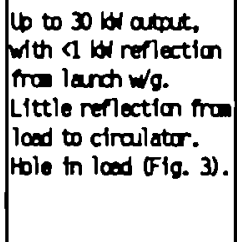 & $\begin{array}{l}\text { Intenittert } \\
\text { arcing at } \\
215 \text { kH. } \\
\text { Inssive } \\
\text { spalling } \\
\text { Fig. 4). }\end{array}$ & $\begin{array}{l}\text { First soall } \\
\text { after only } 5 \\
\text { wins. Gig. } \\
\text { 5). Test } \\
\text { staped to } \\
\text { rocond effect. }\end{array}$ & $\begin{array}{l}\text { First spall } \\
\text { after } 4 \text { atn. } \\
\text { Thereafter, at } \\
\text { apox. } 1 \text { iln. } \\
\text { tintervals. }\end{array}$ & 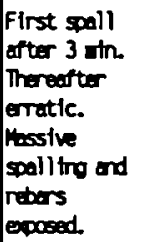 \\
\hline $\begin{array}{l}\text { Centro of wevaride vilev } \\
\text { (ca) }\end{array}$ & $30 / 28$ & $30 / 20$ & $30 / 20$ & $30 / 20$ & $30 / 20$ \\
\hline $\begin{array}{l}\text { Contre of spoll ino effects } \\
\text { (ca) }\end{array}$ & $30 / 38$ & $30 / 20$ & $30 / 30$ & $30 / 30$ & $30 / 30$ \\
\hline Reflected power to ginerater & verlable & 16 & $400 \mathrm{H}$ & 600 & $200 \mathrm{n}$ \\
\hline Rerlected powe to ciraulator & verlable & Wa are tolp & N/A & $\begin{array}{l}1.2 \mathrm{~W} \text { (start) } \\
600 \mathrm{~N} \text { (later) }\end{array}$ & $\begin{array}{l}1.2 \text { WN (start) } \\
800 \text { W (later) }\end{array}$ \\
\hline $\begin{array}{l}\text { Mox. teip. of fractared } \\
\text { fece }\left({ }^{\circ}\right)\end{array}$ & 190 & 270 & $154^{(c)}$ & $297^{(\Delta)}$ & $20^{10}$ \\
\hline $\begin{array}{l}\text { Herawen power genarated } \\
\text { to final explosion (hat) }\end{array}$ & $1.5-2.5^{(\mathrm{b})}$ & 5 & 1 & 6.2 & 7.3 \\
\hline Nhber of eolosions & 1 & 1 & 1 & 10 & 11 \\
\hline $\begin{array}{l}\text { Whight of cancrete collected } \\
(\mathrm{kg})\end{array}$ & $3.5^{(\mathrm{b})}$ & $34.5^{(b)}$ & $0.2^{(b)}$ & 22 & 54.3 \\
\hline $\begin{array}{l}\text { Adusted wight (redced by } \\
\text { a comer spall ing estinate) }\end{array}$ & 3.5 & 24.2 & 0.23 & 19.8 & 38.0 \\
\hline \multirow{2}{*}{ 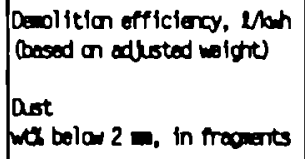 } & $\varphi$ to 1 & 2 & 0.1 & \multirow{2}{*}{1.4} & \multirow{2}{*}{2.3} \\
\hline & \multicolumn{3}{|c|}{ 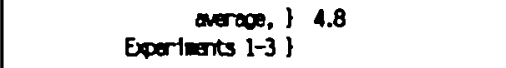 } & & \\
\hline \multicolumn{6}{|l|}{ NDIES } \\
\hline \multicolumn{6}{|c|}{ 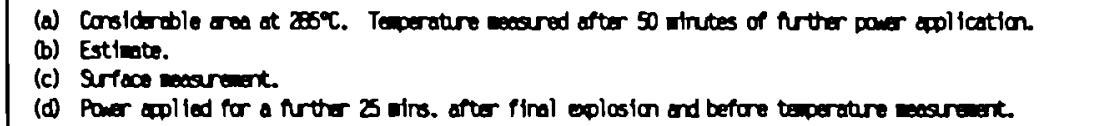 } \\
\hline
\end{tabular}


depths dependent on the power level. The relatively small area of the face $(0.6 \times 0.6 \mathrm{~m})$ resulted in an unrepresentative loss of concrete at the edges if the block was attacked other than at the centre-line of the face. Figure 3 shows the area of concrete spalled after one variable power attack near the centre; concrete was removed to the depth of the reinforcement, $100 \mathrm{~mm}$, at the centre of the crater. Figure 4 shows the same block attacked again just below the position of the first attack; spalling is much more extensive due to failure of the block edges. Figure 5 shows the very near-surface spall obtained at $15 \mathrm{~kW}$ and above, on a fresh surface. Table III summarises all the numerical results.

Conclusions drawn from the results of the experimental work are summarised as follows:

a) Reinforced concrete can be spalled by microwave attack at $896 \mathrm{MHz}$ frequency.

b) The concrete cover can be removed as far as the reinforcement.

c) At high power densities $\left(>350 \mathrm{~kW} / \mathrm{m}^{2}\right)$ a superficial spall of about 30 sm depth or less can be achieved.

d) Removal efficiency when demolishing the cover is about $2 \mathrm{l} / \mathrm{kWh}$ regardless of power density.

e) Removal efficiency for a superficial spall at high power density is only about $0.2 \ell / \mathrm{kWh}$.

f) Power reflection problems can be reduced to an inconsequential level by adequate impedance matching and horn design.

g) Power reflection from exposed reinforcement is sufficiently low to justify further exploration of the direct attack of underlying concrete. h) Power reflection changes during the traversing motions required in demolition work may be appreciable and may require on-load tuning.

i) Explosive cracking is due to steam pressure generated at a hot spot. Fragments about $30 \mathrm{~mm}$ in size are ejected from the central region with considerable force. Internal temperatures of up to $300^{\circ} \mathrm{C}$ in the concrete are attained.

j) Non-explosive internal cracking occurs, adjacent to the main explosion zone, resulting in weakening of surrounding concrete.

k) The depth at which explosive cracking occurs is about 100 mm for low power densities, and the explosion is correspondingly vigorous. At the higher power densities the explosion depth is less, making possible the superficial spalling option of (c) above and also the removal of the cover by a series of similarly shallow explosions when employing high power density.

1) Surface material adjacent to the explosion zone is torn off when the main fragments are ejected.

m) Microwave leakage from an exposed microwave horn is seen to be a main problem for future site application of the process, unless access to the immediate areas is restricted, as in many nuclear tasks.

$\mathrm{n}$ ) Dust arisings were measured only on the last test (using a Royco light-scattering technique) in order to obtain some additonal information. They seem to be comparatively low. In particular, as Figure 6 shows, only some $0.01 \%$ of all the debris was found to be in the sub- 4 micron size range that constitutes the main ingestion hazard.

\section{PROTOTYPE MACHINE}

There are two main options for a remotely-operated prototype microwave concrete demolition or stripping machine. One is to position the microwave generator well away from the working area and to transmit microwaves to the applicator via a long, steerable waveguide. This option 
is shown at the top of Figure 7. The other option is to position the generator, on a manipulator, directly at the work face so that the transmission distance to the device for launching the microwaves at the concrete aurface (the applicator) is minimal. A major disadvantage of this method is that the generator would be in an unfavourable environment and susceptible to damage and contamination. This option may be improved by positioning only the magnetron at the surface, connecting it by flexible cables and coolant tubes to the power source. This is illustrated at the bottom of Figure 7 .

Prototype demolition machines based on these concepts have been considered in outline. Such a machine would represent an intermediate development stage between the small-scale static tests undertaken as part of the current programe and a fully developed machine to operate inside a reactor biological shield. It would be used to investigate important aspects of microwave power transmission which have been identified, such as the feasibility and performance of flexible or articulated waveguides, applicator design for optimum concrete removal and minimum power reflection, and the control of reflection by on-line network analysers. It would also provide more informetion on realistic concrete removal rates, in various orientations, on large panels with reduced edge effects, and on concretes of different composition and embedded metal

configuration. Microwave leakage and safety aspects would form an important. part of the work.

The machine proposed for initial tests consists of a remote, static microwave generator of high power (at least $60 \mathrm{~kW}$ ) protected by a circulator, and a steerable waveguide assembly, suitably supported, consisting of rigid and flexible sections capable of transmitting microwaves to an applicator mounted on a simple three-axis manipulator. As required, the components of this machine can be employed to provide the second option of Figure 7, the flexible sections being used to steer the horn only.

\section{REFERENCES}

1. Watson A (1968) Microwave Power Engineering 2., 111-114.

2. Smith J L (1971) "Advances in Concrete" Symposium. Concrete Society of London.

3. Boyko L L (1978) IEEE Microwave Symposium Ottawa, 360-362.

4. Jeppson ME (1984) USDOE/CE/15173-T1 (DE 85-004194).

5. Baillot G (1986) BNCE conference, Cambridge, Paper 4.5.

6. Marganov E L (1979) Russ. Pat. SU 641681.

7. Misawa S (1971) Q.Rep. Railway Tech. Res. Inst. Jap. 12(4) 187-90.

8. Kasai Y (1985) EDA/Rilem Conf. Proc. Vol 1.

9. Moskalev A N (1978) Sov. Min. Sci 14 (3) $274 / 8$.

10. Thourel B (1973) Electron Fisc Appli, 16 (2) 128-130.

\section{ACKNOWLEDGEMENT}

This work was funded by the CEC and the Department of the Environment (DOE). UK. In the DoE context, the results of this work will be used in the formulation of Government Policy, but views expressed in the report do not necessarily represent Government Policy. 


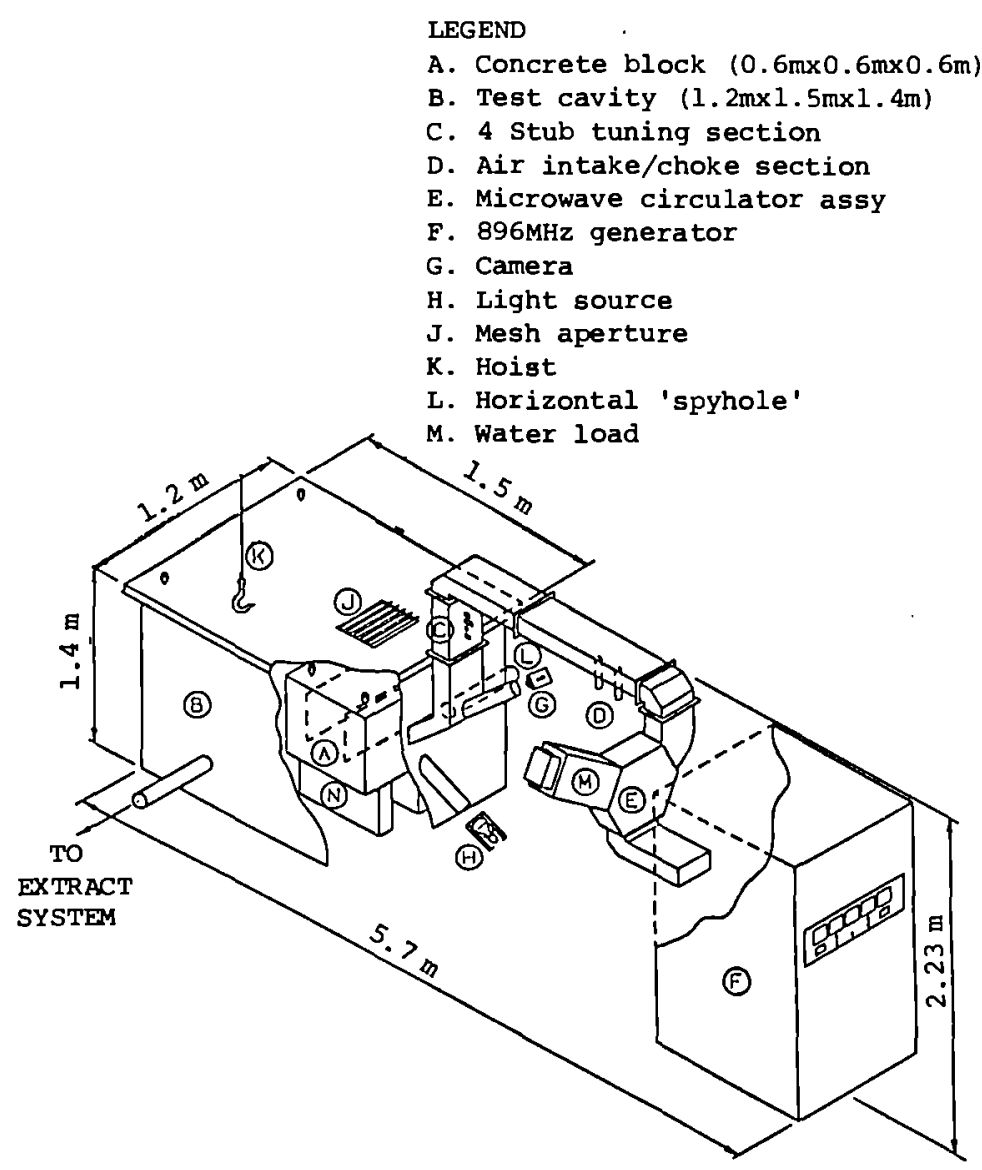

FIGURE 1. Schematic of mlcrowave demolition experment

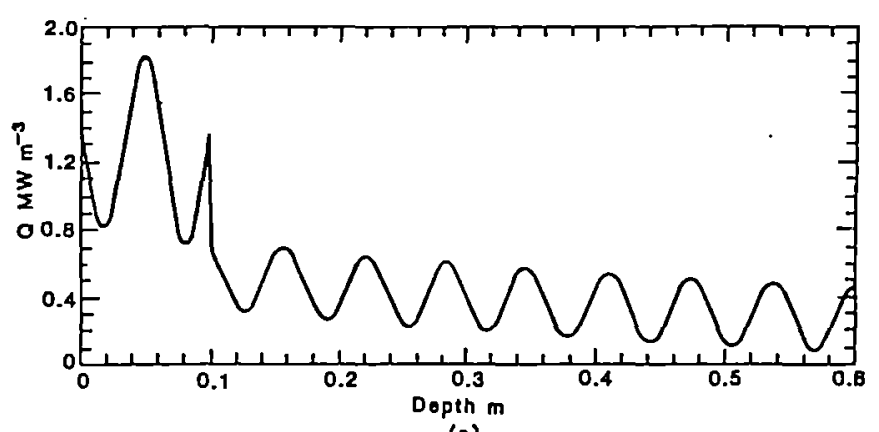

(a)

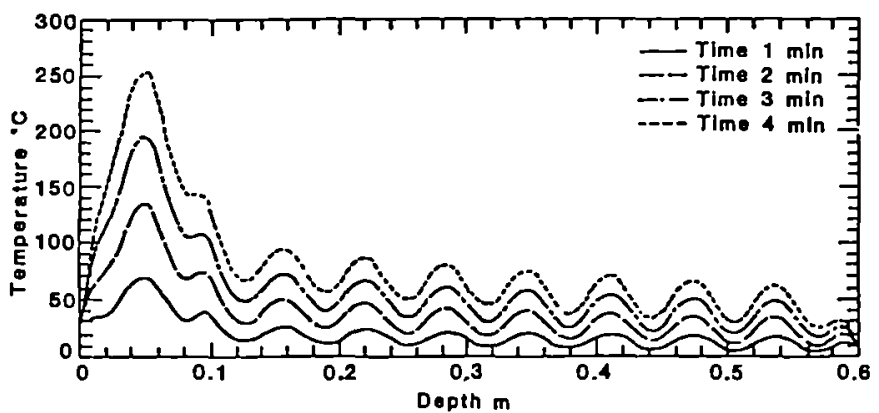

FIGURE 2. Profiles of (a) deposited power density and (b) temperature rise. Both at $896 \mathrm{MHz}, 20 \mathrm{~kW}$ with reinforcement at $100 \mathrm{~mm}$ 


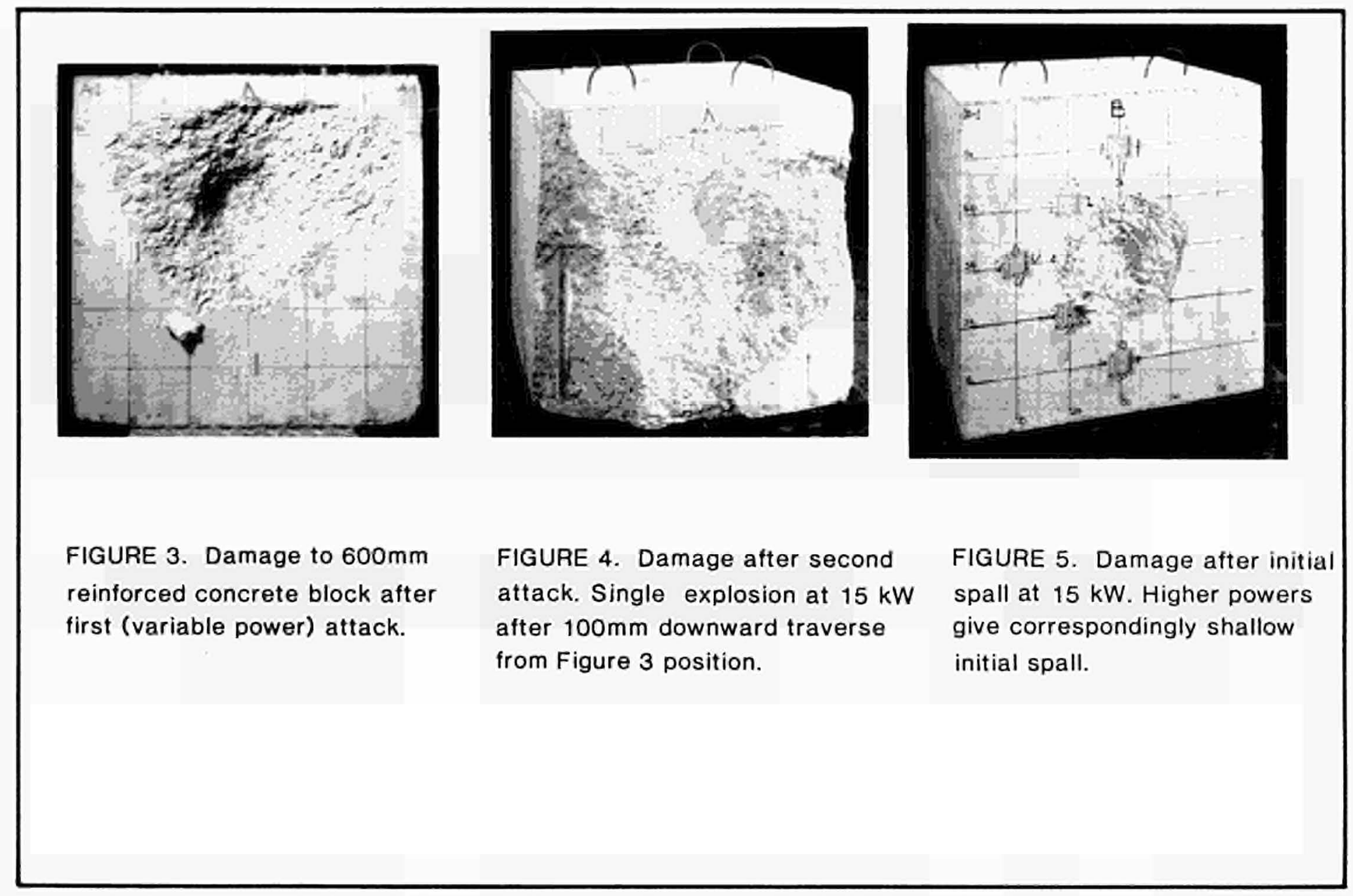




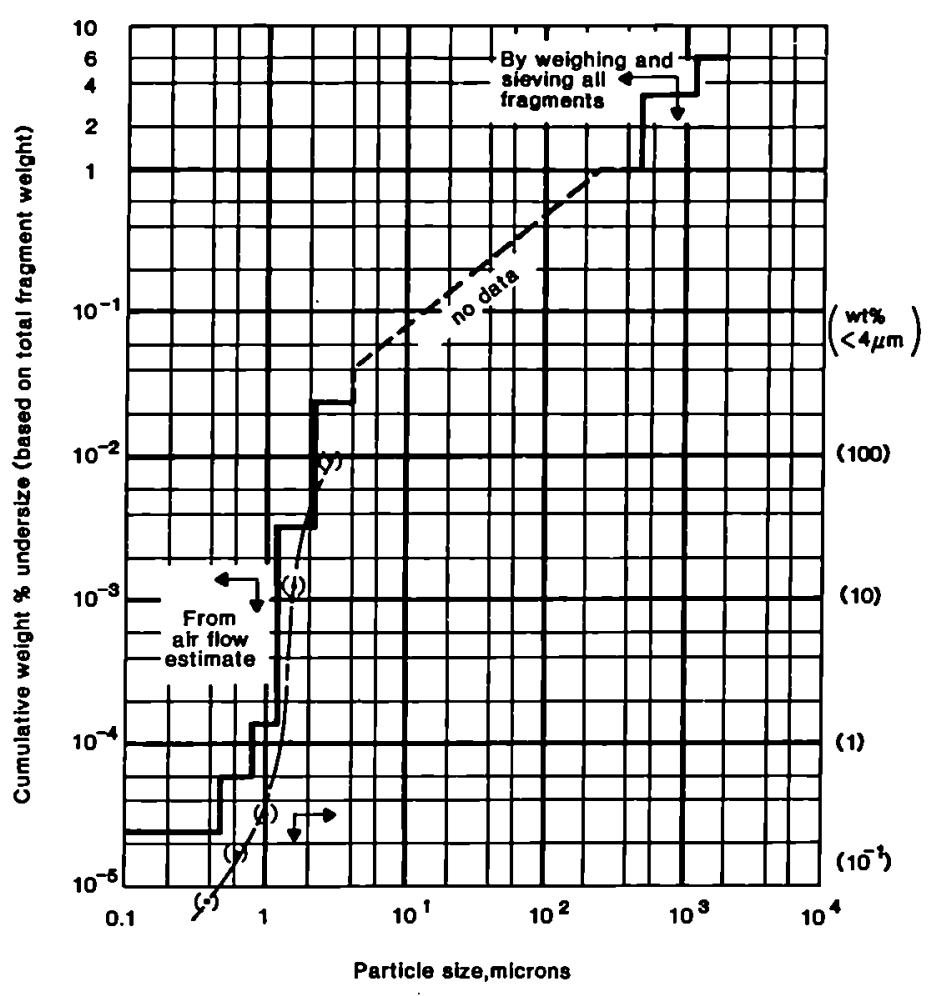

FIGURE 6. Ske distribution of fragments below $2 \mathrm{~mm}$ (experment 5)

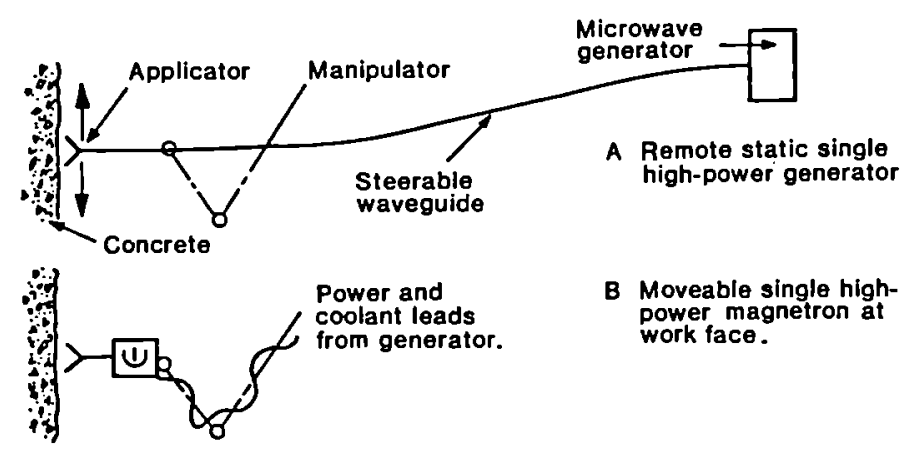

FIGURE 7. Main generator / magnetron options. 
EXPLOSIVE TECHNIQUES FOR THE DISMANTLING OF RADIOACTIVE CONCRETE STRUCTURES

\author{
FLEISCHER, C.C. \\ Taylor Woodrow Construction Limited \\ Taywood House, 345 Ruislip Road \\ Southall, Middlesex, UBI 2QX \\ United Kingdom \\ FREUND, H.U. \\ Battelle - Institute e.V, Am Romerhof 35 \\ D-6000 Frankfurt/Main 90 \\ Federal Republic of Germany
}

\begin{abstract}
The decomissioning of nuclear facilities calls for the controlled removal of activated and/or contaminated materials from the insides of blological shielding heavy reinforced or prestressed concrete structures whilst relying on the outer layers of non-activated or non-contaminated material to contain the activity. This paper describes development work being carrled out on the controlled use of explosives to cut and remove activated parts of nuclear facilities without impairing the overall structural integrity. The paper discusses the results obtained and concludes that the controlled usage of explosives offers a safe and favourable dismanting technique for the decomissioning of nuclear facilities.
\end{abstract}

1. INTRODUCTION

To Investigate the problems associated with the controlled removal of activated material from nuclear facilities, the Commission of European Communities (CEC) established, as part of its research programme on decomissioning such systems, research projects aimed at studying the various techniques which might be used for the removal of activated material (1). In Phase 1 of this research programme, Taylor Woodrow Construction (TWC), in consideration of a technique based on the controlled usage of explosives for sequential concrete layer stripping, demonstrated the feasibility of this technique using one approach $(2)$. During the same period, the Battelle - Institute e.v (BF) also demonstrated the feasibility of this approach using line charges (3) as opposed to the "point charges" used by TWC. The work carried out by both TWC and BF indicated that although general feasibility had been demonstrated, there were still a number of $18 s u e s$ to be addressed in order to bring the technique to the high level of efficiency that would be required for the decomissioning of a nuclear facility.

In order to bring the explosive cutting technique to the degree of control, with respect to safety and radiation protection, that would be needed in decommissioning nuclear facilities a Phase 2 progrante of work was prepared. This programme of work is aimed at complementing, expanding and optimising on the work undertaken in Phase 1 of the CEC programme on decominissioning.

This paper describes the development work carried in the Phase 2 programme of work and presents the conclusions arrived at. 


\section{PROGRAMME}

The Phase 2 programme of work was drawn up to include tests to investigate the following:

- Adjustment of blasting parameters to optimise for charge effects;

- Material and structural effects of buried charges;

- Drilling and boring techniques;

- Structural responses including mathematical modelling;

- Particle size distribution and debris scatter;

- Remote handling;

The detailed progranmes of work to cover the above were scheduled to be carried out by TWC and BF in close collaboration with each other. Wherever possible duplication of tests was eliminated although some experiments were repeated by TWC and BF for referencing and cross-checking purposes.

3. ADJUSTMENT OF BLASTING PARAMETERS

The following investigations were continued from preceding research efforts:

- optimising charge mass and depth of burial firing for single charges in concrete (2)

- influence of reinforcement layers on the concrete removal efficiency (3)

- effect of tamping (bore hole plugging) material on the efficiency of concrete removal

In addition borehole-pressure-time characteristics were measured for relevant charge masses to provide quantitative data. It was established that there is a minimum charge mass for a given depth of burial to achieve cratering. Exceeding this amount of explosive mass by a definable value does not result in further increase in removed concrete material. This is shown in Fig. 1a. It can be deduced that for optimum gain the reduced depth of burial for single bore hole blasting lies around $5 \mathrm{~cm} / \mathrm{g}^{1} / 3$. This is in agreement with scaled model experiments of TWC (2). A higher value has been found for sequential blasting. In the case of exact simultaneous blasting of an array of bore holes, it reaches an even higher value of about $7 \mathrm{~cm} / \mathrm{g}^{1}$.

A damage criterion, based on counting a weighted number of cracks on the surface of the test body has been established in order to quantitatively estimate the degree of damage inflicted. This is shown in Fig. 1b. The damage for low values of the reduced depth of burst, i.e. shallow burial of the explosive or overloading the bore hole, seems to reach a saturation value. The strength capacity of the remaining concrete structure does not depend on the cracking alone but quite significantly on the amount of steel reinforcement. 
The Influence of the steel reinforcement has been found to be complex. The lateral reinforcement together with the shear bars stiffens the structure and thus prevents the concrete fracturing. On the other hand the lateral reinforcement layers enhance lateral fracturing originating from the shock waves produced by the detonating charges. As a consequence, 10 to 30 reduced cratering is observed in single charge firing when comparing strongly reinforced concrete to low reinforcement concrete. However, no signiflcant effect was observed in exact simultanueous blasting of plane surfaces.

Tamping plugs serve to confine the high pressures produced by the detonating charges. The measured confinement times 110 between 0.5 and 2ms. Compared to cement tamping plugs, steel tarming plugs were observed to achieve longer confinement times which correlates to more efficient concrete removal. For practical reasons rapid bonding cement plugs were chosen in all subsequent experiments.

The pressure in the bore hole was measured with different types of carbon resistor pressure gauges. The fallure rate $18 \mathrm{high}$ due to the extreme dynamic states of pressure and temperature. In Fig. $2 \mathrm{a}$ the measured pressure-time curve is shown for a $22.5 \mathrm{~g}$ of explosive which corresponds to a reduced depth of burlal value of $5.2 \mathrm{~cm} / \mathrm{g}^{1} / \mathrm{s}$. The typical feature is a narrow high pressure peak (width<1 s) followed by a quasistatic lower pressure which decreases and lasts for the plug confinement time. The sensor in Fig.2a tracks only the first $8 \mathrm{~s}$, thereafter it is destroyed. From varlous measurements, idealized pressure-time curves were obtalned which are to be used as input data for theoretical analyses. In Fig $2 b$ this curve is shown for a $22.5 \mathrm{~g}$ charge with two different confinement times.

Bxact simultaneous firing versus sequential firing of a given array of 7 charges was investigated. It was found with near optimum loading $(22.5 \mathrm{~g}$ charges) that exact simultaneous firing gives better results due to the in-phase cumulative action of all charges. This fact holds for low and high reinforcement as can be seen from Table 1. In Fig. 3 the blasting performance with $1.4 \mathrm{~m}$ diameter - test bodies of low relnforcement 18 shown. A sumary of the results obtained are:

- Exact simultaneous blasting of an array of bore-hole charges results in more efficlent concrete removal than sequential blasting.

- The improvement is present both in cases of low reinforcement and of heavy reinforcement.

- A better surface smoothness is achleved for the crater formed in simultaneous blasting than in sequential blasting.

- Adequate timing accuracy in simultaneous firing of the charges can be achloved by pyrotechnical initiation, e.g. NONEL rather than by electric circult initiation thus avolding high power electric transient circultry in the vicinity of the explosive charges. 
Initial calculations have supported these findings. It was found that peak stress values may be higher by a factor of three in simultaneous firing as compared to sequential firing. This fact is considered to be the cause for the increased concrete removal efficiency, (based on the stress threshold concept for concrete fracturing).

\section{LINED CONCRETE STRUCTURES}

Typical pressure vessels and some biological shields will have steel liners on the inside surface of their containment structures to provide impermeable membranes. In the decomissioning of such structures it will be necessary to remove both liners and the activated parts of the containment structures beyond them. (In the preceding programme of work, it was assumed that any liner had already been removed.) To meet this requirement for liner removal, investigations have been carried out to determine the efficiency with which the liner and it's anchoring system may be debonded from the concrete by firing explosive charges buried in the concrete below and adjacent to the liner.

To achieve this objective within the confines of the current experimental progranme, a section through the biological shield was modelled by a circular concrete disc having a steel plate front face to represent the liner. This steel plate was anchored to the concrete disc in a similar manner to a steel lined concrete structure (see Fig 4).

Single charges were used in preliminary firings to investigate charge weight and depth of burial requirements to achieve optimum results. This was followed by tests in which multiple charges were fired to investigate the combined effects of the charges on the debonding and cratering characteristics. Post test investigations and subsequent sectioning of the model indicated that the liner and its anchoring system had been debonded from the concrete in the local areas of the charges, with considerable break up of the concrete beneath (see Fig 5). The selected charge separations were shown to be adequate in ensuring that liner removal within the area covered by the charges was complete and without leaving sections still anchored to the concrete.

It was concluded that the feasibility of using explosives to debond the liner and its anchoring system from the concrete and to break-up a layer of the concrete adjacent to the liner had been demonstrated.

\section{GEOMFIRICAL SHAPE OF STRUCTURE}

In the decommissioning of nuclear facilities, many occasions will arise when material will have to be removed from re-entrant corners on near penetrations, gas ducts, etc. Tests carried out have examined the feasibility of material removal from re-entrant corners (see Fig 6). The effect of charge separation from a re-entrant corner on the cratering characteristics has been investigated and shown to influence crater formation. It has been shown that a simultaneous firing of multiple charges produces desired results with optimum results being obtained when one charge is positioned into the re-entrant corner. Curvature of the structure has been shown to influence the cratering characteristics. It was found that for smaller diameter penetrations the structural shape gives rise to a passive restraint against the formation of a crater and results in smaller sized craters being produced in comparison with larger penetration results. 
It has been shown that it is feasible to remove material from the region of lined gas ducts although shock wave reflections can influence crater formation. Crater dimensions in the regions away from these ducts are only marginally affected by the presence of the ducts.

\section{GENERATED DUST FROM BLASTING}

Tests have been carried out to investigate the particle size distribution of the dust generated from a simulated cutting process involving the use of explosives on reinforced concrete targets. The test block was enclosed in a PVC tent to contain the generated dust and the entrained particulate was removed using suitable fans and ducting. Standardized experimental conditions were chosen which allowed representative measurement of both the total amount of dust below a given grain size and the particle size distribution to be assessed (Fig 7).

The test results indicated that small quantities of submicron particles were present in the airspace after the explosives were fired. Further investigation into the source of the submicron particles suggested that these may have originated mostly from the explosive used and not from the concrete material. The results obtained from subsequent firings of the explosives alone in air substantiated this. Tests were also carried out to investigate the effectiveness of dust suppression techniques. The use of an explosive water bag to produce a fine water spray mist, at the exact $t$ ime the dust is generated, (see Fig 8) has been shown to produce significant reduction in the total count of airborne particles in the airspace. Figure 9 shows typical comparisons between aerosol content with and without dust suppression methods, obtained from an Andersen Impactor. As can be seen the results show significant reductions in the aerosol content when the dust suppression method is used. Wetting the surface before firing was also shown to produce a reduction in the total amount of airborne particles in the airspace, although this was not as effective as the water spray mist technique.

\section{DRILLING OF BOREHOLES}

In the Phase 1 programe of work (2), it was demonstrated that shaped charges may be used to produce boreholes suitable for placing cratering charges. However the dimensions of the hole produced did not meet current borehole requirements for cratering charges. Theoretical work has been carried out in Phase 2 to modify the shaped charge design to establish a charge capable of producing a hole of the required dimensions. Shaped charges have been manufactured based on the modifled design and these have been used in field trials. The test results indicated a significant dependency of the formed borehole characteristics on the concrete material properties, resulting in the test borehole characteristics being smaller than predicted for a weaker concrete structure. The tests, however, demonstrated the feasibility of using theoretical techniques to modify shaped charge designs for specific borehole requirements. 
8. STRUCTURAL RESPONSE OF TEST BODY - LOCAL RESPONSE

A concrete model has been loaded with an idealised transient and the response of the structure analysed using a finite element formulation (ADINA) and a finite difference formulation (DYNA3D). The ADINA formulation considered a two dimensional exisymmetric simulation whilst the DYNA3D considered the problem as a plane strain calculation. Both analyses assumed a small layer of mesh elements surrounding the charge represented by "compaction" material models. The results from both analyses showed the formation of a crater having characteristics similar to the crater produced on the physical model during field trials. It is anticipated that with better definition of concrete properties for the high rates of loading experienced under blast loading the agreement between predicted and model test results could have been even better for both analytical methods.

9. GLOBAL STRUCTURAL RESPONSE

Associated tests which were performed in the German HDR facility (former power reactor) included concrete slabs $2 \mathrm{~m} \times 2 \mathrm{~m}$ mounted to the inner structural column (4). Extensive measurements of the building excitation were taken during these tests. The experimental work was supported by calculations of the building's structural response. Using the measured force-time characteristics, the agreement between experimental and calculated results was found to be satisfactory as can be seen in Table 2. Since the blast excitation shows a wide frequency spectrum with dominant frequencies of several $100 \mathrm{HZ}$, the measured acceleration spectra were filtered in order to be comparable with the calculated values and to demonstrate that within the damage relevant frequency range of 0 to about $100 \mathrm{HZ}$ no critical amplitudes were reached.

10. REMOTE CONTROLTED OPERATION

To reduce radiation exposure and occupational hazards during decomissioning tasks in nuclear facilities and to allow intervention at an early stage after shutdown, remotely controlled autonomous systems will be needed for nuclear facilities dismantling operations. The explosive cutting technique being investigated under this project will need such remotely controlled manipulation systems to be developed. As a first attempt in addressing this problem, desk top studies have been carried out to define the likely requirements such a system will need.

The general requirements of the remote controlled system are seen to include the following:-

a. To have sufficient reach and dexterity to position the various tool packages to any position within the biological shield.

b. To be adaptable for handling of drill/shaped charge, placing and tamping cratering charges and liner and reinforcement cutting. 
c. To be capable of introducing explosive charges in controlled quantities.

d. To have sufficlent payload capability to carry any of the various tool packages to any position within the blological shield.

e. To be capable of sensing the exact stand-off distance between tool and work face.

f. To be radiation resistant.

g. To be sufficiently robust to withstand shock and vibrations.

h. Treatment and transport of resulting debris.

Figure 10 illustrates a conceptual design in which some of the requirements listed above are catered for. This manipulator has a telescopic extend/contract main mast and arm sections together with rotational facilities. A similar concept has been developed with shoulder, elbow and wrist movements with associated rotate, bend and extend movements. Possible methods for charge hole preparation, charge placement and tamping, together with a viewing camera arrangement, have been considered.

11. CONCLUSIONS

On the basis of the results obtained from this programme of work, the following conclusions have been drawn.

a) Optimum charging is found to correspond to reduced depth of burial values of about $5 \mathrm{~cm} / \mathrm{g}^{1} / \mathrm{s}$ for single bore holes. In multiple firing of an array of charges a higher concrete removing efficiency was found for exact simultaneous compared to sequential firing. This holds for concrete with low and high stell reinforcement. Exact simultaneous firing can be achieved practically using the new Nonel pyrotechnic cord.

(b) Pressure-time curves for the explosively loaded bore hole have been measured. Also force-time characteristics were measured for the transient response imposed on a reactor facility building structure. These loading functions are to be used for calculations on concrete cratering and bullding vibratory response, respectively.

(c) Small explosive charges may be fired in a controlled manner to debond steel liner and 1ts anchoring system from the surrounding concrete and to break-up a layer of the concrete adjacent to the liner. Charge positions and numbers can be designed to remove material from re-entrant corners and adjacent to penetrations and gas ducts.

(d) Shaped charges with small explosive weights can be designed and used to produce bore holes sultable for placing cratering charges. The shaped charge designs can be modifled to produce charge holes of specifled dimensions. 
(e) Compared to other cutting techniques, only small volumes of dust are generated during cutting of concrete with explosives. The large majority of the aerosol content of this dust would appear to come from the explosive itself. Fine water spray mists can be used effectively to suppress the dust content within the enclosure.

(f) The feasibility of using a finite element and finite difference formulation to analyse the response of concrete to explosive loads have been demonstrated. It was concluded that the comparison with field trials can be improved with better definitions of concrete properties under high rates of loading.

(g) Measured and calculated building vibrations were found to be in good agreement for the German HDR reactor facility. Finite element models were used for the building structure.

\section{REFERENCES}

1. I. Ll. Davies, A. R. Gregory, H. G. Knackstedt. Demolition of concrete structures. Proceedings of first CEC conference on Decommissioning of Nuclear Power Plants. Luxembourg, 22-24 May 1984. Ref. EUR 9474

2. C. C. Fleischer. A study of explosive demolition techniques for heavy reinforced and prestressed concrete structures. CEC Report No. EUR 9862 EN, 1985.

3. H. U. Freund et al. Durchfuhrbarkeit der Zerlegung des Biologischen Schilds mittels Bohrlochsprengtechnik. Battelle - Bericht BI ev-R-65.036-4 (1983)

4. Forschungsvorhaben des BMFT KWA 3313 Sprengtechnische Zerlege verfahren, Versuche in der HDR-Anlage (1983-89) 
TABLE 1. Concrete removal efficiency and relative damage to the residual test body equal amount of explosive $\underline{7} \underline{x} \overline{22.5} \underline{\mathrm{g}} \equiv \underline{158}$ g applied to each test bodyl

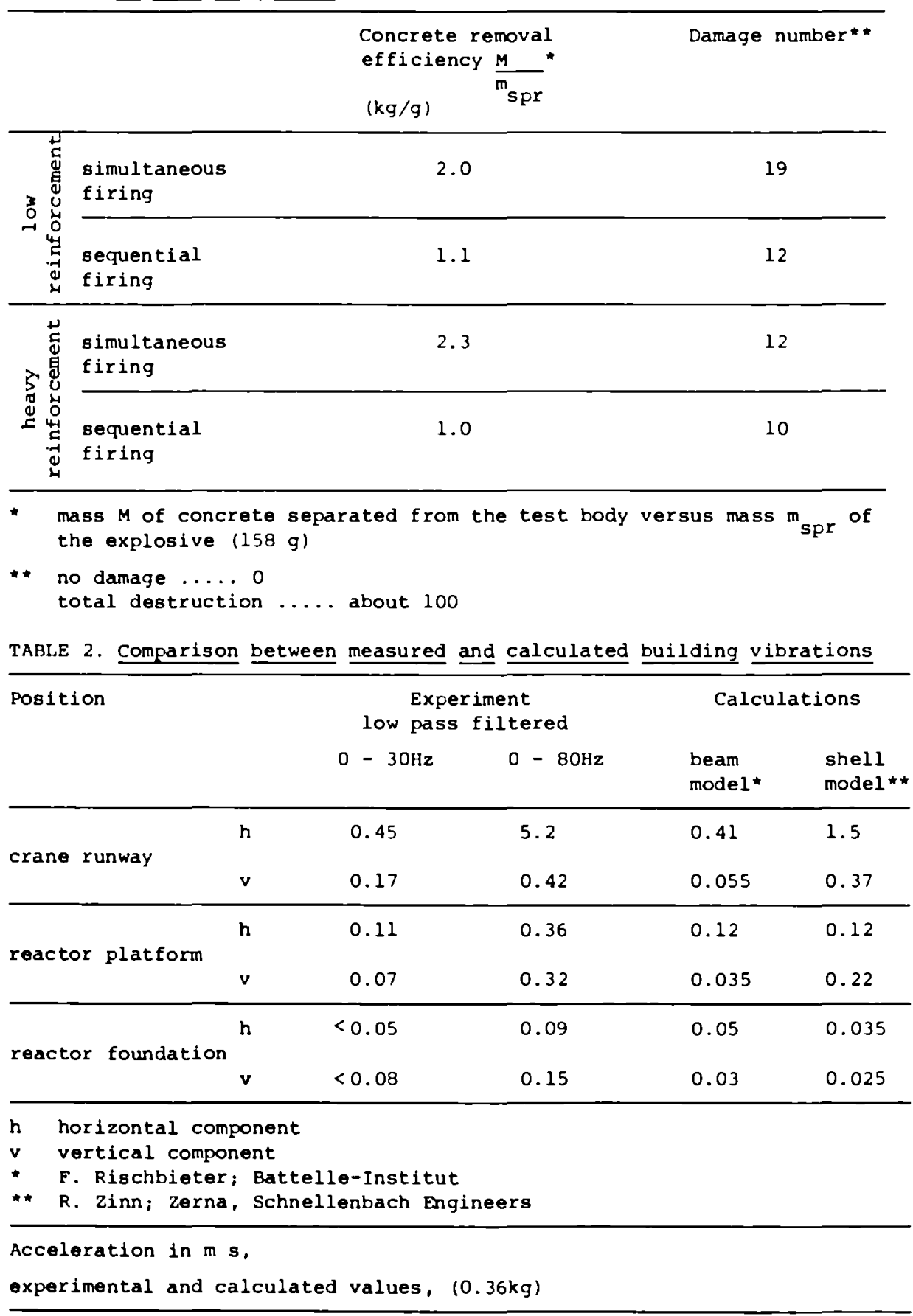



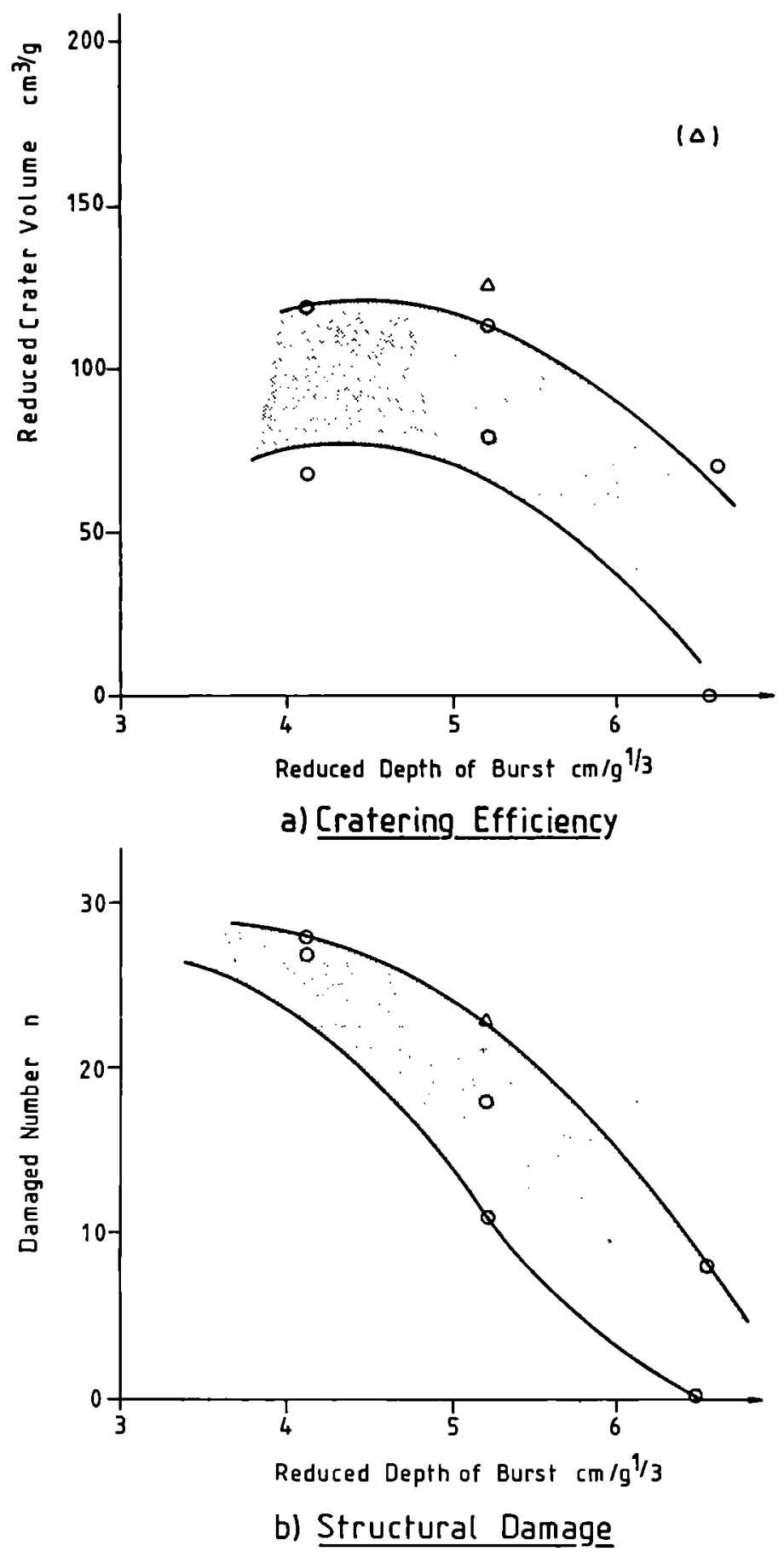

Figure 1 Influence of Specific Bore Hole Loading 


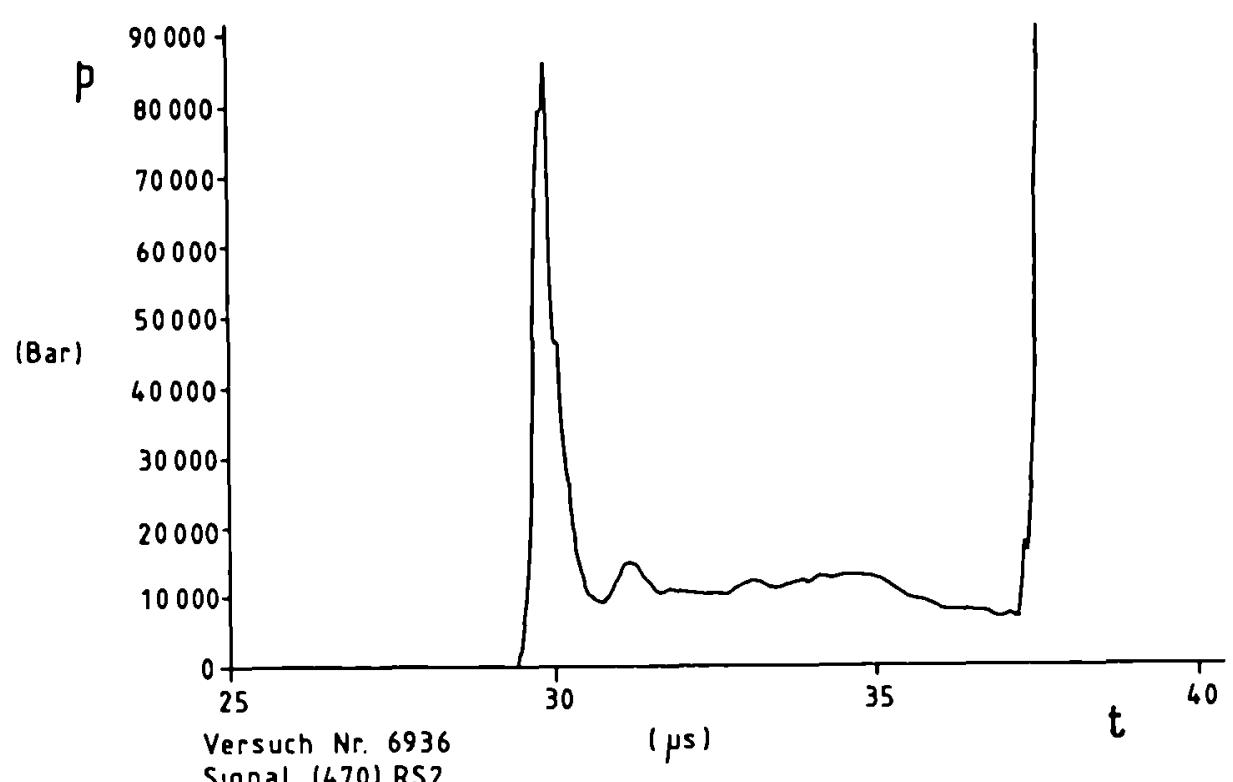

Signal (470) RS2

a) Experimental Results

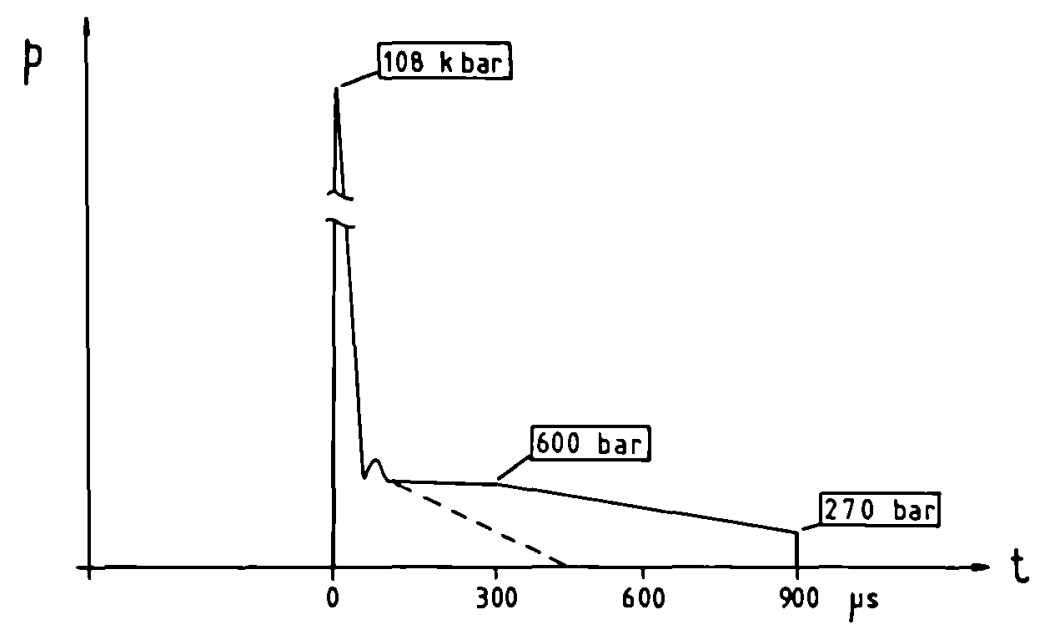

b) Idealised for Calculation of Concrete Material Response

Figure 2 Pressure - Time $(p-t)$ Curves for a Borehole Charge of $22.5 \mathrm{~g}$ 


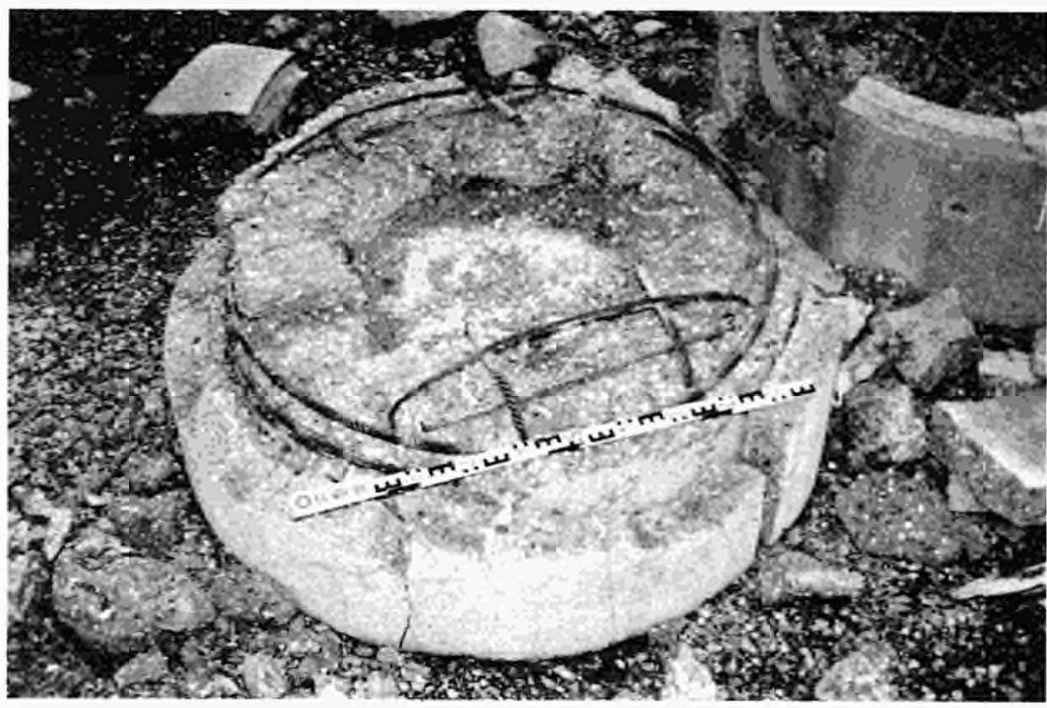

\section{a) Simultaneous Firing}

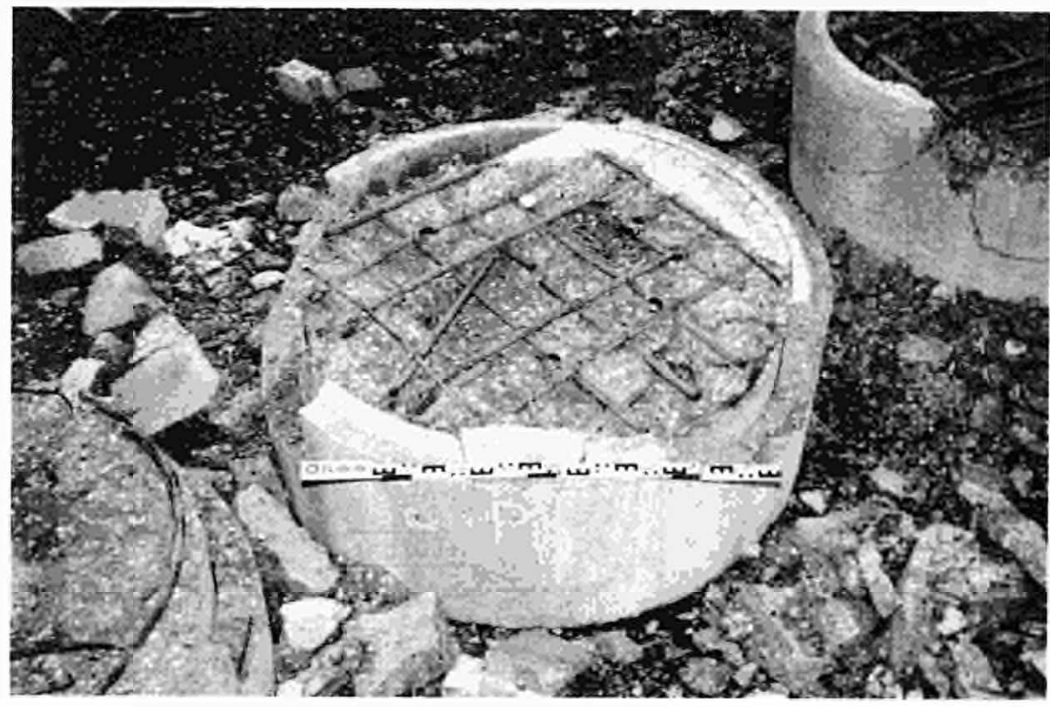

b) Sequential Firing

Figure 3 Model Discs after Blasting. Low Reinforcement 


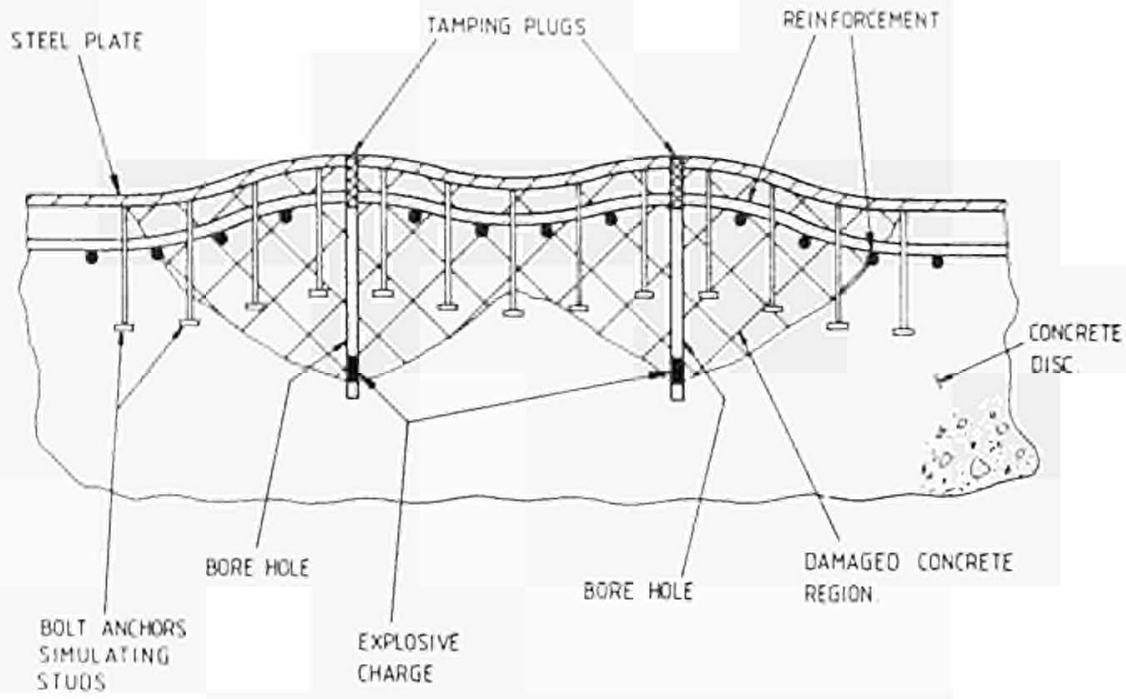

Fig. 4. Sketch of simulation of a steel lined concrete face after firing of multiple charges.

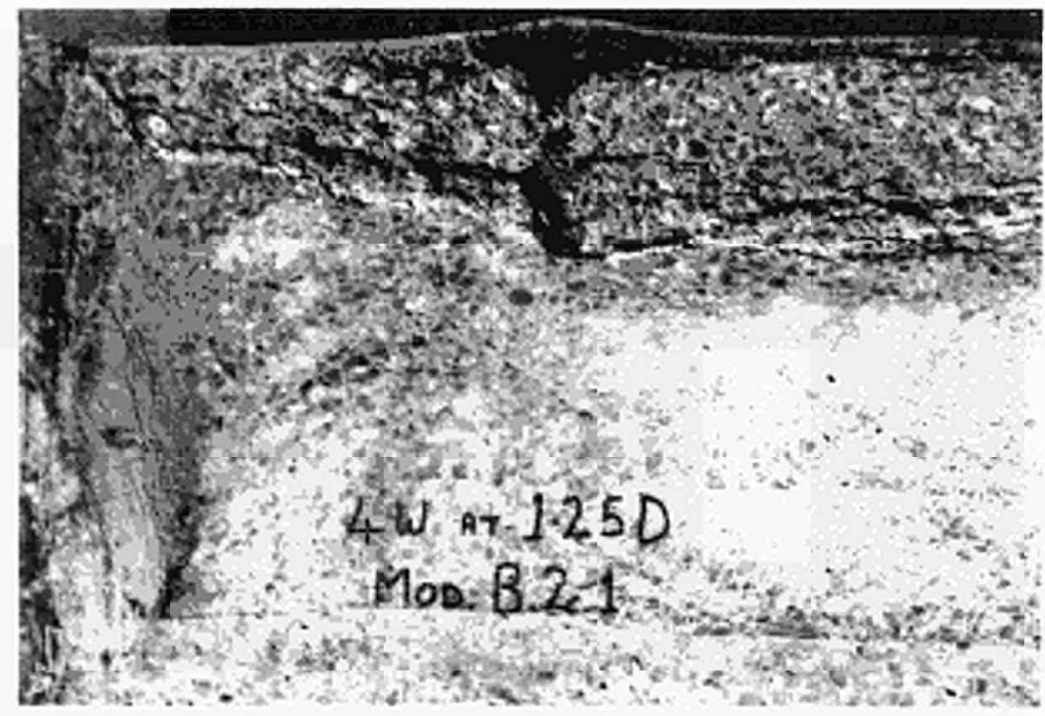

Figure 5 Example of Material Break-up Beneath Liner 


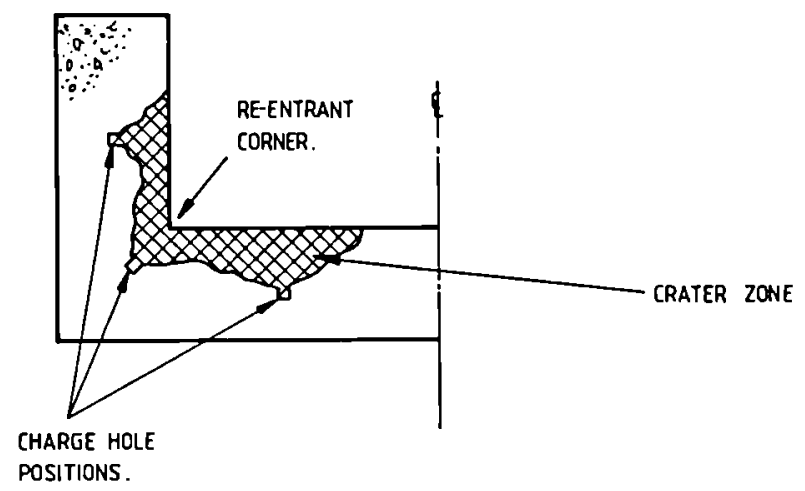

Fig. 6. Section showing removal of concrete from a re-entrant corner.

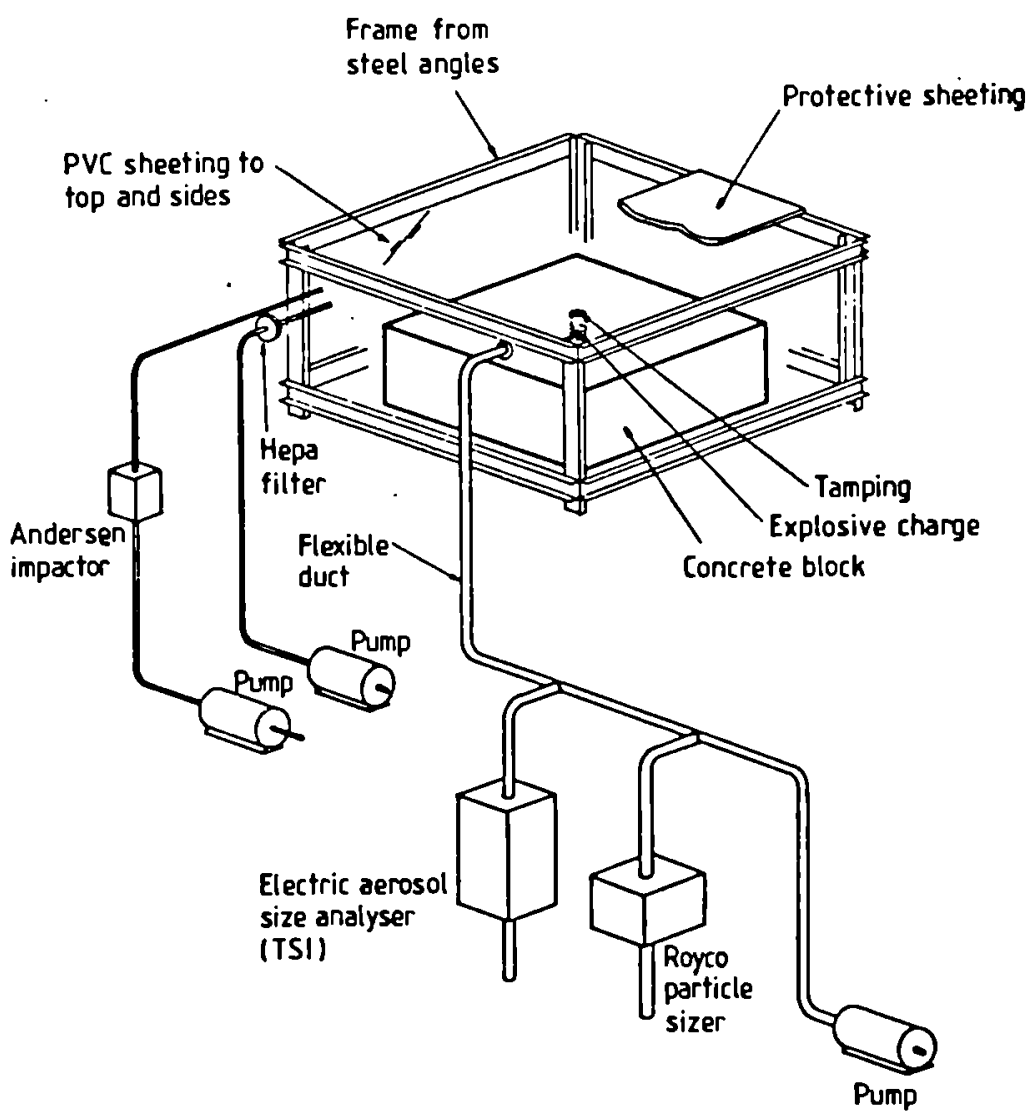

Figure 7 Apparatus for Particle Size Distribution Analysis 


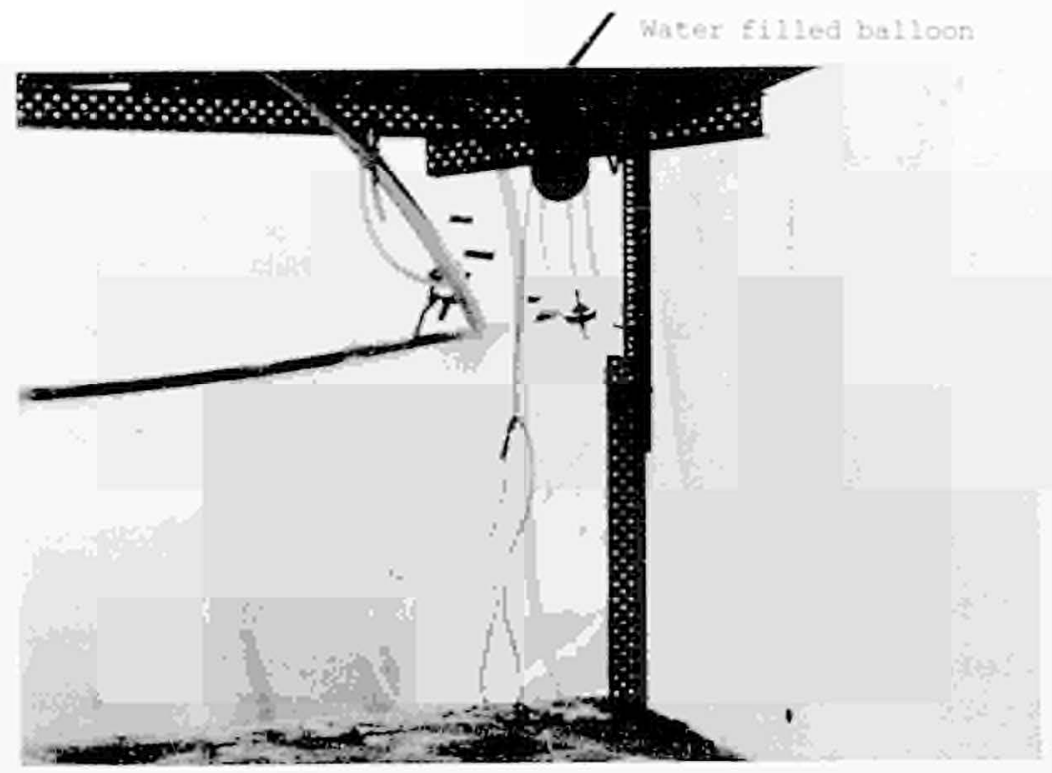

Figure 8 Experimental Arrangement for Water Spray Test

Cumulative withou:

undersize

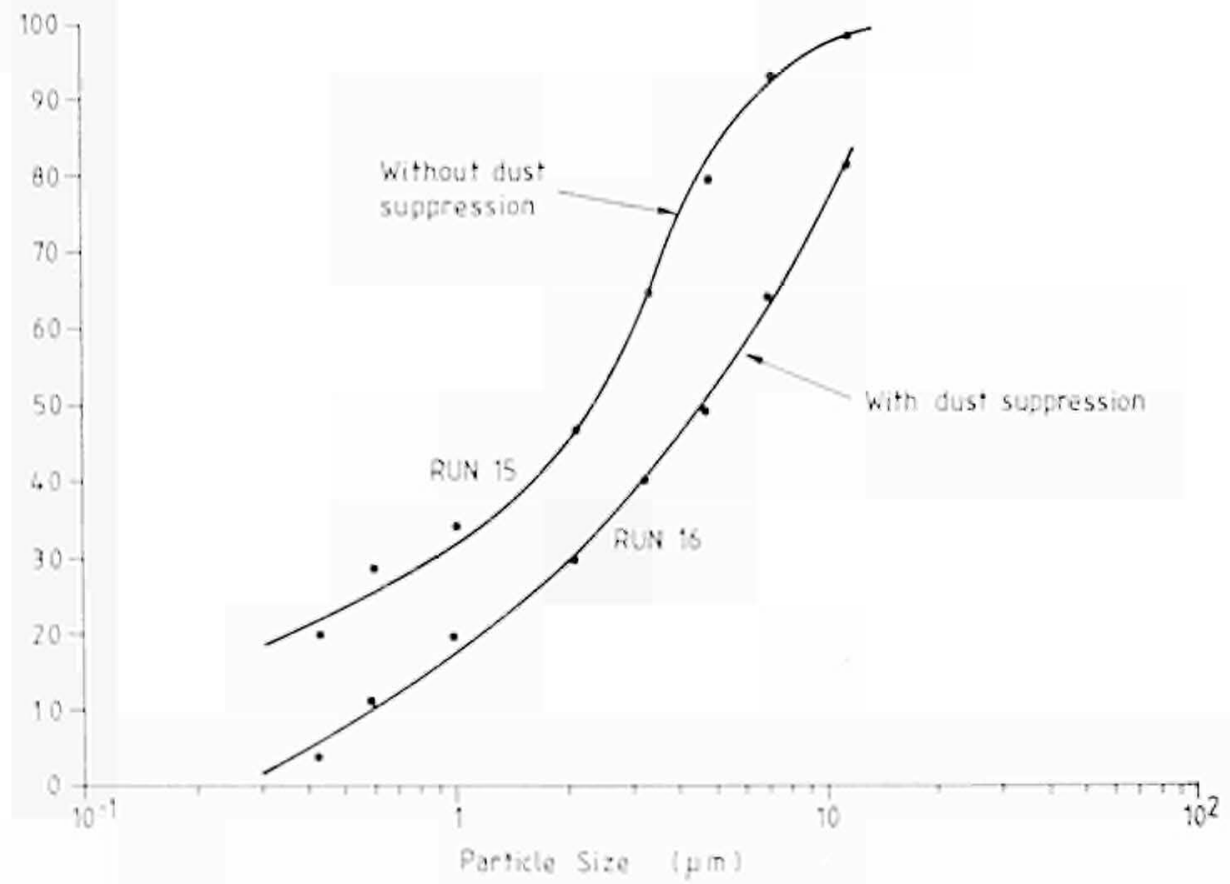

Figure 9 Size Distribution Data Measured by Andersen Impactor 

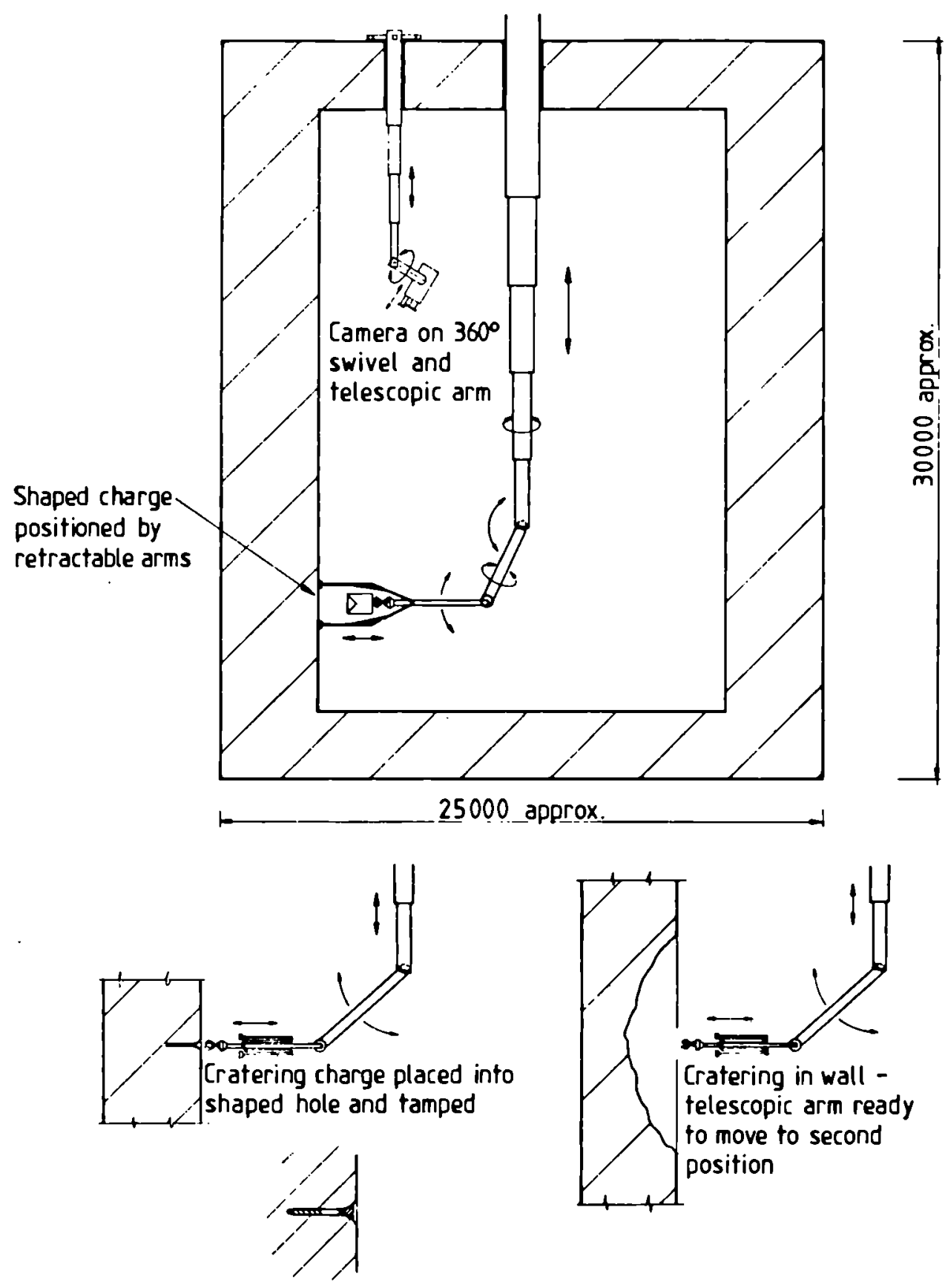

Figure 10 Conceptual Design for Remotel y Controlled Manipulator 


\section{DISCUSSION}

Question: L GILLON, SCK/CEN Mol - By what factor is the waste increased when the high-pressure water jet cutting method is used?

Answer: G PILOT, CEA-Saclay - During these cold tests, for which the cutting conditions were not necessarily the best as regards minimising the production of waste, the volume of material removed accounted for about 28 of the overall solid mass that had precipltated. The factor (solid phase) is thus 50. However, the question implied that there was an increase in radioactive waste, and account must be taken of the origin of the radioactivity in the equipment removed (irradiation, contamination), the level of activity, the isotopes concerned and the distribution of the activity in the waste, before it can be decided whether or not special treatment is required.

Comment: W STANG, KGB - I have complementary information concerning the final amount of secondary waste created by the electrochemical machining technique, after processing of the resulting iron-hydroxide sludge. This is $2 \mathrm{~kg}$ of dried waste mass for $1 \mathrm{~kg}$ of dissolved kerf material.

Comment: A CREGUT, CEA - In connection with Mr Gillon's question - It should be considered that the secondary waste generated consists of kerf material, deposited abrasives, recovered water and aerosols. This should amount to a total of some percents with respect to the initial value.

Comment: B GASC, Technicatome - The quantification of waste should be considered in relation to the initial waste (weight of the component to be dismantled). The total amount of generated secondary waste should be compared to the initial waste amount.

Question: J F JOUANNEAU, COMEX - With regard to the underwater experiments I received the impression that the storage vessel for the abrasives was not pressurised but open to atmospheric pressure. In my view a very important element is the difference in pressure that exists between the storage vessel for the abrasives and the mixing head. My question is the following: would pressurising the storage vessel itself improve cutting? In your experiments the hopper $1 \mathrm{~s}$ apparently not pressurised. Is there any polnt in increasing the pressure of the hopper so that the pressure differential $\Delta p$ between the hopper and the head is greater?

Answer: G MEIER, Unıversität Hannover - The abrasive cutting head produces a virtual vacuum. So the $\Delta p$ from the hopper to cutting nozzle is, in our case, about 1 bar. That is more than enough to transport pneumatically the abrasives to distances of $20 \mathrm{~m}$ or more. A $\Delta \mathrm{p}$ of 0.2 bar $1 \mathrm{~s}$ sufficient to create an adequate alr stream. Greater $\Delta p$ has therefore never been tested.

Question: K SPIES, RWTH Aachen - Have you measured the velocity differential between water and solid material at the end of the mixing head? If not, what difference do you assume there to be on the basis of your experiments?

Answer: G MEIER, Universität Hannover - Given the jet velocity of around $700 \mathrm{~m} / \mathrm{s}$ at $3000 \mathrm{bar}$ water pressure and several thousand particles per second, a velocity measurement is practically impossible. A number of calculations and literature data suggest that the particles reach a velocity of 30:-70 of the jet velocity. 
Question: H J C BOEKSCHOTEN, KEMA - What is the leakage of microwaves in your facility and what is its importance to the safety of the operations?

Answer: P F WACE, UKAEA-Oxon - Our leakage could not be measured, as the microwave horn is located inside the steel microwave cavity. Leakage is seen to be an important problem, which will be addressed when we design a more mobile horn for use in the open air. It is noted that in some nuclear applications, beta-gamma radiation shielding will also provide microwave shielding. In remote operations, the inverse square law will also greatly reduce distant doses.

\section{CONCLUSION}

Session $V$ has enabled a number of dismantling techniques to be reviewed which are not currently applied to radioactive components. Their assessment either at laboratory scale or at intermediate scale has been presented. The following conclusions can be drawn:

- The feasibility of electrochemical segmenting has been shown on small samples of ferritic steel clad by stainless steel. Further intermediate-scale demonstration testing will be needed to show its potential for application to an activated reactor pressure vessel.

- The experimental work on the feasibility of using miniaturised arc saws for internal cutting of tubes and pipes has led to the conclusion that such a technique has only a limited potential to actual scale work due mainly to the difficulty of access for high power input.

- Extensive testing of high pressure water jets with abrasives on numerous samples of steel and reinforced concrete, including as original tasks the determination of cutting effluents and the assessment of remote operation and maintenance, has resulted in the definition of optimum working parameters and in the confirmation of the appropriateness of this technique for nuclear dismantling.

- The feasibility of controlled blasting with high removal rates and preservation of the containment function of the outside wall has been demonstrated in numerous tests, as well as the removal of concrete layers by microwaves.

- An overview on various cutting tools for underwater dismantling identified their potential and limits concerning maximum wall thickness, maintenance problems and effluent generation rates.

- Extensive work has been presented on underwater cutting with plasma arc, including the determination of cutting effluents. It can be concluded that the plasma arc torch has found an additional wide application to nuclear components, but mainly for wall thicknesses below $100 \mathrm{mr}$.

As a general statement it can be concluded that a number of appropriate tools are presently available for the dismantling of nuclear components, although limited to a wall thickness of about $100 \mathrm{~mm}$, otherwise cutting is associated with a high effluent generation rate. For segmenting of reactor pressure vessels further work is needed; this will probably be oriented to combination tools.

W ZIMMERMANN, KfK 


\section{SESSION VI}

\section{RADIOACTIVITY MEASUREMENT METHODS}

CHAIRMAN: H J C BOEKSCHOTEN, KEMA,NL

SECRETARY: K PFLUGRAD, CEC 



\title{
DEVELOPMENT OF MEASURING SYSTEMS FOR CONTAMINATION MEASUREMENTS ON REGULARLY AND IRREGULARLY SHAPED SURFACES
}

B. HERRMANNS

Reaktorwartungsdıenst + Apparatebau GmbH, Jülıch, FRG

\begin{abstract}
Summary
In 1983/84, Reaktorwartungsdienst + Apparatebau $G m b H$ in Jülich $(R+A)$, in cooperation with Kernforschungsanlage Jülich GmbH (KfA), set itself the task of closing the gaps which existed in the contamination measuring technology representıng standard practice at the time.

Fundamental considerations led for the first time to the possibility of recording alpha and beta contaminations on surfaces with difficult accessibility such as pipes, angular sections etc. by measuring processes.

The laboratory models conceived by the KfA were to be optimized as regards efficiency, dimensions, performance characteristics and practically orlented handling and were to be developed further up to the production stage. Accordingly, particular attention was paid to the construction of a complete family of radiation counters for all conceivable applications including the basic electronic units and appropriate connection elements.
\end{abstract}

\section{INTRODUCTION}

The large number of commercial nuclear power stations, research reactors, radiation installations and medical diagnosis and therapy devices has led to a substantial increase in the problem of nuclear waste disposal. In view of the limited final dumping capacities for radioactive waste and the fact that some of the materials can be profitably recycled, efforts are being made to reduce the highest possible percentages of the overall stock of activity to the smallest possible volumes. This is underscored by the planned or approved concepts for the disposal of waste from commercially operated nuclear power stations. In addition to treatment and conditioning technologies, this also calls for a high standard measuring technology to detect the contaminated material. Although today a whole series of concelvable and practicable measuring methods exist and are ready for use, only a few of them are suitable for large-scale engineering applications. These comprise:

\section{I-Chamber}

only suitable for relatively high dose values

Gelger-müller radiation counter tubes

conditionally suitable, but the detector possesses a high energy dependence

gamma spectroscopy

extremely sensitive to gamma rays, but involves a very high measuring input

- proportional counting tube (gas purged)

highly sensitive to alpha and beta rays, satisfactorily sensitive to gamma rays, justifiable measuring input. 


\section{TERMS OF REFERENCE}

Within the framework of the EC Programme 'Decommissioning of Nuclear Installations', $R+A$ GmbH Jülich has set itself the task of substantially improving the possibility of alpha and beta contamination measurements with the aid of gas-purged proportional flow meters and of developing its new measuring system design up to the production stage. The basis for these planned improvements were the special geometries for proportional counting tubes presented by the KfA Jülich.

It frequently happens in practice that after decontamination of, for example, heat exchangers or condenser tubes, it must be ensured prior to their release that any residual activity still present on the outer and/or inner walls lies below the permissible boundary values. This presupposes that suitable measuring systems are available, in particular detectors with which the whole surface area in places of difficult accessibility can be scanned. In order to solve this measuring problem, detector geometries for achieving the highest possible counter efficiencies are required in order to be able to demonstrate even slight contaminations with justifiable measuring times.

In the Safety and Radiation Protection Department of Kernforschungsanlage Jülich $\mathrm{GmbH}$ special proportional flow meters were developed on a laboratory scale for a few typical measuring geometries. For contamination measurements in angles, concave moulds, sections, channels (i.e. for approximately plane surfaces) so-called flat counters were available, and for strongly concave curved surfaces, in vessels and tubes, so-called round counters were available on a laboratory scale. Taking the prototypes of the KfA Jülich as a basis, specific and necessary geometries were considered, i.e. it was examined what geometries occur most frequently in practice.

Although it was possible to carry out adequate contamination surveillance of slightly arched or plane surfaces with the proven standard commercial large area flow meter tubes operating in accordance with the proportional principle, this was not the case for tubes of relatively small diameters and for corners.

If we assume the presence of alpha-emitting nuclides too, the problem complex is multiplied again. On the grounds of the very low reach of the alpha particles in the range, recording is only possible at minimal distances between the subject to be measured and the counting tube.

\section{WORK PROGRAMME}

Right from the start the work programme for the development of this novel contamination measuring technique was divided into two phases.

In the first phase a basic electronic system was to be developed for the existing laboratory versions of the proportional counting tubes allowing essential parameters to be defined for the further proceedings. These investigations relating to practically oriented mechanical dimensions, optimization of the gas supply, response capability and energy dependence, demands to be made of a basic electronic system which might be in need of revision and not least practical handling trials were carried out at the nuclear power stations Gundremingen (A) and Brunsbüttel.

Parallel to this a technique was developed for spanning the detectors with the thinnest possible counting gas-tight windows and for producing a compact, gas-tight plug connection.

In the second phase the findings gained were to lead to solutions of the problem in detail which would allow the complete measuring system to be designed in such a manner that it would soon be ready for series production. This included a more advanced 'intelligent' design of the basic electronic 
system and the construction of a partially automated contamination measurement device for frequently occurring mechanical geometries and a detailed documentation of all the findings obtalned.

\section{PERFORMANCE OF THE WORK}

Parallel to the development of a pulse amplifier for the existing laboratory model of the proportional counting tubes, the demands to be made of a first generation basic electronic system were specified:

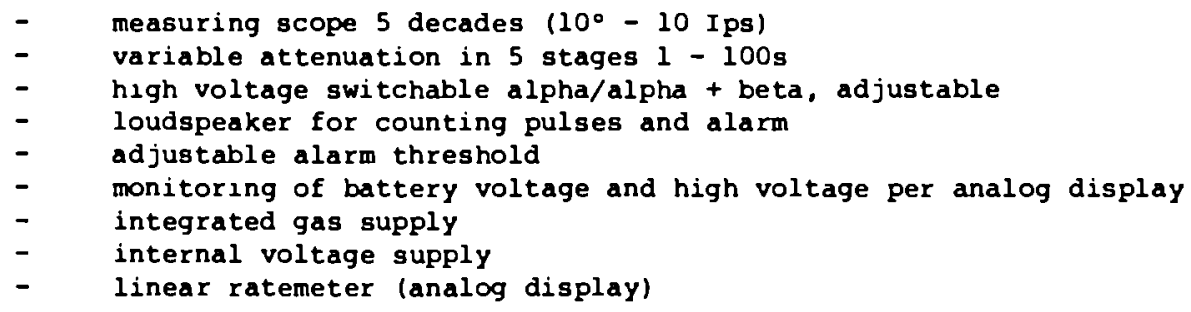

The operating panel of the basic unit largely corresponded to the standard form for such measuring technologies, but the compact integrated gas supply via a special cable which contained all the electrical conductors and the gas supply hoses and was also designed to be plugged in was an absolute innovation. Purging was performed by a push button switch. Major problems were posed for a long time by the tightness of the gas supply in the area of the plug connections, but these were finally solved with the aid of multiple bonding and double o-rings.

The electronic unit, which was available as a laboratory model at the end of 1984, operated on the principle of C-MOS (complementary metal oxide semiconductor) technology in order to achieve the lowest possible power loss, which was urgently necessary in view of the battery operation ( $2 \times 1.5 \mathrm{~V}$ monocells). Via a preamplifier and the range changeover switch a pulse stage with differing time constants was biased and passed to the measuring system designed as an integrator. The attenuation was achieved with the aid of RC elements connected before the measuring system.

The switchable alarm trip also worked with monoflop and was passed to the loudspeaker via the appropriate low level power amplifier.

In this version the high voltage component formed a stabilized LC converter. It functioned without any notable problems in the laboratory sector, but during routine operation at Grundremmingen and Brunsbüttel it was seen - on the basis of electromechanical stresses - that there was potential for improvement.

The first function tests with the laboratory models of the proportional counting tubes were conducted in about March 1985. Even during the run-up phase of the project countless considerations were made as regards the mechanical dimensions of the planned detector family, these being based essentially on the experience gained during the conversion phases of the 4 large HWR plants: Brünsbuttel, Isar I, Philippsburg I and mirgassen. It had been shown there that facilities for measuring contamination were urgently required for special pipelines. However, the laboratory models avallable up to this stage were only suitable to a limited extent since they were still too large and not yet sophisticated enough.

The smallest pipe diameters are generally assumed to be 20-30 mm - or 1" - as insıde diameter, in other words roughly condenser tubing. Smaller diameters which occur in practice (e.g. nominal widths of $10,12,15)$ can hardly be monitored by measurement. 
In the case of the aforementioned condenser tubing it will generally be possible to assume that this is free of internal contamination, but it should still be possible to measure this, if only in view of the greatest possible conventionally recyclable component.

These facts led to tests with a 15 mu proportional counting tube towards the end of 1984. With a protective cage this had an effective outer diameter of $22 \mathrm{~mm}$. As expected, the existing $30 \mathrm{~mm}$ counting tube proved to be expedient, especially for the large quantities of scaffolding material in the areas under surveillance. The staggering of the counting tube diameter from $30 \mathrm{~mm}$ to $40 \mathrm{~mm}$ did not appear justifiable in practice, so that the $40 \mathrm{~mm}$ diameter was to be expanded to become $50 \mathrm{~mm}$. The applications for which this was conceived were also scaffolding material and in addition pipes with an inner diameter in excess of 2 ".

special problems are presented, for example by sharp edges, corners etc., which can only be covered in the longitudinal direction with thin round counting tubes, but not in corners where tnree surfaces join together. The basic idea of an angular counting tube design with four active window faces (bottom, two sides, head end) was retained therefore, and this has still proved to be right today, especially with regard to the alpha measurements.

The assimilation of the working points necessary for a family of counting tubes was carried out in the second half of 1985 by means of appropriate adjustment of the counting wire strengths and the mechanical structure. Parallel to the revision of the basic electronic system a semi-automatic measuring device was also tested at the KfA Jülich. It contained an automatic intake and discharge of the items to be measured (piping) and a 'contaminated' and 'non-contaminated' separation, and provided information about possible detection boundaries as a function of the measuring speed.

At the start of 1987 the concept of the basic electronic system was subjected to a further thorough revision which produced new advantages. Thus the gas supply was made fully automatic, which meant considerable simplifications in practice. When the device is switched on a quick purge is activated, followed by permanent purging with a small gas flow rate which maintains the counting tube in a state of permanent operational readiness.

The display unit was converted to a digital display (LCD) on the grounds of practical considerations, which also results in substantial advantages in the handling of the unit.

\section{CONCLUSION}

A system of measuring contamination on regularly and irregularly shaped surfaces was developed to meet market requirements.

The counting family, comprising five differing gas flow proportional counting tubes, can be used fully compatibly in conjunction with the newly developed basic unit.

Enquiries from large numbers of German and foreign operators of nuclear power stations and other nuclear installations have confirmed this impressively.

$R+A$ possesses extensive know-how in the field of contamination measuring technology and in addition to the special proportional counting tubes presented in this paper, considers itself capable of solving practically any problem complex in this sector from virtually any form of counting tube right up to fully automatic measuring stations. 
A NEW METHOD FOR THE MNALYSIS OF SMALL PEARS IN GAMMA RAY SPECTRA, AND A DETECTOR SYSTEM FOR MONITORING GAMM ACTIVITY IN LAND AREAS

\title{
Anne D'Eer, Peter Gray, Christos Koutsoyannopoulos, Desmond Mac Mahen and Abdul Nabouls 1
}

Imperial College Reactor Centre, Ascot, England.

\begin{abstract}
The report describes a collection of techniques, based on a Bayestan approach, that can be used to make inferences about spectral peak area, and hence about source activity, for radionuclide spectra in general, and for the spectra of gamma emitting radionuclides in particular. Also described is a dataadaptive moving array detector system for monitoring gamma activity remaining on, or buried in, a land area from which a nuclear installation has been removed.
\end{abstract}

\section{ANALYSIS OF SMALL PEAKS IN GAMMA RAY SPECTRA}

This research is concerned with one aspect of radionuclide spectrometry: the construction of inferences about spectral peak area, and hence radionuclide activity, in those cases where spectral peaks are poorly defined, either because the area of the spectral peak is very small and its shape tends to be obscured by the statistical fluctuations due to background, or because there is a large degree of overlap between the spectral peak and one or more other spectral peaks. The techniques that have been developed can be applied to the analysis of radionuclide spectra in general, but particular attention has been paid to gamu-ray spectra for the purpose of providing concrete illustrations of the research results.

In particular, the objective of this research has been to develop a methodology for spectral analysis that

- provides accurate peak area uncertainties and confidence intervals for poorly defined spectral peaks;

- allows the precision with which spectral peak area can be estimated to be Increased;

- permits the peak centrold separation at which overlapping spectral peaks can be resolved to be decreased;

- extends the circumstances in which peak area detection 1 imits and hypothesis tests can be constructed to include those cases where a spectral peak overlaps with one or more other spectral peaks;

- offers a lower detection limit for radionuclide activity than that currently available with gross-counting;

- can be used to calculate the extent to which testing simultaneously for the presence of a number of radionuclides within a sample lowers the detection limit associated with each radionuclide;

- provides an empirical probabilistic model for the uncertainties in the peak shape and location parameters arising from calibration uncertainties and spectral drift in a spectrometry system;

can be used to increase the rate of convergence and the robustness of a peak-fitting algorithm.

\subsection{Mathodology for Peak-ritting}

\section{(1) Sample and response parameters}

The basis of the methodology is to divide all those parameters associated with the shape of a spectrum within a region of interest into two types: sample parameters, which depend on the characteristics of the sample being measured; and response parameters, which depend on the 
characteristics of the spectrometry aystem, and about which some information can be obtained by calibrating the spectrometry system.

For example, in the case of a Gaussian spectral peak on a linear background, the expected value of the count in the ith channel equals

$$
\left.x\left(2 \pi \sigma^{2}\right)^{-1 / 2 \operatorname{axp}}\left[-(1 / 2)(1-\mu)^{2} / \sigma^{2}\right)\right]+B+C(1-\mu)
$$

In this case the sample parameters are the peak area, A, the average background count per channel, B, and the background slope, $C$; and the response parameters are the peak centroid, $\mu$, and the Gaussian halfwidth, o. For more complicated peak shape functions, several other response parameters may be added, to account for peak-tailing for example; and another sample parameter may be added to permit a parabolic representation of the background within the region of interest.

\section{(2) Free and fixed parameter peak-fitting}

Information about the response parameters can be obtained by calibrating the spectrometry system. Most approaches to peak-fitting assume that a response parameter is either free or fixed - for example, the value of the peak centroid, $\mu$, can vary considerably in many spectrometry systems due to spectral drift, and hence it is almost always left free, while the value of the Gaussian half-width, $\sigma$, is less variable, and is sometimes held fixed at a value determined by calibrating the spectrometry system.

Neither of these approaches is satisfactory. For example, even when a spectrometry system is subject to a considerable degree of spectral drift, there is still a good deal of information available about where the peak centroid is likely to lie, and in the free parameter approach this valuable information is discarded; even when a spectrometry system is very stable, there will be some residual spectral drift or calibration uncertainty in the Gaussian half-width, so that if this parameter is held fixed the uncertainty in the estimate of the spectral peak area will be underestimated, particularly in the case of closely separated doublets.

\section{(3) Pre-acquisition Bayesian prior probability density function}

A probability density function provides an effective representation of the information that is known about the components of the response parameter vector: if the value of a parameter is very variable, the probability density function is broad, with a large standard deviation; if the value of a parameter is well known, the probability density function is highly concentrated, and the standard deviation is small. This approach accomodates both the free and fixed parameter representations, together with a large number of intermediate representations.

It is possible to construct a pie-acquisition Bayesian prior probability density function for any number of response parameters from calibration measurements of the spectrometry system. Because this density function is a joint density function, information is retained about the correlations between different response parameters, as well as information about their standard deviations.

The most likely values of the response parameters, the standard deviations in the response parameters, and the correlations between the response parameters are determined empirically from a collection of replicated spectra. Hence, the pre-acquisition Bayesian prior probability density function reflects the true variability in the spectrometry system in the intervals between system calibrations.

while it is possible to construct a pre-acquisition Bayesian prior probability density function for the response parameter vector associated with a particular spectral peak, it is more useful to first 
calibrate each component of the response parameter vector as a function of energy by means of a set of auxillary parameters and then to determine the pre-acquiation Bayeaian prior probability density function of the auxillary parameter vector.

The pre-acquisition Bayesian prior probability density function of the auxiliary parameters is very useful for fitting overlapping spectral peaks, when spectral instabllity makes the values of the peak centroids or Gaussian half-widths of the spectral peaks very uncertain: the very strong correlations between the auxiliary parameters ensures that even though the absolute values of the response parameters are 111 -defined, the relative values of the response parameters are defined with considerable precision. For example, the separation between the peak centroids will be known with considerable precision, as will the ratios of the Gaussian half-widths, effectively reducing the number of response parameters that must be varied by the peak-fitting algorithm in this case by a factor of two.

(4) Post-acquisition Bayesian prior probability density function

Further information about the response parameter vector can be obtained after the spectrum of interest has been recorded: one or more isolated, large-area spectral peaks within the spectrum of interest are selected (whether naturally occurring peaks, or artificial pulser peaks): the product of the likelihood function of these peaks and the pre-acquisition Bayesian prior probability density function is taken to form a post-acquisition Bayesian prior probability density function. Because the response parameter vector associated with an isolated, large-area spectral peak is defined with considerable precision, the components of the auxiliary parameter vector are defined with considerable precision, and hence the components of the response parameter vector associated with any other peak within the spectrum are also defined with considerable precision.

Hence, a post-acquisition Bayesian prior probability density function effectively converts an unstable spectrometry system into a stable spectrometry system. Because the response parameters associated with a small-area spectral peak or with a number of overlapping spectral peaks can now be very well defined, virtually all the peak-fitting effort is devoted to estimating the sample parameters. For example, to define three overlapping peaks within a region of interest might require 12 response parameters and 6 sample parameters. A free parameter approach would require the estimation of 18 parameters, whereas the Bayesian approach would require effectively only the estimation of 6 parameters.

(5) Posterior Bayesian probability density function

The likelihood function associated with one or more poorly defined spectral peaks is multiplied by the pre-acquisition for postacquisition) Bayesian prior probaoility density function of the auxiliary parameter vector to form a posterior Bayesian probability density function.

This function is then maximized to obtain an estimate of the sample parameter vector. From the posterior Bayesian probability density function, the marginal probability density function of any sample parameter, such as the spectral peak area, can be obtained, and this marginal density function can then be used to calculate the uncertainty in the parameter estimate and to calculate a Bayesian confidence interval for the parameter.

\subsection{Results}

(1) Estimation and confidence intervals

Some of the features of the Bayesian approach to peak-fitting have been demonstrated using simulated spectra. Spectra were generated using 
a pair of Gaussian peaks on a constant background. The expected value of the area of each peak was 500 counts, and tl:e expected value of the background count per channel was 100 counts. The spectra were fitted using a Gaussian peak shape and a linear background (three sample parameters and two response parameters).

Three sample spectra with three different peak centroid separations have been considered. With a peak centroid separation of 3.8 times the Gaussian half-width, the uncertainty in the area of each spectral peak equals 108 if a conventional free parameter approach to peak-fitting using maximum likelihood (or least squares) is used. with a reduced peak centroid separation of 2.2 times the Gaussian halfwidths, the uncertainty in the area of each spectral peak is still equal to $10 \%$ if the Bayesian approach to peak-fitting is used in the case of an unstable spectrometry system and a pre-acquisition Bayesian prior probability density function. At a still smaller peak centroid separation of 1.5 times the Gaussian half-width, the uncertainty in the area of each spectral peak is still equal to 108 if the Bayesian approach to peak-fitting is used with eithar a stable spectrometry system and a pre-acquisition Bayesian prior probability density function, or with an unstable spectrometry system and a post-acquisition Bayesian prior probability density function.

Simulations using the spectral doublet described above have been used to determine the percentage decrease in the uncertainty in spectral peak area that can be obtained by using Bayesian peak-fitting instead of free parameter maximum likelihood (or least squares) peak-fitting.

A decrease in the peak area uncertainty of the order of $(15-20)$ \% was found for an isolated spectral peak, and for doublets with peak centroid separations in the range of one to two times the Gaussian halfwidth, the decrease was found to be $80 \%$ for a pre-acquisition density and an unstable spectrometry system, and $85 \%$ for a pre-acquisition density and a stable spectrometry system (a similar percentage decrease should apply for a post-acquisition density and an unstable spectrometry system).

Simulations using the spectral doublet described above have been used to determine the percentage decrease in the peak centroid separation at which spectral peaks can be resolved. The components of a doublet were considered to be resolved at the $Y$ o level if the uncertainty in the area of each component was $Y 8$.

At the 108 level, the Bayesian approach of fers an improvement over the free parameter maximum likelihood (or least squares) approach of $43 \%$ in the case of a pre-acquisition density and an unstable spectrometry system, and $67 \%$ in the case of a pre-acquisition density and a stable spectrometry system. At the $50 \%$ level, the Bayesian approach offers an improvement over the free parameter maximum likelihood lor least squares) approach of $83 \%$ in the case of a pre-acquisition density and an unstable spectrometry system, and 918 in the case of a pre-acquisition density and a stable spectrometry system (the percentage improvement should be similar for a post-acquisition density and an unstable spectrometry system).

Bayesian statistics do not have the same solid foundation as frequentist statistics when it comes to modelling the measurement uncertainty in a quantity that is in reality a fixed constant, and not a random variable.

The validity of the Bayesian approach, in which information about the spectral peak area is represented by the probability distribution of a random variable, was confirmed for the spectral doublet described above. No evidence was found to suggest that the Bayesian approach is invalid at a peak centroid separation as small 0.5 times the Gausian half-width. At this peak centroid separation, the uncertainty in the area of each spectral peak is 228 .

Estimates of the sample and auxiliary (or response) parameters are obtained by estimating the maximum value of the posterior Bayesian 
probability density function. Because the value of the posterior Bayeaian probability density function is a non-linear function of the parameters, an 1terative algorithm 1s required to estimate the mode of the density function, and this algorithm needs an initial estimate for the value of each parameter.

In the case of the auxillary (or response) parameter vector, the mean of the pre-acquistion (or post-acquistion) Bayesian prior probability density function provides a good initial estimate.

In the case of the sample parameter vector, a good initial estimate can be obtained by using the general linear model. Because the expected values of the channel counts are a linear function of the ample parameters, an analytical solution could be obtained for the estimate of the sample parameter vector if the variances in the channel counts were known to within a sale factor, and if the auxiliary (or response) parameter vector was known without error.

Because of the manner in which the variances in the channel counts enter into the general inear model formula, the resulting estimate is very robust when the variances are replaced by sultable estimates. If the auxiliary (or response) parameter vector is estimated using a preacquisition density for a stable spectrometry system, or using a postacquistion density for an unstable spectrometry system, then the estimate of the auxillary (or response) parameter vector will also be known with considerable precision.

since the requirements of the general linear model are very nearly fulfilled, the resulting estimate of the sample parameter vector will be very close to that obtained from the mode of the posterior Bayesian probability density function. For some applications, the discrepancy between the two estimates will be sufficiently small so that the nonlinear iterative estimation procedure can be avolded altogether, and the sample parameters can be estimated with little more effort than that required to invert a positive definite matrix of dimension $n+m$, where $n$ 1s the number of parameters defining the background within the region of Interest (usually 2 or 3 ), and $m$ is the number of spectral peaks within the region of interest (one peak area parameter for each peak).

Maximization of the posterior Bayesian probability density function can be replaced by the minimization of a function which equals the conventional negative log-likelihood function (or sum of squares) plus an additional term. The presence of this additional term increases the time taken to evaluate the function on each step of the minimizing algorlthm, and would increase the time taken to fit a spectral peak if the number of iterations were unchanged.

Fitting of the spectral doublets at different peak centrold separations has shown that Bayesian peak-fitting takes more time than maximum likelihood (or least squares) peak-fitting when the peak centroids are far apart (an increase of 258-508), but less time when the peak centroids are close together (a decrease of 258-508).

The fact that Bayesian peak-fitting takes less time than maximum likelihood (or least squares) peak-fiting in certain circumstances supports the ldea that the Bayesian prior probability function acts as a penalty function during minimization, and reduces substantially the number of iterations required for the minimizing algorithm to converge by confining the auxiliary (or response) parameters to a small region of the parameter space. This behaviour greatly enhances the robustness and reliablifty of a minimization algorithm whenever spectral peaks are not well defined.

(2) Hypothesis tests and detection limits

An LR-Bayesian statistic for testing the hypothesis that the area of apectral peak is zero has been constructed using the likelihood ratio test statistic of the general linear model and a pre-acquisition (or post-acquisition) Bayesian prior probability density function. It has been shown that the probability distribution of this test statistic 
is adequately approximated by an F-distribution when the uncertainties in the components of the response parameter vector are small.

The power function of this statistic has been compared with the power function of the test statistic based on gross-counting. It has been shown by simulation that the use of the LR-Bayesian test statistic rather than the gross counting test statistic leads to a reduction in the source activity detection limit of 28 for a fixed counting time, and to a decrease in the counting time required to obtain a specified detection limit of $48 \%$.

The test statistic based on gross-counting can only be used in those cases where the spectral peak under test lies on a linear background. The LR-Bayesian test statistic can be used when the background under the test peak is non-linear, when, for example, the spectral peak under test overlaps with one or more other spectral peaks.

The best detection limit that can be obtained for a particular source when that source 13 one of a number of sources about which detection limits are required is substantially greater than the detection limit that could be obtained for that source if the source had been considered in isolation.

It has been shown that the counting time required to obtain a specific detection limit for a source when that source is one of a number of sources for which detection limits are required is increased by 418 for a group of two sources, by 998 for a group of five sources, and by 248 for a group of 50 sources. These results indicate that there is an important trade-off in the design of an experiment aimed at detecting weak sources of activity between the number of sources about which hypothesis tests are to be made and the detection limits than can be obtained for each source.

Conventional peak-search routines, as they run through a spectrum, effectively perform many hundreds of hypothesis tests when looking for the presence of spectral peaks. It does not seem from the literature that a peak area detection limit has been determined for these simultaneous (and correlated) hypothesis tests for specified values of the type I and II error probabilities (the significance level that is input to these routines seems to be no more than a parameter than can be adjusted to increase or decrease the number of peaks found by the peaksearch routine).

In principle, a statistically meaningful detection limit can be obtained for a peak-search routine by simulation, though it would be difficult, if not impractical, to determine the dependence of the detection limit on the large number of parameter combinations encountered in the case of a test peak that fell among other overlapping peaks. However, the results quoted above indicate that lower detection limits can be obtained if the experimentalist determines in advance those energies which are of specific relevance to the experiment, and then looks only for the corresponding peaks within the spectrum (a database of particle or photon energies can be used in conjunction with a Bayesian prior probability density function for the auxiliary parameters to pinpoint those locations within a spectrum where a hypothesis test should be made).

The approach adopted by some peak-search software in which a peak is first located and then a database is searched to see whether the peak represents a random statistical fluctuation in the background, or whether the peak corresponds to a known particle or photon energy wastes information; if information is available where a peak is likely to lie, then this information should be incorporated into the test statistic that is used to decide whether or not the peak is, in fact, present in the spectrum; the IR-Bayesian test statistic represents an extension of this principle to include all the response parameters associated with a spectral peak.

When a spectrometry system is very stable, the calculation of the LR-Bayesian test statistic is greatly simplified: randomization by the 
Bayesian prior probablitty density function can be avolded, and the 11 kelihood ratio test statistic can aimply be evaluated at the mean of the Bayesian prior probability density function.

\section{A DETECTOR SYSTEM FOR MONITORING GAMMA ACTIVITY IN LAND AREAS}

This section of the report is concerned with a category of measuring techniques - survey techniques - that seem 11 kely to play an important role in the task of establishing that the doses recelved by persons using a site, on which a nuclear facility once stood, do not oxceed statutory limits. The principal objective is to provide the information needed to determine the cost effectiveness of applying survey techniques to detect the presence of locallzed sources of gamma emitting radionuclides.

\subsection{Compariaon of ampling and survey techniquea}

In a sampling technique samples are collected at points on a ampling grid that covers the site, and are subsequently analysed for their radionuclide content off-site in a laboratory. The principal difficulty with sampling techniques is that it is not possible to estimate the activity at locations between the points on the sampling grid without making the assumption that the activity distribution changes slowly from one grid point to the next. Hence, with a sampling technique, a localized source of activity is unlikely to be detected. Consider, for example, a site of area 1 hectare and depth 1 metre. Suppose that high activity material, which, if collected together, would fill a cube of side $10 \mathrm{~cm}$, is scattered in some arbltrary manner throughout the site. If the probablilty of not detecting any high activity material in the samples collected from the site is to be no greater than 0.01 , then the number of samples required is of the order of 50,000,000. Clearly sampling techniques are likely to prove unacceptably costly unless they are carried out on a very modest scale.

In a survey technique measurements of radionuclide activity are made at a number of locations on a survey grid, covering the site, by an instrument located on the site. In princlple, survey techniques can be used to detect the emissions from active material located anywere in the site. The main limitation of survey techniques is the extent to which radionuclide emissions are absorbed by the site material before reaching the detector. The ranges of alpha and beta particles are too short to allow their detection by survey techniques, and in this case a sampling technique would be preferred. Gamma rays, however, do not have a defined range: the intensity of gamma rays decreases exponentially as they pass through matter. Hence, survey techniques can be used to detect gamma-omitting radionuclides irrespective of their locations within the site, though the counting time required will depend strongly on the intensity of the gamma ray source and on the distance, and material, between the source and the detector.

For activity distributions that vary slowly over a site, sampling techniques are probably the most usefil for alpha, beta and gamma omittors. For localized sources of gamma emitters, survey techniques are probably the most useful. For locallzed sources of alpha and beta emitters, an indirect approach, based on the statistical correlation between the locations of these emitters and gamma emitters, seems to be the only, if rather poor, detection method avallable.

\subsection{Adaptire moring array detactor (MND) systam}

An adaptive moving array detector (AMAD) system has been selected for a detalled examination in this work. The principal objective has been to determine the scanning time per unit area of the AMAD system as a function of the activity of a point gamma ray source, the energy of the emitted gamma rays, the depth of the source below the site surface and the composition of the site material. 
The survey equipment consists of a linear array of gamma ray detectors, mounted an equal distance apart in a detector harness, each detector being connected to its own multichannel analyser. The detector harness is mounted on a carrier vehicle. The site is divided into a number of parallel tracks. While scanning, the vehicle moves along a track at a constant speed; and the detector harness oscillates from side to side in a direction perpendicular to the vehicle motion.

All detectors start counting simultaneously, and continue counting for a fixed interval of time - the scan interval. At the end of this interval, the spectra recorded in the multichannel analysers are stored, the channels of each multichannel analyser are initialised to zero, and the counting cycle is repeated. The positions of the detectors at the start of the counting cycles define a set of grid points or reference points within a track.

At the end of a scan interval, a spectrum has been acquired by each multichannel analyser in the array. The collection of spectra acquired during a number of contiguous scan intervals will be referred to as a spectral block. To detect the presence of a localized gamma source in a particular region of the site, the collection of spectra in the spectral block corresponding to this region are analysed simultaneously.

The analysis of the spectra within a spectral block is performed immediately after the spectra needed to define the block have been acquired. If, following this analysis, it is clear the the probability of a localized gamma source being present in the region corresponding to the spectral block is very high or very low, then the carrier vehicle starts scanning the next region of the site. If, however, this probability is neither high nor low, so that there is some uncertainty as to whether or not a localized source is present, then the carrier vehicle reverses to the site location corresponding to the beginning of the spectral block just scanned. This region is then scanned again, and the two spectral blocks are combined. The probability that a localized source is present in the region is recalculated; if the probability is high or low the carrier vehicle moves on to the next region of the site; if the probability is neither high nor low the region is scanned once again. Hence, the control of the scanning procedure is data adaptive, in that the amount of time spent scanning a region of the site is dependent on the probability that the region contains a localized gammasource.

The optimum number of detectors to use in the array depends on the ratio of the capital cost of the survey equipment to the operating cost of the survey equipment throughout its lifetime. Adding more detectors to the array will increase the capital cost (by a substantial amount if germanium detectors are used). However, since the scanning time per unit area is inversely proportional to the number of detectors carried, and the operating costs are roughly proportional to the scanning time per unit area, increasing the number of detectors will lead to a substantial reduction in operating costs.

\subsection{Parameters of a typical AMAD system}

For further study of a typical AMAD system the following parameters have been chosen:-

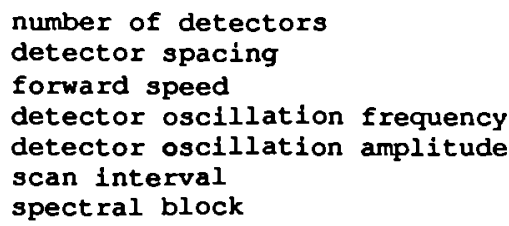

5

$25 \mathrm{~cm}$

$1 \mathrm{~cm} \mathrm{~s}^{-1}$

$0.08 \mathrm{~Hz}$

$12.5 \mathrm{~cm}$

25s

$125 \mathrm{~s}$ 
The spectrum from each detector accumulated in the 25 scan interval indicated will correspond to a land area of $25 \mathrm{~cm} \times 25 \mathrm{~cm}$. The spectral block will then consist of 5 spectra from each of the 5 detectors and wil correspond to a land area of $1.25 \mathrm{~m} \times 1.25 \mathrm{~m}$. It is this data which wil be tested for non-uniformity of the gamma ray activity distribution. The above parameters will allow the surveying of a 1 hectare area in a period of 9-10 days.

The type of gamma ray detector (NaI or Ge) and the method of spectral analysis (photopeak or total spectrum counts) to be used have been given careful consideration. Because of the degradation of the gamma ray spectrum resulting from multiple Compton scattering of gamma rays passing through soil, it was found that, for sources deeper than 35 $\mathrm{cm}$ below the soll surface the best detection limits would be obtained by recording total spectrum counts with NaI detectors. However, for sources closer than $35 \mathrm{~cm}$ to the soil surface better detection limits would be achievable by recording photopeak counts in a Ge solid state detector. Since only one detector type will be used in practice, it is proposed to use high efficiency Ge detectors and to record both individual photopeak counts and total spectrum counts simultaneously. This will allow the detection of sources below $35 \mathrm{~cm}$ and Ge detectors have the added advantage of permitting the identification of discovered radionuclides.

\section{Calculation of detection limits}

In order to determine radioactivity detection limits as a function of depth for the AMAD system with parameters indicated above, it was necessary to determine a typical terrestrial background spectrum and to measure gamma ray attenuation coefflcients in various soil types and as functions of gamma ray energy and of soil molsture content. These measurements were carried out at silwood Park, Ascot, and full details and results will appear in the final report of the project.

The measured terrestrial background radiation and the gamma ray attenuation coefficients were used as input for detection limit calculations. These calculations were carried out in two ways; the flrst method made use of a standardized normal distribution function, while the second method involved maximum likelihood parameter fitting and likelihood ratio hypothesis testing. The detection limits calculated in each case were such that the probability of detection would be 958 ,

For lllustrative purposes the detection limits have been calculated for the $662 \mathrm{keV}$ gamma rays of ${ }^{137} \mathrm{Cs}$, assuming a typical soil linear attenuation coefficient at this energy of $15 \mathrm{~m}^{-1}$. Table I shows $137 \mathrm{Cs}$ detection limits as a function of depth below the soil surface, determined using likelihood ratio techniques. The figures shown relate to an AMAD system with the typical parameters listed in section 2.3 above. Detection limits are proportional to the square root of the vehicle speed, so that detection limits for longer or shorter survey times may be easily determined from the d:ata of Table I.

\section{5 rield test}

In order to test the validity of the calculations and statistical analyses under realistic conditions a $130 \mathrm{MBq}{ }^{137} \mathrm{Cs}$ source was placed at a depth of $0.4 \mathrm{~m}$ below the surface of a site at silwood park. A germanium detector was used to record spectra for 1 minute at 25 points on the soll surface corresponding to a $1.25 \mathrm{~m} \times 1.25 \mathrm{~m}$ spectral block area. Analysis of the total counts in each spectrum revealed clearly the existence of the source with a confidence limit greater than 958 . The maximum peak-to-Compton ratio observed allowed the depth to be est Imated as $0.36 \mathrm{~m}$, and the source activity estimated from the 3dimensional Gaussian fit to the spectral block data was $90 \mathrm{MBq}$. 
Having located a source within a particular spectral block, it would, of course, be possible for the AMAD system to relocate in the position of maximum count rate and to accumulate a spectrum over a longer period to enable more precise estimates of source depth and activity to be made.

\subsection{Tuture development}

Plans are now being drawn up for a project covering the design, construction and testing of a prototype AMAD system.

\section{TABLE I}

Detection limits for a typical AMAD system for the gamma rays $(662 \mathrm{keV})$ of ${ }^{137} \mathrm{Cs}$

\begin{tabular}{|l|l|}
\hline Source Depth & Detection Limit \\
\hline $0.1 \mathrm{~m}$ & $95 \mathrm{kBq}$ \\
$0.5 \mathrm{~m}$ & $5.0 \mathrm{MBq}$ \\
$1.0 \mathrm{~m}$ & $1.9 \mathrm{GBq}$ \\
$2.0 \mathrm{~m}$ & $1.5 \times 1015 \mathrm{~Bq}$ \\
$3.0 \mathrm{~m}$ & $2.5 \times 1021 \mathrm{~Bq}$ \\
\hline
\end{tabular}




\title{
OPTIMIZATION OF MEASUREMENT TECHNIQUES FOR VERY LOW LEVEL RADIOACTIVE WASTE MATERIAL
}

\author{
HOFFMANN R., LEIDENBERGER $B$.
}

Siemens Aktiengesellschaft, Bereich Energieerzeugung KWU E143, Postfach 3220, D-8520 Erlangen

\section{ABSTRACT}

In order to optimize measurements of waste material, relative radiotoxicities of waste nuclides were defined. It was found that the hard to detect nuclides like $\mathrm{Pe} \mathrm{55,Ni} 59$, Ni 63 are of minor radiological relevance and that standard beta or gamma measurements suffice if alpha contamination can be excluded.

Por the determination of suitability for release measurements, 20 different detectors were used in test measurements covering 5 typical geometries of contaminated waste material, the contamination consisting of standards of $C 14$. Pm 147, Co 60, Cs 137, Sr 90/Y $90 \mathrm{Cr} 51$ and Am 241.

It was found that in most geometries proportional counters are adequate for release measurements while for the detection of alpha radiation small detectors like surface barrier detectors, photodiodes or GM counters are needed in difficult geometries.

\section{INTRODUCTION}

In decommissioning nuclear installations, various types of waste materials which are either free of activity or activated/contaminated have to be released. Unrestricted use of these materials may be permitted if the residual activity concentrations are below limits set by the licensing authority with regard to the radiological risk. In order to prove compliance with these limits, residual activity concentrations have to be measured on every single piece of material, which can be very complicated and time-consuming. The derivation of dependable results is difficult because of the non-ideal conditions usually prevaling and the high degree of precision required.

It was the aim of this project to derive a measurement strategy which takes into account the waste composition as well as the radiological impact of the waste nuclides, and which optimizes the eligible measurement techniques with respect to accuracy, time and cost.

\section{BOUNDARY CONDITIONS FOR RELEASE MEASUREMENT OF WASTE MATERIAL}

\subsection{ACTIVITY INVENTORIES AND NUCLIDE ABUNDANCES}

Extensive compilations of activity inventories of different waste materials have been published, e.g. $\mid 1,21$.

Table I shows the most prominent nuclides of NPP waste material with half-lives greater 300 days along with the principal radiation emitted (alpha, beta, gamma, X-ray; beta-radiation has been divided up into radiation of medium to high endpoint energy and low endpoint energy LE (smaller $300 \mathrm{keV}$ )) because of differing applicable measure- 
ment techniques.

A few examples of relative abundances in different NPP wastes are shown in Table II. Except for activated steel waste, Co 60 and Cs 137 alone make up for $>70 z$ of the volume - or surface activity.

\subsection{ACTIVITY CONCENTRATION LIMITS (EXEMPTION LIMITS)}

According to the German Strahlenschutzverordnung (StrlschV), there are two limits applicable for the release of waste materials: - surface contamination limit

- mass related activity concentration limit. The surface contamination is limited to either $0,037 \mathrm{~Bq} / \mathrm{cm}^{2}$ or $0,37 \mathrm{~Bq} / \mathrm{cm}^{2}$ depending on classes of nuclides (socalled limits of unrestricted use (LUU) classes, ranging from $3,7 \mathrm{E} 3 \mathrm{~Bq}$ to $3,7 \mathrm{E} 6 \mathrm{~Bq}$ ). The mass related activity concentration limit is based on the LUU classes as well: $1 \mathrm{E}-4 \times \mathrm{LUU} / \mathrm{g}$.

For release of waste material, both limits which can be - and have been - modified by the licensing authorities must not be exceeded.

\subsection{RELATIVE RADIOTOXICITIES}

The two limits defined above are based on the 4 LUU classes.

These classes do not necessarily reflect the radiotoxicity of a particular nuclide. Therefore, the annual limits of inhalation respective ingestion (ALI) that reflect the toxicity of a particular nuclide in a much better approximation have been taken as a base for comparing the waste nuclides.

By normalizing these ALI or the gamma dose factors DF for external irradiation to Co 60 as the most prominent nuclide in most waste categories and to the two different activity concentration limits as defined in 2.2, we obtain measures of relative radiotoxicity RR (Table I) of nuclides.

The relative radiotoxicities (RR) are normalized to Co 60 and the contamination limit (Table I) by:

$R R=\frac{A L I \text { (Co 60) }}{A L I \text { (nuclide) }} \quad$ resp. $\frac{D F \text { (nuclide) }}{D F(C 060) F}$

with

$F$ = weighting factor acc. to StrlSchV

- 10 for alpha-emitting nuclides with LUU $=3,7 \mathrm{E} 3 \mathrm{~Bq}$

- 1 for all other nuclides.

The RR based on the mass activity concentration limits ( 1 E-4 * $L U U / g$ ) are calculated by:

LUU (nuclide) • ALI (Co 60)

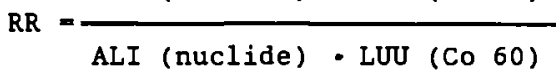

LUU (nucl.) . DF (nucl.)

resp. $\frac{\text { LUU (Co 60) . DF (Co 60) }}{\text { LUU }}$

As can readily be seen, the $R R$ of most of the nuclides are overestimated, particulary $\mathrm{H} 3, \mathrm{Ca} 45$, Ni 59, Ni 63, Tc 99, Cs 135. The actinides, on the other hand, are underestimated in their radiotoxicity. 
of course, these considerations are valid only if the paths of inhalation/ingestion that have been assumed are realistic. In many cases, an incorporation of waste nuclides will be highly improbable so that direct irradiation will be the only possible health hazard (Table I. fifth column).

Since the radiotoxicities of most waste nuclides other than the actinides are overestimated in regard to predominant Co 60 , the measurement efficiency of many of the hard-to-detect low energy beta or electron capture nuclides like $\mathrm{B} 3, \mathrm{C} 14, \mathrm{Ca} 45, \mathrm{Ni} 59, \mathrm{Ni} 63$, Tc 99, Cs 135 respective the accuracy of their assessment will only be of secondary interest if these nuclides make up only a minor part of the nuclide composition and if radiation protection aspects like radiotoxicities are taken into consideration by the licensing authorities. On the other hand, if alpha-activities are present in waste in nonnegligible amounts and there is some possibility of intake, the limits set for unrestricted release should be lowered in regard to those of the beta/gama-enitters.

\subsection{ABUNDANCE WEIGHTED RELATIVE RADIOTOXICITIES}

Combination of RR with nuclide abundances yields a measure of overall toxicity of a particular waste material as well as a measure of the relative importance of sufficient detection efficiencies for certain nuclides.

Table II shows examples of different NPP waste categories, the nuclide abundances and abundance weighted relative radiotoxicities for inhalation. It follows that for the waste category compressible raw waste, more than $90 z$ of the radiologically significant impact of the nuclides present in that waste will be covered by a standard gammaor beta measurement.

Even in activated steel waste where more than $80 \mathrm{Z}$ of the activity is not directly measurable (Fe 55, Ni 59, Ni 63), about $90 \mathrm{I}$ of the radiological impact will be covered by standard gamma- or beta mea surements.

Only when alpha activity is not negligible (in the order of $10^{-3}$ of gross activity). pure gamma - or beta measurements will miss about 50 of the radiological relevance, if intake by inhalation cannot altogether be excluded.

\subsection{CONSEQUENCES TO MEASUREMENT STRATEGY}

Radioactive waste material can be classifled according to its activity distribution: (surface)-contaminated and (volume)-activated/ contaminated. Direct release measurements of activated material cannot as readily be standardized as those of contaminated material because of the widely differing geometry of the waste material and because of unknown activity inhomogeneities within the volume as well as selfabsorption effects. The only reliable way to assess the activity and nuclide content of volume activated/contaminated waste is to take samples and analyse them by standard laboratory methods. These measurement techniques can be very complex and time consuming and therefore cannot be employed as standard release measurement techniques.

Contamination measurements, on the other hand, are relatively simple and straightforward, their only difficulty being the wide range of waste geometries and the strong dependency of detector efficiency on the energy and type of radiation. Because of the radiological considerations above, only standard beta and gamma-measurements as 
well as direct measurement of alpha-contamination will be considered.

\section{EXPERIMENTAL WORK}

\subsection{SELECTION OF DETECTORS}

Table III lists the different detectors that were used in the test measurements. Included are standard large area proportional counters, Geiger Muller counters, special proportional counters with side windows, a plastic scintillator, NaI(Tl) gamma detectors, surface barrier detectors and large area photodiodes.

\subsection{SELECTION OF GEOMETRIES}

Geometries examined were standard plane area, tube and corner/edge. All other types can be approximated by these three. As for tube geometry, inside and outside contamination as well as measurement inside and outside of the tubes or on tubes cut in halves were considered.

For most of the measurements, detector efficiencies have been obtained for different detector-source distances, namely "in contact" (as close as possible without touching), 1,3 and $5 \mathrm{~cm}$, in accordance with practical requirements.

\subsection{SELECTION OF STANDARDS}

The activity standards used in the test measurements had to fulfill three conditions:

1) The nuclide spectrum should approximate that of real waste:

- C 14 and PIn 147 as LE beta emitters

- Cs 137 and Co 60 as medium energy beta and gamma emitters

- Sr $90 / Y 90$ as high energy beta emitter

- Cr 51 as pure gamma emitter

- Am 241 as alpha emitter

2) The carrier material should approximate the self-absorption behaviour of typical waste material: chromatographic paper was used for standard beta/gamma emitters, chromatographic paper, paper filter, glass fibre filter, writing paper, textile tissue for Am 241 .

3) The standards should be easily fabricated in the selected geometrical forms.

For testing detectors with small sensitive entrance areas, a homogeneous distribution of activity on the standards is required. Dropping radioactive solution on the carrier material proved - by autoradiography - to be the most appropriate way.

\subsection{MEASUREMENTS AND RESULTS}

Detector efficiencies and laboratory background count rates were measured with the detector-geometry combinations shown in Table III. From these data the detection limits in $\mathrm{Bq} / \mathrm{cm}^{2}$ ( 1 sigmastatistic, measuring time respective time constant -58 ) and the minimum measuring times required for verification of the applicable contamination limits were calculated.

\subsubsection{PLANE AREA GEOMETRY}

The range of detection limits as calculated from absolute detection efficiencies and laboratory background (unshlelded) is shown in Table IV, the minimum and maximum values denoting those detection 
limits which were achieved with those nuclides and geometries which yielded measurable results. C 14 as a representative of LE beta-emitters can only be detected by the large area proportional counter but with unsatisfactory low efficiency. Cr 51 as pure gama-emitter can only be detected by the proportional counters. The Hamamatsu photodiodes are sensitive for alpha-particles only.

For better comparability of detector performances the minimum measuring times required for verification of the contamination limit have been calculated (Table V).

\subsubsection{TUBE GEOMETRY}

Since acceptable measuring times will only be achieved for Co 60 and Cs 137 (besides Sr 90/Y 90) for most detector types, these two nuclides were used for the measurements in tube geometry (Inside and outside contamination).

Table VI shows the minimum measuring times; since they have been calculated from the worst case geometry, they can even be better for certain combinations detector position - inside/outside measurements tubes cut in halves.

\subsubsection{CORNER/EDGE GEOMETRIES}

For the detection of activity in corners or edges, small detectors must be employed. Three different standards were fabricated:

- Corner area sources (three rectangular areas arranged to form a corner)

- Point sources positioned in corners

- Line sources placed in edges

The range of measuring times is shown in Table VII; GM counters are adequate for measurement of beta emitters, but not of alpha radiation. The surface barrier detectors are better able to detect alpha radiation when a close distance can be realized. The same holds true for the photodiodes - they might be a cheap alternative to surface barrier detectors for these geometries.

\section{CONCLUSION}

Proportional counters are for most of the geometries encountered in the measurement of real waste the most adequate detectors. Large area proportional counters are best sulted for plane or slightly curved geometries while for the more complex geometries specially shaped proportional counters are adequate.

For the detection of particle radiation in corners or edges, small detectors like surface barrier detectors, photodiodes or GM counters should be employed.

For quantitative measurement of activity or activity concentration, the range of efficlencles as encountered by varying nuclide content, selfabsorption and effective measurement distances has to be taken into account.

\section{REFERENCES}

/1/ Hulot et al: State of the art review on technology ... Report EUR $1063 \mathrm{EN}, 1986$

|2/ Lorcher et al: Klassif. endzulagernder St1llegungsabfalle aus KKH NIS Bericht 621 Rev. 1, 1983 
Table I:

Principal nuclides in waste from NPP/fuel manufacturing plants, their radiative properties and Relative Radiotoxicities based on limits contamination

\begin{tabular}{|c|c|c|c|c|}
\hline nuclide & $\begin{array}{l}\text { principal } \\
\text { radiation } \\
\text { emitted }\end{array}$ & $\stackrel{\text { RR }}{\text { inhalation }}$ & $\begin{array}{c}\text { RR } \\
\text { ingestion }\end{array}$ & ${ }_{\text {external irradiation }}$ ir \\
\hline H 3 & $\operatorname{LE} \beta$ & 0,002 & 0,01 & - \\
\hline C 14 & LE $\beta$ & 0,03 & 0,04 & - \\
\hline $\mathrm{Ca} 45$ & $\beta$ & 0,27 & 3,75 & - \\
\hline Mn 54 & $\gamma$ & 0,26 & 0,27 & 0,36 \\
\hline $\mathrm{Fe} 55$ & $\mathrm{x}$ & 0,01 & 0,04 & - \\
\hline $\mathrm{Ni} 59$ & $\mathrm{X}$ & 0,02 & 0,17 & - \\
\hline $\mathrm{Ni} 63$ & $L E \beta$ & 0,14 & 1,2 & - \\
\hline Co 60 & $\beta, \gamma$ & 1,0 & 1,0 & 1,0 \\
\hline $\ln 65$ & 8 & 0,14 & 0,35 & 0,23 \\
\hline Sr 90 & $\beta$ & 7,4 & 83 & - \\
\hline Y 90 & $\beta$ & 0,08 & 1,7 & - \\
\hline $\operatorname{Zr} 93$ & $\mathrm{LE} \beta$ & 0,07 & 0,04 & \\
\hline Tc 99 & $\beta, \gamma$ & 0,14 & 0,21 & \\
\hline Ru 106 & $\mathrm{LE} \beta$ & 1,6 & 2,7 & $0,09(\mathrm{Rh} 106)$ \\
\hline $\mathrm{Ag} 110 \mathrm{~m}$ & $x$ & 0,84 & 1,1 & 1,07 \\
\hline Sb 125 & $\stackrel{0}{\beta}, X$ & 0,35 & 0,35 & 0,19 \\
\hline I 129 & $\operatorname{LE}_{\beta}, X, \gamma$ & 11,1 & 182 & 0,004 \\
\hline Cs 134 & $\beta, \gamma$ & 0,68 & 3,75 & 0,70 \\
\hline Cs 135 & $L E \beta$ & 0,10 & 0,30 & - \\
\hline Cs 137 & $\beta, \gamma$ & 0,63 & 2,3 & 0,25 \\
\hline Ce 144 & $\operatorname{LE} \beta, \gamma$ & 1,4 & 2,7 & 0,006 \\
\hline Pm 147 & $L E \beta$ & 0,14 & 0,15 & - \\
\hline Sm 151 & $L E \beta$ & 0,14 & 0,09 & 0,005 \\
\hline Eu 152 & $\beta, \gamma$ & 0,74 & 0,43 & 0,41 \\
\hline Eu 154 & $\beta, \gamma$ & 2,3 & 1,5 & 0,49 \\
\hline Fu 238 & $\alpha$ & 445 & 0,67 & - \\
\hline $\mathrm{Pu} 239$ & $\alpha$ & 510 & 0.77 & - \\
\hline $\mathrm{Pu} 240$ & $\alpha$ & 510 & 0.77 & - \\
\hline $\mathrm{Pu} 241$ & $L E \beta$ & 9,6 & 0,02 & - \\
\hline Am 241 & $\alpha, \gamma$ & $144^{\circ}$ & 0,91 & 0,01 \\
\hline $\mathrm{Cm} 242$ & $\alpha^{0}$ & 7,4 & 0,14 & - \\
\hline $\mathrm{Cm} 244$ & $\alpha$ & 96 & 0,46 & - \\
\hline
\end{tabular}


Table II

Abundance and abundance weighted relative radiotoxicities (RR) of prominent nuclides in different NPP wastes. RR of contamination 1 imit for inhalation

1. Compressible raw waste

abundance abundance normalized measurement method $x$ RR abund.x RR gamma beta

\begin{tabular}{llllll}
\hline Cs 137 & 0,43 & 0,27 & 0,32 & $x$ & $x$ \\
Co 60 & 0,40 & 0,40 & 0,47 & $x$ & $x$ \\
Cs 134 & 0,15 & 0,10 & 0,12 & $x$ & $x$ \\
Mn 54 & 0,01 & 0,003 & 0,004 & $x$ & \\
Sr $90 / Y 90$ & 0,01 & 0,07 & 0,08 & & $x$ \\
I 129 & 5 E-7 & $5,6 \mathrm{E}-6$ & $6,6 \mathrm{E}-6$ & & \\
E I pha & $1 \mathrm{E}-6$ & $5,1 \mathrm{E}-4$ & $6,0 \mathrm{E}-4$ & & \\
\hline & & & 1,0 & 0,91 & 0,99
\end{tabular}

2. Steel waste of NPP FR 2

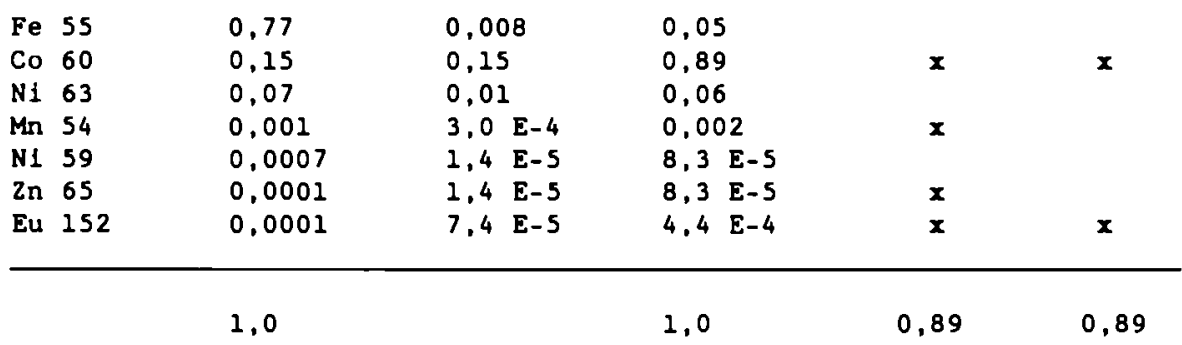

3. Waste of NPP Gundremingen

\begin{tabular}{|c|c|c|c|c|c|}
\hline Co 60 & 0,67 & 0,67 & 0,42 & $x$ & $x$ \\
\hline Fe 55 & 0,06 & 0,0006 & 0,0004 & & \\
\hline Sb 125 & 0,006 & 0,021 & 0.013 & $x$ & $x$ \\
\hline $\operatorname{Pan} 147$ & 0,06 & 0,008 & 0,005 & & \\
\hline $\begin{array}{ll}C 8 & 137\end{array}$ & 0.06 & 0.04 & 0,025 & $x$ & $x$ \\
\hline C8 134 & 0,03 & 0,02 & 0,012 & $x$ & $x$ \\
\hline Sr $90 / Y 90$ & 0,03 & 0,23 & 0,144 & & $x$ \\
\hline N1 63 & 0.01 & 0,0014 & 0.0009 & & $x$ \\
\hline Pu 241 & 0.01 & 0,10 & 0,06 & & \\
\hline Zalpha & 0,001 & 0,51 & 0,32 & & \\
\hline
\end{tabular}


Table III

Configuration of detectors and geometries in test measurements

$\begin{array}{llll}\text { Detector } & \text { type } & \text { plane area } & \text { geometry } \\ & & & \\ \text { corner/edge }\end{array}$

Table IV

Plane area geonetry: range of limits of detection (Bq/ $\left./ \mathrm{cm}^{2}\right)$, 1 sigma statistics, measurement time $=5 \mathrm{~s}$

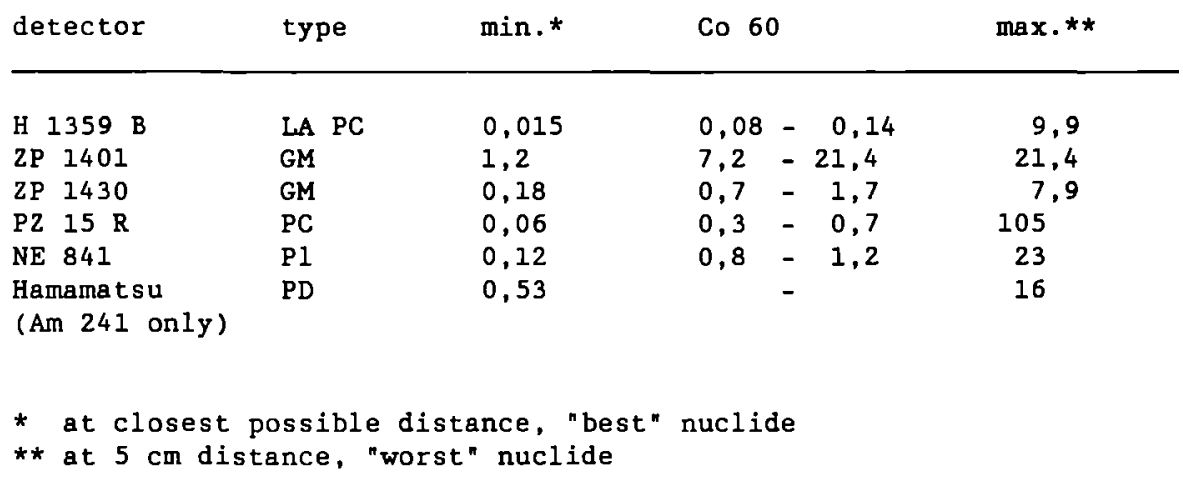


Table $\mathrm{V}$

Plane area geometry: range of measuring times (8)

\begin{tabular}{|c|c|c|c|c|c|}
\hline detector & type & min. & \multicolumn{2}{|c|}{ Co 60} & $\max$. \\
\hline P2 $15 \mathrm{R}$ & PC & 0,2 & 3. & -16 & $>1000$ \\
\hline PZ $32 \mathrm{~F}+\mathrm{S}$ & PC & 0,1 & 1 . & -5 & $>1000$ \\
\hline $2 P \quad 1401$ & GM & $49^{\circ}$ & $>$ & 00 & $>1000$ \\
\hline $2 P \quad 1430$ & GM & 1.2 & 20 & -102 & $>1000$ \\
\hline Hamamat 84 & PD & 1030 & & - & $>1000$ \\
\hline H 1359 B & LA PC & $<0,1$ & 0 . & -0.8 & $>1000$ \\
\hline NE 841 & P1 & 0,8 & 39 & -90 & $>1000$ \\
\hline
\end{tabular}

Table VI

Tube geometry: measuring times (s) for worst case geometry (tube diameter, inside/outside measurements)

\begin{tabular}{llccc} 
detector & type & Cs 137 & Co 60 & type of contam. \\
\hline BZ 45 & GM & 1,0 & 22 & inside \\
B2 120 & GM & 0,34 & 7,1 & inside \\
H 1359 B & LA PC & 0,07 & 0,2 & inside \\
& & 0,06 & 0,15 & outside \\
FHT 111 G & LA PC & 0,07 & 0,06 & inside \\
& & 0,04 & 0,1 & inside \\
LB 1210 B & LA PC & 820 & 74 & inside \\
(Xe) & & & & inside \\
3"x 3" & NaI & 1,9 & 0,5 & outside
\end{tabular}

Table VII

Corner/edge geometry: range of measuring times (s)

detector

type

min

Co 60

Am 241

$\begin{array}{llccr}2 P 1401 & \text { GM } & <0,1 & 0,1-37 & 70->1000 \\ 2 P 1430 & \text { GM } & <0,1 & 0,1-13 & 15->1000 \\ \text { SPD } 600 & \text { SB } & <0,1 & 0,1-65 & 8->1000 \\ \text { SPD } 300 & \text { SB } & 0,5 & - & 0,5->1000 \\ \text { IPK } 250 & \text { SB } & 1 & - & 1->1000 \\ \text { Hemamatsu } & \text { PD } & & & 0,1->1000\end{array}$




\title{
DEVELOPMENT OF SAMPLING AND ASSAY METHODS FOR WINDSCALE ADVANCED GAS COOLED REACTOR RADWASTE*
}

\author{
BRIGHTMAN $\mathbf{F}$ G. \\ UKAEA, Windscale Laboratory, Seascale \\ Cumbria, England.
}

\begin{abstract}
Reviews have been made of the impurity concentrations and of the long-lived radioactivities in material to be consigned to low and intermediate level waste disposal facilities. Sampling methods have been developed and available optical $X$-ray and neutron activation analysis routes used to assess radwaste activity at the Windscale Advanced Gas Cooled Reactor (WAGR). A calculation code, WESTD, for inventory checking has also been developed.

The paper reviews the experience of sampling, assay and inventory checking at WAGR. Simple schemes are proposed for assay during WAGR dismantling which can be applied elsewhere.
\end{abstract}

\section{INTRODUCTION}

The Windscale Advanced Gas Cooled Reactor (WAGR) was shut down on 3 April 1981 after completing 18 years as a development facility for this type of reactor. An account of the experimental programme for this $100 \mathrm{MW}(\mathrm{t}) / 33 \mathrm{MW}(\mathrm{e})$ prototype power reactor is given in Reference 1 . A series of concluding experiments, which included fuel transients affecting the magnitude and disposition of radioactive species within the pressure circuit, was carried out in 1981 (2). Both these development programmes defined the reactor conditions prior to the complete dismantling, now in progress, to a 'greenfield' site as described by Adams $(3,4)$.

One important objective of decommissioning development is to demonstrate sufficiently detailed knowledge of the radioactivity of packaged material. It is necessary to identify the principal beta, gamma and $x$-ray emitters, in waste steel, graphite, and concrete, and from a knowledge of their prcperties show that:

(a) the radiation emitted from the packages is always acceptably low,

(b) the specific activity is below a defined limit,

(c) the total activity of the packages is known from a combination of measurement and calculation, so that costly space in a repository is most effectively and efficiently used.

The Windscale development work was aimed at gaining experience to help minimise sampling and analysis costs for the much larger steel tonnages which may be packaged in the future.

The principal radioactivities associated with WAGR steel, graphite and concrete are listed, and the sampling and analysis methods chosen for future application are indicated. A brief account of an inventory checking code (for individual radwaste consignments) is given; and proposals made, in outline, for sampling and measurement during actual dismantling of the plant.

* This work was partly funded by the Commission of the European Communities. 
2. GUIDING PRINCIPLES POR WAGR ACTIVITY ASSAY

WAGR decommissioning should produce clearly applicable methods for measuring radioactive contents, calculating the quantity if this is not directly measured, and demonstrating the costs associated with activity measurement and with sampling. Overall, the principle adopted will be that where an initial gamma activity measurement shows that the waste has a low activity level, only very 1 imited assessment will be required. For those parts of the inventory identified as more active - for example in the range $0.37 \mathrm{TBq} /$ te to $18.5 \mathrm{TBq} / \mathrm{te}(10 \mathrm{Ci} /$ te to $500 \mathrm{Ci} / \mathrm{te})$ - careful gamma measurements will be required. Material of the highest specific activity $>18.5 \mathrm{TBq} / \mathrm{te}$ ( $) 500 \mathrm{C} 1 / \mathrm{te})$ will be sampled sufficiently extensively to ensure an accurate assessment.

\section{PRINCIPAL ACTIVITY ARISINGS}

The original inventory calculations showed a total WAGR activity of some $2800 \mathrm{TBq}$ at 7 years decay, in steel, graphite and in the shield concrete as revealed in Table $I$.

Table I: Overall Activity Inventory

\begin{tabular}{|l|c|r|}
\hline \multicolumn{1}{|c|}{ MATERIAL } & MASS (te) & ACTIVITY (TBq) \\
\hline Mild Stee1 & 761 & 525 \\
Stainless Steel & 89 & 2194 \\
Graphite & 283 & 65 \\
Concrete & 750 & 3 \\
Total & 1883 & 2787 \\
\hline
\end{tabular}

Radioactivities in the main waste materials are:

(a) In steel waste

The isotopes present in WAGR steel are shown in Table II.

Table II: Radioisotopes in WAGR steel

\begin{tabular}{|c|c|c|c|}
\hline Isotope & \multicolumn{2}{|c|}{ Half-life } & Type of emission \\
\hline $\mathrm{Co}-60$ & 5.27 & $y$ & Beta and gamma \\
\hline $\mathrm{Fe}-55$ & 2.7 & $\mathbf{y}$ & Electron capture, $x$-ray \\
\hline $\mathrm{N} 1-59$ & 75,000 & $y$ & Electron capture, $x$-ray \\
\hline $\mathrm{Ni}-63$ & 100 & y & Beta \\
\hline $\mathrm{Nb}-94$ & 20,000 & y & Beta and gamma \\
\hline$A_{B}-108$ & 127 & y & Beta and gamma \\
\hline Eu- 154 & 8.5 & $y$ & Beta and gamma \\
\hline
\end{tabular}

The information avallable from direct measurements of active WAGR 
steel suggests that no other isotopes are likely to be encountered, apart from the fission product caesium present on the surfaces of some items. The principal components contributing to active steel arisings are shown in Table III.

Table III: Principal Active Steel Arisings, WAGR

\begin{tabular}{|l|c|c|c|}
\hline \multicolumn{1}{|c|}{ Description } & $\begin{array}{c}\text { Mass } \\
\text { Tonnes }\end{array}$ & Material & $\begin{array}{c}\text { Activity } \\
\text { at } \begin{array}{c}\mathrm{yr} \text { decay } \\
\mathrm{Bq} / \mathrm{te}\end{array}\end{array}$ \\
\hline Pressure vesse1 & 210 & MS & $8.5 \times 10^{10}$ \\
Thermal shield & 186 & MS & $12.6 \times 10^{11}$ \\
Neutron shield & 13 & SS & $15.9 \times 10^{12}$ \\
Core support plate & 18 & MS & $8.1 \times 10^{12}$ \\
Support bearings & 2 & SS & $12.2 \times 10^{12}$ \\
Core restraint & 17 & Mixed & $55 \times 10^{12}$ \\
Loop tubes & 4 & SS & $17.4 \times 10^{12}$ \\
\hline
\end{tabular}

The steel waste is important because it includes the items of highest specific activity. In particular, the uncontrolled cobalt impurity results in ${ }^{60} \mathrm{Co}$ activity, which dominates the steel activity inventory throughout the planned period for WAGR dismantling.

(b) In graphite waste

The most important radioisotopes are ${ }^{60} \mathrm{Co},{ }^{154} \mathrm{Eu},{ }^{3} \mathrm{H}$, and ${ }^{14} \mathrm{C}$. It can be expected that some graphite moderator surfaces are contaminated with ${ }^{237} \mathrm{Cs}$, resulting from the fission product release from failed fuel pins during reactor operation.

(c) In concrete

Sampling of WAGR bioshield concretes has shown that the most important activities are due to ${ }^{152} \mathrm{Eu},{ }^{154} \mathrm{Eu}$ and ${ }^{60} \mathrm{Co}$.

4. SAMPLING AND ANALYSIS METHODS

For steel, simple drilling methods and a surface sampling method using an abrasive diamond-impregnated film were selected. Early investigations of spark spectrographic and laser-based ablation methods were abandoned as too costly and unsatisfactory to achieve the principal aim. The analytical techniques used for analysis of WAGR steel were:

ICP-ES - Inductively-Coupled Plasma Emission Spectrometry.

AAS - $\quad$ Atomic Absorption Spectrometry

ICP-MS - Inductively-Coupled Plasma Mass Spectrometry. 
XRP - X-ray Pluorescence.

NAA

Neutron Activation Analysis.

of these, the most sensitive for elemental cobalt detection was ICP-MS. However, X-ray fluorescence methods, sensitive to approximately $25 \mathrm{wpm}$ of cobalt in a steel, are likely to prove generally adequate during plant dismantling.

Por graphite, fuel channel wall coring methods were used during the operational lifetime of WAGR. Activity analyses used complete combustion methods, followed by liquid scintillation counting for beta emitters $\left({ }^{3} \mathrm{H}\right.$, ${ }^{14} \mathrm{C}$ ) and gamma spectrometry for ${ }^{60} \mathrm{Co}$.

For concrete, germanium diode gamma spectrometry was the chosen analysis method, following use of a coring machine to produce cylindrical cores ( $15 \mathrm{~cm}$ diameter) from the WAGR side bioshields.

\section{RESULTS OP SAMPLING}

Detalled results are collected in the final contract report, which is in preparation. Important findings are:

Steel - the Cobalt impurity range is from 100 wpm in mild steel to $3200 \mathrm{wpm}$ in stainless. The higher figure is about twice the maximum expected. However, no seriously adverse effects on waste packaging strategies are anticipated.

Graphite - the presence of tritium, in concentration up to 300 $\mathrm{MBq} / \mathrm{kg}$, in core graphite will affect the strategy for minimising use of waste boxes for graphite disposal; further investigation will be required.

Concrete - activity due to ${ }^{152} \mathrm{Bu}$ ranges up to $100 \mathrm{KBq} / \mathrm{kgm}$ approximately. The presence of ${ }^{3} \mathrm{H}$ is being investigated at present. It is this radioisotope, rather than the gamma-emitter, which determines how much WAGR concrete is classified as active waste (above the statutory limit, $400 \mathrm{~Bq} / \mathrm{Kgm}$ in UK).

\section{CODE DEVELOPMENT}

A code, WESTD, has been written to calculate the total activity in a waste box from measurements of gamma ray dose rate at various points outside the box. The code assumes that all the dose rate is due to the cobalt-60 nuclide. The code provides an estimate of the activity, and also of the uncertainty in the estimate.

The code has been tested by considering a series of cases with differing source activities. A more comprehensive shielding code was used to calculate the dose rates outside the box, and these values were then used in WESTD. The tests varied from a uniform source activity throughout the box to a small source region, and a combination of these. The results were generally satisfactory, with the source activity calculated to within about $30 z$ of the true value.

Further tests of the code are needed during the actual dismantling phase. During the contract period, schemes were considered for simulation of waste box contents using point sources, with gamma dose rate measurements outside prototype waste boxes. These plans were abandoned when it became clear that: 
(a) the activity distribution of real waste could not be adequately simulated using point sources,

(b) box design was changing,

(c) the code could, and should, be demonstrated on individual large waste items (eg steel plates) as a test of code capability. Comparison with large shielding codes, and with results of steel sampling, are expected to give confidence that WESTD will assess waste box total activity adequately.

7. SAMPLING DURING DISMANTLING

Provision has been made in the WAGR Waste Packaging Building for a sampling station. As steel and graphite are handled to boxes, samples will be taken using a simple drilling tool. In order to ensure that only the absolute minimum of concrete is treated as radioactive, sampling will be needed. The methods for obtaining such samples have not yet been decided.

\section{CONCLUSIONS}

Steel, graphite and concrete sampling methods have been identified during the period of this contract. It has become clear that all three materials are important from the viewpoint of minimising decommissioning costs. In particular, for WAGR, too much emphasis was placed inftially on steel sampling. Whilst this is important, because the steels have the highest specific activities, it is now clear that graphite and concrete sampling, with conventional activity analysis methods, will also be required during the plant dismantling (STAGE 3 ) phase.

\section{REFERENCES}

1. GALLIE R R and HEWITT P V. Eighteen Years Operating and Development Experience with the Windscale AGR. Nuclear Energy, 1982, vo1 21, $\mathrm{Feb}$, No1 21-28.

2. BRIDGE $M$ J, GALLIE $R$, HEWITT $P V$ and PERCIVAL $K$ G. Concluding Experiments in the Windscale AGR. Nuclear Energy, 1982, Vol 21, Feb, No1, 29-39.

3. ADAMS A L. Engineering Problems Associated with Decommissioning WAGR. ATOM 349, page 3. November 1985.

4. UKAEA. Update on WAGR Decommissioning. ATOM 374, page 2. December 1987. 
DEVICE FOR DECISIVE MEASUREMENTS OF

WASTE FROM DISMANTLING OF KKN

Auler I., Helk F., Neukäter E., Zimmermann U. NIS Ingenleurgesellschaft mbH, D-6450 Hanau, FRG

\section{ABSTRACT}

During the dismantling of nuclear facllitles large quantitles of potentlally releasable materlals from the controlled area and with very low radioactivity levels have to be screened. For this purpose NIS has developed a device for decisive measurements as a decisionmaking ald which 18 sensitive to gana radiation. The detectors are arranged on the outer surface of a tunnel with a cross section of $1.2 \mathrm{~m}$ by $1.2 \mathrm{n}$. This $1 \mathrm{~s}$ why activities on complex surfaces and hidden activities with different, but known nuclide compositions can be measured. The mininum detectable level for shielded activities (2 cm steel) is lower than 500 Bq Co-60 at any location within the measuring chamber. By Id-1989 more than $100 \mathrm{Mg}$ of varlous materials originating from the dismantling of the Kernkraftwerk Niederaichbach (KKN) had been screened for unrestricted release.

\section{INTRODUCTION}

An important task to be performed during the dismantling of nuclear facilities is the detection of very low levels of radioactivity with a view to releasing large quantities of dismantled components without any restriction. In the past, measurements for unrestricted release were performed manually and in a time-consuming way by analyzing a large number of representative samples at radiological laboratories or by carrying out direct contamination measurements with beta-sensitive large-area gas flow proportional counters. In many cases these $k$ inds of measurements were not feasible because of the activity distribution, geometry or for economic reasons. Hence large anounts of material had to be treated and disposed of as radloactive waste which could otherwise have been released. For the fast and safe screening of significant amounts of materials fron dismantling nuclear facilities with low-level activities, differing nuclide compositions and shapes, a device for decisive measurenents to serve as a decision-making ald had to be developed.

\section{RELEASABLE MATERIAL MASSES FROM DECOMISSIONING}

When a $1,300 \mathrm{WW}$ nuclear power plant with a KWU standard-class presourized water reactor 1s dismantled, approximatly $10,000 \mathrm{Mg}$ of plant components arise from the controlled areas reactor building, annulus and auxillary bullding. not including activated components. An estimated $70 *$ $(7.000 \mathrm{Mg}$ ) of these components are only slightly contaninated by radioactive operating media or are only affected at the surface by airborne contamination. These components can be released without any restriction - if necessary, after slight decontanination -, if it can be demonstrated by neasuring that the residual activity of the components does not exceed defined linits. In nuclear power plants with bolling water reactors (1.300 MW) which in comparison have a larger controlled area, the mass of releasable conponents is larger than in power plants with a pressurized water reactor in both absolute $(19,000 \mathrm{mg})$ and relative $(85 *)$ terns. 
The controlled area of the reactor bullding of the Kernkraftwerk Niederalchbach (KKN) contains approx. $2,300 \mathrm{Mg}$ of plant components, not including activated conponents. About $800 \mathrm{Mg}(35 *)$ of these were contaminated by alrborne activity, if they were contaninated at all. In the case of the KKN, no provision was made for decontanination beyond the wiping of external surfaces so that at first only these $800 \mathrm{Mg}$ will be considered for release. Part of the remaining contaminated masses will be reused after melting at an external facility, while the rest will be directly disposed of as radioactive waste. The releasable conponents are listed in Table I.

It was not necessary to measure the concrete shielding blocks for release after they had been dismantled, since they could be reused in another controlled area. A large proportion of the steel components - in terms of mass - could be measured and released in the conventional way because of the size of the components and their even, easily accessible surfaces. Another part of potentially releasable components will only be disasseabled during a later KKN dismantling phase, since their functions are still needed while the plant is being dismantled (e.g. crane). It 18 expected that also part of those components which inftially were classified as nonreleasable will be measured with the declsive measuring device and released.

\section{CONFIGURATION OF THE MEASURING DEVICD}

The device consists of a measuring chamber, an outer shielding, a conveyor chain and a data processing unit. Scales for weighing the components to be measured are integrated in the conveyor chain which passes through the measuring chamber (Fig. 1). The measuring chamber was supplied by Münchner Apparatebau für elektron1sche Geräte GmbH (MAB).

The measuring chamber consists of a detector systen, a data acquisition and control unit and a supporting rack. The detection system comprises twelve detector cases, each filled with a liquid scintillator. The detectors are arranged on the outer surface of the measuring tunnel in such a way that a large portion of $4 \pi$-geonetry is covered (Fig. 2).

Each detector has 1 ts own measuring line which transmits the counts to the data acquisition unit (Fig. 3). Th1s unit preprocesses the counts and stores them in a micro-processor memory.

Further processing is done with a personal computer connected to the data acquisition unit. This computer offers great sophistication and flexibility of programming for the complex data analysis.

\section{BASIS OF LAYOUT}

The components to be measured may have a size of up to $0.9 \mathrm{~m} \times 1.1 \mathrm{~m}$ $x 4 \mathrm{~m}(\mathrm{H} \times \mathrm{x}$ L) and a mass of up to $1,000 \mathrm{~kg}$. The average mass per batch will presumably be between 200 and $400 \mathrm{~kg}$.

The basis for the radiological layout of the measuring chamber was provided by the release limits specifled in the licence for dismantling the KKN. The KKN limit values for unrestricted release including all nuclides are $0.37 \mathrm{~Bq} / \mathrm{g}$ and $0.37 \mathrm{~Bq} / \mathrm{cm}^{2}$. On the basis of cobalt-60 alone, these threshold values are $0.33 \mathrm{~Bq} / \mathrm{g}$ and $0.31 \mathrm{~Bq} / \mathrm{cm}^{2}$. With these values scaled to a reference mass of $10 \mathrm{~kg}$ and a reference surface of $1 \mathrm{~m}^{2}$, a minimum activity of $3,300(3,100) \mathrm{Bq}$ for a component has to be detected. To allow for the confidence interval of measured data, differing nuclide composi- 
tions. complex geonetries and self-shlelding effects of the components to be neasured, the nininu unshielded activity detectable by the neasuring chaber was dealgned to be $300 \mathrm{~Bq}$ of cobalt-60.

\section{LICENS ING}

The device has been avallable for neasurenents since June 1988. After prelininary measurenents, the features and calibration of the neasuring device were denonstrated to the inspection agency. The licensing authority gave 1 ts final approval for the operation of the device at the KKN in Noveber 1988. Inmediately after the authority had given the green light the neasuring device was used for routine operation at the KKN.

\section{ROUTINE MEASUREMENTS}

Routine neasureaents with the newly developed device were started on steel covering plpe insulation (Fig. 4). About $13 \mathrm{Mg}$ of contaninated cover sheets were measured for unrestricted relesse. Less than $2 *$ of these cover sheets had an activity level slightly above the linit value of $3.300 \mathrm{~Bq}$ per $10 \mathrm{~kg}$ of material (equivalent to $0.33 \mathrm{~Bq} / \mathrm{g}$ ). The specific activity averaged over the actual mass of a batch of cover sheets (mean value $160 \mathrm{~kg}$ ) was $0.01 \mathrm{~Bq} / \mathrm{g}$. Th1s was lower than about one thirtieth of the mass-8pecific lintt value (F1g.5).

The authorities gave their approval of the unrestricted release of the measured cover sheets. The released sheets were sold as non-radioactive scrap.

The time required for manual measurements of cover sheets would be about one hundred times longer than with the autonated neasuring device. Without It all of these cover sheets would have had to be disposed of as radioac$t$ ive waste because of the long $t$ ime needed for manual measurement.

\section{ADDITIONAL MEASUREMENTS ON DISMANTLED COMPONENTS}

The components neasured next were insulation wool ( $20 \mathrm{Mg}$ ), electr1cal cables (7.5 Mg), cable supports (steel) (10 Mg), activated insulation sheets $(7 \mathrm{Mg})$ and activated steel $(1.5 \mathrm{Mg})$. More than $95 *$ of these conponents were found to be releasable for unrestricted use or disposal. 0ther interesting decisive neasurements were performed on exhaust air filter boxes.

Most of the 200 boxes measured up to now were found to be releasable. The conditioning for final disposal alone would have cost about DM 500 per box, not Including the disposal costs proper.

Measurements with the device will be continued at the KKN on other types of dignantled components such as sall steel parts, concrete rubble, ventllation ducta. lead wool and sand.

\section{CONCLUSIONS}

The measuring device described above allows fast, rellable and approvable measurements on large components or batches of different naterials with low activity levels on complex or hidden surfaces. If the device had not been used at the KKN, such parts would have had to be disposed of In total as radioactive waste, because connonly used neasuring nethods would not have pernitted that release. Therefore, the application of the device 1s useful to preserve naterlal resources and reduce the amount of aterial which has to be disposed of as radioactive waste. 
Table I: List of releasable components orginating

from dismantling the KKN

Type of component

Mass

$/ \mathrm{Mg} /$

Pipings

Fittings

Containers, tanks

Actuators

Terminal boxes 10

Cable ducts

Heat-insulating material 46

Cover sheets 40

Steel components

Concrete shielding blocks 260

Total 


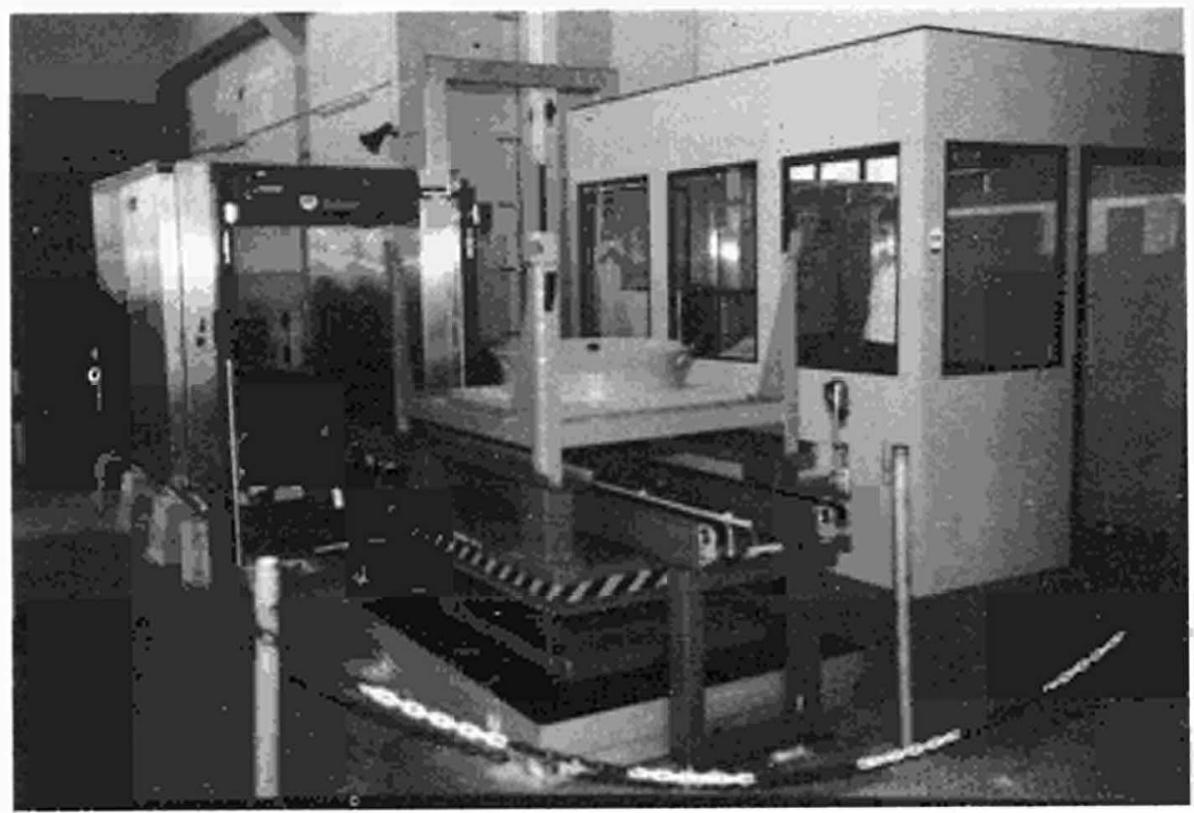

Figure 1: Arrangement of Measuring Device at KKN

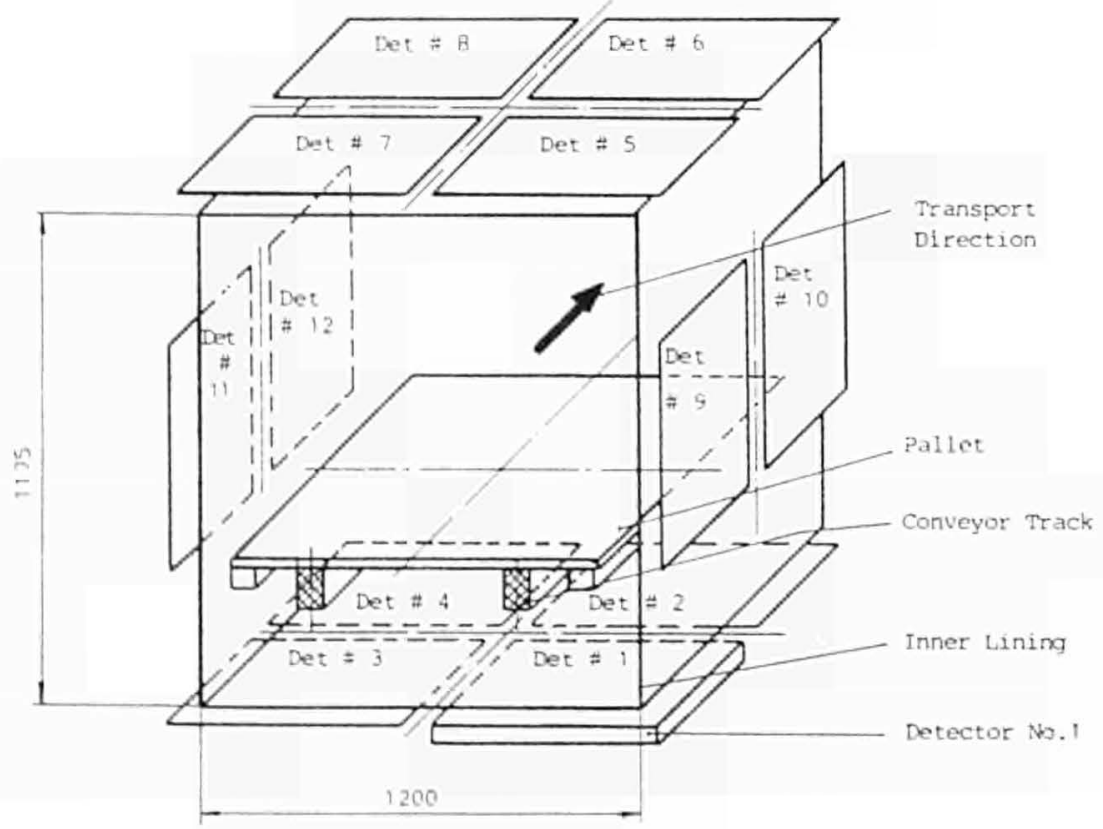

Figure 2: Configuration of the Detectors 


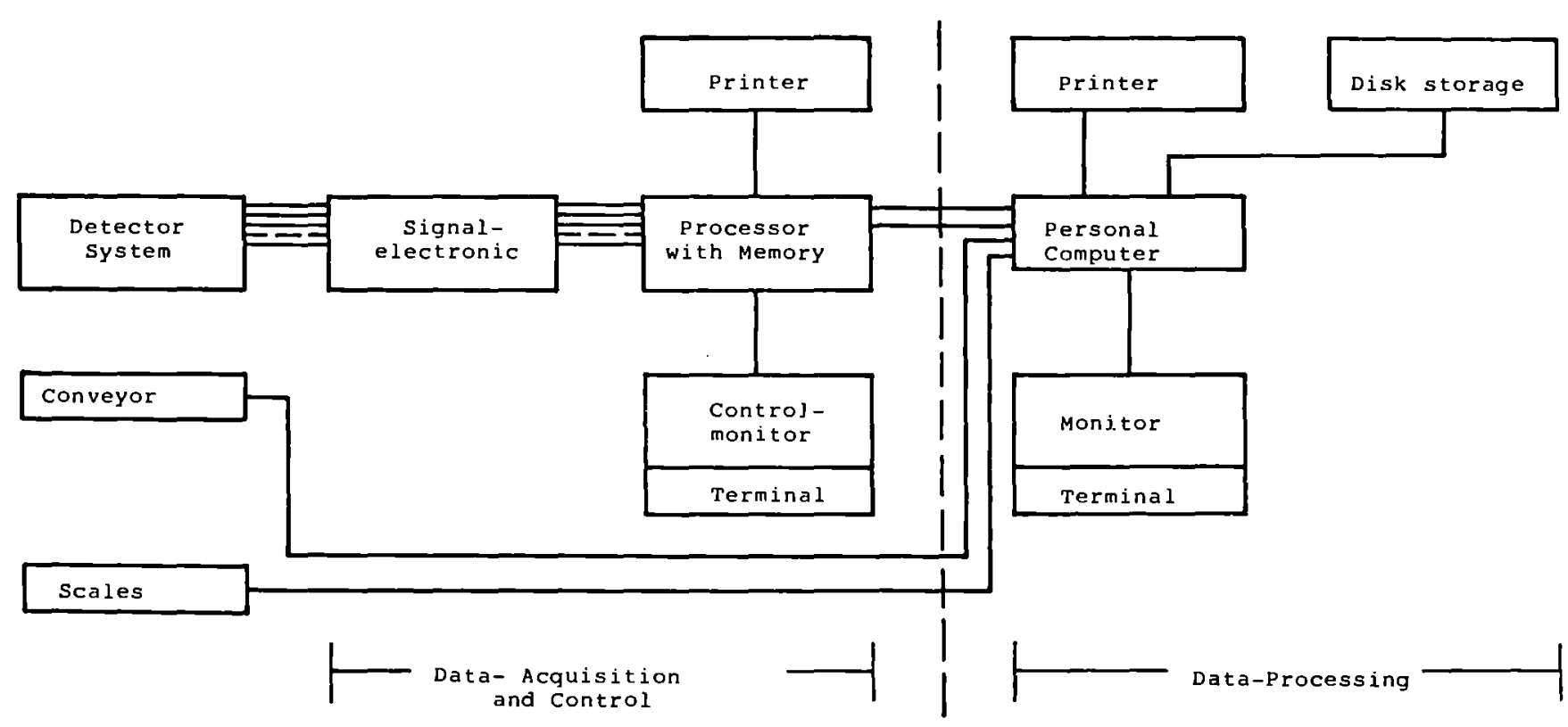

Figure 3: Configuration of Data Acquisition and Processing 


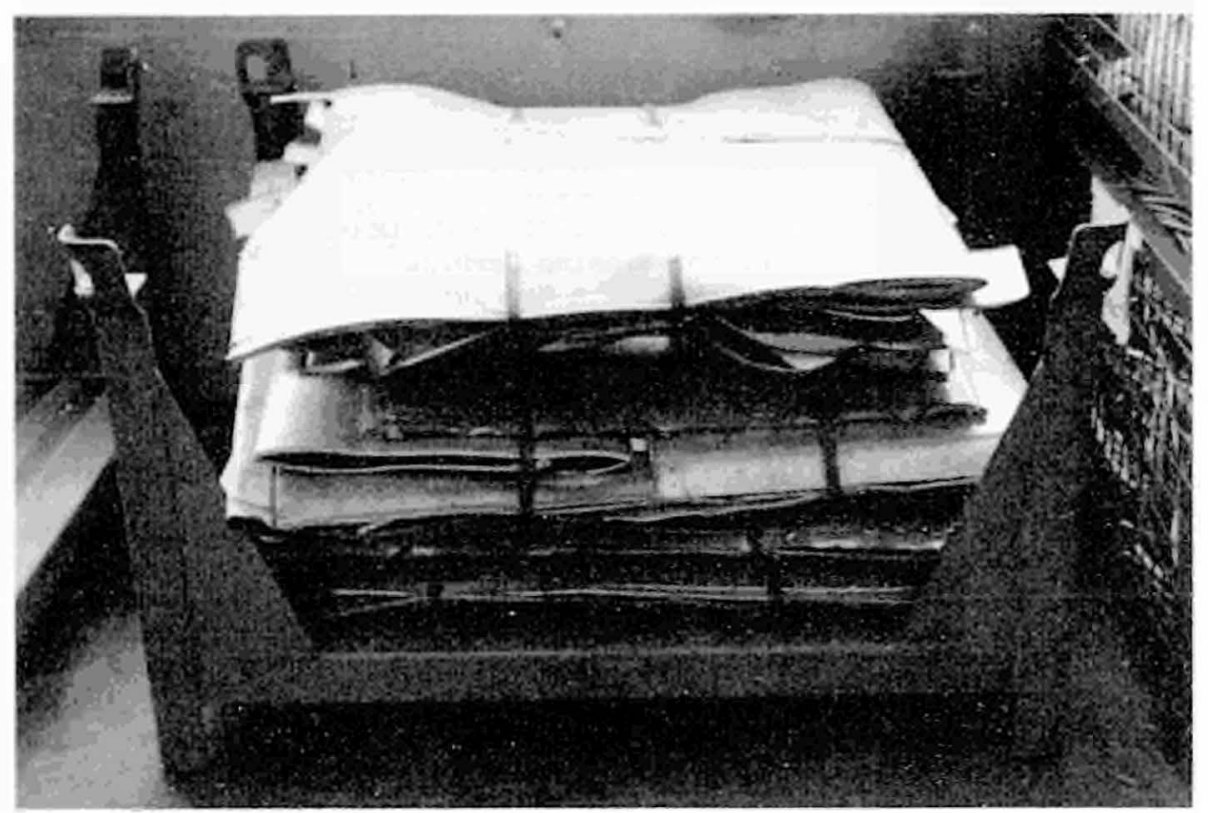

Figure 4: Configuration of Cover Sheets

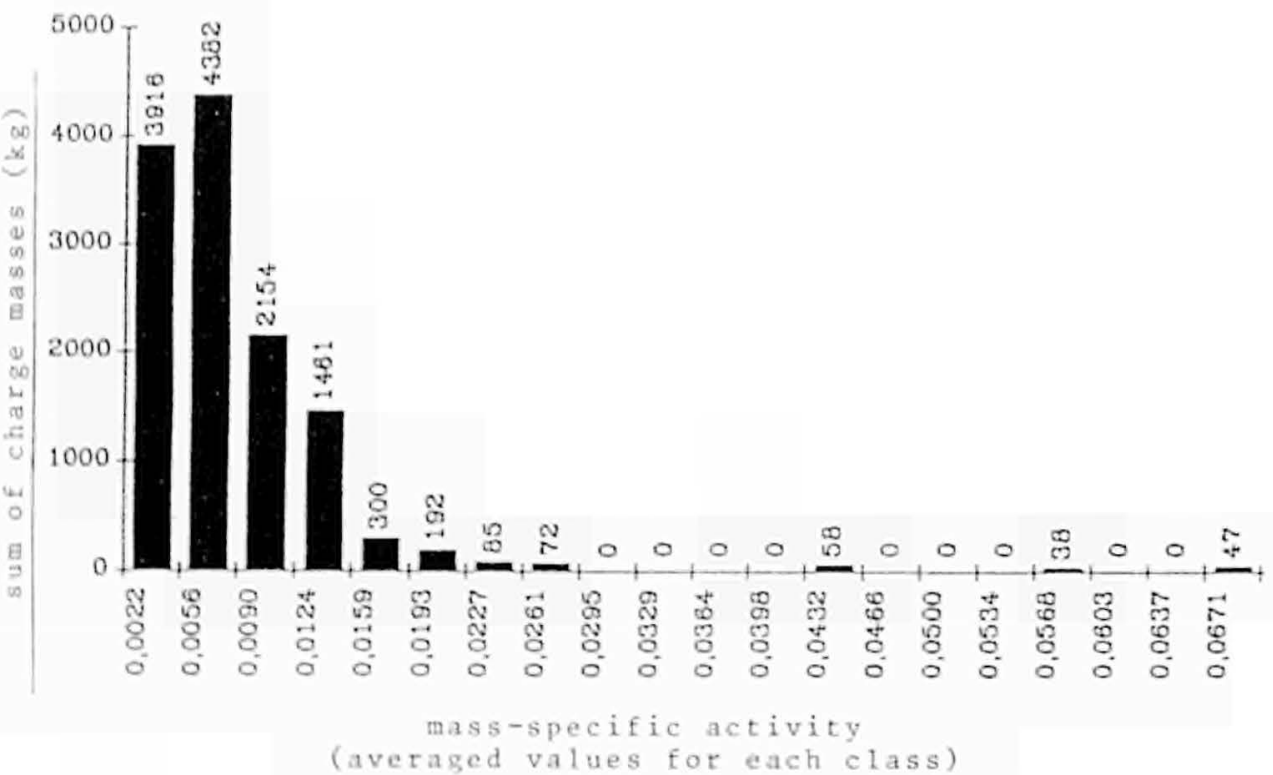




\title{
MEASUREMENT AND SORTING TECHNIQUES FOR UNRESTRICTED RECYCLING OF METAL FROM THE NUCLEAR INDUSTRY
}

\author{
JR COSTES - D. DA COSTA - G. IMBARD \\ Decommissioning Service \\ CEN VALRHO - Marcoule \\ Commissariat à l'Energie Atomique (France)
}

\begin{abstract}
This report describes a low-level radioactivity controller (LLC) with a large detection surface area used at a decommissioning site to sort parts weighing up to $500 \mathrm{~kg}$ as they move past the detectors. The device calculates the specific activity and the mean activity per unit area, while logging the measurement parameters and the number of parts scanned.
\end{abstract}

\section{INTRODUCTION}

The servicing, maintenance and decommissioning of nuclear reactors and fuel cycle facilities will increasingly result in the production of materials and equipment contaminated or activated to different degrees. Scrap metal recovery and unrestricted release will only become industrially feasible with the development of new large-scale monitoring systems capable of measuring very low activity levels. Such systems are indispensable if the materials are to be decontaminated prior to recycling in accordance with the principle of maintaining external irradiation "as low as reasonably achievable' (ALARA), rather than melted for disposal.

\section{LLC DEVICE REQUIREMENTS}

Under the procedures for decommissioning a nuclear reactor at Marcoule to stage 2, it must be demonstrated that the radioactivity of the metal wastes removed from controlled areas does not exceed the local regulatory limit of $1 \mathrm{Bg}^{-1}$. The very low residual radioactivity consists of 95\% $60 \mathrm{Co}$ and $5 \% 137 \mathrm{Cs}$.

With some 500 metric tons of metal to be controlled, conventional methods which monitor the entire waste surface area would be too costly and too unreliable. In order to avoid cutting up the waste into small fragments, the system must be capable of monitoring parts weighing up to $500 \mathrm{~kg}$ with dimensions of up to $0.9 \times 0.9 \times 2$ meters in less than 15 minutes.

About $60 \mathrm{wt} \%$ of the waste materials are large diameter $(0.5-1.6 \mathrm{~m})$ pipe sections cut along their generatrices, and contaminated on the inner surface. The remaining $40 \mathrm{wt} \%$ are compact objects such as parts of large valves or bellows.

The controller was also required to print out a report for each waste item, and to record individual measurement data and parameters in a data base for use by other networked computers. 


\section{General pRinciples}

A large area $(0.5 \mathrm{~m} 2)$ photoscintillator measuring $100 \times 50 \times 5 \mathrm{~cm}$ was selected in order to ensure a significant counting rate. Unlike smaller detectors, the large surface area means that the detection efficiency is no longer inversely proportional to the square of the distance. Figure 1 shows a certain linearity with the reciprocal of the distance for values greater than about $17 \mathrm{~cm}$.

By totalling the counts for two detectors facing each other between which the part is measured. the results should be relatively independent of the shape of the part or the extent of contamination, as shown in Figure 2.

The 100-second counts shown in Figure 1 were obtained during preliminary tests using specimens artificially contaminated with $0.4 \mathrm{~Bq} \cdot \mathrm{cm}^{2}$ of $60 \mathrm{Co}$ (S1) and $137 \mathrm{Cs}$ (S2). The standard deviation of the background variation determining the detection threshold was:

$$
4 \sqrt{\frac{2 B}{t}}=35 \mathrm{c} \cdot \sec ^{-1}
$$

Contamination by $60 \mathrm{Co}$ was easily detectable even at a distance of $60 \mathrm{~cm}$ from the detector: $35 \mathrm{c} \cdot \mathrm{sec}^{-1}$ compared with a $100-\mathrm{sec}$ counting rate of $75 \mathrm{c} \cdot \mathrm{sec}^{-1}$.

The detection sensitivity can be further improved by modifying the signal/noise ratio in the $60 \mathrm{keV} 10 \mathrm{MeV}$ energy band to allow for the background spectrum at the decommissioning site.

Solid angle calculations were performed to determine the effect of the distance between the detectors and the moving waste material. Figure 3 indicates the parameters used for the Monte Carlo method to obtain the geometric detection efficiency of a detector facing a rectangular object of length 1 at a distance $d$. The $L$ parameter represents the longitudinal distance from the detector centerline OD to the source centerline OS. When the distance $d$ and offset $L$ are both zero, points OD and OS coincide. When detector and waste are no more facing each other, than $L=L m$.

The calculated detection efficiency represents the mean solid angle for a shift from 0 to $\mathrm{Lm}$. Figure 4 shows that the overall geometric efficiency $\mathrm{R}$ varted from $3.8 \%$ to $11 \%$ depending on the distance, and was relatively unaffected by source motion until the 2-meter long specimen exited the detection zone. Figure 5 shows the effect of the specimen length on the overall detection efficiency, which was higher for short objects than for longer ones, at the abcisse Lm.

To simplify the design and reduce costs, a single high speed photomultiplier was used for longitudinal observation of photons created in a scintillator located in a sealed receptacle with light lead shielding on all the inactive surfaces.

Figure 6 is a sensitivity map obtained using a lead collimated 137Cs 
source, showing a drop in sensitivity along the vertical edges $(55 \%$ of the center value). This sensitivity pattern was taken into account in building the unit, since the scintillator is mounted vertically and the parts move horizontally. The slight falloff in sensitivity from the upper to the lower portion was also compensated by placing the two detectors top-to-bottom. The result is a measurement volume in which the gamma photons are detected with relative uniformity.

Figure 7 shows a series of test results for specimens ranging from a point source to the dimensions of the detector itself, indicating that the device is not significantly affected by the source dimensions.

\section{BACKGROUND NOISE}

In the present version, the detection threshold is closely related to the magnitude and variations of the background level. In addition to electronic attenuation ( $\mathrm{cf} 3$ ) the unit was located in a room selected for its low background noise, and measures were taken to reduce the background even further : for example solid masonry walls and metal doors. The inactive detector surfaces are lead shielded so the background level varies slightly with the distance between the detectors.

When a waste component more than about $5 \mathrm{~mm}$ thick passes between these wide-area detectors the background level drops due to a shadow effect, partially "masking" the contamination on the specimen. Measurements were obtained in a configuration with the detectors $120 \mathrm{~cm}$ apart using a 60Co point source strong enough $\left(4.4^{*} 10^{5} \mathrm{~Bq}\right)$ to provide counting rates well above the background level. The detector efficiency was $2.2 \%$, and background shadowing by a panel $15 \mathrm{~mm}$ thick was evaluated at $100 \mathrm{c}$. $\sec ^{-P}$. The difference in efficiency compared with the measured geometric efficiency was due to the gamma photon capture yield of approximately $30 \%$. A thick detector enhences this yield.

\section{MAXIMUM CONTAMINATION PER UNIT AREA}

Area test measurements can be supplemented by printing the histogram of activity as measured during the transit. Given the component dimensions, the activity per unit area in $\mathrm{Bq} \cdot \mathrm{cm}^{2}$ can be determined for consecutive vertical bands scanned by the counter.

\section{CONSTRUCTION}

Mechanically, the unit consists of a rail secured to the ceiling of the measurement room, supporting a motor-driven dolly carrying two electronic load cells with a rated accuracy of $\pm 3 \mathrm{~kg}$. The waste component is held by self-closing grippers suspended from the load cells.

The waste component automatically transits through the measurement zone, after being scanned by a pattern recognition system using a light curtain to determine its shape. The operator enters the part thickness to allow compensation for self-shielding effects. 
The part then moves between the two counters which are positioned $15 \mathrm{~cm}$ beyond the maximum width of the 1 tem. The counting phase lasts until the trailing edge of the part passes in front of the detectors. The part is then placed on a support rack at the end of the counting line.

The entire operation is controlled by a microcomputer which also calculates the detector efficiency, component length, shadow effect, distance between detectors and attenuations to determine the final activity value. A typical printed data sheet is shown in Figure 8.

\subsection{Specifications}

Overall dimensions : 7 m long $\times 2$ m wide $\times 2$ m high

Control board : $1.2 \mathrm{~m}$ wide $\times 0.9 \mathrm{~m}$ deep $\times 2 \mathrm{~m}$ high comprising

electronic power supply and processing units

- control and monitoring systems:

- microcomputer (Bull Micral 30)

- analog recorder

- printer (NEC PInWriter)

Detectors : the unit includes 2 plastic scintillators measuring $1000 \mathrm{x}$ $500 \times 50 \mathrm{~mm}$ weighing $32 \mathrm{~kg}$ each

Electrical specifications:

Pulse output: $5 \mathrm{~V}$ into $50 \propto$ (pulse width: $1 \mu \mathrm{sec}$ )

- Dead time: 0 - $100 \mu \mathrm{sec}$

- Discrimination level: $0.2-2.5 \mathrm{~V}$

- Analog output: $1 \mathrm{~V}$ for 10000 counts $\cdot \sec ^{-1}$

- EHT supply: $1000-2000 \mathrm{~V}$

Waste material characteristics:

- Overall dimensions: $900 \times 1900 \times 1000$ mm maximum

- Weight: $20-500 \mathrm{~kg}$

- Radionuclides measured: 60Co, $134 \mathrm{Cs}, 137 \mathrm{Cs}$

\subsection{Current Performance}

- Counting rate : $\dot{6}$ maximum-size parts per hour (travel speed: $120 \mathrm{~cm} \cdot-$ min ')

- Background level: $2000 \mathrm{c} \cdot \sec ^{-1}$

- Detection efficiency: depends on detector gap $2 \%$ for 600 with detectors $1200 \mathrm{~mm}$ apart)

- Detection threshold: < $2000 \mathrm{~Bq}$ within $95 \%$ confidence interval for a flat part measuring $1900 \times 1000 \mathrm{~mm}$ and with a $1200 \mathrm{~mm}$ detector gap.

Figure 9 shows the detector portion of the controller.

\section{OPERATING EXPERIENCE TO DATE}

The residual specific activity break down for 109 metric tons of decontaminated scrap is shown in figure 10. 


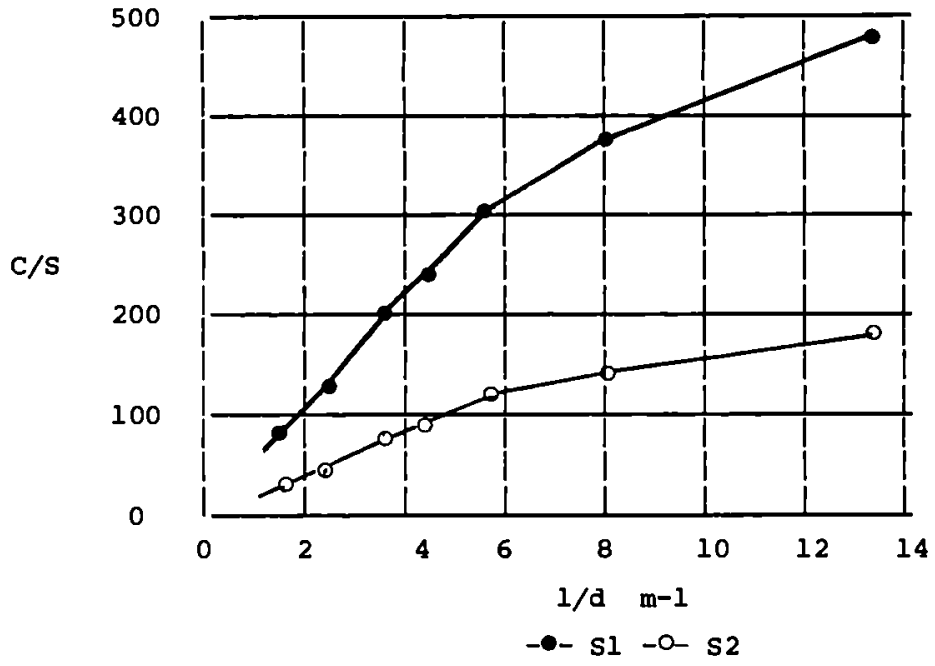

Fig. 1. Counting rate versus distance from contaminated surface

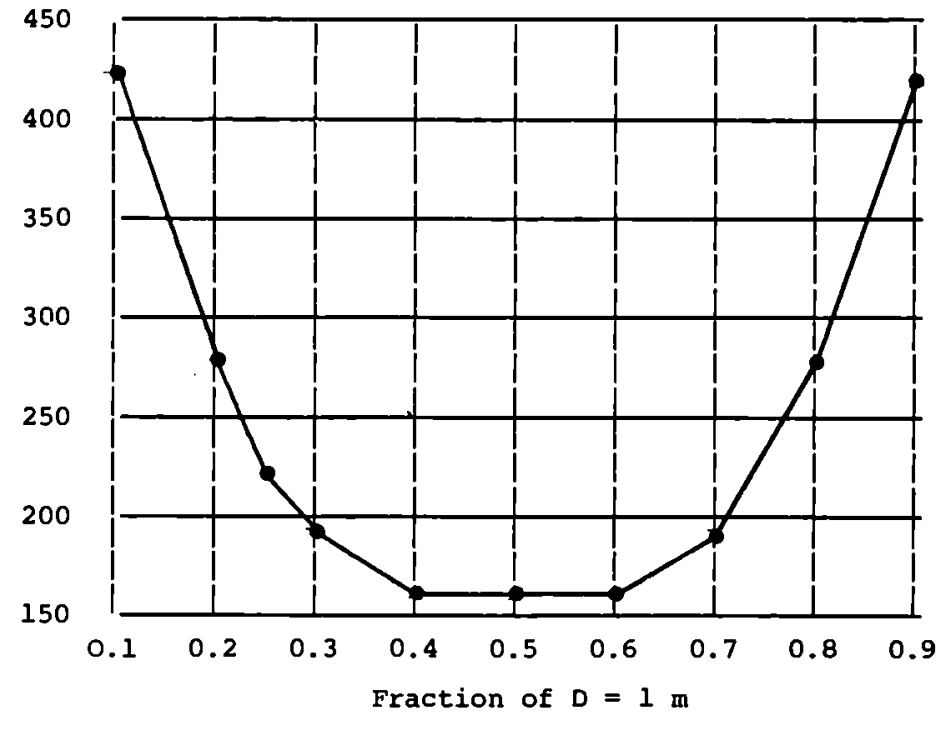

D: distance between two counters facing each other

Fig. 2 Response from two counters for specimen sl 


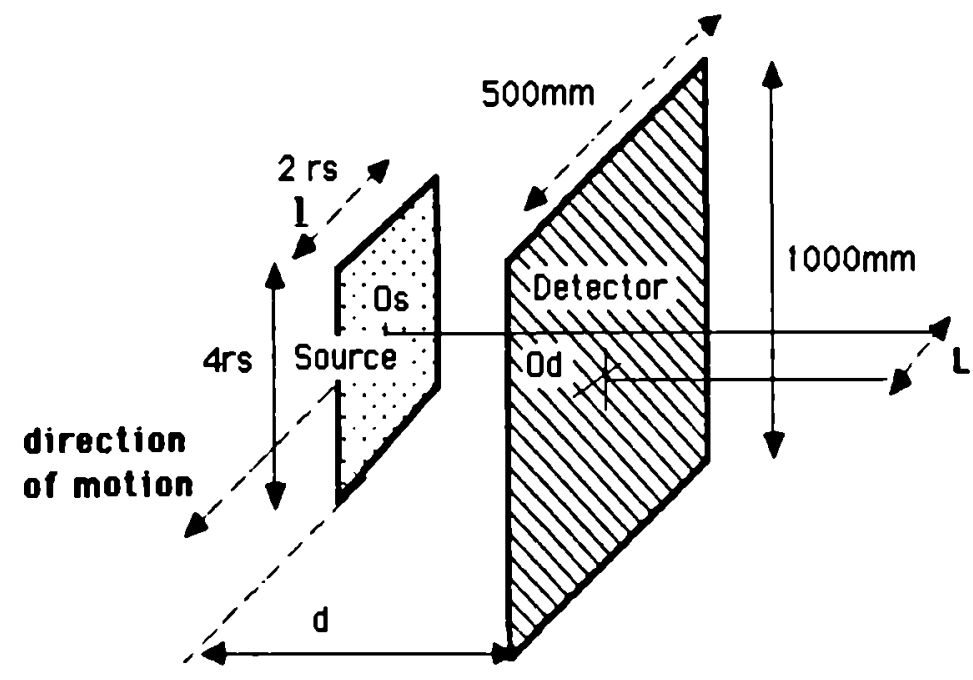

Fig 3. Calculated solid angle - Monte Carlo procedure

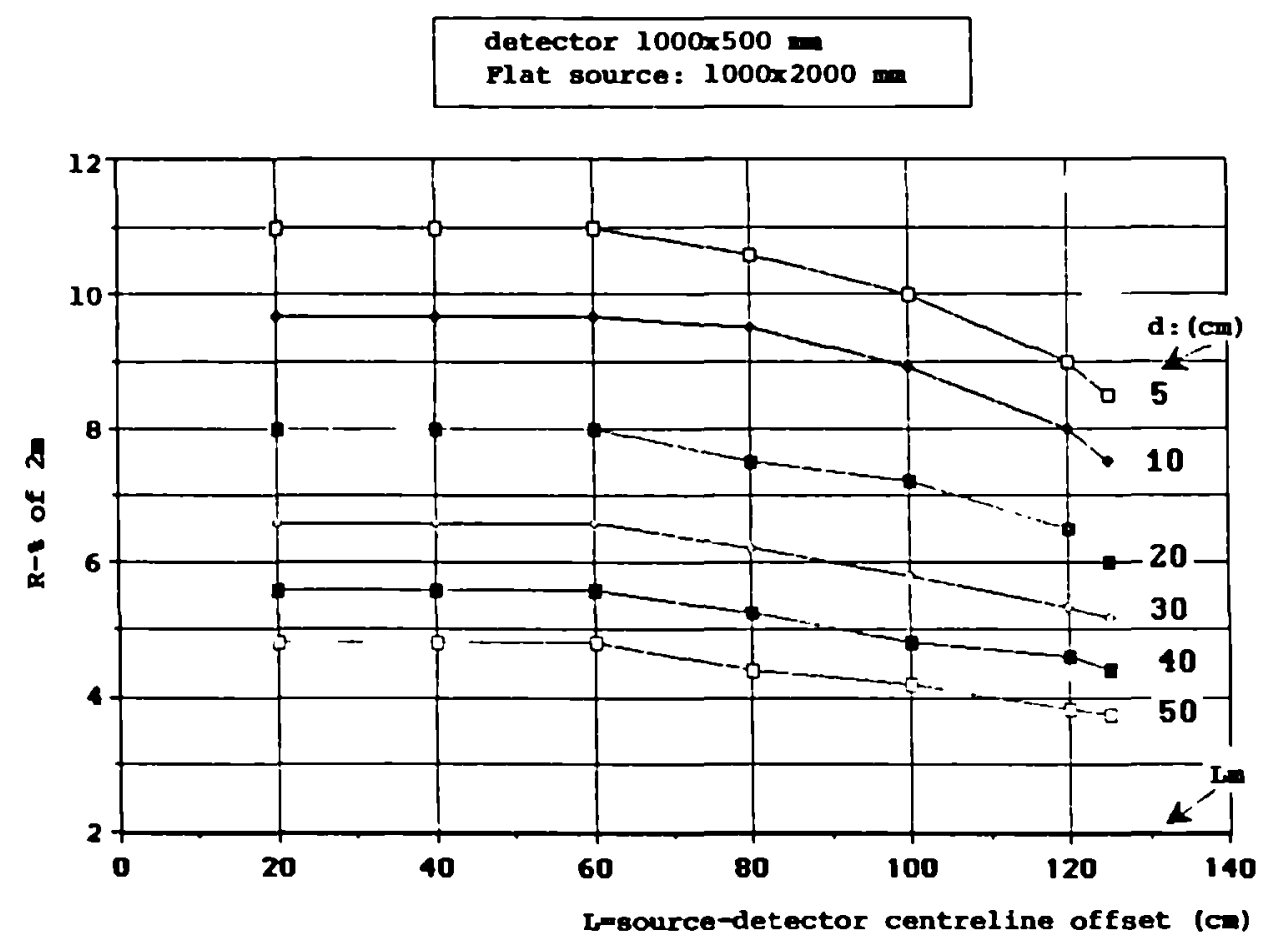

Fig 4. Mean solid angle: $R=f(L)$ 


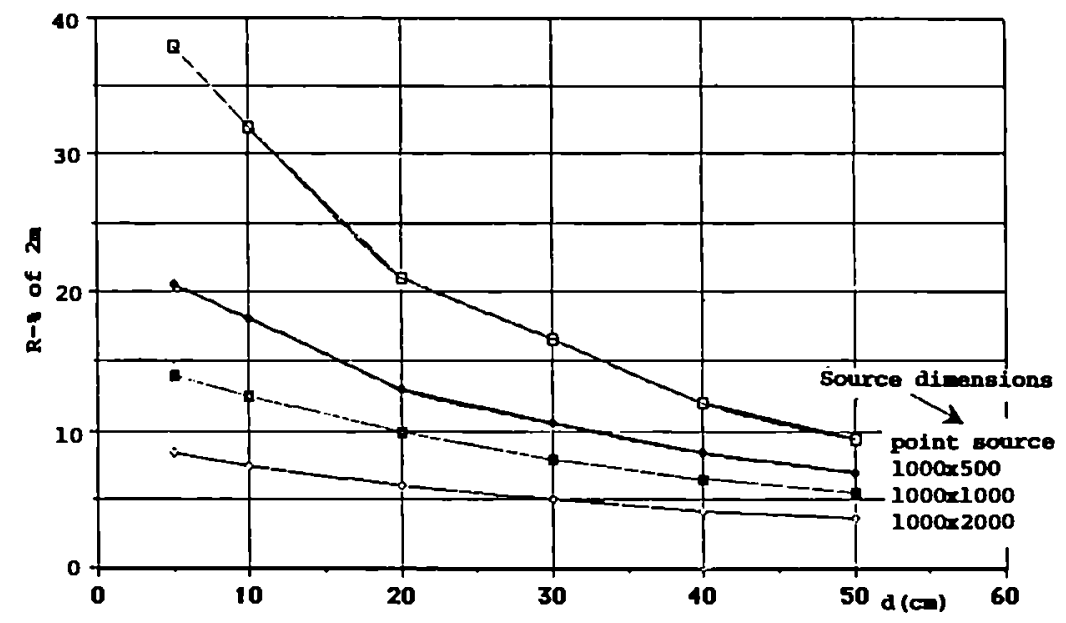

Fig. 5. $R=f$ (Source-detector distance) for offset $\mathrm{Lm}$

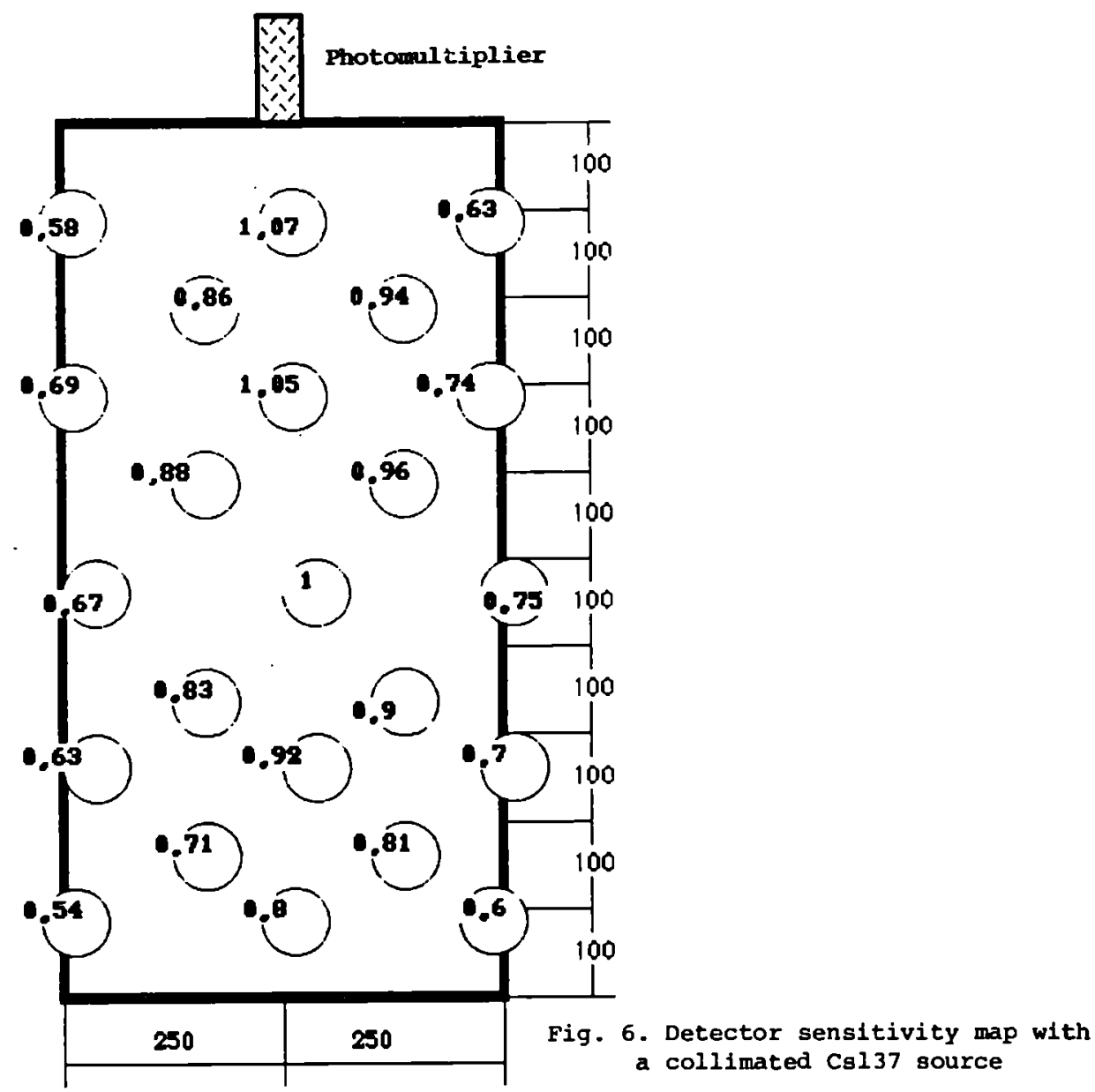


Calculated solid angle curves ( $84 \mathrm{pl}$ St)

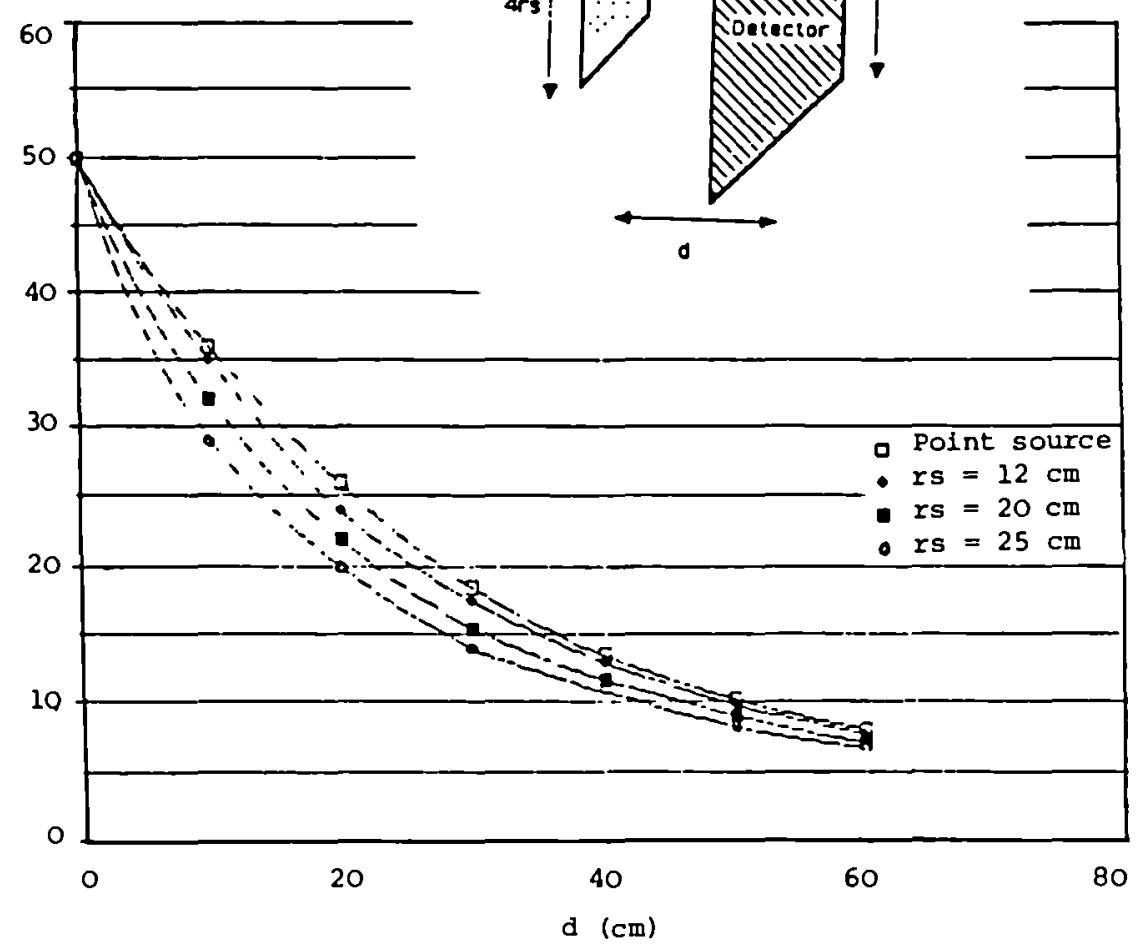

Fig. 7. Calculated solid angle - Monte Carlo procedure

July 22, $1988 \quad 14: 53$

Residual Activity of $\mathrm{G} 2 / \mathrm{G} 3$ Reactor Scrap Metal

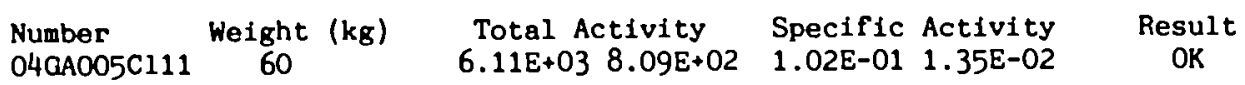

Background No 1 Count No 1 Background No 2 Count No 2 Time $\begin{array}{lllllllll}3.18 E+03 & 1.13 E+01 & 3.19 E+03 & 1.38 E+01 & 4.32 E+03 & 1.36 E+01 & 4.32 E+03 & 1.66 E+01 & 80\end{array}$

$\begin{array}{cccccc}\text { Spacing } & \text { Clearance Speed } & \text { Efficiency } 1 & \text { Efficlency } 2 & \text { Threshold } \\ 120 & 60 & 2.00 \mathrm{E}-02 & 1.76 \mathrm{E}-02 & 2.20 \mathrm{E}-02 & 1.00\end{array}$




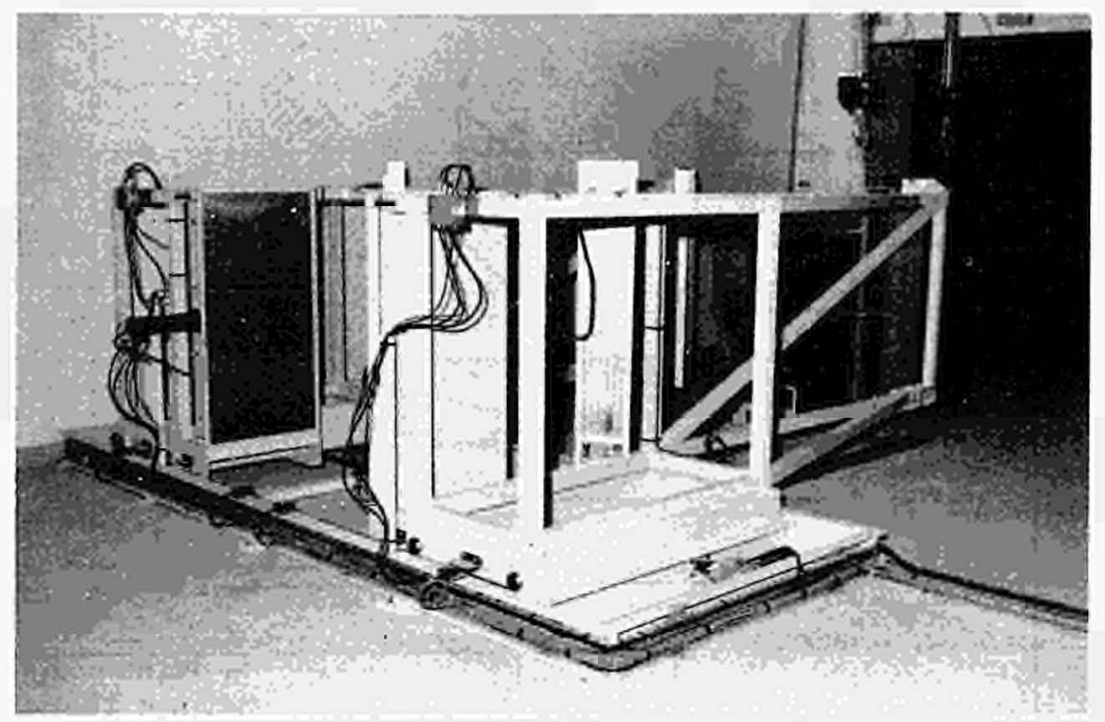

Fig 9 Detector portion of the controller

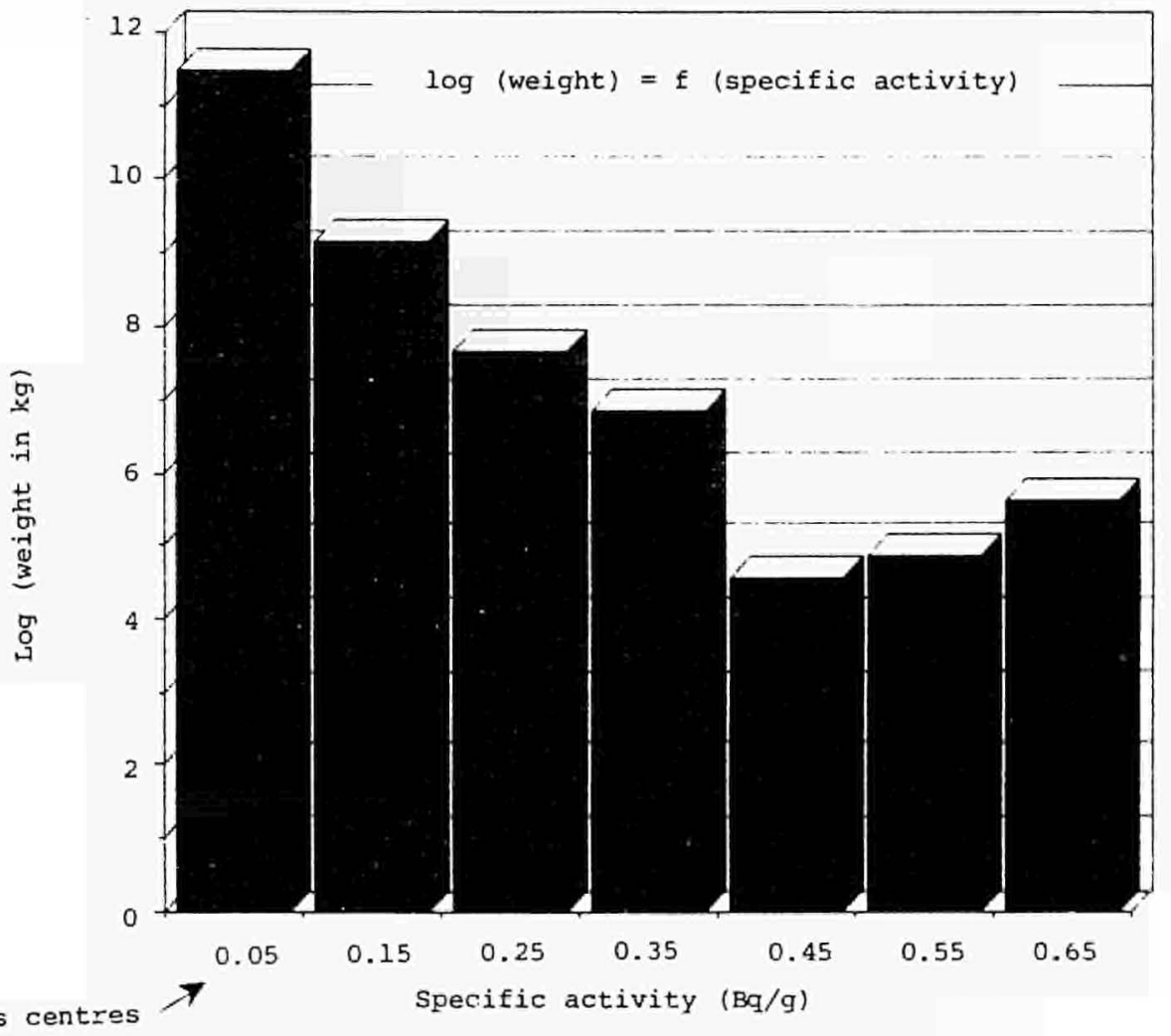

Fig. 10. G2 waste management: counting statistic 
MEASUREMENT TECHNIQUES APPLICABLE TO

RESIDUAL RADIOACTIVITY ON A DECOMMISSIONED REACTOR SITE

\author{
Paul B. Woollam \\ National Power Division of the Central Electricity Generating Board, \\ Technology Division, \\ Berkeley Nuclear Laboratories, \\ Gloucestershire, GL13 9PB, UK.
}

\begin{abstract}
During the likely deferral period between stages 2 and 3 of the decomissioning of National Power's reactors there is an incentive to move the present security fence inwards to encompass the minimum possible area of site. This could release land which might be made available to the local population for certain recreational purposes; this would be more attractive than an unused security controlled zone. In addition, there will be a significant financial saving in not maintaining a long security fence, and possibly security personnel, over a 100 year period. Before the Authorising Ministries accept any proposal to reduce the area of secure site they must be assured that the radiological consequences of such a change will be acceptable. National Power will still own the land and will still be responsible for safety; there need not be an unconditional release of any part of the site. The public might be allowed to use the land as they would a municipal park or managed woodland. This paper discusses techniques by which the site could be monitored to assure compliance with some possible criteria, together with the implications of existing levels of radioactive contamination resulting from airburst nuclear weapons tests and the Chernobyl accident.
\end{abstract}

\title{
1. INTRODUCTION
}

The most likely timescale for decommissioning the nuclear power stations in England and Wales will be immediate implementation of stages 1 and 2 followed by a deferment period of some 100 years before the start of stage 3. During the intervening period the reactors will be safely housed within their thick concrete shields or pressure vessels and will be the only structures remaining on site, with the exception of the decomissioned steel pressure vessel Magnox stations, where there is likely to be an additional building housing the slightly contaminated boiler units and, temporarily, the packaged waste from stage 2. During the deferment period, the National Power Company will retain ultimate responsibility for both conventional and nuclear safety on the decommissioned site.

At this time it will be preferable for the present security fence to be moved inwards to encompass the minimum possible area of the decommissioned site. There are two significant advantages in moving the fence. The first is that the land which might be released could be made available to the local population for certain recreational purposes; this will be aesthetically and visually more attractive than the prospect of an unused and inaccessible security zone. The second advantage is financial; the total cost over a period of some 100 years of maintaining a long security fence, and possibly additional security personnel, becomes very large.

Before the Authorising Ministries accept any proposal to reduce the area of secure site they will need to be assured that the radiological consequences of such a change will be acceptable. Because the National Power Company will still own the land, and will still be responsible for 
safety, there need not be an unconditional release of any part of the site. For example the Company, as landowner, could actively prevent any form of building or inappropriate agricultural use, allowing only public access onto and across the land for recreation. Then the radiological impact to members of the public accessing the land would result only from whole body exposure, inhalation of resuspended radioactivity and, possibly, ingestion of contaminated soil. The public might be allowed to use the land in a similar way to that in which they would use a municipal park or managed woodland.

There is no current UK legislation which specifically deals with the question of releasing a decommissioned nuclear site. It is however reasonable to suppose that the Authorising Ministries will develop criteria leading to a primary dose equivalent rate limit. Following some process of monitoring or administrative practise whereby the Authorising Ministries are satisfied that the residual risk to the public is less than the defined criterion, the site could be released for conditional reuse. Eventually, following stage 3 dismantlement, it may be that National Power would wish to release the site unconditionally so that no further regulatory controls would apply.

This document briefly summarises the types of radiological criteria which need to be developed to cover the release of a partly or totally decommissioned nuclear site and then looks at the methods whereby the site could be monitored to assure compliance with possible legislation. In particular, the implications of existing levels of radioactive contamination resulting from airburst nuclear weapons tests and from the Chernobyl accident are discussed.

\section{POSSIBLE RADIOLOGICAL CRITERIA FOR RELEASE OF A DECOMMISSIONED SITE}

Purely for the purposes of this paper it will be assumed here that criteria might be developed, in discussions with the Authorising Ministries, such that the dose rate to the most exposed individual from residual site radioactivity will not, in general, exceed $100 \mu \mathrm{Sv} / \mathrm{y}$ and will be as low as reasonably achievable below this with the aim of being less than $10 \mu \mathrm{Sv} / \mathrm{y}$, at which point regulatory control would cease. These dose rates currently relate to mortality risks of $10^{-6}$ to $10^{-7} / \mathrm{Y}$, although there is, of course, a continual review of the relationship between risk and dose.

These assumptions are, in broad terms, consistent with the USA approach (1) and also with the recommendations of some international bodies $(2,3)$. They serve here simply as a hypothetical basis from which to consider the type and sensitivity of equipment required for residual site contamination monitoring; their inclusion in this paper does not necessarily imply that they should be adopted for use in the UK.

It may be noted that the radiological consequences of setting residual contamination criteria based on de minimis, or recycling, type limits at around $1 \mathrm{~Bq} / \mathrm{g}$ would be dose rates of $430 \mu \mathrm{Sv} / \mathrm{y}$ to individuals continuously exposed above soil contaminated at this concentration with Cs-137 or 5500 $\mu \mathrm{Sv} / \mathrm{y}$ for continuous exposure to Co-60 (1). These consequences are clearly outside the $10 \mu \mathrm{Sv} / \mathrm{y}$ criterion noted above, and would not be consistent with international guidelines $\{2,3\}$.

It is important to keep all radiation levels in perspective. For example the dose rate limit of $10 \mu \mathrm{Sv} / \mathrm{y}$, resulting from residual radioactivity in soil, should be compared with natural dose rates from terrestrial sources. Around Berkeley the annual dose from rock and soil is about 300 $\mu \mathrm{Sv}$; this is about $20 \%$ of the total annual dose of $1500 \mu \mathrm{Sv}$ received on average by a typical member of the local population from all sources of radioactivity. If residual radioactivity were to remain on site at a 
concentration leading to a dose rate of $10 \mu \mathrm{Sv} / \mathrm{Y}$, the total exposure to this typical person if he continuously occupied the site would be increased by only 0.78. Many people receive technologically enhanced doses; for example a one-way subsonic flight from London to New York exposes passengers to an additional $15 \mu \mathrm{Sv}$ from cosmic radiation.

An important aspect of any residual site contamination criterion is the area of land over which the dose rate, or other primary quantity. should be averaged: it is of major importance in assessing the practicability and consequent cost of surveying a decommissioned site. This point is dealt with in a subsequent section of this paper.

3. EXISTING LEVELS OF RADIOACTIVE CONTAMINATION ON THE BERKELEY SITE Berkeley is the first large nuclear power station to be decomissioned in the UK. Although this section refers to measurements made on the adjoining Berkeley Nuclear Laboratories (BNL) site, the data, which refer to weapons test and Chernobyl deposited radioactivity, will clearly be applicable to the Berkeley Power Station site also. All the data were obtained before National Power announced its intention to cease generation at Berkeley; the BNL site was used purely as a matter of convenience.

A measurement of the total dose equivalent rate experienced by a person wholly resident on the Berkeley site would show about $1500 \mu \mathrm{Sv} / \mathrm{y}$ even if no nuclear power generation activities had ever been undertaken there. The vast majority of this dose rate is, of course, from natural sources including cosmic rays, $\mathrm{K}-40$ and the radium and thorium radioactivity in the ground. Here we are only concerned with isotopes potentially generated in the nuclear power station. This immediately leads to the conclusion that any measurements made to assure compliance with a site residual radioactivity release limit expressed as a dose equivalent rate must be isotope dependent, even if the limit were to be set considerably above the hypothetical criteria assumed in Section 2. In practical terms this requires a high resolution energy dependent gamma spectrometry measurement: there is no other method by which small additions to an existing, natural dose rate can be determined.

However, even an energy dependent total dose rate measurement, to determine the radiological consequence of man made isotopes, will necessarily include contributions from fallout following the 1960s weapons tests and the Chernobyl accident in 1986. These sources will set a lower limit to any practical release criterion, simply because they cannot realistically be distinguished from those in the UK nuclear fuel cycle.

There are three major routes by which the public might be exposed to Ionising radiation on a decommissioned reactor site which had been released for conditional access only: whole body exposure to ground contamination, inhalation of resuspended material and, possibly, consumption of contaminated soil. This Section estimates the contribution to total exposure from each of these routes.

\subsection{Whole Body Exposure to Ground Contamination}

An extensive series of high resolution gamma spectrometry measurements made above various surfaces on the BNL site (4) showed the following average full energy photon fluxes one metre above ground level:

$\begin{array}{llr}\text { Above grass/soil: } & \mathrm{Cs}-137 & 624 \mathrm{r} / \mathrm{m}^{2} / \mathrm{s} \\ & \mathrm{Cs}-134 & 71 \mathrm{r} / \mathrm{m}^{2} / \mathrm{s} \\ \text { Above concrete: } & \mathrm{Cs}-137 & 266 \mathrm{r} / \mathrm{m}^{2} / \mathrm{s} \\ & \mathrm{Cs}-134 & 59 \mathrm{r} / \mathrm{m}^{2} / \mathrm{s} \\ \text { Above tarmac: } & \mathrm{Cs}-137 & 230 \mathrm{r} / \mathrm{m}^{2} / \mathrm{s} \\ & \mathrm{Cs}-134 & 60 \mathrm{r} / \mathrm{m}^{2} / \mathrm{s}\end{array}$


The data for Cs-137 refer to the $661 \mathrm{keV}$ photon and for Cs-134 to the $604 \mathrm{keV}$ photon. These were the only man-made isotopes detectable. To determine the individual dose rates which result from these isotopes, account must be taken of scattered radiation. However, using Taylor buildup factors and a knowledge of the depth profile of the radioactivity, it can be shown (5) that scattered fluxes increase the overall dose rate above the grass/soil areas by only 15\%. Because the contamination on concrete and tarmac is essentially surface bound, there is no scattered contribution to total dose equivalent rate. The contribution to dose rate from Cs-134 must also, of course, include photons from other than the 604 keV transition.

Assuming for the moment that a member of the public continuously occupies the decommissioned, conditionally released site, the whole body exposure rate he receives from standing on each surface is:

$\begin{array}{lr}\text { Above grass/soil: } & 10.5 \mu \mathrm{\mu v} / \mathrm{Y} \\ \text { Above concrete: } & 4.8 \mu \mathrm{\mu v} / \mathrm{Y} \\ \text { Above tarmac: } & 4.4 \mathrm{\mu Sv} / \mathrm{Y}\end{array}$

Taking the largest of these exposure rates, above the grass/soil surface, the photon flux data show that point-to-point variability across the BNL site is such that there is a $99.7 \%$ certainty that the annual dose comitment, for continuous occupancy, from whole body exposure outdoors on the BNL site from man-made isotopes is less than $12.7 \mu \mathrm{Sv}$. The question of realistic occupancy factors has not so far been addressed; this is dealt with in a subsequent section of this paper.

\subsection{Soil Ingestion}

Although National Power will own and will therefore control the decommissioned site so as to supervise any agricultural usage and the consequent dose incurred in foodchain routes to man, the potential for ingestion of soil cannot be totally eliminated. Detailed measurements following the Chernobyl accident (6) showed that total Cs-137 soil contamination levels at $\mathrm{BNL}$ were $390 \mathrm{~Bq} / \mathrm{m}^{2}$ resulting from Chernobyl and $3440 \mathrm{~Bq} / \mathrm{m}^{2}$ from the $1960 \mathrm{~s}$ airburst weapons tests. The weapons contamination has measurably diffused to a depth of $16 \mathrm{~cm}$. Using transfer factors applicable to the consumption of soil, the committed effective dose equivalent rate from ingestion of $\mathrm{Cs}-137$ contaminated soil is $0.12 \mu \mathrm{Sv} / \mathrm{Y}$ assuming a soil ingestion rate of $1 \mathrm{~g} /$ day and also assuming that the layer of contaminated soil is uniformly mixed. This soil consumption rate is an assumption; it seems unlikely that an individual would normally consume more than $360 \mathrm{~g} / \mathrm{y}$ of soil, especially outside of an agricultural context.

The latest published measurements by AEA Technology, Harwell, of Cs-137 and $\mathrm{Sr}-90$ in rainwater (7) show a Cs-137/Sr-90 ratio of 1.7 . Although this ratio was measured before Chernobyl it is unlikely to have changed significantly (see Section 3.3). Using this ratio, together with appropriate Cs-137 data (6) and transfer factors, the annual committed effective dose equivalent from ingesting $1 \mathrm{~g} /$ day of Sr-90 contaminated soil is $0.19 \mu \mathrm{Sv}$. Further airborne data (7) show the ratio $(\mathrm{Pu}-239+\mathrm{Pu}-240) /$ Cs-137 to be 0.053 in rainwater. Similar calculations then show that ingestion of $1 \mathrm{~g} /$ day of $\mathrm{Pu}$ contaminated soil leads to an annual committed effective dose equivalent of $0.05 \mu \mathrm{Sv}$.

Thus, if a member of the public ingests $1 \mathrm{~g} / \mathrm{day}$ of soil from the BNL site, his total annual committed effective dose equivalent from this route is $0.36 \mu \mathrm{Sv}$. This assumes that the primary source of contamination is airburst weapons test fallout, and that the contamination levels at BNL are no higher, because of the adjacent nuclear power station, than elsewhere in the area. The post-Chernobyl data (6) clearly show this to be the case; 
BNL site contamination levels are similar to those elsewhere in the River Severn valley, and lower than those on the surrounding hills. The exceptions are those sites which have been extensively altered since the 1960 s weapons tests, such as National Power of $f$ ices in Gloucester and Bristol. Here, surface contamination levels are lower because weapons test material has been buried during relatively recent building operations.

\subsection{Airborne Radioactivity}

Routine AEA Technology measurements in the UK (7) showed typical airborne concentrations of weapons fallout radioactivity in 1983 to be:

$$
\begin{array}{ll}
\mathrm{Cs}-137 & 3.3 \times 10^{-6} \mathrm{~Bq} / \mathrm{m}^{3} \\
\mathrm{Sr}-90 & 1.9 \times 10^{-6} \mathrm{~Bq} / \mathrm{m}^{3}
\end{array}
$$

$$
\left.\begin{array}{l}
239, \\
240
\end{array}\right) 4.4 \times 10^{-1} \mathrm{~Bq} / \mathrm{m}^{3}
$$

Using standard ICRP data for the dose conversion factors, the annual comitted effective dose equivalent to a person who continuously breathes this air is:

$$
\begin{array}{ll}
\text { Cs-137 } & 4 \times 10^{-} \mu \mathrm{Sv} \\
\mathrm{Sr}-90 & 9 \times 10^{-3} \mu \mathrm{Sv}
\end{array}
$$

$$
\left.\begin{array}{r}
\text { Pu-238, } \\
239^{\prime} \\
240
\end{array}\right) \quad 1.3 \times 10^{-1} \mu \mathrm{Sv}
$$

leading to a total of $0.14 \mu \mathrm{Sv}$. This dose equivalent commitment is gradually reducing as weapons test material becomes less resuspendible. Again, from measurements made on the BNL site, there is no reason to suppose that these typical UK data differ from local airborne concentrations. Comparison between $\mathrm{Cs}-137$ weapons contamination levels in surface soll at BNL $\left(\sim 160 \mathrm{~Bq} / \mathrm{m}^{2} / \mathrm{cm}\right)$ and the measured UK airborne level leads to a resuspension factor of $2 \times 10^{-8} \mathrm{~m}^{-1}$, if it is assumed that the top centimetre of soll is resuspendible and responsible for the airborne Cs-137. This is somewhat greater than the values of $10^{-9} \mathrm{~m}^{-1}$ recommended for typical 20 year weathered soils by both USNRC (8) and NRPB (9), giving confidence that local airborne levels, if they resulted from resuspension of local contamination, will not be significantly greater than typical UK values. Airborne radioactivity measurements at BNL some six months after the Chernobyl accident (6) showed that concentrations of Cs-137 had returned to their pre-Chernobyl levels; thus this accident source will not significantly increase the dose comitment from airborne contamination.

\subsection{Overall Radiological Consequence}

The total best estimate radiological consequence, from existing man-made radioactive contamination, primarily from nuclear weapons tests but including fallout from the Chernobyl accident, to a person continuously occupying the Berkeley site is:

$\begin{array}{lll}\text { Maximum whole body exposure: } & 10.5 & \mu \mathrm{Sv} / \mathrm{Y} \\ \text { Soil ingestion: } & 0.4 & \mu \mathrm{Sv} / \mathrm{Y} \\ \text { Inhalation of airborne radioactivity: } & 0.14 & \mu \mathrm{Sv} / \mathrm{Y},\end{array}$

leading to a total of $11 \mu \mathrm{Sv} / \mathrm{y}$. As noted previously, the data indicate that the dominant route, whole body exposure, is 99.78 certain not to exceed $12.7 \mu \mathrm{Sv} / \mathrm{y}$, so the greatest annual dose commitment from continuous occupancy is unlikely to exceed about $13 \mu \mathrm{Sv}$.

\section{DISCUSSION}

After the completion of Stage 2 decommissioning, National Power might perhaps decide that part of the residual site should be conditionally released for public access. Because National Power will still own the land it can control both managed agricultural activity and also building work which would result in significant site intrusion. It could be difficult to control natural crops such as blackberries or pheasants and rabbits, but 
the contribution to the average person's diet from such routes is negligible. The residual buildings on the site can be designed in such a way that direct shine from any radioactivity they contain gives rise to a dose rate below any limits which might be imposed on National Power.

Thus the main routes in this scenario by which the public could be exposed are whole body exposure from ground contamination, ingestion of contaminated soil and inhalation of airborne radioactivity. Data presented here and elsewhere (6) show that exposures from man made isotopes via these routes are no higher on the Berkeley nuclear licensed site than elsewhere in the surrounding district, because they are controlled primarily by fallout from weapons testing. The overall annual dose for continuous occupancy of the Berkeley site is unlikely to exceed about $13 \mu \mathrm{Sv}$. The problem is that it is extremely difficult to differentiate weapons fallout radioactivity from long decayed radioactivity originating in the nuclear fuel cycle. Therefore, existing levels from weapons tests set a minimum to the quantity of man-made radioactivity and consequent dose rate which, in practise, will be found on a nuclear licensed site.

\subsection{Measurement Techniques}

These dose rates are dominated by whole body exposure from gamma emitting isotopes which it is feasible, though not straightforward at the necessary low levels, to measure with reasonable accuracy by high resolution garma ray spectrometry. In the event that significant additional radioactive material were to be deposited on site during either stages 1 or 2 of decommissioning it will be possible to measure the increased radiological consequences. These would be detected from additional levels of Cs-137, if the release came from fuel cooling ponds or radioactive effluent treatment plant dismantlement, or from Co-60, not currently measurable on the BNL site, if releases resulted from removal of the boilers or primary circuit ducts.

It is not possible to measure the dominant radiological consequence from residual man made isotopes at the levels of interest here without using high resolution gamma ray spectrometry. Unfortunately, site surveys using this type of equipment are, in general, both labour intensive and time consuming. Techniques are however available to speed up the process, by using an ultrasonic ranging system which allows an operator's position to be determined accurately by triangulation. The data being measured by the operator's radiation detector are transmitted, together with his position, to a computer by VHF radio. A basic systern (10) designed by the Oak Ridge National Laboratory on behalf of the USDOE is now commercially available (USRADS) with a positional accuracy of about $30 \mathrm{~cm}$. It could readily be developed to operate with HPGe detectors which would then allow high resolution gamma spectrometry site surveys at low action levels to be undertaken faster and therefore more economically. The commercial system currently uses a simple dose meter which, of course, measures natural as well as man made radioactivity.

It remains to consider the potential for in-situ gamma spectrometry with a residual radioactivity source distribution leading to an annual dose equivalent of between $10 \mu \mathrm{Sv}$ and $100 \mu \mathrm{Sv}$, as discussed in Section 2 . HPGe detectors with $30 \%$ relative efficiencies are widely available; it is possible now to purchase detectors having twice this efficiency. Such an instrument would have a photopeak response of about 12 counts $/ \gamma / \mathrm{cm}^{2}$ in a gamma photon flux of $661 \mathrm{kev}$. Thus for the best estimate of current weapons Cs-137 levels in the soil on the BNL site the response would be 
about 0.7 count/s (CPs). This corresponds to an annual exposure of $10 \mu \mathrm{Sv}$ with 100 occupancy.

\subsection{Occupancy Factors and Averaging Area}

The next question to consider is the realistic occupancy factor to be applied to a member of the public using the land for recreation. A further question is the area of land over which the measurement should be averaged. Let us consider three possible scenarios. In the first, a person walks over the land exercising his greyhound for four hours each day of the year. He then has a 178 occupancy and, if he walks at $3 \mathrm{~km} / \mathrm{h}$, is exposed to the average gamma radiation from an area of land of about one metre either side of his path which is, in total, about $25000 \mathrm{~m}^{2}$. In the second scenario, children are playing ball games on the land, again for four hours each day of the year but they are now exposed to the average radiation from an area of land, say $5000 \mathrm{~m}^{2}$. In the third, a person having a picnic occupies the site every summer weekend for $6 \mathrm{~h}$, which is $120 \mathrm{~h} / \mathrm{y}$ or 1.58 of the year. He is exposed to the average radiation from an area of about $10 \mathrm{~m}^{2}$.

Given that National Power will still own the decommissioned site, and will therefore control erection of buildings, it is unlikely that any member of the public will have an annual occupancy which significantly exceeds 20 or be exposed to radiation averaged over an area which is significantly less than $10 \mathrm{~m}^{2}$. A 208 occupancy factor would allow an annual exposure of only $10 \mu \mathrm{Sv}$ on a site where the exposure for continuous occupancy is $50 \mu \mathrm{Sv} / \mathrm{Y}$. A 60 z efficient $\mathrm{HPGe}$ detector would have a photopeak countrate of $4 \mathrm{cps}$ in a dose rate equivalent to $50 \mu \mathrm{Sv} / \mathrm{Y}$ of Cs-137.

A radiation measurement to be averaged over an area of $10 \mathrm{~m}^{2}$ could be made by a man walking at about $3 \mathrm{~km} / \mathrm{h}$ across the site covering tracks $3 \mathrm{~m}$ apart. Each measurement would be integrated over four seconds, to average the countrate over a distance of $3.3 \mathrm{~m}$. The limiting number of counts in the Cs-137 photopeak measured above a source equivalent to a dose rate of $10 \mu \mathrm{Sv} / \mathrm{y}$, averaging over $10 \mathrm{~m}^{2}$ with 208 occupancy factor, would then be about 15. The response from existing Cs-137 resulting from weapons tests would be about 3 counts in 4 seconds.

It would therefore be possible to verify compliance with a residual site radioactivity $l$ imit based on a dose rate of $10 \mu \mathrm{Sv} / \mathrm{y}$ with 208 occupancy, averaging over $10 \mathrm{~m}^{2}$. Clearly the task would be easier if the criterion was $100 \mu \mathrm{Sv} / \mathrm{Y}$, even for 1008 occupancy. Sites could be surveyed at a rate of approximately 1 hectare per hour. In addition to the detailed survey described here it would also be necessary to undertake a small soil sampling programme to measure the concentrations of non gamma emitting isotopes. From this measurement an isotopic fingerprint could be deduced, relating the non gamme emitters (which are difficult to detect) to the more readily measured gamma emitting isotopes. The overall contribution to total committed effective dose equivalent from soil ingestion and inhalation following resuspension can then be readily determined from the garma spectrometry site survey. It has been noted (4) that gamma isotope concentration measurements made by in-situ spectrometry are consistent with those based on sample measurements. It would be straightforward to make measurements similar to those described here for Co-60; this would allow verification that no radioactive material had contaminated the site as a result of dismantling the gas circuits.

However, if the residual radioactivity limit were to be set at $10 \mu \mathrm{Sv} / \mathrm{Y}$ it would be difficult to verify because of the existing levels of weapons contamination. It is possible that a detailed statistical treatment of the point-to-point variations in Cs-137 fluxes across the site 
could yield information on areas which were significantly above the $10 \mu \mathrm{Sv} / \mathrm{Y}$ limit, but this might require impracticably long measurement periods. Similarly, any requirement to average radioactivity measurements over site areas significantly smaller than the $10 \mathrm{~m}^{2}$ assumed in this paper would lead to a measurement progranme which might be considered too time consuming .

\section{CONCLUSIONS}

1. Any practical criteria for acceptable levels of residual radioactivity on a decommissioned reactor site released for public access must address the area over which the verification measurement is to be averaged.

2. Any levels likely to be publicly acceptable will be at or below natural background, thus the only feasible measurement technique will be high resolution garma spectrometry using portable germanium detectors.

3. At the decommissioned Berkeley site in England, deposition from the 1960s airburst weapons tests and from the Chernobyl accident gives a best estimate annual dose of about $11 \mu \mathrm{Sv}$ to a person continuously occupying the site, primarily from whole body exposure to Cs-137. This sets a practical lower threshold to any legislated limit on residual contamination from reactor operations.

4. Using currently available, but state-of-the-art, germanium detection systems, a deconmissioned site could be surveyed to verify compliance with an annual dose limit of $10 \mu \mathrm{Sv}$, if a realistic maximum occupancy factor of 208 were to be assumed. With an averaging area of $10 \mathrm{~m}^{2}$ the survey could measure up to one hectare each hour at this dose rate.

\section{ACKNOWLEDGEMENT}

This paper is published with the permission of the National Power Division of the Central Electricity Generating Board.

\section{REFERENCES}

(1) USNRC, 1981, 'Draft generic environmental impact statement on decommissioning nuclear facilities', NUREG-0586.

(2) IAEA, 1987, IAEA report, IAEA-TECDOC-401.

(3) ICRP, 1985, ICRP publication 46, Annals of the ICRP vol. 15, no. 4.

(4) Woollam, P.B. and Sadler, R.M., 1988, CEGB memorandum, $\mathrm{RD} / \mathrm{B} / \mathrm{NM} / 0031 / \mathrm{M} 88$.

(5) Price, B.T., Eorton, C.C. and Spinney, K.T., 1957, 'Radiation Shielding', Pergamon, London.

(6) Hancock, R. and Woollam, P.B., 1986, CEGB report TPRD/B/0809/R86.

(7) Cambray, R.S., Lewis, G.N.J. and Playford, K., 1984, AERE report, R11475.

(8) Hanson, W.C. (Ed), 1980, 'Transuranic elements in the environment' USDOE.

(9) Simmons, J.R., Linsley, G.S. and Jones, J.A., 1979, NRPB report, NRPB-R89.

(10) Bervin, B.A., Blair, M.S. and Little, C.A., 1987, Proceedings of Pittsburgh International Deconmissioning Symposium, p. V-127.

(C) Copyright Central Electricity Generating Board, 1989 


\section{DISCUSSION}

Question: B W EMMERSON, HM Nuclear Installations Inspectorate - Bearing in mind that the more robust the detector, the lower the sensitivity is likely to be, have the various detectors discussed been ranked in terms of their 'robustness' for use in the type of industrial conditions associated with large-scale decommissioning operations?

Answer: R HOFFMANN, Slemens KWU - The detectors used in the test measurements were selected according to their specifications as well as to their avallability on the market. They have not been tested on site, so their ruggedness has not been ranked.

Question: P GUETAT, CEA-FAR - In your calculations of relative radiotoxicity, you use simultaneously dose factors and Limits for Unrestricted Use. These last values most probably also include dose factors. In that way, are you not using the same factors twice?

Answer: R HOFFMANN, Siemens KWU - The relative radiotoxicitıes define a relationship between the dose factors and the Limits for Unrestricted Use of nuclides as compared with Co-60. Therefore, they describe the radiological under/over estimation as resulting from the definitions of the exemption $11 \mathrm{mits}$. The real range of radiotoxicities is higher than that denoted by the two contamination limits or the four mass-related activity concentration limets.

Question: H J C BOEKSCHOTEN, KEMA - Mr MacMahon, do you have contact with an instrument manufacturer to apply your method for the detection of small peaks to a commercial instrument?

Answer: D MacmAHON, Imperial College - There are not yet direct contacts, but the information is now freely available in the EUR report $12183 \mathrm{EN}$.

Question: R NEIDER, BAM - Mr Hermanns, how difficult is it to replace a damaged window in the counter tube you described?

Answer: B HERMANNS, Reaktorwartungsdienst - In the case of round counter tubes the whole cage can be unscrewed, rewound and bonded or it can be simply replaced. In the case of flat counters with front-end and side windows, the cage replacement must include removal of the input discriminator.

Question: J ESSMANN, Preussen Elektra - You have presented an interesting monitoring system for measurement of land areas. Have you ever calculated the costs especially for deciding that the area is free of radioactivity?

Answer: D MacmAHON, Imperial College - Costs for developing a prototype have been calculated. Overall costs per scan are not yet fully calculated.

One can never decide that an area is completely free of radioactivity. our project almed to show what level of localised gamma activity can be measured, and at what depth.

Question: H J C BOEKSCHOTEN, KEMA - What is the impact of a delay of 100 years or so of the dismantling on the detection methods? 
Answer: R HOFFMANN, Siemens KWU - If the easily measurable nuclides have all decayed, a different measurement technique would have to be employed. An assessment of the relative radiotoxicities would be needed.

question: R NEIDER, BAM - with your measuring installation, how do you ensure compliance with the German surface contamination limit of $0.37 \mathrm{~Bq} / \mathrm{cm}^{2}$ ?

Answer: I AULER, NIS - We can satisfy this requirement if we know the surface-to-mass ratio of the component to be measured and the measured weight.

Answer: G IMBARD, CEA-Valrho - Since the measurement of the waste is dynamic we split into 10 equal intervals and use the counts to calculate the average surface activity for the vertical surface bands ( $\max =0.2 \mathrm{~m}^{2}$ ). However, in France mass activity measurement (limit: $1 \mathrm{~Bq} / \mathrm{g}$ ) is sufficient; the resultant mobile surface activity need not be taken into account for steel to be melted, with resulting homogenisation and stabilisation of activity.

Question: P FUNKE, Ministry of the Environment and Reactor Safety, Wieskaden - In the UK the measurement of individual samples is sufficient to obtain a licence whereas in the Federal Republic of Germany and in France 100\% measurement is still the rule. What special conditions apply in the UK with regard to the AGR that allows such an approach to be adopted?

Answer: F G BRIGHTMAN, UKAEA-Windscale - we do not expect to measure 1008 of our activated materials. We will sample the highly activated material (such as WAGR stainless steel) very carefully during dismantling and also graphite and steel. We think that sampling is sufficient to ensure that we know how much activity is present. However, the volume and mass over which we average the result is important. Not all countries agree yet on what fraction to sample, or on how to average. Where most of the activity is due to surface contamination different arrangements are needed.

Question: A HUSAIN, Ontario Hydro - How is self-shielding taken into account?

Answer: I AULER, NIS - Our conservative assumption is that self-shielding for $2 \mathrm{~cm}$ steel is not very high.

Answer: G IMBARD, CEA-Valrho - In our method self-shielding is determined by a number of parameters such as the height and weight of the component or the spacing of the detectors. These values fluctuate and cannot be theoretically equated. A preliminary experiment with various pieces of clean steel and varied spacing of the detectors produced a table of 'correction' values. For example, a heavy piece $1 \mathrm{~m} \mathrm{high} \mathrm{and} 2 \mathrm{~m}$ long causes attenuation of $100 \mathrm{c} / \mathrm{s}$ in background noise per detector at a distance of $120 \mathrm{~cm}$ (or approximately 48 of the background noise).

Question: P De REGGE, SCK/CEN Mol - Did you find any correlations between Co-60 and other gamma emitting isotopes and C-14, for instance in the graphite, or is C-14 not a matter of concern in the measurements that are carried out?

Answer: F G BRIGHTMAN, UKAEA Windscale - Correlations are not observed in general, because both $\mathrm{CO}-60$ and $\mathrm{C}-14$ production is from uncontrolled 
impurity reactions, eg Co-59 ( $\mathrm{n}$, gamma) Co-60 and $N-14$ (n,p) $c-14$. The impurity concentrations can vary over whe ranges.

CONCLUSION

The session this morning provided a broad view on measurement methods. We heard about the development of new instruments, and electronic treatment of the spectrum data and the application of measurements and calculations.

I think we must thank the Community not only for the financial support but also for the stimulating opportunity for the exchange of ideas and results.

H J C BOEKSCHOTEN, KEMA 


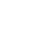




\section{SESSION VII}

ESTIMATION OF WASTE QUANTITIES AND THEIR DISPOSAL PROSPECTS

CHAIRMAN: S ORLOWSKI, CEC

SECRETARY: K PFLUGRAD 


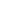


INVENTORY OF GLOVE BOXES DISMANTLING OPERATIONS

in the Fuel Fabrication Complex of Cadarache from 1986 to 1988

CAILLOL A.

Commissariat l'Energie Atomique, Paris, France.

\section{ABSTRACT}

several plutonium processing lines belonging to the Fuel Fabrication complex of Cadarache (CFCa) had to be dismantled after long service, in the frame of plant modernisation.

The importance of the plutonium quantities (several tons) that have been processed in these obsolete lines, the volume of the glove boxes which have been dismantled (more than $100 \mathrm{~m} 3$ ) and the variety of their functions made of general interest to set up an inventory of these operations and to evaluate the waste management problems involved in the decommissionning of such a facility.

Depending on the type, size and plutonium retention of the concerned glove boxes, different ways in dismantling procedures, plutonium recovery, waste size reduction and decontamination, have been tried.

As a final result, a $400 \mathrm{~m} 2$ area, corresponding to 4 laboratories (working cells) has been made available for new equipments after complete cleaning.

\section{PRESENTATION}

The Fuel Fabrication complex of CEA-CADARACHE (CFCa) is committed since its creation in 1960 with the fabrication of all plutonium bearing nuclear fuel elements required for the implementation of the French fast breeder reactor programme : RAPSODIE, now stopped, PHENIX and SUPERPHENIX.

It is composed of two independent INB buildings (INB : Installation Nucléaire de Base) authorised for processing illimited quantities of fissile materials :

- ATPu (Atelier de Technologie du Plutonium) is the main facility where finished fuel elements are fabricated, starting from $\mathrm{PuO}_{2}$ and $\mathrm{UO}_{2}$ powders, with metallic structural components purchased from specialized manufacturers. Typical operations are $\mathrm{UO}_{2}$ and $\mathrm{PuO}_{2}$ powders weighing and mixing, prepressing, crushing and granulating, cold pressing, and sintering followed by pin filling and welding, and finally fuel element assembling, with all associated control operations.

- LPC (Laboratoire de Purification Chimique) is an associated facility providing for chemical reprocessing of fabrication scraps, physico-chemical and chemical analysis, and solid waste management, including routine monitoring operations and $R+D$ facilities aiming to reduce the volume and recover plutonium from the wastes. 
Due to plant modernisation and especially to the creation of a fabrication line for LWR reactors fuel elements, numerous obsolete plutonium processing installations belonging to both buildings, had to be dismantled between 1984 and 1989 : on the whole, 76 glove boxes with various sizes and 51 parts of transfer tunnels, corresponding to more than $200 \mathrm{~m} 3$ volume. This paper deals with significant parts of this total, dismantled between 1986 and 1988. An important feature of these operations is that they had to be performed during plant functioning, hindering fabrications as little as possible.

\section{DISMANTLING AND WASTE MANAGEMENT}

2.1 Organisation

The decommissioning work is carried out under the direction of the operating service (CFCa) by the waste treatment service of Cadarache center, named SAR (Section d'Assainissement Radioactif) and the company STMI, specialized in works in radioactive environment. The responsibilities are shared as follows :

- preparation of the glove boxes (crude cleaning) : CFCa staff

- disconnection and "on site" dismantling : STMI

- plutonium monitoring : CFCa

- waste treatment for Pu recovery : CFCa

- transport, final dismantling of voluminous packages and waste conditioning : SAR

The health physics surveillance in all phases of decommissioning is assumed by the SPR (Service de Protection contre les Rayonnements).

2.2 Waste Management

The solid wastes management is based upon particular rules proper to Cadarache center :

- non voluminous wastes generated in CFCa are conditioned in 100-litre drums, plutonium monitored and segregated into three categories :

a) waste drums with a plutonium content higher than 5 g have to go through a treatment for plutonium recovery; before this treatment, these drums are stored in a special depository building ;

b) waste drums having an alpha activity lower than $200 \mathrm{MBq}$, roughly equivalent to $10 \mathrm{mg}$ of a plutonium with a mean isotopic composition, could be sent to the national shallow land burial : they can also be incinerated by SAR in its own facilities. In this category, we find especially wastes from labs out of glove boxes (overboots, etc...); wastes from glove boxes must be strongly decontaminated in order to fall into this category ;

c) waste drums before these two previous limits are sent to SAR facilities for waste conditioning: they are size reduced by pressing (2500 kN press) and disposed in 870 litre metallic containers $(20$ drums maximum in one container). These containers are subsequently filled with cement and temporarily stored inside shelters, waiting for the creation of a deep geological repository. 
- voluminous waste packages such as entire glove boxes and associated equipments leaving CFCa buildings are plutonium assayed and delivered to $S A R$ for dismantling in a manually operated size reduction cell. Then they are conditioned in 100-litre drums or directly in 870-litre containers.

2.3 Plutonium recovery treatments

Wastes corresponding to the category (a) can be treated in the LPC facilities where some $R+D$ works are performed in two main equipments :

- a laboratory scale acid digestion glovebox, specific for cellulosic waste : more than $100 \mathrm{~kg}$ of cotton containing $2,2 \mathrm{~kg}$ of plutonium have been treated there; plutonium is recovered as sulphate precipitate, then dissolved for reprocessing ;

- an industrial scale facility for low temperature impact crushing, consisting of a cryogenic tunnel, an industrial hammer mill and a washing equipment : 5 to 10 drums, or fully equipped glove boxes ( 2 m3 maximum), can be processed in a single operation. The reducing factor is about 3 or 4 for drums, and up to six for glove boxes. After washing the residual Pu content is less than 10 of the original one.

During this campaign, two plastic glove boxes have been treated by this way.

\section{PLUTONIUM ASSAYING}

All the waste packages carried out from CFCa to SAR are plutonium assayed by one of the following means :

3.1 Wastes conditioned in 100-litre drums are assayed by coincidence counting of spontaneous fission neutrons emitted by the even number plutonium isotopes. It is a well type apparatus consisting of $18^{3} \mathrm{He}$ tubes encased in polythene moderator and connected to a variable dead time electronic circuit. The percentage of these even number plutonium 1sotopes is determined using a gamma spectrometry system with Ge-Li detector.

3.2 Regarding the $200 \mathrm{MBg}$ limit, SAR has commissioned a neutron activation monitoring chain to control it; in the meantime, concerned waste drums can be sorted using a gamma detection with a large Xenon detector, in comparison with a standard drum, in the case of light matrices.

3.3 Voluminous packages are monitored using a total neutron counting system : a set of eight $3 \mathrm{He}$ detectors enclosed in cylindrical polythene blocks are fixed on the sides of a $2,5 \mathrm{~m} \times 2,5 \mathrm{~m}$ frame, able to scan large packages positioned on a $2,5 \mathrm{~m} \times 3,5 \mathrm{~m}$ platform. The counting yield $(0,3$ z) is not sufficient to allow a coincidences measurement. So the results involve some uncertainty due to (alpha, n) reactions with plutonium containing matrices. Correcting factors are used to reduce this uncertainty, for example by the means of bagged-out representative samples.

$$
\text { 3.4 Plutonium rich powders recovered during }
$$
dismantlement are assayed by calorimetry combined with gama spectrometry. 


\section{DISMANTLING OPERATIONS}

4.1 Routine operations

They concern the detached glove boxes up to about $2 \mathrm{~m} 3$ volume and containing little residual nuclear material.

After a cursory clean-up powder recovery with brush and cotton, the removable, small equipments are taken out in bags then drums, and the remaining contamination is fixed generally with lanoline using a spray-nozzle. Then the glovebox can be disconnected from ventilation ductworks and packed inside several PVC or polythene sheets.

This package is carried off, first for plutonium assaying in a special room containing the neutron counting gantry described in paragraphe 3.3, then to SAR facilities where it can be stored before dismantling.

The glovebox is entered in the size reduction alpha cell where operators are working with ventilated suits on, using various techniques for breaking or cutting the different parts of the glovebox : hydraulic scissors, circular saws, flame cutting systems, etc...

All heavy wastes generated through these size reduction operations are disposed loose into 870-litre metallic containers, others and secondary wastes such as contaminated protective clothing, plastics, cottons, are disposed off in 100-litre drums.

A typical example of these operations was the Lab. 6/ATPu, where numerous small glove boxes made up different lines for dry recycling of powders (about $500 \mathrm{~kg}$ of plutonium processed).

A size reduction factor of about 2 is obtained with this type of dismantlement : here, $18,7 \mathrm{~m}^{3}$ have been treated in alpha-cell and have produced $12 \times 870-1$ itre containers to be cemented (mean volume reduction factor $=1,8$ ). But plutonium recovery was not so good as hoped and $234 \mathrm{~g}$ of polluted, non recoverable plutonium were put in these containers.

4.2 Dismantling of large or complex systems

In the case of lab.7/ATPu, operations were more complicated because of larger glove boxes and of connections between them : this suite consisted of a screw-type $\mathrm{PuO}_{2}$ calcination furnace (about $1000 \mathrm{~kg}$ of plutonium processed) with surrounding glove boxes for powder carrying in and out $\left(4,4 \mathrm{~m}^{3}\right.$ on the whole), and a tunnel for transferring $\mathrm{PuO}_{2}$ powder containers $(7000 \mathrm{~kg}$ of plutonium transferred) with a chain system ( 7 segments of $6 \mathrm{~m}^{3}$ total volume). Disconnecting these different parts was made on site by tight operations after the remaining contamination was fixed by means of a spray-nozzle mobile with the transfer system. The largest glove boxes could not be entered in the geometry of the neutron counting gantry, so a mobile scaffolding with a 3,3 m height was created in a low level background room of the building, and equipped with measuring devices of the routine apparatus. The difficulties encountered in plutonium recovery $(350 \mathrm{~g})$ can explain that three glove boxes have been found too "dirty" and will be stored in ATPu for subsequent cleaning ( $\mathrm{Pu}$ content $=940 \mathrm{~g}$ for all) and that 
other equipments dismantled by SAR contained $720 \mathrm{~g}$ of plutonium in 10 containers.

During these operations, some experiments were made about quality of plutonium assaying and in particular comparisons between total neutron counting of large packages and coincidence measurement of the same after size reduction and conditioning in 100-litre drums. The total neutron balance was satisfactory (less than $20 \%$ ), but the influence of the fixation product due to (alpha, $n$ ) reactions was higher than expected and involved a systematic over-estimation of plutonium content.

Another example of a complex equipment is the experimental powder transfer located in labs 8 and 010 of the LPC. The object of this equipment was to test pneumatic filling-up and emptying of a $25 \mathrm{~kg} \mathrm{PuO}_{2}$ containȩr. It was composed of the air lift transfer circuit $\left(2 \mathrm{~m}^{3}\right)$, seven glove boxes containing auxiliary equipment $\left(4,9 \mathrm{~m}^{3}\right)$ and the connecting ducts $\left(4,5 \mathrm{~m}^{3}\right)$. Because of a limited number of tests, made with a single lot of powder, plutonium residual content was especially well known (inventory result $=2292 \mathrm{~g} \mathrm{Pu}$ ). An exhausting circuit, consisted of stainless steel "Poral" filter in a subcritical container, a very high efficiency ventilation filter, a decanter drum and a fan, was set up in order to make the powder recovery easier : $1187 \mathrm{~g}$ of $\mathrm{Pu}$ have been recovered by this way. The units composing this system have been separated from each other and from auxiliary services of building, yielding 79 voluminous packages sent to SAR, containing a total of $829 \mathrm{~g} \mathrm{Pu}$. The general balance shows a rather good result from plutonium assaying methods, with a difference of 4,5 of total residual plutonium.

4.3 Dismantling of the granulation line of lab.2/ATPu

This processing line $(4000 \mathrm{~kg}$ of plutonium processed) consisted of five separate glove boxes connected to each other, without intermediary dividing panels so as to form for all pratical purposes a single glovebox of $50.5 \mathrm{~m}^{3}$.

This particularly bulky configuration did not allow the disconnection of the single glove boxes and their delivery to SAR for dismantling according to the routine procedure. Consequently, all dismantling work had to be performed on site. For this purpose, the line has been entirely enveloped in a rigid alpha-tight size reduction tent permitting complete dismantling and waste bag out by specialised personnel operating in ventilated suits.

The functions of different glove boxes were : introduction of $\mathrm{PuO}_{2}$ and $\mathrm{UO}_{2}$ powders, weighing, milling, binder mixing and compacting,granulating. The size reduction tent was set using Al-polyurethane-Al composite panels and plexiglass viewing windows, with air-locks for personnel access and waste bag-out. This enclosure was ventilated by a special circuit with fan and filters, connected to the main air exhaust network of the building. 
The work was performed by 2 or 3 operators teams protected by masks fed with breathable air and ventilated suits. The man power demanding for this campaign was of 400 men-days and concerned 11 operators. The total gamma exposure of this group equalled $48 \mathrm{mSv}$.

The dismantling techniques used in this campaign were the same ones as described in paragraphe 4.1 for SAR $\alpha$-cell.

A total quantity of $2,9 \mathrm{~kg}$ Pu was recovered during these operations.

Solid wastes resulting from were disposed in 24 870-litre containers, containing $76 \mathrm{~g} \mathrm{Pu}$ each in average ; the gross factor of volume reduction was about 2,5 , but if we add the volume of secondary wastes after compaction $\left(7,3 \mathrm{~m}^{3}\right)$, this factor becomes 1,8 .

4.4 Fuel transfer tunnel interconnecting

labs. 2, 3, 4/ATPu

This dismantling operation was taken as an opportunity of testing further decontamination in order to declassify the resulting wastes. The transfer tunnel (total volume : $\left.12 \mathrm{~m}^{3}\right)$, anchored to the ceilings, ran over the glove box processing lines, located in the labs 2,3 and 4 of ATPu, for an overall length of about 50 metres and was connected to these underlying lines by vertical branches. It was mainly composed of all-metal parallelepipedic modules (typically $0,5 \mathrm{~m} \times 0,5 \mathrm{~m} \times 1,5 \mathrm{~m}$ ) held together by nuts and bolts and small dimension glove boxes $(0,6 \mathrm{~m} \times 0,6 \mathrm{~m} x$ $0,8 \mathrm{~m})$ interposed at 13 points of the installation, for control and sorting purposes. Fuel movement from one point to the other of the tunnel was assured by means of a motorised monorail transport device, and between the tunnel and the main processing line by lifts housed in the vertical branches.

A preliminary estimation made before dismantling (visual inspection using a video camera attached to the fuel transport system, smear tests in manually accessibles areas, external babyline monitoring) indicated a total quantity of about $76 \mathrm{~g} \mathrm{PuO}_{2}$ present in the form of a black submicronic powder homogeneously distributed along the lower part of the tunnel. Preliminary decontamination tests indicated that this powder could be wiped out leaving residual contamination levels compatible with the disposal of the metallic scraps generated in this particular campaign as non TRU wastes.

After disconnection, the different parts were transported to SAR alpha-cell for cutting down to pieces of typical dimensions $0,25 \mathrm{~m} \times 0,25 \mathrm{~m}$, cursory decontamination (wiping out the $\mathrm{Pu}$ bearing powder with cotton moistened with TRIAXOL), estimation of the residual contamination (surface alpha counting) and disposal in 100-litre metallic drums. These drums were sent back to CFCa for plutonium assaying with coincidence neutron system.

The balance is obtained as follows :

- metallic wastes : 55 drums containing 9,4 g Pu

- burnable wastes : 13 drums containing $10,0 \mathrm{~g} \mathrm{Pu}$

- total volume before compaction : $6,3 \mathrm{~m}^{\frac{1}{3}}$ 
- total volume after conditioning : $3,5 \mathrm{~m}^{3}(4 \times 870-1$ itre containers)

- general volume reduction factor $=3,4$

17 drums from 68 ( 1 for 4 ) were found beneath the shallow land burial limit.

\section{CONCLUSION}

The works described in this paper are only a part of the dismantling campaign led in CFCa for several years in order to set same space available for new fabrication lines : an area of $400 \mathrm{~m}^{2}$ has been vacated in seven labs of ATPu and three labs of LPC by moving-out highly-contamined equipments. These operations are, going on, with the dismantlement on site of a $15 \mathrm{~m}^{3}$ granulation line in lab.8/ATPu and later of several large glove boxes waiting for further plutonium recovery.

Because of stopping operations in the SAR size reduction cell for alterations, only 70 of the total volume has been completely dismantled; but this volume of about $100 \mathrm{~m}^{3}$ is sufficient for the inventory to be reasonably extrapolated to an entire plant, according to used techniques : the volume reduction factor $(1,8$ to 2$)$ obtained by the classical ways can be improved if we go further in cutting-up; but it appears necessary to use remotely operated size reductions to avoid an increase of dose rate for operators : this way has been chosen in SAR alpha cell with the future introduction of a hydraulic manipulator system. Another way is the use of new techniques, like low temperature crushing which has been tested here.

concerning the plutonium inventories, some important problems have stood out : retentions in old-designed glove boxes, which have processed hundreds or thousands kilograms of plutonium, are very high ; accessibility for plutonium recovery is generally difficult : fixing the contamination for transport gives some disadvantages for plutonium monitoring and later recovery, so it can be convenient to perform dismantling on site when it is possible.

Improvements are now effected in two fields: plutonium assaying with commissioning of a neutron activation monitoring system, and decontamination with testing ultrasonic freon cleaning and electrolytical dissolution of plutonium oxide. 
TESTING OF NEW TECHNIQUES IN DECOMMISSIONING OF A FUEL (U,TH) FABRICATION PLANT, ESPECIAL CONSIDERATION TO FREE RELEASE MEASUREMENT OF LOW URANIUM ACTIVITIES

W. in der Schmitten, B. Sohnius, E. Wehner

NUKEM GmbH, Box 110080, D-6450 Hanau 11, FRG

ABSTRACT

For the decommissioning of a fuel fabrication plant like NUKEMA the identification of uranium isotopes and thorium in large residue masses and volumes with contents down to natural levels is an important task. A contamination map of NUKEM-A was prepared and compared with the natural contents of uranium isotopes and thorium in conventional building materials. A liquid scintillation equipment was tested for detection of low uranium activities. A computer program was created to calculate calibration factors allowing to judge mathematically the measuring techniques as used by a barrel scanner combined with height resolution gamma spectrometry.

\section{INTRODUCTION}

In the framework of the RTD program a contamination map of NUKEM-A was prepared and the penetration depth of $U$ and $T h$ in walls and floors was determined. Representative systems and installations were dismantled thus allowing investigation of dismantling techniques and decontamination processes for the further use of plant parts.

Building structure was decontaminated by removal of active layers and the recovery of uranium from these and other mineral materials was undertaken.

Accompanying all investigations activity measurements were carried out for the determination of activity in waste materials and also to provide evidence that radiation protection limits were maintained. The following is limited to description of the investigations concerning the determination of contamination levels in building structure and free release measurement techniques.

\section{PREPARATION OF A CONTAMINATION MAP OF NUKEM-A}

In order to estimate the degree of contamination of building materials of NUKEM-A samples were taken by scrubbing plaster from areas with a high contamination risk and from not contaminated locations like offices. Grinding machines were used allowing sample collection by exhausters. Thus also raising of dust was prevented. The material was sampled in 21 vessels and measured by gamma spectrometry. Mainly uranium and thorium daughter products and $\mathrm{K} 40$ were detected. The gamma spectrometric detection of low U235 contents using the main gamma line at $185 \mathrm{keV}$ is disturbed by a Ra226 contamination at the same gamma energy which has to be subtracted. A correction is difficult due to the lack of information about the equilibrium in the uranium radium chain (the measured isotopes are Bi214 and $\mathrm{Pb214}$ ). Therefore gamma spectrometric results normally overestimate the U235 contents especially at low values.

The results of a selected part of this work are shown in Tab.1 in comparison with the natural content of conventional building material. As can be seen the content of U235 ranges from natural level up to $10 \mathrm{~Bq} / \mathrm{s}$. The contents of the U238 daughter Th234 depends also on contamination while the U238 daughters Pb214 and Bi214 do not exceed naturally occuring values. This is caused by the half life values of the chain members. Concerning the thorium daughters Ac228, Pb212, Bi212, T1208 no 
eignificant difference is detected between the content of each chain member. A contamination of the area were thorium ras handled is observed.

The total amount of contamination of RUKEM-A is extrapolated to about $600 \mathrm{~B}$ U235 and $2 \mathrm{~kg}$ thorium from these values. The contamination map will be actualized during the destruction of the buildings.

\section{SUITABILITY OF LIQUID SCINTILLATION COURTERS POR DETECTION OP LON URANIUA ACTIVITIES}

Liquid ecintillation counters are commonls used for free release measurements at nuclear porer plants. To test the ouitability of these measuring devices for fuel fabrication plant nuclide spectra, measuremente were done using the Nuclear Ingenieur Service (NIS) equipment at Niederaichbach and a detector system submitted by Minchener Apperatebau (MAB).

For measurements a barrel of 2001 was filled with crushed clay bricks with a mass of $226 \mathrm{~kg}$. Two rode were installed for insertion of uranium sources, one in the center and one in the diagonal path. An aboorption coefficient was determined for the U235 line at $185 \mathrm{keV}$ of about $13.5 / \mathrm{m}$ and for the U238 daughter line at $1001 \mathrm{keV}$ of about $7.4 / \mathrm{m}$.

The barrel was traneported into the counting area of the NIS device lying on a hoigting cage. Different natural uranium masses rere positioned at the center of the berrel and the resulting gama counte were measured. The results are shown in Fig.1. A net count effect was meseured down to 18 of natural uranium. Liquid scintillation detectors cannot distinguish between the different gama emitters, because only the sum of the photons is detected. Conservatively all measured photons have to be related to U235 with a free release limit of about $30 \mathrm{mg}$ U235 in a $200 \mathrm{~kg}$ barrel.

Since enriched uranium is not allowed to be handled at Niederaichbach the influence of the different enrichments on the gamma count rate was measured with a MAB device at NUKEM, Hanau. As can be seen from Pig.2 the gama count rate decresses with increasing enrichment at a constant U235 content. This effect is caused by registration of additional photon emitters at low enrichment. The difference between natural uranium and enriched uranium ( $10 \%$ U235) is about a factor of 5 . As a second effect the different absorption at different enrichments reduces the count rate. In Fig.3 count rates are plotted as a function of thickness of absorber (steel). Converting these results into absorption coefficients of clay bricks a count rate reduction of a factor of 4 has to be considered.

Therefore the count rate of about 100 counts per second (cps) related to the free release mass of $30 \mathrm{mg}$ U235 in natural uranium (see Fig.1) has to be reduced to $5 \mathrm{cps}$, when high enriched uranium has to be supposed conservatively. This count rate cannot be distinguished from natural background fluctuations.

4. CALCULATION OF CALIBRATION FACTORS WITH SPECIAL RESPECT TO THE OPTIMIZATION OP FREE RELEASE MEASUREMENTS WITH GAMMA SCANNING DEVICES

\subsection{Calculation procedure}

In gamma epectrometry the activity of a nuclide is determined by multiplying the measured count rate (I) of a gamma line with a calibration factor $(K)$. This calibration factor $(K)$ is a product of three factors $K-K A * K D * K G$ where $K A$ is the reciprocal gamma ray line intensity (values from literature), KD is the reciprocal detector efficiency not influenced by sample matrix absorption and geometry, KG is the ratio of 
the gamma rate of the source to the gamma rate entering the detector, j.nfluenced by absorption and geometry.

The product $\mathrm{KD}^{*} K G$ usually determined in total is separated into the constant KD fixed by detector design and into KG calculated by a computer program. This program simulates the measuring techniques of a barrel scanner and considers geometry and absorption by integrating the room angle over the measuring time and by the exponential law, respectively.

\subsection{Cross check with experiment}

The measurements were done by insertion of a Ra-266 source of known activity into positions of a 2001 barrel filled with crushed clay bricks as indicated in Fig. 4. The barrel was rotating on a barrel scanner and the gamma rate was measured by a Ge detector. The experimental parameters auch as source/detector distance, barrel/detector distance, barrel geometry, matrix absorption coefficients were used in the calibration factor calculation program. In Fig. 4 the crose check of the calculated calibration factors with measured values is shown ( $r=$ diatance point source/central axis, $\mathrm{Z}(0)=$ distance point source/barrel base). Calculated valueg are identical or higher (conservative).

\subsection{Applications}

The program is generally applicable to the calculation of experimental errors. It also can be used to design the equipment thus enhancing the sensitivity for low activities. The potential of the program can be illustrated by numerical data derived from NUKEM-A conditions.

\subsubsection{Estimation of experimental errors}

a) Inhomogeneous activity. distribution in calibration and measurement barrel.

Different activity distributions in a barrel to be measured and the calibration barrel result in an error of activity determination. The maximum error occurs when activity is concentrated in a point source positioned at the mid height of the cylinder surface (maximum overestimation) or positioned at the center of bottom or top (maximum underestimation). In Fig. 5 the ratio of the count rate of a possible point source in a sample and the count rate of the homogeneous calibration barrel is plotted a a function of the absorption coefficient. Calculations were done at constant activity. When activity in both barrels is distributed homogeneously, the ratio is one. With increasing absorption coefficient the ratio for the point source at the center axis decreases wile the ratio for the point source at the aurface of the cylinder increases. This is due to the fact that the intensity of the homogeneously loaded barrel decreases with increasing absorption not as fast as the intensity of a point source at the most unfavorable center. On the contrary the intensity of the homogeneously distributed activity decreases faster with increasing absorption than the intensity of a point source at the most favorable surface position. At an absorption of $15 / \mathrm{m}$ the overestimation causes a factor of 20 and the underestimation of about $1 / 5$ of the calibration intensity. This effect is less pronounced when the point source is replaced by a more extended source, e. g. of $10 \mathrm{~cm}$ linear dimension as shown by the dotted lines. The resulting count rate ratios get closer to one.

b) Number of barrel rotations per measurement.

Barrel rotation serves to compensate a possible activity distribution asymetry. The highest possible asymetry is caused by a point aource at 
the barrel surface. It can be calculated that about 10 rotations per measurement are sufficient to eliminate asymetry.

\subsubsection{Modifications of apparatus}

Modifications of the apparatus aim at the reduction of the detectable activity in order to meet activity limits. The effect of modification is expressed by the ratio KG/KGmax where KGmax is the limit for KG resulting from the activity limit. The following modifications may be applied singly or in combination; results refer to a residue material with an absorption coefficient of $16 / \mathrm{m}$.

a) Increasing detector ecanning length

Increasing detector scanning length allows a better detection of a point source located at the center point of the barrel top or bottom. The optimum gcanning length is the initial length (L) plug the addition (d) at which $K G(L+d)$ adopts a minimum. This length is calculated to be $1 \mathrm{~m}$ reducing the ratio $K G / K G m a x$ from 13.6 for the initial detector scanning length of $0.75 \mathrm{~m}$ to 8.7 . Further increase of d beyond the optimum value enlarges the average diatance between point source and detector.

b) Reduction of radiug

Reduction of radius reduces the absorption length and thus $K G$. The achievable minimum value of KG/KGmax 18, however, about 2 (compared to 1 or less required for free release), no matter whether the barrel height 1s kept constant (reduction of volume) or ia adapted to keep the volume constant. The minimum at constant barrel height is due to the fact of faster decreasing of KGmax compared to KG below a certain radius with decreasing radius (volume). Adapting (increasing) the barrel height to keep the volume congtant the minimum is caused by the increaging average distance between point source and detector.

c) Insertion of a concentric hollow cylinder (radius $r$ )

The hollow cylinder reduces KG/KGmax more efficiently than the radius reduction and yieldg a minimum value of $K G / K G m a x=1.1$ (aes fig. 6a), the minimum caused by the same effect as in the preceeding section b) for congtant height.

The reduction of $K G / K G m a x$ is improved by combining the hollow cylinder ineertion with suitable measures:

Adapting the height for keeping the volume constant jields $K G / K G m a x=1.07$ (see fig. 6c), the minimum caused by the same effect as for adapted helght in the preceeding section b).

Adapting the radius for keeping the volume constant jields $K G / K G \max =1$ (see fig. $6 \mathrm{~b}$ ), however, the required radius (about $1.30 \mathrm{~m}$ ) 1a too high for practical purposes.

Adapting height (H) plus radius (a) at a constant ratio $\mathrm{H} / \mathrm{a}$ (e.8. 2,7 ) for keeping the volume constant yields KG/KGmar - 1 (see fig. 6d) at $\mathrm{H}=1.19 \mathrm{~m}, \mathrm{a}=0.44 \mathrm{~m} \mathbf{r}=0.37 \mathrm{~m}$, the values being already technically acceptable.

An even better result is obtained using an increased detector scanning length $I$ in addition to radius and height adaption (e.8.

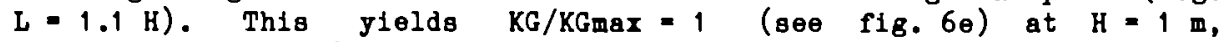
a $=0.37 \mathrm{~m}, \mathbf{r}=0.26 \mathrm{~m}$.

These exemplary reaults show the potential of the program to optimize the conditions for apecific measuring problema.

\section{CONCLUSIONS}

No particular difficulties were found during performance of the decontamination work. Thus decontamination can be achieved utilizing usual techniques but in some cases with the use of modified chemical 
decontaminants. More problematic is the determination of residuel contamination due to non-homogeneous materials and activity distribution on surfaces. Hence it is not always possible free release metals. Scrapping can only be achieved by melting.

The determination of activity levels for a contamination map can be performed without problems since updating is possible thoughout the dismantling procedure.

The free release of a 2001 drum containing rubble using liquid scintillation counters is not without problems thus the aspected count rate lies in the range of background count rates.

The examples described above concerning the calculation of calibration factors show the feasibility of achieving a maximum sample size. If a second detector is installed at the central axis inside the hollow cylinder further improvement may be obtained.

An investigation of other geometries and measurement arrangements concerning both measurement techniques could follow in a further program. 


\begin{tabular}{|c|c|c|c|c|c|c|}
\hline $\begin{array}{l}\text { Bld } \\
\text { No. }\end{array}$ & $\begin{array}{l}\text { Roon } \\
\text { No. }\end{array}$ & $\begin{array}{r}\mathrm{U}-235 \\
\Sigma 185 \mathrm{keV} \\
(\mathrm{mBq} / \mathrm{g})\end{array}$ & $\begin{array}{r}\text { Th-234 } \\
63 \mathrm{keV} \\
(\mathrm{Bq} / \mathrm{g})\end{array}$ & $\begin{array}{r}\text { pb-214 } \\
352 \mathrm{keV} \\
(\mathrm{BBq} / \mathrm{g})\end{array}$ & $\begin{array}{r}B 1-214 \\
609 \mathrm{keV} \\
(m \mathrm{~Bq} / \mathrm{g})\end{array}$ & $\begin{array}{r}\mathrm{Pa}-234 \mathrm{~m} \\
1001 \mathrm{keV} \\
(\mathrm{mBq} / \mathrm{g})\end{array}$ \\
\hline $\begin{array}{l}671 \\
674 \\
681 \\
680 \\
674 \\
671 \\
682 \\
680 \\
--1\end{array}$ & $\begin{array}{l}29 \\
10 x \\
3 \\
16 \\
55 \\
41 \\
19 \\
1, t\end{array}$ & $\begin{array}{r}1.4 \\
1.6 \\
1.7 \\
2.0 \\
2.0 \\
2.1 \\
2.2 \\
2.2 \\
-----\end{array}$ & $\begin{array}{l}24.8 \\
17.0 \\
23.8 \\
26.9 \\
31.3 \\
19.6 \\
30.6 \\
20.0 \\
-1--\end{array}$ & $\begin{array}{r}11.6 \\
10.5 \\
12.0 \\
12.3 \\
9.5 \\
10.7 \\
8.7 \\
14.6 \\
-\quad--\end{array}$ & $\begin{array}{l}11.2 \\
10.7 \\
15.7 \\
13.5 \\
11.0 \\
11.6 \\
13.0 \\
13.6\end{array}$ & $\begin{array}{r}- \\
\overline{-} \\
\overline{-} \\
\overline{-} \\
- \\
-\end{array}$ \\
\hline $\begin{array}{l}680 \\
674 \\
674 \\
682 \\
680 \\
674 \\
674 \\
674\end{array}$ & $\begin{array}{l}20 \\
62 \\
57 \\
2 \\
12 \\
57 \\
62 \mathrm{~b} \\
62 \mathrm{~b}\end{array}$ & $\begin{array}{l}13.0 \\
13.6 \\
13.8 \\
15.0 \\
17.9 \\
19.5 \\
19.6 \\
21.8\end{array}$ & $\begin{array}{r}192.9 \\
70.8 \\
24.1 \\
68.3 \\
92.7 \\
32.7 \\
172.6 \\
156.0\end{array}$ & $\begin{array}{r}12.6 \\
10.7 \\
9.1 \\
10.4 \\
15.6 \\
10.8 \\
12.3 \\
14.9\end{array}$ & $\begin{array}{r}13.8 \\
13.6 \\
8.6 \\
11.5 \\
15.9 \\
9.5 \\
12.7 \\
14.0\end{array}$ & $\begin{array}{c}197.6 \\
- \\
- \\
- \\
- \\
- \\
190.4 \\
177.5\end{array}$ \\
\hline $\begin{array}{l}-\overline{672} \\
674 \\
672 \\
672\end{array}$ & $\begin{array}{l}24 \\
62 \\
24 a \\
25\end{array}$ & $\begin{array}{r}597.7 \\
775.6 \\
810.5 \\
1099.2\end{array}$ & $\begin{array}{r}5700 . \overline{3} \\
9010.9 \\
7445.7 \\
179.8\end{array}$ & $\begin{array}{l}-\overline{-}- \\
13.2 \\
10.6 \\
13.3 \\
11.5\end{array}$ & $\begin{array}{r}13.4 \\
13.0 \\
15.8 \\
9.9\end{array}$ & $\begin{array}{r}5190 . \overline{0} \\
8158.3 \\
6869.7 \\
132.4\end{array}$ \\
\hline $\begin{array}{l}672 \\
672\end{array}$ & $\begin{array}{c}3 \\
25 a\end{array}$ & 2216.2 & $\begin{array}{r}377.0 \\
5804.0\end{array}$ & 32.7 & 27.6 & $\overline{3}$ \\
\hline $\begin{array}{l}672 \\
672 \\
672\end{array}$ & $\begin{array}{l}25 a \\
24 \\
25\end{array}$ & $\begin{array}{r}2329.0 \\
4503.8 \\
10750.0\end{array}$ & $\begin{array}{r}30903.8 \\
1358.1\end{array}$ & $\begin{array}{l}13.4 \\
13.4 \\
10.8\end{array}$ & $\begin{array}{l}12.4 \\
13.0 \\
13.4\end{array}$ & $\begin{array}{r}25734.1 \\
1626.1\end{array}$ \\
\hline \multirow{7}{*}{\multicolumn{2}{|c|}{$\begin{array}{l}\text { Alzenau } \\
\text { Erlensee } \\
\text { Hammersbach } \\
\text { Neuwled (1) } \\
\text { Neuwied (2) } \\
\text { Neuwled (3) } \\
\text { Wolfgang (1) } \\
\text { Wolfgang (2) } \\
\text { Wolfgang (3) }\end{array}$}} & 5.0 & 36.6 & 38.5 & 36.5 & - \\
\hline & & 6.6 & 47.9 & 40.5 & 42.3 & - \\
\hline & & $\begin{array}{r}5.4 \\
18.8\end{array}$ & $\begin{array}{r}48.9 \\
251.0\end{array}$ & $\begin{array}{r}44.9 \\
139.3\end{array}$ & $\begin{array}{r}44.1 \\
146.8\end{array}$ & $\overline{-}$ \\
\hline & & 16.3 & 267.1 & 119.6 & 114.0 & - \\
\hline & & 8.3 & 62.4 & 53.8 & 53.5 & - \\
\hline & & $\begin{array}{l}5.0 \\
4.2\end{array}$ & $\begin{array}{l}47.0 \\
29.0\end{array}$ & $\begin{array}{l}41.5 \\
34.0\end{array}$ & 42.0 & - \\
\hline & & $\begin{array}{l}9.2 \\
5.7\end{array}$ & $\begin{array}{l}29.0 \\
39.6\end{array}$ & $\begin{array}{r}34.0 \\
42.8\end{array}$ & $\begin{array}{r}34.5 \\
43.2\end{array}$ & - \\
\hline
\end{tabular}

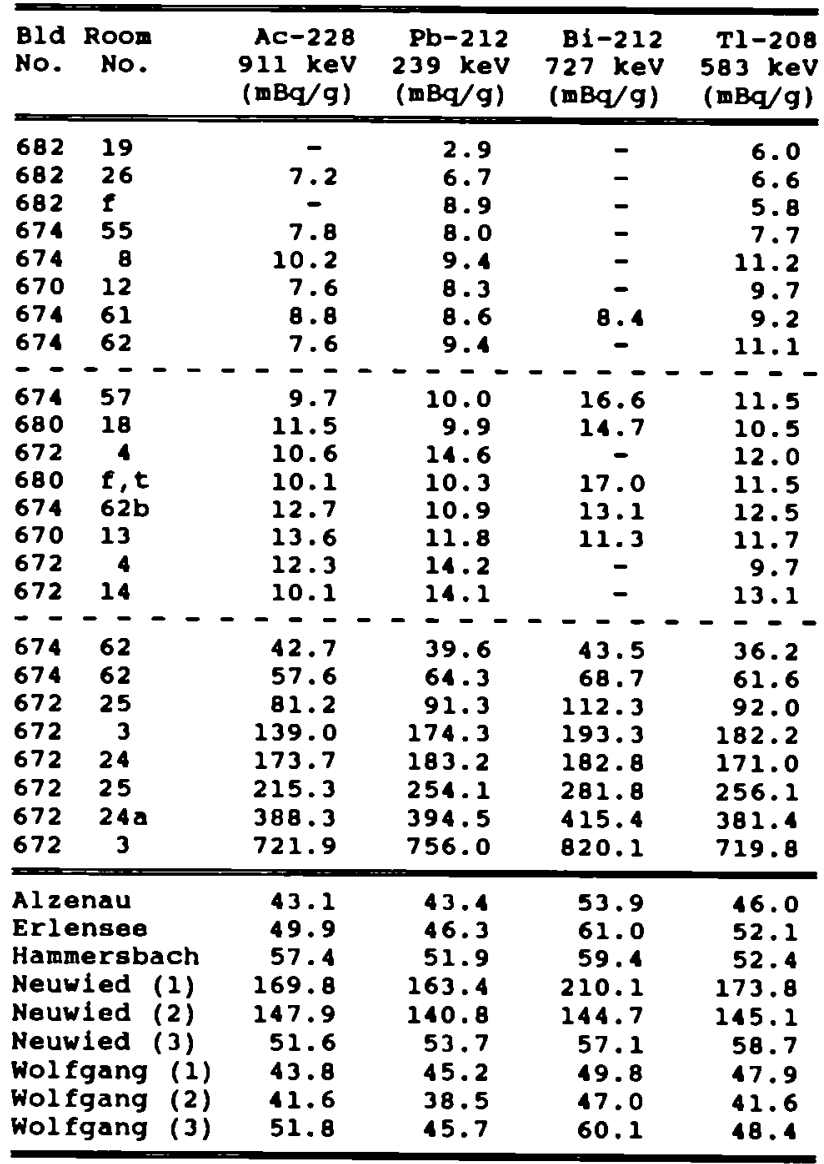




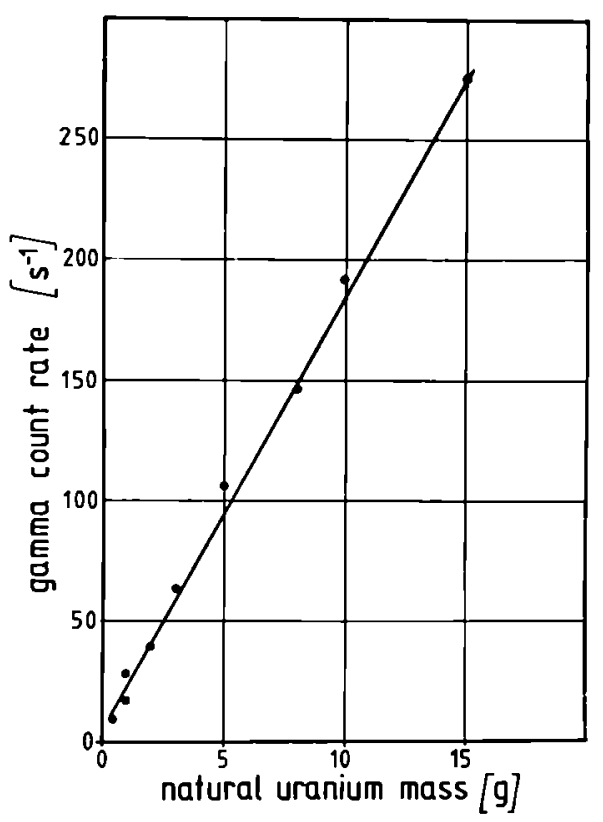

Figure 1: gamma count rate of different natural uranium masses at the center of a 2001 barrel, clay brick matrix

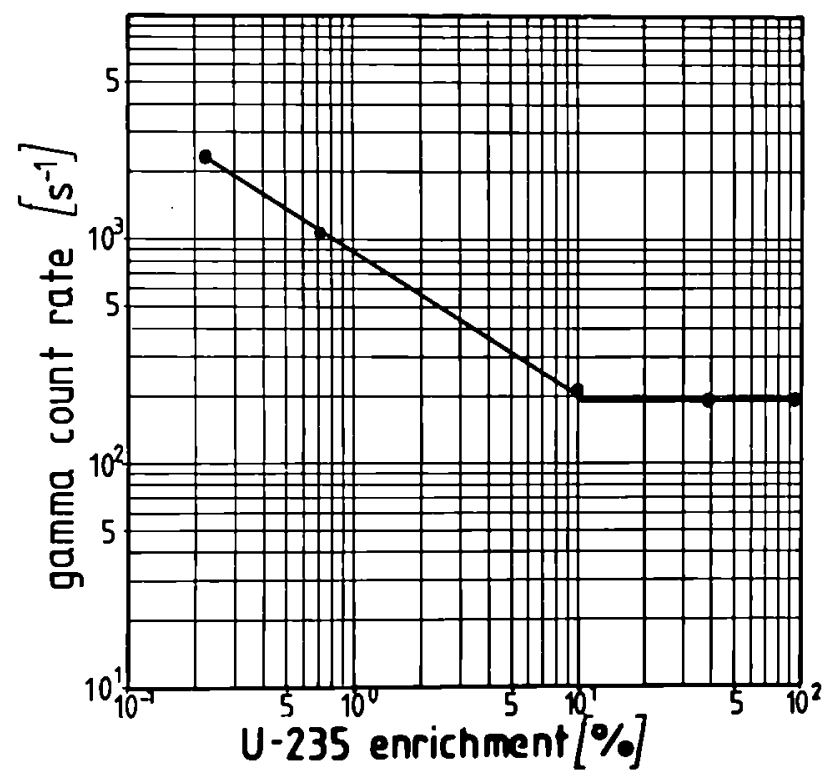

Figure 2: gamma count rate as a function of U235 enrichment 


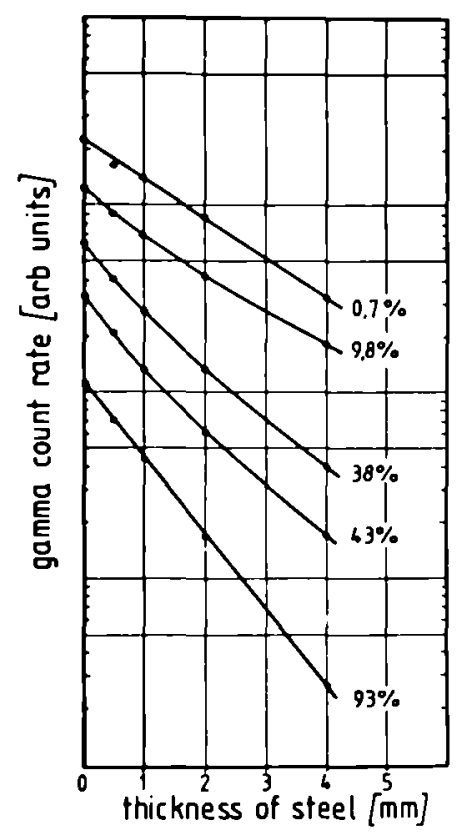

Figure 3: gamma count rate as a function of absorber thickness (ateel) at different U235 enrichment

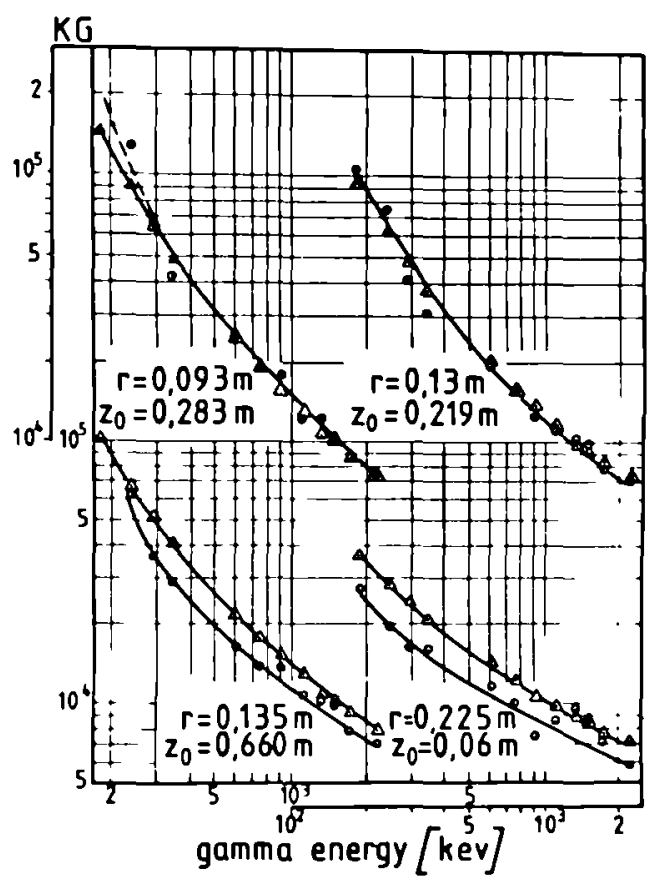

Figure 4: Calculated calibration factors $(\bullet)$ in comparison with experimental values $(\Delta)$ at different point source positions 


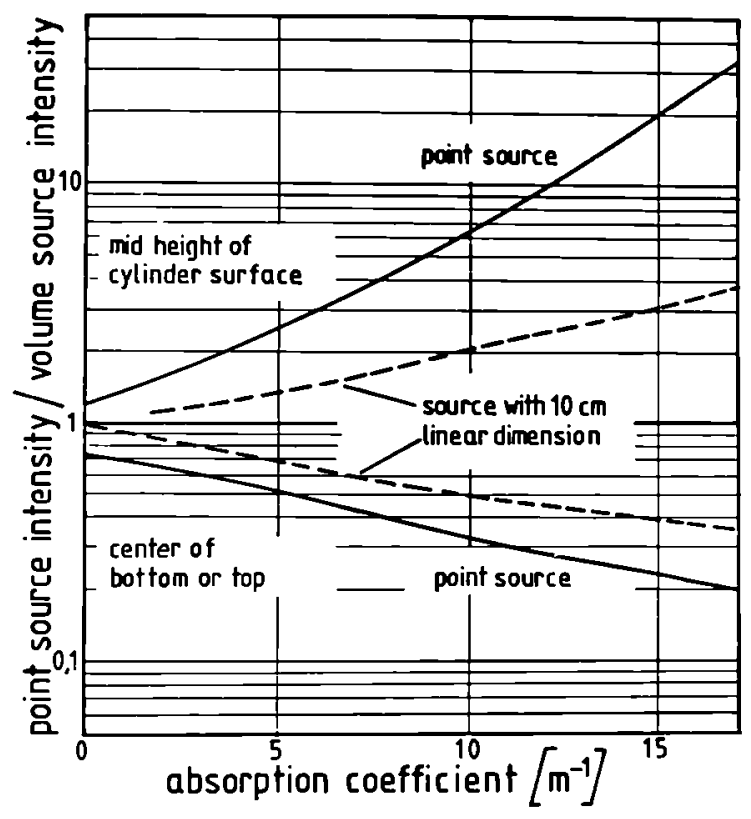

Figure 5: Ratio point source intensity to volume source intensity versus absorption coefficient; point source at mid hight of cylinder aurface or at center of barrel bottom or top

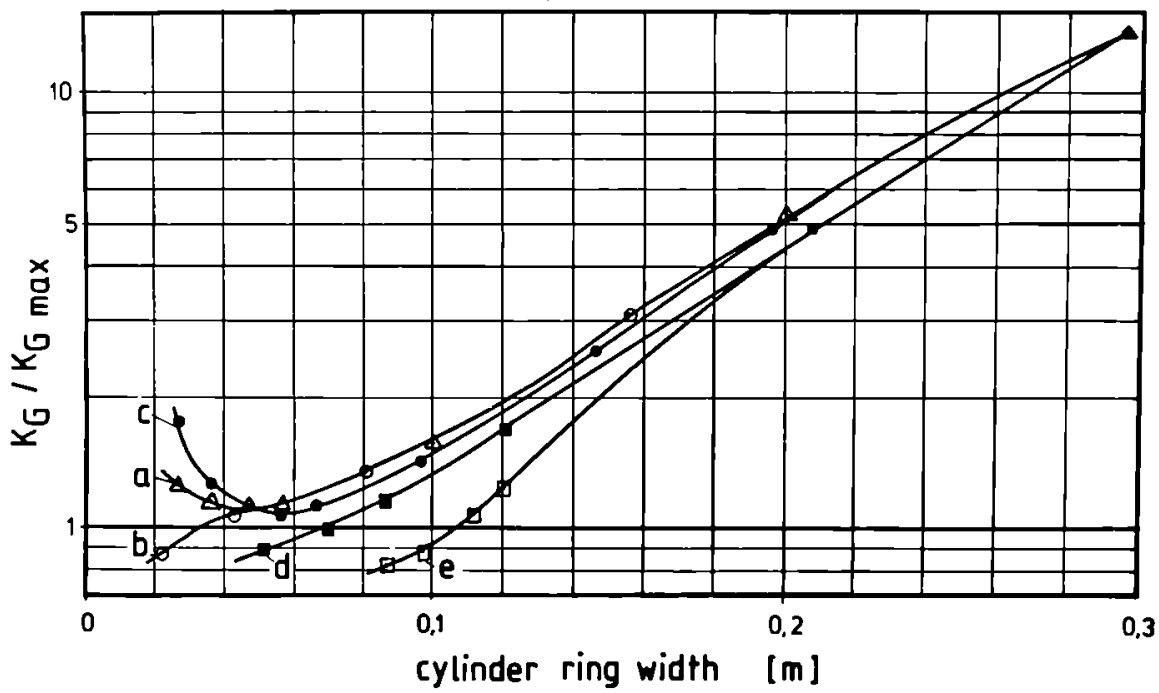

Pigure 6: Ratio KG/KGmar versus width of cylinder ring received by inserting a concentric hollow cylinder; symbols a-e see tert 
DEMONSTRATION OF A METHODOLOGY FOR ASSESSING SUITABLE
SYSTEMS FOR MANAGEMENT OF REACTOR DECOMMISSIONING WASTES

Barraclough, I M, Mobbs, S F and Davis, J P

National Radiological Protection Board

Chilton, Didcot, Oxon OXI1 ORQ, United Kingdom

\section{ABSTRACT}

A methodology has been developed for aiding decisions relating to the decomoissioning of nuclear facilities. The method uses multi-attribute utility analysis (MAUA) to break complex decisions down into a series of quantitative judgements as to the relative importance of different economic, radiological, environmental, social and political factors. As many of these judgements are subjective, a number of different weighting schemes have been used to reflect the views of different 'preference groups' or sections of society holding particular opinions. The methodology has been demonstrated in the context of three specific waste streams, using broadly representative data to show how choices between different decommissioning strategies might be made in a systematic way. The methodology is suitable both for broad policy decisions on general approaches to decomissioning and for decisions on particular aspects of specific decommissioning projects. It also allows the most important factors in the decision to be identified so that research effort may be concentrated in the appropriate areas.

\section{INTRODUCTION}

During the next decade, work will begin on decommissioning the first generation of commercial nuclear reactors in Europe. In making decisions as to the strategies to be adopted for the decommissioning work, it will be necessary to ensure compliance not only with statutory dose limits, but also with the ALARA principle, le, that doses should be kept as low as reasonably achievable, economic and social factors being taken into account. This is equivalent to saying that the radiologically optimum solution should be identified in each case. The study described here (1) demonstrates methodology for comparing, quantitatively, the options open to decision-makers at various stages of the decommissioning process, taking into account as many radiological protection and other factors as might be considered relevant. The results of such an analysis may then form an important input into the final decision.

The methodology has been demonstrated by means of three examples, in which the options avallable for the handling of wastes from stage 3 of PWR decommissioning and those from stages 2 and 3 of Magnox reactor decommissioning were considered. These all fall into the category of broad policy decisions, but the methodology could equally be applied to far more specific, detalled decisions.

\section{ASSESSMENT OF IMPACTS}

In order to compare different decommissioning options, the lopacts shown in Figure 1 were assessed. With the exception of post-disposal 
radiological impact, data were based on the literature. Since the purpose of this study was to develop a methodology rather than to make specific conclusions or recommendations as to actual decommissioning policy, broadly representative data were considered to be adequate. The post-disposal radiological impact was calculated for four generic disposal concepts (near surface, deep geologic, coastal tunnel and deep ocean bed) using established NRPB models for the transfer of radionuclides through the environment to man $(2)$. In general, environmental and social factors cannot be quantified in the way costs and doses can be, so these were assessed semi-quantitatively or qualitatively, quantitative judgements being left to the decision analysis stage.

\section{MULTI-ATTRIBUTE UTILITY ANALYSIS}

Many methods have been developed for analysis complex decisions in a systematic, quantitative manner ${ }^{3}$. Traditional methods such as cost -benefit analysis (CBA) allow only those factors which can readily be expressed in absolute monetary terms to be included. Multi-attribute utility analysis (MAUA), on the other hand, allows all relevant factors to be included in the analysis together. The aim is to calculate a total utility, U, for each option under consideration, the total utility being a weighted sum of the utility, Ui, of the option on each factor (or attribute) $i, i e$;

$$
\mathrm{U}=\sum W_{i} U_{i}
$$

where Wi is the weight on attribute 1 . In the version of MAUA used here, for a particular attribute, eg the maximum individual risk to a member of the public, the utility for each option lies on a scale of 0 to 100 . The 'best' option (in this case the one giving the lowest risk) always scores 100 , the 'worst' scores 0 . Since the weights are all normalised so that $\sum W 1=1$, the total utility for each option is between 0 and 100 , and the highest utility indicates the preferred option. It should be noted that MAUA deals only with the differences between options, not with any absolute measure of 'performance' for each option. Therefore the total utility of an option is only significant in terms of its value relative to the other options in the same analysis.

Figure 1 shows the factors or attributes considered in this study, arranged into an impact hierarchy or decision tree. The factors at the bottom of each branch (ie, those which are not further subdivided) are the basic attributes on which the options are scored ( 0 to 100). These attributes are then grouped together at nodes to make the process of assigning weights simpler; weights are applied at each node to give a utility (a weighted sum) for each option on a more general attribute. For example, the utility of each option for 'worker dose' will be a weighted sum of its utilities for 'dismantling dose', 'packing dose', 'transport dose' and 'disposal dose'. The weights have two components:

a. an objective component which simply reflects the relative sizes of the ranges being considered, eg if there is a difference of 10 man Sv between the best and worst options on one attribute, and a difference of 1 man Sv on another, then the relative weights will be $10: 1$.

b. a subjective component reflecting the relative importance of the different attributes to the person assigning the weights, eg supposing the two ranges mentioned above represent collective doses to workers and the public respectively, it may be felt that doses to 
the public are 5 times more important than those to rorkers. This means that the subjective weights would be $1: 5$, and the actual weights assigned would be the product of the objective and subjective ones, 1e $2: 1$.

At nodes where the attributes being compared are similar in nature, the weights will usually be primarily objective, but when dissimilar attributes are involved there must be some subjective judgement. For instance a range of 10 man Sv will almost always be more important than a range of 1 man Sv, but how does a range of 10 man Sv compare with one of $\mathcal{L} 20,000 ?$

In this study, weighting schemes were established a priori for simplicity. The internal weighting scheme is represented in terms of general utility range points or gurps. These are universal, dimensionless units into which all ranges of impact are converted; thus when two or more attributes are being compared, the relative sizes (in gurps) of the ranges between best and worst give the weights to be assigned. For most factors, the range in gurps between best and worst is proportional to the magnitude of the impacts, eg 1 gurp per man Sv or 10 gurps per fmillion. For a few factors, such as political impact, the range of gurps is assumed to be fixed, irrespective of the waste stream being considered, eg a particular disposal option may be less popular than the others regardless of the quantity or type of waste being disposed of.

Five separate sets of weights were chosen to represent notionally the views of different sections of society. These five preference groups were:

\author{
Group 1: "The Industrialist" \\ Group 2: "The Environmentalist" \\ Group 3: "The Local Business Person" \\ Group 4: "The Local Parent" \\ Group 5: "The Politician"
}

The weighting schemes used for these preference groups are summarised in Table I. The units in the second column indicate whether the range in gurps depends on the magnitude of the impact, eg gurps/man Sv, or whether it is fixed at particular number of gurps. Remember that the actual number of gurps is irrelevant; it is the relative sizes of the ranges at a given node which determines the weights.

The application of MAUA to anything other than an extremely simple problem involves a large number of calculations. To do these by hand would be extremely laborious, so a computer programme, HIVIEW(4), was used in this study. This programme not only performs the arithmetic for the analysis, but also provides visual aids for use in sensitivity analysis and the identification of the most important factors. It is an interactive system which allows changes to be made easily to utilities (1e, scores on the 0 to 100 scale), weights and even the decision tree.

\title{
4. DEMONSTRATION OF THE METHODOLOGY: EXAMPLES
}

The methodology described above was applied to three examples of the types of decision which will need to be made. These examples all fall into the category of policy-type decisions, but the methodology would also be suitable for more specific decisions relating to particular decomissioning projects. For simplicity, the same decision tree 
structure (Figure 1) was used throughout, with only utilities and weights changed, but this need not have been the case as different decisions will involve different factors. Indeed, the very act of choosing relevant factors and arranging them in a hierarchy is itself part of the decisionmaking process, and therefore the decision tree is potentially dependent on preference group.

\subsection{Example 1: PWR Stage 3 Wastes}

Eight options were considered in this example, covering both the timing of stage 3 and the disposal method for the wastes:

a. Stage 3 takes place 10 years after shutdown (ie, immediately after stage 2) or 100 years after shutdown (ie deferred stage 3 ).

b. Waste disposal takes place by one of four methods;

(i) near surface disposal on land;

(ii) deep geologic disposal on land;

(iii) deep disposal under the sea bed (coastal tunne1);

(iv) deep ocean disposal.

With the data and weighting schemes used, it was found that deferred stage 3 was not favoured. This was primarily on the basis of cost, as the cost of stage 3 was assumed to be unaffected by deferment so that the cost of maintaining the site for an extra 90 years was critical. It is worth noting, however, that if a discount rate of a few percent is applied to the costs, deferment becomes preferred because the cost of stage 3 all but disappears.

With the weights assigned to the five preference groups it was also found that there was no consensus on the favoured disposal option; groups 1 and 3 favoured near surface disposal which is cheaper, while the others preferred the deep disposal options.

\subsection{Example 2: Magnox Stage 3 Wastes}

The same eight options as in the previous example were considered here. However, the radiological impact calculations predicted a peak individual risk from ${ }^{14} \mathrm{C}$ following near surface disposal in excess of the ICRP limit of $10^{-5} \mathrm{y}^{-1}$. Thus near surface disposal would not be an acceptable option, and should be excluded from the analysis.

The main conclusion arrived at with the data and weights used was just the opposite of that for PWR stage 3; for Magnox stage 3 deferment was found to be clearly preferable on grounds of cost, even with the $0 \%$ discount rate used here. The other important factor, radiological impact, did not distinguish between immediate and deferred stage 3 as it was dominated by ${ }^{14} \mathrm{C}$.

Just as in example 1 , the different weights assigned to the five preference groups resulted in different choices of the best disposal option; groups 1 and 3 favoured the cheaper deep sea disposal, while the others again preferred deep disposal.

\subsection{Example 3: Magnox Stage 2 Wastes}

For this waste stream, the same four disposal options were considered as for the previous examples, but in this case the other variant was the exemption level below which waste can be regarded as non-active. The two 
values considered were $0.37 \mathrm{~Bq} 8^{-1}$ (the present 'blanket' level for the UK) and $74 \mathrm{~Bq} 8^{-1}$, the highest exemption level found to apply in Europe.

In this example, there was no consensus at all amongst the $f$ ive notional preference groups. Groups 1 and 3 supported the higher exemption level and near surface disposal for the non-exempt wastes (primarily on the basis of cost), while groups 4 and 5 favoured deep disposal and retention of the lower exemption limit. Group 2 favoured deep disposal, but barely distinguished between exemption levels. This decision appeared to reduce to a trade-off between the cost savings from increasing exemption levels and the social attitudes to what wight appear to be a relaxation of safety standards.

\section{DISCUSSION}

The limitations of some of the data used in this study are such that the conclusions arrived at in the examples described above cannot be considered to have much relevance to actual decommissioning decisions. However a number of general polnts can be made concerning both the methodology and its Implementation.

(1) Care is needed in the selection of both the options to be considered and the factors to be included in the analysis. Some factors have been omfted from this study, conventional (non-radiological) Industrial risks for example, but it seems likely that all of the important factors, those which might actually affect the decision, have been included. On the other hand, a number of options which have not been considered in the examples here may warrant Investigation, even if only to show that they have been considered, eg, recycling/re-use of materials from the reactor, or long-term storage of wastes on site as an alternative to disposal.

(ii) In the examples above, the deep geologic and coastal tunnel disposal concepts were difficult to differentiate, as few of the factors actually discriminated between them. In such cases, the comparison between all optlons may only be the first step, and the analysis may need to be repeated, having eliminated some options, concentrating on particular factors which do distinguish between the remaining options.

(11i) Clearly the choice of weighting factors has a large bearing on the results of the analysis. Whilst it is unrealistic to suppose that there could be a universally applicable set of weights, it might be possible to devise a standardised set of preference groups and associated weighting schemes. These would need to cover a wide, but representative, range of opinion. In this study, "the industrialist" and "the local business person" were virtually indistinguishable. It may be useful to add more detail to the preference groups; for example some groups may be assumed to favour discounting of costs while others might oppose it.

(iv) Perhaps the most important requirement is to know how robust any conclusions of these analyses might be. For generic studies in particular there is a great deal of uncertainty in the avallable data (eg, cost estimates, radionuclide inventorles), and it is virtually impossible to ensure that all parameter estimates include the same degree of conservat $1 \mathrm{sm} / \mathrm{realism}$. There is a need to investigate how, and indeed whether, uncertaintles may be treated systematically in this type of methodology. 


\section{REFERENCES}

1. Davis, J P, Barraclough, I M and Mobbs, S F, Methodology for assessing suitable systems for management of reactor decommissioning wastes. CEC/NRPB Report to be published.

2. Hill, M D (Ed), Verification and validation of NRPB models for calculating rates of radionuclide transfer through the environment. National Radiological Protection Board NRPB-R223, Chilton (1989).

3. International Commission on Radiological Protection, Optimization and decision-making in radiological protection. ICRP Publication 55, Ann. ICRP 20 (1), Oxford (1989).

4. Barclay, S, A User's manual to HIVIEW. Decision Analysis Unit, London School of Economics, London (1987). 
Table I

Weighting schemes for Preference Groups 1 to 5

\begin{tabular}{|c|c|c|c|c|c|c|}
\hline & \multirow[t]{2}{*}{ Units } & \multicolumn{5}{|c|}{$\begin{array}{l}\text { Weights given according } \\
\text { to Preference Groups: }\end{array}$} \\
\hline & & 1 & 2 & 3 & 4 & 5 \\
\hline \multicolumn{7}{|l|}{ Radiological Impacts } \\
\hline Worker Collective Dose & gurps/man Sv & 0.1 & 0.01 & 0.1 & 0.1 & 0.1 \\
\hline $\begin{aligned} \text { Public } \begin{array}{l}\text { Collective Dose } \\
\text { (short term) }\end{array}\end{aligned}$ & gurps/man Sv & 0.1 & 0.01 & 0.1 & 10 & 0.1 \\
\hline $\begin{array}{l}\text { Public Max. Ind. Risk } \\
\text { (post-disposa1) }\end{array}$ & gurps $/ 10^{-6} \mathrm{y}^{-1}$ & 10 & 10 & 10 & 10 & 10 \\
\hline $\begin{array}{l}\text { Public Collective Dose } \\
\text { post disposal: }\end{array}$ & gurps/man Sv & & & & & \\
\hline $\begin{array}{l}<10^{3} \\
10^{3} \text { to } 10^{4} y \\
>10^{4} y\end{array}$ & $\begin{array}{l}\text { local } \\
\text { regional } \\
\text { global } \\
\text { local } \\
\text { regional } \\
\text { global } \\
\text { local } \\
\text { regional } \\
\text { global }\end{array}$ & $\begin{array}{l}0.01 \\
0.01 \\
0.01 \\
0 \\
0 \\
0 \\
0 \\
0 \\
0\end{array}$ & $\begin{array}{l}0.1 \\
1 \\
1 \\
1 \\
10 \\
10 \\
1 \\
10 \\
10\end{array}$ & $\begin{array}{l}0.01 \\
0.01 \\
0.01 \\
0 \\
0 \\
0 \\
0 \\
0 \\
0\end{array}$ & $\begin{array}{l}1 \\
0.1 \\
0.1 \\
1 \\
0.1 \\
0.1 \\
1 \\
0.1 \\
0.1\end{array}$ & $\begin{array}{l}0.1 \\
0.1 \\
0.1 \\
0.01 \\
0.01 \\
0.01 \\
0.01 \\
0.01 \\
0.01\end{array}$ \\
\hline$\underline{\text { Costs }}$ & gurps/fmillion & 10 & 0.01 & 10 & 0.1 & 0.1 \\
\hline \multicolumn{7}{|l|}{ Environmental Impacts } \\
\hline Non-radiological pollution & gurps & 1 & 10 & 10 & 10 & 1 \\
\hline $\begin{array}{l}\text { Loss of resource } \\
\text { Social and Political } \\
\text { Impacts }\end{array}$ & gurps/fmillion & 10 & 10 & 10 & 0.1 & 0.1 \\
\hline Jobs & gurps/man y & 0.1 & 0.01 & 0.1 & 0.01 & 0.01 \\
\hline Local spin-off effects & gurps & 5 & 0.5 & 50 & so & 5 \\
\hline Public perception & gurps & 0 & 1 & 0 & 10 & 10 \\
\hline Political impact & gurps & 5 & 0 & 5 & 0 & 50 \\
\hline
\end{tabular}

Note

gurps = general utility range points, a dimensionless measure of the importance of an impact. 


\section{Figure 1 : Impact llierarchy}

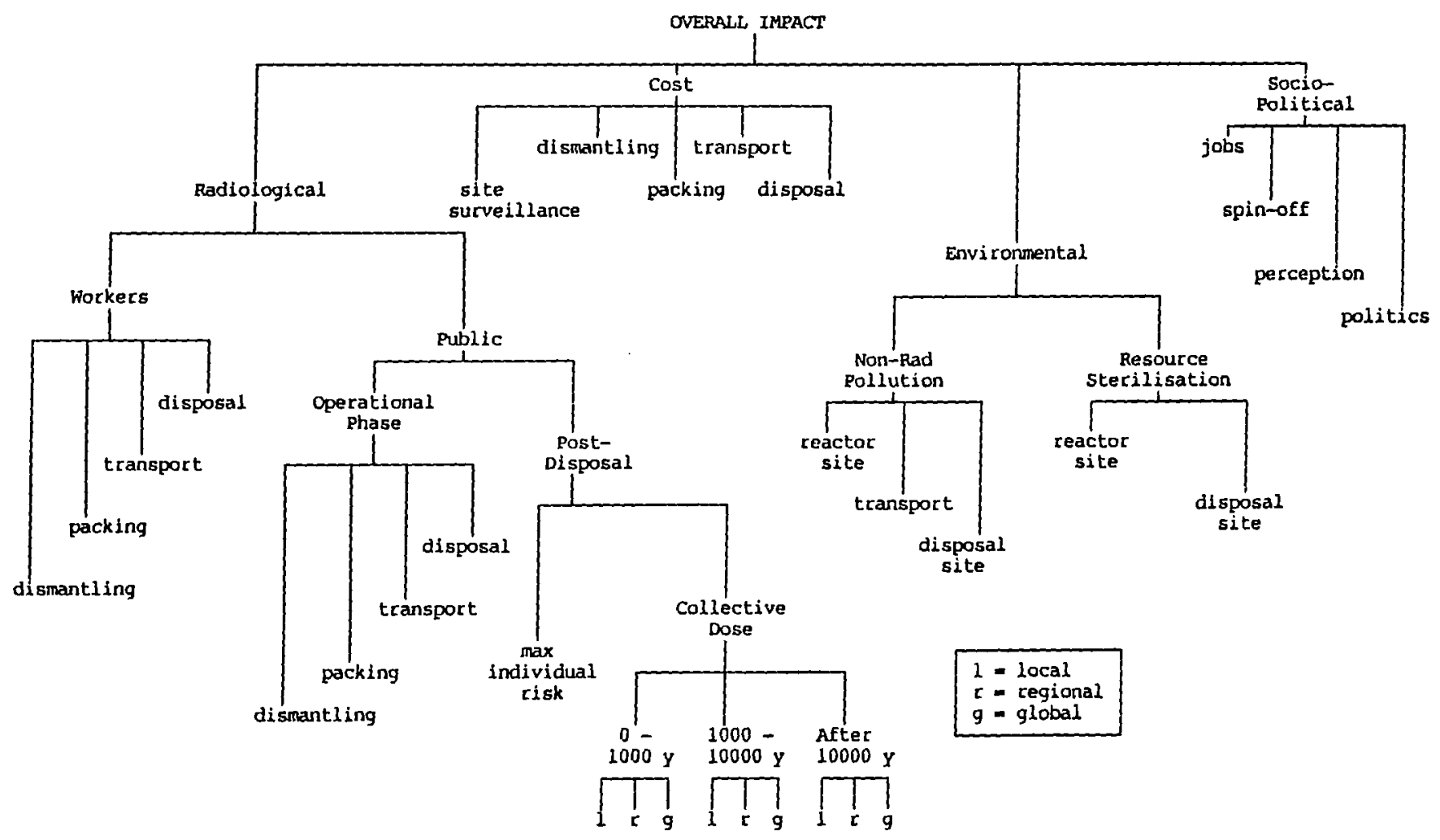




\section{ANTICIPATED ASSESSMENT OF THE AMOUNT OF RADIOACTIVE WASTES ARISING FROM POOL LMBFR DISMANTLING}

\section{C.ALARY D.MAIRE G.PEYRARD}

Novatome, Lyon, France.

\section{ABSTRACT}

This report is a part of the studies of nuclear installation decommissioning, which concerns power fast breeder reactor of the European system.More precisely, it deals with the assessment of the amount of radioactive wastes arising from decommissioning.

Activities are produced through neutronic captures in materials. In the following pages, radioactive wastes arising from the Super Phenix 1 reactor structure and component dismantling are described.Following assumptions have been used :

- The reactor has been run at full power for 30 years.

- Results assume a 2 year decay time after ultimate reactor shut down.

The more active structures and components are situated on the core axis (core cover plug, diagrid, diagrid-support.....). Radially beyond the core are the lateral neutron shielding assemblies which reduce primary pump and intermediate heat exchanger activation. Main contributors arise from the following isotopes ${ }^{59} \mathrm{Co},{ }^{54} \mathrm{Fe}$, ${ }^{62} \mathrm{Ni}$.

Stellite (about $50 \%$ of ${ }^{59} \mathrm{Co}$ ) coating of spherical seats on the props which the subassemblies are stuck in, and stellite coatings on diagrid-diagrid/support seats, have a high maximum local volumic activity (about $10^{12}$ and $10^{9} \mathrm{~Bq} / \mathrm{cm}^{3}$ ). While $85 \%$ of the analysed 3000 tons of steel, have an activity lower than $100 \mathrm{~Bq} / \mathrm{g}$.

Above the roof slab and outside the safety tank, structures and components are not active.

\section{1- INTRODUCTION}

Problems generated by nuclear reactor dismantling are radioactive waste handling, transportation and storage. Specific studies about every reactor type must be carried out. The fast breeder reactor of the European system Super Phenix 1 is used as reference in the following calculations.

While dismantling feasability of this power plant on the three type levels defined by I.A.E.A have been studied previously (1),the present work consists in building the radioactive waste inventory versus their specific activity. Waste management and processing will be the consequence of the obtained results.

\section{2- SUPER PHENIX 1 REACTOR BLOCK}

Super Phenix 1 is a pool reactor.All the primary loop is inside the main 


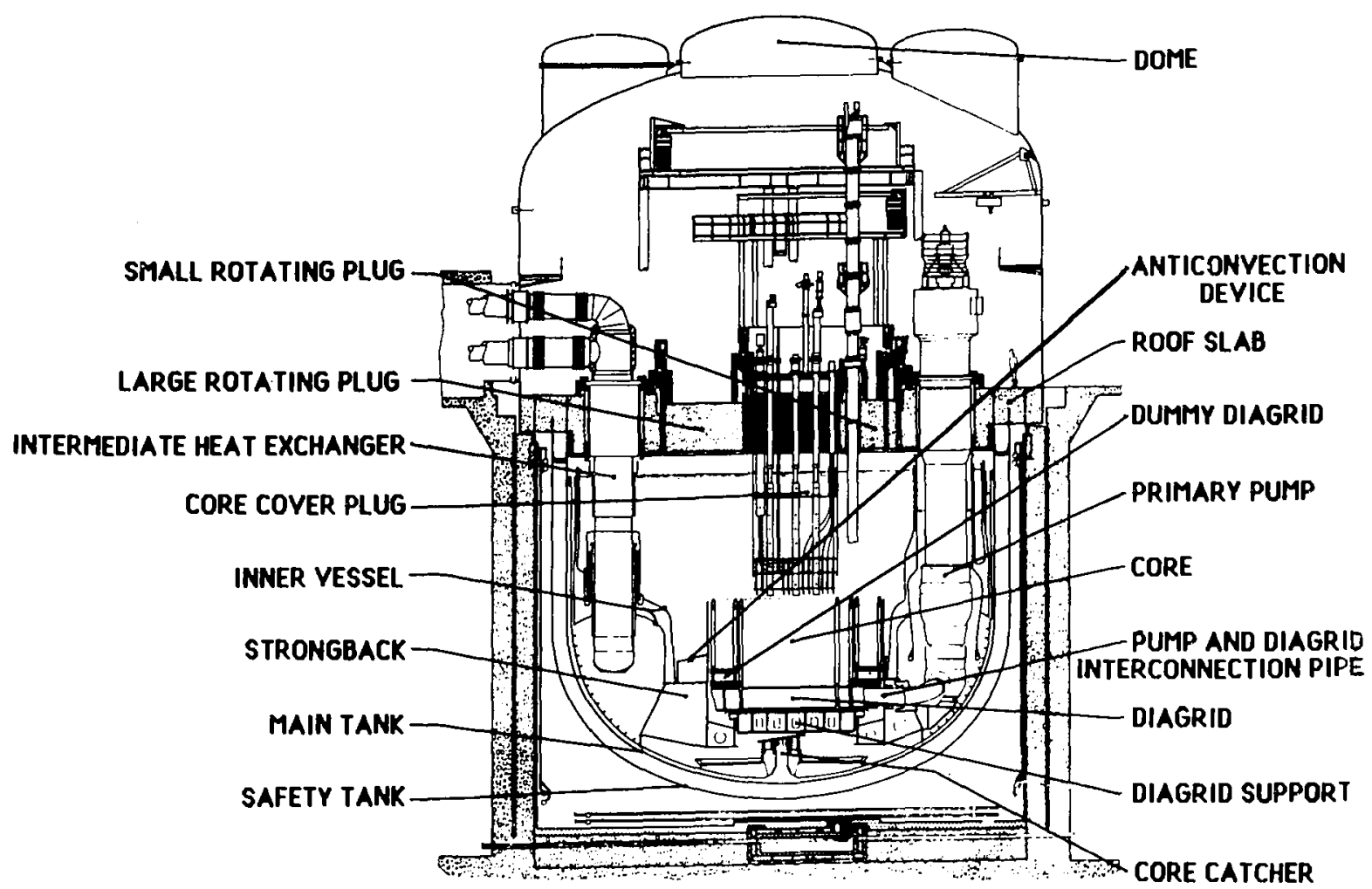

Figure 1 : REACTOR BLOCK 
Table I: Activation reaction characteristics

\begin{tabular}{|c|c|c|c|c|c|c|c|c|}
\hline $\begin{array}{l}\text { Initial } \\
\text { isotope }\end{array}$ & $\begin{array}{c}\text { Abundance } \\
\mathbf{8}\end{array}$ & $\begin{array}{l}\text { Reaction } \\
\text { type }\end{array}$ & $\begin{array}{l}\text { Final } \\
\text { isotope }\end{array}$ & $\begin{array}{l}\text { Thermal } \\
\text { cross } \\
\text { section } \\
\text { (barn) }\end{array}$ & $\begin{array}{c}\text { Resonance } \\
\text { integral } \\
\text { (barm) }\end{array}$ & $\begin{array}{l}\text { Fast } \\
\text { cross } \\
\text { section } \\
\text { (barn) }\end{array}$ & $\begin{array}{c}\text { Threshold } \\
\text { energy }\end{array}$ & $\begin{array}{c}\text { Half-life } \\
\text { (year) }\end{array}$ \\
\hline I5IEu & 47,8 & $(\mathrm{Nth}, \mathrm{G})$ & $152 \mathrm{Eu} \mathrm{g}$ & 5900 & 5564 & & & 12,4 \\
\hline 153Eu & 52,2 & $(N \operatorname{th}, G)$ & $154 E \mathrm{E}$ & 390 & 1635 & & & 8,5 \\
\hline $154 E u$ & ortificial & (Nth,G) & 155Eu & 1500 & 1240 & & & 4,65 \\
\hline $151 \mathrm{Eu}$ & 47,8 & $(N, P)$ & $151 \mathrm{sm}$ & & & $49 E-06$ & 10 & 93 \\
\hline $151 \mathrm{Eu}$ & 47,8 & $(N, 2 N)$ & 150Eu $\mathrm{m}+\mathrm{g}$ & & & 3.7 E-03 & 9 & 35 \\
\hline 153Eu & 52,2 & $(N, 2 N)$ & 152Eu $\mathrm{m}-\mathrm{-g}$ & & & $2.1 E-03$ & 9 & 12,4 \\
\hline $14 N$ & 99,635 & (Nth,P) & $14 C$ & 1,81 & $87 E-02$ & & & 5734 \\
\hline $39 K$ & 93,1 & $(N \operatorname{th}, G)$ & $40 K$ & 2,1 & 0 & & & $1.28 E+09$ \\
\hline $39 K$ & 93,1 & (N,P) & $39 A$ & & & $20 E-03$ & 3 & 269 \\
\hline $39 K$ & 93,1 & $(N, A)$ & $36 \mathrm{Cl}$ & & & $13 E-03$ & 4 & $3 E+05$ \\
\hline $59 \mathrm{Co}_{0}$ & 100 & (Nth,G) & $60 \mathrm{Co}$ & 37 & 77 & & & 5,27 \\
\hline $93 \mathrm{Nb}$ & 100 & (Nth,G) & $94 \mathrm{Nb}$ & 1,2 & 9 & & & 20000 \\
\hline $93 \mathrm{Nb}$ & 100 & $(N, 2 N)$ & $92 \mathrm{Nb}$ & & & 1,1 & 9 & 2. $E+07$ \\
\hline $93 \mathrm{Nb}$ & 100 & $\left(N, N^{*}\right)$ & $93 \mathrm{Nb} \mathrm{m}$ & & & 0,1 & 0,1 & 13,6 \\
\hline $107 \mathrm{Ag}$ & 51,35 & $(N \operatorname{th}, G)$ & $108 \mathrm{Ag} \mathrm{m}$ & 4,5 & 0 & & & 127 \\
\hline $60 \mathrm{Ni}$ & 26,2 & $(N, P)$ & $60 \mathrm{Co}$ & & & $4.4 E-03$ & 12,55 & 5,27 \\
\hline $56 \mathrm{Fe}$ & 91,52 & $(N, 2 N)$ & $55 \mathrm{Fe}$ & & & $68 E-06$ & 12 & 2,7 \\
\hline $64 \mathrm{Ni}$ & 1,1 & $(N, 2 N)$ & $63 \mathrm{Ni}$ & & & $38 E-05$ & 9,124 & 100 \\
\hline $62 \mathrm{Ni}$ & 3.7 & (Nth, G) & $63 \mathrm{Ni}$ & 14,5 & 7 & & & 100 \\
\hline $54 \mathrm{Fe}$ & 5,9 & $(N t h, G)$ & $55 \mathrm{Fe}$ & 2,25 & 1,2 & & & 2,7 \\
\hline $60 \mathrm{Ni}$ & 26,2 & $(N, 2 N)$ & $59 \mathrm{Ni}$ & & & $60 \mathrm{E}-05$ & 11,574 & $7.5 E+04$ \\
\hline $63 \mathrm{Cu}$ & 69,09 & $(N, A)$ & $60 \mathrm{Co}$ & & & $56 E-05$ & 12,3 & 5,27 \\
\hline $78 S e$ & 23,61 & (Nth,G) & $79 \mathrm{Se}$ & $43 E-02$ & 4,7 & & & 6500 \\
\hline $78 \mathrm{Se}$ & 23,61 & $(N, P)$ & $78 \mathrm{As}$ & & & $1.0 E-03$ & 3,244 & 17,5 \\
\hline $40 \mathrm{Ca}$ & 96,92 & $(\mathrm{~N} t h, \mathrm{G})$ & $41 \mathrm{Co}$ & 0,4 & $18 E-02$ & & & $1.3 E+05$ \\
\hline $42 \mathrm{Ca}$ & 0,64 & $(N, A)$ & $39 A$ & & & $2.7 E-03$ & 0,33 & 269 \\
\hline $35 \mathrm{Cl}$ & 75,4 & (Nth,G) & $36 \mathrm{Cl}$ & 43 & 17 & & & 3. $E+05$ \\
\hline $135 \mathrm{Ba}$ & 6,56 & $(N, P)$ & $135 \mathrm{Cs}$ & & & $95 E-06$ & 0,546 & $2.3 E+06$ \\
\hline $58 \mathrm{Ni}$ & 67,88 & (Nth,G) & $59 \mathrm{Ni}$ & 4,9 & 2,4 & & & $7.5 E+04$ \\
\hline
\end{tabular}


tank.Sodium is used as coolant. This reactor features an intermediate sodium loop between core and steam generators. All main structures and components are described on figure 1.

\section{3- HYPOTHESES}

- Calculations have been made for a 2 year decay time.

- The reactor has been run at full power for 30 years.

- The activities are produced through neutronic captures in materials.29 possible activation reactions had been studied(2)(3)(4) (table I). The half life of their products are longer than one year.Few other reactions of minor importance are neglected because of lack of information.

\section{4- CALCULATION METHOD (figure 2)}

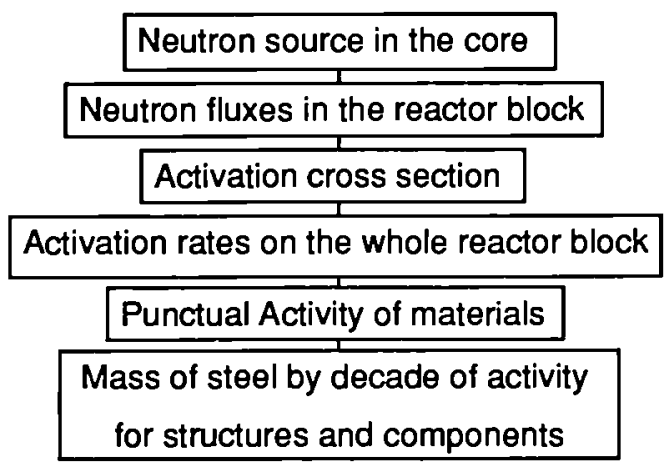

Figure 2 : Main steps of calculation

In the first step we have determined the in-core neutron source, diffusion $R-Z$ calculations were used.

From the obtained fission densities, a neutron transport calculation using the discrete ordinate method has given the neutron fluxes in the reactor block.

After collecting the activation cross sections we have obtained the activation rates on the whole reactor block.

The next step of calculation worked out the punctual volumic activities in matenials.

Axially and radially on core mid-plane,volumic punctual activities have been calculated in several points. To describe the more or less active zone structures and components, the following way has been used :

On the basis of the previous results, a network of square meshes has been worked out by interpolation of activities values.

The following approximation has been used : radial and axial activity variations between two calculation points follow the total flux variations. 
For points farther from the core centre a two dimension $R-Z$ total flux was helpful.

The components, for instance : the core cover plug, have been shared into simple shaped parts like : plates,tubes.......the activities of which have been separately studied.The distribution of activity over these elements is described meshwise. decade.

The final result is the steel mass belonging to every volumic punctual activity

\section{5- RESULTS}

\section{5-1 Volumic punctual activities}

The higher levels of activity are found in the lower axial direction.Lateral and upper axial regions comprise neutron shields which reduce radial and upper axial fluxes.

Maximum values are obtained for stellite coatings on the prop spherical seats where the subassemblies are in touch with their support. The main contributor is the activation of ${ }^{59}$ Co contained in the stellite.

\section{5-2 Steel mass by decade of punctual volumic activity}

For every main active structure and component inside the reactor block (figure I),steel masses by decade of ponctual volumic activity were calculated.

Results are displayed on tables II-III.and figure 3

Steol mass $(\mathrm{Kg})$

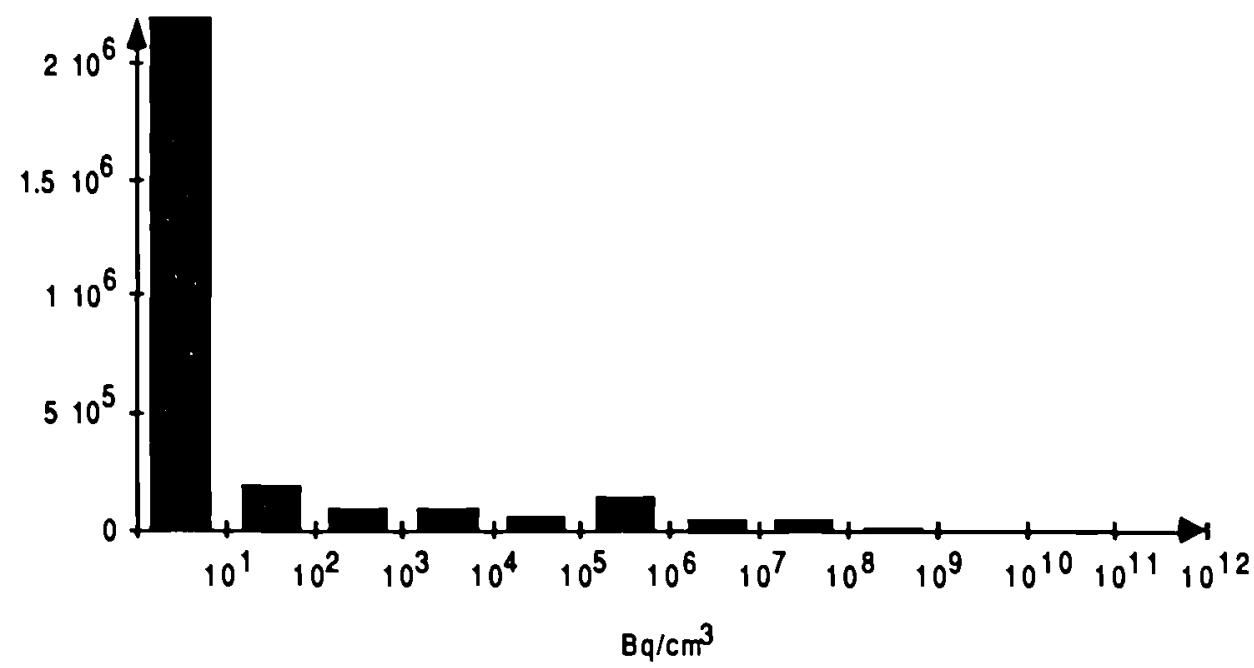

Figure 3 : Mass balance versus activity 
Table II : Mass balance versus activity

\begin{tabular}{|c|c|c|c|c|c|c|c|c|}
\hline $\begin{array}{l}\text { Components and } \\
\text { Structures }\end{array}$ & $\begin{array}{l}\text { Core Co- } \\
\text { verplug }\end{array}$ & $\begin{array}{l}\text { Control } \\
\text { rods } \\
\text { Meca- } \\
\text { nisms } \\
24 \\
\end{array}$ & $\begin{array}{l}\text { I.H.X. } \\
8 \\
\end{array}$ & $\begin{array}{l}\text { Main } \\
\text { tank }\end{array}$ & $\begin{array}{l}\text { Diagrid } \\
\text { Support }\end{array}$ & $\begin{array}{l}\text { Dummy } \\
\text { Diagrid }\end{array}$ & Diagrid & $\begin{array}{c}\text { Strong- } \\
\text { bock }\end{array}$ \\
\hline $\begin{array}{c}10^{11}<\mathrm{A}<10^{12} \mathrm{~Bq}: / \mathrm{cm}^{3} \\
\text { Moss of steel (Kg) }\end{array}$ & & 240 & & & & & & \\
\hline $\begin{array}{c}10^{10} \text { \& } A<10^{11} \mathrm{~Bq}: / \mathrm{cm}^{3} \\
\text { Mass of steel (Kg) }\end{array}$ & & 768 & & & & & 2644 & \\
\hline $\begin{array}{c}10^{9}<A<10^{10} \mathrm{~Bq}: / \mathrm{cm}^{3} \\
\text { Mass of steel }(\mathrm{Kg})\end{array}$ & & 720 & & & & & 7691.5 & \\
\hline $\begin{array}{c}10^{8}<\mathrm{A}<10^{9} \mathrm{~Bq}: / \mathrm{cm}^{3} \\
\text { Mass of steel }(\mathrm{Kg})\end{array}$ & & 792 & & & & 2257 & 12386.1 & \\
\hline $\begin{array}{c}10^{7}<\mathrm{A}<10^{8} \mathrm{~Bq}: / \mathrm{cm}^{3} \\
\text { Moss of steel }(\mathrm{Kg})\end{array}$ & 17309.6 & 1872 & & & 840 & 7759 & 15425.2 & \\
\hline $\begin{array}{c}10^{6}, \mathrm{~A}<10^{7} \mathrm{~Bq}: / \mathrm{cm}^{3} \\
\text { Mess of steel }(\mathrm{Kg})\end{array}$ & 6932.2 & 456 & & & 5542 & 9492 & 11011 & \\
\hline $\begin{array}{c}10^{5}, \mathrm{~A}<10^{6} \mathrm{~Bq} / \mathrm{cm}^{3} \\
\text { Mass of steel }(\mathrm{Kg})\end{array}$ & 15406.2 & 1200 & & & 10052.2 & 8401 & 39053.8 & \\
\hline $\begin{array}{c}10^{4}, A \cdot 10^{5} \mathrm{~Bq}: / \mathrm{cm}^{3} \\
\text { Mass of steel }(\mathrm{Kg})\end{array}$ & 6467 & 1776 & & & 5607 & 7852 & 14506.4 & \\
\hline $\begin{array}{l}10^{3}<\mathrm{A}<10^{4} \mathrm{~Bq}: / \mathrm{cm}^{3} \\
\text { Mass of steel }(\mathrm{Kg})\end{array}$ & 688.4 & 4272 & 38400 & & 9694.4 & 3053 & 8580.9 & 8461.5 \\
\hline $\begin{array}{c}10^{2}<\mathrm{A}<10^{3} \mathrm{~Bq}: / \mathrm{cm}^{3} \\
\text { Mass of steel }(\mathrm{Kg})\end{array}$ & 1431.6 & 2160 & 25680 & 2736.2 & 3131.6 & & 2227 & 21388 \\
\hline $\begin{array}{c}10^{1}, \mathrm{~A}<10^{2} \mathrm{~Bq}: / \mathrm{cm}^{3} \\
\text { Mass of steel }(\mathrm{Kg})\end{array}$ & 1586.4 & 2856 & 107200 & 1203.9 & & & 1504 & 13797.8 \\
\hline $\begin{array}{l}\mathrm{A}<10^{1} \mathrm{~Bq}: / \mathrm{cm}^{3} \\
\text { Mass of steel }(\mathrm{Kg})\end{array}$ & 116018.6 & 37944 & 418904 & 349349.9 & & & & 157352.7 \\
\hline
\end{tabular}


Table III : Mass bolance yersus activity

studied total steel moss $=2,915 \mathrm{t}$

\begin{tabular}{|c|c|c|c|c|c|c|c|}
\hline $\begin{array}{l}\text { Components and } \\
\text { Struct ures }\end{array}$ & $\begin{array}{c}\text { Pumpond } \\
\text { Diegrid } \\
\text { intercont } \\
\text { noction } \\
\text { pipe } \\
8 \\
\end{array}$ & $\begin{array}{l}\text { Inner } \\
\text { vessel }\end{array}$ & $\begin{array}{c}\text { Core } \\
\text { cotcher }\end{array}$ & $\begin{array}{c}\text { Pimary } \\
\text { pumps. } \\
4 \\
4\end{array}$ & $\begin{array}{l}\text { Safety } \\
\text { tonk }\end{array}$ & $\begin{array}{l}\text { Anticon } \\
\text { vection } \\
\text { device }\end{array}$ & Total \\
\hline $\begin{array}{c}10^{11} \cdot \mathrm{A} \cdot 10^{12} \mathrm{~Bq} / \mathrm{cm}^{3} \\
\text { Mass of steel (Kg) }\end{array}$ & & & & & & & 240 \\
\hline $\begin{array}{c}10^{10} \times A \cdot 10^{11} \mathrm{~Bq} / \mathrm{cm}^{3} \\
\text { Mass of steel (kg) }\end{array}$ & & & & & & & 3412 \\
\hline $\begin{array}{c}10^{9} \cdot \mathrm{A} \cdot 10^{10} \mathrm{~Bq} / \mathrm{cm}^{3} \\
\text { Mass of steol (Kg) }\end{array}$ & & & & & & & 8411.5 \\
\hline $\begin{array}{l}10^{8} \cdot \mathrm{A} \cdot 10^{9} \mathrm{Bg} / \mathrm{cm}^{3} \\
\text { Mass of steel (kg) }\end{array}$ & & & & & & & 15435.1 \\
\hline $\begin{array}{l}10^{7}+\mathrm{A} \cdot 10^{8} \mathrm{~Bq} / \mathrm{cm}^{3} \\
\text { Moss of gteel }(\mathrm{kg})\end{array}$ & & & & & & 411.5 & 43617.3 \\
\hline $\begin{array}{c}10^{6} \cdot A \cdot 10^{7} B q / \mathrm{sm}^{3} \\
\text { Mogs of steel (kg) }\end{array}$ & & & 4907.6 & & & 498.9 & 38919.7 \\
\hline $\begin{array}{c}10^{5} \cdot A \cdot 10^{6} \mathrm{~Bq} / \mathrm{cm}^{3} \\
\text { Mogs of } 3(00)(\mathrm{kg})\end{array}$ & 9960 & 51220 & 613401 & & & 4091.5 & 145662.8 \\
\hline $\begin{array}{l}10^{4} \cdot \mathrm{A} \cdot 10^{5} \mathrm{~Bq} / \mathrm{cm}^{3} \\
\text { Mass of stoel }(\mathrm{kg})\end{array}$ & 94214 & 88520 & 7309.1 & & & 5055.4 & 61926.3 \\
\hline $\begin{array}{l}10^{3} \cdot A \cdot 10^{4} \mathrm{~Bq} / \mathrm{cm}^{3} \\
\text { Moss of steel (Kg) }\end{array}$ & 93203 & 77720 & 820.0 & 99932 & & 4390 & 105454.5 \\
\hline $\begin{array}{c}10^{2} \cdot \mathrm{A} \cdot 10^{3} \mathrm{~Bq} / \mathrm{cm}^{3} \\
\text { Mogs of steel }(\mathrm{kg})\end{array}$ & 126001 & 49000 & & 24541.2 & 89.3 & 2090.8 & 102975.8 \\
\hline $\begin{array}{l}10^{1}+A+10^{2} \mathrm{~Bq} / \mathrm{cm}^{3} \\
\text { Moss of stoel }(\mathrm{kg})\end{array}$ & 80056 & 37840 & & 445916 & 52770 & 8897 & 190696 \\
\hline $\begin{array}{l}A \cdot 10^{1} \mathrm{Ba} / \mathrm{cm}^{3} \\
\text { Moss of } 3(0 e l(\mathrm{~kg})\end{array}$ & 36485 & 3615700 & & 412700 & 3396337 & 898.7 & 21980861 \\
\hline
\end{tabular}


High values are noticed for control rod mechanism, diagrid, dummy diagrid.....

In the calculations, the control rod mechanisms have been considered to be made of stainless steel (Z2 CND 18/12) in fact all elements are constituted of several differents steels, inconel, stellite. The lower parts of mecanisms are housed in the core cover plug, they drive the absorbers.. These parts have a high activity because they are close to the core. These active parts represent a small amount of material as can be seen in table II.

In the lower part of the reactor block the more active components are the diagrid and the dummy diagrid.

The diagrid is situated just under the core,so its upper part is very active $\left(10^{10} \mathrm{~Bq} / \mathrm{cm}^{3}\right.$ in the central part at the bottom of subassemblies).

The dummy diagrid lies on the diagrid around the hexagonal stainless steel subassemblies, then the activity of this component is very important(table II).

The less active components and structures are the intermediate heat exchangers (I.H.X), the primary pumps, the strongback, the main tank, the safety tank.

The I.H.X and the primary pumps are settled beyond the lateral neutron shield logs (figure 1), at about $7 \mathrm{~m}$ from the core centre.

Strongback, main tank, safety tank are also far from the core centre.Only few percents of these components are considered active.

Diagrid

Control rod mechanism (24)

Dummy diagrid

Core cover plug

Diagrid support

Core catcher

Anticonvection device

Inner vessel

Pump and diagrid interconnection pipo (8)

Intermediate heat exchanger (8)

Primary pump (4)

Strongback

Main tank

Safety tank

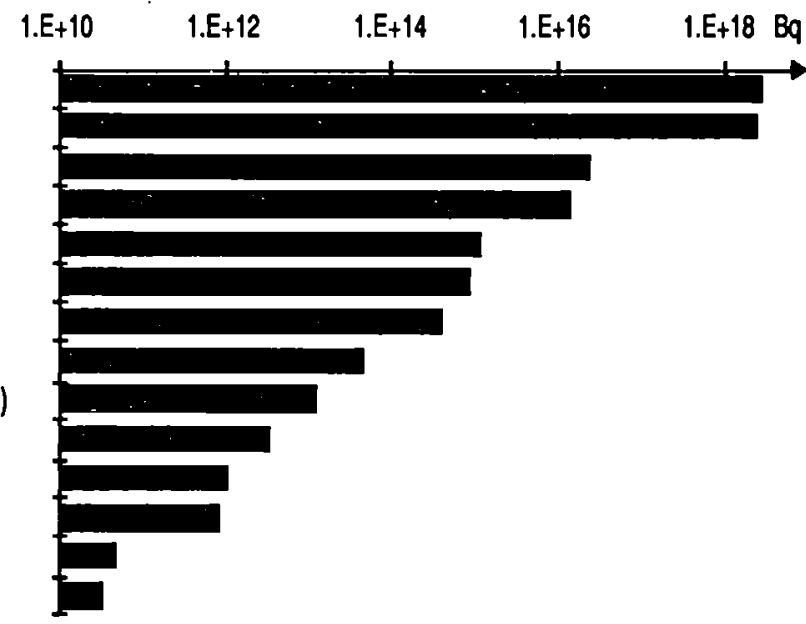

Figure 4 : Structure and component total activities issued from steel activation

\section{6- MISCELLANEOUS}

197 steel reflectors and 1076 lateral neutron shielding logs which represent 114 and 473 tons of very active steel $\left(10^{11} \rightarrow 10^{5} \mathrm{~Bq} / \mathrm{cm}^{3}\right.$ ), have not been taken into 
consideration in previous calculations. These components are removable.

3000 tons of Na contained in primary loop and 1000 tons filling the fuel storage drum are also very active. The activation is issued from ${ }^{22} \mathrm{Na}$ and ${ }^{137} \mathrm{Cs}$ arising from fission products, in the hypothesis of a clad failure.

Reactor block and roof slab concrete are not active.

Iable IV: Sinucture and component total activities issued from steel activation

\begin{tabular}{|l|c|c|}
\hline \multicolumn{1}{|c|}{ Structures and components } & $\begin{array}{c}\text { Steel mass } \\
(\mathrm{Kg})\end{array}$ & $\begin{array}{c}\text { Steel mass maxi- } \\
\text { mum total activity } \\
(\mathrm{Bq})\end{array}$ \\
\hline Core cover plug & 165840 & $1,4 \mathrm{E}+16$ \\
\hline Control rod mechanism (24) & 55056 & $2,6 \mathrm{E}+18$ \\
\hline Intermediate heat exchanger (8) & 590184 & $3,4 \mathrm{E}+12$ \\
\hline Main tank & 353290 & $5,0 \mathrm{E}+10$ \\
\hline Diagrid support & 34867 & $1,2 \mathrm{E}+15$ \\
\hline Dummy-diagrid & 38814 & $2,5 \mathrm{E}+16$ \\
\hline Diagrid & 115030 & $2,8 \mathrm{E}+18$ \\
\hline Strongback & 201000 & $8,8 \mathrm{E}+11$ \\
\hline Pump and diagrid interconnection pipe (8) & 39000 & $1,2 \mathrm{E}+13$ \\
\hline Inner vessel & 392000 & $4,8 \mathrm{E}+13$ \\
\hline Core catcher & 74537 & $8,8 \mathrm{E}+14$ \\
\hline Primary pump (4) Total & 491892 & $1,1 \mathrm{E}+12$ \\
\hline Safety tank & 345000 & $3,2 \mathrm{E}+10$ \\
\hline Anticonvection device & 18326 & $4,0 \mathrm{E}+14$ \\
\hline \multicolumn{1}{|c|}{ Tol } & 2914836 & $5,4 \mathrm{E}+18$ \\
\hline
\end{tabular}

\section{CONCLUSION}

A steel mass balance versus activity of every main structure and component is represented on tables $\mathrm{II}-\mathrm{III}$ and figure 3 .

These components and structures are settled in the reactor block,under the roof slab,inside the safety tank.Beyond the activity is negligible.

After a 30 year running time and a 2 year decay time, $85 \%$ of component and structure steel studied previously can be handled, stored or shipped without declaration (5).

On figure 4 and on table IV we can see the total activities issued from steel activation.As already remarked the more active structures and components are situated just above and just under the core.

The main contributor isotopes to the activity are ${ }^{60} \mathrm{Co},{ }^{55} \mathrm{Fe},{ }^{63} \mathrm{Ni}$. 


\section{8- REFERENCES}

-1 - A.CREGUT - R. LURIE - P.POMIE - P.BIANCALE .Le démantèlement des réacteurs de puissance du système français à neutrons rapides. International symposium on the decommissioning of nuclear facilities.Vienna 13-17 NOVEMBER 1978.

-2- Gerhard ERDTMANN .Neutron activation tables.

-3- Donald J.HUGHES and Robert B. SCHWARTZ .BNL Neutron Cross sections 2nd edition.

-4- R.PANNETIER .Vade Mecum du technicien nucléaire - Tome II - Tables des caractéristiques - 2 ème édition.

-5- Official Journal of the European Communities N $N^{\circ} 246$ 17/09/80. 


\title{
DECOMMISSIONING WASTE ARISINGS \\ IN THE EUROPEAN COMIUNITY AND WESTERN EUROPE
}

PASSANT $F$ H and WARD $R \quad D$

CEGB, National Power Division

Barnwood, Gloucester, England

(Prepared on behalf of the UNIPEDE Study Group on Radioactive waste)

\begin{abstract}
Some of the first commercial nuclear power stations in Europe are reaching the end of their useful lives. This paper considers the volumes and timing of decommissioning wastes that will thus arise over the coming decades. Using national decomissioning policy statements ( or, failing that, stated assumptions) the volume of structural radioactive waste from all Western European comitted commercial power stations is derived and presented graphically. This has been done for each country, the European Community, and for the whole of Western Europe.
\end{abstract}

\section{INTRODUCTION}

The commerclal nuclear power industry is coming to the end of its third decade. Already some small experimental facilities have been decomissioned and in the fourth decade one will see a build up in decommissioning work. The industry recognises that some development of techniques will be required, but most of these developments are only modest extensions of procedures already in use for plant refurbishment. The public in most countries is wary of nuclear power, decommissioning being one of the concerns along with the associated radioactive waste that remains when the stations' useful generating lives are at an end. The industry's handling of this matter has implications for safety, economics and, above all, public acceptance of nuclear power.

Therefore it is opportune to take stock of the task ahead. In this paper an attempt is made to give a broad overview of the timing and quantities of radioactive decomissioning waste that will arise and need management in Western Europe.

\section{THE STAGES OF DECOMMISSIONING}

The Mult1-Stage Concept The IAEA (1) has considered the process of decomissioning nuclear power plants and divides it into three major stages described below. This concept is widely accepted and influences decomissioning plans in most countries.

Stage 1 Stage 1 decomissioning comprises the removal of fuel from the reactor and the site. The wastes arising during this stage are similar to those which arise during normal operation and include technological low level waste, Ion exchange resins, sludges and filters. These relatively small volumes of waste will not be considered in this paper. stage 1 is likely to take from one to five years and in most countries the intention is to commence this immediately after the end of generation. The removal of the fuel takes away a very large proportion of the total activity from the site and removes the possibility of inadvertent criticality. This means that the need for continuous manning by large numbers of highly trained professional staff and the need for elaborate safety procedures are both significantiy reduced.

Stage 2 Stage 2 decomissioning comprises the removal of all plant from the site except the reactor, its shielding and possibly its contalnment. Of the waste removed at this stage some 908 is conventional scrap plant and demolition rubble from the removal of non-radioactive facilities (2). Such material is not accounted for in this paper.

The remalning proportion of the plant removed at this stage will be assoclated with the fuel route ( fuelling machinery, ponds, pond water treatment, etc.) and the coolant circuit ( water pipes , heat exchangers. pressurisers and pumps etc; or gas ducts, blowers and bollers). such plant becomes contaminated with radloactive materlals and to a lesser extent activated during station life. 
Stage 2 might take between three and ten years to carry out. It is also the stage that varies most in the timing and extent of implementation between countries and reactor types. In some instances stage 2 will be fully implemented immediately after stage 1. In other cases a minimum will be done to remove or seal contaminated plant and the major part will be done later as part of Stage 3 .

Stage 3 Deferral Depending on a whole range of technical, political, and economic issues stage 3 may follow immediately or some time after stage 2. Where stage 3 is deferred the defuelled reactor must be sealed up and made safe. Such a deferral might span thirty (3) to a hundred years (2). The main advantage of deferring stage 3 is that many shorter lived nuclides will have decayed away; for example the specific activity of cobalt-60 will be about one millionth its original value after a hundred years.

Stage 3 Stage 3 decommissioning comprises the final clearance of the reactor, its shielding and containment. A larger proportion of these structures will be radioactive than at stage 2 and on average their specific activity will be higher. A large part of the activity will be due to activation rather than contamination.

Stage 3 might take between two and five years to complete.

\section{VARIATIONS AND UNCERTAINTIES IN ACTIVE WASTE VOLUMES}

De Minimis Levels Few, if any, materials are absolutely free of radioactivity. The more active materials in the natural environment exceed the levels at which the nuclear industry must consider material as radioactive. For practical waste management a level must be set below which material is non-radioactive in regulatory terms. This level is known as de minimis. The actual level and the practicality of its measurement can have a large effect on what is included in decommissioning waste volumes. Several European countries are still in the process of establishing what the de minimis level should be.

Decontamination of Wastes Consideration needs to be given to whether there is any overall advantage to be gained from decontaminating surfaces and transferring the activity in the first instance into solution and subsequently onto filters and ion exchange beds. Once these practices have been critically assessed a reduction in primary waste volume might be achieved without the detriment of excess secondary wastes. Reduction of worker dose whilst handling waste may be an alternative or parallel objective to volume reduction.

cutting and conditioning

For most decommissioning wastes it will be packages. The pieces themselves require stabilisation within the package possibly by using cement grout. Trade-offs and experience will influence the final volumes of waste that are created. Where a large amount of effort is expended on cutting into small pieces and neatly placing them into packages relatively small overall package volumes may be achieved. However, the cost in worker dose commitment and secondary wastes arising from fume and dust trapped in filter systems may not make it worthwhile.

The most elaborate conditioning currently contemplated is for steel components to be placed in a furnace and melted. This gives a very good volume reduction and enables the activity to be uniformly distributed amongst the mass facilitating sampling and analysis for application of de minimis. Cut up steel components will only be able to be packed to a density of about $1 \mathrm{Mg} / \mathrm{m} 3$. However melted steel can reach its material density of $7.8 \mathrm{Mg} / \mathrm{m} 3$. That is a very great difference but there are additional costs in capital plant, industrial man hours and secondary wastes.

Packaging and Shielding Decommissioning wastes will normally be placed into large packages (possibly like Iso Freight Containers) made out of steel or concrete. Some packages, particularly the concrete ones, will provide the necessary shielding. Some of the very active wastes that might be anticipated from early stage 3 decomissioning will either require a great deal of shielding material to be used in the construction of the packages or may require the use of reusable shielding overpacks.

Whenever one is considering volumes of radioactive waste one has to recognise three distinct bases. Firstly there is the raw waste as it exists in the first instance in the reactor structure or as resin or sludge in a 
tank. Secondly there is conditioned waste as it exists within the package. Thirdly there is the external volume of the package which will ultimately have to be found space in the repository. Conditioning can multiply the volume of decomissioning waste between $x 1.25$ and $x 8$. The difference in volume between the inside and the outside of a package can increase the volume to be disposed of between $\times 1.2$ and $\times 2$, compounding the volume increase from conditioning.

\section{REVIEW OF NATIONAL DECOMMISSIONING SITUATIONS}

Approach to Gathering and Presenting Data to $f$ ind detailed data for the power stations of a particular country such data has been used and referenced. No data has been included for the decomissioning of any uranium extraction, enrichment, fabrication or reprocessing facility. Also a number of experimental fusion rigs, accelerators and small research reactors have been ignored.

In several countries no clear policy has been declared nor have detailed data on volumes and timing been given. Where such a lack of data exists a series of standard assumptions have been used. Those assumptions are related to lists of power stations, station size and start-up dates taken from (4). It must be emphasised that it is not the intention to prefudge what individual countries could or should do but to attempt a complete and reasonably credible overview of the situation within Western Europe. The specific assumptions used are shown in Table I. Taking the masses from (5) and the density in Table I gives the rounded volumes of conditioned waste for each of the major reactor systems as shown in Table II.

Belgium At present there is no real need of a policy for decommissioning commercial reactors in Belgium. All the comnercial reactors are running with high availability. No need for dismantling is anticipated before 2025 . Thus the data for Figure 1 come from the standard assumptions given in Tables I and II.

Some decomissioning work is under consideration for research reactor BR3, the Eurochemic reprocessing plant and old waste treatment facilities at Mol. BR3 is a very early experimental PWR and ceased generation in 1987. studies are in hand, but major dismantling is likely to be deferred for about thirty years.

The national disposal agency NIRAS/ONDRAF is developing surface stores at Mol, pending the availability of final disposal. Disposal studies are in hand at the same location in an underground laboratory in clay.

France Electricite de France have given some indication of their intentions (6) for decommissioning as an adjunct to their policy for replanting. As groups of reactors on existing sites get within the last decade of their life additional units will be built. These units in previously unused space on the site will form a second phase of development. As the second phase reactors approach their last decade first phase reactors will be dismantled to allow the building of a third phase.

Such an approach is not inconsistent with the standard assumptions in

Tables I and II, so these simpler assumptions have been used along with standard assumed volumes to produce Figure 2.

There exists a surface repository at Centre de la Manche near Cherbourg and another is being developed at soulaines east of Paris. However neither of these is currentiy designated for decommissioning wastes. The heavy water reactor at Brennilis ceased operation in 1985 and the gas cooled reactors are due to close in the early i990s. The intention is to proceed somewhat beyond stage 1 producing mainly operational type wastes. The sealed-up units will then be equipped with suction ventilation and kept under surveillance, the biological shields effectively becoming compact and robust stores. significant arisings of packaged decomissioning wastes are many decades away and so there are no immediate repository plans.

Federal Republic of Germany Two possible cases are considered for the German Federal Republic in (7). The first looks at 40 years reactor operation followed by 2 years for stage 1 immediately followed by stage 2 and 3 . The second case is more consistent with the others presented here and has been used to generate the data for Figure 3 . That case assumes 40 years of operation followed by 2 years for stage 1 and one year for sealing and making safe. The reactor is then left to benefit from radioactive decay during thirty years of containment under surveillance. The volumes of waste 
are taken directly from (7) where packaged volumes are given. Stages 2 and 3 are assumed to take 5 years together. The resultant data are presented on the graph in Figure 3.

Italy In Italy two plants are permanently shut down with a view to decommissioning, one being the Magnox reactor at Latina and the other the boiling water reactor at Garigliano. The intention is to wait at least 30 years before any significant degree of dismantling is carried out and at present no detailed studies have been made of the decommissioning wastes that are likely to arise (8). The results of applying the standard assumptions to the Italian reactors give Figure 4 .

No decisions have yet been made about the type or timing of an Italian repository. At present operational wastes are packaged with a high quality cement matrix and stored on the site of origin.

Netherlands The standard assumptions have been applied to the programme of existing nuclear power stations in the Netherlands. The results of this are given in Figure 5 .

COVRA the national waste management organisation will construct a central facility for interim storage of waste near the nuclear power station at Borssele (9).

Spain ENRESA is responsible for all aspects of radioactive waste management in Spain. ENRESA manages a final storage facility at El Cabril for low and intermediate level waste containing short lived beta-gamma emitters and a limited amount of alpha bearing wastes. These are subject to ENRESA's acceptance criteria and the storage will consist of near surface burial in concrete facilities. In (10) the total volume of decomissioning waste arising from Spain's present nuclear programe is given. This is in close agreement with the information supplied by Nuclenor for individual stations (11). The plan is based upon a minimum station life while recognising that in practice this might be exceeded by 10 years. All three stages of decommissioning will be undertaken in rapid sequence over a period of 5 years. The results of this are shown on Figure 6 .

United Ringdom A detailed inventory of operational and decommissioning wastes has been produced for the United Kingdom (12). This gives conditioned waste volumes and the time scale on which the wastes are likely to arise. This data, modified to allow for the early closure of Berkeley this year, has been used to produce Figure 7 .

At present operational wastes are disposed of at a shallow repository at Drigg in NW England. However this is not designated for the disposal of power station decommissioning wastes. These will need interim storage in some cases before the deep Nirex repository becomes available in about 2005 . The current intention in the United Kingdom is that Stages 1 and 2 will follow immediately after the end of operation and together take about ten years. During that time provision of some waste storage facilities will be made for the large boilers and for packaged waste at the earlier Magnox Stations. Stage 3 decommissioning to clear the site may be deferred up to 100 years.

European Community The data for all the countries noted above has been sumed and shown in Table III and in Figure $B$.

Finland The Finnish utilities are obliged to produce reports setting out the means, timing and waste volume of decommissioning. These reports are required to be updated every five years. The most recent reports for the Loviisa power plant (13) and for the olkiluoto power plant (3) have been used as the basis to supply the data that has been set out on the graph in Figure 9.

Each station has its own intermediate depth repository on the power station site. These repositories will take the operational wastes of the station and will be extended to include all the decommissioning wastes. Decomissioning will take place according to a carefully prepared programe and should be complete through to stage 3 for the entire Loviisa site within 13 years of the end of generation. For the olkiluoto power plant the preferred case for decommissioning, is dismantling after a period of 30 years. The current plans also allow for different assumptions on volumes depending on whether no volume reduction is used at one extreme or steel melting is used at the other.

Sweden Sweden has 12 reactors with a capacity of $9.9 \mathrm{GW}$. After the referendum in 1980, the Swedish Parliament decided that the nuclear programme should be limited to 12 reactors and that they should be closed according to a programe with the last one being shut down in 2010 . The 
programme dates together with Table II data were used to produce the graph shown in Figure 10. This is in close agreement with the figure for total Swedish decomissioning wastes of $130,000 \mathrm{~m} 3$ reported in (14). Furthermore current work indicates that this figure will be revised downards by about 108 .

In Sweden there is already a repository in existence for operational wastes at Forsmark. It is a silo and a series of caverns below the bed of the Baltic Sea in crystalline rock. Access to the repository is via tunnels from the shore. This repository is currently for operational wastes, but is designed to be expanded to take the decomissioning wastes also.

Switzerland The responsible authority for radioactive wastes in Switzerland is NAGRA. The situation in Switzerland is reported in (15). The Swiss currently have 3 GW(e) of nuclear power plants but base their waste management plans on the expansion of this to $6 \mathrm{GW}(\mathrm{e})$. However, information for this paper is limited to committed stations so that for consistency data taken from (15) have been divided by 2 . The Swiss anticlpate having a full range of nuclear wastes (including vitrified high level waste returned from reprocessors, and to accomodate this they intend to have three separate repositories of the following types. The first will be a surface repository relying on 100 years of administrative control and some technical barriers to store waste. It is anticipated that between 608 and 908 of decomissioning waste could go there. The second repository for which a variety of host rocks is possible, is a horizontally accessed facility planned with an overburden of up to 600 metres. Twenty possible locations have already been identified. Intermediate level waste will be stored in this repository. There will also be a high level waste repository at least 500 metres below crystalline base rock in the northern part of Switzerland. The base rock itself is below be an overlying sediment layer of between 600 and 1700 metres. The Swiss Federal Department of Energy required all the nuclear power plant operators to submit decomissioning plans to them by the end of 1980 . These plans required the inclusion of the total amount of wastes which for Switzerland totalled $130,000 \mathrm{~m} 3$. Two cases were considered; dismantling starting 2 years or 30 years after shutdown. The latter has been chosen for this paper because it is compatible with the case for other countries described here. The standard assumptions on volumes have been applied to the current Swiss nuclear power programme. The data are presented in Figure 11 and the total agrees very well with the overall total volume given above.

W Europe The data for the above three countries have been added to those for the European Community and this gives the data for $w$ Europe shown in Table III and on Figure 12 .

\section{DISCUSSION AND CONCLUSIONS}

The volume of decommissioning wastes arising from the present nuclear power programme in Western Europe amounts to a little less than 2Mm3. To put this into perspective it is comparable to one day's domestic refuse arising within $w$ Europe.

The volume of decomissioning wastes for a given reactor programme is not fixed but depends on regulation and application of de minimis, efficient conditioning and well designed packaging.

Decommissioning wastes will arise from the current reactor programe in Western Europe from now until about 2100. Three peaks may be observed; the first generation of reactors around 2005, stage 3 decomissioning of PWR's \& BWR's around 2060 and stage 3 decommissioning of UK gas cooled reactors around 2100 .

\section{REFERENCES}

(1) IAEA

Factors Relevant to the Decomissioning of Land-Based Nuclear Reactor Plants

Safety Series No 52

IAEA Vienna 1980 
(2.) Passant FH

Hinkley Point C Power Station Public Inquiry. Proof of Evidence on On-site Radioactive Waste Management and Decommissioning Central Electricity Generating Board. London 1988

(3) Nykyri M, Peltonen E, Pollanen L \& Salonen $\mathbf{P}$ Decomissioning of the olkiluoto Nuclear Power Plant IVO, TVO and the Nuclear waste Commission of Finnish Power Companies Helsinki 1987

(4) World Nuclear Industry Handbook 1989

Nuclear Engineering International Special Publications Sutton, Surrey, England 1988

(5) Lasch $M$, Schaller $\mathrm{KH}$, Stang $\mathbf{W} \&$ Watzel GVP Estimation of Radioactive Waste Quantities Arising During Decommissioning .

Decommissioning of Nuclear Power Plants - Proceedings of a European Conference held in Luxemburg

Pub: Graham Trotman Ltd for the CEC. Iondon 1984

(6) Le Demantelment des Centrales Nucleaires de 1'EDF. Commentaire Enerpresse No 4838 Monday 5 June 1989

(7) Private Communication From J Essman to R D Ward 28.06.89

(8) Private Communication

T Marzullo to P D Ward 14 July 1989

(9) UR Nirex Ltd

Deep Repository Project: Preliminary Environmental \& Radiological Assessment and Preliminary Safety Report

Appendix D

Harwell, England, 1989

(10) Melches C \& Espejo-Hernandez JM Management of Nuclear waste in Spain International Atomic Energy Agency

Reference IAEA-SM-294/95 pp41-47

(11) Private Communication

$F$ E de Lucas to $R$ D Ward 17 July 1989

(12) The 1988 United Kingdom Radioactive Waste Inventory

Published on behalf of: UK Nirex Ltd/Department of the Environment By: Electrowatt. Horsham, England 1989

(13) Harkonen $\mathrm{H}$

Decommissioning of the Loviisa Power Plant

IVO/TVO and the Nuclear Waste Commission of the Finnish Power companies Helsinki 1987

(14) Hedman T\& Aronsson I

The Swedish Final Repository for Reactor Waste (SFR)

Siting Design and Construction of Underground Repositories for Radioactive wastes

Proceedings of IAEA Symposium in Hannover IAEA SM 280/16 IAEA Vienna 1986

(15) Alder JC \& Tunaboylu $\mathrm{K}$

Classifying Decommissioning Wastes for Allocation to Appropriate Final Repositories

US Department of Energy. Seattle, USA October 1982 
7. TABLES

Table I: Standard Assumptions

- Station start up date as in reference (4)

- Waste masses taken from reference (5)

- Station life-time for generating electricity 40 years

- Delay until the start of Stage 2

- Combined duration of Stages 2 \& 3

30 years

- Mean density of waste*

5 years

$1.5 \mathrm{Mg} / \mathrm{m}^{3}$

*Mass of waste in a package, excluding grout, divided by package internal volume.

Table II : Rounded Dismantling Volumes

- Ilght water reactor $(<400) \quad 5500 \mathrm{~m} 3$

- Light water reactor (400-800 MW )6500 m

- Light water reactor ( $>800 \mathrm{MW}), 8000 \mathrm{~m} \frac{3}{3}$

- Gas cooled reactor $11000 \mathrm{~m} \underline{3}$

Table III : Total Volumes

- European Comunity $1.6 \mathrm{Mm}$

- Finland. Sweden and Switzerland $0.17 \mathrm{Mm} \frac{3}{3}$

- Western Europe $1.77 \mathrm{Mm} \overline{3}$

\section{EIGURES}

The flgures are presented on the following three pages. Figure 8 is enlarged and placed on the third page with the similar Figure 12 . 


\section{DECOMMISSIONING WASTE VOLUMES}

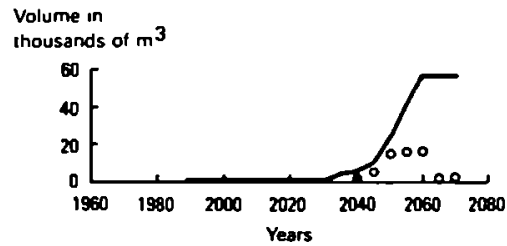

Figure 1. BELGIUM

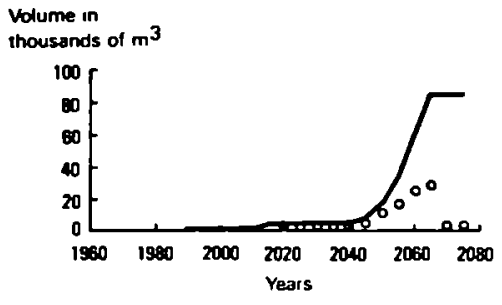

Figure 3. GERMAN F R

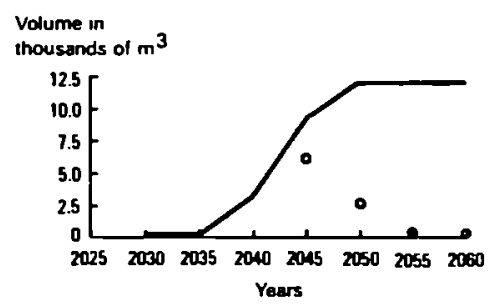

Figure 5. NETHERLANDS

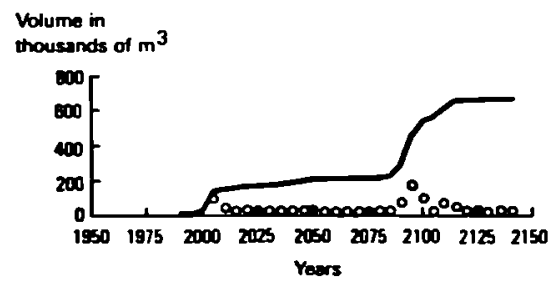

Figure 7. UK

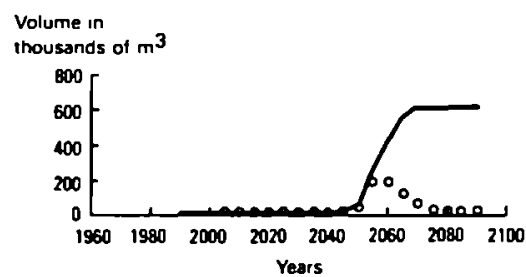

Figure 2. FRANCE

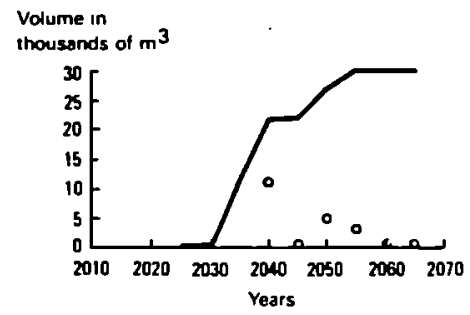

Figure 4. ITALY

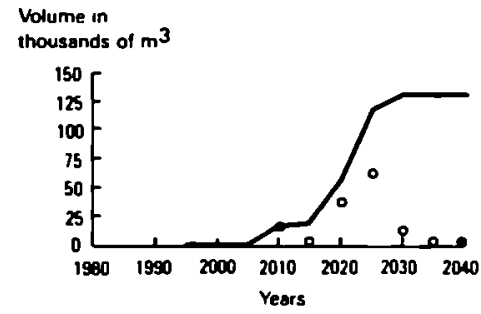

Figure 6. SPAIN

\section{LEGEND FOR ALL FIGURES}

Total 5 Yearly o Cumulative 


\section{DECOMMISSIONING WASTE VOLUMES}

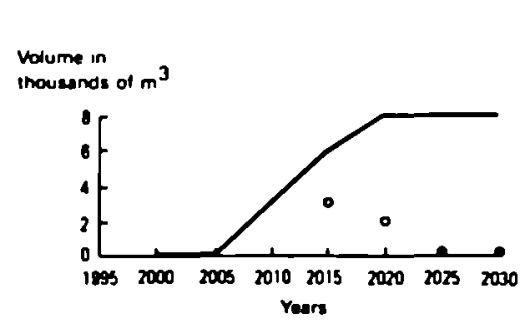

Figure 9. FINLAND

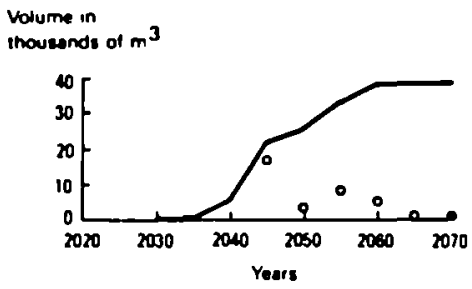

Figure 11. SWITZERLAND

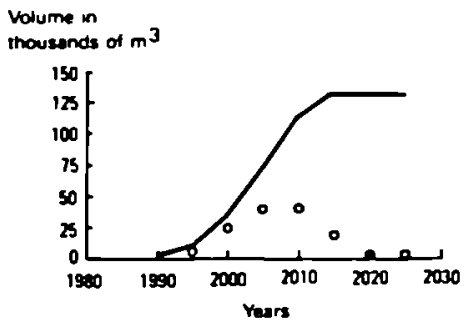

Figure 10. SWEDEN

Figure 12. W.Europe

\section{LEGEND FOR ALL FIGURES}

Total 5 Yearly 。

Cumulative 


\section{DECOMMISSIONING WASTE VOLUMES}

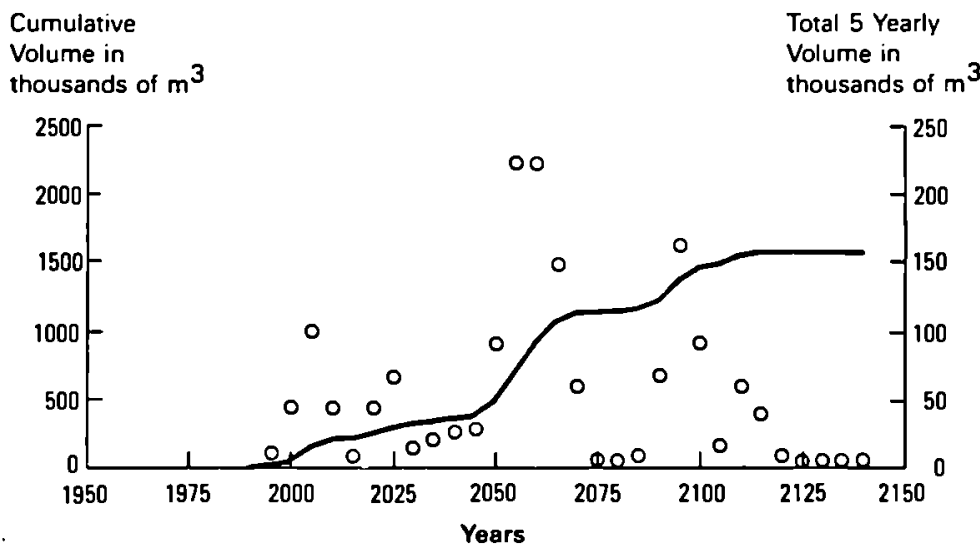

Figure 8. European Community

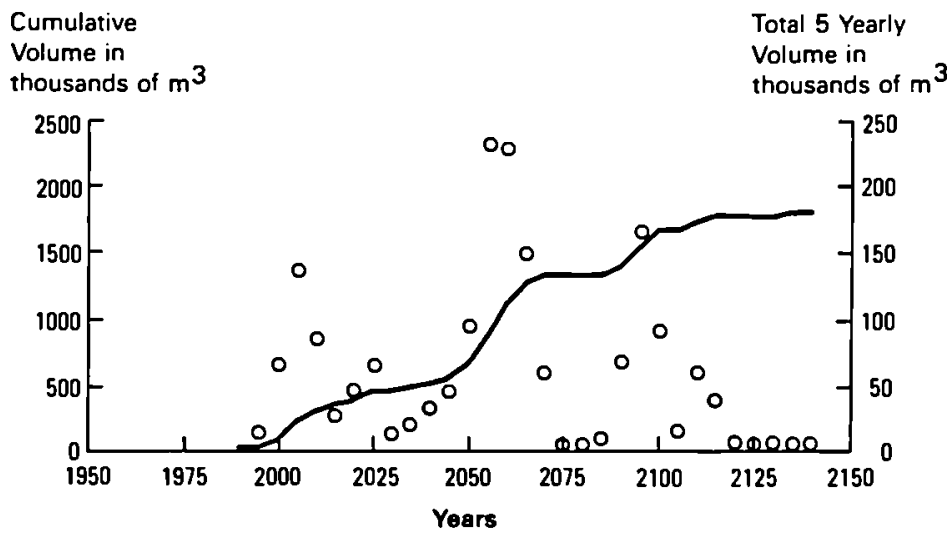

Figure 12. W.Europe 


\title{
SITUATION AND PROSPECTS OF RADIOACTIVE WASTE DISPOSAL
} IN THE MEMBER STATES OF THE EUROPEAN COMMUNITY

\author{
SCHALLER K.H., ORLOWSKI S. \\ Commission of the European Communties, Brussels \\ Research Programme on Radloactive Waste Management \\ and Disposal
}

\begin{abstract}
All Nember States of the European Community with a nuclear power production programe are preparing for the disposal of radioactive waste produced in the nuclear fuel cycle and through the use of radionuclides in health care, research and industry. The situation of storage and planned, on-going - and already performed - disposal of radioactive waste in these States is first summarised.

Sultable stes for disposal of radloactive waste of all cacegories exist in all Member States concerned. The general principles and International recommendations, and common principles, standards and requirements applicable to disposal in the European Communtey are then presented, followed by a description of existing disposal facilities and of those which are in an advanced planning stage, and the implementation of basic criteria by national authorities.

Finally, policies and strategies for long-term storage and disposal for definitively shut-down nuclear installations, and contributions to research in this field in the "Communities" Radioactive Waste Management Programme" are discussed.
\end{abstract}

\section{PRESENT SITUATION AND FORECASTS FOR RADIOACTIVE WASTE PRODUCTION}

The Member States of the European Comounity apply radionuclides in a number of flelds, like medical health care, research and energy production, and consequently all are producers of radioactive waste. The annual arisIngs of radloactive waste in activities not linked to the nuclear fuel cycle vary between dozens of $\mathrm{m}^{3}$ for the smaller Communtty countries to amounts between 1,000 to $2,000 \mathrm{~m}^{3}$ for large ones. The ma1n quantities of radloactive waste from peaceful applications arise from the nuclear power production programes and the associated nuclear fuel cycle in those countries operating nuclear power plants (Belglum, France, the Federal Republic of Germany, the Netherlands, Spain, the United KIngdom; Italy actually is not operating its nuclear power plants). The net capactey was 92.6 GWe at the end of 1988 , and the overall percentage of nuclear energy in electrictey production is slightly higher than $30 z$.

The European Communtey plan of action in the fleld of radioactive waste asks for the continuous analysis of the situation, and the Commission and a dedicated working group have drawn up a report describing the rad1oactive waste situation and giving a forecast t111 the year 2000 ( 1 ). The estimations and forecasts cover 3 flve-year perlods from 1986 on. Not taking Into account uranium m1ll tallings, total production of conditioned waste ready for disposal (or supposed to be treated, when present as raw waste in order to allow meaningful cumlation of quantities) is at present around $70,000 \mathrm{~m}^{3}$ annually, and $1 \mathrm{~s}$ expected to rise to approximately 100,000 $\mathrm{m}^{3}$ annua11y in 2000 . 
The bulk of that waste, about $85 \%$ in volume, is waste from normal reactor operations and from reprocessing, containing almost exclusively short-lived radionuclides; this type of waste decaying after some centurles to levels near the natural radloactivity of solid matter, 18 sultable for disposal near the surface in installations as they are operated by the largest producers of radioactive waste in the Community, France and the United Kingdom.

Almost all of the radloactivity generated is concentrated in spent fuel, which is unloaded at a rate of 3,500 tons of heavy metal per year now, a value increasing to slightly more than 4,000 tons in 2000. Most of this fuel is to be reprocessed, and the vitrified high activity residues w11 cumulate at a rate of some hundreds of $\mathrm{m}^{3}$ annually.

Waste from dismantilng of decommissioned nuclear Installations is appearing only in very small quantities (less than 5\%) in forecasts by the Member States. Actually, more than 10 medium-size nuclear power plants, and a multitude of small nuclear Installations are closed down definftively; in the year 2000 more than 50 large nuclear Installations, with expected amounts of waste between 20,000 and $40,000 \mathrm{~m}^{9}$ per Installation after dismantilng will be out of service (2). Arisings from delayed dismantling, In order to benefit from decay, and due to lack of disposal factlitles at this point in time, are expected to grow from year 2000 on and reach annual quantities comparable to arisings from reactor operation in the thirties of the next century.

It Is interesting to note that, before 1986, already 1 mil11on $\mathrm{m}^{3}$ of radloactive waste had been disposed of by the Communtty Member States, and about $120,000 \mathrm{~m}^{3}$ were in store. $90 \%$ of the volume had been disposed of at near-surface disposal factlities (Drigg and Dounreay in the UR, and Centre de la Manche in France), the remalnder being dumped in joint undertakings organised by a multi-national body under the auspices of the organisation for Economic Co-operation and Development before 1983 in the North Atlantic (Belglum, the Netherlands and the UK on a regular basts, the Federal Republic of Germany and Italy with very small quant1ties), and burled In a deep geological formation (by the Federal Republic of Germany in the Asse salt mine).

\section{PRINCIPLES, STANDARDS AND REQUIREMENTS FOR DISPOSAL}

Disposal of radioactive waste is carried out or is planned within regulatory frameworks based on a number of general principles encompassing a broader field than waste disposal or nuclear energy, on comon standards, recommendations and criterla at international level, and on national and site-related regulations. A working group, set up within the task "Jolnt elaboration of radioactive waste management policies" of the Commission's shared-cost action programme on "Radioactive Waste Management and Disposal (1985-1989)", wrote a detalled report on this subject ("Object1ves, standards and criteria for radioactive waste disposal in the European Community", to be published at the end of 1989); hereafter, the main elements of this report are summarised.

The general principles are lald down at international, Communty and national (or even reglonal) level, and cover the following fields: radiation protection, ethical and soctological questions, environment and natural resources protection, and nuclear safeguards. 
In radiation protection, the well-known syatem of dose 11mitation 18 expressed in terms of fustification, opt1misation and Individual dose 1imftation. Justification is given through a net benefit of the whole energy production cycle or the use of radloactive substances, and 18 consequently not applicable to waste disposal standing alone; on the contrary, optimlsation of protection may be applled to the cycle as a whole, as well as to Individual management steps. Optimisation reflects the princlple that exposure should be kept "as low as reasonably achievable, economic and soctal factors being taken into account", and 18 of paramount importance in site selection. Individual dose limitations for doses presumed to occur with a high degree of certalnty are well established: $50 \mathrm{mSv} /$ year In any one year for whole body occupational exposure (effectively, average occupational exposure for radiation workers 18 about 10 to $20 \mathrm{mSv}$ with a tendency to decrease) and $5 \mathrm{mSv} /$ year for members of the general public. Although these values are legally blinding limits in all Communfty Member States through the provisions of the EURATOM Basic Safety Standards (3), the view of the International Commission for Radiation Protection to IImit exposure of the public over a lifetime to an average of $1 \mathrm{mSv} /$ year, $1 \mathrm{~s}$ at the stage of reconmendation. These $11 \mathrm{~m} 1 \mathrm{ts}$ are well sulted for the operational perfod of a repository, but do not cover the postoperational phase of a disposal factlity where a probabilistic approach is needed. The International Commission for Radiation Protection (ICRP) favours a risk-based approach, with a limit to harm to members of the critical group of $10^{-5}$ /year from probabilistic events; clearly, for a low probabllity event, rlak to Individuals may be higher than the indicated value. Individual states may take the risk from a repository to a given critical group as only one of a number of possible risks and spectfy a fraction as being an acceptable value: the United Kingdom and Spain have already suggested a risk of $10^{-6}$ /year as a target for a single repository.

The system of control in radiation protection requires that no source or practice involving exposure to man to lonising radiation shall be authorised unless it 18 subject to control by a system of notification, reglstration and licensing as established by the competent authoritles; the system of control with the "source" being radioactive waste is applied in all stages of waste management and disposal.

The principles included under ethical and soctological questions are often expressed in an indirect manner in current legislation; the most relevant for waste disposal are shortly discussed. The principle of care Includes the well-established "care for nelghbours" princlple, ma1nly based on Information exchange, and the "care for future generations" principle. Under the EURATOM Treaty, each Member State of the European Communtty shall provide the Commission with data relating to plans for disposal of radioactive waste in order to enable the determination of whether such a plan is liable to result in the radloactive contamination of the water, soll or alr space of another Member State. After having consulted an expert group, the Commission delivers 1ts opinion concerning the plan. The "public involvement principle" is now included in Community legislation (4), specifying that 11censing projects and the supporting information will be made aval1able to the public, and that the public has the opportunity of making known 1ts opinton before the profect 1s started. The "polluter should pay" principle also was introduced formally into European legislation; 1t 1s part of the new Art1cle $130 R$ of the EEC-Treaty (5), and is the basis for financing waste management and disposal. It was Incorporated Into the laws of a number of Member States (Belglum, France, Federal Republic of Germany, Italy, Spain). 
The principle of compensation for damage, or otherwise the civil liabllity in the fleld of nuclear energy, asks for adequate and equitable compensation to persons suffering damage caused by nuclear incidents, Including those involving radioactive wastes. States have concluded multilateral Conventions (the "Par1s" Convention, and a supplementary convent1on, the so-called "Brussels" Convention), defining limits of liability and perfods of responstbility after an Incident; a particular aspect of the Additional Protocol (Brussels Convention) is that the operator has an absolute llability 1rrespective of fault. The Conventions came Into force In 1968 and 1974 respectively and have been ratifled by most of the Commun1ty Member States.

In the field of environmental and natural resources protection, three relevant principles may be 1dentifled: prevention of damage, rectification of damage, and protection of natural resources. The non-radiological concerns related to radioactive waste disposal are adverse effects to future utflisation of natural resources, release of non-radioactive contaminants, degradation of water supplies, effects on plant and animal life, etc. In European Community legislation (5), the requirements to preserve, protect and 1mprove the quality of the environment, and to ensure a prudent and rational utilisation of natural resources have been institutionalised, and an environmental 1mpact statement has to be established for new installations.

Nuclear safeguards are well implemented in the control of fissile material for the prevention of nuclear materials diversion. The Community already has 1 ts own safeguards required since 1957 through the EURATOMTreaty. Normally, radioactive waste disposal should not be concerned with safeguards problems, as by definition, fissile material is included in waste in such low quantities that it is not retrievable in an economically sensible way by current technology. The EURATOM rules define measured discards, which are covered by safeguards unt1l the 1rretrievability has been verifled.

\section{EXISTING AND PLANNED RADIOACTIVE WASTE DISPOSAL INSTALLATIONS}

All Communfty Member States with a nuclear power production programe have practised, are practising or Intend to perform disposal of radioactive waste. Sultable geological formations and sites seem to be avallable in any of those Member States, thus allowing disposal of all types of waste.

The highest degree of geological isolation quality is requested for heat-generating waste contalning long-lived radionuclides in large quant1ties. Possible formations avaflable are salt, clay and hard rock formations (6). This category of waste does almost not exist in decommissioning (perhaps the heavily activated core structures, the thermal shield and part of the cladding of reactor vessels of nuclear power plants have to be assimflated to high-level waste).

Non-heat-generating waste containing long-lived radionuclides (mostly alpha-emitters) leading to more than $370 \mathrm{~Bq} / \mathrm{g}$ of 1 long-lived radionuclides averaged over the reposttory, and more than $3,700 \mathrm{~Bq} / \mathrm{g}$ per package 15 nowadays commonly assumed, in the Community, to need burlal in deep geological formations. Besides salt, clay and hard rock formations, other dry formations like potash or lron-ore containing formations are suitable and avallable. 
Short-lived waste, with alpha-emitter contents lower than mentioned above may be disposed of elther by near-surface disposal or, depending on national waste management policy, by deep geological disposal. The underlying principle for near-surface disposal 18 to emplace waste into engineered structures, which are 1solated from the human environment under controlled conditions (sitting generally on a watertight clay-layer), and to return the site to unrestricted access after a period of control.

Sea dumping would be a possible disposal route for waste from decommissioning; however, the contracting parties to the international "London Dumping Convention" agreed on establishing a moratorium on such a practice, and consequently, no sea-dumping operation has taken place since 1983.

Before the actual situation of radioactive waste disposal in the Community Member States Involved In nuclear energy 18 described, it has to be underlined that all these States have a national regulatory framework, which incorporates general principles, International and European Communty regulations and recommendations, and national policy requirements. Within this framework, the management of waste and disposal 18 entrusted to an executive body or a national Agency; they act separately from competent authorities and are either themselves directly responsible for waste disposal or act through subsidiaries or shareholder companies by means of a public or private statute.

In Belglum, the financially Independent and legal entity ONDRAF/NIRAS has responsibility for all aspects of radioactive waste disposal. Belgium has practised sea-dumping t1ll 1982 Inclusively; later, all waste has been stored in englneered facilities. Vartous possibilities for disposal near the surface or at depth are under consideration, and an investigation programe to Identify acceptable land disposal sites is underway. Highlevel, alpha-bearling and some medium-level waste are planned to be disposed of in deep geological formations, and a pllot underground research facility In clay (HADES) 18 operating at Mol. Geological disposal is now expected to be in operation before 2030 .

The Federal Republic of Germany has decided to dispose of all. types of radioactive waste in deep-lying geological formations. The PTB, a federal body, 18 responsible for construction and operation of the federal disposal Installations. As mentioned earlier, disposal of low- and medium-level waste has been practised in the Asse salt formation, where a pilot test Installation simulating disposal of high-level waste in salt is in operation. Non-heat-generating waste 18 expected to be disposed of (a decision 18 to be taken towards 1990) at the KONRAD mine. Th1s facility 1s located near Salzgitter in Lower Saxony. Mining of iron-core stopped there in 1976 for economic reasons. Disposal of radioactive waste is planned in the Oxfordium formation in newly excavated galleries at depths between 800 and $1,300 \mathrm{~m}$. With a total excavation of 1 million $\mathrm{m}^{3}$, between 500,000 and $650,000 \mathrm{~m}^{3}$ of conditioned waste may be emplaced. Limit values for rad1onuclides in waste packages and maximum inventory of the repository were calculated in detalled safety assessments, and provisional specifications for waste packages were 1ssued. The total inventory at the end of the operational phase 18 expected to be $5 \times 10^{18} \mathrm{~Bq}$ for beta-gamma emitters and $1.5 \times 10^{1} \mathrm{~Bq}$ for alpha emitters. For long-lived and heat-emitting waste, the salt dome of GORLEBEN, also in Lower Saxony, 18 under Invest1gation; the underground Investigation will last unt11 the end of the nineties. A depth of 800 m 18 envisaged for emplacement of the disposal galleries, but 
the dome will closely be Investigated between 700 and $850 \mathrm{~m}$. Depending on the disposal strategy, some millions of $\mathrm{m}^{3}$ waste, including vitrified high-level waste and conditioned spent fuel, may be stored.

In France, management and disposal of radioactive waste $1 \mathrm{~s}$ the responsibllity of ANDRA, a public body. Disposal of waste containing essentlally short-lived radionuclides $1 s$ performed by near-surface disposal using engineered barriers. The Centre de la Manche located near the La Hague reprocessing plant in Normandy has been operating since 1969 and almost $300,000 \mathrm{~m}^{3}$ of waste have been disposed of; the maximum capacity of $450,000 \mathrm{~m}^{3}$ w11l be reached shortly after the year 1990 . Waste packages with a specific total activity for alpha-emitters lower than $3,700 \mathrm{~Bq} / \mathrm{g}$ may be accepted, but the average specific alpha activity of the repository must be kept below $370 \mathrm{~Bq} / \mathrm{g}$. Limits for some particular radionuclides have been set (H-3, Co-60, Sr-90, Ru-106, Cs-134, Cs-137). For decomnissioning waste, 1t may be of 1mportance that Tritium be $11 m i t e d$ to $74 \mathrm{GBq} / \mathrm{t}$, and that betagamma emitters with half-lives larger than 31 years are taken on only in a case-by-case basis. As this disposal facility is reaching 1 ts capacity limit, a new near-surface Installation $1 s$ under development, the Centre de l'Aube, which is located near Soulaines, in the department Aube. The conditions, requirements and design features are simflar to the ones of the Centre de la Manche. The facility is expected to be avallable for the disposal of at least 1 million $\mathrm{m}^{3}$ of conditioned waste from 1991 onwards. All waste containing long-lived radionuclides 18 to be disposed of in deep geological formations. Research in underground formations has already been performed at Fanay-Augères, and sites for investigation of four possible host formations (salt, granite, clay and shale) have now been selected. After having chosen one site, the construction of an in-situ validationinstallation should start around 1990/1991. A deep repository may become operational at the earliest at the beginning of the next century for alpha waste and around 2010 for heat-generating high-level waste.

Italy has ceased to produce energy from its nuclear power plants, but has of course to take care of existing and potential waste in redundant nuclear Installations. The folnt stock company NUCLECo (owned by the public body ENEA and the state-owned AGIP company) deals with the management of low- and intermediate-level waste. ENEA 18 to elaborate proposals for Implementing the waste management programme for all types of radioactive waste. Studies of possible disposal sites are in progress; in the meantime waste 18 stored at the production site and in regional centres.

The Netherlands have given the responsibility for management of all types of waste to COVRA, a private company, where two Government representatives on the Board of Directors have the power to veto any decision contrary to government policy. All wastes are stored for a period of 50 to 100 years, allowing studies for waste disposal in deep salt formations of the country, and Investigations of the possibility of disposal abroad in the frame of an International agreement.

In Spain, the management company ENRESA, with shareholders being exclusively public institutions, takes care of radioactive waste management. For low- and 1ntermediate-level waste containing only very limlted amounts of long-lived radionuclides (conditions simflar to the French Centre de la Manche ones), near-surface disposal in engineered structures Is planned at the El Cabril site in the Sierra Albarrana region. ENRESA presented in 1988 a request to the Spanish authorities for a construction 
licence for the facility, which should recelve $58,000 \mathrm{~m}^{3}$ of conditioned waste. The disposal of spent fuel in deep geological formations is subject of a research programe.

The United Kingdow has given responsibllity for managing radioactive waste, high-level waste excepted, to the United KIngdom N1rex Ltd, where the Government holds, through the Secretary of State for Energy, a spectal I1-share. BNFL is responsible for operation of the Drigg facility and vitrification and storage of high-level waste from reprocessing; UKAEA takes over similar responsibilities in relation to activities at Dounreay. In the UK, sea-dumping of low-level waste was practised t111 1982. Lowlevel wastes have also been buried in trenches at the Drigs site since 1971. Th1s site 1s located In West Cumbria, near Sellafleld, and consists of stratifled deposits of gravel, sand and clay, with the clay layers 1solating surface disposals from the underlying sandstone. About $600,000 \mathrm{~m}^{3}$ of waste have been buried in trenches, which are $8 \mathrm{~m}$ deep, $25 \mathrm{~m}$ wide and up to 700 m long. In a new authorlsation for disposal 1ssued in 1988, more stringent requirements for waste packages and emplacement were formulated. These are derived 11mits of activity for annual disposal of different specific radionuclides, as well as for the total activity, and specific activity of any consignment 18 limited to an average of $4 \mathrm{CBq} / \mathrm{ton}$ for alpha-activity and $12 \mathrm{GBq} /$ ton for beta-activity. The Dounreay disposal site, located in the north of Scotland, was first authorised in 1971 and recelved almost exclusively low-level waste from the Dounreay facility. About $24,000 \mathrm{~m}^{3}$ of waste has been consigned $1 \mathrm{n}$ pits dug $1 \mathrm{n}$ the Caithness flagstone. In pits 5 and 6 , the UKAEA 18 planning to retrieve the waste drums and to supercompact them; in this way, sufficlent capacity will be created to accommodate Dounreay's low-level waste t1ll the early years of the next century. Low-level waste will be disposed of at Drigg and Dounreay to the limits of capacity near the surface, but 1t 1 s present national policy to dispose of both low- and intermediate-level waste in a suitably located deep facility, which hopefully will be avallable at about the year 2005. Heat-emitting high-level waste 1 s to be stored for at least 50 years, a period which allows the evaluation of various disposal options.

\section{POLICIES AND STRATEGIES FOR MANAGEMENT OF DEFINITIVELY SHUT-DOWN NUCLEAR INSTALLATIONS}

Actually, the well-known safe storage option has been chosen as a management strategy for almost all shut-down nuclear 1nstallations, even in cases where no perceptible advantage can be obtalned through decay of short-lived radionuclides. Th1s strategy, which 1s relatively well accepted by the public, will be the dominant one well 1nto the next century, and the storage period till dismantling is quite open-ended in some Community Member States. In particular cases, decommissioned installations are even used as interim storage fac1lities for radloactlve waste from other sources. This state of the matter allows time for doing research and prepare optional disposal routes for the perlod, when dismantling really will be done on a large scale.

From the radioactive waste management point of view, and with a view to minimising waste arisings, radloactive matters and material sultable for unrestricted release have to be separated carefully during the dismantling operations. Practically applicable rules for exemption of material have to be avallable, which define exemption from reporting to competent national authorities and the need to obtain prior authorisation for handling, 
transport, storage and disposal. The EURATOM basic safety standards (3) quantify limits on radioactive substances in any consignment, depending on radiotoxicity, and give a general concentration 1 lmit of $100 \mathrm{~Bq} / \mathrm{g}$. Increased to $500 \mathrm{~Bq} / \mathrm{g}$ for solld natural radloactlve substances. Th1s part of the directive, with 1ts very high allowed concentration limits, is due to be revised. For scrap arising in dismantling of nuclear 1nstallations, appropriate criteria for unrestricted recycling have been recommended (7). The next step would be development of similar criterla for concrete from dismantling of nuclear installations.

Restricted reuse of slightly contaminated material has been practised on a large scale In the Federal Republic of Germany. It might be interestIng to generallse this concept at least at a European Community level and to develop appropriate Communfty-agreed criter1a.

As far as disposal is concerned, it has been shown in the previous chapter that on-land disposal, elther near surface (for acceptable waste for th1s options) or in deep geological formations, is the preferred disposal option 1n all Communtty countries. Decommissioning waste tends to be bulky and contalns mostly radionuclides in very low concentrations. Sea-dumping, which has not been practlsed any more since 1983, 1s probably the opt1mal disposal route for a large proportion of decommissioning waste, and in particular for tritiated waste. Nevertheless, large disagreements exist even between Communtty Member States on the question, whether the option should be kept open: in a recent London Dumping Convention survey (LDC 2/ C1rc. 217/Rev. 1), 11 out of 12 Member States had completed a questionialre, and 3 of them wanted the option kept open, 4 were opposed, and $4 \mathrm{~d} 1 \mathrm{~d}$ not mention a preference.

\section{DECOMMISSIONING WASTE IN THE COMMISSION'S RADIOACTIVE WASTE PROGRAMMES}

As in the Commisston's shared-cost decommissioning research programme, the waste management programmes have the objective to ensure health and safety of public and workers in the nuclear field in an economically acceptable manner; the three components of the management system, waste packages, repository and geological environment are covered, elther through experiments or by theoretical evaluation.

D1rect research at the Commission's Jo1nt Research Centre and sharedcost research in the fleld carried out in laboratorfes, unfversities and by Industrial organisations of the Member States are closely coordinated and Interact strongly. About 400 scientists are now involved in these European Communtty programmes, with annual expenses of about 40 million ECU.

Despite the fact that waste from decomissioning is not explicitly mentioned in the current programmes, a lot of research is directly useful and applicable to this type of waste. It 1s worth singling out the work on safety of geological disposal of the shared-cost programme, to which the Jolnt Research Centre also has contributed. In the PAGIS profect (Performance Assessment of Geological Isolation Systems), an 1mportant phase has Just been completed with respect to high-level waste (8), the assessment of the 1solation performance of deep repositories in clay, grante and salt formations, and the sediments of the deep ocean. It is worth summarising the main conclusions:

- durfing many thousands of years after disposa1, no radioactivity at all will reach the blosphere; 
- the most efficient barrier 18 the natural geological barrier; if well chosen, 1 ts chem1co-physical properties and hydrology impose radionuclide travel times which allow a substantial decay and dilution before the blosphere 18 reached;

- the engineered barriers may play a role essentially in accidental situations; their contribution in the normal evolution of the repository 18 very low;

- the analysis of a selection of natural events which may alter the normal evolution of the disposal system (e.g. climatic changes, tectonic displacements etc.) has shown no significant Increases of the potential dose rate;

- human intrusion scenarios into or near the underground repository need consideration since exposure may occur at earlier times and at significantly higher dose rates than in the normal evolution scenarios.

Applying the methodologies used for the PAGIS project, work 15 now extended to cover alpha-bearing waste.

Testing and evaluating conditioned waste and engineered barriers is devoted to the characterisation of waste forms and barrier materials, a better qualification of the source term needed for performance analysis calculations, and the 1mprovement of quality assurance and quality control of waste packages. The characterisation activities include the currently produced waste forms: cement, bltumen and polymer encapsulated low-level waste, cemented and bituminised waste containing alpha-emitters, and ceramics and borosilicate glass products for alpha and high-level waste. Tests provide data in respect to leaching, waste form stablilty, radiation resistance and compatibility with the respective disposal environments. In the course of the programme, the development of methods for quality assurance and in particular quality control became an important 1ssue: the control of the nuclide inventory, of the chemical composition of the waste as well as of the correct operation of treatment and conditioning processes are being Investigated in specialised laboratorles. The Jolnt Research Centre direct research programme develops actinide monitoring equipment for non-destructive detection of Plutonlum and other alpha-emitters.

Research in support of development of disposal fac1lities, with studies on disposal in continental geological formations and in shallow land burlal deals with design and englneering problems of repositories; this task Includes the characterisation and the modelling of geological formations surrounding the repository (the so-called far-field) and the quantitative description of the migration of radionuclides through the geologlcal barrier to the blosphere (the MIRAGE project). The profects are orlented towards research and testing under fleld conditions.

A high proposition of the research budget is allocated to research in experimental underground fac1l1t1es, with collaboration of a number of Community countries.

In the Commission's proposal for the follow-up shared-cost research programme on radioactive waste management $1990-1994$ (9), most of the research 18 carried on, and waste from dismanting of nuclear installations 18 especially mentloned in the system studies task. The adequacy of currently proposed disposal schemes will be examined, and the spectfic requirements of these wastes will be 1 dentifled as vell. In research on waste exempted fron regulatory control, parametric investigations of the conse- 
quences on waste management systems of varlous levels of exemption are planned, with particular attention to concrete rubble from dismantilng operations.

Concluding the Commission's contribution to research on disposal of decomissioning waste, It 18 worth quoting one of the Commission's recommendations in the Communication of the Commission to the Council preceding the report on the situation of radloactive waste management mentioned earlier (1):

"- Radioactive waste management is an important feature of safety and environmental protection. Immediate priority must be accorded to the adoption of management practices, particularly the selection and opening up of disposal sites (for permanent disposal)".

\section{REFERENCES}

(1) Commission of the European Communities: "Present situation and prospects in the field of radloactive waste management in the European Commun1ty", $\operatorname{COM(87)} 312$ final, 1987.

(2) Lasch M., Stang W., Schaller K.H., Watzel G.V.P.: "Estimation of radioactive waste quantities arising during decomisioning", In "Decommlssioning of Nuclear Power Plants", EUR 9474, Graham \& Trotman, London, 1984.

(3) Counc1l Directive 80/836 EURATOM of $15 \mathrm{July} 1980$, amending the Directives laying down the basic safety standards for the health protection of the general public and workers against the dangers of lonising radiation, - Officlal Journal of the European Communtt1es, L 246 of 17 September 1980 .

(4) Counc1l Directive 85/337/EEC of 27 June 1985 on the assessment of certaln public and private projects on the environment, - officlal Journal of the European Communtties, L $175 / 40$ of 5 July 1985.

(5) Single European Act, Bulletin of the European Communities supplement 2/86, office of official Publications of the EC, Luxembourg, 1986.

(6) Commission of the European Communtties: "Geological confinement of radioactive wastes within the European Community - Catalogue of geological formatlons having sultable characteristics for the disposal of solldifled high-level and/or long-lived radloactlve waste", EUR 6891, Office of offlclal Publications of the EC, Luxembourg, 1980.

(7) Commission of the European Communtties: "Radiological protection criteria for the recycling of materials from the dismantling of nuclear Installations", Radiologlcal Protection Ser1es No. 43, December 1988 .

(8) Cade111 N., et al: "PAGIS - Performance Assessment of Geologlcal Isolation Systems", EUR 11775, Office of Officlal Publications of the EC, Luxembourg, 1988.

(9) Commission of the European Communities: "Proposal for a Counc1l Dectsion, adopting a specific research and development programe in the fleld of management and storage of radloactive waste" (1990-1994, COM(89) 226 final, Brussels, 1989. 
DISCUSSION

Question: P B WOLLAM, CEGB (NPD) - Which isotopes will be important, perhaps for waste disposal at long decay times, from LMFBRs? Are these different from those in a thermal reactor? Did you include the fast neutron flux in your calculations?

Answer: G PEYRARD, Novatome - After 100 years $\mathrm{Nb}-94$ becomes important and after 200 years Eu-152. However, Ni-63 and Ni-59 remain the main isotopes with regard to the activity of the steel contained in the reactor block of Super Phenix 1 .

Question: D MAIRE, Novatome - Could Mr Caillol tell us the level of radiation in the work areas during the dismantling operation he described? In this radiation, what proportion is attributable to neutrons?

Answer: A CAILLOL, CEA-Cadarache - The level of radiation could be significant and impose limits on working times during the operations. It is for this reason that remote handling techniques are currently being developed. The neutron factor may account for about 508 in some cases.

Question: S ORLOWSKI, CEC - In the operation described, what proportion of waste goes for surface storage and what proportion for deep storage?

Answer: A CAILLOL, CEA-Cadarache - In the operations carried out the proportion is one to four (in the case of a transfer tunnel) for waste originating directly from the alpha cell.

Question: M S T PRICE, UKAEA-Winfrith - I have a comment relevant to Mr Caillol's paper and a question. The paper is very interesting because at winfrith also we have been decomissioning a large number of plutonium fuel fabrication glove boxes, using the winfrith modular containment system. Turning to the plutonium waste which is compressed, cemented and stored, awalting deep disposal, do you have a specification for the organic content? Do you believe the organic content to have any importance since its decomposition products might affect the release of long-lived radionuclides arising from elsewhere in the repository?

Answer: A CAILLOL, CEA-Cadarache - We have no specification about the organic content for our conditioned wastes.

Question: A G GREGORY, CEGB (NPD) - I have had an interest in 'decision tree analysis'/multi-attribute utility analysis' and reached the view of 'no confidence' in the results. This is because it requires decisions on a very wide range of measurable and non-measurable parameters, eg public perception. Is this method suitable for national/international decisions?

Answer: I M BARRACLOUGH, NRPB - The fact that a large number of factors are included in the decision-aiding analysis is surely an advantage. I agree that there are many subjective decisions involved, but such judgements need to be made in any case, and the technique I have described makes them explicit. It also allows a range of views on such judgements to be considered. I feel that, by making the decision-making process more transparent, such a methodology will make the decisions which are reached, more acceptable. 
Question: H EGURE, Randec -

1. What is the name of the transport calculation code?

2. How many groups of neutron cross section did you use?

3. Did you use a 1-D or a 2-D calculation code?

Answer: G PEYRARD, Novatome -

1. C.ANISN.

2. 113 energy groups.

3. 1-dimension code.

Question: P FUNKE, Ministry of the Environment and Reactor Safety, Wiesbaden - Has experience with dismantling, such as the discovery of large quantities of plutonium $(72 \mathrm{~g})$, for example in the transfer system, in any way influenced the design philosophy for new installations?

Answer: A CAILLOL, CEA-Cadarache - The design philosophy for installations has undergone some change in that installations are becoming smaller and easier to clean and, consequently, to decontaminate.

Question: M SAPPOK, Siempelkamp - Do you think that it will be possible to store radioactive waste in countries other than where it was produced, especially under the Single Market after 1992 within the EC? In addition, will it be possible to store it in distant countries like China or USSR?

Answer: $\mathrm{K}$ H SCHALLER, CEC - Radioactive waste will be transported throughout EC countries because of reprocessing contracts and in order to use treatment installations efficiently. The Commission is currently preparing a Directive on transport, which is quite in line with the Directive on transport of dangerous waste.

Any transport to third countries must be subject to the agreement of the safety authorities of all parties concerned.

\section{CONCLUSION}

The dismantling of several nuclear facilities of various types (glove boxes, fuel fabrication plant, breeder reactor structures) provides a sound basis not only for testing processes and learning about radiological exposures, but also for evaluating the types and volumes of waste to be expected in the future from the dismantling of large industrial plants. The volume of decommissioning waste arising from the present nuclear power reactor programme in Western Europe amounts to a little less than $2 \mathrm{Mm}^{3}$. However, this volume, for a given programme, will depend on the selected techniques and national regulations, existing or under consideration. Disposal options are being developed and should be available when needed, ie at the beginning of the next century. Methodologies are being developed, notably multi-attribute utility analysis, to aid decision making relating to the decommissioning of facilities and the disposal of the waste.

$S$ ORLOWSKI, CEC 


\section{SESSION VIII}

LARGE TRANSPORT AND/OR DISPOSAL CONTAINERS

CHAIRMAN:: A URIARTE HUEDA, CIEMAT, E

SECRETARY: K PFLUGRAD, CEC 
- 


\title{
DEVELOPMENT OF A LARGE CONTAINER CAST OF LOW-LEVEL RADIOACTIVE STEEL
}

H. Deipenau, Siempelkamp Giesserei, Krefeld, FR of Germany K. Pflugrad, Commission of European Communities, Brussels, Belgium

\begin{abstract}
Low-level radioactive solid waste from the decommissioning of nuclear installations, if transported and disposed of in large containers, may cause less cutting work and therefore less radiation exposure of workforce. The use of steel waste from decommissioning for manufacturing large transport and/or disposal containers is a promising route for recycling that waste and for saving storage volume and new resources. The development and testing of a large prototype container type KONRAD VI cast by using very low radioactive carbon steel from reactor refurbishing is the subject of this paper.
\end{abstract}

1. INTRODUCTION

The Commission of the European Communities has carried out assessments on large containers within the frame of two five-year (1979-83 and 1984-88) programmes of research on the decommissioning of nuclear installations, by way of cost-sharing contracts with organisations and companies in Member States. The results of the 1979-83 programme were presented at a Conference held in 1984 in Luxembourg from May 22 to 24, in Annual Progress Reports and in final reports, generally published as unrestricted available EUR-Reports/l/.

The Community's technological research aims at catalysing the setting up of regulatory frameworks within which industrial activities can develop. An example where particular progress has been achieved, is the re-use/-recycling of nuclear metal waste/2/. One of the possible recycling routes is the use of containers for final disposal cast of low-level radioactive waste. Large packages reduce cutting work considerably and, consequently, radiation exposure of the work force. The use of "nuclear" steel waste for manufacturing transport and disposal containers saves high cost disposal volume and, at the same time, the consumption of $r$ aw steel. This route is also strongly considered by PTB (Physikalisch-Technische Bundesanstalt, the Federal Institute for Science and Technology, i.e. the highest technical authority under the auspices of the Federeal Ministry of Economy), and BAM (Bundesanstalt für Materialforschung, the Federal Institute for Material Research) for the proposed German Konrad disposal site where packages of up to $10.9 \mathrm{~m}^{3}$ disposal volume of a maximum total weight of \& $20 \mathrm{Mg}$, may be disposed beyond 1995. Before casting large containers, knowledge was needed with respect to specific problems occurring in the presence of radionuclides during the melt work.

\section{EXPERIENCE IN MELTING RADIOACTIVE CONTAMINATED STEEL}

Siempelkamp Giesserei has developed and tested a melting facility in the framework of previous investigations (financed by the CEC and the German BMFT) involving the melting of $1500 \mathrm{t}$ of steel waste with an average radioactivity level of $1.5 \mathrm{~Bq} / \mathrm{g}$. This facility (Taurus II) had then been used for various test series. It comprised a $20 \mathrm{t}$ capacity induction furnace and is authorised to process scrap with activity levels up to $74 \mathrm{~Bq} / \mathrm{g}$. 
Three main series of specific melting tests have been performed until now. In particular:

- In the first series of tests, $35 t$ of mixed steel waste with an average activity level of about $7 \mathrm{~Bq} / \mathrm{g}$ was melted to produce shielding plates (the high chromium content excluded other uses)

- In the second series, $30 \mathrm{t}$ of carbon steel waste (activity: $5 \mathrm{~Bq} / \mathrm{g}$ ) was melted to produce high-quality castings such as type- $A$ and type- $B$ waste containers.

- In the third series, $34 \mathrm{t}$ of austenitic steel (activity: $12 \mathrm{~Bq} / \mathrm{g}$ ) was melted to produce bars for later recycling.

Further meltings carried out related to $139 \mathrm{t}$ of mixed steel waste coming from KWO. Thus, a large amount of results and experience is supporting the casting of waste containers suitable for transport and final disposal in the Konrad mine.

3. DESIGN, MANUFACTURING AND TESTING OF A LARGE STEEL CONTAINER SUITABLE FOR TRANSPORT AND DISPOSAL IN THE KONRAD MINE

Research work undertaken related to the development of a prototype container WACO I. The main working steps were as follows:

- Technical optimisations based on Konrad type VI steel container $(1600 \times$ $2000 \times 1700 \mathrm{~mm}$ high, total weight $20 \mathrm{t}$, loading capacity of $14 \mathrm{t}=5.4$ $\mathrm{m}^{3}$ ), taking into account all relevant requirements for safe transport and the disposal in the Konrad mine.

- Stability calculations showing that the container can withstand shocks resulting from transport and handling hazards.

- Design and casting of a prototype container using $20.4 \%(4.22 \mathrm{t})$ of contaminated steel $(<10 \mathrm{~Bq} / \mathrm{g})$ and its testing under conditions as required by the IAEA and the German authorities: PTB, Physikalisch-Technische Bundesanstalt and BAM, Bundesanstalt für Materialforschung.

- Establishment of a radiological measurement programme to measure radioactivities occurring before and after manufacturing the container.

- Testing the prototype container with representative loading materials and development of conceptions to repair an accidentally damaged (during handling or transport) container, with a particular view to tightness and protection of workforce and environment.

3.1 Requirements taken into account for the final depository Konrad /3/

The Konrad disposal requirements for classification I are as follows:

- stacking of five times the containers' weight for a period of 24 hours without loss of tightness, i.e. a load of $100 \mathrm{Mg}$ on the lowest container;

- then, in case of a thermal load, the entrance of oxygen to the waste is to be delimited by the container in such a way that waste products with melting points above 300 degrees $C$ do not burn with open flame.

- one of the essential requirements for design and calculation was the fluctuation of temperature the package may possibly be exposed to. Thus, $-40^{\circ} \mathrm{C}$ and $+70^{\circ} \mathrm{C}$ were considered.

3.2 Regulations for the safe transport of radioactive material /4/

Besides the IAEA limits of the permissible dose rate of $2 \mathrm{mSv} / \mathrm{h}$ at the surface and $0.1 \mathrm{mSv} / \mathrm{h}$ at a distance of 2 metres during transport, requirements for packagings and packages, as given in the German regulations for the safe transport of dangerous material (GGVS) were taken into account. 


\subsection{Material specification}

It was one of the major target of this project to demonstrate that carbon steel waste from nuclear installations can be used to produce containers with respect to requirements of the IAEA regulations and the final disposal in the Konrad mine. For this purpose, the quality of the original material must ensure the specified chemical composition. Table I shows required and measured mechanical properties.

To ensure that a container will meet the required regulations for transport and disposal in the Konrad mine, the mechanical properties had to be specified with respect to type-A conditions, i.e. a yield stress of $>250 \mathrm{~N} / \mathrm{mm}^{2}$, a tensile strength of $210 \mathrm{~N} / \mathrm{mm}^{2}$ and an elongation of $\geq 3$.

The prototype container WACO I was therefore designed for conservative conditions, e.g. by choosing the chemical composition at the upper limit (Table II) and the mechanical properties at the lower limit of the specified values.

of major interest are elements which can cause a disturbed structure accompanied by a decrease of the mechanical properties, e.g. $\mathrm{Cr}, \mathrm{Ti}, \mathrm{Pb}$, $\mathrm{Mn}$, and $\mathrm{Cu}$. These elements usually come from stainless steel and impurities, so it is essential to separate carbon steel from stainless steel (easily done by using a small magnet).

\subsection{Selection of the container sizes and design optimisation}

An estimation of the demand for cast iron containers usable for wastes arising from the dismantling of nuclear installations was made by means of a computer programme. The nuclear power plants BWR-Brunsbuittel and the PWR-Biblis $A$ were taken as reference decommissioning plants. On the other hand, the wastes coming from operating power plants were taken into account. Depending on waste activity, the type VI-Konrad container seems usable for about $65 \%$ of the total waste mass of a reference nuclear power plant. The wall thickness of this container may vary from 100 to 150 $\mathrm{mm}$ with a weight of $13-16 \mathrm{Mg}$ and a load capacity of 4 to $7 \mathrm{Mg}$.

The basic design of the container $c$ an be seen on Figure 1 . For the fixing of the IS0-corner fittings, two alternative possibilities were assessed:

- ISO-corner fittings fastened by screws, made of cast iron GS 45.3 material. Dimensions and test loads correspond to DIN ISO 1161. The corner fittings (screws, dowel pins and distance plate) are supplied together with a test certificate established with an agreed works inspector. The corner fitting itself is welded to the distance plate with a $10 \mathrm{~mm}$ fillet weld.

- ISO-corner fittings cast together with the container. The dimensions of these corner fittings also correspond to DIN ISO 1161. Here, the shrinkage of the cast iron has to be considered and the cores within the necessary dimensional tolerances. The spacing of holes of the ISOcorner fittings are decisive because of the later handling with spreader technique.

\subsection{Prototype test programine and results}

The prototype container was tested in the frame of the licensing procedure for agreement by PTB/BAM (licensing authorities for the Konrad mine).

The tests were planned with respect to relevant transport and storage regulations. While the IAEA regulations for the transport of type-A pack ages are well known, the storage regulations for the Konrad mine are in draft form at present. Over the next few years, this situation may be improved. IAEA type-A regulations require a drop test from a height of 
$0.3 \mathrm{~m}$, whereas the Konrad conditions require for $0.8 \mathrm{~m}$ drop tests. Konrad requires a fire test, which is not in the IAEA regulations; IAEA requires a waterspray test, which is not needed for Konrad (but requiring tests of the corner fittings for loads on top of the container and, for special purposes, the tightness of the container must be demonstrated).

For the prototype, the requirements were met by choosing the harder conditions in every case, i.e.

- drop test from a height of $0.8 \mathrm{~m}$

- fire test at $800^{\circ} \mathrm{C}$ for one hour

- stacking test by loading $100 \mathrm{t}$ on top of the container

- spreader test to check the corner fittings.

of major importance is the ultrasonic test, which makes sure that no allowed shrinkage within the wall either reduces the shielding effect of the container or reduces the strength of the wall to withstand accidents.

In detail, following tests were carried out:

- Water spray test

It had to be carried out just before all other tests. The quantity of water per surface unit shall correspond to a quantity of rain of approximately $5 \mathrm{~cm}$ per hour.

- Free drop test

The container must fall on a target test plate, so that it suffers the greatest possible damage regarding the safety factors. The height of drop depends on the weight. The distance is measured from the lowest point of the container to the surface of the target test plate.

- Stacking test

The container was exposed - for at least 24 hours - to a load being five times higher than the mass of the packaging, i.e. for the Konrad container a load of $100 \mathrm{Mg}$.

- Side wall spreader test

In the Konrad mine the container will be lifted, transported and stacked by handling at two top corner fittings. The dynamical loads from handling with a fork lift truck are considered by load factor 2. An additional test weight of $20 \mathrm{Mg}$ is necessary.

- Test conditions for freight containers

Those tests conditions relate to ISO 1496. The load factors relate to DIN 15018 and KTA 3902, i.e. 2.

The tests carried out on the prototype WACO I demonstrated that the requirements of the IAEA regulations were met completely. Also the drop test results under "Konrad" conditions, as well as the staple tests and the tests of the corner fittings were satisfactory. A leakage test and a dye penetration test were performed after the a.m. test, showing no cracks, even in highly forced areas.

A problem arose with the seals after the fire test (for "Konrad" all containers have to resist against a fire for one hour). This problem arose because of the high temperature in the seal area. The temperature increased above $300^{\circ} \mathrm{C}$. That means that synthetic seals like viton and teflon fail. Tests with seals on a graphite base, which are resistant up to $800^{\circ} \mathrm{C}$, did not give the required tightness of $10^{-5} \mathrm{mbarl} / \mathrm{s}$. The only solution to this problem seems to be metallic seals of an aluminium of a silver base, i.e. costly items. It is therefore of paramount importance to decide whether a container needs tightness or not and, if yes, at which level. 


\section{CONTAINER REPAIR CONCEPTION}

It cannot be ensured during handling and transport of the container that a corner fitting will not break. This means that a repair conception is necessary to be able to handle the container without unloading. Therefore, after having qualified the container, with respect to the various regulations, additional special repair conceptions had to be assessed:

- repair/replacement of damaged corner fittings due to a transport/handling hazard,

- tightness welding between the lid and the container.

The proposed solutions are as follows: In a machine shop defect corner could be ground out. On the machined surface, a new steel plate is fixed by screws and the new fitting - made out of cast steel - is welded against the base plate. Another solution to tighten the container was tested by welding a seam between lid and container (in this case, the lid is not removed, reducing exposure of the worker). A dye-penetrant test can be used to prove the tightness of the seam.

\section{RADIOLOGICAL ASSESSMENT}

An inherent radioactivity of the container $c$ an be expected, because it is cast by using low-radioactive steel. However, as melting has a decontamination effect caused by branching off radionuclides into filter dust and slag, the radioation level of a cast product should diminish. Furthermore, the radioactivity in the cast product exists no longer as a surface contamination but is now fixed in the steel matrix. Thus the radiation level decreases also due to self-shielding effects.

For transport and disposal packages, the determination of the radiation field of the empty container is essential. The IAEA regulations for the safe transport of radioactive material authorise a maximum radiation level at any point of the external surface of a package of $2 \mu \mathrm{Sv} / \mathrm{h}$. In $2 \mathrm{~m}$ distance to containers, respectively in $1 \mathrm{~m}$ distance to cylindrical pack ages, the limit is $0.1 \mu \mathrm{Sv} / \mathrm{h}$.

\section{5.l Estimation of the radiation level by calculation and measuring}

The dose rates of the empty KONRAD type VI container and of cylindri cal casks of the type III were calculated by means of a computer programme of the NIS-Ingenieur-Service. To verify the results of these calculations, dose rate measurements on a cylindrical cask were carried out to show the influence of the radiation level of the empty container on the dose rate of a container filled with radioactive waste.

The calculations were carried out for the wall thicknesses of $120 \mathrm{~mm}$ (prototype container) and of $100 \mathrm{~mm}$ (cyclindrical) respectively. As average specific activity, $10 \mathrm{~Bq} / \mathrm{g}$ and $2.02 \mathrm{~Bq} / \mathrm{g}$ input were chosen, resp. Only the Co-60 nuclide was taken as reference nuclide. Further, the main elements of cast iron as shielding material were considered.

The results of the calculations are given in Table III. Measured values of the cylindrical casks are comparable and calculated. It is shown that specific activities up to $10 \mathrm{~Bq} / \mathrm{g}$ in the castings have no significant influence on the radiation level of the container.

The dose rates at the surface and in $1 \mathrm{~m}$ or $2 \mathrm{~m}$ distance to the empty containers are lying far below the admissible limits of the IAEA transport regulations.

\subsection{Activity calculation of a filled container}

The maximum activity content of a container supposed to be filled with 
a resin is defined by the IAEA-regulations for type-A packages:

$\mathrm{A}_{2}: 0.4 \mathrm{El} 2 \mathrm{~Bq}\left(1.3 \mathrm{E5} \mathrm{Bq} / \mathrm{cm}^{3}\right)$ for $\mathrm{C} 0-60$, whereas the activity limit according to the preliminary conditions for the final depository KONRAD is fixed at $1.1 \mathrm{E} 13 \mathrm{~Bq}\left(3.6 \mathrm{E} 6 \mathrm{~Bq} / \mathrm{cm}^{3}\right)$ for $\mathrm{Co}-60$, which is higher than for the IAEA-type-A packages.

For a powder resin of a density of $0.6 \mathrm{~g} / \mathrm{cm}^{3}$, the container needs a shielding of $150 \mathrm{~mm}$, to respect the admissible dose-rate of $0.1 \mu \mathrm{Sv} / \mathrm{h}$ at a distance of $2 \mathrm{~m}$ (Figure 2 ).

\subsection{Pyrolytic decomposition of powder resins}

During the fire test $\left(800^{\circ} \mathrm{C}, 1 \mathrm{~h}\right)$, the inner wall of the container reached temperatures in the range from $250^{\circ} \mathrm{C}$ to $300^{\circ} \mathrm{C}$. The results (Figure 3) show that the pyrolysis ends after a time of about 1 minute at a temperature of $200^{\circ} \mathrm{C}$, producing $100 \mathrm{ml} / \mathrm{g}$ of gas.

To estimate the pressure rise due to produced gas, the following assumptions were made for $400 \mathrm{Kg}$ of resin and the pyrolysis of the resin in a layer of $5 \mathrm{~cm}$ from the inner wall $\mathrm{s}$.

The generated gas volume of $40 \mathrm{~m}^{3}$ may lead to a pressure rise of 12 bar if the container is completely leaktight. To verify this estimation, a specific fire test of a container filled with powder resins will be necessary.

\subsection{Activity release rate during normal handling}

A maximum admissible leakage rate for normal transport of type-A packages has never been defined quantitatively in the Regulations by the IAEA. For special purpose, the preliminary conditions for the final depository KONRAD established leakage limits (He) in the range from $10^{-5}$ $\mathrm{Pam}^{3} / \mathrm{s}$ to $10^{-7} \mathrm{Pam}^{3} / \mathrm{s}$ for normal transport conditions.

For the prototype container, a Helium leakage rate of $10^{-5}$ to $10^{-6}$ $\mathrm{Pam}^{3} / \mathrm{s}$ was measured. Activity release calculations were made with the following assumptions:

- maximum temperature difference: $110^{\circ} \mathrm{C}$ during transport, giving a pressure rise of 0.38 bar;

- radiolyse gas coming from the resin itself and from the water content and resulting in an additional pressure rise of 1.5 bar (i.e. total pressure: 1.88 bar) for 1 bar as maximum pressure difference and a free volume of 12001 ;

- a leakage rate of $0.36 \mathrm{mbarl} / \mathrm{h}$ corresponding to $1.7 \mathrm{E7}$ per hour (reference free volume: 1200.1 .

The maximum activity concentration for resins due to Caesium is 0.88 $E 13 \mathrm{~Bq} / \mathrm{m}^{3}$, of which 0.01 of the total Caesium content is assumed to be released as gas. These assumptions result in a release rate for Caesium of $3.3 \mathrm{E} 4 \mathrm{~Bq} / \mathrm{h}$, i.e. by about a factor 10 lower than required $(5 \mathrm{E} 5 \mathrm{~Bq} / \mathrm{h})$.

\section{CONCLUSIONS}

The cast prototype WACO I has fulfilled all conditions to reach the qualification as a type-A package according to the IAEA Regulations for the Safe Transport of Radioactive Material. Also, the preliminary conditions of the final depository KONRAD were met. The complete documen tation about the test results inclusive measurements, dye penetration tests and pressure tests were checked by the German authorities: PTB, Physikalisch-Technische Bundesanstalt and BAM, Bundesanstalt für Materialforschung.

Under normal transport conditions a leakage rate lower than $10^{-5}$ 
$\mathrm{Pam}^{3} / \mathrm{s}$ could be achieved.

The tested container demonstrated that it is possible to cast transport and disposal containers for radioactive wastes by using up to $20 \%$ of low-carbon steel waste coming from the refurbishing or dismantling of nuclear installations.

The research work finished in May this year. As regards the industrial aspect of the project, it may qualify as a successful one. Until now, 12 containers of this type have been produced and shipped to the customer, and another 23 are under construction.

Is this not a clear indication that recycling of nuclear steel waste is a realistic route to reduce the radioactive waste volume and to save steel resources.

One of the main conclusions of the assessments carried out is that the quality of the material to be reused is of paramount importance. Therefore a qualitative selection of the material on the decommissioning site is very important to obtain well-known material categories allowing the casting of quality items.

\section{REFERENCES}

1. The Community's research and development programme on decommissioning of nuclear installations. Fourth annual progress report (year 1988). Commission of the European Communities, EUR 12338.

2. Commission of the European Communities, Radiation Protection no. 43, Radiological Protection Criteria for the Recycling of Materials from the Dismantling of Nuclear Installations, Recommendations from the Group of Experts set up under the terms of Article 31 of the Euratom Treaty. Luxembourg, November 1988.

3. P. Brennecke, E. Warnecke

Anforderungen an endzulagernde radioaktive Abfälle (Vorläufige Endlagerungsbedingungen, Stand Mai 1989) - Schachtanlage KONRAD PTB-SE-IB-53, Braunschweig, Mai 1989

4. IAEA Safety Standards

Regulations for the Safe Transport of Radioactive Material, Safety series $\mathrm{Nr} .6,1985$ 
Table I: Measured mechanical properties

\begin{tabular}{|c|c|c|c|c|c|}
\hline & $\begin{array}{l}\text { Testing } \\
\text { temperature }\end{array}$ & $\begin{array}{l}\mathrm{Rm} \\
\mathrm{N} / \mathrm{mm}^{2}\end{array}$ & $\begin{array}{l}\mathrm{R}_{\mathrm{po} .2^{2}} \\
\mathrm{~N} / \mathrm{mm}^{2}\end{array}$ & $\begin{array}{l}\mathrm{A}_{5} \\
\%\end{array}$ & $\begin{array}{l}\mathrm{Z} \\
\%\end{array}$ \\
\hline $\begin{array}{l}\text { required GGG } 60 \\
\text { DIN 1693, T.2 }\end{array}$ & RT & 550 & 340 & 1 & - \\
\hline $\begin{array}{l}\text { required for } \\
\text { WACO I }\end{array}$ & $\mathrm{RT}$ & 250 & 210 & 3 & - \\
\hline $\begin{array}{l}\text { Test-no. } \\
\text { 904-010-01/1 } \\
12 \\
/ 3 \\
14\end{array}$ & $\begin{array}{l}\mathrm{RT} \\
\mathrm{RT} \\
\mathrm{RT} \\
-40^{\circ} \mathrm{C}\end{array}$ & $\begin{array}{l}558 \\
536 \\
554 \\
489\end{array}$ & $\begin{array}{l}370 \\
379 \\
361 \\
398\end{array}$ & $\begin{array}{l}3.0 \\
2.9 \\
3.0 \\
1.7\end{array}$ & $\begin{array}{l}3.0 \\
3.1 \\
4.8 \\
1.0\end{array}$ \\
\hline $\begin{array}{r}904-011-01 / 1 \\
/ 2\end{array}$ & $\begin{array}{l}\mathrm{RT} \\
-40^{\circ} \mathrm{C}\end{array}$ & $\begin{array}{l}539 \\
523\end{array}$ & $\begin{array}{l}370 \\
420\end{array}$ & $\begin{array}{l}2.6 \\
1.7\end{array}$ & $\begin{array}{l}4.6 \\
0.7\end{array}$ \\
\hline
\end{tabular}

Table II: Chemical composition of container and container lid in comparison to the required values

\begin{tabular}{|c|c|c|c|}
\hline & required & $\begin{array}{l}\text { composition } \\
\text { container }\end{array}$ & $\begin{array}{c}\text { composition } \\
\text { lid }\end{array}$ \\
\hline $\begin{array}{ll}\mathrm{C} & \% \\
\mathrm{Si} & \% \\
\mathrm{Mn} & \% \\
\mathrm{P} & \% \\
\mathrm{~S} & \% \\
\mathrm{Cr} & \% \\
\mathrm{Mo} & \% \\
\mathrm{Cu} & \% \\
\mathrm{Ni} & \% \\
\mathrm{Mg} & \%\end{array}$ & $\begin{aligned} 3.60- & 3.75 \\
2.2 & -2.4 \\
& 0.40 \\
& 0.025 \\
& 0.010 \\
& 0.5 \\
& 0.1 \\
& 0.15 \\
& 0.50 \\
0.040- & 0.060\end{aligned}$ & $\begin{array}{l}3.52 \\
2.30 \\
0.34 \\
0.02 \\
0.005 \\
0.43 \\
0.02 \\
0.19 \\
0.26 \\
0.037\end{array}$ & $\begin{array}{l}3.47 \\
2.27 \\
0.32 \\
0.02 \\
0.005 \\
0.46 \\
0.02 \\
0.2 \\
0.28 \\
0.038\end{array}$ \\
\hline
\end{tabular}


Table III: Dose rates of the empty WACO I and an empty cylindrical cask with a respective specific activity of $2.02 \mathrm{~Bq} / \mathrm{g}$ and $10 \mathrm{Bg} / \mathrm{g}$

\begin{tabular}{|c|c|c|c|c|c|}
\hline type & $\begin{array}{c}\text { wall thickness } \\
(\mathrm{mm})\end{array}$ & $\begin{array}{l}\text { distance } \\
(\mathrm{mm})\end{array}$ & $\begin{array}{l}\text { dose rate due to } \\
\text { specific activi- } \\
\text { ty of } 2,02 \mathrm{~Bq} / \mathrm{g} \\
(\mu \mathrm{Sv} / \mathrm{h})\end{array}$ & $\begin{array}{l}\text { dose rate due to } \\
\text { specific activi- } \\
\text { ty of } 10 \mathrm{~Bq} / \mathrm{g} \\
(\mu \mathrm{Sv} / \mathrm{h})\end{array}$ & $\begin{array}{l}\text { admissible } \\
\text { dose rates } \\
(\text { IAEA) } \\
(\mu \mathrm{Sv} / \mathrm{h})\end{array}$ \\
\hline WACO I & 120 & $\begin{array}{r}0 \\
1000 \\
2000\end{array}$ & $\begin{array}{l}1.21 \\
0.39 \\
0.14\end{array}$ & $\begin{array}{l}6.0 \\
1.92 \\
0.71\end{array}$ & $\begin{array}{l}2 \times 10^{3} \\
-1 \times 10^{3}\end{array}$ \\
\hline $\begin{array}{l}\text { cylindrical } \\
\text { cask type III } \\
\text { (calculated } \\
\text { values) }\end{array}$ & 100 & $\begin{array}{r}0 \\
1000\end{array}$ & $\begin{array}{l}1.17 \\
0.14\end{array}$ & $\begin{array}{l}5.81 \\
0.67\end{array}$ & $0.1 \times 10^{3}$ \\
\hline $\begin{array}{l}\text { cylindrical } \\
\text { cask type III } \\
\text { (calculated } \\
\text { values) }\end{array}$ & 100 & $\begin{array}{r}0 \\
1000\end{array}$ & $\begin{array}{l}1.05 \\
0.36\end{array}$ & - & - \\
\hline
\end{tabular}



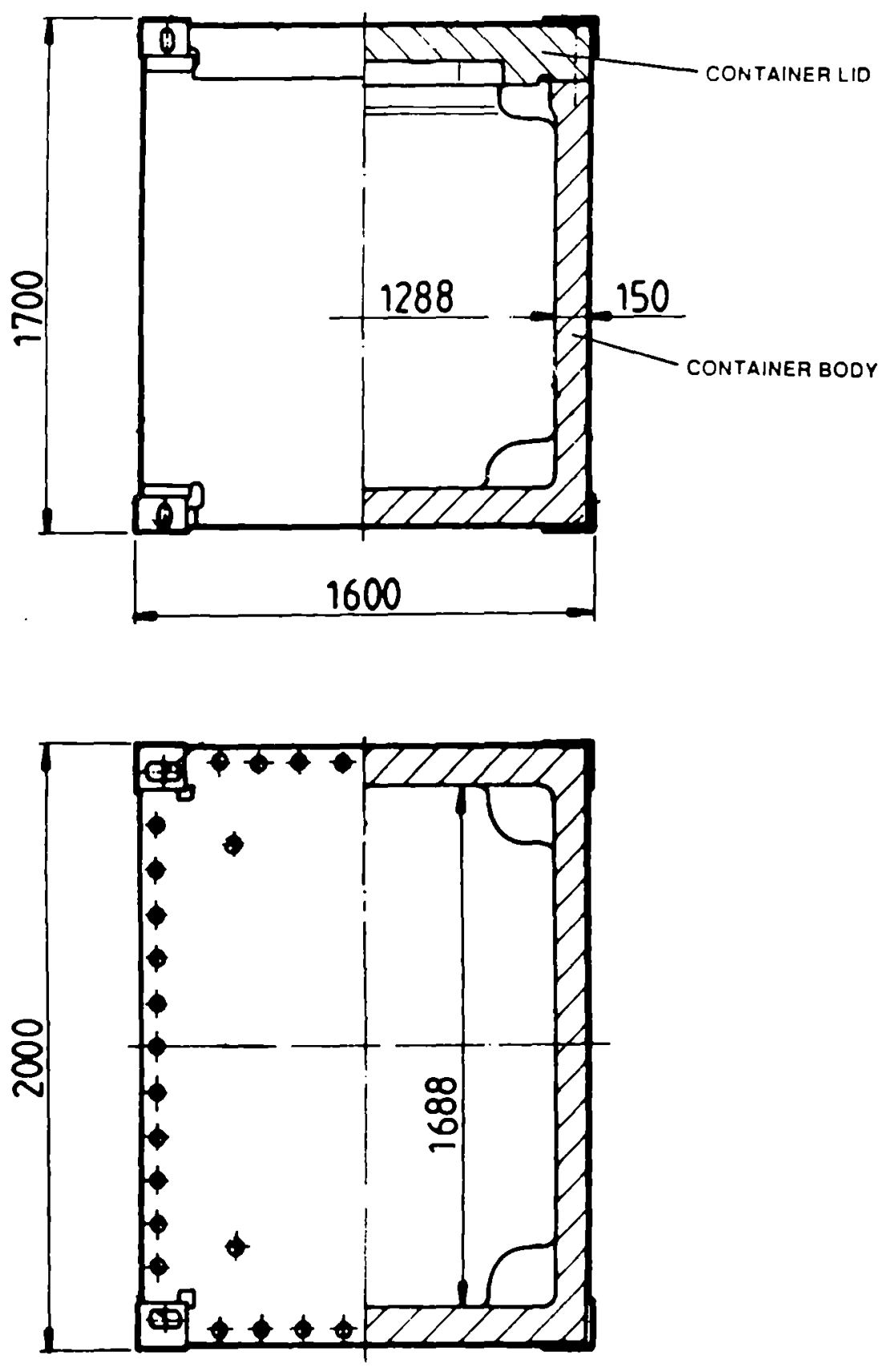

Figure 1: Basic Design 


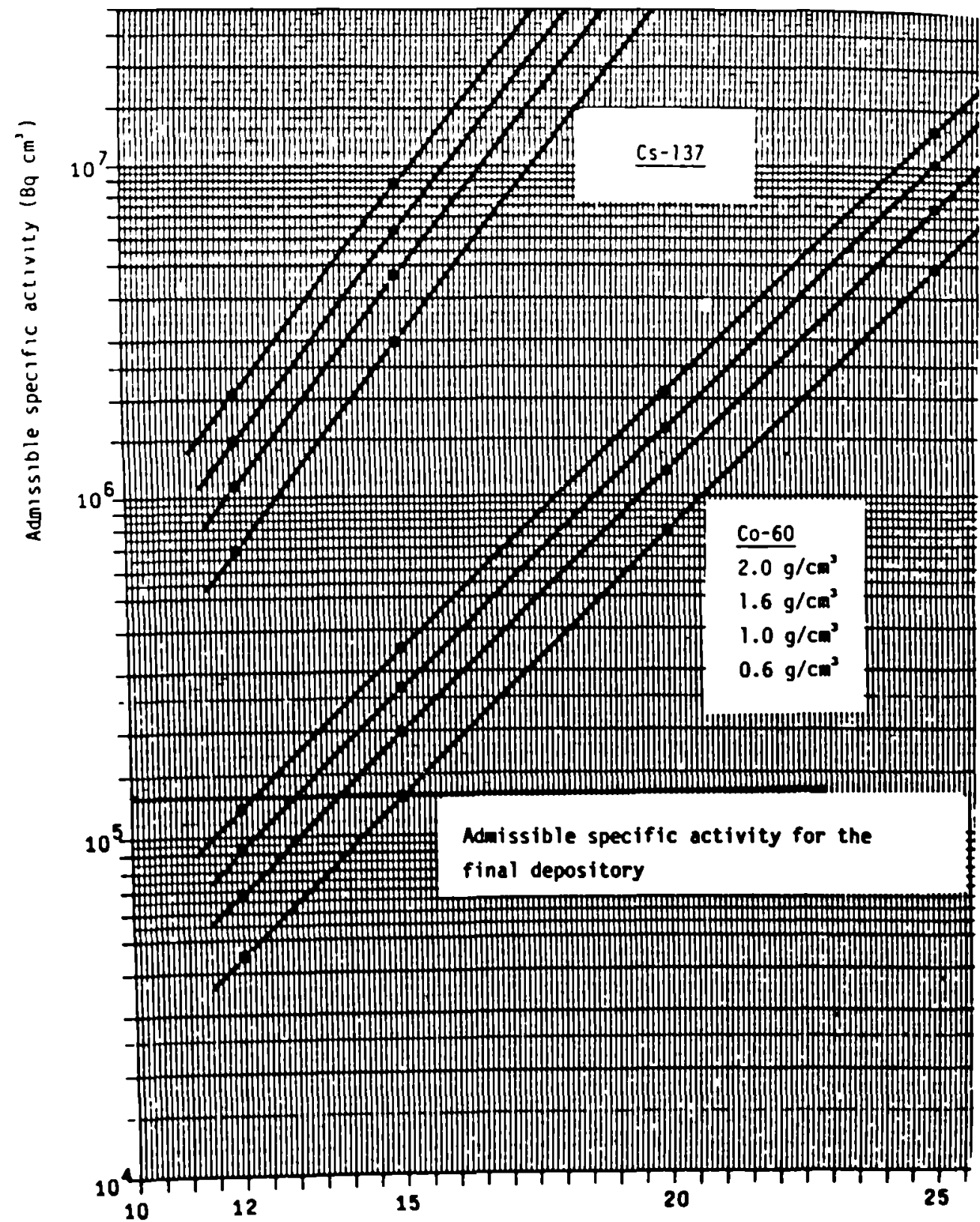

Mall thickness (m)

Figure 2: Calculated activity content for a container as function of wall thickness 
temperature $\left[{ }^{\circ} \mathrm{C}\right]$

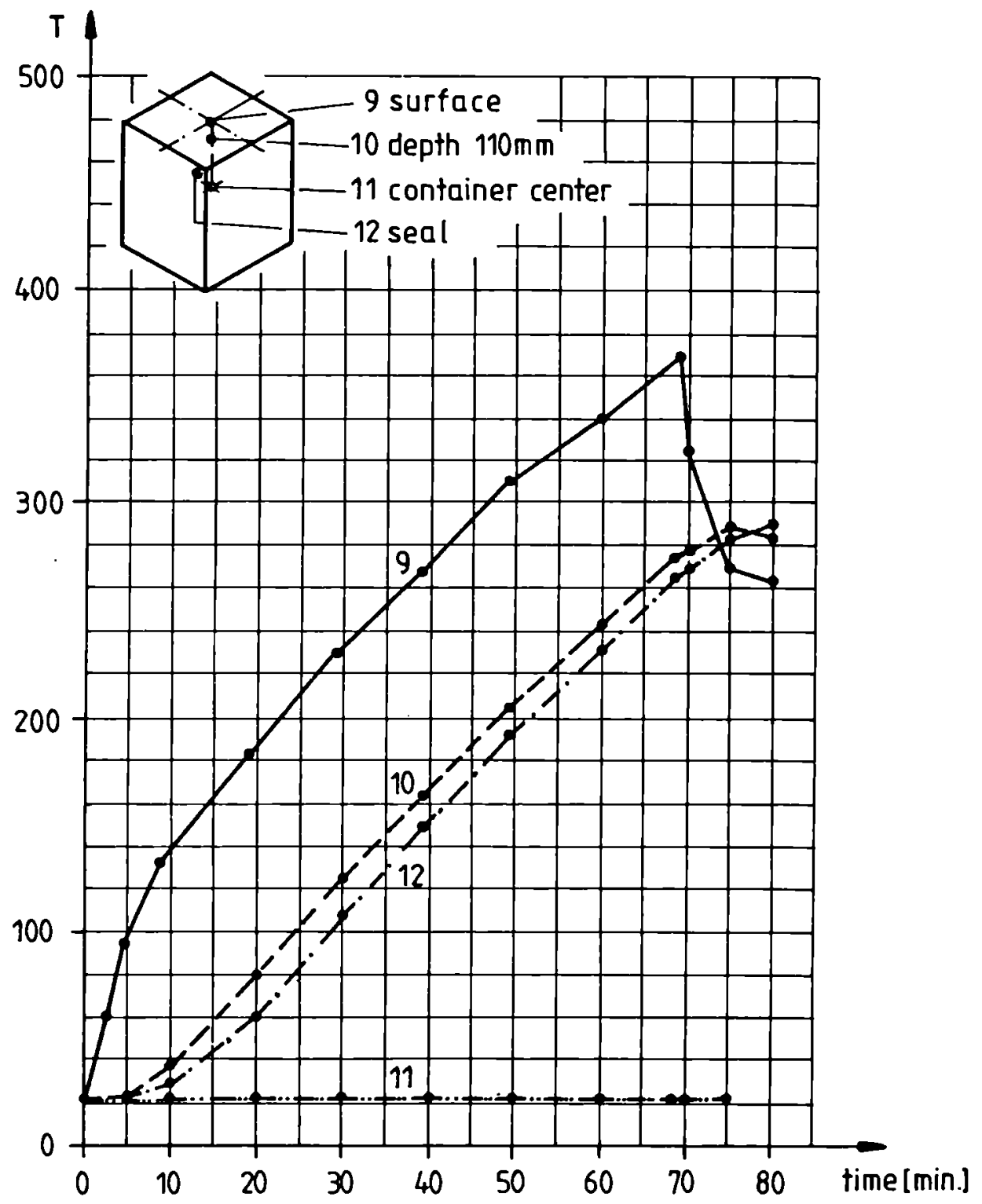

Figure 3: Fire test

Temperature $800^{\circ} \mathrm{C}$, duration $1 \mathrm{~h}$ 


\title{
LARGE MASTE CONTAINERS MADE OF FIBRE REINFORCED CONCRETE
}

\author{
C. Jaouen \\ Société Générale pour les Techniques Nouvelles \\ Saint Quentin en Yvelines, France
}

\begin{abstract}
The production of large-sized metallic waste by dismanting operations, and the evolution of the specifications on the waste to be stored in the different European countries will create a need for large standard containers for the transport and final disposal of the corresponding waste. The research conducted during the 1984/1988 programme, supported by the Commission of European Communities, and based on a comparative study of high-grade concrete materials, reinforced with organic or metallic fibres, led to the development of a high performance container meeting international transport recommandations as well as French requirements for shallow-ground disposal.

The material selected, consisting of high-performance mortar with metal fibre reinforcement, was the subject of an intensive programme of characterization tests conducted in close cooperation with Lafarge Company, demonstrating the achievement of mechanical and physical properties comfortably above the regulatory requirements. The construction of an industrial prototype and the subsequent economic analysis served to guarantee the industrial feasibility and cost of this system, in which attempts were made to optimize the 'finished package' product, including its closure system.
\end{abstract}

\section{INTRODUCTION}

In the same way as the maintenance of plants in operation, dismantling procedures on nuclear facilities will produce low-and mediumlevel technological wastes, which will require high-quality containers for their final disposal, meeting the specifications of the regulations imposed on radioactive waste transport and storage. The research conducted by $S G N$ under the 1984/1988 Community Programme was aimed to develop and characterize a large container, designed for this technological waste, made of fibre-reinforced concrete, within a regulatory framework corresponding to the IAEA transport recommendations, and to French specifications for shallow-ground disposal.

\section{A NEH MATERIAL, HHY?}

The concrete containers normally used for technological and process waste consist of a moulded drum, reinforced by a metal armature with rods at least $6 \mathrm{~mm}$ in diameter, and a lid, with tightness procured by a mortar, an organic resin or a seal.

Three essential problems arise in such a configuration:

- to minimize the well-known difficulties that would be caused by corrosion of the reinforcement, a minimum alstance is set between the reinforcement rods and the outer surface of the container, as well as its 11d. The resulting heterogeneity in the mechanical properties of the different zones of the container implies sensitivity to cracking of the non-reinforced parts, under the effect of thermal cyclings or handing impact. 
- The durability assessments of this container, essential for the disposal safety analysis, are generally based on that of the concrete employed, without accounting for the possible influence of the metal reinforcement.

- The shrinkage properties of the mortars, and dimensional variations and ageing of the organic materials make it difficult to establish a timebased assessment of the plug and of its connection with the container.

Two alternatives were investigated to solve this problem:

(a) The use of fibre reinforcement, besides improving the mechanical properties, and without altering the material's homogeneity, gives it greater compacity favourable ductility to withstand impact, and better corrosion resistance than a conventional reinforcement.

(b) Since special attention must be focused on the container closure system, the method selected for this study involves the use of a highperformance expansive mortar, recreating the mechanical properties of the container material itself.

\section{STUDY SPECIFICATIONS}

The container considered as a reference is an industrial package, according to IAEA classifications, and the wastes contained are assumed to give rise to a non-irradiating ( $I<200 \mathrm{mrem} / \mathrm{h}$ in contact and $I<10 \mathrm{mrem} / \mathrm{h}$ at $2 \mathrm{~m})$, non-alpha package (alpha activity $<0-1 \mathrm{Ci} / \mathrm{t}$ ), which can be transported in accordance with the reference recommendations to a shallowground disposal site.

The size of the package required will depend on that of the metallic waste to be incorporated. Quantity forecasts for waste of this type, based on the dismantling of reactors, and on cutting techniques existing or under development at the present time make it impossible today to draw up a precise specification in terms of dimensions and quantity to be provided for the container.

For the implementation constraints and the economic assessments, the study was therefore based on data corresponding to technological waste from French reprocessing plants, for an arbitrary production of 2000 to 10,000 containers per year.

Dimensions: $840 \mathrm{~mm}$ in diameter and $1200 \mathrm{~mm} \mathrm{high}, 1000 \mathrm{~mm}$ in diameter and $1500 \mathrm{~mm}$ high, and $1000 \mathrm{~mm}$ in diameter and $3000 \mathrm{~mm} \mathrm{high}$.

\section{MATERIALS TESTED}

Following an exploratory study of different types of fibre reinforcements (organic, glass, alumina, metallic), three materials were selected for the experimental programme.

Material 1, Everite

This material is processed by the Hatscheck pipe manufacturing process, by winding thin films of a low moisture content paste around a spindle.

The reinforcement base is an alkali-resistant glass fibre in a compact cement/silica fumes matrix, the other materials of the composition (cellulose and polyethylene) being necessary for implementation by the process.

Material 2, SGN "Farsil"

A second material based on alkali-resistant glass fibre reinforcement in a cement/silica fumes matrix was evaluated, using a moulding process avoiding fibrous organic additives, for purposes of comparison.

Material 3, Lafarge Nouveaux Matériaux

This is a concrete/fibre material developed by Lafarge Nouveaux Matériaux and Tréfileries de Conflandey, available on the market, and for which, using a moulding process, the same assessment programme was carried 
out. The corresponding concrete consists of a special high-compacity mortar (carefully selected cement, aggregates, fines and addition), and steel metal fibre reinforcement.

Other types of mortar and metal fibre have also been investigated by COCEMA for the needs of reprocessing plants.

\section{EXPERIMENTAL PROGRAME}

The experimental programme was conditioned by the technical specifications applicable to French shallow-ground disposal centres, with the corresponding test standards, as part of the characterization programmes necessary for type approval of the packages by ANDRA (French National Agency for Radioactive Waste Management). Certain tests were not performed: radiolsotope diffusion tests ( $\mathrm{H}_{3}$ and $\mathrm{Cs}$ )across the material for economic reasons and because of the time allotted to our programme, and full-scale package tests (dropping, thermal cyclings on package, immersion) demanding a definition of the typical packages with actual or simulated waste.

The programme hence concerned the following:

- mechanical tests (compressive and tensile strength),

- physical properties (porosity, permeability, shrinkage/swelling),

- resistance to thermal cycles, with mechanical measurement after cyclings,

- resistance to irradiation up to 5.107 rad integrated dose, with mechanical measurement after irradiation,

- corrosion resistance by immersion in $1 M$ nitric acid for 50 days, and mechanical test after corrosion.

This last test, which is not included in ANDRA standards, is designed for a qualitative assessment of behaviour under severe aggression. samples:

The following experimental facilities were employed to make the

- a pilot plant for preparing prototype pipes 150 m in diameter and $600 \mathrm{~mm}$ long for Everite,

- a pllot $501 \mathrm{mixer}$ useful for the Farsll and Lafarge materials, with standardized moulding of the corresponding specimens (Guedu propeller mixer for Farsil and planetary mixer for the Lafarge material). 
6. RESULTS OBTAINED AND MATERIAL SELECTION

The results are listed in the table below.

Table I: Comparitive results

\begin{tabular}{|c|c|c|c|}
\hline \multirow[b]{2}{*}{ TEST } & \multicolumn{3}{|c|}{ MATERIAL } \\
\hline & $\begin{array}{l}\text { Metal fibre } \\
\text { reinforced } \\
\text { concrete }\end{array}$ & $\begin{array}{l}\text { Glass fibres } \\
\text { Everite } \\
\text { process }\end{array}$ & $\begin{array}{l}\text { Glass fibres } \\
\text { moulding }\end{array}$ \\
\hline Compressive (28 days) & $119 \mathrm{MPa}$ & $80^{*}$ & $79.5 \mathrm{MPa}$ \\
\hline Split tensile (28 days) & $10 \mathrm{MPa}$ & not measured & bending $13 \mathrm{MPa}$ \\
\hline Shrinkage at 28 days & $-340 \mu \mathrm{m} / \mathrm{m}$ & rot measured & $2240 \mu \mathrm{m} / \mathrm{m}^{* *}$ \\
\hline Porosity to water & $6 \%$ & $17,5 \%$ & $21,10 \%$ \\
\hline Porosity to mercury & $7,26 \%$ & not measured & $15,70 \%$ \\
\hline Permeability to water & $* * *$ & not measured & $1.1 .10-19 \mathrm{~m}^{2}$ \\
\hline Permeability to nitrogen & $8 \cdot 10-20 \mathrm{~m}^{2}$ & not measured & $3.3 .10-17 \mathrm{~m}^{2}$ \\
\hline Specific gravity & 2.5 & 1.7 & 2 \\
\hline $\begin{array}{l}\text { Compression after thermal } \\
\text { cycling freeze/thaw }\end{array}$ & $160.4 \mathrm{MPa}$ & not measured & $96.4 \mathrm{MPa}$ \\
\hline $\begin{array}{l}\text { Compression after irradia- } \\
\text { tion (age: } 5 \text { months) } \\
5.107 \text { rad }\end{array}$ & $175 \mathrm{MPa}$ & $70 \%$ decrease & $24 \%$ decrease \\
\hline $\begin{array}{l}\text { Compression after } \\
\text { corrosion (50 days, } \\
1 \mathrm{MHNO} \text { ) }\end{array}$ & $172 \mathrm{MPa}$ & $30 \%$ decrease & $90 \mathrm{MPa}$ \\
\hline \multicolumn{4}{|c|}{$\begin{array}{l}\text { * Calculated in the most favourable case from the crush strength of } \\
\text { ** The hm diameter pipes. } \\
\text { agregh shrinkage in this case results from the absence of sand and } \\
\text { other criteria with the Everite material. } \\
\text { *** The valve of water permeability in this case is too low to be } \\
\text { measured by conventional techniques }\left(\leq 10-21 \mathrm{~m}^{2}\right) \text {. }\end{array}$} \\
\hline
\end{tabular}

The immediate observations from these results indicate a preference for the concrete/metal fibre matrix, whose overall properties are well above the performance characteristics required by ANDRA for container materials. In particular, it exhibits excellent mechanical and physical properties, and very good resistance to thermal aggression and corrosion. For the two glass fibre based materials, note the significant loss of mechanical strength after irradiation (even without organic fibres), probably due to embrittlement of the mortar/fibre bond.

The Lafarge concrete/metal fibre material was therefore selected for the rest of the study.

The need to have a solution for plugging the container was taken into account for the development and assessment of a high-performance expansive mortar, whose properties are summarized in Table II. The main objectives 
are to preserve the swelling properties after thermal cyclings, and a good permeability of the plug/container connection, with a mortar whose mechanical properties must indicate at least $50 \mathrm{MPa}$ compressive strength and $4.5 \mathrm{MPa}$ tensile strength.

Table II: Results obtalned for the plugging mortar

\begin{tabular}{|l|c|}
\hline \multicolumn{1}{|c|}{ TESTS } & RESULTS OBTAINED \\
\hline Compressive (28 days) & $75 \mathrm{MPa}$ \\
\hline Tensile (28 days) & $5 \mathrm{MPa}$ \\
\hline Compression after thermal cyclings & $95.5 \mathrm{MPa}$ \\
\hline Shrinkage after thermal cyclings & $+25 \mathrm{\mu m} / \mathrm{m}$ \\
\hline Permeability to nitrogen (plugging mortar) & $10-19 \mathrm{~m}^{2}$ \\
\hline Permeability to nitrogen (plug/container connection) & $3.4 .10-17 \mathrm{~m}^{2}$ \\
\hline Specific gravity & 2.35 \\
\hline Weight loss after 28 days & $11 \mathrm{~kg} / \mathrm{m}^{3}$ \\
\hline
\end{tabular}

\section{PREPARATION OF A PROTOTYPE AND ECONOMIC EVALUATION}

Prototypes of $1000 \mathrm{~mm}$ in diameter and $1500 \mathrm{~mm}$ high were prepared by moulding, as indicated in Figure 1, taking account of the handling facilities currently avallable, either on the production site or on the disposal site. The possibilities of checking surface contamination and/or possible decontamination were also taken into account in the fabrication method. The enclosed photographs show an example of construction, with a representative test specimen of plugging by expansive mortar.

The cost of this container would be 800 to 2000 ecus depending on the size of the containers and the scale of production.

\section{COHCLUSIONS}

Development work carried out with the support of the Commission of European Communities, on a high-quality container for dismantling waste, culminated in the selection of a high-performance material, and the concept of a container meeting the handling and plugging requirements, with a view to the disposal of the waste packages according to IAEA recommendations at a shallow-ground disposal centre subject to French regulations. The culmination for waste generators in a range of standard containers approved by the disposal organizations is one of the mediumterm objectives of this type of programme, with the view to optimise the resulting overall waste management system.

The projects completed under the Community programme on the material selected based on high compacity concrete with metal fibre reinforcements, served to demonstrate essential technical advantages over the conventional systems currently employed. These, advantages led COCEMA, one of the main French operators in the fleld, to pursue this investigation further for technological waste of reprocessing plants, and the corresponding application is now in the industrial optimisation phase. 


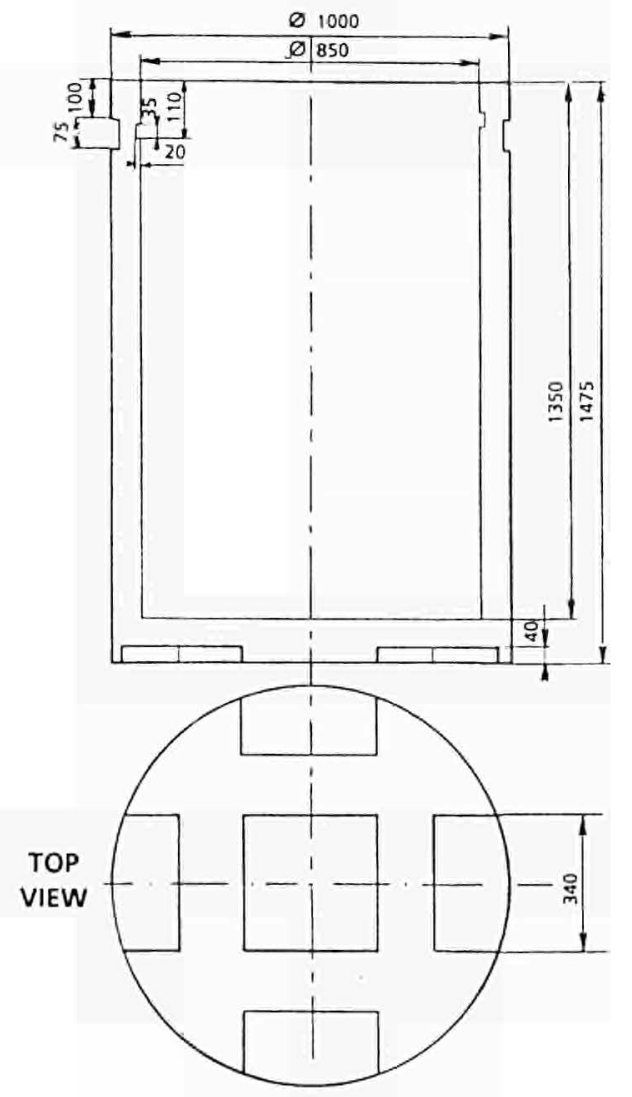

Figure 1: Drawing of prototype container

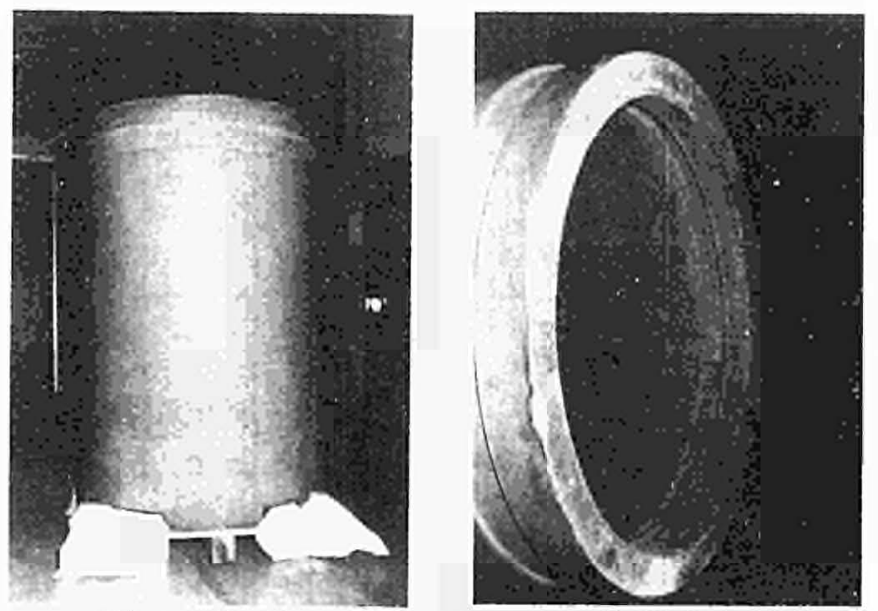

Figure 2: Container prototype $\emptyset 1000$ H 1500

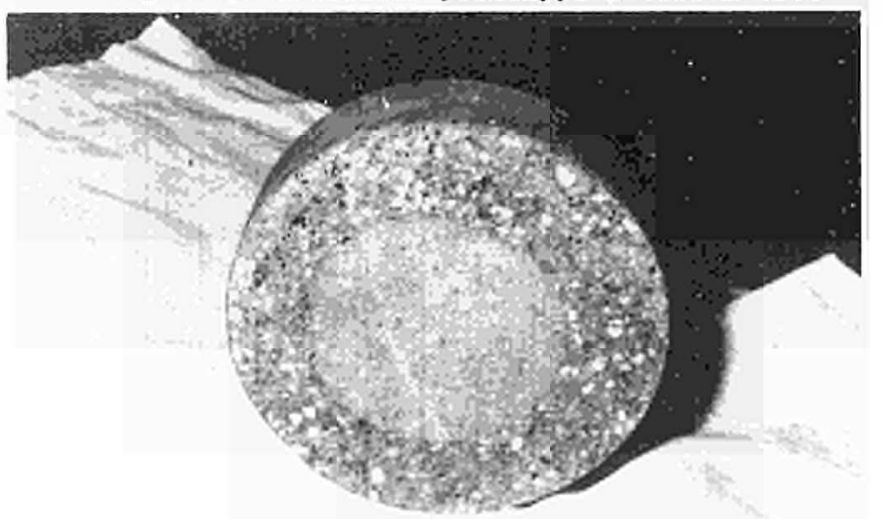

Figure 3: Specimen for plug/container connection 


\title{
LARGE SHIELDED INDUSTRIAL PACKAGES \\ FOR THE TRANSPORT OF INTERMEDIATE LEVEL WASTE
}

\author{
PRICE M S T
}

winfrith Technology Centre, winfrith, Dorchester, Dorset, UK

\begin{abstract}
A study of the factors which affect the design of large shielded containers for the transport of intermediate level waste from the decommissioning of nuclear power stations has been carried out culminating in the development of concepts for self shielded and returnable shielded industrial packages. The latter design is relatively insensitive to changes in disposal costs and is more adaptable to possible regulatory changes. Designs with an all-up weight of $65 \mathrm{t}$ are described. A novel proposal is to make the walls of the inner disposable container of sprayed fibre-reinforced concrete.
\end{abstract}

\section{INTRODUCTION}

A preliminary study of large transport packages for waste from nuclear reactors was carried out under the first five year joint action programme of research on the decommissioning of nuclear plant sponsored by the Commission of the European Communities (CEC) (Ref 1). Work began on a further study under the second CEC joint action programme in september 1986 on five interactive tasks which were aimed at leading to prototype designs of large transport packages viz:

A the effect of manufacture on design;

B a survey of transport hazards and constraints;

C the constraints of disposal criteria on package design;

D package design/performance criteria; and

$E$ the assessment of proposed package designs.

The study was carried out jointly by the winfrith Technology Centre (WTC), Ove Arup and Partners (OAP) and windscale Laboratory (WL), with the safety and Reliability Directorate, Culcheth (SRD), acting as consultant.

The status of decommissioning operations in the Federal Republic of Germany (FRG), France and the United Kingdom was established as these countries have large civil nuclear power programmes. Initially the factors affecting package design were examined. The study of large reinforced concrete packages was led by the $\mathrm{WL}$, which was already involved in the decommissioning of the windscale Advanced Gas Cooled Reactor (WAGR). The work on ferrous metal packages was led by WTC. Task B, carried out by OAP was concerned with desk and route studies of transport hazards as well as the definition of physical and regulatory constraints. Reference routes in the FRG, France and the United Kingdom were selected for detailed survey to estimate accident probabilities. In carrying out Task $C$ the following aspects were examined by WTC:

a) the radionuclide inventory for disposal;

b) the estimated toxicity of the leachate from packages;

c) disposal implications of the radionuclide inventory;

d) disposal site restrictions: 
e) the migration of key radionuclides from the package;

f) the corrosion behaviour of ferrous metals; and

g) gas production from a package.

The results of the three data collection tasks, A, B and $C$, were synthesised in the two final tasks of the study, led by OAP - Package Design Criteria and the Assessment of Package Designs. Overall coordination of the project was carried out by WTC.

\section{MAIN FACTORS AFFECTING PACKAGE DESIGN}

Waste Inventory

The total mass and activity of decommissioning waste will vary with the type of reactor and when it is decommissioned. The majority of the decommissioning waste from large PWRs, BWRs and gas cooled reactors will fall in the low level and ultra low level waste categories, ie outside the scope of this study. For a Magnox station the total mass of waste is estimated to be 20,000 te with around 2000 te consisting of activated items. Even for immediate decommissioning only a minor proportion of the latter will require to be transported in a Type B package, falling to around $3 \%$ at one hundred years after final shutdown.

The design approach for large Type $B$ containers for irradiated fuel transport is well established and design of a Type B package to transport intermediate level waste (ILW) is easier because there is insignificant heat generation.

The majority of intermediate level waste arising from decommissioning is suitable for transport as Type 2 Industrial Packages, so the remainder of this paper concentrates on aspects of their manufacture; handling and transport. Container Manufacture

The main rival materials for the construction of large containers are ferrous metals and concrete. Ferrous metals are dense, have good mechanical properties, are easily decontaminated and quality assurance does not present complications. The choice of ferrous metal is linked to the fabrication process and the overall dimensions. For shielding a minimum wall thickness of about $30 \mathrm{~mm}$ is required for ILW.

The options on the method of construction are:

a) welded steel plate fabrication;

b) using spheroidal graphite cast iron;

c) casting of steel; and

d) forging.

It may be noted that a parallel programme of development aims at investigating the recycling of low level radioactive steel by casting into waste containers (Ref 2 ).

welded plate fabrication - steel plate is readily available and relatively inexpensive compared with cast iron, cast steel or forged steel. The simplest way to make a transport package is to weld flat plates together. However, welding is labour intensive so that, beyond a certain plate thickness, it becomes uneconomic. Furthermore, quality control is increasingly difficult as plate thickness increases. A maximum wall thickness of $50 \mathrm{~mm}$ therefore seems likely for this construction method. Where complex shapes are 
required it is possible to adopt cast weld fabrication. Individual components would be cast in steel and welded together to complete the package.

Spheroidal graphite cast iron - The development of large spheroidal graphite cast iron (SGI) flasks began in 1979 and several hundred SGI flasks were reported at the PATRAM '89 conference to be in service in Western Europe and the USSR for transport and storage of irradiated fuel. The acceptance of SGI for Type B flasks rests mainly on numerous impact tests carried out by the Bundesanstalt fur Materiels Forschung und Prüfung. The design of the casting is closely interrelated with the casting process. Consultation with the foundry from the earliest stages of design is imperative. Features for consideration include simplicity of shape especially if internal moulds are required, shrinkage during cooling, corner radii and section thickening to control solidification. A transport package with walls around $4 \mathrm{~m}$ long would generally be most simply and economically fabricated from SGI for wall thicknesses greater than $50 \mathrm{~mm}$ although casting thicknesses down to $30 \mathrm{~mm}$ may be feasible.

steel casting - Casting of steel would produce a package with better performance than SGI, particularly in the areas of tensile strength and ductility, although the properties of SGI are likely to be adequate. Cast steel is more difficult to machine than SGI, although weld repair is more straightforward. The greater purity required, the higher casting temperature and the more complex solidification process make it a more expensive material than SGI.

steel forging - The forging of steel produces material with excellent, albeit strongly directional properties and this process is significantly more expensive than the other options.

Concrete packages - The influence of construction, such as package shell manufacture, types of cement, types of concrete, reinforcement, grouting, lid placement and final closure, on the design of reinforced concrete packages has been discussed in Refs 2 and 3 . The great advantage of reinforced concrete is its low cost and universal availability coupled with the ability to provide a material of adequate properties for an Industrial Package. An important development which has been taken into account in this study is the ability to make thin-walled structures by the use of sprayed fibre-reinforced concrete.

Lifting Features

At the inception of the study, the WAGR Decommissioning Project was already under way and a large cuboidal self shielded package had been proposed which incorporated large steel lifting lugs cast into the walls of the package. Such a design has not been adopted on the grounds of cost and long term integrity. For self shielded package designs the exterior can be featureless with spacers used between packages so that they can be lifted from the base. With a returnable shield, the outer container can use standard Iso corner fittings or grappler pockets. The disposal package within the returnable shield has no lifting features and is designed to be handled from the base by lifting or by roller conveyor. 
Temporary Storage

During temporary storage prior to disposal the package must remain intact for handling and transport. Packages might be stacked up to six high in temporary storage thereby imposing strength and stability requirements.

Transport

Possible combinations of transport methods were discussed in Ref 1. The main modes of transport are likely to be road and rail but where suitable dock facilities exist the use of marine transport should be considered. For road transport the greatest flexibility is provided if the gross weight of the package does not exceed about $25 \mathrm{t}$, thereby enabling standard vehicles to be used. In Western Europe the rail network is extensive and a package larger than $25 t$ can easily be transported by rail with the advantage of increased payload. A package of 110 - $120 \mathrm{t}$ could be carried on an eight axle wagon and such weights are common for Type $B$ flasks for spent PWR fuel. However, possible handling difficulties for waste packages led to a preference for a package with a gross weight of about $65 t$.

The requirements for Type 2 Industrial Packages are laid down in the IAEA Transport Regulations (Safety Series 6). For a package of mass $>15$ t it must undergo a stacking test as well as a free fall of $0.3 \mathrm{~m}$ onto an unyielding target. Transport by rail implies compliance with the appropriate railway gauge.

Desk and route surveys of transport hazards were carried out for typical rail routes in FRG, France and the UK, augmented by accident data from railway operations in these countries. This data is useful in giving information on the spectrum of accidents to be considered when enhanced performance requirements are assessed.

Disposal

The repository can impose constraints on package design covering aspects such as shape, size, weight and permissible surface radiation dose level. Designs of disposal sites for ILW are in their early stages of development and, except for pre-existing constraints, such as for the Konrad mine in the FRG, it must be anticipated that packages up to 65 t gross weight can be handled.

In general, the influence of disposal on design, ie the radionuclide inventory, site restrictions, behaviour of cement/concrete and ferrous metal performance have a relatively minor influence on design. Nevertheless gas will be produced from the degradation of waste and packaging materials. Hydrogen generation from corrosion of a waste package could be double that from radiolysis. If a disposal package were to be clad with carbon steel the pressure build up is likely to be unacceptable unless there is a vent. Unclad concrete packages will be sufficiently permeable to allow gas release. Gases generated from the waste package will be less important than those from corrosion of the reinforcement in the repository. 


\section{PACKAGE SPECIFICATION}

The inputs summarised in section 2 were used to develop a specification which included both 'mandatory' requirements and design targets, the latter being designed to explore safety margins or 'cliff-edge' effects.

The only truly 'mandatory' requirements are those involving compliance with the law and physical realities. Nevertheless other requirements are likely to be imposed. For the purposes of this paper all such requirements have been put together and cover:

a) packages are designed for low specific activity waste;

b) compliance with IAEA Safety Series 6 and regulations which limit the radiation dose to operators and the public;

c) maximum weight of any individual item of waste;

d) maximum gross weight of a package;

e) external shape to comply with the appropriate Railway Loading Gauge;

f) venting of the package; and

g) maximum storage period prior to disposal.

The design targets or requirements, include:

a) keeping the radiation doses as low as reasonably achievable;

b) minimisation of radionuclide release for the first hundred years after disposal:

c) lifting from the base;

d) the package to remain intact under loads encountered during manufacture and handling both before and after filling;

e) packages should be capable of being stacked up to six packages high under a horizontal acceleration of $0.3 \mathrm{~g}$ and analysed for the effects of a fall off the top of the highest stack;

f) the package shall be analysed for loss or dispersal of contents and any impairment of shielding efficiency caused by a 5 m free fall drop at any attitude onto a tarmac road surface; g) the appearance of those parts of the package which can be viewed by the public should be smart, with no external cracks or other defects, clean and robust. The package surface should also be easy to decontaminate; and

h) additional analyses shall be carried out to determine the performance of the package in the $9 \mathrm{~m}$ free fall drop test and the half hour fire test specified in the IAEA Transport Regulations for Type B packages even though the packages are not designed to Type B standards.

\section{SELECTION OF PACKAGE CONCEPTS}

There are two general design concepts for decommissioning waste packages:

a) the self shielded package, disposed of in its entirety termed concept SS; and

b) the package with returnable shielding - termed concept RS.

A number of concepts was examined all of which complied with the mandatory requirements of the specification but which met the additional design targets to a varying extent. The main features of the five cuboidal designs which were developed are summarised in Table $I$. In all cases the width and height are derived from railway gauge limits and the 
payload (assuned to be steel waste) is about $30 \mathrm{t}$. The length is the free dimension which is dictated by a target limit for the gross weight of the package of $65 \mathrm{t}$. A decommissioning inventory, deliberately simplified to be $600,000 \mathrm{t}$ of steel waste and a packing efficiency of about $25 \%$ (by volume) was assumed. Any change in packing factor or type of waste would simply lead to a change in length of the proposed design.

The comparative costs of the five designs are given in Table II as a function of disposal cost. These costs result from perturbation calculations and are only those costs which contribute to the total decommissioning cost but which vary between concepts, ie package manufacture, transport, disposal and total number of packages. At the lower end of the range of disposal costs, manufacturing costs are dominant such that the best package will be the self shielded concrete package (SS 100/000). At the higher end of the disposal cost range, the best package is the one most efficient in volume terms, ie the self shielded metal package (SS 000/030). Lack of sensitivity to variation in disposal cost is an important factor in selection of the minimum design when disposal costs for ILW are not yet confirmed. In Fig 1 sensitivity is indicated by the gradients of the curves for each concept; less steeply sloped curves are less sensitive to disposal cost. It can be seen that, as the disposal cost increases, the steel clad self shielded concepts suffer. The effect is more marked with increasing proportion of steel in the package. The concept with an overall shallow gradient is the RS 075/008 returnable shield design as illustrated in Fig 1. It has the advantages of providing greater protection against impact and fire accidents and an easily decontaminated exterior. The returnable shield is easily maintained and standard lifting features are used. Crucial additional advantages are that the design flexible to changes in requirements and the shield thickness need not be defined until the time of transport. UK Nirex specifications call for packages to be capable of being stored for up to fifty years.

The inner box of the returnable shielded design has only to function as a container for the waste. It can be made therefore as thin as possible, and consistent with this requirement. The use of sprayed concrete to make the thin wall inner disposable container is novel and because it is an important element in the economics this idea should be pursued. It is also potentially useful for low level waste disposal boxes.

\section{DESCRIPTION OF THE RS 075/008 DESIGN}

Internal Concrete Package

The internal concrete package is shown in Fig 2 with details given in Fig 3 . Features to be noted include the steel angle section running through the top of the wall which is related to the manufacture of the package and the larger steel angle around the base of the box, the running strip, which facilitates handling. The package is designed to be lifted from the base and to withstand stacking and handling loads, and the pressure load due to grouting for which a support frame is required. 
Details of the manufacture of the internal concrete package have been developed. Although sprayed fibrereinforced concrete has been chosen to permit thin walls to be fabricated, such a process is not suitable for base construction. It should be simple to achieve excellent quality by pouring the base slab conventionally.

The waste is remotely placed in the package, either directly, or in baskets or racks, with attendant monitoring as required. The self levelling grout is poured to $25 \mathrm{~mm}$ below the top of the wall, avoiding any spillages or contamination. The lid cage is then positioned and the flat plate around it is placed on the angle at the top of the wall and joined by a continuous remotely controlled weld. This ensures good reinforcement continuity through the wall/lid joint. Finally, the lid concrete is poured against the support frame/shutter, with a superplasticizer to help self levelling. After initial setting the support frame is removed.

Returnable outer Shield

The returnable shield together with various sectional details is shown in Figs 4 and 5 . Probably the most notable feature is that the shield is front rather than top loading. The shield which has been designed to BS 449, incorporates a number of fittings for lifting, ie ISO corner fittings and grappler lifting pockets.

A number of load cases, adapted from the Iso certification scheme for freight containers, was analysed using the PAFEC finite element computer code. By this means, sizes were determined for the stiffening members, which comprise various channel and rectangular hollow sections, in particular, the portal frame around the open end and the rectangular hollow section around the base. The six high stacking load mentioned earlier is the most demanding load case. To resist the load the shield would in fact require additional diagonal stiffeners in the first side wall panels, which are not shown in the present design. The load case originates in the IAEA Transport Regulations as a requirement for all Type 2 Industrial Packages. However, it is felt that the packages envisaged by the Regulations were not of this size, and that such a requirement for large decommissioning packages is unreasonable.

The shield is a relatively straightforward welded fabrication similar to existing Iso freight containers of $8 \mathrm{~mm}$ steel plate and structural steel sections, together with a number of cast fittings such as Iso corner fittings. The doors of the package open on hinges and closure is effected by a lever operated push rod and dowel mechanism which will be lockable.

\section{DESIGNING FOR ENHANCED PERFORMANCE}

All five of the design concepts listed in Table I achieve the minimum requirements of the Package specification outlined in section 3. Consideration has been given to the robustness of these designs in relation to the achievement of additional, extra regulatory, standards including potential handing accidents, transport accidents and the 9 m IAEA drop test. Although there is no mandatory requirement for a package of 
this type to resist fire, the IAEA fire test (for Type B packages) is specified as a benchmark for the purpose of making comparisons.

Fig 6 shows the relative cost of achieving improved impact performance for SS and RS concepts for a constant disposal cost of $5600 / \mathrm{m}^{3}$. It can be seen that the RS concept is the cheapest way of achieving enhanced impact resistance, further underlining its usefulness.

\section{CONCLUSIONS}

A design methodology has been presented which takes account of the various constraints on design over the complete life cycle of an ILW decommissioning waste package, including the waste inventory, container manufacture, handling, storage, transport and disposal. Large self shielded and returnable shielded concepts were developed. A novel approach for the returnable shielded design is the manufacture of the inner, disposable, container of thin walled sprayed fibre-reinforced concrete and this could be extended to containers for the disposal of low level waste. The advantage of the large returnable shielded design, containing a separate internal disposable package and a gross weight of $65 t$, is that it provides a robust solution as well as minimising the volume of waste placed in the repository. Such a solution is relatively insensitive to changes in disposal costs and much more resistant to changes in regulations which might involve enhancements in performance under accident conditions than a self shielded reinforced concrete package.

\section{ACKNOWLEDGEMENTS}

I would like to acknowledge the important contributions to this work which were made by $\mathrm{Mr} R$ Beddows and $\mathrm{Dr} J$ Wakefield (WL), $\mathrm{Dr} J \mathrm{C}$ Miles, $\mathrm{Mr} \mathrm{T} P$ Dutton, $\mathrm{Mr} \mathrm{T}$ Molyneaux and $\mathrm{Mr} C \mathrm{~J}$ Milloy (OAP), Mr A Emmerton, $\mathrm{Mr} T \mathrm{~T}$ Holland and $\mathrm{Dr}$ $D$ J Lee (WTC) and $M r D$ Poulter (SRD); and to express $m y$ appreciation to $M r K$ Pflugrad for $h$ is support as the CEC Project officer for this study.

\section{REFERENCES}

(1) M S T Price and I Lafontaine (Editors); System of Large Transport containers for Waste from Dismantling and Light Water and Gas Cooled Nuclear Reactors; EUR-10232 (2 volumes); Commission of the European Communities, Luxembourg; 1985; pp 141 (Vol 1) and pp 136 (Vol 2).

(2) M Sappok and $\mathrm{K}$ Pflugrad, Development of a Large container Cast of Low Level Radioactive Steel; Paper presented at PATRAM '89 Washington DC, 11-16 June 1989; see also this conference. (3) $M S T$ Price (Editor); Large Transport Packages for Decommissioning Waste; Semi-Annual Report for Period 1 July 31 December 1987; AEEW-M2507, Issue 2 (1988).

(4) M S T Price (Editor); ibid; Semi-Annual report for Period 1 January - 30 June 1888; AEEW-M2527 (1988). 
Table I: Details of design concepts

\begin{tabular}{|c|c|c|c|}
\hline $\begin{array}{l}\text { DESIGN } \\
\text { CONCEPT } \\
(\text { see } \star \star)\end{array}$ & $\begin{array}{l}\text { OVERALL } \\
\text { DIMENSIONS } \\
\text { (mm) }\end{array}$ & $\begin{array}{l}\text { VOLUME FOR } \\
\text { DISPOSAL } \\
\left(\mathrm{m}^{3}\right)\end{array}$ & COMMENTS \\
\hline SS $100 / 000$ & $2400 \times 1850 \times 4550$ & 20.2 & $\begin{array}{l}\text { Base thickness } 150 \mathrm{~mm} \\
\text { to sustain lifting from } \\
\text { base. }\end{array}$ \\
\hline ss075/008 & $2400 \times 1850 \times 4300$ & 19.1 & $\begin{array}{l}\text { Cladding used as } \\
\text { shutter for moulding } \\
\text { concrete. Lifted from } \\
\text { base. }\end{array}$ \\
\hline ss055/015 & $2400 \times 1850 \times 4100$ & 18.2 & $\begin{array}{l}\text { Variant on ss075/008 to } \\
\text { examine effect of } \\
\text { increased packing effi- } \\
\text { ciency by using } 15 \mathrm{~mm} \\
\text { metal cladding thereby } \\
\text { reducing thickness of } \\
\text { concrete. }\end{array}$ \\
\hline ss000/030 & $2400 \times 1850 \times 3800$ & 16.9 & $\begin{array}{l}\text { No external handling } \\
\text { features. Lifted from } \\
\text { base. }\end{array}$ \\
\hline RS 075/008 & $2400 \times 1850 \times 5100$ & 18.6 & $\begin{array}{l}\text { Outer shielded contain- } \\
\text { er fitted with handling } \\
\text { features. } \\
\text { disposable waste pack- } \\
\text { age dimensions } 2260 \times \\
1600 \times 4960 \text { mm has no } \\
\text { external lifting fea- } \\
\text { tures and walls are } \\
\text { made from fibre- } \\
\text { reinforced sprayed } \\
\text { concrete } 75 \mathrm{~mm} \text { thick. }\end{array}$ \\
\hline
\end{tabular}

The first three numbers indicate concrete thickness in $\mathrm{mm}$ and the second three the ferrous metal thickness in $\mathrm{mm}$.

Table II: Perturbation calculations for comparative costs of package design concepts as a function of disposal cost (EM)

\begin{tabular}{|l|l|l|l|l|}
\hline \multirow{2}{*}{ DESIGN CONCEPT } & \multicolumn{4}{|l|}{ DISPOSAL COST } \\
\cline { 2 - 5 } & $£ 600 / \mathrm{m}^{3}$ & $£ 1400 / \mathrm{m}^{3}$ & $£ 2500 / \mathrm{m}^{3}$ & $£ 7000 / \mathrm{m}^{3}$ \\
\hline $\mathrm{SS} 100 / 000$ & 281.1 & 603.7 & 1047 & 2862 \\
$\mathrm{SS} 075 / 008$ & 312.2 & 612.5 & 1025 & 2714 \\
$\mathrm{SS055/015}$ & 361.4 & 652.2 & 1052 & 2688 \\
$\mathrm{SS000/030}$ & 482.9 & 749.6 & 1116 & 2617 \\
$\mathrm{RS} 075 / 008$ & 287.5 & 600.0 & 1030 & 2788 \\
\hline
\end{tabular}




\section{4}

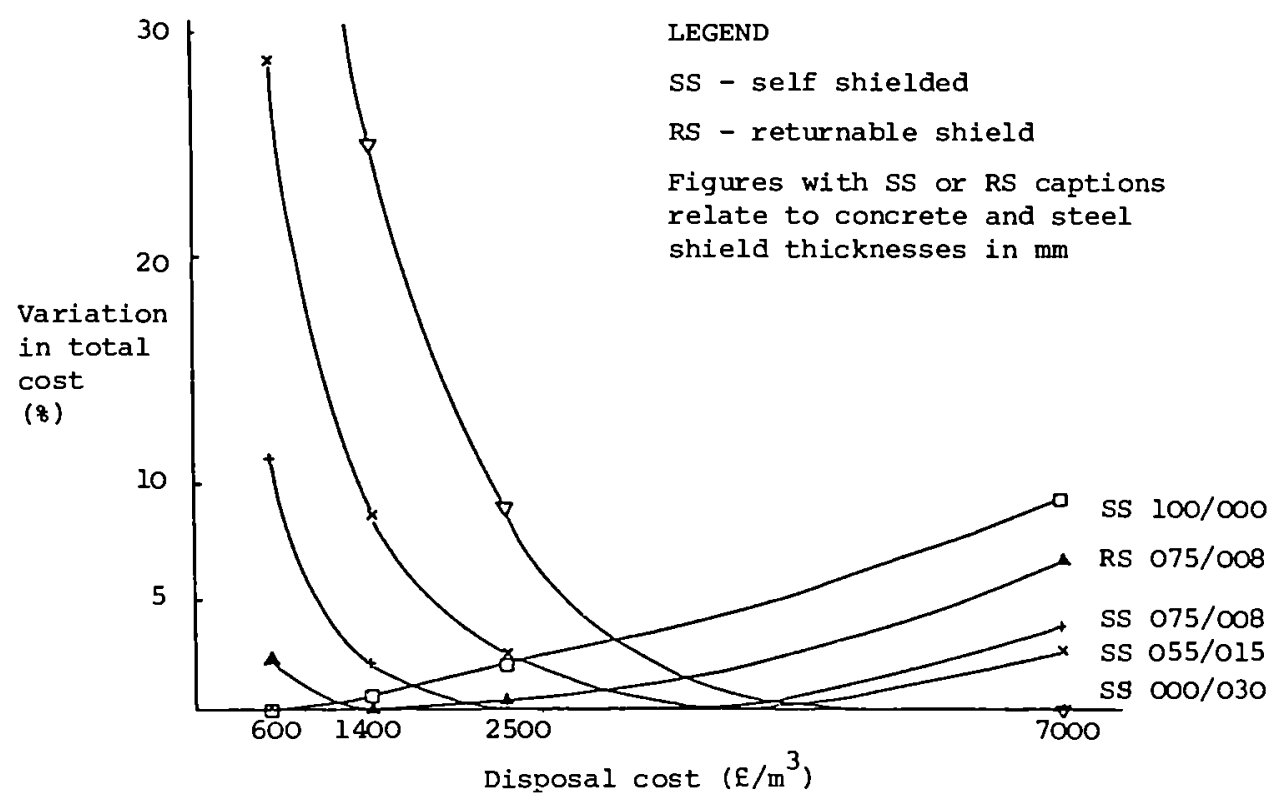

Fig. 1. Relative cost as a function of disposal cost

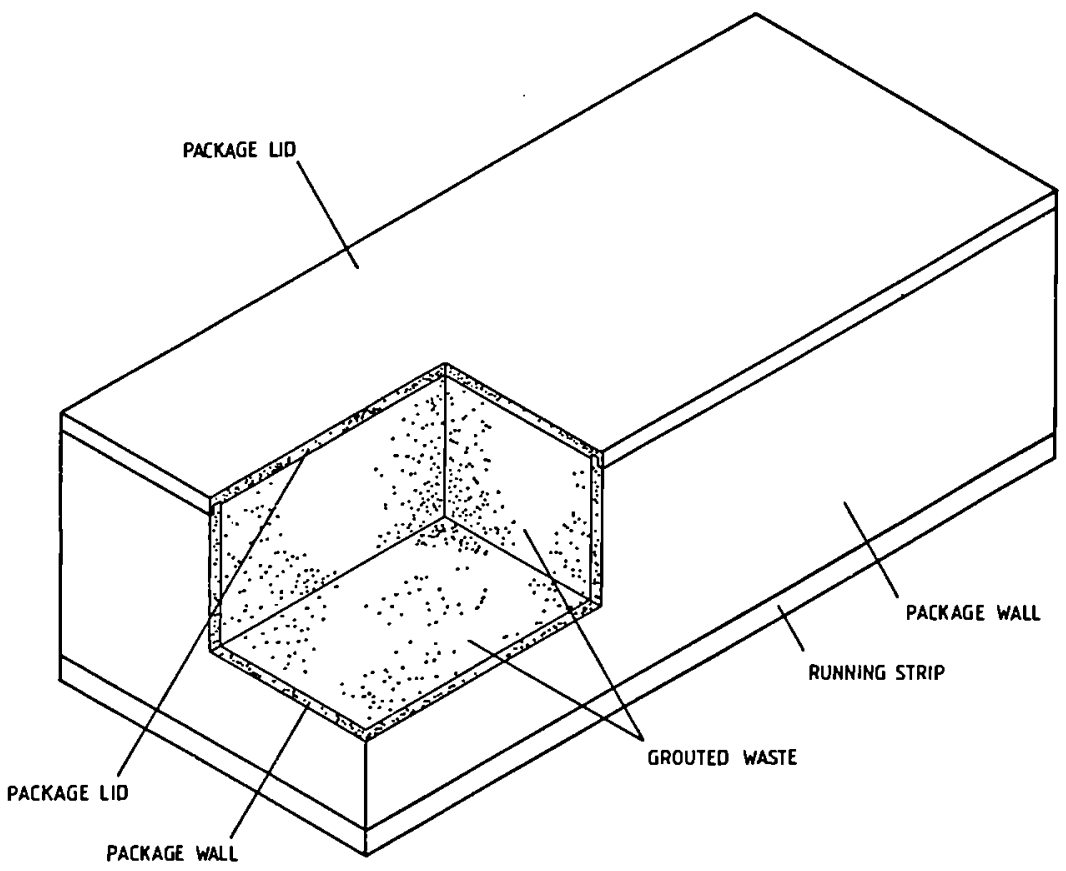

Fig. 2. Inner concrete package 

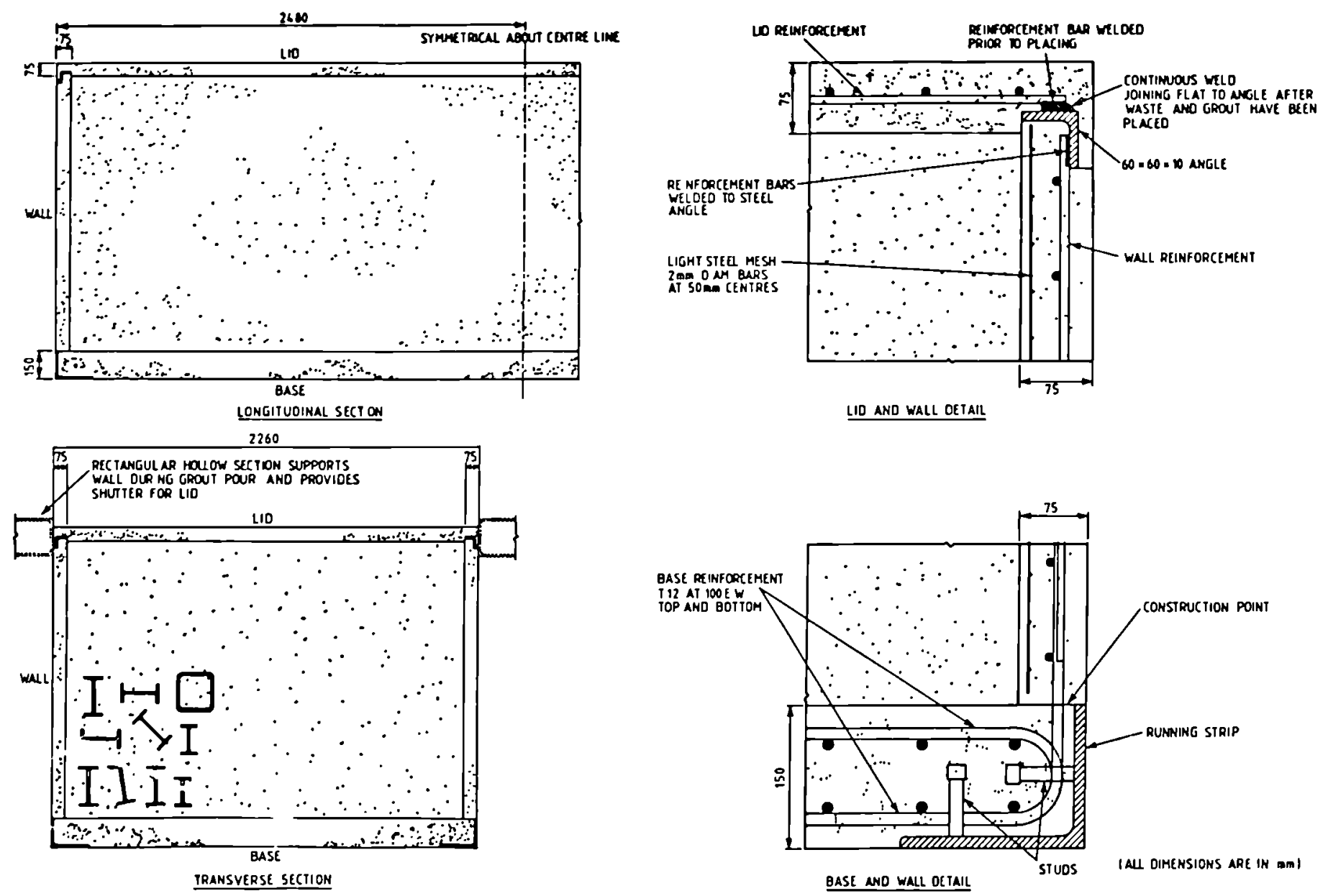

Fig. 3. Arrangement of inner concrete package 


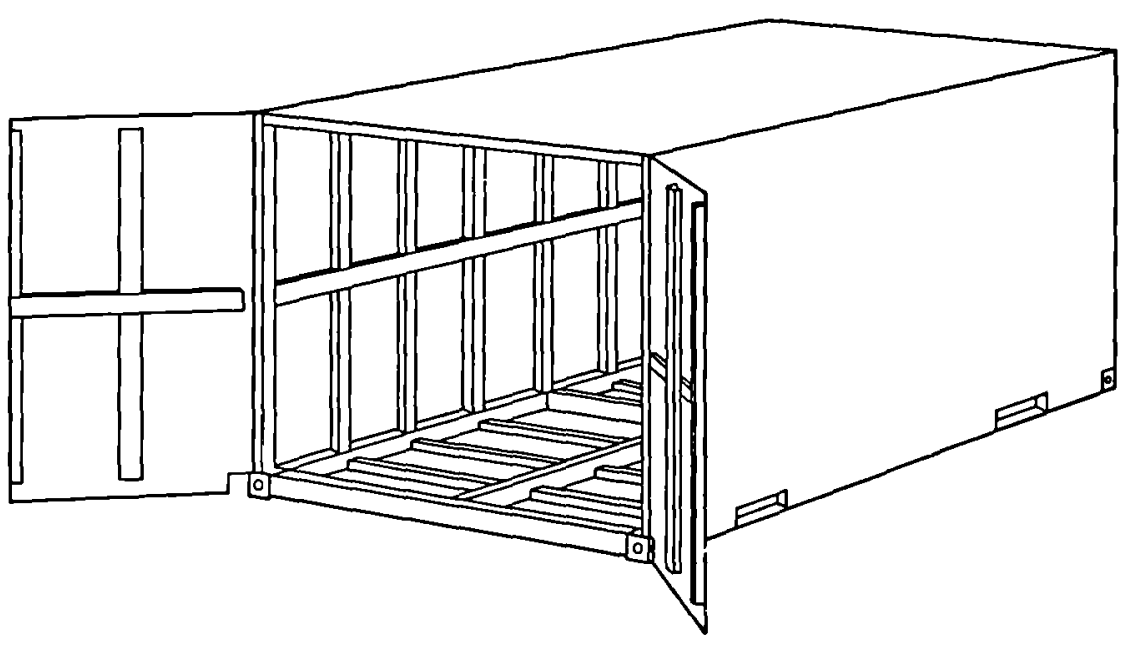

Fig. 4. Returnable shielded outer container (shown with end doors open)

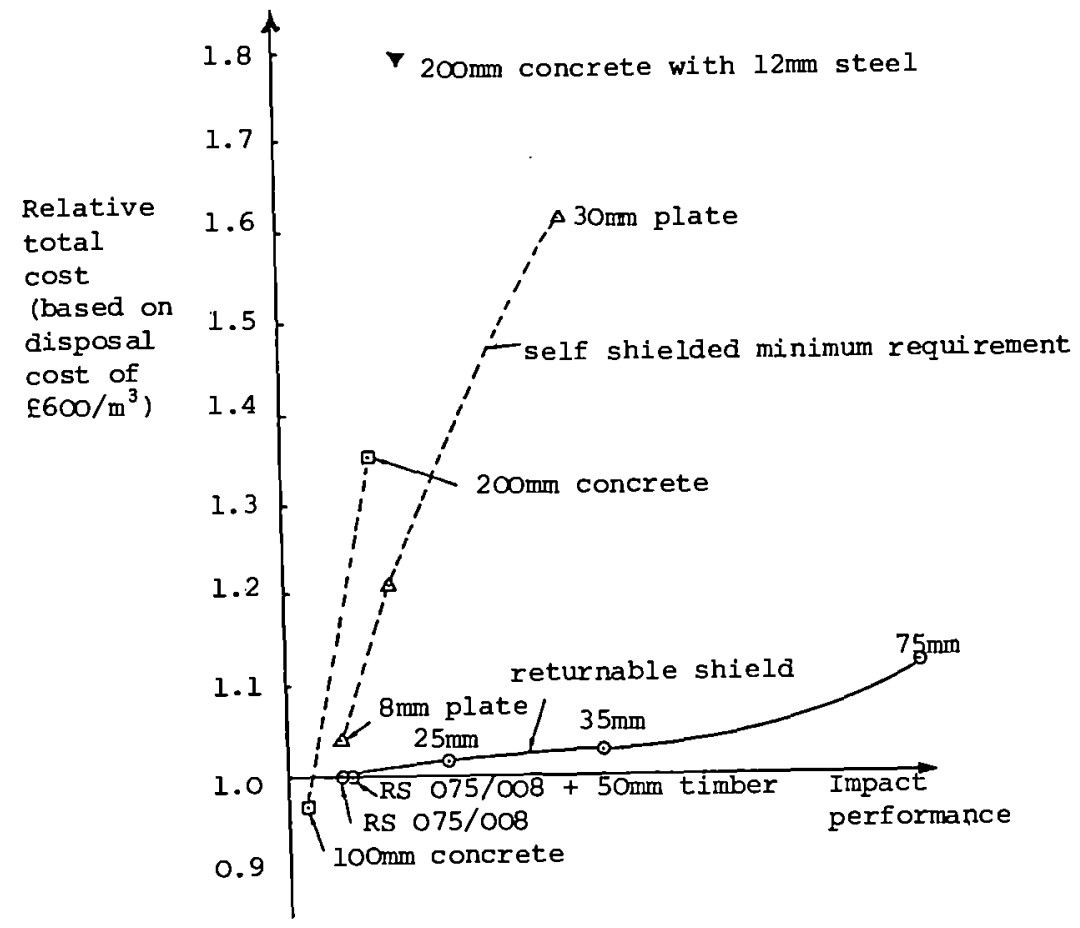

Fig. 6. Relative cost of enhanced impact performance (based on disposal cost $\mathrm{f} 600 / \mathrm{m}^{3}$ ) 

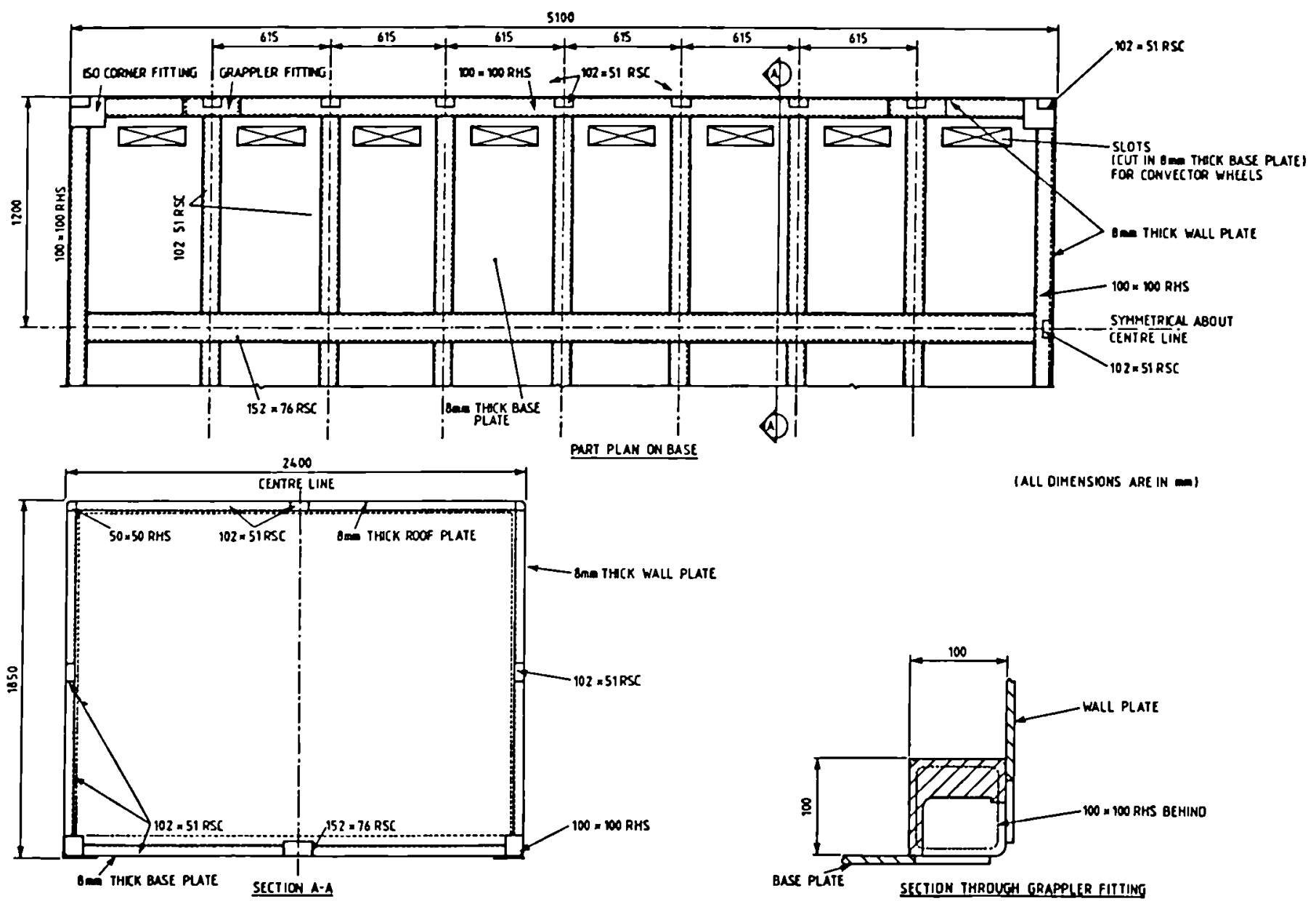

(ALL DIMENSIONS ARE IN m)

Fig. 5. Arrangement of returnable shielded outer container 


\section{DISCUSSION}

Question: O MEEUWIS, Westinghouse - Will economic aspects favour a square or round container for final disposal?

Answer: M SAPPOK, Siempelkamp - Based on our experience the specific cost of a square container is lower than that of a round one. Specific cost means: price per container or cask, divided by the usable volume. So we think that the future will favour the square containers.

Question: MS T PRICE, UKAEA-Winfrith - Can you comment on whether the recycling of low-level radioactive steel is ALARA relative to alternative processes?

Answer: M SAPPOK, Siempelkamp - As we know from various studies the exposure of personnel is much lower during melting than during electropolishing. So this is a step in the right direction. Handling the container, filled with waste, brings an amount of 18 to 38 of dose rate in addition to the usual rates. We think that we are ALARA.

Question: M SAPPOK, Siempelkamp - Do you see any problems due to hydrogen gas production in a container with cement fixation, when they are packed with metal and, in particular, aluminium scrap?

Answer: M S T PRICE, UKAEA-Winfrith - There are many potential processes for gas generation in a repository, and repository designers have to prevent large pressure build-up whilst at the same time not providing short-circuit paths for the release of important radionuclides to the environment. A metal container for waste containing cement will need a gas release system, such as a porous filter. Aluminium reacts with cement and the amount of aluminium has to be controlled. We have carried out experimental work at Winfrith (not under the EC programme) to define the maximum amount of aluminium which can be permitted in a 500-litre drum. This work also studied the effects of surface treatment and of compacting the aluminium. It is my personal view that the aluminium cans, which are very commonly used in laboratories, should be banned from the nuclear industry. This would assist in quality assurance of the materials going into a general solid waste package.

Question: K TUNABOYLU, Colenco - In your paper you give two activity limits for your large steel container (KONRAD type VI): (a) for type A packages according to the IAEA transport regulations (eg for Co-60: $0.4 \mathrm{E} 12 \mathrm{~Bq}=$ $10 \mathrm{Ci})$, (b) activity limit for the final repository KONRAD (for Co-60: $1.1 \mathrm{E}$ $13 \mathrm{~Bq}=297 \mathrm{Ci}$ ). Between these two possible activity inventories, there is a difference of about a factor of 30 .

- Which of the above-mentioned activity limits will finally apply to your KONRAD type VI steel container for decommissioning waste from nuclear power plants?

Is the application of the IAEA limit $(10 \mathrm{Ci} /$ container for type A packages) not restrictive for your container although KONRAD specifications allow a 30 times higher activity inventory? This also has consequences for costs.

Is the classification of your large steel container for nuclear power plant decommissioning waste as an IAEA type A container really correct? According to IAEA transport regulations $(\$ 520$ and $\$ 525$ to 538) the type A container for solid or solidified waste is defined as Industrial Package IP-3. As an IP-3 package, your steel container 
could have a higher activity inventory according to IAEA (\$131 c and $\S 422$ for LSA-III).

Answer: $M$ SAPPOK and $H$ DEIPENAU, Siempelkamp -

\begin{abstract}
- The cast iron container KONRAD type VI has to fulfil both requirements; hence the more restrictive IAEA regulations are applicable. The boundary conditions for the maximum activity content given by the IAEA regulations differ from the KONRAD preliminary conditions.

The requirements for an IAEA type $A$ container and an industrial package IP- 3 are the same. The licensing procedure for an IAEA type A package includes the procedures for an industrial package IP-3.

Taking into account $\$ 422$ of the IAEA regulations, the calculated dose rate resulting from solid waste without shielding showed that the admissible activity content $(\mathrm{CO}-60)$ of an industrial package IP- 3 is about the same as that of an IAEA package type A (see also IAEA safety series No. 7 and No.37).
\end{abstract}

Question: J P WENGER, NOK-Beznau - what are the main differences between the container presented and the 'coque' containers used in La hague? Will the 'coque' containers be replaced in the future?

Answer: C JAOUEN, SGN - It is mainly the use of metal fibres, instead of asbestos, and the moulding process instead of standard pipe manufacturing. Problems remain with sealing of the bottom and lid.

The 'coque' containers will probably be replaced (for the low-level waste) with a similar type of container.

Question: K PFLUGRAD, CEC - You showed packages with dimensions of $\rho=1 \mathrm{~m}$, $\mathrm{H}=1.5 \mathrm{~m}$. Can you make larger packages and if yes, up to what dimensions can you go?

Answer: C JAOUEN, SGN - We are now producing three container types: $\phi=0.84 \mathrm{~m}, \mathrm{H}=1.2 \mathrm{~m} ; \varnothing=1.0 \mathrm{~m}, \mathrm{H}=1.5 \mathrm{~m} ; 1.7 \mathrm{~m} \times 1.7 \mathrm{~m} \times 1.7 \mathrm{~m}$.

Larger sizes are certainly feasible, but there is no industrial experience so far. The only difficulty with this type of material is long vertical walls requiring additional reinforcement.

\title{
CONCLUSIONS
}

In this session, which was devoted to Project No.5 of the 1984-88 programme on decommissioning, having as a subject the study and development of large containers for radioactive wastes produced in the dismantling of nuclear installations, three papers were presented.

The first paper from siempelkamp, showed a large container suitable for transport and disposal of low-active solid wastes. The novelty of this contalner is the use of low-active steel coming from the dismantling of nuclear installations, to cast a prototype square container type A according to the IAEA transport regulations and final disposal requirements in the KONRAD repository.

The second paper from SGN, related to the development of concrete containers reinforced with organic or metal fibres. This concept meets the IAEA transport regulations as well as the French regulations for shallow land disposal.

The third paper, from UKAEA-Winfrith, related to a study of factors affecting container design, showing that concrete might be the preferable 
construction material. Both self-shielded and returnable-shielded concepts were investigated.

The transport and disposal of radioactive wastes are very important aspects to be considered in the decommissioning of nuclear installations. The different solutions given for large transport and/or disposal containers allow each country to use the most suitable one as a function of its needs and disposal facilities.

A URIARTE HUEDA, CIEMAT

General comment: K PFLUGRAD, CEC - Research on large containers will not be continued in the new EC programme (1989-93) on the decommissioning of nuclear installations, as it was considered that industry could do the further development work required in this area without needing support from the EC.

It seems to me that some more interesting work could be done on large container development, in particular with a view to possible transnational transport of low-level solid waste (eg steel, copper, aluminium) in the context of the 1992 internal market.

I would invite interested persons to contact me during the next year in order to make arrangements for an informal meeting on this item. 


\section{SESSION IX}

STEEL WASTE MELTING WITH A VIEW TO RECYCLING OR CONDITIONING

CHAIRMAN: A BERTINI, ENEL, I

SECRETARY: K PFLUGRAD, CEC 


\section{.}


MRLIIMG OP CONTAYIRATED STBEL SCRAP FROM DECOMEISSIOHTHG

\author{
HARVEY, D.S. \\ British Steel Technical \\ Swinden Laboratoriea \\ Moorgate \\ Rotherham S60 3AR \\ England
}

ABSTRACT

Practical work on the melting of materials wa completed early in 1988 and no further work is planned. The object was to establish the use of melting processes as means of aiding disposal of slightly radioactive steel from nuclear power atations. The behaviour of cobalt, caesium, and europium was studied under a range of steelmaking conditions. It was concluded that the use of steel scrap containing low levels of radioactivity would not be viable and the work will not be continued by British Steel.

\title{
1. INTRODUCTION
}

The decomissioning of nuclear power plants will release large tonnages of steel categorised as low level radioactive wate. One means of handling the steel is to melt it and form it in to products for easier disposal. The melting process reduces the volume of the scrap substantially and binds the radioactivity. The route for disposal of the ateel from melting would depend on its level of radioactivity. It might be committed to long term storage or fabricated into atorage containerg for other wates.

The feasibility of the melting of steel wastes was establighed by British Steel and others in the first phase of the CEC programme on decomissioning(1.2). Studies by British steel have been completed in the second phase of the programme, the main emphasis being on detailed studies of the relevant radiolsotopes in steelmaking. The three chemical elements which have been studied in detail are cobalt, caesium and europium, which usually migrate to the steel, the waste gases and the slag, respectively. Their behaviour might, however, be modifled by the steelmaking conditions.

The steelmaking processes which have been used are the induction furnace, the arc furnace, and the basic oxygen furnace. The last two are the main methods of steel manufacture on an industrial scale. In the arc furnace steel scrap is melted by electrical power supplied via 3 graphite electrodes. (See Pig la). The roof of the furnace is moved aside to allow scrap to be added. The furnace can be tilted to allow slag and ateel to be poured out. Typical industrial furnaces have capacities in the range 50 to 150 tonnes and power inputs in the region of $0.5 \mathrm{MVA}$ per tonne. British Steel has a pilot plant arc furnace of 3 tonnes capacity, and this was used for the experimental work.

The main phase of the basic oxygen steelmaking process is shown in Fis 1b. The vessel is charged with molten iron ( $\sim 4 Z$ carbon, $80 z$ of the total charge), ocrap steel and alag making materials. Oxygen is blown into the vessel via a lance over period of 30 to 40 minutes. Carbon and silicon are oxidised, together with small amounts of some other elements and heat is evolved. Once the process has been completed the ressel 18 tilted so that the steel pours into a ladle.

The BOS process is the main means of producing steel in the induetrialised nations. If contaminated steel were to be disposed of by dilution the BOS process could absorb the greatest annual tonnage. Since the melt size can be 300 tonnes the amount of scrap used can be larger than 
in the arc furnace or induction furnace and so the cost per tonne of monitoring and processing the material would be 1 ess.

The work allows the processes to be assessed with respect to safety, minimisation of radiation exposure and creation of secondary wates.

\section{COBALT}

Cobalt 60 is the main source of radioactivity in steelwork from nuclear power plants in the early years after shutdown. Its behaviour at the trace levels found in steel from decommissioning was studied by several groups in the first CEC programe on decommlssioning(2). The findings of several groups, including British Steel, were that cobalt partitioned almost exclusively to the steel. This 18 consistent with general experience and the thermodynamic properties of cobalt in steelmaking. Andrleux et al and Schenker et al found however that, in induction furnaces 257 or more of the cobalt 60 was present in the 8 lag under some circumstances. One of the objects of the present work has been to resolve this anomaly. A second area of study has been the behaviour of cobalt 60 In basic oxygen steelmaking.

Cobalt 60 in Basic Oxygen Steelmaking (BOS)

The behaviour of cobalt 60 in BOS steelmaking was studied using the 3 tonne pllot plant unft at British Steel's Grangetown Laboratorles. Steel plates (250kg) containing cobalt $60(2.7 \mathrm{~Bq} / \mathrm{g}$ ) were included in the raw materials. The oxygen blowing process was performed in the normal manner. Samples. of steel $\mathrm{slag}$, and off gas dust were taken during and after the blow. Nelther the slag nor the dust contained cobalt 60 at above 0.02 $\mathrm{Bq} / \mathrm{g}$. The activity of the steel was $0.16 \mathrm{~Bq} / \mathrm{g}$ which was consistent with that expected from the amount of radloactivity added.

The absence of cobalt in the slag demonstrates that even under powerfully oxidising non-equilibrium conditions the formation of cobalt oxide 18 not favoured. Kinetic factors apparently do not outweigh thermodynamic factors. Hence the BOS process could be used to melt steel contaminated with cobalt 60 in the knowledge that the slag and fume would not become secondary wastes.

Cobalt 60 in Induction Furnace Slags

The indications f:om previous work were that cobalt 60 might be retalned in induction furnace slags if it were initially present as surface contamination and the melts were made under oxidising conditions(2). To test this hypothesis a 0.5 tonne induction furnace melt was prepared without the usual additions of deoxidant. Steel plates with a surface contamination of cobalt 60 were added to the melt and samples of slag were taken from it over the next 10 minutes. The $81 \mathrm{ag}$ samples were examined for radioactivity, passed over a magnet to remove particles of steel and then re-examined. The results are shown in Table 1. One sample of slag did inltially contain radioactivity but this declined markedly after treatment by the magnet showing that it had been present in metallic particles. The small quantity of particles extracted (< 17 of the sample) had a level of radioactivity much higher than that finally reached in the bulk 8 teel. Th1s could have happened only if the cobalt 60 had been transferred from the steel plate to the slag. There it would be converted to the metallic form and then transferred back to the steel. The findings tend to support the observations of Andrleux et al (2) and Schenker et al(2) that cobalt 60 can be present in the slag under certain circumstances. It also suggests that the presence of cobalt $60 \mathrm{in}$ the $8 \mathrm{lag} 1 \mathrm{~s}$ transient. The actual residence time in the slag is likely to be dependent on slag viscosity. For the viscous or semi-solid slag found in the induction furnace metallic globules might be retained until the end of the process. In the arc 
furnace and BOS vesgel slage are fluid so that residence times of metallic globules would be short and cobalt 60 would not normally be found in the glag.

These tudies show clear tendency for cobalt 60 to partition to the steel, usually with negligible amounts in the slag. It should be realised that in a practical industrial process another consideration 18 important. No large ecale ateelmaking process achleves precise separation of the slag from the steel. It is inevitable that the physical actions involved in pouring the steel from the furnace will result in some mixing of the steel and the alag. The teel produced from the process will contain traces of alag, and the $81 \times 8$ will contain traces of the steel. The presence of steel particles in slag is regarded as normal in industrial steelmaking and large eteelworks use magnetic extraction to remove the steel. It 18 1ikely that the problems of eeparating ateel from slag will set the practical limit on the amount of cobalt 60 which 18 contained in the 8 lag.

\section{CAESIUM}

Experimente in Induction furnaces and arc furnaces by British Steel and others have shown that caesium from steel gcrap is transferred to the 8198 and the off gases (2.2). None is retalned in the steel. The proportion retained in the $81 \mathrm{ag}$ is variable and depends primarily on whether the $81 \mathrm{gg}$ la basic or acidic.

Because the steelmaking chemistry of caesium was not well defined tt was decided to undertake further studies using the induction furnace and the arc furnace.

Caesium in the Induction Furnace

Two series of experiments were undertaken to investigate the effect of $381 \mathrm{ag}$ compositions $\left(\mathrm{CaO}^{3} \mathrm{SH}_{2}, 1: 4,1: 1.4: 1\right)$ and 3 melt temperatures $\left(1400^{\circ} \mathrm{C}, 1500^{\circ} \mathrm{C}, 1600^{\circ} \mathrm{C}\right)$ on the retention of caesium.

In the first serles the slag was added to the melt and then the caestum was introduced to the melt in the form of surface contamination on ateel plates. Samples of slag were taken over a perlod of time and were analyoed for caesium content.

The caesium contents rose to high values after the addition and then declined markedly. The amount of caesium inftially absorbed in the slag was very variable from melt to melt, which suggests that the efficlency of transfer of caesium from the steel plate to the slag was not congistent. The subsequent 108 of caesium from the 81 ag was also very variable and was not clearly dependent on elther melt temperature or slag composition. The results were difficult to interpret because the measured caesium contents contained oome anomalieg. These probably arose because the caesium content of the lag was not homogenous and samples obtained were not representative. The main finding was that for all slag compositions and temperatures the amount of caesium lost was at leagt $50 \mathrm{z}$ of that which had or1ginally been aborbed.

A second serles of experiments was performed to study more accurately retention of caesium by the slag. The caesium was mixed with the slag. which was then added to the melt so some of the uncertainties in the previous experiments were avolded. Some of the results are shown in Fig 2 . In all experiments there was some initial loss of caesium. After that there was little further $108 \mathrm{~s}$ from the acidic slag. The neutral slag gave erratic results which suggested that caesium was moving from hotter to cooler aress of the slag. The basic slag gave erratic results and also showed large $108 \mathrm{ses}$ of caesium.

Considering all the results from both sets of experiments it is concluded that in the induction furnace acidic slags do tend to retain 
caesium better than neutral or acidic slags. The effect of temperature on retention of caesium is not marked in the range $1400^{\circ} \mathrm{C}$ to $1600^{\circ} \mathrm{C}$. The results show that the behaviour of caesium in the induction furnace 18 not easily controlled, and complete retention of caesium in the slag could not be achieved.

Caesium in the Arc Furnace

Previous studies of the fate of caesium in the 3 tonne capacity arc furnace had shown that up to 967 of caesium was volatilised when a basic slag was used, and considerably less when a neutral slag was used (2). In the present study an acidic slag was used in combination with an acidic refractory lining. Steel plates contaminated with caesium 134 were added to the melt and samples of steel and slag were taken over the next 20 mins. The results are shown in Fig 3 together with those from previous work. 567 of the radioactivity had been retained in the slag, and this was evidently a much greater amount than had been retained in the more basic slags. It is of interest that some caesium was retained in the furnace and 37 of the original addition was present in the slag from the next melt.

The work in the induction furnace and arc furnace demonstrates that, under a range of steelmaking conditions, the caesium is divided between the slag and the off gases. It proved impossible to ensure that a high proportion would be retained in the slag, but it was possible to direct a high proportion to the off gas system.

\section{EUROPIUM}

Europium is not used in steelmaking, but the closely related elements lanthanum and cerium are used. They are very readily oxidised and because of this are normally encountered in the slag, or as non-metallic inclusions. Some previous work with europium suggests it too will be transferred to the slag during steelmaking.

Initial experiments were undertaken with Europium 152 and 154 in the induction furnace. Europium $152 / 154$ as oxide contained in a steel cube was added to a $500 \mathrm{~kg}$ melt and samples were taken from the slag, steel and off gases over the next 10 minutes. The europium was found to be contained wholly within the slag, none could be detected in the steel or the off gases (see Table 2).

A larger experiment was then performed by adding europium-contaminated steel plates to a melt in the 3 tonne arc furnace. It was again found that the europium was absorbed by the slag and was retained there under both oxidising and reducing conditions. None was detectable in the steel or in the off gases. See Table 3 .

\section{INTERACTIONS WITH STEELMAKING REFRACTORIES}

There are practical difficulties in studying the movement of radiolsotopes into refractories during steelmaking. Studies were therefore made on the movements within samples of refractory bricks by a method used in routine studies of refractories. Acidic and basic refractory bricks were prepared with central cavities, see Fig 4. The cavities were filled with a powdered refractory impregnated with cobalt 60 or caesium 134 or europium 152/154. The bricks were then heated at $1600^{\circ} \mathrm{C}$ for several hours, cooled and cut to expose the material in the cavity. Autoradiography of the samples revealed the extent of movement of radioisotopes into the bricks. It was found that none of the radioisotopes had penetrated the bricks to a measurable extent (>1mm). Caesium 134 had been largely volatilised (75\%) from the basic brick, and to a much lesser extent (6z) from the acidic brick. 
It 18 concluded that concentration of radioactivity in the refractorles will not normally be a problem during steelmaking. In general the surface layer of the refractories 18 gradually eroded and transported to the $8 \mathrm{lag}$ and 80 the radioactive layer 19 likely to remain thin. In the case of caesium it may be preferable to use basic refractories, thereby limiting the amount of radioactivity in the surface layer, and minimising the amount of secondary waste created when the refractory lining of the furnace 18 removed.

\section{RADIATION EXPOSURE AND HAZARD ASSESSMENT}

These studies were undertaken partly to assess the possible use in commercial steelmaking of steel scrap containing low levels of radioactivity. The work has shown that the effort involved in controlling and monitoring the process would outwelgh the value of the scrap. There 18 therefore no intention by British steel to use this scrap. It is of interest nonetheless to mention assessments of the radiation exposure of the workforce, during the process, and the users of the steel products. The conclusions by British Steel are that the exposure of the workforce would be very low both during routine steelmaking, and during any likely accident involving expulsion of radioactive material from the furnace. The process would be acceptable in terms of published criteris used to assess the detriments and benefits.

The exposure of the users of the steel has also been assessed by Britioh Steel and by otherg(s.as.cs. It appess that the product would be acceptable according to published criteria on detriments and benefits, but nonetheless British Steel does not intend to make such material.

\section{CONCLUSIONS}

The melting experiments have shown that cobalt 60 , the main radionuclide in material from decomissioning 18 rarely present in any phase but the steel. In large scale steelmaking, however, the slag may well contain cobalt 60 in globules of steel because steel and slag cannot be separated perfectly. As a result cobalt 60 may be an important contributor to the radioactivity of the slag.

Caesium radionuclides are usually the other main source of radioactivity in steel from decommissioning. The behaviour of caesium is dependent on steelmaking conditions; it can be partially absorbed by an acidic slag, but very little 18 absorbed by a basic slag. These characteristics are evident in the arc furnace, but in the induction furnace where the $8 \mathrm{lag} 18$ not fully melted the results are erratic.

Europium radionuclides are usually a minor component in scrap from decommissioning. The element is strongly absorbed by the slag under all normal steelmaking conditions. read11y.

None of the three elements studied penetrated steelmaking refractories

Considerations of costs and benefits suggest that some steelwork of low radioactivity could be incorporated in industrial steelmaking and its use would comply with published safety criterls. There 18, however, no intention by Britioh Steel to undertake such a programme.

\section{B. REFERENCES}

1. Gomer, C.R. and Lambley, J.T., CEC Report 'Smelting of Contaminated Steel Scrap Arising in the Dismanting of Nuclear Power Plants', British Steel Corporation, 1985. 
2. Melting and Recycling of Radioactive Metals from Decommissioning of Nuclear Installations', CEC Report, Proceedings of a Workshop, Karlsruhe, 27-28 May 1986.

3. CEC Radiation Protection Document 43, Published Nov. 1988.

4. Clark, M.J. et al, NRPB and Chapuis, A.M., CEA France, 'Methodology for Evaluating Radiological Consequences of the Management of Very Low Level Solid Waste'.

5. Carlson, G., Studsvik, Sweden, 'Release of Low contaminated Reactor Wastes for Unrestricted Use'.

6. O'Donnell, F.R. et al, Oakridge National Laboratory, USA, 'Potential Radiation Dose to Man from Recycle of Metals Reclaimed from a Decomissioned Nuclear Power Plant'.

The author wishes to thank Dr R. Baker, Director of Research, for permission to publish this paper and also colleagues who have assisted in its preparation. 
TABLB I

COBALT 60 ACTIVITY OP SLAGS

\begin{tabular}{|l|c|cc|}
\hline \multicolumn{1}{|c|}{ Sample } & Counts/min Above Reference & Activity Bq/8 Co60 \\
\hline Reference Slag & 0 & 0 & \pm 0.03 \\
Slag 1 & 7 & $0.06 \pm 0.03$ \\
Slag 2 & 68 & $0.46 \pm 0.03$ \\
Slag 3 & 8 & $0.07 \pm 0.03$ \\
Slag 1 without metal & 5.2 & $0.04 \pm 0.03$ \\
Slag 2 without metal & -2.7 & 0 & \pm 0.03 \\
Slag 3 without metal & 4.5 & $0.04 \pm 0.03$ \\
\hline
\end{tabular}

TABLE II

OSE OF BUROPIUA IN AN INDUCTION FURKACB

\begin{tabular}{|l|c|r|}
\hline Sample & $\begin{array}{c}\text { Count } / \text { /min } \\
\text { Above Reference }\end{array}$ & $\begin{array}{c}\text { Europium 152/154 } \\
\text { Bq/g }\end{array}$ \\
\hline Steel before addition & 0 & $0.00 \pm 0.04$ \\
Steel after addition & 0 & $0.00 \pm 0.04$ \\
Slag before addition & 0 & $0.00 \pm 0.04$ \\
Slag 1.5 min after addition & 135 & $0.74 \pm 0.04$ \\
Slag 2.10 min after addition & 100 & $0.55 \pm 0.04$ \\
Slag 8tandard & 2098 & $11.56 \pm 0.01$ \\
Dust from extraction duct & 0 & $0.00 \pm 0.04$ \\
Dust from gas cleaning filters & 0 & $0.00 \pm 0.04$ \\
\hline
\end{tabular}

* Non-radioactive steel slag and dust as appropriate

TABLE III

USB OP BUROPIUM IN THE ARC PURKACE

\begin{tabular}{|l|c|r|}
\hline & Counts/min Above Reference & Activity Bq/8 \\
\hline Metal Samples & 0.0 & $<0.02 \pm 0.02$ \\
Before europlum addition & 0.7 & $<0.02 \pm 0.02$ \\
After europium addition & 1.2 & $<0.02 \pm 0.02$ \\
After oxidation & -0.1 & $<0.02 \pm 0.02$ \\
Before tapping furnace & 6 & $0.03 \pm 0.02$ \\
Slas Samples & 18 & $0.08 \pm 0.02$ \\
Before europium addition & 18 & $0.07 \pm 0.02$ \\
After europlum addition & 16 & $0.08 \pm 0.02$ \\
After oxidation & 18 & $0.07 \pm 0.02$ \\
Before tapping furnace & 2111 & $11.00 \pm 0.08$ \\
Prom ladle & 9 & $0.05 \pm 0.02$ \\
Standard reference sample & 15 & $0.10 \pm 0.02$ \\
Dust & & \\
\hline Before europium addition & & \\
After europium addition & & \\
\hline
\end{tabular}




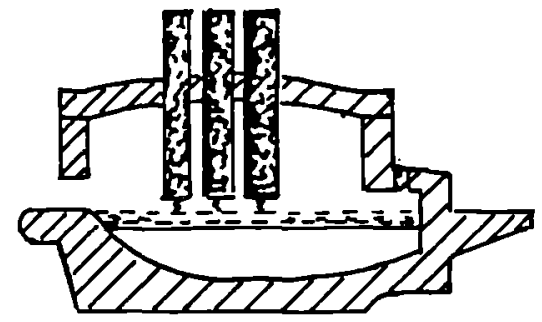

(a) Arc Furnace

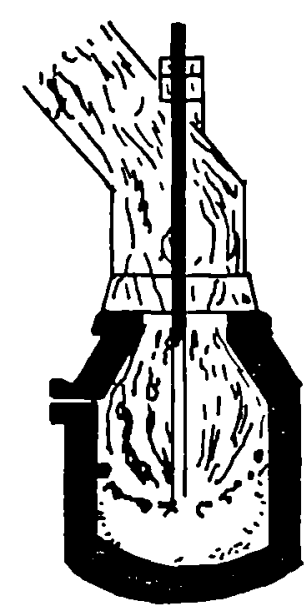

(b) BOS Vessel

Fig 1 STEEIHAKING METHODS

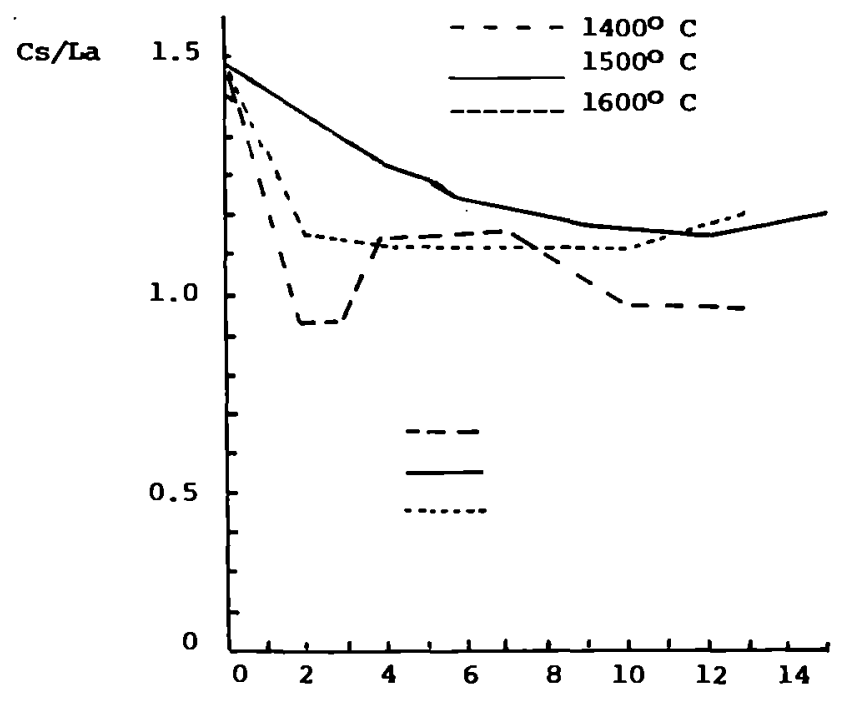

Fig 2 LOSS OF CAESIUM FROM ACIDIC SIAG 


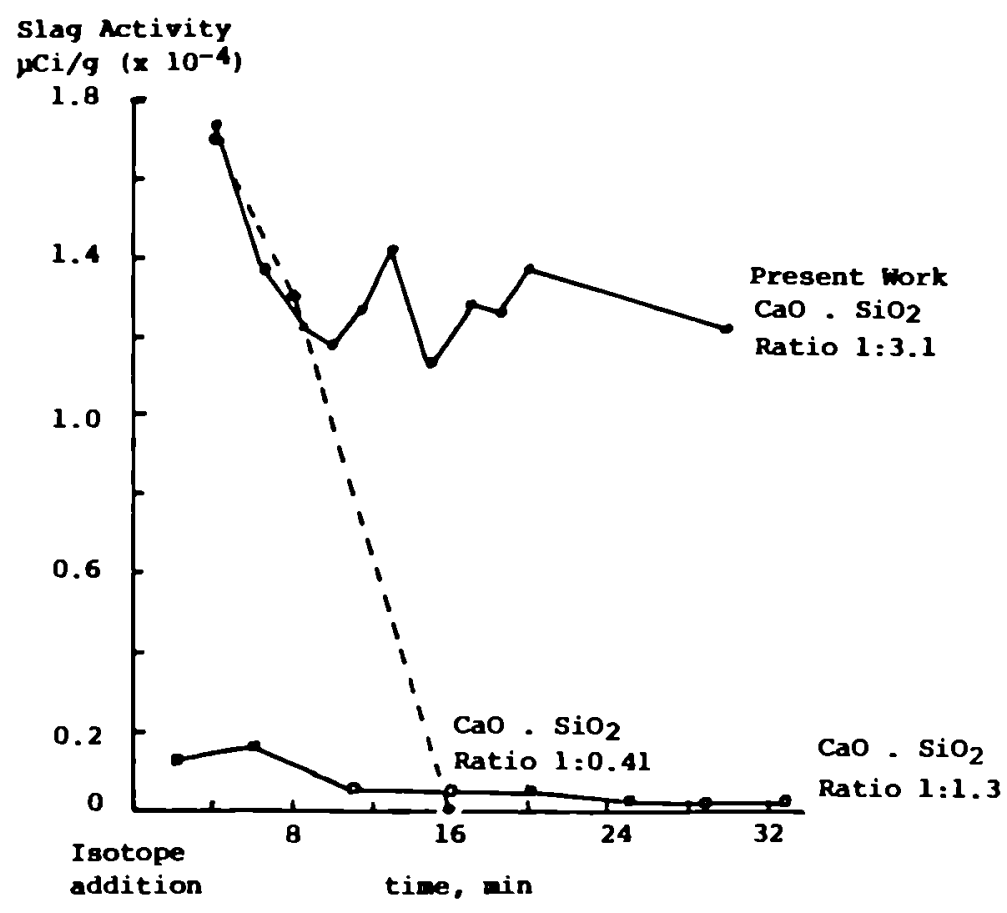

Fig 3 RETENTION OF CABSIUU 134 IN SLAGS

(a) Prepared for firing

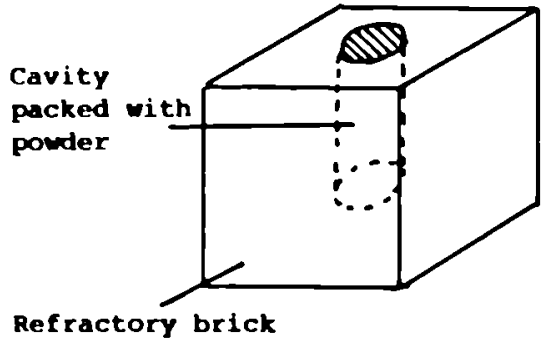

(b) Cut for exanination

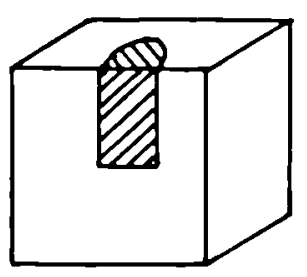

FIg 4 PREPARATION OF RRFACTORY BRICKS 


\title{
MELTING OF RADIOACTIVE METAL SCRAP FROM NUCLEAR INSTALLATIONS
}

\author{
SAPPOK M., Managing Director Technical Division, \\ Siempelkamp Giesserei GmbH \& Co., D-4150 Krefeld, FRG, \\ LUKACS G., Officer Abt. Reaktoranlagen \\ NIS Ingenieurgesellschaft mbH, D-6450 Hanau, FRG, \\ ETTEMEYER A., Senior Engineer, STANG W. Project Manager, \\ KGB Kernkraftwerke Gundremmingen Betriebsgesellschaft mbH, \\ D-8871 Gundremmingen, FRG
}

\begin{abstract}
Within the time of 1984 to 1989 in Germany the process of melting radioactive scrap was established. Up to now more than 2000 tons of low level contaminated scrap ( $\leqslant 74 \mathrm{~Bq} / \mathrm{g}$ ) have been melted and recycled.

Looking to the scrap which was shipped to the plant, about $95 \%$ of the activity was Co 60 and $C s$ 137. In the average the ratio between $C o$ and $C s$ was 60 : 40. This is a ratio, which might be different in other plants, especially in plants which have no bigger damage on fuel elements, the Cs contents should be lower. Cs quantitatively was found in slag and filter dust, whereas cobalt remained in the melt.

A separate and modernised facility had to be errected taking into consideration the results from the previous tests. The maximum activity level to be handled will be $500 \mathrm{~Bq} / \mathrm{g}$. It is planned to test here the "onion-casting" as it was described by the KRB-A plant people. A first casting was done using non-contaminated material.
\end{abstract}

\section{HISTORICAL REVIEW AND PHISOLOPHY}

It was at the Luxembourg Conference, the 1984 Status report of the EC decommissioning project, that the first steps of melting contaminated scrap was reported. The two companies NIS and Siempelkamp - where NIS was experienced in dismantling technology and Siempelkamp in producing castings for nuclear applications - had the idea, that besides direct disposing and decontaminating, melting could be a third way of treating contaminated metal scrap from nuclear power plants.

In the first step, the idea was to come to a volume reduction for saving space in the final depositry. But very soon, in the second step, the philosophy was born to reuse the material by producing components, which were needed in the nuclear industry.

Knowing the public controversy about the use of nuclear power - which takes place more or less in all European countries - it was simple to demand, that all the material coming from the nuclear industry should become returned to these installations. Only by going this way, could discussions with the public about possible harm caused by the release of decontaminated material to free reuse be avoided.

After having made the first successful steps in this direction within the last EC decommissioning programme, the basic development work was made within this project, about which this paper reports. 
2. THE TWO STEPS TO THE TODAY'S STATE

It took about 8 years to come to the today's state. The first step was to develop a special device, with which it was possible to melt low-level contaminated scrap under special cleanliness conditions in a conventional melting shop of a foundry. Fig. 1 shows this facility - a special charging device above a 20 ton coreless induction furnace. The facility itself has been described in several papers before.

In this test facility appr. 2000 tons of low-level contaminated metal scrap were melted until now. Many useful results were won in this first project, which ran from 1985 till now. The major items of this work will be described later.

It was obvious, that a conventional used furnace could not be sulted under economical aspects to melt larger quantities of scrap year by year. Consequently, in the second project the development of a prototype plant was undertaken. This job begun in 1988 and $\mathrm{fig}$. 2 shows the new melting bay as it was two months ago. Today this facility is in operation and the first tons have been melted. All experience gained in the old test facility found entrance to the new plant and safety aspects have been considered consequently.

The plant was designed to melt higher activities up to $500 \mathrm{~Bq} / \mathrm{g}$ to get results about this activity level and especially to see the behaviour of the nuclides in activated steel.

\section{THE SAFETY PHILOSOPHY FOR THE MELTING PLANT}

Knowing the behaviour of radionuclides during melting - as seen below - made it possible, to develop a one purpose facility for melting low-level contaminated scrap.

The base for melting is a 3.2 tons medium frequency induction furnace with a changeable crucible, which makes it possible to melt steel scrap as well as non-ferrous materials.

On top of the furnace is set an adapter ring with a $1 \mathrm{id}$, so that the furnace itself can become closed tightly. The adapter $r$ ing is connected to a filter device which ensures low pressure in the space above the melting bath.

For charging a specially developed charging device is set on top of the adapter, which has an open lid now. Charging is done by emptying the 2001 drum filled with scrap on a vibration desk. On this the material is transported tc the furnace. This charging device itself is connected to the same filter system, which also sucks off the adapter ring so during charging there is low pressure in the complete device as well. The layout of the plant is to be seen in fig. 4 .

All the melting is done in an inner housing, which means, that the furnace and charging device is in a small bay within the big bay. This housing is connected to a second rilter system, which is identical to the first one. In this small bay there is low pressure as well, so that no aerosols can escape to the big bay.

In case of accidents at the primary filter device this one is cut off by flaps, while the second system is connected to the charging device and adapter ring. This procedure ensures that no radioactivity during melting can escape from the furnace. 
4. LICENSING

The licensing procedure in Germany is done by

- the Federal Immission Protection Law

- the Radiation Protection Ordinance.

This means, that two licensing procedures have to be done for operation of one plant. In the course of time - getting more knowledge about the behaviour of radionuclides during the melting process - conditions of the licence had to be changed to meet the demands of running these plants.

Actually four licences are valid for this research work:

- two for melting steel scrap up to a specific activity of $74 \mathrm{~Bq} / \mathrm{g}$ in the facility with the 20 tons furnace

- two for the new facility with the 3.2 tons furnace in the new bay.

Due to the higher safety of the plant the possibilities to melt are bigger. The activity level was rised up to $200 \mathrm{~Bq} / \mathrm{g}$ for $\mathrm{\beta}-/ \mathrm{\gamma}$-nuclides. The level for a-emitting nuclides was set to $100 \mathrm{~Bq} / \mathrm{g}$. The material to be melted is no longer limited to steel, the licence also includes non-ferrous materials like brass, aluminium, copper, iron etc. In addition to that graphite - which becomes solved in the liquid is bath to a contents up to $4 \%$ - can be treated in this plant. In total the licence covers most of the metallic materials coming from dismantling.

\section{RESULTS OF MELTING}

\subsection{Secondary waste}

Up to now appr. 2000 tons of metal scrap have been melted. One of the most important questions was to quantify the amount of secondary waste being produced during melting. Table I shows the results as an average over 2000 tons. The quantity of slag and filter dust depends primarily on the degree of impurities within the metal to be melted. More impurities mean more secondary waste. The average as shown in table I represents scrap in a mixture as it comes from dismantling. As one can see, the amount of waste is below $2 \%$ in weight, which is a favourable quantity compared to other material treatment methods.

A special position has zinc plated metal. During melting zinc disappears from the melt and is found in the filter dust. In that case the quantity of secondary waste increases rapidly. It comes up to $6 \%$.

\subsection{Behaviour of the radionuclides}

In previous papers the basic results of the behaviour of the radionuclides were described. From these publications it is known, that caesium disappears totally from the melt. Cobalt however remains in the iron and only a small percentage has been found in the slag and filter dust. The distribution of activity is shown in table II, also shown in table II is the behaviour of other nuclides found during the melting periods.

Based on different material resources the behaviour of nuclides other than caesium and cobalt could be assessed. In table III, the behaviour of these nuclides during two melting periods, especially for $\mathrm{Ce}$ 144, Mn 54, $\mathrm{nn}$ 65, Ag $110 \mathrm{~m}$ and $\mathrm{Eu} \mathrm{154,} \mathrm{is} \mathrm{given.}$ 
It was found, that Ce 144 was only in the slag, not in the melt and not in the filter dust. Manganese, zinc and europium as well left the melt. The explanation could be the low vaporisation temperature, which causes this effect. Only silver remains in the melt.

\subsection{The enrichment of activity in slag and filter dust}

During the melting period of about 400 tons in 1987, an enrichment of activity in filter dust and slag was found. Caused by this a partial decontamination of the slag happened. As mentioned above the amount of secondary waste was about $2 \%$ in weight. Caesium and partially cobalt leave the melt and can be found quantitatively in the slag and filter dust. This means, compared to the amount of the initial activity that the concentration of caesium and cobalt in slag and dust increases rapidly. As seen in table IV, an enrichment factor of 100 between melted metal and filter dust could be measured. For the slag this factor was found to be about 50. Calculated to an initial activity of $100 \mathrm{~Bq} / \mathrm{g}$ this leads to specific activities of $10000 \mathrm{~Bq} / \mathrm{g}$ in the filter dust and to $5000 \mathrm{~Bq} / \mathrm{g}$ in the slag.

This increase of activity in the filter dust and slag leads to a decontamination of the metal bath. As an average of over 400 tons a deco-effect of about $45 \%$ was measured. By taking into account, that Cs disappears totally from the melt, only Co with a half 1 ife of 5.3 years gave the level of activity. This means, that a shorter time for decreasing the level of free release is given.

\subsection{Treatment of activated or contaminated graphite}

In producing iron castings it is known, that an additon of about $4 \%$ in weight of graphite to the iron is made. This led to the idea to add graphite coming from gas cooled reactors to the steel melt.

In some tests we could show, that graphite from the Jilich Research Center was solved in steel. The amount of $4 \%$ is not very high, but there is another effect of interest to be regarded: if there is $\mathrm{C} 14$ as an activation product in the graphite, about $95 \%$ of it will be bound in the iron, only $5 \%$ - caused by the efficiency of this process - will leave the furnace as $\mathrm{CO}_{2}$.

Summarising the results it was shown that carbon can be treated in an metal bath as well, even if the amount compared to this quantity of steel is low.

\section{CONCLUSION - FUTURE WORK}

The work to be done as fixed in the contracts with the EC is not yet concluded. Two major items are scheduled for the last two months of this year:

- melting of higher active metal scrap up to $500 \mathrm{~Bq} / \mathrm{g}$ with evaluation of the behaviour of nuclides in this case

- melting of non-ferrous metals like copper, brass and aluminium

- demonstration of an onion casting by inserting higher activated/contaminated material into a cast container and pouring the 1 iquid iron with $500 \mathrm{~Bq} / \mathrm{g}$ into it.

After the start up of the plant as scheduled, a succesful conclusion of the work is expected. 


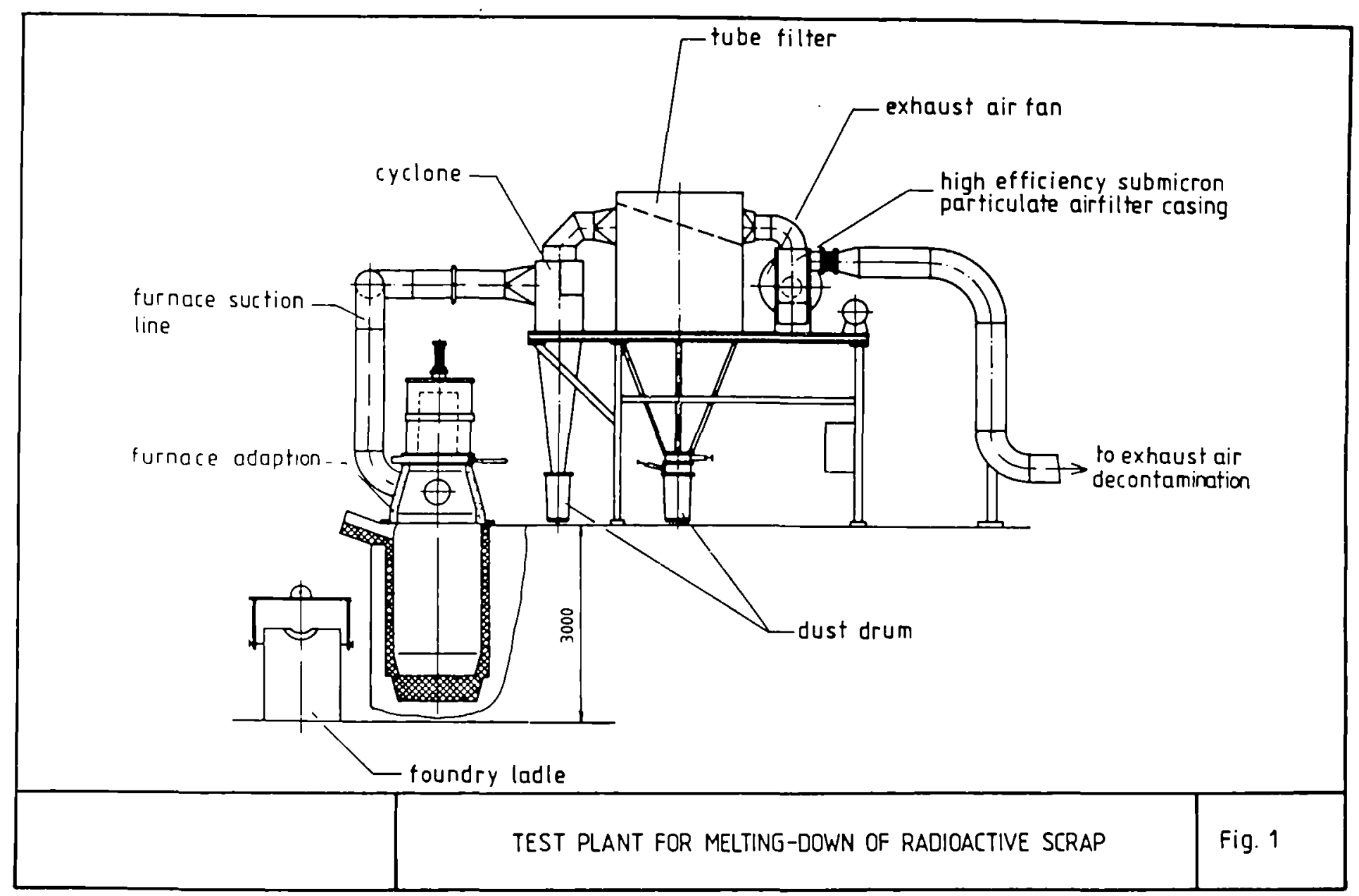



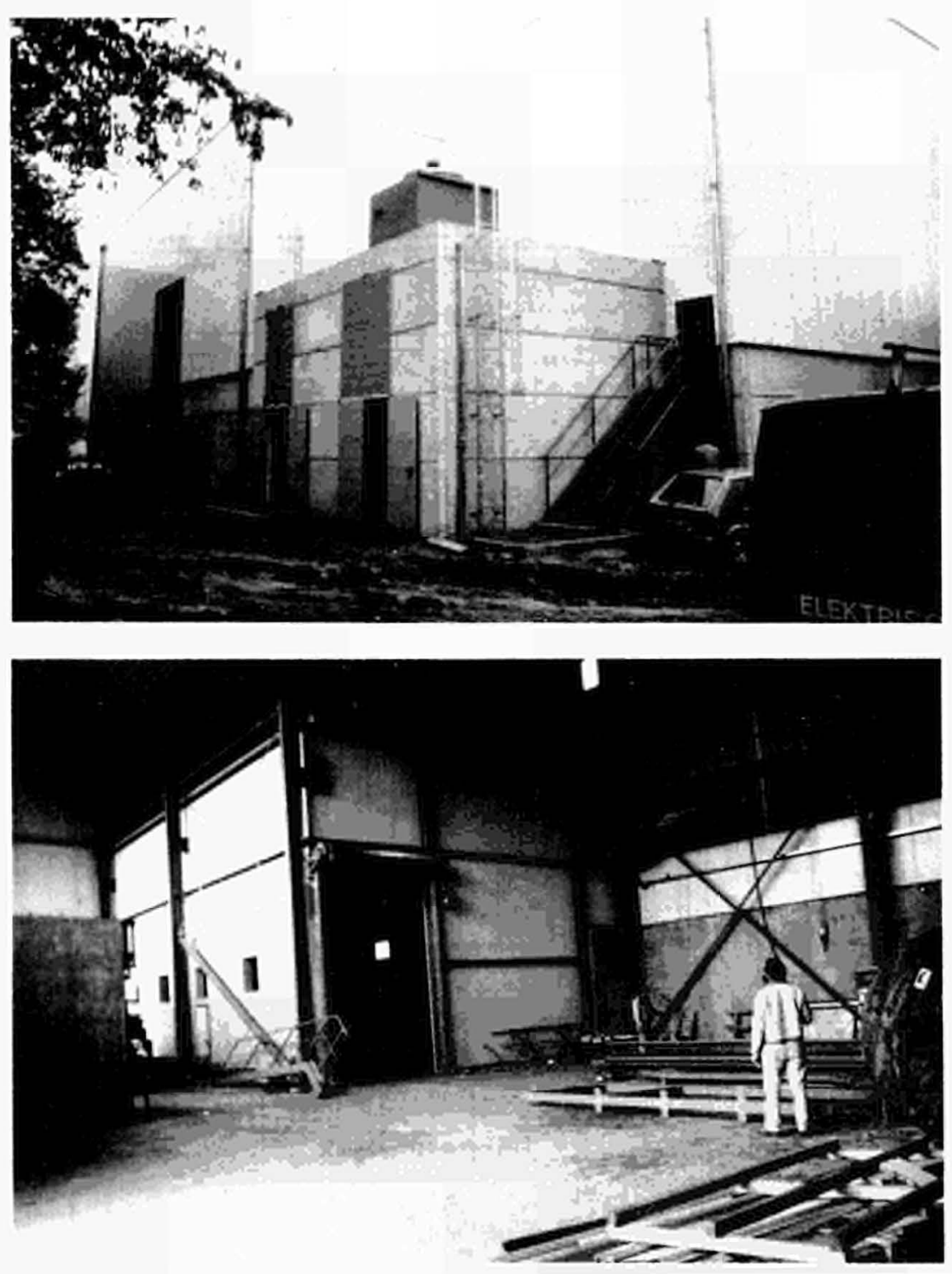

Fis, 2: The new melting bay

above: Molting bay with building for auxiliary systems and fllter systems (left)

below: Inner houslng within the big bay. 


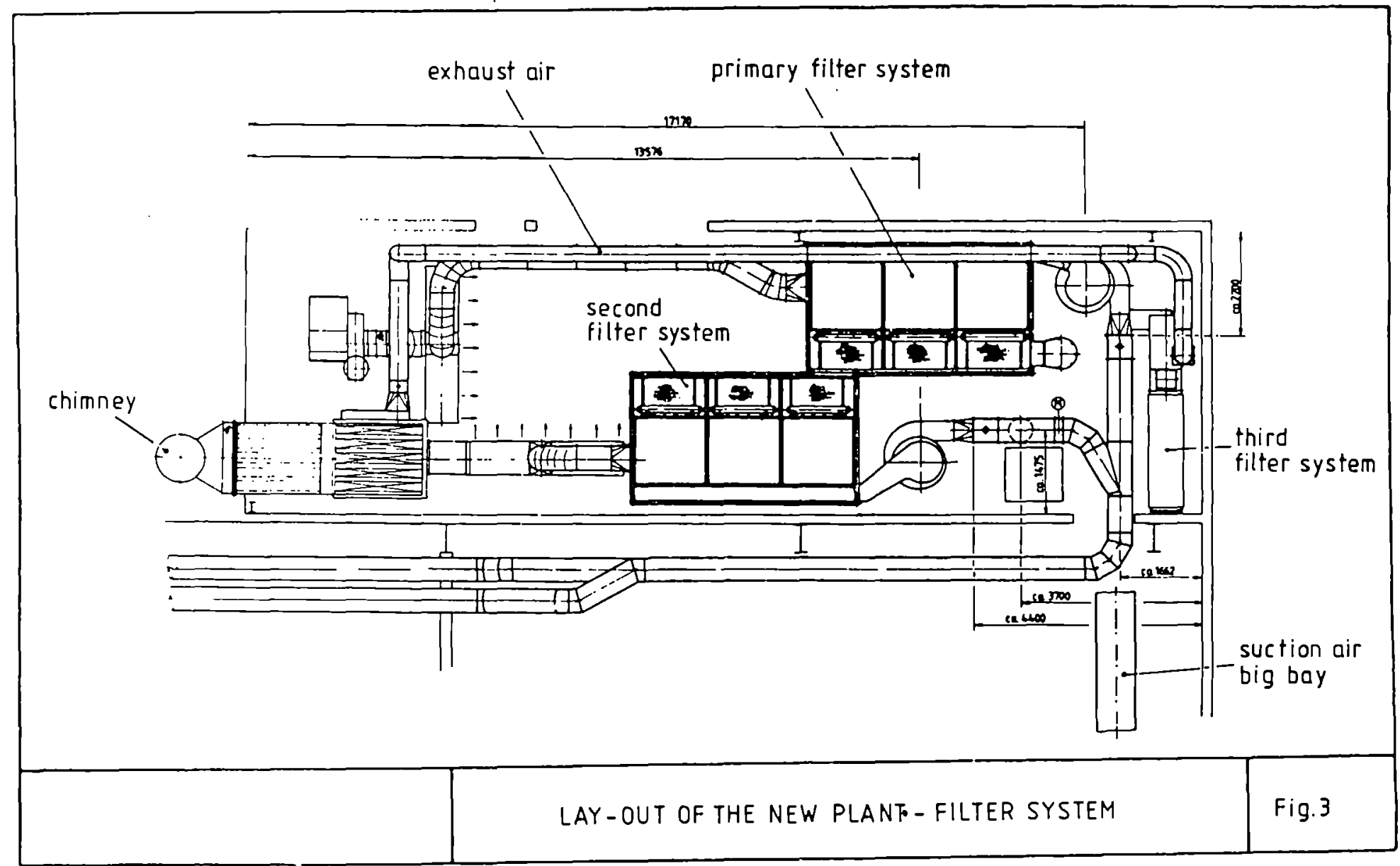




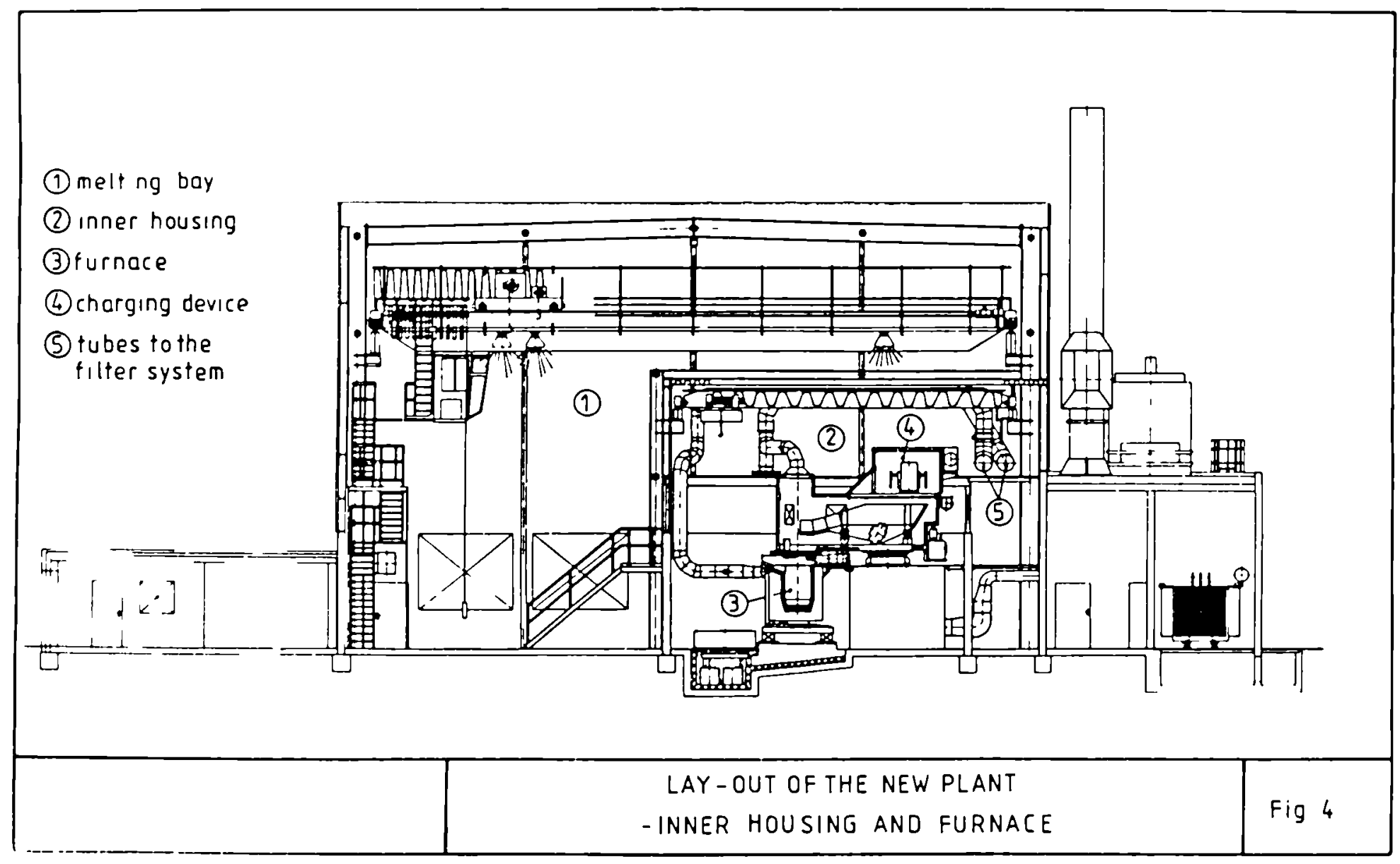


Taㅡ므르늘 Amount of secondary waste as an average over 1000 tons

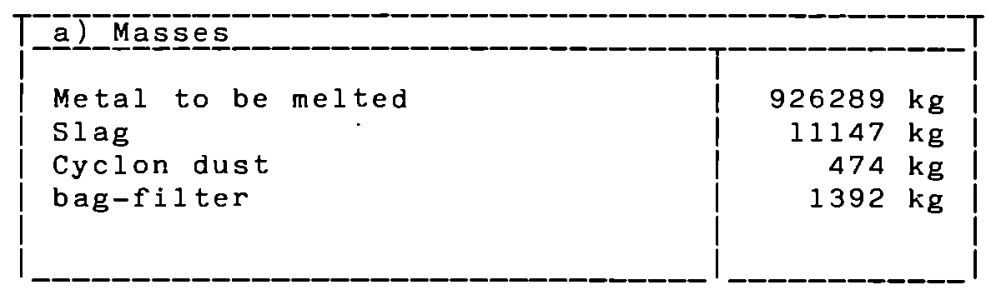

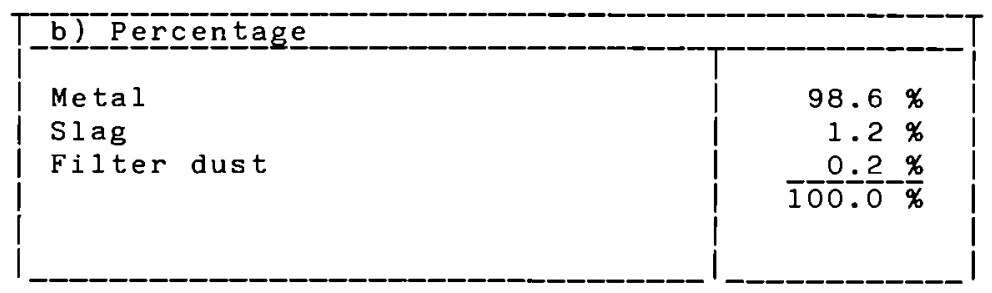


Table II: Distribution of radionuclides in melt, slag and filter dust during two melting periods.

Date: 17. 5. 1985

\begin{tabular}{|c|c|c|c|c|c|c|c|c|}
\hline Sample & $\begin{array}{r}\text { Co } 60 \\
\\
\%\end{array}$ & $\begin{array}{cc}\text { Cs } 137 \\
& \% \\
\end{array}$ & $\begin{array}{cc}\text { Ce } 144 \\
& \% \\
\end{array}$ & $\begin{array}{cc}\text { Cs } 134 \\
\% \\
\end{array}$ & $\begin{array}{r}\text { Mn } 54 \\
\% \\
\end{array}$ & $\begin{array}{r}\ln 65 \\
\quad \% \\
\end{array}$ & $\begin{array}{c}\mathrm{Ag} 110 \mathrm{~m} \\
\%\end{array}$ & $\begin{array}{r}\text { Eu } 154 \\
\%\end{array}$ \\
\hline melt & 100.0 & - & - & - & - & - & - & - \\
\hline slag & $3.5-96.5$ & $3.5-93.9$ & $0.0-2.6$ & $0.0-2.3$ & $0.0-4,4$ & - & - & - \\
\hline cyclone & $86.4-86.8$ & $4.4-13.6$ & - & - & $0.0-0.9$ & $0.0-7.9$ & - & - \\
\hline bagfilter & $33.3-48.2$ & $22.8-51.7$ & - & $1.7-4.3$ & - & $3.3-42.2$ & - & - \\
\hline
\end{tabular}

Date: 27. / 28.9. 1985

\begin{tabular}{|c|c|c|c|c|c|c|c|c|}
\hline melt & 94.0 & - & - & - & - & - & 6 & - \\
\hline slag & $3.5-100.0$ & $\begin{array}{ll}0 & -87.8\end{array}$ & - & $0-18.3$ & $0-3.5$ & - & $0-5.9$ & $0-1.5$ \\
\hline cyclone & |75.5-83.7 & $13-22.3$ & - & - & $1-2.2$ & - & $0-2.3$ & - \\
\hline bagfilter & $\mid 25.3-47.4$ & $30.6-31.1$ & - & $1.4-1.5$ & $0-0.7$ & $10.3-12.2$ & $10.3-28.8$ & - \\
\hline
\end{tabular}


Table III: Percentage distribution of nuclides during a melting campaign of 200 tons

\begin{tabular}{|c|c|c|c|c|c|c|}
\hline Sample & $\begin{array}{r}\text { Co } 60 \\
\%\end{array}$ & $\begin{array}{c}\text { Cs } 137 \\
\%\end{array}$ & $\begin{array}{c}\text { Cs } 134 \\
\%\end{array}$ & $\begin{array}{r}\text { Mn } 54 \\
\%\end{array}$ & $\begin{array}{r}\mathrm{Zn} 65 \\
\%\end{array}$ & $\begin{array}{c}\mathrm{Ag} 110 \mathrm{~m} \\
\%\end{array}$ \\
\hline $\begin{array}{l}\text { melt } \\
\text { slag } \\
\text { cyclone } \\
\text { bagfilter }\end{array}$ & $\begin{array}{r}87.7-100.0 \\
7.4-88.6 \\
14.3-91.6 \\
9.1-71.4\end{array}$ & $\begin{array}{c}- \\
6.5-86.7 \\
3.9-27.4 \\
6.0-36.5\end{array}$ & $\begin{array}{l}0- \\
0-5.7 \\
0-1.3 \\
0-0.8\end{array}$ & \begin{tabular}{l}
\multicolumn{1}{c}{-} \\
$0-21.9$ \\
$0.6-2.1$ \\
$0-1.3$
\end{tabular} & $\begin{array}{ll}0 & -5.7 \\
0 & -4.5 \\
0 & -54.7 \\
9.8-47.4\end{array}$ & $\begin{array}{l}0-7.8 \\
0-1.0 \\
0-5.4 \\
0-6.2\end{array}$ \\
\hline
\end{tabular}

Test melt date: $24.1-14.3 .1986$ 
Table IV: Enrichment of activity in slag and filter dust as well as decontamination effect as an average over 400 tons

1. Test results

\begin{tabular}{|c|c|c|c|c|c|}
\hline $\begin{array}{l}\text { activity } \\
(\mathrm{Bq} / \mathrm{g})\end{array}$ & & dust & slag & $\begin{array}{l}\text { metal } \\
\text { after } \\
\text { melt }\end{array}$ & $\begin{array}{l}\text { metal } \\
\text { as } \\
\text { delivered }\end{array}$ \\
\hline average & activity & 401 & 205 & 4 & 8 \\
\hline $\max$. & activity & 909 & 457 & $5 / 2$ & $11 / 8$ \\
\hline min. & activity & 37 & 26 & 1 & 2 \\
\hline
\end{tabular}

Results in $\mathrm{Bq} / \mathrm{g}, \mathrm{min}$. and $\max$. values referred to one melting campaign.

2. Calculated values on the delivery of $100 \mathrm{~Bq} / \mathrm{g}$

\begin{tabular}{|l|l|l|}
\hline & dust & slag \\
\hline average activity & 5400 & 2500 \\
max. activity & 5200 & 5700 \\
min. activity & 1000 & 1300 \\
\hline
\end{tabular}

3. Decontamination effect by melting

Entry activity:

$7.8 \mathrm{~Bq} / \mathrm{g}$

After melting in the metal:

Decont-effect:

$4.4 \mathrm{~Bq} / \mathrm{g}$

$43.8 \%$ 
Noell GmbH, würzburg, Federal Republic of Germany

\begin{abstract}
The EIRAM melting plant for radioactive metals was constructed in connection with the decommissioning and dismantling of the Niederaichbach nuclear power plant. According to the licensing certiflcate, contaminated parts and metallic parts from the Niederalchbach power plant with low radioactivity of up to $200 \mathrm{~Bq} / \mathrm{s}$ can be melted down. The core of the plant is a $2 t$ mains frequency induction furnace with a capacity of 600 KVA. About $150 \mathrm{t}$ of material with a total activity of 20 million Bq were melted in the period from March to August 1989.
\end{abstract}

\title{
1. INTRODUCTION
}

The melting plant for radioactive metals is used to melt down contaminated metal waste and metal waste with low levels of radioactivity. Melting offers the essential advantage over the process previously used to treat this waste that the volume of waste for final storage is minimized, safe enclosure of the radionuclides in the basis material, the possibility to exactly determine the activity inventory as well as partial decontamination and possible recycling of the material.

The melting plant was Installed in parts of the decommissioned research reactor bullding FR 2 ( on the grounds of the Nuclear Research Centre, Karlsruhe). The core of the plant is a $2 t$ mains frequency induction crucible furnace. This has a ceramic cruclble surrounded by an alr-flow cooling jacket and a water-cooled induction coll. The electric current in the induction coll produces a magnetic alternating field, which induces secondary current in the melting charge. This secondary current produces heat in the melting charge and therefore causea the charged material to melt. The maximum power required for the crucible furnace is $600 \mathrm{KVA}$. The melting plant is provided with an alr-conditioning plant separate from the ventilation system of the bullding. This supplies the rooms with fresh air to carry off the heat given off into the room air and to carry off with the waste air the radioactive materials released. All the waste air is conveyed through a filter plant. This filter plant is a cleanable filter with a mechanical filter following, Class $S$ (removal rate above 99.97 \%). 


\section{TESTS CARRIED OUT}

According to the license for dismantling the Flederaichbach power plant, the material 18 divided into 4 activity classes:

Class I: below $0.37 \mathrm{~Bq} / 8$

Class IIa: between $0.37 \mathrm{~Bq} / \mathrm{s}$ and $3.7 \mathrm{~Bq} / \mathrm{s}$

Class IIb: between $3.7 \mathrm{~Bq} / \mathrm{g}$ and $74 \mathrm{~Bq} / \mathrm{g}$

Class III: above $74 \mathrm{~Bq} / \mathrm{s}$

Only material of I and II classes was melted down until the end of August 1989. Material of varlous classes is not melted down together.

Samples were taken of the 126 castings produced. Samples were also taken from the slag removed before each discharge.

In previous operation one fllter change was made and one crucible change.

During the filter change one sample was taken from each of the 5 dust hoppers of the cleanable filter plant.

During the cructble change samples were taken from 5 places of the ceramic crucible ( 1 at the bottom, 2 in the middle and 2 in the upper area of the cructble).

\section{TEST RESULTS}

Table 1 shows the average activities of the melting charge, castings and slag for 37 melting days.

The activity of the casting and slag is almost the same with the majority of the tests (Class I). In the tests with Class II a material, an enrichment of the activity in the slag can be determined, so that in these cases a partial decontamination of the material used occurred. It can be supposed that this effect will occur even more strongly when the activity is higher; this conclusion has, however, not yet been practically conflrmed.

Examination of the behaviour of radionuclides at different slag removal temperatures resulted in no correlation between temperature and slas activity.

Analysis of the filter dust samples as well as the cructble amples resulted in activities below the detection limit, so that the total activity of the melted down drums 18 divided into activity of the castings and activity of the slag. Measureable values are also to be expected for the activity of filter dust and crucible with higher activities of the melting material. 


\begin{tabular}{|c|c|c|c|c|}
\hline $\begin{array}{l}\text { Melting } \\
\text { Date }\end{array}$ & $\begin{array}{l}\text { Melted } \\
\text { Mass/kg }\end{array}$ & $\begin{array}{l}\text { Average } \\
\text { Activities } \\
\text { of the [Bq:g] } \\
\text { Inset Material }\end{array}$ & $\begin{array}{l}\text { Average } \\
\text { Activites } \\
\text { of [Bq:g] } \\
\text { Castings }\end{array}$ & $\begin{array}{l}\text { Average } \\
\text { Activities } \\
\text { of [Bq:g] } \\
\text { slag }\end{array}$ \\
\hline $\begin{array}{l}06.06 .89 \\
07.06 .89 \\
08.06 .89 \\
09.06 .89 \\
13.06 .89 \\
14.06 .89 \\
15.06 .89 \\
19.06 .89 \\
20.06 .89 \\
21.06 .89 \\
22.06 .89 \\
28.06 .89 \\
30.06 .89 \\
03.07 .89 \\
04.07 .89 \\
05.07 .89 \\
13.07 .89 \\
17.07 .89 \\
18.07 .89 \\
19.07 .89 \\
07.08 .89 \\
08.08 .89 \\
09.08 .89 \\
10.08 .89 \\
11.08 .89 \\
14.08 .89 \\
15.08 .89 \\
16.08 .89 \\
17.08 .89 \\
18.08 .89 \\
21.08 .89 \\
22.08 .89 \\
23.08 .89 \\
24.08 .89 \\
28.08 .89 \\
29.08 .89 \\
30.08 .89\end{array}$ & $\begin{array}{l}1910 \\
4710 \\
4500 \\
2260 \\
2220 \\
4575 \\
4680 \\
3440 \\
2710 \\
3215 \\
3365 \\
4450 \\
3420 \\
3490 \\
2150 \\
3950 \\
2690 \\
3120 \\
4040 \\
2240 \\
2290 \\
3540 \\
3530 \\
3440 \\
2320 \\
1220 \\
3220 \\
3220 \\
4390 \\
2240 \\
3450 \\
3460 \\
3390 \\
3450 \\
3570 \\
4760 \\
4420\end{array}$ & $\begin{array}{l}<0,01 \\
<0,01 \\
<0,01 \\
<0,01 \\
<0,01 \\
0,02 \\
<0,01 \\
0,05 \\
0,32 \\
0,24 \\
0,09 \\
0,21 \\
1,19 \\
0,12 \\
1,88 \\
0,12 \\
0,22 \\
0,19 \\
0,15 \\
0,16 \\
0,05 \\
0,09 \\
0,53 \\
1,34 \\
0,11 \\
0,18 \\
0,12 \\
0,11 \\
0,13 \\
0,17 \\
0,12 \\
0,17 \\
0,08 \\
0,13 \\
0,27 \\
0,57 \\
0,69\end{array}$ & $\begin{array}{l}<0,01 \\
<0,01 \\
<0,01 \\
<0,01 \\
<0,01 \\
0,016 \\
<0,01 \\
<0,01 \\
0,15 \\
0,07 \\
0,04 \\
0,17 \\
0,41 \\
0,09 \\
0,49 \\
0,10 \\
0,14 \\
0,12 \\
0,14 \\
0,07 \\
0,05 \\
0,09 \\
0,49 \\
0,39 \\
0,09 \\
0,16 \\
0,10 \\
0,05 \\
0,06 \\
0,16 \\
0,15 \\
0,12 \\
0,08 \\
0,08 \\
0,25 \\
0,43 \\
0,67\end{array}$ & $\begin{array}{l}<0,01 \\
<0,01 \\
<0,01 \\
<0,01 \\
<0,01 \\
<0,01 \\
<0,01 \\
<0,01 \\
<0,01 \\
<0,01 \\
0,02 \\
0,25 \\
0,92 \\
0,30 \\
1,11 \\
<0,01 \\
<0,01 \\
0,29 \\
0,19 \\
0,14 \\
<0,01 \\
0,02 \\
0,98 \\
0,75 \\
0,11 \\
0,12 \\
0,07 \\
<0,01 \\
0,03 \\
<0,01 \\
0,11 \\
0,11 \\
0,05 \\
0,02 \\
0-- \\
0,-78 \\
0,78\end{array}$ \\
\hline
\end{tabular}

Table I

Average activities of the melting charge, ingots and slag for 37 melting days. 


\section{MELTING OF LOW-LEVEL CONTAMINATED STEELS}

S. Menon; G. Hernborg; L. Andersson Studsvik AB, Sweden

\section{INTRODUCTION}

The melting facility at Studsvik was taken Into operation at the end of October 1987. By the end of 1988, more than $400 t$ of low active metall1c acrap had been melted.

The contaminated scrap has originated from nuclear power plants in Sweden and the Pederal Republic of Germany or has been produced In-house at the varlous laboratorles at Studsvik. The delivery of scrap has been elther as miscellaneous Items such as plpes, beams, valves, etc or as large Individual pleces of equipment such as pre-heaters and molsture separators from commercial BWRs. These latter pleces of equipment have had to be segmented before introduction to the melting furnace.

The experiences galned so far show that melting 18 a safe, environmentally acceptable and commercially viable method of treating contaminated metallic low-active scrap.

\section{WHY MELTING?}

Repalr and change-out of equipment at nuclear power plants produce large quantities of low-level, contaminated metallic scrap. The dismantlIng of a reactor untt w111 produce even more. Much of the scrap consists of bulky equipment auch as heat exchangers, molsture separators and steam generators.

If these pleces of equipment are sent directly to the final disposal stte, they would occupy large (and correspondingly expenstve) volumes. Moreover, much of the contaminated scrap is made of valuable material such as pressure vessel steels, atalnless steels, Inconel, etc.

The concept of melting 18 almed at achleving a re-usable product, while at the same time saving expensive space at final disposal factlit1ea.

Nuclide-specific analyses of samples allow a very exact determination of the radioactivity in each ingot resulting from melting. In the cases of many pleces of equipment, such exact determination is extremely difficult and time-consuming, if not impossible. Thus, an Ingot can be released for unrestricted recycling or stored for decay to release 11m1ts.

In some cases, the calculated decay time to release 1 imits may be unreasonably long. These Ingots would have to be sent to the final disposal facility. Even in auch cases, the volume reduction achieved would save valuable space there.

\section{THE STUDSVIR MELTING FACILITY}

The main component in the facility is an Induction smelting furnace, with a capacity of melting about 1.5 t of scrap per hour. Each charge is of about $3 \mathrm{t}$. The furnace 18 provided with a remotely operable top 11d wth a suction of gases at the top of the cructble. There 18 a hydraul1cally-operated tipping mechanism for pouring the molten metal into moulds (F1gure 1), F1gure 2 is the photograph of a pour.

The melter has been Installed in an existing bullding at the studsvik site. The bullding, which formerly housed a re-generation plant 
for heavy water, has been renovated and remodelled to recelve the furnace and its auxiliary equipment.

The facflity has a preparation area, where the scrap is segmented into pieces suitable for loading into the furnace and a cooling-off area for the ingots. Elsewhere on the Studsvik site are storage facilities for the ingots awafting release or, in some cases, shipment to a disposa 1 site or back to the owner of the waste. A perspective sketch of the facility is shown in Figure 3 .

There are separate ventilation systems for the reparation area and the furnace area. Both systems are provided with $99 \%$ effective filters before the ventilation air is released to the atmosphere 20-25 m above the ground. The radioactivity in the afr released is continuously monitored.

\section{EXPERIENCES DURING TEST OPERATION}

The first operational 1icense granted for the Studsvik Melting Facility covered a test period from October 1987 to the end of July 1988 . A report (1) was submitted to the authorities in May 1988, the main contents of which are summarfsed here.

Between start-up on 26 October 1987 and 3 May 1988, 93 melts had been performed, durfing which some $190 \mathrm{t}$ of scrap had been melted. Apart from some teething problems, the furnace with its auxfllary systems and ventilation had functioned satisfactorily.

All the scrap treated was Swedish in origin, about $70 \%$ of it from Studsvik, the rest from Swedish nuclear power plants. Most of the scrap (about $90 \%$ was of carbon steel, the remaining $10 \%$ being of stainless stee1).

Three samples were taken from each melt for nuclide specific analys1s. The results of some of these analyses, as well as those on slag (during cutting and during melting) and the dust collected in the ventilation filters, are reported below.

\subsection{Results from Carbon Steel}

The secondary waste resulting from the melting of carbon steel varies with the materlal thickness, degree of rusting, etc. In the melting series described below, the charges consisted of thin-walled, large diameter pipes, thereby giving rise to a relatively large percentage of rest products (4\%):

\begin{tabular}{|l|l|l|l|l|}
\hline $\begin{array}{l}\text { Quantity } \\
\text { melted } \\
t\end{array}$ & $\begin{array}{l}\text { Weight of } \\
\text { Ingots } \\
t\end{array}$ & $\begin{array}{l}\text { Slag } \\
t\end{array}$ & $\begin{array}{l}\text { Cutting } \\
\mathbf{s l a g} \\
t\end{array}$ & $\begin{array}{l}\text { Dust } \\
t\end{array}$ \\
\hline 33.61 & 32.27 & 0.87 & 0.45 & 0.019 \\
\hline
\end{tabular}

The ingots had no measurable levels of CS-137. The melt slag was packed in 2001 drums for measurement on the equipment used for activity registration on ashdrums from the Incineration Facility at Studsvik. The activity content in the melt slag was below the measurement threshold of the equipment.

The dust collected in the ventilation filters contained:

$\begin{array}{lrl}\mathrm{Co}-60 & 1 & 300 \mathrm{~Bq} / \mathrm{kg} \\ \mathrm{Zn}-65 & 14 & 400 \mathrm{~Bq} / \mathrm{kg} \\ \mathrm{Cs}-137 & 21 & 800 \mathrm{~Bq} / \mathrm{kg}\end{array}$


4.2 Regults from sta1nless steel melts no 92 and 93:

Total quantity melted

Weight percent of slag

melt no 92

melt no 93
$5409 \mathrm{~kg}$

1.17

0.57

Activity contents of 1ngotg (Bq/ $\mathrm{kg}$ )

\begin{tabular}{|c|c|c|c|c|c|c|}
\hline Me1t No & $\begin{array}{c}\text { Co-60 } \\
(5.3 \mathrm{y})\end{array}$ & $\begin{array}{c}\text { Mn-54 } \\
(0.9 \mathrm{y})\end{array}$ & $\begin{array}{c}\text { Co-58 } \\
(0.2 \mathrm{y})\end{array}$ & $\begin{array}{c}\mathrm{Zn}-65 \\
(0.7 \mathrm{y})\end{array}$ & $\begin{array}{c}\text { Ag-1 10m } \\
(0.7 \mathrm{y})\end{array}$ & $\begin{array}{c}\text { Sb-125 } \\
(2.7 \mathrm{y})\end{array}$ \\
\hline 92 & 1330 & 8.2 & 20 & 34 & 54 & $\begin{array}{c}29 \\
50\end{array}$ \\
\hline 93 & 3440 & & & & & \\
\hline
\end{tabular}

( ) : Half lives

Activity contents of $81 \mathrm{ag}(\mathrm{Bq} / \mathrm{kg})$

\begin{tabular}{|c|c|c|c|c|c|c|}
\hline Me1t No & Co-60 & Mn-54 & Co-58 & C8-134 & C8-137 & Ag-110m \\
\hline 92 & 703 & 73 & 17 & 127 & 2193 & 30 \\
93 & 207 & 10 & & 98 & 1395 & \\
\hline
\end{tabular}

Act1vity contents of dust

Total quantity for both melts

$2.49 \mathrm{~kg}$

Activity contents:

$\begin{array}{lrl}\mathrm{Co}-60 & 31 & 200 \mathrm{~Bq} / \mathrm{kg} \\ \mathrm{Mn}-54 & & 146 " 1 \\ \mathrm{Co}-58 & & 264 " \\ \mathrm{Zn}-65 & 52 & 250 " \\ \mathrm{Ag}-110 \mathrm{~m} & 37 & 450 " \\ \mathrm{C}-134 & 1 & 125 " \\ \mathrm{C}-137 & 134 & 650 " \\ \mathrm{Sb}-125 & & 670 "\end{array}$

4.3 Comments on the test melting

The results highlight the decontamination effect of melting. This 1s very significant from the point of view of unrestricted recycling of material. If the $\mathrm{Cs}-137$ had been uniformly distributed in the case of $5.4 \mathrm{t}$ of stainless steel, there would have been an average concentration of $80 \mathrm{~Bq} / \mathrm{kg}$ of just this nuclide, which has a half-life of $30 \mathrm{y}$.

After melting, the dominant nuclide 18 Co-60 with the more manageable half-life of $5.3 \mathrm{y}$. The $\mathrm{C}_{8}-137$ and a considerable part of the cther nuclides can be contalned in a small volume and conditloned as secondary waste. 


\subsection{Occupational exposure}

S1x persons, health physics staff included, participated in the work at the Melting Facility during the test perfod. From start-up on 26 October

1987 up to 31 March 1988, only one had an exposure that could be registered. Th1s person recelved $0.3 \mathrm{mSv}$.

Whole body measurements have not revealed any internal contamination in any of the staff.

\section{EXPERIENCES TO DATE}

5.1 Amount melted below:

A table showing the origin and quantity of scrap melted is given

\begin{tabular}{|l|c|c|}
\hline Origin & Quantity $(t)$ & Number of Ingots \\
\hline Studsvik & 168 & 220 \\
Reactor site A, Sweden & 15 & 19 \\
Reactor site B, Sweden & 34 & 48 \\
Reactor site C, Sweden & 42 & 55 \\
Reactor site D, West Germany & 155 & 206 \\
\hline
\end{tabular}

\subsection{Activity in inguts}

Figure 4 is a block diagram showing the number of ingots produced from Swedish material. The ingots are grouped according to level of activity concentrations. Figure 5 shows a simflar block diagram over material melted from abroad.

\subsection{Radioactive alrborne releases}

During 1988, a total of $640 \mathrm{kBq}$ of beta-gamma activity was released through the stack as well as $200 \mathrm{~Bq}$ of alpha activity.

\section{THE FUTURE}

The results of the operation of the Studsvik Melting Facflity have confirmed that melting is a safe, environmentally acceptable, costeffective method for treating low-active, contaminated metallic scrap for possible unrestricted recycling.

Up to now, the surface actlvity levels on the material treated has been very low. In some cases, simple methods of decontamination have been utilised. Studsvik is at present developing a single-step, room temperature scrap decontamination method which could, in the future, enable the treatment of equipment with considerably higher degrees of contamination (3).

\section{REFERENCES}

1 HERNBORG G, ANDERSSON L (1988) Report on Test Operation of Melting Plant for Low-active Scrap, Studsvik Technical Note NS-88/327

2 HERNBORG G, ANDERSSON L (1989) Report on Scrap Melting between October 1987 and December 1988, Studsvik Techntcal Note NS-89/43

3 MENON S (1989) Chemical Decontamination of Scrap from Nuclear Power Plants, Studsvik Technical Note NS-89/99 
(4)

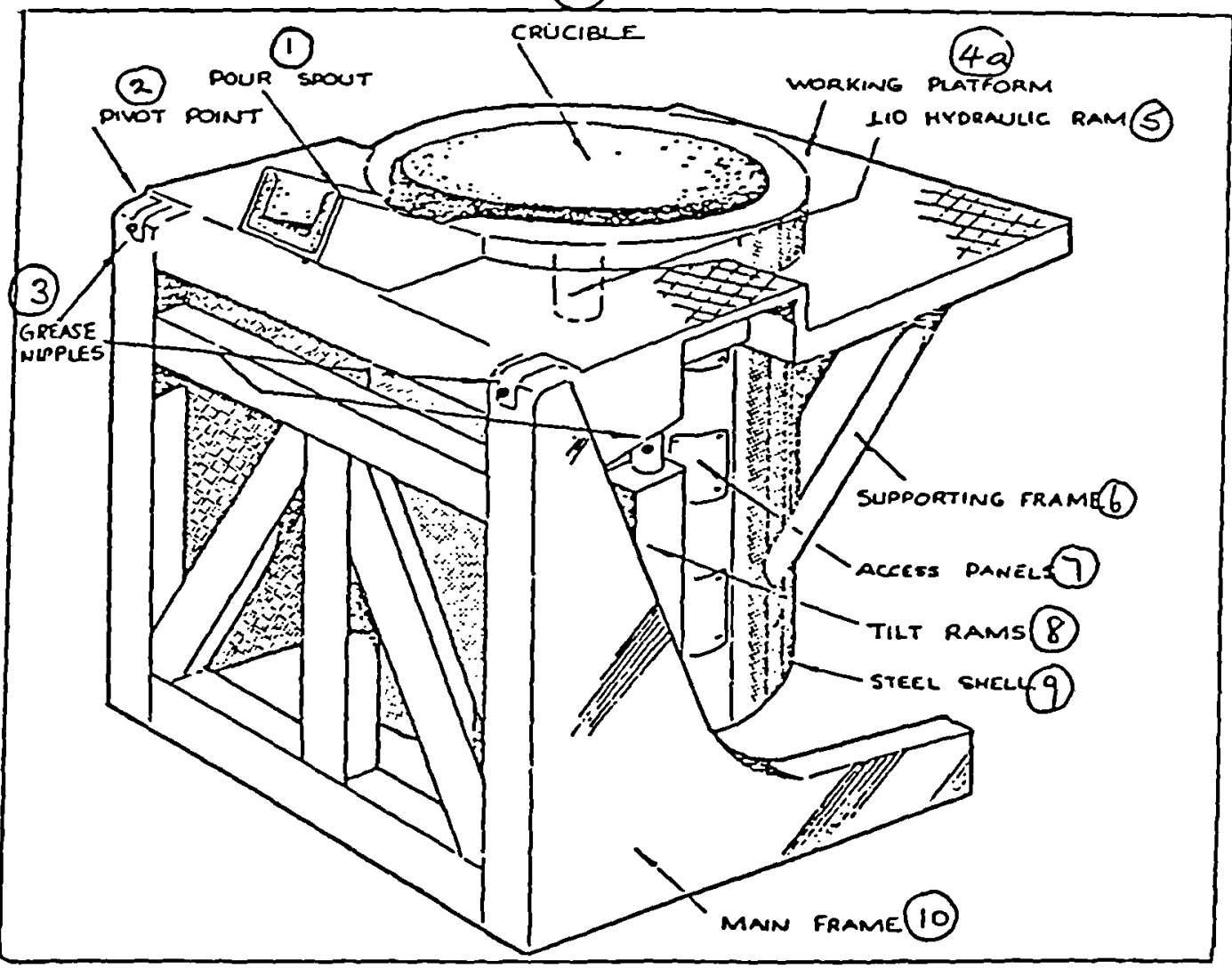

电

Fig. 1. Crucible with tipping mechanism 


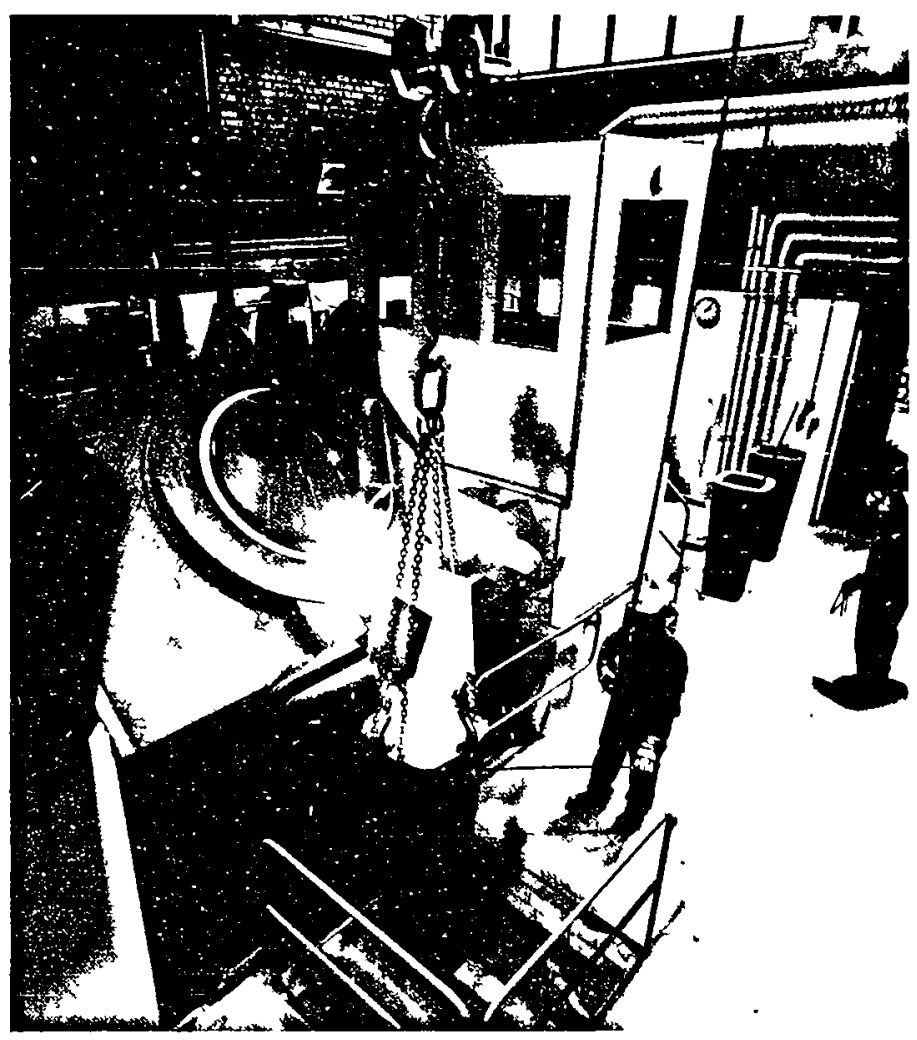

Fig. 2. Pour-in process

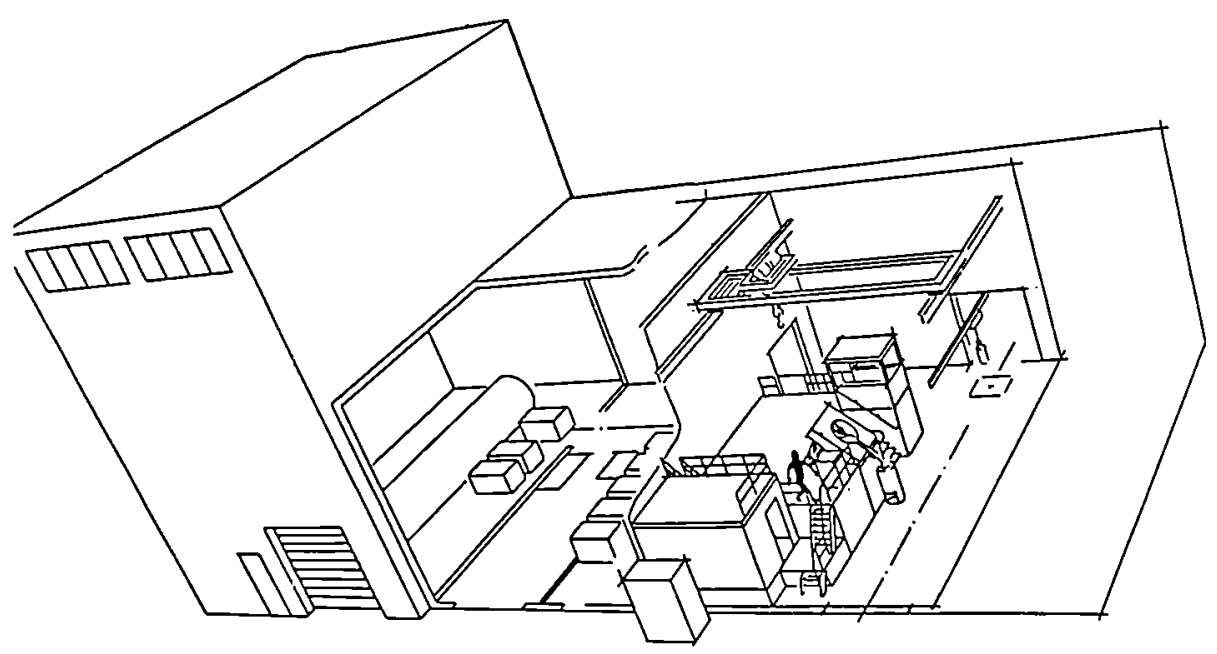

Fig. 3. Perspective sketch over melting facility 
No. of Ingots

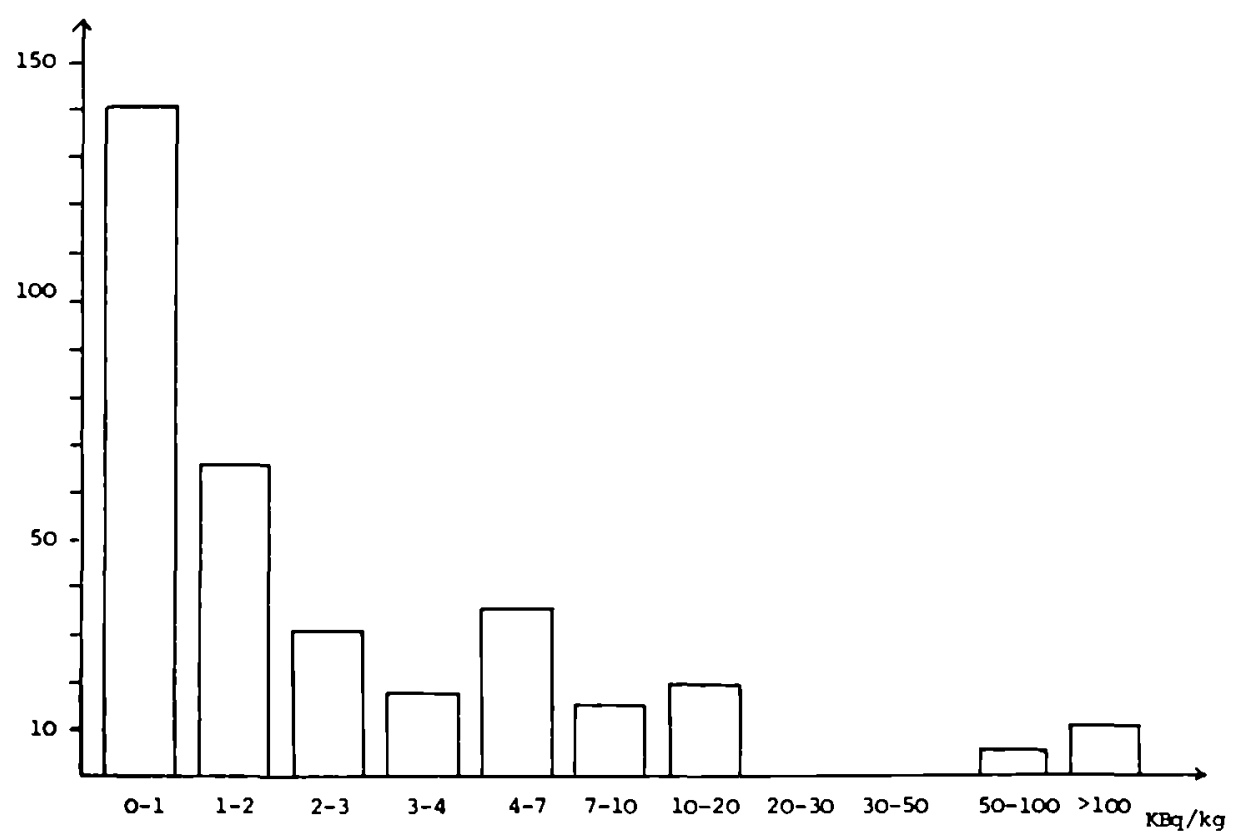

Fig. 4. Activity in Ingots (Swedish)

No. of ingots

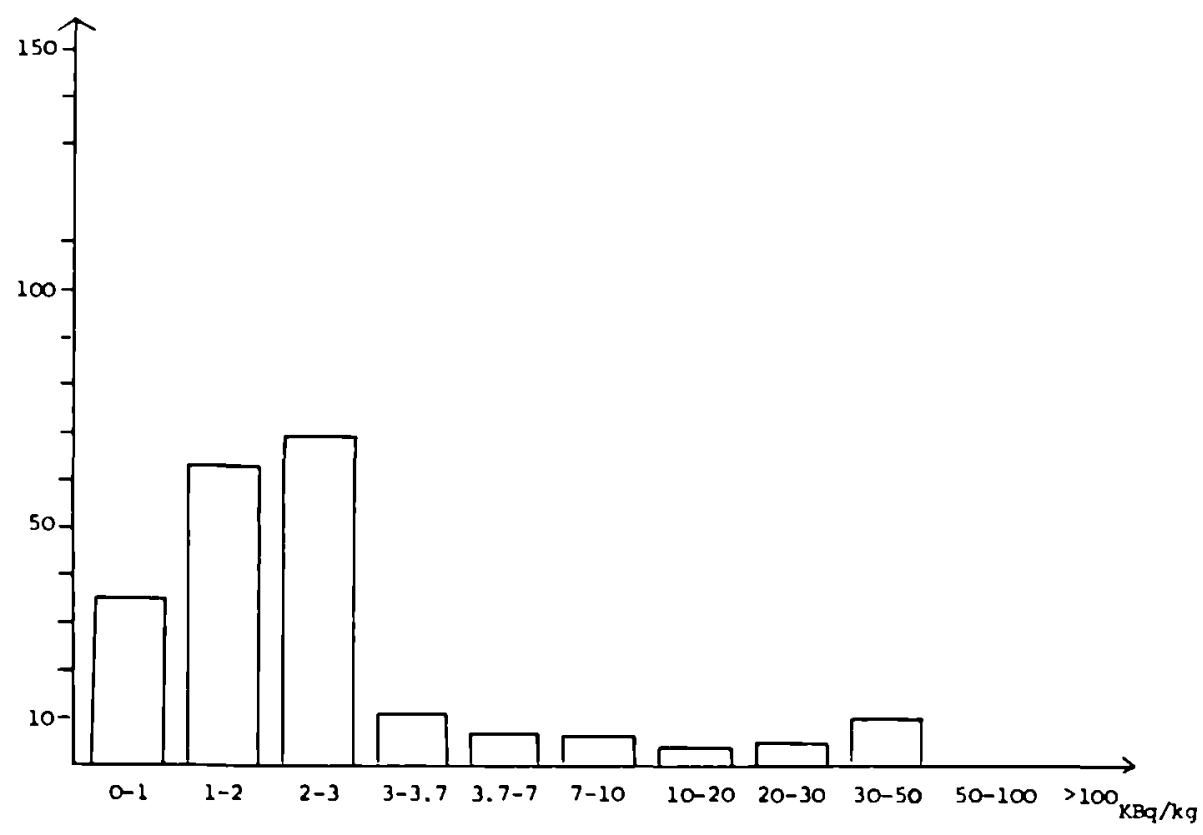

Fig. 5. Activity in ingots (West German) 
SEPARATION BY VAPOUR PHASE TRANSPORT OF STAINLESS STEEL CONSTITUENTS

M. ALLIBERT ${ }^{\star}$, G. GIBON $^{\star \star}$, G. KURKA $^{\star \star}$, G. TANIS $^{\star \star}$

* Laboratoire de Thermodynamique et Physico-Chimie Métallurgiques, ENSEEG, BP 75 - 38402 SAINT MARTIN D'HERES - FRANCE

**

Centre d'Etudes Nucléaires de Grenoble, Département de Métallurgie, $85 \mathrm{X}$ - 38041 GRENOBLE CEDEX - FRANCE

\begin{abstract}
A process for separating the constituents of radioactive steels is proposed for conditioning of materials originating in the dismantling of reactor pressure vessels. This process is based on the transport, by a vapour phase made of iodides in a thermal gradient inside a gastight device, of the constituent elements of the steels.

Test were carried out at a $2 \mathrm{~g}$ scale in quartz ampoules to determine the effectiveness of the separation as a function of temperature ranges, pressure and temperature gradient. From the results it is deduced that cobalt can be separated from the other elements after about 150 elementary transports with a productivity of about 1. $\mathrm{kg}$ of steel treated by square meter and by day.

The principle of this process is also applicable to other metallic or even non metallic wastes.
\end{abstract}

\title{
1. INTRODUCTION
}

The problem of steel processing has arisen with the dismantling of nuclear plants and specially of the P.W.R. vessels which are lined with stainless steel. During the operating period of the reactor this lining underwent radiations producing ${ }^{60} \mathrm{Co}$ mainly from ${ }^{59} \mathrm{Co}$ which is present in the steel as an element accompanying $\mathrm{Ni}$. The activity of $60^{\circ} \mathrm{Co}$ remains important with respect to other sources in the steel, for about 100 years after shutdown. This time depends on the initial Co content of the metal (from $0.03 \%$ to $0.3 \%$ for stainless steel and 0.01 to $0.03 \%$ for mild steel) and on the regulations classifying the nature of the wastes. The processing of steel wastes a few decades after shutdown in view of a permanent storage or a recycling would require a separation of activated elements such as Co. For this purpose a process was sook after which could allow a separation of Co without creating extra amounts of waste and without changing its metallic nature.

A process involving vapour phase transport in a thermal gradient satisfies the above requirements. It takes place in a gastight device and does not permanently create additional waste. Two processes of this type are known :

- The one century old carbonyl process (Mond Process) used for the obtention of pure $\mathrm{Ni}$ by transport under pressure (200 bars) by carbon monoxide $\mathrm{CO}$.

- The half a century old iodine process (Van Arkel) used to purify IVB elements ( $\mathrm{Ti}$ ).

The first, although applicable to $\mathrm{Fe}$, Co and $\mathrm{Ni}$, has the disadvantage of having a large amount of contaminated gas because of the operating pressure needed for acceptable kinetics. Such a transient dilution of activity is an inconvenience in case of casualty. The second is thus a better candidate for the treatment as it works under low pressure. 


\section{THERMODYNAMICS OF SEPARATION}

Principles

The vapour phase transport consists in a gaseification of a material at a given place inside of a gastight vessel by reaction with a carrier gas (iodine in the present case). The reverse reaction is obtained by changing the local temperature in another place inside the vessel. Metals or solid compounds have already been transported this way at laboratory scale. In the case of alloys it is likely that the composition of the deposited alloy differs from the composition of the alloy remaining after partial gaseification. Thus, successive transports will lead to an evolution of the composition of the transported alloy as it happens in distillation for liquid mixtures. The separation rate will depend on the relative amounts of the various constituents of the alloy, on their thermodynamic activities and on the respective stabilities of the corresponding gaseous species.

The main species involved are the monoatomic iodine and the gaseous diiodides according to the reversible reaction :

$2 \mathrm{I}(\mathrm{g})+\mathrm{M}(\mathrm{s}) \leftrightharpoons \mathrm{MI}{ }_{2}(\mathrm{~g})$
with $\mathrm{M}=\mathrm{Fe}, \mathrm{Co}, \mathrm{Ni}, \mathrm{Cr}$.

As represented on figure 1 I reacts on the alloy, at the so called "source" end of the vessel, to form gaseous iodide. The iodide is transported to the so called "sink" end, by molecular diffusion or convection, where it decomposes into a metal and monoatomic iodine. This decomposition occurs because of the change of stability of the iodide with temperature. In the present case the sink temperature is to be greater than the source temperature (it is not always so, depending on the carrier gas).

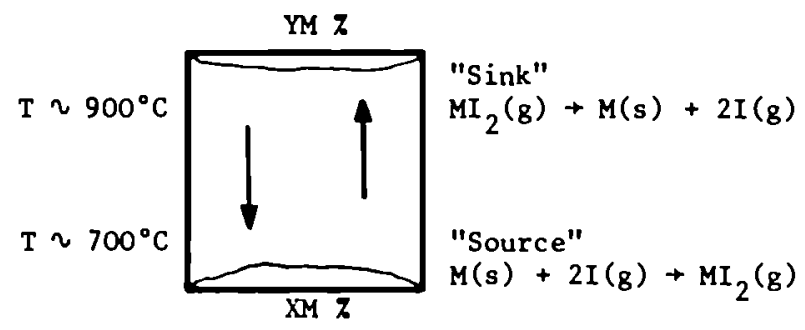

Figure 1 : Schema of the transport of a Metal (M) by Iodine (I)

The concentration $X_{M}$ of a given element $M$ in the alloy remaining at the source end, after the transport of a fraction of the alloy, differs from the concentration $Y_{M}$ of this same element in the deposited alloy. The ratio of these two quantities is the separation coefficient :

$r_{M}=Y_{M} / X_{M}$

Assuming as a first approximation that this ratio is constant for $n$ successive transports the over-all separation coefficient $R_{M}$ would be :

$$
R_{M}=r_{M}{ }^{n}
$$

This gives a rough approximation of the number of transport needed to reach a given amount of $C o$ in the major part of the waste. For instance with a permissible amount of $0.3 \mathrm{ppm}$ of $\mathrm{Co}, \mathrm{R}_{\mathrm{Co}}$ would range from 100 for a mild steel to $10^{3}$ for a selected stainless steel. As shown after the values of $r_{\text {co }}$ are close to 2, figure which gives a number of transport of the order of 10 but for a small yield. For a large yield this number is much greater $\left(n^{2}, n^{3}, \ldots\right.$ to $n !$ for a $100 z$ yield). 
Thermodynamic simulation

An estimate of the separation coefficients is possible by thermodynamic simulation of the transport and gives results in reasonable agreement with measurements.

This simulation consists in calculating the composition of a given volume of gas at equilibrium with the source alloy after reaction of a given amount of iodine. This gas is isolated and its temperature is changed resulting in a deposit of an alloy. The amount of alloy deposited gives e mean of comparison for the kinetics of transport and the alloy composition gives a value of $r_{M}$. Obviously these conditions are arbitrary and the calculated results should be used for comparison purposes only. However this simulation showed that a transport by chlorine and chlorides would have lead to a very low kinetic of transport due to the low volatility of chlorides compared to that of iodides (about $10^{3}$ times less).

The standard conditions used are the following :

- 1 mole of metal or alloy

- 101 volume of gas

- $100 \mathrm{~K}$ temperature difference between source and sink.

A given amount of iodine is placed in the 101 volume in presence of 1 mole of alloy. This amount is called iodization rate as it is the number of mole of iodine per mole of metal. The gas-alloy equilibrium is then calculated for a given temperature : Tsource = Tsink - 100K. The gas is then separated from the remaining "source alloy" and placed at Tsink where a new equilibrium is calculated. This gives the composition of the "sink alloy". From these two calculated compositions a separation coefficient for each element may be deduced. The thermodynamic calculation was carried out using the SOLGASMIX software and account was taken of the free energy of mixing of alloys. The thermodynamic data were taken from the S.G.T.E. (Scientific Group Thermodata Europe) data base.

The separation coefficients were calculated for treatments by iodine or HI of a typical 304 AISI steel or of typical simplified alloys obtained after successive eliminations of $\mathrm{Fe}$ and $\mathrm{Cr}$ or for the elimination of Co from $\mathrm{Cr}$. An example is presented in figure 2.

In all cases the separation coefficients are of about 2 (or 1/2) except in the case of Co compared to $\mathrm{Cr}$ for which a very difficult separation is expected. The first point was confirmed by experiments but not the latter, perhaps due to large uncertainties in the values of Gibbs free energies of formation of gaseous chromium iodides. The predicted variation of the separation coefficient with iodization rate was not confirmed either may be because its experimental range of variation was not very large but more likely because the thermodynamic calculation is sensitive not only to this parameter but also to the total pressure of iodide. The simulation does not take this experimental parameter into account.

Physicochemistry of the transport

The kinetics of transport can be controlled by one out of several elementary processes such as :

- diffusion in the source alloy

- interfacial reaction between gas and source alloy

- gaseous phase diffusion and convection

- interfacial reaction between gas and sink alloy

The expected consequences of each of these possible limiting steps are the following :

- a diffusion controlled transfer leads to a congruent gaseification of the source alloy and thus to the absence of separation effect if a single sink is used. It is the reason why deposits on two sink alloys at different temperatures were experienced. 
- a gaseification reaction limited by surface reaction is sensitive to the steel surface structure and composition i.e. the origin of the metal. Transports of powder, turnings and deposits were thus carried out,

- the experiments were carried out under conditions unfavorable to convection set-up thus molecular diffusion was supposed to take place. From basic considerations it is to be noticed that the diffusion flow under stationary condition is independant of pressure and is proportional to $\mathrm{T}^{1 / 2}$. A rough estimate of this flow gives $1 \mathrm{~kg} / \mathrm{m}^{2} /$ day as rate of metal transport,

- the depositing of metal may be limited by nucleation but not likely by interfacial decomposition of $\mathrm{MI}_{2}$ giving atomic species, conversely to the case of formation of a gaseous molecule from atomic species on the source alloy.

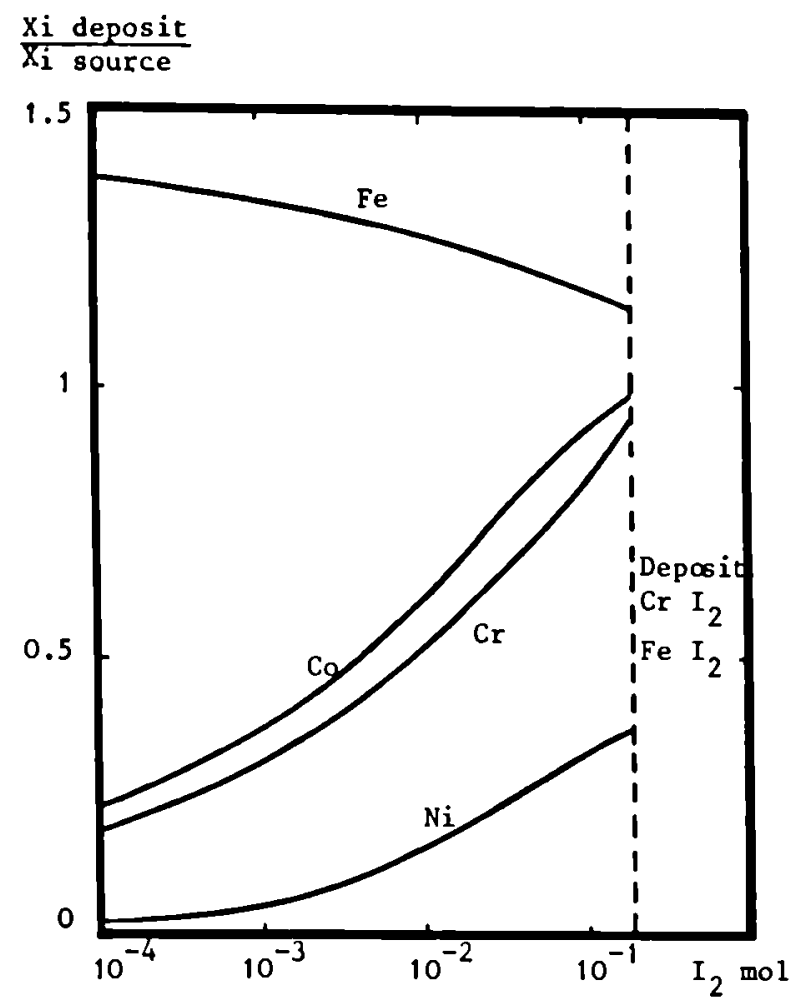

Figure 2 : Separation coefficients calculated at $1400 \mathrm{~K}$ $(1300 \mathrm{~K}$ at the source) for a stainless steel $21.2 \mathrm{z} \mathrm{Cr}-$ $9,4 \times \mathrm{Ni}-0.09 \times \mathrm{Co}-69.3 \times \mathrm{Fe}$ and in the presence of iodine 
3. EXPERIMENTAL CHARACTERIZATION OF TRANSPORT

Experimental procedure

Preliminary tests were carried out in quartz ampoules $(\emptyset 15 \mathrm{~mm}$, length $80 \mathrm{~mm}$ ) loaded with stainless steel powder as a source alloy and steel wool as sink deposition surface to avoid nucleation problems. These ampoules were sealed under vacuum after introduction of a known amount of solid iodine. They were placed in a thermal gradient such that the source was at about $1000^{\circ} \mathrm{C}$ and the sink at about $1250^{\circ} \mathrm{C}$ for five days. A transport occured and depositings were observed on the steel wool as well as on the quartz, showing that the presence of steel surface at sink was unnecessary. The depositings were in several parts of the ampoule and not only in the hottest end of it showing that the thermal gradient was not defined well enough in this rough experiment.

Quartz beeing proved to be a satisfactory material at temperature below $1250^{\circ} \mathrm{C}$ new cylindrical ampoules were designed according to the schemes presented in figure 3.

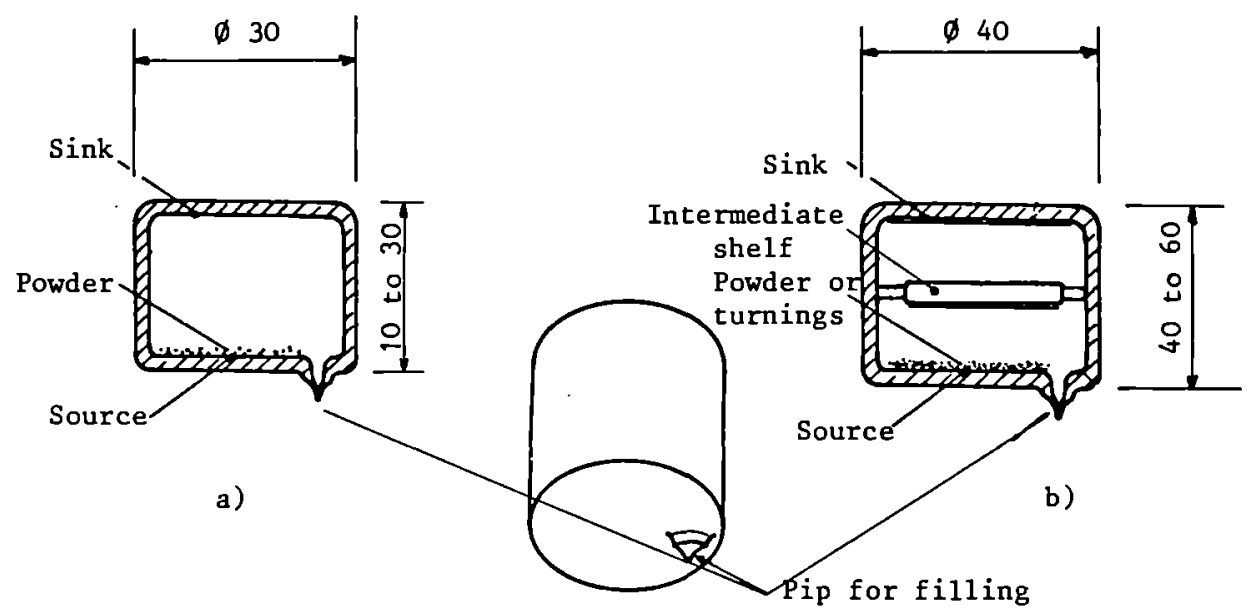

Figure 3 : Characterization test ampoules

It is made of a quartz cylinder limited by two flat discs. These flat faces are placed between two metal cylinders. The upper is a stainless steel cylinder heated by a radiation furnace when the lower is cooled through a stack of cylinders as shown in figure 4.

This assembly is intended to produce a longitudinal thermal flux resulting in depositing on the upper flat disc of the ampoule.

For a given upper temperature, measured by the thermocouple TC1 located in the stainless steel cylinder close to the ampoule surface, the 10wer temperature is adjusted by modifying the cylinder stack : cylinders of copper, nickel or stainless steel of various sizes were used to modify the thermal resistance of the stack. The ampoules were loaded with $354 \mathrm{~L}$ stainless steel powder of 100 to 200 microns (previously hot degassed under high vacuum) and with iodine grains. Two parameters were defined at this stage :

- the number of moles of iodine or of iodide which determines the pressure of the gases in the ampoule (from 0.5 to 2 atmospheres),

- the ratio of iodine to metal which could have an influence on the composition of the gases during the transport. 


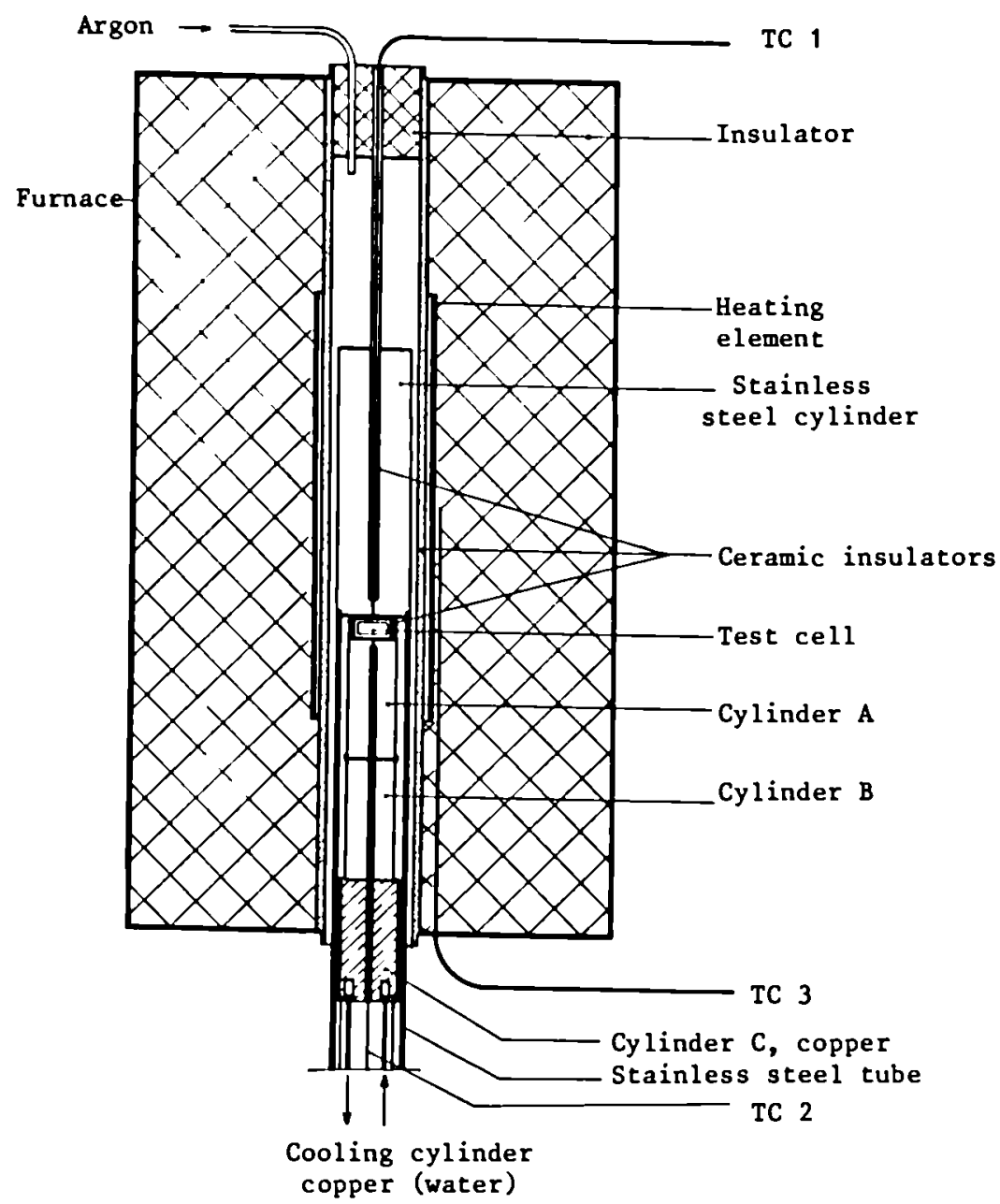

Figure 4 : Test set-up

The ampoules are sometimes hot-degassed under low vacuum before being filled. Once filled they are placed under low vacuum at room temperature for 5 to 15 minutes befores being sealed. Since iodine is volatile, it is advisable to restrict the temperature and the duration of the degassing as much as possible.

The experimental conditions of the tests carried out are indicated in Table I. The typical duration for a period of constant temperature is 48 hours preceeded and followed by heating and cooling period of about 4 hours each. The effect of several parameters was tested :

- the distance between source and sink varied from $5 \mathrm{~mm}$ to $40 \mathrm{~mm}$ without any noticeable ef fect,

- an intermediate quartz stool or shelf placed between the two flat discs allowed the depositings to occur in several places. As expected the compositions of the depositings were different,

- the iodization rate ranged from $13 \mathrm{mg} \mathrm{I}_{2}$ for $512 \mathrm{mg}$ steel to $54 \mathrm{mg} \mathrm{I}_{2}$ for $59 \mathrm{mg}$ steel, 
- the source temperature changed from $680^{\circ} \mathrm{C}$ to $1175^{\circ} \mathrm{C}$ when the sink temperature ranged from $1160^{\circ}$ to $1300^{\circ} \mathrm{C}$,

- the duration of the isothermal period varied from $12 \mathrm{~h}$ to $144 \mathrm{~h}$,

- the nature of the source alloy were also modified : steel powder, depositings or turnings.

Table I : Experimental results

\begin{tabular}{|c|c|c|c|c|c|c|c|c|c|c|}
\hline \multirow{2}{*}{$\begin{array}{l}\mathrm{N}^{\circ} \\
\text { test }\end{array}$} & \multirow{2}{*}{$\begin{array}{c}\text { Iodine/ } \\
\text { stainless } \\
\text { steel }\end{array}$} & \multirow{2}{*}{$\begin{array}{c}\text { Time } \\
\text { hours }\end{array}$} & \multirow{2}{*}{$\begin{array}{l}\text { Temp. }{ }^{\circ} \mathrm{C} \\
\text { source/sink }\end{array}$} & \multirow{2}{*}{$\mid \begin{array}{l}\Delta \mathrm{T} \\
{ }^{\circ} \mathrm{C}\end{array}$} & \multirow{2}{*}{\begin{tabular}{|l|}
\multicolumn{1}{c}{ Deposit } \\
$\quad$ mg \\
$\mathrm{U}$ :up.face \\
$\mathrm{T}$ :shelf \\
\end{tabular}} & \multirow{2}{*}{ mg/day } & \multicolumn{4}{|c|}{ Chemical analysis } \\
\hline & & & & & & & Cr \% & $\mathrm{Fe} \%$ & $\mathrm{Ni \%}$ & $\begin{array}{c}\text { Co } \\
\text { ppm }\end{array}$ \\
\hline 1 & $16 / 1000$ & 48 & $1030 / 1165$ & 135 & 48 & 24 & 35 & 62 & 2.5 & 83 \\
\hline 4 & 5 & 48 & $1000 / 1170$ & 170 & & & 34.3 & 59.4 & 1.2 & $<100$ \\
\hline 7 & $0 / 1000$ & 48 & $1090 / 1250$ & 160 & 65 & 32 & 31 & 65 & 3 & 80 \\
\hline 14 & 18 & 48 & $1008 / 1220$ & 212 & 83 & 42 & 32.4 & 64.8 & 2.5 & $<100$ \\
\hline 15 & $48 / 500$ & 34 & $990 / 1290$ & 225 & $\begin{array}{l:l}\mathrm{U}: & 71 \\
\mathrm{~T}: & : 37\end{array}$ & 76 & \begin{tabular}{|l|}
31.2 \\
22.5
\end{tabular} & \begin{tabular}{|l|}
67 \\
68.6
\end{tabular} & $\begin{array}{l}2 \\
6.3\end{array}$ & $\begin{array}{r}67 \\
147\end{array}$ \\
\hline 16 & $51 / 500$ & 73 & $990 / 1216$ & 226 & 90 & 30 & 22.4 & 62 & 9.4 & 156 \\
\hline 17 & $53 / 503$ & 24 & $1000 / 1225$ & 225 & $\begin{array}{l}\mathrm{U}: 100 \\
\mathrm{~T}: 68\end{array}$ & 168 & & & & \\
\hline 18 & $55 / 498$ & 12 & $990 / 1210$ & 220 & $\begin{array}{l:l}\mathrm{U}: & 37 \\
\mathrm{~T} & : 25\end{array}$ & 124 & & & & \\
\hline 19 & $50 / 500$ & 48 & $780 / 1220$ & 440 & $\begin{array}{l:l}\mathrm{U}: 81 \\
\mathrm{~T}: 91\end{array}$ & 86 & \begin{tabular}{|l|}
36.5 \\
28.8
\end{tabular} & $\begin{array}{l}62 \\
69 \\
\end{array}$ & $\begin{array}{l}1.4 \\
2.2 \\
\end{array}$ & $<100$ \\
\hline 22 & 51 & 24 & $900 / 1210$ & 310 & 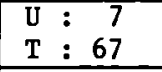 & 74 & & & & \\
\hline 23 & $13 / 512$ & 24 & $900 / 1220$ & 320 & $\begin{array}{l:r}U: 10 \\
T: & 8 \\
\end{array}$ & 18 & & & & \\
\hline 25 & $49 /$ & 48 & $770 / 1220$ & 450 & $\begin{array}{l:l}\mathrm{U}: 41 \\
\mathrm{~T}: 51 \\
\end{array}$ & 46 & 34.8 & 58 & 1.8 & $<100$ \\
\hline 26 & \begin{tabular}{|c|}
$54 / 59$ \\
$\mathrm{~T}$ deposit \\
19
\end{tabular} & 24 & $770 / 1240$ & $470 \mid$ & 36 & 36 & 13.2 & 84 & 2.7 & 152 \\
\hline 27 & \begin{tabular}{|c|}
$44 / 60$ \\
U deposit \\
19
\end{tabular} & 24 & $835 / 1240$ & 405 & 47 & 47 & 24 & 76 & 1 & 68 \\
\hline 28 & $138 / 500$ & 48 & $820 / 1240$ & 420 & 225 & 112 & 18 & 76 & 5.2 & 225 \\
\hline 29 & $55 / 2000$ & 48 & $700 / 1230$ & 530 & $\begin{array}{l:l}\mathrm{U} & : 15 \\
\mathrm{~T} & : 129 \\
\end{array}$ & 72 & 38.4 & 59 & 2.4 & 88 \\
\hline 30 & 106 & 144 & $30 / 1210$ & $530 \mid$ & $\begin{array}{l:l}\mathrm{U}: 387 \\
\mathrm{~T}: 210\end{array}$ & 100 & 39 & 58 & 1.5 & 71 \\
\hline $3 \overline{1}$ & $100 / 2000$ & 72 & $690 / 1210$ & 520 & 416 & 139 & 36.6 & 37 & 5.8 & 205 \\
\hline 32 & $107 / 1900 *$ & 72 & $690 / 1210$ & 520 & $\begin{array}{l:l}\mathrm{U} & : 420 \\
\mathrm{~T} & : 124 \\
\end{array}$ & 181 & 30.2 & 68.6 & 1.1 & 753* \\
\hline 33 & $107 / 2000 *$ & 72 & $690 / 1210$ & 520 & $\mathrm{U}: 558$ & 268 & 28.4 & 70.2 & 1.2 & $920 *$ \\
\hline \multicolumn{7}{|c|}{ Stainless steel powder } & 19 & 70 & 11 & 280 \\
\hline \multicolumn{7}{|c|}{ *Stainless steel turnings } & 19 & 06 & 12 & $2860 *$ \\
\hline
\end{tabular}




\section{Analysis of the results}

\section{Temperatures}

The highest sink temperature is limited by the softening of the quartz at about $1250^{\circ} \mathrm{C}$. The lowest possible source temperature lies between $500^{\circ} \mathrm{C}$ and $690^{\circ} \mathrm{C}$ as no more precise experimental determination has been made.

All the experimental values given in this text correspond to thermocouple temperatures taken outside the ampoules and thus not to the actual deposit or source alloy temperatures. It is to be noticed that assuming a purely radiative heat transfer the actual temperature difference between source and sink may be only one third of the presented values. Under this assumption the highest sink temperature is $1200^{\circ} \mathrm{C}$ and the lowest source temperature is $860^{\circ} \mathrm{C}$.

\section{Temperature difference}

The minimum temperature difference at which a deposit was always observed is $150^{\circ} \mathrm{C}$ (measured) or $50^{\circ} \mathrm{C}$ under radiative conditions.

However many experiments did not lead to a deposit on the upper disc perhaps because of the presence of light stray gas accumulated against the hotter part of the ampoule by thermodiffusion, effect sensitive here because of the high molecular weight of iodine and iodides. Thus it was not proved that depositing will not occur for smaller temperature differences in absence of stray gas. When deposits were obtained on the upper disc and under the intermediate shelf this temperature difference could have been of $55^{\circ} \mathrm{C}$ assuming a purely radiative thermal exchange (samples 15, 17, 18).

Iodization rate

Conversely to the thermodynamic estimate no effect of the iodization rate was found on the separation coefficients within the scattering range.

The overall kinetics of transport is increased with either the pressure of iodides or the iodization rate. For instance tests number 29,30 and 31 showed that when the amount of iodine is doubled the kinetics changes from $70 \mathrm{mg} /$ day to $120 \mathrm{mg} /$ day. No iodide saturation 1 imit is apparent from the experiments but it is obvious that the iodization rate cannot be increased indefinitely without formation of condensed iodide and progressive transformation of the alloy into an ioxide mixture. This trend is illustraded in rigure 9 where the observed transport rate for a $48 \mathrm{~h}$ experiment is plotted as a function of iodine absolute load.

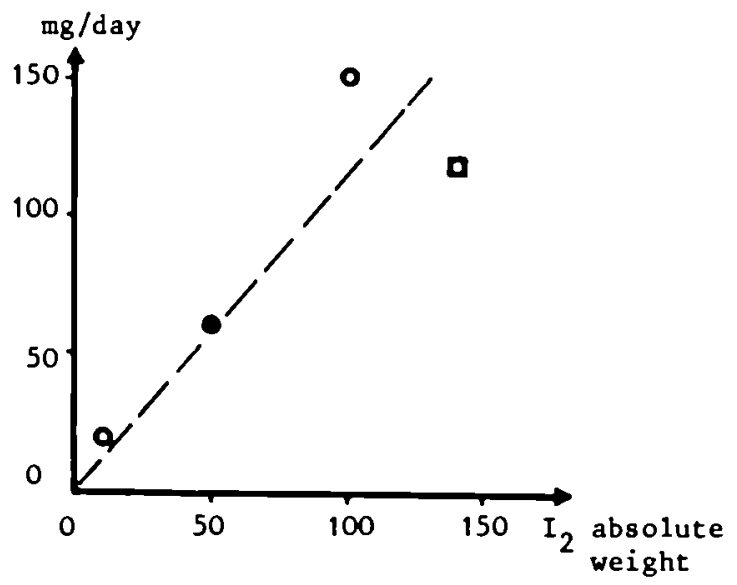

Figure 5: Transport rate as a function of iodine content of the ampoules 
The limiting step of the kinetic

By plotting the mean transport rate as a function of duration of transport it appears, at least for two source temperatures $\left(700^{\circ} \mathrm{C}\right.$ and $1000^{\circ} \mathrm{C}$ ), that this rate decreases with time more rapidly at high temperature (figure 6) and seems to tend toward the same limit for short duration whatever the temperature. A consistent explanation of such behavior as well as of the fact that turnings are transported easierly than powders can be found in the action of the dislocations of the alloys.

Indeed under the assumption that the kinetic of transport is limited by a surface reaction step on the source alloy on sites where the dislocations reach the surface all these facts can be explained :

- the transport rate is higher for turnings than for powder (more than 200 mg/day versus less than $100 \mathrm{mg} /$ day), despite of a factor of 5 on their respective specific macroscopic area resulting in an increase of one order of magnitude for the transport rate per unit area. The most obvious difference between the two materials is that turnings underwent large plastic deformation and probably accumulated dislocations when powder, quenched from liquid drops, has only a very small amount of dislocations,

- the dislocations are eliminated from metals at a rate depending on temperature. This process is almost instanteneous at the recristallization temperature of the alloys $\left(1000\right.$ to $1100^{\circ} \mathrm{C}$ in the present case) and become very slow below $600^{\circ} \mathrm{C}$. This explains qualitatively the observed behavior of the transport rate with duration and temperature.

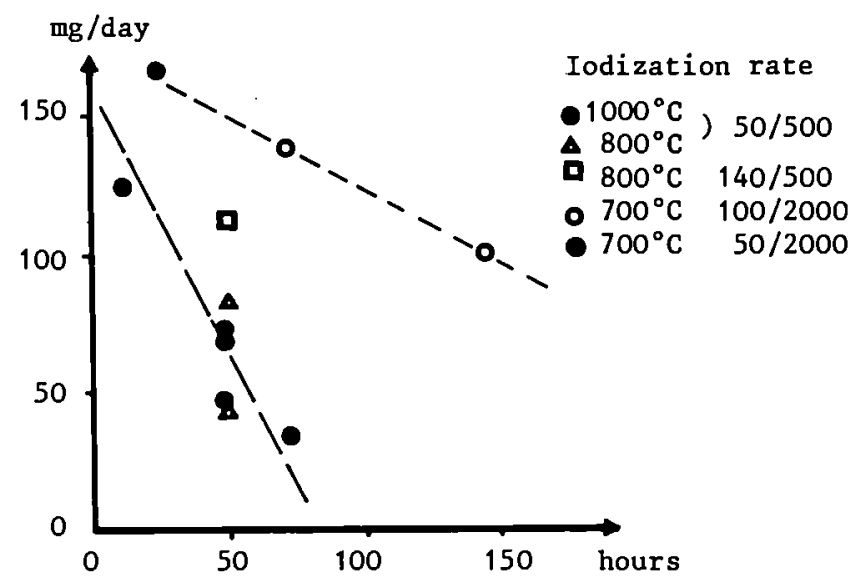

Figure 6 : Change of transport rate with experiment duration for several source temperatures

Separating power (Table II)

The ratio of the separation coefficients of cobalt and nickel from the deposit to the residue is about 1.6 (2.3 for the secondary treatment of the deposits). By adopting a ratio of 2 , nickel and cobalt are separated in 10 phases (factor of 1000). The thermodynamic estimate of 1.75 is confirmed and the good correlation allows the cobalt contents of tests number 14,19 and 25 to be estimated. 
Table II : Separation coefficient of $i: Z i$ in the deposit $Z i$ in the residue

\begin{tabular}{|c|c|c|c|c|c|}
\hline Test & $\mathrm{Cr}$ & $\mathrm{Pe}$ & $\mathrm{Ni}$ & Co & Comments \\
\hline $\begin{array}{l}19 \\
26 \\
27\end{array}$ & $\begin{array}{l}2.2 \\
0.25 \\
0.28\end{array}$ & $\begin{array}{l}1 \\
1.8 \\
2\end{array}$ & $\begin{array}{l}0.08 \\
1.9 \\
0.3\end{array}$ & $\begin{array}{l}0.13 \\
1.5 \\
2.4\end{array}$ & $\begin{array}{l}\text { Secondary treatment of the de- } \\
\text { posits } 19 \text { - very high rate of } \\
\text { iodine - almost total transport }\end{array}$ \\
\hline $\begin{array}{l}28 \\
31 \\
30 \\
32 \\
33\end{array}$ & $\begin{array}{l}0.9 \\
2.5 \\
2.9 \\
1.9 \\
2\end{array}$ & $\begin{array}{l}1.17 \\
0.77 \\
0.67 \\
1.05 \\
1.11\end{array}$ & $\begin{array}{l}0.33 \\
0.46 \\
0.1 \\
0.06 \\
0.05\end{array}$ & $\begin{array}{l}0.7 \\
0.7 \\
0.18 \\
0.20 \\
0.22\end{array}$ & High iodization rate of iodine \\
\hline $\begin{array}{l}1 \\
7 \\
15 \\
16 \\
25 \\
29 \\
14\end{array}$ & $\begin{array}{l}1.8 \\
1.6 \\
1.7 \\
1.23 \\
1.8 \\
2 \\
2\end{array}$ & $\begin{array}{l}0.9 \\
0.9 \\
0.96 \\
0.86 \\
0.83 \\
0.83 \\
0.91\end{array}$ & \begin{tabular}{|l|}
0.25 \\
0.3 \\
0.27 \\
0.8 \\
0.15 \\
0.21 \\
0.2
\end{tabular} & $\begin{array}{l}0.3 \\
0.3 \\
0.28 \\
0.51 \\
0.25 \\
0.3 \\
0.32\end{array}$ & \\
\hline $\begin{array}{l}\text { average } \\
\text { value } \\
\text { except } \\
26.27\end{array}$ & $1.9 \pm 0.5$ & $0.9 \pm .14$ & \pm .2 & $0.34 \pm 0.18$ & \\
\hline
\end{tabular}

It is advisable, however, to correct the approximate measurements by taking account of the evolution of the composition of the residue in at least 7 of the tests. In the case of deposits occurring on two levels at two different temperatures, the separation coefficient calculated corresponds to the lower temperature differences. This factor does not seems to have an influence on the separation when close to the thermal efficiency. On the other hand, the results is not always the same for two successive treatments. In order to standardise the results, only the average composition of the deposits were considered.

Except for test numbers 26 and 27 , where the masses concerned were small and the transport was almost total, and for test 28 , where the ratio of iodine to metal was high and where the quantity of iodide produced was able to vitiate the results of the mass, the coefficients of separation are the following :

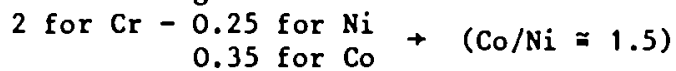

Conclusions drawn from the transport tests

Despite the difficulties of reproducibility which were encountered due to the experimental techniques used, the tests carried out have allowed the kinetic characteristics and the efficiency of the proposed separation process to be defined. The most significant results are detailed below :

- the treatment of steel turnings, even when these are thick, lead to very good transport speeds, perhaps owing to significant plastic deformations undergone by the metal, 
- the minimum treatment temperature which has been observed is below $700^{\circ} \mathrm{C}$ as measured which may correspond to $800^{\circ} \mathrm{C}$ in actual source temperature,

- it is probable that the productivity of the installation would be distinctly improved by increasing the iodide pressure ( 10 bars),

- the separating power observed for each element is rather better than expected and varies little in relation to the temperature or the iodine rate or the composition of the alloys.

Using figures available to us at the present time, it is possible to estimate the flux of the metal treated per surface unit of the installation to be $1 \mathrm{~kg} / \mathrm{m}^{2} /$ day. A total of 40 to 150 successive transport would be necessary to reduce the cobalt content in the greater part of the metal $(>90 \%)$ by a factor of $10^{3}$.

\section{OUTLINE OF A POSSIBLE PROCESS}

In order to figure out the caracteristics of a separation process based on the present study of elementary transport it is necessary to fix a minimum of assumed operating conditions. Our arbitrary choice is as follows. The transport takes place inside a gastight vessel furnished with independently heatable shelves. The metal to be treated (preferably turnings) is introduced on the first shelf along with an iodide (or iodine) load. The vessel is put under vacuum and sealed before beeing heated at about $700^{\circ} \mathrm{C}$. The shelf next to the loaded one is superheated, of $100^{\circ} \mathrm{C}$ for instance, and transport takes place. This situation goes on until a given fraction of metal is transported : $50 \%$ in the present example. For such a single transport the separation coefficient depends on the fraction transported and on the alloy composition. A simplified estimate of this dependence, in agreement with the experimental results, is given by the expression :

$$
r_{i}=\sum_{j} a_{i}^{j} \cdot x_{j}
$$

where $i$ designates the element under consideration and $j$ all the elements of the alloy with a concentration $x_{j}$ expressed in weight fraction. The $a_{i} j$ matrix adopted in the present calculation is :

\begin{tabular}{|c|l|l|l|l|}
\hline $\mathrm{i}^{\mathrm{j}}$ & $\mathrm{Cr}$ & $\mathrm{Ni}$ & $\mathrm{Co}$ & $\mathrm{Fe}$ \\
\hline $\mathrm{Cr}$ & 1 & 8 & 0 & 2 \\
$\mathrm{Ni}$ & 0.06 & 1 & 0 & 0.12 \\
$\mathrm{Co}$ & 0.08 & 1.5 & 1 & 0.16 \\
$\mathrm{Fe}$ & 0.4 & 4 & 0 & 1 \\
\hline
\end{tabular}

The first transport beeing completed, the two first shelves are put back to $700^{\circ} \mathrm{C}$ and the third is superheated for transporting the deposit of the second shelf. Then the remaining alloy on the first shelf is treated. The composition of the alloys of two origins on the second shelf are almost identical. This constitutes the second step of the treatment.

The same basic process is repeated untill the alloy on the last shelf occupied has a cobalt content less than $0.3 \mathrm{ppm}$ or the alloy on the first shelf contains more than $1500 \mathrm{ppm}$ Co. Then the deposits on these shelves may be removed or transported to a definite storage inside the vessel.

With the present figures the number of shelf occupied at each step is not greater than 6 . The total number of step needed to recover $80 \%$ of the metal is of about 40. The number of elementary transport at each step is 4 in most cases. The over-all number of elementary transport is thus 160 . 
As we admitted that a transport rate of $1 \mathrm{~kg} / \mathrm{m}^{2} /$ day is possible the productivity of such a device would be of about $6 \mathrm{~g} / \mathrm{m}^{2} / \mathrm{day}$. This rate is far from suitable for the initial goal which was the treatment of about $1000 t$ of steel per dismantled vessel.

\section{CONCLUSION}

Experiments were carried out on a $2 \mathrm{~g}$ scale to measure the characteristics of a vapour phase transport process in view of its application to cobalt separation from the other constituents of PWR vessel steels (stainless and mild). The figures obtained show that this separation is possible but at a cost likely more than one order of magnitude higher than the cost of storage after casting into ingots.

The physicochemical factors of this cost are the kinetics of transport and the separation coefficient for a single transport. This last factor was found to be fairly large with respect to what is to be expected and in good agreement with thermodynamic calculations. It is not likely to be improved enough, using other carrier gases for instance, to be able to decrease very significantly the total number of transport needed to achieve a given separation. This number should always be of the order of 100 to reach an overall separation coefficient of $10^{3}$ to $10^{4}$.

The kinetics of the process was not investigated throughout. It was only shown that, under the present conditions, it is sensitive to the presence of dislocations. This fact is favourable to the treatment of turnings but prohibits elevated temperatures that would allow higher iodide pressure without condensation. It is thus not obvious that an increase in iodization rate would accelerate the transport. No real improvement on that point seems achievable in view of the physicochemistry of the process.

The proposed separation process, although presenting the advantages of not creating extra waste nor changing the nature of the waste, is not suitable for cobalt separation in steels but may be of some importance in cases where a lower separation coefficient is requested. 
BEHAVIOUR OF DIFFICULT TO MEASURE RADIONUCLIDES IN THE MELTING OF STEEL

\author{
SCHUSTER E., HAAS E.W. \\ Siemens Aktiengesellschaft Unternehmensbereich KWU, \\ Fachbereich Zentrale Entwicklung und Technik, \\ U9 241, Postfach 3220, D-8520 Erlangen
}

\begin{abstract}
In general the melt experiments confirmed the expected behaviour of the radionuclides selected for the experiments. $55 \mathrm{Fe}$ and $63 \mathrm{Ni}$ distribute homogeneously in the metal ingot as was expected from the behaviour of $60 \mathrm{Co}$. The latter radionuclide may be used as an indicator nuclide for $55 \mathrm{Fe}$ and $63_{\mathrm{Ni}}$ which are both difficult to measure. ${ }^{14} \mathrm{C}$ shows a comparable behaviour and is homogeneously distributed in carbon steel.
\end{abstract}

\begin{abstract}
As expected strontium is released to the slag in the melt process. In principle this is valid for actinides too. The behaviour of actinides in the melt process depends to some extent on the chemical form (elemental uranium, $\mathrm{UO}_{2}$ ), the added tracer quantity and the quantity of slag forming material added in the melt process.
\end{abstract}

A direct $\propto$-measurement technique was developed to measure $\boldsymbol{\alpha}$ radionuclides in steel samples. Only this type of measurement has to be applied in case of $\alpha$-emitters as a decision measurement to assure that the steel decontaminated by the melt process can be released for unrestricted reuse.

\title{
1. INTRODUCTION
}

Various types of contaminated components (e.g. piping, valves, heat exchangers, vessels, etc.) are to be removed during decommissioning of nuclear installations. Depending on their origin, these components may be contaminated with alpha, beta, and gamma emitters. Unrestricted reuse or recycling into nuclear facilities are possible pathes to reduce the volume of waste. Unrestricted reuse is possible, if the residual activity concentration can be proven to be below the authorized limits.

To achieve this goal, known decontamination and free release measurement techniques can be used. In the case of components with complex surface geometry, however, decontamination and free release measurements cannot be achieved economically. The conditioning of those materials may be better achieved by melting in many cases.

The objective of the research contract was to extend the melt decontamination technique to steel components that are contaminated with actinides and other difficult to measure radionuclides.

\section{LABORATORY SCALE MELTING EXPERIMENTS}

Melting experiments were performed in the radiochemical laboratory of Siemens AG, KWU-Group, using a Nernst-Tammann high-temperature furnace. A continuously adjustable transformer allows a power output of up to $23 \mathrm{kVA}$ and thus temperatures up to $1700{ }^{\circ} \mathrm{C}$. An adjustable chimney head was installed above the furnace and connected by a metal tube to the of $\mathrm{f}$ gas system of the controlled area. An additional aerosol filter was installed after the chimney head to collect all aerosol activity that may be released during melting. The aerosol activity was measured after each 
experiment. The melt temperature was measured by a ceramic tube-covered platinium-rhodium-platinium thermocouple.

For the melting experiments, carborundum tube crucibles with an inside diameter of $60 \mathrm{~mm}$ were usually used, which were located inside a arety crucible with an inolde diameter of $105 \mathrm{~mm}$ to avoid contamination of the furnace in the event of a crucible failure. The crucible had a melt capacity of 3 to $5 \mathrm{~kg}$.

The use of rather high tube crucibles with, for example, an overall length of $300 \mathrm{~mm}$ (to obtain fairly thin ingots) facilitates the separation of the 8 lag and melt ingot and allowed easy control of the activity distribution along the axis of the small ingot.

For the first laboratory-8cale melt experiment with ${ }^{60} \mathrm{Co}, 55_{\mathrm{Pe}}$ and $241 \mathrm{Am}$ these three isotopes were deposited on the surface of small steel discs by electrodeposition methods. In all following experiments the tracers were either prepared on $\mathrm{SiO}_{2}-\mathrm{filters}$ in form of carbonate or hydroxide precipitates (NI, Sr) and in elementary form (C14) or were directly inserted $\left(\mathrm{U}_{\text {met., }} \mathrm{UO}_{2}\right)$. The tracers were inserted into a hole of the inactive steel rod near the bottom. The steel rod was the quality St37-2 (german steel grade 1.0161) and was used in all tracer experiments. After cooling down of the melts the crucibles have been demolished to obtain the ingot and the slag. Only about $60-80 \mathrm{z}$ of the $81 \mathrm{gg}$ could be obtained. It was than powdered in a ball or powder mill to a grain size of about $1 \mu \mathrm{m}$ for activity measurements.

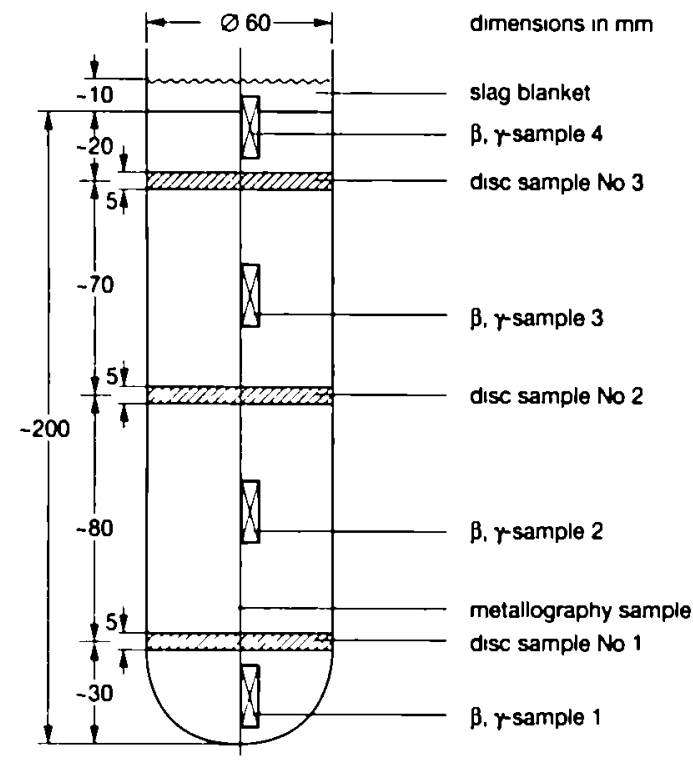

Fig. I Cutting scheme of ingots 
From the ingot sample-discs were cut and polished. The discs were taken for activity measurements and autoradiographs. These samples contained also the original surface of the ingot and could show the real relation-ship in the native state. Smaler samples were taken from the center of the ingot without an influence by the surface. These samples also have been used for additional activity measurements and in the case of U-melts for Neutron Activation Analyses (NAA). The cutting scheme is shown in Fig. 1

The aerosolfilters were prepared in such a form, that representative samples of the whole volume and surface area could be obtained.

\section{BEHAVIOUR OF THE RADIOACTIVE ISOTOPES OF FE, CO, NI AND CARBON IN THE MELTING OF STEEL}

Components of reactor cooling systems of nuclear power plants (NPP) contain steel alloys of varying composition (e.g. austenitic steel, incoloy 800 , inconel 600 , stellites and others).

Corrosion product radionuclides commonly found in oxide layers and contamination films on primary system components are $51_{\mathrm{Cr}}, 54 \mathrm{Mn}, 55 \mathrm{Fe}$, $58^{\mathrm{Co}},{ }^{59} \mathrm{Ni},{ }^{60} \mathrm{Co}$ and $63_{\mathrm{Ni}}[1,2,3]$. These radioisotopes belong to the alloying elements of steel. Melt-down of components beeing contaminated with these radionuclides should result in a homogenious distribution of the mentioned isotopes in the metal melt [4]. Another radioisotope which should be distributed homogeneously in the metal melt too should be ${ }^{14} \mathrm{C}$. This radioisotope is produced in light water reactors (LWR) as well as in advanced gas cooled reactors (AGR) and may be incorporated in contamination films. In the melt-down of steel this radioisotope should also be distributed homogeneously in the metal melt.

Considering the half lifes of the above mentioned radionuclides only isotopes with half lifes longer than one year may contribute essentially to the total activity of contaminated components from decommissioned NPPs, these are ${ }^{14} \mathrm{C},{ }^{55} \mathrm{Fe},{ }^{59} \mathrm{Ni},{ }^{60} \mathrm{Co}$ and ${ }^{63} \mathrm{Ni}$.

${ }^{60} \mathrm{Co}$ is a gamma emitter and may easily be determined by gamma spectrometry. ${ }^{14} \mathrm{C}$ and $63 \mathrm{Ni}$ are pure beta emitters and may be measured either by direct beta counting or after separation from a dissolved steel sample by liquid scintallation counting. $55 \mathrm{Fe}$ and $59_{\mathrm{Ni}}$ decay by electron capture and emission of low energy $X$-ray radiation. They can only be determined after dissolution of a steel sample and special separation of iron and nickel from the solution.

Goal of the investigation was dlso to develope separate measuring methods for each hard to measure isotope and to demonstrate that ${ }^{60} \mathrm{Co}$ may be used as an indicator isotope for those difficult to measure radionuclides which will be distributed homogeneously in the metal melt.

The added activities and other parameters of laboratory-scale melt experiments are summarized in Table $I$. After cooling down, crucible, ingot and slag were separated for measurements. 
Table I Material, additives and boundary conditions of $60 \mathrm{Co}, 55 \mathrm{Fe},{ }^{14} \mathrm{C}$, ${ }^{63} \mathrm{Ni}$ melt experiments

\begin{tabular}{|c|c|c|c|c|}
\hline $\begin{array}{c}\text { Materıal } \\
\text { steel } \\
\text { St37-2 }\end{array}$ & Additives & $\begin{array}{l}\text { Added tracers } \\
\text { and activities }\end{array}$ & $\begin{array}{c}\text { Tracer } \\
\text { quantities }\end{array}$ & $\begin{array}{c}\text { Boundary Conditions } \\
\text { of melt }\end{array}$ \\
\hline $3210 \mathrm{~g}$ & $\begin{array}{l}\text { coal: } 90 \mathrm{~g}(3 \%) \\
\text { SiC: } 75 \mathrm{~g}(2,5 \%) \\
\text { slag former: } 30 \mathrm{~g}(1 \%)\end{array}$ & $\begin{array}{l}\text { Co60: } 2.5 E+4 \\
\text { Fe55: } 33 E+5\end{array}$ & $\begin{array}{r}2 \mathrm{mg} \\
10 \mathrm{mg}\end{array}$ & $\begin{array}{c}\text { temperature: } 1480-1530^{\circ} \mathrm{C} \\
\text { dwell tıme of melt: } 15 \mathrm{~min} \\
\text { cooling down tıme: } 6 \mathrm{~h} \\
\text { cover gas: argon with } 10 \% \\
\text { hydrogen }\end{array}$ \\
\hline $3155 \mathrm{~g}$ & $\begin{array}{l}\text { coal: } 90 \mathrm{~g}(3 \%) \\
\text { SiC: } 75 \mathrm{~g}(2.5 \%) \\
\text { slag former: } 30 \mathrm{~g}(1 \%)\end{array}$ & $\begin{array}{c}\text { Ni63: } \\
3.3 \cdot 10^{6} \mathrm{~Bq}\end{array}$ & $10 \mathrm{mg}$ & dwell time: $30 \mathrm{~min}$. \\
\hline $3180 \mathrm{~g}$ & $\begin{array}{l}\text { coal: } 90 \mathrm{~g}(3 \%) \\
\text { SiC: } 75 \mathrm{~g}(2.5 \%) \\
\text { no slag fromer }\end{array}$ & $\begin{array}{c}\text { C14: } \\
3.4 \cdot 106 \mathrm{~Bq}\end{array}$ & $1 \mathrm{mg}$ & dwell time: $30 \mathrm{~min}$. \\
\hline
\end{tabular}

Radionuclides 1 ike ${ }^{55} \mathrm{Fe},{ }^{60} \mathrm{Co},{ }^{59} \mathrm{Ni}$ and ${ }^{63} \mathrm{Ni}$ belonging to alloying elements and to impurities of steel qualities used in nuclear installations remained totally in the metal melt as was expected. The release to the slag and to the of $\mathrm{fgas}$ system is negligibly low. The experiments demonstrated that $60^{\circ} \mathrm{Co}$, easy to measure by $\gamma^{2}$-spectrometry, may be used as an indicator isotope for the other difficult to measure isotopes mentioned above.

The results of the tracer experiments are summarized in Table II.

Table II Results of test melt experiments with ${ }^{60} \mathrm{Co},{ }^{55} \mathrm{Fe},{ }^{63} \mathrm{Ni},{ }^{14} \mathrm{C}$

\begin{tabular}{|c|c|c|c|c|}
\hline $\begin{array}{l}\text { Measured } \\
\text { Sample }\end{array}$ & $\begin{array}{c}\text { Content } \\
\text { of Co60 } \\
x\end{array}$ & $\begin{array}{c}\text { Content } \\
\text { of Fe55 } \\
x\end{array}$ & $\begin{array}{c}\text { Content } \\
\text { of } \mathrm{N} 163 \\
\%\end{array}$ & $\begin{array}{c}\text { Content } \\
\text { of C14 } \\
x\end{array}$ \\
\hline $\begin{array}{l}\text { Ingot } \\
\text { - segments 1-4 }\end{array}$ & 108 & 70 & $\begin{array}{c}\sim 82 \\
106-110-89-24\end{array}$ & $\begin{array}{c}91 \\
86-90-96-90\end{array}$ \\
\hline slag & 0.2 & n. d. & 0.04 & 0.4 \\
\hline Aerosolfilter & 0.2 & n. d. & 0.06 & $<0.001$ \\
\hline
\end{tabular}


Regarding varying cobalt contents of materials, different lifetime of NPPs and varying standby time between final shutdown and demolition of the plant, proven methods for the individual determination of $55 \mathrm{Fe},{ }^{59} \mathrm{Ni}$ and $6{ }^{3} \mathrm{Ni}$ are required.

Though ${ }^{63} \mathrm{Ni}$ may be measured directly by $\beta$-counting; dissolution of a steel sample, separation of $\mathrm{Ni}$ from the solution and liquid scintillation counting is the method to be selected for ${ }^{63} \mathrm{Ni}$ measurement with respect to the radiation background of other radionuclides in the steel sample. The same measurement sample can be used to determine ${ }^{59} \mathrm{~N} 1$ by $\mathrm{X}$-ray measurement with a $\mathrm{Ge}(\mathrm{Si})$-detector, while $55_{\mathrm{Fe}}$ is measured separately after separation from a dissolved steel sample.

The pure $\beta$-emltter ${ }^{14} \mathrm{C}$ has to be determined separately, though this isotope is distributed homogeneously in the metal ingot too. ${ }^{60} \mathrm{Co}$ cannot be used as an indicator isotope for ${ }^{14} \mathrm{C}$ because of completely different sources of formation of these two isotopes.

Melted scrap from NPPs contains several $\beta$-emitting radionuclides. Hence the best method to determine ${ }^{14} \mathrm{C}$ in steel and slag samples is to separate this nuclide via combustion as ${ }^{14} \mathrm{CO}_{2}$ with subsequent conversion into $\mathrm{BaCO}_{3}$ for $\beta$-measurement. The results of the melt experiment with $14 \mathrm{C}$ are included in Table II.

4. BEHAVIOUR OF RADIOACTIVE STRONTIUM

Contaminated scrap from NPPs may contain some fission product radionuclides. Because of the great significance of the longlived radioisotope. ${ }^{90} \mathrm{Sr}$ in health physics this element has to be considered in the melting of contaminated steel. From the chemical behaviour of this earthalkaline element one can expect, that $90 \mathrm{Sr}$ will be totally released to the slag in the melting of steel.

Separation of ${ }^{90} \mathrm{Sr}$ from various matrices and measurement of this isotope are well established methods but they are time-consuming and expensive to perform. Therefore the $\mu$-emitting ${ }^{85} \mathrm{Sr}$ was used for the melt-experiments (Table III). The uptake of strontium in the steel melt is very low, about one part of thousand was measured. The transport of this element to the aerosol filter is extremly low too.

Table III Material, additives and boundary conditions of Sr85 melt experiment

\begin{tabular}{|c|c|c|c|c|}
\hline \multirow[t]{2}{*}{ Material } & $\begin{array}{l}\text { Added radio- } \\
\text { activity }\end{array}$ & \multicolumn{2}{|c|}{$\begin{array}{c}\text { Additives } \\
* \text { of steel mass }\end{array}$} & Boundary conditions of melt \\
\hline & & & & $\begin{array}{l}\text { all melts: } \\
\text { temperature: } 1480-1530{ }^{\circ} \mathrm{C} \\
\text { cover gas: argon, } 10 \times \mathrm{H}_{2} \\
\text { colling time: } 6 \mathrm{~h}\end{array}$ \\
\hline $\begin{array}{c}\text { steel St37-2; } \\
3150 \mathrm{~g}\end{array}$ & $\begin{array}{l}\text { Sr85: } \\
3.7 \mathrm{E}+6 \mathrm{~Bq}\end{array}$ & $\begin{array}{l}\text { C: } \\
\text { SiC: }\end{array}$ & $\begin{array}{l}3 \% \\
2.5 \%\end{array}$ & dwell time 30 min \\
\hline $\begin{array}{c}\text { steel St37-2; } \\
3150 \mathrm{~g}\end{array}$ & $\begin{array}{l}\text { Sr85: } \\
3.7 \mathrm{E}+6 \mathrm{~Bq}\end{array}$ & $\begin{array}{l}\mathrm{C}: \\
\mathrm{SiC}: \\
\mathrm{SiO}_{2} \\
\mathrm{CaO}: \\
\mathrm{Al}_{2} \mathrm{O}\end{array}$ & $\begin{array}{l}3 \% \\
2.5 \% \\
1 \% \\
1 \% \\
0.5 \%\end{array}$ & dwell time $30 \mathrm{~min}$ \\
\hline
\end{tabular}


On the other hand only a small part of the doped ${ }^{85} \mathrm{Sr}$ could be detected in the separated 8 lag. Further investigations showed, that the ${ }^{85} \mathrm{Sr}$ was washed out of the melt and was than deposited on the melt auface near to the insertion hole. Autoradiographs taken from the rodsurface showed a distance from the bottom of the crucible of $7 \mathrm{~cm}$ for the normal melt respectively $4 \mathrm{~cm}$ for the melt with additional slag work.

Differences in the results for segments and discs (Table IV) show the strong influence of the surface contamination at the edge of the discs on the results. These findings corroborate the suspicion that convection between steel melt and 8 lag former is insufficient. But the results show the way to an excellent decontamination of Sr during steel melt.

Table IV Results of ${ }^{85} \mathrm{Sr}$ melt experiments

\begin{tabular}{|l|l|c|}
\hline Melt Additives & \multicolumn{1}{|c|}{ Sr85 content in } & $x$ \\
\hline \multirow{4}{*}{ 1 normal } & segments 1 - 4, average value & 0.1 \\
& disks 1 - 3, average value & 7.8 \\
& surface layer of the ingot & -80 \\
& slag ( - 80 $\%$ ) & 0.6 \\
& aerosol filter & 0.01 \\
\hline \multirow{3}{*}{ additional } & segments 1 - 4, average value & 0.07 \\
slag former & surface 1ayer of the ingot & 0.5 \\
& slag 1 - 3, average value & 6.3 \\
& aerosol filter & 0.02 \\
\hline
\end{tabular}

\section{BEHAVIOUR OF URANIUM AND TRANSURANIUM ISOTOPES}

Uranium in the elemental and oxidized state and $241_{\mathrm{Am}}$ as indicator isotope for transuranium elements were used to study the behaviour of these elements in the melting of steel. These tracer experiments were supplemented by melt experiments with uranium contaminated scrap originating from a fuel fabrication plant. The parameter of these laboratory scale melt experiments are summarized in Table $V$, while the results on the behaviour of americium and uranium in the melt decontamination process are shown in Table VI and VII. 
Table V Material, additives and boundary conditions of uranium and americium melt experiments

\begin{tabular}{|c|c|c|c|c|c|}
\hline $\begin{array}{l}\text { Melt } \\
\text { No. }\end{array}$ & Material & $\begin{array}{c}\text { Added } \\
\text { radionuclides }\end{array}$ & \multicolumn{2}{|c|}{ Additives } & Boundary Conditions of melt \\
\hline \multirow[t]{2}{*}{1} & \multirow[t]{2}{*}{$\begin{array}{l}\text { steel St37-2; } \\
\quad 3250 \mathrm{~g}\end{array}$} & \multirow[t]{2}{*}{$1 \mathrm{~g}$ elem. U } & \multirow[t]{2}{*}{$\begin{array}{l}\text { C: } \\
\text { SiC: } \\
\text { slag former: }\end{array}$} & \multirow[t]{2}{*}{$\begin{array}{l}3 \% \\
2.5 \% \\
1 \%\end{array}$} & $\begin{array}{l}\text { all melts: } \\
\text { temperature } 1480-1530{ }^{\circ} \mathrm{C} \\
\text { cover gas: argon, } 10 \% \mathrm{H}_{2} \\
\text { cooling time: } 6 \mathrm{~h}\end{array}$ \\
\hline & & & & & dwell time $15 \mathrm{~min}$ \\
\hline 2 & $\begin{array}{c}\text { steel St37-2; } \\
\quad 3200 \mathrm{~g}\end{array}$ & $1.15 \mathrm{~g} \mathrm{UO} 2$ & $\begin{array}{l}\mathrm{C:} \\
\mathrm{SiC}: \\
\text { slag former: }\end{array}$ & $\begin{array}{l}3 \% \\
2.5 \% \\
1 \%\end{array}$ & dwell time $25 \mathrm{~min}$ \\
\hline 3 & $\begin{array}{c}\text { steel St37-2; } \\
2000 \mathrm{~g}\end{array}$ & $0.75 \mathrm{~g} \mathrm{UO}_{2}$ & $\begin{array}{l}\mathrm{C}: \\
\mathrm{SiC}: \\
\mathrm{SiO}_{2}: \\
\mathrm{CaO}: \\
\mathrm{Al}_{2} \mathrm{O}_{3}:\end{array}$ & $\begin{array}{l}3 \% \\
2.5 \% \\
2.7 \% \\
2.7 \% \\
1.4 \%\end{array}$ & dwell time $45 \mathrm{~min}$ \\
\hline 4 & $\begin{array}{c}\text { contaminated } \\
\text { austenitic } \\
\text { scrap; } 3000 \mathrm{~g}\end{array}$ & $\begin{array}{c}\text { U-contamination } \\
\text { (3.4\% U235) }\end{array}$ & $\begin{array}{l}\text { C: } \\
\text { SiC: } \\
\text { slag former: } \\
\text { VL63M: } \\
\text { DISPERSIT: }\end{array}$ & $\begin{array}{l}3 \% \\
2.5 \% \\
1 \% \\
1.2 \% \\
0.1 \%\end{array}$ & dwell time $40 \mathrm{~min}$ \\
\hline 5 & $\begin{array}{c}\text { contaminated } \\
\text { austenitic } \\
\text { scrap; } 3700 \mathrm{~g}\end{array}$ & $\begin{array}{l}\text { U-contamination } \\
\text { (3.4\% U235) }\end{array}$ & $\begin{array}{l}\text { C: } \\
\text { SiC: } \\
\text { slag former: } \\
\text { VL63M: } \\
\text { DISPERSIT: }\end{array}$ & $\begin{array}{l}3 \% \\
2.5 \% \\
1 \% \\
1.2 \% \\
0.1 \%\end{array}$ & dwell time $40 \mathrm{~min}$ \\
\hline 6 & $\begin{array}{c}\text { steel St37-2; } \\
\quad 3100 \mathrm{~g}\end{array}$ & $\begin{array}{c}\text { Am241 } \\
5 \cdot 10^{4} \mathrm{~Bq} \\
4 \cdot 10^{-7} \mathrm{~g} \mathrm{Am}\end{array}$ & $\begin{array}{l}\text { C: } \\
\text { SiC: } \\
\text { slag former: }\end{array}$ & $\begin{array}{l}3 \% \\
2.5 \% \\
1 \%\end{array}$ & dwell time $15 \mathrm{~min}$ \\
\hline
\end{tabular}


Table VI Results of the test melt with 241 Am

\begin{tabular}{|c|c|}
\hline Measured sample & Content of Am241; $\boldsymbol{x}$ \\
\hline ingot & 1 \\
\hline slag & 110 \\
\hline aerosolfilter & 0.05 \\
\hline
\end{tabular}

The experiments showed that uranium and transuranium elements will be released to the 8 lag to a great extend in the melt-down of steel. The experiment with $241_{\mathrm{Am}}$ resulted in decontamination factor of about 100 . The remaining americium of 17 in the steel ingot matches about $0,08 \mathrm{~Bq}$ $\alpha / 8$. The experiments with uranium demonstrated that the release of $\mathrm{UO}_{2}$ to the $8 \mathrm{lag}$ is higher than that one of elemental uranium. A melt experiment with enhanced $8 \mathrm{lag}$ formation increased the decontamination factor of uranium. The remaining uranium contamination of $0.1 \mathrm{~Bq} \alpha / 8$ meets the recommendations of the German Radiation Protection Commission for unreatricted release and 18 below the recommandations of the Commission of the European Communities by one order of magnitude. Similar corresponding values have been attained with uranium contaminated scrap from a fuel fabrication plant. These melt-down runs prove the comparability of tracer experiments with those of original contaminated scrap. The comparability of laboratory scale melts experiments with large scale melts of contaminated scrap was demonstrated elsewhere (4).

6. ALPHA-MEASURING TECHNIQUES

A further objective of the Investigations was to develop a fast reliable and general applicable method for $\alpha$-emitting radionuclides which can by applied in free release measurements of melted scrap.

$\alpha$-spectrometry though being the most reliable method is time consuming and expensive. According to the possible presence of $\alpha$-emitting elements with resembling $\alpha$-energies separation of these elements from the matrix and from each other by sophisticated chemical separation techniques and the preparation of thin and uniform layers for precise activity measurement are necessary. These restrictions make $\alpha$-spectrometry not applicable in routine measurements of $\alpha$-contamination. 
Table VII Uranium content from neutron activation analyses

\begin{tabular}{|c|c|c|c|c|c|c|}
\hline \multirow{2}{*}{ Melt } & \multirow{2}{*}{ Added Uranium } & \multirow{2}{*}{$\begin{array}{c}\text { Melt } \\
\text { position }\end{array}$} & \multicolumn{2}{|c|}{$\mu \mathrm{g} \mathrm{U} / \mathrm{g} \mathrm{Fe}$} & \multicolumn{2}{|c|}{ Average of analysis 1 and 2} \\
\hline & & & analysis 1 & analysis 2 & $\mu \mathrm{g} \mathrm{U} / \mathrm{g} \mathrm{Fe}$ & $\doteq \mathrm{Bq} a / g \mathrm{Fe}$ \\
\hline 1 & U elem. & $\begin{array}{l}1 \\
2 \\
3\end{array}$ & $\begin{array}{r}93 \\
161 \\
150\end{array}$ & $\begin{array}{r}146 \\
- \\
102\end{array}$ & 130 & $2^{3)}$ \\
\hline 2 & $\mathrm{UO}_{2}$ & $\begin{array}{l}1 \\
2 \\
3\end{array}$ & $\begin{array}{l}4.5 \\
37 \\
52\end{array}$ & $\begin{array}{r}10 \\
- \\
30\end{array}$ & 27 & $0.7^{1)}$ \\
\hline 3 & $\mathrm{UO}_{2}$ & $\begin{array}{l}1 \\
2 \\
3\end{array}$ & $\begin{array}{l}2 \\
7 \\
6\end{array}$ & $\begin{array}{l}4 \\
4 \\
6\end{array}$ & 5 & $0.1^{1)}$ \\
\hline 4 & $\begin{array}{l}\text { cont. scrap } \\
(3.4 \% \text { U235 }\end{array}$ & $\begin{array}{l}1 \\
2 \\
3\end{array}$ & $\begin{array}{r}10 \\
5 \\
16\end{array}$ & $\begin{array}{r}9 \\
10 \\
4\end{array}$ & 9 & $0.2^{2)}$ \\
\hline 5 & cont. scrap & $\begin{array}{l}1 \\
2 \\
3\end{array}$ & $\begin{array}{l}0.8 \\
6 \\
0.7\end{array}$ & $\begin{array}{l}0.7 \\
1 \\
0.6\end{array}$ & 1.6 & $0.04^{2)}$ \\
\hline$(1-3)$ & $\begin{array}{l}\text { inactive star- } \\
\text { ting material } \\
\text { steel St } 37-2\end{array}$ & & n. a. & 0.8 & 0.8 & $0.02^{1)}$ \\
\hline
\end{tabular}

1) calculated by $99.27 \%$ U238

$$
\begin{aligned}
& 0.72 \% \mathrm{U} 235 \\
& 0.005 \% \mathrm{U} 234 \doteq 25300 \mathrm{~Bq} / \mathrm{gU}
\end{aligned}
$$

2)

"

(small influence of U235, unknown ratio of highly influencing U234)

3) calculated by 99.28 \% U238

$0.22 \%$ U235

$0.001 \%$ U234 
Using integral $\alpha$-measurement these restrictions become void. Applying this method a lot of questions arose which initiated intensive calibration work. In practice satisfying calibriation of $24 I_{\text {Am }}$ and uranium in order to measure these isotopes in steel and slag samples could be performed. But several questions concerning the band-width of efficiencies from range or from infinite thick samples, the relationship between efficiency and mol weight, bulk weight or range showed inapplicable results. Not understood are increasing efficiencies for materials with increasing average atomic numbers or increasing densities too. These basic questions need further intensive investigations.

If uranium is the only contamination element the $\propto$-content of samples can be measured either by direct integral $\propto$-measurement or calculated from $\%$ measurement of the $186 \mathrm{keV} / \mathrm{line}$ of $235 \mathrm{U}$ provided that the lootope ratio of the contaminating uranium is well known.

$A$ very important fact seems to be the uranium determination in the inactive oteel starting material St 37-2 used in the melts with radioactive tracers. The measured natural uranium content of 1 ppm uranium (Table VII) means a 207 preload of the german limit of $0.1 \mathrm{~Bq} / \mathrm{B}$ for unrestricted release of melted scrap from nuclear installations and to our opinion supports the corresponding limit of $1 \mathrm{~Bq} / \mathrm{g}$ proposed by the Commission of the European Communities. It seems to be very necessary to investigate much more steel samples with respect to the natural uranium content. This 18 so much the more necessary because all process materials used in foundaries in the casting of steel contain natural o-emitting isotopes. The natural preload range should then be used as a basis in the assessment and final definition of limits for the unrestricted release.

\section{References}

II/ SCHUSTER E. and NEEB K.H. Chemische Reaktionen und Verhalten von Radionukliden in Leichtwassereaktoren. 2. Radionuklide in Kreislaufen und Systemen, GIT Fachz. Lab. 33 (1989) 13-19.

121 SCHUSTER E. and HOFFMANN R. Charakterislerung Innerer Kontaminationsochichten auf Rohrleitungen durch zerstorungsfreie nuklidspezifische Aktivitatsmessungen, Siemens Porsch.- und Entwickl.-Bericht 12 (1983) 357-362.

|3/ SCHUSTER E. Untersuchungen Uber Quellen, Bildungsmechanismen, Transport- und Ablagerungsverhalten von aktivierten Rorrosionsprodukten in den Kuhlkreislaufen von Leichtwasserreaktoren, Report Bundesmin. fur Forschung und Technologie (Bonn), BMFT 1500209 (April 1983).

141 SCHUSTER E. TRUMMER, K.H., STANG, R. Non-hazardous Re-use of Components Removed from Nuclear Pacilities by Melting Processes, Waste Management '87, Tucson, March 1-5, 1987, Vol. 3, p. 79-82. 


\section{DISCUSSION}

Question: R NEIDER, BAM - What are the release limits for unrestricted use of material in Sweden?

Answer: G THAM, Studsvik AB - We are expecting the authorities to set the release limits at $1000-15000 \mathrm{~Bq} / \mathrm{kg}$ in the next couple of months.

Question: P GUETAT, CEA-FAR - What price do you charge to waste producers for the melting of contaminated steel?

Answer: M SAPPOK, Siempelkamp - The price depends on the quantity, the quality and the type of activity of the material. For gamma-contaminated steel the price for melting will be in the range of $4-6 \mathrm{DM} / \mathrm{kg}$.

Comment: Mr KAUFMANN, DWK - Melting of scrap from reprocessing plants, containing higher $\mathrm{Cs}$ and $\mathrm{Sr}$ contamination, would require remote operation, especially for removing the slag from the furnace, sampling, renewal of the filters, and removal of the filter dust.

Answer: M SAPPOK, Siempelkamp - For the new programme a proposal was made by Ansaldo and Siempelkamp to develop a robot for slag removal, temperature measurement and sampling. Changing the filter and removing the dust is done by remote techniques right now. We think it is necessary to develop this.

Question: P FUNKE, Ministry of the Environment and Reactor Safety, Wiesbaden - Have you any experience with the melting of U/Th/Pu-contaminated material? If so, what happens to the ingots, slag and filter dust?

Answer: M SAPPOK, Siempelkamp - Up to now we have no experience with melting alpha-contaminated scrap. Preliminary laboratory tests have been carried out at KWU and it was found that there were traces of thorium and uranium in the slag, but not in the melt or in the filter dust. Work on this will be done within the next year.

Question: J R COSTES, CEA-Valrho - How do you compare the electric arc furnace and the induction furnace for nuclear melting purposes?

Answer: D S HARVEY, British Steel - The arc furnaces can use much larger pieces of scrap, and this is an advantage in that less preparation of the scrap is needed. The arc furnace creates more dust than the induction furnace and the dust is not so easy to confine because the arc furnace has many openings. There are plants where the arc furnace is placed in an enclosure, and if this was done, the problems of dust emission would be much less. Another consideration is the economics. An arc furnace would usually be more costly to build, but it could melt scrap more quickly. So, if there is a lot of scrap available, the arc furnace might be the better choice.

Question: M CONTI, ENEA - In my view themelting of waste is a very interesting and effective method. However, very small parts have to be produced for using 200-litre capacity drums. Are there possibilities to avoid cutting the waste components?

Answer: M SAPPOK, Siempelkamp - New plans envisage the installation of a shredder alongside the furnace and the material will be brought in 20-foot containers to the plant. The waste will be brought to the shredder and then 
fed directly into the furnace. I agree that the material must be made easier to handle.

Question: C J MILLOY, OVE ARUP - Could an author explain the economics of melting active metal - when it is worthwhile alming to produce a high quality product capable of reuse and when it is only worthwhile as a volume reduction technique?

Answer: M SAPPOK, Siempelkamp - Regarding the cost of final disposal, it is economic to melt the material and reuse it. The proof is that 2000 tons have been melted and 6000 tons are on order.

Experience with the KRB-A Gundremingen decomissioning shows that the problem of getting a final depository also poses a financial risk.

Question: P GUETAT, CEA-FAR - Do you have some idea on the distribution of strontium during the melting of steel?

Answer: M SAPPOK, Siempelkamp - We made some tests in 1985. As far as I remember, strontium remains in the melt.

Comment: P HEBRANT, Westinghouse - Westinghouse has been involved in recycling metal scrap. We found that the recycling would cost between $1 / 5$ and $1 / 3$ of the cost for final disposal.

Question: G IMBARD, CEA-Valrho - Regarding the comparison between arc furnaces and induction furnaces, is the contamination satisfactorily homogenised in the ingots? Is a single sample taken during the melt considered representative of the specific activity of the ingot?

Answer: M SAPPOK, Siempelkamp - We melt only in an induction furnace because it makes it possible to get a tight enclosure and negative pressure above the melt. We believe it would be difficult to do this with an arc furnace. We carried out tests in 1985 and took samples from different parts of the ingot and found an homogenous nuclide mix within the casting.

Comment: R NEIDER, BAM - Mr Schuster, you mentioned in your paper a release $11 \mathrm{mit}$ for alpha emitters of $0.1 \mathrm{~Bq} / \mathrm{g}$. That is not true. Until now neither the Radiation Protection Commission nor the CEC have made recommendations for the release limit of the specific activity of alpha emitters.

Question: A BERTINI, ENEL - Mr Schuster has said that the limits set by the CEC on release of alpha-contaminated materials are better than those imposed by the safety authorities in Germany. What does he mean by better? I should also like to hear the opinion of $\mathrm{Mr}$ Neider.

Answer: E SCHUSTER, Siemens KWU - 'Better' was meant in the sense of 'preferable' because of the preload of natural activity in nearly all materials. Preloads by natural activity should not consume the margin for radionuclides origlnating from contamination layers after melt-down of contaminated scrap, especially in those cases where high decontamination factors may lead to an unrestricted release of melted materials. For example, natural uranium is present in inactive steel as stated in my paper. It 13 completely impossible to distinguish by measuring techniques between natural uranium and uranium originating from the fuel cycle. The preload of natural activity should be considered in fixing limit values for the unrestricted release of such materials. 
Answer: R NEIDER, BAM - 'What is better?' If you pose this question in the context of radiation protection, one has to refer to the principles of radiation protection established by ICRP. These are: justification, ALARA and optimisation.

This means that the question cannot be answered just by referring to economic arguments nor to pure radiation protection goals. You have to optimise with respect to both economic aspects and radiation protection of the people. When establishing the release limits of $0.1 \mathrm{Bg} / \mathrm{g}$ for beta-gamma emitters for steel scrap from nuclear power plants for completely unrestricted release, and $1 \mathrm{~Bq} / \mathrm{g}$ for the release of the scrap in order to be molten in a common furnace, we had in mind that the material after release and melting will, in any case, have a specific activity of only $0.1 \mathrm{Bg} / \mathrm{g}$. That was also assumed by the Working Group of the EC which established the EC criteria for recycling. When calculating the different scenarios they estimated a dilution factor of 10 for the material.

We also had in mind that decommissioning of nuclear power plants is just in an early phase and that in the next 50 to 100 years very large amounts of slightly contaminated scrap will arise, and the contamination of important quantities of steel should be avoided. Therefore we required the reuse of the material within the nuclear field.

Consequently, the 'better' solution is the one which takes all factors into account and makes a compromise between all of them.

\section{CONCLUSION}

The session was particularly interesting because most presentations dealt with practical experience gained on an industrial scale. Organisations in Germany, Great Britain and Sweden reported the remarkable successes achieved in melting substantial quantities of contaminated steel scrap, without particular difficulties in terms of radiation protection.

Melting is now a reasonably proven technique which may help a decommissioning project in many ways. The main result of this technique is a drastic reduction in the volume of conditioned waste to be disposed of, either by the reduction of bulk volume in itself, or by the production of ingots which are suitable for recycling in accordance with the recent recommendation of the $\mathrm{EC}$.

Progress is still to be made in the actual implementation of this technique, and the most reputable industries are extending and improving their facilities. Progress is also to be made in the regulatory field, so that uniform criteria are accepted and put in force in the Member states.

There is no doubt that the Research Programe of the CEC has brought to light valuable results for the benefit of the industrial commuity.

A BERTINI, ENEL 


\section{SESSION X}

\section{DECONTAMINATION FOR DECOMMISSIONING PURPOSES}

CHAIRMAN: M LARAIA, ENEA,I

SECRETARY: R BISCI, CEC 



\title{
A PROCESS FOR THE COMPLETE DECONTAMINATION OF ENTIRE SYSTEMS
}

\author{
W. AHLFÄNGER \\ Kernkraftwerk Ensland, Postfach 1640,4450 Lingen (Ems), FRG
}

\begin{abstract}
Summary
The oxidic layers of the samples examined from the primary system of the Nuclear Power Station Lingen (KWL) contain more than 998 of the activity deposited on the surface. The rest is distributed by grain boundary diffusion in the base material up to a penetration depth of $90 \mu \mathrm{m}$. In order to reach a complete decontamination, it is therefore necessary to take down not only the oxidic layers, but also the surface of the base material up to the penetration depth of the radionsotopes. When applying this process, the oxide layer is therefore at first completely removed by a treatment with a LOMI reagent. Subsequently, the required layer thickness is separated from the base material by a treatment with a mixture of nitric acid and hydrochloric acid.

A DN 50 primary steam pipe piece was decontaminated with this process. The effect of the different treatment stages was checked by the determination of the surface depth profiles of the essential elements.
\end{abstract}

\section{REPORT}

The pre-condition for complete decontamination is a knowledge of the distribution of corrosion product activities on the material surfaces of the primary systems.

Examination results on this at samples from the Bolling Water Reactor Lingen are summarized in the Report EVR 9352 DE. A result of these studies was that the oxidic protective layer of the components contained more than 990 of the corrosion product activity. The rest is contained in the base material. The distribution of the activity of ${ }^{6} \mathrm{Co}$ in the base material shows the activity depth profile of a pipe sample from the primary steam and condensate system (Figure 1).

The existence of radiolsotopes in the base materials of the examined material samples has different causes.

The deposition of radioactive corrosion products, preferably into the grain limits widened by corrosion, has a special quantitative importance. This can be established by light-microscopy and autoradiographic studies. It depends on the damage depth by the corrosion attack when penetration depth $1 \mathrm{~s}$ reached.

A further cause can also be the diffusion of radioisotopes into the base material. Due to the essentially higher diffusion speeds, only the grain limit diffusion is important for this process.

One can conclude from the course of the depth profile of Figure 1 that the activity distribution near the surface up to a depth of some micrometers can in all probability be ascribed to depositions in the corrosion damage sites while further distribution was brought about by grain limit diffusion. 
According to the activity distribution - oxide layer/base material one can reach a complete decontamination only in two steps:

1. removal of the oxidic layers

2. removal of a certain material layer of the base material according to the diffusion depth of the radioisotopes.

Different chemical treatments were tested in laboratory tests and a process was developed from results up to the maturity of use (Report EVR $9352 \mathrm{DE})$. Subsequently, the process was checked according to the technical gauge.

A pipe piece with a length of about $20 \mathrm{~m}$ was the decontamination object of a primary line $\mathrm{NW} 50$.

The basic scheme of the decontamination circuit is presented in Figure 2. The treatment steps for the removal of the oxide layer are summarized in Table 1.

TABLE 1. Treatment cycle = removal of the oxide layer

Treatment with

a. LOMI-solution

$\begin{array}{ll}\mathrm{VSO}_{4} & 0.75 \mathrm{~g} / 1 \\ \mathrm{H}_{2} \mathrm{SO}_{4} & 0.3 \mathrm{~g} / 1 \\ \text { formic acid } & 1.0 \mathrm{~g} / 1 \\ \text { picoline acid } & 2.5 \mathrm{~g} / 1 \\ \text { hydrazine (158) } & 1.2 \mathrm{ml} / 1 \\ \mathrm{pH} & 2.5 \\ \text { treatment } & \\ \text { duration: } & 0.5 \mathrm{~h} \\ \text { temperature: } & 90^{\circ} \mathrm{C} \\ \text { KMno } & 1.0 \mathrm{~g} / 1 \\ \text { nitric solution } & \mathrm{pH} 2.5 \\ \text { treatment } & 1.5 \mathrm{~h} \\ \text { duration: } & 90^{\circ} \mathrm{C} \\ \text { temperature: } & 1.0 \mathrm{~g} / 1 \\ \text { oxalic acid } & 1.5 \mathrm{~h} \\ \text { treatment } & 88^{\circ} \mathrm{C}\end{array}$

The treated surface was optically metallically bare after the first treatment cycle.

Table 2 contains all treatment steps which were carried through for the removal of a certain layer thickness of the base material.

The results of the decontamination course are summarized in Table 3 . Columns 2 and 3 contain the data on the removed activities or remaining contaminations. One can see from column 4 at which point time pipe samples were taken. 
TABLE 2. Treatment cycle $=$ material removal from the surface of the base material

\begin{tabular}{|c|c|c|c|c|c|}
\hline Treatment with & & $\begin{array}{l}\text { 1. Acid } \\
\text { treatment }\end{array}$ & $\begin{array}{l}\text { 2. Acıd } \\
\text { treatment }\end{array}$ & $\begin{array}{l}\text { 3. Acid } \\
\text { treatment }\end{array}$ & $\begin{array}{l}\text { subsequent } \\
\text { treatment }\end{array}$ \\
\hline \multicolumn{6}{|l|}{ acid solution } \\
\hline $\begin{array}{l}\mathrm{HCl} / \mathrm{HNO}_{3} \\
\text { treatment duration: } \\
\text { temperature: } \\
\text { dissolved material } \\
\text { removed layer }\end{array}$ & $\begin{array}{l}g / 1 \\
h \\
{ }^{\circ} \mathrm{C} \\
\mathrm{gFe} \\
\mu \mathrm{m}\end{array}$ & $\begin{array}{l}13 / 4.7 \\
6.5 \\
60 \\
552 \\
15.3\end{array}$ & $\begin{array}{l}22 / 4.7 \\
7 \\
60 \\
592 \\
16.4\end{array}$ & $\begin{array}{l}6.5 / 2.35 \\
8 \\
60 \\
194 \\
5.4\end{array}$ & \\
\hline \multicolumn{6}{|l|}{ oxidation solution } \\
\hline $\begin{array}{l}\mathrm{KMnO}_{4} / \mathrm{NaOH} \\
\text { treatment duration: } \\
\text { temperature: }\end{array}$ & $\begin{array}{l}\mathrm{g} / 1 \\
\mathrm{~h} \\
{ }^{\circ} \mathrm{C}\end{array}$ & $\begin{array}{l}0.5 / 0.5 \\
2 \\
90\end{array}$ & $\begin{array}{l}1 / 0.5 \\
2 \\
90\end{array}$ & $\begin{array}{l}1 / 0.5 \\
2 \\
90\end{array}$ & $\begin{array}{l}2 / 2 \\
2 \\
95\end{array}$ \\
\hline \multicolumn{6}{|l|}{ oxalic acid solution } \\
\hline $\begin{array}{l}\text { oxalic acid } \\
\text { treatment duration: } \\
\text { temperature: }\end{array}$ & $\begin{array}{l}\mathrm{g} / 1 \\
\mathrm{~h} \\
{ }^{\circ} \mathrm{C}\end{array}$ & $\begin{array}{l}0.5 \\
0.5 \\
33\end{array}$ & $\begin{array}{l}1 \\
0.5 \\
30\end{array}$ & $\begin{array}{l}1 \\
0.5 \\
32\end{array}$ & $\begin{array}{l}2 \\
1 \\
60\end{array}$ \\
\hline
\end{tabular}

TARLE 3. Decontamination course

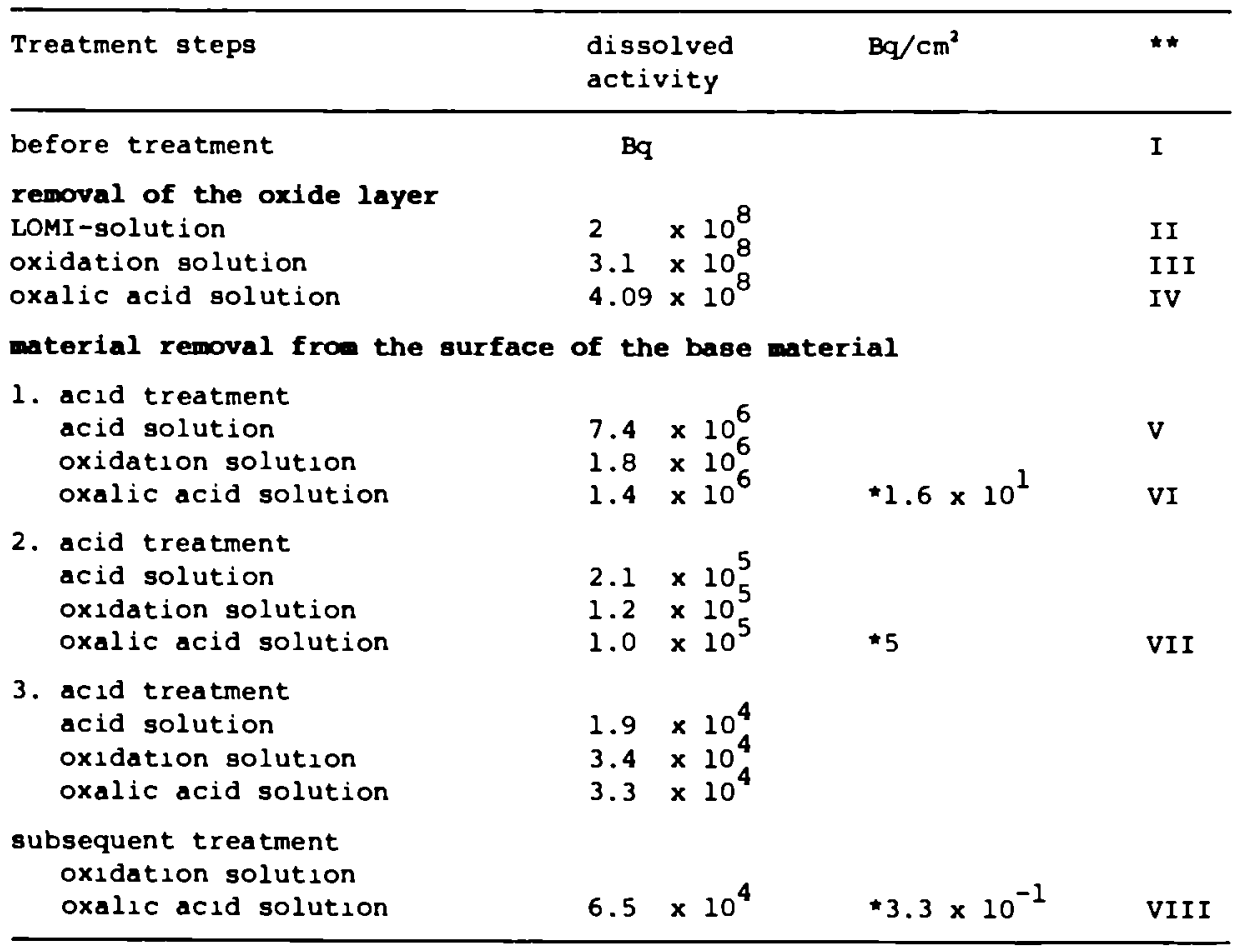

* Determined by electrolytic removal. 
Concerning the pipe samples $I-V$, the depth profiles of the elements Fe, $\mathrm{Cr}, \mathrm{Ni}, \mathrm{Mn}$ and $\mathrm{O}$ were determined in the oxide layers. The results allowed concrete statements with respect to oxide layer thicknesses, changes of the element distribution in the oxide layers during the different treatment steps and on the thickness and composition of hydro-oxide precipitations.

With respect to the samples VI-VIII, the rest contamination was determined by the electrolytic removal. As the value of sample VIII was below the free limit of the German radiation protection order, the decontamination was given up after this treatment step.

The results show altogether that a complete decontamination can also be reached according to the technical gauge.

The optimization and transfer of the process to a $1300 \mathrm{MW}$ DWR is described in detail in Report EVR $11435 \mathrm{DE}$.

Concerning the application of the process, one has to pay attention to the following criteria:

1. The process was especially developed for the decontamination of high-alloy materials. A limitation results from this concerning an application with respect to other materials. But as the highly contaminated components of the primary are manufactured from high-alloy materials, it can be used with success especially in this area.

2. If one decides to decontaminate complete systems and if the systems of a plant are still in a state ready for operation, time consuming works at the highly contaminated plant parts are not necessary. The radiation exposure of the personnel is considerably reduced by this in connection with the process execution.

It can be immediately applied after the shutdown of a plant.

3. The dosage of chemicals, heating, cooling and pre-treatment of the treatment solutions can be carried through in the facilities belonging to the power station.

4. The application of large quantities of solutions of chemicals is disadvantageous. But the production of concentrates can be minimized by the application of low concentrations of chemicals. 


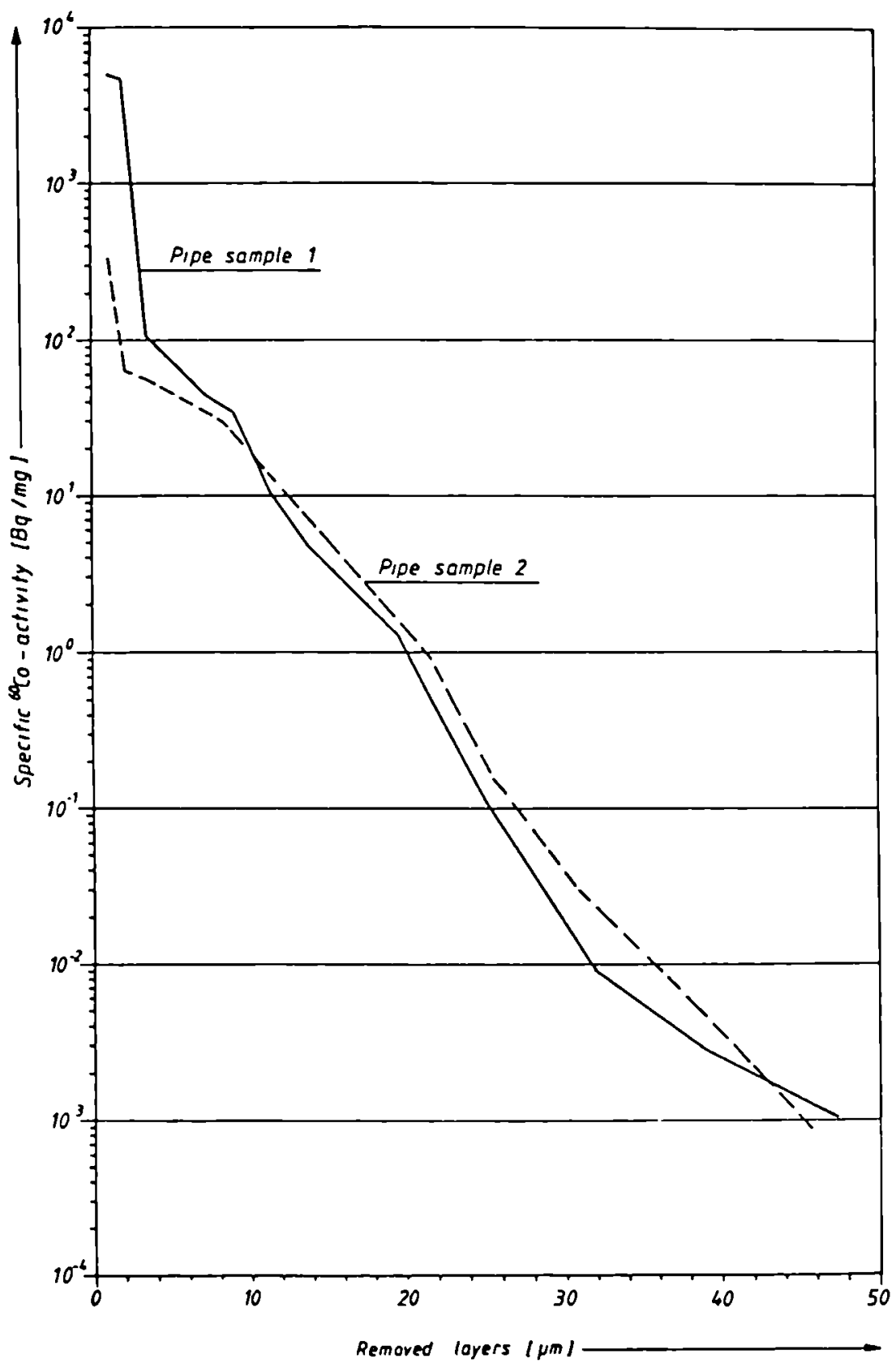

Fig. 1. Course of the specific ${ }^{60}$ co activity in the removed layers 


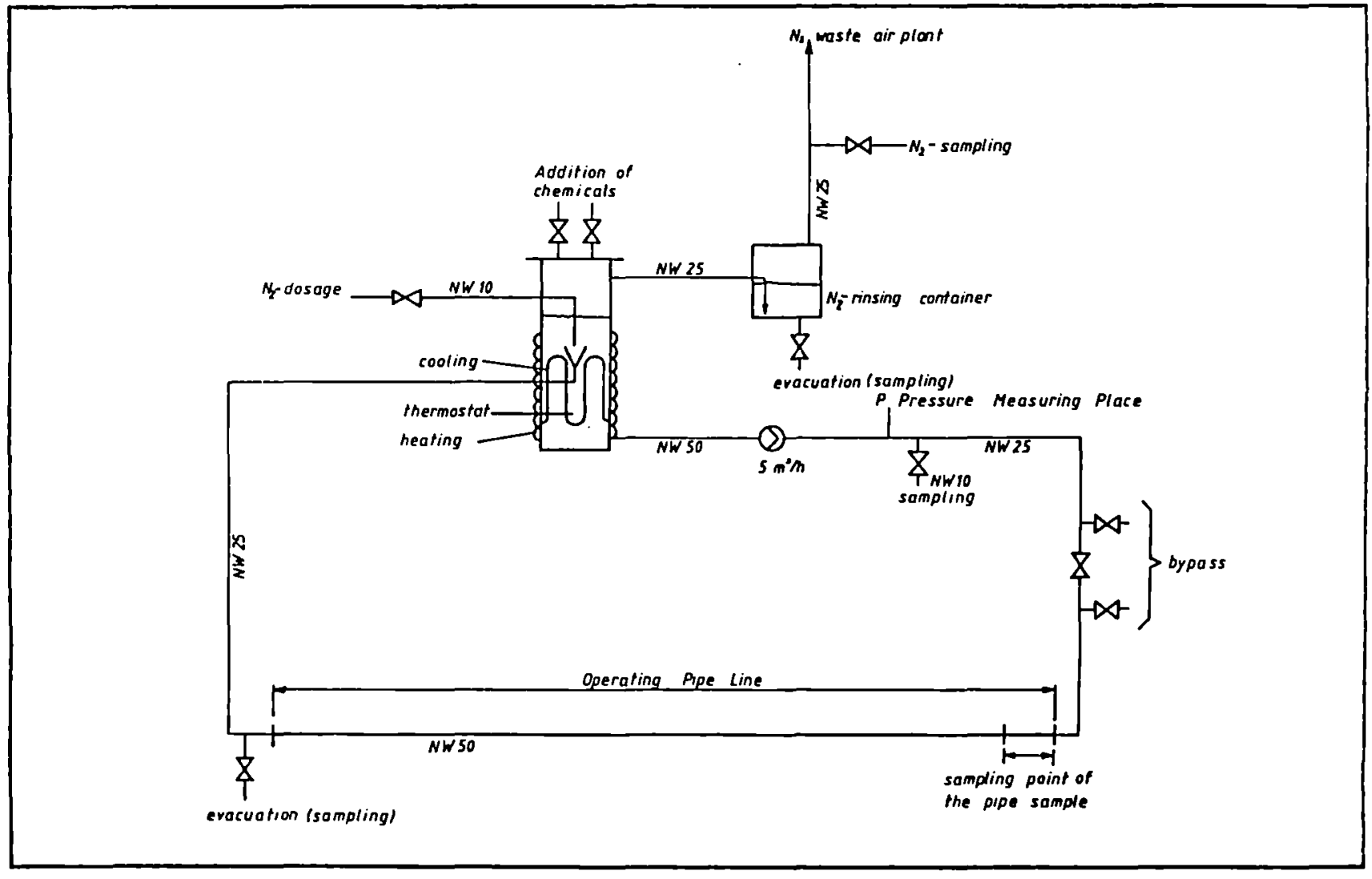

Fig. 2. Basic scheme of the decontamination circuit 
AGGRESSIVE CHEMICAL AND ULTRASOUND DECONTAMINATION TESTS ON SMALL VALVES, AND TUBES FROM A FEEDWATER PREHEATER, OF GARIGLIANO-BWR

\author{
F. BREGANI \\ ENEL - Ente Nazionale per l'Energia Elettrica, \\ R\&D - Division, Thermal \& Muclear Research Centre, Milan, Italy
}

\author{
A. GAROFALO \\ ENEL - Ente Nazionale per l'Energia Elettrica, \\ G\&T - Division, Special Unit for Decommissioning, Garigliano, Italy
}

\title{
ABSTRACT
}

Decontamination tests performed by processes based on aggressive chemicals on components of Garigliano-BWR are described.

Decon tests carried out on small valves (1-2 inches) showed that some residual radioactivity remains in deep crevices. Therefore these kinds of complex components cannot be totally decontaminated, even if decon can reach residual average values of less than $1 \mathrm{~Bq} / \mathrm{g}$.

For decontaminating the tube-bundle of feedwater preheaters a new decon process based on the simultaneous use of ultrasounds and aggressive chemicals was developed and tested under real conditions. One thousand tubes $1 \mathrm{~m}$ long were fully decontaminated at 1 ess than $0.3 \mathrm{~Bq} / \mathrm{g}$.

\section{INTRODUCTION}

Decontamination is a common practice in nuclear installations. It is widely used during their life to clean systems, components, areas or tools in order to handle them for maintenance works. In the field of decommissioning, during dismantling activities, decontamination can be considered an indispensable technique (1), in the sense that no decommissioning can be made without using decontamination.

During dismantiling decontamination can be used for:

- reducing the radiation levels on systems or components before (or during) cutting and dismantling works;

- clean as much as possible the contaminated materials for allowing 1ts release (and possible reuse) as uncontaminated wastes;

the former $1 \mathrm{~s}$ addressed to save man-rem while the latter is finalized to reduce the amount of wastes to atore.

Because the decontamination techniques for reducing the radiation levels are quite similar to the techniques used during the plant ilfetime, when one talks of decontamination for decommissioning purposes he intends a class of decontamination techniques designed for reaching the unrestricted (or uncontrolled) release of the contaminated materials.

ENEL, in the frame of 1 ts R\&D activities, has been studying decontamination for decomissioning purposes since 1980 . 
The first stage of research dealt with the development of aggressive chemical solutions able to totally remove thick and tenacious oxide layers with a minimum generation of secondary wastes; this work was supported by the CEC in the frame of its first programme on decommissioning of nuclear plants $(2,3,4)$.

From 1983 ENEL activities were focused on Garigliano-BWR and significant materials arising from the plant were used for testing. In 1984 two specific programmes were undertaken: the first dealt with aggressive chemical decon tests on small valves and the second, more important, was related to decontamination and dismantling of a tube-bundle of a feedwater preheater. The results of these programmes, supported by the CEC in the frame of its second programme on decommissioning of nuclear installations, are presented in this paper.

The activities are jointly carried out by the CRTN (Thermal and Nuclear Research Centre of Milan) of R\&D Division and the USD (Special Unit for Decommissioning) of G\&T Division, with the external support of CISE.

\section{GARIGLIANO-BWR AND ITS DECOMMISSIONING PLAN}

Garigliano power plant is a 160 MWe Boiling Water Reactor with dual cycle. It operated from 1964 to 1978 generating $12.5 \cdot 10^{9} \mathrm{kWh}$ with a capacity factor of $68 \%$. In August 1978 it was stopped due to damage to one of the two Secondary Steam Generators (SSG).

In March 1982 the ENEL Board of Directors declared it definitively out-of-service. In December 1982 an "Action Plan" was approved to put the Garigliano plant in safe storage conditions for at least 30 years $(5,6)$.

In the safe storage of the plant the turbine building is considered a boundary part and, in principle, it could be decommissioned before 30 years. Therefore a feasibility study on dismantling and decontamination (up to unrestricted release limit) of all the building components was performed as a possible alternative to decommissioning. Direct melting of scraps for both release and reuse in the nuclear field, was also considered as another alternative.

About 1930 tons of materials are installed in the turbine building with about $33000 \mathrm{~m}^{2}$ of contaminated surface. The base materials are carbon and low-alloyed steels. The radioactivity inventory in December 1988, was about 27GBq (710 $\mathrm{mCi}$ ) mainly due to $60-\mathrm{Co}(47 \%), 55-\mathrm{Fe}(22 \%), 63-\mathrm{Ni}$ (21\%) and $137-\mathrm{Cs}(9 \%)$, with traces of $134-\mathrm{Cs}$ and $90-\mathrm{Sr}$.

The purpose of the feasibility study was to select techniques wich can decontaminate components as much as possible, in order to allow the unrestricted release of the materials (a limit of $1 \mathrm{~Bq} / \mathrm{cm}^{2}$ or $1 \mathrm{~Bq} / \mathrm{g}$ for beta and gamma emitters, was considered). 
The results showed that there is no single decontamination technique which can be used for all components or parts and that the use of more decontamination techniques is needed. At least four decontamination techniques were selected for decontaminating all components: electropolishing, for pleces with simple geometries (flat and concave shapes); water jet with abrasive, for quite complex pleces (malnly convex shape); ultrasounds in aggressive chemicals, for heat-exchangers and condenser tube-bundles; freon jet, for engines and all parts with loose contamination. A small part of the materials about $5 \%$ wt. was considered for direct storage without decontamination, for economic reasons in particular.

In this context the two specific programes mentioned before were undertaken. The programme on aggressive chemical decontamination tests on small valves aimed to evaluate the possibility to reduce as low as possible the amount of undecontaminated material to store, while the programme on dismantling and decontamination of a tube-bundle of a feedwater preheater aimed to test and quallfy, under real conditions, a new decon process based on the simultaneous use of ultrasounds and aggressive chemicals.

\section{DECONTAMINATION OF SMALL VALVES BY AGGRESSIVE CHEMICALS}

The main objective of this programme was the evaluation of the effectiveness of aggressive inorganic acid solutions, such as $\mathrm{HCl}$, $\mathrm{HF}$ and $\mathrm{HNO}_{3}$ and their mixtures, in the decontamination of small and complex components, composed of different materials and with the presence of dead areas such as crevices, welds, bends, gaskets and so on. The small valves, 1 or 2 inches in nominal size, contalned all these features and so were selected for the experimental activities. For this study a target of $1 \mathrm{~Bq} / \mathrm{g}$ or $1 \mathrm{~Bq} / \mathrm{cm}^{2}$ was considered as the 1 imit for unrestricted release of materials.

The aggressive chemical decontamination tests were performed on the DECO experimental loop in the DECO lab at JRC-Ispra, mainly using the aggressive chemical solutions selected in the previous studies. $\mathrm{HCl}$ and $\mathrm{HF} / \mathrm{HNO}_{3}$ acid solution were used in particular. Four complete decon tests were made, using each run one valve.

These valves, belonged to the primary system of the Garigliano-BWR, were cut from auxillary lines in the Secondary Steam Generators (SSG) houses, in 1979. All the valves are stainless steel base material and they were operated for about 15 years, the entire life of the plant, in contact with the primary recirculation coolant, at high temperature and high pressure. The main features of these valves are given in Table I.

The duration of the tests was not predetermined but was defined during the run itself taking into account the on-line measurements (corrosion potential, corrosion rate and Co-60 radioactivity).

For the test valves the decon effectiveness has been measured by evaluating the radioactivity profiles before and after the run, both in the direction of flow and in the direction along the stem. For each measurement point the decon effectiveness (decontamination factor - DF) has been de- 
fined as the ratio between the before (initial) and the after (final) measurements.

Before and after the run the test valves were treated by ultrasounds in demineralized water in order to remove the loose residual deposits and to produce a reference surface. Sometimes at the end of the aggressive chemical decontamination the external surfaces of the valves were further cleaned with common detergents, or submitted to more decontamination in order to make them as clean as possible and to have a clear localization of the residual radioactivity. In the last two tests before the aggressive chemical decontamination a step with soft chemicals, such as oxalic and citric acid mixtures, was made in order to see $i$ ts possible effect on the decon effectiveness.

Table II.

A list of the decon tests by aggressive chemicals is given in

As an example of test results the radioactivity profiles of valves No. 1 is shown in Figure 1. It shows the presence of residual radioactivity in correspondence to the end-welds and in the stem.

In order to clearly evidence the location of the residual radioactivity, all valves were cut to take samples to submit to low background gamma spectrometries. Results of these counters for samples taken from valve No. 1 , as indicated in Figure 2, are shown in Table III.

The total residual radioactivity after decontamination, in each valve was estimated from spectrometric data. The results are summarised in Table IV and they show very different ranges: about $5 \mathrm{kBq}$ for valves No. 1 and 3 (globe valves) and more than $50 \mathrm{kBq}$ for valves No. 2 and 4 (Y-type valves). The specific residual radioactivity data in terms of both weight and surfaces are presented in Table $\mathrm{V}$ for each valve.

Assuming $1 \mathrm{~Bq} / \mathrm{g}$ and $1 \mathrm{~Bq} / \mathrm{cm}^{2}$ as limits for the unrestricted release of materials, the following conclusions can be drawn:

- in terms of average Bq/g valves No. 1 and 3 could be released (in fact they have 0.44 and $0.41 \mathrm{~Bq} / \mathrm{g}$ respectively), while valves No. 2 and 4 could not (in fact they have 3.41 and $2.08 \mathrm{~Bq} / \mathrm{g}$ respectively);

- in terms of maximum Bq/g all the valves could not be released;

- In terms of $\mathrm{Bq} / \mathrm{cm}^{2}$ all the valves could not be released.

After the experiments on the decontamination in the DECO loop of small valves from the Garigliano-BWR, the following conclusions can be drawn and extended to all small components:

- before deciding whether or not to decontaminate for decommissioning purposes, a small and complicated component or part, it is absolutely necessary to establish clearly how the residual radioactivity can be measured;

- the final residual radioactivity is quite independent from the initial dose rate level;

- whatever the decontamination process may be, some hot spots may remain in the valve (or components); these hot spots will definitely be greater than $1 \mathrm{~Bq} / \mathrm{g}$ or $1 \mathrm{~Bq} / \mathrm{cm}^{2}$. 
In order to increase the effectiveness of the decontamination even more some investigations were made on the process using aggressive chemicals combined with ultrasounds (see also Chap. 4). After a great deal of lab testing to select the best test procedure, two valves were tested in a special ultrasonic machine $(22 \mathrm{kHz},>50 \mathrm{w} / 1)$ in aggressive chemical bath $\left(3 \% \mathrm{HF}+5 \% \mathrm{HNO}_{3}\right)$, at Garigliano power station.

Radioactivity profiles and low background measurements were made, as on the valves previously described. The results show that also using this decon process some residual radioactivity remains in deep crevices inside the valves.

\section{DECONTAMINATION OF THE TUBE-BUNDLE OF A FEEDWATER PREHEATER}

The tube-bundles of feedwater preheaters are characterized by very large contaminated surfaces (both $I D$ and $O D$ ) and relatively low weights. As a consequence direct melting could be considered only for disposal and not for release.

Among decontamination techniques the use of aggressive chemicals could meet the objective of unrestricted release. Nevertheless direct (dynamic) chemical decontamination would need too large solution volumes. Therefore chemical decontamination in a tank after dismantling the tube bundle was considered. Taking into account the geometric features of the bundle pintubes and previous results from aggressive chemical decontamination experiments, the use of ultrasounds in connection with aggressive chemicals was considered in order to enhance the effectiveness of the process $(6,7)$.

For the experimental activity the preheater No. 4, which was operated at the highest temperature, was selected. The bundle has tubes with $16 \mathrm{~mm}$ OD In AISI Type 304; the full length of tubes in the preheater 18 about $12000 \mathrm{~m}$. The tubes are covered with an adherent contaminated oxide layer both inside and outside mainly composed of magnetite and hematite with traces of $\mathrm{N} 1, \mathrm{Cr}$ and $\mathrm{Cu}$. The contamination was about $30 \mathrm{~Bq} / \mathrm{cm}^{2}$ of $60-\mathrm{Co}$ on ID and about $5 \mathrm{~Bq} / \mathrm{cm}^{2}(90 \% 60-\mathrm{Co}$ and $10 \%$ 137-Cs) on OD.

The main tasks of the programme have been:

- lab tests on pin-tube specimens, in order to select decon conditions;

- In scale testing on small tube assembles;

- selection of procedures for residual radioactivity measurements;

- dismantling works to sample the tubes to decontaminate;

- demonstration testing on real tube assemblies.

The lab tests were performed to optimize the process decon parameters such as the kind and concentrations of aggressive chemicals, temperature, time, ultrasonic frequency and power. Concerning aggressive chemicals the use of aggressive acids such as $\mathrm{HCl}, \mathrm{HF}, \mathrm{HNO}_{3}$ and their mixtures was conaidered. The concentration of chemical ranges from 2 to $10 \%$ vol.

The results show the presence of a synergetic effect between aggressive chemicals and ultrasounds. In particular the weight losses $(\Delta P)$ and the decontamination effectiveness (DF) can be expressed by: 


$$
P=\Delta P_{u}+\Delta P_{c}+\Delta P_{s} ; \quad D F=D F F_{c} D F_{s}
$$

where $u$ is the ultrasonic effect in water, $c$ is the aggressive chemical effect without ultrasounds and $s$ is the synergic effect between chemicals and ultrasounds. $\Delta P_{s}$ and $D F_{s}$ are function of many parameters such as kind and nature of oxide layers, temperature, time and so on. The synergetic effect was more evident in the $\mathrm{HF} / \mathrm{HNO}_{3}$ solution.

After lab tests some in-scale tests were made on assembling 20 tube specimens $40 \mathrm{~cm}$ long, using a special ultrasonic machine. In these tests, because the effect of other radionuclides such as Fe-55, Ni-59 and Ni-63, a target was set of decontaminating all the tube specimens to less than $0.25 \mathrm{~Bq} / \mathrm{g}$.

Before in-scale testing, the following topics were defined:

- to perform the decontamination with ultrasounds by a phase in water followed by a phase with aggressive chemical;

- the phase in water was scheduled in a single step half an hour long, at $60^{\circ} \mathrm{C}$;

- for the phase in aggressive chemicals the $3 \% \mathrm{HF}+5 \% \mathrm{HNO}_{3}$ solution was selected and it was scheduled both at room temperature and at $60^{\circ} \mathrm{C}$.

As an example the results of a test are shown in Figure 3. They allow the following considerations:

- all the tube specimens were found to be decontaminated to less than the prescribed limit of $0.25 \mathrm{~Bq} / \mathrm{g}$; nevertheless only 6 tube specimens $(30 \%$ of total) were decontaminated to less than $0.25 \mathrm{~Bq} / \mathrm{g}$ working at room temperature during the phase with aggressive chemicals; furthermore 1 of the 6 tube specimens required only 30 minutes;

- the final average value of 60-Co residual radioactivity was around $0.07 \mathrm{~Bq} / \mathrm{g}$ and only one tube specimen was still contaminated at more than $0.1 \mathrm{~Bq} / \mathrm{g}$;

- the ultrasounds in aggressive chemicals must be applied at temperatures around $60^{\circ} \mathrm{C}$ to be sure of meeting the decon limits prescribed;

- some tube specimens, always different, behave differently in terms of time required for total decontamination; this behaviour was not clearly understood.

After this in-scale testing, a decontamination procedure for industrial testing was set up as summarized in Table VI.

The demonstration of the total decontamination of the tube bundle of the preheater No. 4 was scheduled by performing "10 full-scale demo tests" with an assembly of 100 tubes, each $1 \mathrm{~m}$ long, for a total of $1000 \mathrm{~m}$ of tube which represents about $10 \%$ of the preheater.

To perform the demo test a new special ultrasonic machine was designed; it is composed of four main tanks (Figure 4):

- two tanks with ultrasonic transducers, (20 kHz, $10 \mathrm{w} / \mathrm{l}$ ) applied on all immersed sides, for performing the decontamination with water and with aggressive chemicals ( 3001 each tank); 
- a tank for washing and rinsing with water (300 1);

- a tank for treating (neutralization/flocculation) the spent decontaminants (400 1).

The machine was installed at the Garigliano Power Station in the controlled area in the decontamination work shop of the turbine building.

Direct gamma spectrometry was selected as base techniques for measuring the residual radioactivity on the decontaminated tubes. The full scale measurements on $40 \mathrm{~cm}$ and $1 \mathrm{~m}$ long tubes were performed in special systems made by two large cylindrical ( $\left.5^{\prime \prime} \times 4^{\prime \prime}\right)$ Na-I detectors connected to a multichannel analyzer. They were located in a shielded box commonly used for Whole Body Counter measurements with a very low background level $(25 \mathrm{nSv} / \mathrm{h})$.

To optimize the systems, several measurement geometries were checked. The selected geometry considers the tubes located around the detectors at a distance of about $5 \mathrm{~cm}$ (Figure 5). The systems were calibrated using a standard 60-Co source to mark the inside surface of tubes similar to the tubes to be measured both for dimension and material.

These systems allow us to measure the residual radioactivity on a number of tubes from 1 to 25 in a few minutes (5-10 $\mathrm{min})$ with a detection limit much less than $1 \mathrm{~Bq} / \mathrm{cm}^{2}$; in the worst case of a single tube the detection $11 \mathrm{mit}$ is about $0.1 \mathrm{~Bq} / \mathrm{cm}^{2}$ and $0.1 \mathrm{~Bq} / \mathrm{g}$ (Figure 6 ).

As mentioned above the demo tests were made on an assembly of 100 tubes using a two-phase decontamination procedure. Due to some problems which occurred during the set up of the new ultrasonic machine (ultrasonic power lower than requested: $10 \mathrm{~W} / 1$ vs $>25 \mathrm{~W} / 1$ ) some process parameters were changed during the first tests. The optimized procedure considers an increased duration of both phases, a test temperature of $70^{\circ} \mathrm{C}$ (Instead of $\left.60^{\circ} \mathrm{C}\right)$ during the phase with aggressive chemicals and a solution of $4 \% \mathrm{FF}+$ $6 \% \mathrm{HNO}_{3}$ (1nstead of $3 \% \mathrm{HF}+5 \% \mathrm{HNO}_{3}$ ).

During the tests the progress of the decontamination was evaluated by performing radiometric measurements by the preliminary system on 5 control tubes, random selected among the 100 tested tubes. A test was finished when all tubes were visually clean and at least four of the five control tubes showed a Co-60 radioactivity less than $0.3 \mathrm{~Bq} / \mathrm{g}$.

At the end of each demo test, all the $1 \mathrm{~m}$ long tubes were quickly checked, one by one, by a preliminary measurement system. The tubes that passed this control were sent to the final measurement system in the shielded box while the tubes that did not pass this control were stored and they were redecontaminated in a further test.

If the final measure gave a value lower than $0.3 \mathrm{~Bq} / \mathrm{g}$ all the tubes of the controlled assombly were released, while if the final measure gave a value $\mathrm{h}$ igher than $0.3 \mathrm{~Bq} / \mathrm{g}$ the tubes of the controlled assembly were recontrolled, one by one, and all the tubes that still showed a radioactivity greater than $0.3 \mathrm{~Bq} / \mathrm{g}$ were redecontaminated together with the tubes that did not pass the preliminary control (Figure 7). 
A summary of the results obtained in the demo tests are presented in Table VII.

In conclusion all the 1000 pin-tubes were decontaminated below the unrestricted release limit, (about 100 of them by a further redecontamination) indicating that the new decon procedure is a very effective alternative for decommissioning works.

During the demo tests a total amount of 21001 of aggressive solution wastes were generated. By chemical neutralization with $\mathrm{NaOH}$ these wastes were reduced below 3001 of sludges, to be conditioned.

All the demo program spent about $2.3 \cdot 10^{-3}$ man-Sv: $2.0 \cdot 10^{-3}$ man-Sv for dismantling works for sampling the 1000 tubes, $0.3 \cdot 10^{-3}$ man-Sv for decontamination works.

With the hypothesis of the use of the industrial machine for decontaminating all the tube-bundles of the feedwater preheaters of Garigliano-BWR, a cost of about 6 ECUs for each $\mathrm{kg}$ of contaminated material, was estimated. For the full decontamination of all the tube-bundles a total cost of about 1 MECUs was evaluated.

\section{TREATMENT OF THE WASTES ARISING FROM THE PROCESS}

Decontamination processes using mineral acids give rise to spent decontamination solutions that are the most likely radioactive wastes with undesirable characteristics. The so-called exhausted or spent decontaminant solutions contain the surface radioactivity of the cleaned material and are generally big in volume; consequently, the radioactivity removal and the volume reduction become indispensable.

In order to gain knowledge about the treatment processes of these contaminated solutions before disposal, specific investigations were made ( 8 ).

The results showed that spent radwaste solutions coming from surface decontamination by aggressive mineral acids can easily be treated for volume reduction by means of the simple chemical process of neutralization with sodium hydroxide and calcium oxide. Improvement of the purification was noticed by adding a special flocculative agent (chitosan) to the early radwaste solution. The radioactivity of the treated spent rad solutions was less than or around $0.1 \mathrm{~Bq} / \mathrm{cm}^{3}$.

The residual sludges arising from neutralization and precipitation were also characterized. The main result shows that the residual sludges retain more than $80-90 \%$ of water.

After the experiments on the neutralization-precipitation process, the following procedure has been proposed for the treatment of secondary liquid waste arising from aggressive chemical decontaminations:

- to put the waste solution in a suitable tank;

- to neutralize with sodium hydroxide up to $\mathrm{pH} 5$; then to stir and to decant;

- to filter or separate to eliminate $\mathrm{Fe}(\mathrm{OH})_{3}$ precipitates which should retain very low radioactivity; 
- to add some more $\mathrm{NaOH}$ with chitosan powder $(0.5 \mathrm{~g} / 1)$ up to $\mathrm{pH} 7$;

- to filter or separate to recover other hydroxide precipitates, such as $\mathrm{Co}(\mathrm{OH})_{2}$, which should retain almost all radioactivity;

- If possible to discharge the floating liquid;

- if necessary, and possible, to treat the residual sludges further by evaporation.

\section{CONCLUSIONS}

Studies related to Garigliano-BWR decommissioning show that decontamination is an interesting possibility; for releasing the turbine building components four decontamination techniques would need: electropolishing, water jet with abrasives, ultrasounds in aggressive chemical and freon jet. Direct melting for release or reuse in the nuclear field is another alternative, of course.

The preheater tube-bundles are a particular case and for their release decontamination is the only possible way. The experimental tests on the new decon process using aggressive chemicals with ultrasounds show that this technique is a very promising alternative.

The tests performed on small valves, by aggressive chemical decontamination, show that some hot spots always remain on the decontaminated parts. Therefore it is very difficult to establish "a priori" if the component or part can be released or not.

Spent waste solutions from aggressive chemical decontamination can easily be treated by chemical neutralization and precipitation.

\section{ACKNOWLEDGEMENTS}

The authors thank CEC coordinators and all the participants in WG-A.2 and WG-C. of CEC decommissioning programme, for their useful comments and discussions during the coordination meetings.

An appreciative thanks to $\mathrm{Mr}$. Colafato, Mr. De Canditils (of ENEL) and Mr. Borroni and Mr. Endimiani (of CISE) for performing the experimental activities.

Finally the authors thank ENEL management of Thermal \& Nuclear Research Centre of R\&D Division, Special Unit for Decommissioning of G\&T Division, and Garigliano-BWR Power Plant, for their useful contribution during the development of the programme.

\section{REFERENCES}

(1) Decontamination and Demolition of Concrete and Metal Structures During Decommissioning of Nuclear Facilities; IAEA TRS-286, 1988.

(2) F. BREGANI, R. PASCALI and R. RIZZI; Chemical Decontamination for Decommissioning Purposes (Vigorous Decontamination Tests on Steel Samples In a Special Test Loop); EUR 9303 EN, 1984. 
(3) W. AHLFANGER, F. BREGANI, J.P. GAUCHON, M. LASCH and R. PASCALI; Chemical and Electrochemical Decontamination; CEC Conference on Decommissioning of Nuclear Power Plants, May 22-24, 1984, Luxembourg, L.

(4) J.P. GAUCHON, F. BREGANI, W. AHLFANGER and M. LASCH; Composition des couches de contamination; CEC Conference on Decommissioning of Nuclear Power Plants, May 22-24, 1984, Luxembourg, L.

(5) T. VITIELLO; Description and Actual Situation of the Garigliano Plant, Specialist meeting on "Industrial scale decommissioning operations in the European Community", May 1983, Windscale, UK.

(6) F. BREGANI and A. GAROFALO; Decontamination Studies Related to Garigliano-BWR Decommissioning; 1987 International Decommissioning Symposium, October 4-8, 1987, Pittsburgh, USA.

(7) F. BREGANI, P.A. BORRONI, R. COLAFATO and P. PINACCI; Decontamination for Decommissioning Purpose: Enhancement of Aggressive Chemical Decontamination by using Electropolishing or Ultrasounds; Fifth International Conference on Water Chemistry of Nuclear Reactors Systems, October 23-27, 1989, BNES - Bournemouth, UK.

(8) P.A. BORRONI, F. BREGANI and F. SALGHETTI; Treatment of Rad Waste Solutions Exhausted in Decontamination Processes; Fourth International Conference on Water Chemistry of Nuclear Reactor Systems, October 13-17, 1986, BNES - Bournemouth, UK.

Table I: Stainless steel valves from the Garigliano-BWR used in decontamination tests by aggressive chemicals

\begin{tabular}{|c|c|c|c|c|c|c|}
\hline \multirow[b]{2}{*}{ MUMBER } & \multirow[b]{2}{*}{$\begin{array}{l}\text { HOMINAL SIZE } \\
\text { (inches) }\end{array}$} & \multirow[b]{2}{*}{ TYPE } & \multicolumn{2}{|c|}{ DIMENSIOHS } & \multicolumn{2}{|c|}{ RADIOHETRIC FEATURES $(7.2 .83)$} \\
\hline & & & $\begin{array}{l}\text { Length } \\
\text { (a) }\end{array}$ & $\begin{array}{l}\text { Weight } \\
\text { (kg) }\end{array}$ & $\begin{array}{l}\text { Contact } \\
\text { dose } \\
\text { (aren/h) }\end{array}$ & $\begin{array}{c}\text { Snearable } \\
\text { contanination } \\
\left(\mu \mathrm{Ci} / \mathrm{m}^{2}\right)\end{array}$ \\
\hline 1 & 1 & GLOBE & 180 & 9 & \multirow{2}{*}{50} & \multirow{2}{*}{$3 \cdot 10^{-3}$} \\
\hline 2 & $11 / 2$ & Y-TYPE & 150 & 18 & & \\
\hline 3 & 1 & GLOBE & 180 & 9 & \multirow{2}{*}{1000} & \multirow{2}{*}{$8 \cdot 10^{-4}$} \\
\hline 4 & $11 / 2$ & $Y$ Y-TYPE & 150 & 18 & & \\
\hline
\end{tabular}


Iable II: Description of the aggressive chemical decontanination tests on amall valves

\begin{tabular}{|c|c|c|c|c|}
\hline \multirow{2}{*}{$\begin{array}{l}\text { OECOUTAMIMATION } \\
\text { PROCESS }\end{array}$} & \multicolumn{4}{|c|}{ TESI/VAL VE } \\
\hline & 1 & 2 & $\mathbf{3}$ & 4 \\
\hline - Preparation: & $\begin{array}{l}\text { - Uitrasounds } \\
\text { in vater } 15 \text { ein }\end{array}$ & $\begin{array}{l}\text { - Ulerasounde } \\
\text { In veter is ain }\end{array}$ & $\begin{array}{l}\text { - Ultrasounda in } \\
\text { vater } 70 \text { ein } \\
\text { - Lou pressure water }\end{array}$ & $\begin{array}{l}\text { - Ultrasounds } \\
\text { in uater } 60 \text { ein }\end{array}$ \\
\hline $\begin{array}{l}\text { - Soft cheeical } \\
\text { docontenination: }\end{array}$ & - & - & $\begin{array}{l}\text { - Diluite cirrox } \\
0.125 \% \text { ut eltric acid } \\
0.125 \text { ut oxalic acid } \\
26 \text { h at } 80^{\circ} \mathrm{C} \text {. B h ot } 110^{\circ} \mathrm{C}\end{array}$ & $\begin{array}{l}\text { - Diluite Cligox } \\
0.125 \% \text { ut citric aeld } \\
0.125 \% \text { ut oxalic acid } \\
24 \text { h at } 80^{\circ} \mathrm{C}\end{array}$ \\
\hline $\begin{array}{l}\text { - Aggrassive cheoleal } \\
\text { decontacination: }\end{array}$ & $\begin{array}{l}-4.17 \mathrm{rol}, \mathrm{HCl} \\
40^{\circ} \mathrm{C}, 1-2 \mathrm{ol} \\
8 \mathrm{~h}\end{array}$ & $\begin{array}{l}-1.57 \mathrm{rol} \text {. HF } 55 \mathrm{vol} \text {. } \mathrm{MMO}_{3} \\
40^{\circ} \mathrm{C}, 1 \mathrm{o} / \mathrm{s} \\
\mathrm{h}(1.16 \mathrm{~h} \text { in static } \\
\text { conditions) }\end{array}$ & $\begin{array}{l}-0.15 \% \mathrm{rol} . \mathrm{HF}+2.5 \% \mathrm{rol} \\
\text { HMO } 5 \mathrm{l}=\mathrm{s} \\
8 \mathrm{~h}^{3} \text { at } 40^{\circ} \mathrm{C}+0.15 \mathrm{~h} \text { et } 80^{\circ} \mathrm{C}\end{array}$ & $\begin{array}{l}-0.75 \mathrm{rol} \text {. HF }: 2.56 \mathrm{vol} . \\
\mathrm{HMO}_{3} 0^{\circ} \mathrm{C}, \mathrm{3}=/ \mathrm{s} \\
10 \mathrm{~h}\end{array}$ \\
\hline - Final tratuent: & $\begin{array}{l}\text { - Ultrasounds } \\
\text { in vater 15' } \\
\text { - Brushing on } \\
\text { outalde surface } \\
\text { - Ultrasounds } \\
\text { in water } 30 \text { ein }\end{array}$ & 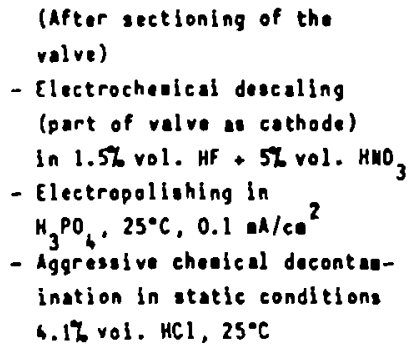 & & \\
\hline
\end{tabular}




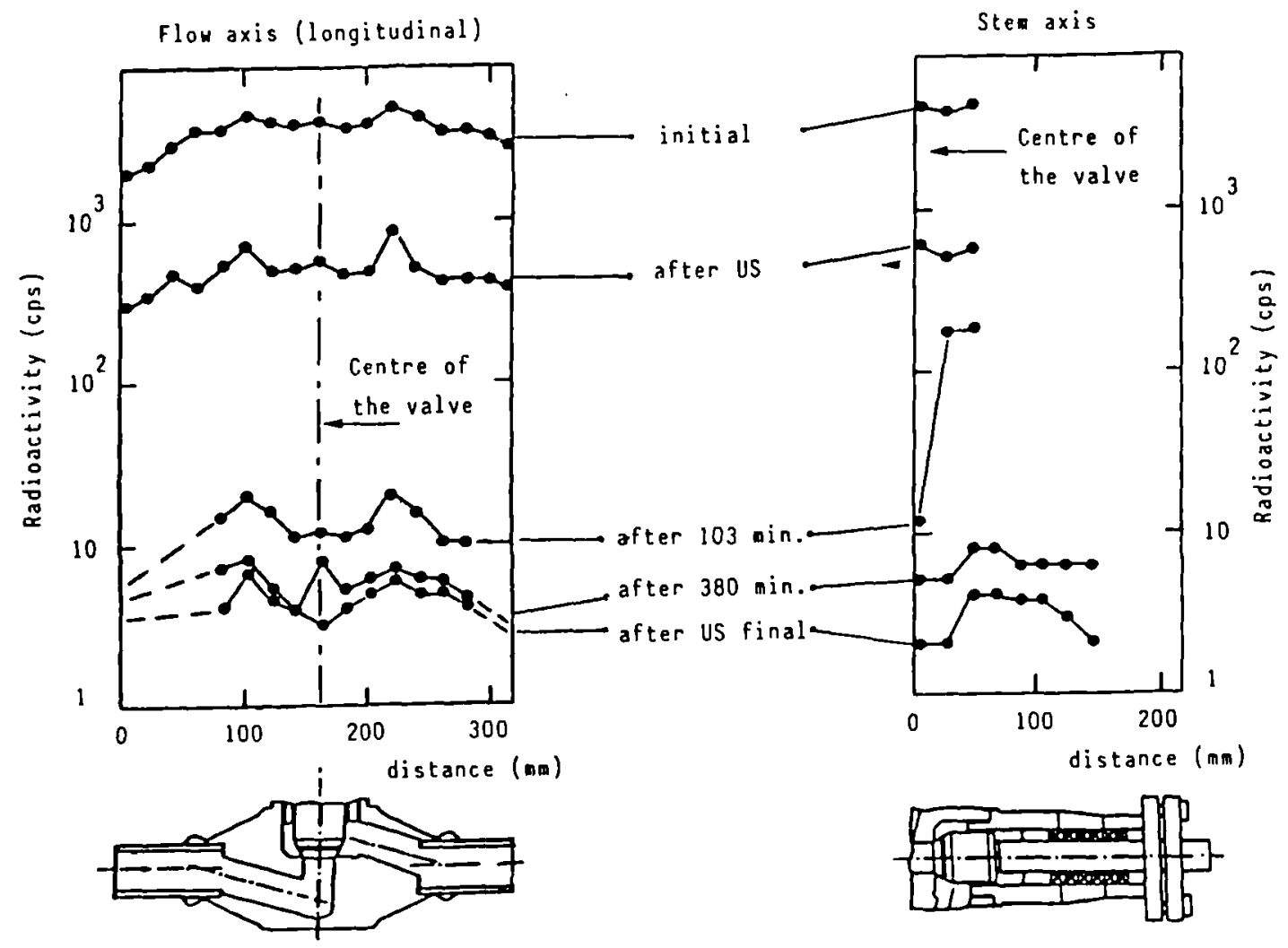

Figure 1: Radioactivity profiles in the decontamination steps of valve No. $1\left(4.1 \% \mathrm{HCl}, 8 \mathrm{~h}, 40^{\circ} \mathrm{C}, 1-2 \mathrm{~m} / \mathrm{s}\right)$. 
Figure 2: Cutting schema of valve No. 1 for removing for gamma spectrometry measurements.

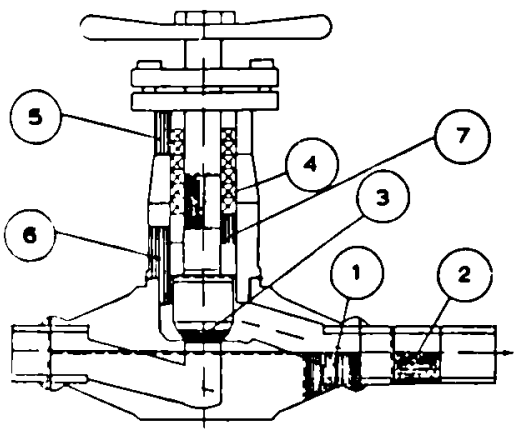

Table III: Results of the low background gamma spectrometry of some samples cut off from value No. 1

\begin{tabular}{|c|c|c|c|c|}
\hline \multicolumn{5}{|c|}{ RADIOACTIVITY } \\
\hline Nuclide & $\begin{array}{l}\text { Total } \\
(\mathrm{Bq})\end{array}$ & $\begin{array}{l}\text { Spec. } \\
\text { Weight } \\
(\mathrm{Bq} / \mathrm{g})\end{array}$ & $\begin{array}{l}\text { Spec. Cont. } \\
\text { Surfaç } \\
\left(\mathrm{Bq} / \mathrm{Cq}^{2}\right)\end{array}$ & $\begin{array}{l}\text { Spec. Tot. } \\
\text { Surfack } \\
\left(8 q / c \Delta^{2}\right)\end{array}$ \\
\hline$C_{0}-60$ & 951 & 11.56 & 56.9 & n.c. \\
\hline Cs -137 & 17.6 & 0.21 & 1.06 & n.c. \\
\hline $\mathrm{CO}_{0} 60$ & 9.84 & 0.42 & 0.90 & 0.46 \\
\hline$C s-137$ & 1.64 & 0.06 & 0.13 & 0.07 \\
\hline Co-60 & 5.66 & 0.27 & 0.64 & 0.33 \\
\hline Cs-137 & 0.91 & 0.05 & 0.10 & 0.05 \\
\hline Co-60 & 3.18 & 0.08 & 0.33 & 0.20 \\
\hline$C s-137$ & 0.244 & 0.006 & 0.025 & 0.015 \\
\hline Co-60 & 10.3 & 0.21 & 0.98 & 0.37 \\
\hline Cs-137 & 0.35 & 0.0075 & 0.03 & 0.01 \\
\hline Co-60 & 24 & 0.30 & 2.66 & 0.68 \\
\hline$C s-137$ & 3.7 & 0.046 & 0.41 & 0.10 \\
\hline Co-60 & 81.6 & 1.89 & 12.9 & 4.2 \\
\hline$C s-137$ & 5.07 & 0.117 & 0.81 & 0.26 \\
\hline
\end{tabular}

n.c. = not calculated

Table IV: Summary of estimated residual radioactivity in the valves decontaminated in the DECO loop

\begin{tabular}{|c|c|c|c|c|c|c|c|}
\hline \multirow{2}{*}{ VALVE Mo. } & \multirow{2}{*}{$\begin{array}{l}\text { DECONTAMIMATION } \\
\text { PROCESS } \\
\text { (see Table II) }\end{array}$} & \multirow{2}{*}{$\begin{array}{c}\text { TOTAL } \\
\text { WEIGHT OF } \\
\text { THE VALVE } \\
\text { (+ connections) } \\
\text { (kg) }\end{array}$} & \multicolumn{2}{|c|}{$\begin{array}{l}\text { ESTIMATED } \\
\left.\text { SURFACE (dn }{ }^{2}\right)\end{array}$} & \multicolumn{3}{|c|}{$\begin{array}{c}\text { RESIDUAL } \\
\text { RADIOACIIVITY (Bq) }\end{array}$} \\
\hline & & & inside & total & Co-60 & Cs-137 & total \\
\hline 1 & $U S+A C+U S+B R$ & 10.5 & 12.5 & 21 & 4512.2 & 135.0 & 4647.2 \\
\hline 2 & $U S+A C+U S+E L$ & 25.5 & 7.0 & 19 & 85870.2 & 864.3 & 86948.2 \\
\hline 3 & $U S+M L+S C+A C$ & 10.2 & 12.5 & 21 & 2832.0 & 1407.8 & 4239.8 \\
\hline 4 & $U S+S C+A C$ & 26.5 & 7.0 & 19 & 50465.8 & 957.4 & 51423.2 \\
\hline
\end{tabular}

Table V: Range of specific residual radioactivity in the valves decontaminated in the DECO loop

\begin{tabular}{|c|c|c|c|c|c|c|}
\hline \multirow{3}{*}{$\begin{array}{l}\text { VAL VE } \\
\text { Mo. }\end{array}$} & \multicolumn{3}{|c|}{ SPECIFIC MEIGHT $(B q / g)$} & \multicolumn{3}{|c|}{ SPECIFIC CONT. SURFACE $\left(8 q / \mathrm{cm}^{2}\right)$} \\
\hline & \multirow{2}{*}{$\begin{array}{c}\text { average on } \\
\text { valve }\end{array}$} & \multicolumn{2}{|c|}{ saeples } & \multirow{2}{*}{$\begin{array}{c}\text { average on } \\
\text { valve }\end{array}$} & \multicolumn{2}{|c|}{ sauples } \\
\hline & & vin & $\operatorname{lax}$ & & nin & $\operatorname{lax}$ \\
\hline 1 & 0.64 & 0.09 & 11.77 & 3.68 & 0.35 & 57.9 \\
\hline 2 & 3.41 & 2.00 & 12.53 & 124.29 & 9.05 & 113.9 \\
\hline 3 & 0.41 & 1.06 & 2.51 & 3.36 & 4.37 & 22.21 \\
\hline 4 & 2.08 & 0.16 & 35.13 & 72.86 & 12.0 & 680.7 \\
\hline
\end{tabular}




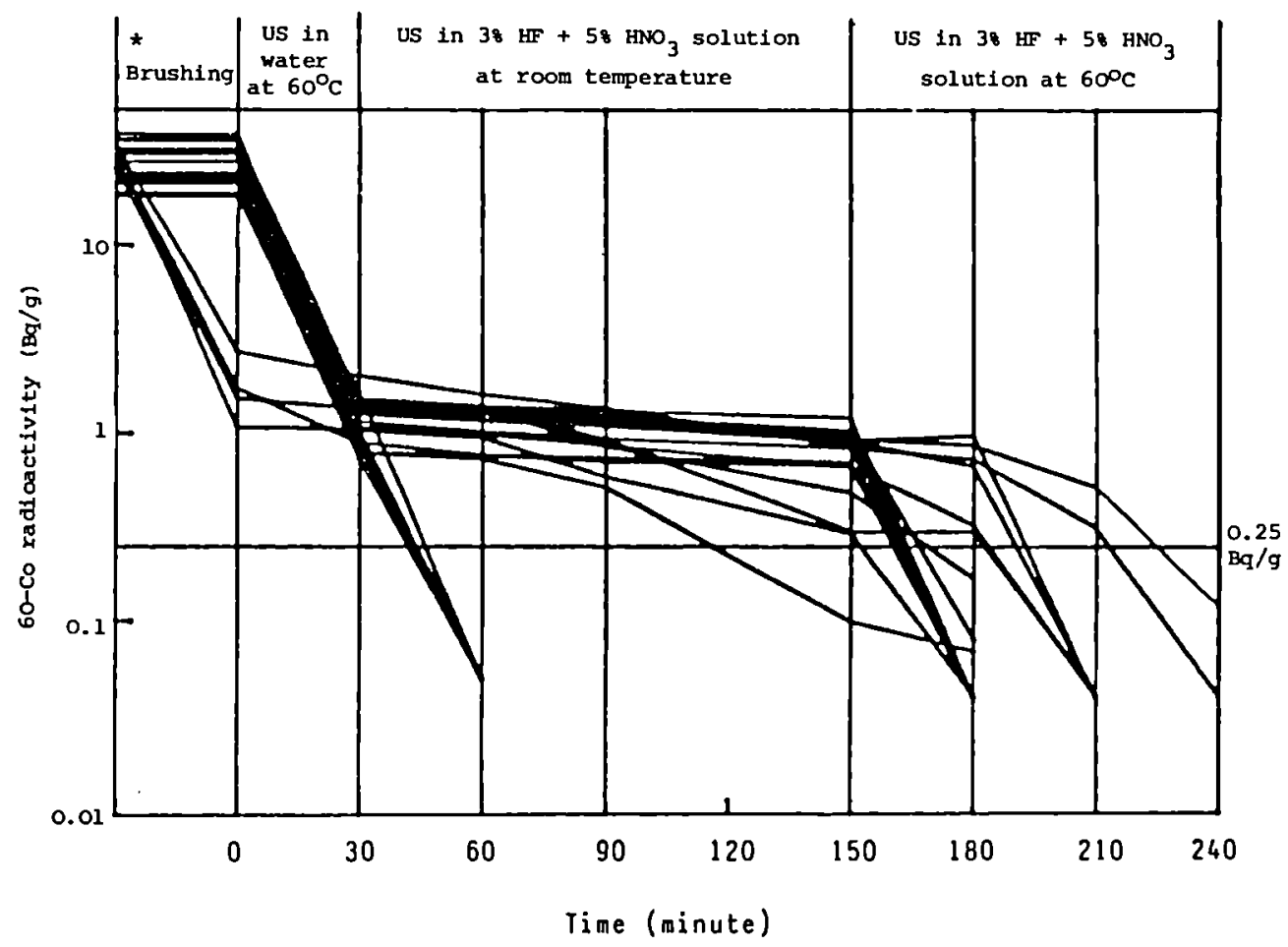

Figure 3: Radioactivity versus test time during an in-scale testing. (* Five tubes were brushed before US decontamination).

Table VI: Decontamination procedure to be used for "10 full-scale demo tests" on $1 \mathrm{~m}$ long tubes taken off from the preheater No.4 of Garigliano-BWR

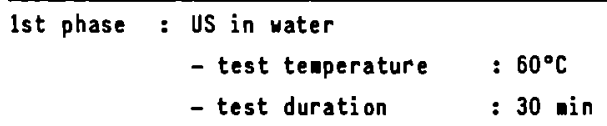

Rinsing with water.

2nd phase : US in aggressive chemical

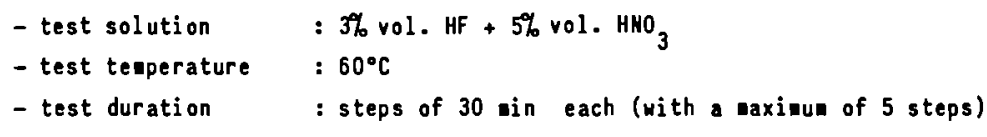

Rinsing with water. 
Table VII: Diamantling and decontamination of the tube-bundle of a feedwater preheater of Garlgliano-BwR. Summary results of rull scale demo tests

\begin{tabular}{|c|c|c|c|c|c|c|c|c|c|c|}
\hline \multirow{3}{*}{$\begin{array}{l}\text { DE MO } \\
\text { IESI } \\
\text { Mo. }\end{array}$} & \multirow{3}{*}{$\begin{array}{l}\text { Wo. of } \\
\text { IUBES }\end{array}$} & \multicolumn{7}{|c|}{ DESCRIPTION OF THE TESI } & \multicolumn{2}{|c|}{ RE SUL IS } \\
\hline & & \multicolumn{3}{|c|}{$1^{\text {st }}$ phase (us in veter) } & \multicolumn{4}{|c|}{$2^{\text {nd }}$ phase (US in cheolcals) } & \multirow{2}{*}{$\begin{array}{l}\text { Tubes oent } \\
\text { to the finel } \\
\text { control } \\
(<0.3 \\
\text { Ba } / g)\end{array}$} & \multirow{2}{*}{$\begin{array}{l}\text { Tubee not } \\
\text { cent to } \\
\text { the final } \\
\text { control } \\
(\bullet)\end{array}$} \\
\hline & & $\begin{array}{c}\text { Teup. } \\
\left({ }^{\circ} \mathrm{C}\right)\end{array}$ & $\begin{array}{c}\text { Ouration } \\
\text { (oin) }\end{array}$ & $\begin{array}{l}\text { Yaste } \\
\text { vater } \\
\text { (1) }\end{array}$ & $\begin{array}{l}\text { Teap. } \\
(\cdot c)\end{array}$ & $\begin{array}{c}\text { Ouretion } \\
\text { (ain) }\end{array}$ & $\begin{array}{l}\text { Test } \\
\text { oolution } \\
(Z \text { vol) }\end{array}$ & $\begin{array}{l}\text { vaste } \\
\text { solution } \\
\text { (1) }\end{array}$ & & \\
\hline 1 & 100 & 80 & 80 & 300 & 60 & 540 & $3 \mathrm{HF} / 5 \mathrm{HNO}_{3}$ & 300 & 98 & 2 \\
\hline 2 & $100^{(\bullet)}$ & 60 & 90 & 300 & 60 & 520 & $3 \mathrm{HF} / \mathrm{S} \mathrm{HNO}_{3}$ & 300 & 68 & 32 \\
\hline 3 & 100 & 60 & 120 & - & 70 & 120 & $4 \mathrm{HF} / 6 \mathrm{HNO}_{3}$ & 300 & 93 & 7 \\
\hline 6 & 100 & Bo & 120 & - & 70 & 135 & $4 \mathrm{HF} / 6 \mathrm{HNO}_{3}$ & 300 & 88 & 12 \\
\hline 3 & 100 & 60 & 180 & - & 70 & 210 & $6 \mathrm{HF} / 6 \mathrm{HHO}_{3}$ & - & 98 & 2 \\
\hline 6 & 100 & 65 & 120 & 300 & 75 & 90 & $4 \mathrm{HF} / 6 \mathrm{HNO}_{3}$ & 300 & 90 & 10 \\
\hline 7 & 100 & 65 & 120 & - & 75 & 150 & $4 \mathrm{HF} / 6 \mathrm{HMO}_{3}$ & - & 95 & 5 \\
\hline 8 & 100 & 63 & 120 & 300 & 78 & 75 & $6 \mathrm{HF} / \mathrm{S} \mathrm{HHO}_{3}$ & 300 & 84 & 16 \\
\hline 9 & 100 & 61 & 120 & - & 75 & 270 & $6 \mathrm{HF} / 6 \mathrm{HHO}_{3}$ & - & 86 & 14 \\
\hline 10 & 100 & 60 & 120 & 300 & 83 & 90 & $4 \mathrm{HF} / \mathrm{O} \mathrm{HNO}_{3}$ & 300 & 92 & 8 \\
\hline
\end{tabular}

(1) These tubes vere redecontaninated in a final test.

(•) Each 0.5 - long. 


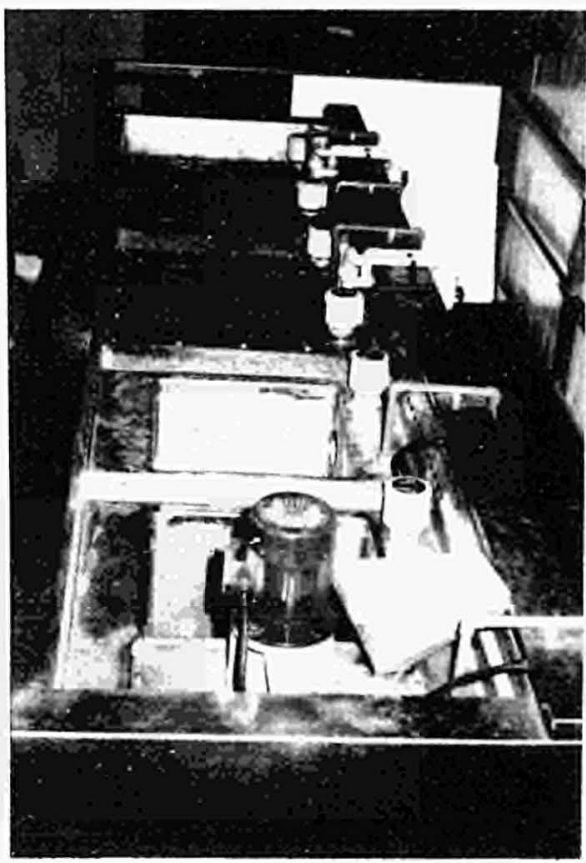

Figure 4: Top view of the full scale ultrasonic machine.

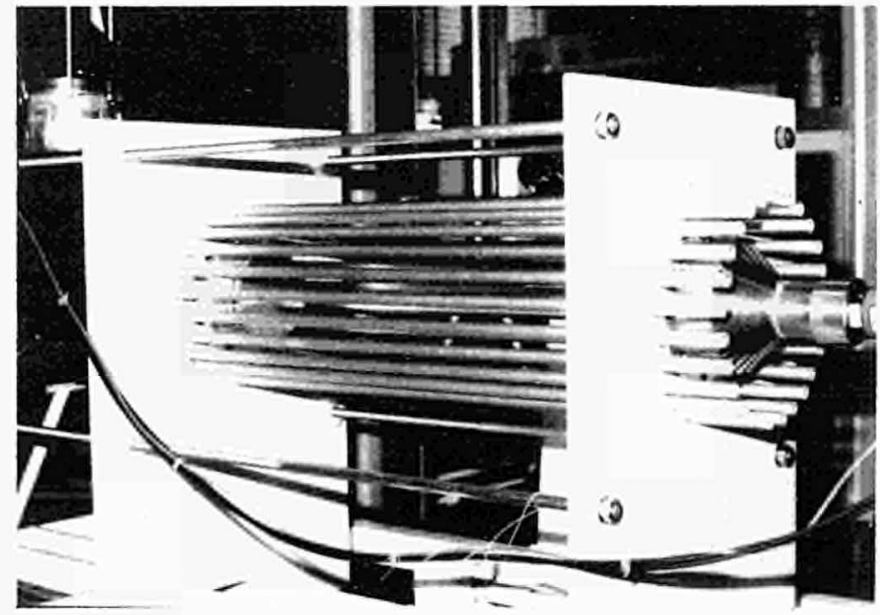

Figure 5: View of the final measurement system. 


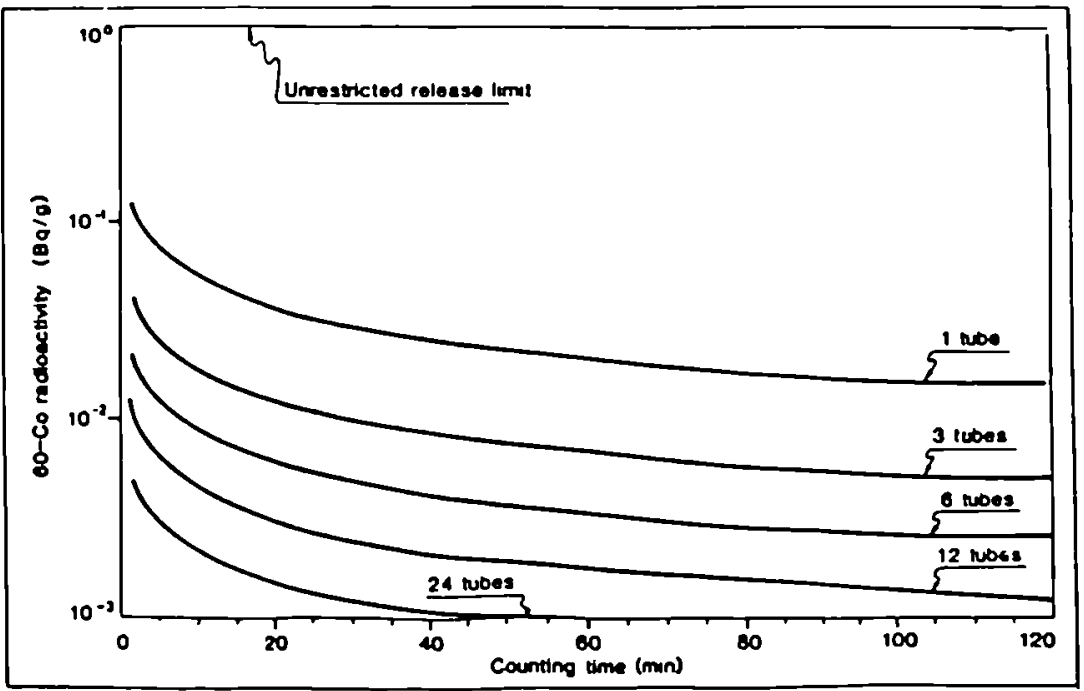

Figure 6: Minimu detectable radiactivity values as a function of counting time $(t)$ and number of tubes $(N)$.

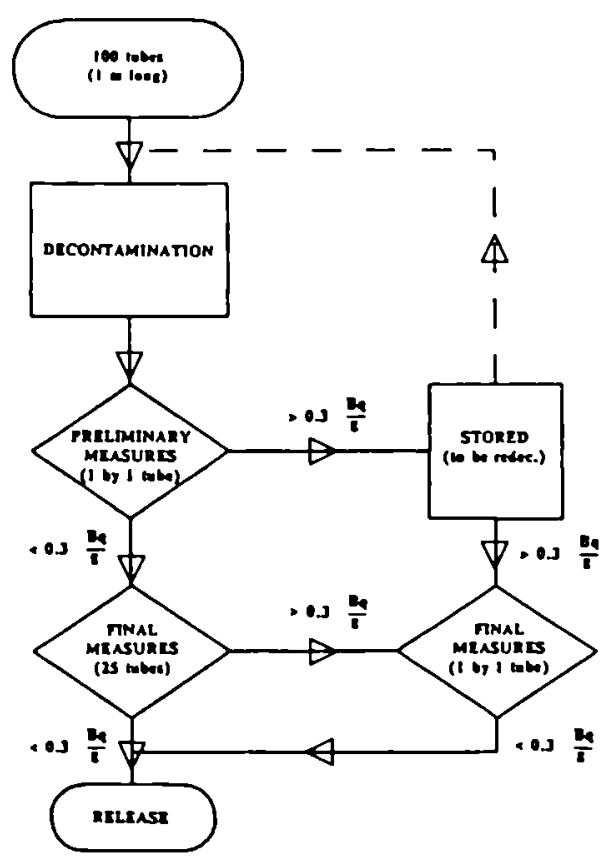

Figure 7: Procedure for final radiometric cantrol of tubes after decontamination. 


\title{
DECONTAMINATION BEFORE DISMANTLING A FAST BREEDER REACTOR PRIMARY COOLING SYSTEM
}

\author{
$\underline{\text { J.R. Costes }}{ }^{1}$, P. Antoine ${ }^{2}$, J.P. Gauchon ${ }^{3}$
}

\begin{abstract}
The large-scale decontamination of FBR sodium loops is a novel task, as only a limited number of laboratory-scale results are available to date. The principal objective of this work is to develop a suitable decontamination procedure for application to the primary loops of the RAPSODIE fast breeder reactor as part of decommissionirg to Stage 2. After disconnecting the piping from the main vessel, the pipes were treated by circulating chemical solutions and the vessels by spraying. The dose rate in the areas to be dismantled was divided by ten. A decontamination factor of about 300 was obtained, and should allow austenitic steel parts to be melted in special furnaces for unrestricted release.
\end{abstract}

\section{INTRODUCTION}

\subsection{The RAPSODIE Reactor}

RAPSODIE was an experimental liquid sodium-cooled fast breeder reactor using mixed uranium and plutonium oxide fuel elements, located at the Cadarache Nuclear Research Center.

The reactor diverged on January 28,1967 , reaching the nominal $20 \mathrm{MW}$ thermal power rating on March 17 of that year. The core and loops were modified in 1970 to increase the thermal power level to $40 \mathrm{MW}$ with a peak instantaneous neutron flux of $3.2 \times 10^{15} \mathrm{n} \cdot \mathrm{cm}^{-2} \mathrm{~s}^{-1}$. RAPSODIE was operated under these conditions until 1978 with a load factor of about $55 \%$, then at reduced power (22.4 MW $\mathrm{MW}_{\text {th }}$ ) until the final shutdown in April 1983.

Decommissioning operations began in 1987. All traces of residual sodium were eliminated by preliminary cleaning and water rinsing after isolation of the main vessel.

\subsection{Why Decontaminate the Primary System before Dismantling?}

The decision to proceed with in situ decontamination of the RAPSODIE primary cooling system was based on three principal considerations:

\subsection{Minimum Radiation Hazard to Dismantling Personnel}

Before the operation the mean dose rate in the cells containing the primary system was $5 \times 10^{-5} \mathrm{~Gy}$. Dismantling without prior decontamination would require 10 months of work by 5 persons including 2 waste conditioning specialists. The integrated dose was estimated at:

1 (conversion factor) $\times\left(5 \times 10^{-5}\right) \times 5 \times 100$ (hours $/$ month $) \times 10=25 \times 10^{-2} \mathrm{man} \cdot \mathrm{Sv}$

\footnotetext{
1 Decommissioning Service, CEA Marcoule

${ }^{2}$ Decommissioning Service, $C E A$ Cadarache

${ }^{3}$ Waste $R \& D$ Service, CEA Cadarache
} 
The decontamination work should leave only a few localized irradiating deposits whose harmful effects can easily be limited. The overall integrated dose should thus be limited to a maximum of $1 \times 10^{-2}$ man.Sv by shortening the work period and reducing the contamination level by a factor of 300 .

\subsubsection{Slmplified Working Conditions}

Prior decontamination will simplify the dismantling work easier by making some operations unnecessary:

- packaging each cutup part in vinyl (saving time and limiting the vinyl waste volume)

- installing and dismantling local containment provisions as the dismantling operation progresses

- using only alternating saws (faster and more specialized cutting tools can be now be used for each step in the dismantling procedure)

- wearing uncomfortable vinyl protective clothing (only cloth garments will be required).

\subsubsection{Sodium Depasit Washing Provisions}

Decontamination is carried out after washing the residual sodium deposits from the system. The safety equipment required for sodium washing can therefore be reutilized at lower cost for decontamination.

\section{CHARACTERIZATION OF THE PRIMARY SYSTEM}

The reactor core was cooled by two identical systems, each comprising a primary sodium circuit (Figure 1) from which thermal power was transferred to a secondary sodium circuit through an intermediate sodium-sodium heat exchanger by means of a primary pump. The system lines were enclosed in concrete cells inside a double containment barrier. The principal geometric specifications were the following:

North or South System (identical)

- core to heat exchanger: $300 \mathrm{~mm}$ I.D. $/ 314 \mathrm{~mm}$ O.D. $\times \sim 16 \mathrm{~m}$ long (part of this line will not be decontaminated)

- heat exchanger to pump: $300 \mathrm{~mm}$ I.D. $/ 314 \mathrm{~mm}$ O.D. $\times \sim 8.5 \mathrm{~m}$ long

- pump to Y manifold: $200 \mathrm{~mm}$ I.D. $/ 208 \mathrm{~mm}$ O.D. $\times \sim 18 \mathrm{~m}$ long

- heat exchanger vessel dimensions: $884 \mathrm{~mm}$ dia $\times \sim 5.2 \mathrm{~m}$ high

- pump vessel dimensions: $850 \mathrm{~mm}$ dia $\times 4.5 \mathrm{~m}$ high

The intermediate heat exchangers and primary pumps were removed from their containment vessels and decontaminated separately.

\section{Sodium Levels}

Under nominal operating conditions the sodium surface was situated at the $-5000 \mathrm{~mm}$ level in the pump and heat exchanger vessels (level 0 corresponded to the reactor slab supporting the rotating plugs). The volume distribution in the two vessels was therefore:

\begin{tabular}{|l|c|c|}
\hline \multicolumn{1}{|c|}{ Volume } & Pump & Heat Exchanger \\
\hline - Cover gas volume & 14001 & 14001 \\
- Sodium volume & 11001 & 11001 \\
- Total volume & 25001 & 33001 \\
\hline
\end{tabular}


The sodium level in the overflow tank ( $R$ 301) ranged from -7660 to $-6300 \mathrm{~mm}$, resulting in the following volume distribution range:

\begin{tabular}{|l|c|c|}
\hline \multicolumn{1}{|c|}{ Volume } & Pump & Heat Exchanger \\
\hline - Sodium volume & 63001 & 94001 \\
- Cover gas volume & 6001 & 37001 \\
\hline - Mean sodium volume & \multicolumn{2}{|c|}{100001} \\
\hline
\end{tabular}

During reactor operation the sodium temperature in the systems was $400^{\circ} \mathrm{C}$ in the cold leg, and $500^{\circ} \mathrm{C}$ in the hot leg. The pipes were manufactured from AISI 316 (AFNOR Z6 CND 17/13) steel.

Reservoir R300, a $40 \mathrm{~m}^{3}$ vessel at the bottom of the facility, will be used systematically to introduce fluids prior to decontamination and to remove them afterward to the liquid waste treatment station.

\subsection{Estimated Contamination}

Table I indicates the analysis results (in \%) on samples taken from an intermediate heat exchanger and from a primary sodium pump to determine typical waste spectra:

\begin{tabular}{|c|c|c|c|}
\hline Nuclide & Cover gas & $400^{\circ} \mathrm{C}$ sodium & $500^{\circ}$ sodium \\
\hline${ }^{3} \mathrm{H}$ & - & $2 \%$ & - \\
${ }^{54} \mathrm{Mn}$ & $2 \%$ & $40 \%$ & $24 \%$ \\
${ }^{60} \mathrm{Co}$ & $1 \%$ & $4 \%$ & $6 \%$ \\
${ }^{63} \mathrm{Ni}$ & - & $25 \%$ & $15 \%$ \\
${ }^{90} \mathrm{Sr}$ & - & $9 \%$ & $2 \%$ \\
${ }^{134} \mathrm{Cs}$ & $1 \%$ & - & $1 \%$ \\
${ }^{137} \mathrm{Cs}$ & $96 \%$ & $20 \%$ & $52 \%$ \\
\hline
\end{tabular}

A conservative estimate placed the mean contamination level at $5500 \mathrm{~Bq} \cdot \mathrm{cm}^{-2}$, i.e. for a surface area of $164 \mathrm{~m}^{2}$ a total activity of $9.25 \times 10^{9} \mathrm{~Bq}(0.25 \mathrm{Ci})$.

\section{SELECTING AND TESTING THE PROCESS IN A PILOT LOOP (GROLABO)}

In view of the complex primary cooling system geometry and the advantages of decontaminating the system before dismantling, it was considered preferable to circulate reagents in the system pipes and spray the interior of system vessels. The reagents were selected after tests conducted on actual specimens from the intermediate heat exchanger or primary pump removed from their containment shells, or on pipe sections available after isolating the main vessel from the remainder of the system (cf $\$ 4$ ). After steam-cleaning the residual sodium, the specimens were highly rusted. One of the first reagents to provide satisfactory results was a mixture of nitric acid and sulfuric acid at $85^{\circ} \mathrm{C}$ : the results are shown in Figure 2. Prior alkaline washing was found necessary to remove greasy deposits that easily retain ${ }^{137}$ Cs.

In order to improve the decontamination effectiveness and to compensate for the temperature drop to $60^{\circ} \mathrm{C}$ as required by the supervising engineer, the aggressiveness of the reagent was enhanced by adding cerium(IV) in sulfate form. This reagent is sufficiently 
oxidizing (redox potential $\mathrm{Eh}=1.610 \mathrm{~V}$ ) to oxidize iron, chromium and nickel in austenitic steels, and presents several additional advantages:

- it is soluble enough not to precipitated cerium(III) on the surface to be decontaminated,

- it allows the metal erosion rate to be controlled by using metered doses at selected cerium(IV) concentrations,

- it results in intergranular corrosion, which is not detrimental to dismantling operations and which should lead to greater decontamination effectiveness.

Erosion tests with AISI 316L steel in the GROLABO loop indicated erosion rates of between 0.18 and $0.25 \mu \mathrm{m} \cdot \mathrm{h}^{-1}$ with an initial $\mathrm{Ce}$ (IV) concentration of $0-2 \times 10^{-2} \mathrm{~mol} \cdot \mathrm{H}^{-1}$ and feed rates of $4-5 \times 10^{-2} \mathrm{~mol} \cdot \mathrm{l}^{-1} \mathrm{~h}^{-1}$.

A comparison of the residual activity on specimens measuring from 625 to $1250 \mathrm{~cm}^{2}$ from the South intermediate heat exchanger and from the primary sodium inlet and outlet lines (Figure 3) revealed the following points:

- Except for the cold side of the intermediate heat exchanger, the results were significantly better with $\mathrm{Ce}(\mathrm{IV})$ at $60^{\circ} \mathrm{C}$.

- The cold side of the intermediate heat exchanger and the primary sodium outlet were more difficult to decontaminate: the higher residual activity due to ${ }^{60} \mathrm{Co}$ rarely exceeded $10 \mathrm{~Bq} \cdot \mathrm{cm}^{-2}$.

- In all the tests where the redox potential was regulated to $1300 \mathrm{mV} / \mathrm{Ag}-\mathrm{AgCl}$, the erosion rates on specimens from the primary system were close to $0.2 \mu \mathrm{m} \cdot \mathrm{h}^{-1}$.

- About $4 \mathrm{~mol} \cdot \mathrm{m}^{-2}$ of cerium(IV) were required to obtain residual activity levels on the order of $10 \mathrm{~Bq} \cdot \mathrm{cm}^{-2}$ after 24 hours.

\section{MODIFICATION OF RAPSODIE SYSTEMS FOR DECONTAMINATION}

The modification work included two principal tasks:

- separating the North and South primary loops from the reactor vessel;

- Modifying the cooling loops and installing spray nozzles in the upper portion of the reservoirs, pumps and heat exchangers.

\subsection{Isolation of the Reactor Vessel}

These operations were carried out for sodium washing:

- Cutting the sodium inlet and outlet pipes and clad failure detection lines

- Isolating the overflow tank from the reactor vessel

- Isolating the sodium purification rack

\section{System Modifications}

These modifications were also performed prior to alcohol rinsing. The reactor vessel sodium inlet and outlet pipes in the South loop were interconnected by a pipe fitted with two valves, and connected to the decontamination loop, the off-gas discharge system and the nitrogen scavenging system via additional valves. Similar connections were also provided for the North loop inlet and outlet pipes.

The drain line was connected across a valve to the inlet orifice of a new pump PPal 463 in order to allow for agitation and removal of the decontaminating fluids outside the reactor building. The pump flow rates and the division into three loops were designed to reach Reynolds numbers of at least 3000 (even for trickling flows in the vessels) without exceeding a flow velocity of $2 \mathrm{~m} \cdot \mathrm{s}^{-1}$ to avoid high pressure drops. The three loops were: R301, the overflow reservoir ( $36 \mathrm{~m}^{2}$ surface area); the South loop (pump, heat exchanger, pipes: $58 \mathrm{~m}^{2}$ ); and the North loop (pump, heat exchanger, pipes: $70 \mathrm{~m}^{2}$ ). 
Five $4 \pi$ spray nozzles with shutoff valves were installed in each vessel and connected to the discharge line from a new pump PPal 481.

\subsection{Additional Equipment Installed}

The following equipment was installed for decontamination purposes:

- a feed station for chemical reagents delivered by industrial suppliers.

- a demineralized water feed system.

- nitrogen supply and off-gas removal systems: the reactor lines were continuously scavenged by nitrogen; the off-gases were collected and discharged to atmosphere after dilution in the ventilation air after aerosol trapping in a demister-cooler and after HEPA filtration. Atmospheric release of off-gases was to be interrupted if the activity level exceeded a setpoint threshold or if the hydrogen content exceeded $1 \%$ in the containment cell exhaust duct, but this eventuality never occurred.

- an on-line measurement cell (pH, redox potential, sampling, radioactivity levels).

- a station for collecting liquid wastes before transfar to the Cadarache waste treatment facility; the liquid waste was transferred to the tank trucks directly by suction without pretreatment.

- a local control room where data from the work site was centralized and decontamination operations were controlled and monitored.

\section{SETTING UP OPERATING PROCEDURES}

The decontamination process was broken down into basic procedures. The complexity of the system piping and the steps required for treatment with different products required a total of 150 instruction sheets. Rather than preparing them by hand, we designed a computer-aided expert system to handle worksheet creation, management and execution.

The system was used by operators from the local control room in the controlled access zone of the RAPSODIE reactor building containing the operation control racks.

The system was used in two different modes: assistance during initial operator training and assistance in carrying out the assigned task procedures. It was not connected to the process, but was available to the operators and covered the following points:

- reactor system: equipment items; system architecture \& shutoff provisions ; instrumentation

- procedures: initial conditions; operational constraints; failure modes and emergency procedures; shutdown criteria; control

For each procedure it provided operator assistance during three phases: preparation of the reactor cooling system, fluid flow monitoring, and interpretation of results. For each phase, detection aids, interpretation aids and troubleshooting aids had to be available. In case of failure, instructions were provided for restoring the facility to safe conditions to help reduce operator stress during the procedure.

The expert system printed out a data sheet specifying:

- valves to be actuated

- chemical reagent preparation

- motor setpoint variations

- initial status of the reactor cooling system.

A worksheet such as the following example is printed out by the system when sensor measurement values are to be recorded: the operator records the values on the sheet, then enters them into the computer. 
Sheet F1: Filling Sodium Reservoir RENA300-4M3-ED

Date:

Time: $8: 22$

Operator's name:

List of sensors to be noted:

DAL504

PGZ861

NALS25

NALS22

NAL523

NALS24

NAL526

AH842

AH847

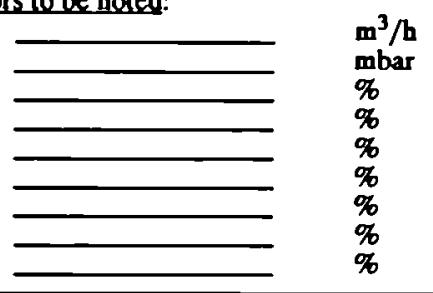

Similarly, the following printout is carried by the operator as he performs the specified tasks at the locations indicated.

\begin{tabular}{|ll|}
\hline $\begin{array}{l}\text { Sheet: Draining RENA301 into RENA300 } \\
\text { Operator's name: TESTA } \\
\text { Operations on valves at beginning of procedure } \\
\text { Date: } 10-1-1989\end{array}$ & Time: $12: 47$ \\
& Open these valves: \\
Valve(s) & Location \\
VNA356 & 2.81 North \\
NNAL460 & 10.5 South Zone C \\
& \\
& Close these valves: \\
Valve(s) & Location \\
VNAL462 & 14 South \\
DTAL482 & 2.81 South \\
VNAL480 & 2.81 South \\
\hline
\end{tabular}

The next example is a data entry screen displayed as the operator keys in recorded values. A menu bar across the top of the screen provides access to related functions.

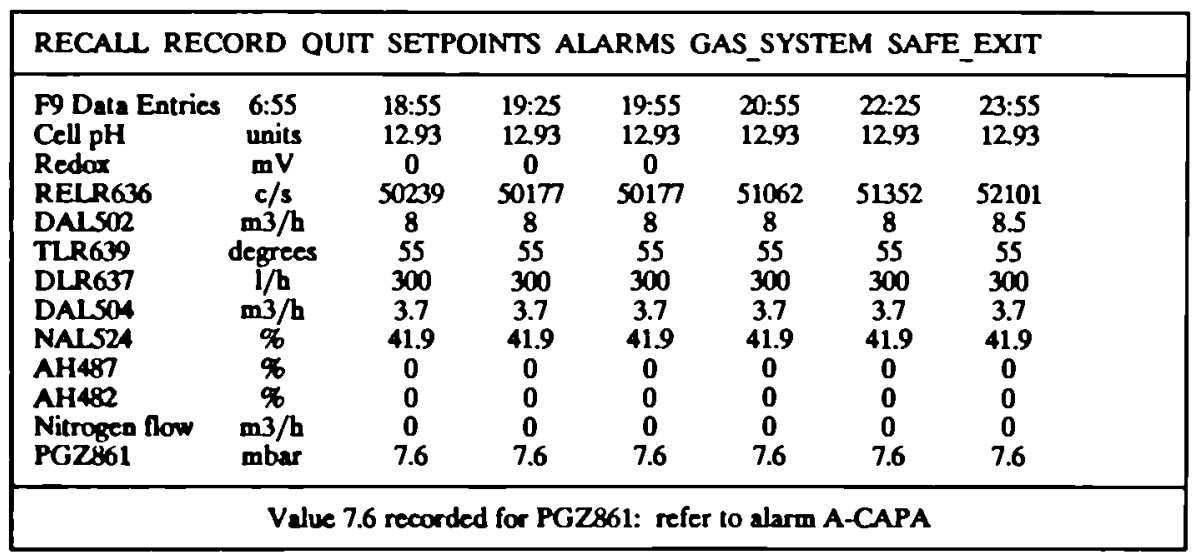


The bottom line in this display alerts the operator that the value for PGZ861 is anomalous, and cautions him to consult the relevant alarm screen.

The following is a typical alarm screen display:

\begin{tabular}{|l|l|}
\hline $\begin{array}{l}\text { Alarm: Abnormal radioactivity } \\
\text { Proceed as follows: }\end{array}$ & \multicolumn{1}{c|}{ [YES] } \\
InO]
\end{tabular}

\section{ALKALINE WASHING}

Alkaline washing began on February 6 and was completed without incident on February 21, 1989. The planned operating procedure was implemented.

Each operation began by heating demineralized water to $60-70^{\circ} \mathrm{C}$ in $\operatorname{Re} 301$, then circulating the hot water through the selected loop while adding sodium hydroxide. Circulation and spraying were maintained for the required time, and the operating parameters (fluid levels, reagent temperature, radioactivity and $\mathrm{pH}$ ) were monitored from the adjacent measurement cell. At the end of the operation, the liquid was drained by gravity flow into $\operatorname{Re} 300$.

Alkaline washing was conducted in three steps:

- washing of Re301, then the South loop, and removal of the liquid waste.

- rinsing of Re301 and the South loop, then washing of the North loop and liquid waste removal.

- rinsing of the North loop and liquid waste removal.

\subsection{Available Measurement Data}

- 20 spectrometric analyses (limited here to ${ }^{137} \mathrm{Cs}$, which was largely predominant) of samples taken during the operation, including samples of liquid wastes sent to the effluent treatment station;

- online spectrometer recordings taken at 30-minute intervals: Figure 4 shows results for ${ }^{137} \mathrm{Cs}$ in $\mathrm{c} \cdot \mathrm{s}^{-1}$ calibrated on the basis of prior measurement data $\left(3.75-3.8 \times 10^{7} \mathrm{~Bq}\right.$ for $\left.1 \mathrm{c} \cdot \mathrm{s}^{-1}\right)$;

- volume recordings for the water, reagents and liquid waste tanks, corroborated by tank level measurements during the treatment;

- contact dose rates for all the samples. 


\subsection{Decontamination Results}

The decontamination effectiveness was estimated for each step in the process by online spectrometer readings which varied for two loops as shown in Figure 4.

Preliminary water circulation (cf $\$ 2$ )

remainder from preceding alcohol rinse: $\quad 5.29 \times 10^{10} \mathrm{~Bq}(1.43 \mathrm{Ci})$

Alkaline washing:

REna301: approx $1.40 \times 10^{9} \mathrm{~Bq}(0.038 \mathrm{Ci})$

South loop: $2.89 \times 10^{9} \mathrm{~Bq}(0.078 \mathrm{Ci})$

TOTAL: $4.29 \times 10^{9} \mathrm{~Bq}(0.116 \mathrm{Ci})$

Alkaline washing of North loop: $\quad 1.49 \times 10^{9} \mathrm{~Bq}(0.040 \mathrm{Ci})$

TOTAL: $5.77 \times 10^{9} \mathrm{~Bq}(0.156 \mathrm{Ci})$

A total of $2.02 \mathrm{Ci}$ were removed from REna300 itself while the water was preheated to $60^{\circ} \mathrm{C}$ and while liquid waste was circulated prior to removal.

\section{DECONTAMINATION BY SULFURIC-NITRIC ACID SOLUTION WITH Ce(Iv)}

\subsection{R301 Loop}

Three thousand two hundred liters of demineralized water preheated to $60^{\circ} \mathrm{C}$ in $\mathrm{R} 300$ were transferred to loop R301 and circulated. After $700 \mathrm{l}$ of nitric acid had been injected into the loop, both circulation pumps seized. The acid-water solution was drained into R300 for removal: it contained $320 \mathrm{mg} \cdot \mathrm{I}^{-1}$ of iron and $670 \mathrm{mCi}, 10 \%$ of which could be attributed to loop R301.

Two months later, after replacing the bearings in both pumps, $3450 \mathrm{I}$ of demineralized water preheated to $60^{\circ} \mathrm{C}$ were circulated in loop R301; $750 \mathrm{I}$ of nitric acid and $560 \mathrm{I}$ of sulfuric acid were added to the circulating water. Over a 54 -hour period, a total of $2401\left(4.5 \mathrm{~mol} \cdot \mathrm{m}^{-2}\right)$ of $\mathrm{Ce}$ (IV) were added. The effluent contained $330 \mathrm{mg} \cdot \mathrm{l}^{-1}$ of iron and $152 \mathrm{mCi}$, including $18 \mathrm{mCi}$ attributable to resumed decontamination of $\mathrm{R} 301$.

Figure 5 shows the close correlation between the $\mathrm{Ce}$ (IV) additive and dissolved Fe versus time. The total material thickness removed by the two successive operations was estimated at $12.8 \mu \mathrm{m}$.

\section{South Loop}

Loop R301 was rinsed for 4 hours by directly injecting and circulating 31501 of demineralized water. The water was then heated to $60^{\circ} \mathrm{C}$ in $\mathrm{R3} 300$ and circulated in the South loop in the same way as for decontaminating loop R301; 5401 of $\mathrm{Ce}$ (IV) were added over a 70-hour period. The effluent contained $692 \mathrm{mg} \cdot \mathrm{l}^{-1}$ of $\mathrm{Fe}$ and $56 \mathrm{mCi}$, including $10 \mathrm{mCi}$ from the South loop. The cobalt fraction was relatively high $(12.4 \%$ compared with $0.04 \%$ for the alkaline washing). The mean metal thickness removed was $12 \mu \mathrm{m}$.

\subsection{North Loop}

Two thousand eight hundred liters of demineralized water were injected directly into the South loop and circulated for 19 hours (substantially longer than before because of the 4 subloops). The water was then heated to $60^{\circ} \mathrm{C}$ in $\mathrm{R} 300$ and circulated to decontaminate the North loop; 6401 of $\mathrm{Ce}(\mathrm{IV})$ were added over a 72 -hour period. The effluent contained $766 \mathrm{mg} \cdot \mathrm{H}^{-1}$ of $\mathrm{Fe}$ and $51 \mathrm{mCi}$, including $12 \mathrm{mCi}$ from the North loop. The cobalt fraction was again relatively high (11\%) and the mean metal thickness removed was $10.3 \mu \mathrm{m}$.

Figure 6 shows the increasing chromium fraction in the effluent after 17,20 and 44 hours to values excoeding the initial chromium content. Schematically, the nitric acid dissolved rust 
from the surfaces of pipes depassivated by sodium circulation, while cerium(IV) dissolved the contamination trapped between chromium-enriched grains.

\subsection{Phosphatation}

The North loop was rinsed, then the surfaces washed in each loop were phosphated with a trisodium phosphate solution $\left(10^{-2} \mathrm{~mol} \cdot \mathrm{l}^{-1}\right)$. This treatment not only neutralized the loops (final pH 10.3-11) but will also protect them against potential contamination seepage that would hinder dismantling operations. The dose incurred by personnel throughout all these operations was $4.8 \mathrm{man} \cdot \mathrm{mSv}$.

\section{DECONTAMINATION RESULTS}

\subsection{Decontamination Effectiveness}

Pending final dismantling, when all the scrap metal will be submitted to residual radioactivity measurements, five $25 \mathrm{~cm}^{2}$ specimens cut from the decontaminated pipes with a circular slitting saw showed a residual contamination ranging from 1.7 to $12 \mathrm{~Bq} \cdot \mathrm{g}^{1}$ due principally to ${ }^{60} \mathrm{Co}$. The high cobalt values $\left(4-6 \mathrm{~Bq} \cdot \mathrm{g}^{-1}\right)$ were due mainly to activation by thermal neutrons in localized zones. The low residual contamination values should allow the pipes to be melted down for reutilization and release: an authorization has been applied for.

The dose rates were uniform throughout the facility, ranging from 1 to $15 \mu \mathrm{Gy} \cdot \mathrm{h}^{-1}$ (with a mean value of $5 \mu \mathrm{Gy} \cdot \mathrm{h}^{-1}$ for 60 measurement points), while the dose rate reduction factors ranged from 3 to 140 with a mean value of 10$)$.

The highest dose rates $\left(15 \mu \mathrm{Gy} \cdot \mathrm{h}^{-1}\right)$ were found in the main pipes of the North loop near their shutoff plates: this probably indicates that these high areas were not immersed in the decontamination fluid. They were also located very near the reactor vessel pipes.

Successive draining of the primary system decontamination solutions into reservoir R300 reduced the dose rate in the reservoir by a factor of 10 to an average of $0.3 \mathrm{mGy} \cdot \mathrm{h}^{-1}$ although they remained significantly higher than in the primary system itself. This was not the objective, however, as this vessel will be reutilized for nuclear purposes.

\subsection{Liquid Waste Production}

A total of $46.5 \mathrm{~m}^{3}$ of effluents generated by the decontamination operations were transferred to the Cadarache liquid waste treatment facility, where they were neutralized, concentrated by evaporation and encapsulated in bitumen or cement. The dry extract attributable to the operation represented $2600 \mathrm{~kg}$ of encapsulated material containing $96 \% \mathrm{Cs}$, $2.6 \%{ }^{3} \mathrm{H}$ and $0.6 \%{ }^{60} \mathrm{Co}$

\section{CONCLUSION}

The RAPSODIE fast breeder reactor primary cooling system and related circuits (excluding the main reactor vessel) representing $164 \mathrm{~m}^{2}$ were decontaminated after two effective working months with an average metal removal depth of $12 \mu \mathrm{m}$. The procedure involved three steps: alkaline washing to remove all the labile cesium, followed by acid decontamination with $\mathrm{Ce}$ (IV) to entrain the fixed contamination including about $10 \%{ }^{60} \mathrm{Co}$, and a final phosphatation step. The estimated initial contamination level of $5500 \mathrm{~Bq} \cdot \mathrm{cm}^{-2}$ was reduced to less than $10 \mathrm{~Bq} \cdot \mathrm{g}^{-1}$, allowing dismantling operations to proceed virtually without constraints, producing waste material suitable for release, and avoiding an occupational dose estimated at $230 \mathrm{man} \cdot \mathrm{mSv}$. The decontamination operations generated $2600 \mathrm{~kg}$ of dry extract encapsulated by the local effluent treatment station. 


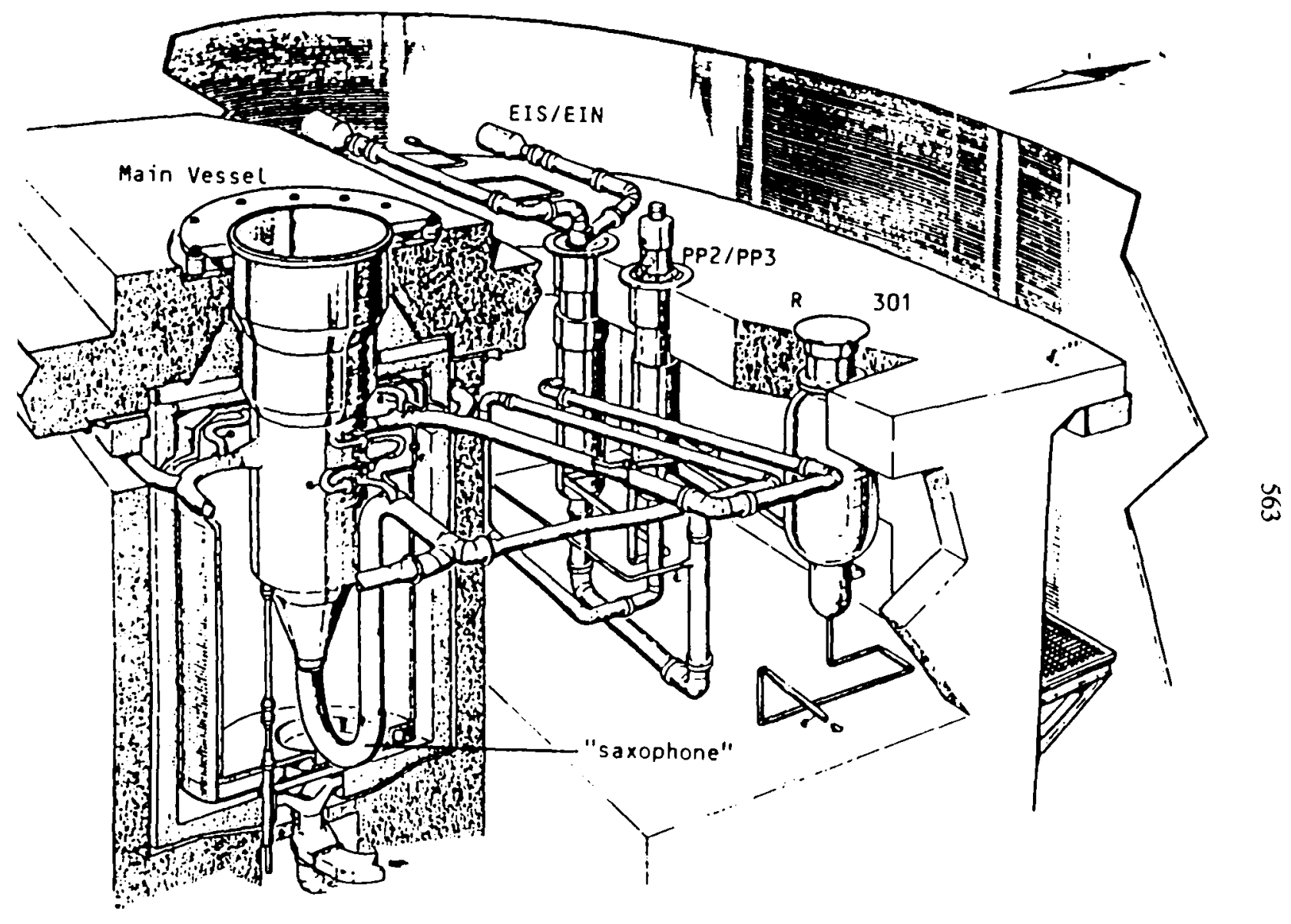

Fig. 1. Primary circuits perspective 
Reagents: $\mathrm{HNO} 32 \mathrm{M}$ and $\mathrm{H} 2 \mathrm{SO} 40.5 \mathrm{M}$ at $85^{\circ} \mathrm{C}$

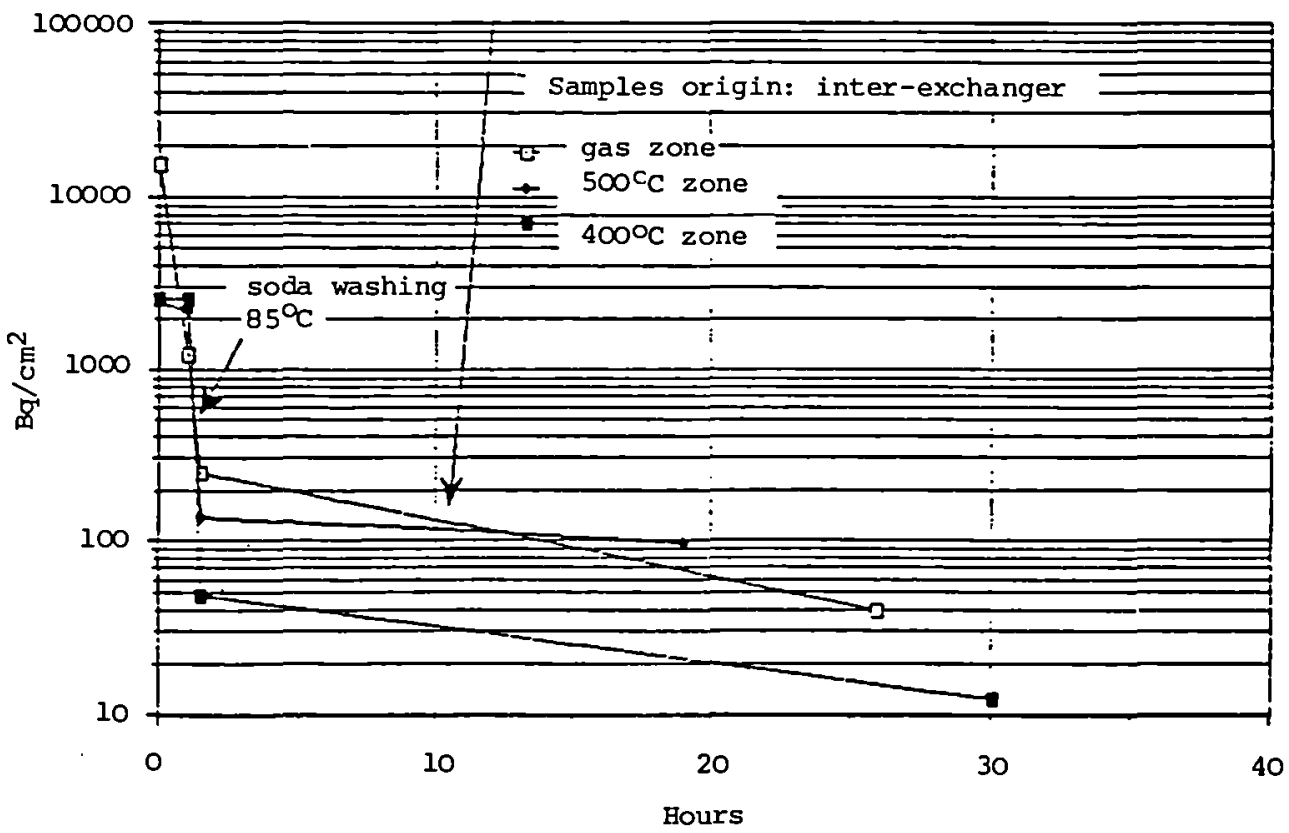

Fig. 2. Sulfo-nitric decontamination

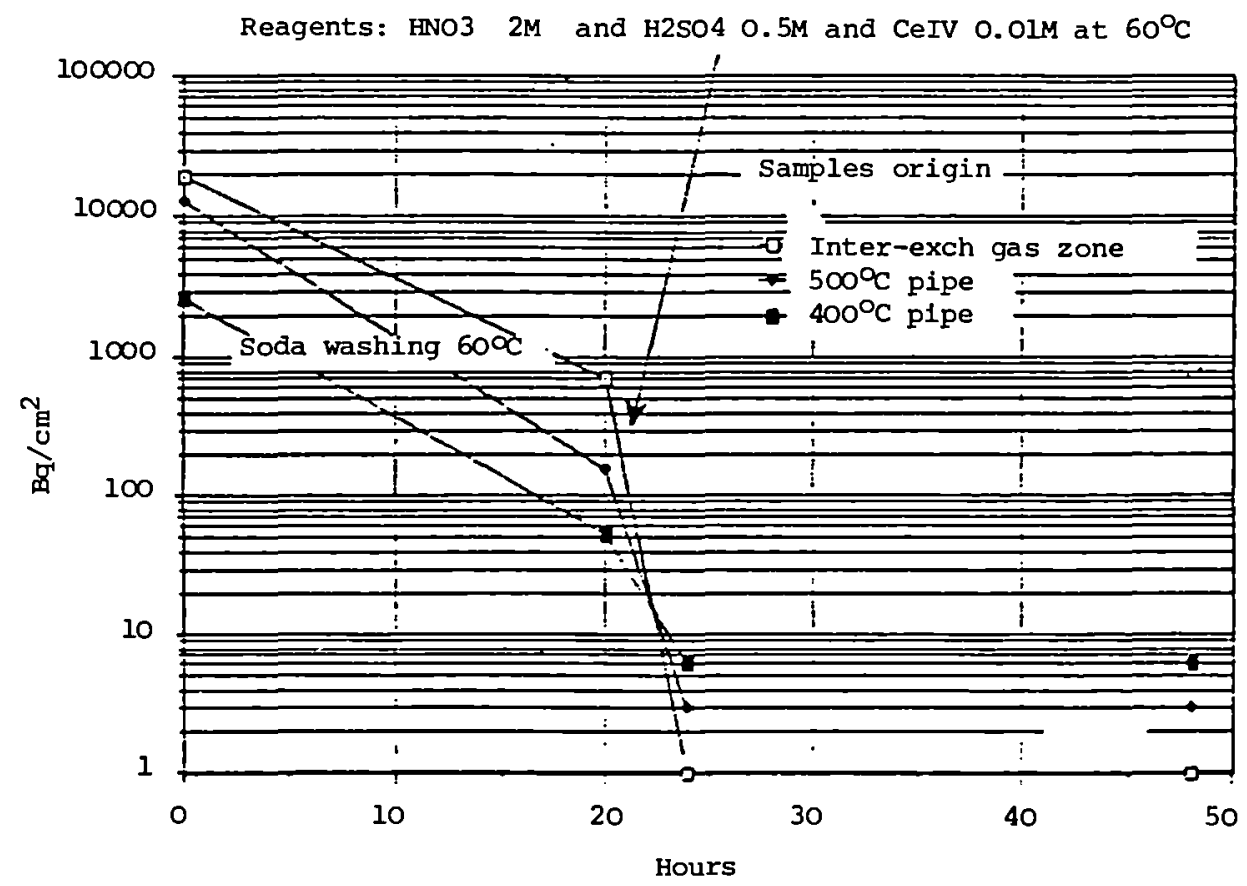

F1g. 3. Sulfo-nitric and Cerium IV decontamination in Grolabo facility 


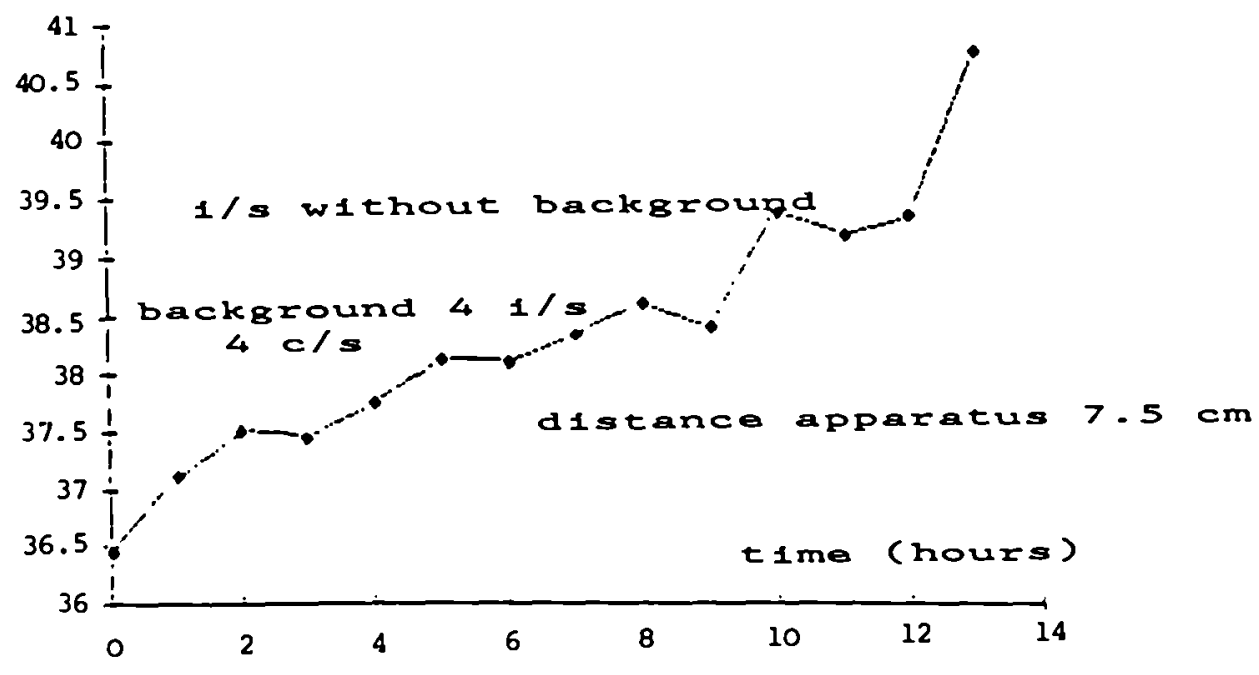

Fig. 4. Spectrometer readings during loop decontamination

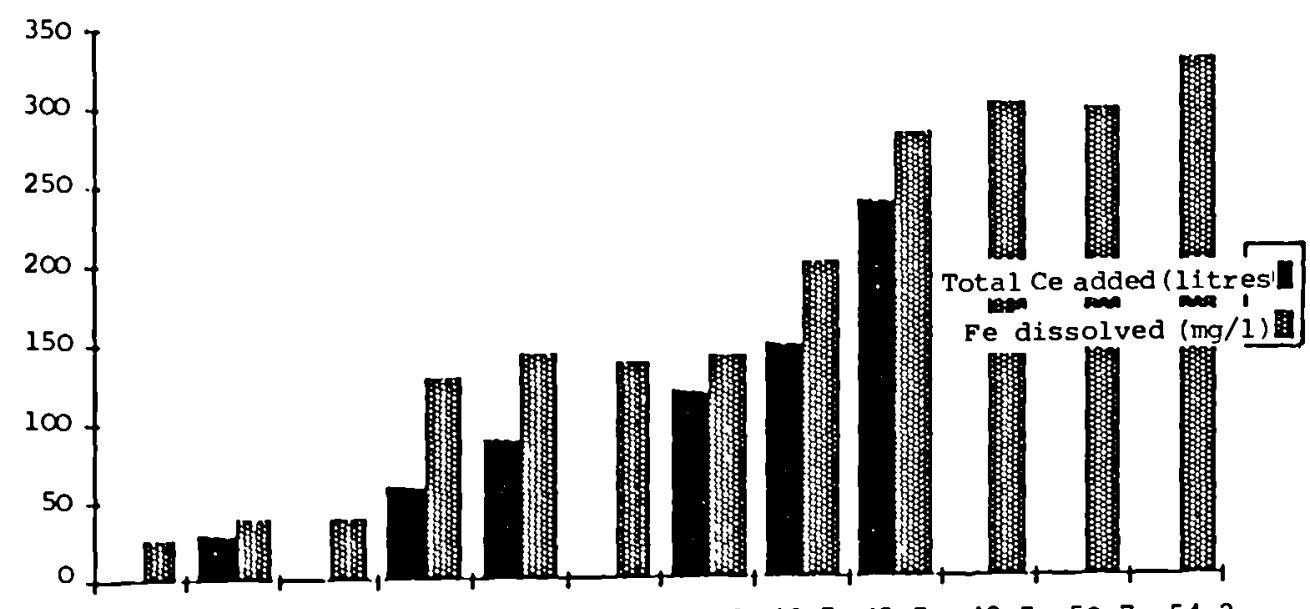

$\begin{array}{lllllllllllll}27.3 & 28.7 & 30.2 & 33.7 & 36.7 & 42.7 & 45.3 & 46.7 & 48.7 & 49.7 & 50.7 & 54.2\end{array}$ Time (hours)

Fig. 5. R3ol decontamination correlation Ce added vs $\mathrm{Fe}$ dissolved 

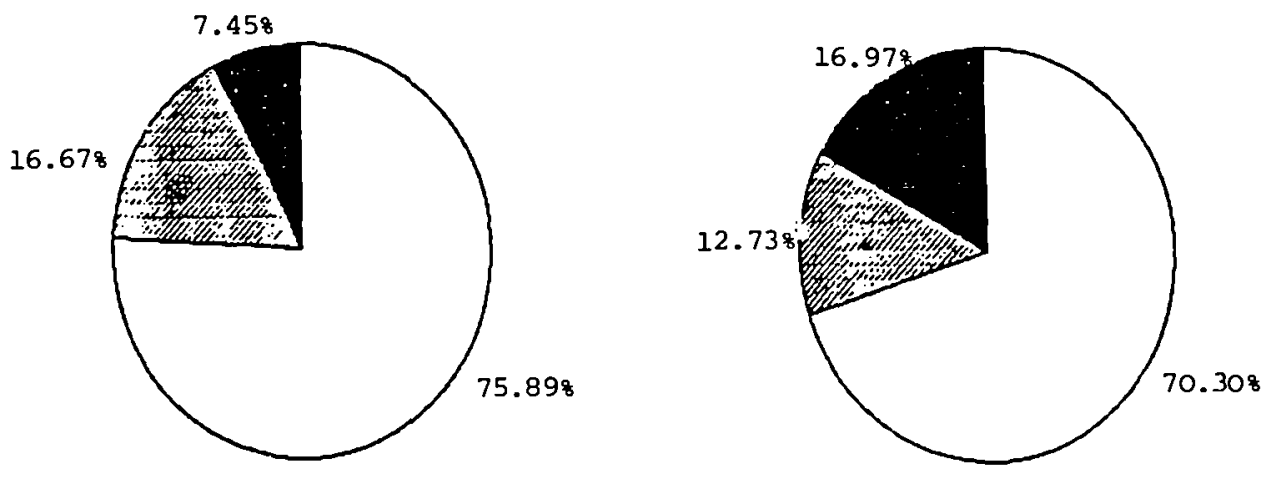

$\square \mathrm{Fe}$
$\square \mathrm{ifi}$
$\mathrm{Cr}$

CATIÓN CONCENTRATION (NL 44 HOURS) CATION CONCENTRATION (NL 71 HOURS)
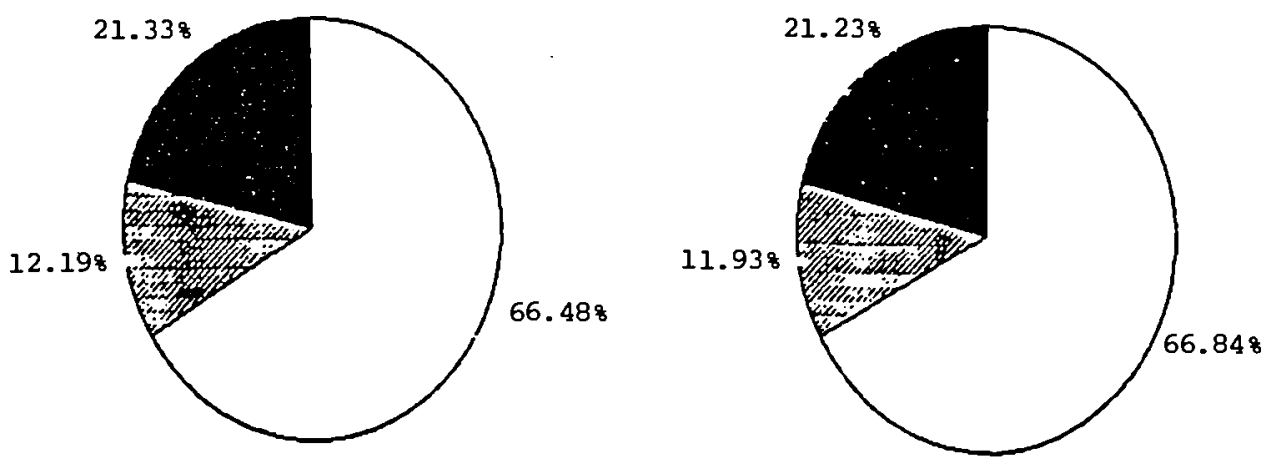

Flg. 6. 


\title{
DEVELOPMENT OF TECHNIQUES TO DECONTAMINATE THE WAGR HEAT EXCHANGERS
}

\author{
CROSSLEY H, WAKEPIELD J R \\ United Kingdom Atomic Energy Authority \\ Windscale Laboratory \\ Seascale, Cumbria, U K
}

\section{ABSTRACT}

A method of decontaminating the four large heat exchangers of the Windscale AGR has been developed. Samples of the boiler tubes were removed and examined in the Laboratory. The contamination present was characterised and a number of reagents were tested. The final recommendation was for a mild acid wash. This method was then converted to a fully engineered system having regard to dose uptake and effluent disposal aspects. Using dilute nitric acid and a recirculating spray technique, some $70 \pi$ of the activity was removed from the superheater section of one heat exchange in a demonstration experiment.

\section{INTRODUCTION}

An important feature of the Windscale AGR dismantling programme is the removal and disposal of the four heat exchangers. These are contained within separate steel pressure vessels measuring $3.5 \mathrm{~m}$ diameter and $21 \mathrm{~m}$ high and each unit weighs 175 tonnes. The gas-side of the tube banks became contaminated with fission products which arose from the deliberate operation with failed fuel elements in the reactor core. The radiation levels were sufficiently high to prevent hands-on dismantling and it was originally intended to remove each unit as a single piece for disposal at sea. However this route was blocked and so an alternative approach of in-situ cleaning followed by hands-on size-reduction was adopted. This was considered to be technically simpler and cheaper than remote dismantling.

\section{BACKGROUND}

Each heat exchanger contains three separate cross-flow tube banks, viz superheater bank with plain $\mathrm{Cr} /$ Mo low alloy steel tubes, evaporator and economiser banks with finned mild steel tubes. A diagram of the superheater bank is given in Figure 1. It will be seen that this is a complex structure and thus can only be cleaned effectively by liquid treatment. Sections of the tubes were removed and the contamination was characterised by laboratory tests. These established that the tubes have an external corrosion layer up to $150 \mathrm{\mu m}$ thick which is mainly magnetite $\left(\mathrm{Fe}, \mathrm{O}_{4}\right)$ and on the superheater with a chromium content, varying between 17 and 107. Contamination was found to be incorporated in this oxide layer and to consist predominantly of $\mathrm{Cs}-137$ with some Cs-134 and Co-60. Average values of $16 \mathrm{kBq} \mathrm{cm}-^{2}$ for $\mathrm{Cs}$ and $0.2 \mathrm{~K} \mathrm{~Bq} \mathrm{~cm}^{-2}$ for Co were obtained, giving a total for the superheater of about $0.1 \mathrm{TBq}(-2.7 \mathrm{Ci})$. To remove the activity it is necessary to remove the oxide layer from the tubes. A reduction in the contact level from 15 to $0.5 \mathrm{mSv} \mathrm{h}^{-1}$ would permit hands-on operations.

Trials were conducted with a number of reagents and it was concluded that a mild acid treatment would be suitable. Although dilute ( 0.5 molar) hydrochloric acid was favoured, dilute nitric acid was chosen for the pilot scheme because it was acceptable for disposal via the on-site BNPL waste stream. Three methods of application of the acid were considered. They were: 
a. Pill and drain. This involves filling the complete heat exchanger shell with acid, allowing to soak and then draining off. The operation is repeated with fresh acid until an equilibrium state or the required decontamination factor has been reached. The disadvantages of this method are that the acid would attack all the steel surfaces present removing large amounts of clean steel and $160 \mathrm{~m}^{3}$ of effluent would require disposal at each $\mathrm{f} 111$.

b. Refluxing. A constant boiling mixture of acid and water is established at the base of the heat exchanger and the vapour is allowed to condense on the cooled tubes. By careful adjustment of tube temperatures the condensate can be directed to each tube bank in turn. It was considered that the control and safety problems that this method would present would require expensive solutions.

c. Recirculating spray. A suitable spray nozzle is introduced above each of the tube banks in turn to deluge the acid downwards. The liquor is collected at the heat exchanger base and recirculated until equilibrium or the required decontamination factor is reached. This method has the advantage of minimum effluent volume but there was uncertainty in the wetting efficiency. It was decided that there was sufficient potential to warrant a trial run on the superheater section of one heat exchanger.

\section{DESCRIPTION OF THE PLANT}

The schematic arrangement of the recirculating spray system is shown in Figure 2. A cylindrical tank of 5000 litres capacity is located on the ground floor of the reactor containment building directly below the heat exchanger. The tank stands in a cylindrical bund of 4400 litres capacity. Reagent is stored in 1000 litre industrial bulk containers (IBCs) sited outside the containment building and is transferred into the tank by means of a 66 litre.min-1 electric pump (P1 on the diagram). A second electric pump (P2) of 500 litre. $\min ^{-1}$ capacity delivers the reagent, via a $50 \mu \mathrm{m}$ filter and a flowmeter, to a $120^{\circ}$ spray nozzle positioned above the superheater bank, at a height of $16.5 \mathrm{~m}$ above ground floor level. Reagent falling through the superheater bank is collected at the bottom of the hot gas duct and returned through pipework and a $250 \mu \mathrm{m}$ strainer located within the tank. Spent reagent is transferred $\mathrm{f}$ rom the tank to a road tanker outside the containment building via pump P2 and the $50 \mu \mathrm{m}$ filter. Any spillage or leakage collected in the bund can be pumped out by pump Pl and either returned to the tank or discharged to the road tanker. A small pump, P3, is used for draining the filter housing before changing the filters. The tank, the heat exchanger shell, and a temporary chemical analysis room sited on the first floor are ventilated via a demister into the existing gas discharge treatment plant which exhausts into the reactor building stack. It was considered that no significant quantity of hydrogen would be generated during the experiment, therefore no provision was made for purging the heat exchanger.

The shell ventilation line was, however, sampled continuously by a hydrogen monitor throughout the experiment.

The tank, bund, pipework, valves, $50 \mu \mathrm{m}$ filter and the spray nozzle are manufactured from copolymer polypropylene. Joints are made by heat fusion or flanges as appropriate. The pumps and the $250 \mu \mathrm{m}$ strainer are stainless steel. The filling and discharge pipes within the containment building are fitted with through connectors fixed to the containment shell. Removable hoses connecting these, respectively, to the IBCs and the road tanker are flexible polypropylene reinforced with stainless steel. Simllar 
hose is used for connecting the spray lance to the fixed delivery pipe to permit the position of the spray nozzle to be adjusted.

The plant was installed in the reactor building by NEI-IRD Co Ltd following functional tests at their Works. Preparatory work carried out by Windscale Laboratory included removal of the hot gas inlet bend at the bottom of the tube-bank casing and drilling holes in the bioshield for pipework. In accordance with standard procedure a Safety Case was prepared and submitted for authorisation to carry out the project.

\section{HEALTH PHYSICS AND SAPETY (HP and S)}

It was considered that the operation did not involve any chemical or electrical hazard that could not be avolded by taking normal precautions.

To ensure that background radiation dose rates in the operating area did not significantly exceed the normal level of $2.0 \mu \mathrm{Sv} \mathrm{h}^{-1}$ contact dose rate at any point on the plant was initially restricted to $100 \mu \mathrm{Sv} \mathrm{h}^{-1}$. Fixed monitors, Eberline type EGA-1, with alarms set to this level were installed on the main drain pipework close to the heat exchanger, and on the process tank wall. In addition, Health Physics monitors took frequent dose readings at 14 specified points in the circuit.

Pollowing the commissioning phase of the experiment, in which a rapid build-up of activity in the process tank occurred, the limit was raised to $2 \mathrm{mSv} \mathrm{h}^{-1}$ at contact with the tank and $50 \mu \mathrm{m}$ filter housing. These plant items were shielded when the limit was raised.

Operations personnel wore thermoluminescent dosemeters supplied by the National Radiological protection Board and carried film-badge dosemeters and QFEs issued by the Laboratory HP and S Department. Personnel entering higher radiation areas, eg within the heat exchanger shell, or when changing filters, were issued with Pocket Personnel Dosemeters which have digital readout and an alarm, to ensure that their daily dose did not exceed the Laboratory limit of $0.4 \mathrm{mSv}$ per day.

\section{COMMISSIONING}

The plant was commissioned using water only. With 3000 litres of water in the tank and the circuit valved to spray-head by-pass the system external to the heat exchanger was tested for leaks at full pump head. The valves were then adjusted to give the prescribed flowrate of 300 litres $m^{-1}{ }^{-1}$. The spray-head valve was opened, the bypass closed and flow was adjusted to 300 litres $\mathrm{min}^{-1}$. After only 3 minutes operation the tank radiation alarm sounded and the plant was shut-down.

Maximum dose-rate at the tank wall was $1200 \mu \mathrm{Sv} h^{-1}$ in 1 ine with the surface of the water. Through the inspection window in the tank lid the water was seen to contain solids in suspension with some fine floating debris at the surface.

Shielding was erected round the tank and the filter housing. The tank contents were then recirculated through the $50 \mu \mathrm{m}$ filter, with the circuit valved to spray by-pass, until radiation level at the filter housing reached the new revised 1 imit of $2 \mathrm{mSv} \mathrm{h}^{-1}$. The filters were changed and recirculation resumed. The highest recorded dose rate at contact with an unshielded filter element was $5 \mathrm{mSv} \mathrm{h} \mathrm{h}^{-1}$. The filters were packaged and transported in a shielded container to UKAFA active laboratories for examination. In the second clean-up run the radiation level at the filter housing stabilised before reaching the limit. The tank contents were discharged to the road tanker and despatched to the BNFL effluent treatment plant for disposal, and the filters were changed. 
The tank was refilled with 3000 litres of water and spraying through the superheater was resumed, this time at 150 litres min-1. After one change of filter the flow was increased to 300 litres min-1. The filter dose-rate reached equilibrium below the $2 \mathrm{mSv} \mathrm{h}^{-1}$ limit, indicating that no further activity was being removed from the heat exchanger. The water was discharged and the filters were changed.

\section{OPERATIONS WITH ACID}

The process tank was filled with a 3000 litre mixture of 0.5 molar (3.15\% by weight) nitric acid and 0.0025 molar citric acid at ambient temperature. Spraying was initiated at a low flow rate. There was no sudden increase in radiation levels so the flowrate was increased to 300 litres min $^{-1}$. Spraying was terminated after 15 minutes because an unacceptably large leak had developed through the seal of an access door in the transition duct below the superheater. The leak was repaired and spraying was resumed. Radiation levels at the tank rose rapidly from $500 \mu \mathrm{Sv} \mathrm{h}^{-1}$ to the $2 \mathrm{mSv} \mathrm{h} \mathrm{h}^{-1}$ limit. Spraying was terminated and the liquor was recirculated on spray-head by-pass in an attempt to filter out activity and avoid discharging the acid. This had negligible effect and the acid was therefore discharged to the road tanker and diluted with 3000 litres of water to bring down the tanker surface radiation level from $2.5 \mathrm{mSv} \mathrm{h}^{-1}$ to below the transport limit of $2.0 \mathrm{mSv} \mathrm{h}^{-1}$. The filters were changed although they had not reached the dose-rate limit.

A second 3000 litre charge of acid was pumped into the tank and spraying was continued. Radiation at the tank surface rose slowly to 2.0 $\mathrm{mSv} \mathrm{h} \mathrm{h}^{-1}$ and the filter housing reached $500 \mu \mathrm{Sv} \mathrm{h} \mathrm{h}^{-1}$. The system was shut down and the acid was discharged. Although activity was still being removed from the superheater, albeit slowly, it was decided to terminate the experiment with a final water wash.

\section{EXPERIMENTAL MEASUREMENTS}

\section{Tube Bank Radiation}

The superheater radiation profile along the centre-line of the tube bank was measured before the experiment and after each of the 4 decontamination stages. The gamma radiation results are shown in Figure 3 . The method of measurement was by lowering a string of $15 \mathrm{film}$ dosemeters into the superheater between the tube platens and leaving them for a measured time period - in this case one hour. The dosemeters were sealed $0.3 \mathrm{~m}$ apart in a "layflat" polythene tube. The method was used throughout reactor operating life for measuring change in heat exchanger activity. After the second acid wash two additional measurements were made at positions away from the centre line. These results for gamma radiation are shown in Figure 4. The corresponding beta results are almost an order of magnitude higher than the gamma dose-rates and are currently under investigation.

A Harwell 6000-series continuous-reading gamma monitor was used to measure radiation at the top of the superheater. Its detector probe was fixed at the centre of the tube bank and was shielded with lead against dose from the evaporator tube-bank above it.

The results of readings taken with a hand-held monitor at the outer surface of the tube-bank duct before and after the experiment are shown in Figure 5.

Liquor Sampling for Chemical and Isotopic Analysis

Except during the first commissioning run with water when operating time was too short, $250 \mathrm{ml}$ liquor samples were taken every few minutes during the experiment from the liquor return line close to the superheater 
outlet. The samples were subsequently analysed for isotopic content and, during the acid runs, for iron content which was established by a comparator method and used to indicate acid condition.

Before each discharge of 1 iquor to the road tanker $250 \mathrm{ml}$ samples of the tank contents were taken and analysed to ensure that the elements and activities present were acceptable for disposal via the BNFL effluent treatment plant. Chromium, which is present in the superheater tube alloy, was of particular interest. Average values from each set of samples were extrapolated to the quantity of liquor in the tank ( 3000 litres) to give the totals removed by each wash. The results are given in Tables I and II.

The first water wash was terminated so quickly that liquor returning from the superheater did not pass through the $50 \mu \mathrm{m}$ filter. The particulate washed down was, therefore, retained in the tank. Analysis showed it to contain $22 \mathrm{~g}$ of insoluble material all of which was below $160 \mu \mathrm{m}$ with $85 z$ below $50 \mu \mathrm{m}$ and $50 z$ below $25 \mu \mathrm{m}$. After the first water-wash clean-up run the $50 \mu \mathrm{m}$ filters were replaced by $10 \mu \mathrm{m}$ size. The solids also had a high beta to gamma ratio.

Hydrogen Monitoring

During the acid runs the ventilation air flow from the heat exchanger was monitored for hydrogen that might have been generated by the reaction. As expected, none was detected.

\section{DISCUSSION OF RESULTS}

Liquor Analysis

The experiment involved 2 water washes followed by 2 acid washes and a final water wash. The first water washes were terminated by activity in the filter whereas the acid and final water washes were terminated by activity in the tank, despite the fact that after the first tank liquor analysis the filter size had been reduced from $50 \mu \mathrm{m}$ to $10 \mu \mathrm{m}$. The activity analysis shown in Table 1 gives Cs:Co ratios of about 500:1 for the water but only $40: 1$ for the acid and the final water wash. The final water result is no doubt due to dissolution of activity by the acid from the second wash remaining on the tubes. These results indicate that the Co contamination was not mainly in the form of loose iron oxide particulate, as formerly supposed, but was fixed to the tubes and removable only by dissolution. Conversely, more Cs was available for dissolution by water than was suggested by the earlier laboratory trials.

A total of nearly $2 \times 10^{11} \mathrm{~Bq}(-5 \mathrm{C} 1)$ was removed, with a $\mathrm{Cs}$ : Co ratio of around $50: 1$.

The total weight of iron dissolved during the acid runs was about 2.5 $\mathrm{kg}$, with $23 \mathrm{~g}$ chromium. The final water wash removed iron that had clearly been taken up by the acid remaining in the heat exchanger. However, no chromiun was present in this water, which suggests that a significant proportion of the iron came from the shell and fittings, and not from the tubes. Acid depletion was not a significant factor in the experiment. The maximum iron uptake measured was $40 \pi$ compared with the limit of $70 \pi$, although the method of estimating this during operation was subject to error.

Radlation Measurements

Comparison of mean radiation levels in the superheater derived from areas under the curves in Figure 3 indicates reductions of $13.4 \pi, 12.97$, $27.6 \%$ and $6.9 \%$, respectively, for the 4 washes. The activity removed in the final water wash (Table $I$ ) indicates a further reduction of 107 making a total of about $70 x$ of the original activity removed. However, the radiation results and the analysis result from the second acid wash do not show the same relativity as in the other washes. Results of the final film-badge survey, when available, may help to clarify the issue. 
It seems certain, however, that there was more activity in the superheater than the $2.7 \mathrm{Ci}$ estimated from the results of the Winfrith work. The present results indicate that the original contamination could have been as high as $7 \mathrm{Ci}$, if the $5 \mathrm{Ci}$ removed represents $70 \%$, not including the activity removed by the filters.

The $\gamma$-radiation measurements show that the decontamination factors in the centre of the tube bank are consistently high. The low values obtained at the top and bottom are no doubt due to shine from the high radiation areas above and below the superheater. Also, the centre and offset measurements are almost co-incident. These results indicate that the spray was effective and the reagent reached all regions of the tube bank.

Measurements taken by the fixed gamma monitor at the top of the tube bank show a reduction of $36 \%$ (DF 1.6) over the whole experiment. This is in reasonable agreement with the top film results which would be expected to suffer from geometrical errors.

The radiation measurements taken in contact with the outside of the tube bank duct in the region of the superheater (see Figure 5) show a reduction of around $25 \%$ on the pre-experiment figures. It is reasonable to assume that this is entirely due to decontamination of the tubes since contamination on the duct and in the duct insulation will not have been significantly affected by the spraying.

Health Physics

The total incurred dose for AEA personnel, including Health Physics Monitors, was $7.64 \mathrm{mSv}$ and the maximum individual dose was $2.78 \mathrm{mSv}$. The total dose for the $4 \mathrm{NEI}$ operators was $5.0 \mathrm{mSv}$, around $80 \%$ of which was incurred during installation and modification of the plant - which involved entry into the heat exchanger.

The total man-dose uptake for the experiment was therefore $12.64 \mathrm{mSv}$. It should be noted that this dose could be substantially reduced were an entire heat exchanger to be decontaminated since the spraying could be carried out from above the economiser. The major part of the installation and survey work would therefore be in a low radiation region. The modifications found necessary in the present experiment would not have to be repeated.

\section{CONCLUSIONS}

This trial succeeded in reducing the radiation levels throughout superheater tube bank by approximately $70 \%$ at a total man-dose uptake of $12.64 \mathrm{mSv}$ although this would be substantially lowered in practice because there would be no need for entry into the high radiation region of the heat exchanger. It demonstrated that the method was effective and can be readily applied and controlled on this type of plant. In order to achieve the necessary decontamination factor to permit hands-on dismanting, a further trial using a stronger acid will be carried out and the equipment will then be transferred to the remaining two tube banks. From the results of this study, it can be concluded that this system, with the correct choice of reagent, is an effective method of in-situ decontamination of large heat exchangers. 
TABLE I

ACTIVITY REMOVED IN BACH STAGE OF WAGR HX'A'DECONTAMINATION

\begin{tabular}{lcccccc} 
& $\begin{array}{l}\text { TOTAL } \\
\text { ALPHA } \\
(\mathrm{mC} 1)\end{array}$ & $\begin{array}{l}\text { TOTAL } \\
\text { BETA } \\
(\mathrm{mC} 1)\end{array}$ & $\begin{array}{l}\text { TOTAL } \\
\text { GAMMA } \\
(\mathrm{eq} \cdot \mathrm{mC} 1)\end{array}$ & $\begin{array}{l}\text { TOTAL } \\
\mathrm{Cs}-137 \\
(\mathrm{mC} 1)\end{array}$ & $\begin{array}{l}\text { TOTAL } \\
\text { Cs-134 } \\
(\mathrm{mC} 1)\end{array}$ & $\begin{array}{r}\text { TOTAL } \\
\text { Co-60 } \\
(\mathrm{mC} 1)\end{array}$ \\
1st WATER WASH & 0.01 & 551.35 & 494.59 & 591.89 & 10.14 & 1.70 \\
2nd WATER WASH & $<0.11$ & 624.32 & 583.78 & 705.41 & 11.68 & 1.21 \\
1st ACID WASH & 0.21 & 1491.89 & 1370.27 & 1572.97 & 25.14 & 43.78 \\
2nd ACID WASH & $<0.10$ & 1264.86 & 1175.68 & 1337.84 & 21.08 & 38.92 \\
3rd WATER WASH & 3.49 & 437.84 & 397.30 & 462.16 & 7.30 & 11.35 \\
TOTAL: & $<3.92$ & 4370.27 & 4021.62 & 4670.27 & 75.33 & 96.96 \\
\hline
\end{tabular}

TABLE II

METALS DISSOLVED IN EACH STAGE OP WAGR HX'A' DECONTAMINATION

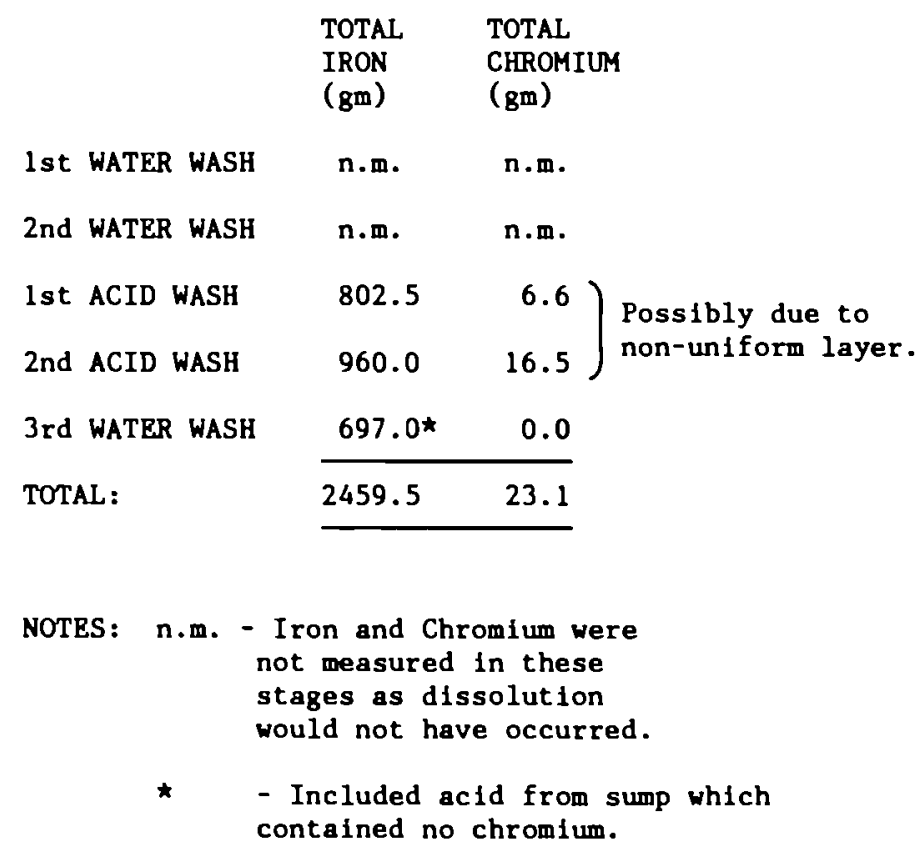


Casing support bracket

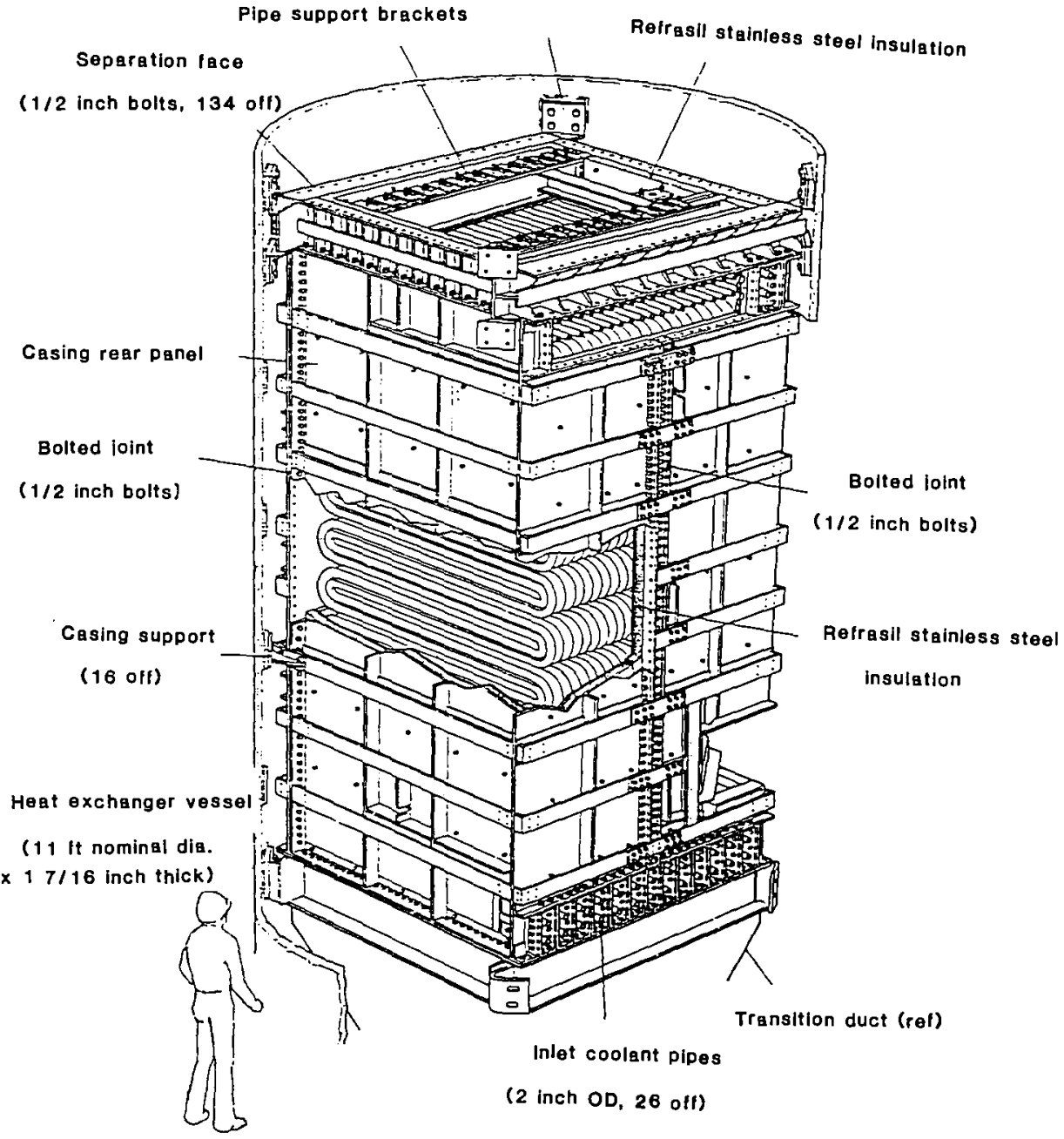

FIGURE 1 VIEW ON FRONT FACE OF SUPERHEATER 


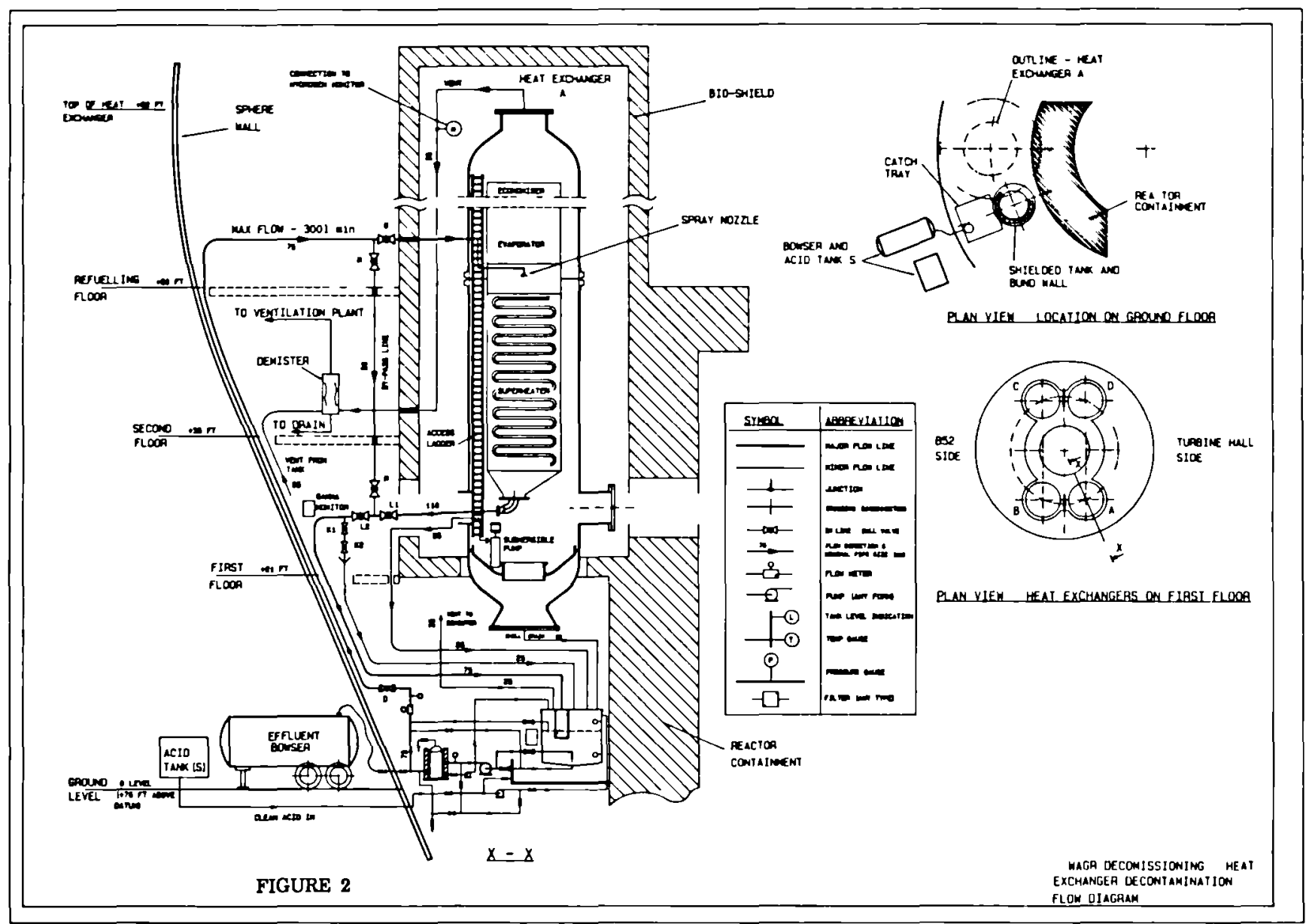




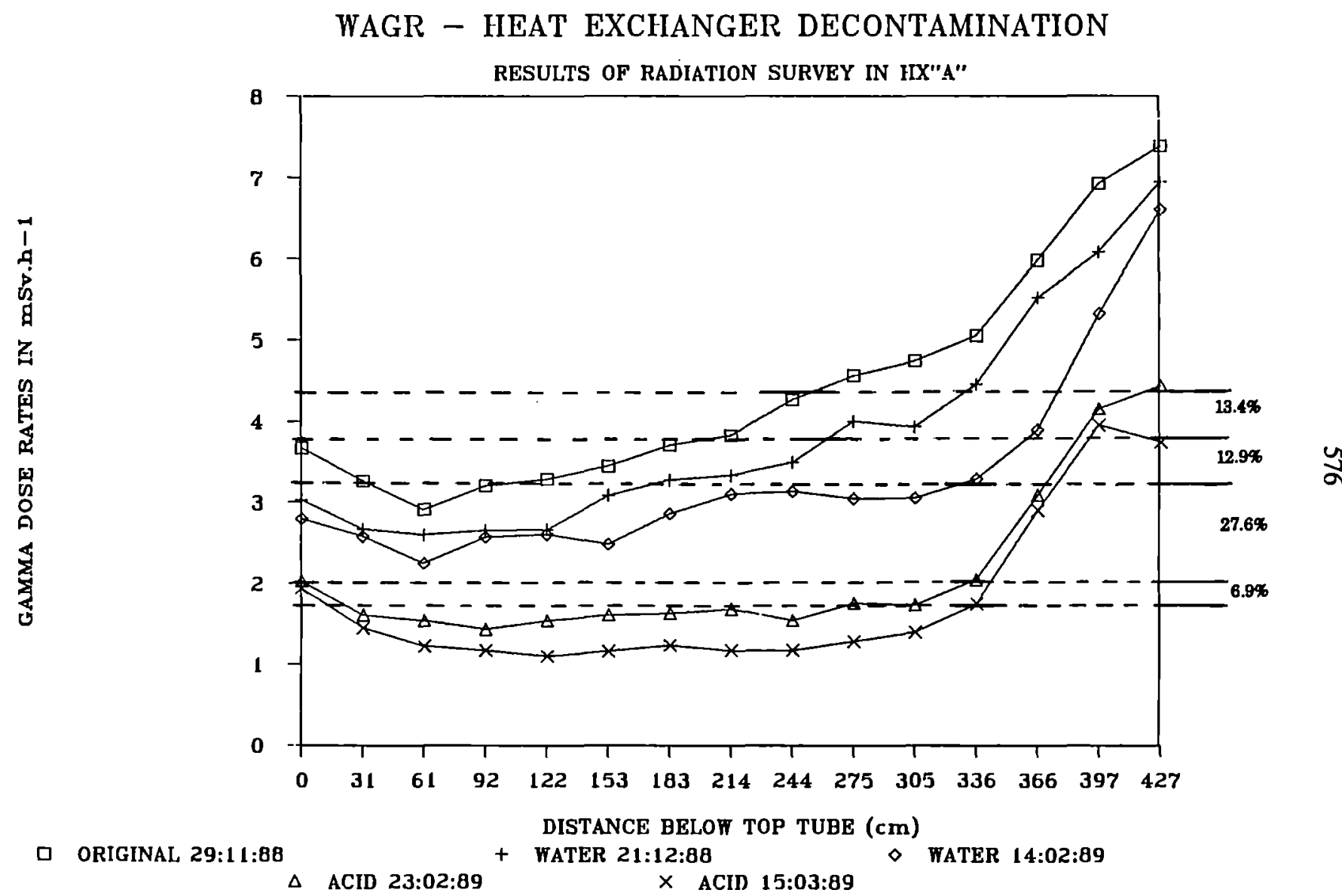

FIGURE a 


\section{WAGR - HEAT EXCHANGER DECONTAMINATION}

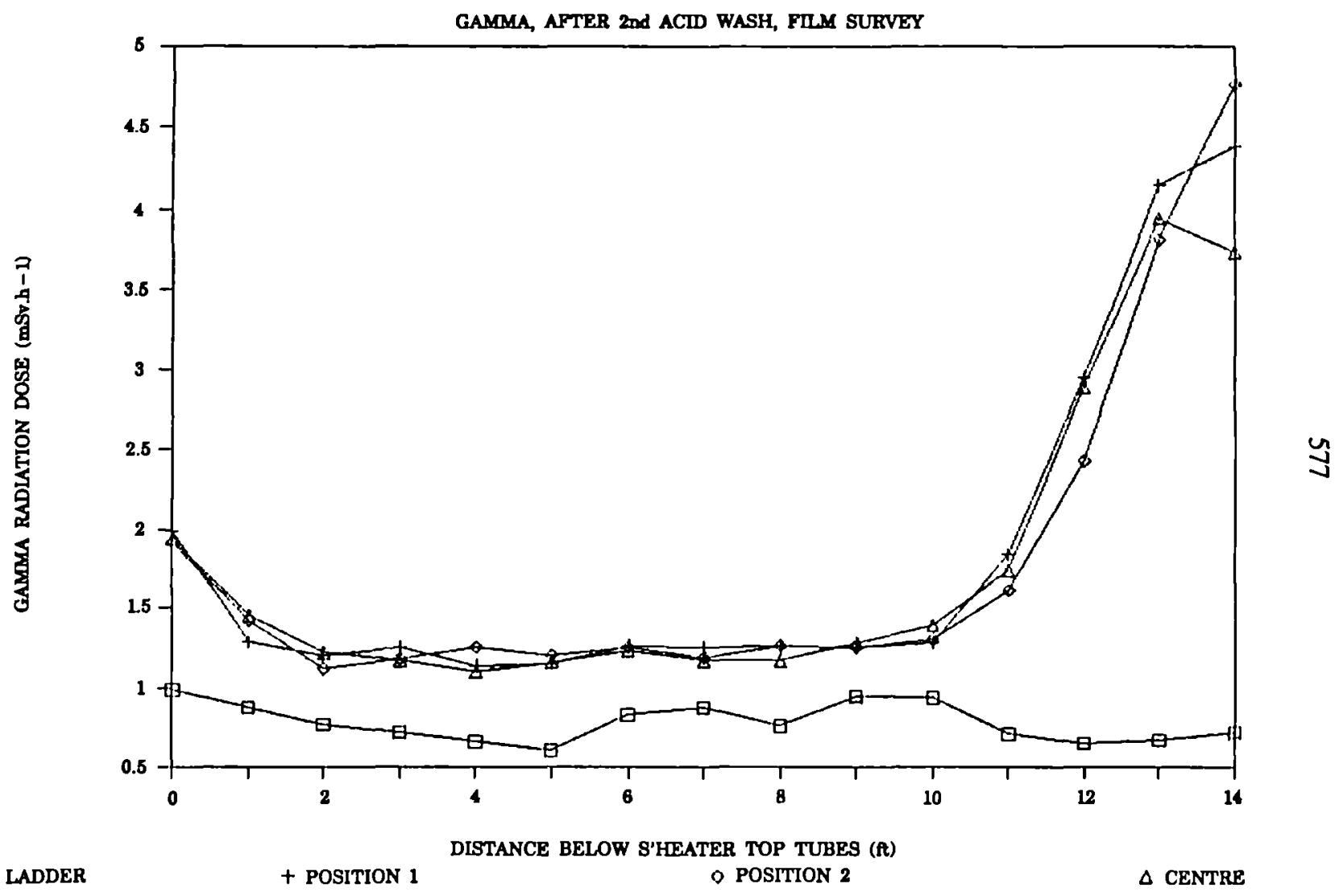

FIGURE 4 


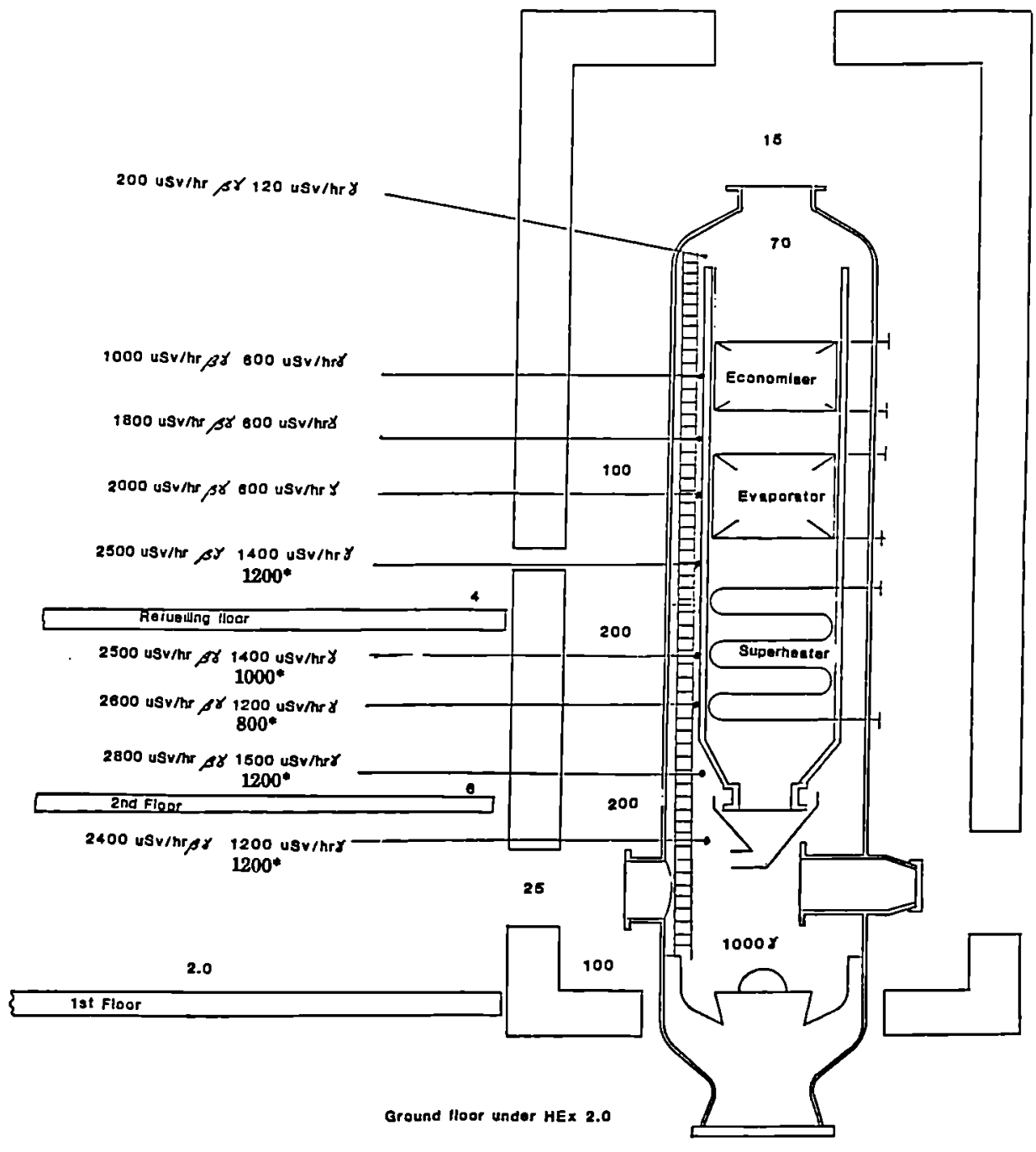

- after experiment

FIGURE 5 HEAT EXCHANGER "A" RADIATION SURVEYS 


\title{
DECONTAMINATION USING CHEMICAL GELS, ELECTROLYTICAL SWAB, ABRASIVES
}

\author{
G. BRUNEL \\ COMMISSARIAT A L'ENERGIE ATOMIQUE \\ CEN CADARACHE \\ IRDI - DERDCA - DRDD - SDFMA
}

\section{INTRODUCTION}

Decontamination for decommissioning purposes differs from usual in-service decontamination procedures. The main factors which have to be considered in setting up decontamination procedures for nuclear installation decommissioning are :

- rapidity and ease of application

- efficiency of decontamination

- possibility of remote operation

- small quantities of secondary generated wastes.

The aim of this research work is to develop three decontamination methods which appear to be well adapted to dismantling. After laboratory tests where several procedures are compared, actual nuclear installation dismantling operations were performed.

Among the decontamination procedures developed by CEA Cadarache, the following have been the subject to extensive studies :

- spraying of gels containing decontaminating agents

- electropolishing with swab device

- abrasive blasting.

Examples of industrial applications of these three techniques which have been carried out are for these procedures :

- Gels spraying performed on pieces coming from German BW Reactor ISAR.

- Brennilis Bitumization plant decontamination and dismantling.

- Gels spraying decontamination performed on the cooling circuit of the graphite gas reactor $\mathbf{G} 2$.

- A mechanical sodium cleaning method by abrasive blasting on SuperPhenix fuel storage drum intervessel. 
For each of these in-situ decontamination operations, a balance has been carried out between the quantity of decontaminated metallic wastes and the amount of chemical reagent used as well as the secondary generated wastes quantity.

\section{GELS SPRAYING PERFORMED ON GERMAN BW REACTOR ISAR}

In this part, an industrial application of gels spraying, performed on pieces coming from German BW reactor ISAR, is presented.

In the first part, we remind you of the laboratory tests, which have already been performed in another study. presented.

In the second part, the results of the industrial scale decontamination are

\subsection{Laboratory tests}

Laboratory tests have been performed with the following processes :

- chemical bath decontamination

- electropolishing.

In a BWR, the oxyde layer is mostly composed of red oxyde (hematite). The test chemical solutions are :

- Fluorhydric acid at room temperature and chlorhydric acid at $80 \mathrm{C}$ with a corrosion inhibitor.

- Sulphuric acid at temperature up to $40 \mathrm{C}$.

- Formol /Formic acid mixture at $80 \mathrm{C}$.

Among these solutions compared at room temperature, only sulphuric and fluorhydric acid can bring decontamination factor of about 200.

Electropolishing is possible with sulphuric, phosphoric and formic acid. An anodic oxydation is not sufficient. But cathodic reduction, and anodic oxydation alternatively reduce decontamination time by a factor of 3 to 5 .

\subsection{Industrial scale decontamination}

A decontamination concerning 17 tons of steel coming from a BW Reactor (11 tons of frame, 6 tons of pipes) has been performed in Cadarache.

The process chosen was : 
- Chemical decontamination in sulphuric acid ( 2 mole/l) followed and fluorhydric acid ( 1.6 mole/l).

With the first step a decontamination factor of 100 is obtained.

The second step gives a decontamination factor of 10 to 15 .

During frame decontamination 100 liters of gels have been produced.

For pipes decontamination, wastes production is :

- liquid wastes : 5340 liters with an activity lower than $740 \mathrm{~Bq} / \mathrm{l}$;

- solid wastes : $180 \mathrm{~kg}$ of low level wastes $(<11 \mathrm{kBq} / \mathrm{l}), 15 \mathrm{~kg}$ of medium level wastes $(<580 \mathrm{kBq} / \mathrm{l})$.

\subsection{Conclusion}

The real test performed in Cadarache on 17 tons of steel has given good results.

The pipes had a residual activity equal to $1.4 \mathrm{~Bq} / \mathrm{g}(\mathrm{FD}=1000$ to 1500$)$.

The decontamination factor could have been improved by adding to the process an electropolishing step for decontaminating the most difficult facts. This part has been shown in the laboratory tests.

\section{3 . BRENNILIS BITUMIZATION PLANT DECONTAMINATION AND DISMANTLING}

Now, an industrial application of gels spraying performed on a bitumization plant is presented.

\subsection{Decontamination results}

The main part of the plant was decontaminated by using gels spraying, that is :

- low level activity cell

- medium level activity cell

- Luwa evaporator platform

- tanks.

For this operation, the gel composition was the following : 
- nitric acid

$: 2$ to $5 \mathrm{~mol} / \mathrm{l}$

- hydrofluoric acid

$: 0.05$ to $1.6 \mathrm{~mol} / 1$

- oxalic acid

: 0.08 to $0.25 \mathrm{~mol} / 1$

The biological protection which was composed of bricks was decontaminated in a chemical bath containing nitric acid ( $7 \mathrm{~mol} / \mathrm{l})$.

The most contaminated bricks were pre-decontaminated with a gel composed of nitric acid $5 \mathrm{~mol} / \mathrm{l}$ and oxalic acid $0.04 \mathrm{~mol} / \mathrm{l}$.

All the parts decontaminated represent :

- 150 to $200 \mathrm{~m}^{2}$ which were decontaminated by gels spraying,

- $70 \mathrm{~m}^{2}$ of soils, $50 \mathrm{~m}^{2}$ of stainless steels and $50 \mathrm{~m}$ of pipes which were decontaminated by chemical solutions circulation.

The residual contamination was always less than $4 \mathrm{~Bq} / \mathrm{cm}^{2}$.

\subsection{Secondary wastes}

The total amount of secondary liquid wastes was equal to 7216 liters :

- For the gels :

. chemical solution

. rinsing water

. neutralization sodium hydroxyde

- For the chemicals solutions used in circulation :

. chemical solution

. rinsing water

. neutralization sodium hydroxyde

- For the chemical bath :

. chemical solution

. rinsing water

. neutralization sodium hydroxyde

- The first $1.6 \mathrm{~m}^{3}$ was embedded in bitumen immediately.

- The rest of liquid wastes were transferred to Cadarache after neutralization, because of failure of the bituminization plant for treating the whole volume of secondary wastes generated by decontamination : 
$.150 \mathrm{~kg}$ of sludges (lead oxydes)

$.5 .4 \mathrm{~m}^{3}$ of low level activity liquid wastes.

The solid wastes were sent to the ANDRA storage center (CSM La Hague).

\subsection{Conclusion}

The amount of decontaminated parts which were transferred to Cadarache for reuse, represent about $140 \mathrm{~m}^{3}$ (60 tons) with a residual activity less than $4 \mathrm{~Bq} / \mathrm{cm}^{2}$.

If all the secondary wastes would have been treated in the bituminization plant, wastes inventory would have been the following :

- 3 cons of bitumen

- 425 I of non compressible wastes (medium level activity)

$-17 \mathrm{~m}^{3}$ of compressible wastes (low level activity)

$-11 \mathrm{~m}^{3}$ of non compressible wastes (low level activity).

\section{GELS SPRAYING DECONTAMINATION PERFORMED ON THE COOLANT CIRCUIT OF THE GRAPHITE GAS REACTOR G2}

Before dismantling the cooling circuit of the graphite-gas reactor G2, a decontamination step will be performed.

Consequently, it is necessary to get the best decontamination process, and therefore there has been three steps in $\mathrm{R}$ and $\mathrm{D}$ studies :

- Laboratory studies for investigating all the processes, and selecting one or two them which are the most promising (The results of this study are not presented in this report).

- Larger scale tests in order to get a confirmation of the Decontamination Factor, and to precisely evaluate the wastes volumes which will be generated by decontamination.

- In-situ tests which are performed on the installation itself, with the means which will be used for the industrial scale operation. 


\subsection{Larger scale tests}

The process chosen after laboratory studies is gel spraying operated in two or three steps :

- gel containing sodium hydroxide $(3 \mathrm{~mol} / \mathrm{l})$ with or without sodium permanganate.

- gel containing sulphuric acid ( $3 \mathrm{~mol} / \mathrm{l})$ and phosphoric acid $(3 \mathrm{~mol} / \mathrm{l})$. This step can be repeated once if necessary.

With this method, tests have been performed on parts $\left(2500 \mathrm{~cm}^{2}\right)$ coming from the cooling circuit.

These parts have been taken both in the "cold" circuit (after the heat exchanger) and in the "hot" circuit (before the heat exchanger).

The main results of these tests are the following:

- Mass of gel sprayed : about $200 \mathrm{~g} / \mathrm{m}^{2}$ for each step.

- Volume of rinsing water : about $28 \mathrm{l} / \mathrm{m}^{2}$

- Initial activity : $30 \mathrm{~Bq} / \mathrm{cm}^{2}$ ("cold" circuit) $100 \mathrm{~Bq} / \mathrm{cm}^{2}$ ("hot" circuit)

- Residual activity : $0.4 \mathrm{~Bq} / \mathrm{cm}^{2}$ ("cold" circuit) $0.5 \mathrm{~Bq} / \mathrm{cm}^{2}$ ("hot" circuit)

- Effluents volume $: 56 \mathrm{l} / \mathrm{m}^{2}$ for two steps (basic gel and acid gel). activity : $8000 \mathrm{~Bq} / \mathrm{l}$ activity after sludges separation: $1000 \mathrm{~Bq} / \mathrm{l}$

\subsection{In-situ decontamination tests}

With a two-step process (basic gel spraying, rinsing, acid gel spraying, rinsing), a test has been performed on pipes of the $\mathrm{G} 2$ cooling circuit.

A length of 10.9 meters of pipes (diameter $: 1.6 \mathrm{~m}$ ) have been decontaminated by gel spraying manually operated, by the means of an air-less compressor.

The operator penetrated in the pipe for gel spraying, and rinsing. 
The results of this operation are the following :

- Mass of basic gel sprayed : $24 \mathrm{~kg}\left(435 \mathrm{~g} / \mathrm{m}^{2}\right)$

- Mass of acid gel sprayed : $17 \mathrm{~kg}\left(310 \mathrm{~g} / \mathrm{m}^{2}\right)$

- Initial activity $: 100 \mathrm{~Bq} / \mathrm{cm}^{2}$

- Residual activity $\quad: 0.2 \mathrm{~Bq} / \mathrm{cm}^{2}$

- Volume of effluents (mixture of basic and acid effluents) : 396 liters $\left(7.21 / \mathrm{m}^{2}\right)$.

- Activity of effluents after mixing and sludges separation $: 810 \mathrm{~Bq} / \mathrm{l}$.

\section{A MECHANICAL SODIUM CLEANING METHOD BY ABRASIVE BLASTING ON SUPERPHENIX FUEL STORAGE DRUM INTERVESSEL}

The aim of this study is to find a mechanical method able to clean both vessel walls of the sodium carbonate coming from the flushing in air of residual sodium after the draining of the intervessel gap.

This work is devided into three main points :

- the preliminary tests which conduct to the choice of the abrasive which would be used.

- the parametric tests where optimal procedure conditions are precised.

- and finally, qualificative tests on laboratory samples and on an intervessel demonstration model scale 1.

The apparatus used in an experimental shot blasting room using free jet, where several parameters are variant : nozzle/target distance, incidence angle for example. In the experiment several abrasive types are tested : spheric and angular particles of glass, iron and steel.

During the preliminary tests, the different qualificative criteria are :

- sodium carbonate cleaning efficiency,

- support erosion,

- abrasive pollution during recycling.

- recycling evaluation cost.

It is shown that the abrasive which gives better results is sintered iron oxide microbeads. 
It is time, now, to precise optimal procedure conditions for utilisation of the abrasive chosen,according to following parameters :

- incidence angles,

- nozzle target /distance,

- air projection pressure,

- moving speed of the blast pipe,

- abrasive granulometry.

The best results are obtained for :

- incidence angles : $451 / 2$ and $751 / 2$

- nozzle/target distance : $6.5 \mathrm{~cm}$

- air projection pressure : 5 bars

- moving speed of blast pipe : $60 \mathrm{~m} / \mathrm{h}$

- abrasive granulometry : 200-1000 İm

- on laboratory samples,

- on an intervessel demonstration model scale 1 (hight $=11 \mathrm{~cm}$; larger = $1.2 \mathrm{~m})$

Finally, the sandblasting of sintered iron oxide microbeads process for cleaning sodium in the intervessel fuel storage drum in the optimal conditions described above, has been validated for its use on SuperPhenix fuel storage drum. 


\title{
ELECTROCHEMICAL DECONTAMINATION IN EASILY PROCESSED ELECTROLYTES
}

\author{
TURNER ANDREW \\ Harwell Laboratory, UKAEA, Oxfordshire, UR \\ STERINGER ANTON \\ Kraftanlagen Aktiengesellschaft, Heidelberg, FRG
}

\begin{abstract}
Metallic surfaces can be reduced to very low levels of residual activity by electrochemical decontamination, thus reducing decommissioning and disposal costs. Two electrolyte systems have been developed which minimize the volume for disposal of secondary waste containing the bulk of the activity. Kraftanlagen, Heidelberg has developed a system for use in an immersion tank based on a $\mathrm{KBr}$ solution of acetylacetone. This leads to a continuous precipitation of the insoluble acetylacetonates of ferrous substrates together with such active species as ${ }^{60} \mathrm{Co}$. The bath performance can be maintained by continuous acetylacetone addition. Frow pilot scale trials, a solids waste volume of $1.1 \mathrm{dm} / \mathrm{m}^{2}$ of surface decontaminated has been determined. Harwell has developed both immersion and in-situ processes based on nitric acid, as the spent electrolyte is compatible with existing UK waste treatment philosophy - potentially yielding an immobilized product volume of $0.6 \mathrm{dm}^{3} / \mathrm{m}^{2}$ area treated. Nitric acid has the additional advantage of suppressing any hydrogen production. Both processes have been developed from laboratory to microprocessor controlled pilot scale units which have been demonstrated successfully for the treatment of genuine waste. The immersion tank process uses electroetching at low current densities for the treatment of extended areas, while the in-situ technique uses electropolishing in $6 \mathrm{M} \mathrm{HNO}_{3}$ in an engineered head connected to a service trolley by an umbilical. This has also shown potential for incorporation in an integrated monitoring/decontamination system under robotic control.
\end{abstract}

\section{INTRODUCTION}

Electrochemical decontamination operates by the dissolution of a thin surface layer, thus releasing activity into the electrolyte. Not only is this effective for absorbed activity, but it can also cope with ingrained or occluded material. Electrochemical decontamination is particularly adaptable, in that higher decontamination factors can be achieved with progressively longer treatment times, thus making it one of the few techniques capable of attaining background levels of residual activity. In addition, electrochemical decontamination has the advantage that it can be operated remotely under mild chemical conditions, as part of the free energy of dissolution is supplied in a selective electrical form rather than by indiscriminate thermal energy or chemically aggressive solutions. As a result, this additional control parameter makes this process ideal for automation.

A number of different electrolyte systems have now been examined. This paper describes two studies carried out under the 1984-1988 European Community Research Programme on the Decommissioning of Nuclear Installations. One, undertaken by Kraftanlagen, Heidelberg, has concentrated on the use of organic acid based systems, while the second approach, adopted by Harwell, has focussed on the use of nitric acid. 


\section{ORGANIC ACID ELECTROLYTES}

\subsection{Electrolyte Selection}

Sma11 scale tests were carried out under constant temperature conditions to identify optimum conditions for the electrochemical dissolution of mild and stainless steel in a range of organic based electrolytes. Critical parameters investigated included the current that could be passed for a given applied voltage and the dissolution current efficiency for a range of $\mathrm{pH}$, current density and electrolyte stirring conditions. Both of these had an important influence on the duration of the treatment process - in that the higher the current and the dissolution efficiency, the shorter was the required decontamination time. A conventional inorganic electrolyte $\left(14 \% \mathrm{H}_{3} \mathrm{PO}_{4} / 47 \% \mathrm{H}_{2} \mathrm{SO}_{4}\right)$ was used as a standard for comparison.

The range of electrolytes examined included oxalic acid (5\%), oxalic acid $(5 \%)+\mathrm{KC} 1(0.5 \mathrm{M})$, oxalic acid $(5 \%)+\mathrm{KBr}(0.5 \mathrm{M})$, formic acid $(10 \%)+$ $\mathrm{KBr}(0.5 \mathrm{M})$, and acetylacetone $(5 \%)+\mathrm{KBr}(0.5 \mathrm{M})$. As can be seen in Figure 1 , with the exception of oxalic acid, the current efficiencies for the dissolution of mild steel is in all cases in excess of that found for the conventional $\mathrm{H}_{3} \mathrm{PO}_{4} / \mathrm{H}_{2} \mathrm{SO}_{4}$ mixture. For stainless steel dissolution, the current yield increased to $85 \%$ in $\mathrm{H}_{3} \mathrm{PO}_{4} / \mathrm{H}_{2} \mathrm{SO}_{4}$, However, it can be seen that the presence of $\mathrm{KCl}$ or $\mathrm{KBr}$ is essential for the organic based systems to match or exceed this performance. A comparison between $\mathrm{KCl}$ and $\mathrm{KBr}$ additions to oxalic acid shows the latter to be the preferred option in giving an enhanced dissolution yield. In all cases, though, it should be noted that significant surface roughening had occurred $\left(R_{2}>30, R_{a}>10\right.$ $\mu \mathrm{m})$. This is due to a variation in the kinetics of dissolution as a function of substrate microstructure rather than selective dissolution of a particular phase, as the analysis of the metal content of the electrolyte and the substrate were identical.

\subsection{Electrolyte Performance}

Subsequent trials were then carried out on inactive samples of mild steel steam pipe whose surface was covered by rust (haematite). Although in all cases, hydrogen gas was evolved at a rate of $0.4 \mathrm{l} / \mathrm{Ah}$, this could easily be diluted to below the $4 \%$ flammability limit. However, the formation of a foam required special remedial action as this contained high local concentrations of hydrogen. It could normally be minimized by alcohol addition.

While tests with formic and oxalic acid electrolytes indicated that their performance was adversely affected by a rise in $\mathrm{pH}$, due to the formation of hydroxides, the acetylacetone electrolyte was found to have a good pH stability - further improved by dosing with acetylacetone to replace that consumed by precipitation of the insoluble salts of the dissolved substrate ( $\mathrm{Fe}, \mathrm{Co}, \mathrm{Cr}, \mathrm{Ni}$ ). The precipitated products are large crystals that settle very easily, and therefore do not require filtration. In the acetylacetone electrolyte, residual metal salt solubility is low $\left(5 \mathrm{~g} / \ell\right.$ ) compared to that found for the conventional $\mathrm{H}_{3} \mathrm{PO}_{4} / \mathrm{H}_{2} \mathrm{SO}_{4}$ electrolyte $(130 \mathrm{~g} / \mathrm{l})$. As a result, the radioactive content of the electrolyte reaches a steady state governed by the solubility of the acetylacetonate salts.

\subsection{A Pilot Plant}

In parallel with the electrolyte development, described above, a $400 \mathrm{~A}$ pilot plant intended for active tests was designed and constructed. This is shown schematically in Figure 2. The plant was constructed of stainless steel and has an electrolyte capacity of $52 \mathrm{l}$. A water cooled jacket was provided to limit any temperature rise during operation. As can be seen from Figure 2, the electrolyte bath is divided into two sections. The upper part is where the electrolytic dissolution is conducted, while the 
lower compartment $1 \mathrm{~s}$ a settling tank. These are separated by a suspended floor to prevent re-entrainment of material that has already settled. A 90 $\ell / m i n u t e$ centrifugal pump ensures good circulation of the electrolyte, thus avolding problems of compositional variation or local overheating. A $400 \mathrm{~A}$ air cooled silicon rectifier set was used to provide DC power.

\subsection{Tests on Radioactive Samples}

Following Inactive optimlzation, an electrolyte of $5 \%$ acetylacetone and $1 \mathrm{M} \mathrm{KBr}$ in water $+25 \%$ n-propanol adjusted to $\mathrm{pH} 4$ reclrculated at a rate of 50-60 $\mathrm{l} / \mathrm{minute}$ was used to decontaminate genuine waste items. During the tests, only acetylacetone was added to replenish that used in acetonate formation, thus maintaining the $\mathrm{pH}$.

The samples used for these active tests had fixed contamination only. Any loosely adherent material had been removed by pre-cleaning and degreasing, as conflrmed by smear tests. Most of the samples used comprised mild and stalnless steel plpe sections $(130 \times 100 \mathrm{~mm})$ from the secondary loop of a decommissioned experimental reactor. Initial contamination levels were between $2-10 \mathrm{~Bq} / \mathrm{cm}^{2}$ as measured by a FHT 111 rate meter. Electrical connection and mechenical support were provided by welded tags, with copper or stainless steel pipe used as an axial cathode. An opt Imum current density of $0.2 \mathrm{~A} / \mathrm{cm}^{2}$ was used for all of the active tests, and the electrolyte maintained between $20-40^{\circ} \mathrm{C}$. The progress of the decontamination was monitored at 5-10 minute intervals.

The results of the tests are shown in Table $I$, from which it can be seen that a DF of 36 could be achieved in 50-100 minutes. Initially, activity was removed relatively rapidly down to a level of $\sim 0.8 \mathrm{~Bq} / \mathrm{cm}^{2}$. However, after this, longer times were needed to reach the $0.37 \mathrm{~Bq} / \mathrm{cm}^{2}$ required for unrestricted release. This can be understood in terms of the bulk of the activity belng removed with the outer layer of the substrate. More metal needs to be dissolved to release the more deeply ingrained contemination. However, due to the poor microsocpic uniformity of dissolution which leads to surface roughening, the amount of metal that has to be dissolved to reach low residual activity levels is increased. In a few of the tests, the shorter decontamination times could be correlated with an improved surface finish after treatment. Unfortunately, metal surfaces covered with a thick, coherent film of oxide (magnetite or haematite) could not be satisfactorily treated by this process, due to secondary reactions which occurred in preference to surface dissolution. 2.5 Waste Treatment

From the active trials described above, $34 \ell$ of electrolyte and $21 \ell$ of sediment were produced. The electrolyte contained some $0.47 \mathrm{~Bq} / \mathrm{g}$ of activity $\left(80 \%^{137} \mathrm{Cs}, 20 \%{ }^{60} \mathrm{Co}\right)$ dissolved in a mixture of water, $3 \%$ acetylacetone, $30 \%$ 1sopropanol, $1 \mathrm{M} \mathrm{KBr}$ and $5 \mathrm{~g} / \mathrm{l}$ of acetylacetonates. After distillation, only the latter two specles ( $4 \mathrm{~kg} \mathrm{KBr}$ and $0.17 \mathrm{~kg}$ acetylactonates) were left together with the activity. The $22 \mathrm{~kg}$ of sediment produced (primarily the ruby coloured Fe(III) acetylacetonate) contalned $2.25 \mathrm{~Bq} / \mathrm{g}$ as $75 \%^{60} \mathrm{Co}, 15 \%^{137} \mathrm{Cs}, 8 \%^{125} \mathrm{Sb}$. The $21 \&$ of precipitate could be further reduced to 16 \& by a 600 bar high pressure compactor. This corresponds to aste volume of $\sim 1.1 \mathrm{e} / \mathrm{m}^{2}$ of surface decontaminated, es the $\mathrm{KBr}$ contained in the electrolyte can be re-used. Wh1le ${ }^{\circ} \mathrm{Co}$ becomes concentrated in the sediment ( $92 \%$ of the total) due to the insolubility of 1 ts acetylacetonate, Cs does not form an insoluble salt so is present in the precipitate only in the ratio of the volumes (37\%). This reduces the ectivity concentrated in the sediment to only $76 \%$ of the total. 


\section{NITRIC ACID ELECTROLYTES}

\subsection{Introduction}

The Harwell work on electrochemical decontamination has focussed on the use of nitric acid based systems for a number of reasons. When used under conditions of impressed current density matched to composition, this can reduce residual actvity by factors $>10^{4}$ to $<37 \mathrm{kBq} / \mathrm{m}^{2}$ with minimal substrate dissolution. They can be used at ambient temperatures, thus simplifying plant construction and operation. In immersion tank applications, they can give a superior uniformity of treatment over complex shapes compared to the more traditional phosphoric acid system. Hydrogen evolution is suppressed in preference to nitrate ion reduction - not only preventing any flammability hazard but also avoiding any aerosol problems. Due to its low viscosity, post-decontamination rinsing is also more simply accomplished. Spent electrolytes can also be conditioned prior to disposal to reduce overall treatment costs further by a range of volume reduction processes already available for reprocessing wastes.

Two processes, initially for the treatment of stainless steel, have been developed - high rate electropolishing in $6 \mathrm{M}$ nitric acid for in situ hot spot removal, and electroetching at a low current density for the treatment of extended surface area and complex geometries in an immersion tank. Both of these systems have been developed from laboratory to pilot scale for remote operation as a way of minimizing occupational radiation exposure. This paper gives details of their construction and performance during commissioning and active trials.

\subsection{Immersion Electroetching}

\subsection{Laboratory trials}

Laboratory trials were carried out initially to define the optimum operating conditions required for the design of the decontamination equipment. A comparison between nitric and oxalic acid systems showed nitric acid to be more attractive, both in terms of its uniformity of treatment and also in minimizing the substrate dissolution needed. Nitric acid (1-5M) can achieve DFs of $10^{3}-10^{4}$ for ionic and colloidal plutonium contamination by the dissolution of $\sim 8 \mu \mathrm{m}$. However, for the removal of particulates, 5M acid is preferred. As long as the free acid concentration is maintained, dissolved substrate levels up to $20 \mathrm{~g} / \mathrm{l}$ have only a minor effect on decontamination - with DFs of $10^{4}$ typically achieved in 2 hours. While re-adsorption of activity is possible under open circuit conditions, at $0.1 \mathrm{~g} / \ell \mathrm{Pu}$ this amounted to only $20 \mathrm{~Bq} / \mathrm{cm}^{2}$ in $1 \mathrm{M} \mathrm{HNO}$. However, at the decontamination potential this is $<5 \mathrm{~Bq} / \mathrm{cm}^{2}$, and $<0.3 \mathrm{~Bq} / \mathrm{cm}^{2}$ under reversed polarity.

A range of cathode materials have also been investigated for their corrosion resistance, and the composition of any off-gases as a function of electrolyte composition and other operational variables. Titanium and zirconium suffered the least attack, followed by 310 stainless steel. From analyses of the off-gases by chemiluminescence and mass spectrometry, hydrogen was limited to only $0.2 \mu \mathrm{l} / \mathrm{C}$ from a Ti cathode immersed in $1 \mathrm{M}$ $\mathrm{HNO}_{3}$ with a $3 \mathrm{mM} \mathrm{Pb}(\mathrm{II})$ additive. At stainless steel and zirconium electrodes, it was suppressed altogether. No traces were found either for a $\mathrm{Zr}$ cathode in $5 \mathrm{M} \mathrm{HNO}_{3}$. $\mathrm{NO}_{x}$ evolution from $1 \mathrm{M} \mathrm{HNO}_{3}$ could be suppressed to $<0.5 \mu \mathrm{l} / \mathrm{C}$ by either $\mathrm{Ti}$ or $\mathrm{Zr}$ cathodes in conjunction with a $\mathrm{Pb}$ (II) additive. Similar values were found in the presence of $0.1 \mathrm{M} \mathrm{NaF}$. However, due to a reduced solubility in $5 \mathrm{M} \mathrm{HNO}_{3}$, $\mathrm{NO}_{x}$ evolution was generally higher (13-17 $\mu \ell / C)$ from $T i$ and stainless steel - even in the presence of a $\mathrm{Pb}$ (II) additive. Zirconium, though, substantially reduced this in the presence of $\mathrm{Pb}$ (II) to $<3 \mu \mathrm{l} / \mathrm{C}$, by encouraging the formation of $\mathrm{NH}_{4}{ }^{+}$. For circumstances where it is preferred to minimize $\mathrm{NH}_{4}^{+}$formation instead, the 
yleld from an anodized $T 1$ cathode was < $0.5 \%$. Due to the high solubility of $\mathrm{N}_{2} \mathrm{O}$ in water, only low levels were detected ( $6 \mu l / \mathrm{C}$ for $\mathrm{TI} / 1 \mathrm{M} \mathrm{HNO}_{3}+$ $\mathrm{Pb}$ (II); $2 \mu \ell / \mathrm{C}$ for $\mathrm{Zr} / 1 \mathrm{M} \mathrm{HNO}_{3}+\mathrm{Pb}(\mathrm{II}),<0.2 \mu \ell / \mathrm{C}$ for $\left.5 \mathrm{M} \mathrm{HNO}_{3}\right)$.

3.2.2 Decontamination unit design and construction

On the bas 18 of these laboratory studies, a demonstration $0.3 \mathrm{~m}^{3}$ decontamination tank unit was designed to fit below the false floor of the decomisstoning cell of one of the Harwell active handling facilities. Th1s was so that the cell could continue to be used during the 2 hour treatment time. For this early work, the tank has been fitted with removable titanium cathodes in order to suppress hydrogen and No $x$ production. Not only is there no flammabllity risk, but due to the small volume of off-gas, contamination spread by aerosol formation is also virtually eliminated. The electrolyte is unstiried during use, as this slightly enhances the treatment rate and reduces off-gas production - as well as simplifying plant construction. From the results of previous work, electrical connection to the ltems to be decontaminated has been made by anodic titanium current feeders - a thick base plate for heavier items, and a basket for smaller objects.

The complete system is managed by a microprocessor controller, which together with the $100 \mathrm{~A}$ power supply, electrolyte stock tank and dosing pumps is located on a mobile service trolley in an inactive area. This automates the system and also permits safe operation without the need for continuous operator involvement due to extensive monitoring of process parameters.

In $1 \mathrm{M} \mathrm{HNO}$ based electrolytes, the decontamination operation is optimized by controlling the voltage between the titanium current feeder and a monitoring reference electrode. As conventional laboratory reference electrodes are unsuited to hot-cell operation, a study was carried out to Identify an alternative system. A dynamic electrode based on the evolution of oxygen from platinum under a controlled current has been adopted as the most sultable on the grounds of not only being maintenance free, but also having a stable voltage response independent of acid concentration, temperature or the presence of dissolved iron. In the plant, the reference electrode is located at the lip of the tank and connected to the solution under the basket by a plastic pipe.

During the final phase of treatment, there is also an option to reverse the cell current so as to minimize any readsorbed activity. Electrolyte is then removed to an adjacent enclosed storage vessel while the potential is still applied. Rinsing and drying are then carried out in the decontamination tank with the lid still in place to prevent activity spread - the rinse water beling continuously pumped out to a waste container. If it is desired to re-use the electrolyte, this can be dosed with concentrated acid equivalent to that consumed during the previous run prior to being pumped back into the decontamination tank.

\subsubsection{Commissioning and active trials}

After construction, simple device and controller testing was carried out prior to calibration of the various sub-systems. These included ADC/DAC interfaces, the signal processing circuitry to display the process variables, thermocouple, acid delivery, electrolyte transfer, reforence - lectrode and level sensors. During the course of this work, some modifications were found necessary to Improve the pump transfer rates and correct some minor electrical faults.

Inactive trials were then carried out in $1 \mathrm{M} \mathrm{HNO}$, on a series of 321 stalnless steol plates. After 2 hours of treatment, it was found that $\sim 5 \mathrm{\mu m}$ had been removed from the surface, leaving a fine etch - as expected from laboratory work. In addition, a high degree of uniformity of 
dissolution was observed between samples positioned in different parts of the current feeder basket.

A series of active tests on contaminated 321 objects have also comfirmed that residual activity can be reduced to background levels. Although spots of dried out $\mathrm{Cs}$ and $\mathrm{Sr}$ solution could be reduced from 333 to $133 \mathrm{~Bq} / \mathrm{cm}^{2}$ by soaking in $1 \mathrm{M} \mathrm{HNO}$, for 2 hours, this was reduced to undetectable levels after 2.5 hours of electrochemical treatment. Similar results were obtained with absorbed ${ }^{60} \mathrm{Co}\left(5-39 \mathrm{~Bq} / \mathrm{cm}^{2}\right)$ and ${ }^{106} \mathrm{Ru} /{ }^{110} \mathrm{Ag}(9-44$ $\mathrm{Bq} / \mathrm{cm}^{2}$ ) contamination which could not be removed by wet swabbing. While $D F^{\prime}$ 's of only 2.7 and 11.4 respectively could be obtained by soaking in $1 \mathrm{M}$ $\mathrm{HNO}_{3}$ for 3.5 hours, 2 hours of electrochemical treatment at $2-3 \mathrm{~mA} / \mathrm{cm}^{2}$ reduced the contamination to below the level of detection by the removal of $\sim 4 \mu \mathrm{m}$.

\subsection{In-Situ Electropolishing}

3.3.1 Laboratory trials

For in-situ decontamination, a more rapid process than that described above needs to be used, as only a limited area is being treated at a time. This can be achleved by raising the nitric acid concentration. Instead of the process being limited by the chemical dissolution of $\mathrm{Fe}$ (III), Ni(II) oxides, these now pass directly into solution as nitrates. The dissolution rate is ultimately limited by the formation of a thin layer of $\mathrm{CrO}_{3}$ precipitated at the surface. This has the effect of balancing the rate of its production from the dissolution of the substrate and its dispersal into the electrolyte. As this is now independent of any excess voltage applied, the surface is electropolished as well as decontaminated. Not only does this minimize the amount of metal dissolved to achleve the desired DF by reducing any non-uniformity in treatment, but it also leaves the surface microscopically smooth. This has the advantage of holding up less activity during re-use.

From laboratory trials, acid strengths in excess of $6 \mathrm{M}$ are suitable giving currents in the range $0.5-2 \mathrm{~A} / \mathrm{cm}^{2}$ over a $10-35^{\circ} \mathrm{C}$ temperature range. Removal of $\sim 5 \mu \mathrm{m}$ from the surface in about 15 seconds can give DFs of $10^{6}$ - as demonstrated in shielded fume hood experiments.

A prototype decontamination head was constructed to determine optimum processing parameters. This was a planar device comprising a $50 \times 50 \mathrm{~mm}$ treatment area - able to encompass most hot spots. Larger areas could be decontaminated by sequential treatment of adjacent squares. The device was held onto the surface by a vacuum applied between concentric soft seals. From a series of trials, titanium was selected for the cathode, as not only does it not suffer any weight loss, but insoluble gas production $\left(\mathrm{H}_{2}, \mathrm{NO}_{\mathrm{x}}\right)$ is suppressed, thus permitting slow electrolyte flow rates $(2.5-3 \mathrm{~m} \ell / \mathrm{s})$ to be used. This makes a 'once through' use of electrolyte practical - thus enabling the electrolyte stock tank and delivery pump to be positioned outside the containment.

The minimum acid strength of $6 \mathrm{M}$ that could support electropolishing was chosen for use in the decontamination unit as not only did this reduce the amount of waste acid requiring treatment, but it also improved the stability of the front face elastomeric seals. From a series of long term trials investigating the chemical stability of potential seal materials in 6,8 and $10 M$ acid, an unloaded silicone tube filled with a soft silicone foam was chosen as the most suitable - both from the point of view of its chemical and radiation stability, but also the ease with which it could be fabricated into 0 ring seals.

\subsubsection{Decontamination unit design and construction}

A mobile hot spot decontamination unit was designed on the basis of these laboratory trials. It comprised a stainless steel trolley on which a 
100 A power supply, microprocessor controller, electrolyte feed tank, solution pumps and electromagetic valves were mounted. For inactive commissioning of the prototype, it also included an effluent tank. This service trolley, whlch could remain in an inactive area, was connected to interchangeable decontamination heads by an umbilical, which contained fluid pipes, vacuum line, and electrical connections. As before, the use of a microprocessor controller enabled the unit to be automatically and safely operated due to monitoring of process parameters with an extensive range of sensors - thus minimizing the need for operator intervention.

After placement of the head on the surface to be decontaminated, the operating sequence can be activated after application of a vacuum to hold 1t in place. Once the head is full of electrolyte, the current is applied between the substrate and the cathode in the head for a preset duration. After this, continued electrolyte flow rinses the surface prior to removal by a vacuum-induced air flow. This minmizes any spillage on subsequent removal of the head. Typical electrolyte usage on a once-through basis was estimated to be $210 \mathrm{l} / \mathrm{m}^{2}$. Subsequent conditioning can reduce this volume further by up to a factor of 30 in order to minlmize the costs of disposal as a cemented waste form.

3.3.3 Commissioning and active trials

After construction, each of the various components was tested individually and then in sections. However, it was found that several changes needed to be made - including modification of the air bleed system in the decontamination head to remove any trapped air which could otherwise disturb the unfformity of fluid flow, and improvements in the means of front face seal retention. Inactive electro-polishing trials were subsequently carried out successfully in 6 and $8 M$ nitric acid on 321 and 316 stainless steel sheet of 1-5 mm thickness to demonstrate all aspects of system operation including the fall-safe management of faults.

In addition, some robotic handling trials have also been carried out using a PUMA 560 in the Harwell Robotic Demonstration factlity to demonstrate that an automatic system of locating and removing activity hot spots is feasible. The decontamination head was modified with two integral Gelger-Muller tubes and inductive proxistors to assist the robot in scanning the head across the surface for activity monitoring, and a compllant head mounting for placement prior to subsequent electropolishing. The head was successfully placed and sealed to both horizontal and vertical surfaces and water passed through the system to simulate the electrolyte. The unique Harwell controller allows the robot to be driven manually from joysticks, under automatic control from the linear inductive sensors, or in - mixed mode by a combination of both. Remote decontamination thus requires the operator merely to bring the decontamination head close to the surface using the joysticks and then to initiate the automatic monitoring and decontamination routine whch is sequenced by the robot and electropolishing control units.

Finally, the mobile decontamination unit was modifled for hot-cell use by providing $5 \ell$ in-cell effluent tank and a minlature multistage alr ejector and aerosol trap to suck out any residual electrolyte after decontamination. This was used in subsequent active trials (Figure 3 ) in which the equipment was used to decontaminate residual hot spots in a stainless steol containment box after cleaning with 10 litres of foamed dilute phosphoric acid to remove any loose activity. The contamination had arisen from spilt dissolved fuel solution, which had dried out and been ground 1nto the surface. Three main areas of $150 \mathrm{~mm}$ square were identifled with activity levels of $300-500 \mu \mathrm{Sv} / \mathrm{h}$. Some 27 treatments were applled in adjacent sites to electropolish the surface virtually to background. For each run, voltage of $6.3 \mathrm{~V}$ was applied to give current of $40 \mathrm{~A}$ for 30 seconds followed by a 10 second rinse. Under the conditions used, $200 \mathrm{ml}$ 
of electrolyte was passed/run. In future campaigns this will be cut to only $\sim 30 \mathrm{mls}$ by reducing the treatment time to 10-15 seconds and the flow rate to $2.5 \mathrm{ml} / \mathrm{s}$ from $4.5 \mathrm{ml} / \mathrm{s}$. Overall electrolyte usage will also be further reduced by the use of activity monitors able to locate the contamination more precisely, thus preventing any unnecessary treatment.

\section{CONCLUSIONS}

Electrochemical decontamination has been demonstrated to be able to reduce residual contamination on metallic surfaces to very low levels. Two electrolyte systems have been developed which offer advantages in simplified disposal over the more conventional phosphoric acid used previously.

The first, developed by Kraftanlangen, Heidelberg for use in an immersion tank is based on a $\mathrm{KBr}$ solution containing acetylacetone which leads to the continuous precipitation of dissolved ferrous substrate together with such active species as ${ }^{60} \mathrm{Co}$. The solid waste volume resulting from tests in a 400 A pilot plant on reactor components corresponds to $\sim 1.1 \mathrm{dm}^{3} / \mathrm{m}^{2}$ of surface decontaminated. The bath performance could be maintained by continuous acetylacetone addition.

The second electrolytic system developed by Harwell is based on 1-6M nitric acid, which is compatible with existing waste streams and can be conditioned by a variety of processes to a product volume of $0.6 \mathrm{l} / \mathrm{m}^{2}$ treated. Nitric acid has the additional advantage of suppressing hydrogen production. Two processes have been developed from the laboratory to microprocessor controlled pilot scale units which have been demonstrated successfully for the treatment of genuine waste. The first is an immersion tank process able to treat complex shapes of extended surface area, yielding DFs up to $10^{4}$ in 2 hours. The second process is high rate electropoplishing in $6 \mathrm{M} \mathrm{HNO}_{3}$ in an engineered head requiring treatment times of only 10-20 s. Active trials on the stainless steel lining of a containment box reduced activity levels from $0.5 \mathrm{mSv} / \mathrm{h}$ to background. Preliminary trials with a robot demonstrated the potential for the integration of automatic, remote activity monitoring and decontamination using such a system.

The choice of a particular electrolytic system for a given application will not only be determined by economic considerations of secondary waste conditioning and disposal costs but also by constraints placed on the nature of secondary waste by national waste disposal strategies. Local safety requirements and operating practice may also make one system preferable over another.

In conclusion, therefore, it can be seen that electrochemical decontamination has the potential to play an increasingly important role in the management of metallic waste in being able to reduce it to levels of residual activity appropriate for shallow land burial or even unrestricted free release. 
Table I: Electrochemical decontamination of steel pipe sections in a $5 x$ acetylacetone based electrolyte

\begin{tabular}{|c|c|c|c|c|c|c|c|c|c|c|c|c|c|c|}
\hline \multirow{2}{*}{$\begin{array}{l}\text { Test } \\
\text { Number }\end{array}$} & \multirow{2}{*}{$\begin{array}{l}\text { Current } \\
\text { (A) }\end{array}$} & \multirow{2}{*}{$\begin{array}{l}\text { Applied } \\
\text { Potential } \\
\text { (v) }\end{array}$} & \multicolumn{11}{|c|}{ Activity $\left(\mathrm{Bq} / \mathrm{cm}^{2}\right)$ as a function of process time (minutes) } & \multirow{2}{*}{$\begin{array}{l}\text { Final } \\
\text { Decontamination } \\
\text { Factor }\end{array}$} \\
\hline & & & 0 & 10 & 20 & 30 & 40 & 50 & 60 & 70 & 80 & 90 & 100 & \\
\hline 1 & 90 & 23 & 8.1 & 5.3 & 0.7 & 0.45 & 0.3 & & & & & & & 28 \\
\hline 2 & 90 & 15 & 9.0 & 6.4 & 0.9 & 0.6 & 0.4 & 0.25 & & & & & & 36 \\
\hline 3 & 70 & 18 & 4.1 & 1.2 & 0.8 & 0.45 & 0.4 & 0.3 & & & & & & 17 \\
\hline 4 & 75 & 20 & 4.5 & 1.8 & 0.8 & 0.55 & 0.4 & 0.3 & & & & & & 16 \\
\hline 5 & 90 & 21 & 7.2 & 6.4 & 2.0 & 0.9 & 0.5 & 0.4 & 0.2 & & & & & 36 \\
\hline 6 & 90 & 22 & 4.5 & 1.3 & 0.76 & 0.5 & 0.4 & 0.3 & & & & & & 15 \\
\hline 7 & 80 & 24 & 9.7 & 6.0 & 2.2 & 1.8 & 1.35 & 1.1 & 1.0 & 0.8 & 0.7 & 0.6 & 0.35 & 26 \\
\hline 8 & 80 & 22 & 10.0 & 5.0 & 1.9 & 1.3 & 0.9 & 0.65 & 0.5 & 0.35 & & & & 20 \\
\hline 9 & 80 & 22 & 3.74 & 0.6 & 0.3 & & & & & & & & & 6.5 \\
\hline 10 & 82 & 22 & 4.1 & 3.2 & 0.6 & 0.3 & & & & & & & & 11 \\
\hline
\end{tabular}




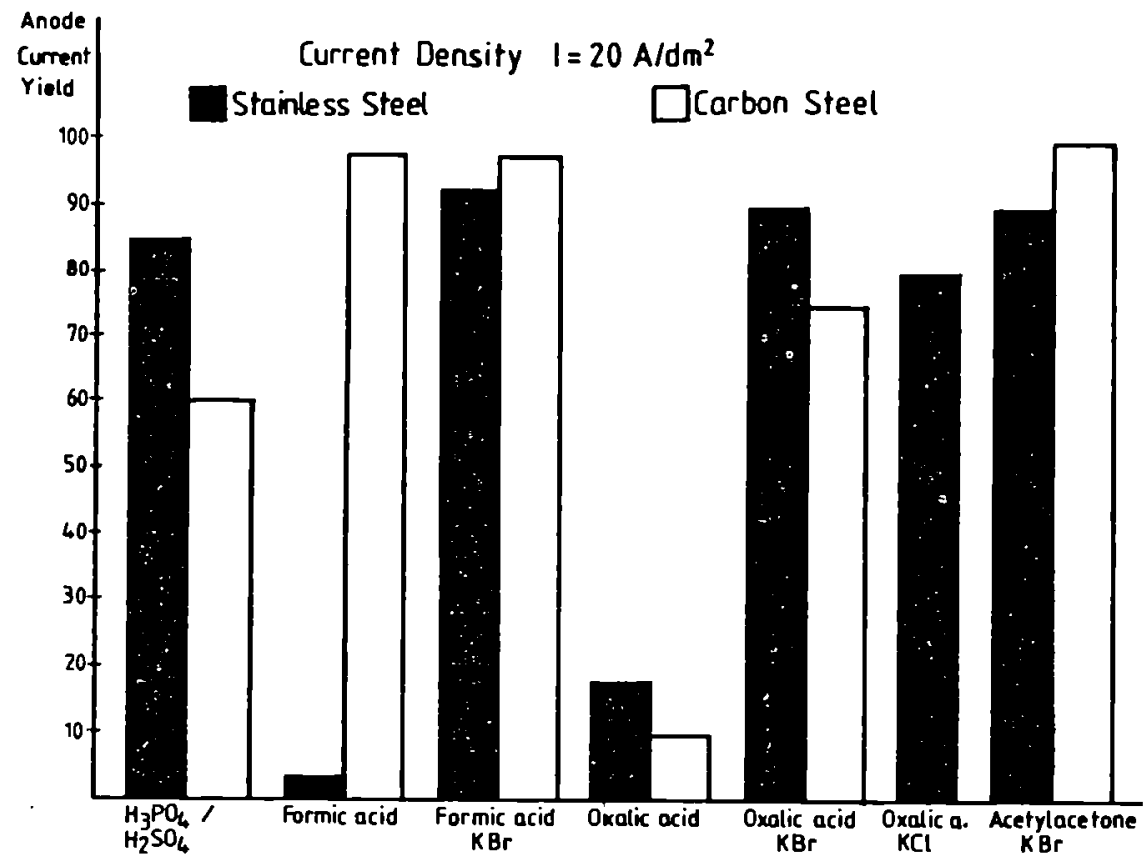

Figure 1: Comparison of steel dissolution efficiency for a range of electrolyte compositions.

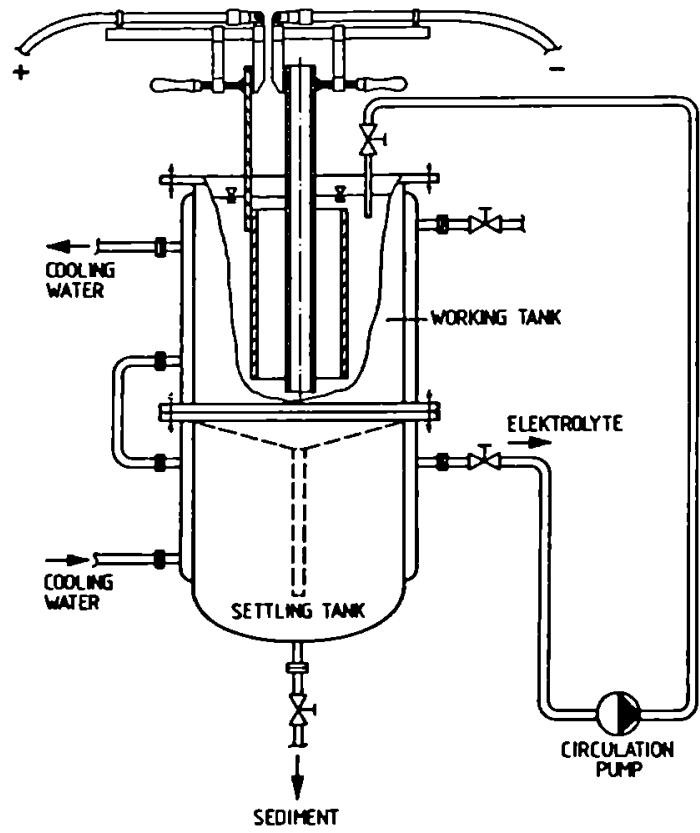

Figure 2: 400 Amp Decontamination Plant Experimental Arrangement. 


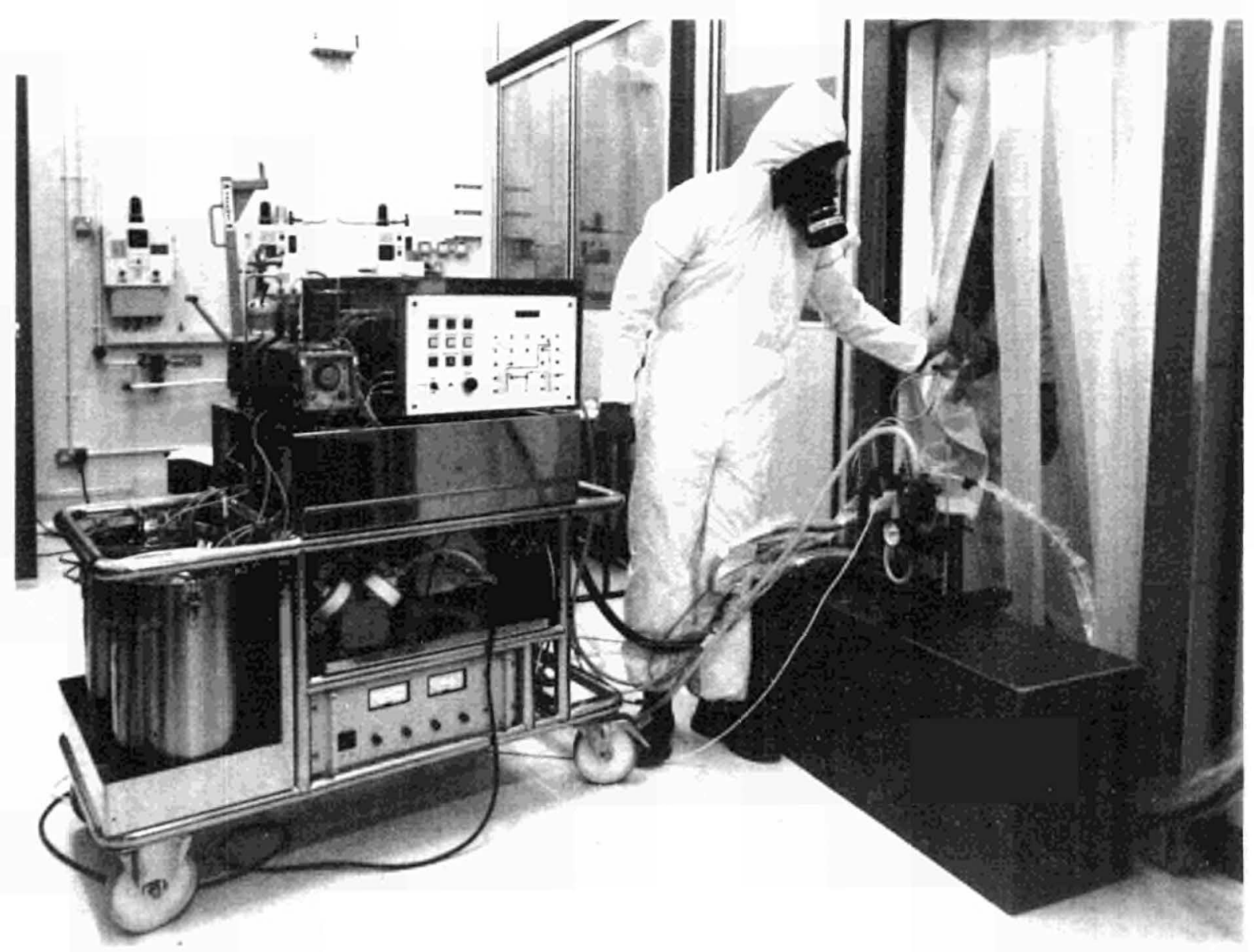


CLOSED ELECTROPOLISHING SYSTEM FOR DECONTAMINATION

OF UNDERWATER SURFACES/

DEVELOPMENT OF VIBRATORY DECONTAMINATION WITH ABRASIVE MEDIA

\author{
E BENAVIDES, M FAJARDO \\ Equipos Nucleares S.A. \\ Madrid - Spain
}

\begin{abstract}
Electropolishing 18 one of the most efflclent techniques to decontaminate stalnless steel surfaces. An underwater closed electropolishing system has been developed to decontaminate large stainless steel areas, specially designed for pool liners avolding electrolyte sp1llage.

Vibratory finlshing 18 commonly used for non-nuclear applications as surface fintshing. This project is directed to the nuclear decontamination field and consists in selecting the optimum blast for decontamination purposes in connection with a cleaning and degreasing method for physically removing soluble and low adherent contamination in pieces normally existing at nuclear power plants.
\end{abstract}

\title{
1. CLOSED ELECTROPOLISHING SYSTEM FOR DECONTAMINATION OF UNDERWATER SUR- FACES
}

1.1. Objectives and Scope

The objective of this project is to develop an electropolishing technique for the decontamination of large stainless steel surfaces in flooded systems without 1088 of electrolyte.

The scope of the programe involves essentially the following activities:

- the Implementation of a closed loop system able to electropolish large stalnless steel surfaces without 1088 of electrolyte;

- the development of several electropolishing cathodes with electrolyte rinsing system for underwater use;

- the underwater application of this technique to contaminated surfaces.

This research is directed mainly at reactor cavities and fuel storage pools of LWRs and other research centres, which need decontamination in maintenance as well as in decomisstoning.

Electropolishing is able to decontaminate completely stainless steel surfaces, enabling 1 t to be treated as conventional scrap afterwards, thus reducing the amount of waste generated during the decomissioning work.

\subsection{Design of electropolishing heads}

Several underwater electropolishing heads are designed in order to be adapted to small and big surfaces. A batch electropollshing process 18 selected in order to avoid spillages from the electropolishing chamber to the pool, due mainly to imperfections on the pool liners (welds, concavity, etc.).

The body of the heads are made of high density polypropylene with two chambers: electropolishing chamber and spillage chamber.

The spillage chamber works under vacuum and collects possible leaks from the electropolishing chamber to the pool (Figure 1).

Tests with different heads were performed In order to observe these features:

- adequate flow distribution of the electrolyte inside the head;

- temperature of the cathode;

- work of the spillage chamber;

- complete rinse of electrolyte chamber. 
As it 1s needed to cover a large surface (1.e. pool liners) and considering that current density limits the electrode surface to no bigger than $0.1 \mathrm{~m}^{2}$ (with a rectifler of $3,000 \mathrm{~A}$ ), a movable electrode has been developed.

The size of this electropollshing head 18 2,000 mm height, 1,000 mm width, $150 \mathrm{~mm}$ thickness. The head creates a chamber of $2,000 \times 1,000 \times 50 \mathrm{~mm}$. Ins1de this head runs a movable electrode of $1,000 \times 100 \mathrm{~mm}\left(0.1 \mathrm{~m}^{2}\right.$ surface) up and down the chamber, electropollohing an area of $2 \mathrm{~m}^{2}$ in only one positioned step.

\subsection{Design of the electropolishing system}

Due to a batch electropolishing process beling selected, a rinse with water 1s necessary before the head moves to the next pollshing position (1n order not to decontaminate the pool with the electrolyte).

The maln objective 18 to minimize the volume of rinse water required, and also minimise the loss of electrolyte during rinsing.

For this reason, two tanks were designed:

Double tank:

Th1s tank has two bodies of 7001 capacity each, one for clean water and the other for electrolyte. The returning electrolyte flows through a coll 1mmersed in the clean water (1n order to cool the electrolyte). Th1s water 18 used as a second rinse. Water tank:

First rinsing of electropolishing 1s directed to the water tank of 7001 capac1ty. The rinse water will contain a little quantity of electrolyte. The operating sequence according to the flow diagram (FIgure 3 ) 18 automatically controlled from the panel. The maln steps and operating sequences are:

- the electropollshing head 18 positioned

By means of the suck1ng disks and vacuum, the head 18 flrmly adhered to the surface to be electropollshed. The sp1llage chamber 18 also drained by vacuum. Drain of the lectropolishing head. After positioning the head, the water has to be taken out of the electropollshing head and sent to the water tank.

- operation of the electropolishing head

The electropolishing may start now. The feed valves allow the electrolyte to fill the electropolishing head and apply direct current to the - lectrode and starts the movement lnside the head to electropolish an area of $2 \mathrm{~m}^{2}$. The electrolyte 18 continuously pumped and filtered through a filter, where particles up to $10 \mu \mathrm{m}$ are retalned. The electrolyte 18 cooled through an existing coll lnside the water tank. After that, the electrolyte 1s sent to the electrolyte tank and the loop closed.

- complete chain of electropolishing

After the electropolishing process has been completed in one position, the clrcult must be emptied of the electrolyte by means of pumping. Drained - lectrolyte 18 directed to the electrolyte tank.

- prewashing

Prewashing of electropolishing head and electropolished surface 18 done unt1l rinsing water $\mathrm{pH}$ reaches approx. 6 , and then this step 18 considered f1n1shed. Drain water. Prewash1ng water 18 dralned to the prewashing tank.

- vash1ng

A final washing 18 performed before a new position of the head 1s reached.

- vater drain

Final washing water is drained to the water tank. New position of the alectropolishing head. A new cycle begins with the positioning of the head. 


\subsection{Tests of the system}

Several cold tests have been performed with the system in order to select the optimum parameters. In a simulated pool of $1,400 \mathrm{~mm} \times 1,700 \mathrm{~mm}$ using the $2 \mathrm{~m}^{2}$ electropolishing head, following optimum values were obtained:

- Electrolyte: mixture of sulfuric and phosphoric acid

- Depth: 4m (under water)

- Initial stainless steel roughness: 0'7 to $1^{\prime} 8 \mu \mathrm{m} \mathrm{Ra}$

- Current density: $2 \mathrm{~A} / \mathrm{cm}^{2}$

- Effective electropolishing time: $2 \mathrm{~min}$.

Hot tests will be performed in an experimental research pool reactor JEN-1 belonging to CIEMAT.

\section{VIBRATORY DECONTAMINATION WITH AN ABRASIVE MEDIA}

\subsection{Objective and Scope}

The objective of the research is to develop a technique for the decontamination of nuclear components using vibratory equipment with self-cleaning abrasives, generating a minimum quantity of waste.

The development is aimed at the following goals:

- decontamination of metal and non-metal 1tems;

- decontamination without personnel attendance;

- high decontamination factors with minimum waste generation;

- self-decontamination equipment which lowers the occupational radiation exposure and can be installed as mobile units.

The research seeks for the best abrasives which do not retain contamination but generate a high decontamination factor and a minimum volume of waste. The process does not require operation personnel except for loading and unloading the components.

\subsection{Design and construction of Vibrodecon prototype}

After a detalled study of vibratory equipment avallable, it was decided to design and bulld a prototype vibratory machine with a hollow cylindrical shape, with an excentric motor that provides a uniform vibratory finishing action, with additional helical movement as the parts and medium advance from starting point to a continuous process. Also, a frequency regulator was added to the motor in order to select frequencles between 0 and 3000 vibrations per minute. Best results, so far, were obtained with 1500 vibrations per minute. The prototype includes supplementary equipment to wash, degrease and decontaminate the pleces and abrasives by means of a solvent. The selected solvent system was a closed FREON distillation unit (Figure 2). Th1s system has the following advantages:

- stable, reusable solvent,

- easy to decontaminate by distillation or filtration,

- Inert solvent that does not react chimfcally.

The contaminated sludge is recovered in the distillation still and the filtration unit.

\subsection{Selection of abrasives and testing on inactive samples}

Different types of abrasives have been tested in the vibratory machine, but two main groups of abrasives have been selected:

- abrasives used in blasting machines (granulated metals, sand and microscop1c glass balls);

- abrasives with different sizes, geometrics, and made of materials such as earthenware (ceramic) and aluminium oxide.

The second group of abrasives achieves better results than blasting abrasives. 


\subsection{Tests of the system}

Cold tests were performed using different ceramic abrasives and the results can be observed on Table I. The selected 1tems were painted and the decontamination factor was evaluated as the percentage of paint removed. Also different size 1tems were selected as bolts, plates, nuts, wrench, etc. Hot tests with contaminated 1 tems are now going to be done in the research centre CIEMAT with small samples in order to evaluate the decontamination factor.

\section{CONCLUSIONS}

Electropolishing process 11terally removes layers of atoms from the surface of the object $(0.05 \mathrm{\mu m})$ with resultant removal of contamination and smoothIng the surface $(0.5 \mu \mathrm{m} R \mathrm{a})$.

The decontamination factors reached with underwater electropolishing are those usually obtalned in conventional electropolishing that can be situated between 100 and 1000 DF.

Underwater electropolishing appears to be an approprlate techn1que to decontaminate large surfaces for decommissioning purpose. The additional shielding provided by the water reduces dramatically the doses recelved during operation.

The vibratory decontamination equipment may reach a decontamination factor similar to others experimented abrasive methods (brush abrasion, abrasive blasting etc.), plus the additional decontanination action provided by the solvent media. So, the estimated decontamination factor ranges between 5 and 50 and a minimum quant1ty of waste are generated. Th1s liquid waste is treated and reduced in volume by filtration and evaporation.

Table I. Cold tests with different abrasives.

\begin{tabular}{|c|c|c|c|c|}
\hline Abrasives & $\begin{array}{l}\text { Vibrations } \\
\text { per minute }\end{array}$ & $\begin{array}{l}\text { Time } \\
\text { (min) }\end{array}$ & $\begin{array}{c}\text { Paint removed } \\
\left(7_{0}\right)\end{array}$ & $\begin{array}{l}\text { Samples* } \\
(\operatorname{man})\end{array}$ \\
\hline Ceramic cones ( $5 \mathrm{~mm})$ & 900 & 30 & $80-95$ & \\
\hline Coramic balls $(9 \mathrm{~mm})$ & 900 & 45 & $50-70$ & \\
\hline Threaded ceramic tubes $(50 \mathrm{~mm})$ & 900 & 30 & $90-95$ & \\
\hline Ceramic saddles & 900 & 40 & $50-80$ & \\
\hline Ceramic balls $(12 \mathrm{~mm})$ & 860 & 40 & $60-90$ & \\
\hline Ceramic disks & 900 & 45 & $80-95$ & \\
\hline Ceramic balls $(6 \mathrm{~mm})$ & 900 & 45 & $30-80$ & \\
\hline Ceramic balls $(3 \mathrm{~mm})$ & 580 & 30 & $20-25$ & \\
\hline Mixture of ceramic abrasives & 900 & 45 & $50-70$ & \\
\hline
\end{tabular}

(*) A mixture of different samples were selected: wrench 13-17, wrench 34-36, bolts $M 40 \times 50$, bolts $M 10 \times 40$, bolts $M 30 \times 50$, plate $50 \times 3 \times 6$, plate $100 \times 45 \times 10$, nut M1O, nut $M 20$, etc. 


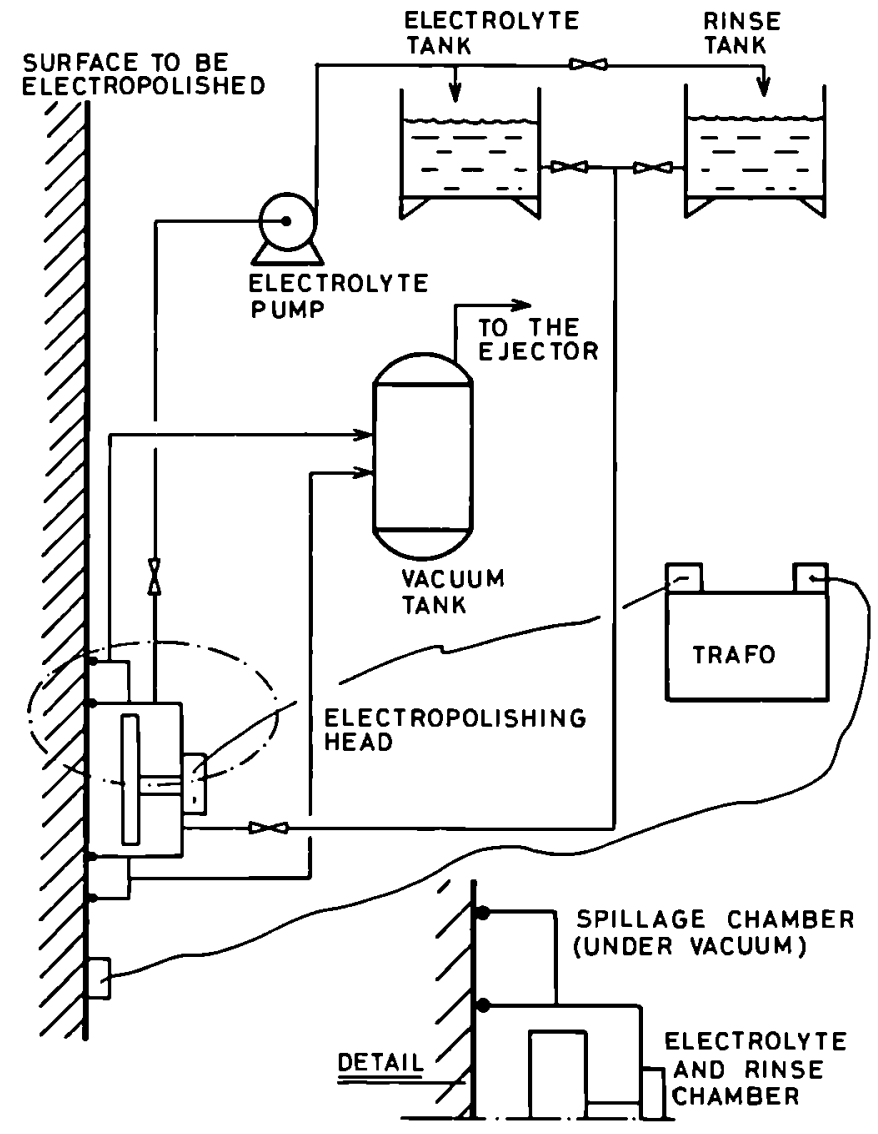

VIBRATORY DECON EOUIPMENT

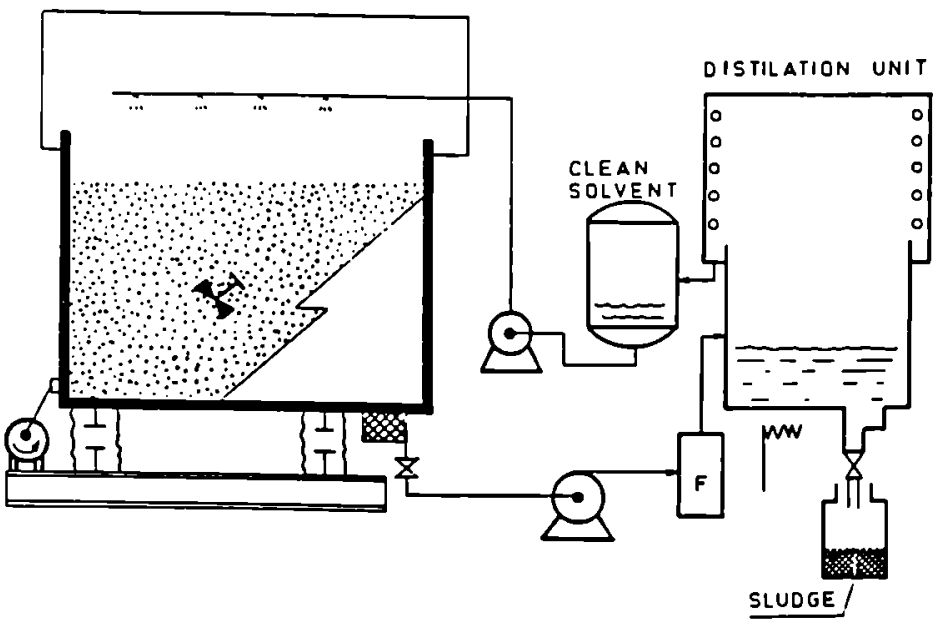

F1g. 1. Basic principle of underwater electropolishing system 


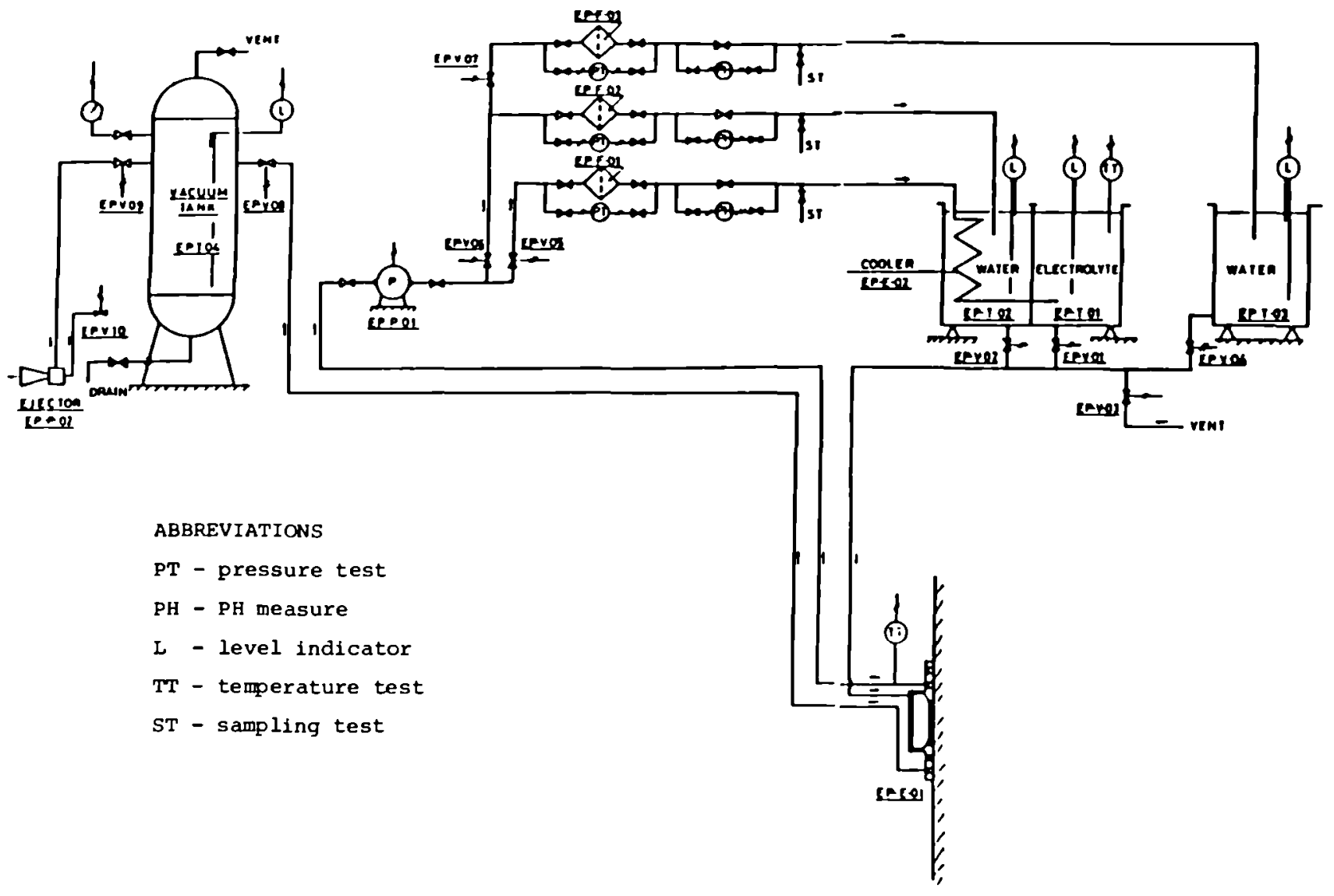

Fig. 3. Submarine electropolishing diagram 


\author{
THERMAL TECHNIQUES FOR SURFACE CONCRETE \\ DECONTAMINATION \\ C. MORILLON \\ Société Bertin \& Cie - Tarnos, France \\ J.F. ROUTIER \\ STMI - Trappes, France \\ G. PILOT \\ CEN Saclay, France
}

\begin{abstract}
When nuclear installations are decommissioned, particular attention should be paid to concrete surfaces which could be contaminated to varying depths. Based on economic considerations, different stripping and non stripping methods could be selected depending on the depth penetration of contamination and on the types of areas. tive :

In this field, thermal techniques seem to be attrac- ability of weakening the material with deep fissuration due to high temperature

- removing concrete by successive thin layers so as to minimize radioactives wastes

- low levels of aerosol emissions.

The aim of this paper is to present developments of two methods :

- a rack-torch unit with a fast cooling system (tested by STMI)

- a plasma augmented burner (tested by BERTIN in collaboration with the CEA Saclay).
\end{abstract}

\title{
1. INTRODUCTION
}

Concrete contamination in nuclear plants is mainly located near to the exposed surfaces to a depth varying from a few millimetres for walls to a few centimetres for floors.

The aim of surface decontamination by superficial layer removing is to reduce personnel exposure and concrete surface activity to a level where unrestricted use of previous controlled area becomes possible. Dismantling operations can then be worked toward an end by treating materials as normal building waste.

In all the cases, radioactive waste volume and aerosol emission should be minimized. Many stripping and non-stripping methods exist as emphasized by $w$. EBELING [1] who gives a review of the available techniques, with particular reference to flame scarfing, and compares the existing methods taking into account the above-mentioned factors and economic aspects.

In this field, this paper concentrates on development of new thermal techniques. 
- a rack torch unit with a fast cooling system investigated by STMI to be developed into an industrial prototype for decontamination of large floor area (horizontal surface)

- a plasma augmented burner adapted by BERTIN to demonstrate feasibility of concrete wall surface decontamination (vertical surface). Some tests were performed with concrete samples impregnated with non-radioactive caesium chloride for contamination simulation. This research was carried out in collaboration with the Comissariat l'Energie Atomique at saclay.

\section{FACILITIES DESIGN}

\subsection{Rack torch unit}

2.1.1. Design and manufacturing of the rack-torch prototype This prototype (see $\mathrm{fig.1}$ ) consists of a burner rack (surfacer) fed by a gas $\left(\mathrm{C}_{3} \mathrm{H}_{4}\right)$ having a high combustion temperature.

It was designed for the following purposes :

- optimization of parameters to remove a concrete layer as thick as possible, without and with liquid nitrogen.

- tests in inactive environment, exclusively. This equipment did not require a particular study, but an adaptation of the equipment designed and manufactured by STMI for tests anterior to this study.

Various thermal surfacers loaned by the company Air Liquide were also tested.

2.1.2. Design of the industrial prototype

The design of the industrial prototype (see fig. 2) inclu-

ded the following components :

- a cover coated with special paint,

- driving wheels,

- pivoting wheels,

- a ventilating device with decanter, filter, and aspirating ventilator,

- a rack for collecting concrete splinters,

- a rotary brush,

- two aspiration pipes,

- a thermal surfacer,

- a cooling rack,

- a protection grid.

\subsection{Plasma augmented burner}

\subsubsection{Facility}

The existing test facility has been adapted for qualifying the electrocombustion technique in inactive environment. It consists of :

- a plasma burner,

- a test cabin, where concrete samples were installed,

- exhaust ducts with measuring points for aerosols emission, Nox levels and temperature of the exhaust gases, 
- a scraping cabin for removing the debris after thermal exposure.

Two main types of plasma were selected for the experiments :

- air plasma

- $\mathrm{C}_{3} \mathrm{H}_{3}$ plasma + air (plasma + combustion).

The gas heating was accomplished by an alternating current arc between three electrodes (fig. 3). The test specimen was positioned downstream of the nozzle exit where the heated gas (plasmajet) impacts its vertical surface.

\subsubsection{Thermal analysis of the process}

Evaluation of heat flux distribution on the concrete surface was carried out by investigation of jet temperature evolution and heat transfer coefficient calculations with the following parameters :

- D : nozzle exit diameter

- $z$ : distance from the nozzle exit to the concrete surface

- heating conditions (gas velocity, gas mass flow, gas temperature, electric power level)

- thermal and mechanical properties of concrete.

A sensitivity analysis showed that higher heat flux conditions could be obtained for $\mathrm{Z} / \mathrm{D} \sim 3$ to 4 ; which is in good agreement with results of K.L. GOIN [2] for such a type of plasmajet. Radial evolutions of the jet temperature are shown in fig. 4 The influence of the jet dilution with surrounding air appeared drastically on these curves determined with the same theoretical models as Popiel [3] and Ricou \& al [4]. Radial heat flux distributions were calculated after evaluating heat transfer coefficients with semi-empirical correlations given by Popiel [3] and Martin [5] : Nu $=f(\operatorname{Re}, \operatorname{Pr}, \mathrm{Z}, \mathrm{D}, \mathrm{T})$ with Nu, Nusselt number; Re, Reynolds number and Pr, Prandtl number.

Heat fluxes of 1.6 to $1.7 \mathrm{MW} / \mathrm{m}^{2}$ (see fig. 5) on a surface with a diameter of $40 \mathrm{~mm}$ can be achieved by impingement of the jet with the main following characteristics :

- electric power : $50 \mathrm{~kW}$ (with alternating $380 \mathrm{~V}$ current)

- plasma gas mass flow : $3 \mathrm{~g} / \mathrm{s}$

- exhaust gas temperature : $4500 \mathrm{~K}$

- gas velocity : 135 - $150 \mathrm{~m} / \mathrm{s}$.

\subsubsection{Concrete samples}

Concrete samples were cylinders with a diameter of $0.16 \mathrm{~m}$ and a length of $0.16 \mathrm{~m}$ and included two different aggregate materials :

- A : standard concrete with rock and sand aggregates (essentially $\mathrm{SiO}_{2}$ and $\mathrm{CaO}$ )

- B : heavy concrete with baryte aggregates.

In order to simulate a radioactive Cs contamination, some samples of concrete $A$ were impregnated with caesium chloride.

3. TESTS ON CONCRETE SURFACE 
3.1. Rack torch unit testing type STMI performed 3 series of tests with the rack torch proto-

\subsubsection{Preliminary tests}

These tests carried out without liquid nitrogen allowed the removal of 1 to $2 \mathrm{~mm}$ of concrete.

\subsubsection{Additional tests}

In order to create higher thermal shocks, a cooling device with liquid nitrogen was set up on a new equipment loaned by Air Liquide Company. Nevertheless, experimental results were not satisfying :

- an average of $2 \mathrm{~mm}$ of concrete were removed

- no actual effect was observed by adding liquid nitrogen

- this new equipment was not more efficient than the one used for the preliminary tests

- after removal of concrete, the surface was very rough and glass-like surfaces (from molten concrete) occurred in some places.

\subsubsection{Optimization tests}

During this optimization campaign, many more tests than planned were performed, in order to find a way to remove a layer of concrete corresponding to the depth into which contamination can penetrate $(5 \mathrm{~cm})$. The tests showed that the use of a thermal surfacer to decontaminate concrete surfaces is not satisfactory, for the following reasons :

- the average removed layer is only $2 \mathrm{~mm}$ thick, while contamination could penetrate as deep as $5 \mathrm{~cm}$,

- the surface obtained by thermal surfacing is very irregular, which makes necessary the use of a mechanical process (appropriate rotary brushes) to remove all the particles of fractured or molted concrete that came off the surface before a new passage of the thermal surfacer :

- the use of liquid nitrogen in order to cool down rapidly the concrete surface and intensify the thermal shock, does not substantially improve the process. The cooling with liquid nitrogen hardly increases $(7$ t) the temperature difference causing the thermal shock :

- after a first fracturation, additional passages do not produce further fracturation and too many of them can glaze the surface.

\subsection{Thermal stripping with the plasma generator}

\subsubsection{Experimental results}

In all the experiments performed with the plasma burner, no molten phase occurred and after a thermal exposure of $30 \mathrm{~s}$, an erosion depth of 3 to $5 \mathrm{~mm}$ could be obtained with large and deep cracks under the surface in the concrete bulk. These brittle parts could be removed easily by mechanical scraping. 
With an exposure time larger than $30 \mathrm{~s}$, the erosion depth is more important but not proportionally greater.

Figure 6 shows the erosion depth measurements as a function of the thermal exposure time for different experiments. The obtained results, although dispersed, are in agreement with those given by H. Sutherland [6] and J. Muir [7], as presented on Figure 6 .

The superficial spalling of concrete, which may be the cause of the dispersion of results, can be explained as follows : the shallow aggregate particles are exposed to important thermal shocks due to the strong energy supply and react by changing the intercrystalline structure.

During heating, the concrete is losing small chips from its surface by following combined actions :

- inter-crystalline forces due to the effect of temperature and high thermal flux

- thermo-mechanical stresses induced by temperature gradients

- dehydration and decarbonation on the surface and in the bulk of material, which set free gases $\left(\mathrm{H}_{2} \mathrm{O}\right.$ and $\left.\mathrm{CO}_{2}\right)$, thus reducing adhesion and material strength.

The degraded concrete particles are removed from the vertical surface and fall into the containment without having reached the fusion point.

\subsubsection{Aerosol emission}

The results of the experimental measurements are reported in table 1. During thermal stripping, aerosol mass represents on an average 0,25 of the total mass removed with a mean mass aerodynamic diameter (MMAD) of about $1 \mu \mathrm{m}$.

For the consecutive mechanical scraping, the ratio is on an average 0,7 with a MMAD of about $7 \mu \mathrm{m}$ and for a mechanical scraping without thermal stripping, the ratio is around $1,3 \%$ with a MMAD of $9 \mu \mathrm{m}$.

\subsubsection{Simulation of caesium concentration}

Caesium, being a rather volatile product, thermal stripping induces an enrichment of this element in the aerosols (by a factor 20 to 30 ) and with a size distribution different from that of the total mass (MMAD $=0,4 \mu \mathrm{m}$ instead of $1,45 \mu \mathrm{m}$ for these tests). The caesium is thus mainly concentrated in submicronic particles.

The concrete samples are decontaminated on the part faced to the plasma jet but also on the peripheral parts as can be noticed on figure 7 (comparisons between profiles with thermal stripping + mechanical scraping and mechanical scraping only).

\section{Conclusive assessment}

Comparison of the two thermal techniques tested taking into account the exposed surface position (horizontal and vertical) shows that a deep erosion and damage by stripping could be obtained only with high heat fluxes $\left(1,5\right.$ to $\left.2 \mathrm{MW} / \mathrm{m}^{2}\right)$ and high temperatures to balance the fact that concrete is a poor heat conductor (Thermal conductivity of about $1 \mathrm{~W} / \mathrm{mK}$ ). 
The rack torch unit does not appear to be a suitable tool for achleving high flux levels. On the other hand, the plasma generator seems to be a more promising technique due to a good thermal efflciency of the high-temperature high-velocity jet.

Nevertheless, in order to characterize more completely the technique, the following step of development should be the design and construction of a pilot unit with a thermal plasma to be tested under more representative conditions : larger samples simulating walls and also floors, with continuous sweeping. A close cooperation will be planned between Bertin and STMI in order to get benefit from all expertise to go on with this development.

\section{REFERENCES}

[1] W. EBELING, B. BOEDEKER, K. ROSE and R.H. SCHALLER

- Decontamination of concrete, with particular reference to flame scarfing.

Proc. of Eur. Conf. Luxembourg 22 - 24 May 1984 - $161-176$

[2] K.L. GOIN

- 2 MW plasmajet facility thermal tests of concrete. SAND 77-0952 (1977)

[3] POPIEL, VAN DER MEER, HOOGENDOORN.

- Convective heat transfer on a plate in an impinging round hot gas jet of low Reynolds number.

Int. J. Heat Mass Transfer - 22, 1055 (1980)

[4] F.P. RICOU \& D.B. SPALDING

- Measurements of entrainment by axisymetrical turbulent jets.

J. Fluid Mech., 11, 21-32 (1961)

[5] H. MARTIN

- Heat and mass transfer between impinging gas jets and solid surfaces.

Adv. Heat Transfer 13, 1 (1977)

[6] H. SUTHERLAND, L. KENT

- Erosion rate measurements using an acoustic technique Rev. Sci. Instrum. 48, 1010 (1977)

[7] J. MUIR

- Response of concrete exposed to a high heat flux on one surface

SAND 77 - 1467, Sandia National Laboratorles. 
Table 1 - Aerosols emissions - Thermal (T) stripping by Plasma augmented burner with mechanical (M) scraping

\begin{tabular}{|c|c|c|c|c|c|c|c|c|c|}
\hline Seoples roformcen & \multicolumn{2}{|c|}{$\begin{array}{c}\text { Concontration } \\
m_{8 / m} / m^{3}\end{array}$} & \multicolumn{2}{|c|}{$\begin{array}{l}\text { Slas mase } \\
\text { Mase of reooved concrete } \\
\text { in } x\end{array}$} & \multicolumn{2}{|c|}{$\begin{array}{l}\text { Aerosol mass } \\
\text { Mass of removed concrete } \\
\text { In } x\end{array}$} & \multicolumn{2}{|c|}{$\begin{array}{l}\text { Moan eorodynamio } \\
\text { di emotor in } \mu \text { m }\end{array}$} & \\
\hline $\begin{array}{l}A 372-10 \\
A 376-11 \\
A 370-12 \\
A 371-24 \\
A 374-25 \\
A 378-26\end{array}$ & $\begin{array}{l}13,8 \\
35 \\
28 \\
16 \\
6 \\
38\end{array}$ & $\begin{array}{l}584 \\
686 \\
268 \\
212 \\
337 \\
308\end{array}$ & $\begin{array}{c}17,6 \\
8,36 \\
21,3 \\
35,6 \\
9,0 \\
11,2\end{array}$ & $\begin{array}{l}100 \\
81,6 \\
85,6 \\
98,1 \\
94,7 \\
85,3\end{array}$ & $\begin{array}{l}0,13 \\
0,56 \\
0,28 \\
0,07 \\
0,03 \\
0,32\end{array}$ & $\begin{array}{l}0,41 \\
0,56 \\
0,70 \\
0,45 \\
0,88 \\
0,62\end{array}$ & $\begin{array}{l}1 \\
1,38 \\
0,64\end{array}$ & $\begin{array}{l}12,1 \\
9,8 \\
4,6 \\
7,2\end{array}$ & Concret॰ A \\
\hline $\begin{array}{l}A 411-13 \\
A 420-14 \\
A 421-31 \\
A 416-32\end{array}$ & $\begin{array}{l}38 \\
26 \\
48 \\
28\end{array}$ & $\begin{array}{l}307 \\
722 \\
804 \\
581\end{array}$ & $\begin{array}{c}28,3 \\
30,4 \\
40,4 \\
7,73\end{array}$ & $\begin{array}{l}94,4 \\
94,5 \\
97 \\
92,4\end{array}$ & $\begin{array}{l}0,46 \\
0,28 \\
0,48 \\
0,28\end{array}$ & $\begin{array}{l}0,52 \\
0,84 \\
0,62 \\
0,44\end{array}$ & $\begin{array}{l}0,86 \\
0,47\end{array}$ & $\begin{array}{r}8,8 \\
8,1 \\
10,1 \\
-\end{array}$ & Conerote B \\
\hline $\begin{array}{l}\text { D28TM - } 33 \\
\text { DOTM - } 34\end{array}$ & $\begin{array}{l}39 \\
47\end{array}$ & $\begin{array}{l}323 \\
286\end{array}$ & $\begin{array}{l}15,8 \\
50\end{array}$ & $\begin{array}{l}98,2 \\
83,8\end{array}$ & $\begin{array}{l}0,15 \\
0,09\end{array}$ & $\begin{array}{l}1,05 \\
1,16\end{array}$ & 1,45 & $\begin{array}{l}7,7 \\
2,1\end{array}$ & $\begin{array}{l}\text { Conerete A } \\
\text { improgneted } \\
\text { with cecl }\end{array}$ \\
\hline
\end{tabular}



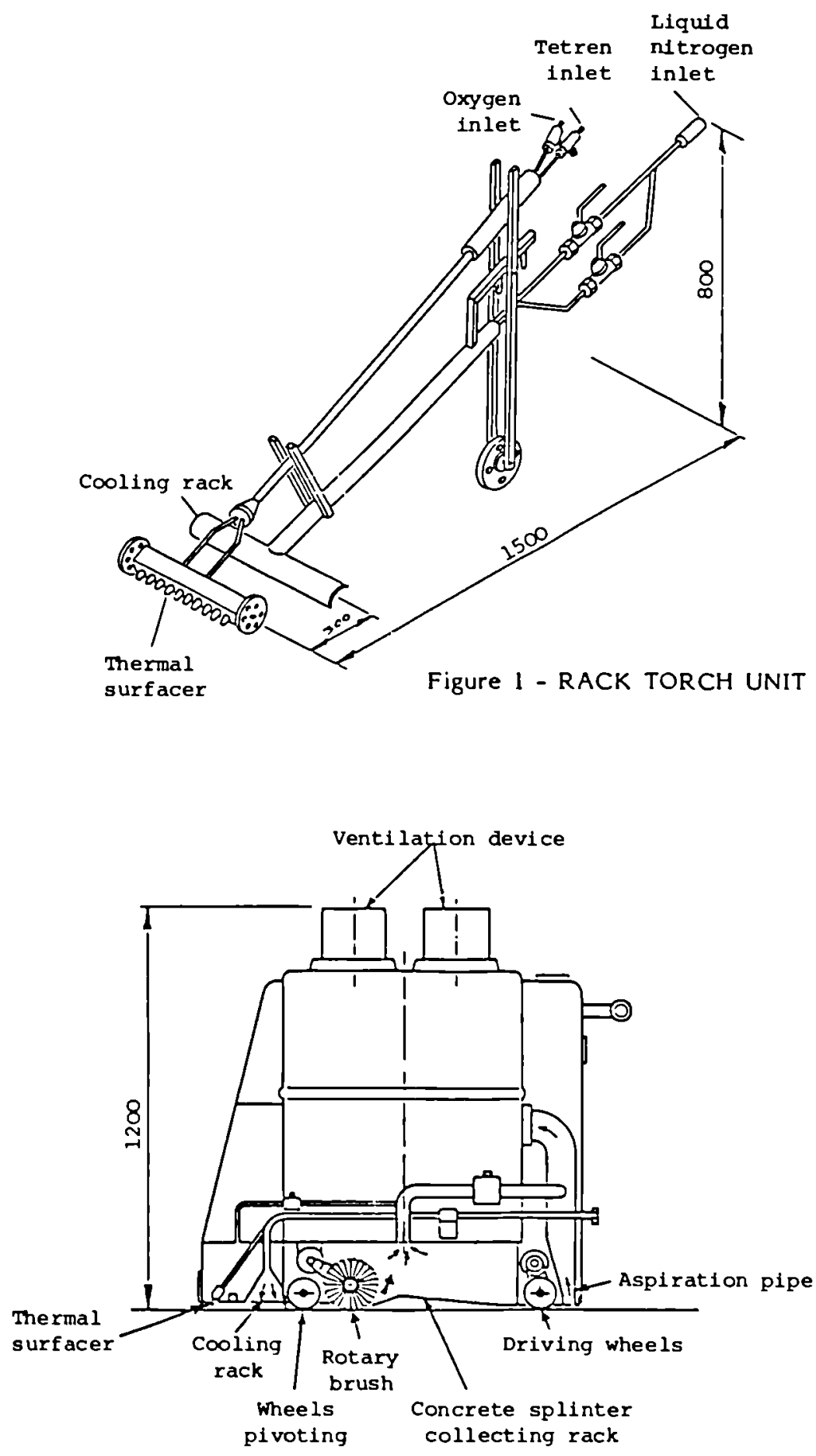

Figure 2 : INDUSTRIAL PROTOTYPE (PROJECT) 


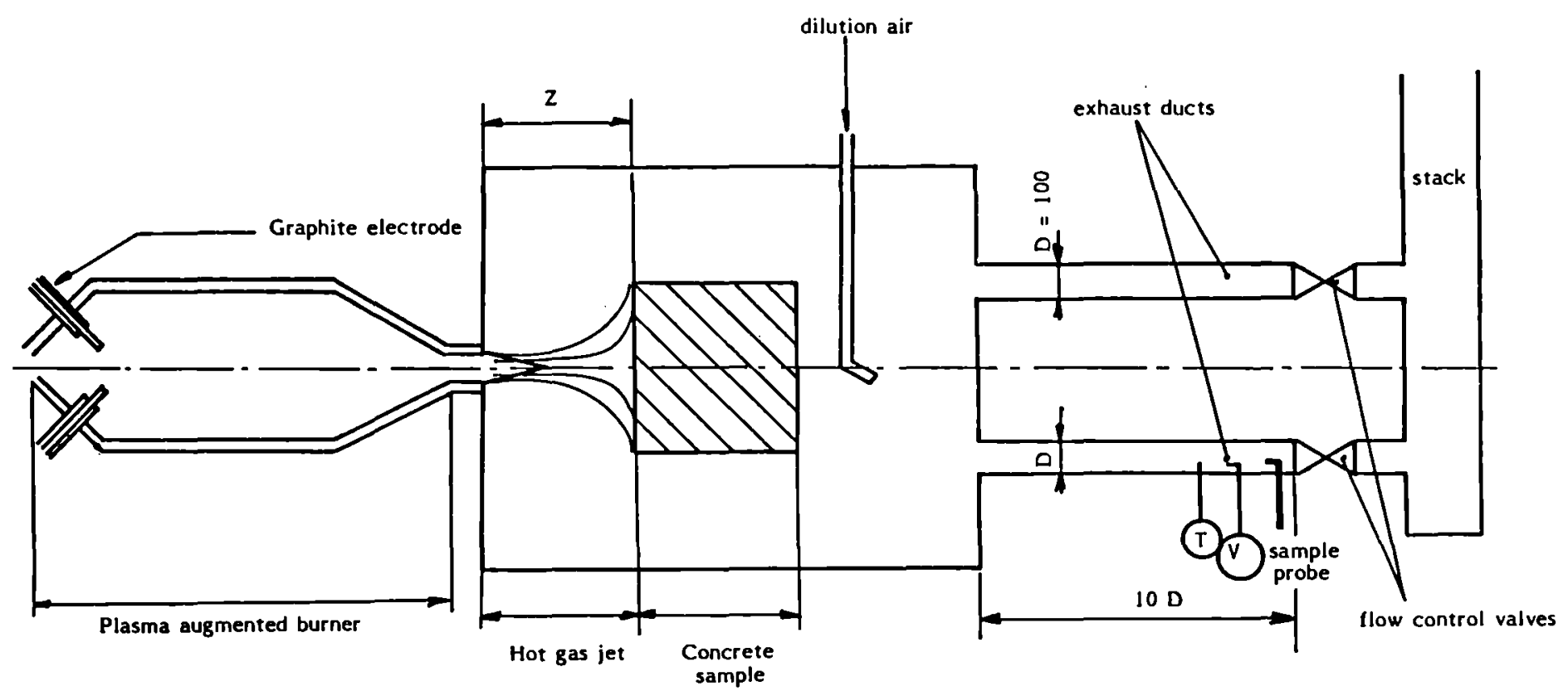

Figure 3 - PLASMA AUGMENTED BURNER Schematic diagram of the test facility 


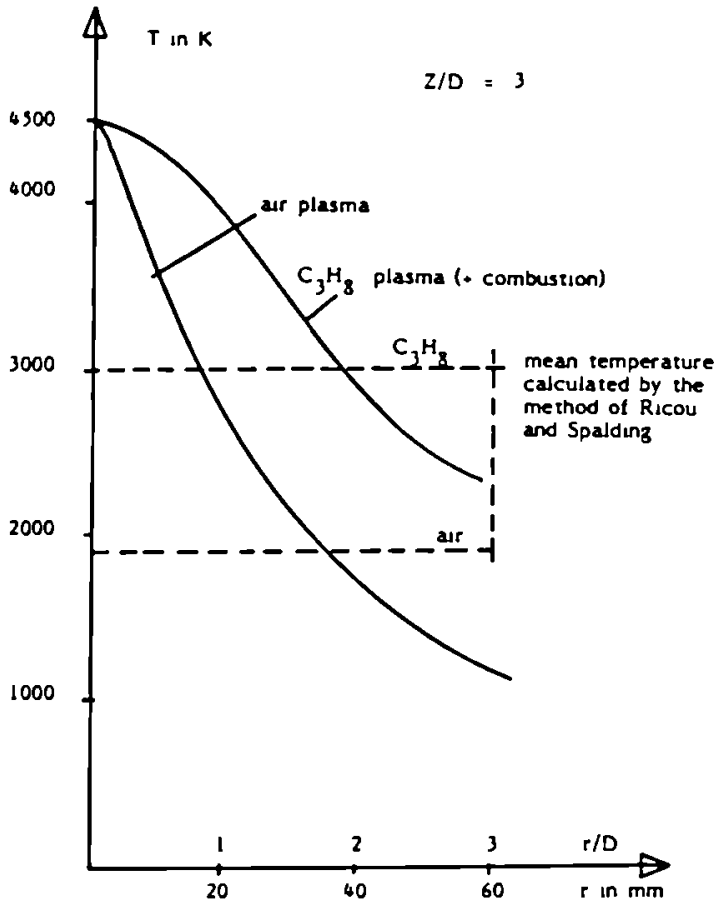

Figure 4 - RADIAL EVOLUTION OF THE PLASMA JET TEMPERATURE

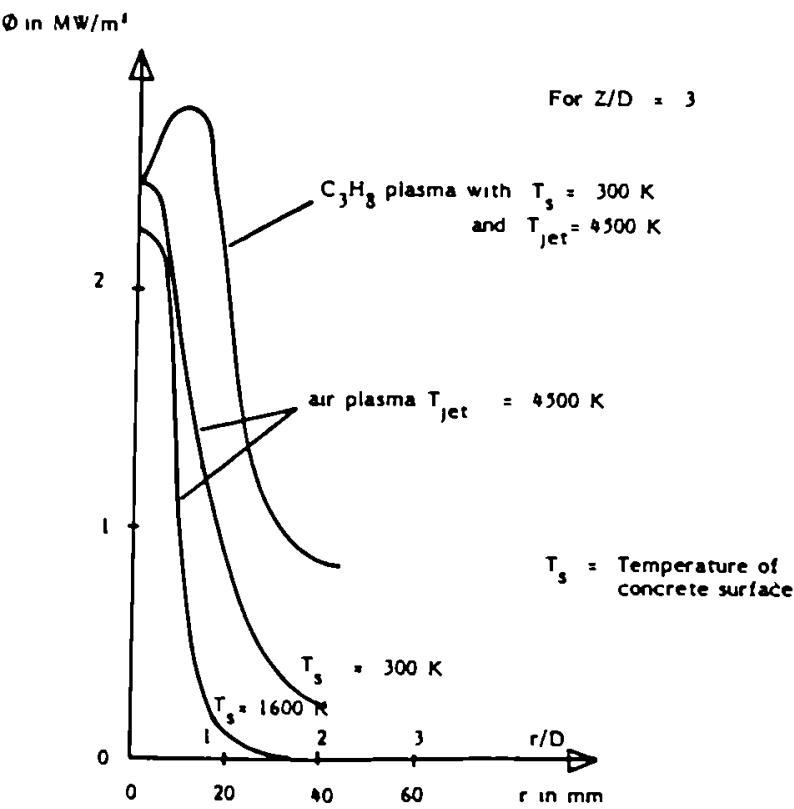

Figure 5 - RADIAL EVOLUTION OF THE HEAT FLUX 
From ref. (6), (7) (1) $2.8 \mathrm{~mW} / \mathrm{m}^{2}$ fine basalt aggregate

(2) $1.2 \mathrm{MW} / \mathrm{m}^{2}$ coarse basalt aggregate

(3) $1.04 \mathrm{MH} / \mathrm{m}^{2}$ basalt

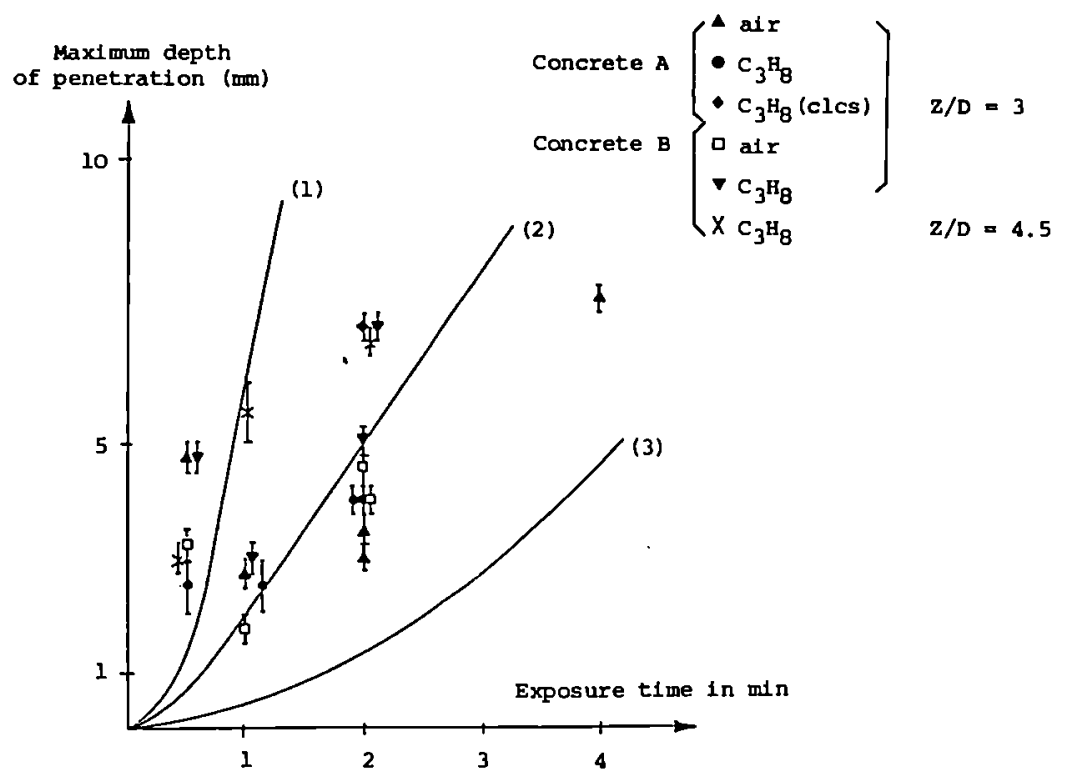

Figure 6 : RESULTS OF CONCRETE-PLASMA TESTS

(Maximum heat flux $1.6-1.7 \mathrm{MW} / \mathrm{m}^{2}$ )

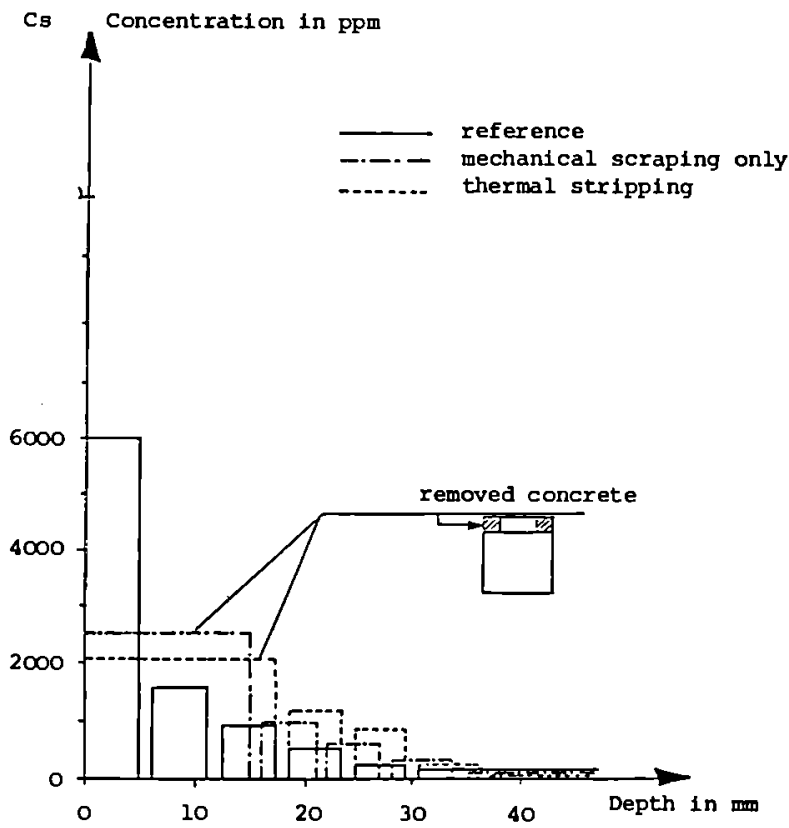

Figure 7 : Cs CONCENTRATION PROFILES

CONCRETE A IMPREGNATED AFTER 28 DAYS 


\title{
SOME REMARKS ABOUT DECONTAMINATION
}

\author{
A. BERTINI \\ ENEL, Roma, Italy
}

\begin{abstract}
Decontamination in itseff is not the elimination of a problem, but corresponds to move that problem from one place to another. It is beneficial only if the contamination is less of a nulsance when moved to the "other place". Therefore any prospective decontamination process is to be considered essentially in terms of cost-benefit, and in particular in terms of reducing the burden on the waste management systems. The paper is not intended to deal with and to review critically the technical aspects of the various decontamination processes which are currently available. Its aim is to call the attention of those who may be faced with the problem of large-scale decontamination, so that this operation is carried out after all practical aspects have been examined.
\end{abstract}

These few words of mine are not intended to be what may be called a "technical paper". Technical aspects of decontamination, advantages and disadvantages of individual decontamination processes, suitability of these processes to solve particular instances or decommissioning problems have been extensively covered by the reports already presented during this Conference and by the work performed by the Contractors in the frame of the Decommissioning Programme of the CEC. These few words are intended to be only a practical comment by a "lay" person, who has some practical experience with the operation of nuclear facilities and is now confronted with practical problems of real decommissioning of nuclear power plants.

As you know, and as you may easily realize, decommissioning of a nuclear facility may be compared to a large - or small - mosaic, made of a certain number of coloured stones. Each stone is represented by a particular operation or activity, known in its merits to the technical world and to be selected among many other stones. While the mosaic consists of not more than, say, a hundred stones, one thousand of these are available, and the artist must select the ones which are necessary, or helpful, to complete his work. The work, of course, may be eventually found to be either a masterpiece admired through the centuries like those of Ravenna, or a 
minor, even ugly-looking contraption. It is the hand, the eye, the experience of the artist which build up the work by putting the best stone at the right place.

Decontamination concepts and the various decontamination processes which are available on the market are some of the "stones" among which the decommissioning engineer may make his choice. And, to this purpose, a few practical comments may be helpful to the aim of answering the basic questions: whether, when and how decontamination is to be performed.

First of all, a statement which could well have rejoiced Monseigneur de la Palice: decontamination is not the elimination of a problem, it is only a modification of its aspects. Decontamination is not the elimination of radioactivity; it means only to move it from point $A$ to point $B$ or to change the physical-chemical properties of radioactive substances from form $A$ to form $B$. If there was one curie of Caesium 137 before decontamination, one curie remains afterwards; it has been only moved somewhere else or changed into another physical or chemical form.

Then, why is decontamination performed? It is performed if that one curie of Caesium 137, after been moved to point $B$ or changed to the form $B$, represents a smaller operational embarrassment, or a substantial help in solving other problems which are necessarily to be solved. Decontamination is not an objective in itself, and therefore it must be considered in the light of other problems.

Some examples may clarify this argument, even if only partially applicable to decommissioning questions:

a) - a facility, or a system, or a component is to be re-used for other purposes, which require it to be "free" from contamination (let us not enter now into the problem of the definition of "free" or "de minimis" levels);

b) - a system or a component is to be worked on for inspection, maintenance or modification, and it is so contaminated that the radiation levels in the work areas are above acceptable values with reference to the established regulations or to the ALARA principle; c) - a facility, or system, or component is to be dismantled and the wastes arising from such proceedings shall be collected, conditioned and disposed of in a safe - and economical - way according to national practices and regulations and consistently with an operational national waste management system. 
In the first case, complete decontamination is assumed as the main goal, and the problem is a question first of feasibility (is it possible to obtain the required level of decontamination?) and second of cost (is it less expensive, as a whole, to decontaminate, or to dismantle everything and use new components?).

In the second case, the objective is only to obtain a reduction of the contamination without damaging the components to be decontaminated. Here the problem is to weigh the overall decontamination costs, including the management of the secondary wastes, against the costs of the provisions necessary for a safe work in radiation areas, such as reduced individual working hours, shields, remote operation, telemanipulation.

The third case is common to any decommissioning strategy for nuclear facilities, although in particular instances also cases like the first and the second one may arise. We shall therefore deal a bit longer with the factors influencing the decision whether to decontaminate or not to decontaminate, and, if the decision is affirmative, by which of the several available processes.

Let us assume that the facility to be dismantled is a rather large one. Although, in a strict sense, the problems are the same both for a large and for a small facility, it is obvious that, if the quantity of scrap material for which the decontamination question arises is small, the general consequences of an incorrect optimization are also small. In addition, the time and the costs "per unit mass or surface" can be accepted even if high, because in any case the "overall" costs will be limited. One thing is to handle a few tons of scrap material, another is to handle several thousand tons, where the dismantling activities by themselves may even create a significant issue in the radiation protection of the site personnel and of the general public.

But let us go back to the main question, the decontamination of large quantities of scrap material arising from the dismantling of a large nuclear facility.

We have already mentioned the two cases where decontamination is necessary or highly recommended, that is, re-use of components and reduction of radiation levels in work areas; both cases may also be applicable to dismantling operations. However, very high radiation levels during dismantling are generally due to activated materials, for which decontamination does not enter into question.

Here, in deciding about dismantling options, it may be found that, due to the presence of contamination, the radiation in the (dismantling) work areas, even if small in absolute, will result in a total collective dose which would not be justifiable against optimization or ALARA principles. Decontamination prior to dismantling may be helpful, but often impractical, 
or too expensive, or even materially impossible. Let us consider, as an example, the dismantlement of a large steam generator in a gas-cooled reactor plant. Even if the radiation levels - due to contamination only - are low (and in fact, during the operating life of the reactor, no difficulties were encountered for normal short work like the periodic internal inspection), if dismantlement is to be carried out, a large quantity of working hours inside the generator shell is required, and the total collective dose may be unacceptable. Filling the generator shell (gas side) with decontaminating liquids may be impracticable because of their mass, and even impossible because of their weight; other methods, for instance by spraying liquids or vapours, may introduce other practical difficulties and costs. Therefore, consideration should be given to deferring dismantlement, if a careful analysis of the composition of the contaminants leads to the conclusion that a reasonable decay period will enable radiation levels to decrease to an acceptable level. Of course this is only an example, just to indicate that many considerations can substantially influence a decision about decontamination.

In other cases, however, pre-dismantlement system decontamination "in situ" may be practicable, not too expensive, and not leading to difficulties in handling the secondary wastes.

We may now go further, and assume that no decontamination is required before dismantling, or that a pre-decontamination, of course partial, has been performed. The decommissioning programme will then proceed to the "dismantlement" stage. Which is the next step? A system, or a large component, will be thereby reduced to scrap. This scrap material will consist of more or less contaminated pieces (activated parts are not of interest in this context). A good survey prior to deciding the decommissioning strategy, and a good working method with reliable quality assurance provisions will enable the resulting scrap to be classified according to nature of materials, contamination levels, mass-to-surface ratio.

But now the planning organization is confronted with a decision about decontaminating or not the various classes of scrap material. At this point, it is important to know the boundary conditions established by the national regulations and by the national waste management system and its practices. information:

In particular, these are examples of the required basic

- is there an established regulatory "exemption", "recycling", or "free release" limit, in terms of maximum activity per unit mass or surface? 
- which are the regulatory requirements or the industrial standards for the packages to be sent to an intermediate storage or to a final repository?

- which are the costs per unit volume of the transport and of the storage - intermediate and/or final - of the packages? in other words, is volume at a premium or not, and which is the premium?

Obviously, the costs of decontaminating and conditioning. including volume reduction, of a given quantity of given material can be obtained from the current prices for the various processes available on the market, but the decision must be taken by weighing these costs against those arising from the basic information which has been mentioned above.

Decontamination comes only into question if in terms of costs safety can always be taken care of - such a process is an operational help and leads to savings in the overall waste management costs.

It is my opinion that, for the large majority of the cases, decontamination in order to recycle the materials is not in itself of economic interest, because the income from the sale of the scrap thus made "recyclable" is far from compensating the cost of decontamination. However, recycling may render the disposal costs for this scrap unnecessary and may reduce the required size of the storage facilities, and this is a positive advantage both for the owner of the decommissioned plant and for the national community.

We may consider that the contaminated scrap can be divided into three categories, according to national regulations and practices. Therefore, we shall not indicate figures, because they may vary from country to country; however, the concept is always valid.

1) - Regulations may set an upper limit to the radioactivity which can be contained in a single package sent to the repository or to the intermediate storage. This is in practice a limit "per unit volume of the package" independent from any other limit "per unit mass or surface of the contaminated scrap" to be disposed of. The contamination of the scrap may be so high that the volume and weight of a standard package cannot be fully utilized, and consequently the transport and disposal costs for a given weight of contaminated scrap will be higher.

2) - The contamination may be lower than in the previous case, and the volume and weight of a standard package can be fully utilized. However, the contamination is still above the "free release" limit, and 
therefore the costs for conditioning, transport and disposal shall still be met.

3) - The contamination is below the "free release" limit, and therefore the costs for conditioning, for "nuclear" transport and for disposal can be avoided.

In general, and of course only in general, in absence of other constraints, decontamination is useful and should be considered only if it allows substantial fractions of the subject material to pass from the above category 1) to category 2) or from category 2) to category 3). Otherwise it is unlikely that decontamination may bring practical advantages; on the contrary, it may even bring disadvantages in the management of the wastes arising from dismantlement.

Let us suppose, for instance, that the exemption limit for recycling the material is $0,4 \mathrm{~Bq} / \mathrm{cm}^{2}$ beta-gamma. Let us also suppose that we have a significant quantity of scrap steel with a surface contamination level of $30 \mathrm{~Bq} / \mathrm{cm}^{2}$. This case belongs clearly to the above category 2) and therefore the material as such should be conditioned, packaged and sent to a storage or to a disposal facility.

If we can decontaminate it till under $0,4 \mathrm{~Bq} / \mathrm{cm}^{2}$, then the scrap is free and can be recycled. But if we decontaminate it only partially, say, down to $10 \mathrm{~Bq} / \mathrm{cm}^{2}$, what shall we have? We shall have the same quantity of scrap steel, still to be conditioned, packaged and disposed of because it still belongs to category 2), plus the secondary wastes arising from the decontamination process, which are also to be conditioned, packaged and disposed of. We are, in the end, in a worse condition than before.

In my opinion, this is one of the main points to be considered, in order both to avoid making a fetish of the decontamination and to give a correct answer to the question: "What is decontamination good for?"

Of course there may be a number of other solutions which help to reduce the volume of the material to be treated as radioactive waste. There is the melting option, whereby materials, which cannot be released nor recycled on grounds of surface contamination, may become free with respect to both surface and mass activity limits. We all know that, in order to evaluate the actual advantages of the melting process in terms of burden on the waste management system, also the volume of the secondary wastes arising from this process (slag, filter cartridges etc.) shall be assessed.

And we also know that somebody objects that this is a "dilution" process, by which we may recycle a quantity of becquerels larger than it would be without melting, because the original scrap was not recyclable. It could also be answered that also the volume of materials conditioned, 
packaged, stored and disposed of as radioactive is a burden to the community, and that the ALARA principle considers also economical and social factors. But this is not the proper place for such a discussion.

My purpose was only to give indications and to call the attention to some general aspects of the question of decontamination in itself, and not to go further and deeper into the problem. 


\section{DISCUSSION}

Question: F G MANTEGA, CISE - Starting from $10000 \mathrm{~Bq} / \mathrm{cm}^{2}$ of magnetitespinel oxide on a $42 \mathrm{~mm}$ ID tube we obtained $0.1-0.3 \mathrm{~Bq} / \mathrm{cm}^{2}$ dissolving not more than $3 \mu \mathrm{m}$ of base material. The required base material dissolution of $90 \mathrm{\mu m}$ seems to us to be excessive. Was the problem of recontamination solved?

Answer: W AHLFANGER, KW Emsland - The depth of penetration was approximately $45 \mathrm{\mu m}$. Approximately $37 \mu \mathrm{m}$ were removed. Corrosion product activity is deposited up to approximately $40 \mathrm{~Bq} / \mathrm{mg}$.

Question: P De REGGE, SCK/CEN Mol - How do you take account of subsequent processing of the liquid waste that you produce when decontaminating the installations you described?

Answer: G BRUNEL, CEA-Cadarache - The subsequent processing of effluents and the conditioning of solid waste has always to be taken into account. Decontamination has to be adapted to make allowance for the specific constraints of each operation. In certain cases we reduced the efficiency of the decontamination in order to avoid the production of effluents which are difficult to process.

Question: P De REGGE, SCK/CEN Mol - What was the residual surface contamination in the Rapsodie circuits that you decontaminated, and what were the isotopes present?

Answer: $G$ BRUNEL and $J$ R COSTES, CEA-Cadarache - The main radio-element in the contamination of the circuits was caesium. Residual activities were mainly due to cobalt-60 contained in the base material, ie 1.7 to $12 \mathrm{~Bq} / \mathrm{g}$ (4 to $6 \mathrm{~Bq} / \mathrm{g} \mathrm{Co-60}$ and some $\mathrm{Mn}-50$ and $\mathrm{Cs}-137$ ).

Question: A HUSAIN, Ontario Hydro - What was the material of the gels?

Answer: G BRUNEL, CEA-Cadarache - The gels are supports that carry the actual decontaminant. In this case the gel was composed of silica-based products in which the grain size partly determined the setting time and, consequently, the action time. It is thus possible to adjust the erosion and, thereby, the resulting decontamination.

Question: A HUSAIN, Ontario Hydro -

1. Did you apply ultrasounds in the decontamination of the valves?

2. Have you attempted the regeneration of the acids?

Answer: $F$ BREGANI, ENEL -

1. We have used ultrasounds in water for the pretreatment of the valves (a common practice) and ultrasounds in aggressive chemicals for decontaminating valves. Results were not good for not easily accessible areas.

2. We did not work on the regeneration of acids because we use acids of relatively low concentration (about 58 vol) and the quantity of the final secondary waste was small.

Question: M LARAIA, ENEA - Can the decontamination methods that you have tried, replace on a large scale the more traditional methods, for example, 
those involving chemical solutions? Or can your methods only be us particular applications?

Answer: G BRUNEL, CEA-Cadarache - The spraying of gels is a metho particularly suited to the decontamination of large surfaces or for decontamination purposes where major, non-controlled erosion is to be avolded. The method is similar to the industrial-scale spraying of paint, and the setting time of the gel determines the duration of the operation. clearly, this method cannot be considered as universally applicable.

Question: R ENGELFRIED, University of Dortmund - What happens to the radioactively contaminated off-gases when polymer-coated concrete surfaces are removed with the plasma arc and the coatings burnt off? Are the off-gases then also radioactively contaminated?

Answer: C MORILLON, Bertin - The process gases are collected and conveyed with the aerosols towards the filter system (electrostatic pre-filter followed by HEPA filters) after their contact with the concrete surface. Polymers should not pose any problem but it would be useful to know their chemical composition in order to ascertain whether there is a risk of formation of toxic gases during the thermal attack by the plasma arc.

Question: M LARAIA, ENEA - Can the methods you tried (in particular the plasma torch, which appears to be the most promising) largely replace the more conventional mechanical abrasion method, or will they remain restricted to particular cases? If so, which?

Answer: C MORRILLON, Bertin - The plasma torch has been developed with a view to decontaminating large concrete surfaces. The treatment of individual items or inaccessible areas (under pipes, for example) needs the development of a special plasma tool. The plasma method should find a broader application than mechanical methods. Further R\&D work can certainly improve the plasma technique.

Comment: J R COSTES, CEA-Valrho - we are developing new decontamination methods. Decontamination costs will therefore rapidly fall whereas the costs of storage will very probably rise. Decontamination concentrates the contaminant non-destructively and allows it to be safely conditioned.

Answer: A BERTINI, ENEL - I did not say that decontamination was unnecessary and should be abandoned. I would like to thank all those who have contributed to its progress. However, all aspects of the general problem should be considered before any planned dismantling operation is started.

\section{CONCLUSION}

Following the presentations, some of the questions I posed at the beginning of the session have been answered. What is decontamination good for? Where to decontaminate? To what extent?

The first presentation (Ahlfänger, Lingen) gave evidence that unrestricted release of long pipes and maybe of entire systems is achievable only by chemical decontamination. The second paper (Bregani, ENEL) highlighted the difficulty of achieving unrestricted release of complex-geometry components, eg valves. For these components chemical decontamination alone may be not enough; however, a combination with other techniques such as melting, could achieve the objective. 
The third paper (Costes, CEA) demonstrated a possibility to reach unrestricted release conditions also in special applications, as in the case of chemical decontamination of sodium-cooled reactors.

The next paper (Wakefield, UKAEA) illustrated how difficult it is to push in situ decontamination to the greatest efficiency in the case of big, complex-geometry components, like the steam generators of gas reactors. In particular, this paper showed the operational difficulties which arise under such circumstances.

The paper by Mr Brunel (CEA) described a few promising techniques, such as chemical gels and abrasives, and that of Mr Turner (UKAEA) illustrated the advantages of two novel electrolytical systems aimed at minimising the volumes of secondary radioactive wastes and achieving unrestricted release.

The presentation by Mr Benavides (Equipos Nucleares) showed electropolishing systems to decontaminate underwater surfaces, as well as decontamination systems using vibratory finishing. The next paper, by Mr Morillon (Bertin), illustrated thermal techniques for decontamination of concrete surfaces. The plasma technique appears more promising than the combustion torch, since a high temperature, high velocity jet can be obtained.

The last, but not least, paper (Bertini, ENEL) had the merit of drawing attention to a simple, but sometimes forgotten, fact: each decontamination case is a special case.

M LARAIA, ENEA 


\title{
SESSION XI
}

\section{VENTILATION AND FILTRATION TECHNIQUES} FOR DECOMMISSIONING PURPOSES

\author{
CHAIRMAN: J WILLIAMS, UKAEA, UK \\ SECRETARY: E SKUPINSKI, CEC
}





\title{
VENTILATION AND PILTRATION TBCHNIQUES POR HANDLING AEROSOLS PRODUCED BY THERMAL CUTTING OPERATIONS
}

\author{
BISHOP A. \\ United Kingdom Atomic Energy Authority \\ Northern Research Laboratories - Windscale
}

\section{ABSTRACT}

The decomissioning of nuclear installations using thermal cutting techniques in air has been shown to generate considerable amounts of aerosol that shorten the working life of filters in a ventilation system. A programe of work was initiated to characterise the aerosols from different thermal cutting operations. Suitable ventilation and filtration systems were developed and assessed in an inactive environment for use in a radioactive, semi remote decommissioning operation. The results of the work programme are reported.

\section{INTRODUCTION}

When decommissioning a radioactive facility different materials and composites have to be cut up. In the Windscale Advanced Gas-cooled Reactor (WAGR) Decommissioning Profect thermal processes will be used wherever possible to cut the materials. The main process is oxypropane cutting. An iron/aluminium powder injection system is used to increase the flame temperature to speed up penetration and to enable refractory material to be cut. The main disadvantage of the oxypropane flame cutting process (and other thermal processes) is the large amount of aerosols and dust produced. This is offset by the flexibility of the cutting process and the small reaction force on the tool manipulator.

To minimise absolute filter consumption prefilters are required to extract a large fraction of the aerosol, particularly sub-micron, produced by thermal cutting operations. A work programme was undertaken to categorise the aerosols, select and test suitable prefilters and specify a suitable system to minimise secondary waste and operator exposure. Cutting was done on non-radioactive steel samples.

\section{DEVELOPMENT FACILITIES}

\subsection{B2.1 Cutting Aerosol Generation and Ventilation Rig}

This facility housed - at different times in the work programme - an oxypropane torch and a 400 watt carbon dioxide laser. Figure 1 shows the facility with the laser installed. The oxypropane torch was deployed by a remotely-operated XYZ frame. An auxiliary pipe delivered in iron/aluminium powder mixture into the flame to increase its temperature from approximately $2000^{\circ} \mathrm{C}$ to $6000^{\circ} \mathrm{C}$. In the laser cutter configuration, the laser beam remained stationary while the target material was moved on an indexing frame.

Both configurations used a similar ventilation system consisting of an aerosol collection hood placed behind the target material, a prefilter, then HEPA filters. The filtered air exhausted outside the building via a $5000 \mathrm{~m}^{3} \mathrm{hr}^{-1}$ centrifugal fan. Aerosoi sampling points in the duct work allowed the aerosols to be characterised and the performance of the 


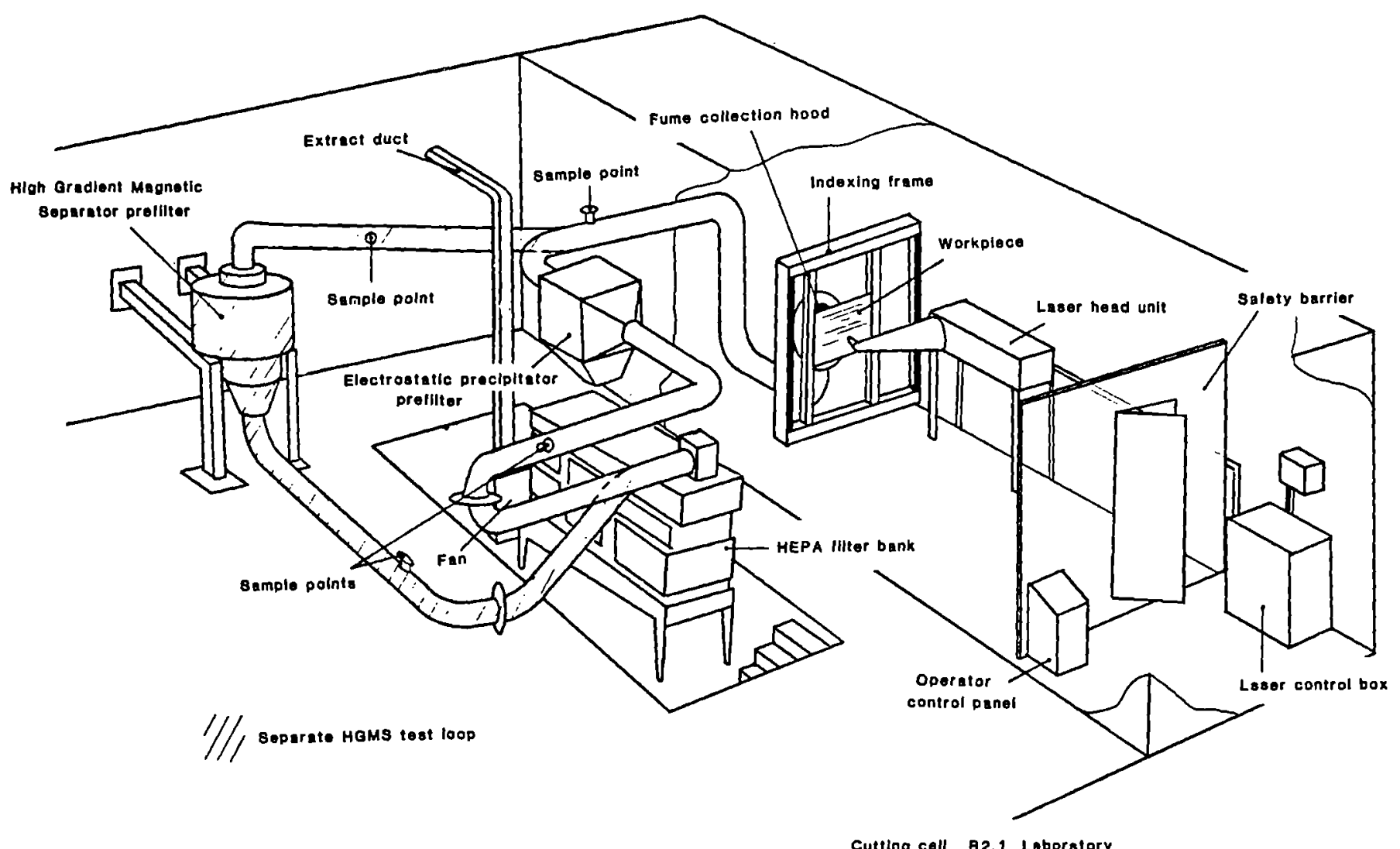

Figure 1. B2.1 development facility 
prefilters measured.

\subsection{HERO Plame Cutting and Ventilation Pacility}

The facility was constructed within the empty biological shield of the former zero energy HERO reactor which has principal dimensions similar to those of WAGR. A manipulator was supported in the vault and used to remotely deploy an oxypropane cutting torch as shown in Pigure 2. Viewing was remote using closed-circuit television cameras with monitors located in the facility control room.

The downward ventilation flow of about $15,000 \mathrm{~m}^{3} \mathrm{hr}^{-1}$ resulted in approximately 16 air changes per hour in the vault, and a mean air velocity of $0.07 \mathrm{~m} \mathrm{~s}^{-1}$. The ventilation and filtration system was bullt in the former HERO plant room, shown in Figure 3. A separate loop branched from the main duct for aerosol sampling and prefilter testing. This facility enabled full scale ventilation and filtration tests to be conducted and the operating parameters for the WAGR system to be defined.

\section{GENERAL INVESTIGATION INTO AEROSOL BEHAVIOUR}

The development work described in this section has concentrated on oxypropane flame cutting of mild steel, stainless steel and composite materials. This process will be used extensively in gas-cooled reactor decominissioning.

\subsection{Optinisation of the Oxypropane Torch Parameters}

A series of experiments was carried out in the B2.1 cutting facility to find the optimum cutting parameters for minimum aerosol generation. Several target materials were used. The aerosol produced was analysed by mass sample filters and an Andersen Impactor. Variations of powder injection rate and cutting rate was found to affect the aerosol generation rate. Variation of the other parameters had little effect. A cutting speed of 1.7-2.5 mm s $\mathrm{s}^{-1}$ and a powder injection rate of $100 \mathrm{~g} \mathrm{~min}-1$ were found to give minimum aerosol production.

\subsection{Aerosol Characterisation of Oxypropane Cutting}

Analysis of the sampled aerosols from the experiment detalled above showed that $40 \mathrm{z}$ was below $0.5 \mu \mathrm{m}$ and $40 \mathrm{z}$ was above $12 \mu \mathrm{m}$. Quantitative data indicated that $0.3 \pi$ of the kerf materfal formed sub-micron aerosol. This earlier work indicated several points of interest for further evaluation. In November 1986 a joint project was undertaken at the Windscale Laboratory with colleagues from Commissarlat a l'Bnergle Atomique, (CEA) Saclay, France, to characterise aerosols and test various pre-filters. The Hero facility was modified to incorporate the Prench test loop in which nine experiments were carried out (see Plgure 3). A range of aerosol measurement equipment was used including a Differential Mobility Particle Sizer (DMPS), our Electrical Aerosol Analyser (BAA), Andersen impactors, and mass sampling filters. The main findings of the aerosol analyses are $g$ iven in Table I. Later sections detail the results of tests on the prefilters used.

The results of the experiments closely agreed with earlier work on aerosols. Powder injection increased the aerosol concentration by two orders of magnitude. The size distribution was bimodal with 507 of the particles being sub-micron. The majority of sub-micron particles were from fully vaporised material in the heart of the kerf. The mean diameter of the particles was lower $(0.223 \mu \mathrm{m})$ in flame-only cutting compared to powder injection flame cutting $(0.464 \mu \mathrm{m}$ and $0.594 \mu \mathrm{m})$. This is seen in Figure 4, 


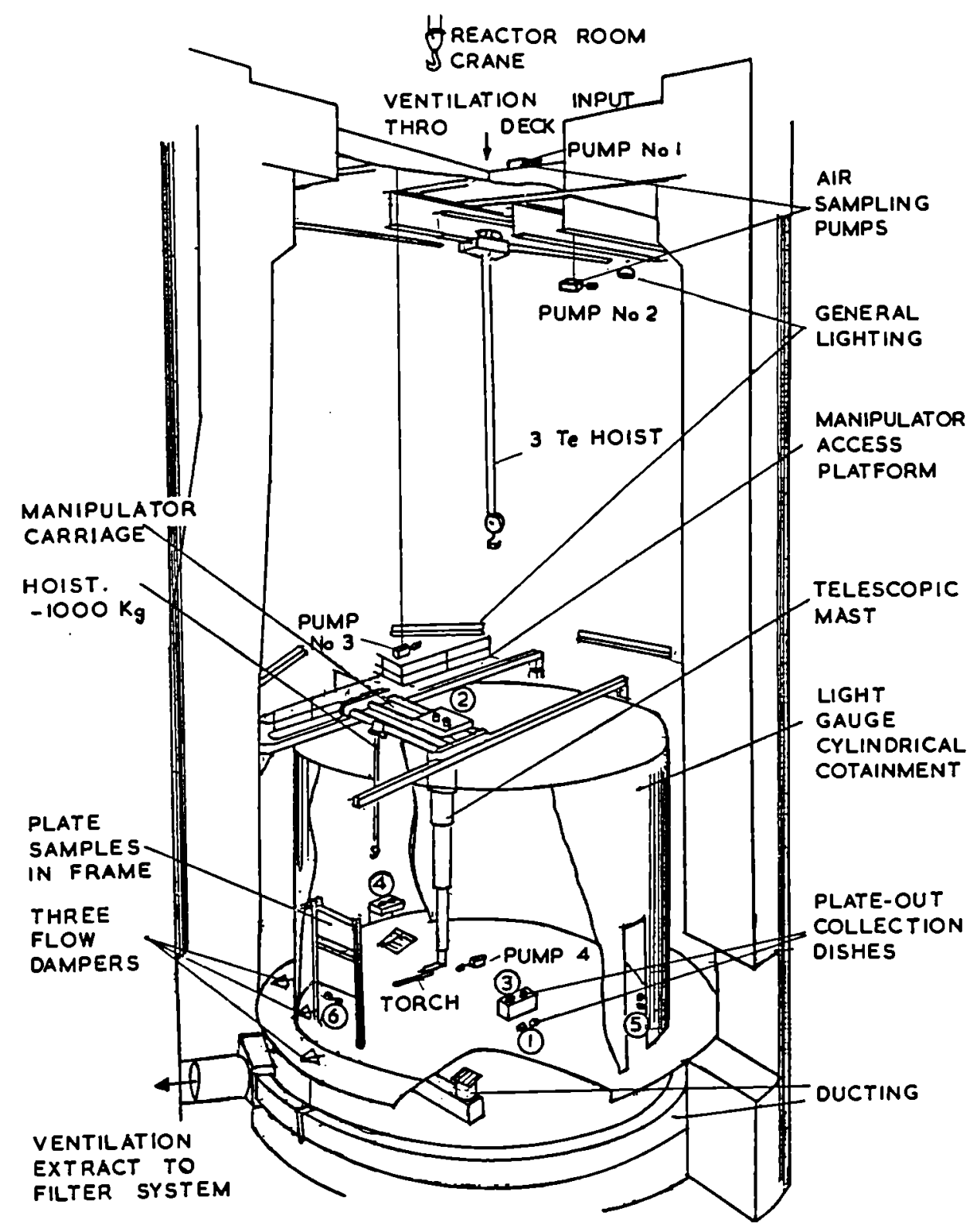

Figure 2. HERO vault development facility 


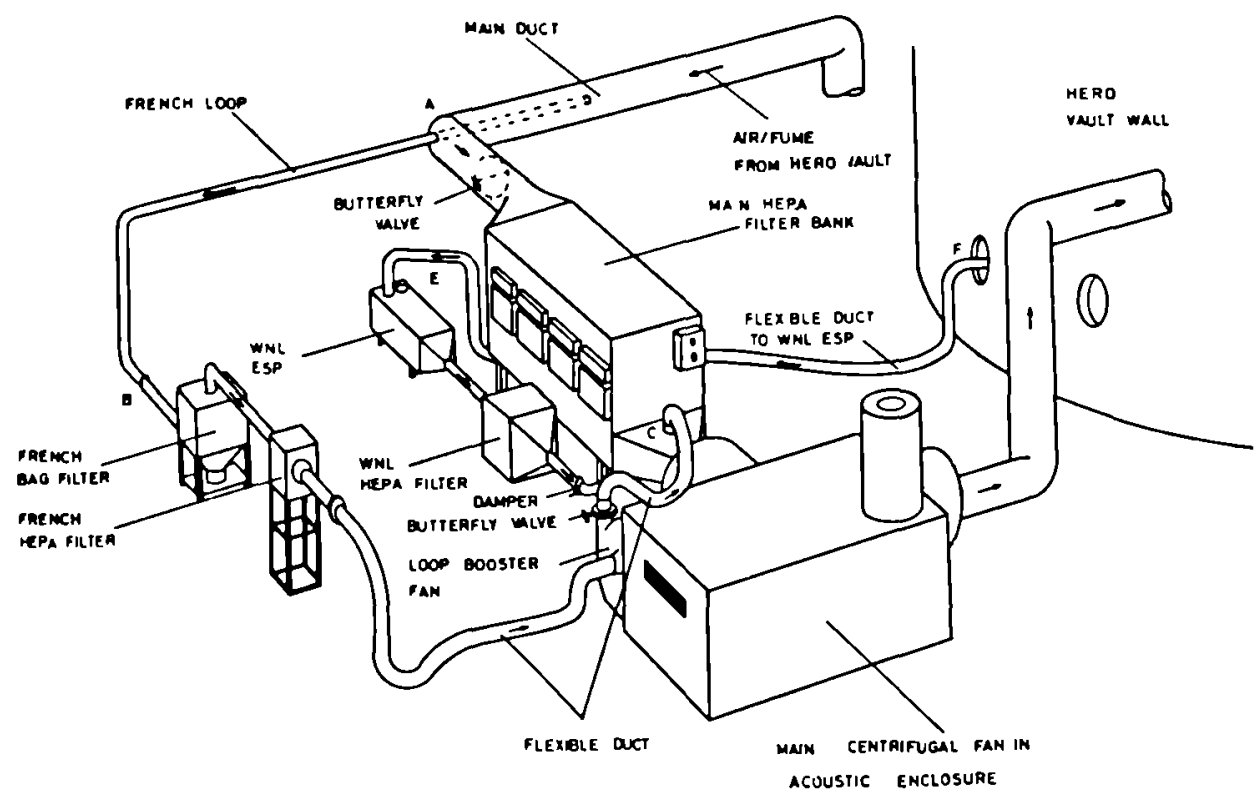

Figure 3. Isometric view HERO plant room

NUYARR CONC V8 PARTTCLE GIKS
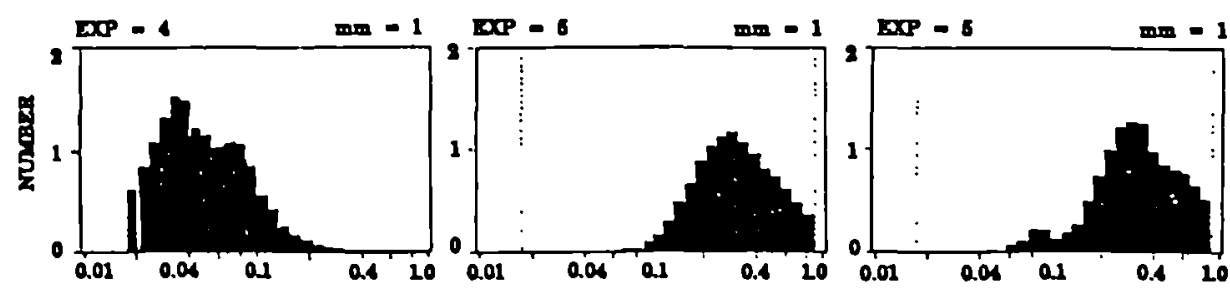

Mild stoel

$$
\begin{aligned}
& \text { Mild stoel with } \\
& \text { powder injection }
\end{aligned}
$$

Stainleas ateel

Figure 4. Typical particle size distribution (DMPS data) 
which shows typical distribution for the submicron region of the aerosol. Results from Andersen Impactor measurements confirm the bimodal distribution from earlier work.

TABLE 1 Aerosol Characterisation Results

(Averaged from 9 Experiments)

\begin{tabular}{|c|c|c|c|}
\hline & $\begin{array}{l}\text { Mild } \\
\text { Steel }\end{array}$ & $\begin{array}{l}\text { Mild Steel } \\
\text { with powder }\end{array}$ & $\begin{array}{l}\text { Stainless Steel } \\
\text { with powder }\end{array}$ \\
\hline $\begin{array}{ll}\text { Aerosol } & \left(\mathrm{mg} \mathrm{m}^{-3}\right) \\
\text { concentration/ } & \left(\mathrm{mg} \mathrm{min} \mathrm{min}^{-1}\right) \\
\text { generation } & \left(\mathrm{mg} \mathrm{m} \mathrm{m}^{-1} \text { of cut }\right)\end{array}$ & $\begin{array}{r}0.3 \\
65 \\
46\end{array}$ & $\begin{array}{r}24 \\
5200 \\
2318\end{array}$ & $\begin{array}{r}44 \\
9530 \\
4323\end{array}$ \\
\hline Powder flow $\left(\mathrm{g} \mathrm{min}^{-1}\right)$ & 0 & 92 & 109 \\
\hline $\begin{array}{l}\text { Volume median diameter ( } \mu \mathrm{m}) \\
\text { DMPS } \\
\text { EAA }\end{array}$ & $\begin{array}{l}0.223 \\
0.142\end{array}$ & $\begin{array}{l}0.464 \\
0.177\end{array}$ & $\begin{array}{l}0.594 \\
0.255\end{array}$ \\
\hline
\end{tabular}

\subsection{Laser Cutting Aerosol Characterisation}

The aerosols produced from cutting $3 \mathrm{~mm}$ thick stainless steel using a laser in the B2.1 cutting facility were measured. Results using a DMPS indicated that they were similar in particle size distribution to those from oxypropane cutting (see Figure 4). The distribution lay between those from oxypropane flame-only and powder injection indicating that the aerosols were produced from vaporising the metal in the kerf.

\section{DETAILED STUDY OF VENTILATION PLANT}

\subsection{Early Electrostatic Precipitator Measurements}

Prefilter studies concentrated on the commercial Electrostatic Precipitator Prefilter (ESP) installed in the B2.1 laboratory during the early part of the work programme. It was found that over $90 \%$ of particles $>0.5 \mu \mathrm{m}$ were removed. Maximum penetration was found in the range $0.02-0.12 \mu \mathrm{m}$, mainly due to a change in the aerosol charging mechanism in this region. This is typical of ESP operation.

\subsection{Collaborative Work on Prefilter Testing}

Section 3 detailed work by Windscale and Saclay on aerosol

measurements. During these experiments, three prefilters were installed and tested. Details of the experimental method, measuring equipment and results are given in Reference 1. Three filters (an ESP, an electrocyclone and a bag filter) were subjected to similar cutting fumes. The main results are given in Table II.

It can be seen that both the ESP and bag filter have excellent collection efficiencies. The bag filter required frequent cleaning to reduce the pressure drop across it. The efficiency of the ESP rapidly deteriorated with a relatively small deposited mass and would likewise require frequent cleaning. Both units were considered suitable for further development. Additional tests were carried out on the small ESP unit installed in a separate loop. The tests were principally to provide a 
comparison with the ESP in the B2.1 laboratory. A relationship was established between ESP efficiency and collector plate voltage for the various cutting modes. The relationship is discussed later in the report.

TABLE II Prefilter tests (averaged).

\begin{tabular}{|c|c|c|c|c|}
\hline \multicolumn{2}{|c|}{ Prefilter } & \multirow{2}{*}{$\begin{array}{c}\text { ESP } \\
98.3-79.2 \\
99.3-96.3 \\
99.7-89.3\end{array}$} & \multirow{2}{*}{$\begin{array}{c}\text { Electrocyclone } \\
66.1-61 \\
\text { not used } \\
78.9-51\end{array}$} & \multirow{2}{*}{$\begin{array}{c}\text { Bag Filter } \\
<99.9-97.9 \\
99.9-92.3 \\
98.3\end{array}$} \\
\hline $\begin{array}{l}\text { Efficiency } \\
\text { Range ( }(\overline{)})\end{array}$ & $\begin{array}{l}\text { (by mass) } \\
\text { (by DMPS) } \\
\text { (by EAA) }\end{array}$ & & & \\
\hline $\begin{array}{l}\text { Aerosol mass } \\
\text { seen by } \\
\text { prefilter ( })\end{array}$ & $\begin{array}{l}\text { (calculated) } \\
\text { (collected) }\end{array}$ & $\begin{array}{l}85.9 \\
70\end{array}$ & $\begin{array}{l}27-7 \\
13-7\end{array}$ & $\begin{array}{l}68 \\
84\end{array}$ \\
\hline
\end{tabular}

\subsection{Pulse-Clean Cartridge Pilter Trials}

A Donaldson-Torit cartridge filter with reverse pulse-jet cleaning equipment together with a HEPA filter were set up as a prefilter test loop in the HERO ventilation system. The equipment was provided by the Chemical Engineering Division, UKARA, Harwell, who used a TSI 3030 EAA for aerosol measurements and prepared the pressure drop data. The cartridge, type P14 5891 'Ultraweb' filter, comprises 322 pleats with a total area of filtration of about $20 \mathrm{~m}^{2}$. The cartridge medium is cellulose-based, and consequently has poor fire resistance, but the experiments at WL were primarily intended to show whether the captured aerosols would produce a filter cake that could be removed by reverse pulse cleaning. Aerosol laden air from the cutting enclosure at a flow rate of $-1250 \mathrm{~m}^{3} \mathrm{~h}^{-1}$ passed through a flow control valve to the cartridge filter unit and finally through a $1700 \mathrm{~m}^{3} \mathrm{~h}^{-1}(1000 \mathrm{cfm})$ HEPA filter.

Measurements of the pressure drop across the filter are shown in Figure 5. The unit was compared with the increase in pressure drop across the main HEPA filters. No change in pressure drop of the HEPA unit downstream of the cartridge filter was observed at 600 minutes cutting. The overall DP (decontamination factor) of the cartridge filter was measured and found to be $3000-4000$ during this period - an efficiency of Breater than $99 \%$.

The pulse clean system was shown to be effective in cleaning the cartridge. The cartridge filter was shown to have efficiencies comparable with HEPA filters. Work continues at Harwell to construct and evaluate a high strength glass-fibre filtration medium cartridge unit with improved resistance to high temperatures. This work falls outside the timescale and scope of the report.

\subsection{High Gradient Magnetic Separation Prefilter Tests}

Tests were carried out on a High Gradient Magnetic Separator prefilter (HGMS) in the B2.1 laser cutting facility. The unit performed with a poor collection efficiency of between $10 z-30 z$ (by mass). The work was terminated following a decision not to use the HGMS as a prefilter. The results of the tests are being analysed to identify possible reasons for the units poor performance. 


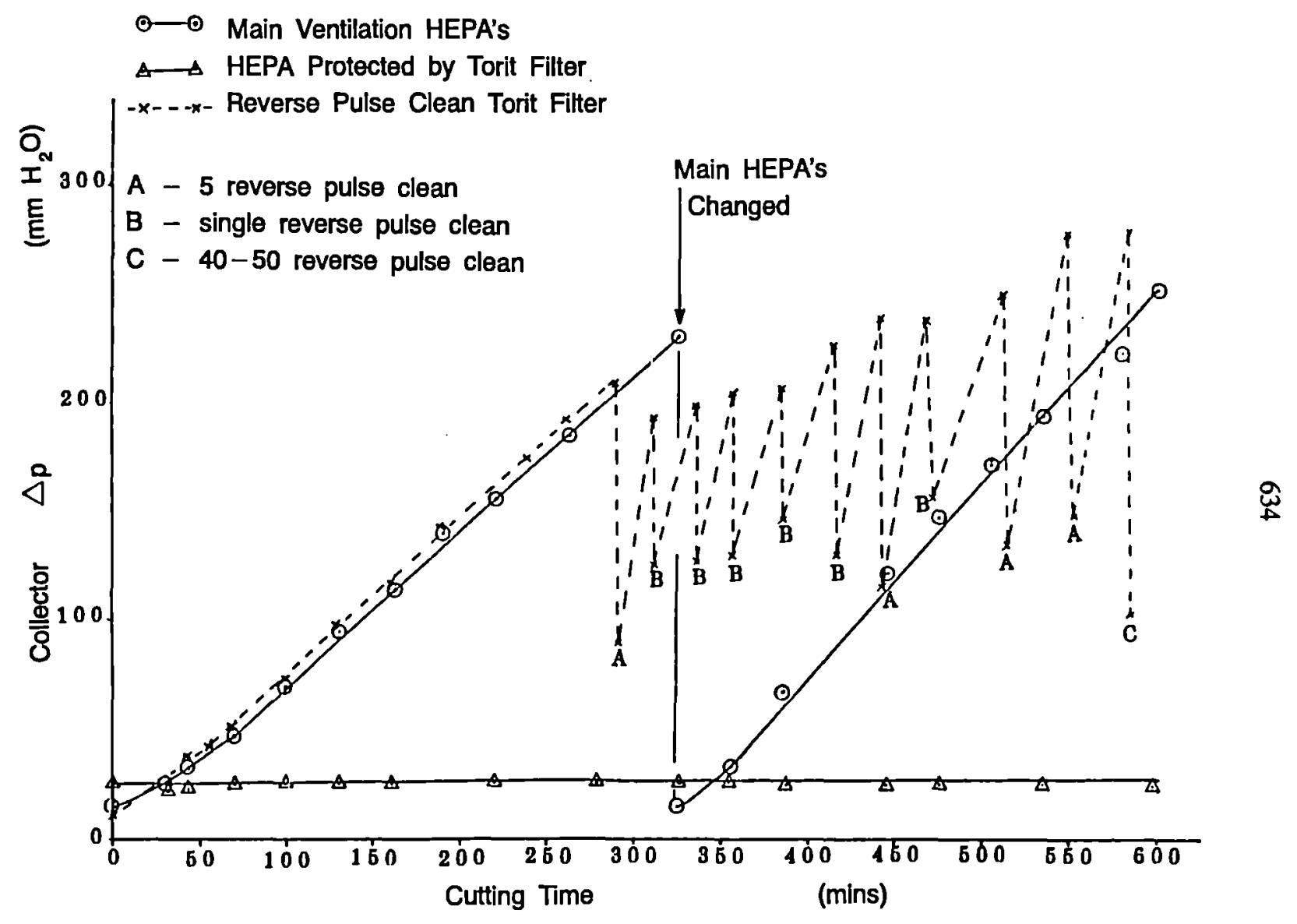

Figure 5. Variation in filter pressure drops with operating time 


\section{SUITABILITY OF PLANT POR DECOMMISSIONING}

\subsection{ESP Cleaning Trials}

As a result of earlier work, including the joint venture between Hindscale and CEA Saclay on prefilters described in Section 4, the RSP was chosen as the prefilter device for the WAGR Decommissioning Project. An experiment was conducted into the effectiveness of an in-built vibratory cleaning system used on an ESP in removing collected dust. The purpose of the vibratory cleaning system was to extend the operating period between manual changing of the ESP cells.

Fume, produced by cutting steel with an oxyproprane torch with powder infection, was ducted to a commercial ESP unit in the B2.1 facility. The efficiency of the ESP was measured by upstream and downstream sampling using a total light scattering photometer. The RSP voltages were measured in order to explore their relationship with the changes in efficiency. (Pigure 6 shows the efficiency and voltages measured). The RSP worked between 997 and 857 effictency during the trials. The voltage measurements related to the efficiency but were erratic due to fluctuating fume generation affecting the discharge between the plates.

The trials showed that vibratory cleaning of the RSP cells effectively extends the period before manual cleaning and that the fall in the collector plate voltage can be used as a pointer to when the ESP cells require cleaning.

\subsection{Modifications to an ESP for changing Contaminated Plates}

To enable the safe removal of active dust and contaminated plates from the ESP during operation, the unit will be modifled. Alternative proposals to remove the plates were considered. One proposal was to use a 'bagging-out' technique similar to that used to remove contaminated HEPA filters. This proposal was not developed because of the awkward shape and sharp edges of the components to be handled. The alternative approach was to 'box-out' the components one complete module at a time (a total weight of $35 \mathrm{~kg}$ ) into a receptacle. A schematic of an ESP modified for this purpose is shown in Pigure 7 .

The dust burden is collected in the hopper and ducted away by vacuum to a shielded receptacle. The vacuum extract system is also used to provide a depression in the ESP while the plates are removed for cleaning or repair.

In effect the ESP cabinet becomes a glove box with a continuous depression to prevent the escape of disturbed dust to the main HEPA filters downstream or to atmosphere. The torch is not operated and the main ventilation bypasses the ESP while the cells are removed.

At present, the receptacle box has not been designed in detail. The designs have concentrated on the modifications to the ESP to enable them to be completed for comissioning of the WAGR ventilation system. These designs have been completed. Purther work to develop the design for the receptacle to hold the cells for decontamination will continue shortly.

\section{PULL SIZED VENTILATION TRIALS}

\subsection{Aerosol concentrations and Deposition Within the HERO Facility}

Measurements were made of the fume concentration within the vault using personal air samplers. The position and concentrations are shown in Pigure 8. The results show that the fune diffuses to all parts of the vault. No fume was detected above the reactor room floor. 

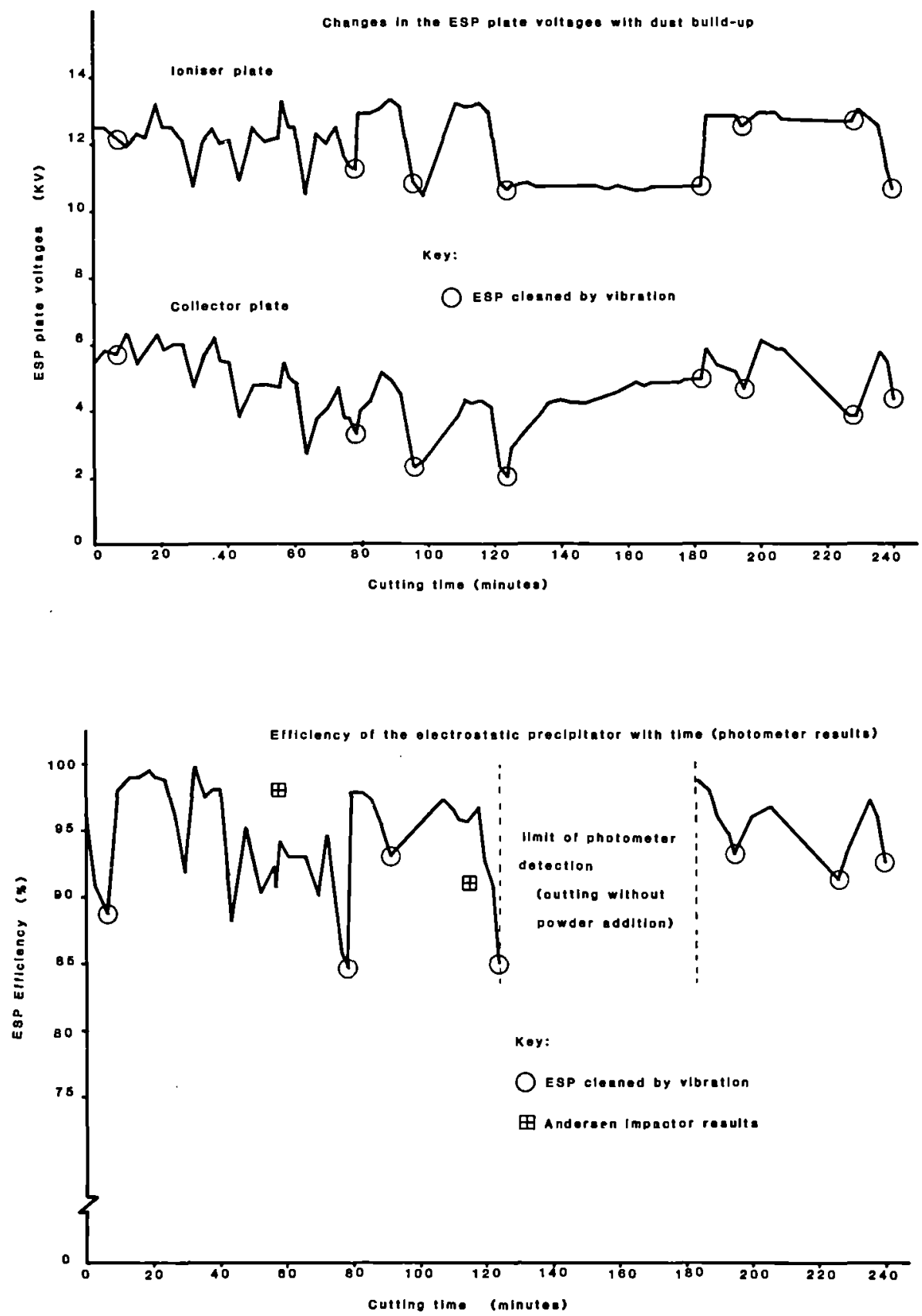

Figure 6. Relationship between ESP efficiency and plate voltages with time 
In addition, measurements were made of the amount of dust that plated out on horizontal surfaces. Plastic and metal foil surfaces were placed at various levels within the vault and left undisturbed throughout. The deposits were in close agreement with an average value of $24 \mathrm{~g} \mathrm{~m}^{-2}$ for the plastic and $27.2 \mathrm{~g} \mathrm{~m}^{-2}$ for the foll samples. Two results were much higher than the others $\left(68.5 \mathrm{~g} \mathrm{~m}^{-2}\right.$ and $77.8 \mathrm{~g} \mathrm{~m}^{-2}$ ) possibly due to a concentration of denser particles leaving the thermal plume in the region around the samples.

\subsection{Aerosol Penetration}

The results from the collaborative experiment were used as a measure of the amount of aerosols reaching the filters. Earlier work had found that 0.37 of the material cut (kerf) formed sub-micron aerosol. Of the aerosol produced $40 \%$ was below $0.5 \mu \mathrm{m}$. From this a pessimistic assumption was made that 17 of the kerf formed aerosols. The amount of aerosol reaching the filter in HERO was calculated and is shown in Table III.

TABLE III Fraction of aerosol reaching filters.

\begin{tabular}{lcc}
\hline Cutting method & $\begin{array}{c}\text { Material } \\
\text { thickness } \\
(\mathrm{mm})\end{array}$ & $\begin{array}{c}\text { Amount of Aerosol generated } \\
\text { reaching filters }\end{array}$ \\
\hline Plame only - mild steel & 80 & 2.6 \\
Powder injection - mild steel & 80 & 6.4 \\
Stainless steel & 25 & 11.2 \\
\hline
\end{tabular}

As the table shows the amount of aerosol generated that reaches the filters is low, typically 10\%. These results have a direct bearing on the WAGR ventilation circuit and can be used for assessment of the aerosols reaching the HEPA filters

\section{CONCLUSIONS}

(a) Valuable experience and data has been gained on the characteristics of aerosols generated by oxypropane flame cutting on different materials. Optimum cutting parameters have been evaluated.

(b) Several forms of prefilters have been tested. Two - the ESP and cartridge filters - have proved sultable for further development. The ESP has been specifled for use as a prefilter on a major decomissioning demonstration project.

(c) A detailed design has been completed to modify the ESP to enable the removal of radioactive dust and contaminated plates. The design minimises operator dose rates and prevents active dust from escaping to the atmosphere.

(d) Data has been collected on aerosol concentrations and deposition rates on full size ventilation facilities. These can be used in determining contamination rates in active decommissioning projects.

(e) Future work would include obtaining experience and data on ESP during active decomissioning. Additionally, work on plasma-arc cutting aerosol characteristics is required. 
8. ACKNOWLEDGEMENTS

The cooperation of British Nuclear Fuels plc for permission to publish the laser cutting trials is gratefully acknowledged.

9. REFERENCES

(1) K Wilson, A Bishop, I Le Garreres, G Pilot, J Vendel, Joint Report on the French Prefilter Tests on the HERO Development Facility, WNPDL, Contract Nos. FI1D0006 (UK) and FIID0007 (F).

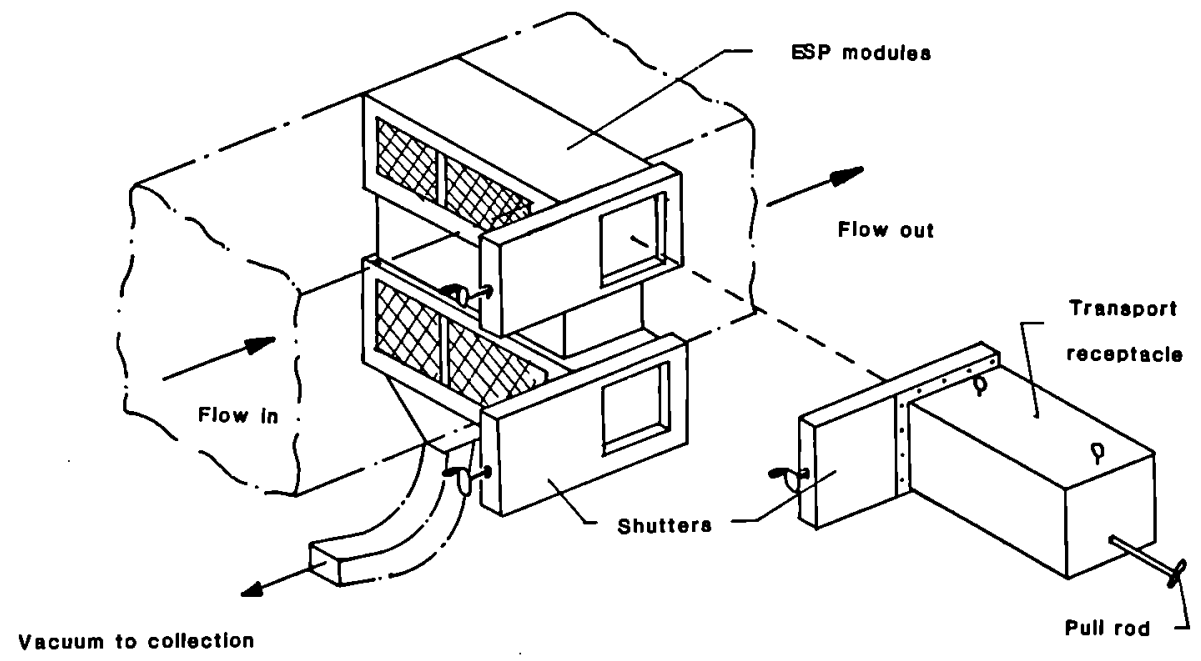

Figure 7. Schematic of an ESP for remote handling

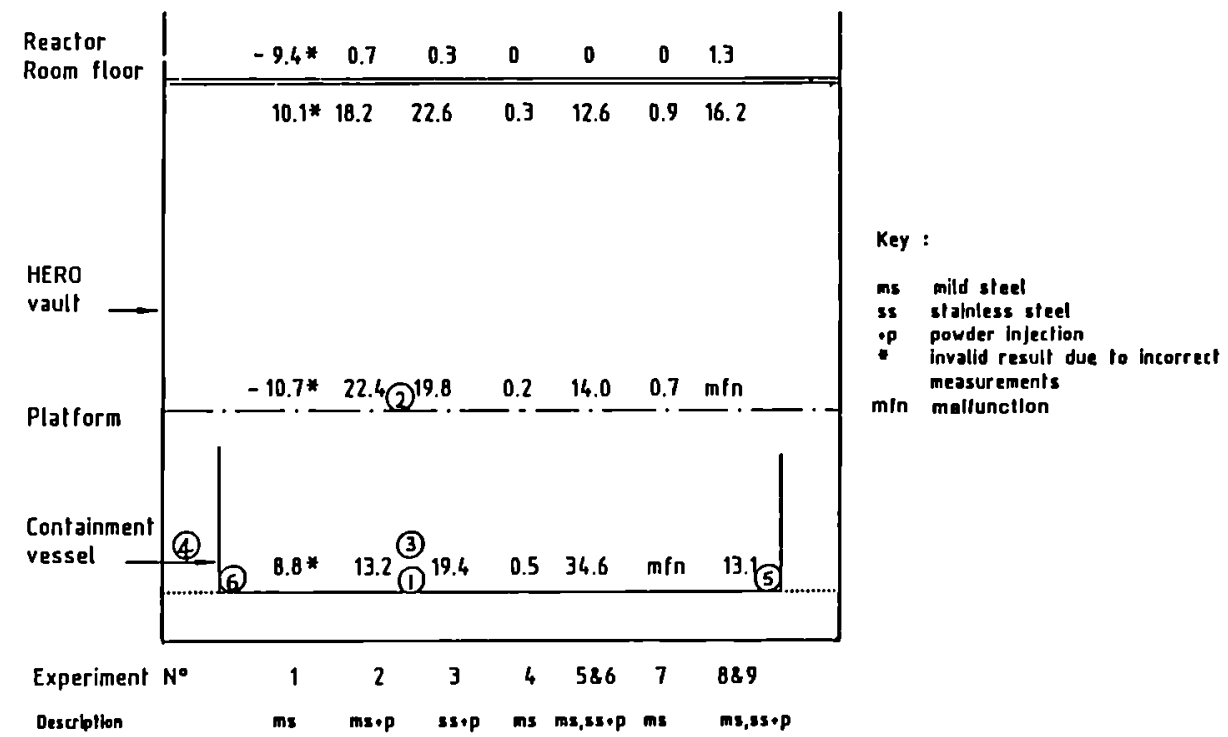

Figure 8. Fume concentration in the HERO vault $\left(\mathrm{mg} \mathrm{m}^{-3}\right)$ 


\title{
PREFILTERING DEVICES POR GASEOUS EFFLUENTS FROM DISMANTLING OPERATIONS
}

\author{
PILOT G., POURPRIX M. \\ Commissarlat à l'Energle Atomique \\ IPSN/DPT/SPIN, CEN SACLAY, FRANCE
}

\begin{abstract}
D1smantling processes produce em1ssions of aerosols which can disseminate contamination in the cell where the cutting operation takes place, and in the ventilation ducts up to the HEPA filters, the last barrier before releases into the environment. Cutting processes, and mainly thermal ones, cause rapid plugging of HEPA filters because of the high concentrations of ultrafine particles produced. To increase the life of HEPA filters and thus to reduce the amount of solid wastes, an efficient cleanable prefiltering device is necessary.

The object of this work was to select one or several cleaning devices, selection that can be done from the knowledge of the physico-chemical characteristics of the gas and aerosols to deal with, the range of the avallable cleaning devices and the 1mplied factlity. Thus, we :

- collected data on secondary emissions produced by varlous cutting techniques of metallic structures and made complementary experimental studies. Underwater plasma cutting and especially the influence of water depth have been studied jointly with Herlot-Watt University (Edinburgh),

- designed and bullt a prefiltration test rig, rig which has been used at Windscale, in cooperation with UKAEA, on a facility simulating the Advanced Gas Cooled Reactor in dismantilng stage, in order to select an appropriate cleaning device,

- made an assessment of a selected captation and prefiltration device by application to radioactive secondary emlosions in an underwater plasma dismantling facility of the CEA/STEC of Cadarache.
\end{abstract}

\section{INTRODUCTION}

The dismantilng of nuclear installations implies a stage of disassembly of the structures which, if the materials are radioactive, have to be packed in standard containers. Putting these wastes in containers of ten necessitates to cut them, that produces an aerosol emission. Thus, there is a risk of dissemination of the contamination in the cell where the cutting technique takes place, but also in the exhaust ducts up to the BEPA filters, the ultimate barrier before release into the environment.

Some cutting processes (especially thermal ones) create important concentrations of submicronic aerosols that cause a rapid clogging of HEPA filters which can become a source of irradiation if the particles are radioactive.

Thus to Increase the life of HEPA f1lters and thus to reduce the amount of solid wastes, it 18 necessary to choose a cleanable prefiltration device. Th1s cholce needs the knowledge of the nature, of the concentration and of the size distribution of particles created by cutting. In order to avold a dissemination in the cell, a captation at the emfosion source can be essential. 
The objectives of the present work were :

- to characterize the aerosols produced by varfous cutting tools of metallic structures,

- to Identify the possible cleanable prefiltration and captation systems,

- to evaluate the performance of selected prefilters on a real scale rig,

- to use a captation system and a prefilter optimlsed as far as possible on a real active dismantling site.

The work, has been done, as prevtously foreseen, in cooperation with a team of UKAEA/Windscale. Furthermore, during this time we had profitable cooperations with Herlot-Watt University of Edinburgh and CEA/IRDI/STEC of Cadarache.

\section{CHARACTERIZATION OF AEROSOLS PRODUCED BY CUTTING TOOLS}

A 11terature survey and personal experiments on the secondary emfssions produced by mechanical and thermal techniques on metallic structures have been carried out. Mechanical cutting tools evaluated include disc saw, reclprocating saw, band saw, chop saw and grinding wheels. Thermal cutting techniques Include oxy-acetylene torch and plasma torch.

We can notice that :

- the thermal cutting techniques produce higher aerosols rates by unit of time and even by unit of cut length (In spite of their rapidity) than mechanical ones. For example, by the cut of 2 inch schedule 40 type $304 \mathrm{~L}$ stalnless steel, aerosol production rate ranges from $50 \mathrm{mg} /$ cut for the reclprocating saw to about $1000 \mathrm{mg} /$ cut for plasma torch (1) ( $f 1 g .1)$,

- all devices create aerosols in the respirable size range (less then $10 \mu \mathrm{m}$ aerodynamic diameter). Our experiments and literature survey (table I, fig. 2) show that the mass median aerodynamic diameter range from 1 to $10 \mu \mathrm{m}$ for mechanical cutting tools (reciprocating saw, band saw, grinder) and from 0.1 to $0.5 \mu \mathrm{m}$ for thermal ones (oxy-acetylene torch and plasma torch),

- the aerosol production rate and distribution in size are dependent upon :

- the cut plate nature (production is higher for example for stainless steel alone than for carbon steel alone (2), Its cleanness degree (with or without grease for example), its thickness and its impurities,

- the cutting tool of course and for a same cutting tool upon 1ts power, its speed and eventually upon the choice of the gases,

- the cutting environment, for example underwater plasma arc cutting produce a lower aerosol rate at least 30 times than air plasma cutting and the median diameter 18 smaller ( $f \mathrm{fg} .3$ ),

- the underwater depth. In the experiments with Heriot-Watt

University of Edinburgh (3), stainless steel plates were cut by plasma torch in a column $(\varnothing=60 \mathrm{~cm})$ at depths up to $9.55 \mathrm{~m}$. The release of aerosols decreased by a factor over 5 by increasing the water depth from 0.08 to $9.55 \mathrm{~m}$, most of the decrease occurred in the first $3.5 \mathrm{~m}$,

- and evidently upon the sampling point (we point out, for example, that distribution in size are different at the source, near the operator's nose and in the ventilation duct). 
A comparison between three tools (grinder, oxy-acetylene torch and plasma torch) on a dismantling site (G2, gas cooled reactor) to cut carbon steel pipes showed what is the most approprlate for this work and that keeping a suction effect in the tube is an efficient captation at the source especially for submicronic particles.

All our experiments emphasized the interest to collect the aerosol at the generating source and to insert prefiltration devices upstream of the HEPA filters which do not have particularly a high efficiency for thermal cutting generating aerosol (HEPA filter efficlency is minimum for about $0.15 \mu \mathrm{m})$.

3. EVALUATION OF SELECTED PREFILTERING SYSTEMS IN A FULL SCALE TEST SECTION WITH REAL CUTTING EFFLUENTS

3.1 Experiments at Saclay (CEA)

The test rig (f1g. 4), bullt for qualifying prefilters with callbrated monodisperse particles and for examining their performance with the aerosol produced by the cutting tool itself, comprises :

- a $10 \mathrm{~m}^{3}$ vinyl tent $(2 \times 2 \times 2.50 \mathrm{~m}$, height $=2.50 \mathrm{~m})$,

- an exhaust ventilation with :

- an 1sokinetic sampler upstream of the prefilter (P1),

- an 1sokinet1c sampler downstream of the prefilter (P2) (HEPA

f1lter upstream sampling, too),

- an 1sokinetic sampler downstream of the HEPA f1lter (P3),

- a prefilter (electrocyclone, or electrostatic precipitator, or bag filter),

- a HEPA f1lter (with a manometer to follow the pressure drop),

- an orffice plate which has been calibrated in order to have flow versus pressure drop,

- a fan with a rated flow of about $800 \mathrm{~m}^{3} / \mathrm{h}$.

The electrocyclone 18 a cyclone with an axial electrode which has two functions : to charge particles by a corona effect and to create an electric fleld in order to precipitate particles on the cyclone wall. It has a rated flow of $280 \mathrm{~m}^{3} / \mathrm{h}$ (pressure drop - $840 \mathrm{~Pa}$ of water). In the submicron particle range, the efficlency 18 essentially linked to the electrostatic effects. On the other hand, the collection of particles whose size 18 superior to $1 \mu \mathrm{m} 18$ malnly governed by centrifugal forces although the electrostatic effects are always appreclable.

In rated conditions, against particles produced by the cutting of mild steel plates (thickness - 5 mm or $15 \mathrm{~mm}$ ) with an oxyacetylene torch (cutting speed $=10 \mathrm{~cm} / \mathrm{min}$ ), the efficlency of the electrocyclone was $71 \mathrm{z}$ $( \pm 97)$.

The bag filter has two parts, a filtration part with 9 GORE-TEX bags presenting a surface of $5 \mathrm{~m}^{2}$ and a recuperation part for the filtrate at the bottom ( $f 1 \mathrm{~g} .4$ ). It has a rated flow of $500 \mathrm{~m}^{3} / \mathrm{h}$ (pressure drop for new bags - $200 \mathrm{~Pa}$ ). The calibration curve is indicated on figure 5 .

The electrostat1c prectpltator (ESP) has two stages in serles with an Ionization part and a collection part for each.

It has a rated volume of $800 \mathrm{~m}^{3} / \mathrm{h}$ (pressure drop $=150 \mathrm{~Pa}$ ). In the range 0.1 to $10 \mathrm{\mu m}$, the efficlency 18 superior to $90 \%$ (f $1 \mathrm{~g} .5$ ). 
If we compare the efficlency of these 3 prefilters in rated conditions, it seems that the electrocyclone in spite of its possibility to recover more easily the wastes could be eliminated.

\subsection{Experiments at Windscale (UKAEA)}

This study was a cooperation with UKAEA Windscale on the prefiltration of cutting fume generated by oxypropane torch when cutting steel plates. The objective of this work was to characterise the aerosol produced in vartous conditions (mild steel and stalnless steel cutting by oxypropane torch with and without infection of powder) and to evaluate the performance of 3 prefilters described above in order to ald the selection of a prefiltration system for nuclear decommissioning (4).

The experiments took place in HERO Development Facility which const1tutes a full scale mock-up of the Windscale AGR plant. Nozzles were

Inserted 1nto the main ventilation duct $\left(13,000 \mathrm{~m}^{3} \mathrm{hr}^{-1}\right)$ to allow an 1sok1netic sample flow to be diverted to our loop to sult the flow requirements of each pre-filter. The loop was then connected to the main duct at the fan Inlet.

The aerosol concentration produced when cutting with powder is 2 orders of magnitude greater than when cutting without. The size distribution $1 \mathrm{~s}$ bimodal and $50 \%$ of the particles are submicronic.

In the experimental conditions, the efficiency of the electrocyclone, ESP and bag filter were respectively $60 \%, 98 \%$ and $99 \%$. The pressure drop of the bag filter was increasing rapidly when using powder, so 1t would need frequent cleaning.

The ESP was clogged with a relatively small mass ( $80 \mathrm{~g}$ ) which means a low density of the deposit and also the necessity to clean very often. The Windscale maln HEPA filters (with coarse prefilters upstream) were changed three times during these experiments, emphasising the need for protecting them by approprlate prefilters.

\section{CAPTATION AND PREFILTRATION POSSIBILITIES}

Let us consider figure 6 , which represents the most difficult case of thermal cutting in a ventilated cell.

To IImit the effects due to the emission of aerosols, it is possible to schematically consider three levels of protection which will be graded $A, B$ and $C$. Level $A$ is that where protection 18 maximum.

- Leve1 A

It 1s desirable to reduce the disperston of contamination in the cell where cutting takes place and, all the more so, throughout the general ventilation system up to the HEPA filters. In practice, this corresponds to the Implementation of a capture device at the source 1 , associated with a secondary ventilation network comprising prefiltration 2 capable of connection or not to the general exhaust ventilation.

- Leve1 B

If capture at the source 1s 1mpossible, we accept the effects of cell pollution, but the general ventilation exhaust network 18 protected by the Installation of a prefilter 3 .

- Leve1 C

The effects of cell pollution and that of the extraction network are accepted, but the HEPA filtration stage 18 protected by the Installation of a prefilter 4 . 
Table II 1llustrates these different levels of protection and the expected consequences. On this point, the following remarks might be made :

- the protection technique considered at levels $A, B$ and $C$ may be accumulated to 1mprove the overall protection of the installation,

- the role of ventilation to maintain dynamic containment within the cell where cutting takes place is essential, but has not been dealt with here. We will simply consider the problem by stating that the exhaust flow should be as low as possible so as to avold the need of overdimensioning the cleaning devices, but must be sufficlently high to satisfy safety needs, Imposing the maintenance of dyamic conta1nment, In particular for thermal cutting likely to cause overpressure by overheating the alr.

\section{EVALUATION OP A CAPTATION-PREFILTRATION SYSTEM DURING THE CUTTING OF RADIOACTIVE PLATES}

Th1s work was a cooperation with the CEA/STEC of CEN Cadarache $(5,6)$.

Several radioactive plates coming from the dismantling of two nuclear facilities (TRITON and RAPSODIE) have been cut by underwater plasma torch at Pegase (CEN Cadarache) with selected captation and prefiltration devices for the aerosol secondary emissions.

The tests on underwater plasma torch cutting of contaminated and activated plates ( $0.7 \mathrm{~Bq} / \mathrm{g}$ and $1900 \mathrm{~Bq} / \mathrm{g}$ ) emphasize the following points :

- the aerosol concentration in the exhaust duct (flow : $1000 \mathrm{~m}^{3} / \mathrm{h}$ ) varies from 1 to $4 \mathrm{mg} / \mathrm{m}^{3}$, the volumic activity of ${ }^{137} \mathrm{Cs}$ varying from 380 to $900 \mathrm{~Bq} / \mathrm{m}^{3}$,

- the mass mean diameter of aerosols 18 about $0.2 \mu \mathrm{m}$ with og (standard geometric deviation) $=2.5$,

- the sedimented drosses and the aerosols represent respectively about $85 \pi$ and $0.1 z$ of the removed mass.

137 Furthermore, with the radioactive balance (the distribution of the Cs (major radiolsotope $\approx 95 \%$ of the total activity) in the facility is 1llustrated in reference 6 ), we note that :

- the difference of the behaviour of the various radiolsotopes $\left({ }^{137} \mathrm{Cs}_{8}{ }^{60} \mathrm{Co},{ }^{54} \mathrm{Mn}\right)$ with an enrichment of the caesium in the aerosols and an probable ${ }^{137} \mathrm{Cs}$ decontamination of the cutting edges (width $=5 \mathrm{~mm}$ ), the caeslum being more volatile that the other radioelements.

A captation at the aerosol generating source was made with the exhaust tube placed fust above the water in order to collect the aerosols as close as possible of the emission source. This installation allows to avold the dissemination of contamination Inside the cell and to obtain air change rates fust above the tank of $1000 \mathrm{~h}^{-1}$.

The ESP put in the exhaust duct had an efficlency superior to $90 z$ for the radiolsotopes involved, mainly carried by submicronic particles.

\section{CONCLUSION}

The studies about secondary emlssions and especially aerosols produced by dismantilng techniques and mainly cutting thermal tools have clearly demonstrated the benefits of captation at the source assoclated with adequate prefiltration. 
These devices have thus the advantages :

- to reduce the volume of wastes by trapping the radioactive aerosols at the emission source increasing therefore the life of HEPA filters of the facility,

- to avold the dissemination of the contamination in the cell and to reduce the radioactive deposit in the exhaust ducts,

- to diminish the frequencies of decontamination workers' interventions in the cell, on the exhaust ducts and for the change of HEPA filters,

- to decrease thus the exposure time of the workers and therefore the collective dose.

The choice of these prefilters is dependent upon parameters that have to be well known (characteristics of the aerosols and gas to deal with, Implied facility).

Among the different prefilters viewed in this paper and especlally after the Windscale experiments, our cholce goes more towards the bag filter or rather the electrostatic filter by its high efficlency, its low pressure drop, its weak volume and the possibility of automatic declogging (for example by pneumatic vibrators).

But it must not be limitative because tests underway on new devices with declogging HEPA filters or granular beds are also promising.

\section{REFERENCES}

1. NEWTON G., HOOVER M., BARR E., WONG B., RITTER P., International Decommissioning Symposfum, Seattle 10-14 0ctober 1982

2. WONG B.A., NEWTON G., OBARSKI G., HOOVER M., Aerosols from oxy-acetylene gas cutting operations on metal plates : a laboratory study, Inhalation toxicology research institute, 1981

3. WALDIE B., PILOT G., HARRIS W., LOYER H., Solid and gaseous secondary emissions from underwater plasma arc cutting, International Conference on the decommissioning of nuclear Installat lons, Bruxelles 20-27 October 1989

4. WILSON K., BISHOP A., PILOT G., VENDEL J. and LE GARRERES I., Characterization and prefiltration techniques for aerosols from oxy-propane torch cutting in nuclear facility decommissioning URAEA Northern Division. Report ND-R-1533(W) (August 1987)

5. PILOT G., LEAUTIER R.,

Découpage sous eau à 1 'arc plasma de matérlels radioactifs. Evaluation des émfssions secondaires en gaz et aérosols. 15ème congrès ATSR, Grenoble 5-6-7 octobre 1988.

6. LEAUTIER R., PILOT G., Development of a prototype system for remote underwater plasma arc cutting and secondary emission mearurements, International Conference on the decommissioning of nuclear installations, Bruxelles 20-27 October 1989. 
Table I : (extracted from (1))

Aerosol particle size distribution and cutting time for metal cutting tools used on 2" schedule 40 type 304 L stalnless steel plpe

\begin{tabular}{|c|c|c|c|c|}
\hline \multirow{2}{*}{ Tool } & \multirow{2}{*}{$\begin{array}{c}\text { Range of MADD } \\
(\mu \mathrm{m})\end{array}$} & \multirow{2}{*}{$\begin{array}{l}\text { Geometrle } \\
\text { gtandard } \\
\text { deviation }\end{array}$} & \multicolumn{2}{|c|}{ Cutting Time (min) } \\
\hline & & & Range & Mean \\
\hline Reciprocating saw & bimodal & N.A. & $1.8-4.5$ & 3.1 \\
\hline Band saw & $1-5$ & 2.3 & $0.9-1.9$ & 1.5 \\
\hline Side arm grinder & b1modal & N.A. & N.A. & N.A. \\
\hline Chop saw & $1.5-9.0$ & 4.6 & $1.1-1.7$ & 1.5 \\
\hline oxy-acetylene torch & $0.1-0.3$ & 2.3 & $3.0-4.2$ & 3.6 \\
\hline Plasma torch & $0.2-0.3$ & 3.7 & $0.5-0.7$ & 0.6 \\
\hline
\end{tabular}

aass Median Aerodynamic Dlameter by cascade Impaction N.A. - not applicable

Table II : Levels of protection and expected consequences

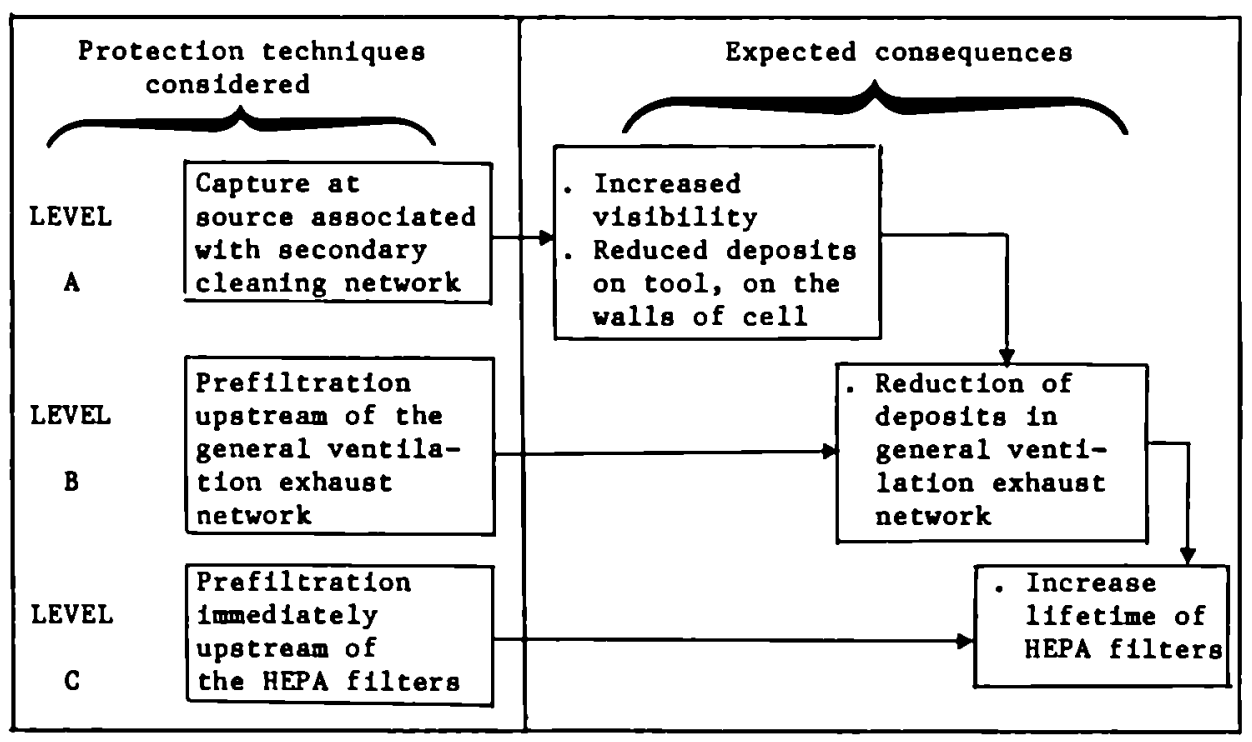




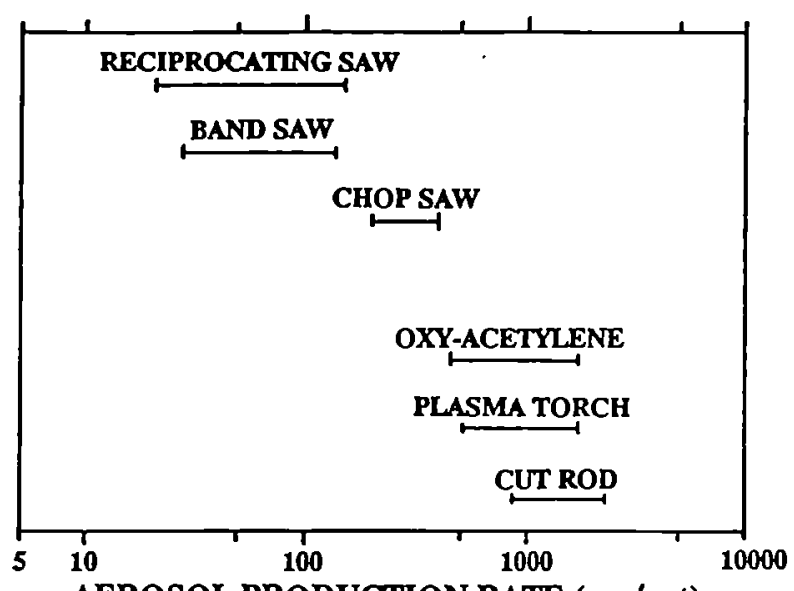

AEROSOL PRODUCTION RATE (mg/cut)

FOR 2" SCHEDULE 40 TYPE 304 L STAINLESS STEEL PIPE

Fig. 1 - Aeroso1 production rates in milligrams per cut with the various tools used on 2-inchs Schedule 40, Type 304L stainless steel pipe (extrated from (1))

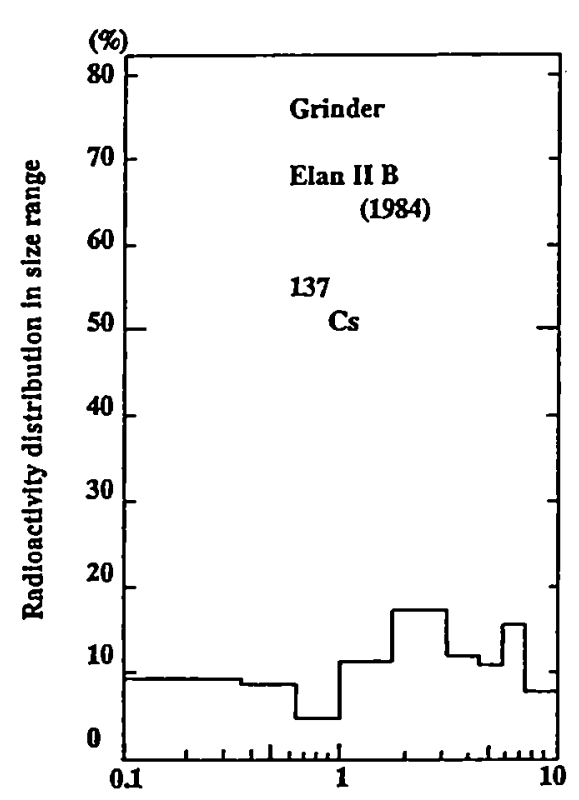

Fig. 2 - Radioactivity distribution in particle size range in cutting stainless steel using grinder

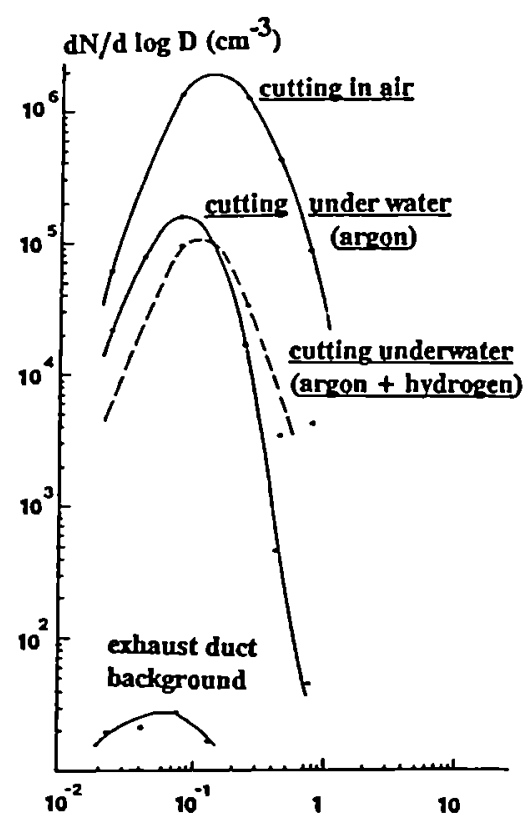

Fig. 3 - Numeric particle concentration distribution with plasma torch cutting in air and underwater used on stainless steel plate 

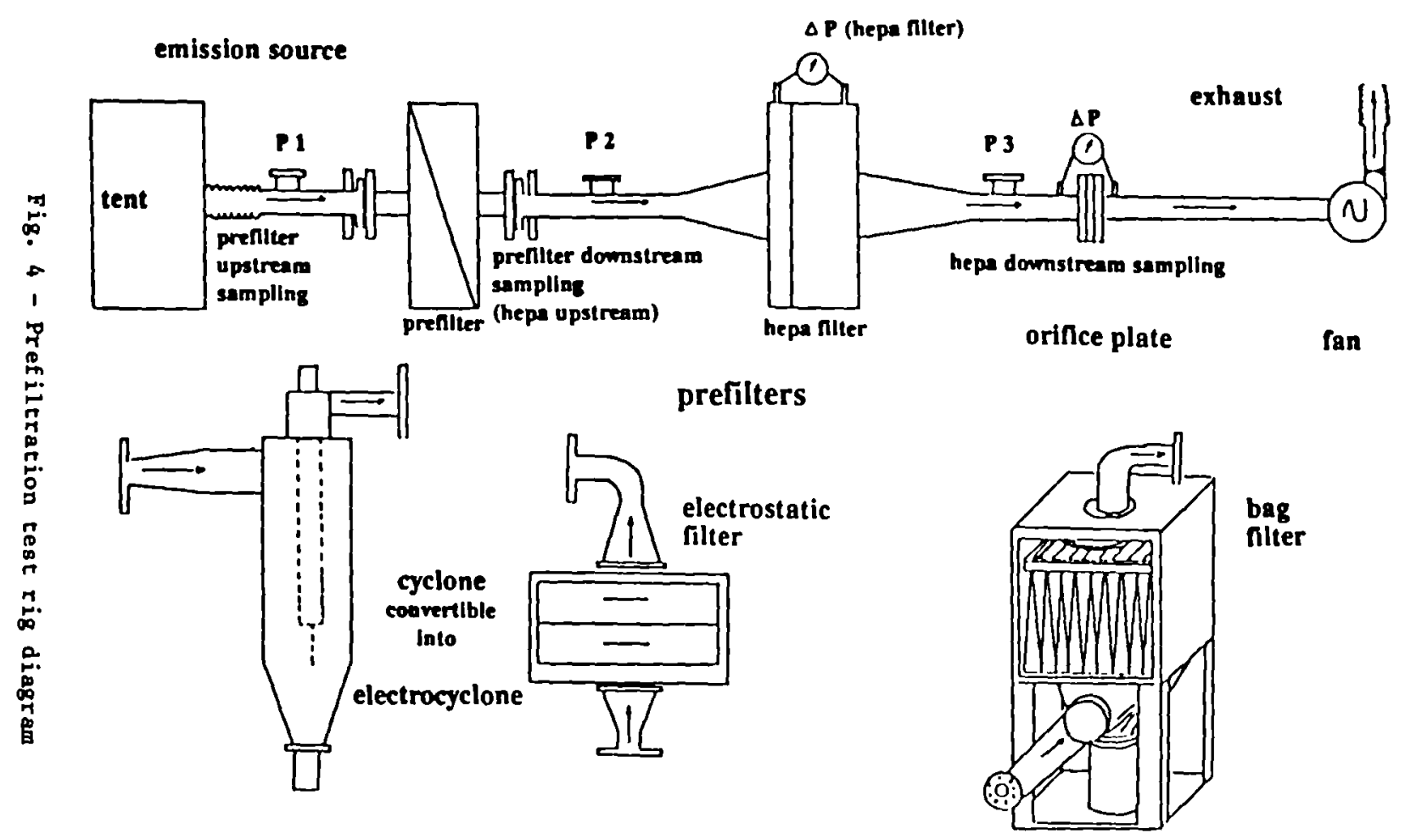


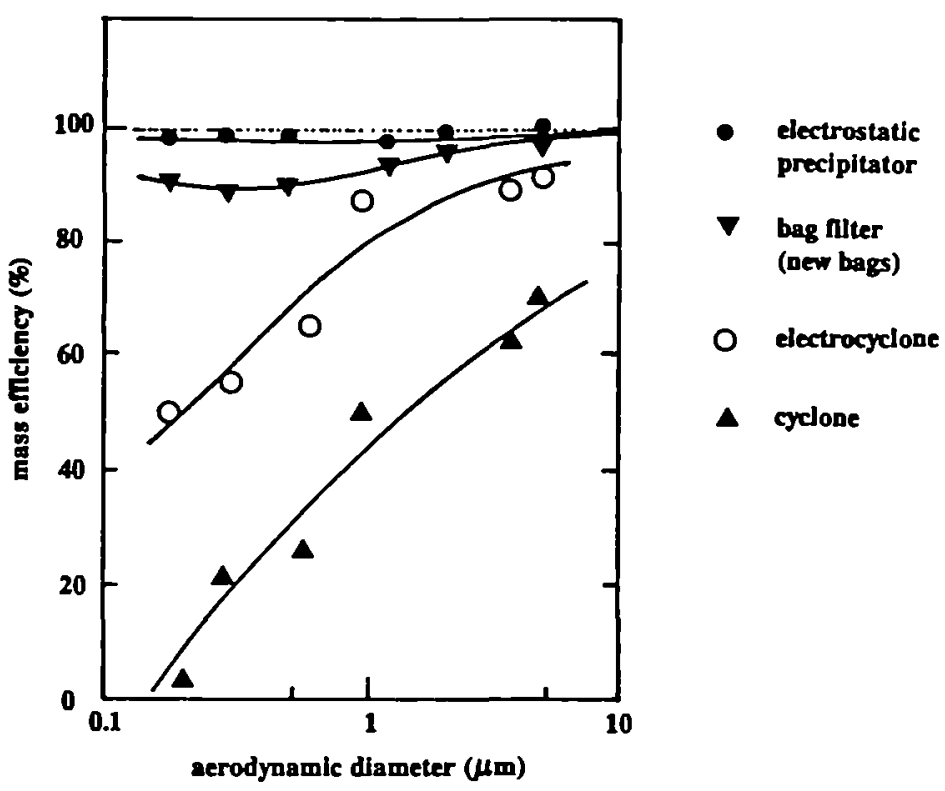

Fig. 5 - Efficiency of the cyclone, the electrocyclone, the ESP and the bag filter made

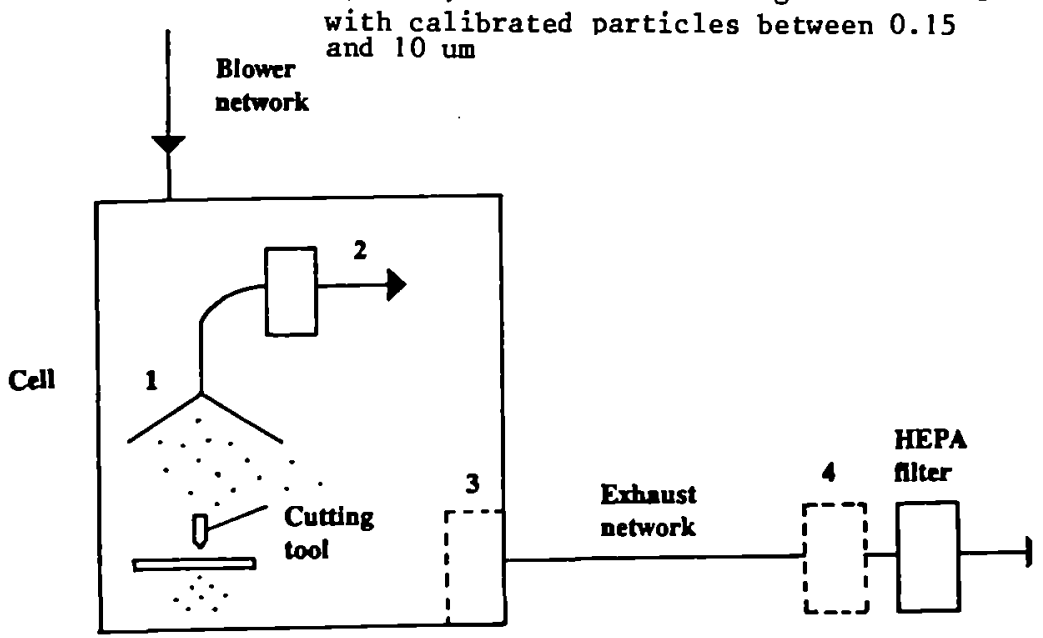

\section{1 : capture at source} $2,3,4:$ prefilters

Fig. 6 - A few of the protection techniques which may be considered 


\title{
SPREADING AND PILTERING OF RADIOACTIVE BY-PRODUCTS FROM UNDERHATER SEGMENTING
}

\author{
B. Steiner, $\mathbf{F r}$.- W. Bach, H. Haferkanp
}

Universitát Bannover, Bannover, Germany

\begin{abstract}
The generated cutting effluents in atmosphere and in vater of the plasma arc cutting and grinding have been found out for the under water cutting of stainless steel, mild steel and aluminiun. Different filter systems for air and water filtration have been tested. The effluent generation is strongly connected to the used parameters. No aerosol generation could be measured with the orinding technique when cutting stainless steel or aluminium.
\end{abstract}

\section{INTRODUCTION}

Thermal and mechanical underwater cutting of metallic nuclear components lead to cutting by-products, which have to be collected and stored safely. In this case the underwater segmenting was done with the plasma arc as an example for a thernal cutting technique and with grinding as an example for a mechanical cutting technique with inactive samples.

Every cutting procedure generates particles, which stay in the water or come to atmosphere depending on their size and density. The material of the produced kerf may cause serious disadvantages. These are the reduction of the visibility, the contamination of the water, the basin and the cutting equipment, and the rising of the level of radiation at the water surface followed by danger for the operating personal.

There are different types of cutting effluents:

- particles, which come to atmosphere as aerosols;

- gaseous effluents, e.g. the plasma gas and products from the reaction between the hot metal and surrounding naterials as there is the water;

- suspended particles which have a great influence to the possibility of observation to the cutting process and may reduce the quality of protection of the water against radiation;

- sedimented particles which settle to the ground of the basin;

- solved naterial from the reaction of the hot netal with the vater, noticed in a changing of the $\mathrm{pH}$-degree and the conductivity of the water.

The aim of this research vork was to find out the cutting parameters for underwater plasma arc cutting and grinding in the view to minimize the enission of particles in air and water, to collect all produced cutting byproducts in air and water, to bring them to various filter systems and measure their efficiencies and to give proposals for air and water filter systems for cutting radioactive materials.

The work was done with grinding and plasma arc cutting up to a sheet thickness of $60 \mathrm{~mm}$ for stainless steel (1.4301 or AISI 304, cladded carbon steel, carbon steel (St 37 ) and aluniniun (AlHg3).

\section{DESCRIPTION OF EQUIPKENT}

The cutting tests with plasma arc cutting and grinding under water took place in the facility shown in figure 1. The main parts of this facility are the water tank (1) with the plasma torch or other tool nounted at the $x-y-z-m a n i p u l a t o r(2)$ and the ventilation duct (3) with several measuring points (5) for the analysis of airborne cutting effluents. The dimensions of the water tank are $2.4 \mathrm{~m} \times \mathrm{m} \times 2 \mathrm{~m}(\mathrm{~b} \times 1 \times \mathrm{h})$. The wall of the tank is made out of Plexiglas to allow a good vien to the cutting process. $A$ hood, which is made out of plexiglas too, is dipped a little in the 


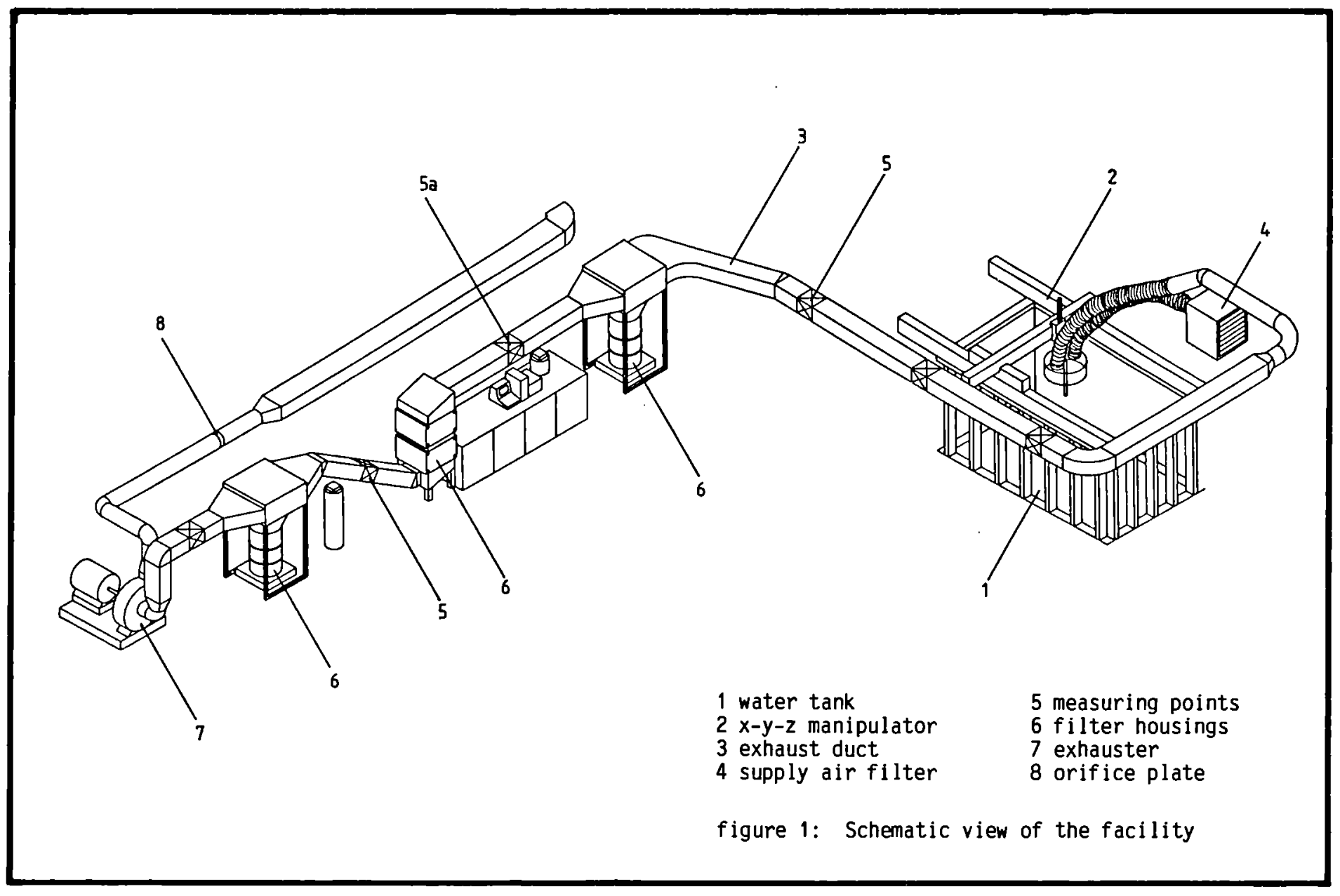




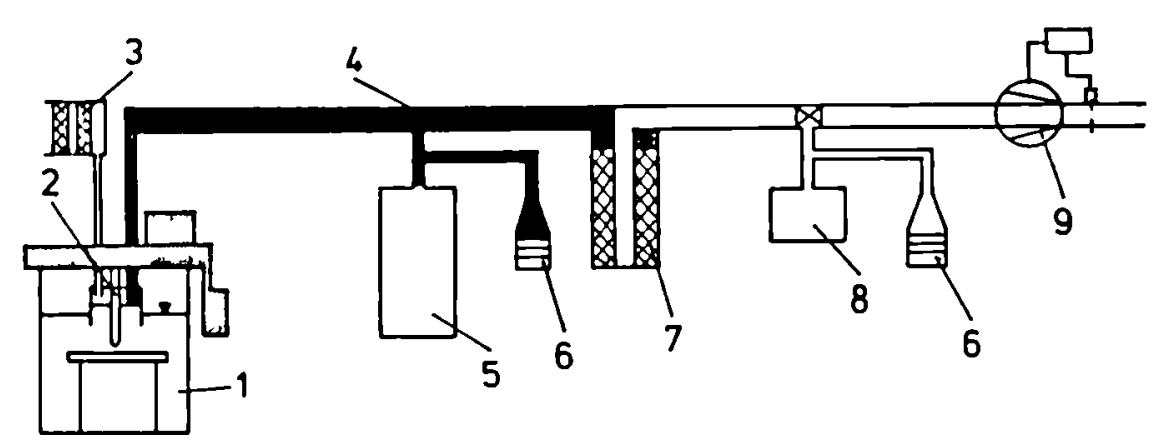

1 Waterbassin with $x-y \cdot z$-manipulator

6 impactor

2 Plasma forch with suction hood

7 Filter

3 Supply air filter

B Condensation nucleous counter

4 Measuring point

9 Exhouster with flow control

5 Electrical aerosol analyser

figure 2: Schenatic view of the facility with the aerosol measuring equipment

water to ensure that all particles coming to the surface of the water are sucked off. Clean air is supplied to the suction hood by a BEPA filter with a nominal efficiency of 99,99995 * (class "U", Delbag company). This is done to get a certain speed of flow in the duct and to minimize the particle losses during the transport to the measuring points. The duct has a rectangular cross section of $300 \mathrm{~mm} \times 400 \mathrm{~mm}$. It is made out of zinc coated sheets and it is vell grounded in order to prevent electrostatic effects. The aerosol sampling was done with isokinetic probes at the measuring point (5a). There is a distance of 28 between the cutting tool and this measuring point. Three air filtration units (6) are integrated in the duct. The exhauster (7) allows a variable flow up to $3600 \mathrm{~m}^{3} / \mathrm{h}$ corresponding to a velocity in the duct up to $8 \mathrm{~m} / \mathrm{s}$. The flow is checked continuously by recording the pressure drop at a standard orifice plate (8). rigure 2 gives a schematic view of the aerosol equipment.

The cutting tests for the analysis of the cutting effluents in the water vere done with the same manipulator and facility but in a small basin of a volume of 3001 in order to reduce the spreading of the particles in the big pool and to raise the concentration of solved elements.

The plasma arc cutting under water was done with a plasma torch of the type PrC-grun, made by Messer-Griesheim, Frankfurt, FRG. The torch is constructed for a maximal current of $500 \mathrm{~A}$. It has a tipped electrode of thoriated tungsten. The cooling of the torch is done with water, but there is an additional secondary gas flow of compressed air for the cooling of the nozzle and the stabilization of the arc. The initial strike of the pilot arc in the torch is done by use of a high frequency starter. Argon is used at start-up. If the arc is established, the bigh frequency is switched off and nitrogen is added to get more power for the process. The power source PC-600 is nade by Messer-Grieshein too. The maximal power output is $100 \mathrm{~kW}$ at a current of $600 \mathrm{~A}$. The source works with an electronic current stabilization. 
The cutting tests with the grinding technique were done with a conventional vertical grinder which was driven by compressed air. The nominal output power was $1.2 \mathrm{~kW}$. The grinding disc was driven directly without any gearbox and had a diameter of $178 \mathrm{~mm}$ and a thickness of $3.5 \mathrm{~mm}$. The speed of rotation was measured by an inductive sensor. Air flow and air pressure were controlled continuously.

The analysis of the solid effluents in air was done at the measuring point 5 a (see fig. 1). Several nozzles were installed in the main duct to allow isokinetic sampling into

- a low pressure impactor (Hauke LPI 0,015/25)

- an electrical aerosol analyser (EAA 3030)

- a condensation nucleous counter (CNC 3020)

The low pressure impactor (Hauke LPI $0,015 / 25$ ) allows the determination of the particle size distribution between $15 \mathrm{~nm}$ and $16 \mu \mathrm{m}$ aerodynamic diameter in eleven classes. The gas flow through the impactor is held constant by use of a critical orifice. The deposited particles are weighed to analyse the mass distribution.

The electrical aerosol analyser EAA 3030 (TSI Co.) gives a size distribution of particles between $0.01 \mu \mathrm{s}$ and $1 \mu \mathrm{m}$ in eight size classes depending on the electrical mobility. The instrument needs a constant aerosol concentration and distribution during a measuring period. The result of this instrument is a size distribution of the electrostatic diameter of the particles, which is not comparable to the aerodynamic diameter without calibration. It is only possible to calculate the mass of the aerosol when the density of the particles is known.

The condensation nucleous counter measures the concentration of the particles of a size below $3 \mu \mathrm{m}$. This instrument gives the results "online", therefore the particle concentration in the duct can be observed. The range of concentration is 0.01 to $10^{7}$ particles per $\mathrm{cm}^{3}$. The used equipment is a CNC 3020 , manufactured by TSI.

\section{RESULTS}

In the first stage of work the cutting tests were done to find out cutting parameters which are optimized in the sense of a safe cut and a minimal production of cutting effluents. It is a matter of fact, that the aerosol generation of the plasma arc cutting can be taken for an on-line control of the cutting quality. Table I gives the parameters for the plas-

Table I Plasma arc cutting - cutting parameters

\begin{tabular}{|c|c|c|c|c|c|c|c|c|c|c|c|}
\hline material & . & 1 & \multicolumn{2}{|c|}{1.4301} & 1 & \multicolumn{2}{|c|}{ St 37} & \multicolumn{2}{|c|}{ |cladd. | } & \multicolumn{2}{|c|}{ AlMg 3} \\
\hline thickness & [mm] & 20 & 40 & 60 & 20 & 40 & 60 & 18 & 10 & 20 & 40 \\
\hline waterdepth & [mm] & 100 & 100 & 100 & 100 & 100 & 100 & 100 & 100 & 100 & 100 \\
\hline current & [A] & 270 & 410 & 400 & 260 & 420 & 400 & 255 & 250 & 260 & 420 \\
\hline voltage & [v] & 110 & 135 & 160 & 120 & 125 & 140 & 130 & 130 & 130 & 140 \\
\hline $\begin{array}{l}\text { speed } \\
\text { plasma gas }\end{array}$ & [mm/min] & 350 & 230 & 180 & 380 & 300 & 150 & 600 & 500 & 330 & 300 \\
\hline argon & [1/min] & 30 & 36 & 36 & 30 & 36 & 36 & 30 & 30 & 30 & 36 \\
\hline nitrogen & {$[1 / \min ]$} & 20 & 18 & 18 & 20 & 18 & 18 & 20 & 20 & 20 & 18 \\
\hline sec. air & {$[1 / \min ]$} & 70 & 70 & 70 & 70 & 70 & 70 & 70 & 70 & 70 & 70 \\
\hline nozzle & [mm] & 2.5 & 3.5 & 3.5 & 2.5 & 3.5 & 3.5 & 2.5 & 2.5 & 2.5 & 3.5 \\
\hline distance: & & & & & & & & & & & \\
\hline nozz . -workp. & [mm] & 8 & 8 & 8 & 8 & 8 & 8 & 8 & 8 & 8 & 8 \\
\hline
\end{tabular}


ma arc cutting of the different tested naterials and thicknesses. There is no changing of the parameters observed up to a water depth of $1.5 \mathrm{~m}$.

The cutting parameters of table I can be used for the cutting in the gravity position $(g)$. This cutting position is not very realistic for a real dismantling of complex structures. Therefore the cutting behaviour of a plasma torch in the positions horizontal (b) and overhead (o) was analysed. With a little changing of the parameters it is possible to cut in these positions without secondary arcs. Table II gives the results of the aerosol measurement when cutting stainless steel.

Table II Plasma arc cutting - aerosol generation for stainless steel

\begin{tabular}{|lcccccccccc|}
\hline thickness & [mm] & & 20 & & & 40 & & 60 & \\
cutting position & $g$ & h & 0 & $g$ & $h$ & 0 & $g$ & $b$ & 0 \\
aerosolemission & {$[g / m]$} & 0,2 & 0,3 & 0,3 & 0,5 & 0,6 & 0,7 & 1,3 & 1,3 & 1,4 \\
\hline
\end{tabular}

The cutting parameters of the grinding tool are given in table III. The grinding produces a rather small seam and a very smooth cutting edge compared with the plasma technique. It needs a very solid construction of the manipulator because of the large cutting forces. The table gives the cutting parameters for cutting stainless steel and aluminium at atmosphere and under vater. There is a great decrease of the speed of rotation when the cutting is done underwater because of the great loss of power in the water. The rate of abrasion is an indirect definition of the cutting speed. The resulting cutting speed is about $0.4 \mathrm{~mm} / \mathrm{min}$ when cutting stainless steel of $10 \mathrm{~mm}$ thickness, and about $45 \mathrm{~mm} / \mathrm{min}$ when cutting the same thickness of aluminium. The result of the aerosol measurement by underwater grinding of stainless steel and aluminium is, that an emission of particles could not be detected even with a condensation nucleous counter.

Table III Grinding - cutting parameters

\begin{tabular}{|c|c|c|c|c|c|}
\hline $\begin{array}{l}\text { condition } \\
\text { atmosphere } \\
1.4301 \\
\text { AlMg } 3\end{array}$ & $\begin{array}{l}\text { flow rate } \\
{\left[\mathrm{nm}^{3} / \mathrm{h}\right]} \\
73.5 \\
86.7\end{array}$ & $\begin{array}{l}\text { rotation } \\
\text { [1/min] } \\
6880 \\
5100\end{array}$ & $\begin{array}{l}\text { feed } \\
\text { [mm/min] } \\
50 \\
500\end{array}$ & $\begin{array}{c}\text { infeed } \\
\text { [mm] } \\
1 \\
2.3\end{array}$ & $\begin{array}{c}\text { abrasion } \\
\text { [mm/min] } \\
150 \\
3450\end{array}$ \\
\hline $\begin{array}{c}\text { underwater } \\
1.4301 \\
\text { AlMg } 3\end{array}$ & $\begin{array}{l}72.3 \\
75.6\end{array}$ & $\begin{array}{l}2200 \\
2200\end{array}$ & $\begin{array}{r}10 \\
500\end{array}$ & $\begin{array}{c}0.5 \\
1\end{array}$ & $\begin{array}{r}15 \\
1500\end{array}$ \\
\hline
\end{tabular}

For the plasma arc cutting under water the aerodynamic particle diameter of the generated aerosols is below $0.3 \mu \mathrm{m}$. Therefore only high efficiency filtration systems have been tested. The noninal efficiencies and the standard test conditions are defined in the german standard DIN 24184 for several filter aalities. The behaviour of the different filters was tested during the cutting of $60 \mathrm{~mm}$ stainless steel, mild steel and aluminium (AlMg 3 ) with the cutting parameters of table I but a cutting speed of only $100 \mathrm{~mm} / \mathrm{min}$ in order toraise the generated amount of effluents. The technical data of the tested filters are given in table IV. The pressure drop as a function of cutting length and the transnission range as a function of cutting length are shown in figure 3 and 4 for the filtering of aluminium aerosols. Each of the tested filters bad an active filter area 


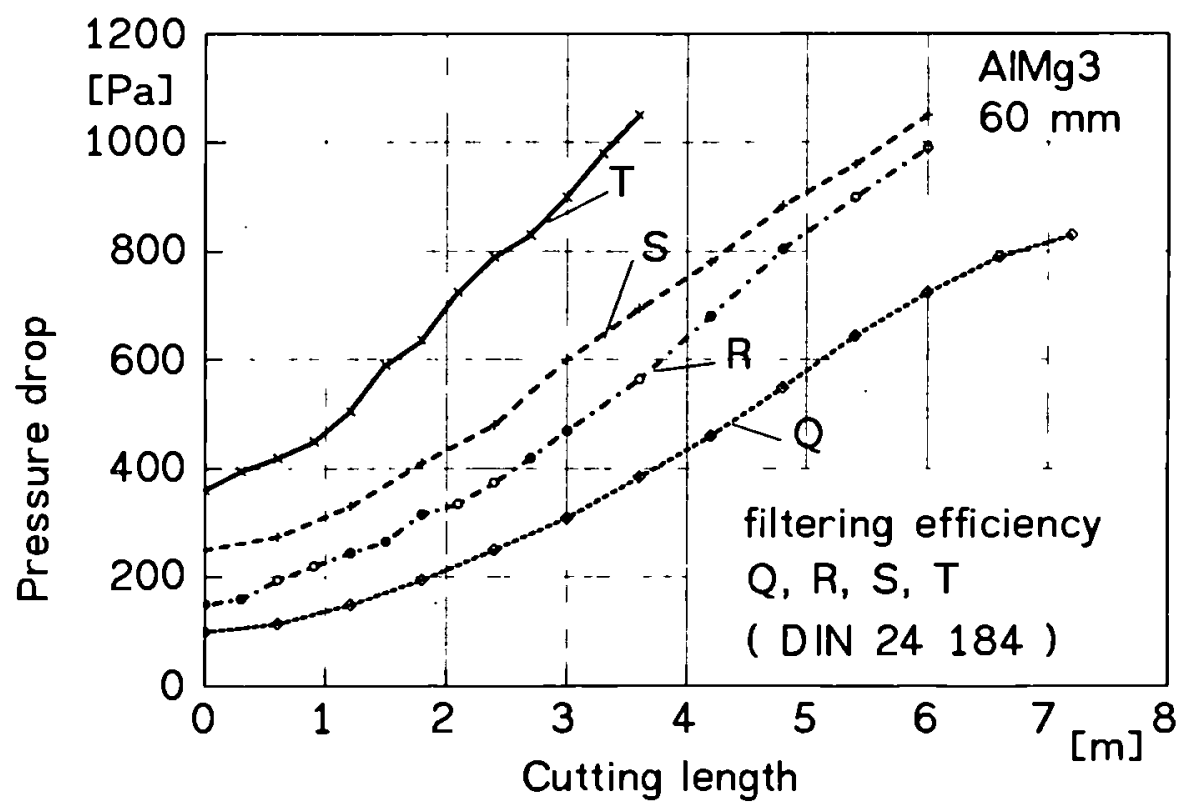

figure 3 Plasma arc cutting - pressure drop as a function of cut length of aerosol filters

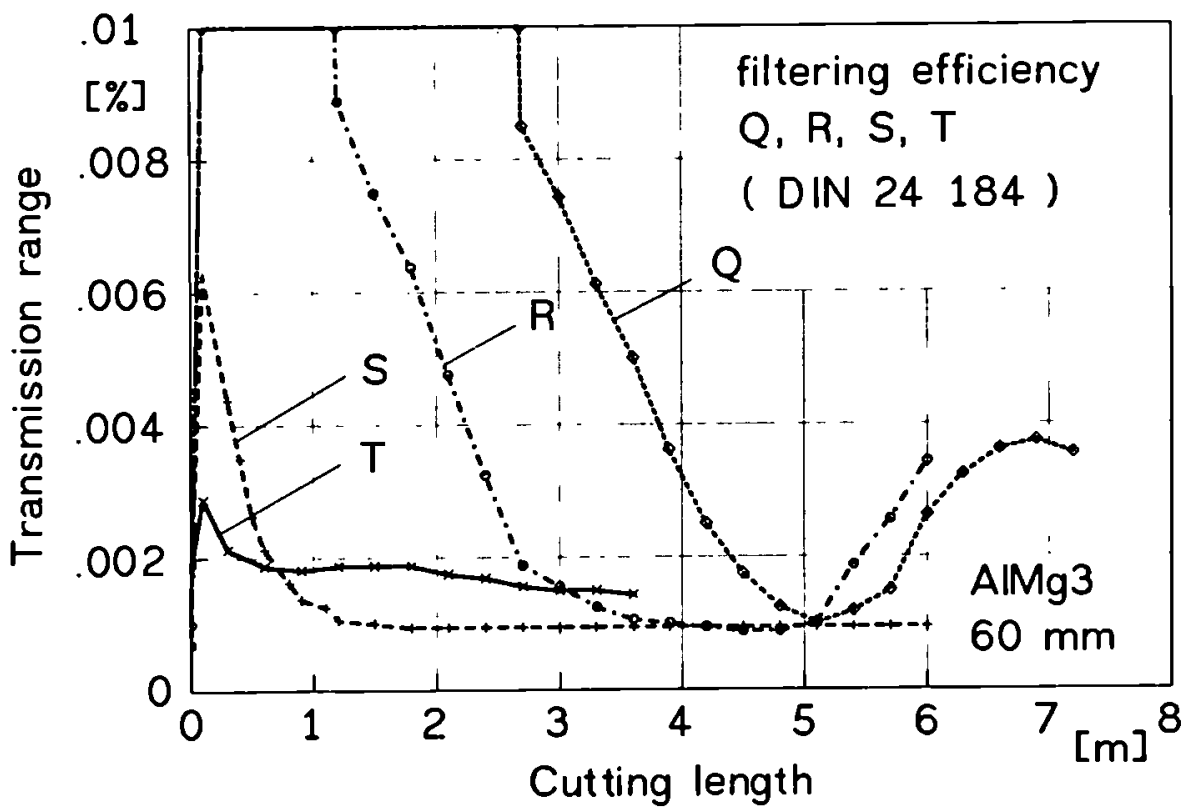

figure 4 Plasma arc cutting - transmission range of aerosol filters as a function of cut length 
Table IV Aerosolfiltration - technical data of tested filtersystems

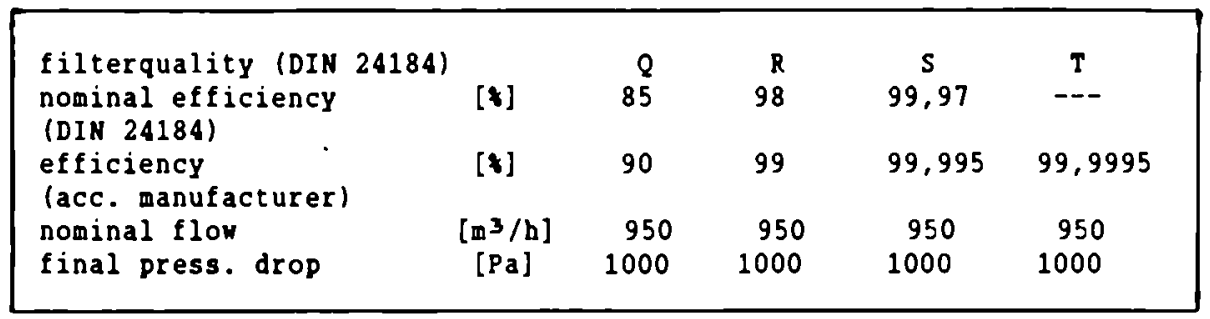

of about $5.3 \mathrm{~m}^{2}$ to be comparable.

The sedimented dross is collected at the bottom of the small cutting tank and then dried and weighed. A sieve size analysis is done with the dried dross. The following table $V$ gives the total amount of the sedimented dross per meter length of cutting and the changing of the conductivity and the $\mathrm{pH}$-degree.

Table V Plasma arc cutting - sedimented dross, pH-degree, conductivity

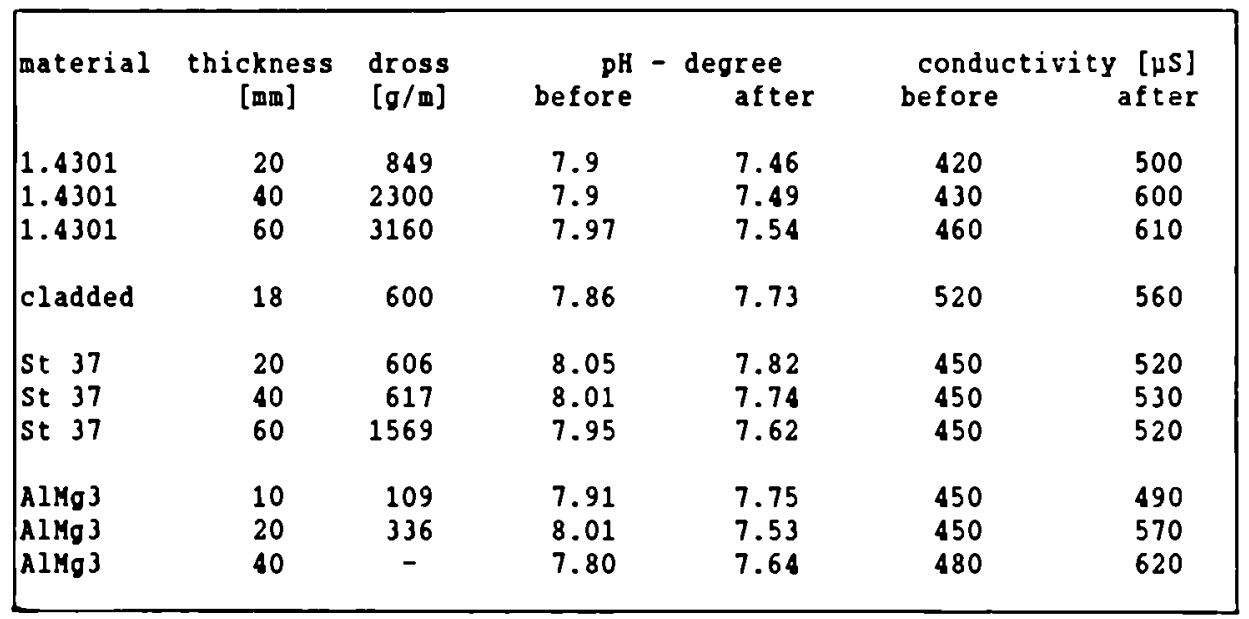

The particles of the cutting effluents, which do not settle down to the bottom of the tank but stay in the water over several minutes or hours, are called suspended particles. They reduce the visibility and may cause radiological problems because the spreading of contamination. Their behaviour is changing with increasing time after the cutting procedure. There is a cloud of particles around the place of cutting short time after the cut. Then the particles follow the upward flow of the heated water and form a well marked layer just beneath the water surface. After that there is an agglomeration of these fine particles followed by their sedimentation to the bottom of the basin. The result of this particle behaviour is a bad visibility to the torch and the cut. The total mass concentration of these particles is analysed by filtration and weighing. Fibreglass filters are used with a diameter of $47 \mathrm{~mm}$. The analysis of the particle size was done with an optical particle counter within the first two ninutes after the end of the cut to beware of an agglomeration of the particles. The results of these measurements are given in table VI.

The filtration test of the water filters were done with stainless 
Table VI Plasma arc cutting - Generation and size of suspended particles

\begin{tabular}{|c|c|c|c|c|c|c|}
\hline thickness & {$[\mathrm{mm}]$} & 10 & 18 & 20 & 40 & 60 \\
\hline $\begin{aligned} 1.4301 & \\
& x=08\end{aligned}$ & $\begin{array}{l}{[\mathrm{g} / \mathrm{m}]} \\
{[\mu \mathrm{m}]} \\
{[\mu \mathrm{m}]}\end{array}$ & - & $\overline{-}$ & $\begin{array}{l}1.09 \\
8.1 \\
25\end{array}$ & $\begin{array}{c}12.2 \\
5.8 \\
32\end{array}$ & $\begin{array}{l}6.06 \\
4.5 \\
22\end{array}$ \\
\hline St $37 \begin{array}{ll} & \\
& x_{m} \\
& x_{50}\end{array}$ & $\begin{array}{l}{[\mathrm{g} / \mathrm{m}]} \\
{[\mu \mathrm{m}]} \\
{[\mu \mathrm{m}]}\end{array}$ & $\begin{array}{l}- \\
-\end{array}$ & - & $\begin{array}{l}2.56 \\
6.1 \\
20\end{array}$ & $\begin{array}{l}5.46 \\
3.5 \\
20\end{array}$ & $\begin{array}{l}2.87 \\
6.1 \\
21\end{array}$ \\
\hline $\begin{array}{l}\text { AlMg } 3 \\
\\
\quad x_{m} \\
x_{508}\end{array}$ & $\begin{array}{l}{[\mathrm{g} / \mathrm{m}]} \\
{[\mu \mathrm{m}]} \\
{[\mu \mathrm{m}]}\end{array}$ & $\begin{array}{l}13.24 \\
5.4 \\
28\end{array}$ & - & $\begin{array}{l}24.75 \\
6.7 \\
27\end{array}$ & $\begin{array}{c}107.22 \\
7.7 \\
22\end{array}$ & $\begin{array}{r}113 \\
- \\
-\end{array}$ \\
\hline $\begin{array}{l}\text { cladded } \\
\qquad X_{\text {m }} \\
X_{50 \%}\end{array}$ & $\begin{array}{l}{[\mathrm{g} / \mathrm{m}]} \\
{[\mu \mathrm{m}]} \\
{[\mu \mathrm{m}]}\end{array}$ & - & $\begin{array}{l}8.05 \\
5.6 \\
30\end{array}$ & - & $\begin{array}{l}- \\
-\end{array}$ & - \\
\hline
\end{tabular}

and mild steel with a sheet thickness of $60 \mathrm{~mm}$ and aluminium with sheet thickness of $40 \mathrm{~mm}$. All filters are filter cartridges with a length of 250 $\mathrm{mm}$ and a diameter of about $60 \mathrm{~mm}$. They were mounted in a housing made out of plexiglas to control their behaviour. A list of the analysed filters with their nominal and measured datas is given in table VII.

Table VII Results of the water filtration tests

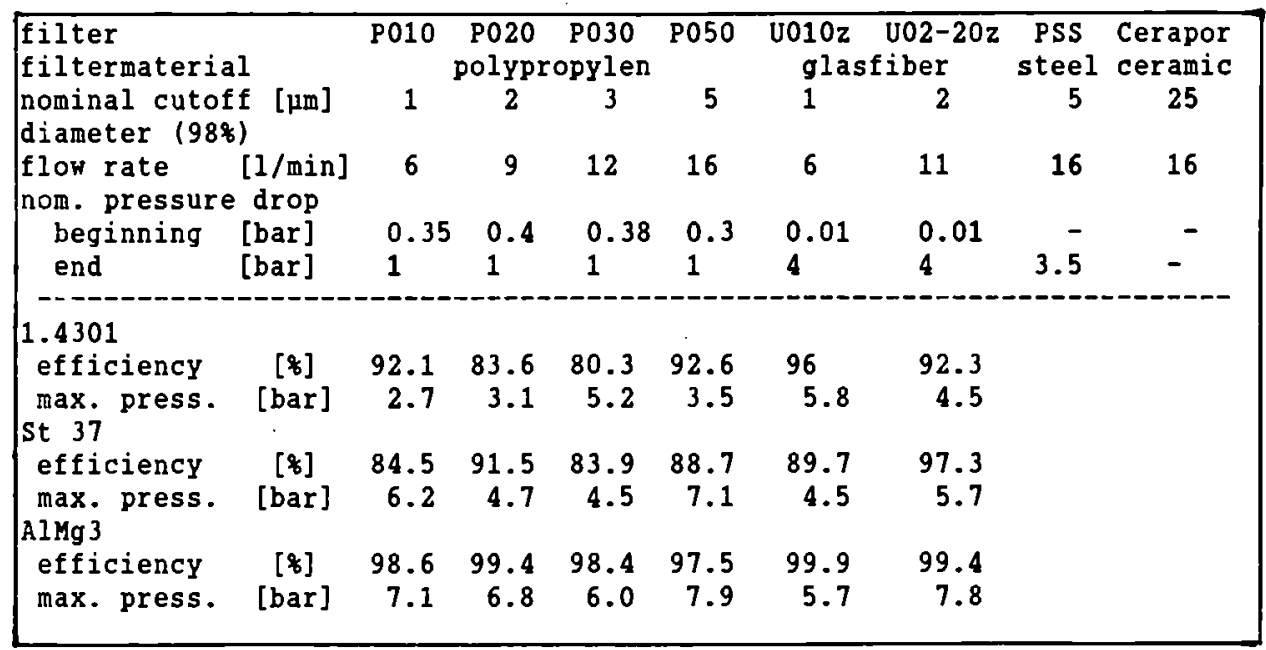

The results of the filtration with polypropylene and fibreglass filters were quite reasonable. The exact behaviour for stainless steel and aluminium is shown in figure 5. The polypropylere type is very insensitive against a higher then nominal pressure drop. The results of the experiment with the PSS filter were not successful. When filtering suspended AlMg 3 particles, the PSS type reached the nominal pressure drop of ten bar after a few seconds. Recleaning was not possible. The result of the available ce- 

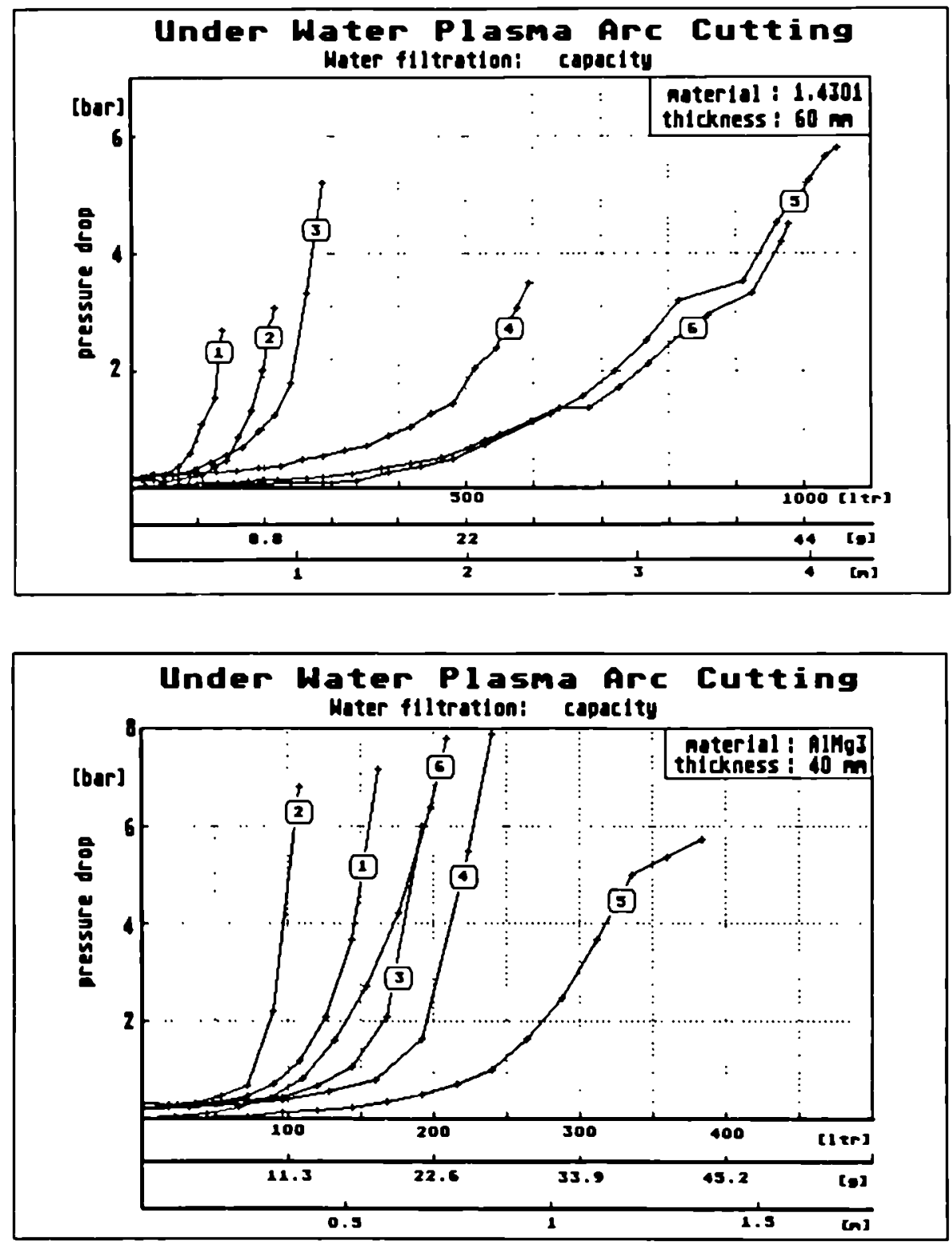

figure 5 Plasma arc cutting - capacity of the tested water filters for the suspended particles of stainless steel and aluminium as a function of filtered watervolume, collected mass and cutting length

1 - polypropylen filter $1 \mu \mathrm{m}$

2 - polypropylen filter 2 $\mu \mathrm{m}$

3 - polypropylen filter $3 \mu \mathrm{m}$

4 - polypropylen filter $5 \mu$

5 - glasfiber filter $1 \mu \mathrm{m}$

6 - glasfiber filter 2 un 
ramic filter is bad, because the nominal particle cut-of $f$ diameter is too large.

The comparison of the chemical analysis of the original materials and the sedimented kerf materials gave the result, that there is nearly the same composition of elements. Only the concentration of manganese in the kerf material of stainless steel is decreasing compared to the sheet material. Another decrease is found in the concentration of magnesium in the kerf material of the aluminium sheets.

The analysis of the water quality after plasma cutting of the different materials and the different sheet thicknesses (table VIII) corresponds

Table VIII Plasma arc cutting - Amount of solved elements in the water

\begin{tabular}{|c|c|c|c|c|c|c|c|}
\hline material & $\begin{array}{c}\text { thickn. } \\
\text { [mm] }\end{array}$ & $\underset{[\mathrm{mg} / \mathrm{m}]}{\mathrm{Al}}$ & $\begin{array}{c}\mathrm{Cr} \\
{[\mathrm{mg} / \mathrm{m}]}\end{array}$ & $\underset{[\mathrm{mg} / \mathrm{m}]}{\mathrm{Mg}}$ & $\underset{[\mathrm{mg} / \mathrm{m}]}{\mathrm{Mn}}$ & $\underset{[\mathrm{mg} / \mathrm{m}]}{\mathrm{Ni}}$ & $\underset{[m g / m]}{2 n}$ \\
\hline 1.4301 & $\begin{array}{l}20 \\
40 \\
60\end{array}$ & $\overline{-}$ & $\begin{array}{r}30 \\
184 \\
115\end{array}$ & - & $\begin{array}{r}99 \\
555 \\
255\end{array}$ & $\begin{array}{l}n \cdot n \\
n \cdot n \\
n \cdot n\end{array}$ & - \\
\hline st 37 & $\begin{array}{l}20 \\
40 \\
60\end{array}$ & - & $\begin{array}{l}- \\
-\end{array}$ & - & $\begin{array}{r}87 \\
0 \\
0\end{array}$ & - & - \\
\hline AlMg 3 & $\begin{array}{l}10 \\
20 \\
40\end{array}$ & $\begin{array}{r}\text { n.n } \\
73 \\
559\end{array}$ & $\begin{array}{l}\overline{-} \\
\text { - }\end{array}$ & $\begin{array}{l}1754 \\
1416 \\
4026\end{array}$ & - & - & $\begin{array}{l}16 \\
11 \\
17\end{array}$ \\
\hline cladded & 18 & - & 36 & - & 164 & $\mathrm{n} . \mathrm{n}$ & - \\
\hline
\end{tabular}

to the results of the analysis of the kerf material. There is a decrease of the manganese concentration in the kerf material of stainless steel and an increase of the solved manganese. The same happens with the magnesium in the kerf material of the aluminium sheets.

\section{CONCLUSION}

The parameters of the plasma arc cutting and grinding have been found out for the cutting of stainless steel, mild steel and aluminium. The generated cutting effluents in atmosphere and in the water were analysed. The amount of aerosol generation for the plasma arc cutting is strongly connected to the used parameters. The aerosol generation is increasing when the cutting is done not in the gravity but in horizontal or overhead position. No aerosol generation could be measured with the underwater grinding technique when cutting stainless steel or aluminium.

Systems for the filtration of the aerosols and suspended particles in the water have been tested. The results are data about the efficiency of a filter and the collected mass in a filter until the nominal pressure drop of the different systems. 
OPTIMISATION OP FILTERING SYSTEMS FOR VARIOUS CONCRETE DECONTAMINATION TECHNIQUES

\author{
Ebeling. Wolfgang. \\ salzgitter AG, Berlin, FRG \\ Rose, Klaus W. \\ NOELL GmbH, Wuerzburg, FRG
}

\title{
1. Objectives and scope
}

The effectiveness of mechanical and thermal methods for the decontamination of concrete surfaces has already been demonstrated. However, the collection and conditioning of the important amount of generated dust, aerosols and toxic gases needs further development.

As concerns the filtration during thermal decontamination, multistage storing filters, as currently used in the nuclear industry. have shown adequate efficiency. but their limited storage capacity precludes an economic operation. Concerning the effectiveness of filtration systems for mechanical decontamination, no extensive investigations have been undertaken, so far.

The alm of this research programme is to investigate various filter systems, such as storing filters, regenerative mechanical filters, electrostatic filters, concerning their separation efficiency, their storage capacity and service life, Including an analysis of the amount and size distribution of dust avallable at each filtering stage. The experiments will use dust generated by the above decontamination methods on non-radioactive concrete samples.

Based on existing data on radioactive concrete surfaces, a theoretical assessment on possible radioactivity inventories in the investigated filter systems will be made, with a view to thelr optimization for real applications.

\section{Progress and Results}

Due to 1 iterature and market analyses only regenerative filter units were tested.

To determine the separation behaviour, the dust contents in the crude gas and clean gas were measured. Moreover, grain size analyses were carried out before and after the filter.

The total separation degrees during separation of the dust, which arise during flame scarifying and the subsequent brushing of the concrete surface were more than 99.97 .

One filter system was tested at the premises of the GKSS Research Centre, where contaminated steel plates from Brunsbutel nuclear power plant were decontaminated by grinding. About $250 \mathrm{~kg}$ dust was separated from the exhaust a ir during machining of an area of about $200 \mathrm{~m}^{2}$. The suitability of the filter for decontamination operation could thus be proven. 
3. Tests on uncontaminated concrete samples

All investigations carried out to date have shown that the highest raw gas dust loadings are achieved with flame scarfing and subsequent cleaning with a wire brush. As the particle sizes of the dusts arising from this removal method are also smaller than with the other processes (chisel hammer, spike hammer, grinder), the tests were continued using only the flame scarfer and the wire brush. If these dusts, which are unfavourable for a filter plant, can be sufficiently separated, there is no problem to be expected in the filtering of the dusts arising from the other removal processes.

In the tests, a dedusting plant of the DELBAG company was used. The filter was a cartrige filter, type ITK.

3.1. Dust loadings and separation performance of the filter The dust loadings measured in the raw gas and the clean gas show that both with flame scarfing and with subsequent cleaning of the concrete, excellent separation degrees were achieved with the investigated filter ( Table I).

3.2. Particle size analyses

The particle size analyses upstream and downstream of the filter can be seen in Figures 1 and 2 . A shifting towards smaller particle diameters in the cleangas can also be seen with this filter plant.

3.3. Filter cleaning

As already described in the previous annul report. the automatic filter cleaning is adjusted to meet the conditions present in the raw gas. According to the manufacturer, the filter should be cleaned after reaching a pressure drop of approximately 1200 Pa with the dusts arising during flame scarfing and brushing. In continuous operation, the automatic timer is set at the appropriate values. In a trial operation, the cleaning unit was manualiy started after reaching the given maximum pressure drop.

The degrees of separation of the filter were comparably good after several periods of operation at full power and cleaning. The pressure drop of the new filter was $120 \mathrm{~Pa}\left(\mathrm{~V}=2500 \mathrm{~m}^{3} / \mathrm{h}\right)$. After cleaning of the full filter, the pressure drop was approximately 500 Pa. Figure 3 shows the pressure drop at the filter as a function of the amount of dust filtered.

4. Decontamination tests

In decontamination operation by Noell GmbH on the premises of the GRSS, a regenerative filter of the AmaFilter company (similar to the DELBAG ITK type) was used.

4.1. Test performed

During the tests, contaminated plates were decontaminated using grinders. The contamination was composed of approximately $80 \mathrm{Z}$ Co-60 and $20 \mathrm{ZCs}$ Cl37. During the grinding of these plates, attention was paid to generate as much dust as possible, deviating in this regard from realistic conditions. 
The grinding of the plates was carried out under a tent. During extraction, a differentiation was made between:

- dicect suction at the location of the dust arising.

- extraction of the air in the tent.

The extracted dust is retained in the filter. When the filter is cleaned, the dust falls into a collection vessel installed below the filter plant. Bypass lines were installed in the raw gas and clean gas lines of the filter line. Using a dust sample collector. filter paper was exposed to dust in these by-pass lines. The exposure time of the filter was appoximately 5 minutes and the air volume approximately $4.5 \mathrm{~m}^{2}$. The filter papers exposed to the dust in this way were evaluated radiologicaliy in a counter with a large surface area.

4.2. Results

An area of approximately $200 \mathrm{~m}^{2}$ was decontaminated during the tests. The specific activity of the contamination layer was determined by scraping off samples. The average specific activity was 22.5 Bq/ $\mathrm{g}$. The dust collected in the vessel below the filter plant had a weight of $250 \mathrm{~kg}$, a volume of $0.05 \mathrm{~m}^{3}$, and an activity of 2.5 $\mathrm{MBq}$ (specific activity: $10 \mathrm{~Bq} / \mathrm{g}$ ). This means that approximately $55 \mathrm{y}$ of the dust results from the wear of the grinding discs. As therefore approximately $45 z$ of the dust results from the contaminated surface, $1 . e .112 .5 \mathrm{~kg}$, this indicates an average removal of $57 \mathrm{mg} / \mathrm{cm}^{2}$ over an area of $200 \mathrm{~m}^{2}$. The separation rates of the filter for both types of suction are given in Table II.

The results clearly prove the suitability of the filter for decontamination operation. For safety reasons (rupture of the filter), however, any filter plant in decontamination operation should be equipped downstream with a filter of "S" filter classification. 
Table I: Dust loadings in raw gas and clean gas and separation degree of ITK-filter

\begin{tabular}{|l|l|l|l|}
\hline $\begin{array}{l}\text { Stripping } \\
\text { method }\end{array}$ & $\begin{array}{l}\text { Dust loading } \\
\text { in raw gas } \\
\left(\mathrm{mg} / \mathrm{m}^{3}\right)\end{array}$ & $\begin{array}{l}\text { Dust loading } \\
\text { in cleangas } \\
\text { (mg/ms) }\end{array}$ & $\begin{array}{l}\text { Degree of } \\
\text { separation } \\
(Z)\end{array}$ \\
\hline $\begin{array}{l}\text { Flame scarfing } \\
\text { Wire brush }\end{array}$ & 55.4 & $2.14 \times 10^{-3}$ & 99.996 \\
687.5 & $2.45 \times 10^{-3}$ & 99.9996 \\
\hline
\end{tabular}

Table II: Degree of separation of the AMA-filter in the decontamination operation

\begin{tabular}{|l|l|c|c|}
\hline $\begin{array}{l}\text { Type of } \\
\text { suction }\end{array}$ & $\begin{array}{l}\text { Average con- } \\
\text { tamination in } \\
\text { rawgas } \\
\left(B q / \mathrm{m}^{3}\right)\end{array}$ & $\begin{array}{l}\text { Average con- } \\
\text { tamination in } \\
\text { cleangas } \\
\left(B q / \mathrm{m}^{3}\right)\end{array}$ & $\begin{array}{c}\text { Degree of } \\
\text { separation }\end{array}$ \\
\hline $\begin{array}{l}\text { Direct dust } \\
\text { suction } \\
\text { the air in tent }\end{array}$ & 39.5 & 7 & 99.52 \\
\hline 443 & 4.5 & 98.9 \\
\hline
\end{tabular}


663

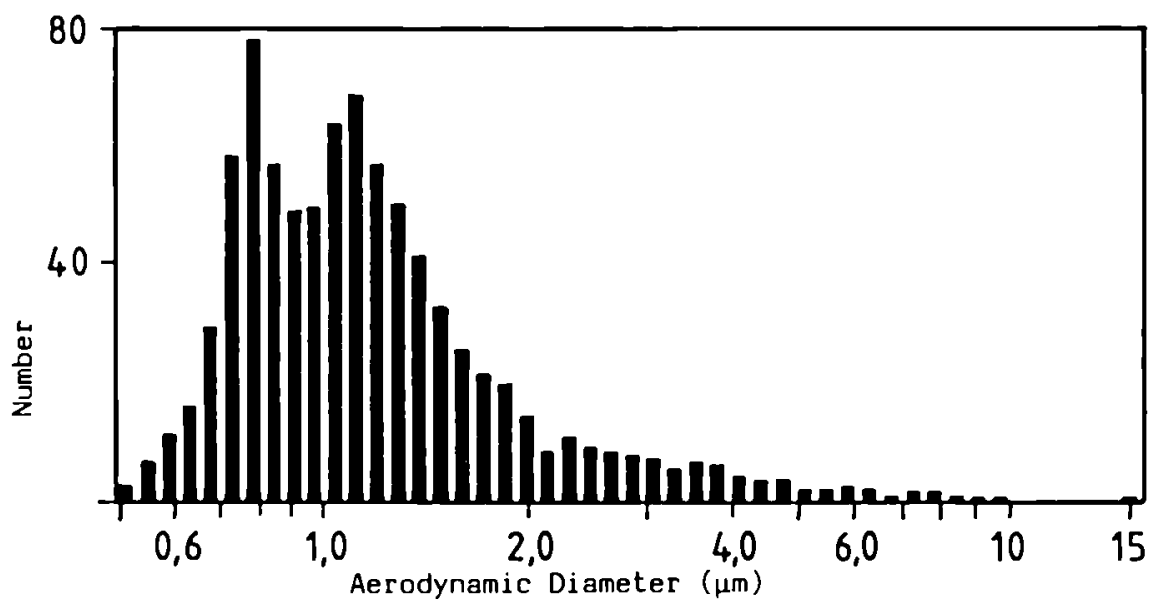

a) Raw gas

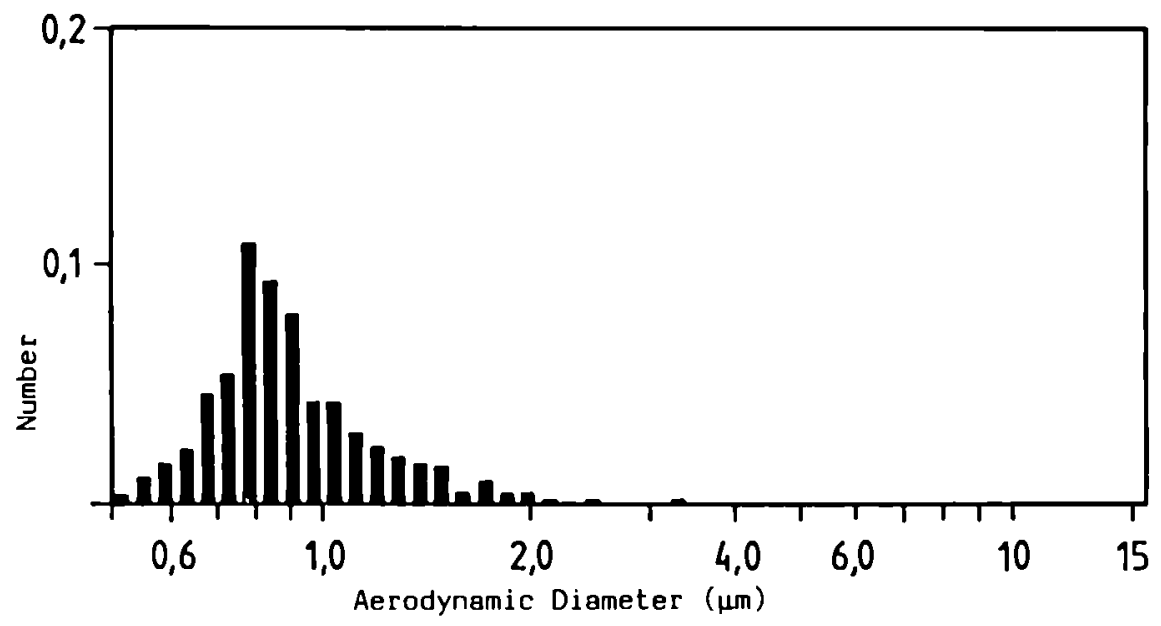

b) Clean gas

Figure 1: Histogram of particle size distribution (flame scarfing) 


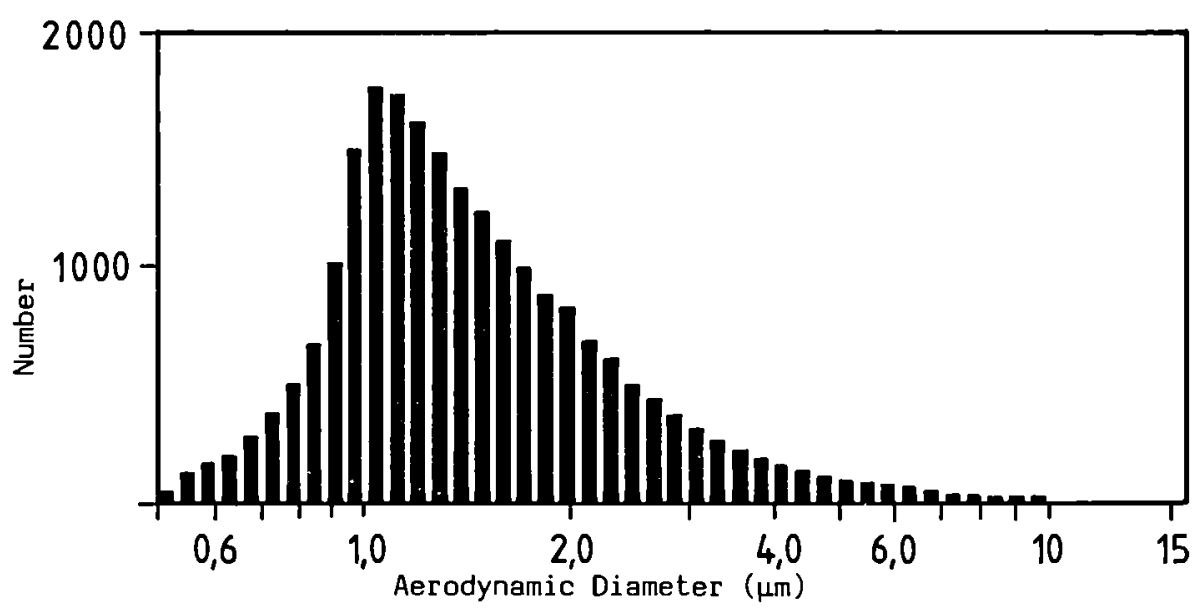

a) Raw gas

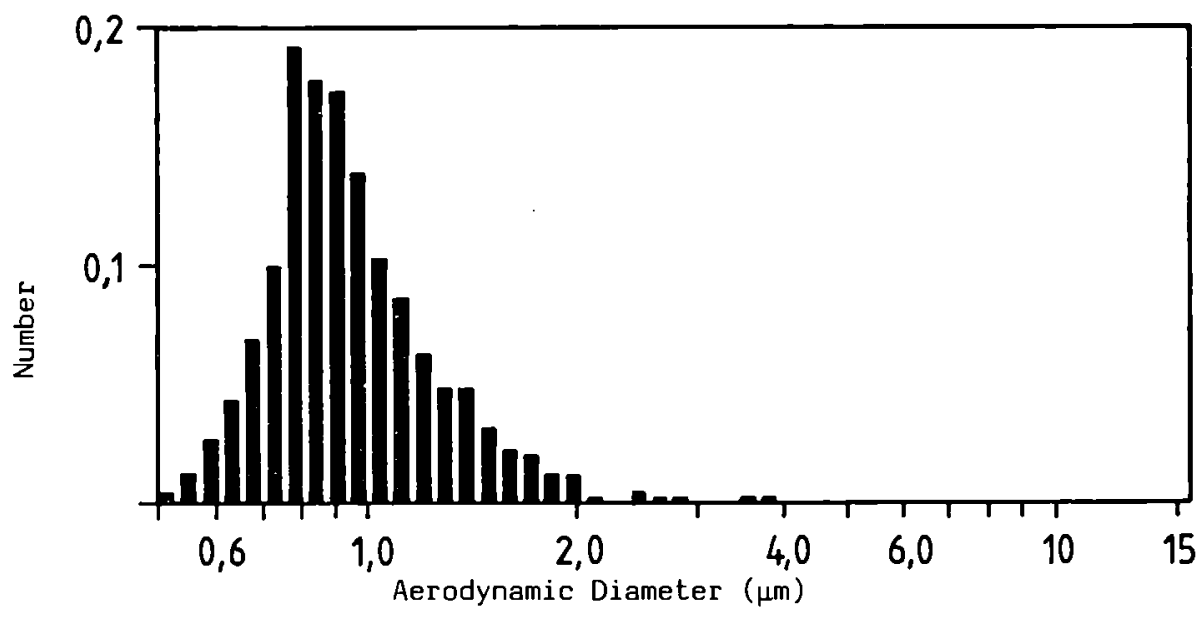

b) Clean gas

Figure 2: Histogram of particle size distribution (wire brush) 
Pressure dorp
at filter ( $\mathrm{Pa})$

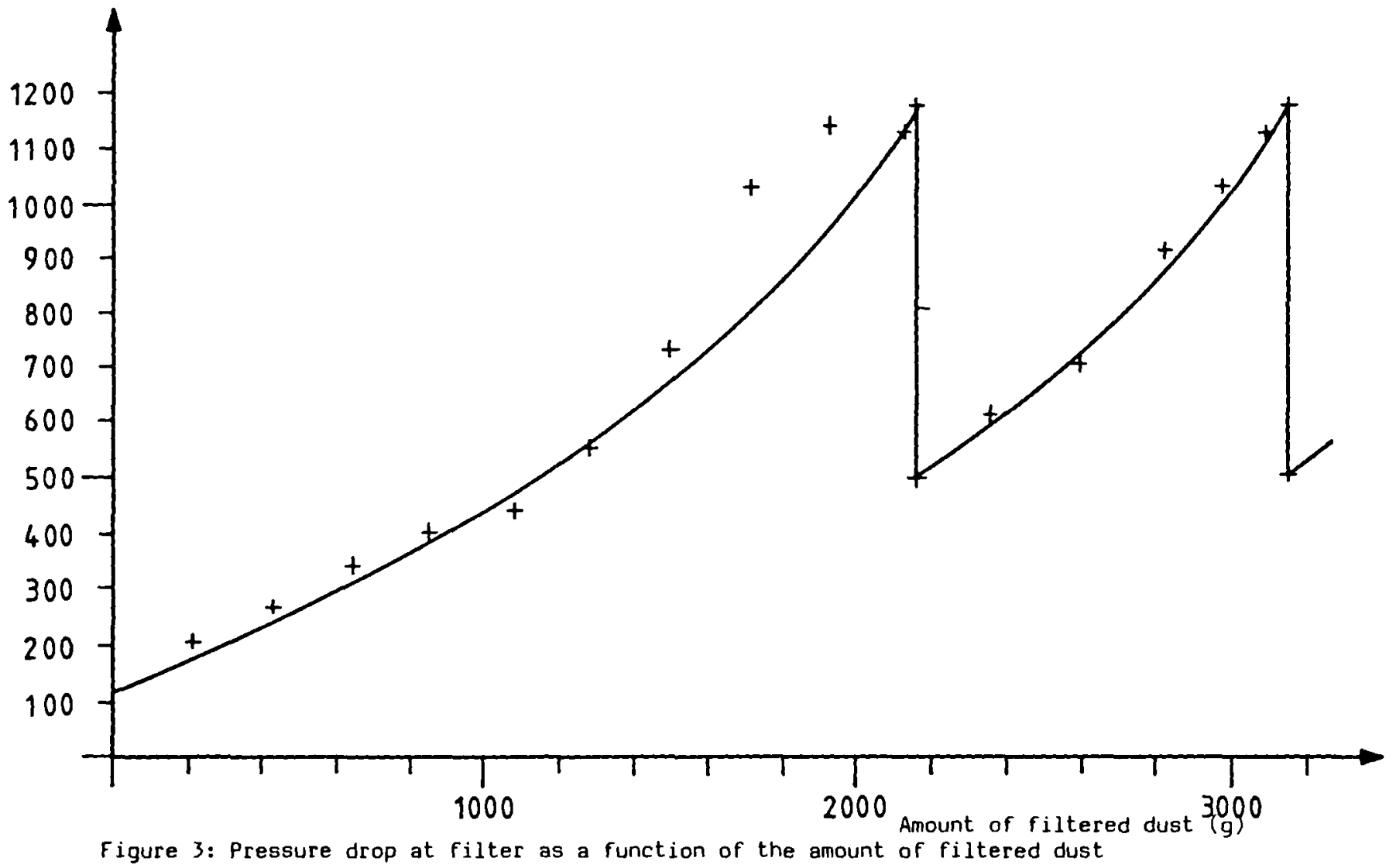

点

Figure 3: Pressure drop at filter as a function of the amount of filtered dust 
Measurements of secondary emissions from plasma arc and laser cutting In standard experiments

G. P1lot, Commissarlat à 1'Energle Atomique CEN Saclay, France

R. Léautler, Commissarlat à l'Energie Atomique CEN Cadarache, France

M. Noë1, Commlssarlat à $1^{\prime}$ Energ1e Atomlque CEN Saclay, France

H. Steiner, Universität Hannover, Federal Republic of Germany

G. Tarron1, ENEA Bologna, Italy

B. Waldie, Heriot-Watt University, Edinburgh, Scotland

\section{ABSTRACT}

As part of an Inter-facility comparison of secondary emissions from plasma-arc and laser cutting techniques, standard cutting tests have been done by plasma arc underwater and in air and laser beam in air.

The same team, CEA/DPT/SPIN, was commissioned to measure the secondary emissions (solid and gaseous) In each contractor's facility with the same measuring rig.

$20 \mathrm{~mm}$ and $40 \mathrm{~mm}$ thick grade 304 stainless steel plates were cut by plasma-torch in three different facilities. Herlot Watt University of Edinburgh, Institute für Werkstoffkunde of Hannover and CEA/CEN Cadarache. $10 \mathrm{~mm}$ and sometimes $20 \mathrm{~mm}$ thick grade 304 stainless steel plates were cut by laser beam in four different facilities : CEA/CEN Fontenay, CEA/CEN Saclay, Institute für Werkstoffkunde of Hannover and ENEA/FRASCATI.

The results obtained in the standard experiments are rather similar, the differences that appear can be explained by the various scales of the facilities (semi-industrial and laboratory scale) and by some particularity in the cutting parameters (additional secondary gas flow of oxygen in plasma cutting at Hannover for example).

Some supplementary experiments show the importance of some cutting parameters.

\section{INTRODUCTION}

In the framework of standard cutting experiments by plasma torch and laser beam, the same measurement rig for secondary emissions has been used in order to eliminate the uncertainties coming from the use of different measuring apparatus.

The contractors involved in the standard cutting experiments by plasma torch are "Universität Hannover" (contract FI 1D-0036), "Herlot Watt Un1versity, Edinburgh" (contract FI 1D-0008) and CEA/CEN Cadarache (contract FI 1D-0037).

The contractors involved in the standard cutting experiments by laser beam are : "CEA/DEMT/CEN SACLAY" (contract FI 1D-0013), "FIAT CIEI-ENEA" (contract FI 1D 0014) and "Universität Hannover" (contract FI 1D-0036). CEA/DPT/SPIN has been charged to measure in the different contractors' facilities the secondary emissions (except for contract FI 1D-0014 for which ENEA/BOLOGNE has carried out the measurements) and to interpret with them the results obtained. 
In this paper the results of the experiments are summarized and compared.

2. OBJECTIVES

The obfectives of the standard cutting tests were as follows:

- Gaseous effluent measurements - aerosols : concentration, size distribution, chemlcal analysis

- gas : nature, concentration

with the same measurement $r i g$ in order to avold numerous uncertainties between different measuring apparatus.

- Assessment of secondary emissions balance in gaseous form and solid form (sedimented drosses, attached slags, suspended particles, aerosols).

- Assessment of Installation and scale effects (laboratory or semiIndustrial level).

- Comparison of gas and aerosol effluents between two cutting tools.

The common stainless steel cutting parameters for plasma torch and laser beam have been chosen-taking into account the constrainsts linked to every Installation and after agreement of all contractors involved.

The optimisation of cutting parameters was not among the objectives of this study and has not been taken into account in choosing their common value.

3. DESCRIPTION OF EQUIPMENT

3.1 Plasma cutting

3.1 .1 Plasma equipment

The main points of the plasma equipments are given in table $I$.

3.1 .2 Plasma factlity

The main characteristics of the facilities where the experiments took place are given in table II.

\subsection{Laser cutting}

3.2.1 Laser equipment

The main characteristics of the laser equipments are given in table III.

\subsubsection{Laser fac1l1ty}

The main characterlotics of the factlities where the experiments took place are given in table IV.

4. OPERATING CONDITIONS

4.1 Plasma arc cutting

The operating conditions of the plasma arc cutting are differentiated in the table $V$ where it 18 indicated the number of testa according to the experimental place.

The current and voltage used are about $200 \mathrm{~A}$ and $110 \mathrm{~V}$ for $20 \mathrm{~mm}$ thickness plate (cutting speed $=60 \mathrm{~mm} / \mathrm{m} / \mathrm{n}$ ), $250 \mathrm{~A}$ and $125 \mathrm{~V}$ for $40 \mathrm{~mm}$ th1ckness plate (cutting speed $=60 \mathrm{~mm} / \mathrm{mln}$ ), $400 \mathrm{~A}$ and $100 \mathrm{~V}$ (Hannover), $300 \mathrm{~A}-350 \mathrm{~A}$ and $130 \mathrm{~V}$ (Cadarache) for $40 \mathrm{~mm}$ thickness plate (cutting speed -180 and $300 \mathrm{~mm} / \mathrm{m} / \mathrm{n})$.

Furthermore, in all experiments, we have the common cutting parameters as follows : 

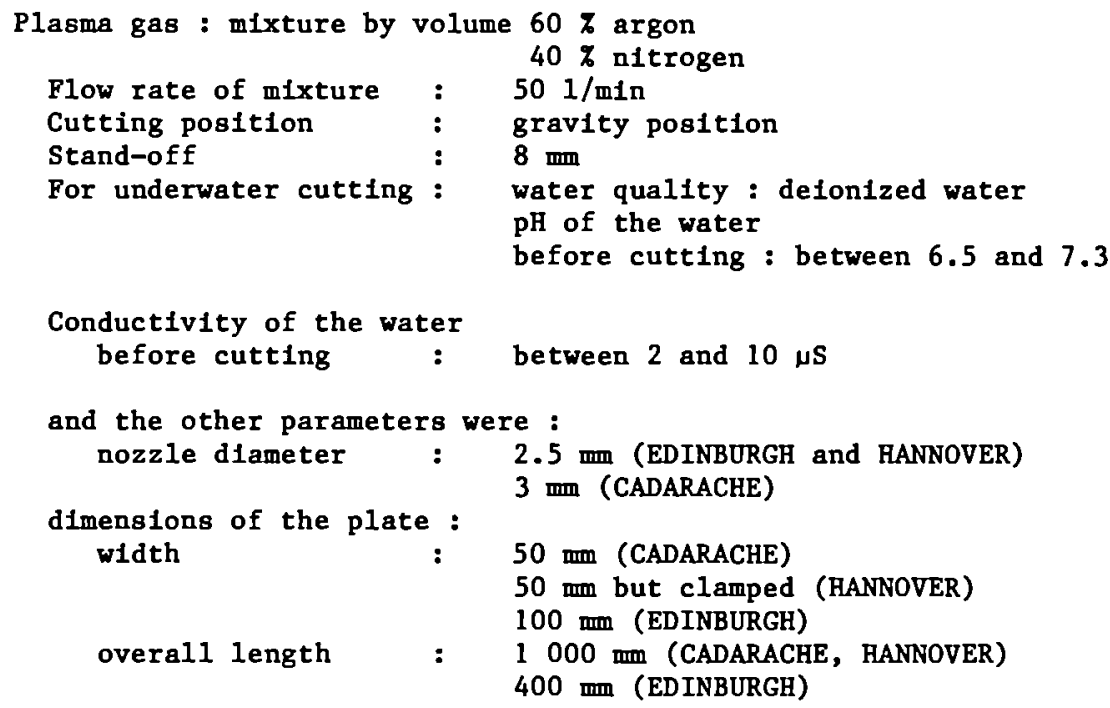

In Edinburgh, the plasma cutting torch was fixed in the vertical position and the workpfece moved horfzontally beneath it whereas in Cadarache and Hannover, the workplece was put in an horizontal position and the plasma cutting torch moved horizontally above it.

\subsection{Laser cutting}

The operating conditions of the laser cutting are indicated in table VI which gives also the number of tests according to the experimental place. Furthermore, in all experiments, we have the common cutting parameters as follows :

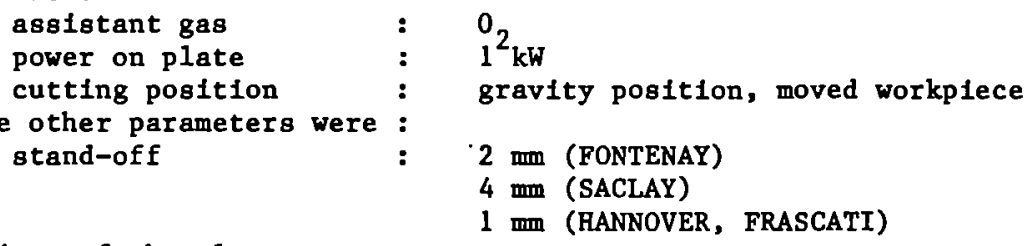

5. ANALYTICAL TECHNIQUES

Aerosol size and concentration and gas measurements were carried out with the same instruments by the same team.

5.1 Aerosol size and concentration

Nozzles were installed in the exhaust pipe (mainly a 125 mm pipe, part of the SPIN mobile measuring $\mathrm{rig}$ ) to allow fsokinetic sampling into :

- a filter of $130 \mathrm{~mm}$ diameter,

- a filter of $47 \mathrm{~mm}$ diameter,

- an Inertial and diffusional spectrometer (SDI 2001). 
Total aerosol mass concentrations are measured by filtration and weighing. The fibreglase filters used are $130 \mathrm{~mm}$ and $47 \mathrm{~mm}$ in diameter. They have a collection efficiency of more than $99.99 \%$ for particles of size superior to 0.3 micron.

The SDI 2001 is an apparatus which combines an Andersen 1mpactor with a diffusion battery containing beds of spheres of specified sizes. It allows determination of the size distribution of particles between 0.075 and 15 microns.

In Hannover experiments, the contractor used simultaneously his own devices, that is to say, a sampling filter and a low pressure Impactor.

In Frascat 1 experiments, ENEA used an Andersen 1mpactor.

\subsection{Gas analysis}

Principles of operation of the maln analytical instruments are as follows :

- Hydrogen

The hydrogen analyzer (Hartman and Braun) ut1lizes the thermal conductivity principle. The range selected is from 0 to $3 z$ volume. Before every measurement, the analyzer 18 callbrated with a known mixture. Sample gas from the main effluent pipe 18 extracted by a $601 / \mathrm{h}$ pump and passed across a dessicant and through a HEPA filter. The dried dust free gas then passes to the hydrogen analyzer.

- Ozone

The ozone analyzer (S.A. Environment) works on the principle of UV absorption using the Beer-Lambert law. Measurement 18 made by comparing absorption of UV radiation across an empty cell with that across a cell containing the gas.

- N1trogen oxides

Chemi-luminescence is used in this instrument (Topaz-Cosma) to determine the concentration of NO. Molecules of NO are converted to NO by reaction with ozone. Light 18 emitted as the exc1ted $\mathrm{NO}_{2}$ molecules return to their fundamental level. The measured light energy 18 proportional to Intital No concentration. convertêx.

NO 18 measured by passing the (NO + NO$_{x}$ ) mixture first through a

\subsection{Suspended particles}

The mass concentration of particles remalning in suspension after a cut was measured by filtration and welghing. The solved elements are also accounted.

\subsection{D1spersed dross}

The dross 18 collected under the workplece and welghed. Particle size distributions of the total dispersed dross were measured by sieving.

\subsection{Attached $81 a 8$}

Attached slag was broken of manually or machlned off and the amont assessed from the change in the workplece welght.

\subsection{Water quality}

Electrical conductivity and $\mathrm{pH}$ of the delonized water before and after a cut were measured with standard laboratory instruments. 


\subsection{Chemtcal analysis of particles}

Samples of aerosol particles from the filters and samples of suspended particles from the water were analysed for elemental metal content. The analytical method used was mainly ICP (Induction coupled plasma spectroscopy).

\section{RESULTS}

The results are here after summarlzed. A lot of comparisons can be made :

- comparison of standard experiments in the different faclilties,

- comparison of these standard experiments with supplementary experiments based on working parameters that seemed more optimal for the contractors concerned (espectally for laser cutting),

- comparison between two cutting tools about the secondary emission production,

- comparison between two aerosol measuring devices.

\subsection{Plasma cutting, standard experiments}

6.1 .1 Kerf geometry

The kerf geometries are not simflar in the different places, but these differences are due to the deformations of the plates (relaxation of thermal constraints following a previous cut by plasma arc) and to the dimensions of the plate. These deformations were, for example, less important in Edinburgh than In Cadarache because the plates were shorter and wider (In Hannover, several plates were clamped together). kerf.

Nevertheless, we can say that the top kerf is wider than the bottom

For example, in Edinburgh the top kerf and bottom kerf widths are respectively 7.5 and $6 \mathrm{~mm}$ for the $40 \mathrm{~mm}$ thickness plates and 6.8 and $3.6 \mathrm{~mm}$ for the 20 min thickness plates.

\subsubsection{Solid secondary emisstons}

6.1.2.1 Balance of sol1d secondary em1 ssions

Data on mass loss from the workp fece and amounts of solid emtsstons, all per unit of length, are summarized in table VII.

Solld emfssions are categorlzed as attached slag, larger dispersed dross which form a sediment, fine particles remaining in suspension in water and aerosols carried in the effluent gas.

The results were rather simflar in the different places but we can remark that :

- the cuts at Edinburgh were more regular than at Cadarache and Hannover because of the rigidity of the torch (the plate was moving beneath $1 t$ ). At the contrary, the plate was fixed at Cadarache and Hannover and the torch was flextble.

- the attached slag was almost non-existent in Hannover because of the additional secondary gas flow of compressed alr that draws a higher kInetic energy.

- the percentage of aerosols is higher at Edinburgh due to a collection nearer the emfssion source.

- the total mass of solid emlssions collected exceeds the mass loss by the workplece, this increase is considered to be due to formation of metal oxides. For Hannover we could explain the negative figures by a loss of sedimented dross when emptying the tank. 
The results obtained at Cadarache and Hannover in conditions $C$ (table VII) are simllar. By cutting in alr, the gield of aerosols 18 substantially increased (factor $>25$ ). At Hannover, some water was put just beneath the plate in order to cool the drosses and not to make holes in the bottom of the tank. So, the 8 lag was cooled rapidly by the proximity of the water and formed slags like stalactites, this 18 the reason why the proportion of slags is more Important at Hannover than at Cadarache.

\subsubsection{Sedimented dross}

In mass terms, sedimented dross 18 the major solld emlssion, being more than 907 of the total (table VII), the mean diameter 18 around 1 m.

\subsubsection{Suspended part $1 \mathrm{cles}$}

These particles, finer than the sedimented dross, are those which remain suspended in the water for at least 5 minutes after the end of cutting. They represent between 0.1 and 0.57 of the total mass collected (cutting speed $-60 \mathrm{~mm} / \mathrm{min}$ ), they seem to decrease with the cutting speed (table VII), the mean diameter in mass 18 around $25 \mu \mathrm{m}$.

The ratio of $\mathrm{N} 1 / \mathrm{Fe} 1 \mathrm{~s}$ generally simllar, within experimental scatter, to that for the 304 stainless steel plate. There 18 a slight Increase of the rat1o $\mathrm{Cr} / \mathrm{Pe}$ (factor $=1.2$ to 2) and an important one of the ratio $\mathrm{Mn} / \mathrm{Fe}$ (factor $>25$ ). Th1s could be explained by the respective different vaporisation temperatures.

The rat1o between the mass and the elements (between 1.7 and 2.1) suggests that the suspended particles are oxide compounds.

The proportion of elemental metals dissolved in water compared to the total mass in water (d18solved and suspended) 18 higher at Edinburgh (86T) and Hannover (797) than at Cadarache (317), this 1s linked to the pH levels of the water after the cuts (see 6.1.4).

- the percentage of suspended particles 1s more Important at EdInburgh, this could be due to the geometry of the tank and/or the sampling method. The volumes are taken by emptying the column at Edinburgh and at the water surface at Hannover and Cadarache.

\section{1 .2 .4 Aerosols}

In mass terms, they represent 1 ess then $1.10^{-4}$ of the total mass collected for the underwater cutting speed of $60 \mathrm{~mm} / \mathrm{m} 1 \mathrm{n}$.

When this proportion 18 largely increased that means that the cut 18 not perfect.

- Size distribution

In most of the results obtained, the size distribution 18 bimodal wth the maln mode around $0.25-0.40 \mu \mathrm{m}$. The histograms obtalned at the different places are simllar, they are In quite good agreement for the cuts in conditions $A$ and conditions $C$ for which the aerosol masses collected are the most important.

- Chemlcal analyoes

The rat 108 of $\mathrm{N} / \mathrm{Pe}$ and $\mathrm{Co} / \mathrm{Pe}$ are simllar, within experimental scatter, to those for the 304 stalnless steel workplece.

There is a slight enrichment in Cr especially for the lower cutting speed and a b1g enrichment in manganese (factor $>20$ ).

The measurement of the rat $10 \mathrm{Cu} / \mathrm{Pe}$ allows to know the degree of norzle vear. The ratlo between the total mass and the elements 18 between 1.5 and 2 for Cadarache and Edinburgh and around 2.5 for Hannover, that means that the serosols are oxided. Th1s oxidation 18 mor Important In Hannover, this is probably due to the additional oecondary gas flow of compressed alr. 
By cutting with higher cutting speeds ( 180 and $300 \mathrm{~mm} / \mathrm{m} 1 \mathrm{n}$ instead of $60 \mathrm{~mm} / \mathrm{min}$ ), the quantity of aerosols decreases. The results obtained at Cadarache and Hannover are in good agreement if we consider firstly that the accuracy on the aerosol mass in not good due to the sma1l masses collected for these short experiments and secondly that again the additional secondary gas flow compressed afr explains the smaller proportion of slags at Hannover.

- Comparison between aerosol measuring devices.

The results obtained from SDI 2001 and low pressure 1mpactor are in quite agreement.

We could say that these devices are complementary as they have been designed until now.

\subsubsection{Gases evolved}

Analysis of the effluent gas stream showed that the main gases present bestdes the argon and nftrogen supplied were $H_{2}$ and NO.

The concentration of $\mathrm{NO}$ and $\mathrm{NO}_{2}$ are more important at Hannover than at Cadarache or Edinburgh, this is due to the additional secondary gas flow of compressed air used in Hannover.

The concentration of $\mathrm{H}_{2}$ is more Important at Edinburgh than at Cadarache or Hannover and at Cadarache than at Hannover for the higher cutting speed ( 180 and $300 \mathrm{~mm} / \mathrm{min})$, this could be explained by the higher powers used ( $35 \mathrm{KW}$ instead of $30 \mathrm{KW}, 41 \mathrm{KW}$ Instead of $39 \mathrm{KW}$ and $45 \mathrm{KW}$ Instead of $39 \mathrm{KW}$ ).

The concentrations of $\mathrm{O}_{3}$ are low and in the same order of magnitude in the different places.

Taking mean values of the concentrations of the gases evolved over the near steady state parts and the appropriate dilution factor allows calculation of the flow rates of the effluent gases leaving the water (table VIII).

\section{1 .4 Water quality}

The $\mathrm{pH}$ of the water decreases in Hannover and Edinburgh experiments (from about 7 to 3.5) whereas it stays constant in Cadarache ones.

The conductivity of the water increases strongly in Hannover and Edinburgh experiments (from about 4 to $130 \mu \mathrm{s}$ ) whereas it increases a little in Cadarache ones.

These differences are due to the volume of the water concerned in the three places (table II).

\subsection{Laser cutting, standard experiments}

6.2.1 Kerf geometry

Due to the big deformations of these plates of small dimensions, it was not possible to compare the different kerf geometries.

\subsubsection{Solid secondary emissions}

6.2.2.2 Balance of solid emissions

Data on mass $108 s$ from the workpiece and amounts of solid emfssions, all per unit of length, are summarized in table IX.

Solid emissions are categorized as attached slag, larger dispersed dross which sediment and aerosols carried in the effluent gas.

About the workpiece mass 1oss, the attached slag and the sedfmented dross there is a good agreement between Saclay and Hannover experiments ; the cut made at Fontenay was not perfect due to the deformation of the workplece that explains the increase of total secondary emfssions. 
In mass terms sedimented dross represents the mafor part of secondary em18sions.

The proportion of attached slag is more Important in Prascat1 experiments, we could explain this difference by the dependence of slag formation on the focal point position, the power density, the cutting speed accuracy, the lens cooling and also the local varlations of laser power.

The aerosol concentration 18 varlable in the different places but it depends on the velocity of the exhaust a1r (flow rate and dimensions of the exhaust tube), the a1r change rate (flow rate and volume of the containment) and the emlssion source collection system if any. Thus the aerosol concentration at Frascat 18 more important because the collection was made in a gmaller cutting box with a higher change rate and with a higher air velocity In exhaust duct than in the other places.

The total amount collected exceeds the mass loss workplece, this ind1cates the formation of metal oxides.

\subsubsection{Aerosols}

In mass terms, they represent less than $4 \zeta$ of the total mass collected. Size distribution.

In most of the results, the size distribution is bimodal with the main mode around $0.25 \mathrm{\mu m}$ (SACLAY, HANNOVER and PONTENAY).

A second mode around $15.5 \mathrm{\mu m}$ collected at Prascat 1 is due to a collection with higher change rate and alr velocity in exhaust duct. In the other places, these particles sediment into the contalnment mainly (FONTENAY and SACLAY) and/or in the exhaust duct mainly (BANNOVER where furthermore there are baffles on which the larger particles can impact).

The agreement is quite good between the different histograms of size distribution based on chemical analysis.

\section{CHEMICAL ANALYSES}

The ratios of $\mathrm{Cr} / \mathrm{Fe}$ and $\mathrm{Co} / \mathrm{Fe}$ are relatively simflar, within experimental scatter to these for the 304 stainless steel workplece. and 4 .

We remark an enrichment in manganese by a factor comprised between 2

The ratio $\mathrm{Cu} / \mathrm{Fe}$ indicates the degree of nozzle wear which $1 \mathrm{~s}$ not excessive, and considered as normal, in these experiments.

The ratio $\mathrm{N} 1 / \mathrm{Pe}$ indicates an enrichment in $\mathrm{N} 1$ (factor $\& 3$ ) at Pontenay, Saclay and Prascat1 that does not appear at Bannover, th1s difference could be explained by the different laser modes (TEMO0 mainly at Fontenay, Saclay, Frascati and TEM10 at Hannover) thus by different power density and temperatures values and profiles. Contrarily to the plasma torch cutting, the vaporization temperatures of the various elements are not reached and there 18 an equilibrium between 3 phases (solid-11quid-gas) and an enrichment in $\mathrm{N} 1$ and not in $\mathrm{Cr}$ in the liquid phase can be supposed.

The ratio between the total mass and the elements which 18 comprised between 1.5 and 1.8 Indicates on oxidation of the aerosols.

\subsubsection{Gas evolved}

The quantities of oxides of nitrogejn and ozone produced during the cutting are respectively inferior to $3.10^{-3} 1 / \mathrm{min}$ and $4.10^{-4} 1 / \mathrm{min}$ at the emission source. 
6.3 Laser cutting, supplementary experiments

When cutting is made with more optimised conditions :

- with conditions (M) Instead of conditions (L) at Hannover (lower oxygen pressure) the quantity of wastes is reduced and especially the aerosols which are divided in this example by 2. (Table IX).

- with conditions (0) Instead of conditions (N) at Saclay (higher cutting speed) the quantity of wastes 18 also reduced and the aerosol mass is divided by 5 .

The conditions (N) were made for laser cutting in order to compare the two tools (plasma and laser) with the same cutting speed in air for a similar plate (composition, thickness). Taking into account the differences of the facllities, we remark that :

- the total amount of secondary emlssions 1s smaller for laser cutting especlally the sedimented dross (tables VII and IX) that means that the kerf produced is notably narrower.

- the aerosol mass is conslderably higher for laser cutting but the working conditions were far from optimal especially the cutting speed.

- the aerosols Induced by the two cutting tools are mainly submicronic.

- the productions of oxides of nitrogen and ozone by laser cutting are negligible compared to those produced by plasma cutting.

- due to different operation temperatures, the proportions of the varlous elements, constituting the workpiece, are not similar in the aerosols.

\section{CONCLUSION}

The results of the measurement of the secondary emissions (solid and gaseous) produced by the cutting of stainless steel plates with plasma torch and laser beam in nearly common working conditions are comparable in the different places.

The differences that we have emphasized are due to :

- the various scales of the factlities (semi-1ndustrial scale in Cadarache, laboratory scale in Hannover and Edinburgh for plasma cutting, semi-industrial scale in Fontenay and laboratory scale for Saclay, Hannover and Frascat1 for laser cutting),

- some particularity in the cutting parameters. For example, the additional secondary flow of oxygen used in standard plasma cutting at Hannover explains the diminution of the attached slag and the Increase of aerosol oxidation and of NO production.

The supplementary experiments have underlined the importance of the optimisation of the cutting parameters and have allowed the comparison between two thermal cutting tools about the secondary emission production.

Moreover, the quality of the cut which can be appreclated by a recording in ine of the aerosol concentration 1s of particular importance for the amount of secondary emlssions, the better the cut, the lower the waste volume. 
TABLE I Plasma equipment in the different places

\begin{tabular}{|c|c|c|c|c|c|c|}
\hline & $\begin{array}{c}\text { Maximal } \\
\text { Current A }\end{array}$ & $\begin{array}{c}\text { Type of } \\
\text { electrode }\end{array}$ & $\underset{\text { Injection }}{\mathrm{HF}}$ & $\begin{array}{c}\text { Water } \\
\text { Injection }\end{array}$ & Coollng & $\begin{array}{c}\text { P1lot } \\
\text { gas }\end{array}$ \\
\hline $\begin{array}{l}\text { CADARACHE } \\
\text { EDINBURGH } \\
\text { HANNOVER }\end{array}$ & $\begin{array}{l}600 \\
250 \\
600\end{array}$ & $\begin{array}{l}\text { tipped } \\
\text { tIpped } \\
\text { tipped }\end{array}$ & $\begin{array}{l}\text { yes } \\
\text { yes } \\
\text { yes }\end{array}$ & $\begin{array}{l}\text { no } \\
\text { no } \\
\text { no }\end{array}$ & $\begin{array}{l}\text { by water } \\
\text { by water } \\
\text { by water } \\
+ \text { a1r }\end{array}$ & $\begin{array}{l}\text { argon } \\
\text { argon } \\
\text { argon }\end{array}$ \\
\hline
\end{tabular}

* There is an additional secondary gas flow of compressed alr for the cooling of the nozzle and the stabilization of the arc.

TABLE II Main characteristics of the facilities for plasma cuteing

\begin{tabular}{|c|c|c|c|c|c|c|c|c|}
\hline & \multicolumn{3}{|c|}{ Tank } & \multicolumn{5}{|c|}{ Exhaust duct } \\
\hline & $\begin{array}{l}\text { Main } \\
\text { form }\end{array}$ & $\begin{array}{c}\text { Average } \\
\text { dimensions } \\
n\end{array}$ & $\begin{array}{c}\text { Wacer } \\
\text { voluge } \\
\mathrm{m}^{3}\end{array}$ & $\begin{array}{l}\text { Length } \\
\text { before } \\
\text { sampling } \\
\text { point m }\end{array}$ & $\begin{array}{c}\text { Dlamecer } \\
\text { m }\end{array}$ & $\left|\begin{array}{c}\text { Flow race } \\
\mathrm{m}^{3} / \mathrm{h}\end{array}\right|$ & $\begin{array}{c}v \\
m / s\end{array}$ & $\begin{array}{c}R \\
\text { Reynolds } \\
\text { number }\end{array}$ \\
\hline $\begin{array}{l}\text { CADARACHE } \\
\text { EDINBURGH } \\
\text { HANNOVER }\end{array}$ & $\begin{array}{l}\text { cylinder } \\
\text { cylinder } \\
\text { parallele- } \\
\text { piped }\end{array}$ & $\begin{array}{l}0=0.6 \\
L=1.1 \\
1 \approx 0.3\end{array}$ & $\begin{array}{c}5.6 \\
2.2^{(1)} \\
0.28 \\
0.3\end{array}$ & $\begin{array}{c}12.3 \\
\text { wth three } \\
\text { elbows } \\
1.2 \\
28 \\
\text { wh fh five } \\
\text { elbows }\end{array}$ & $\begin{array}{c}0.350 \quad(1=4 \mathrm{~m}) \\
0.125 \\
(1=8.3 \mathrm{~m}) \\
0.125 \\
0.3(1=2.5 \mathrm{~m}) \\
20.39^{(4)} \\
(1=25.5 \mathrm{~m})\end{array}$ & $\begin{array}{c}80 \\
1060\end{array}$ & $\begin{array}{l}0.9 \\
6.8 \\
\\
1.8 \\
4.2 \\
\\
2.5\end{array}$ & $\begin{array}{ll}19 & 300 \\
54 & 000 \\
& \\
14 & 400 \\
79 & 500 \\
& \\
69 & 500\end{array}$ \\
\hline
\end{tabular}

(1) experiments with cutting speed -18 and $30 \mathrm{~cm} / \mathrm{min}$

(4) mean equivalent diameter (the exhaust duct has a rectangular section)

TABLE III Laser equipment in the different places

\begin{tabular}{|c|c|c|c|c|c|c|}
\hline & Type & Flux & Mode & $\begin{array}{l}\text { Power on the } \\
\text { workplece } \\
\text { In } W\end{array}$ & $\begin{array}{c}\text { Focal length } \\
\text { in mon }\end{array}$ & $\begin{array}{c}\text { Focal } \\
\text { position }\end{array}$ \\
\hline FONTENAY & $\mathrm{CO}_{2}$ & Fast axtal & $\begin{array}{r}\text { TEMOO } \\
\text { aninly }\end{array}$ & 1000 & 127 (lens) & $\begin{array}{l}\text { on the } \\
\text { workplece }\end{array}$ \\
\hline SACLAY & $\mathrm{CO}_{2}$ & Fast exial & $\begin{array}{r}\text { TEMOO } \\
\operatorname{man} I n l y\end{array}$ & 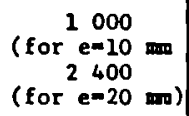 & 150 (mirror) & $\begin{array}{l}\text { on the } \\
\text { workpiece }\end{array}$ \\
\hline HANNOVER & $\mathrm{CO}_{2}$ & Axial & TEM1O & 1000 & & $\begin{array}{l}\text { on the } \\
\text { workplece }\end{array}$ \\
\hline FRASCATI & $\mathrm{CO}_{2}$ & Fast axial & $\begin{array}{r}\text { TEMOO } \\
\text { malnly }\end{array}$ & 1000 & 50 & $\begin{array}{c}\text { on the } \\
\text { workplece }\end{array}$ \\
\hline
\end{tabular}


TABLE IV Mafn characteristics of the facilities for laser cutting

\begin{tabular}{|c|c|c|c|c|c|c|c|c|}
\hline & \multicolumn{3}{|c|}{ Containment } & \multicolumn{5}{|c|}{ Exhaust duct } \\
\hline & $\begin{array}{l}\text { Main } \\
\text { form }\end{array}$ & $\begin{array}{c}\text { Average } \\
\text { dimenstons } \\
m\end{array}$ & $\underset{\mathrm{m}^{3}}{\text { Volume }}$ & $\begin{array}{l}\text { Length } \\
\text { before } \\
\text { sampling } \\
\text { point m }\end{array}$ & $\begin{array}{c}\text { Diameter } \\
\text { m }\end{array}$ & $\begin{array}{c}\text { Flow rate } \\
\mathrm{m} / \mathrm{h}\end{array}$ & $\underset{m / s}{V}$ & $\begin{array}{c}R \\
\text { Reynolds } \\
\text { number }\end{array}$ \\
\hline $\begin{array}{l}\text { FONIENAY } \\
\text { SACLAY } \\
\text { HANNOVER } \\
\text { FRASCATI }\end{array}$ & $\begin{array}{l}\text { parallele- } \\
\text { piped } \\
\text { parallele- } \\
\text { piped } \\
\text { parallele- } \\
\text { piped } \\
\text { parallele- } \\
\text { piped }\end{array}$ & $\begin{array}{c}3.2 \times 2.4 \\
\times 3.6 \\
2.75 \times 1.3 \\
\times 2.15 \\
2 \times 1 \times 0.7 \\
1.4 \times 1.4 \\
\times 1.08\end{array}$ & $\begin{array}{c}32 \\
7.7 \\
1.4 \\
2.1 \\
1.5(1)\end{array}$ & $\begin{array}{r}4.0 \\
2.5 \\
4.0 \\
4.15\end{array}$ & $\begin{array}{l}0.125 \\
0.125 \\
0.400 \\
0.150\end{array}$ & $\begin{array}{c}300 \\
80 \\
1170 \\
360\end{array}$ & $\begin{array}{l}6.8 \\
1.8 \\
2.6 \\
6.1\end{array}$ & $\begin{array}{l}54000 \\
14400 \\
65800 \\
54000\end{array}$ \\
\hline
\end{tabular}

(1) internal "free" volume (the laser head and the system to move the workplece are inside the box)

TABLE $V$ Number of plasma cutting standard experiments

STANDARD EXPERIMENTS

\begin{tabular}{|l|c|c|c|c|c|}
\hline \multicolumn{1}{|c|}{ Conditions } & $\begin{array}{l}\text { SS304 } \\
\mathrm{e}=40 \\
\mathrm{~h}=0.5 \\
\mathrm{v}=60\end{array}$ & $\begin{array}{l}\text { SS304 } \\
\mathrm{e}=20 \\
\mathrm{~h}=0.5 \\
\mathrm{v}=60\end{array}$ & $\begin{array}{c}\text { SS } 304 \\
\mathrm{e}=20 \\
\mathrm{in} \text { air } \\
\mathrm{v}=60\end{array}$ & $\begin{array}{l}\text { SS304 } \\
\mathrm{e}=40 \\
\mathrm{~h}=0.5 \\
\mathrm{v}=180\end{array}$ & $\begin{array}{c}\text { SS304 } \\
\mathrm{e}=40 \\
\mathrm{~h}=0.5 \\
\mathrm{v}=300\end{array}$ \\
\hline Place & $\mathrm{A}$ & $\mathrm{B}$ & $\mathrm{C}$ & $\mathrm{D}$ & $\mathrm{E}$ \\
\hline $\begin{array}{l}\text { CADARACHE } \\
\text { EDINBURGH } \\
\text { HANNOVER }\end{array}$ & 3 & 3 & 2 & 2 & 2 \\
\hline
\end{tabular}

NOTES :

SS = Stainless steel, e = thickness of the plate (In m), h = water depth (in $\mathrm{m}$ ), $v=$ cutting speed (in $\mathrm{mm} / \mathrm{min}$ ).

TABLE VI Number of laser cutting experiments

\begin{tabular}{|c|c|c|c|c|}
\hline Conditions & $\begin{array}{l}\mathrm{SS} 304 \\
\mathrm{e}=10 \\
\mathrm{v}=150 \\
\mathrm{PO}_{2}=1.5\end{array}$ & $\begin{array}{l}\mathrm{SS} 304 \\
e=10 \\
\mathrm{v}=150 \\
\mathrm{PO}_{2}=0.3\end{array}$ & $\begin{array}{l}\mathrm{SS} 304 \\
\mathrm{e}=20 \\
\mathrm{v}=60 \\
\mathrm{PO}_{2}=1.5\end{array}$ & $\begin{array}{l}\mathrm{SS} 304 \\
\mathrm{e}=20 \\
\mathrm{v}=200 \\
\mathrm{PO}_{2}=3\end{array}$ \\
\hline $\begin{array}{l}\text { Reference } \\
\text { letter }\end{array}$ & L & M & $\mathbf{N}$ & 0 \\
\hline Place & $\begin{array}{c}\text { standard } \\
\text { experiments }\end{array}$ & & & \\
\hline $\begin{array}{l}\text { FONTENAY AUX ROSES } \\
\text { SACLAY } \\
\text { HANNOVER } \\
\text { FRASCATI* }\end{array}$ & $\begin{array}{l}1 \\
2 \\
2 \\
8\end{array}$ & $\begin{array}{l}\overline{-} \\
\overline{2} \\
\overline{2}\end{array}$ & $\begin{array}{l}\overline{1} \\
\overline{-} \\
-\end{array}$ & $\begin{array}{l}\overline{2} \\
\overline{-}\end{array}$ \\
\hline
\end{tabular}

NOTES :

SS = Stainless steel, e = thickness of the plate (in mon), v = cutting speed (in mm/min) $\mathrm{PO}_{2}=$ pressure of oxygen (in $10^{\mathrm{Pa}} \mathrm{Pa}$

* The measurements were carried out by the italian team with their own instruments. 
Table VII Comarative balance of solid secondary enissions for plases cutting

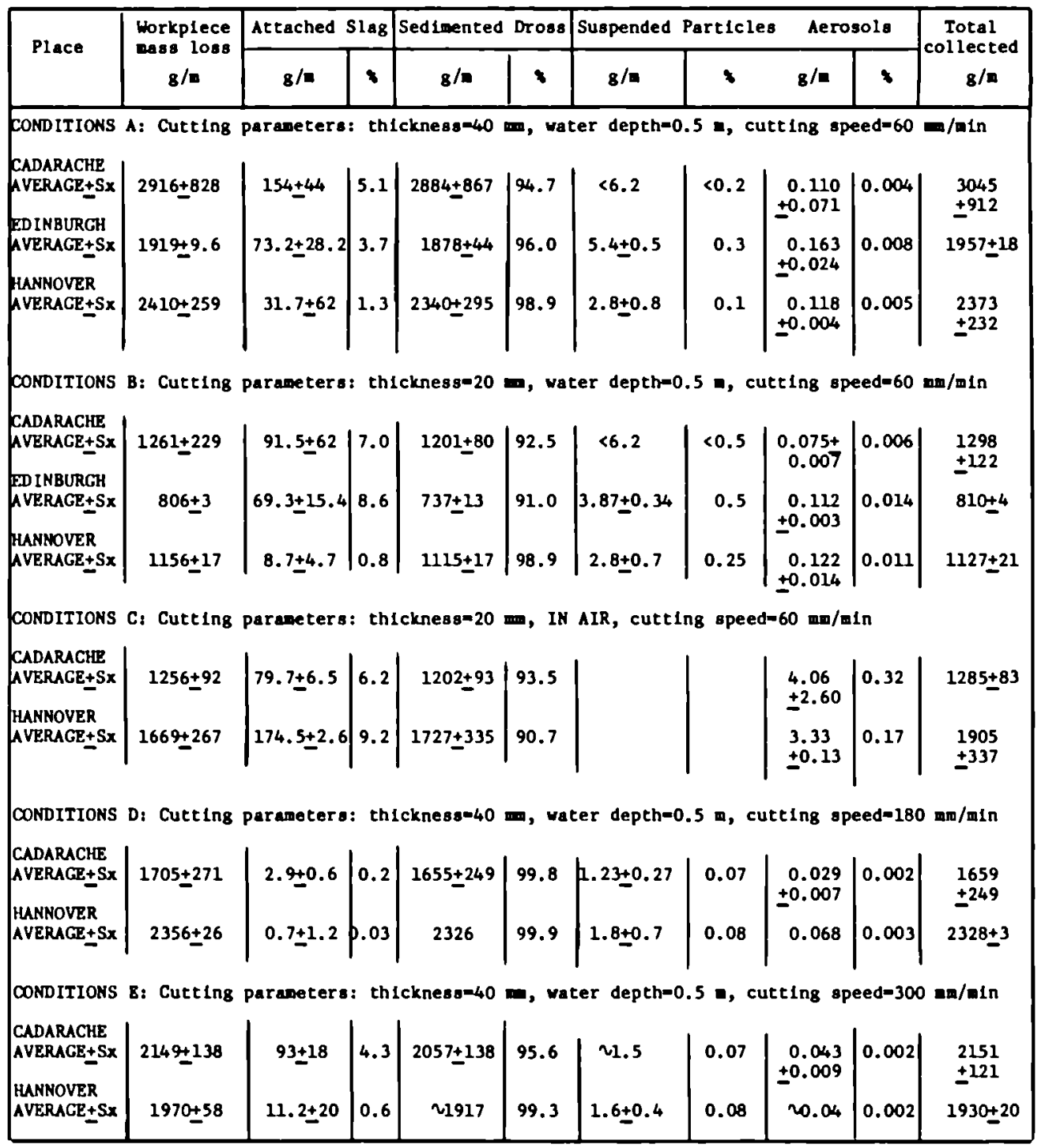

Sx - standard deviation 
Table VIII Comparative balance of calculated flow rates of plasma gas effluent stream before dilution

Flow rates, $1 /$ mln at n.t.p.

\begin{tabular}{|c|c|c|c|c|c|c|}
\hline Gas & Place & $\begin{array}{l}20 \text { mon } \\
\text { underwater } \\
v=60 \text { molmin }\end{array}$ & $\begin{array}{l}40 \mathrm{ma} \\
\text { underwater } \\
v=60 \mathrm{~mm} / \mathrm{min}\end{array}$ & $\begin{array}{c}20 \mathrm{~m} \\
\text { in } \mathrm{air} \\
\mathrm{v}=60 \mathrm{~mm} / \mathrm{min}\end{array}$ & $\begin{array}{c}40 \mathrm{~mm} \\
\text { underwater } \\
v=180 \mathrm{mom} / \mathrm{min}\end{array}$ & $\begin{array}{c}40 \mathrm{~mm} \\
\text { underwater } \\
v=300 \mathrm{~mm} / \mathrm{min}\end{array}$ \\
\hline $\mathbf{A R}$ & $\begin{array}{l}\text { CADARACHE } \\
\text { EDINBURGH }\end{array}$ & $\begin{array}{l}30 \\
30 \\
30\end{array}$ & $\begin{array}{l}30 \\
30 \\
30\end{array}$ & 30 & 30 & 30 \\
\hline $\mathrm{N}_{2}$ & $\begin{array}{l}\text { CADARACHE } \\
\text { EDINBURGH } \\
\text { HANNOVER }\end{array}$ & $\begin{array}{l}19.8 \\
19.7 \\
18.9\end{array}$ & $\begin{array}{l}19.8 \\
19.7 \\
18.7\end{array}$ & $\begin{array}{l}19.5 \\
17.2\end{array}$ & $\begin{array}{l}19.5 \\
18.8\end{array}$ & $\begin{array}{l}19.5 \\
18.8\end{array}$ \\
\hline NO & $\begin{array}{l}\text { CADARACHE } \\
\text { EDINBURGH } \\
\text { HANNOVER }\end{array}$ & $\begin{array}{l}0.4 \\
0.7 \\
2.2\end{array}$ & $\begin{array}{l}0.4 \\
0.7 \\
2.6\end{array}$ & $\begin{array}{l}1.0 \\
5.7\end{array}$ & $\begin{array}{l}1.1 \\
2.5\end{array}$ & $\begin{array}{l}1.0 \\
2.4\end{array}$ \\
\hline $\mathrm{H}_{2}$ & $\begin{array}{l}\text { CADARACHE } \\
\text { EDINBURGH } \\
\text { HANNOVER }\end{array}$ & $\begin{array}{l}2.2 \\
5.9 \\
2.7\end{array}$ & $\begin{array}{l}2.4 \\
7.9 \\
2.9\end{array}$ & $\begin{array}{l}0.08 \\
<0.1\end{array}$ & $\begin{array}{l}7.1 \\
3.1\end{array}$ & $\begin{array}{l}9.1 \\
4.7\end{array}$ \\
\hline $\begin{array}{c}\mathrm{H}_{2} \mathrm{O} \\
\text { vapour }\end{array}$ & $\begin{array}{l}\text { CADARACHE } \\
\text { EDINBURGH } \\
\text { HANNOVER }\end{array}$ & $\begin{array}{l}1.7 \\
1.8 \\
1.7\end{array}$ & $\begin{array}{l}1.7 \\
1.9 \\
1.7\end{array}$ & $\begin{array}{l}0.8 \\
0.8\end{array}$ & $\begin{array}{l}1.9 \\
1.8\end{array}$ & $\begin{array}{l}1.9 \\
1.8\end{array}$ \\
\hline $\mathrm{NO}_{2}$ & $\begin{array}{l}\text { CADARACHE } \\
\text { EDINBURGH } \\
\text { HANNOVER }\end{array}$ & $\begin{array}{l}<0.02 \\
<0.03 \\
0.16\end{array}$ & $\begin{array}{l}<0.02 \\
<0.03 \\
0.09\end{array}$ & $\begin{array}{l}<0.02 \\
0.19\end{array}$ & $\begin{array}{l}<0.2 \\
0.09\end{array}$ & $\begin{array}{c}<0.2 \\
0.1\end{array}$ \\
\hline$o_{3}$ & $\begin{array}{l}\text { CADARACHE } \\
\text { EDINBURGH } \\
\text { HANNOVER }\end{array}$ & $\begin{array}{r}<2.10^{-4} \\
<10^{-4} \\
<10^{-4}\end{array}$ & $\begin{array}{r}<2.10^{-4} \\
<10^{-4} \\
<10^{-4}\end{array}$ & $\begin{array}{l}<2.10^{-4} \\
<5.10^{-4}\end{array}$ & $\begin{array}{l}<2.10^{-4} \\
<10^{-4}\end{array}$ & $\begin{array}{l}<2.10^{-4} \\
<10^{-4}\end{array}$ \\
\hline
\end{tabular}


Table IX Comparative balance of solld secondary emissions for laser cutelng

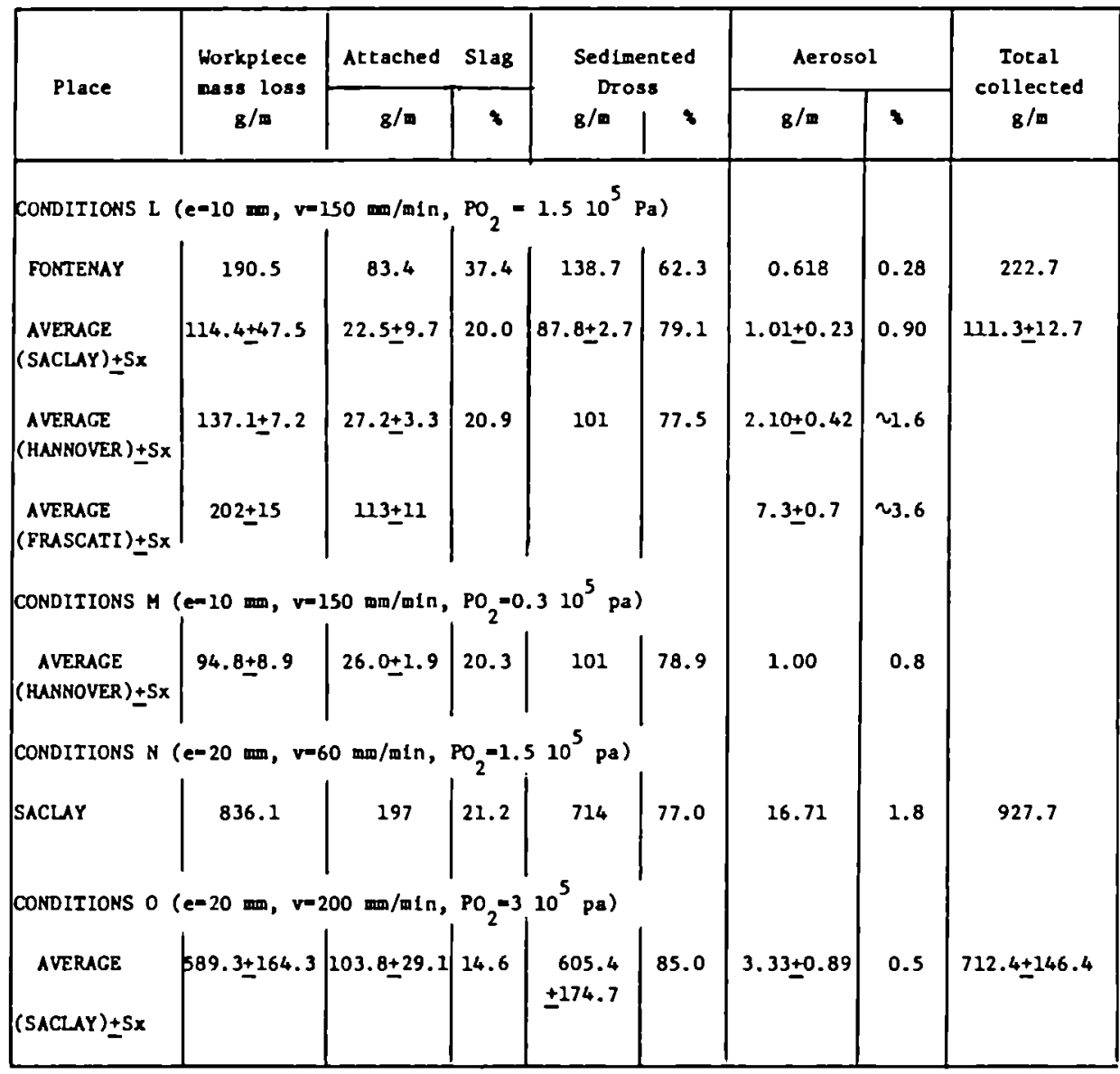

Sx - standard deviation 
Analysis of results obtained with different cutting techniques and associated fitration systems

for the dismantling of radioactive metallic components

\author{
Fr.-W. Bach, H.Steiner, Institut für Werkstoffkunde \\ Universitat Hannover (FRG) \\ G. Pilot, Commissariat a l'Energle Atomique, CEN Saclay (F) \\ E. Skupinski. CEC Brussels (B)
}

\begin{abstract}
The present joint study performed by Commissariat a l'Energie Atomique and Universität Hannover and coordinated by the CEC was intended to analyse the results generated in a number of research contracts concerned with cutting tests in air and underwater, with consideration to the prevalling working conditlons. The analysis has led to a large database, giving broadly accessed information for the dismantling of radioactive components. The study was enlarged, where posslble, to a broader scope including also recently obtained results outside the present research programme, considerIng also supplementary cutting tools and filtration systems not covered by the present programme.

Data was concentrated in structured information packages on practical experience avallable for a series of cutting tools and filters. These were introduced into a computerized user-friendly data bank, to be considered as a first stage development, which should be continuously updated and possibly orlented in the future to an expert system.
\end{abstract}

\title{
1. Introduction
}

The present work programme has been performed as joint study between CEA/CEN Saclay (CEA) and Universität Hannover (UH). It was firstly Intended to analyse the results generated in a number of research contracts within the 2nd EC research programme on decommissioning concerned with cutting tests in air. and underwater, with consideration to the prevailing working conditions. The same target was fixed for the associated filtration systems. Concerned research contracts are presented in Table I giving the name of the involved contractors, their main research activities, some information of the prevalling cutting/filtration environment and some key issues.

The fact that the main objectives underlying in the different contracts are different constitutes difficulties for a rigorous comparison. Nevertheless, it was tried to make a maximum use of all avallable data.

To consider the above imperfections, a test programme with nearly common maln working conditions and with the same measuring system was performed concerning cutting with the plasma arc and laser beam on samples of 304 stainless steel plates of the same origin. This programme Involved six different cutting facilities.

Finally, the study has been enlarged to a broader scope including also recently obtained results outside the present research programme, considering aiso supplementary cutting tools and filtration systems not covered by the present programme.

Wherever possible, it was tried to assess considered data on cutting performance, effluent generation and flltration performance and to extract practical information for applications under real condltions. Dispersion of avallable data originates mainly from different working conditions, from difficult cutting effluent measurements (aerosols) and from often neglected parameters considered as secondary, such as the definition of the prevai- 
Table I: Overview on cutting and filtration tests in the EC progranme

\begin{tabular}{|c|c|c|c|c|c|c|}
\hline Contractor & Metn objectires & $\begin{array}{l}\text { Usod cutting } \\
\text { tool(s) }\end{array}$ & $\begin{array}{l}\text { Cutting } \\
\text { enriron- } \\
\text { ent }\end{array}$ & $\begin{array}{l}\text { Effluent } \\
\text { eessure- } \\
\text { gonts }\end{array}$ & $\begin{array}{l}\text { Filter as- } \\
\text { sessuent }\end{array}$ & $\begin{array}{l}\text { Other paraneters/ } \\
\text { important foatures } \\
\text { reloted to offluent } \\
\text { generation }\end{array}$ \\
\hline & & & Air/uater & Air/uater & Arr/uater & \\
\hline UKAEA/WML & $\begin{array}{l}\text { Study of ventilation and fileration during theral } \\
\text { cutting - Ouantification t charecterisation of } \\
\text { aerosols }\end{array}$ & $\begin{array}{l}\text { Oxypropan } \\
(+ \text { Dovder })\end{array}$ & Air & Air & Atr & $\begin{array}{l}\text { Use of lerge-scale } \\
\text { Hero-factliey }\end{array}$ \\
\hline $\begin{array}{l}\text { CEA/CEN } \\
\text { Saclay }\end{array}$ & $\begin{array}{l}\text { Assessment of pre-filter systeas during therad } \\
\text { cutting - Quantification t characterisation of } \\
\text { derosols - Application to radioactive components }\end{array}$ & Oxyacetylene & Air & Air & Air & $\begin{array}{l}\text { Complete derosol } \\
\text { measuring systea- } \\
\text { detalled assossment } \\
\text { of } 4 \text { pre-filers }\end{array}$ \\
\hline $\begin{array}{l}\text { Heriot Hatt } \\
\text { University. } \\
\text { Edinburgh }\end{array}$ & $\begin{array}{l}\text { Cheracterisation of eolten sleg. fine particulates. } \\
\text { fume particles during Uu cutting - Variation t } \\
\text { simulation of ater depeh }\end{array}$ & Plasmo arc & Woter & Airt & $\begin{array}{l}\text { A1r } \\
\text { Woter }\end{array}$ & $\begin{array}{l}2 \text { test sections: } \\
\text { - variation of water } \\
\text { depth H } 0-10 \text {. } \\
\text { - siaulation of } \\
\text { weter depth by } \\
\text { pressure H. } 50 \text { m }\end{array}$ \\
\hline $\begin{array}{l}\text { CEA/CEN } \\
\text { SAClay }\end{array}$ & $\begin{array}{l}\text { Development of prototype systens for remote laser } \\
\text { cutting-Design. fabrication and testing of a robot } \\
\text { ara for leser bean transmission into hot cell - } \\
\text { Development of osystem for automatic teaching of } \\
\text { cutting trajectory }\end{array}$ & Laser & Air & Arr & Ho & $\begin{array}{l}\text { Limited cerosol } \\
\text { measuring progranme }\end{array}$ \\
\hline $\begin{array}{l}\text { FIAT/ENEA } \\
\text { Tortno }\end{array}$ & $\begin{array}{l}\text { Further development of remote laser cutting with } \\
\text { view to application to decomissioning of Garig- } \\
\text { liano BWR - Categorisation t quantification of } \\
\text { adrosols feasibility study for large-scale } \\
\text { application }\end{array}$ & $\begin{array}{l}\text { Loser } \\
(2-7 \mathrm{kH})\end{array}$ & Air & Air & No & $\begin{array}{l}\text { Complete aerosol } \\
\text { mesuring system - } \\
\text { extensive erosol } \\
\text { measuring progremme }\end{array}$ \\
\hline $\begin{array}{l}\text { Universitat } \\
\text { Hannover }\end{array}$ & $\begin{array}{l}\text { Study of cutting offluents in atr and water during } \\
\text { un cutting with different tools. Assossment of } \\
\text { filter systens in dir and vater. Miniaising of } \\
\text { cutting offluents } \\
\text { Standerd laser cutting tests }\end{array}$ & $\begin{array}{l}\text { Plasina ore } \\
\text { M. Grinder } \\
\text { Laser }\end{array}$ & Water & $\begin{array}{l}\text { Âr } \\
\text { Woter } \\
\text { A1r }\end{array}$ & $\begin{array}{l}\text { Airt } \\
\text { Water } \\
\text { No }\end{array}$ & $\begin{array}{l}\text { Complete ourosol } \\
\text { moasuring system - } \\
\text { Detailed assessment } \\
\text { of water filters }\end{array}$ \\
\hline $\begin{array}{l}\text { CEA/CEN } \\
\text { Caderache }\end{array}$ & $\begin{array}{l}\text { Improvement of an existing lnstallation for auto- } \\
\text { mated un plasma are cutting of irregular shape- } \\
\text { minimising of gas and aerosols - Application to } \\
\text { active components - Study of interaction with } \\
\text { environment }\end{array}$ & Plasme arc & Hater & $\begin{array}{l}\text { Alrt } \\
\text { Water }\end{array}$ & A1r & $\begin{array}{l}\text { Detalled essessment } \\
\text { of phystochemical } \\
\text { properties of water }\end{array}$ \\
\hline $\begin{array}{l}\text { CEA/CEN } \\
\text { VALRHO }\end{array}$ & $\begin{array}{l}\text { Adaptotion of the existing high pressure water jet } \\
\text { technology to cutting of radioactive components - } \\
\text { Dovelopment and testing of components for remote } \\
\text { operation ond maintenance - Detolled assossment of } \\
\text { cutting offluents }\end{array}$ & $\begin{array}{l}\text { High pressure } \\
\text { woter jet } \\
\text { abrastras }\end{array}$ & Air & A1r & A1r & $\begin{array}{l}\text { Extensive offluont } \\
\text { messuring programme }\end{array}$ \\
\hline
\end{tabular}


ling physico-chemical conditions and the cutting environment (ventllation of the cutting cell, prevalling convection at the work point etc.).

\section{Work programme}

The work programme comprises the following working steps:

- Preparation of a complete list of Important working parameters to be considered for a useful comparison of experlmental data obtained withln cutting tests on metallic components, as concerns cutting performance, cutting effluent generation and performance of assoclated flltration systems.

- Collection, analysis and comparison of data on cutting performance.

- Collection and analysis of data on generated cutting effluents in air and under water obtained with the considered cutting tools.

- Collection, analysis and comparison of data on various prefllters for protection of HEPA fllters.

- Collection, analysis and comparison of data on water-filter systems.

The following tools are appropriate for the dismantling of metallic radioactive components:

Plasma arc, Oxy-Flame with and without powder, Laser, Consumable electrode, Combination plasma arc/oxy-flame, Combination consumable electrode/oxyPlame, Waterjet with abrasives, Mechanical devices, Arc-saw and Electrochemical cutting.

These tools are considered at different extents in this work programme.

\section{Implementation of work}

A total of about 1500 data sets have been collected and considered for treatment and analysis. These data originate from

- cutting and filtration tests in the current EC programmes with different main objectives

- comparatlve testing with plasma arc and laser beam, as reported in detall in this session

- published results from outside the EC programmes.

Presently only a small amount of data from nuclear application is available.

For the aquisition of complete sets of information, a number of different questionnaires on cutting tests, effluent determination and filtration in alr and underwater were developed, see for example flg. 18 for plasma arc cutting. They were distributed to involved contractors and also used for the aquisition of outside data. In these data sheets is considered also information on cutting environment, cutting position, torch specification, important cutting parameters and on a definition of the cut material.

For the measurement of cutting effluents, information on the measuring system and on relevant parameters of efpluent distribution were asked por. Information on filter tests considered data on filtration efficiency, pressure drop and collected mass.

Collected data sets are more or less complete. They are only complete for the specially undertaken standard cutting test programme on plasma arc and laser beam. The presence of "white spaces" on the structured data sheets (due to incompleteness of information) may explain existing discrepancles with other more complete data. Information on important features of the measuring line is needed for comparison of particle generation and granulometric size distributions. As an example, the commonly used systems for aerosol determination, working with different measuring princlples are not 
directly comparable.

In a first step, data are stored in a computer with a common structure, according to the relevant questionnaires. In a second step, outside of the present contract, the Information should be standardised in order to create a real access base giving also the possibilty to be used as part of an expert system. The presently avallable software package allows for data treatment such as statistics, comparison of technical data, preparation of information, flow sheets etc. But due to the limited scope and budget of the present contract extenslve data processing could be undertaken only in a limlted way. Further work with hlgher performing data processing systems is foreseen in the future.

\section{Results}

\subsection{General Overview}

Among the avallable data sets only those with a minimum of relevant information have been considered for further treatment. On figures 1 and 2 is indicated the number of retalned experiments for each considered cutting tool, respectlvely in alr and under water, as generated inside or outside the EC programme. As an example for the underwater application of the arcsaw only one reference with flve experiments reported with some detalls was found.

\section{RELEVANT AMOUNT OF EXPERIMENTS}

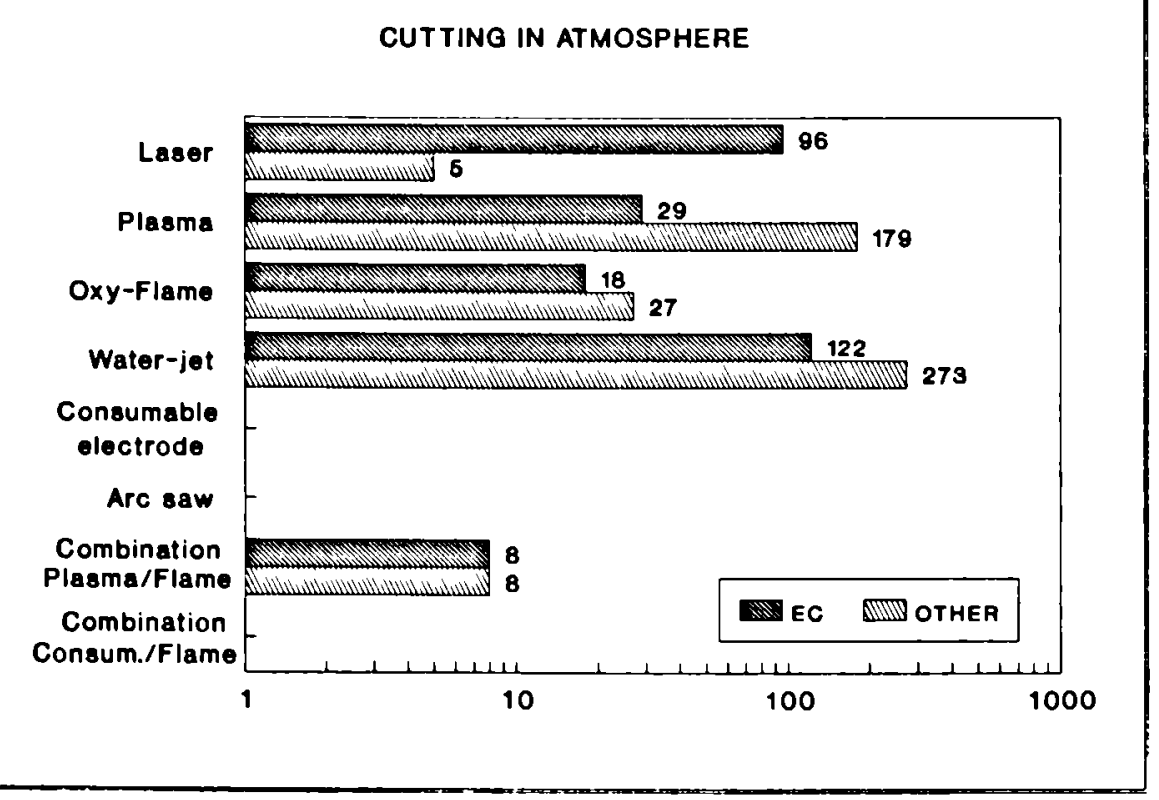

Fir. 1: Cuttlng in atmosphere - Amount of collected experiments

Existing references about the application of the arc saw in air did not give relevant information. Much information was avallable on plasma arc, laser beam, oxy-flame and waterjet. 


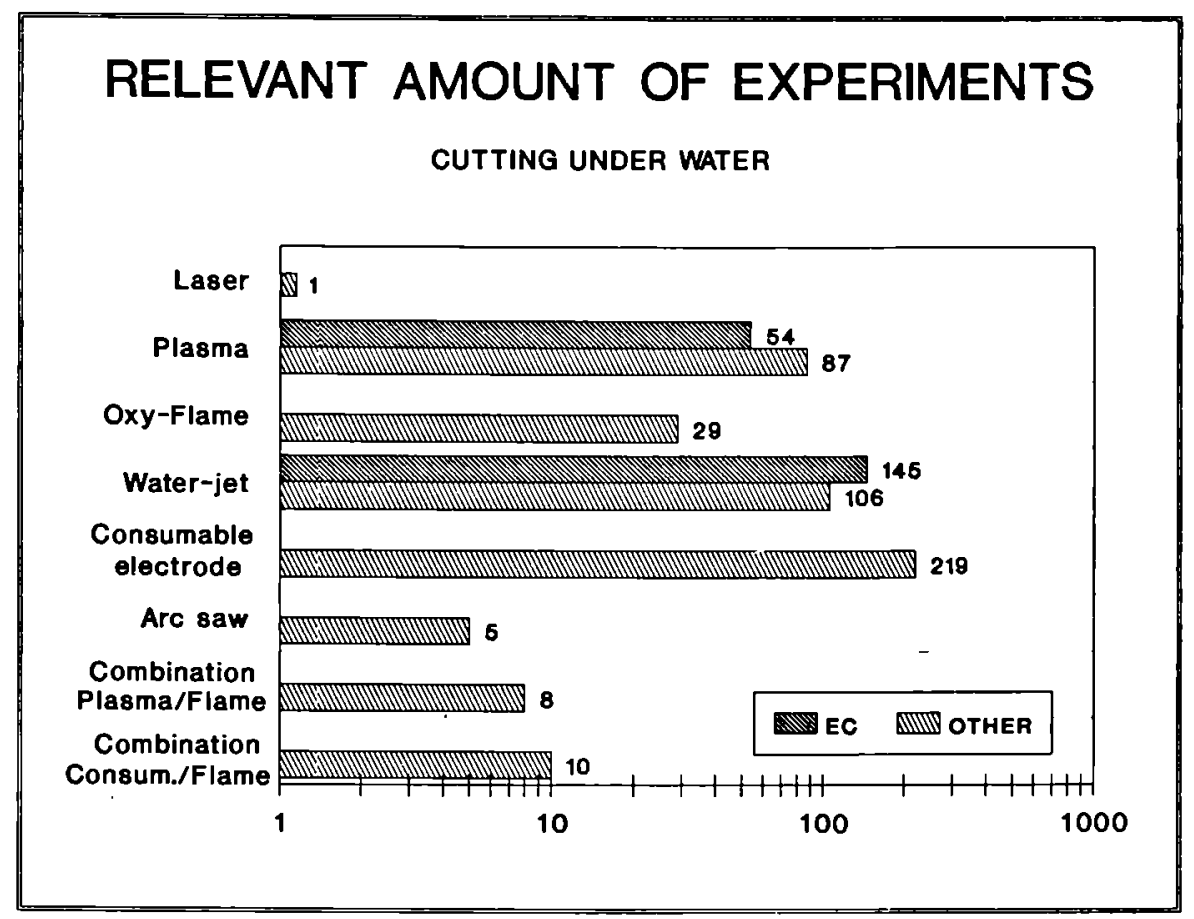

Fig. 2: Cutting underwater - Amount of collected experiments

Due to the limited space for this paper, in the following only one tool is presented exemplarily. This is the plasma arc cutting in atmosphere and underwater having a wide range of application, and for which data of filtration experiments are avallable.

\subsection{Plasma Arc Cutting}

Plasma arc cutting (see fig. 3) is a process which severs metal by melting a localized area with the heat of a constricted arc and removes the molten material in forming a kerf with the high velocity jet of hot, lonized gas Issuing from the oriflce. The temperature in the jet is about $20.000 \mathrm{~K} 80$ that all metals are melted instantly. This high temperature causes a melting and vaporisation of the kerf material so that particles with a large slze range and also gaseous effluents (e.g. nitrogen oxides, ozone) are produced.

The characteristics of plasma jet and cutting performance can be influenced signiflantly by changing the main parameters of the process such as:
- arc current
- gas type
- nozzle size
- cutting speed,
- gas flow rate
- standoff nozzle/workplece.

Commercial plasma cutting equipments for large wall thicknesses are usually working with $100 \mathrm{~kW}$ power sources, supplying an arc current of $600-600 \mathrm{~A}$. The start-up of the process is mostly done with a high frequency starter with argon as plasma gas. After the ignition of the pilot arc nitrogen 


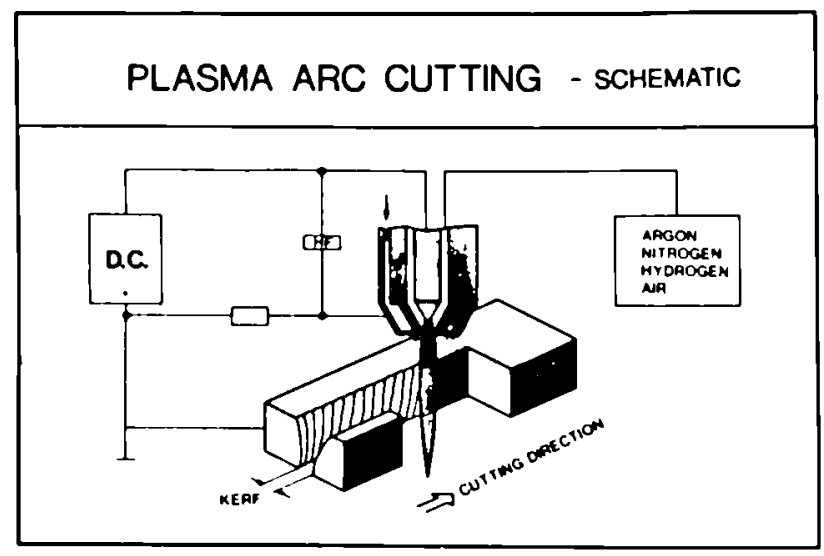

Flg. 3: Schematic principle of plasma arc cutting

and/or hydrogen is added to increase the performance of the process.

A part of the generated particles may come to the atmosphere as aerosols, even if the cutting is done underwater. Depending on the small size of these aerosol particles and thelr content of chromium and nickel oxides when cutting stainless steel. It is necessary to use for the protection of workers filtration systems even if the partlcles are not radioactlve.

Fig. 4 gives the amount of aerosol generation per meter of cutting length for plasma arc cutting underwater and in the atmosphere of stalnless steel (SS) and mild steel (MS). In flg. 4 and the following flgures, the presented curves are mostly mean values based for each polnt on a number of tests and presenting rather strong dispersions which are a consequence of

\section{AEROSOL EMISSION}

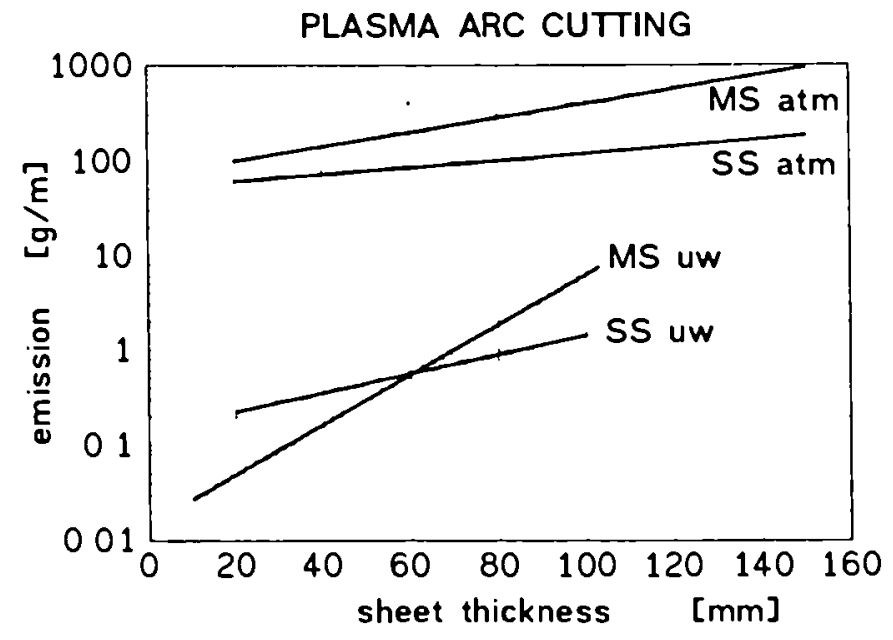

Flg. 4: Plasma arc cutting - Aerosol emission 


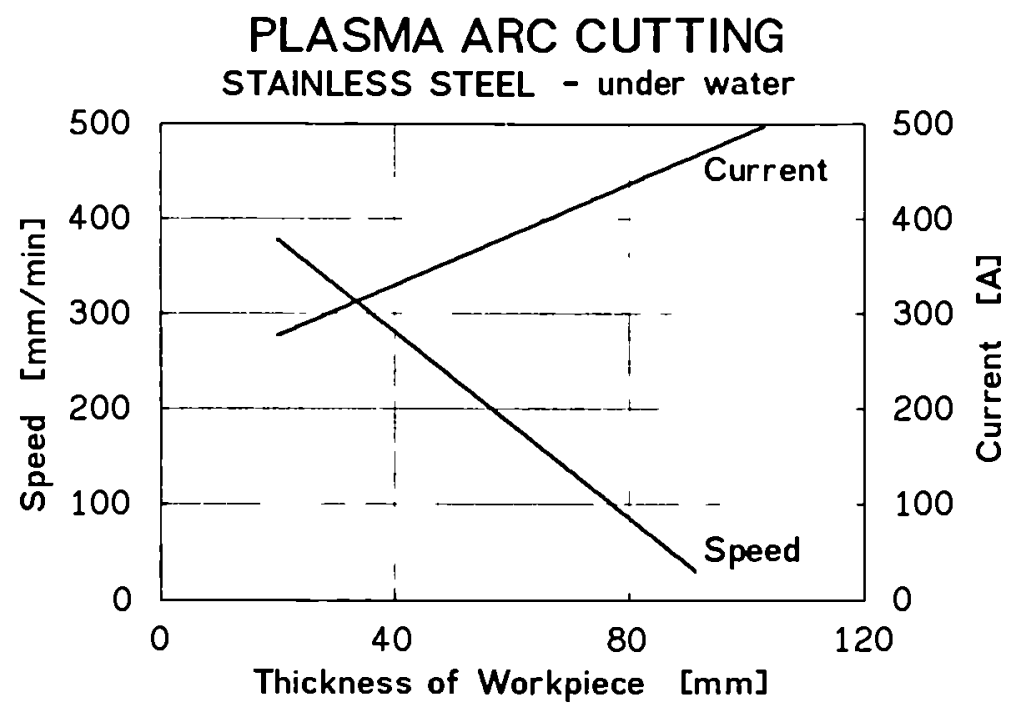

Fig. 5: Plasma arc cuttling - obtained cutting speed and associated electric arc current as function of wall thickness

\section{PLASMA ARC CUTTING} STAINLESS STEEL - under water

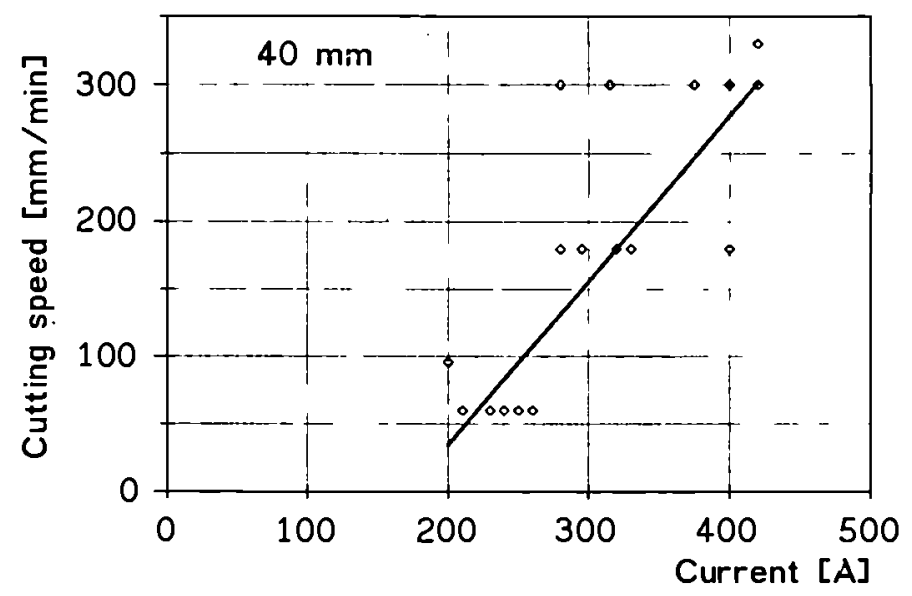

Fig. 6: Plasma arc cutting - cutting speed as function of arc current for a wall thickness of $40 \mathrm{~mm}$

the influence of a number of inherent working parameters, but not expressivly Identified on the diagrams. As an example in the case of flg. 4 , the parameters having an Influence on the aerosol generation rate, are such as the arc current, the composition of the plasma gas and the cutting speed.

Figure 4 shows the reduction of the generation rate in the order of a 
factor of hundred for underwater cutting with respect to cutting in air. The following flgures $5,6,7$ and 8 show the specific influence of some relevant parameters on cutting performance and aerosol generation for the cuttlng of stalnjess steel. The presented curves are calculated mean values

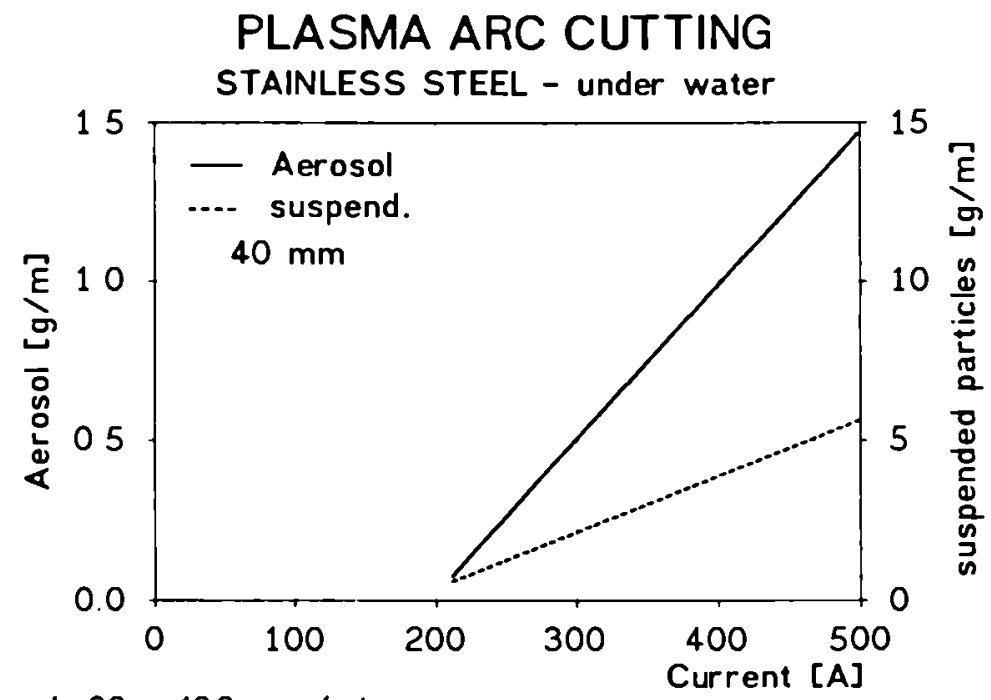

Speed: $60-100 \mathrm{~mm} / \mathrm{min}$

Flg. 7: Plasma arc cutting - generation rate of aerosols and suspended particles as function of arc current.

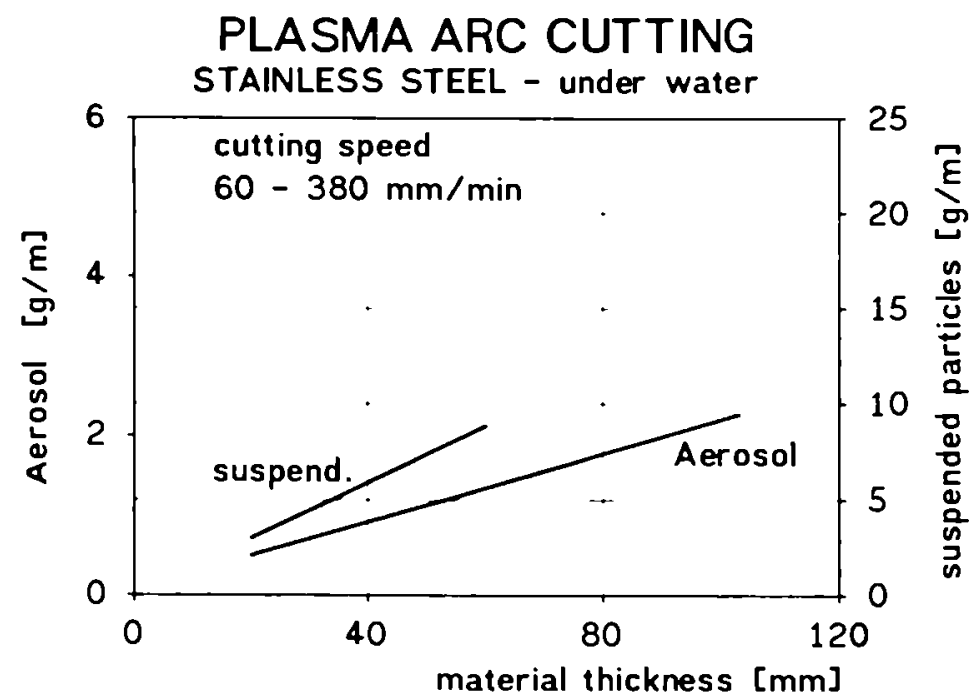

Flg. 8: Plasma arc cuttlng - generation rate of aerosols and suspended particles as function of wall thickness 
of the collected experimental data.

The cutting speed and the arc current as a function of the thlckness of the workplece are shown in figure 5 . It is obvlous, that for a glven current the possible speed is limited. If the cutting speed is too fast, then the cutting will not be successful and if the traverse rate is too slow the process will stop.

The possible variation of speed as a function of current for a material thickness of $40 \mathrm{~mm}$ is shown in flgure 6 .

The generation of particles is strongly influenced by the arc current and cutting speed. Figure 7 shows the influence of the arc current on the production rate of aerosols and suspended particles, thls in the case of under water with stainless steel of a thickness of $40 \mathrm{~mm}$. For this curve, the range of the cutting speed 1860 to $100 \mathrm{~mm} / \mathrm{min}$.

Fig. 8 shows the above effluent generation rates as a function of the workplece thickness.

The main conclusion of these results is, that it is useful to follow some important rules for the reduction of particle generation. The particle emission is decreasing with

- low concentration of energy in the plasma arc

- Increasing cutting speed

- low current and electric power

- increasing nozzle size.

\subsection{Alr Filtration}

In all nuclear facilitles, the last barrier of the exhaust systems is composed by HEPA (high efficiency for particulate in air) filters and in order to protect and to increase the life of the HEPA filters, prefilters have to be Installed between them and the emission source, especlally when the dismantling technique produces a high rate generation of dust.

In principle, the choice of a prefliter has to be done with the knowledge of three categorles of characteristics:

1. The physlco-chemical characteristics of gas and of particles to treat:

- for the gas:

flow rate, composition, volumic mass, humidity, temperature, pressure, dew point

- for the particles:

concentration, size distribution, shape factor, chemical composition, actual and apparent volumic mass, humidity.

2. The characteristics of the facillty:

- the facility or machine or process type for which the cleaning device is Poreseen

- the working type (continuous or discontinuous)

- the maximal value of concentration at the exhaust of the cleaning device

- the allowable pressure drop.

3. The characteristics (performance and cost) of cleaning devices on the market.

Table II shows a list of different prefliter systems that were tested with the aerosols of oxy-flame and plasma cutting. The main parameters for practical application are classified according to their application for the filtration of aerosols from thermal cutting processes.

In conclusion among the presented devices, the ESP can be considered 
as a good cholce, If an appropriate cleaning procedure is defined. The parameters for the cholce of a prefllter for a glven task are numerous and are not always known with good accuracy. For thls reason, experimental verification on a mock-up at a reduced scale (or a full slze scale if it is possible) is recommended.

Table II: Propertles of prefllters for alr filtration

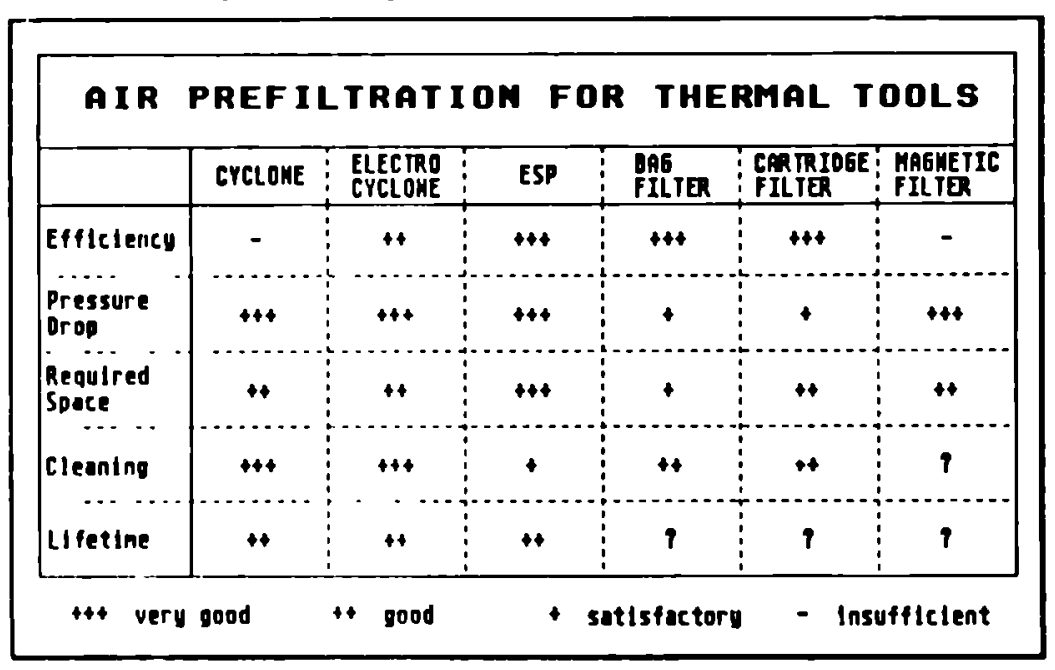

\subsection{Water filtration}

During underwater cutting with a thermal tool, the molten kerf material is spread into single partlcles of a large slze range. The particles which are staying In the water are

- suspended particles, whlch have a strong Influence on the vlslblllty of the cutting process and may reduce the quallty of protection by the water against radiation.

- solved materlal from the reactlon of the hot materlal with the water and/or process gases. This is the reason for the changing of the pHdegree and the conductivity of the water.

- sedimented particles which settle to the bottom of the water basin.

So the maln alm of the water flltration ls to collect and store the suspended partlcles in order to reduce the dispersion of actlvated materials and to keep acceptable vislblilty. The baslc types of fluld fllters are well known and are not repeated here. The table III glves a list of fllter types Table III: LIst of documented waterfllters

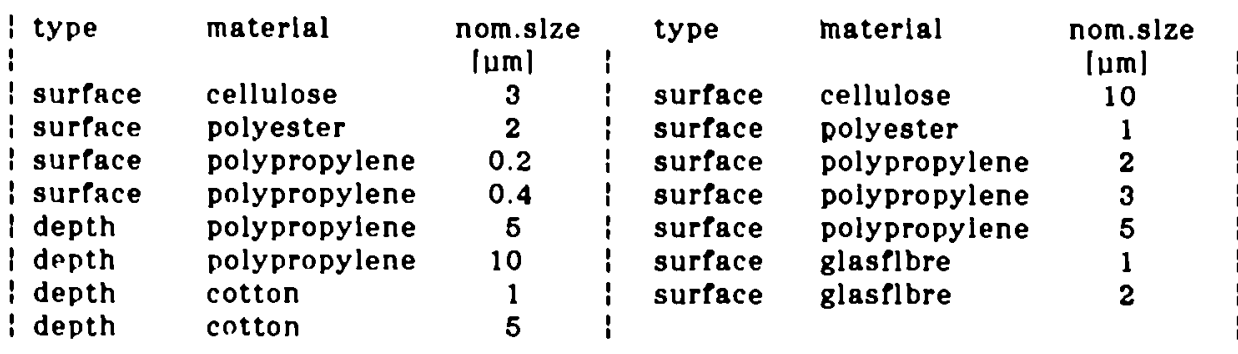


presented in the literature as approprlate for water filtration with plasma arc cutting. All listed types are cartridge filters.

The results of the fllter tests are given in fig. 9 for the filtration of water after cutting stalnless steel with plasma arc. The figure shows the measured filter efficlencles and the maximum cut length before blockage. The Indicated pore sizes are nominal particle sizes for a $100 \%$ flltration efficiency as given by the manufacturer. A strict comparison (e.g. in view of the storage capacity and pressure drop) between the different types is not possible, because these data are not always available. The particle size distributions for underwater plasma cutting have a maximum at about $5 \mu \mathrm{m}$ to $8 \mu \mathrm{m}$ by number and at about $22 \mu \mathrm{m}$ by mass.

\section{WATERFILTRATION - Plasma cutting STAINLESS STEEL}

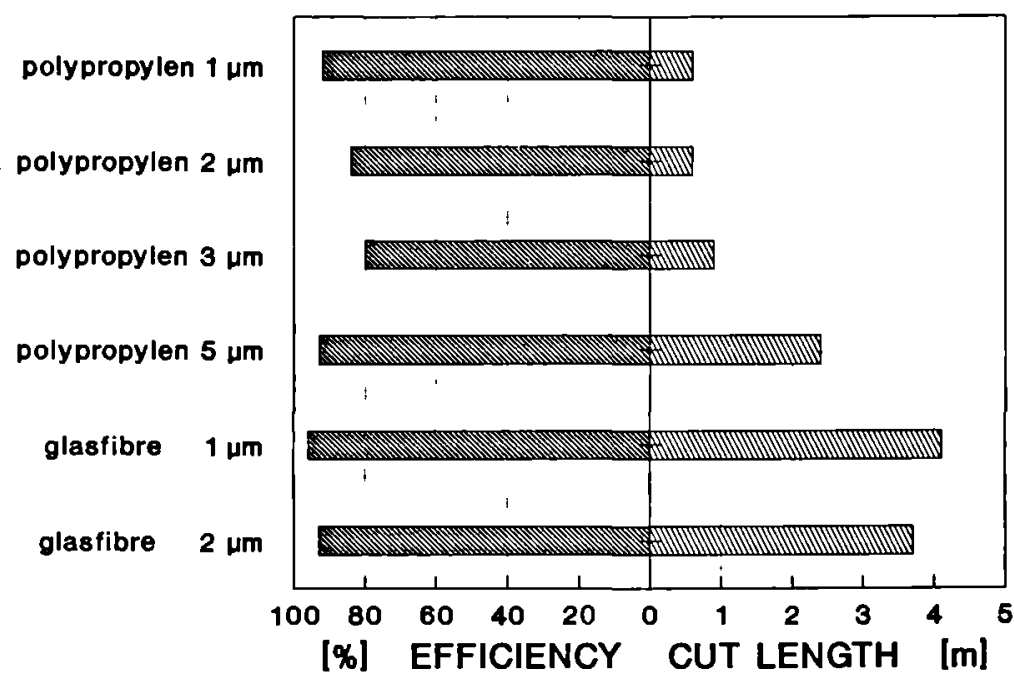

Fig. 9: Water fllters - plasma arc cutting of stalnless steel

For the real application of water filtration some other practical properties have to be considered as there is the resistance of the fitermaterial against radiation, the compression resistance and the easy handling and changing of used filter elements.

\subsection{Overview on the application of relevant tools}

According to the list of considered cutting tools for the dismantling of metailic components the flgures 10 and 11 present the documented wall thickness for the indicated materials (SS - stainless steel, MS - mild steel, Al - aluminium, cladded - mild steel cladded with stainless steel) for each tool. The overview presented on flgures 10 and 11 does not give information on the extent of application and on the degree of development 


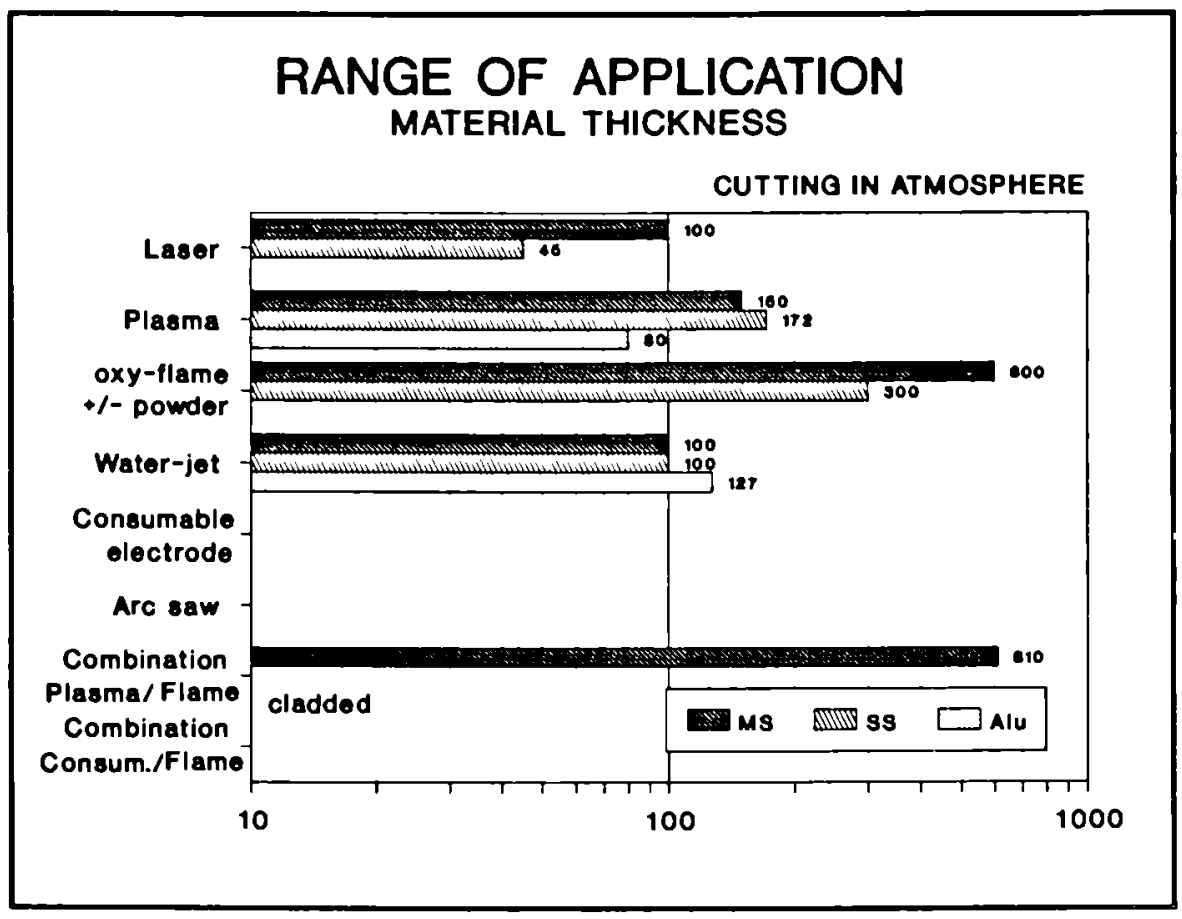

Fig. 10: Range of Application - materlal thickness, in atmosphere

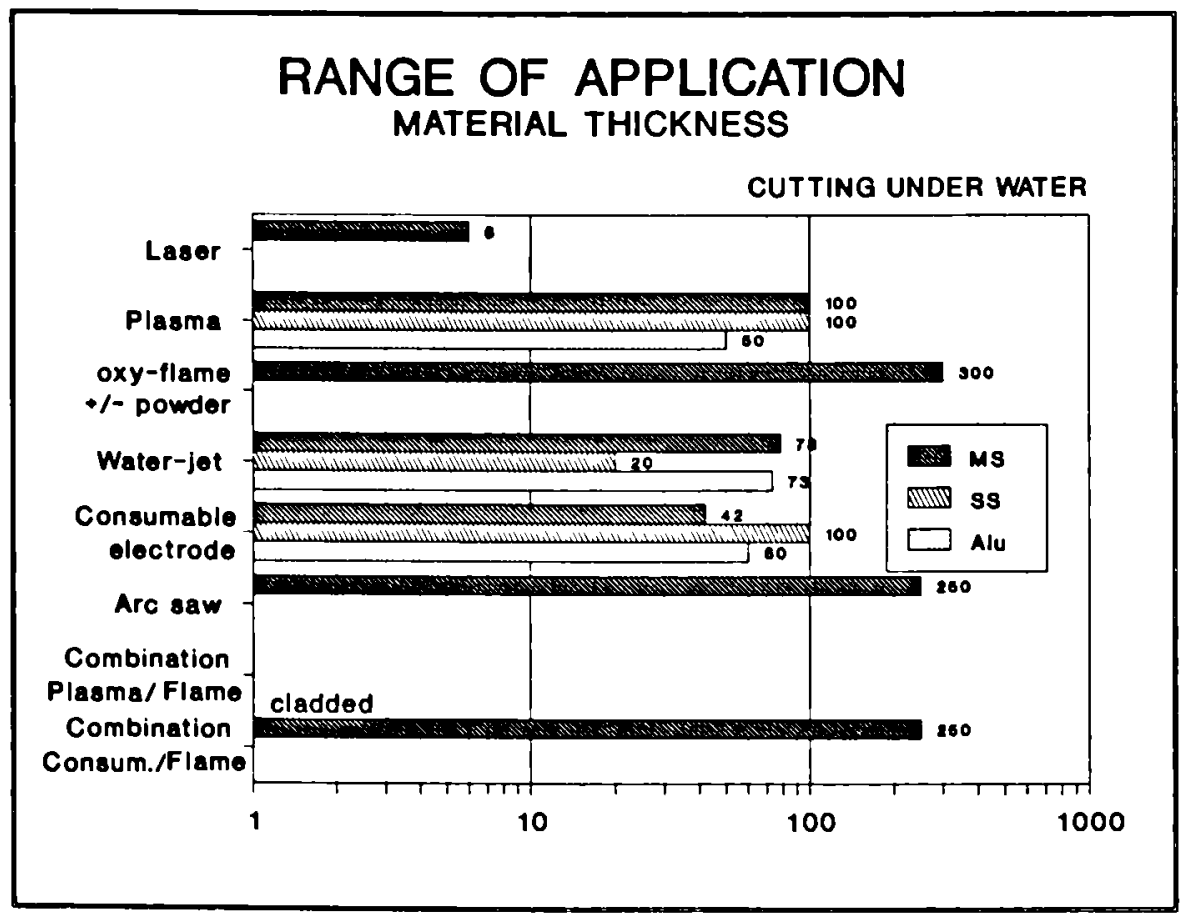

Fig. 11: Range of application - material thickness, underwater 
on the given technique.

The figures 12, 13 and 14 give the distribution by number of the documented applications as a function of the materlal thickness for cutting of stainless and mild steel in alr and under water with different techniques.

Figure 12 shows the cut thicknesses for the plasma arc cutting. Most of the considered experiments are done with a thickness of 20 to $60 \mathrm{~mm}$. There is one application for cutting $172 \mathrm{~mm}$ stainless steel in air. The maximum thickness for cutting under water seems to be $100 \mathrm{~mm}$.

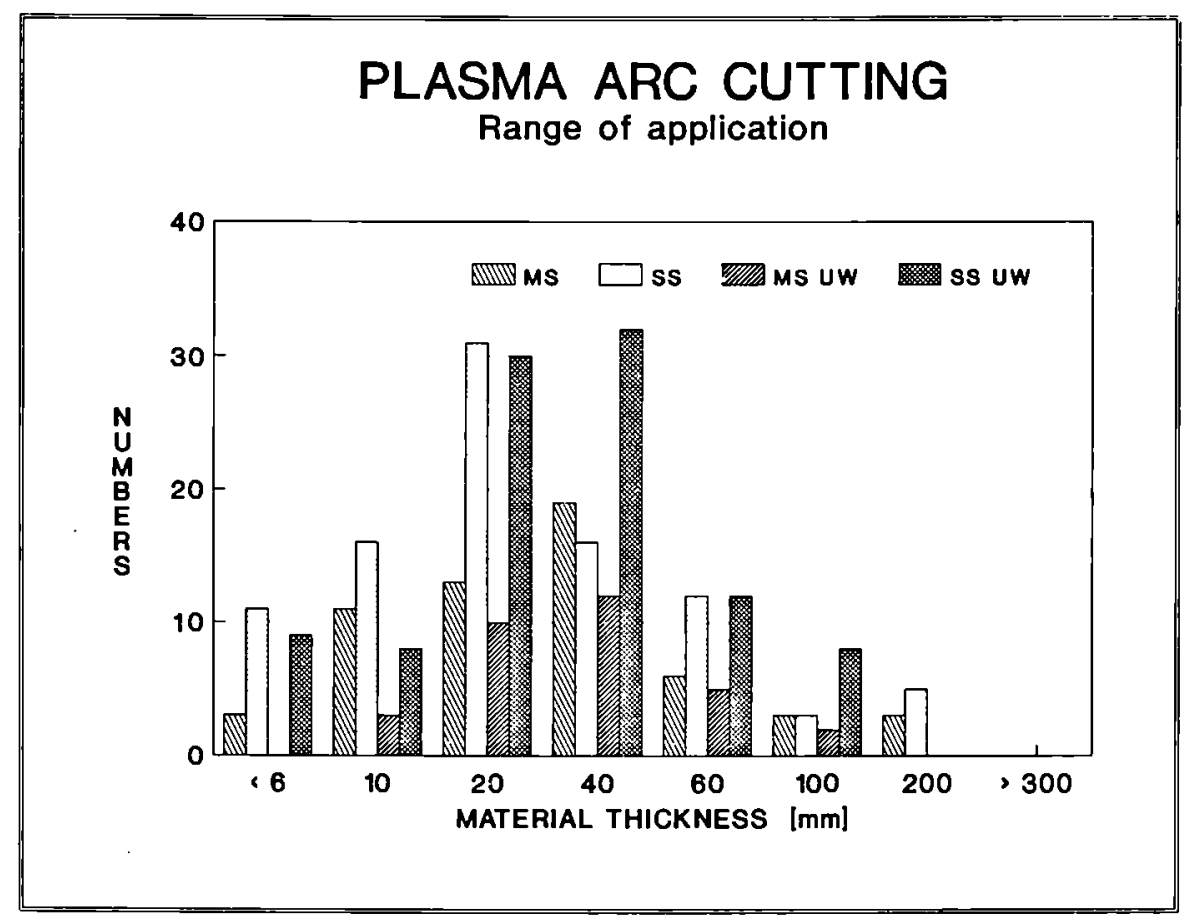

Fig. 12: Plasma cutting of MS and SS, distribution of data sets

Nearly all the cutting tests (except one) with laser beam (fig. 13) were done in atmosphere. One cutting experiment with $100 \mathrm{~mm}$ of mild steel is reported.

Most of the experiments with waterjet cutting (fig. 14) were done in air with mild steel of a material thicknesses up to $10 \mathrm{~mm}$. There are two experiments with a wall thickness of $100 \mathrm{~mm}$ of mild steel which were cut under water.

Figure 15 and 16 give the comparison of documented cutting speed as a function of the wall thickness for cutting stalnless steel with some of the considered tools respectively in air and underwater.

The most powerful cutting tool for the cutting in air of blg thicknesses of stalnless steel is the oxy-flame cutting (with powder) and the plasma arc cutting.

For the application underwater, the highest cutting speed can be done with the consumable electrode cutting and with the oxy-flame cutting. All these curves are calculated mean values without identification of the inherent working parameters. 


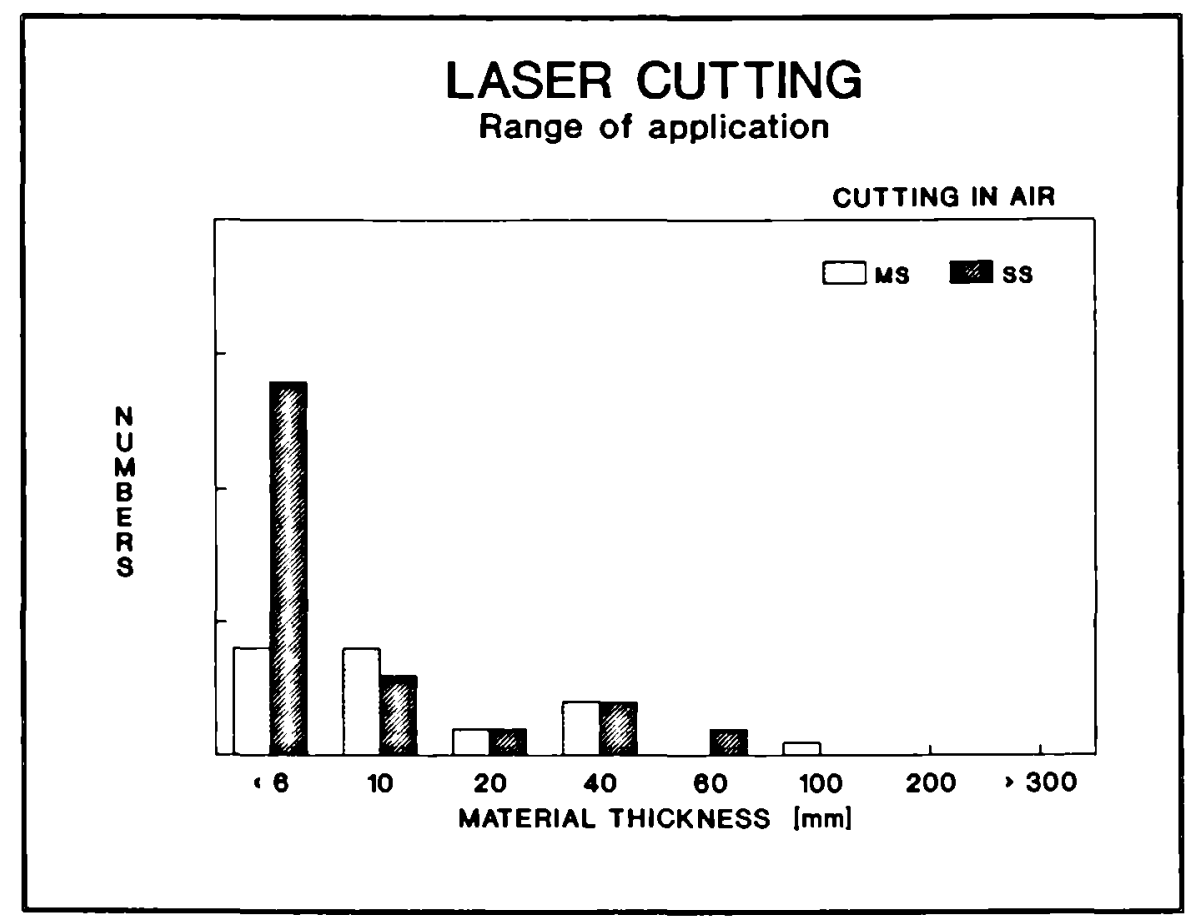

FIR. 13: Laser cutting of MS and SS, distribution of data sets

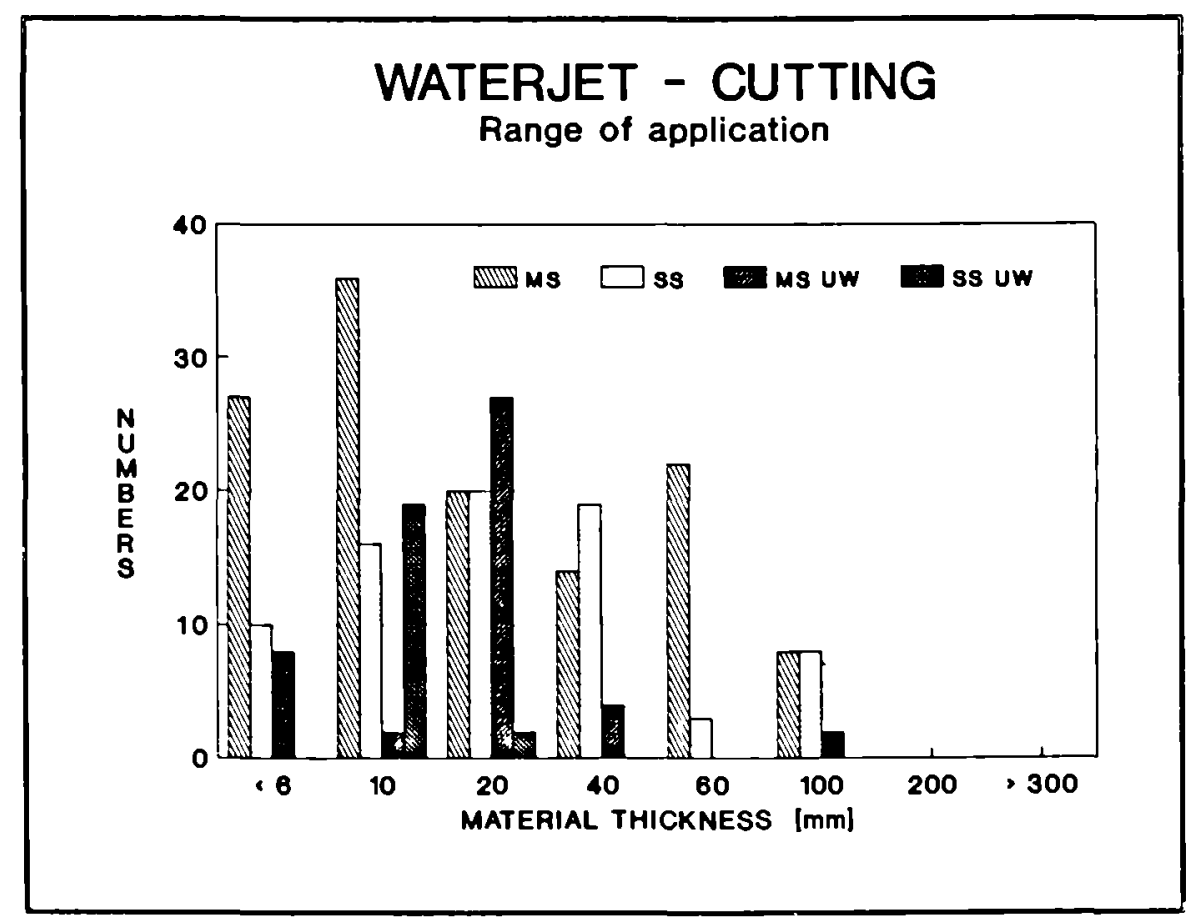

Flg. 14: Waterjet cutting of MS and SS, distribution of data sets 
CUTTING SPEED

VARIOUS TOOLS

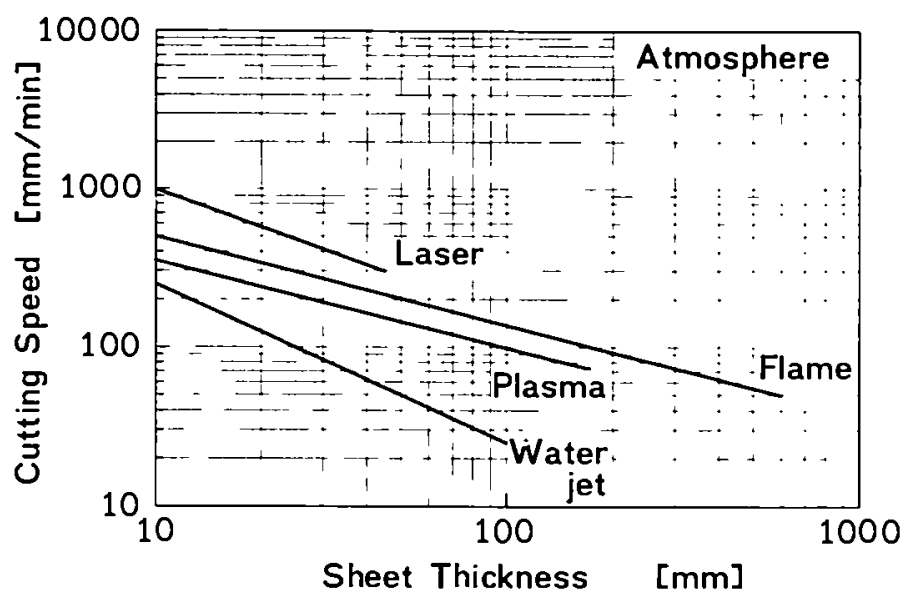

Fig. 15: Range of cutting speed for cutting in air with different tools

CUTTING SPEED

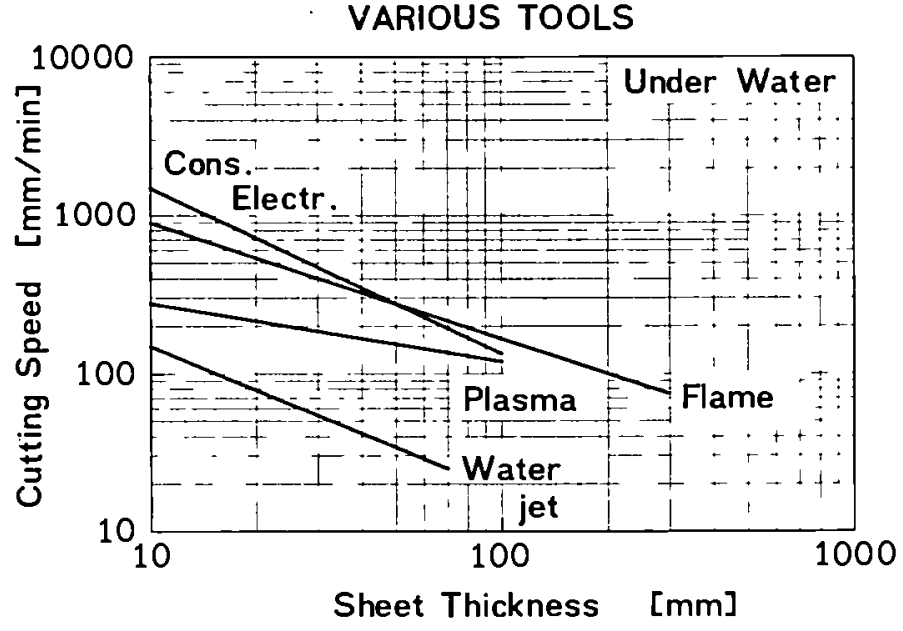

Fig. 16: Range of cutting speed for cutting under water with different tools 


\section{Conclusions}

The objective of this Investigation was to collect, analyse and if posslble. compare existing date on cutting tools and filtration systems whlch are approprlate for the dismantling of radioactlve metallic components.

About 1500 data sets. mainly for cutting tools, but less for filters, have been collected and treated according to structural data sheets aiming for complete Information (fig. 17). Data are orlginating from tests or

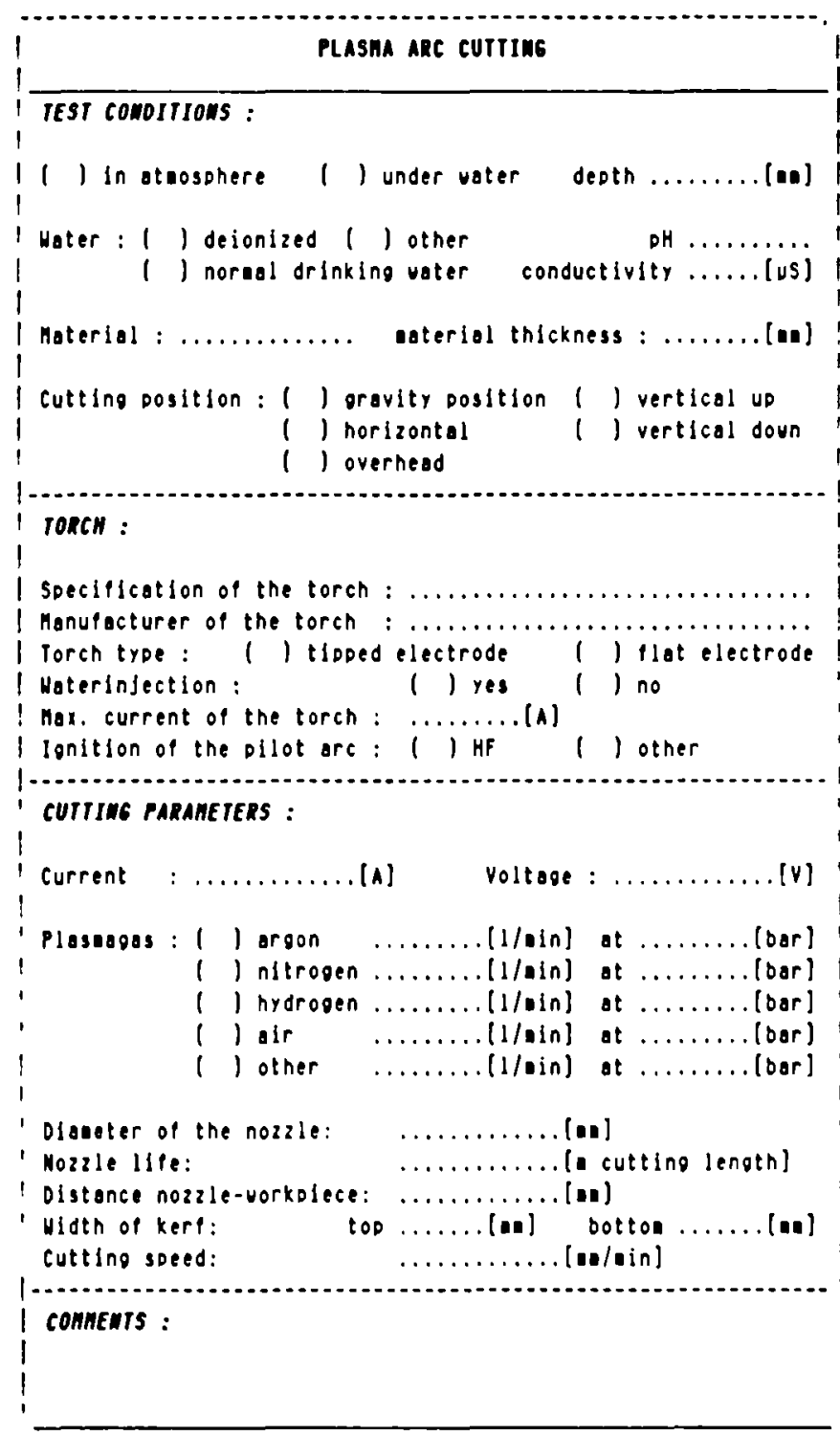

Fig. 17: Example: Data questionnalre for plasma arc cutting applications, mostly on non-radioactlve components, made in the current EC programmes or elsewhere. The consldered cutting tools are Plasma arc, Oxy-Flame with and without powder, Laser, Consumable electrode, Combination plasma arc/oxyflame, Comblnation consumable electrode/oxy-flame. Waterjet with abrasives, Mechanical devlces, Arc-saw and Electro-chemical cutting. The considered air fllters are cyclone, electrocyclone, electrostatlc precipltator, bag fllter. cartridge fllter. magnetlc pilter and several qualitles of HEPA Pllters. Those for water are surface and depth fllter cartridges made out of different materlals.

On the basls of the results from this Investigation the following conclusions can be made:

Among the avallable data sets a large part contalned sufflclent detalls for belng considered for further treatment. Data were analysed for their information on cutting or flltra- 
tion performance, on effluent generation and on detalls of the prevalling working conditions. Notwithstanding the lack of full information, the extraction and condensation of Information on practical parameters for an application to nuclear installations was tried.

- For cutting tools: cutting speed, maximal wall thickness being cut, effluent generation and distributions, comparison of cutting in air and underwater. For example: maximal cutting thicknesses for cutting of stainless steel in air of about $300 \mathrm{~mm}$ have been found for an oxy-flame torch (with powder) and a thickness of $172 \mathrm{~mm}$ for a plasma torch. Stainless steel

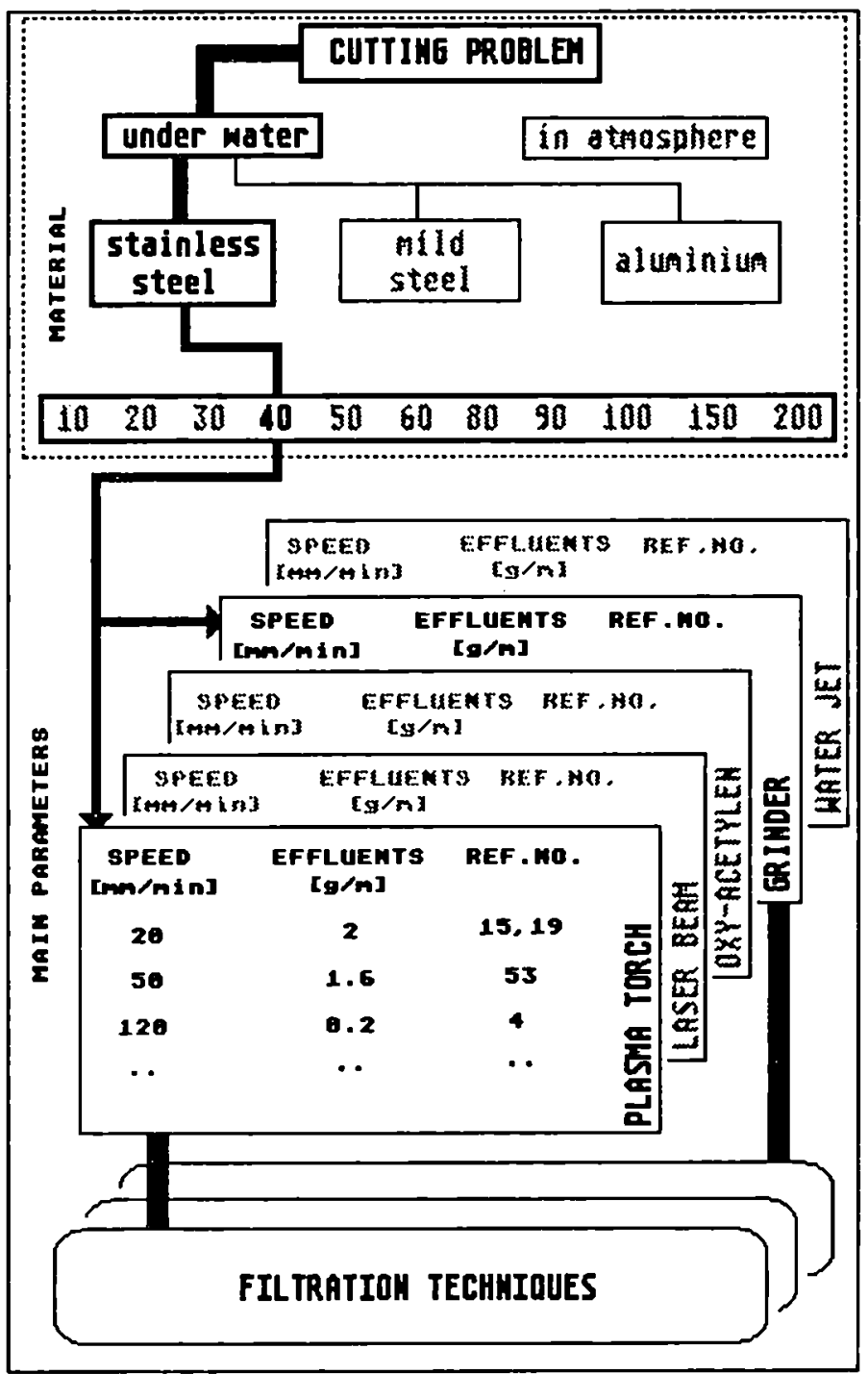

Fig. 18: Flow diagram for a given cutting problem of a thickness of $100 \mathrm{~mm}$ can be cut underwater with plasma torch and consumable electrode. Mild steel of a thickness of $250 \mathrm{~mm}$ has been cut underwater with an arc saw and (cladded with stainless steel) with a comblnation tool of consumable electrode and oxy-flame.

It should be underlined that the presented working parameters are mostly calculated mean values, based for each point, on a number of tests presenting statistically the obtalned experience for a global couple of parameters but having inherently dlfferent working parameters which are not expressly identifled on the dlagrams.

- For air and water fllters: possible cut length on a given component before fllter blockage (storage capacity), pressure drops. The investigated air and water fllters have led to the statement that presently efficient 
systems for air filtration as the electrostatlc precipltator and, for water nitration, cartridge fliters of different filter materials are avallable and appropriate for the nitration of cutting effluents arising from the above cutting tools.

- Accesslbillty of data: presently a user can extract from this data collectlon varlous working parameters in the form of figures and tables and also Information flow dlagrams, see the example on figure 18 . The user Introduces the definition of a cutting problem and recelves proposals and options for possible solutlons: avallable cutting technlques, information on expected rates and forms of cutting effuents and on approprlate filter systems.

Besides thls, If more detalls are wanted, references are Identifled containing, In many cases, detalled information on working parameters for a practlcal application.

It is considered as useful to continue such Investigatlons with a view to develop an easily accessible and application-orlented data bank, with the possible connection to an expert system. The data bank can only give results for a certaln cuttling tool based on already published results. The decision for a certain tool will be mainly influenced by the special conditions in the facllity but the use of thls data bank may give a basis to choose a certain cutting technique for a given problem.

\section{Reference}

G. Pllot, R. Léautler, M. Noêl, H. Stelner, G. Tarronl, B. Waldie Measurements of secondary emissions from plasma arc and laser cutting in standard experiments

CEC-contract FIID-0070 and FIID-0071 


\section{DISCUSSION}

Question: R P PRATT, UKAEA Harwell -

1. Are there any quantitative data on the increase in HEPA filter life through the use of prefilters?

2. In view of the technical problems of using electrostatic precipitators (ESPs), would the bag filter not be preferable for this application?

Answer: G PILOT, CEA-Saclay -

1. In the $\mathrm{G} 2$ reactor (gas-graphite), where big tubes $(\varnothing=1.6 \mathrm{~m}$, wall thickness $=18 \mathrm{~mm}$ ) were cut by automated plasma torch, it was necessary to change the HEPA filters every week. Then ESPs were put upstream of the HEPA filters, which are now changed only after several months.

2. The efficiencies of bag filter and ESP are respectively $>998$ and 958 for example, the cleaning of a bag filter for radioactive particles is easier nowadays (eg by reverse compressed air) but for the ESP the pressure drop is much smaller (eg $150 \mathrm{~Pa}$ instead of $2000 \mathrm{~Pa}$ ), the required space can be three times less (for the same flow rate) and the ESP lifetime seems to be lower. In the paper entitled 'Analysis of results obtained with different cutting techniques and associated filtration systems for the dismantling of radioactive metallic components', a comparative table about air prefilters is given. I would add that for the bag filter it is necessary to have the 'filter cake' formed before reaching the optimal efficiency and that the ESP cannot be used, of course, with explosive mixtures.

Question: J WILLIAMS, UKAEA-Harwell - Mr Pilot's paper showed three positions to place the prefilters in a cutting cell. Our aim is to minimise the spread of contamination, particularly to ductwork. If a prefilter is placed inside the enclosure to capture the aerosols close to the point of production, do the authors consider it necessary to fit a second prefilter either in the duct or in the duct entrance?

Answer: G PILOT, CEA-Saclay - Very often the efficiency of a captation device at the emission source (hood, for example) is not 1008, so the spread of contamination in the cell and in the exhaust duct is not completely avoided. Therefore, if you want to minimise as much as possible the contanination of the duct, it is necessary to put a second prefilter in the duct entrance.

Question: J WILLIAMS, UKAEA-Harwell - The organisations undertaking decommissioning work will want to optimise their cutting and filtration methods with other parameters specific to that plant. Will the CEC be making available the database they are generating? How will it be available - as a computer database? When will it be available?

Answer: E SKUPINSKI, CEC - In principle all results obtained in the EC programmes are available, as will be the results of this investigation, first as a final report of the contract, later on, after further development of the software for data processing, access to the database can be made available. 
Question: E SKUPINSKI, CEC - Could you compare thermal cutting tools, ie plasma arc, with a mechanical grinder in relation to cutting effluents, and could you comment on the preference of mechanical tools over thermal tools.

Answer: H STEINER, Universität Hannover - For the underwater cutting of stainless steel and aluminium with the grinder, no aerosols could be measured. The suspended particles in the water are rather large, so that there is no real filtration problem, compared with the plasma torch.

Question: I GILLON, SCK/CEN MOl - What are the results for underwater cutting using the grinder?

Answer: H STEINER, Unıversität Hannover - Effluent release to the atmosphere was not measurable with our equipment. The amount of suspended particles is smaller than the amount of particles generated by plasma torch cutting. The filtration of the effluent from underwater grinding operations poses no problem.

Question: N SANDERS, Hypertherm - Why are the aerosol emission data not reflecting the decrease of the material thickness, especially for mild steel? It should because of the measure in energy input into the dross, vaporising it.

Answer: F-W BACH, Universität Hannover - The data are incomplete. It has to do with specific energy input. It is a fact that the thinner the material, the more energy will go into vaporising the material and the more aerosols will be generated.

Comment: E SKUPINSKI, CEC - An important conclusion of the investigations on cutting performances and generation of secondary waste undertaken in the EC programe is the statement that rather important dispersions of results exist, even in the case of standard cutting tests with plasma arc and laser beam, with comparable working parameters, as presented by Mr Pilot. As an example, a current precision of aerosol measurement, even with sophisticated equipment, is in the order of magnitude of 308, because of different inherent working parameters influencing the results of, eg size distributions. A main finding of the comparative testing performed is that it is possible to explain different results if most of the significant working parameters, including characteristic parameters of the cutting facility, are known.

The dismantler does not need very precise values, he needs ranges of values and the parameters which may influence their variation. The CEC will continue the analysis of data on dismantling and filtration in its new programme, but before doing this, it will ask dismantling teams to specify the type of information needed and how it should be presented.

\section{CONCLUSION}

There should be few problems regarding the emission of radioactive aerosol particulate material from plants during decommissioning operations as HEPA filters should effectively remove all the aerosols generated during the cutting process. These aerosols will, however, impose a considerable burden on the HEPA filters and hence the HEPA filter inserts will need to be changed frequently and the ventilation systems before the filter inserts wll become heavily contaminated. Therefore, pre-filter devices are essential to reduce the challenge to the HEPA filters and so reduce the need to change the ingerts frequently. Two types of pre-filter have been shown to 
be acceptable, ESPs (electrostatic precipitators) and pulse-cleaned bag filters, each with advantages and drawbacks.

Cutting underwater produces effluents but less aerosols than cutting in air, and there are cartridge filters which will effectively remove these effluents from the water; the type needs to be chosen to meet the appropriate conditions.

This Session has shown, more than any other of the Conference, the effectiveness of the collaboration between the various EC countries and organisations in these countries. Most of the papers involve collaboration and the final paper by Bach, Steiner, Pilot and Skupinski showed that the EC programes have produced one-third of worldwide data sets available on emissions during cutting processes and the filtration of emissions. The pilot projects in the next EC programme should benefit from this work and they should provide data on the large-scale application of the above techniques.

J WILLIAMS, UKAEA-Harwell 
SESSION XII

TREATMENT OF DECOMMISSIONING WASTE

CHAIRMAN: M CONTI, ENEA,I

SECRETARY: K PFLUGRAD, CEC 

THE DECOMMISSIONING OF LARGE AND COMPLEX GLOVE BOX STRUCTURES IN A MIXED OXIDE FUEL FABRICATION PLANT

\author{
Draulans Jos
}

BELCONUCLEAIRE, Dessel, Belgium

ABSTRACT

Information is given concerning the different techniques applied during the decommissioning of glove boxes and equipment inside the BELGONUCLEAIRE Mixed Oxide fuel fabrication plant. The techniques have been selected on the basis of the glove box dimensions, the capability of being removed out of the building and/or being transported on the public road, the inner contamination level etc...

Different techniques applied are explained.

\title{
1. INTRODUCTION
}

The worn condition of equipment, the modifications in the process, the increase of capacity and the reduction of manual operation inside the glove boxes, necessitate the replacement of glove boxes and equipment

in Mixed Oxide fuel fabrication plants. These decommissioning and dismantling operations are non-routine operations representing a serious risk for a spread of radioactive contamination.

This risk has to be reduced as much as possible. Different techni ques have to be applied depending upon the specific glove box characteristics.

\section{GLOVE BOXES}

Due to the radiotoxicity of the plutonium the whole fabrication Iine in a Mox plant - up to the rod fabrication - is built in or between glove boxes, kept at a negative pressure in order to keep operators and product safely separated. These glove boxes are mainly built of a metal frame onto which windows are mounted on a leaktight way. Manual interventions inside the glove boxes are mainly performed by means of gloves mounted on glove ports installed in the windows and the walls.

More than 200 glove boxes with a total volume of about $750 \mathrm{~m}^{3}$ are in use in the plant. Depending on the manipulations carried out inside and/or the equipment mounted in the glove boxes the latter have different sizes and shapes.

\section{DISMANTLING ON SITE VERSUS DISMANTLING IN A SPECIALIZED INSTITUTE - CHOICE}

The decommissioning operations and even more the dismantling operations are non-standard and non-rout ine operations. This means that they have to be considered as difficult and that they present a serious risk for a spread of contamination.

Spread-risk will be higher in case of heavily contaminated glove boxes than for example in case of those in which only sintered pellets are treated.

For the management of a MOX plant it is important to reduce this risk as much as possible for the safety of its personnel and to control the time period necessary for the removal of the equipment to be decomissioned.

The decomissioning up to the final disposal of plutonium contaminated glove boxes or any other large radioactive contaminated or irradiated equipment includes several steps : 
a) the preparation for the dismanting,

b) the dismantling of the equipment,

c) the embedding of the dismantled parts in preparation for their final disposal,

d) the temporary storage of the embedded parts up to the moment of their transportation to the final repository,

e) the transportation to the final repository,

f) the final disposal.

From these steps only the steps a and b could eventually be performed on the BELGONUCLEAIRE site.

Indeed step c : - the embedding of dismantled parts - requires a very special equipment which was not available on the BELGONUCLEAIRE site. Furthermore the construction of such an equipment on the BELGONUCLEAIRE site was not possible, either in terms of time or cost.

Step a : the preparation for the dismantling has to be performed whether it is to be carried out on site or in a specialized facility.

Step b : the dismantling of the glove boxes and their equipment can be performed either on site or in a specialized facility.

BELGONUCLEAIRE has chosen for the dismantling of all heavily contaminated glove boxes, which could be transported, in a specialized facility for several reasons :

- the short time available for the decommissioning operation on site,

- the risk of a dismantling operation of heavy contaminated equipment inside a hall which was not especially built for it (plasma cutting, etc.),

- the problems associated with hoisting, rotating and in general manipulating heavy equipment with a high contamination level inside a temporary alphacell.

- etc.

Although being aware of the fact that hoisting, rotating, packing and transporting huge glove boxes with a high contamination level and with heavy equipment inside could create serious risks BELGONUCLEAIRE was on the other hand convinced that these problems were minor compared to the ones to be matched in case of a dismantling on site.

Both solutions however have been applied by BELGONUCLEAIRE in the frame of a large decommissioning task, set up as a part of an elaborate equipment renewal programme.

4. DESCRIPTION OF THE DECOMMISSIONING TASKS PERFORMED AT THE BELGONUCLEAIRE MOX FUEL FABRICATION PLANT

Decommissioning tasks have been performed at both ends of the fuel fabrication line :

- at the head end : all glove boxes used for the introduction of the $\mathrm{PuO}_{2}$, the $\mathrm{UO}_{2}$, the blending of these products together with recycled scrap, the sintered scrap recovery and for the supply of the blend to the pellet presses,

- at the tail end : the glove boxes for drying the sintered pellets and the first built "pellet into rod" loading unit.

The total volume of the 14 glove boxes, decommissioned within these tasks was about $90 \mathrm{~m}^{3}$, namely $82 \mathrm{~m}^{3}$ at the head end and about $8 \mathrm{~m}^{3}$ at the tail end. 
4.1. IIMITING DIMENSIONS OF THE UNPACKED GLOVE BOXES FOR TRANSPORTATION

The maximum allowable dimensions of the unpacked but eventually

reinforced glove box were defined by the 3 following criteria :

- the possibility of the glove box removal out of the plant,

- the possibility of the glove box transportation over the public road,

- the possibility of the glove box introduction into the entrance lock of the existing dismantling room at C.E.N. Mol.

The limiting dimensions found are given in Table 1.

Table I: Maximum allowable dimensions in $m$ of the unpacked but eventual. ly reinforced glove box

\begin{tabular}{|l|c|c|c|}
\hline \multicolumn{1}{|c|}{ Operation } & \multicolumn{3}{c|}{ Glove box dimension } \\
\cline { 2 - 4 } & length & width & height \\
\hline Glove box removal out of the plant & 4,70 & 3,60 & 3,40 \\
\hline $\begin{array}{l}\text { Glove box transportation over the public } \\
\text { road }\end{array}$ & 5,00 & $3,50^{\star}$ & $3,00^{\star}$ \\
\hline $\begin{array}{l}\text { Glove box 1ntroduction in the dismantling } \\
\text { entry lock }\end{array}$ & 4,33 & $\underline{2.63}$ & 2,40 \\
\hline $\begin{array}{l}\text { * In case of a special transport } \\
\text { - Iimiting dimensions }\end{array}$ & & & \\
\hline
\end{tabular}

\subsection{GLOVE BOX GROUPS}

The glove boxes have been divided into 4 groups on the basis of on the one hand the above given limiting dimensions and on the other hand their inner contamination level. Information concerning these glove boxes is given in Table II. The $4^{e}$ group is composed of the glove boxes A4-A5-A6-A7 which formed 1 large glove box to be dismantled partially in situ.

\subsection{GROUP I GLOVE BOXES}

These glove boxes were the easiest to treat. Indeed their weight and dimensions were such that no specific problems were encountered during the decommissioning.

The glove boxes have been treated as follows :

- after their separation from adjacent glove boxes, all loose equipment parts have been removed;

- careful cleaning, dry and wet, of all surfaces inside the glove box and removal af all cleaning waste, collected powder and dust;

- careful stowing of all inner equipment;

- covering of all inner surfaces by means of a contamination fixing agent;

- covering of outer surfaces of all window parts by means of a reinforcing adhesive tape;

- fitting of a clean exhaust filter for connection to a glove box exhaust system;

- enveloping the whole glove box, except the filter connecting tube, by 
Table II : Infonmation concerning the decommissioned qlove boxes

\begin{tabular}{|c|c|c|c|c|c|c|c|c|}
\hline \multirow{2}{*}{$\begin{array}{c}\text { Glove } \\
\text { box } \\
n^{\circ}\end{array}$} & \multirow{2}{*}{$\begin{array}{c}\text { Product Treated } \\
\text { in G.B. }\end{array}$} & \multicolumn{3}{|c|}{$\begin{array}{l}\text { Dimensions in m of the } \\
\text { UNPACKED glove boox }\end{array}$} & \multirow{2}{*}{$\begin{array}{l}\text { Approx } \\
\text { volume } \\
\text { in } \mathrm{m}^{3}\end{array}$} & \multirow{2}{*}{$\begin{array}{l}\mathrm{PuO}_{2} \\
\text { content } \\
\text { in } \mathrm{g}\end{array}$} & \multirow[t]{2}{*}{ Special conditions } & \multirow[t]{2}{*}{ Group } \\
\hline & & 1 & w & $\mathbf{h}$ & & & & \\
\hline $\begin{array}{l}\mathrm{Al} \\
\mathrm{A} 2\end{array}$ & Powder & $\begin{array}{l}3,2 \\
3,6\end{array}$ & $\begin{array}{l}1,0 \\
1,1\end{array}$ & $\begin{array}{l}2,0+2,9 \\
2,0+2,5\end{array}$ & $\begin{array}{l}6+1 \\
4+0,6\end{array}$ & $\begin{array}{r}194 \\
63\end{array}$ & $\begin{array}{l}\text { removal of U part before transp. } \\
\text { rotation over } 90^{\circ} \text { before removal } \\
\text { out of the plant }\end{array}$ & $\begin{array}{l}3 \\
3\end{array}$ \\
\hline $\mathrm{A3}$ & $"$ & 3,2 & 1,1 & $2,0+2,9$ & $7+1,2$ & 128 & " & 3 \\
\hline A4 & $"$ & 1,1 & 1,0 & 1,9 & 2 & 13 & none & $1 / 4$ \\
\hline $\begin{array}{l}\mathrm{A} 5 \\
\mathrm{~A} 6\end{array}$ & " & $\begin{array}{l}1,9 \\
3,3\end{array}$ & $\begin{array}{l}1,1 \\
1,1\end{array}$ & $\begin{array}{l}2,1 \\
2,5\end{array}$ & $\begin{array}{l}4,4 \\
9,1\end{array}$ & $\begin{array}{l}114 \\
188\end{array}$ & $\begin{array}{l}\text { " } \\
\text { rotation over } 90^{\circ} \text { before removal } \\
\text { out of the plant }\end{array}$ & $\begin{array}{l}1 / 4 \\
3 / 4\end{array}$ \\
\hline $\begin{array}{l}\text { A7 } \\
\text { AB }\end{array}$ & $"$ & $\begin{array}{l}1,2 \\
2,2\end{array}$ & $\begin{array}{l}1,0 \\
1,1\end{array}$ & $\begin{array}{l}2,1 \\
2,8\end{array}$ & $\begin{array}{l}2,5 \\
6,8\end{array}$ & $\begin{array}{l}103 \\
\text { n.a.* }\end{array}$ & $\begin{array}{l}\text { none } \\
\text { rotation over } 90^{\circ} \text { before removal } \\
\text { out of the plant }\end{array}$ & $\begin{array}{c}1 / 4 \\
3\end{array}$ \\
\hline A10 & $"$ & 2,7 & 1,0 & 3,5 & 9,4 & 179 & out ot the plant " & 3 \\
\hline All & " & 1,5 & 1,0 & 3,5 & 5,2 & 85 & " & 3 \\
\hline $\mathrm{Al2}$ & $"$ & 1,5 & 1,0 & 3,4 & 5,0 & 103 & $n$ & 3 \\
\hline Al3 & $"$ & 2,4 & 1,0 & 4,1 & 10,0 & 78 & $n$ & 3 \\
\hline $\mathrm{B} 1 / 1$ & " & 1,6 & 0,6 & 0,5 & 0,5 & n.a.* & see G4 & - \\
\hline $\mathrm{Bl} / 2$ & $n$ & 2,5 & 0,75 & $0,6+0,8$ & 1,35 & 130 & nane & 1 \\
\hline $\begin{array}{l}\text { D5 } \\
\text { D6 }\end{array}$ & Sint. Pellets & $\begin{array}{l}3,5 \\
2,6\end{array}$ & $\begin{array}{l}0,5 \\
1,0\end{array}$ & $\begin{array}{l}3,0 \\
1,0\end{array}$ & $\begin{array}{l}5,25 \\
2,6\end{array}$ & $\begin{array}{l}5 \\
0,1\end{array}$ & $\begin{array}{l}\text { cannot be sent to a foreign plant } \\
\text { none }\end{array}$ & 2 \\
\hline G4 & Anal. Sampl. & 4,0 & 1,0 & 1,0 & 4,0 & $16^{12}$ & (containing B $1 / 1$ ) - none & 1 \\
\hline
\end{tabular}


means of 2 1ndependent plastic bags;

- packing of the unit in a plywood case.

The packed glove boxes were then transportedover $7 \mathrm{~km}$ on the public road to the dismantling plant.

\subsection{GROUP 2 GLOVE BOX}

One glove box ( $n^{\circ} D 5$ ) having the following approximative dimensions : $3,5 \times 0,5 \times 3,0 \mathrm{~m}(\mathrm{~h})$ and a volume of about $5,25 \mathrm{~m}^{3}$ - got to be dis mantled on place. The following actions were taken before the start of the glove box dismantling :

- careful cleaning and decontamination (target value $500 \mathrm{~Bq} / \mathrm{dm}^{2}$ ) of the Inner glove box surfaces;

- fixing of the remaining contamination by means of a thin film of "spray-1at" :

- building of a dismantling area in P.V.C. foll around the glove box.

The dismantling area was divided into 3 zones :

- the work area where the dismantling tasks were performed;

- the contamination control area where the operators were controlled and decontaminated if necessary;

- the access area where a final alphacontrol was performed.

The area was kept at a slightly lower pressure than the building hall, furthermore an air monitoring system was provided for continuous registration of the contamination of the air in the work area.

A bagging out lock was provided in a wall of the work area for the evacuation of the dismantled parts.

The operators performing the dismanting tasks were equipped with a complete PVC protective suit and an Independent mask connected to a compressed air supply. On leaving the work area, this protective equipment was left in the contamination control area.

The following dismantling operations have been carried out :

- replacing all window panels by PVC foll in order to keep the glove box as closed as possible and to avold contamination release into the work area;

- wrapping of the PVC foll around the glove box structure followed by cutting the latter into manageable pleces;

- bagging out of the structure pleces;

- demolishing of the concrete glove box socle.

About 210 manhours were required per $\mathrm{m}^{3}$ glove box for the performance of this dismantling tasks, including 16,7 manhours in protective sult. About $2,93 \mathrm{~m}^{3}$ packed waste per $\mathrm{m}^{3}$ glove box has been sent to the waste treatment.

\subsection{GROUP 3 GLOVE BOXES}

8 glove boxes from this group have to be rotated over $90^{\circ}$ before lea ving the plant, 4 have been rotated and transported to the dismantiling $f a$ cility.

This rotation operation was not without risk. The glove boxes were in service for about 12 years and they contained heavy equipment weighing up to $1000 \mathrm{~kg}$ and up to $3 \mathrm{~m} \mathrm{high}$. Furthermore, windows and gaskets being in place for the lifetime of the glove box and exposed to strong alpharadiation had certainly lost part of their mechanical characteristics and therefore required careful treatment.

So it was absolutely necessary to avold any supplementary load, coming from the equipment on the glove box structure during these delicate operations.

For this reason each glove box was surrounded at the outside by a 
strong stiffening frame and all heavy equipment inside was directly fixed on this stiffening frame by means of special fixing equipment, passing through glove ports and transfer lock ports.

The operation of 1 ifting and rotating the glove box was carried out by means of a special built frame, easy to mount and dismount.

A glove box with stiffening frame placed inside the structure for rotation is shown on figure 1 .

The following working steps have been performed :

- a dry cleaning of the inside of the glove box, followed by wet cleaning,

- the fixation of the inner equipment onto the outer stiffening frame.

- the filling up of all voids by means of polystyrene chips.

- the reinforcement at the outside of the window panels by means of self stick plastic foil.

- the mounting of the lifting- and rotating frame.

- the rotating operation.

- the packing of the rotated glove-box in 2 plastic bags and in a transport case.

- the transportation to the dismantling site.

The complete operation required :

- 25 manhours $/ \mathrm{m}^{3}$ glove box for the cleaning operation

- 194 manhours $/ \mathrm{m}^{3}$ glove box for the removal of the glove box

- 159 manhours $/ \mathrm{m}^{3}$ glove box for the dismantling operation giving a total of 378 manhours $/ \mathrm{m}^{3}$ glove box

An average value of 0.71 was obtained for the Ratio $\frac{\text { Volume Final Disposal }}{\text { Volume of glove box }}$

$$
\begin{aligned}
& \text { Weight of condit. Fin } \\
& \text { Disposal Drums }
\end{aligned}
$$

Weight of glove box + stiffening frame

\subsection{GROUP 4 GLOVE BOXES}

Some glove boxes were built together as one unit, about $4,7 \mathrm{~m}$ long and about 4,6 $\mathrm{m}$ high. The unit is shown on figure 2.

The unit was dismounted partially on place also by means of a specially built lifting device.

The separation into different glove box parts was performed by means of plastic bag welding around the flat gaskets.

The different steps up to the separation in smaller parts required 79 manhours $/ \mathrm{m}^{3}$ glove box, from which 7 for the specific separation and putting down operation.

A waste volume of $0,178 \mathrm{~m}^{3} / \mathrm{m}^{3}$ glove box has been obtained.

4.7. NOTE

All time values, given before, do not include any preparation-meeting or supervision time.

\section{SAFETY AND PLANNING}

These operations have been carried out almost entirely within the foreseen - time period, within the original cost estimation and without any major incident.

6. SUGGESTIONS FOR THE CONCEPT OF A NEW INSTALLATION

A part of the problems to be solved during these decommissioning 


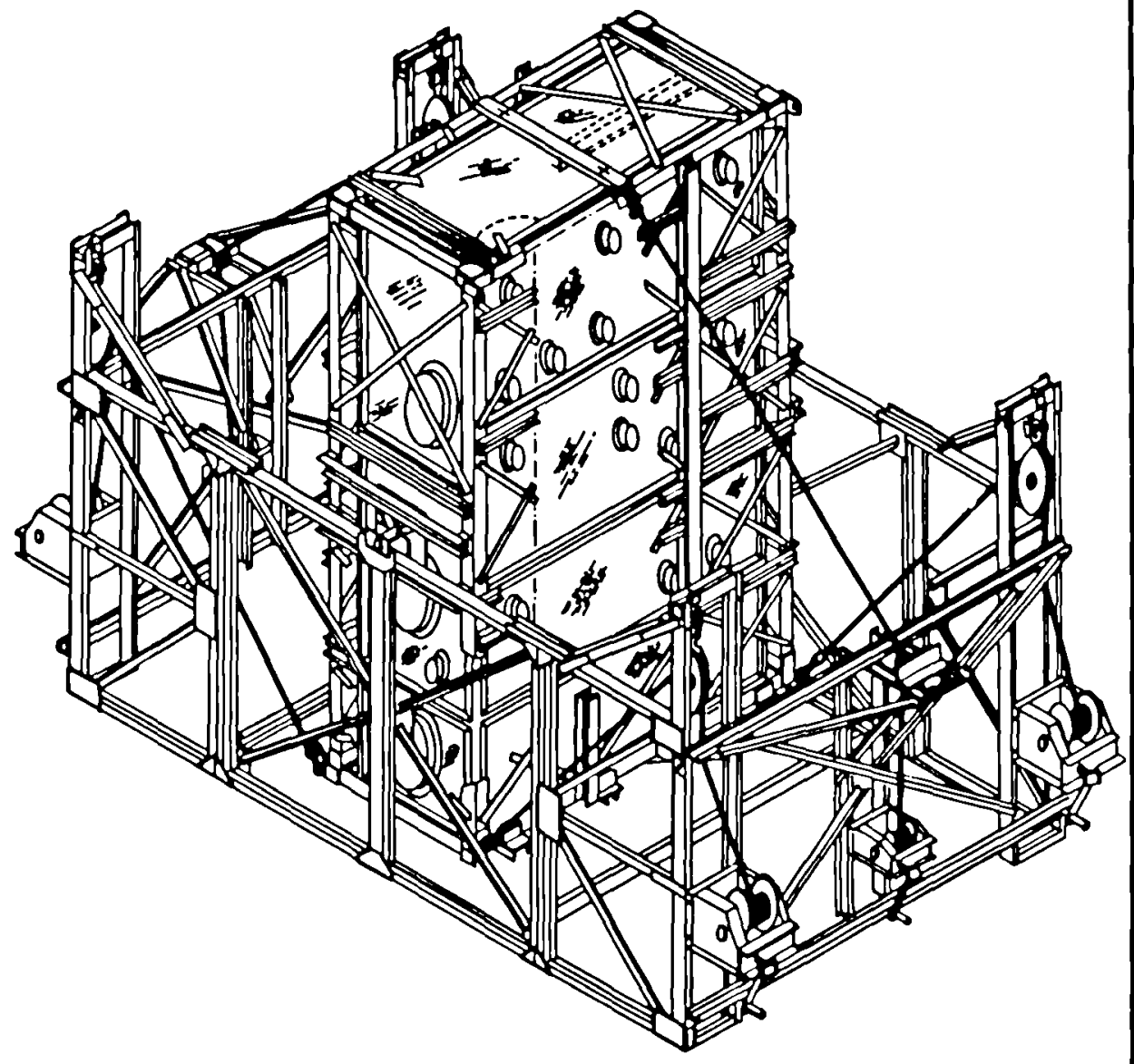

Figure 1 : Glove box with stiffening frame inside the structure for rotation. 


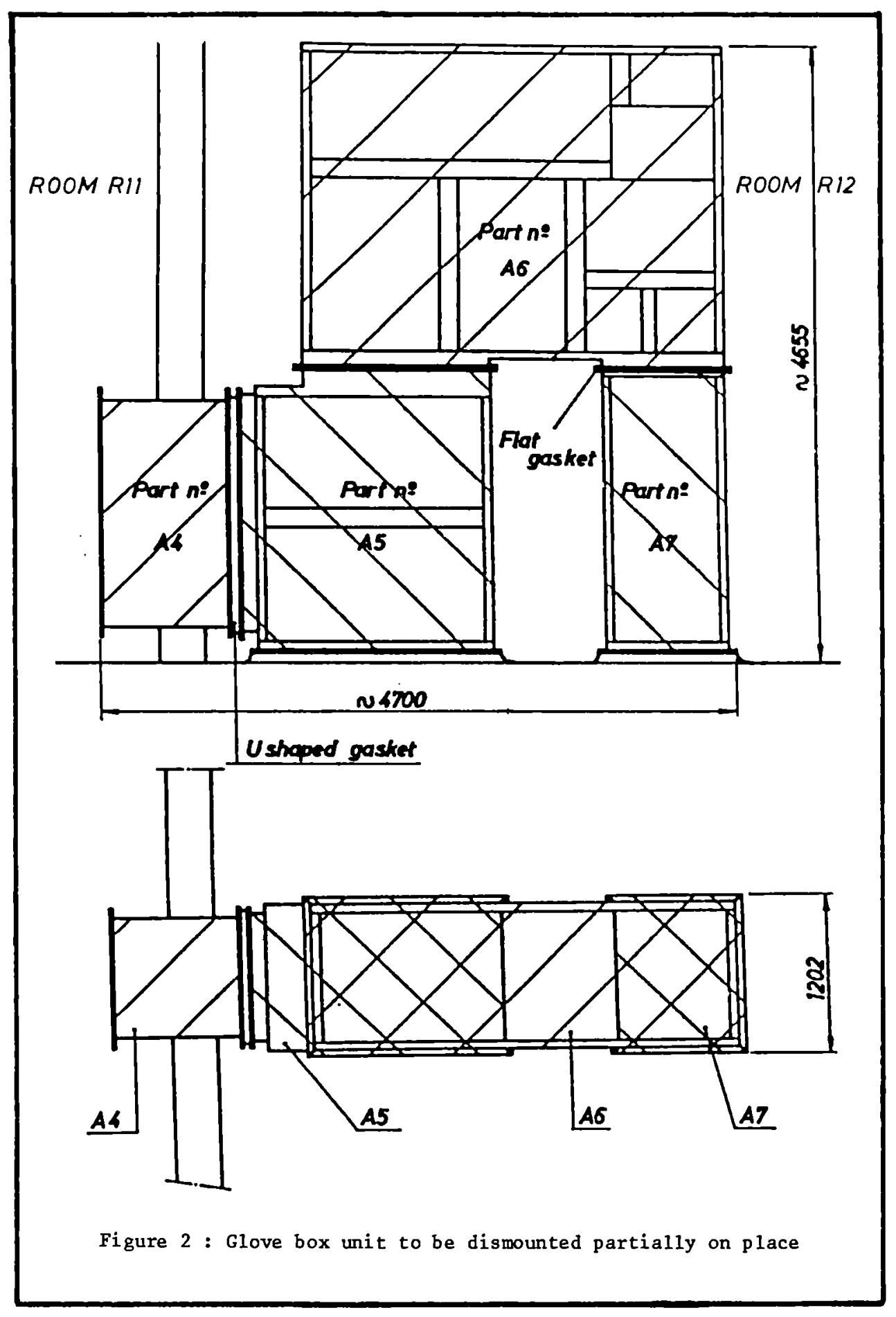


operations could perhaps be eliminated or simplified if certain rules were applied during the concept of the new equipment, by searching new cleaning techniques to be applied during the glove box life time and for the decontamination during the preliminary decommissioning operation.

During the concept of new equipment :

- all edges or holes, onto or into which powder can accumulate have to be filled with a convenient paste.

- the Inner metal surface of the glove box and the outer surface of the inner equipment have to be polished.

- all equipment for the treatment and/or transportation of radioactive powder should be collected to a dust collecting system, keeping on the one hand the equipment at a negative pressure and creating an air screen as anti-dust barrier at all transfer points of powder where the 2 equipment parts cannot be connected on a leak-tight way.

- to limit, if possible, the glove box and equipment dimensions to such values that the whole unit can be evacuated.

- to provide during the mounting of the equipment the necessary fixation points for the equipment in order to reduce later on the flxation time and at the same time the received radiation dose.

During the glove box lifetime :

- to $11 \mathrm{mit}$ the contamination of inner surfaces of the glove box and the equipment as much as possible by periodic cleaning of the inside of the glove box.

A quick and efficient method is here required in order to reduce the radiation dose recelved by the cleaning operators.

- to keep a file "as bullt" of the whole unit 1ncluding drawings, technical documentation and description notes.

At the level of the decomissioning :

- to have at one's disposal a rapid and efficient method for the preliminary decontamination before decommissioning

- to have realistic decontamination values to be attained during the preliminary decontamination.

\section{CONCLUSION}

BELGONUCLEAIRE performed several types of glove box decommissioning tasks. All this work has been carried out without any contamination of the operators and within the required time period.

An abllity to perform such tasks on an industrial scale has been proved.

The experience gained during the performance of these tasks has been used for the concept of new equipment. Furthermore research work has started in order to make available a quick and efficlent cleaning method for the glove boxes in service and a quick and rapid system for the preliminary decontamination of the glove boxes to be decommissioned. 


\title{
IMMOBILIZATION OF CONTAMINATION BY THE COATING OF POLYMERS \\ ON LARGE-SIZE WASTE PRODUCTS
}

\author{
C. de TASSIGNY - CEA. CENG.SPR.GARC \\ 85X - 38041 - GRENOBLE - CEDEX-FRANCE
}

\section{ABSTRACT}

Basic research in the field of epoxys and polyurethanes has enabled several polyurethane formulations to be chosen which are suitable for the application of quickly hardening thick coats.

The mechanical and physico-chemical cheracteristics of these polymeric systems have been studied and in particular the diffusion of radio-elements such as $3 \mathrm{H}, 60_{\mathrm{Co}} 137 \mathrm{Cs}$. Progress has been made with respect to resistance to temperature and diffusion of radio-elements in aqueous medium.

Several "bi-component" industrial devices have been tested to verify their aptitude for spraying thick coats.

The feasibility study was completed by applications on an industrial scale for the dismantling of AT1 cells at the Nuclear Centre of the HAGUE.

\section{INTRODUCTION}

\subsection{Conditioning of large-size waste products}

Some polymer families possess the characteristics required for the production of particularly long lasting and resistant coats.

These coats directly protect the surface of contaminated objects; moreover, if they are deposited in a thick layer, they enable diffusion of the radionuclides to be reduced.

These thick, mechanically resistant, coats, therefore fulfil the function of a container which they replace around radioactive waste products.

This process avoids large-size waste product cutting up operations being carried out, it no longer being necessary to introduce them into drums or caissons.

The process seems particularly well suited to the dismantling of nuclear plants producing large-size and varied waste products: steels, concrete, graphite, lead of all shapes.

These coats may be applied by spraying. The suppression of the irradiant waste product cutting up stages and the possibility of conditioning from a distance also helps reduce the amounts taken in by the staff.

New possibilities are thus opened up in the field of evacuation, handling, transport and storage of large-size waste products resulting from the decommissioning of nuclear plants.

\subsection{Objectives}

The industrial application of this process is linked to the quality of the barrier obtained and the conditions of its implementation.

The imperatives to be achieved are summarized in Table 1 below: 


\begin{tabular}{|c|c|}
\hline IMPERATIVES & MEANS \\
\hline $\begin{array}{l}\text { Coating in conformity } \\
\text { - with the ANDRA storage } \\
\text { rules } \\
\text { - with radioactive } \\
\text { transport } \\
\text { regulations }\end{array}$ & $\begin{array}{l}\text { Resistant coating material } \\
\text { - mechanical resistance } \\
\text { - to impacts } \\
\text { - to wrenching } \\
\text { - behaviour in fire and } \\
\text { temperature } \\
\text { - good properties with } \\
\text { respect to diffusion } \\
\text { of radio-elements }\end{array}$ \\
\hline $\begin{array}{l}\text { Conditioning process } \\
\text { - easy to use } \\
\text { - reliable }\end{array}$ & $\begin{array}{l}\text { - Spraying machine } \\
\text { - efficient at high } \\
\text { flow rate } \\
\text { - "nuclearlzed" } \\
\text { (dismountable) } \\
\text { - transportable } \\
\text { - decontaminable } \\
\text { - Material } \\
\text { - rapid setting } \\
\text { - high flash point } \\
\text { - not toxic } \\
\text { - available in } \\
\text { industrial quantities } \\
\text { - may be sprayed in } \\
\text { thick layer }\end{array}$ \\
\hline $\begin{array}{l}\text { Implementation in nuclear } \\
\text { environment. } \\
\text { contaminating. } \\
\text { compatible with the } \\
\text { safety rules }\end{array}$ & $\begin{array}{l}\text { - Process } \\
\text { - no aerosol generation } \\
\text { - contamination fixer } \\
\text { - without solvent } \\
\text { - applicable under } \\
\text { ventilated tent }\end{array}$ \\
\hline
\end{tabular}

Table 1 : Imperatives to be respected for the coating of large-size objects

\subsection{Specifications retained}

The large-size waste products coated with a thick layer of paint are likened to a heterogeneous waste product coated with a polymer whose perishable container had disappeared.

In the eventuality of these waste products being placed in a storage centre, those specifications most approaching them are those concerning heterogeneous waste products coated in a hardenable binder (hydraultc or polywer) and delivered in a perishable container : specifications of ANDRA (Agence Nationale pour la gestion des déchets radioactifs - National Agency for the management of radioactive waste)

By analogy with the heterogeneous waste product specifications, the following values are retained : 


\begin{tabular}{|c|c|}
\hline PROPERTY & SPECIFIED VALUE \\
\hline $\begin{array}{l}\text { Coating material } \\
\text { - Inflammation temperature } \\
\text { (standard NFT } 60118 \text { ) } \\
\text { - breaking stress } \\
\text { (standard NFT S1 101) } \\
\text { - water stability } \\
\text { (ANDRA test) } \\
\text { - diffusion coefficient D } \\
\text { (ANDRA test) } \\
\text { - supercoating thickness } \\
\text { Finished packages } \\
\text { - leachable annual fraction }\end{array}$ & 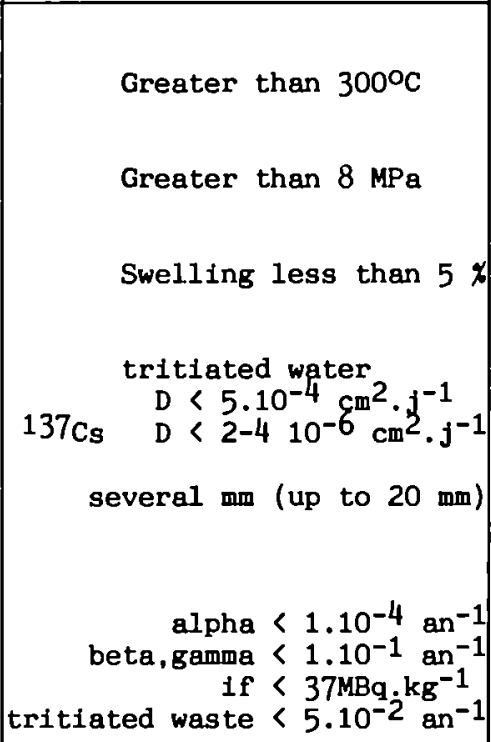 \\
\hline
\end{tabular}

Table 2 : Specifications for the coating of large-size objects

\section{MATERIALS}

\subsection{Choice of polymer}

The polymer families complying with the objectives are limited to epoxys and polyurethanes.

Polyurethanes have been selected which are commercially available on the scale of several metric tons.

Polyurethane chemistry has for some years now of fered the means of obtaining polywerization reactions in mass or quick paint drying, of the order of a second.

The rapidity with which the first layer dries enables other layers to be immediately applied and thicknesses of several $\mathrm{mm}$ to be thus achieved in only a few minutes. solvent.

The basic components (polyalcohol and isocyanate) are without

Moreover, the properties of the polyurethane may be adjusted according to the functional structure of the polyalcohol or the isocyanate.

It is therefore possible for example to anticipate and choose the hydrophobic property of the polymer enabling diffusion of the radioelements to be slowed down across the coat in the presence of water. The polyurethane formulations have been enhanced in the field of fire and temperature resistance : the class $M 2$ is generally reached for fire resistance. This result is obtained by choosing a functional structure with cycles (e.g. aromatic) or by adding suitable mineral fillers (silica, carbonates, etc). 


\subsection{Composition of the polyurethanes}

Table 3 groups together 10 polyurethane formulations which have been studied with a view to an industrial cholce.

The choice results from the application considered and the preponderant properties requiring to be obtained, for example :

- fire resistance with mineral fillers.

- good diffusion properties with a castor ofl based hydrophobic polyalcohol or a rigid polyether.

- resistance to hydrolysis with a ether polyalcohol,

- rapid polymerization with a MDI based isocyanate

\begin{tabular}{|c|c|c|c|c|}
\hline Reference & Isocyanate & Polyalcohol & $\begin{array}{l}\text { Aineral } \\
\text { Pillers }\end{array}$ & $\begin{array}{l}\text { Pot-11fe } \\
\text { (min) }\end{array}$ \\
\hline$\overline{\mathrm{PU} 1}$ & $\begin{array}{l}\text { prepolymer MDI } \\
\text { polyether }\end{array}$ & polyether & $0 \%$ & $<1$ \\
\hline PU 3 & MDI "standard" & $\begin{array}{l}\text { polyether/ } \\
\text { polyester }\end{array}$ & silica 30: & 20 \\
\hline PU 5 & $\begin{array}{l}\text { prepolymer MDI } \\
\text { polyether }\end{array}$ & polyether & $3 \%$ & $<1$ \\
\hline PU 8 & MDI "standard" & $\begin{array}{l}\text { unsaturated } \\
\text { ofl } \\
\text { polyether/ } \\
\text { polyester }\end{array}$ & silica $30 \%$ & 20 \\
\hline PU 9 & $\begin{array}{l}\text { prepolywer MDI } \\
\text { polyether }\end{array}$ & polyether & $1 \%$ & $<1$ \\
\hline PU 10 & MDI "standard" & $\begin{array}{l}\text { polyether/ } \\
\text { polyester }\end{array}$ & $\mathrm{CaCO}_{3}$ & / \\
\hline PU 11 & MDI "standard" & $\begin{array}{l}\text { unsaturated } \\
\text { ofl }\end{array}$ & $\mathrm{CaCO}_{3}$ & 7 \\
\hline PU 13 & $\begin{array}{l}\text { prepolymer MDI } \\
\text { polyether }\end{array}$ & polyether & $0 \%$ & $<1$ \\
\hline PU 14 & $\begin{array}{l}\text { prepolymer MDI } \\
\text { polyether }\end{array}$ & polyether & $0 \%$ & 10 \\
\hline PU 16 & MDI "standard" & polyether & $\mathrm{BaSO}_{4}$ & $<1$ \\
\hline
\end{tabular}

Table 3 : Composition of commercial polyurethanes sprayed with a ISOTHERM-GETRASUR unit

\section{SPRAYING DEVICE}

\subsection{Specifications sheet}

In a nuclear environment, the conditions of use for spraying systems are more severe. The points appearing to be important are the following : 
- Absence of aerosol generation which might :

- clog up the nuclear ventilation filters.

- convey the contamination,

- provoke risks of fire

- Ease of implementation (the intervention times are of ten

limited and the dismounting/remounting of a faulty part

is not easy with several glove thicknesses).

- Large degree of reliability for mixing of 2 components

(ratio, homogenization)

3.2 Choice of a spraying unit

The solution retained consists in using an "air-less" gun to spray a bi-component, solvent-less mixture with a setting time of a few seconds.

Tests have enabled a type of machine satisfying the

Specifications Sheet defined above to be selected.

The proportioning of the 2 reagents is achieved by 2 inter-

connected pumps enabling a constant ratio to be guaranteed.

The 2 components are mixed by bursting in the gun nozzle which is mechanically self-cleaning (limited sealing risk).

Spraying units supplied by 5 manufacturers have been tried out: GRACO/DEBORHA

ISOGET

REXSON

ISOTHERM

GETRASUR

A spraying unit comprises the following main components :

- constituent tanks (polyalcohol and isocyanate)

- proportioning unit, preheat and pressurizing

- spray gun

The choice of an ISOTHERM PSM70 machine was completed by GETRASUR (tanks, preheating...) and GUSMER (gun) elements.

This unit has several advantages :

* an airless spraying system (minimum aerosol generation).

* a mixing head automatically cleaned by mechanical action (no cleaning solvent).

* a single operator to run the machine.

* a ratio between the 2 components displayed in real time which is difficult to vary since the 2 proportioning piston pumps are activated by the same motor jack.

The head is cleaned by a needle perfectly adjusted to the diameter of the base : when the gun stops operating, all the polymer traces are removed prior to hardening ( 1 second).

\section{COAT PROPERTIES}

\subsection{Main physical properties}

Table 4 groups together the properties of 5 types of polyurethane coats used for spraying in thicknesses of several $\mathrm{mm}$. The main results observed are as follow :

Inflammability of the constituents

The measurements carried out using the flash point method in an open cupel showed that the constituents of the polyurethanes studied have a flash point greater than $55^{\circ} \mathrm{C}$ : they are considered to be non inf lammable. 


\begin{tabular}{|c|c|c|c|c|c|c|}
\hline & \multicolumn{2}{|c|}{$\begin{array}{c}\text { Flash point } \\
\text { oC }^{-}\end{array}$} & \multirow{2}{*}{$\begin{array}{l}\text { X of loss } \\
\text { in weight } \\
\text { of organic } \\
\text { matter at } \\
400^{\circ} \mathrm{C}\end{array}$} & \multirow{2}{*}{$\begin{array}{l}\text { \% in weight } \\
\text { of mineral } \\
\text { fillers }\end{array}$} & \multirow[t]{2}{*}{$\begin{array}{l}\text { Hardness } \\
\text { Shore D }\end{array}$} & \multirow[t]{2}{*}{$\begin{array}{l}T_{8} \\
\mathrm{O}_{\mathrm{C}}\end{array}$} \\
\hline & \begin{tabular}{|l|} 
Iso- \\
Eyanate
\end{tabular} & \begin{tabular}{|l|} 
Poly- \\
alcohol
\end{tabular} & & & & \\
\hline PU 1 & 150 & 165 & 70 & 0 & 30 & -55 \\
\hline PU 3 & 212 & 250 & 36 & 30 & 60 & 42 \\
\hline$\overline{\mathrm{PU}} 8$ & 212 & 248 & 45 & 30 & 55 & 18 \\
\hline PU 9 & $>200$ & $\begin{array}{l}123- \\
135\end{array}$ & 83 & 0 & 50 & 10 \\
\hline PU 16 & $>200$ & $>200$ & 66 & 34 & 65 & 10 \\
\hline
\end{tabular}

\section{Behaviour in temperature}

Polyurethanes with $30 \%$ of mineral fillers (silica, $\mathrm{CaCO}_{3}, \mathrm{BaSO}_{4}$ ) have a relatively low loss in weight of organic matter at $400^{\circ} \mathrm{C}$. The $\mathrm{Tg}$ values are characteristically those of elastomeric polyether polyurethane (PU 1) and rigid polyether polyurethane for the other formulations.

\section{Hardness}

Hardness Shore $D$ at $20^{\circ} \mathrm{C}$ is sufficient for the applications considered (handling risks).

\subsection{Optimal characteristics of a coat}

The characteristics of a polyurethane PU 16 which appear to be the best compromise currently available are given below :

This rigid polyether polyurethane has good properties of :

- resistance to hydrolysis (polyether function)

- diffusion (rigid. compact molecular structure)

- temperature and fire resistance (34\% of mineral fillers BaS04)

The implementation conditions are a compromise between:

- rapidity of polymerization (drying time ( min)

- good explosion of particles in the spraying fog (fine droplets)

The final appearance is :

- smooth (decontaminable)

The coat adheres to metal, concrete, graphite, etc supports.

Table 5 summarizes the results of the mechanical tests.

\subsection{Water diffusion}

Study of the diffusion of tritiated water enables several factors to be verified :

- the integrity of the barrier

- the resistance of the coat to hydrolysis

- water permeability

- a relative classification of the diffusion properties which may be obtained in a very short time (1 week). 


\begin{tabular}{|c|c|c|}
\hline & $\begin{array}{l}\text { coat } \\
\text { only }\end{array}$ & $\begin{array}{l}\text { coat on } \\
\text { steel support }\end{array}$ \\
\hline breaking elongation at $20^{\circ} \mathrm{C}, \mathrm{x}$ & 50 & \\
\hline breaking stress at $20^{\circ} \mathrm{C}$, Mla & 12 & \\
\hline hardness Shore D at $20^{\circ} \mathrm{C}$ & 65 & \\
\hline glass transition temperature $\mathrm{Tg}{ }^{\circ} \mathrm{C}$ & 10 & \\
\hline impact strength at $20^{\circ} \mathrm{C}, \mathrm{hJm}^{-2}$ & & 20.2 \\
\hline $\begin{array}{l}\text { wrenching stress at } 20^{\circ} \mathrm{C} \text { in } \mathrm{MPa} \\
\text { - adhesive rupture }\end{array}$ & & $3-10$ \\
\hline $\begin{array}{l}\text { punching : breaking stress in } \mathrm{MPa} \\
\text { - elastic behaviour }\end{array}$ & & 220 \\
\hline $\begin{array}{l}\text { behaviour in fire } \\
\text { - steel support }\end{array}$ & & $\begin{array}{l}\text { (M2) } \\
\text { (B2) }\end{array}$ \\
\hline
\end{tabular}

Table 5 : Characteristics of the polyurethane PU 16

Although the study of diffusion of other radio-elements requires longer periods of time, it is necessary for the drawing up of a special finished package file.

The study of the diffusion of water in membranes is carried out according to standardized procedures of ANDRA with tritiated water. Table 6 recalls the values obtained for various types of materials. Moreover, the results of the diffusion coefficients given have been translated into $\mathrm{dm}^{3} \cdot \mathrm{m}^{-2}$ an $\mathrm{n}^{-1}$. This unit gives a leakage rate per $\mathrm{m}^{2}$ and for a standardized thickness of $1 \mathrm{~mm}$.

The following general remarks may be made :

- the chemical composition of the polyurethanes has a very strong effect on their impermeability capacity.

- a great dispersion of values according to the materials is observed : a divergence of 1 to 100 for the polyurethanes.

These divergences show that the diffusion criterion is essential in the choice of the material to be used to deposit a thick coat.

Table 5 gives the results obtained by way of comparison on membranes of other polymers. The very low values of the PTFTE, PE and epoxy polymers whose waterproofness properties are known, are observed. The polyurethanes with a so-called rigid structure and the polyurethanes with polyester functions also exhibit good waterproofness qualities.

\section{FEASIBILITY OF THE SPRAYING PROCESS ON AN INDUSTRIAL SCALE}

The waste product coating process using the ISOTHERM "PSM 70" spraying equipment was tried out in a hostile environment on contaminated parts. This operation was carried out in collaboration with the nuclear plant decommissioning unit in the AT1 installation (CEA/UDIN) at the COGEMA centre of the HAGUE. 


\begin{tabular}{|c|c|c|c|}
\hline \multirow{2}{*}{$\begin{array}{l}\text { Product } \\
\text { Reference }\end{array}$} & \multirow{2}{*}{$\begin{array}{l}\text { Material } \\
\text { Type }\end{array}$} & \multicolumn{2}{|c|}{ Diff. liquid water at $23^{\circ} \mathrm{g}$} \\
\hline & & $\mathrm{dm} \mathrm{m}^{3} \cdot \mathrm{m}^{-2} \cdot \mathrm{an}^{-1}$ & $\begin{array}{l}\times 10^{-10} \\
\mathrm{~cm}^{2} \cdot \mathrm{s}-1\end{array}$ \\
\hline PU 1 & $\begin{array}{l}\text { Polyurethane } \\
\text { ether flexible }\end{array}$ & 36.2 & 115 \\
\hline PU 3 & $\begin{array}{l}\text { Polyurethane } \\
\text { ether - ester }\end{array}$ & 0.66 & 2.1 \\
\hline PU 8 & $\begin{array}{l}\text { Polyurethane } \\
\text { polyether - polyester }\end{array}$ & 0.70 & 2.2 \\
\hline PU 9 & $\begin{array}{l}\text { Polyurethane } \\
\text { ether }\end{array}$ & 4.4 & 14 \\
\hline PU 13 & $\begin{array}{l}\text { Polyurethane } \\
\text { ether flexible }\end{array}$ & 32 & 102 \\
\hline PU 14 & $\begin{array}{l}\text { Polyurethane } \\
\text { ether flexible }\end{array}$ & 36.0 & 116 \\
\hline PU 16 & $\begin{array}{l}\text { Polyurethane } \\
\text { ether rigid }\end{array}$ & 1.57 & 5.0 \\
\hline Standard & PTFE Film & 0.0044 & 0.014 \\
\hline Standard & PE Film & 0.038 & 0.12 \\
\hline Standard & PVC Film & 0.66 & 2.1 \\
\hline Standard & Methacrylic resin & 2.82 & 9.0 \\
\hline$\overline{X Y} 1$ & Epoxy resin & 0.23 & 0.74 \\
\hline
\end{tabular}

Table 6 : Diffusion coefficient of tritiated water across polymer membranes

\subsection{1st Worksite : sheet leads}

The experimental workshop for the reprocessing of rapid AT1 nuclear fuel types is currently being decommissioned. This building is located at the HAGUE. The CEA/UDIN is the prime contractor for its dismantling.

The dismounting of a biological protection protecting a filtering unit made it necessary to block the contamination of 9 sheet leads which made it up for possible re-use on the worksite prior to their being abandoned as waste. These sheet leads represent 25 metric tons for a surface area of approximately $40 \mathrm{~m}^{2}$ and are contaminated (108 Bqx and $\beta$,

The parts were coated in a vinyl tent. The parties involved wore 2 cotton overalls plus one made of vinyl with a supply of respirable air connected on to the mask filter insert.

The part to be painted was suspended to a lifting block across the removable roof of the tent. 
The actual spraying machine was placed outside the hall in another room. Only the heating cords, protected by 3 vinyl jackets, and the gun were exposed to the contamination.

Throughout the 3 worksite days, the distribution of tasks mainly concerned the handling of the sheet leads (70\% of the time) and the spraying ( $30 \%$ of the time).

The surface contamination of each sheet lead was measured before and after spraying. Following coating, no surface contamination was detected.

Likewise, the spraying tent was monitored between each sheet lead and no trace of contamination was detected in the atmosphere.

\subsection{2nd Worksite : cast Iron slabs}

This operation concerned the replacement of gray cast iron slabs (hard cementite) which make up the upper biological protection of several AT1 cells : 12 slabs from 4 to 12 metric tons of thickness from 400 to $600 \mathrm{~mm}$.

It was not possible to completely eliminate radioactivity so that these slabs could then be evacuated as non radioactive waste :

- the contamination was fixed in the first $100 \mathrm{um}$

- steeping would not have solved the problems of decontamination in depth and would have presented handling risks.

The removal of the slabs cut up to the dimensions of the ANDRA finished packages would make it necessary due to their weight to manufacture very costly special caissons.

This type of coating is justified for several reasons:

- it is more economical than cutting up and placing in special caissons.

- the thick coat principle permits an individualized check of each slab prior to evacuation to ANDRA, facilitated by the smoothness of the surface.

- the total volume of waste to be stored is three times less with a coat than with a caisson.

- vinyl sheets cannot be used on heavy fillers since experience has shown their fragility and ageing.

Spraying on the worksite took place over one month. The mean thickness of the coat is $4 \mathrm{~mm}$. Approximately $1 \mathrm{t}$ of polymer was deposited on the 12 slabs.

Two important results are to be noted :

- the ambient contamination in the spraying tent was fixed and there was no placing in suspension of the superficial contamination of the waste products.

- After coating, no surface contamination was detected, thereby enabling the slabs to be stored outside the building. 


\section{IMMOBILISATION OF ACTIVE CONCRETE DEBRIS USING SOLUBLE SODIUM SILICATES \\ BY \\ S.P. Jull and S.N. Field}

Taylor Woodrow Construction, London, U.K.

\section{ABSTRACT}

Demolition of biological shields will generate large quantities of active concrete debris. Sodium silicate solutions have already been shown capable of immobilizing such debris in a pellet form; this new study investigates debris immobilization via a silicate solution/debris slurry. A study of the physical and chemical properties of demolition debris has been undertaken. Laboratory scale trials have shown that only the finer ( $\langle 5 \mathrm{mun})$ debris fractions set satisfactorily when mixed with a sodium silicate solution. Debris from ordinary portland cement concrete set more quickly than that containing a $30 \%$ pulverized fuel ash cement replacement. The particle size of the debris is a major factor in the setting process, but chemical interactions are also significant. A ratio of 1.2:1 debris:sodium silicate solution $\left(\mathrm{SiO}_{2} / \mathrm{Na}_{2} \mathrm{O}=3.30\right)$, produced an optimum mix. A brief study of the logistics of a full scale process plant has also been made.

1. INTRODUCTION

Demolition of concrete biological shields will generate large quantities of active debris. The size distribution of such concrete may range from pieces of the order of one tonne in weight down to dust. Materials at the lower end of the size distribution represent a particularly severe hazard; wetting the dust provides only a short term method of reducing the potential amount of airborne material.

Sodium silicate solutions have interesting properties when in contact with cementitious materials. The hydration products of cement (predominantly a lime/silica gel, together with excess lime in a crystalline form) cause gelation of the silicate solution leading to setting of a mixture of concrete demolition debris and sodium silicate solution. The set develops gradually, and the possibility thus emerges of stabilising the volatile dust fraction by mixing it (at the demolition site) with sodium silicate solution.

Two possibilities exist. Firstly, the ratio of concrete debris to silicate solution may be low, leading to a soft, malleable composite material which may be pressed into briquettes or pellets. A previous CEC contract (1) assessed the feasibility of this pelletising approach. The second possibility is the use of higher silicate solution/demolition debris ratios, producing a slurry rather than a pellet. The production of such a slurry would be simpler in principle than an encapsulation plant using dry cement. Such a slurry would not only be a convenient method of handling the fine active material, but once the slurry had set into suitable containers, would provide an excellent means of stable short or medium term storage before final disposal in a repository. It is with the second (slurry setting) process scenario that this project is concerned.

2. SODIUM SILICATE - HARDENING MECHANISMS

The properties of soluble sodium silicates have been widely studied. Solutions are manufactured with a wide range of $\mathrm{SiO}_{2} / \mathrm{Na}_{2} \mathrm{O}$ ratios and concentrations depending on their end use.

As the inmobilization of concrete debris with sodiun silicate solutions involves a gelation or setting process, it is appropriate to consider the different ways in which sodium silicate solutions can be 
set. The simplest gelation process occurs by evaporation, and addition of dehydrating agents can cause gelation in a similar way. Certain alcohols and ketones also have this effect. Simple alkali metal salts such as sodium chloride precipitate the silicate by preferential dissolution (common ion effect).

A reduction of the amount of alkali present increases the $\mathrm{SiO}_{2} /$ $\mathrm{Na}_{2} \mathrm{O}$ ratio, lowers $\mathrm{pH}$ and causes a set. This occurs on addition of an acid, or an acid forming compound, by leaching out of the alkali, or by interaction with certain amorphous materials.

Chenical reaction with multivalent ions, or almost any acidic or heavy metal compound will cause gelation. In most cases this reaction is almost instantaneous. Calcium ions present in the free calcium hydroxide in cement paste would react with silicate anions forming insoluble calcium silicates.

It is clearly the latter mechanism that is most likely to be responsible for gelation and setting of a concrete debris/sodium silicate slurry kept under sealed conditions. Furthermore, as most of the available calcium ion will reside within the concrete debris, and must diffuse to the particle surface before becoming available to react with the silicates, it is likely that the setting reaction will be time-dependent.

\section{CHARACTERISATION OF DEMOLITION WASTE}

As part of the project a desk study was undertaken to establish the features of concrete demolition debris relevant to a slurry-setting process.

Concrete structures are demolished and fragmented using a variety of techniques (2), for example, using explosives, hydraulic and pneumatic hanmers and internal bursting. It is convenient to characterise the debris produced by the demolition of concrete in terms of the resulting particle size distribution. However, different techniques subject the concrete to different strain rates and fracture modes and hence it might be expected that the different techniques produce different particle size distributions. It is also important to consider the potential differences in chemical composition between differing size fractions.

A literature review has shown that very little information is available regarding the particle size distribution of concrete demolition debris. It is apparent that the average particle size of fractured concrete is related to the strain rate during loading (3); for explosive demolition, it has also been shown that mean particle size can be correlated with the excess blast load available over the resistance of the structure (4). No reasons were found not to assume that the particle size distributions of the finer material from differing demolition methods are similar. Checking this assumption was however outside the scope of this project.

other conclusions from this part of the study were that the engineering properties of the concrete are less important than the loading regime in determining the physical characteristics of the resulting debris, that cracking under strain is generally initiated at the matrix aggregate interface (5), and that there is considerable evidence to show that normally the finer material is enriched in cement paste $(6)$. 
MIX TRIALS

A major component of the project was to undertake a series of mix trials to determine the range of types and sizes of concrete demolition debris on which the process could be successfully applied, and also to determine the optimum proportions for a typical suitable debris fraction. The final slurry would be required to remain in a flowable form for handling purposes, but to solidify reasonably quickly in the chosen receptacle.

The effects of the following concrete and sodium silicate solution variables were investigated:-

i) concrete type

ii) maximum particle size of the demolition debris

iii) silica/alkali ratio (by weight) of the sodium silicate solution

iv) debris/silicate solution ratio.

The mixes were assessed in terms of initial workability, setting times and strength.

\section{Experimental}

Two progranmes were undertaken, a small scoping study (see below), and a more extensive series of tests on mixes of likely suitable proportions.

Details of the types of sodium silicate solution used are given in Table I. Two main concretes were used, a relatively young (56 day) OPC concrete, and a mature (1 year) high strength concrete with $30 \%$ partial replacement of the cement by pulverised fuel ash. (The latter concrete is typical of a UK prestressed concrete pressure vessel). The composition of the concretes is given in Table II.

The concrete was mechanically crushed to simulate demolition. Only <5m debris was used in the experimental programme as the scoping study (see below) had shown slurries based on coarser material to be unsuccessful. This < $5 \pi m$ fraction amounted to approximately $20 \%$ of the demolition debris for both types of concrete for the crushing process used. Sieve analyses of this fraction for both types of concrete debris are given in Table III.

\section{Scoping study}

The concrete used was a one year old Ordinary Portland cement pulverized fuel ash blend. Two types of sodiun silicate solution were used, with $\mathrm{SiO}_{2} / \mathrm{Na}_{2} \mathrm{O}$ ratios of 3.3 and 2.0 .

The solutions were easily hand mixed with the concrete debris in small containers (approx. $250 \mathrm{~cm}^{3}$ ) in ratios of $1.6,1.4,1.2,1.0$ and 0.8 debris:silicate solution. However, segregation of the mixture took place immediately and recurred consistently despite thorough mixing. No gelation took place even after 1 week.

In order to overcome the problem of segregation the larger pieces of debris were separated out. A $<5 \mathrm{~mm}$ fraction was sieved out and mixed with the silicate solutions in ratios of $1.2,1.9$ and $0.8: 1$ debris: solution. It was found that these ratios produced slurry consistencies, and that segregation was much reduced. These proliminary mixes indicated that the higher $\mathrm{SiO}_{2} / \mathrm{Na}_{2} \mathrm{O}$ ratio (3.30) silicate solution had the best initial binding properties, and that only fractions of $<5 \mathrm{~mm}$ are likely to gel satisfactorily.

\section{Main Programe - slurry Characteristics}

Illustrative results for the PFA concrete (initial and final gel times for each mix, and observations of the final product) are detailed in Table IV. Much additional data is also available although not shown. 
The higher $\mathrm{SiO}_{2} / \mathrm{Na}_{2} \mathrm{O}$ ratio silicate solutions were more viscous and therefore produced more viscous slurries when mixed with concrete debris. Using the lowest ratio solution (Crystal $100 \mathrm{~A} \mathrm{SiO}_{2} /$ $\mathrm{Na}_{2} \mathrm{O}=2.00$ ) debris fractions could be added at up to 1.6 or 1.8 times by weight of silicate solution and the mix maintained a slurry consistency. It was also noticed that the finer debris fractions from both types of concrete produced more viscous mixes than the coarser ones for any given debris:silicate ratio.

\section{Main Programme - Gelation and Setting}

The initial and final gel times were monitored manually by probing the mixtures with a spatula. Results for both the PFA and the OPC concretes indicated the same trends as observed on initial mixing:-

i) Settings times are fastest with the higher $\mathrm{SiO}_{2} / \mathrm{Na}_{2} \mathrm{O}$ ratio solutions.

ii) The finer debris fractions set faster than the coarse ones for any given type of silicate solution.

iii) OPC concrete fractions set faster than the corresponding PFA concrete fractions.

The higher $\mathrm{SiO}_{2} / \mathrm{Na}_{2} \mathrm{O}$ ratio silicate solutions are known to be more reactive and it is not surprising that these solutions produced the quickest setting times. This higher reactivity is potentially due to a combination of physical and chemical effects. Higher $\mathrm{SiO}_{2} / \mathrm{Na}_{2} \mathrm{O}$ ratio solutions contain more polymeric silicate ions, and are chemically more reactive.

However, even the most reactive silicate solutions did not produce any gelation when mixed with the original crushed debris at slurry consistency in the scoping study. As debris fractions became finer. their setting times decreased markedly indicating that particle size effects were a dominant factor in the setting process. Further investigations were undertaken to determine whether particle size was the only factor controlling gelation. The complete debris was ground to a particle size of <600um and mixed with silicate solution of $\mathrm{SiO}_{2} / \mathrm{NaO}=3.3$ in a ratio of $1: 1$. The resulting mixture gelled immediately, and was hard after 30 minutes, confirming the strong particle size effect.

On demolition, finer fractions of concrete debris contain a higher proportion of cement paste than the coarser ones which consist mainly of aggregate. Experiments had already shown that the fine, cement-rich, debris fractions gelled very quickly on mixing with the sodium silicate solution, so work was carried out to see if the same effect occurred with finely ground aggregate in the absence of cement paste. Silicious aggregate (as used in the simulated demolished concrete) was crushed to a particle size of (600um and mixed with silicate solution of $\mathrm{SiO}_{2} / \mathrm{N}_{2} \mathrm{O}=3.3$ in a $1: 1$ debris/solution ratio. Initial gelation took place after 12 hours, but the mixture had not set hard after a further $2 \frac{1}{2}$ days. The smaller particle size obtained on grinding made available a large surface area for absorption of the silicate solution, indicating that physical effects were not wholly responsible for the setting and hardening reaction.

In conclusion it is clear that fine debris fractions must set more quickly than coarse ones because of their small particle size and their cement content. It is reported that amorphous phases such as the calcium silicates, (as found in hardened cement paste) remove soda from the silicate solution by reaction, lower $\mathrm{pH}$ and rapidly decrease the gel time of the mix. Reaction also clearly occurs between calcium ions from the free lime in hardened cement paste and the silicate solution. 
It is not known which reaction is the one controlling the gelation process, although precipitation of calcium silicates is believed to be more likely at present.

\section{Main Programme - Development of Strength}

Strength was assessed empirically by noting the resistance and general nature of set mixes to a spatula blade. Results showed a similar trend to those for setting times. Based on this rudimentary assessment, the mixes which set the quickest appear to be the strongest; that is, those with high $\mathrm{SiO}_{2} / \mathrm{NaO}$ ratios and smaller particle size.

It is well documented that the best silicate binders are formed with low silica:alkali ratios because these can be obtained with higher solids contents for a given viscosity (6). This is however true only where evaporation constitutes the hardening mechanism; all slurries in this programme were set under sealed conditions (no water loss - to simulate setting in a container) and there is therefore no discrepancy between the data in this programme and that of the literature.

Main Programme - Effect of Concrete Type

Mixtures containing only OPC produced more viscous slurries than those of the same debris:silicate ratio containing the OPC/PFA blended concrete. These more viscous mixes also had quicker setting times.

OPC debris mixtures set quicker than PFA/OPC debris for any given debris fraction. This difference in setting times was most noticeable in the lower particle size fractions (i.e. those with higher cement contents). The difference between all-OPC concrete and concrete with partial PFA replacement indicates that the setting and hardening reactions are chemical in origin. The OPC would contain much more free lime than the PFA/OPC blend and it is therefore further indicated that the reaction between this free lime and the sodium silicate solution is the predominant setting and hardening mechanism. The alternative hypothesis discussed earlier (a physical effect based on the presence of amorphous calcium silicates) cannot explain the diferences between the concretes due to the presence of approximately equal amounts of similar calcium silicate hydrates in both concretes.

5. CHOICE OF OPTIMUM MIX DESIGN FOR FURTHER TESTING

The choice of optimum mix for further testing was based on the following criteria:-

1) an initial slurry which is neither too mobile or too viscous

2) a slurry which stays mobile long enough to be emplaced before a set occurs

3) a design which uses up as much of the debris as possible.

4) the strength of the chosen $\mathrm{mix}$ should develop sufficiently after placing in the final containers.

All slurries produced from the highest $\mathrm{SiO}_{2} / \mathrm{Na}_{2} \mathrm{O}$ ratio solution (Crystal 66, $\mathrm{SiO}_{2} / \mathrm{Na}_{2} \mathrm{O}=3.65$ ) were too viscous and were eliminated. OPC debris was chosen for this mix rather than the PFA/OPC blend, although it would not have been unreasonable to use this. The OPC data available from the main testing programme indicated that debris with a maximum particle size of $5 \mathrm{~mm}$ could be successfully set with one of two combinations of silica/soda ratio and debris/solution ratio. Values chosen for the optimum mix design were a $\mathrm{SiO}_{2} / \mathrm{Na}_{2} \mathrm{O}$ ratio of 3.3 with debris:solution silicate solution and debris in a ratio of $1.2: 1$ debris:solution. 
6. ENGINEERING PROPERTIES OF SET SLURRIES

As fresh and set slurries will require to be transported, handled and ultimately emplaced in a repository, a series of simple tests was undertaken to establish parameters important to the engineering design of systems associated with the slurry setting process. All tests were undertaken on the optimum proportions described above.

\section{Rheology/Setting Time/Sedimentation}

Although no detailed rheological measurements were undertaken, the flow properties of the optimum mix can best be described as similar to a 'flowing' superplasticised concrete. Setting times were established by the penetrometer method of BS 5075: Pt. 1, 1982. Initial and final set times were approximately 30 minutes and 9 hours respectively. The time for initial set is slightly shorter than for a conventional cementitious mix. Slight bleed (sedimentation) occurs during this period, a layer of liquid forming on top of small samples equal to 1 to 28 of the sample volume. This liquid was largely reabsorbed, although soluble ions acquired from contact with the debris caused it to partially gel.

Short-Term Properties in the Hardened slate

The density of the hardened optimum slurry was $1770 \mathrm{~kg} / \mathrm{m}^{3}$ (c.f. the density of the original debris of about $2400 \mathrm{~kg} / \mathrm{m}^{3}$ ). The compressive strength of the set slurry was measured in a 'cube' test (as used in concrete technology i.e. a partially triaxial stress state). Strengths were still increasing after 90 days, indicating that the strength-giving reaction was continuing. Approximate average 3,7 , 28 and 90 day compressive strengths were $0.7,1.1,1.6$ and $2.2 \mathrm{MPa}$ respectively. Uniaxial tensile strengths showed similar development, and were of the order of 0.2 MPa at 28 days.

As the object of the slurry setting process is to ' $f$ ix' radioactive debris, it is important that the hardened material is not excessively friable or prone to generate dust. A simple attrition test (adapted from BS 3900) indicated that although the material could be worn away with plastic brushes, no significant dusting occurred.

\section{Long Term Properties}

Dimensional changes are important in that the formation of voids (from autogenous or drying shrinkage) or disruptive pressures (caused by swelling on wetting) and affect repository performance. Both drying shrinkage and wetting expansion were of the order of 1-1.58 which is very large for a cementitious system. The origin of these significant movements is clearly the sensitivity of the phase resulting from the hardening of the original silicate solution (which volumetrically occupies 20-308).

Immersion of samples in distilled water for a few weeks brought about a softening of a surface zone of the order of $2-3 \mathrm{~mm}$. Considerable quantities of sodium and calcium ion leached into the water. The mechanism is thus presumably dissolution and outward diffusion of the calcium silicates from the hardened silicate solution phase.

7. OUTLINE PROCESS PLANT DESIGN

Figure 1 shows a schematic layout for a plant for the encapsulation of the sub-5mm material by the slurry setting process. Typically a concrete bioshield might be demolished in $5 \mathrm{~m} \times 5 \mathrm{~m} \times 150 \mathrm{~mm}$ sections, of which (depending on demolition method) up to 208 might be below 5nun. The debris would thus be encapsulated in batches of the 
order of 5-10 tonnes. Pneumatic transport could remove the fine debris directly from the demolition site. This would necessitate setting up the process plant and its associated active area adjacent to the bioshield. With the use of breathing equipment and protective clothing, operative exposure could be kept to 1 usvhr $^{-1}$ without necessitating remote handling equipment.

The plant could be designed around batch or continuous mixing, in a mixer, or around batch mixing in the final receptacle. Fig. 1 shows the main plant, together with the necessary washout and air filtering plant. The estimated capital cost is $\mathbb{E} 1.1 \mathrm{M}$.

8. CONCLUSIONS, RECOMMENDATIONS AND ACKNOWLEDGEMENTS

Although the literature indicates that the mechanisms of silicate/concrete interaction are not well understood, successful setting of the smaller size fraction of concrete demolition debris can be achieved at laboratory scale. Hardened properties of the set slurry are also acceptable. A study of the full scale process has resulted in an outline design for a suitable on-site plant. Estimated capital costs of such a plant are of the order of $\varepsilon 1.1 \mathrm{M}$.

The project has shown that only the material of less than $5 \mathrm{~mm}$ particle size can be set by this technique. Whilst this meets the original objectives of inmobilising dust, it had been hoped that the $10 \mathrm{~mm}$ size material, (which will require removal from the larger debris before grouting can take place) could also be disposed of by the slurry setting technique.

The slurry setting concept is now available for larger scale tests and a full feasibility study, once bioshield demolition methods are selected, and acceptance standards for active concrete at repository sites become more clear.

The work was carried out as Contract FI 1D 0042 UK(H), (Project 4) under the European Community's Research Programme 'Decommissioning of Nuclear Installations'.

Acknowledgements are due to $T$. Molesworth and $w$. Price of Taylor Woodrow for assistance given and also to the CEGB, UKAEA, HSE, NII, DOE and Taylor Woodrow Construction Ltd. for partial funding of the package of work which this project forms part.

\section{REFERENCES}

1. Barody et al, Treatment of Active Concrete Waste Arising from the Dismantling of Nuclear Facilities, CEC Contract DE-D-005-81-UK(H) 1984.

2. Demolition Waste, The Construction Press, Lancaster 1980.

3. Shah, S.P. Adhesion Problems in the Recycling of Concrete, Nato Adv. Res. Inst. Proc. 1980, 245-261.

4. Depauw, c. Adhesion Problems in the Recycling of Concrete, Nato Adv. Res. Inst. Proc. 1980, 311-320.

5. Hilsdorf, H.K. Zielgeldorf, S. Adhesion Problems in the Recycling of Concrete, Nato. Adv. Res. Inst. Proc. 1980, 112-123.

6. Ravindrarajah, R., Tam, C.J., Int. J. Cen. Composites and Lightweight Concr. $9,1987,235-241$. 


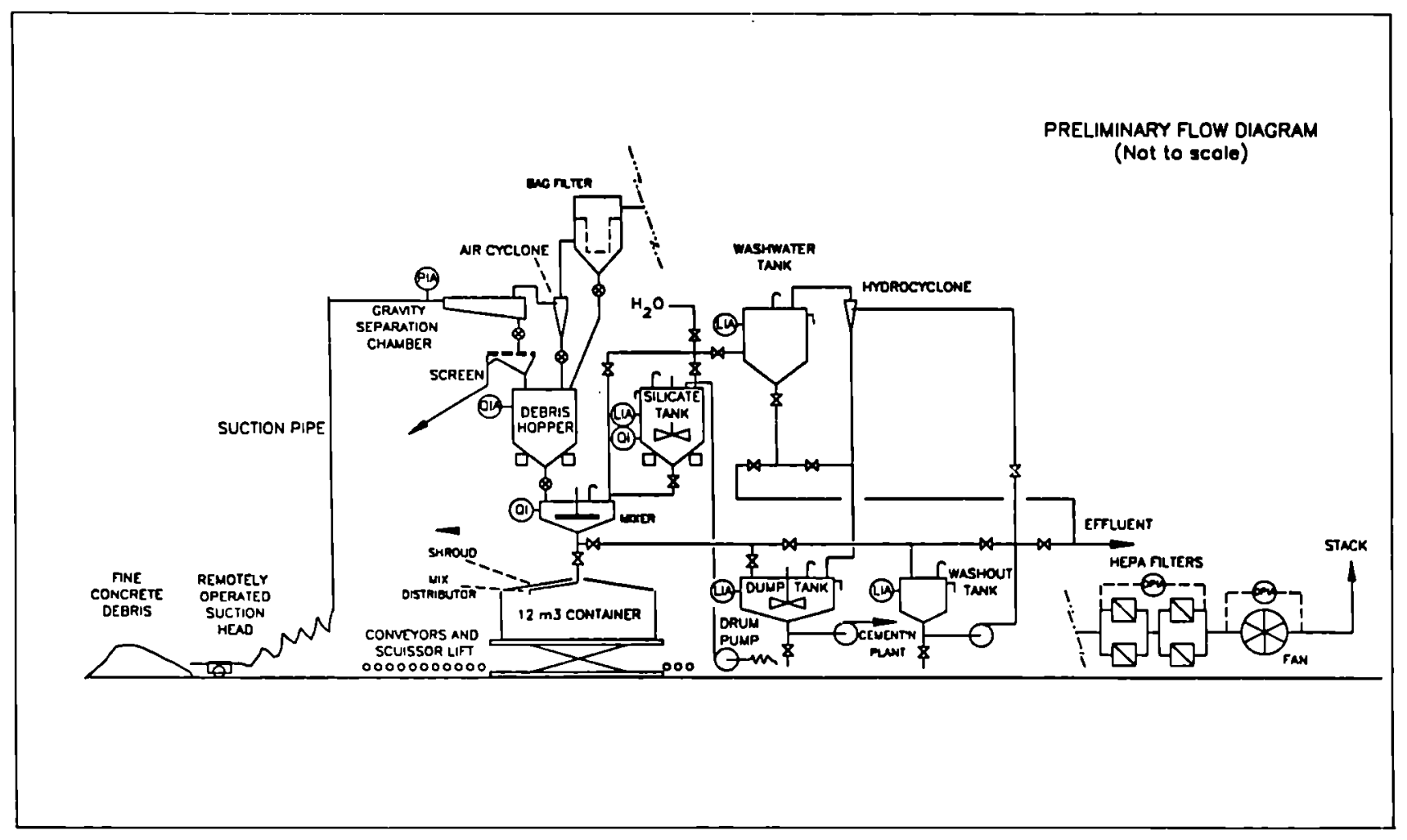

Fig. 1. Concrete debris/sodium silicate immobilisation plant 
TABLE I. Sodium Silicate Solutions

\begin{tabular}{|c|c|c|c|c|c|c|c|}
\hline Grade & $\begin{array}{l}\text { Density } \\
\text { at } 20^{\circ} \mathrm{C}\end{array}$ & $\begin{array}{c}\text { Mean Weight } \\
\text { Ratio } \\
\mathrm{SiO}_{2}: \mathrm{Na}, \mathrm{O}\end{array}$ & $\begin{array}{c}\text { Mean } \\
\text { Total } \\
\text { Solids } \\
\end{array}$ & $\left\{\begin{array}{l}\text { Mean } \\
\mathrm{Na}, \mathrm{O} \\
t\end{array}\right.$ & $\begin{array}{c}\text { Mean } \\
\mathrm{SiO}_{2} \\
k\end{array}$ & $\begin{array}{l}\text { Viscosity } \\
\text { at } 20^{\circ} \mathrm{C} / \\
\mathrm{CP}\end{array}$ & pH \\
\hline Crystal 100A & 1.50 & 2.00 & 42.1 & 14.03 & 28.05 & 200 & 12.7 \\
\hline Crystal 79 & 1.40 & 3.30 & 38.1 & 8.85 & 29.25 & $200-500$ & 11.6 \\
\hline Crystal 66 & 1.33 & 3.65 & 33.4 & 7.19 & 26.25 & 200 & $10.9-11.6$ \\
\hline
\end{tabular}

TABLE II. Mix Design of Concretes Subsequently Demolished and Used for Slurries

\begin{tabular}{|lc|}
\hline OPC (56 days old) & \\
\hline Constltuent & $\mathrm{kg} / \mathrm{m}$ \\
\hline Ordinary Portland Cement & 288 \\
Thames Valley Gravel 20mm & 831 \\
Thames Valley Gravel 10mm & 409 \\
Natural Sand & 660 \\
Water & 190 \\
\hline
\end{tabular}

\begin{tabular}{|lr|}
\hline $\begin{array}{l}\text { OPC/PFA Blended Concrete } \\
\text { (1 Year old) }\end{array}$ & $\mathrm{kg} / \mathrm{m}^{3}$ \\
\hline Constituent & 310 \\
\hline OPC & 130 \\
PFA & 820 \\
Granite 20mm & 360 \\
Granite 10mm & 640 \\
Granite Fines & 4 \\
Superplasticiser & 154 \\
Water & \\
\hline
\end{tabular}

TABLE III. Sieve Analysis for $45 \mathrm{~mm}$ Fractions of Concrete Debris Used

\begin{tabular}{|l|c|c|c|c|}
\hline & \multicolumn{2}{|c|}{ OPC Concrete } & \multicolumn{2}{c|}{ OPC/PFA Blended Concrete } \\
\hline Fraction & Weight & Cumulative Weight & Weight & Cumulative Weight \\
\hline $2.36-5 \mathrm{~mm}$ & 77.0 & 100 & 79.3 & 100 \\
$600 \mu \mathrm{m}-2.36 \mu \mathrm{m}$ & 13.4 & 23 & 12.3 & 20.7 \\
$150-600 \mu \mathrm{m}$ & 6.9 & 9.6 & 6.1 & 8.4 \\
$<150 \mu \mathrm{m}$ & 2.7 & 2.7 & 2.3 & 2.3 \\
\hline
\end{tabular}


TABLE IV. 1 Pear oid 30 PFA/OPC Bleoded Concrete Slurries

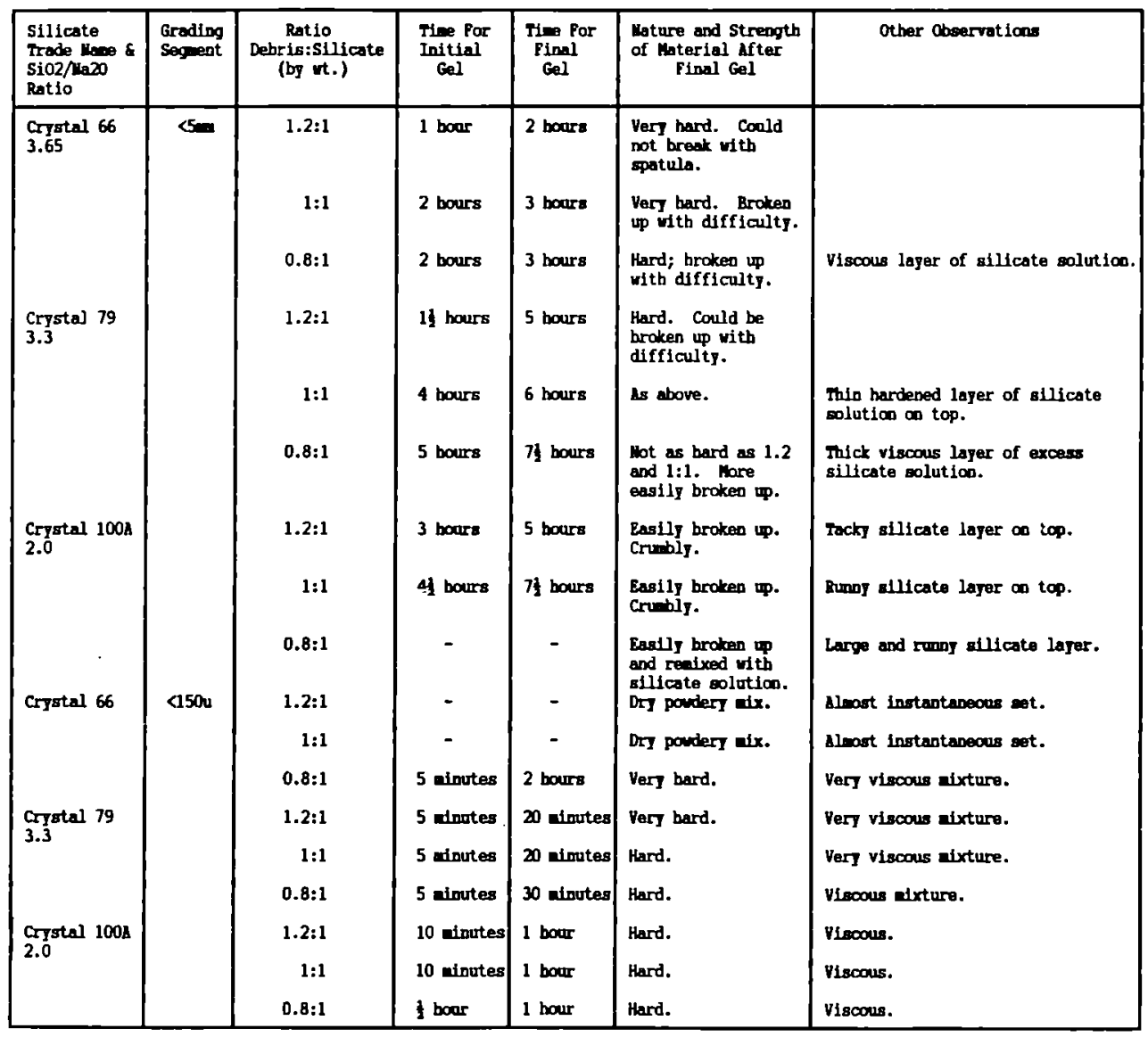

Note Illustrative data avallable far othar grading segents of differing axinn particle size, and for otber concretes. 


\title{
SEPRRATION OP CONTAHINATED CONCRETE
}

CORnelissea, H.A.H.

U.V. Kan, Arnhen, The Netherlands

\begin{abstract}
It could be proved that in concrete mainly the porous cement stone and not the dense aggregates (sand and gravel) will be contaminated by radloactive fluids. So by separation of these components a considerable reduction of material that has to be handled and stored as radio-active waste, can be achleved.

In this research project separation techntques were based upon miling in combination with cooling (liquid nitrogen) or heating $\left(750^{\circ} \mathrm{C}\right)$. Concretes of varlous qualities and with three different maximum grain sizes were tested.

It was possible to separate the fine porous material from the coarse ag- gregate, resulting in a volume reduction of about 60-70\%. Especially the heat treatment up to $750^{\circ} \mathrm{C}$ facilitated the separation process signiflcantly.
\end{abstract}

\section{INTRODUCTION}

In a nuclear installation. concrete in varlous bullding structures may become contaminated during operation. When the installation is withdrawn from service and eventually dismantled the contaminated concrete has to be conditioned and disposed of as radio-active waste. Global calculations indicate that per reactor about 3 to 4 thousands tons have to be conditioned (1).

In normal quality concretes, the volume of the porous cement stone is only approximately 30\%. whlle the remaining part consists of dense aggregates (gravel and sand).

Assuming that mainly the cement stone will be contaminated, separation of the porous and dense components of the concrete will result in a substantial volume reduction of radio-active waste.

The research prograrme started with the verification of the assumption that mainly the cement stone will be contaminated. Then the techniques for separation were developed. based on milling of crushed materlal preceded by either cooling in liquid nitrogen or heating up to $750{ }^{\circ} \mathrm{C}$.

The separation process refered to in this paper 13 focussed on dismantling activities which produce concrete parts with size of a few centimeters. When, however, a technique like waterjet is used the resulting fine powder will demand a specific approach.

All tests were carrled out under responsibility of the Institute of Applied Physics (TWO-TPD) by TWO-TPD with respect to the verification of the assumption that mainly cement stone will be contaminated, and the development of separation by milling and cooling. Separation by milling and heating was performed by N.V. KBaA. The emphasis of this paper will be on the latter part of the research programe.

\section{CONCRETE CONTAMINATION}

In order to verify the assumption that mainly porous cement stone is contaminated concrete samples were supplied by the Borssele and Dodewaard nuclear power plants. The Borssele sample was taken from a concrete element wich was used in a room were the handling with radio-active flutds took place. 
The main nuclide was co 60 , which caused a total radio-activity of $120 \mathrm{kBg}$ $(0.23 \mathrm{kBg} / \mathrm{g})$. The Dodewaard sample, from a core, was especially contarninated for these tests. Therefore the core was submerged in radio-active water $(150 \mathrm{kBq} / \mathrm{l})$ consisting mainly of Cs 137 , Co 60 and $\mathrm{Mn} 54$. The total amount of radio-activity of the sample measured with a Germanium detector was $137 \mathrm{~Bq}$ for Co $60(0.34 \mathrm{~Bq} / \mathrm{g}), 700 \mathrm{Bg}$ for Cs $137(1.76 \mathrm{~Bq} / \mathrm{g})$ and $827 \mathrm{~Bq}$ for m $54(2.1 \mathrm{~Bq} / \mathrm{g})$. cedure:

Both concrete samples were separated according to the following pro-

a. grinding and separation by sleving

b. washing in $\mathrm{HNO}_{3}$

c. grinding again and separation by sieving

d. washing in $\mathrm{HCl}$

e. selection (visual) of aggregates just covered with a low or no percentage of cement stone remainings.

After each separation step the activity of the components was measured. The results with respect to Co 60 are given in table $I$.

TABLE I: Separation of contaminated and non-contaminated parts (activity due to co 60)

\begin{tabular}{|c|c|c|c|}
\hline Separation step & $\begin{array}{l}\text { Aggregates } \\
\text { (KBq) }\end{array}$ & $\begin{array}{l}\text { Cement stone } \\
(\mathrm{KBq})\end{array}$ & $\begin{array}{l}\text { Residue * } \\
\text { (KBq) }\end{array}$ \\
\hline $\begin{array}{l}\text { Borssele sample } \\
\text { a } \\
\text { b } \\
\text { c } \\
\text { d } \\
\text { e }\end{array}$ & $\begin{array}{l}59(0.15){ }^{\star \star} \\
19(0.05) \\
14(0.04) \\
12(0.04) \\
4(0.03)\end{array}$ & $\begin{array}{l}65(0.50) \\
- \\
- \\
- \\
-\end{array}$ & $\begin{array}{r}- \\
34 \\
5 \\
3 \\
-\end{array}$ \\
\hline Separation step & $\begin{array}{l}\text { Aggregates } \\
\text { (Bq) }\end{array}$ & $\begin{array}{l}\text { Cement stone } \\
\text { (Bq) }\end{array}$ & $\begin{array}{l}\text { Residue * } \\
\text { (Bq) }\end{array}$ \\
\hline $\begin{array}{l}\text { Dodewaard sample } \\
\text { a } \\
\text { d }\end{array}$ & $\begin{array}{l}59(0.20) \\
13(0.06)\end{array}$ & $84(0.85)$ & $\overline{49}$ \\
\hline
\end{tabular}

* cement stone, leaching fluid, filter residue

* * specific activity ( $\mathrm{KBq} / \mathrm{g}$ and $\mathrm{Bq} / \mathrm{g}$ )

With respect to co 60 it can be derived from table $I$, that the remainIng activity of the aggregates after process step $d$ is about 10 times smaller than the activity of the concrete samples, being $120 \mathrm{kBq}$ and $137 \mathrm{Bg}$ for the Borssele and Dodewaard sample respectively. For the other nuclides, reduction factors were found being 5 for Cs 137 and 16 for m 54. In terms of specific activity the reduction factors turned out to be 6 for Co 60, 3 for Cs 137 and 9.5 for Mn 54 .

From the verification tests it can be concluded that the contamination of concrete is mainly concentrated in the porous cement stone.

In these tests the separation process was not yet optimized, therefore further improvement of the separation can be expected by the application of an appropriate technique as described in the following chapters. 


\section{MII.LING AND COOI.ING}

\section{General}

Cement stone and aggregate can be separated by milling. In order to optimize this milling process the effects of important influential factors belng the diameter of the w1ll, Its filling ratio and the water content were tested. Also tests were performed with an additive which prevents conglomeration of fine particles and may reduce the energy necessary for separation.

Separation by milling can be improved if the integrity of the cement stone and 1 ts bond to the aggregate particles can be reduced. This can be realized by cooling down which gives rise to damage because of the temperature gradient, the difference of coefficient of thermal expansion of the concrete components and the expansion caused by the formation of ice in the pores.

The results of the various tests on milling and cooling have been reported by TNO-TPD for the Comission of the European Communities. In this paper only main conclusions on this subject will be put forward.

\section{Concrete samples}

Normal (B45), medium (B22,5) and low strength $(B 17,5)$ concretes were made. For each of these concretes three different maximum grain sizes were used (31.5 mm, $16 \mathrm{~mm}$ and $4 \mathrm{~mm}$ ). These concretes cover the normal range of types of concretes used in practice for main and secondary structural and nonstructural applicat lons.

The mafority of the tests were performed with normal strength concretes which are similar to the OPC-types given in table II (chapter 4 ).

\section{Milling}

Milling was performed in polyethylene vessels on an rolling-mill. Out of $95 \mathrm{~mm}$ and $121 \mathrm{~mm}$ diameter vessels, the last one showed the best results. As the conglomerates have to roll and fall in the vessels, the filling ratio is important. A filling ratio of about 50 proved to be most efflclent for dry milling. For wet milling (water amount 20 of the vessel volume) 35t was more approprlate. For wet milling 20 water with maximum grain size of 31,5 and $16 \mathrm{~mm}$ was most efficient while for 4 mm concretes dry milling is recomended. The addition of the additive (detergent) dinatrlumphosphate (DNP) $(0.018$ of the washing water) to the water for wet-milling enchanced the efficiency.

It was found that during milling the separation occurs in the first 20 hours. After that the aggregate particles will be crushed with reduces the separation eff Iclency.

\section{Thermo-shock}

Liquid nitrogen was poured over the concrete sample until it was completely covered. After the evaporation of the nitrogen (In about 30 seconds) the sample was milled for several periodes of 15 minutes. It could be concluded that especially for the concretes with maximum grain sizes of $31.5 \mathrm{~mm}$ and $16 \mathrm{~mm}$ the thermo-shock Improved the separation. The molsture content of the sample proved to be very important; a percentage of 30 showed an optimum.

In all combinations of thermo-shock and milling no complete separation of aggregate and cement stone could be realized. The aggregates remained covered with cement stone which necessitates the development of an appropriate washing process. 


\section{SEPARATION BY HEATING}

\section{General}

It is well known that concrete disintegrates at high temperatures. During heating many transformations and reactions occur. From about $200{ }^{\circ} \mathrm{C}$ onwards substantial damage can be expected which will increase especially above $500{ }^{\circ} \mathrm{C}$ (decomposition of portlandite) and above $570{ }^{\circ} \mathrm{C}$ (alpha to beta inversion of the quartz aggregates accompanied by a sudden increase of volume). At higher temperatures further decomposition of the hardened cement stone will take place. This results for instance in a 608 reduction of strength at $750{ }^{\circ} \mathrm{C}$.

In the testing programme it was checked, if heating before milling would result in a suitable separation technique. The tests were performed with non-contaminated concrete except for one experiment where the release of radioactivity during heating was investigated.

\section{Mix compositions}

Normal quality concretes were made with three maximum grain sizes, 1.e. $4 \mathrm{~mm}, 16 \mathrm{~mm}$ and $31.5 \mathrm{~mm}$. Furthermore ordinary portlandcement (OPC) and portland blastfurnace cement (PBC) was used. A total of 6 different mixes were therefore cast. Some characteristics are given in tabel II.

TABILE II: Mix compositions and compressive strength results

\begin{tabular}{lllll}
\hline & $\begin{array}{l}\text { Cement } \\
\left(\mathrm{kg} / \mathrm{m}^{3}\right)\end{array}$ & WCr & $\begin{array}{l}\text { Aggregates } \\
\left(\mathrm{kg} / \mathrm{m}^{3}\right)\end{array}$ & $\begin{array}{l}\text { Compressive strength } \\
\left(\mathrm{N} / \mathrm{mm}^{2}\right)\end{array}$ \\
\hline OPC 31.5 & 461 & 0.38 & 1758 & 56.8 \\
OPC 16 & 500 & 0.38 & 1687 & 60.4 \\
OPC 14 & 658 & 0.38 & 1367 & 60.0 \\
& & & & 60.5 \\
PBC 31.5 & 461 & 0.38 & 1740 & 61.4 \\
PBC 16 & 500 & 0.38 & 1656 & 61.9 \\
PBC 4 & 658 & 0.38 & 1338 & 64.9 \\
\hline
\end{tabular}

* water-cement ratio $(\mathrm{m} / \mathrm{m})$

After a period of 28 days wet curing (in water of $20^{\circ} \mathrm{C}$ ) the cubes were crushed in a Blake Jaw crusher.

Heating and milling

From some preliminary tests it was concluded that heat treatment up to at least $750{ }^{\circ} \mathrm{C}$ would be necessary. So all combinations were heated to that temperature for about 8 hours in an electrical oven. Then the samples were milled during 8 hours in $200 \mathrm{~mm}$ diameter polyethelene vessels which were filled for 50 \% by volume. After heating and milling the material was sieved. TYpical results of the sieve analyses for OPC 31.5 and OPC 4 samples are shown in figure 1 and 2 . 


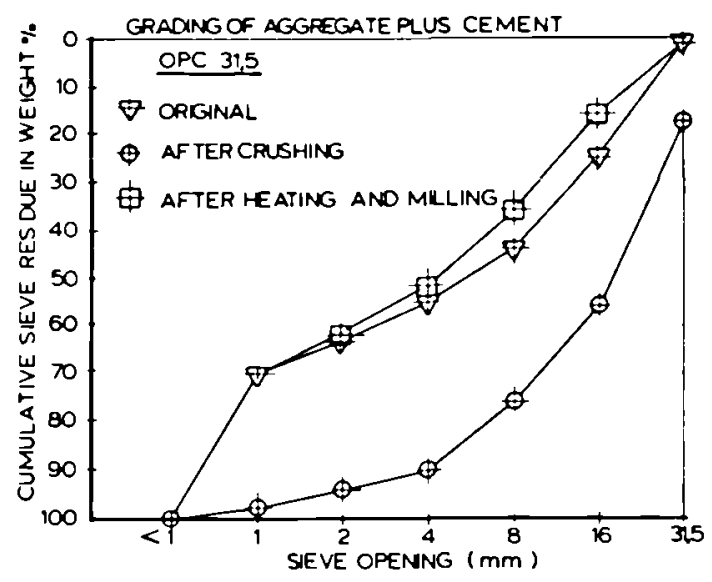

Pigure l: sleve curves of OPC 31.5 after crushing, heating and milling in comparison to the original grading

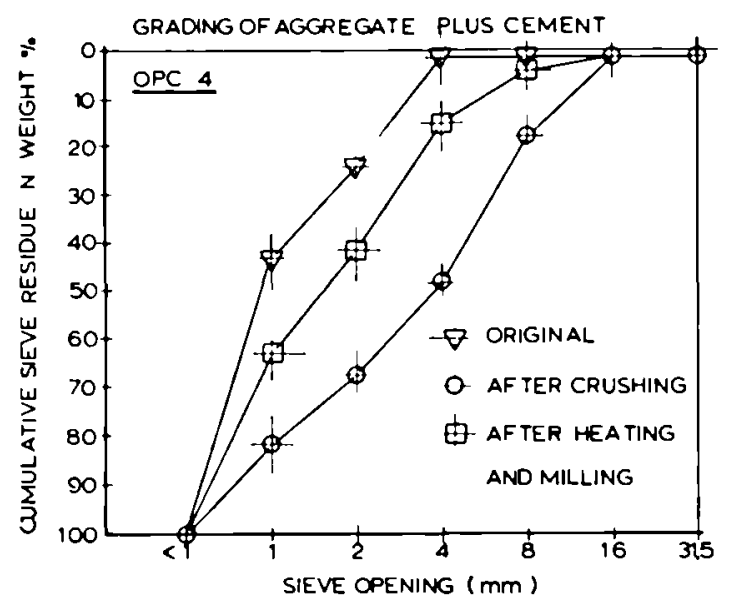

Plgure 2: Sleve curves of OPC 4 after crushing, heating and milling in comparison to the or iginal grading

It can be seen that after heating and milling the sleve curve of OPC 31.5 approaches the original sleve curve (aggregates plus cement). That means that a nearly complete separation was established.

It can also be concluded that the amount of fine material $(<1 \mathrm{~mm})$, which can be regarded as "contaminated" will mainly depend on the original concrete composition. An overview of the fine material that was separated by the process for the vartous mixes is given in table III. Also the amount of fine material in the original mixes is given. By comparing these two sertes of numbers. It can be concluded that in general for mixes with larger maximum grain size the separated fine material was closer to the original amount. 
For the concretes with smaller maximum grain size, more fine material (contaminated) remained in the "clean" material. In these cases it has to be considered if the contaminated and non-contaminated parts should be separated at larger sleve openings.

TABLE III: Amount of fine materlal after heating and milling

\begin{tabular}{lll}
\hline Type & $\begin{array}{l}\text { Original* } \\
\leq 1(8)\end{array}$ & $\begin{array}{l}\text { After processing* } \\
\leq 1(8)\end{array}$ \\
\hline OPC 31.5 & 30.3 & 30.0 \\
OPC 16 & 35.9 & 26.4 \\
OPC 4 & 58.8 & 36.0 \\
PBC 31.5 & 30.4 & \\
PBC 16 & 36.2 & 26.8 \\
PBC 4 & 52.7 & 27.2 \\
\end{tabular}

* cement plus fine aggregates

After heating and dry milling, many aggregate particles were covered with a thin layer of cement. Depending on the activity, this layer has to be removed. So a complementary treatment of the aggregates ( $1 \mathrm{~mm}$ ), (washing in water), was performed. This process step resulted in a weight decrease of about 1-4\%. The quality of the washing process was assessed by a subsequent treatment with 128 nitric acid solution which gave rise to another $2 \%$ decrease of the total weight.

The necessity of the complementary washing steps in practice will be determined by the requirements and regulations which are operative for handling and storage of waste materials.

\section{Analysis of flue gas}

During the heating of contaminated materlal the flue gas might become radio-active. To check this an indicative test was carried out. Therefore a crushed specimen (OPC 4) was contaminated with radio-active water from the spent fuel storage pond (SFSP) of the Dodewaard nuclear power plant.

The concrete sample was heated up to $750{ }^{\circ} \mathrm{C}$ for 8.5 hours and the gases which escaped were extracted by a water-jet pump. Then the absorbed nuclides in the water were measured. A Ge-L1 detector was used for the measurements of the water and the sample before and after heating. The results are shown in table IV. It can be seen that the activity of the concrete before and after heating is about similar and that the activity of the jet system is very low. So a neglectable amount escaped by the flue gases. 
IABLE IV: Measured radio-activity during heating

\begin{tabular}{|c|c|c|c|c|}
\hline \multirow[b]{2}{*}{ nucl1des } & \multicolumn{2}{|c|}{ Before heat Ing } & \multicolumn{2}{|c|}{ After heating } \\
\hline & $\begin{array}{l}\text { Jet } \\
\text { system } \\
\text { (Bq) }\end{array}$ & $\begin{array}{l}\text { concrete } \\
\text { sample } \\
486 \mathrm{~g} \\
\text { (Bq) }\end{array}$ & $\begin{array}{l}\text { Concrete } \\
\text { sample } \\
472 \mathrm{~g} \\
\text { (Bg) }\end{array}$ & $\begin{array}{l}\text { Jet } \\
\text { system } \\
\text { (Bq) }\end{array}$ \\
\hline $\begin{array}{ll}\text { Co } & 60 \\
\text { Cs } & 137 \\
\text { in } & 54 \\
\text { In } & 65\end{array}$ & $\begin{array}{l}\text { ND } \\
\text { ND } \\
\text { ND } \\
\text { ND }\end{array}$ & $\begin{array}{r}6390 \\
639 \\
655 \\
1080\end{array}$ & $\begin{array}{r}6300 \\
698 \\
618 \\
1070\end{array}$ & $\begin{array}{r}45 \\
8 \\
5 \\
\text { ND }\end{array}$ \\
\hline
\end{tabular}

Note: ND = not detectable

\section{CONCLUSIONS}

In concrete mainly the porous cement stone will be contaminated and not the dense aggregates (sand and gravel). So separation will result in a substantial reduction of the volume that has to be handled and stored as radio-active material. Por normal quality concretes a reduction of 50-608 can be achleved.

on laboratory scale, separation techniques were investigated based on elther cooling or heating followed by milling. Although both techniques need further optimization, especially the combination with heating up to $750^{\circ} \mathrm{C}$ was successful. It was shown that during this treatment only a minor amount of activity escaped from the concrete.

It can be concluded that the results of this research programe form a basis for the development of an installation for separation of concrete on mediun scale (pllot plant).

\section{REFERENCES}

1 Lasch $M$. et al.. Estimation of radioactive waste quantities arising during decomissioning Proceedings of the International conference on the decomissioning of nuclear Installations, 1984, PP 75-88 


\title{
CONDITIONING FOR DISPOSAL OF RADIOACTIVE GRAPHITE
}

\author{
BRICKS FROM REACTOR DECOMMISSIONING
}

Jean R. Costes . Decommissioning Service, CEA, Marcoule France
Christian de Tassigny, Radioprotection Service, CEA, Grenoble France
Charles Koch, Metallurgy Department,
Hugues Vidal and Alain Raymond, Wastes R and D Department,
CEA, Cadarache France

\begin{abstract}
The decommissioning of gas-graphite reactors in the EC (e.g French UNGGs, British Magnox reactors and AGRs, and reactors in Spain and in Italy), will produce large amounts of graphite bricks.

Evaluations of the radioactivity inventory of graphite moderators made in France and the UK (ref. EUR 9232), show that this graphite cannot be accepted without particular conditioning by the existing shallow land disposal sites.

The aim of the study is to examine the behaviour of graphite waste and to develop a conditioning technique which makes this waste acceptable for shallow land disposal sites.
\end{abstract}

\section{INTRODUCTION}

The future of decommissioned gas-cooled reactor (GCR) cores has been widely discussed (1) . Apart from generally unacceptable solutions resulting in waste dilution (e.g. incorporation in steel), two solutions are of ten advanced for disposal of graphite bricks removed from a GCR core : incineration or surface storage.

Although the long-term conditioning solution proposed here does not result in any volume reduction, it is simple and considerably less expensive than other methods. The conditioning process was investigated on standard samples about $80 \mathrm{~mm}$ high and $80 \mathrm{~mm}$ in diameter core-drilled from a reactor shut down after 20 years of operation. Based on the radiochemical and physical properties of the graphite samples, core impregnation of the graphic blocks appears to be a feasible and industrial practicable solution.

\section{GRAPHITE SAMPLE EXTRACTION FROM A GCR CORE}

After a thorough review, a graphite core sample $74 \mathrm{~mm}$ in diameter and $2.5 \mathrm{~m}$ long was taken from the power measurement chamber thimble in the G2 gas-cooled reactor at Marcoule. The thimble, with an inside diameter of 161 $\mathrm{mm}$, penetrates through the $3 \mathrm{~m}$ concrete vessel and the leaktight outer shell. The tip of the thimble is located near the heat shield, which is replaced by a metal plate at this point.

The core sample was situated on a horizontal plane between the fuel channels. The rectangular prism-shaped graphite bricks measuring $200 \times 200 \times 1500$ $\mathrm{mm}$ were drilled transversely. The cored brick samples were in excellent condition and did not adhere to one another. The contact dose rate was 1 
mGy $\cdot h^{-1}$. dropping to $0.01 \mathrm{mGy} \cdot \mathrm{h}^{-1}$ at 1 meter.

\section{GRAPHITE CHARACTERISTICS}

\section{Porosity and Kinetics of Water Penetration into graphite}

As part of the graphite characterization program prior to conditioning, and to assess the extent of graphite-water interactions, open porosity and water penetration kinetics were investigated in unimpregnated graphite. These kinetics can account for the leaching behavior of uncoated graphite.

Several parameters must be taken into consideration :

sample size and volume-to-surface area (V/SA) ratio

open porosity and porosity spectrum of the sample, notably porosity variations due to radiolytic corrosion of $\mathrm{CO2}$.

\section{Test Materlals}

Two graphite grades ("G2" and "B") from the moderators of two different gas-cooled reactors were tested. Two sample sizes with different degrees of radiolytic oxidation were used.

All the test specimens were fresh, i.e. with no prior purification, thermal or radiolytic oxidation treatment except for two " $B$ " samples, oxidized to $7.4 \%$ and $16.4 \%$, used to investigate the effects of radiolytic oxidation.

\section{Expertmental Method}

The specimen, suspended from the arm of a Mettler balance, was fully immersed in permuted water. As water penetrated into the graphite porosity, the specimen buoyancy diminished. Measuring the resulting weight increase indicated the mass of the water uptake by the graphite.

The tests were interrupted when the specimen weight gain declined to a negligible value, i.e. after 400 to 1000 hours.

On completion of some tests, the specimen was oven-dried and measured with a mercury porosity tester to obtain the open porosity spectrum for pores ranging from $8 \times 10^{-3}$ to $300 \mu \mathrm{m}$, and to determine the specific surface area. The porosity was also determined on two specimens taken from one of the larger samples.

\section{Results}

The open porosity in the test specimens ranged from 0.135 to 0.145 $\mathrm{cm}^{3} \cdot \mathrm{g}$ (1.e. approx 23 vol\%). (Figure 1)

Figure 2 shows the importance of the graphite grade as reflected in the maximum percentage of porosity reached by water: 17\% for "G2" graphite and 57\% for "B" graphite. This difference is difficult to explain. Water absorption is determined by the graphite porosity, 1.e.the total open porosity volume and the pore dimensions. The actual open porosity volume is roughly the same for" $B$ " and "G2" graphite and their porosity spectra are very similar.

Figure 2 also shows a difference in behavior for specimens of the same grade: the porosity volume fraction filled by water ranged from $41 \%$ to $57 \%$ for "B" graphite; 
the time required to reach these levels varied from 400 to 1000 hours.

These results are based on only three samples of each graphite grade, and are not necessarily representative. Nevertheless, the difference between "B" and "G2" graphite was much more significant than the variation noted among specimens of the same grade.

Figure 3 shows that the kinetics tend to be faster with water access to a slightly larger porosity fraction for larger specimens. This result was unexpected, since a longer time should be necessary for water to penetrate into a larger sample. One explanation could be the air layer surrounding the specimen, with an effect inversely proportional to the sample dimensions $(V / S=0.25$, compared with 1.25 for the larger specimens).

Radiolytic oxidation significantly enhances water penetration into the graphite (Figure 4) by increasing the pore diameter.

\section{Sample Radioactivity Analysis}

A few grams of graphite were coarsely ground, then completely dissolved in a heated chemical solution. During the dissolution, $3 \mathrm{H}$ was trapped by a sulphuric acid bubbler, and $14 \mathrm{C}$ and $36 \mathrm{Cl}$ were trapped by bubbling with a potassium compound.

The dissolution liquid was analyzed by gamma spectrometry. Tritium content was measured after distillation by liquid scintillation in the resulting liquor and the bubbler liquor; $14 \mathrm{C}, 36 \mathrm{Cl}$ and $63 \mathrm{Ni}$ were measured by liquid scintillation after separation, and $93 \mathrm{mNb}$ by $\mathrm{X}$-ray spectrometry after extraction.

Table I - Activity $\left(\mathrm{kBq} \cdot \mathrm{g}^{-1}\right)$ measured 9 years after reactor shutdown

\begin{tabular}{|c|c|c|}
\hline Nuclide & Reflector & Moderator \\
\hline $60 \mathrm{Co}$ & 2 & $6-13$ \\
$133 \mathrm{Ba}$ & 0.06 & $0.1-0.2$ \\
$137 \mathrm{Cs}$ & 0.01 & 0.1 \\
$154 \mathrm{Eu}$ & 0.45 & $0.4-0.8$ \\
$3 \mathrm{H}$ & 400 & 400 \\
$14 \mathrm{C}$ & 6 & $15-25$ \\
$63 \mathrm{Ni}$ & 2 & $5-7$ \\
$36 \mathrm{Cl}$ & 0.4 & $0.5-1.5$ \\
$93 \mathrm{mNb}$ & 50.1 & $\leq 0.1$ \\
\hline
\end{tabular}

\section{IMPREGNATION PROCESSES}

Graphite is both contaminating (it wipes off under finger pressure) and porous (water penetrates easily). Industrial processes are available for impregnating blocks weighing over $500 \mathrm{~kg}$ with pitch for subsequent graphitization. The conditioning potential of various impregnation materials was therefore investigated. 
Epoxy Resin Impregnation of Nonradioactive Samples

Procedure

A thermosetting epoxy resin of known effectiveness in nuclear application was selected. The hardener was specially selected to initiate curing only at high temperatures. Core impregnation of graphite blocks can thus be performed at room temperature under vacuum conditions, and the resulting material can later be cured by heating to $150^{\circ} \mathrm{C}$.

Table II - Nonradioactive sample weight gain

\begin{tabular}{|c|c|c|c|}
\hline \multirow{2}{*}{$\begin{array}{c}\text { Sample } \\
\text { No }\end{array}$} & \multicolumn{2}{|c|}{ Weight (g) } & \multirow{2}{*}{$\begin{array}{c}\text { Weight } \\
\text { Gain } \\
(x)\end{array}$} \\
\cline { 2 - 3 } & $\begin{array}{c}\text { before } \\
\text { Impregnation }\end{array}$ & $\begin{array}{c}\text { after } \\
\text { Impregnation }\end{array}$ & $(\mathbf{x})$ \\
\hline 1 & 163.7 & 184 & 12.4 \\
2 & 82.2 & 93 & 13.1 \\
3 & 406.2 & 454 & 11.7 \\
4 & 253.4 & 285 & 12.4 \\
5 & 430 & 499.7 & 11.5 \\
\hline
\end{tabular}

The samples were uniformly impregnated to near-saturation of the macropore structure (1.e. pores exceeding $0.1 \mu \mathrm{m}$ in diameter). The following values were measured on prism-shaped sample 3 :

- Volume

- Measured open porosity

- Empty volume

- Absorbed resin mass

- Resin specific gravity

- Absorbed resin volume

- Measured Shore D hardness : Unimpregnated control specimens Impregnated samples

$$
\begin{array}{r}
237.5 \mathrm{~cm} 3 \\
23 \mathrm{vol} \% \\
54.5 \mathrm{~cm} 3 \\
48 \mathrm{~g} \\
1.152 \\
41.7 \mathrm{~cm} 3
\end{array}
$$

$65-70$

81

The resin filled $75 \%$ of the theoretical volume. Lack of saturation can be attributed to the large microporosity fraction and to the resin viscosity $(290 \mathrm{cPo})$.

The sample was cut with a diamond-impregnated saw to observe the core, which appeared smooth and glossy. The numerous pores and microcracks in the untreated graphite were no longer visible.

The porosity was measured on sample 4 (Figure 5). All pores exceeding 0.1 $\mu \mathrm{m}$ in diameter were saturated. The resin penetrated to the center of the sample, with a total cumulative impregnation ratio of $12.4 \%$. The porosity was slightly lower at the centre than around the periphery. This may be due to resin seepage during curing (care was taken to cut the sample slightly beneath the surface). 


\section{X-Ray Tomography}

Full core impregnation was confirmed by $X$-ray examination of 4 rectangular $(50 \times 50 \times 100 \mathrm{~mm})$ radioactive graphite specimens stamped "G" and " $R$ ":

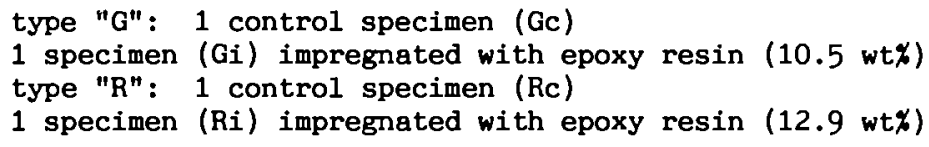

The system used an experimental single-detector setup. The $X$-ray source was used with a small focal point $(1.8 \times 1.8 \mathrm{~mm})$ and a mid-height beam width of $370 \mu \mathrm{m}$. The four samples were placed side-by-side. The sample integration time was 20 msec.

Each image pixel was assigned a relative density between 1 and 1024, with the highest numerical value corresponding to the highest density. Individual zones of the image were statistically analyzed using the mean pixel density values for the desired areas. The actual material density values were the following:

$$
\begin{array}{r}
\text { Ri : } 846.61-171.65=674.96 \\
\text { Rc }: 769.23-171.65=597.58 \\
\text { Gi : } 842.64-171.65=670.99 \\
\text { Gc: } 778.61-171.65=606.96
\end{array}
$$

The ratio between the densities of the control specimens and the impregnated specimen were calculated for each type of sample :

Type "R" :

Type "G" :

$$
\frac{\text { Ri Density }}{\text { Rc Density }}=\frac{674.96}{597.58}=1.1295
$$

$$
\frac{\text { Gi Density }}{\text { Gc Density }}=\frac{670.99}{606.96}=1.1055
$$

The calculated impregnation ratios were therefore $12.95 \%$ for type " $R$ " specimens and $10.55 \%$ for type "G"specimens (comparable to the values indicated above : $12.9 \%$ for type "R" and 10.5\% for type "G").

Except for some visible porosity and incipient cracks, the homogeneity shown by the image of the impregnated specimen cross sections demonstrates that they were in fact impregnated to the core. - Otherwise, given the visible difference in density, the impregnated specimen cross section would have shown a ring pattern.

This technique can be considered suitable for the development of an industrial impregnation system and for random-sample quality control purposes.

\section{Assessment}

The results demonstrate that the experimental objectives were attained for representative nonradioactive samples : 1.e. increased compression strength and saturation of the macropore structure. 


\section{B1 tumen Impregnation}

Six different bitumens were tested :

- a direct distillation bitumen (80/100) selected for its fluidity.

- two air-blown bitumens (R75/30 and R90/40) selected for their high irradiation resistance.

- three special bitumens selected for their temperature susceptibility.

The bitumen treatment effectiveness was assessed according to the following criteria :

optical or scanning electron microscope examination of the inter-

face layer.

- penetration thickness,

- mechanical properties,

- coating adhesion,

- leaching resistance.

Based on the results of soak tests on nonradioactive samples, the $80 / 100$ bitumen was selected as the most suitable formulation, notably for its adhesion to the graphite substrate. Other $80 / 100$ characteristics included :

$\begin{array}{ll}\text { - Penetrability }(* 0.1 \mathrm{~mm}) & 80-100 \\ \text { - B1-ring temperature } & 41-51^{\circ} \mathrm{C} \\ \text { Flash point } & >230^{\circ} \mathrm{C}\end{array}$

Four graphite samples were impregnated with $80 / 100$ bitumen for leach testing. The samples were placed in an autoclave designed for both vacuum and high pressure operation, and provided with a bitumen gravity-feed line ; the setup itself was located inside an oven with a close-tolerance sample was first heated under vacuum and molten bitumen was fed into the autoclave. The vessel was then pressurized to force the bitumen into the graphite mass before finally cooling to room temperature.

\section{Epoxy Pitch Impregnation}

Th1s method involves room-temperature vacuum 1mpregnation with a formulation containing a delayed-action hardener that allows curing at room temperature.

The epoxy resin/pitch material has a number of advantages for coating the graphite bricks :

- The material $1 \mathrm{~s}$ used industrially. Its water-repellent properties ensure damp aging resistance that is desirable for underground waste storage.

- The properties of pure epoxy resin are well known. Pure resin may be partially replaced by pitch, conferring thermoplastic properties on the coating material to a degree that depends on the pitch content of the final mixture. Optimum proportions can be found to enhance flexibility while maintaining the thermosetting properties of epoxy resins. For example, a mixture of $40 \%$ grade $730 / 30$ pitch and $60 \%$ resin complies with waste storage requirements for hardness, compression strength and polymer deformation under load.

- Blending with pitch is economically interesting, as pure pitch costs 
about 6 times less than the epoxy resin. Material investment and maintenance costs are low.

- The process involves simply mixing two liquid components (the pitch hardener and the epoxy resin base) at room temperature.

The following hardness comparison between the epoxy pitch material and a direct-distillation bitumen clearly reveals the advantages of this method.

Table III - Shore D hardness of epoxy pitch and direct-distilled bitumen

\begin{tabular}{|c|c|c|}
\hline Temperature & Epoxy-Pitch & Bitumen \\
\hline $20^{\circ} \mathrm{C}$ & $\begin{array}{c}70-85 \\
>50\end{array}$ & $<5$ \\
$30^{\circ} \mathrm{C}$ & $>50$ uneasurable \\
\hline
\end{tabular}

The temperature-dependent evolution of epoxy pitch properties corresponds to the thermoplastic qualities introduced by the pitch. This is a reversible phenomenon, and the initial hardness is restored when the temperature diminishes to $20^{\circ} \mathrm{C}$.

The creep strength of the $730 / 30$ pitch mixture with $60 \%$ epoxy resin was determined by oven-heating small (20 x $25 \times 40 \mathrm{~mm}$ ) test specimens from $20^{\circ} \mathrm{C}$ to $90^{\circ} \mathrm{C}$ in $10^{\circ} \mathrm{C}$ steps. No creep phenomena were observed on any of the specimens after a week at each temperature.

One sample was submitted to a $20 \mathrm{~kg}$ load at $90^{\circ} \mathrm{C}$; the contact surface area was $10 \mathrm{~mm}^{2}$, and the local pressure therefore reached about 200 $\mathrm{daN} \cdot \mathrm{cm}^{-2}$. No creep under load was detected on the specimen after one week under these conditions.

Compression strength was tested in compliance with French AFNOR standard $\mathrm{NF}-\mathrm{T} 51.101$ at $18^{\circ} \mathrm{C}$ with the following results :

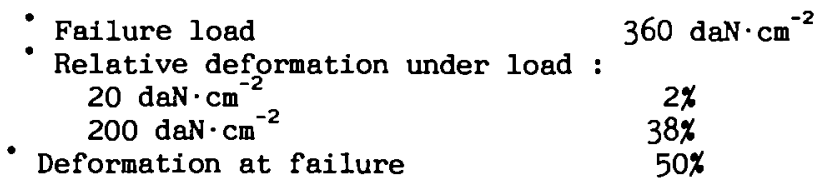

\section{LEACH TESTING}

Leach tests were conducted on $80 \mathrm{~mm}$ orthogonal cylindrical specimens in distilled water completely renewed after $3,14,30,60$ and 90 days. The leachate collected after each renewal was filtered to $0.45 \mu \mathrm{m}$ and any deposits on the leaching vessel walls were recovered using peelable varnish. The filtered leachate, filter and varnish were analyzed.

The leach test results are summarized in Table IV, which indicates the cumulative released fractions standardised to a 200-litre waste package according to the following relation:

$$
\mathrm{Ln}=\frac{\Sigma \mathrm{ai}}{\mathrm{AO}} \times \frac{\mathrm{V}}{\mathrm{S}} \times \frac{\mathrm{Sn}}{\mathrm{Vn}}
$$


where AO : Initial sample activity

af : activity released during each test sequence

$V, S$ : sample volume and surface area

$V_{n}, \mathrm{Sn}: 200-11$ ter drum volume and surface area.

On the unimpregnated samples, 137Cs was released in the largest amounts, followed by $60 \mathrm{Co}, 63 \mathrm{~N} 1$ and $36 \mathrm{cl}$. The wide varlation ranges observed in some cases can be attributed to the differences between reflector and moderator samples.

Impregnation resulted in appreciably better leach resistance for all the elements tested: the leach rates were generally reduced by a factor of 1000, although the analysis threshold prevented accurate determination of the $\beta$-emitters. The best results were obtained with the epoxy resin pitch mixture.

\section{CONDITIONING FOR FINAL STORAGE}

\section{Description of Waste Package Project}

The waste container is an ordinary steel cylinder 1.5 meter high and 1.6 meter in diameter with a flat welded bottom. Such cylinders could be made from sections of primary and secondary $\mathrm{CO} 2$ ducts cut up during decommissioning of the G2 reactor to stage 2, for which this solution would represent an alternative to scrapping the pipes. The pipe wall thickness is either $19 \mathrm{~mm}$ or $26 \mathrm{~mm}$, depending on its origin. These heavy gauge containers would probably be reserved for graphite from the moderator; $5 \mathrm{~mm}$ walls would be sufficient for reflector materials, with about 5 times lower Co content.

Bricks removed intact from the core by robot devices will be placed one by one Inside the container as shown in Figure 6. Calculations show that each container could hold 42 standard bricks. Once the bricks are in place, a flat lid will be welded onto the container before impregnation.

\section{Impregnation}

The slow kinetics and minimally exothermic nature of the epoxy resin-mixture allow graphite bricks to be stacked without fear of a potentially dangerous temperature rise. The complete graphite impregnation, curing and storage procedure can therefore be implemented in the container itself, ready for transport and final storage after hardening.

The lid includes an opening used to create a vacuum inside the container, which is then filled with an epoxy resin pitch that is highly fluid before curing. The container is next pressurized to 3 bars for maximum penetration into the graphite. After welding the lid, the package is allowed to cure for several days.

The total weight of the waste package would be about 6 metric tons, including 4.1 tons of graphite with $10 \times$ impregnation by the epoxy resin pitch mixture.

\section{CONCLUSION}

The principal features of these waste packages are their size and their relatively high $14 \mathrm{C}$ content, hence the strong containers and long-lasting coating material. 
Table IV - Normalized leach test results

\begin{tabular}{|c|c|c|c|c|c|c|c|c|}
\hline \multirow{2}{*}{ Nuclide } & \multicolumn{2}{|c|}{ Unimpregnated } & \multicolumn{2}{|c|}{ Epoxy Resin Impregnation } & \multicolumn{2}{|c|}{ Bitumen Impregnation } & \multicolumn{2}{|c|}{ Epoxy Pitch Impregnation } \\
\hline & 3 days & 90 days & 3 days & 90 days & 3 days & 90 days & 3 days & 90 days \\
\hline${ }^{60} \mathrm{Co}$ & $2-5 \times 10^{-5}$ & $0.9-4 \times 10^{-3}$ & $1-3 \times 10^{-6}$ & $2-4 \times 10^{-5}$ & $1.3 \times 10^{-7}$ & $1.3 \times 10^{-5}$ & $0.4-6 \times 10^{-7}$ & $0.6-8 \times 10^{-6}$ \\
\hline${ }^{133} \mathrm{Ba}$ & $0.6-5 \times 10^{-4}$ & $0.05-1 \times 10^{-2}$ & $1 \times 10^{-5}$ & $0.6-3 \times 10^{-1}$ & $2-4 \times 10^{-6}$ & $0.8-4 \times 10^{-5}$ & $4-6 \times 10^{-6}$ & $0.8-1 \times 10^{-5}$ \\
\hline${ }^{137} \mathrm{Cs}$ & $0.5-1 \times 10^{-3}$ & $0.5-2 \times 10^{-2}$ & $4 \times 10^{-6}$ & $1-9 \times 10^{-5}$ & $4 \times 10^{-6}$ & $2-9 \times 10^{-5}$ & $8 \times 10^{6}$ & $2 \times 10^{-5}$ \\
\hline${ }^{154} \mathrm{Eu}$ & $2-4 \times 10^{-6}$ & $0.8-4 \times 10^{-1}$ & $0.5-7 \times 10^{-6}$ & $0.7-1 \times 10^{-1}$ & $4 \times 10^{-6}$ & $0.7-7 \times 10^{-1}$ & $3-8 \times 10^{-6}$ & $6-20 \times 10^{-6}$ \\
\hline${ }^{3} \mathbf{I I}$ & $0.4-30 \times 10^{-5}$ & $0.4-30 \times 10^{-4}$ & $<1 \times 10^{-7}$ & $<2 \times 10^{-7}$ & $<1 \times 10^{-7}$ & $2-3 \times 10^{-7}$ & $<1 \times 10^{-7}$ & $<2 \times 10^{-7}$ \\
\hline${ }^{14} \mathrm{C}$ & $<4 \times 10^{-7}$ & $0.8-4 \times 10^{-6}$ & $<3 \times 10^{-7}$ & $<6 \times 10^{-7}$ & $<3 \times 10^{-7}$ & $<6 \times 10^{-7}$ & $<3 \times 10^{-7}$ & $<6 \times 10^{-7}$ \\
\hline${ }^{63} \mathrm{Ni}$ & $2-5 \times 10^{-5}$ & $0.8-3 \times 10^{-3}$ & $<2 \times 10^{-6}$ & $0.4-1 \times 10^{-5}$ & $<2 \times 10^{6}$ & $0.6-1 \times 10^{-5}$ & $<2 \times 10^{-6}$ & $<4 \times 10^{-6}$ \\
\hline${ }^{36} \mathrm{Cl}$ & $0.8-5 \times 10^{-4}$ & $0.4-1 \times 10^{-3}$ & $<2 \times 10^{-5}$ & $<4 \times 10^{-5}$ & $<2 \times 10^{-5}$ & $<4 \times 10^{-5}$ & $<2 \times 10^{-5}$ & $<4 \times 10^{-5}$ \\
\hline
\end{tabular}


In fact, the process does not involve a simple coating but true impregnation. The container may corrode and the bricks may becose fragmented, but the normally porous graphite will be unaffected by leaching since all pores larger than $0.1 \mu \mathrm{m}$ will be filled with epoxy resin pitch. This is a true long-term waste packaging concept and has been submitted to the french surface waste storage authorities for examination.

\section{ACKNOWLEDGMENTS}

The X-Ray tomography measurements were performed by the CEA's Computer and Electronics Laboratories (LETI) in Grenoble.

\section{REFERENCES}

(1) White, I.F., Smith, G.M. and Saunders, L.J. Assessment of Management Modes for Graphite from Reactor Decommissioning. Commission of the European Communities Report DE-D-001. 


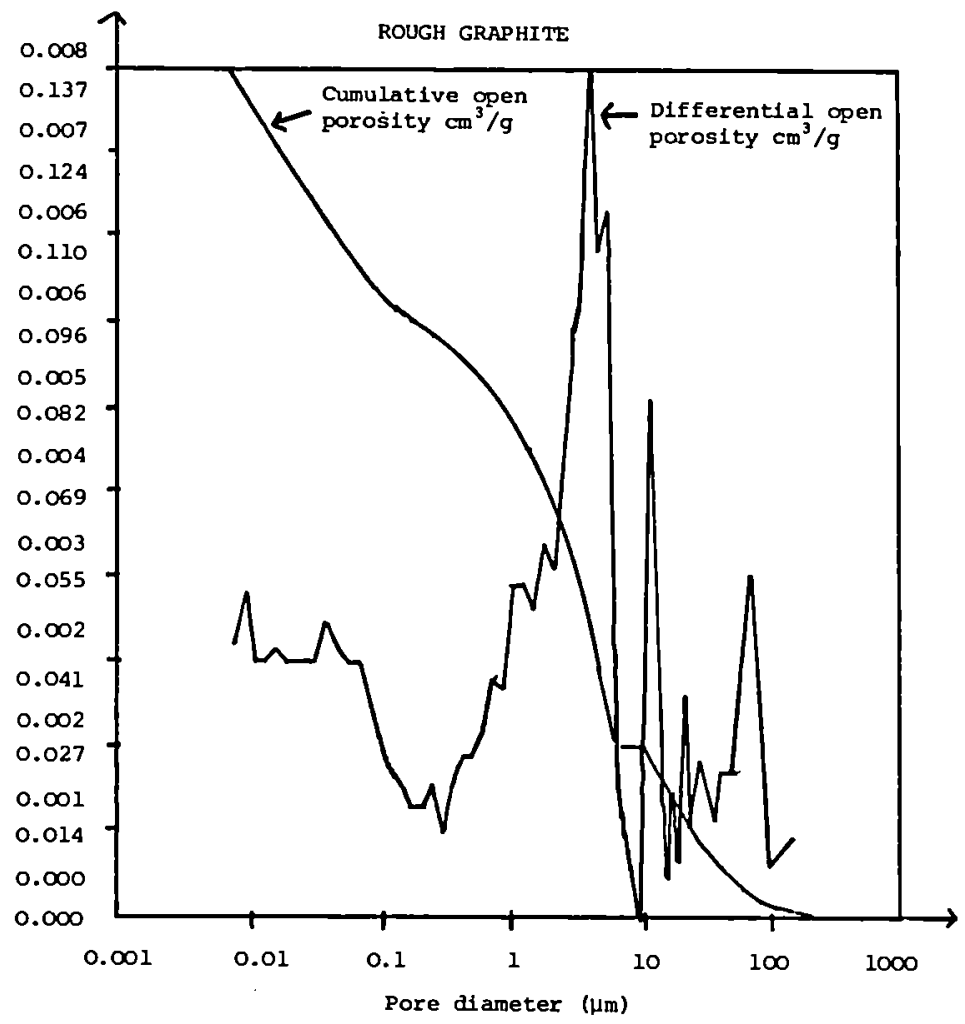

Fig. 1. Mercury porosimeter

Kinetics of water penetration into porosity of fresh graphite: effect of graphite grades

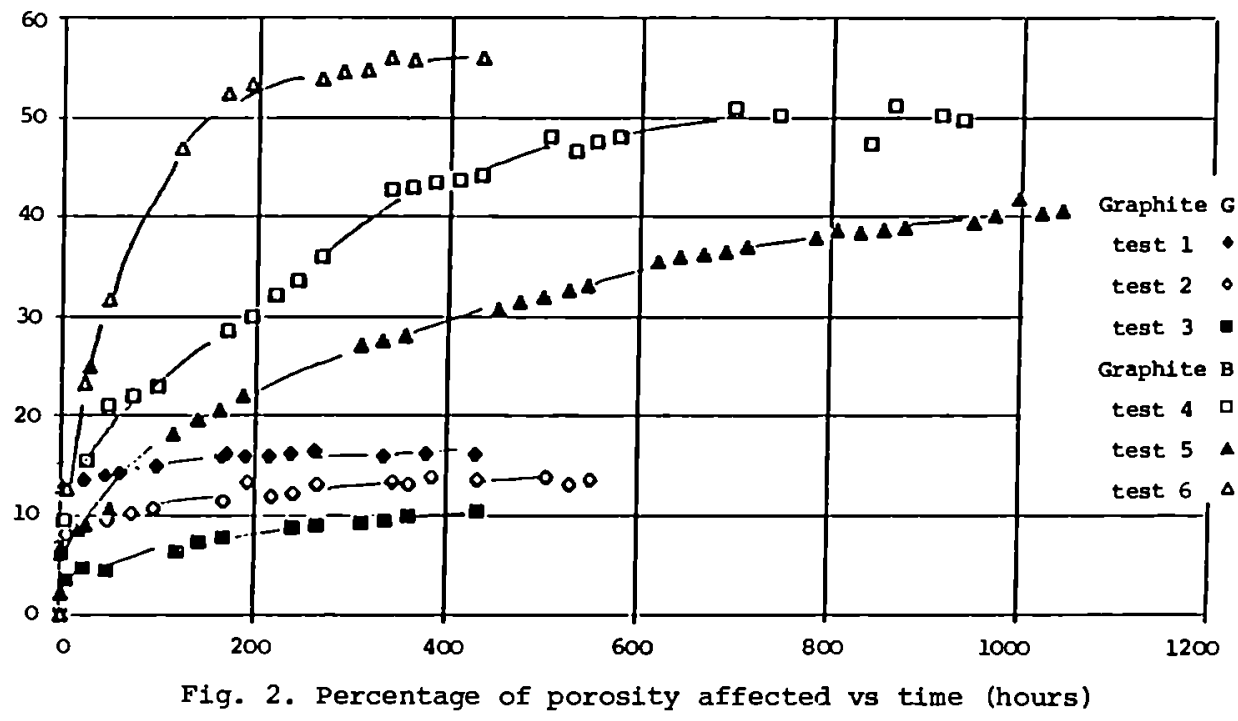


KInetics of water penetration into porosity of fresh B graphite:

effect of specimen dimensions

small specipens: 17 mon dia $\times 14$ wo high

large speclwens: $75 \mathrm{~mm}$ dia $\times 75 \mathrm{~mm}$ high

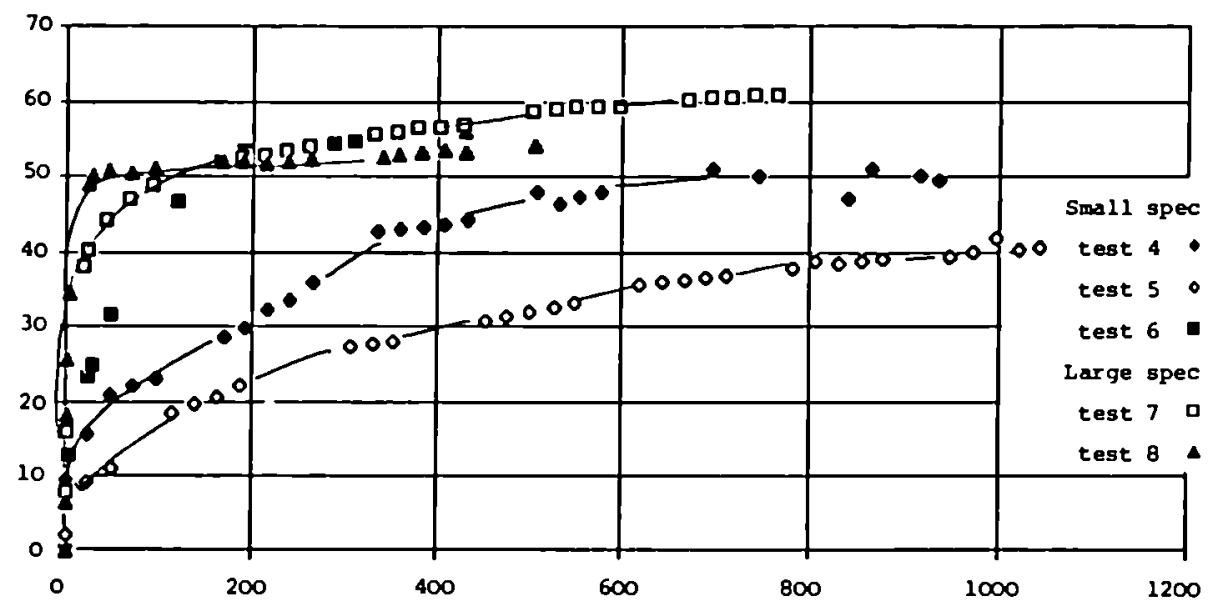

Fig. 3. Percentage of porosity affected vs time (hours)

KInetics of water penetration of $B$ graphite:

effect of radiolytic oxydation

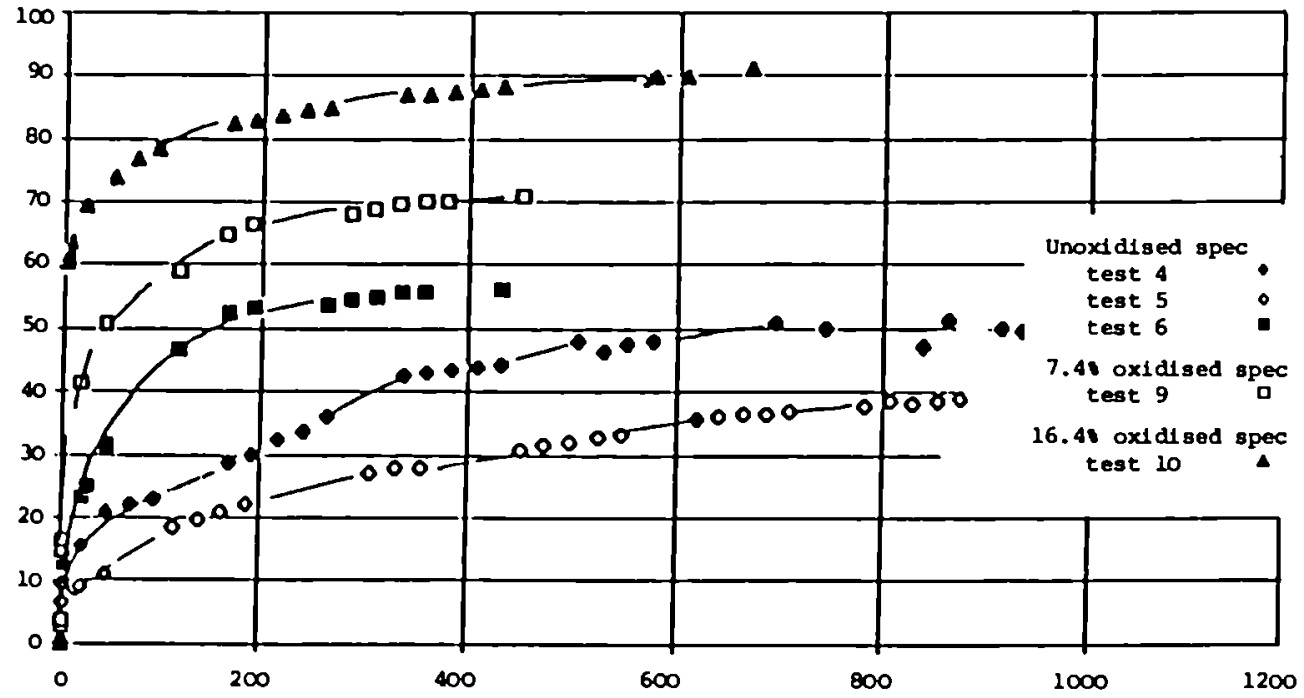

Fig. 4. Percentage of porosity affected vg time (hours) 


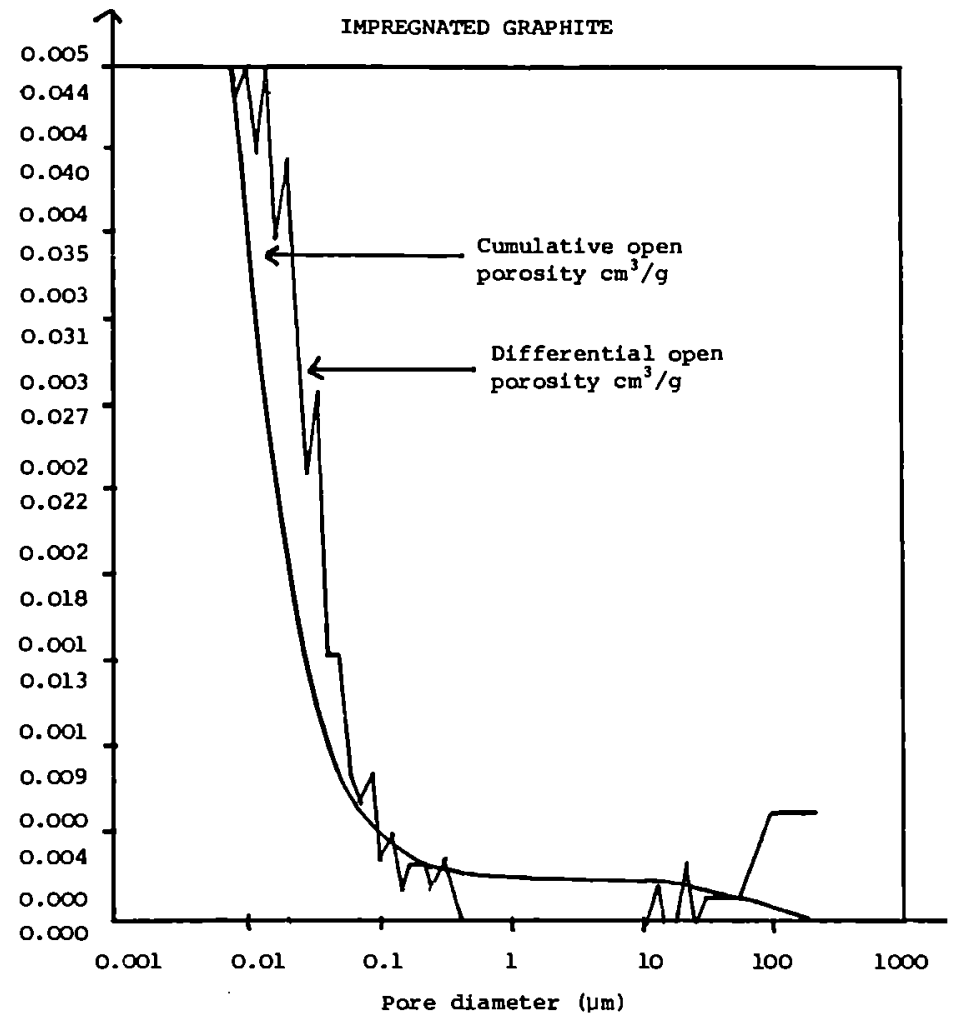

Fig. 5. Mercury porosimeter

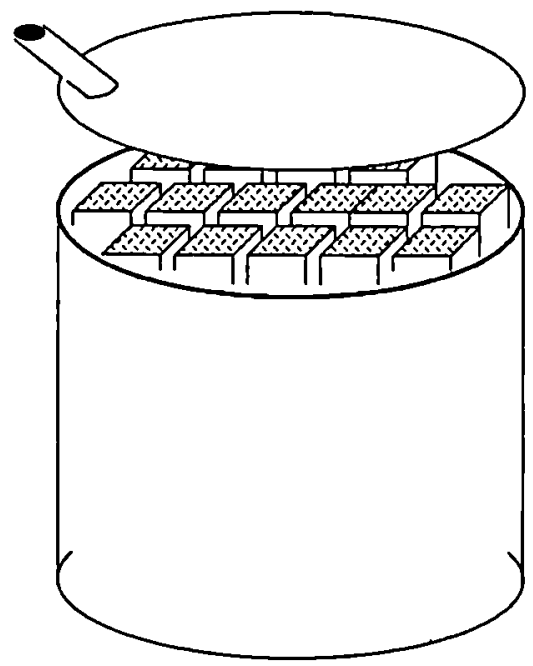

F1g. 6. Waste graphite 1mpregnation container 


\section{DISCUSSION}

Question: H L BERMANIS, United Engineers - Since the purpose of your work was volume reduction of concrete for eventual underground disposal, the enhanced dissolution of the treated cement-stone to a depth of several millimetres appears counter-productive. How do you prevent dissolution and leakage into the aquifer?

Answer: S JULL, TWC - The purpose of this work was not necessarily to achieve a volume reduction. We found only $<5 \mathrm{~mm}$ debris set by slurry. The remaining material will still have to be treated.

We agree that dissolution of the surface of the hardened material is not acceptable and would hope to consider this matter during further work.

Question: A CAILLOL, CEA-Cadarache - Do you envisage extending the decontamination methods you described to include waste from the dismantling of your glove boxes, in particular, with a view to bringing it up to the standards for surface storage?

Answer: J DRAULANS, Belgonucléaire - The work described was carried out before the national level reorganisation of the processing of radioactive waste. For the time being no decision has been taken regarding the possibility of surface storage.

Question: MST PRICE, UKAEA-Winfrith - I have two questions, the first of whlch is addressed to Mr Draulans and also to Mr Caillol, who presented a paper to Session VII yesterday. I appreciate that there are lessons to be learned for future installations. However, do the results of decomissioning and the residues of $\mathrm{Pu}$ found therein lead to any afterthoughts relating to contemporary installations, for example in relation to critlcality safety? My second question (for Mr Draulans) is: What was the IAEA transport category for the glove box 'packages' transported through the public sector? was it a 'special arrangement' and do you think that a 'special arrangement' is a sultable way to continue such work?

Answer: J DRAULANS, Belgonucleaire - First question: the quantity of Pu for glove boxes was always below $180 \mathrm{~g}$. Second question: it was a 'special arrangement'. If a convenient transportation method were available (ship container type $B$ or similar), the 'special arrangement' could be waived.

Answer: A CAILLOL, CEA-Cadarache - The quantities of residual plutonium in the installations are negliglble compared with the quantities to be considered for criticality safety. whlch are themselves defined with important safety margins. Nevertheless, these residual amounts were greater than expected and extreme vigilance should prevail to ensure that no residual plutonium is left in glove boxes.

Question: P B WOOLLAM, CEGB (NPD) - Since the activity ratio between cement-stone and aggregate is not more than a factor of ten, does this not mean that your procedure is very limited - in fact to concretes with specıfic actıvitıes less than ten times the 'de minimis' limit?

Answer: H A W CORNELISSEN, KEMA - Most concretes have a low contamination so a high decontamination factor is not necessary. From the physical and chemical viewpolnt, it is obvious that the porous cement-stone will be more contaminated than the dense aggregate. 
Question: P FUNKE, Ministry of the Environment and Reactor Safety, Wiesbaden - How were the licensing authorities involved in the dismantling of the glove boxes? Was this done on an ad-hoc basis or was there a formal procedure?

Answer: J DRAULANS, Belgonucléaire - Our fuel activities are controlled by an authorised body, which decides whether the scheduled activities fall within the scope of the current licence or whether a new licence is required.

Question: D HARISTOY, CEA-FAR - How do you treat liquid waste from your process? Will the conditioning of this waste not ultimately lead to greater volumes compared with the concrete?

Answer: H A W CORNELISSEN, KEMA - At the washing stage only about 1-48 of solid material will be dissolved. This can be separated off by conventional methods.

Question: M CONTI, ENEA - Impregnation is a very interesting solution for the treatment of the graphite arising from the dismantling of GCRs. However, it seems to me that it should also be demonstrated that impregnation is the most suitable technique and that its radiological impact on the environment is optimum with regard to the alternative solutions.

Answer: J R COSTES, CEA-Valrho - For reactor core graphite one compares generally impregnation and incineration. Our study shows costs of $18 \mathrm{FF} / \mathrm{kg}$ for impregnation, and of $50 \mathrm{FF} / \mathrm{kg}$ for incineration. With regard to the radiological impact on the environment, impregnation appears preferable because the short-lived nuclides, such as $H-3$, Eu-154 and Eu-155, have time to disappear before the diffusing in the environment. For long-lived nuclides, such as C-14, it seems preferable to slow down their diffusion over centuries instead of releasing them into the atmosphere. The containment of Cs-134/137 by impregnation seems preferable compared with retention in fumes.

\section{CONCLUSION}

At the end of this Session, I would like to conclude that the treatment of decommissioning waste has been well presented and discussed in detail both from a technical and scientific point of view.

We have seen interesting results for various specific areas, ie alphaas well as beta-gamma contaminated or activated waste. Remarkable progress has been obtained with the treatment of graphite bricks by impregnation with polymers. The treatment of concrete by separating the contaminated part from the rest showed initially encouraging results which, however, need to be verified.

It is important to continue the technical investigations to identify the best solutions for treating decommissioning waste and to apply them on an industrial scale. Therefore, I hope that in the new 1989-93 EC programme on decommissioning, appropriate waste treatment techniques can be developed and improved, starting either from the results obtained or from new proposals.

M CONTI, ENEA 


\section{SESSION XIII \\ RECYCLING OF MATERIAL AND DECOMMISSIONING METHODOLOGY}

CHAIRMAN: R NEIDER, BAM, D

SECRETARY: K PFLUGRAD, CEC 
. 


\author{
RADIOLOGICAL IMPACT OF VERY SLIGHTLY RADIOACTIVE COPPER \\ AND ALUMINIUM RECOVERED FROM DISMANTLED NUCLEAR FACILITIES \\ H. GARBAY and A.M. CHAPUIS \\ Commissarlat à l'Energle Atomique, Fontenay-aux-Roses, France
}

\begin{abstract}
This article deals with the recycling of copper and aluminium derived from dismantled nuclear facilities. The study is based on evaluation of the quantities of materials likely to be very slightly contaminated by radioactivity. Descriptions are given of scenarios involving exposure of individuals, and derived limits are deduced for exemption of these metals from regulatory control in protection against lonizing radiation.
\end{abstract}

\title{
INTRODUCTION
}

Two criteria must be considered if materials or objects are to be exempted from regulatory control. The individual risk must be sufficiently low as not to warrant regulatory concern, and radiation protection including the cost of regulatory control, should be optimized. This article describes scenarios used to evaluate individual risk and deduce the applicable derived limits. The optimization of protection is not considered.

The applied methodology comprises the following steps :

- choice of a source term and physical, chemical and radioactive characterization of this source,

- description of the processing of materials : all treatments applled to the material or to the resulting by-products,

- description of scenarios that may lead to exposure of individuals during treatment or use of recycled products,

- cholce of parameters characterizing scenarios,

- calculation of annual individual doses,

- comparison of these doses with reference values,

- proposal of derived limits.

\section{CHARACTERISTICS OF METALS RECOVERED FROM DISMANTLED NUCLEAR FACILITIES}

Most nuclear research has been devoted to French facilities and in particular to the pressurized water reactors and the enrichment plant at Plerrelatte, partial dismantling of which is under way.

Copper and alumintum in nuclear facilitles are mainly used in electrical circuits and in measurement and control circuits. In nuclear reactors, aluminium surfaces are limited for safety reasons. In a 900 MWe pressurized water reactor, the total quantity of copper is about 5,000 tonnes, and that of aluminium about 100 tonnes. 
The length of cables in a nuclear plant unit depends on the site, but can be estimated as between 1,000 and 2,000 kilometres. Cables likely to be activated or contaminated are found in the reactor building, the nuclear auxiliary building and the fuel bullding. Taken together, these cables weigh between 450 and 650 tonnes. Given the probable contamination incidents during reactor operation, it seems reasonable to assume that between 300 and 400 tonnes of cable will be weakly contaminated at the time of dismantling. In the Federal Republic of Germany it has been estimated that in pressurized water reactors the reactor building and the nuclear auxiliary building contain between 280 and 600 tonnes. of electric cables.

The metal component of cables may be copper, aluminium or both, the insulating sheath usually being of PVC. The average composition of the cables is :

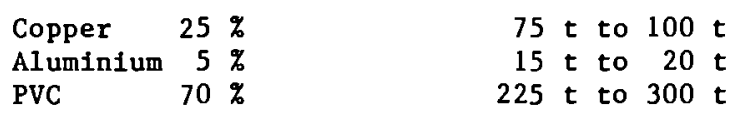

In the reactor building of a nuclear plant, the cables run along the walls, and are therefore potentially subject to neutron flux. The neutron fluence rate at nominal power does not exceed $2 \mathrm{E}+6 \mathrm{n} \cdot \mathrm{cm}^{-2} \cdot \mathrm{s}^{-1}$. The specific activity of impurities in the metal and in the insulating sheath has been calculated for a 30-year operating period with a load factor of 0.75 . Five years after reactor shutdown, the speficic activity of silver $108 \mathrm{~m}$ in the copper is about $8 \mathrm{E}-3 \mathrm{kBq} \cdot \mathrm{kg}^{-1}$ and that of calclum 41 in the PVC is about $0.1 \mathrm{kBq} \cdot \mathrm{kg}^{-1}$. In all probability, the level of contamination reached will be higher than that of activation for all exposed surfaces. The level of activation is difficult to assess and will depend on contamination incidents and accidents occurring during the period of reactor operation.

The uranium enrichment plant at Pierrelatte uses the gaseous diffusion process and contains large quantities of aluminium, the fluid circuits being made entirely of the alloy AG3. Disassembly of the low- and midlevel unit of the plant should produce about 1,500 tonnes per year over a four-year period.

In other facilities of the fuel cycle, copper and aluminium are essentially used in electric cables. It was not possible to collect quantitative data.

\section{RECOVERY AND RECYCLING OF METALS}

\section{1 Industrial overview}

World, European and French production and consumption are given in table $I$, together with the tonnages of recovered copper and aluminium waste in France (1).

\section{II.2. Recovery of cables}

To recover metal in electric cables, Industrialists separate the metal and insulating material. A medium-sized cable-shredding plant produces about 3,000 tonnes of copper waste and about 2,200 tonnes of plastic waste annually. The recovered metal is sold for refining. The plastic waste is generally dumped. When an outlet exists, plastic waste can be recovered by extrusion process for the manufacture of plastic products. The composition of PVC however usually prevents its incorporation into the recovery circuits. 


\section{II.3. Refining of copper and copper alloys}

Plants producing alloys such as bronze and brass use induction furnaces. In these furnaces, oxidation of zinc is avoided and the main aim of refining is to achleve the correct alloy composition. Small plants have an annual production of 1,700 to 3,000 tonnes, and generate about 60 tonnes of slag every year.

Rotating furnaces are used in the manufacture of copper shot or copper phosphide. Annual production of these plants ranges from 1,700 to 3,000 tonnes.

The manufacture of pure copper from copper waste is performed in several steps. A redox reaction is induced in a water-jacketed cupola by introducing a layer of metallurgical coke. Th1s gives "black copper", which contains $80 \mathrm{z}$ copper. Th1s metal is then ladled into a converter where Impurities such as zinc, lron, nickel, lead and tin are oxidized. Copper obtained titrates 98 to $99 \%$. It is then used in the manufacture of anodes, which are electrolytically refined to cathodes containing 99.97 to $99.99 \mathrm{Z}$ copper. Several units are involved in this manufacturing cycle. A waste melting plant manufactures ingots containing 98 to $99 z$ copper at a production rate of 11,000 tonnes per year, and also generates 9,000 tonnes of slag annually, $45 \%$ of which is used in sand blasting, the remainder being dumped. Every year, the plant generates about 1,800 tonnes of dust, which is treated for recovery of zinc. An electrolysis plant produces about 50,000 tonnes of cathodic copper annually, and supplies its own starting materlal in the form of bllster copper $(50 \%)$ and copper waste $(50 \%)$. Manufacture of anodes generates annually about 25,000 tonnes of slag and 100 tonnes of dust. Annual waste production during electrolytic refining of copper consists of about 500 tonnes of residual sulphurlc ac1d, about 30 tonnes of arsenical mud and about 60 tonnes of nickel sulphate.

Copper and 1ts alloys are then used to produce sem1-processed products for use as bars, wires, tubes or laminates, or are cast in moulds and worked into finlshed products.

\section{II.4. Refining of aluminlum and its alloys}

Aluminfum refining plants are usually equipped with rotating furnaces or reverbatory furnaces, in both of which melting is achleved in a salt-bath at about $750-800^{\circ} \mathrm{C}$. A medium-sized plant that manufactures 11,000 tonnes of aluminium alloys every year generates 3,300 tonnes of slag and 30 tonnes of dust over the same perfod. The slag contains many metallic Inclusions which are recovered by mechantcal extraction. Alumintum 1s supplied to the processing plants in the form of ingots, semi-processed products or molten metal.

\section{EXPERIMENTS PERFORMED UNDER INDUSTRIAL AND SEMI-INDUSTRIAL CONDITIONS}

In order to determine the distribution of radionuclides in the metal and by-products during refining of copper or aluminlum, the corresponding chemical elements were deteralned during an average industrial cycle in a copper refining plant and in an alumintum tefining plant.

In addition, an alloy melting test with AG3 contaminated with uranfum was performed in an induction furnace under semi-industrial conditions. 


\section{III.1. Refining of copper}

During copper refining, dust-generation was measured in the hall and samples of molten metal and cupola slag were taken. The mean concentration of dust in the refining hall was $7 \mathrm{mg} \cdot \mathrm{m}^{-3}$. Not all suspended particles are inhalable. In an unperturbed atmosphere, particles of aerodynamic diameter greater than 10 to $15 \mu \mathrm{m}$ (values depend on authors) will be deposited in the nasal and buccal cavities without the risk of penetration into the lower resplratory tract. We have taken this diameter as $13 \mu \mathrm{m}$ in the present study. The Inhalable fraction was therefore equal to 0.4 , thus giving an Inhalable dust concentration of $2.8 \mathrm{mg} \cdot \mathrm{m}^{-9}$.

\section{III.2. Refining of aluminium}

During aluminfum refining, samples of molten metal and slag were taken and analyzed. Measurements of dust-generation 1 n the hall gave the following results : mean dust concentration $4.4 \mathrm{mg} \cdot \mathrm{m}^{-9}$, mean Inhalable dust concentration $3.3 \mathrm{mg} \cdot \mathrm{m}^{-3}$.

\section{III.3. Melting of AG3 contaminated with uranium}

Three melting experiments were performed, each with approximately $200 \mathrm{~kg}$ batches of increasingly contaminated AG3. Melting was achieved in an Induction furnace, and a surfactant $\left(\mathrm{NaCl}, \mathrm{KCl}, \mathrm{CaF}_{2}\right)$ was added at the end of melting to trap oxides and form the slag. Dust concentration was measured in a fume evacuation duct fitted above the furnace and in the melting cell. The mean dust concentration was equal to $1.2 \mathrm{mg} \cdot \mathrm{m}^{-3}$ in the melting cell and $12 \mathrm{mg} \cdot \mathrm{m}^{-3}$ in the duct. The fraction of inhalable dust was about 0.45 in the melting cell and about 0.6 in the duct.

Dust, metal and slag samples were taken and analyzed for uranium content and alpha activity. Table II gives the urantum content and alpha activity noted in the samples.

\section{POTENTIAL RADIOLOGICAL IMPACT OF RECYCLING}

\section{IV.1. Reference scenartos}

Evaluation of the radiological impact of copper and alumintum recycling requires definttion of reference scenarlos and their corresponding parameters. Parameters relating to radionuclide distribution in melting products are derived from experimental results or are based on physicochemical data. Tables III and IV Indicate the maximal radionuclide contents in the melting products chosen in this study.

The amounts of copper and aluminfum likely to be recycled each year are estimated on the basis of the recommendations of the European Community (2) for the dismantling of two reactors per year, 1.e. between 160 and 200 tonnes of copper waste and between 30 and 40 tonnes of aluminfum waste. For AG3 contaminated with urantum, we have used a value of 1,500 tonnes per year over the dismantling perlod.

The exposure scenarios studied correspond to realistic situations, the probability of occurrence being evaluated on the basis of the greatest exposure. The parameters of the different scenarlos are evaluated to represent realistic exposure conditions. The exposure pathways and scenartos are given below : 
Copper Aluminium

\section{EXTERNAL EXPOSURE EFFECTIVE DOSE}

- Occupational exposure to metal waste in the storage area

$\begin{array}{ll}\mathbf{x} & \mathbf{x} \\ \mathbf{x} & \mathbf{x} \\ \mathbf{x} & \mathbf{x} \\ \mathbf{x} & \mathbf{x} \\ \mathbf{x} & \mathbf{x}\end{array}$

- Occupational exposure to products manufactured in the refining plant

- Occupational exposure to slag $x$

- Occupational exposure during manufacture of electrolytic copper

- Occupational exposure to manufactured articles

- Domest1c exposure to manufactured articles

- Occupational exposure in a flshing vessel

EXTERNAL EXPOSURE DOSE TO AN ORGAN

- Exposure due to use of an intra-uterine device

\section{EXPOSURE BY INHALATION}

- Occupational exposure during refining of metal

- Occupational exposure during processing of metal

\section{EXPOSURE BY INGESTION}

- Domestic exposure due to corroded metal utensils

- Public exposure due to ingestion of pork meat $x$ (copper salts are added to pork food to speed up their growth)

EXPOSURES DUE TO DISPOSAL

- Exposures due to slag disposal in landfill $x$

$\mathbf{x}$

The PVC will probably be more contaminated than the metal components of the cables. The recovery of PVC and 1ts disposal in landiff were therefore also studied since it is interesting to know to what extent PVC recycling can be exempted from regulatory control, in order to define if management of PVC during dismantling can be separated from that of metal.

The scenarlos presented can be used to define the dose likely to be received by the most exposed groups during the year in which exposure is maximal. 


\section{IV.2. Recommended dose levels}

The theoretical limit below which a material can be exempted from regulatory control is determined by the level of risk to the public considered acceptable for stochastic phenomena. This has been evaluated as about 1 E-6 per year (3). Considering that the total risk is $10^{-2}$ per sievert, a dose below $100 \mu \mathrm{Sv}$ per year can be considered negligible.

It should be taken into account that an individual may be subject to exposure from several sources. Each scenario therefore has a corresponding value for an acceptable dose level. In the case of occupational exposure the limiting scenario excludes a second critical occupational exposure. The acceptable dose level may be taken as $50 \mu \mathrm{Sv}$ per year $(4,5)$. In the case of general potential exposure of the public, the acceptable dose level may be taken as about $10 \mu \mathrm{Sv}$ per year (6). When the dose is delivered in contact, or very close to a specific organ the effects of lonizing radiations are non-stochastic effects; the dose limit recommended by the ICRP (3) to prevent these effects is $0.5 \mathrm{~Sv}$ per year. Considering a protection factor of 10, the dose level for an organ is $0.05 \mathrm{~Sv}$ per year.

\section{IV.3. Determination of the derived limits for recycling of copper and aluminium}

These exemption levels (expressed in annual dose) are not usable in practice, and it is therefore necessary to define derived limits that can be applied by those in possession of materials intended for exemption. The methodology employed is that used as a basis for the European Community recommendations (2) : annual individual doses for scenarios that may result in exposure are calculated and compared with the reference level for each type of scenario, derived limits are then proposed.

The derived limits for recycling of copper and aluminium, as well as the limiting scenarios, are presented for the main radionuclides in tables $\mathrm{V}$ and VI. Scenarios for PVC recovery (results in table VII) can be used to compare calculated derived values for PVC with the derived limits for the metal components of the cables.

\section{CONCLUSIONS}

The results given in table $V$ show that the scenario relating to use of an intra-uterine device is the most limiting for pure beta emitters, due to the fact that this device is in permanent contact with the organ. The activity of plutonium is limited by the inhalation scenario during processing of the metal, due to the cholce of distribution factors of this radionuclide during copper refining. The scenario relating to the occupational exposure to metal waste in the storage area is the most limiting for beta-gamma emitters.

The results given in table VI show that the activity of radionuclides that do not emit gamma radiation is limited by the inhalation pathway during processing of aluminium except for strontium 90 which limiting scenario is the slag disposal in landfill. The activity of gamma emitters is limited by the pathways of external exposure, and principally by the fishing vessel scenarto where the residence time is long. The activity of the gamma emitter caesium is limited by external exposure to slag due to the choice of caesium distribution factors applied to aluminium refining, and to the residence time of the worker near the slag. 
The study of PVC recovery and disposal was less detalled than that of copper and alumintum recovery, and some selected parameters are therefore very conservative (for example, the parameters for distribution of radionuclides during extrusion have all been taken as unity). Comparison of the activity limits for copper with the activity levels calculated for PVC recovery shows that the copper recycling values are more restrictive or of the same order of magnitude, except in the case of plutonlum. Comparison with the aluminium recycling limits shows that the values calculated for PVC are less restrictive or of the same order of magnitude for gama emitters, they are likely to be more restrictive for alpha or pure beta emitters.

\section{REFERENCES}

1. Annualre stat1st1que M1nemet 1987, éd1tion 1988

2. Radiological protection criteria for the recycling of materials from dismantiling of nuclear installations, Radiation protection $n^{\circ} 43$, Luxembourg, November 1988

3. Recommendations of the International Commission on Radiological Protection, ICRP publication 26, 1980

4. A.M. CHAPUIS, F. LUYKX ; Radiological criteria for unrestricted release of materials from nuclear installations; International Conference on the decommissioning of nuclear installations, 24-27 October, 1989, Brussels

5. Exigences préalables de radioprotection pour exempter certalnes matières radioactives de permis après le transfert pour évacuation Projet de réglementation; Canada

6. IAEA Safety Guide ; Principles for the exemption of radiation sources and practices from regulatory control ; Safety Ser1es $n^{\circ} 89$, IAEA, Vienna 1988 
Table I: Industrial overview

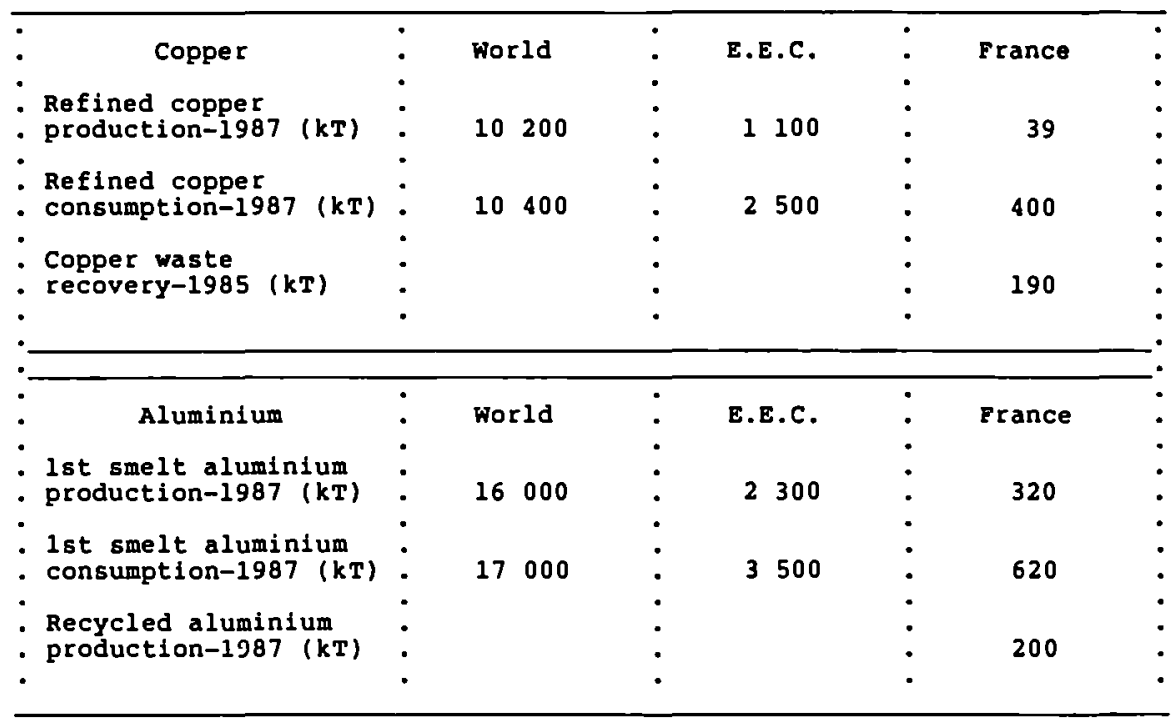

Table II: Distribution of Uranium and alpha activity in ingots and melting waste

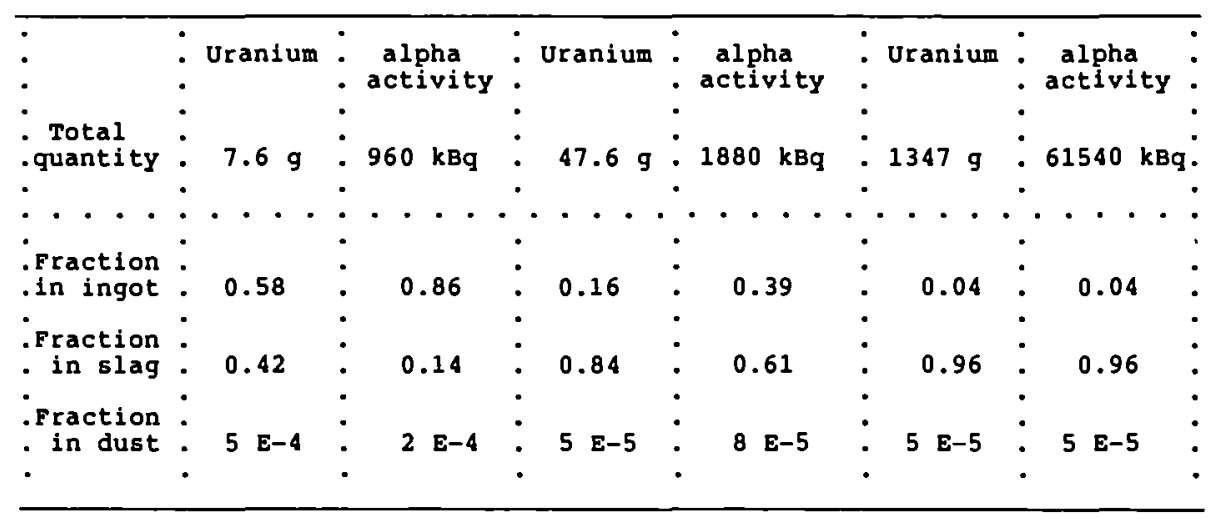


Table III: Radionuclides' distribution during melting of copper (maximua fractions)

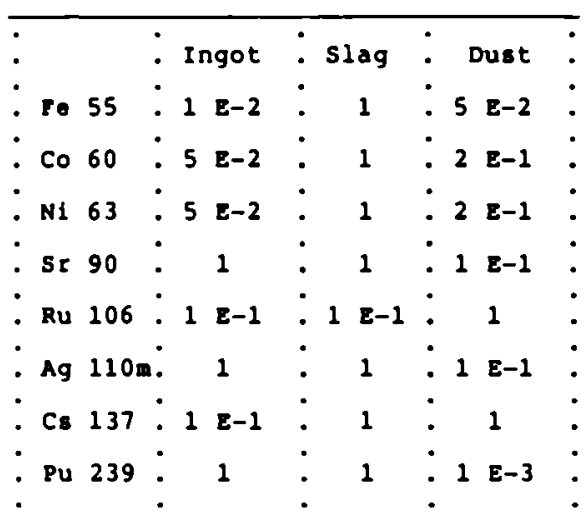

Table IV: Radionuclides' distribution during nelting of aluninium (maximun fractions)

\begin{tabular}{|c|c|c|c|c|c|c|c|c|}
\hline . & & - Ir & ngot & $\dot{0}$ & slag & & Dust & \\
\hline Fe & 55 & $\dot{.}$ & 1 & .2 & E-1 & .5 & $\mathbf{E}-\mathbf{3}$ & \\
\hline Co & 60 & $\dot{.}$ & 1 & .1 & E-1 & $: 1$ & E-3 & \\
\hline N1 & 63 & $\dot{0}$ & 1 & .2 & $E-1$ & . 5 & E-3 & \\
\hline Sr & 90 & • & 1 & & 1 & $\cdot 1$ & E-1 & \\
\hline Ru & 106 & . 1 & E-1 & .1 & E-1 & & 1 & . \\
\hline - Ag & $110 \mathrm{~m}$ & $\dot{.}$ & 1 & .5 & E-2 & . 1 & E-3 & • \\
\hline $\mathrm{Cs}$ & 137 & : 1 & $E-2$ & $\dot{.}$ & 1 & & 1 & . \\
\hline $\mathbf{P u}$ & 239 & $\because 5$ & E-1 & : & 1 & .1 & E-3 & \\
\hline $\mathbf{u}$ & 23 & . 5 & E-1 & $\dot{.}$ & 1 & : 1 & E-3 & \\
\hline
\end{tabular}

Table V: Derived $11 \mathrm{mits}$ and limiting scenarios for copper recycling

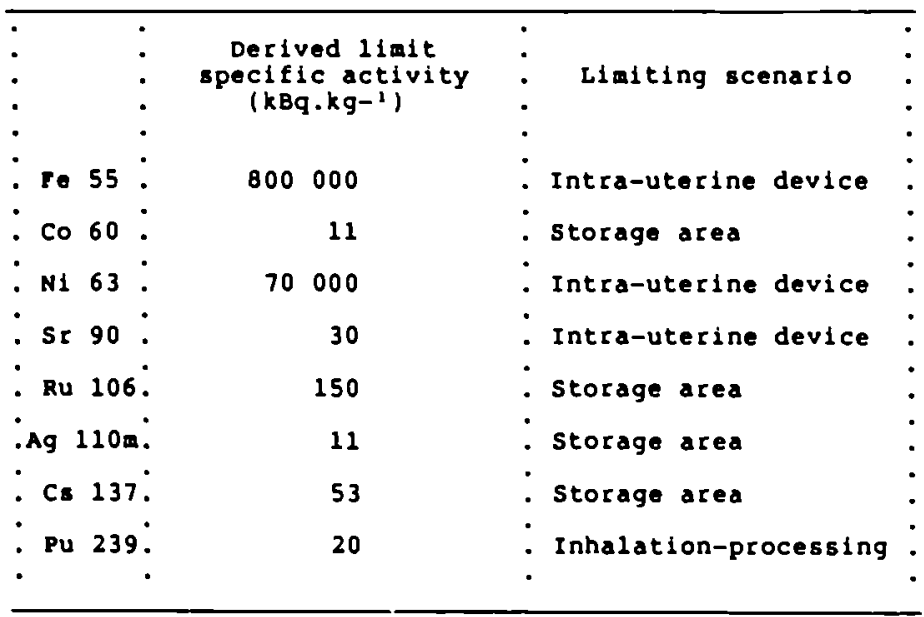


Table VI: Derived limits and limiting scenarios for aluminium recycling

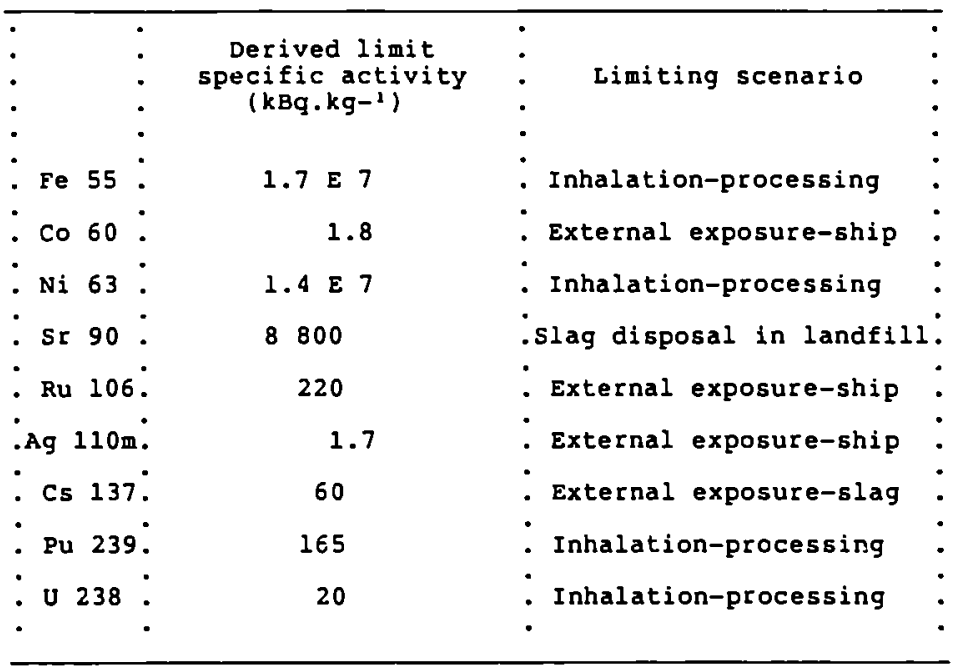

Table VII: Derived levels and corresponding scenarios calculated for recovery and disposal of PVC

\begin{tabular}{|c|c|c|}
\hline : & Derived level & : \\
\hline : & specific activity & - Corresponding scenario \\
\hline • & $\left(\mathrm{kBq} \cdot \mathrm{kg}^{-1}\right)$ & - \\
\hline - & & : \\
\hline - Fe 55 . & $2.8 E 5$ & - Inhalation-processing \\
\hline - Co 60 : & 13 & - External exposure-storage \\
\hline Ni 63 : & $2.3 E 5$ & - Inhalation-processing \\
\hline : Sr 90 : & 210 & - Landfill disposal \\
\hline . Ru $106^{\circ}$ & 220 & - External exposure-storage \\
\hline .Ag $110 \mathrm{~m}$. & 16 & - External exposure-storage \\
\hline - $\operatorname{Cs~} 137^{\circ}$. & 75 & - External exposure-storage \\
\hline - Pu $239^{\circ}$ & 1.4 & - Inhalation-processing \\
\hline • & & - \\
\hline
\end{tabular}




\title{
COMPARISON OF DECONTAMINATION AND MELTING HITH DIRECT DISPOSAL
}

Klaus G. Janberg, Dieter Rittscher

GNS Gesellschaft für Nuklear-Service mbH

4300 Essen 1, Federal Republic of Germany

\begin{abstract}
This report is an up-date and extention of the author's publication EUR 11149 of 1987 and refers to the currently preferred practices in the Federal Republic of Germany. The main changes since then are concerned with the strongly reduced "de minimis"-level and the increased demands placed on waste documentation (AVK-system). Further more, the schedule for start-up of the $f$ inal disposal mine KONRAD has slipped by more than two years since 1987. All these factors together strongly increase the interest in direct melting in the FRG, making it the main route to go. In the beginning direct melting was also considered by some only under the goal of volume reduction. Today, however, definite preference is given to recycling within the nuclear industry. This leads to the need to $f$ ind more applications within this industry as the scrap metal arisings are growing.
\end{abstract}

\section{INTRODUCTION}

How to deal with the growing scrap metal arisings from decommissioning is not only a concern for the FRG but for the whole nuclear community, though with different degrees of urgency.

The shut-down power stations in Germany are already today quite numerous: LINGEN, FR2, KRB A, KKN, MZFR just to name a few, and others are showing up in the near future like AVR, THTR and several research reactors. A particular problem will be presented by the WAK reprocessing plant which is scheduled for shut-down at the end of 1990.

The best solution with respect to public acceptance is the 'green meadow' scheme, which suggests a complete return of the site to do its status prior to construction.

The economy of this solution is not demonstrated and doubtful, as immediate dismantling leads to high dose rates which so far are rarely adequately evaluated. Thus, where public opinion is not creating a high pressure for it and where sites are not in scarce supply, safe enclosure for several years or decades is preferred by the utilities. But in almost all countries some demonstration projects have been carried out or are under way in order to show to the public that it can be done. Some examples herefore are: Shippingport. Brennilis, Rapsodie, JPDR, KRB A, KKN ...

If one takes a closer look at these projects, however, then one has to conclude that none will reach the final goal in the near future as the wastes cannot yet $f$ ind a licensed safe, final disposal. So these projects are essentially limited to dismantling and packaging for disposal except in those cases with a high recycling share as KRB $A$.

This is a frustrating situation for the nuclear community; on one side we are attacked by opponents on the ground that we cannot really decomission due to the lack of eisposal sites and on the other side these same opponents delay their openıng. Really a situation of Freudian complexity. Fortunately the technical aspects are easier to handle and we shall limit ourselves to their discussion. 


\section{MAJOR CHANGES IN THE FRG SINCE THE LAST}

EURATOM DECOMMISSIONING CONFERENCE

When the first comparison was made of the relative merits of super-compaction, decontamination and direct melting, the boundary conditions were as follows:

- free use for $B, \gamma$-scrap was allowable under $3.7 \mathrm{~Bq} / \mathrm{g}$

- the documentation could remain rudimentary and quality assurance/ control interferences with the processes were minimal.

In 1989 the situation has evolved considerably:

- free use is acceptable for $\mathrm{B}, \gamma$-scrap only beyond $0.1 \mathrm{Bg} / \mathrm{g}$

- the scrap has to be traceable closely from birth to grave using ever more sophisticated documentations. Transports have to be announced in advance to the authorities. Wastes for interim storage have to be conditioned with approved procedures and under continuous control of independant inspectors (AVK-system). closely.

These changes lead to consequences which we shall have to examine

\section{CONSEQUENCES OF THE CHANGES}

In 1986/87 the management scheme for scrap metal treatment could be summarized as shown in $\mathrm{fig}$. 1. The actual situation is given in $f i g .2$ and shows particular differences in the "free use" or "de minimis"-level and associated controls.

The expert easily depicts the additional changes hidden behind these new limits:

- decontamination to the new "de minimis"-level takes more process steps, results in greater amounts of secondary wastes, takes more time

- measurement of the residual activity in terms of $\mathrm{Bq} / \mathrm{g}$ or $\mathrm{Bq} / \mathrm{cm}^{2}$ is more difficult and more time-consuming

- the masses of scrap metal which cannot be reduced below the "free use" limit are necessarily increased.

The major conclusion is: in 1986/87 decontamination was still competitive when compared with direct melting, now, in 1989 melting has taken the lead, though the decontamination techniques have been further improved.

How about super-compaction then?

We remind, that super-compaction is a process for the reduction in volume of scrap metal. It does not intend to reduce the mass of scrap to be disposed.

Thus it is still indispensable for all scrap materials which are - of complicated geometry, i.e. small valves

- of a material composition, which does not allow a clear metallurgical analysis (i.e. a composite structure of steel, zinc, rock-wool, seals etc.)

Thus the role of super-compaction in the decommissioning procedure is fairly unchanged. Only the post-compaction process of drying had to be added, as the residual humidity in tight drums could lead to corrosion and hydrogen release causing a pressure build-up in the drums.

The documentation, however, has been increased by a factor of 3 or more and table I shows an example of the different steps to be documented during super-compaction of LLS. 
In the case of MOSAIK-casks with 10 to $20 \mathrm{~cm}$ wall thickness the self-shielding factor is around 25 and measurements have shown, that the resulting surface dose rate rarely exceeds $2 \mathrm{mrem} / \mathrm{h}$. Thus the useful activity to be loaded into the cask is virtually not modified.

- the mass-balance of melting is favorable: of an input of 100 \% about 95 of the material are recycled, up to 4.5 is end in the slag and 0.5 to 1 in the dust particles retained in the filter system (without the oven liner)

- the activity balance shows that 90 - 95 \& remain in the products (Co, Fe, Mn) while $3-5$ are transferred to the slag and $2-3$ to the filters

- the shift of the volatile activity components is measurable in the average activities; i.e. when the original scrap had an average specific activity of $6 \mathrm{~Bq} / \mathrm{g}$, the product showed approx. $1 \mathrm{~Bq} / \mathrm{g}$, while the slag had $5 \mathrm{~Bq} / \mathrm{g}$ but a noticeable enrichment was shown in the filter particles with $75 \mathrm{Bg} / \mathrm{g}$.

\section{5. $\operatorname{cosTS}$}

Major shifts in the cost structure have taken place since 1986/87, as the documentation has easily tripied and risen to $3 \mathrm{DM} / \mathrm{kg}$ and more, depending on the lot constitution and size. Drying of super-compacted LLS for humidity control is another costly item. However, melting is less subject to the rise in documentation as the melted product needs less paper-work per $\mathrm{kg}$. This is one of the reasons why melting now has emerged as the reference treatment for contaminated scrap metal.

\section{CONCLUSION AND FUTURE TRENDS}

Direct melting was developed for volume reduction and scrap metal recycling. 100 recycling needs a 'sink' which consumes as much scrap as arises from decomissioning projects.

The first step was the recycling for MOSAIK casks. Here the metallurgical demands placed on the scrap are high in order to produce a satisfactory product quality. Thus another sink was needed in order to recycle less qualified materials. This was done in the form of shielding blocks and recently also as shielding plates, i.e. to increse the shlelding capability of concrete or steel structure containers for the KONRAD mine.

Messrs. STANG/SAPPOK reported progress on heavy container casting from scrap metal.

More sinks need to be found in the future in order to cope with the Increasing scrap metal arisings; so the search has to go on.

Scrap metal melting has a good public image and it is now not only competitive with other methods but seems to have a decisive advantage; thus we shall see an increasing variety of recycling applications in the future, at least as far as the FRG is concerned. 
Table I: Action list for LLS Super-Compaction - STATUS 1989

1. Sorting of wastes

2. Packaging in drums

3. Documentation of drums:

- contents

- weight

- dose-rate

- contamination

- activity with nuclide vector

4. Loading of container

5. Preparation of transport documents in analogy to 3

6. Sealing of container

7. Advance notice to authority 5 work days prior to transport

8. Transportation by rail

9. Notice to local authority

10. Notice to power station after arrival

11. Super-compaction

12. Documentation:

- pressure $\geq 300 \mathrm{MPa}$

- pellet wall thickness

13. Sorting of pellets

- dry pellets into drums

- 'wet' pellets into drums with special lid for drying

14. Drying under vacuum at approx. $130{ }^{\circ} \mathrm{C}$

15. Lid replacement after drying

16. Measurement of dose-rate/contamination and documentation

17. After 1 week storage period gas sampling and analysis for methane, $\mathrm{H}_{2}, \mathrm{O}_{2}, \mathrm{~N}_{2}$ and hydrocarbons, measurement of humidity

18. Composition of total documentation

19. Transfer of documents to power station

20. Control of documentation and comparison with interim storage criteria

21. Loading into containers and sealing

22. Advance notice to authority 5 work days prior to transport

23. Transport by rail

24. Notice of departure to local authority

\section{EXPERIENCE WITH MELTING}

Special reviews about particular cases will be given during this EC-conference by Messrs. SAPPOK, STANG and others.

Therefore we remind only the most important facts:

- scrap metal melting now is a well-established industrial process intended mainly for recycling of scrap and less for volume reduction of the wastes

- the activity control prior to melting is fairly easy: normalized dose-rate curves help to determine easily the specific activity of the drum content as a function of drum weight, fig. 3 .

- the activity control after melting is executed on a small sample taken from the melted scrap. The measurement is precise and representative for the lot, i.e. $5 \mathrm{t}$. Surface activity measurements need not be made as the activity is homogeneously distributed within the material. 


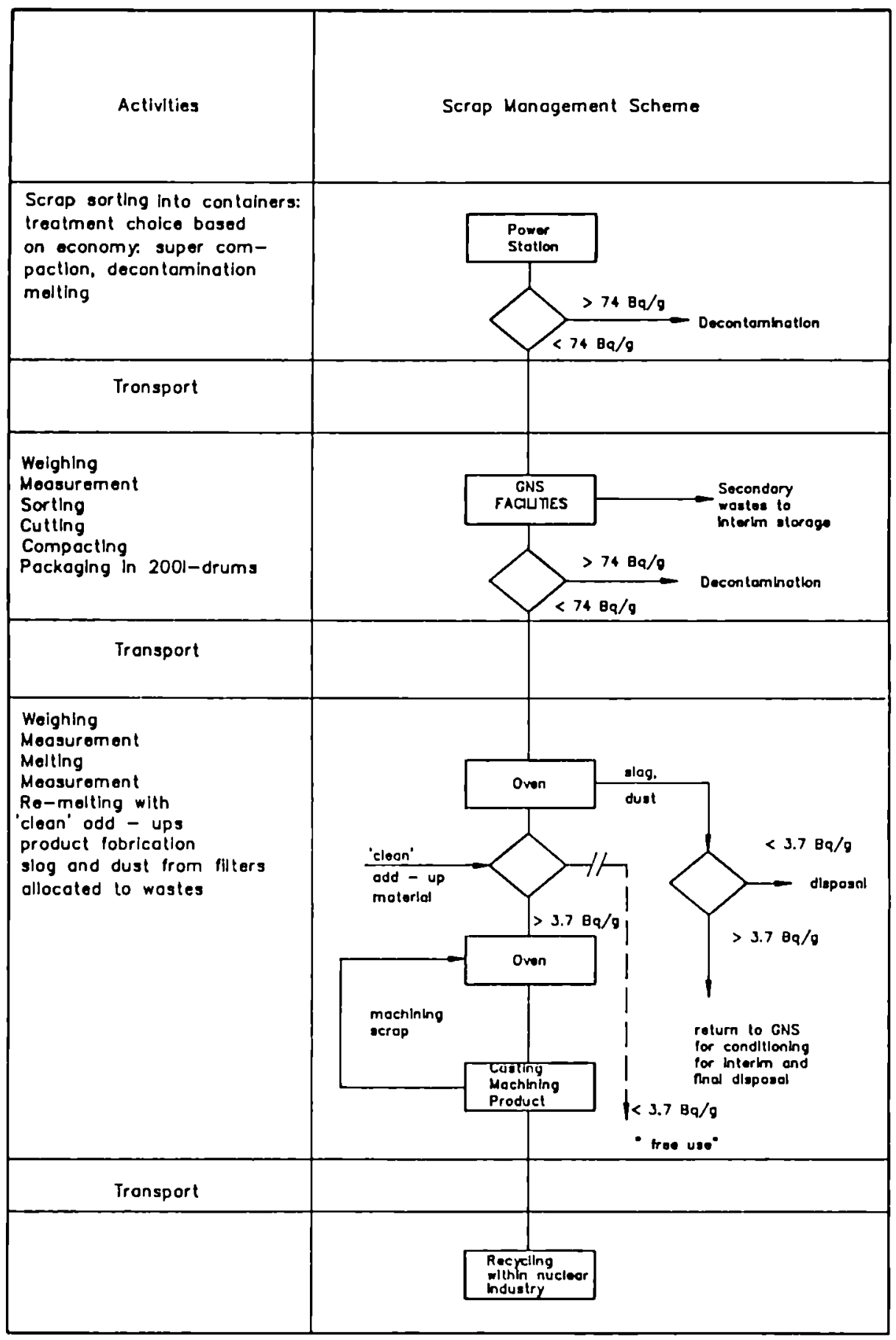

Figure 1: Scrap Management - STATUS 1987 


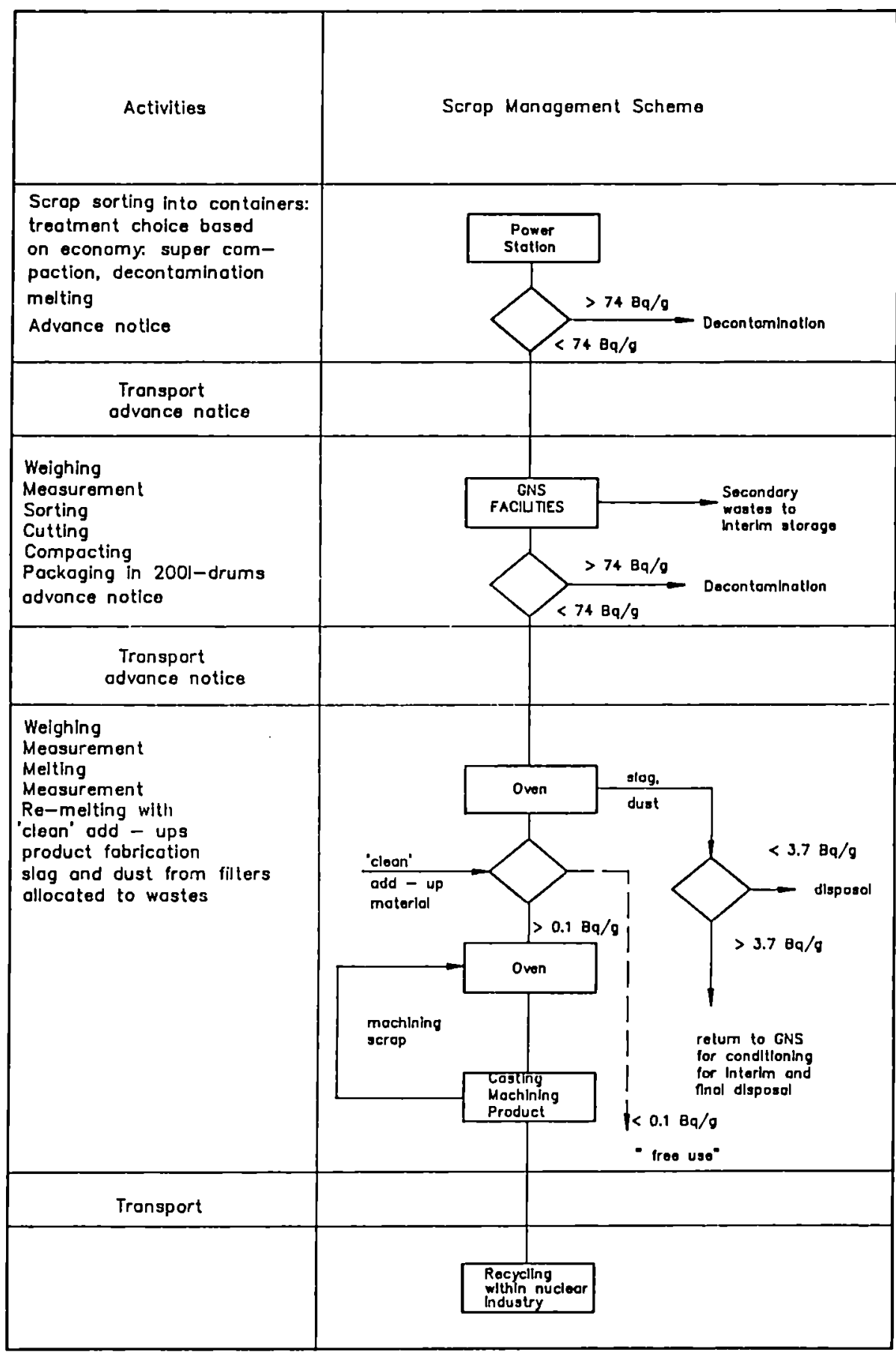

Figure 2: Scrap Management - STATUS 1989 


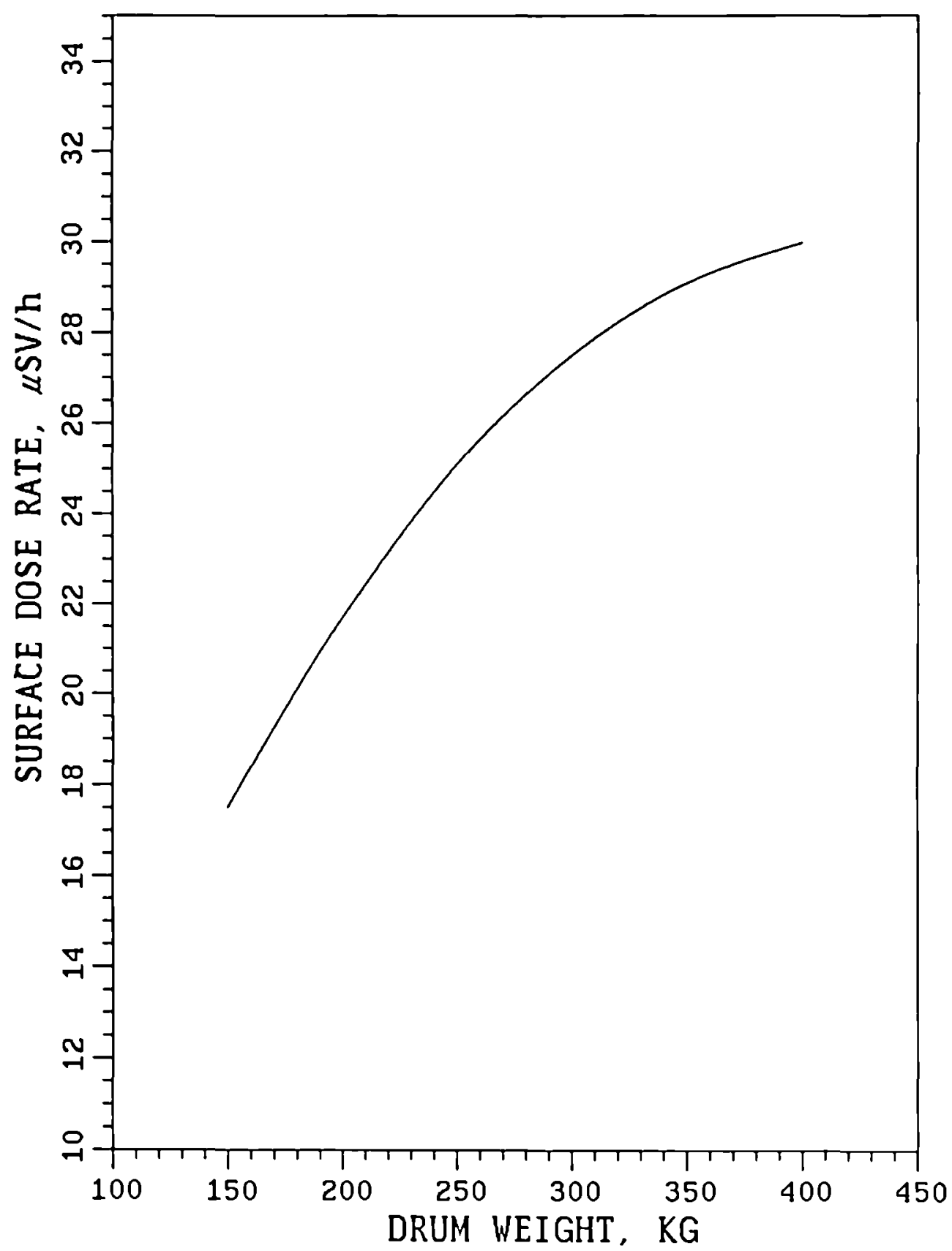

Figure 3: Dose-rate as a function of drum weight for an averaged activity of $37 \mathrm{~Bq} / \mathrm{g}$ Co60 
KEY PARAMETERS FOR THE SAFE AND ECONOMICAL RECYCLING OF CONTAMINATED STAINLESS STEEL.

\author{
HEBRANT P. \\ WESTINGHOUSE EUROPEAN SERVICE CENTER, \\ NIVELLES, BELGIUM.
}

\begin{abstract}
The decontamination and recycling of 8 tons of piping

removed from a nuclear power station in Belgium has been used by Westinghouse as a test case to evaluate the key technical and economical aspects associated with the recycling of large quantities of stainless steel material.

The selection of the decontamination process, the method used to measure the residual activity after decontamination and the amount of waste generated by both the decontamination and the melting, are discussed in detail. The economical data extrapolated to large quantities are shown to justify the selection of recycling as opposed to long-term storage.
\end{abstract}

1. INTRODUCTION

After the modifications to the residual heat removal system at the Tihange 1 plant in Belgium in 1986, the plant operators were faced with the problem of having to dispose of large quantities of contaminated stainless steel piping and valves. The dose rate at contact was ranging from 100 to $3000 \mu \mathrm{Sv} / \mathrm{h}$. Because the cost for conditioning and long-term storage was significant, different other solutions were studied. The one finally chosen was to decontaminate the material to a level where it could be released for unrestricted use in non-nuclear applications.

As Belgian regulations do not presently allow the release of nuclear material, a scheme was selected whereby the decontaminated piping would be melted in a licensed foundry, machined into shielding blocks and returned to the Tihange plant. In addition to substantially reducing the volume and activity of the scrap, this scheme allows for reuse of the material and accurate determination of its remaining specific activity, opening the way for its eventual release should new regulations permitting this be introduced. The overall operation was contracted to the Westinghouse European Service Center located in Nivelles, Belgium.

2. SEQUENCE OF OPERATIONS

The sequence of operations is showed in figure 1.

The material was transported from the plant to the westinghouse Service Center in two qualified containers, each having a volume of $20 \mathrm{~m}^{3}$. It was then cut into pieces and separated into batches of increasing contamination, such as to optimize the chemical decontamination and reduce the radiation dose to the personnel.

After the decontamination, the material was carefully

monitored and transported to Siempelkamp in Krefeld, FR Germany, where it was melted into shielding blocks weighing $28 \mathrm{~kg}$.

Samples were taken during the melting in order to determine

the remaining activity of the metal, and the blocks were shipped to the Tihange plant. 


\section{Key Parameters for the Safe and Economical Recycling of Contaminated Stainless Steel}

Figure 1 - Operations Diagram

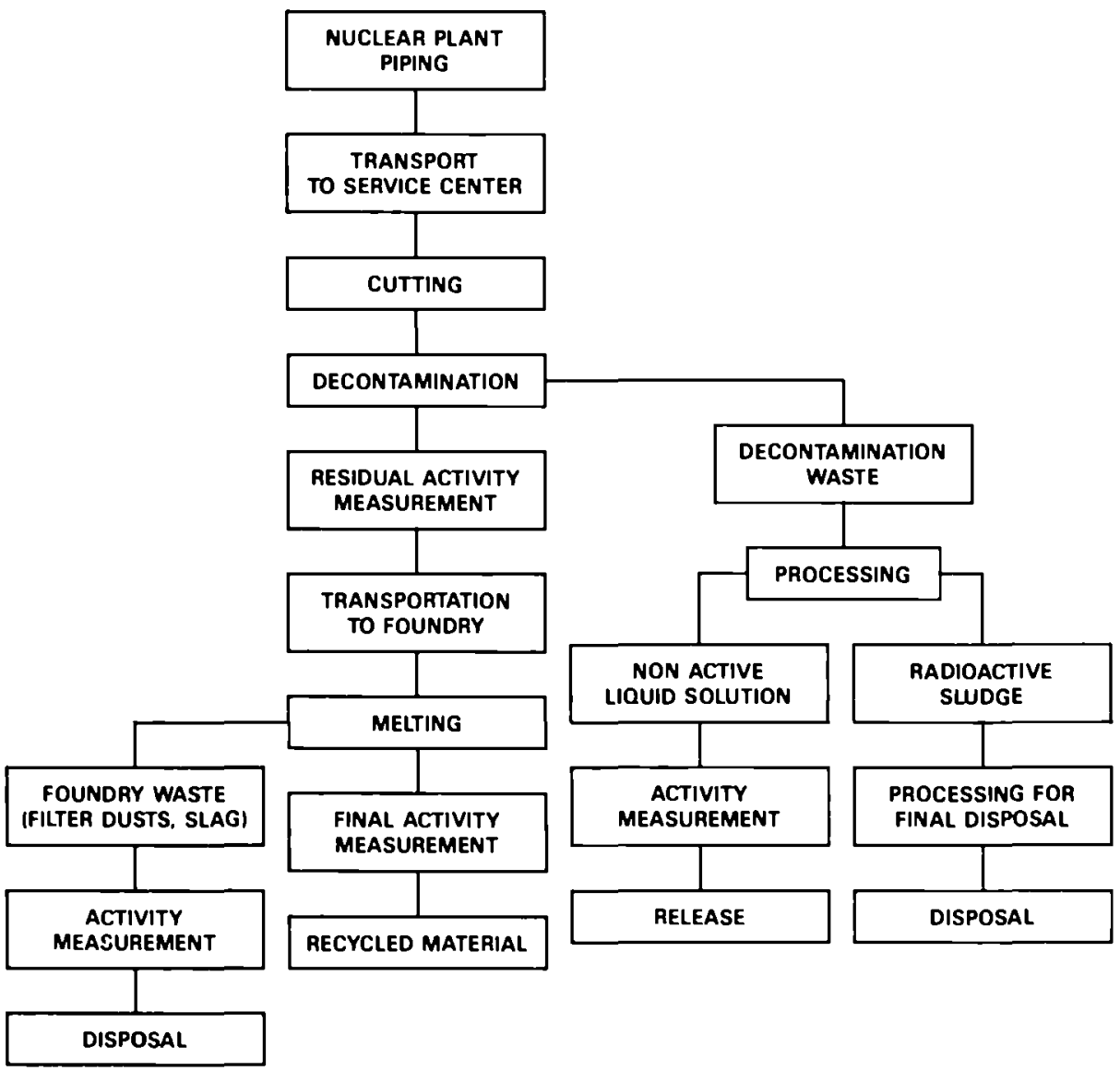

A FEW NUMBERS FROM THE RECYCLING OF THE TIHANGE 1 STAINLESS STEEL PIPING

- INITIAL VOlUME OF CONTAMINATED MATERIAL: $40 \mathbf{~ M}^{3}$

- total Weight: 8 TONS

- QUANTITY OF RADIOACTIVE WASTE TO BE fINALLY DISPOSED OF: 50 liters OF DECONTAMINATION WASTE AND 163 KG OF FOUNDRY WASTE (DUST, SLAG, ...) 
3. THE CONAP PROCESS

To be fully acceptable for use in a recycling operation,

a decontamination process must be very efficient, use small quantities of low-cost chemicals, generate minimal quantities of waste and use simple and inexpensive equipment.

Among the chemical decontamination processes presently

available, the Conap process, developed by Nuclear Services N.V., of Belgium is the one which best fulfills these requirements. Its efficiency is high : decontamination factors of 10,000 have been measured in routine applications on nuclear plant equipment. The process basically uses low-cost chemicals which allow a very efficient waste treatment and is applied at atmospheric pressure at a temperature of $90^{\circ} \mathrm{C}$.

The process comprises four phases (a) an alkaline

pre-treatment, (b) an oxidation phase with potassium permanganate in an acidic media, (c) a dissolution phase using oxalic acid as complexing agent and (d) a rinsing phase. The metal to be decontaminated is sequentially immerged in the four solutions; this represents one cycle. Two or three cycles are normally needed to decontaminate the material to the required level.

4. MEASUREMENT OF THE RESIDUAL ACTIVITY AFTER DECONTAMINATION Each step of the decontamination was closely monitored;

standard ratemeters were used until the decontamination had progressed to a point where an evaluation of the remaining activity in the material as a whole could be carried out.

This evaluation was achieved using a germanium detector

mounted on a mobile cart and coupled to a computer software specifically developed to assess the activity of material packed in closed containers.

Preliminary measurements indicated that over 90 percent of

the piping could be decontaminated to less than $1 \mathrm{Bg} / \mathrm{g} 10.8 \mathrm{Bg} / \mathrm{g}$ for

$7.5 \mathrm{t}$ of piping). The remaining $500 \mathrm{~kg}$, essentially composed of valves, instrumentation taps and one elbow showed a residual activity of $5 \mathrm{MBq}$, corresponding to $10 \mathrm{~Bq} / \mathrm{g}$.

In view of the very low activity of the bulk material, no

attempt was made to decontaminate further the "hot" parts, and the 500 $\mathrm{kg}$ was added to the $7.5 \mathrm{t}$, resulting in an overall specific activity of $1.3 \mathrm{~Bq} / \mathrm{g}$.

This figure is remarkably close to the activity of $1.4 \mathrm{Bg} / \mathrm{g}$

measured on the samples taken during the melting, and confirms that gamma scanning; coupled to a good computer software can give reliable information on the residual contamination of steel equipment, even at an activity level as low as $1 \mathrm{~Bq} / \mathrm{g}$.

The measurements were taken on batches of approximately

$350 \mathrm{~kg}$, and a counting time of 400 seconds was used for each batch, resulting in a total counting time of $2.5 \mathrm{~h}$ for the 8 tons. However, this time does not include the handling time, associated with counting, estimated to be around 12 hours.

The excellent match obtained between the gamma scanning

and the radio analysis of the melted metal is undoubtedly due to the large number of measurements. It is not possible to evaluate the accuracy of the individual measurements.

One of the developments planned for the end of this year is

to obtain a better information on each measurement's accuracy, using for this purpose the decontamination of some 16 tons of stainless steel material still to be decontaminated at the service center. 
5. DECONTAMINATION WASTE DISPOSAL

The major advantage of Conap however is the very low

volume of secondary waste it generates. For the decontamination of 8 tons of piping, the final volume of treated waste was less than 50 liters. This exceptional performance is achieved by a specially developed waste processing method based on co-precipitation.

The first step of this process consists of mixing the

oxidizing and the complexing solutions to decompose the oxalic acid. The second step is the co-precipitation of the activity into a sludge essentially made up of manganese dioxide originating from the decomposition of the permanganate. In this step, 99.99 percent of the activity associated with the cobalt isotopes is separated from the solution, and precipitates with the sludge. After separation from the sludge, the specific activity of the solution is less than $500 \mathrm{~Bq} / \mathrm{l}$, and can normally be released. The sludge is then dried, achieving a total volume reduction factor well above 50 between the original volume of the decontamination solutions and the final volume of radioactive waste.

The waste resulting from the melting must be added to those

generated by the decontamination. However, the total quantity is very low : only $163 \mathrm{~kg}$ of contaminated foundry and dust must be added to the $50 \mathrm{l}$ of decontamination waste. The total process has in fact reduced the $40 \mathrm{~m}^{3}$ of piping to $1 \mathrm{~m}^{3}$ of shielding blocks and 2 drums of radioactive waste.

6. ECONOMICAL ASPECTS

In the case of the piping removed from the Tihange plant,

the only economical constraint imposed on the recycling scheme was to be cheaper than the disposal and long-term storage as applied to the other waste generated by the plant. In Belgium, as in other European countries, it is generally assumed that the cost for conditioning and final disposal of radioactive waste is in the range of 2,500 ECU per 2001 drums, corresponding to some 20 ECU per $\mathrm{kg}$.

Obviously, the recycling of 8 tons cannot be a good illustration of a large decomissioning project. In fact, this small operation could be done economically only because the investment both in development and hardware was minimal, since the technique and the equipment are used on other applications.

However, enough information was gathered from this experience to establish with a reasonable accuracy what would be the cost associated with the recycling of a large quantity of stainless steel.

Figure 2 shows what would be the cost to decontaminate to free release and melt into ingots a nominal quantity of 1,000 tons.

The total cost is well below the $20 \mathrm{ECU} / \mathrm{kg}$ quoted earlier in this presentation. It is interesting to see that the costs of decontamination and melting are similar. This means that if the resale of the decontaminated material on the scrap market was accepted, the cost for disposing of the material would be cut by some 50 s.

No credit has been taken for the sale of the material.

This could be done, but the impact on the profitability of the operation would be minimal.

The decision to recycle has to be made to avoid the long-term storage and not to recover the material.

There is no doubt that conditioning and storing, in addition to be unreasonable in terms of resource management, would also be considerably more expensive. 
KEY PARAMETERS FOR THE SAFE AND ECONOMICAL

RECYCLING OF CONTAMINATED STAINLESS STEEL.

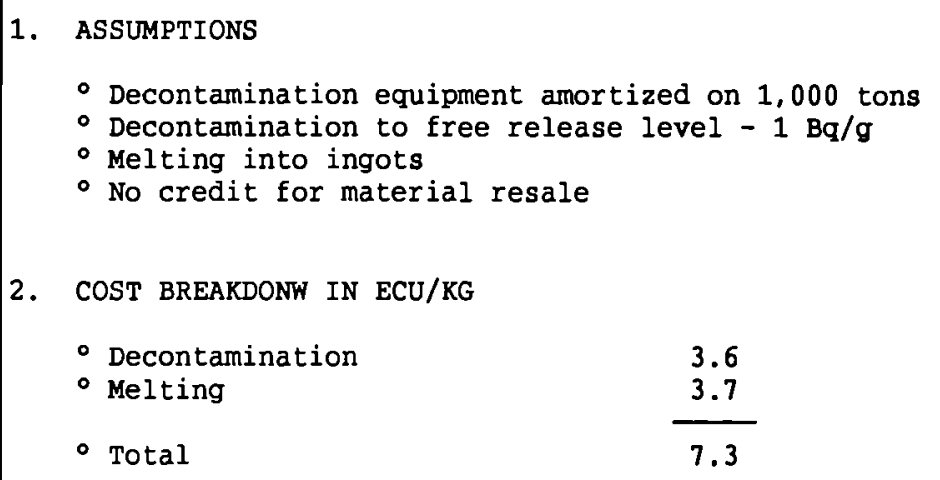

Figure 2 - Economical aspects

CONCLUSION

This experimental recycling of 8 tons of stainless steel

has brought several interesting informations. First, it has demonstrated that large quantities of equipment and piping with a significant contamination resulting from a long operation in a LWR system can be easily decontaminated to levels considered for free release.

This is an important information in view of the upcoming need to decommission nuclear power stations. As the decontaminated material was coming from a syṣtem very close to the reactor vessel, it is assumed that virtually all the stainless steel equipment which has been protected from direct irradiation by the core can be decontaminated.

Second, the decontamination when applied with a good process, does not generate large quantities of waste.

Third, the measurement of the residual contamination, which is often seen as an obstacle to free release, can in fact be made reliably and easily by global methods such as the gamma scanning.

As a conclusion, it seems reasonable to envisage the decontamination and free release of all the stainless steel equipment from a decommissioning light water reactor, except for the part directly exposed to irradiation from the core. With respect to this part, storage still remains the solution, while required storage containers and shielding would be made from carbon steel material too difficult to decontaminate. 
A UTILITY VIEW OF DECOMAISSIONING A GAS-COOLED REACTOR

\author{
McOWAT, P. \\ South of Scotland Electricity Board, \\ Glasgow. Scotland
}

\begin{abstract}
The South of Scotland Electricity Board has begun preparation for the deconisaloning of Hunteraton 'A' Power Station which has two Magnox Gas-Cooled Reactora, comissioned in 1964. Decomissioning w111 take place in three stages, renoval of fuel, renoval of extermal plant, and disanting of the reactor 1tself. Th1s paper is concerned with non-technical aspects, beginning with the inltial planning and the preparation of the necessary papers required by the regulatory authorities "Stage 0". Attention 1s drawn to the large comitnent of speclalised resources needed at this stage. Personnel matters and local lialson are also discussed and the desirability of early work in these areas is highlighted. The tining of stage 2 work 1 s considered and several alternatives are noted. Some implications of site redevelopment are also discussed. It is concluded that non-technical aspects of decomissioning require early consideration and the provision of significant resources, but they should not cause undue delays or cost Increases in the work.
\end{abstract}

\title{
1 INTRODUCTION
}

The SSEB Is a utility covering the south of Scotland, the main industrial area of the country. It has a total installed generating capacity of $9308 \mathrm{MH}$ of which $3044 \mathrm{MH} 1 \mathrm{~s}$ nuclear. There are three nuclear power atations, Hunterston ' $A$ ' which has two nagnox reactors, Hunterston 'B' whlch has two AGRs and Torness with two AGRs, the second of which was comissioned last year.

Hunterston ' $A$ ' was comissioned in 1964 with a total generating capac Ity of $360 \mathrm{MH}$. The magnox reactors use natural uraniun fuel clad in magnox, cooled with carbon dioxide and contained in a spherical steel pressure vessel. The 8 bollers are outside the reactor shielding, but are contained in a weatherproof building (FIgure 1). On-load refuelling is carried out by charge nachines situated beneath the reactors. The fuel elements go to a desplittering unit were graphite sleeves and some nagnox nembers are removed and put into a waste store. The fuel rods are then sent to the Cartridge Cooling Pond to avalt despatch to British Nuclear Fuels plc (BNF) for reprocessing. The on-load refuelling system is designed to replace the fuel continuously during normal operation, so a high rate of fuel removal is not required.

The station has been very rellable, being at the top of the Nuclear Engineering International league table for eany years, but changing econonics require that future operation is kept under continuing review.

Over the last 10 years a abstantial background of information on the decomiseioning of gas-cooled reactors has been built up through studies in collaboration with the Central Electricity Generating Board and the United KIngdon Atonic Energy Authority. 


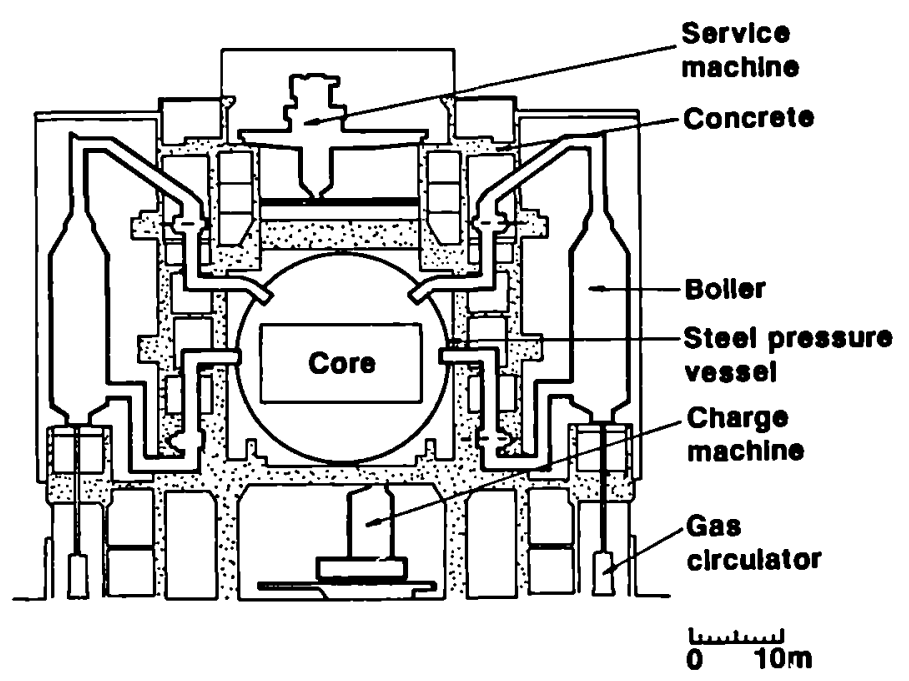

FIGURE 1 HUNTERSTON 'A' SCHEMATIC

Decommissioning w111 take place in three stages;

Stage 1 removing fuel fron the reactor and transporting $1 t$, and any fuel in the cooling ponds, to BNF for reprocessing. This may take about 5 years to complete.

Stage 2 removing all plant outside the reactor shielding and maintaining and supervising the reactors and shielding until the start of Stage 3 .

Stage 3 the clearance of reactors and shielding.

However, in addition, the preliminary planning work, the preparation of the safety cases, and obtaining approvals, require sufficlent effort and time as to constitute a separate Stage 0 , which must be fully taken into account in planning and programing the overall decommissioning procedure. This paper deals with this and other non-technical aspects of the decomisissioning process which have had less public attention than technical work, but which nevertheless have an important effect on the costs and programing of the decommissioning.

\section{REGULATORY REQUIREMENTS}

The Regulatory Authorities require that the arrangements made for ensuring safety, 1.e. the supervisory safety structure and management arrangements, should be submitted for their approval prior to decomissioning (1). They also require that programmes with phased decommissioning should be submitted for approval and specify that consent nay be required before proceeding from one phase to the next. In addition, there is a requirement for information on policy, final objectives, timetable and man-dose for all three stages, and overall strategies for decomissioning and waste management based on an examination of options. This ensures that the full programme is considered and planned through to the end of stage 3, albelt with reduced detail in the later stages. The changeover from the arrangements for an operating station to those appropriate to a decommissioning station, must be carefully specified to avoid ambiguities and overlap. 
Clearly, once decomissioning has begun, much of the plant will no longer be in operation and will not need further aalntenance giving reduced requirements for operating and antenance saff. However, changed procedures cannot be adopted, unt1l revised Kaintenance, Inspaction and Test Schedules have been drawn up and foranlly approves. The defuelling carried out in Stage 1 will take place under different conditions from those of nomal operation, since new fuel is not being loaded and the size of the fuel inventory, and Its decay heat, are continuously reducing. Changes in operating methods will therefore have to be taken into account and revised Operating Rules and Procedures drawn up and approved.

Compllance with Article 37 of the Euraton Treaty on the disposal of radioactive waste 1s required. Although the disposal of vaste connected with the defuelling operation is likely to be an extension of the methods exployed in noral operation and will not require much additional information, the disposal of intermediate level waste is not at present a normal operational activity and may require a submission and approval prior to the National Authority being able to issue an authorisation.

The renoval of any radioactive equipment, whether for re-use - lsewhere, or for disposal, will require a subnission and since the timescale for approval may be protracted, detalled planning several years in advance is necessary.

The work Involved in the preparation of the eafety cases to form the basis of the above requirements, and of the other control paperwork requires many man years of spectallsed resources. Careful planning of the production of this documentation 1 s required to ensure that unnecessary delays do not occur in obtaining consent to begin defueliling, or in carrying out the planned changes in the number of staff employed, on the station.

\section{PERSONNEL MATTERS}

As mentioned above, a decomissioning power station clearly requires fewer staff than a fully operational station. For a magnox station, during Stage 1 , the staff numbers required may be around 30 s to 50 of those employed before shutdown. The actual number will depend on whether it is a dual site shared by an operating station, and on factors such as the requirenents for cover for the Site Emergency Plan, Fire Fighting, control roon manning otc. Although the actual numbers needed may require sone time to finalise, it is important that saff should bo kept fully inforwed, and trade union consultation begun at an early stage to reduce the element of uncertainty as far as practicable. Preferred alternatives for presentation to the taff Include transfer to other jobs within the company or early retirement, and individual counselifing should be carried out as a priority.

In addition to the need for a planned reduction in numbers on the station following receipt of consent, it is necessary to ensure that the requisite quality of staff is retained to fulfil the Stage 1 requirements. In particular, it is recognised that stage 1 defuelling will be seen as work with low job satisfaction (since the station 1a no longer generating electricity). In addition there may be a foeling that the work has poor job prospects, since at the end of stage 1 further job losses will occur. This may result in the nost ablo staff opting for transfer, or oven moving to new jobs before station closure actually occurs. If this is not counteracted, the 
lower abilities of the remaining staff could lead to delays in the Stage 1 programme.

\section{STAGE 2 PROGRAMMING}

The conventional view of stage 2 is that all the plant and waste removal ill take place immediately following Stage 1. In the UK, a repository for intermediate level waste will not be avallable until the year 2005 at the earliest so plant or waste which is removed and packaged will have to be stored on site until at least that year.

The majority of contamination in Magnox gas circuits is due to cobalt 60 , so a reduction in radiation levels by a factor of 10 will occur over a period of some 15 years. A considerable reduction in man-dose can therefore be obtained if delagging, cutting, handling and packaging are postponed, particularly where the lagging is asbestosbased with the consequent high labour content. In addition the effective cost for these activities will be reduced due to the effect of discounting over the period. There is therefore, considerable incentive to consider leaving plant in its present position for as long as practicable. Countering these benefits are the requirements for preparation for in-situ storage, and for maintenance and supervision, all with attendant dose and cost penalties. In addition, the dalay in making the land available for development will also need to be taken into account.

It is likely that the optimum timing for dismantling will be greater than 15 years for some items, since the decay of cobalt 60 continues to provide a benefit up to about 30 years, when the longer lived isotopes become predominant.

At present, this longer storage time would be contrary to UK Government Policy which states that low and intermediate level wastes should be disposed of as soon as possible to avoid the provision of costly and extensive storage facilities (2). However, it is interesting that the European Parliament recently endorsed a proposal for the funding of a decommissioning development programme, based on the reasoning that "it is neither urgently necessary nor desirable to move on to the industrial stage", 1.e. the dismantling of plant (3). It is likely to be in the public interest that the UK Government Policy Statement should be reconsidered to permit greater flexibility.

It is anticlpated that some items (perhaps water treatment plant sludges and fuel element wastes) should be treated early after stage 1 , so 1 it is likely that stage 2 will be divided into several sections taking place at intervals, with storage and monitoring of the remaining plant between sections of work.

\section{REDEVELOPMENT}

Between the completion of Stage 2 and the start of Stage 3 , the area of land occupled by the reactors and any site storage will be relatively small and there is a possibility of re-using the site. Planning permission would be required and a public enquiry may be called for, but 1t would be expected that these should be less onerous and csuse less delay than for a green-field site. However, the requireusnts for a new power station, which might be built 10 years after the original station is shut down are likely to be different from those for the original station designed for the technology of 30 years previously. In particular, the ability of the site to dissipate the waste heat associated with a modern large power station may not be adequate. 
Redevelopment of part of the site would help the provision of security and supervision for the existing reactors. However, after one, or perhaps two stages of redevelopment, there will be no further useful area so operational activities on site will end. All the renaining structures will then have to be suitable for an econonic level of security and supervision.

The local population will be concerned about what is to happen to the station, and particularly, whether any health hazard nay arise or whether there nay be any other detrinental effects such as noise, heavy traffic etc. Since no najor nuclear power station has yet been decomissioned in the UK, there is little public understanding as to what is entalled and how the work will be carried out and controlled.

In addition, the closure of a power station and the reduction of the workforce will mean a reduction of incone to the local econony which could be ignificant if there is little other industry in the surrounding area. Close liaison with the Local Authority is necessary fron an early stage to ensure that the position is clearly understood, together with a public inforwation programe.

Good communications with the press and other media are also important in this area.

\section{CONCLUSION}

Fron the above discussion, it is clear that there are some uncertainties at present which could affect the decomissioning programme, particularly concerning the ragulatory interpretations and the tiaing of stage 2 operations. However, providing careful planning is carried out and flexibility is maintained in the programe with appropriate margins, decomissioning can be achieved in a way which will satisfy the requirements of the regulatory authorities and of the utility.

\section{REFERENCES}

1 Regulatory Procedures for the Decommissioning of Nuclear Installations, P.B. Woods, P.K. Basu, International Seminar on Decomnissioning of Nuclear Facilities, July 1988, London.

2 "Radioactive Waste. The Governnent's Response to the Environmental Comiltee's Report" Cand 9852.

3 "Proposal for a Council Decision Adopting a Research and Technology Development Programe for the EAEC in the field of Decommissioning Nuclear Installations (1989-1993) (COM(88)415 -DOC. (2-145/88). 


\section{DISCUSSION}

Question: K H LEHMANN, TUV Bayern - (1) What are the particle sizes in the case of processing aluminium in the oven hall? (2) Which Medium Aerodynamic Diameter (MAD) was used in the dose calculation? (3) In which cases were the exemption values derived from the value for the organ dose of $0.05 \mathrm{~Sv}$ ?

Answer: H GARBAY, CEA-FAR - (1) The particles have sizes ranging from zero to several tens of micrometres. The parameters characterising the particle sizes are the Medium Aerodynamic Diameter (MAD) and the Standard Deviation of the distribution (SD). Three aluminium melting experiments in the oven hall (which are not representative of an industrial plant) were performed; thereby the particle parameters were determined as follows:

$\begin{array}{cll}\text { Melt } & \text { MAD ( } \mu \mathrm{m}) & \text { SD } \\ \text { A } & 0.833 & 2.89 \\ \text { B } & 1.08 & 3.384 \\ \text { C } & 1.24 & 5.21\end{array}$

(2) In an unperturbed atmosphere, particles of aerodynamic diameters greater than 10 to $15 \mu \mathrm{m}$ will be deposited in the nasal and buccal cavities without the risk of penetration into the lower respiratory tract. In the dose assessment the diameter defining the limit of the inhalable particles is taken equal to $13 \mu \mathrm{m}$; mean inhalable dust concentrations are then $3.3 \mathrm{mg} / \mathrm{m}^{3}$ in the industrial aluminium refining plant, and $0.54 \mathrm{mg} / \mathrm{m}^{3}$ in the experimental melting hall.

(3) The exemption values are derived from the value for the organ dose of $0.05 \mathrm{sv} / \mathrm{a}$ if the dose is delivered in contact or very close to a specific organ; in this case, the effects of ionising radiations are non-stochastic effects. The dose limit recommended by the ICRP to prevent these effects is $0.5 \mathrm{~Sv} / \mathrm{a}$, a protection factor of ten being taken.

Question: R NEIDER, BAM - What was the dilution considered for radioactive materials in the industrial plants?

Answer: H GARBAY, CEA-FAR - In cases of dose assessment for workers in industrial plants, the dilution factor corresponds to the fraction of very slightly radioactive material entering the factory, compared to the total plant consumption of scrap. In the case of dose assessment for use of manufactured materials, the dilution factor is equal to ten in most cases.

Question: S ALAMO, INITEC - According to the importance given by Mr McOwat to the 'paperwork' in a decommissioning process (safety cases, design operations, new or modified procedures, environmental reporting, etc), in your case or in your opinion, which are the organisations to be involved in these activities? Should an organisation similar to an architect engineer or similar be heavily involved? How long in advance of the beginning of the decomissioning operations should the paperwork start?

Answer: P McOWAT, SSEB - In your case the station design organisation does not exist in its original form but any support of that type is very useful. Contractors can also do the work, but if they are not familiar with the plant and its history, a considerable learning time may be required. A large part of the effort must always come from the operating organisation.

The operator should begin planning for decommissioning many years before shutdown is expected. The possibility of forced early shutdown should be taken into consideration. However, working out too much detail too much 
in advance 13 likely to be rendered obsolete by changes in regulatory requirements, and in technology.

Question: J GERARD, FBFC - How do you measure alpha-contaminated scrap coming from fuel manufacturing plants before, during and after melting?

Answer: MSAPPOK, Slempelkamp - Before melting, the alpha activity is measured by a contamat. After melting, samples are taken from metal, slag and filter dust.

We are required to make nuclide-specific measurements. That means that the sample must be dissolved in acid and the nuclides he separated by chemical methods. Finally, an alpha spectrometer is used to determine the specific activities.

\section{CONCLUSION}

We have had three presentations about the radiological impact of the recycling of very slightly radioactive materials and several important questions concerning the procedure. Mrss Garbay described scenarios used to evaluate the individual risk from recycling of copper, aluminium and PVC. She used recommended dose levels of $10 \mu \mathrm{Sv} / \mathrm{a}$ for the general public and $50 \mu \mathrm{Sv} / \mathrm{a}$ for occupational exposure; the latter seems to me a new approach.

Mr Janberg compared the costs of decontamination with those of melting and direct disposal. He came to the conclusion that scrap metal melting has a good public image and seems to have a decisive advantage, and more applications have been found for the molten material.

Mr Hebrant described the melting of $8 \mathrm{t}$ of stainless steel and came to the conclusion that it seems reasonable to envisage the decontamination and free release of all stainless steel equipment from the decommissioning of an LWR, except the parts directly exposed to neutron irradiation.

The last contribution, from Mr Mcowat, discussed the decomissioning procedure of Magnox gas-cooled reactors. He stated that today there are still some uncertainties which could affect the decommissioning programme. But he was confldent that decommissioning can be achieved in a way which wil satisfy the requirements of the regulatory authorities and of the utility.

I thank all the speakers for their presentations and all those who contributed to the discussion.

R NEIDER, BAM 



\section{PLENARY SESSION XIV}

\section{LARGE-SCALE DECOMMISSIONING OPERATIONS}

CHAIRMAN: A CREGUT, CEA, F

SECRETARY: E SKUPINSKI, CEC 


\title{
LARGE-SCALE APPLICATION OF SEGMENTING AND DECONTAMINATION TECHNIQUES
}

\author{
Stang Wolfgang, Fischer Alfred \\ Kernkraftwerke Gundremmingen Betriebsgesellschaft mbH \\ Gundremingen, F.R.G. \\ Rubischung Peter \\ Nusec GmbH Buxtehude, F.R.G.
}

\section{ABSTRACT}

In cooperation with the Commission of the European Community the nuclear power plant KRB A started in 1985, Investigations into decomissioning techniques in order to select effective segmenting and decontamination methods for large-scale applications. Several techniques have been tested and applied to approx. $300 \mathrm{Mg}$ of varfous components out of the turbine house with special regard to efficiency, costs, dose and amount of secondary waste production. In the framework of this research programme a procedure for regeneration of phosphorlc acid was successfully introduced. Several techniques for detecting low residual activity are also briefly described.

\section{INTRODUCTION}

The nuclear power plant KRB A was constructed between 1962 and 1966 and operated by a partnership of Rheinisch-Westfalische Elektrizitätswerke and Bayernwerk. The bolling water reactor (250 MW.) with a primary and an additional secondary steam system has generated about 15 billion kilowatt hours during 11 years of operation. The nuclear power plant was shut down due to an incident which occurred in 1977 after a short circult in the grid involving subsequential damage to the plant.

Because of considerable high costs for backfitting the shareholders declded in 1980 to decommission the plant. Actual decommissioning work began in 1982 and has continued unt 11 now. The first decommissioning step was to dismant le and to decontaminate the shut down systems in the turbine house. Unt 11 now, about $3500 \mathrm{Mg}$ vartous materlals have been removed (table I). The a im was to reduce the radioactive waste volume as much as possible and to reclaim usable materials. Thereby KRB A released most of these residues after decontamination either for unrestricted reuse or for recycling in the nuclear market 1 . e. by producing cast iron waste containers.

The cooperation with the Commisston of the European Community concerning activities mentioned in this paper started in 1985 . The aim was to develop and test different cutting and decontamination techniques, as well as surveying methods for the very low residual activity for subsequent large scale-applications. The tests involved dismantling $300 \mathrm{Mg}$ material out of the turbine house. Economic and radiological considerations as well as waste quantities have been the main criteria of the evaluation. 
Table I: Dismantled scrap and waste of turbine house

\begin{tabular}{|l|c|c|l|}
\hline Material & $\begin{array}{c}\text { Mass } \\
(\mathrm{Mg})\end{array}$ & $\begin{array}{r}\text { Percentage } \\
(\%)\end{array}$ & Release \\
\hline Metal & 1212 & 34 & \\
Concrete & 517 & 15 & Unrestricted \\
Electric components & 301 & 8 & \\
Lubricating 01 & 56 & 2 & restricted \\
Insulation material & 31 & 1 & for recycling* \\
\hline Metal & 1357 & 38 & to final \\
& & 2 & storage \\
\hline Low active waste & 82 & 100 & Status June 1989 \\
\hline Total & 3556 & &
\end{tabular}

\section{CUTTING TECHNIQUES}

\subsection{Laboratory tests}

The common cutting techniques like sawing, torch cutting and grinding have been investigated on contaminated steel components in order to optimize the dismantling and segmenting methods taking account of economic aspects and radiological requirements. Different ferritic components with a contamination up to $1000 \mathrm{~Bq} / \mathrm{cm} 2$ have been cut on a test facility as shown in figure 1 .

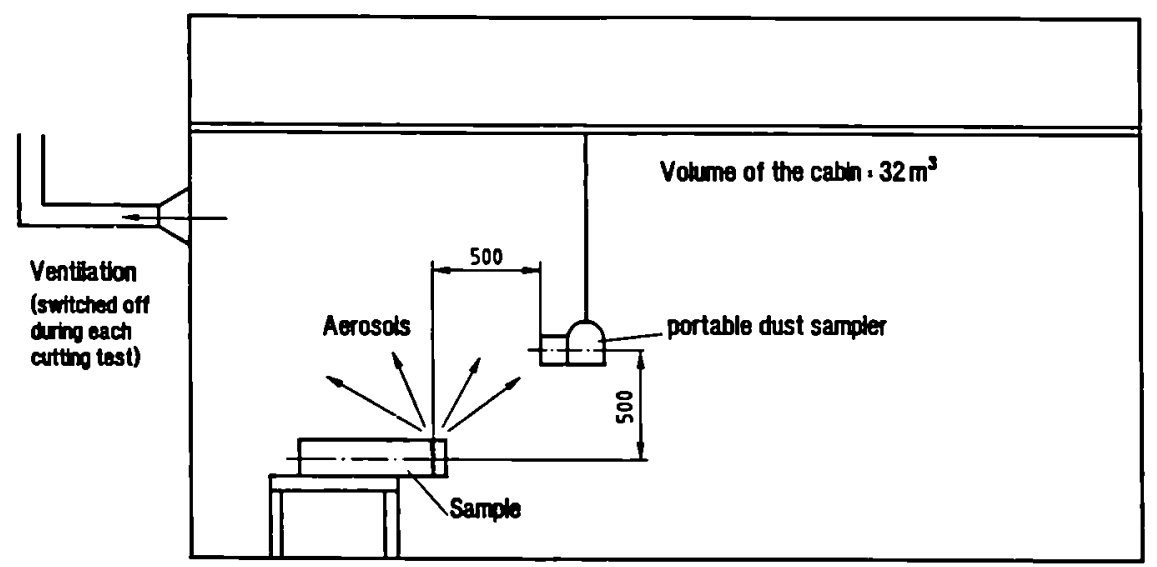

Figure 1: Cutting test facility 
It was recognized that sawing is the most preferable method because of the lowest release of radioactive aerosols and acceptable efficlency. Torch cutting produces more aerosols but has the advantage of more flexibility in case of adverse circumstances such as curved cuts, thick walls and large diameters. If saws and other mechanical tools or machines cannot be used for the removal of components in situ 1. $\theta$. because of narrow rooms or difficult accessibility, torch cutting is the best subtitute. Grinding is recommended only for cutting very low contaminated non-ferrous metals and stainless steel with thin walls. By grinding the release of radioactive aerosols is relatively high. Therefore large-scale grinding has been applied only to low contaminated components like thin tubes or small bars. Due to health protection considerations torch cutting or grinding requires alr cleaning systems and mask protection for the working personnel. Figure 2 indicates the airborne aerosol concentration versus the initial contamination of the material for different cutting techniques.

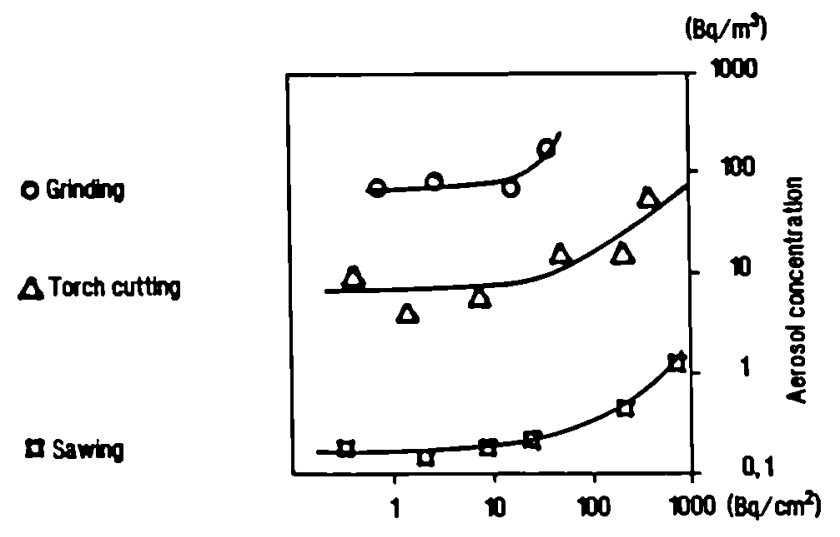

Contemination of the workplece

Figure 2: Airborne aerosol concentration versus initial contamination depending on cutting techniques

\subsection{Large-scale applicat tons}

2.2.1 Condenser tubes and plates

After opening the cooling water inlet and outlet chambers of the main condenser about 17000 brass tubes $(23 \times 1 \mathrm{~mm})$ had to be drilled out and removed. The average contamination of the tubes was about $3 \mathrm{Ba} / \mathrm{cm} 2$, mainly co-60. During the removal the tubes of $15 \mathrm{~m}$ length were cut once in the middle for easier handling. For these cuts grinders were used. The total removal of $160 \mathrm{Mg}$ condenser tubes took about 5660 manhours with a job dose of $14.5 \mathrm{mSv}$. Because of excessive decontamination and surveying costs for unrestricted release the tubes $w 111$ be melted under controlled conditions for reusing the brass.

The ferritic support plates for the condenser tubes have been removed and cut to $2 \times 1 \mathrm{~m}$ pleces for pool decontamination. These plates $(51 \mathrm{Mg})$ with a wall thickness of $25 \mathrm{~mm}$ have been removed and segmented by torch cutting with acetylene within 550 manhours. The actual cutting time was only $20 x$ of the total effort. 80x of the time has been spent for preparation, scaffolding, transport, etc. 
2.2.2 Preheater bundles

From 5 feedwater preheaters 5 condensation and 3 recooler bundles with a total mass of $92 \mathrm{Mg}$ have been disassembled. In spite of relatively low contamination $\left(4-180 \mathrm{~Bq} / \mathrm{cm}^{2}\right)$ the decontamination of heat exchanger tubes for unrestricted release was considered to be uneconomical due to the small wall thickness $(1 \mathrm{~mm})$, large surface $\left(20000 \mathrm{~m}^{2}\right)$ and inside contamination of tubes with $12 \mathrm{~mm}$ diameter. For this reason, controlled melting of the tubes was chosen. Before shipping the material in 20'standard containers to the melting furnace, the bundles consisting of CuNiFealloy had to be segmented. Removal of the tube plates and segmenting of the bundles was executed by the arc-air procedure using graphite electrodes. Radioactive aerosols were successfully kept in limits by the use of a cutting tent with a suction flltering factlity. The personnel working in this tent had to wear protective masks. A Total of 10 cuts through preheater bundles with diameters up to $1.4 \mathrm{~m}$ required 220 manhours.

\subsubsection{High-pressure turbine}

The upper housing of the high-pressure turbine (total mass $22 \mathrm{Mg}$ ) was selected to demonstrate the segmenting of thick-walled ferritic components by using the propane-oxy torch cutting technique. Figure 3 demonstrates the velocities of torch cutting depending on wall thickness of carbon steel plates using propane or acetylene gas.

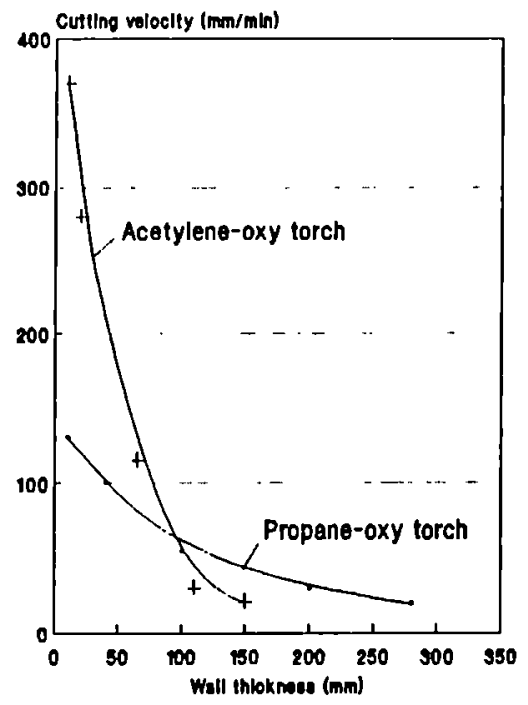

Figure 3: Velocities of torch cutting

The maximum wall thickness was $280 \mathrm{~mm}$ and the average $80 \mathrm{~mm}$. Compared with acetylene gas the propane gas offers the possibility of deeper cuts. Due to the higher gasflow of propane the melted slag is blown out very effectively. The removal of the heavy component by unscrewing the flanged joints took about 95 manhours. Segmenting for decontamination was executed under mask protection in a cutting tent equipped with suction filtering facilities. Table II indicates the effort for the subsequent cutting into smaller pleces for pool decontamination. 
Table II: Effort for cutting the upper turbine housing (22 Mg)

\begin{tabular}{|c|c|c|}
\hline & & Effort (manhours) \\
\hline 1.0 & Preparat ton works & 7 \\
\hline $\begin{array}{l}2.0 \\
2.1 \\
2.2 \\
2.3\end{array}$ & $\begin{array}{l}\text { Cutting and handling } \\
\text { Transport of the components } \\
\text { Torch cutting } \\
\text { Act ivity measurements }\end{array}$ & $\begin{array}{r}11 \\
32 \\
6\end{array}$ \\
\hline $\begin{array}{l}3.0 \\
3.1 \\
3.2 \\
3.3 \\
3.4\end{array}$ & $\begin{array}{l}\text { Subsequent treatment } \\
\text { Cutting out holes for fastening } \\
\text { Removal of slag } \\
\text { Marking all components } \\
\text { Cleaning the working area }\end{array}$ & $\begin{array}{l}47 \\
41 \\
21 \\
12\end{array}$ \\
\hline 4.0 & Documentation & 6 \\
\hline & $+15 x$ for additional works & 27 \\
\hline & Total effort for cutting & 210 \\
\hline
\end{tabular}

Costs of consumable material i.e. for filters, oxygen and propane gas have been calculated to $210 \mathrm{DM} / \mathrm{t}$. Costs for conditioning and final storage of slag and filters have been est imated to $240 \mathrm{DM} / \mathrm{t}$ related to the removed mass. The average dose rate was measured as $12.3 \mu \mathrm{Sv} / \mathrm{h}$ for cutting work and $2.5 \mu \mathrm{Sv} / \mathrm{h}$ for unscrewing.

\subsubsection{Low-pressure turbine}

Torch cutting was also applied to the segmenting of 4 heavy ferritic support plates of the low-pressure turbine. These structures consisted of $60 \mathrm{~mm}$ thick plates which stabllized the upper and the lower housing of the low-pressure turbine inside the main condenser (figure 4).

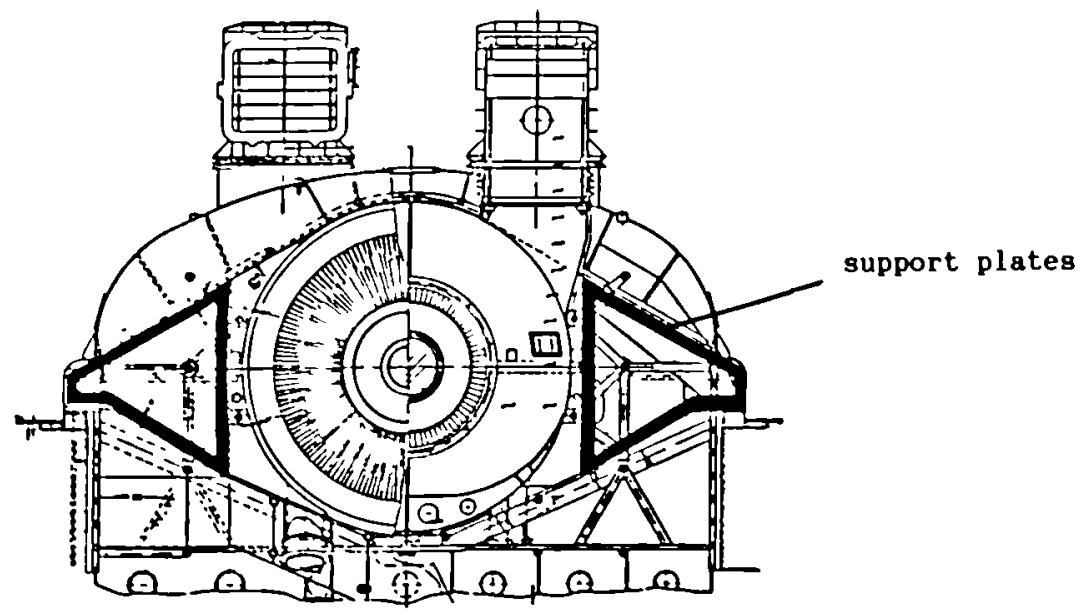

Figure 4: Supports for the housing of the low-pressure turbine 
Removal of the support plates could be executed very easily by disconnecting screws and bolts within 80 manhours. For the subsequent segmenting, propane-oxy torch cutting was also executed in a cutting tent with aerosol filtration and wearing protective masks. Table III presents a review on the segmenting effort and costs. A total job dose of $1.7 \mathrm{mSV}$ has been recorded.

Table III: Segmenting of supports

\begin{tabular}{|l|c|}
\hline Effort/Cost & $\begin{array}{c}\text { Segmenting of } \\
42 \mathrm{Mg}\end{array}$ \\
\hline Manpower & 20 manhours/t \\
Consumable material & $260 \mathrm{DM} / \mathrm{t}$ \\
Waste treatment and disposal & $240 \mathrm{DM} / \mathrm{t}$ \\
Equipment (shared costs) & $100 \mathrm{DM} / \mathrm{t}$ \\
\hline
\end{tabular}

\subsubsection{Vartous pipes and valves}

Pipes and valves of the bleeder steam and drainage system (24 Mg) have been selected to obtain representative data on removal and cutting of this group of components. The pipes of the bleeder steam system between the high-pressure turbine and the feedwater preheaters with diameters from 350 up to $1000 \mathrm{~mm}$ were selected for decontamination and subsequent release for unrestricted reuse. The drainage pipes of the high-pressure turbine $(6 \mathrm{Mg})$ with diameters less than $150 \mathrm{~mm}$, however, have been separated for melting and recycling. These latter components were found to be unfavourable for complete decontamination due to economical reasons (small wall thickness, diameter, etc.). Removal of all components was performed exclusively by torch cutting with acetylene gas because of high cutting velocities and easy handing in narrow rooms. The removed pipes of the bleeder steam system were removed in up to $4 \mathrm{~m}$ lengths and afterwards cut, by a stationary hack saw, into $1 \mathrm{~m}$ pieces for decontamination. The effort and costs for the removal and subsequent segmenting of all components are given in Table IV.

Table IV: Removal and segmenting of pipes and valves

\begin{tabular}{|l|c|c|}
\hline \multicolumn{1}{|c|}{ Work } & $\begin{array}{c}\text { Removal of } \\
24 \mathrm{Mg}\end{array}$ & $\begin{array}{c}\text { Segmenting of } \\
18 \mathrm{Mg}\end{array}$ \\
\hline Manpower & 34 manhours/t & 25 manhours/t \\
Consumable material & $190 \mathrm{DM} / \mathrm{t}$ & $190 \mathrm{DM} / \mathrm{t}$ \\
Waste treatment and disposal & $250 \mathrm{DM} / \mathrm{t}$ & $170 \mathrm{DM} / \mathrm{t}$ \\
Equipment (shared costs) & $100 \mathrm{DM} / \mathrm{t}$ & $100 \mathrm{DM} / \mathrm{t}$ \\
\hline
\end{tabular}

According to thick-walled components, the removal and segmenting of pipes and valves created relatively high mass specific costs in the case of unrestricted release. Pipes and valves with wall thicknesses less than $10 \mathrm{~mm}$ or diameters less than $250 \mathrm{~mm}$ have to be melted under controlled condttions before surveying or recycling. 


\section{DECONTAMINATION TECHNIQUES}

\subsection{Laboratory tests}

3.1.1 Combined decontamination techniques

A combined decontamination method of wire brushing prior to electropolishing with phosphoric acid was tested on different pipes out of the water-steam circuit. In general it was found that merely brushing was not sufficient to achieve complete decontamination. However, brushing prior to electropolishing resulted in $35 \times$ reduction of the time required for the galvanic decontamination process. The reduction of dissolved iron in the electrolyte is also a benefit of prebrushing.

Another combined method consisted in ultrasonic cleaning and pickling with sulphuric acid or a detergent solution of different concentrations. The test results with typical water- or stean contaminated samples have been unsatisfactory because of the tight adhering oxide layers.

\subsubsection{High-pressure water cleaning}

A test series for decontamination by high-pressure water cleaning at up to 800 bars was also executed. Decontamination to below release values could not be reached for steam- or condensate-attacked plant parts. Feedwater-attacked samples could partially be decontaminated for unrestricted release. Decontamination factors between 2 and 15, but mostly near 2 have been achleved. For ordinary decontamination tasks a conventional highpressure water cleaning equipment up to 100 bar is sufficient to remove slightly adhering or smearable contamination layers.

\subsection{Large-scale applications}

3.2.1 Steam channel between high- and low-pressure turbine A demonstration of large-scale application of chemical and electrochemical decontamination was executed with steam channel walls and water separators situated between high- and low-pressure turbine. The ferritic components with a total mass of $120 \mathrm{Mg}$ have been decontaminated prior to melting with the aim of removing silightly adhering contaminated layers and of substantially reducing of fixed contamination. The initial activity of the channel plates $(101 \mathrm{Mg})$ was $20 \mathrm{~Bq} / \mathrm{cm}^{2}$; the average wall thickness was $41 \mathrm{~mm}$. Decontamination has been executed successfully by pickling in pools with phosphoric acid (concentration: 30-40x, temperature: $40-60^{\circ} \mathrm{C}$ ) and by a subsequent high-pressure water cleaning (70 bar). Smear tests showed that the residual contamination of all components was be low $0.37 \mathrm{~Bq} / \mathrm{cm}^{2}$ after decontamination. The decontamination work without actd regeneration and transports took 1700 manhours and a job dose of $2.8 \mathrm{mSv}$ was recorded. The average costs for waste treatment and disposal are generally estimated to $150 \mathrm{DM} / \mathrm{t}$. Shared costs for equipment have been determined to $340 \mathrm{DM} / \mathrm{t}$. This material with a maximum residual activity of $2 \mathrm{~Bq} / \mathrm{g}$ has been melted down in an authorized foundry for recycling in the nuclear market and reused as cast tron waste containers.

\subsubsection{Main condenser housing}

About $104 \mathrm{Mg}$ components of the main condenser housing (carbon plates and pipes) with an average wall thickness of $20 \mathrm{~mm}$ have been successfully decontaminated for unrestricted release. The initial contamination of these parts was in the range of 6 to $25 \mathrm{~Bq} / \mathrm{cm} 2$ (80x Co-60/20x Cs-137). 355 of the total 508 single pleces had to be decontaminated by removing the paint of several layers. Dipping of painted plates into caustic soda (concentration: $20 x$, temperature: $40-50^{\circ} \mathrm{C}$ ) resulted in a removal of the paint within $20 \mathrm{~min}$. Small gaps near weld seams had to be ground and 
closed by overwelding in order to prevent unremovable contamination by the decontamination acid itself on 275 pieces. The flow chart for handling the main condenser plates is given in figure 5. The total effort for the decontamination of $104 \mathrm{Mg}$ of the main condenser housing was determined to 3500 manhours and effected a total job dose of $14 \mathrm{mSv}$.

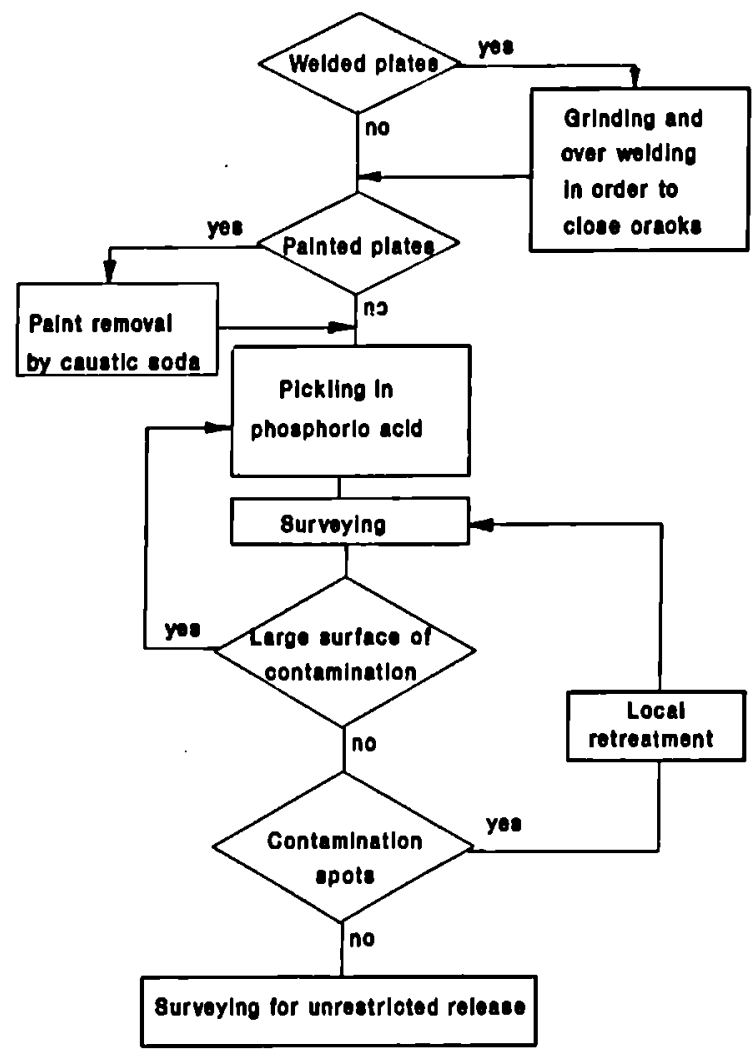

Figure 5: Treatment of plates and pipes of the main condenser housing

\subsubsection{Varlous pipes and valves}

About $35 \mathrm{Mg}$ of different pipes and valves have been selected to prove the efficiency of the recommended decontamination techniques. For primary medium-attacked components (12 $\mathrm{Mg}$ ) mainly pickling and electropolishing with phosphoric acid was applied. Decontamination for alr-only contaminated components and removal of contamination spots after a chemical treatment was executed by the following procedures: brushing with pickling agents, wetting with detergent solutions. Finally all components of the turb1ne house were cleaned by high-pressure water (70 bar) before leaving the controlled area. Decontamination required 300 manhours. A total job dose of $1 \mathrm{mSv}$ was recorded. The applied combination of different decontamination techniques was found to be economical particularly because only a l1ttle amount of secondary waste is produced. 


\section{REGENERATION OP PHOSPHORIC ACID}

\subsection{Procedure}

Chenical and electrochenical decontanination causes a steady increase of the dissolved iron in the phosphoric acid. If the content of iron exceeds $100 \mathrm{~g} / \mathrm{l}$ a precipitation of iron phosphate occurs and stops the decontanination process. Therefore the acid has to be exchanged or regenerated periodically. The regeneration of phosphoric acid is based upon the reaction of $\mathrm{Fe}^{2}+$ with oxalic acid. The following equation describes this chenical process.

$$
\mathrm{Fe}^{2+}+\mathrm{C}_{2} \mathrm{O}_{4}{ }^{2-}+2 \mathrm{H}_{2} \mathrm{O} \longrightarrow \mathrm{FeC}_{2} \mathrm{O}_{4} \cdot 2 \mathrm{H}_{2} \mathrm{O}
$$

Electrochenical decontanination of steel, however, generates a high percentage of $\mathrm{Fe}^{3}$ + in the phosphoric acid, which cannot be precipitated to iron oxalate. The high content of $\mathrm{Pe}^{3+}$ is reduced to $\mathrm{Fe}^{2+}$ by subsequent pickling. When a high portion of $\mathrm{Fe}^{2}+$ is obtainted, the phosphoric acid has to be nixed with an aqueous solution of oxalic acid. The activity (mainly $(0-60)$ is mostly separated fron the solution by precipitation together with the iron. The iron oxalate is dried and stored for subsequent processing. The initial concentration of the phosphoric acid can be achieved by an evaporation process (see figure 6 ).

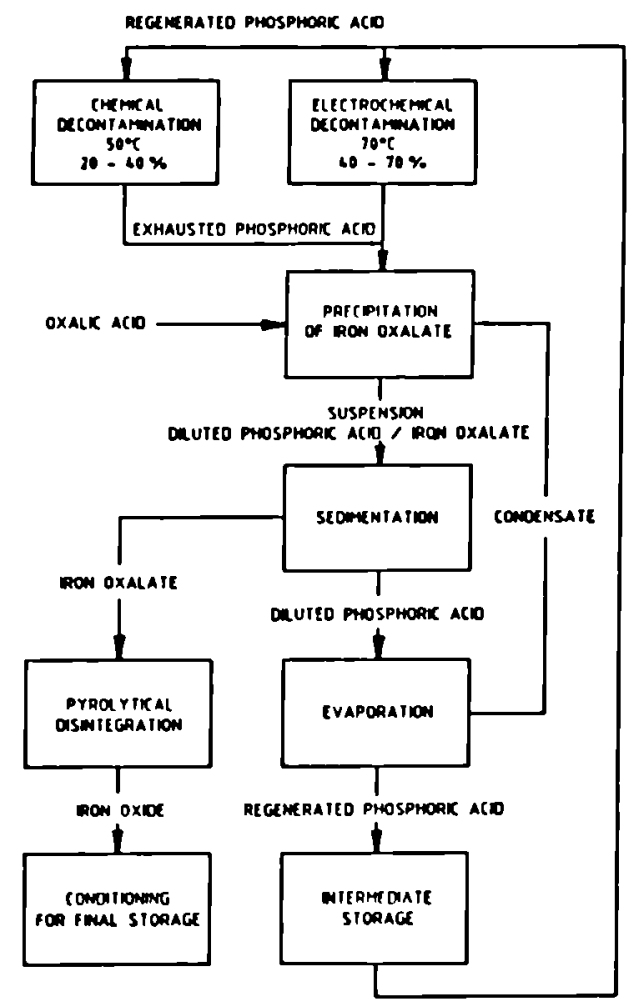

Figure 6: Electrochenical decontanination and regeneration of phosphoric acid 
Until now about $220 \mathrm{~m}^{3}$ of phosphoric acid (concentration 20-40x) have been regenerated. The iron oxalate can be converted to iron oxide by pyrolytic decomposition.

\section{S.2 Enrichment of $\mathrm{Cs}-137$ in the electrolyte}

It was found that the nuclide vector of the steel parts before decontamination differs from the nuclide composition in the decontanination pool as well as in the iron oxalate due to the regeneration process. Because cobalt behaves cheaically like iron the reduction of Co-60 corresponds with the precipitation of iron. After one regeneration cycle iron is reduced by $80 \times$ (from $100 \mathrm{~g} / 1$ to $20 \mathrm{~g} / 1$ ) as well as Co-60. The content of Cs-137 decreases only by $30 \times$ leading to the effect that during each regeneneration cycle the portion of Cs-137 in the phosphoric acid increases relative to Co-60. However, the enrichment of $\mathrm{Cs}-137$ up to $160 \mathrm{~Bq} / \mathrm{l}$ has not influenced the decontamination process.

\section{DETERMINATION OF THE RESIDUAL ACTIVITY}

Unrestricted release of plant parts was achieved by decontamination below the surface-specific limit value of $0.37 \mathrm{~Bq} / \mathrm{cm}^{2}$ (Co-60, Cs-137). In the case of undefinable surfaces, plant parts were also released if the mass-specific activity is below $3.7 \mathrm{~Bq} / \mathrm{g}$.

Several surveying methods for unrestricted release were used to determine the very low residual activity. The following procedures were applied for the determination of the residual activity:

$-a, \beta$-surveying by contamination monitors

With digital signal processing especially a significant reduction of the measurement time was reached. Normally 5 seconds for one measurement position was sufficient to obtain a statement if the residual activity was below or above the surface-specific limit value. Contanination monitors $\left(200 \mathrm{~cm}^{2}\right.$ ) were used for surveying plant parts with definable and measurable surfaces such as plates, pipes, etc.

- $a, \beta$-surveying by probes with special geometry

These measurement instruments were applied to plant parts with holes, corners and edges. Because of their smaller detection area the necessary time for each position amounted to about 20 seconds. This surveying procedure was supported by a digital signal processor.

$-a, b$-surveying by smear tests

This measuring procedure was of ten applied to obtain quick information on the smearable outside contamination of plant parts or transport containers.

- F-surveying with $\mathrm{Ge}(\mathrm{Li})$-detectors

Samples of $5 \times 5 \mathrm{~cm}$ were taken from different plant parts in order to get the nuclide composition of all systems and to check the reliability of the $a, b$-measurements.

- $\gamma$-surveying by liquid-scintillator-columns

This procedure is used for surveying materials without a defined surface e.g. insulation material or concrete which is placed in bags. A special measurement facility for this purpose was constructed (figure 7 ). 


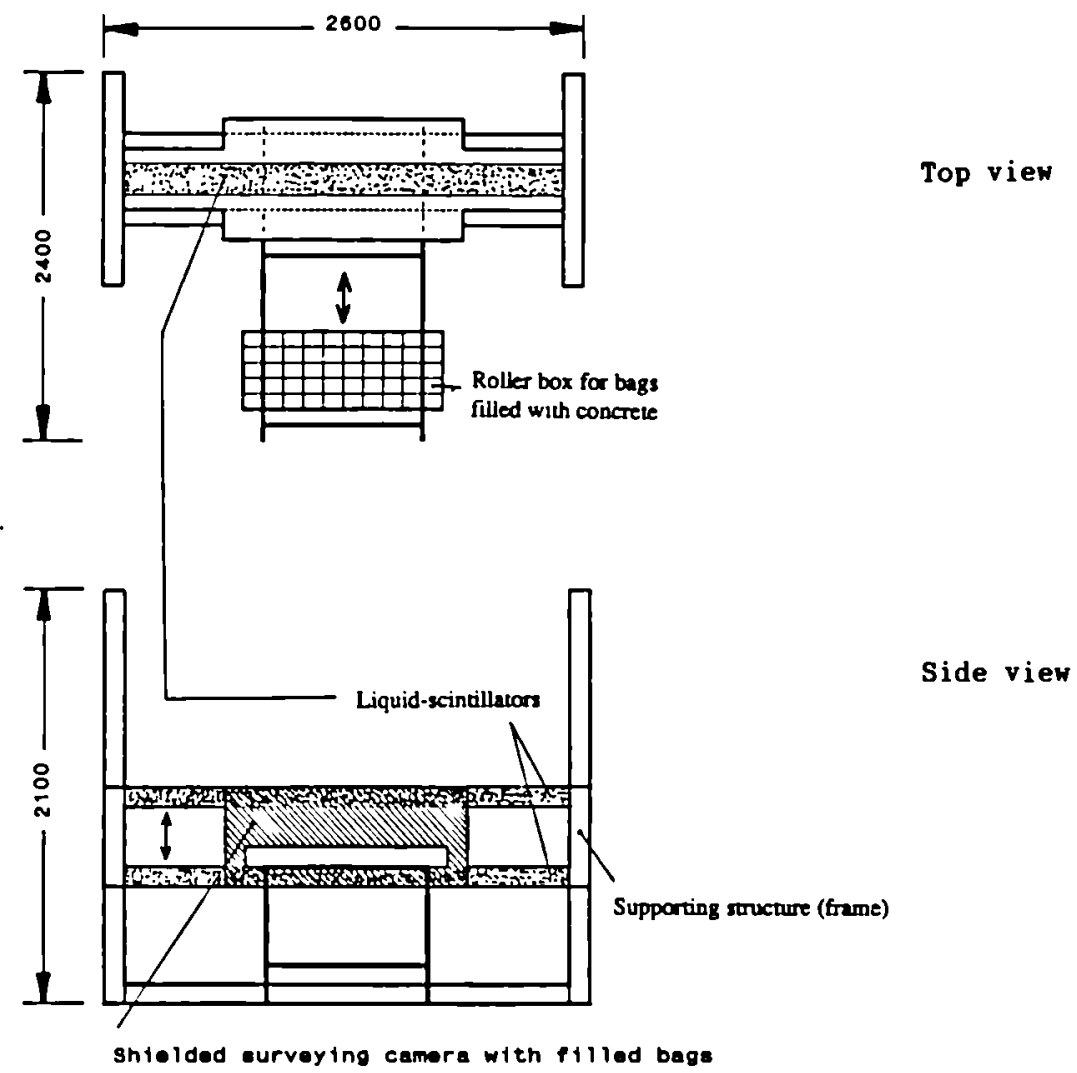

Figure 7: Ganna-neasuring device

With this facility about $100 \mathrm{Mg}$ concrete originating fron the turbine house has been surveyed for unrestricted release. The loose fragnents of concrete were first crushed by a shredder and afterwards filled into bags for subsequent gana-activity-neasurenents. KRB intends to use this naterial for leach out tests on the plant site under open air conditions.

\section{CONCLUSION}

Large scale dignantling and decontanination of low contaninated systens in the turbine house of KRB A has produced a valuable set of data and inportant experiences for sinilar deconisssioning tasks in the future. It has been principally denonstrated that -decomissioning is possible by reasonable cost, -the radiation exposure of the working personnel can be mininized to acceptable values,

-intensive decontanination and nelting of radioactive residues reduces substantially the anount of radioactive waste. 


\title{
DECOMMISSIONING OF A MIXED OXIDE FUEL FABRICATION FACILITY
}

\author{
BUCK, S AND COLQUHOUN, A
}

British Nuclear Fuels plc, Sellafield, United Kingdom

\begin{abstract}
Decomissioning of the Coprecipitation Plant, which made plutonium/uranium oxide fuel, is a lead project in the BNPL Sellafield decommissioning programme. The overall programme has the objectives of gaining data and experience in a wide range of decommissioning operations and hence in this project to pilot the decommissioning of plant heavily contaminated with Plutonium and other actinides. Consequently the operations have been used to test improvements in temporary containment, contamination control and decontamination methods and to develop in situ Plutonium Assay, Plutonium Recovery and Size Reduction methods. Finally the project is also yielding data on manpower requirements, radiation uptake and waste arisings to help in the planning of future decommissioning projects.
\end{abstract}

\section{INTRODUCTION}

Since 1949 Sellafield has handled a range of radioactive materials in appropriate facilities. Some are now redundant and a programme is in hand to safely manage them through the stages of decommissioning.

One of the lead projects is dismantling of the Coprecipitation Plant, including planning and development work. The project had the objectives not only of removing the facility but also of gaining data and experience for other plutonium contaminated facilities with the major radiological requirements of an extremely high standard of particulate containment combined with the need to minimise gamma dose to operators.

The techniques to be tested were those which met the specific constraints and for which previous research had indicated the potential for large-scale application and a contract with the CEC was agreed covering the development aspects of the project.

These included minimising the amount of alpha-contaminated waste material, minimising the radiation exposure to personnel, identification of the best means of in situ decontamination, and the most suitable means of measuring in situ the alpha contamination. Finally, a comparison of costs and radiation exposure from alternative techniques in the real application of decomissioning was made.

\section{PLANT DESCRIPTION}

The Coprecipitation Plant was commissioned in July 1969 for the production of mixed $\mathrm{PuO}_{2} / \mathrm{UO}_{2}$ powder. The process involved the simultaneous precipitation of plutonium and uranium from nitrate solution followed by filtration, drying, calcination, reduction and homogenising of the final dry product. This process was superseded and the plant shut down in 1976. It was subsequently kept under surveillance and maintenance until preparations for dismantling were started in 1986.

The Plant layout is shown in Figure 1, located on part of the ground and first floors of a building housing several other plants. The plant itself occupies $320 \mathrm{~m}^{2}$ floor space and consists of 14 glove boxes, drier, furnace, ball mill, geometrically safe storage vessels and ventilation ducting all within a contained plant access area. Also in this area are motors, gearboxes, electrical and instrument equipment, service pipework 


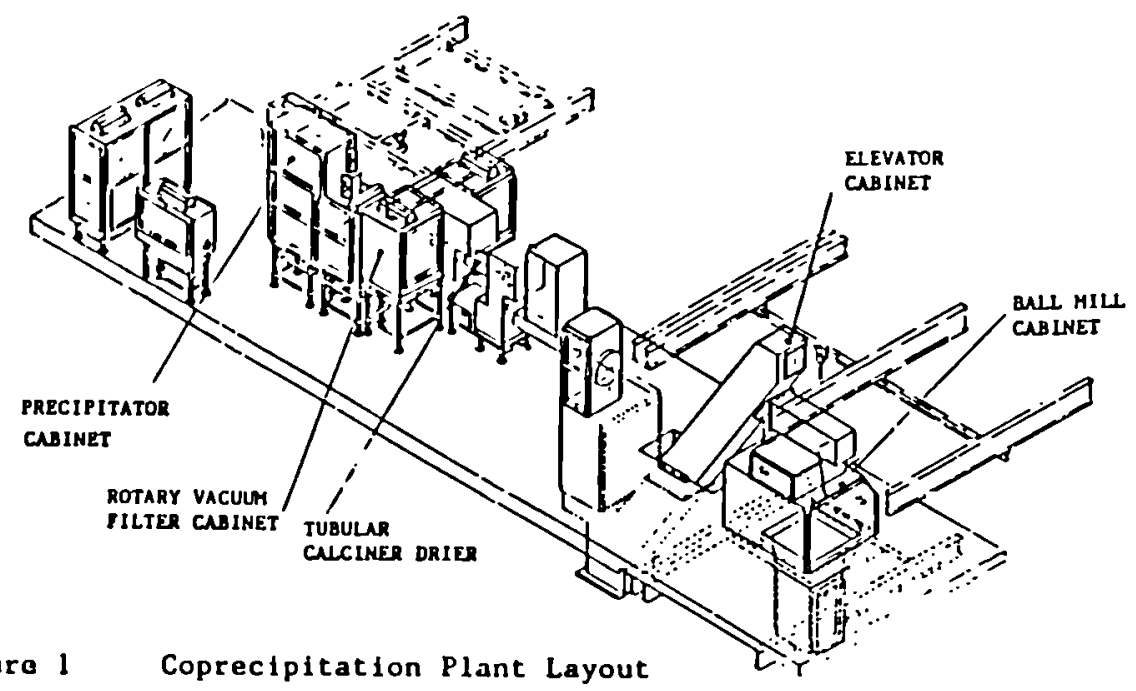

and shielding. Control and inactive feeds were provided from operating and access corridors at the front and rear of the plant respectively.

\section{PLANNING AND PREPARATION WORK}

As with other Decommissioning Projects the first phase consisted of reviewing plant status, alternative methods and sequences of decontamination and dismantling and the fate of equipment and of the building.

With basic principles identified the major steps were defined:

a) Clean up and decontaminate Access Area.

b) Refurbish equipment to operate plant for Post Operational Clean Out.

c) Flushing of "wet section" equipment and cabinet interiors, including transfer of liquors for recovery and removal of redundant services and in-box equipment in wet chemistry section of plant.

d) Clean dry part of the plant using Freon or other new techniques, measure plutonium residues and remove services and in-box equipment.

e) Create exit route from first to ground floor by emptying/dismantling ball $\mathrm{mill}$ and cabinet so that a suitable hole is created.

f) Progressive removal of cabinets with cleaning, fixing activity, assay and size reduction as appropriate.

It was then possible to undertake sufficiently detalled planning, design and outline safety appraisal for cost estimation of the project, and to identify development requirements. With financial approval the detailed design and planning phase began, preparing decontamination and dismantling schedules, engineering instructions, and plant modification procedures for Company and regulatory approval.

\section{PRACTICAL WORK}

This is conventently subdivided and each phase considered in turn.

\subsection{Access Area Clean Out}

The whole of the facility including all the active plant is enclosed in an access area to which access is permitted only with respiratory protection and under control of the plant supervisor. After several years this area had become used for the storage and maintenance of items lecum otler plant and was lin need of considerable cleaning out. 
2 Post Operational Clean Out of the Wet Chemistry Section

This involved washing and swabbing down cabinet interiors and acid washing the interior of process vessels. Lines were rerouted to permit prolonged recycling of nitric acid, whilst any serviceable vessel heater was used to increase the effectiveness of the process. Considerable engineering reinstatement of pumps, valves, interlocks etc was necessary.

In this way all the "wet" section was dealt with, including the Precipitator Cabinet and Rotary Vacuum Filter. Total liquor generated was 1601 , containing $1160 \mathrm{~g}$ of plutonium and $1600 \mathrm{~g}$ uranium and this was stored in the geometrical safe storage tanks awaiting recovery. Subsequently the tanks themselves were washed out with Nitric acid.

It had been the intention to undertake further in situ decontamination at the "wet" end by washing cabinet interiors with dilute $\mathrm{HNO}_{3} / \mathrm{HF}$. Loss of the only disposal route for significant volumes of high alpha effluents, through a plant closed down in 1987, prevented these trials. Such cleaning would not have reduced activity levels on waste sufficiently to permit disposal via a less expensive route, although an improvement in radiation fields might have been achieved.

4.3 Initial Dismantling of Wet Chemistry Section

Once wet flushing had finished, stripping out of the wet cabinets started. Items removed included stainless steel and flexible PVC pipework, stainless and glass vessels, valves, pumps, filter segments and other small items capable of removal by posting out techniques. Equipment from cabinets exteriors was also dismantled. This included motors, gear boxes, control units, support frames etc. More than $90 \%$ was monitored as suitable for shallow land burial after cleaning with decontaminants or paint stripper. This represented a major saving in disposal costs even with allowance for the cost of the cleaning work.

4.4 Partial POCO of Dry Powder Facilities

In preparation for work on the dry (powder handling) section of the plant drive mechanisms were refurbished, but some were beyond economic repair. The plant was then operated to displace any remaining mixed oxide. Small quantities only were recovered and subsequent measurements confirmed that the process had been largely ineffective.

Ancillary equipment was removed here also including support frames, motors, guards, heating elements and furnace insulation and exterior jackets. Again this material was cleaned for shallow land burial.

4.5 Emptying and Removal of Ball Mill

Coprecipitation Plant layout unfortunately required the most difficult dismantling operations at an early stage to create a removal route for glove boxes, ie ball mill and bucket elevator first.

The ball mill was a horizontal $75 \mathrm{~cm}$ right cylinder, made of steel reinforced rubber and containing a $900 \mathrm{Kg}$ ball charge. This sat inside a housing in turn heavily shielded and housed in an outer containment. The mill was designed to be withdrawn from the housing, after emptying powder and balls. The operation required a large temporary containment and was the first trial of the RMC (Reusable Modular Containment).

The first step was to recommission the ball mill drive mechanism and mill was then rotated to remove residual $\mathrm{MO}_{2}$, with negligible results. $200 \mathrm{~g}$ stearic acid was added as a dry lubricant and further rotation released $5 \mathrm{Kg} \mathrm{MO}_{2}$. A further addition of stearic acid was not permitted on nuclear safety grounds due to the unknown mill contents (the combined neutron and gamma shielding prevented meaningful measurements). The ball retaining grid was then distorted to permit a slow discharge of balls and $\mathrm{MO}_{2}$, a further $20 \mathrm{Kg}$ being removed. The balls had little adhering $\mathrm{MO}_{2}$. 


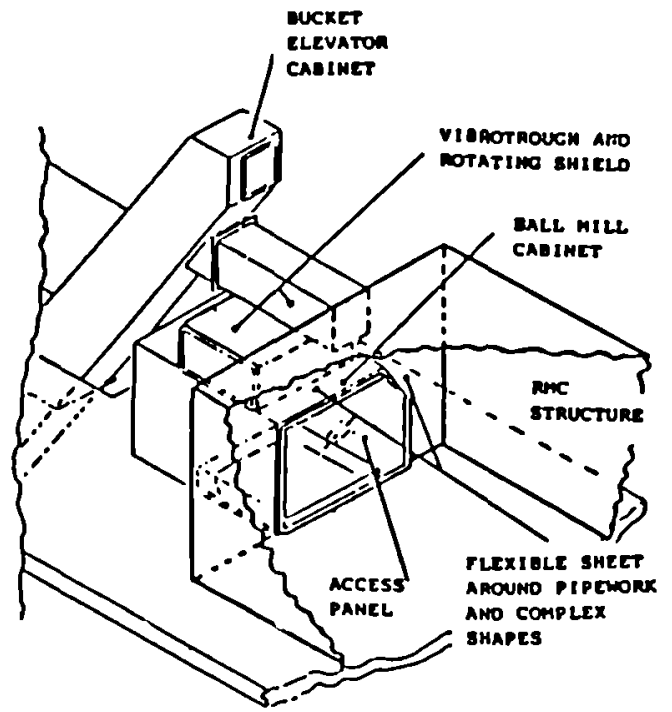

Figure 2 Ball Mill Removal

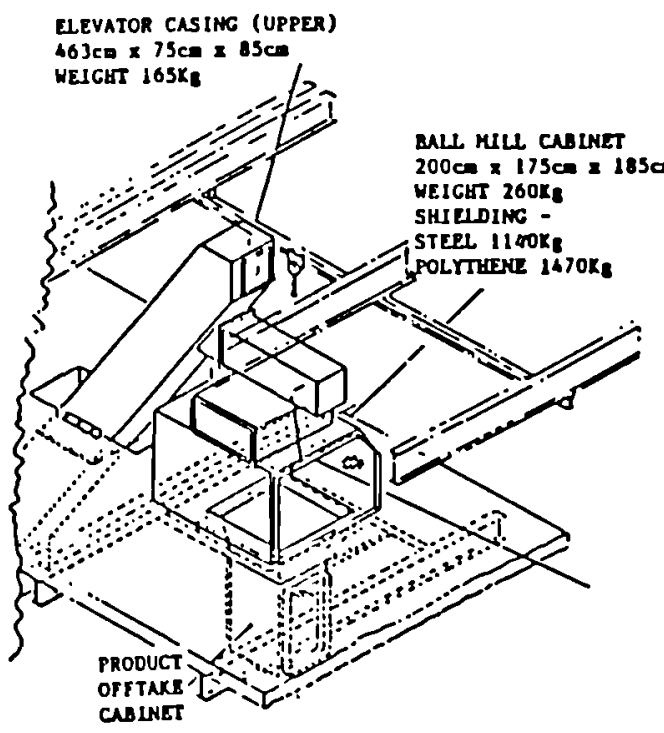

Figure 3 Ball Mill Suite

but overall progress was more rapid and a better packing fraction was achieved such that only two crates of glove box components resulted rather than the five originally estimated.

\subsection{D1smantling of Furnace Sulte}

Attention then turned to the furnace suite (Fig 4). It had been hoped to clean this using the Freon Jetting system but due to development delays, this was not available. Consequently a further $10 \mathrm{Kg}_{\mathrm{g}}$ of mixed 
oxide was removed manually from these units, resulting in significant radiation uptake.

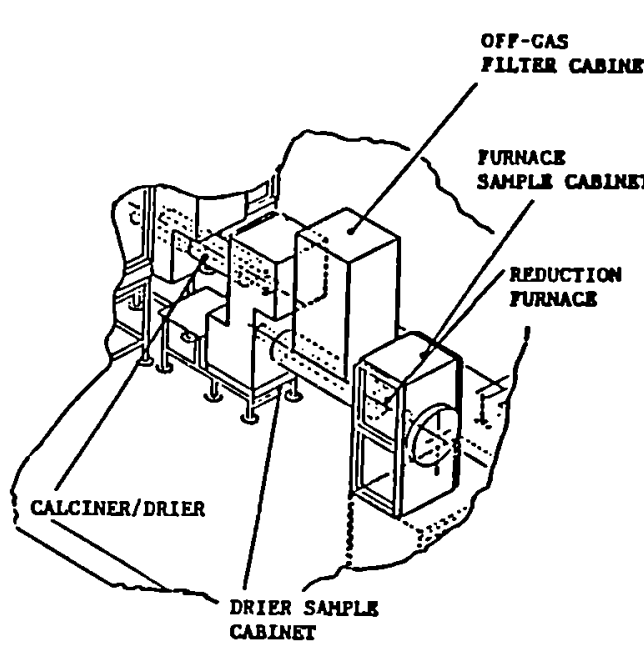

Figure 4 Furnace Suite

The glove boxes and furnace/ drier bodies in this suite were designed to be separable without loss of containment and were small enough to be packaged for storage/ disposal without size reduction. After the plutonium assay work the glove box suite was enclosed only in a flexible PVC structure as the above factors indicated that no containment should be needed. In any case comparison with RMC experience was desirable.

Disconnecting the major

components proved laborious but not difficult. Problems were encountered with extract lines from the cabinets as these were more highly contaminated than expected. The $25 \mathrm{~mm}$ normal extract lines were dealt with by the crimp/shear tool but one failed to seal due to difficulty of access and probable work hardening of the pife. The $75 \mathrm{~mm}$ emergency extract lines caused problems also. These had been foam filled from the cabinet ends and were cut without problems but needed to be cut again to provide space to move the cabinets and the same technique could not be used. Some contamination spread required significant cleaning operations before the containment could be removed.

4.8 Wet Chemistry Suite and Remaining Operations

Although the development work forming part of the CEC contract is essentially complete some main project work will be ongoing through 1989. This consists of work of less technical interest involving largely application of well proven techniques.

The next step for the project is removal of the wet chemistry suite comprising the RVF, precipitator, recovery and scrubber cabinets and this will be carried out within an RMC structure. All the units have been cleaned to much lower contamination levels than was possible for the ball mill suite and no problems are envisaged.

Operations will then move to the ground floor where the lower section of the bucket elevator and buffer storage cabinet will be cleaned using the Freon jetting technique. The final phase will be removal of the geometrically safe storage tanks using an expanding foam filling/cutting technique currently being developed.

\section{DEVELOPMENT ASPECTS}

Due to its lead nature development work has concentrated in several areas under the CEC Contract:
a) In situ plutonium assay equipment.
b) Improved temporary containment structures.
c) Faster methods of recovering substantial nuclear material residues.
d) Decontamination methods.
e) Tools for in situ size reduction. 


\subsection{In Situ Plutonium Assay}

Radiometric Physics Group have developed three measurement systems to determine the residual Pu content of process cabinets:

a) The roving neutron system is a small, very portable, total neutron counting system using a single $12 \mathrm{~cm}$ active length ${ }^{3} \mathrm{He}$ detector surrounded by a layer of polythene moderator. This can be used to determine the location of $\mathrm{Pu}$ within a process cabinet.

b) The roving gamma system is a low resolution spectrometry system using a l" $^{\prime \prime} 2^{\prime \prime}$ NaI (T1) detector. This can be used to determine the relative abundance of $\mathrm{Pu}$ in various locations.

c) The Decommissioning In Situ Plutonium Inventory Measurement (DISPIM) system is a neutron coincidence counting system using up to six counting modules positioned around a process cabinet to determine the correlated neutron flux from the cabinet.

The operating procedure has developed with experience:

a) Use of one of the two roving systems to determine the distribution and the DISPIM system to determine the mass of Pu within cabinets.

b) The DISPIM system is recalibrated, using the "add-a-source" technique, every time the system is set up. This method uses a well characterised, non fissile, neutron source placed at various locations within the process cabinet to determine the sensitivity of the DISPIM system to Pu in those locations.

c) Frequent standardisations (with the neutron source against each module in turn) ensure the reliability of the system.

During early 1989, the DISPIM system suffered a high amplifier fallure rate. The only items that could not be properly inspected were the detectors, at the connection between the cable connector and the anode inside the detector body. Eventually the problem was resolved by replacing all the ${ }^{3} \mathrm{He}^{\prime} \mathrm{s}$ with $\mathrm{BF}_{3}$ detectors. Although less efficient the long counting times available (typically overnight) have meant that the precision of the plutonium mass estimate is little impaired.

Table I: Typical In Situ Plutonium Assay Results

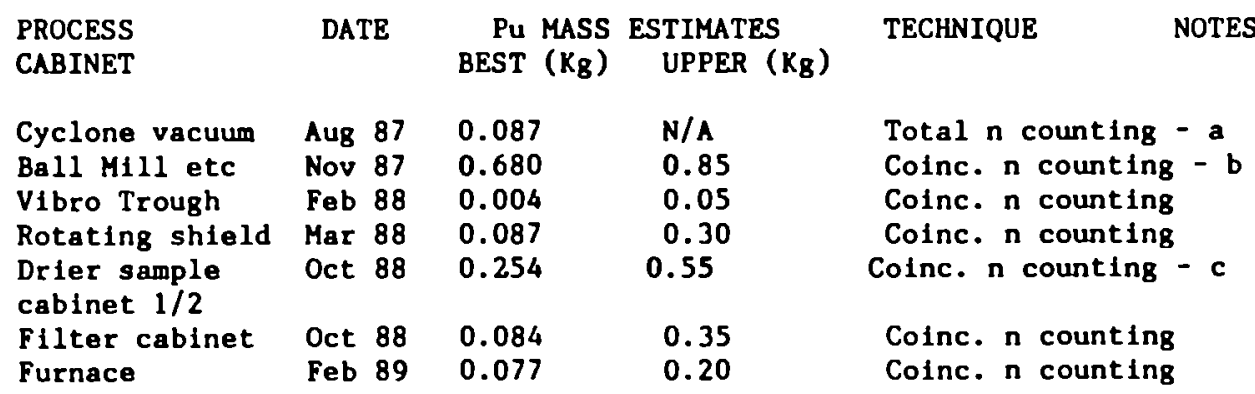

a) Measured by total neutron counting using an early prototype.

b) Calibrated with the aid of a wooden model made to the same dimensions as the real cabinet.

c) Size and shape made it easier to assay this cabinet as more than one unit, measuring each independently.

5.2 Containment System and Strippable Coatings

In plutonium processing facilities there are items of plant which are heavily contaminated with plutonium and other actinides and such that 
in situ size reduction or dismantling is required. For this purpose AEE Winfrith had developed the RMC to provide secondary containment and minimise secondary waste arisings. The opportunity was taken to test this equipment on a major dismantling project.

The system may be likened to a reusable tent, constructed of panels (Modules) bolted together by external flanges. Modules can be plain or contain pressurised suit entry/exit, posting facilities, glove ports, windows ventilation connections. Usually Glass Reinforced Polyester (GRP) they may be metal or other rigid plastics. The System is designed to be used by operators in pressurised suits which are decontaminated by showering at the end of operations. A shower cabinet is included.

During size reduction operations, the inside of the containment becomes highly contaminated. The internal surfaces are therefore protected with strippable coating and on completion of active operations, a tie-down coating is applied and the active 'sandwich' is removed, leaving the unit clean for re-use. The coatings can be used to fix loose activity or as a precoat where activity is likely to be disturbed. In this case a further layer can be applied and the sandwich subsequently removed. Several such layers can be allowed to build up and the coatings reduce loose activity levels by up to 3 orders of magnitude.

\subsection{Solvent Cleaning}

A problem with plants containing solid residues of aged plutonium compounds is the gamma radiation. Measures were sought to remove these residues quickly and with minimum operator involvement and the use of 'Freon'. (Dupont) or 'Arklone' (ICI) was attractive:

a) It is non hydrogenous, so criticality issues are avoided.

b) It is low boiling $\left(47^{\circ} \mathrm{C}\right)$ and easily recycled by distillation.

c) Its solvent properties remove oil, grease and loose contamination.

d) Its high density and low surface tension make it very effective for the penetration of cracks and crevices.

e) It is non-flammable and relatively non-toxic ( TLV $=1000 \mathrm{ppm})$.

The process has been employed on power station sites in the USA and in Europe for low level loose activity removal and small scale trials on plutonium active equipment have been reported. However its use in this project was aimed at removal of bulk residues which represent major sources of radiation to personnel.

A development contract (on NEI, Newcastle with Kraftanlagen AG of Heidelberg) was let, firstly to confirm the validity of the concept; and if successful to design and make a prototype unit. The project has now proceeded to detailed design, and manufacture in parallel with Safety and Nuclear Safety analysis. A considerable period of trials and modifications was necessary with the solvent vapour recovery system which delayed delivery until early June 1989. A programme of $\mathrm{UO}_{2}$ trials will be carried out before a decision on plutonium active operations is made.

5.4 Electrolytic Decontamination

Electrolytic methods for decontaminating metals have been used for many years, the first Sellafield applications being in the mid 1960's. The technique is analogous to chemical methods in that it removes a surface layer of substrate and hence any embedded (fixed) contamination.

In this project we had undertaken to test the method on items generated by decommissioning on a routine basis. For this purpose it was intended that an existing glove box, installed in the access area but remote from the main plant, should be adapted for immersion electrolytic cleaning of items up to $25 \times 25 \times 50 \mathrm{~cm}$. 
After detailed design and costing it was however shown that the process would not be cost effective in this application. This is not to deny the merits of a process which can decontaminate any ferrous metal to unrestricted release levels but due in this case to:

a) The high cost of modifying the only suitable in situ glove box.

b) The degree of size reduction needed for suitable feed stock.

c) the manpower requirements needed for operation of the process and monitoring of the product.

\subsection{Size Reduction Tooling}

Experience of active cutting operations within BNFL and elsewhere was drawn upon for tools for in situ size reduction of the ball mill suite of cabinets. For operational reasons thermal cutting was avoided but a range of hand power tools was tried, including $\mathrm{Jig}$ and reciprocating saws, angle grinder and a portable bandsaw.

In fact the power tools which have been found of greatest value in size reduction operations have been the Nibbler for plate/sheet sections (Duplex type N24D) and a circular "Cut off" saw for thicker sections (Bosch type 1333.4). The vast majority of work has been performed with these although both are heavy to use by operatives in protective clothing, involving considerable physical effort.

For dealing with small bore pipework without loss of containment the crimp/shear tool (Gravatom type 25.S.15) has worked very we11, many hundreds of cuts having been performed. Most have been in $12 \mathrm{~mm}$ pipe although it has been used up to $25 \mathrm{~mm}$, with a marked reduction in blade 11fe. The same manufacturer has now demonstrated a seal and cut technique for the geometrically safe tanks ( $100 \mathrm{~mm}$ bore $6 \mathrm{~mm}$ wall stainless steel) and a prototype is to be tested.

\section{DATA COLLECTION}

A major objective of the project has been the collection of data to assist in the planning and cost estimating of future decommissioning work. This is summarised in Table II and reviewed below.

\subsection{Manpower Requirements and Personnel Radiation Uptake}

The Coprecipitation plant dismantling has been undertaken in a traditional "hands-on" manner. Additionally, because of the pilot nature of the project, a greater degree of in box cleaning and dismantling has been undertaken than might otherwise have been the case. Table II data shows both considerable manpower requirements and significant radiation uptake. The 2000 man hours spent on refurbishment is noteworthy, because in spite of a maintenance regime this shows the work needed to even partially recommission an active plant after 10 years.

Examination of the radiation data also leads to useful conclusions it is clear that the earliest operations involved a much higher rate of exposure than subsequently. The improvement is due to:

a) cleaning of cabinets and removal of bulk nuclear materials.

b) provision of additional temporary shielding.

c) wearing of personal shielding whenever practicable.

In spite of these changes the Process Workers are still incurring a whole body radiation dose of some $10 \mu \mathrm{Sv}$ per man hour during dismantling. Levels are high when working on units which handled bulk dry materials, such as the ball mill, but lower when working on the "wet chemistry" suite. Engineering personnel typically receive doses 2 to 3 times higher wherever they are working, due to their more intensive in-box work. 
Table II: Sumnary of Project Data

\begin{tabular}{|c|c|c|c|c|c|c|c|}
\hline \multirow[t]{2}{*}{ Operation } & \multicolumn{2}{|c|}{$\frac{\text { Whole Body Radiation }}{\text { mSy }}$} & \multicolumn{2}{|c|}{ Man Hours on Job } & \multicolumn{2}{|c|}{ Wastes M3 } & \multirow{2}{*}{$\frac{\text { Recovered }}{\mathrm{K}_{\mathrm{B}}}$} \\
\hline & Process: & Eng Lneering & Process & Engineering & $\overline{P C A}$ & SLB & \\
\hline Access Area Initial Clean & 3.7 & not appliceble & 225 & not applicable & 1.0 & 2.0 & N11 \\
\hline Engineerlng Refurblshment & 40.5 & 17.3 & 1350 & 600 & 1.4 & N11 & Nil \\
\hline $\begin{array}{l}\text { Stripping of Wat } \\
\text { Chanistry Cabinets }\end{array}$ & 8.7 & 7.9 & 980 & 280 & 2.5 & 3.1 & $\begin{array}{l}2.9 \mathrm{~K}_{\mathrm{B}} \text { as } \\
\text { Nitrate }\end{array}$ \\
\hline $\begin{array}{l}\text { Ball Mi11 and Product } \\
\text { Offtake Preparation }\end{array}$ & 20 & $\mathbf{s}$ & 1450 & 70 & 0.4 & N11 & 1.6 \\
\hline $\begin{array}{l}\text { Bell Mill Enptying, } \\
\text { Dismantling and Renoval }\end{array}$ & 13.7 & 11.3 & 1575 & 590 & 7.3 & 0.5 & 26.0 \\
\hline Assembling New RHC & 6.6 & 0.5 & 1000 & 50 & & $t$ appl & cable \\
\hline $\begin{array}{l}\text { In situ S1ze Reduction } \\
\text { Upper Bell Mill Suite }\end{array}$ & 4.6 & 9.7 & 700 & 900 & 3.3 & N11 & N11 \\
\hline $\begin{array}{l}\text { Size Reduction (S/R) } \\
\text { of Ball Mill Floor }\end{array}$ & 12.1 & 11.3 & 500 & 250 & 1.1 & 0.7 & Nil \\
\hline S/R of Powder offtake & 7.4 & 3.9 & 600 & 400 & 1.5 & 0.9 & 4.0 \\
\hline S/R Elavator (Upper) & 7.7 & 6.6 & 750 & 500 & 1.9 & 1.1 & 3.0 \\
\hline $\begin{array}{l}\text { Dacontam/Dismantling } \\
\text { RHC }\end{array}$ & 20.0 & 2.0 & 1200 & 300 & 2.3 & 1.3 & N11 \\
\hline $\begin{array}{l}\text { Preparation for removal } \\
\text { of Purnace Sulte }\end{array}$ & 22.9 & 4.2 & 1050 & 450 & 2.0 & 1.3 & 4.0 \\
\hline $\begin{array}{l}\text { Removal Fumace Sulte } \\
\text { and Decontamination Ops }\end{array}$ & 9.0 & 4.0 & 1200 & 800 & 3.8 & 2.2 & N11 \\
\hline
\end{tabular}

For planning future plutonium plant dismantling, this shows "hands on" methods will require rapid reduction in radiation levels eg by speedy cleaning methods and/or additional local shielding.

\subsection{Waste and Nuclear Material Residues}

Table II also summarises the wastes generated so far, segregated into those measured as suitable for shallow land burial (SLB) and those to be stored pending availability of a repository (PCM). Disposal other than by shallow land burial is more expensive (at least 2 orders of magnitude) and there is great incentive to minimise items disposed by this route. Careful segregation of materials, simple decontamination procedures and careful checking by safety services personnel have been extremely valuable and well justified the man hours thus spent.

It is also clear that the dismantling of plants, which handled tonne quantities of nuclear materials, may find significant residues even though these represent only a tiny fraction of the plant throughput.

7. DISCUSSION

7.1 Achievement of Objectives

The Coprecipitation plant decommissioning project objectives were "to pilot the development of technology for the decomissioning of facilities used in the fabrication of mixed oxide fuels. Based on existing experience, the aim is to establish the procedures which are the most cost effective overall under the specific constraints on the disposal of wastes arising and on the radiation exposure of personnel". Actual progress in removing the plant demonstrates the achievement of "plutonium plant dismantling" - the other objectives are considered below. 


\subsection{Data Collection}

The project has yielded considerable information on decomissioning operations under the major constraints of a very high degree of particulate containment and current permissible radiation uptake levels much more restrictive than those for which the plant was designed. This information includes:

a) manpower requirements for typical and specific operations.

b) Whole body and extremity radiation doses for specific jobs and for the overall project.

c) data on waste arisings by weight, volume, activity, disposal category and the cost effectiveness of decontamination of some materials.

This data will be of great value in planning future plutonium/actinide plant dismanting projects but will require considerable interpretation and extrapolation in terms of plant size and complexity; nature, amount and location of residues; and ease of man or machine access.

Finally control of personal dose commitment will obviously be a major consideration in decomissioning. There is clearly scope for developing techniques such as cleaning and shielding methods and ways of planning and controlling radiation dose uptake as precisely as possible.

\subsection{Development Areas}

Several techniques tested on this project rapidly demonstrated their value and became routine for later stages. These include:

a) means of locating and assaying plutonium residues in situ.

b) alternative size reduction tools and dismantling methods.

c) Improved methods of temporary containment and contamination control. The need for more effective cleaning and decontamination methods for reducing dose rates and recovering nuclear materials was recognised at the start of the project but prolonged development has so far prevented deployment of the Freon cleaning technique, whilst electrolytic decontamination has been abandoned, as explained in Section 5.4.

Clearly there is potential, and need, for further development of many ideas for future applications. These include the in situ plutonium assay equipment which needs to be made suitable for use in much more difficult environments - both in terms of access and in terms of varying chemical and isotopic composition of the material being measured. Secondly the philosophy of cutting active pipework without loss of containment needs to be extended from $12 \mathrm{~mm}$ to $100-150 \mathrm{~mm}$ and still larger sizes. Finally the principle underlying the Freon cleaning work ie quick removal of residues and hence lowering of dose rates needs to be further addressed whether by this technique or some alternative.

\section{CONCLUSIONS}

The objectives of the Coprecipitation plant project were "to pilot the development of technology for decommissioning of facilities used in the fabrication of mixed oxide fuels". Clearly the work has gone some way towards this and given considerable experience in temporary containment, contamination control, tooling and in situ plutonium assay.

We have also gained valuable knowledge in the organisation and control of such projects and much information relevant to the planning and cost estimation of fuel fabrication or other plutonium/actinide plant dismantling operations.

Finally the project has highlighted some inadequacies in our technology for tackling such operations and shown the need, and appropriate direction, for further development to suit other and perhaps more exacting situations in related facilities. 


\title{
DISMANTLING AND DECONTAMINATION OF THE PIVER PROTOTYPE VITRIFICATION FACILITY
}

\author{
JOUAN, Antoine \\ Commissariat a l'Energie Atomique, IRDI/SDHA \\ Centre d'Etudes Nucléaires de la Vallée du Rhône \\ 30205 Bagnols-sur-Cèze, France
}

\begin{abstract}
The PIVER prototype was targeted for dismantling in order to install a new pilot facility for the French continuous vitrification process. Most of the work involved the vitrification cell containing the process equipment, which had to be cleared out and thoroughly decontaminated; this implied disassembling, cutting up, conditioning and removing all the equipment installed in the cell.

Remote manipulation, handling and cutting devices were used and some prior modifications were implemented in the cell environment. The dismantling procedure was conducted under a detailed program defining the methodology for each operation.

Removed activity levels, irradiation in the cell and doses integrated by personnel were monitored to control progress and to adapt procedures to the conditions encountered.
\end{abstract}

\section{OVERVIEW}

PIVER, a demonstration unit designed to qualify the French batch vitrification process for high-level waste solutions, began radioactive operation in 1969 in the south end of building 211 at the Marcoule nuclear center. It comprised a liquid storage cell (75) with three tanks containing fission product solutions on the basement level, and a vitrification cell (74) containing the process equipment. The facility was operated from 1969 to 1973 with solutions produced by reprocessing gas-cooled reactor fuel, and from 1979 to its final shutdown in 1980 with high-burnup oxide fuel reprocessing solutions.

Most of the decommissioning work involved cell 74, which had to be cleared out and decontaminated without interrupting operation of the fission product liquid storage facility. The objective in the near future is to install a new continuous vitrification prototype in the cell using recently designed process equipment.

The cleanup operations began in 1982, and included two major phases:

Phase I (1983-1987): Preliminary operations

- Development of the methodology and telemanipulation systems required to accomplish the task.

- Approval by safety authorities and by ANDRA*, responsible for recovering the waste packages.

- Internal decontamination of process equipment in cell 74.

Phase II (1988-1989): Active work

- Actual cleanup operations in cell 74 to obtain suitable working conditions for installation of the new vitrification facility.

*French national radioactive waste management agency 


\section{ORGANIZATION}

\subsection{Administrative Organization and Regulatory Constraints}

The PIVER prototype being decommissioned is part of the Marcoule pilot reprocessing facility, designated as a "Basic Nuclear Installation" under French regulations and therefore subject to special requirements. These include a mandatory safety report, a quality assurance program and general operating documents (safety instructions, operating instructions, procedures, etc.).

Specific application documents were also prepared in compliance with the regulatory documents:

- General dismantling procedures

- Detailed procedural descriptions for individual PIVER dismantling operations: each such description included an operating procedure and a list of fundamental related actions.

The CEA is responsible for the cleanup operations: the high-level waste service (SDHA) manages the work while continuing to operate the fission product solution storage unit in cell 75 adjacent to the vitrification cell.

\subsection{Methodology and Organization of Cleanup Operations}

The cleanup operations are performed by two groups of 5 or 6 technicians and decontamination specialists under the responsibility of an engineer and two supervisors. The overall work schedule and monthly itemized task schedules were defined to meet the ultimate objective: i.e. to allow human entry into the cell during the second quarter of 1989 . The schedules were revised and procedures or equipment were adapted, improved or modified as the work progressed or as difficulties were encountered.

\subsection{Waste Characterization}

A preliminary study in 1983 provided a qualitative and quantitative estimate of the wastes involved in the PIVER cleanup program:

- Glass fragments and special ruthenium-trapping granules liable to contain from several Curies to several tens of $\mathrm{Ci}$ of $\boldsymbol{\beta \gamma}$ emitters, with contact irradiation levels of up to several Gy.h $h^{-1}$.

- Inductors (concrete-encapsulated copper coils) from the vitrification pot furnace; they were superficially radioactive (up to several hundred $\mathrm{mGy} \cdot \mathrm{h}^{-1}$ ) but the volume activity of the corresponding waste packages did not exceed $3.7 \times 10^{10} \mathrm{~Bq} \cdot \mathrm{m}^{-3}\left(1 \mathrm{Ci} \cdot \mathrm{m}^{-3}\right)$.

- Cutup metallic wastes (tubes, brackets, tanks, etc.) with contact irradiation levels liable to exceed $1 \mathrm{~Gy} \cdot \mathrm{h}^{-1}$; the specific $\beta \gamma$ activity of the waste drums may reach 3.7 to $7.4 \times 10^{10} \mathrm{~Bq}$ $(1-2 \mathrm{Ci})$.

The total activity to be removed from the cell was estimated at $2.2 \times 10^{14} \mathrm{~Bq}(6000 \mathrm{Ci})$ with the following radioactivity reference spectrum:

- $\beta \boldsymbol{\gamma}$ emitters

\begin{tabular}{|ccccccccc|}
\hline${ }^{90} \mathrm{Sr}$ & ${ }^{90} \mathrm{Y}$ & ${ }^{137} \mathrm{Cs}$ & ${ }^{134} \mathrm{Cs}$ & ${ }^{106} \mathrm{Ru}$ & ${ }^{106} \mathrm{Rh}$ & ${ }^{144} \mathrm{Ce}$ & ${ }^{144} \mathrm{Pr}$ & ${ }^{125} \mathrm{Sb}$ \\
\hline $7.25 \%$ & $7.25 \%$ & $77.87 \%$ & $3.13 \%$ & $0.8 \%$ & $0.8 \%$ & $1.3 \%$ & $1.3 \%$ & $0.3 \%$ \\
\hline
\end{tabular}

- a emitters: approximately $0.0024 \%$. 


\section{DISMANTLING AND DECONTAMINATION EQUIPMENT}

\subsection{Remote Manipulation and Handling Devices}

A heavy-duty hydraulic telemanipulator known as Camoline and a 2000-kg monorail were already available in the PIVER cell. The monorail was reliable but with only limited flexibility, while the Caroline robot was precise and versatile but lacking in reliability. Caroline was therefore renovated, and the existing means were supplemented by new telemanipulator devices:

- two La Calhène MT 200 "master/slave" telemanipulators designed to cut up metallic tubing and place the pieces in waste drums were installed in front of a viewing port;

- a new device known as Antoine, capable of supporting 100-kg loads on a pantographic arm, was moved into the cell to carry various cutting tools and to help condition pipes and process lines in waste drums.

\subsection{Related Equipment}

Equipment suitable for use on the Antoine and MT 200 telemanipulators was developed and adapted to the specific requirements of cleaning up cell 74. This included cutting tools (shears, disk grinders, plasma torches) and gripping tools (hydraulic tongs, pneumatic tongs) as well as horizontal and vertical direct-contact plasma torch cutting stations for dismantling process vessels.

\subsection{Waste Removal Paths}

Whenever possible, waste materials are conditioned directly in metal drums inside the cell. The waste drums may then be removed from the cell along two separate paths.

\section{Initial Removal Path}

The first path to be set up uses the glass canister route leading from the cell. Waste materials in containers similar to glass canisters are transferred to a specially designed conditioning station where they are placed in preformed concrete shells after checking their irradiation levels.

Considering the excessive cutup work required to fit the small container size, this removal path has not been used to date.

\section{Direct Removal Path}

This path was intended for removal of bulky wastes. With a few modifications, it has been used for all waste removal while minimizing personnel exposure. The following modifications were incorporated:

- A telescoping crane was installed in room 712, a handling room adjacent to cell 74; the crane is used to transfer waste drums from cell 74 into the shell or ANDRA container in room 712 without human intervention.

- A leaktight lock was built to ensure containment during removal of waste materials from the PIVER zone (between rooms 713 and 715).

- The floor of room 712 was covered with stainless steel plating for easier decontamination.

Additional equipment requirements were specified:

- specially designed 100-liter drums to remove waste materials from the cell;

- a lead hood to comply with onsite irradiation standards for transporting ANDRA containers prior to concrete encapsulation;

- a self-propelled carriage to move waste containers from room 712 outside the PIVER zone. 


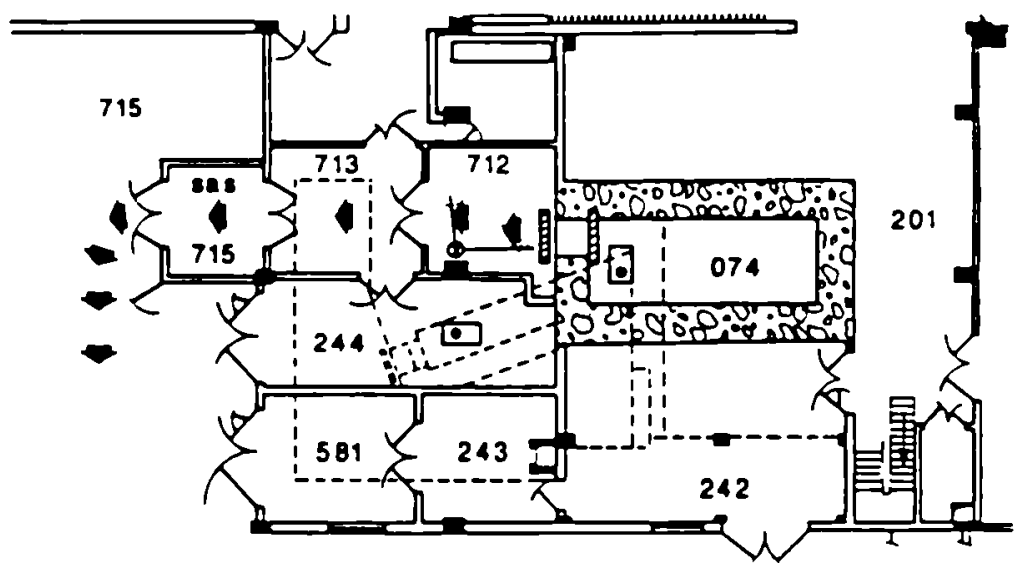

Figure 1: Direct waste removal path from cell 74 via locks 712,713 and 715

\subsection{Fire Protection in Cell 74}

Process equipment and pipes in cell 74 can be cut up using the Antoine shear, the disk grinder or the plasma torch. The last two tools create hot spots with a consequent fire hazard. Safety authorities therefore requested that a fire extinguishing system be installed in cell 74 .

The system installed in August, 1988, comprises:

- a permanently installed spray nozzle suitable for telemanipulated operation in cell 74, designed for connection to the building industrial water supply, to a 45-liter fire extinguisher containing water and a special additive, or to an onsite fire protection tank truck;

- an emergency spray nozzle located in room 712 adjacent to cell 74 , supplied by the building industrial water system and operated directly by the personnel from the cell lock. 


\section{OPERATIONAL SEQUENCE}

\subsection{Chronology}

The principal operations completed to date are indicated in the following chart:

\begin{tabular}{|c|c|c|}
\hline $\begin{array}{l}1 \\
9 \\
8 \\
7\end{array}$ & $\begin{array}{r}1 \\
2 \\
3 \\
4 \\
5 \\
6 \\
7 \\
8 \\
9 \\
10 \\
11 \\
12\end{array}$ & 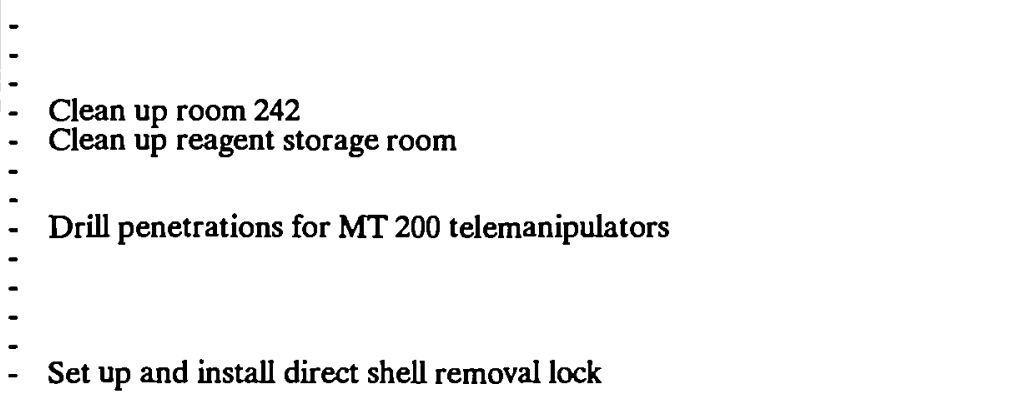 \\
\hline $\begin{array}{l}1 \\
9 \\
8 \\
8\end{array}$ & $\begin{array}{r}1 \\
2 \\
3 \\
4 \\
5 \\
6 \\
7 \\
8 \\
9 \\
10 \\
11\end{array}$ & $\begin{array}{l}\text { - Fabricate special telemanipulatable drums } \\
\text { - Move Antoine telemanipulator with shear and/or disk grinder into cell } \\
\text { - Begin removing wastes via direct path } \\
\text { - Install } \gamma \text { chamber on cell lock door A for waste irradiation measurements } \\
\text { - Set up waste drum handling crane in room } 712 \\
\text { - Test vertical \& horizontal plasma torch cutting stations } \\
\text { - Install two MT } 200 \text { telemanipulators } \\
\text { - Install fire protection } \\
\text { - Set up } \gamma \text { teletopography system } \\
\text { - Install motor for Manulev crane hook } \\
\text { - Move cameras into place } \\
\text { - Take } 3-D \text { photos to identify pipes } \\
\text { - Replace monorail in cell } 74\end{array}$ \\
\hline $\begin{array}{l}1 \\
9 \\
8 \\
9\end{array}$ & $\begin{array}{l}3 \\
4 \\
5 \\
6 \\
7\end{array}$ & $\begin{array}{l}\text { - First water wash } \\
\text { - Move plasma torch into cell } \\
\text { - Chemical cleaning } \\
\text { - Water cleaning } \\
\text { - } \\
\text { - Install curtain to replace lock door A in cell } 74 \\
\text { - Removal of first complete tank ( } 600 \mathrm{~mm} \text { dia } \times 1200 \mathrm{~mm} \text { high) } \\
\text { - } \text { Roam cleaning } \\
\text { - Pemoval of second complete tank } \\
\text { - Pove telemanipulated robot into cell }\end{array}$ \\
\hline
\end{tabular}

\subsection{PIVER Environment}

The PIVER cleanup project covers not only cell 74 , but also the adjacent rooms, which were cleared out and decontaminated while the waste removal paths were being prepared and the remote manipulators were being installed in the cell. 


\subsection{Cell 74}

\section{Equipment Identification}

Equipment items were identified in order to provide a detailed description of the facility and list all equipment and process lines to be left intact for continued operation of the PIVER liquid storage unit. Some of these process lines are located inside or run through the vitrification cell, and had to be left intact. Equipment items were initially identified on construction drawings, and subsequently during the cleanup operations by means of a 3-D viewing system that allowed precise identification of pipes to be cut up or to be left intact.

\section{Radioactive Source Identification}

For positive identification of cell locations with high radioactivity levels, the $\gamma$ emission in the cell was mapped using a radioactive source localization technique (" $\gamma$ teletopography") developed at the Saclay Nuclear Research Center.

The result was a series of black- $\&$-white photos of the cell on which the active zones are identified in a range of false colors indicating the dose rates in rads per hour at a distance of one meter from the source.

The $\gamma$ teletopography method identified the major sources as the recovery pan runoff channel ( $2 \mathrm{~Gy} \cdot \mathrm{h}^{-1}$ at 1 meter $)$, deposits at the bottom of the tanks $\left(10 \mathrm{mGy} \cdot \mathrm{h}^{-1}\right.$ at 1 meter) and operating wastes littering the cell floor (10 to $100 \mathrm{mGy} \cdot \mathrm{h}^{-1}$ at 1 meter), and thus allowed the cleanup operations to be prepared rationally.

\section{Solld Waste Removal}

The first waste materials (filter casings, process inductor, miscellaneous waste) were removed at the beginning of 1987 in five packages. Additional solid wastes were removed starting in May 1988, after installation of the cutting tools, preparation of the removal path and reorganization of the work zone. Scrap and waste materials lying on the cell floor were removed first; then the pipes were cut up and process equipment (furnace inductors, ruthenium filters, vessels, tanks, etc.) were removed.

As of June 1989, the total activity removed in solid form was $1.03 \times 10^{14} \mathrm{~Bq}(2772 \mathrm{Ci})$ representing 35 packages transferred to the radioactive decontamination service, and 2 glass canisters moved to the PIVER glass storage area.

\section{Liquid Decontamination}

Because of the high activity deposited on the cell floor, the recovery pan was washed with water in December 1988 after removal of the operating wastes lying on the floor. The liquid waste was transferred to the fission product storage tank beneath cell 74 . A total of $2.2 \times 10^{13} \mathrm{~Bq}(600 \mathrm{Ci})$ was eliminated in this operation.

Several other cleaning methods were then implemented: water, acid, alkali, acid and alkaline foam, high pressure water spray. The total activity removed by liquid decontamination operations was $6.3 \times 10^{13} \mathrm{~Bq}(1716 \mathrm{Ci})$.

\section{Entry into Cell 74}

The current objective of the PIVER cleanup program is now to use a remote controlled robot to remove the waste materials from the recovery pan runoff channel, which is the last major radioactive source in the cell. This will then allow personnel to enter the cell for specific dismantling tasks.

\section{Chronological Radioactivity Balance}

As of the end of June 1989, the PIVER cleanup program was $41.6 \%$ complete (Figure 2) and the total activity removed was $1.66 \times 10^{14} \mathrm{~Bq}(4488 \mathrm{Ci})$ (Figure 3 ) not including the activity eliminated in liquid form by internal decontamination of the process equipment, representing a further 2.2 to $3 \times 10^{13} \mathrm{~Bq}(600-800 \mathrm{Ci})$. 
- THEORETIC PROGRESS

- - EFFECTNE PROGRESS

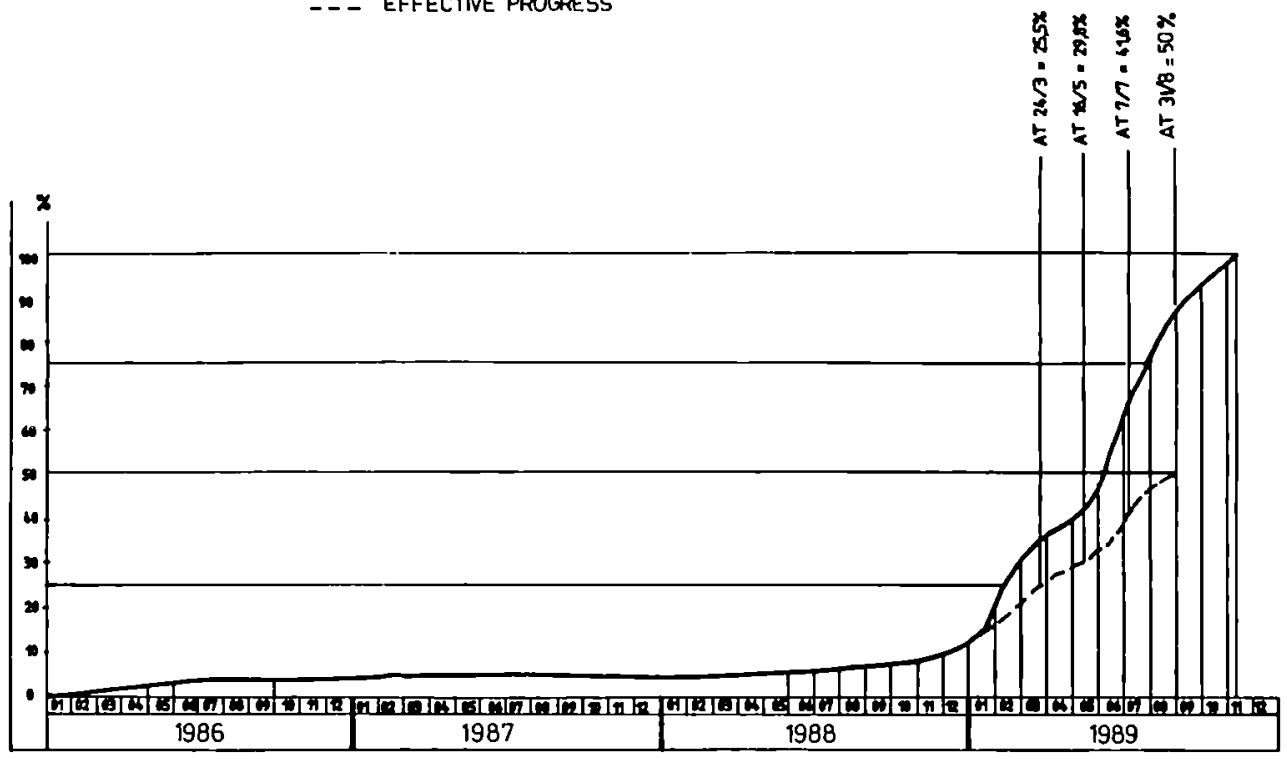

Figure 2 : Physical progress of PIVER dismantling operations

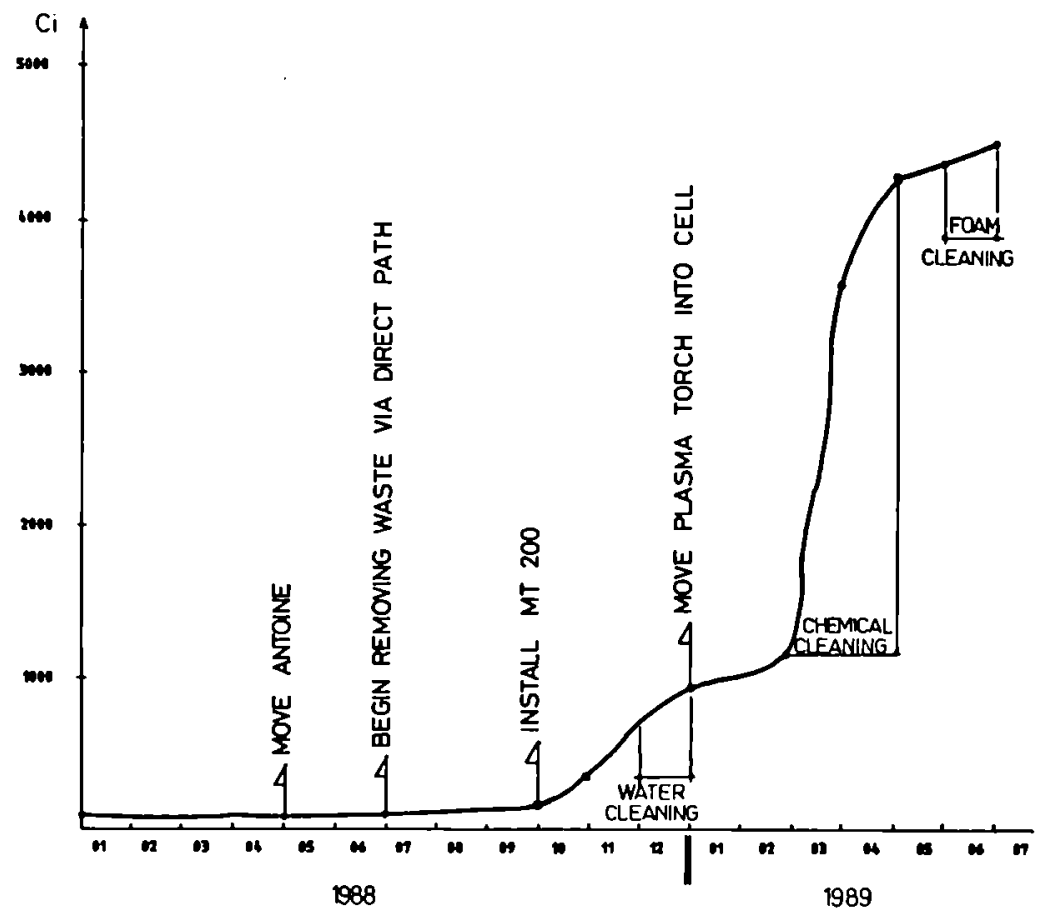

Figure 3 : Activity removed in solid and liquid form 
The radioactivity in the removed waste is itemized in the following table:

\begin{tabular}{|c|c|}
\hline Solid Waste & Activity \\
\hline 35 ANDRA shells or containers & $2.9 \times 10^{13} \mathrm{~Bq}(782 \mathrm{Ci})$ \\
\hline $\begin{array}{l}2 \text { canisters moved to the PIVER } \\
\text { storage area }\end{array}$ & $7.36 \times 10^{13} \mathrm{~Bq}(1990 \mathrm{Ci})$ \\
\hline Total & $1.03 \times 10^{14} \mathrm{~Bq}(2772 \mathrm{Ci})$ \\
\hline
\end{tabular}

\begin{tabular}{|c|c|}
\hline Liquid Waste & Activity \\
\hline 1st wash (water) & $2.22 \times 10^{13} \mathrm{~Bq}(600 \mathrm{Ci})$ \\
\hline 2nd wash (water) & $1.76 \times 10^{13} \mathrm{~Bq}(475 \mathrm{Ci})$ \\
\hline $3 \mathrm{rd}$ wash $\left(\mathrm{HNO}_{3}-\mathrm{NaOH}\right.$ & $1.98 \times 10^{13} \mathrm{~Bq}(535 \mathrm{Ci})$ \\
\hline 4th wash (manual HP) & $0.07 \times 10^{13} \mathrm{~Bq}(18 \mathrm{Ci})$ \\
\hline 5th wash (foam) & $0.33 \times 10^{13} \mathrm{~Bq}(88 \mathrm{Ci})$ \\
\hline Total & $6.36 \times 10^{13} \mathrm{~Bq}(1716 \mathrm{Ci})$ \\
\hline
\end{tabular}

\subsection{Operating Constraints and Incidents \\ PIVER Liquid Storage Facility}

Continued operation of the concentrated fission product storage facility, and notably safety-related system functions, imposed major constraints on the PIVER cleanup procedures and slowed the progress of the work. The vitrification cell contains a large number of the piping and instrumentation required for operation of the facility, and requires constant attention by the cleanup personnel.

\section{Telemanlpulators}

The hostile environment and difficult working conditions required repeated work on tooling as a result of failures or incidents, or simply for routine maintenance. The most significant incident was the collapse of the Caroline heavy telemanipulator arm in August 1988.

\section{Incldents}

Incidents occurring during cell 74 cleanup operations mainly involved surface contamination of personnel or work areas following removal of equipment items that had not been conditioned in drums before leaving the cell, or surface contamination of waste packing shells requiring them to be placed in ANDRA containers. 


\section{RADIOLOGICAL BALANCE}

\subsection{Removed Activity}

Since the operations began, the total activity removed in solid or liquid form from the PIVER vitrification cell is $1.66 \times 10^{14} \mathrm{~Bq}(4488 \mathrm{Ci})$.

Liquid decontamination wastes were transferred to the fission product storage tanks, and have accounted for $6.36 \times 10^{13} \mathrm{~Bq}(1716 \mathrm{Ci})$. Solid wastes were removed in ANDRA shells for concrete encapsulation $\left(2.59 \times 10^{13} \mathrm{~Bq}\right.$ or $\left.700 \mathrm{Ci}\right)$ or in glass canisters for transfer to the glass storage area $\left(7.4 \times 10^{13} \mathrm{~Bq}\right.$ or $\left.2000 \mathrm{Ci}\right)$.

\subsection{Cell 74 Irradiation Levels}

The irradiation level in the cell was monitored to assess the effectiveness of the cleanup operations, and especially the liquid decontamination procedures. Following the series of washing operations, measurements at the cell entry lock door showed that the irradiation level had dropped significantly in the entry area, and is now attributable to a radioactive source located at some distance from the entry. This was confirmed by irradiation measurements inside the cell, showing that after chemical washing the radioactive sources were situated at floor level, and primarily in the recovery pan runoff channel (Figure 4).

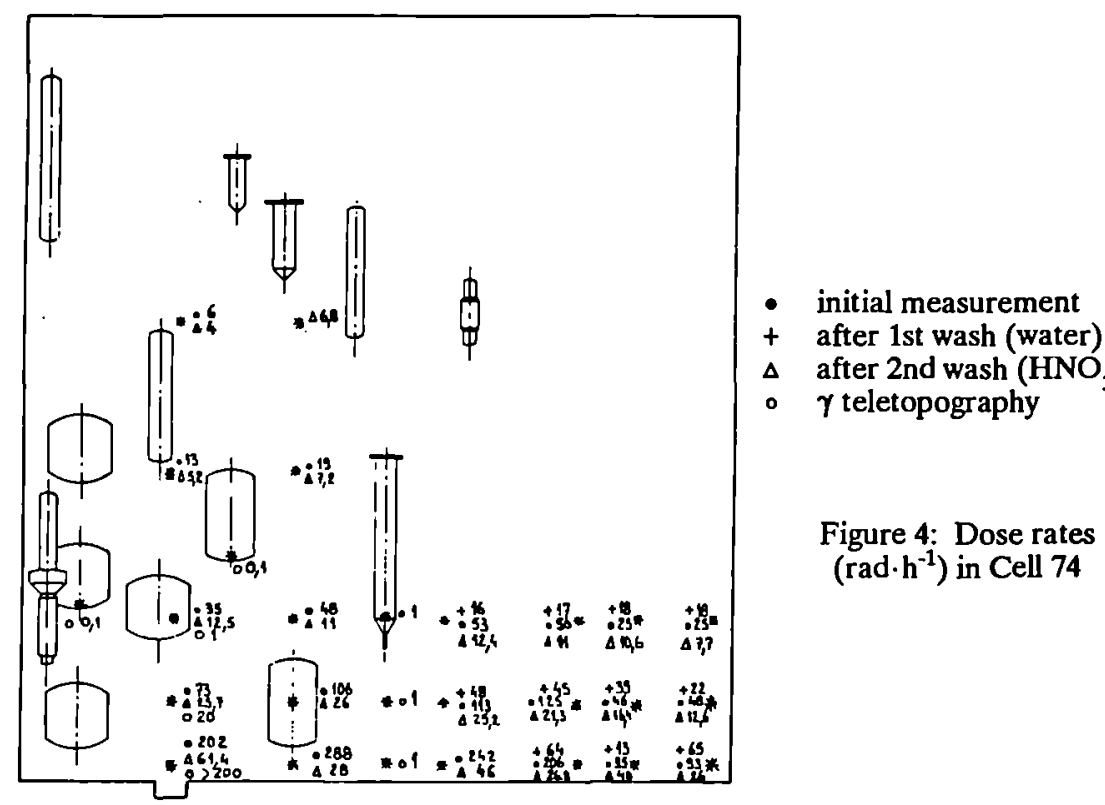

\subsection{Personnel Dose Integration}

The cumulative dose integration curve for the personnel working on the PIVER cleanup project has maintained a relatively constant slope (Figure 5).

As of the end of June 1989, the total cumulative integration since March 1988 (i.e. the beginning of the cell 74 cleanup work) was 18.8 rem for $\mathbf{4 0}$ persons (including about 8 rem in 1988). The collective dose distribution per category of operation was as follows:

- 50 to $55 \%$ of the collective dose was attributable to maintenance and repair of remote manipulator tooling;

- 15 to $20 \%$ of the collective dose was due to filling the waste containers;

- 25 to $30 \%$ of the collective dose was incurred during actual cleanup operations. 


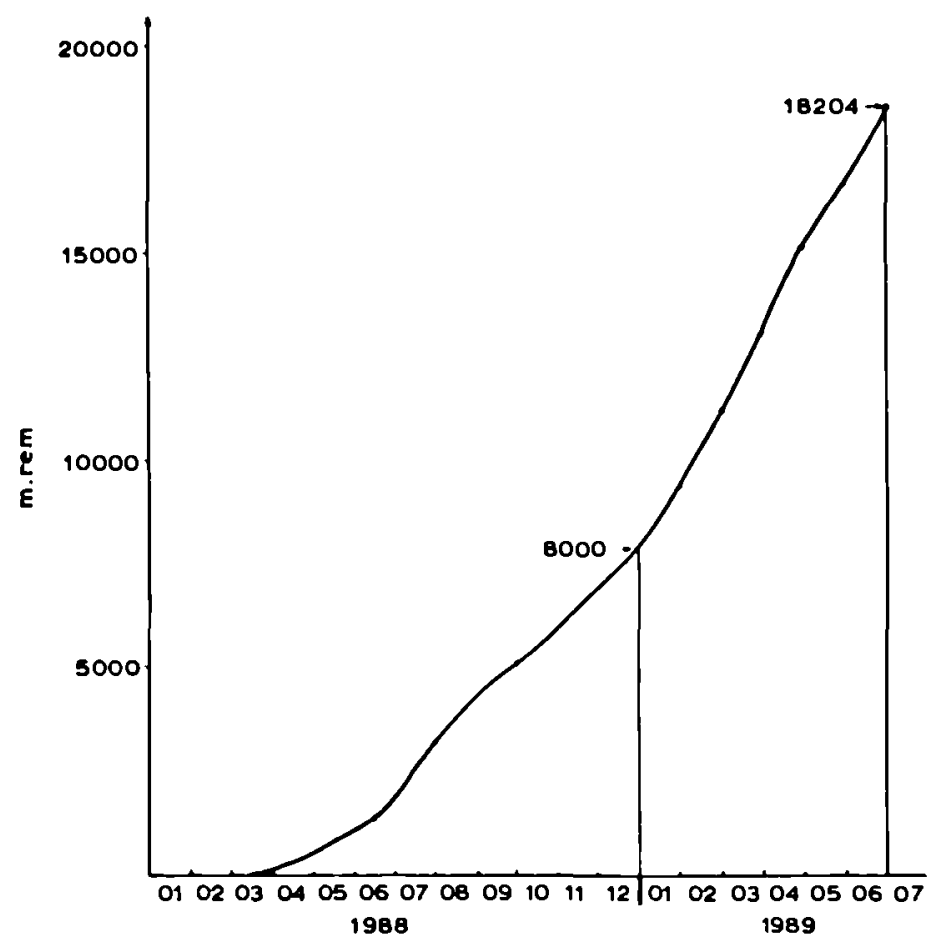

Figure 5: Cumulative integration at PIVER during 1988-1989

Exposure due to work on the telemanipulators and tools accounted for the largest fraction of the man-rem integration. Such operations should therefore be limited by removing a maximum of contamination sources to limit tool contamination and thus minimize irradiation of maintenance personnel.

\section{CONCLUSION}

The cleanup operation consisted in:

- removal of major equipment items and wastes littering the cell floor to allow dismantling;

- identification and elimination of the major irradiation sources.

The immediate objective now is to remove the waste materials that have accumulated in the recovery channel as well as all other irradiating wastes, in order to allow personnel to enter the cell to remove items that are inaccessible or which cannot be dismantled by remote manipulators, and to complete the decontamination procedure.

The following observations may be made at this time regarding the dismantling operations:

- The PIVER decommissioning methodology has been consistently adapted to situations as they arise, rather than following guidelines specified at the outset.

- Few means are available for working in hostile environments: nuclearized cutting tools were unavailable before the AMGA shear was developed.

- The problems encountered were overcome by simple solutions, more often by purchasing or fabricating a tool than by implementing sophisticated existing means. Only the OscarRomain robot was used, the other equipment items were specially designed. 
ADVANCES IN THE DECOMMISSIONING OF THE JPDR

TOMII K., YOKOTA M., HOSHI T.

Japan Atomic Energy Research Institute

Tokai-mura, Ibaraki-ken, Japan

\section{ABSTRACT}

The actual dismantling of the Japan Power Demonstration Reactor (JPDR) has been carried out since 1986 using the dismantling techniques developed in the Japan Atomic Energy Research Institute (JAERI). All the equipment and the piping around the reactor except the utility system in the reactor enclosure have already been removed. Highly activated reactor internals have been being dismantled since 1988 using underwater plasma arc cutting devices developed in JAERI. This paper describes an outline of the progress of the JPDR dismantling and also the experience obtained so far.

\section{INTRODUCTION}

Decommissioning of a power reactor in a safe and rational manner has been a matter of great concern in these years in Japan, as is stated in the current long-term nuclear program issued by the Japan Atomic Energy Commission (JAEC) in 1987.

On the basis of the former long-term nuclear program issued in 1982, the Japan Power Demonstration Reactor (JPDR) Decomissioning Program has been carried out in JAERI not only to develop necessary techniques to be applied to the JPDR dismantling but also to demonstrate these techniques through the actual dismantling of JPDR.

Various useful data and experience for dismantling commercial power reactors in the future are expected to be obtained through the JPDR dismantling *

\section{JPDR DECOMMISSIONING PROGRAM [1]}

\section{1 Outline of JPDR}

JPDR is a BWR-type power reactor starting its electricity generation In 1963. The thermal power was initially $45 \mathrm{MW}$ and was increased to $90 \mathrm{MW}$ in 1972 to enhance its neutron irradiation capability. The major specifications, the operation history and the radioactive inventory of JPDR are shown in Table I. Figure 1 illustrates the reactor enclosure (R/E).

\subsection{Outline of JPDR decommissioning program}

The JPDR decommissioning program generally consists of two major phases. Phase I, Technology Development, was started in 1981 to develop a set of various techniques needed for JPDR dismantling and was almost completed in 1986. Phase II, Actual Dismantling of JPDR, has been carried out since 1986 using developed dismantling techniques to demonstrate these techniques through the actual dismantling for the future comercial power reactor decommissioning.

A present schedule for the actual dismantling of JPDR is shown in Fig. 2 which also includes the various dismantling techniques not only being used but also to be used. The critical-path work in the actual dismantling is the removal of the activated components in the $R / E$ such as the reactor internals, the reactor pressure vessel (RPV) and the biological shield.

The total manpower required and the total radiation exposure to workers during the dismantling work are estimated at 73,000 man-days and less than 1 man-Sv (100 man-rem), respectively. 
Table I: Major specifications, operation h1story and radioactive Inventory of JPDR

\begin{tabular}{cl}
\hline Specifications & \\
Type of reactor & BWR \\
Thermal power & $90 \mathrm{MWt}$ (45 MWt initially) \\
Pressure vessel & \\
material & ASTM-A302-56 Gr B \\
inner diameter & $2.1 \mathrm{~m}$ \\
height & $8.1 \mathrm{~m}$ \\
thickness & $7 \mathrm{~cm}$ \\
Biological shield & \\
material & reinforced concrete \\
thickness & $1.5 \mathrm{to} 3 \mathrm{~m}$ \\
Reactor enclosure & \\
inner diameter & $15 \mathrm{~m}$ \\
height & $38 \mathrm{~m}$
\end{tabular}

Operation history

Operation time

Output of electricity

\section{7,000 hours}

$1.4 \times 10^{\circ} \mathrm{KWH}$

Radioactive inventory

$4,100 \mathrm{Ci}$ (2s of December, 1986)

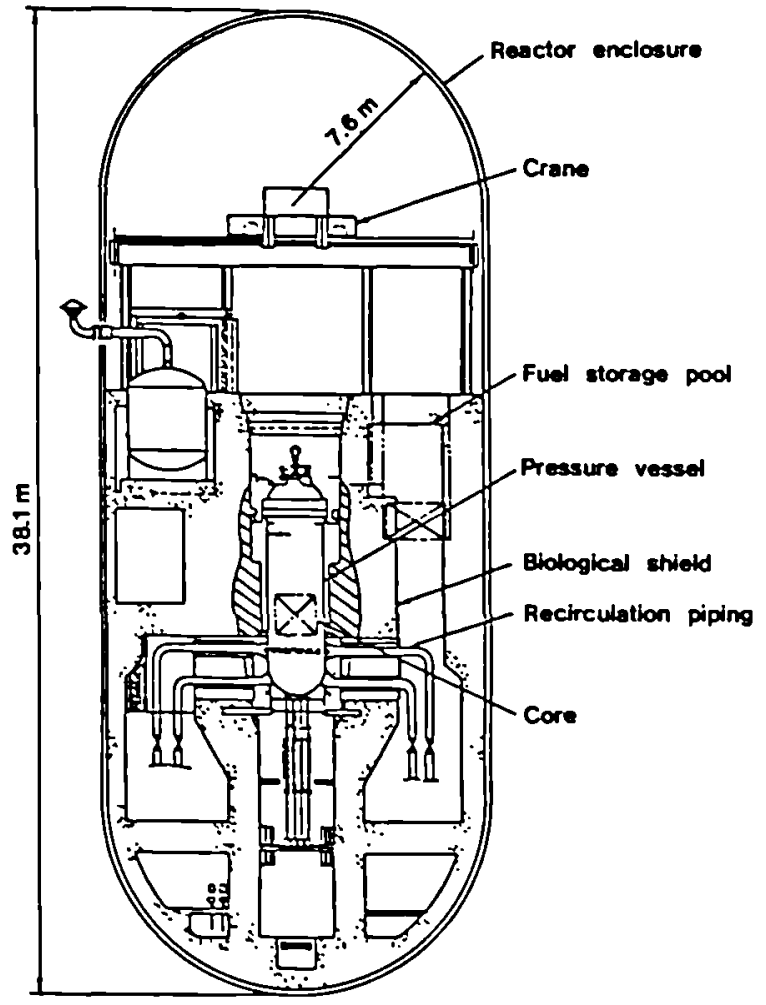

Fig. 1: JPDR reactor enclosure 
The total radioactive waste produced from the dismantling is also calculated at about 4,100 tons in total 27,800 tons of waste from the dismantling.

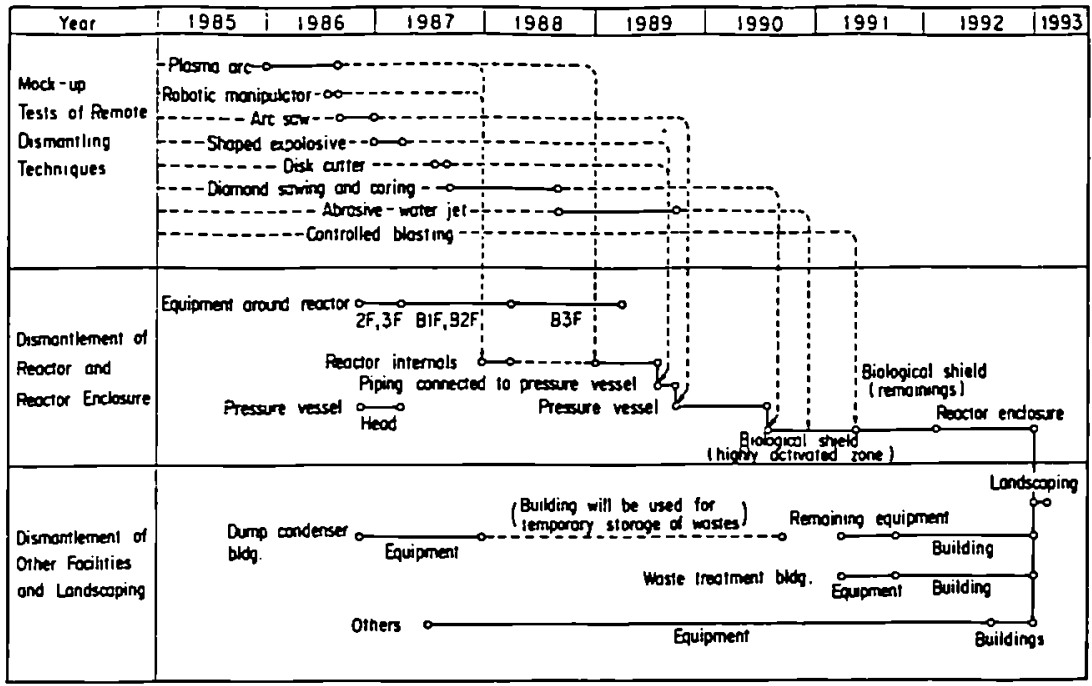

Fig. 2: JPDR decommissioning schedule

\section{PROGRESS OF DISMANTLING WORK}

Before the radioactive components were dismantled, a preparatory work was performed as follows: the entrance to radiation controlled area was enlarged and new monitoring equipment for radiation exposure to workers was installed at the entrance to control the entering/exiting efficiently. In addition, the components in the dump-condenser building which had been in little service, were removed so that the building could be used as a temporary waste storage yard as well as a working space for decontaminating dismantled components.

\subsection{Removal of components a round the reactor}

Before the removal of the reactor internals and the RPV, the components around the reactor as in the following were removed to enlarge a working space in the $\mathrm{R} / \mathrm{E}$ : the pressure vessel head, the emergency condenser, the shielding cooling pump, the heat exchanger, the forced circulation pump, the piping and the valves. The pressure vessel head was cut with an oxygen torch in a contamination control envelope, because the radiation dose rate on its surface was below $50 \mu \mathrm{Sv} / \mathrm{h}(5 \mathrm{mR} / \mathrm{h})$. When the forced circulation system was dismantled by an in-air plasma cutting device in a contamination control envelope, the radiation dose rate in the envelope was below $100 \mu \mathrm{Sv} / \mathrm{h}(10 \mathrm{mR} / \mathrm{h})$ at most and the maximum radiation exposure to workers was $400 \mu \mathrm{Sv} / \mathrm{h}(40 \mathrm{mR} / \mathrm{h})$. The dismantled pieces were put into $3 \mathrm{~m}^{3}$ steel containers and placed at a storage facility in JAERI.

\subsection{Removal of components in fuel storage pool}

There are two fuel storage pools in the JPDR facility, namely the fuel storage pools located both inside and outside the $R / E$. Components in each pool were removed as follows. 
(1) Components in the pool outside R/E

The components in the pool were dismantled so that the drained pool could be used as a temporary storage place for shielded containers. The major components removed are as follows: 75 channel boxes for the spent fuel assemblies, the fuel storage racks and the underwater cask stand. Most of the components in the pool were removed underwater by remote control. Before the dismantling work, a channel box cutting machine, a contamination control envelope and a local ventilation equipment were installed. Each channel box was cut into four segments using the cutring machine with a plasma torch to pack the cut pieces into containers efficiently as shown in Fig. 3. The maximum radiation dose rates on the surface of the channel boxes and the shielded containers with a wall thickness of $235 \mathrm{~mm}$ were about $3 \mathrm{mSv} / \mathrm{h}(300 \mathrm{mR} / \mathrm{h})$ and $20 \mu \mathrm{Sv} / \mathrm{h}(2 \mathrm{mR} / \mathrm{h})$, respectively.

The spent fuel storage buflding has been used as a temporary storage yard for the shielded containers after the above work was completed in August, 1988.

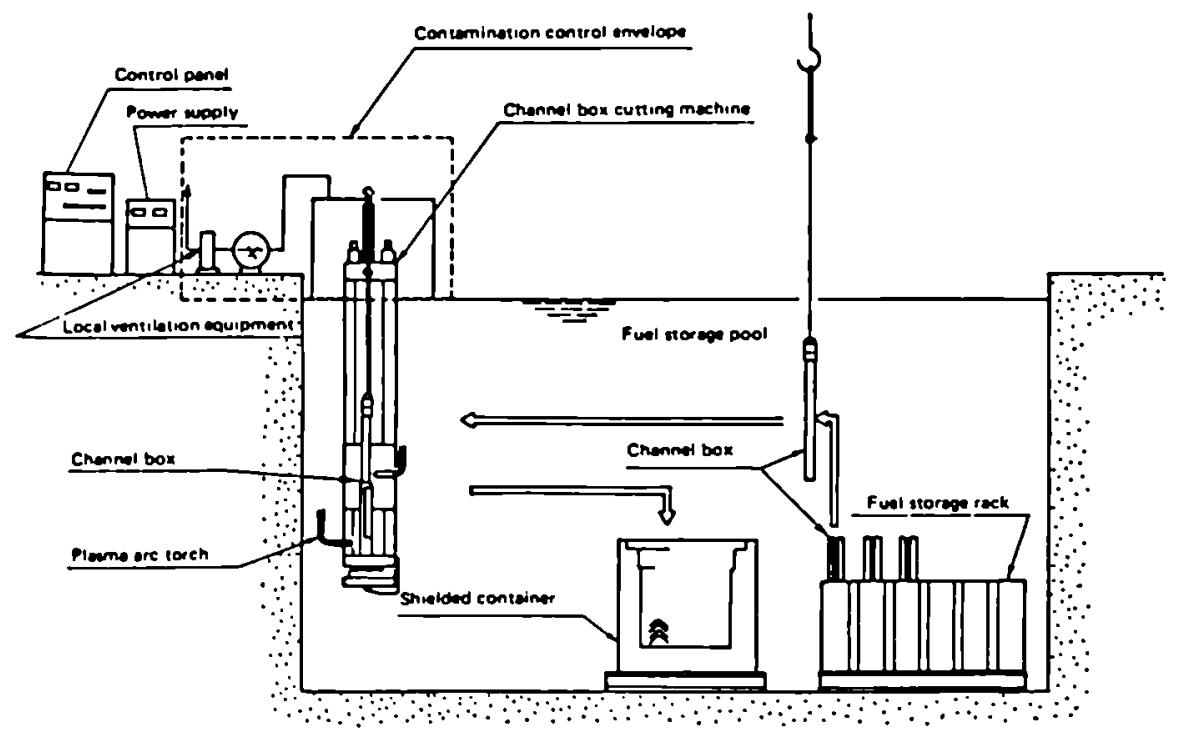

Fig. 3: Schematic of channel box cutting

(2) Components in the pool inside $R / E$

The components stored or installed in the spent fuel storage pool in the $R / E$ were dismantled so that a secondary cutting device could be installed in the pool. The dismantling work was performed either in-air or underwater in accordance with both the radioactivity level and the shape of each component. When several components such as the steam riser frame and the steam separator were dismantled in-air, they were moved into the contamination control envelope and then cut using an in-air plasma arc cutting device. The cutting work was performed by workers wearing respirators supplied with an external source of filtered air. During the work in the air, the radiation dose rate at each worker's location was carefully maintained at less than $100 \mu \mathrm{Sv} / \mathrm{h}(10 \mathrm{mR} / \mathrm{h})$ with the help of radiation protection for the cutting object.

The highly activated components such as the control rods and the sample coupon hangers were cut using an underwater plasma arc cutting device prepared for these cuttings. The cut pieces were put into cast-iron 
shielded containers. The maximum surface radiacion dose rate of these pieces was over $10 \mathrm{~Sv} / \mathrm{h}(1000 \mathrm{R} / \mathrm{h})$ for the control rods and $200 \mathrm{mSv} / \mathrm{h}(20$ $\mathrm{R} / \mathrm{h}$ ) for the sample coupon hangers. However, the maximum radiation dose rate on the surface of the shielded containers was $250 \mu \mathrm{Sv} / \mathrm{h}(25 \mathrm{mR} / \mathrm{h})$. Photo 1 shows the shielded container for the control rod.

After these components were removed, the pool was drained and decontaminated. The atmospheric radiation dose rate in the pool was less than $25 \mu \mathrm{Sv} / \mathrm{h}(2.5 \mathrm{mR} / \mathrm{h})$ after the decontamination.

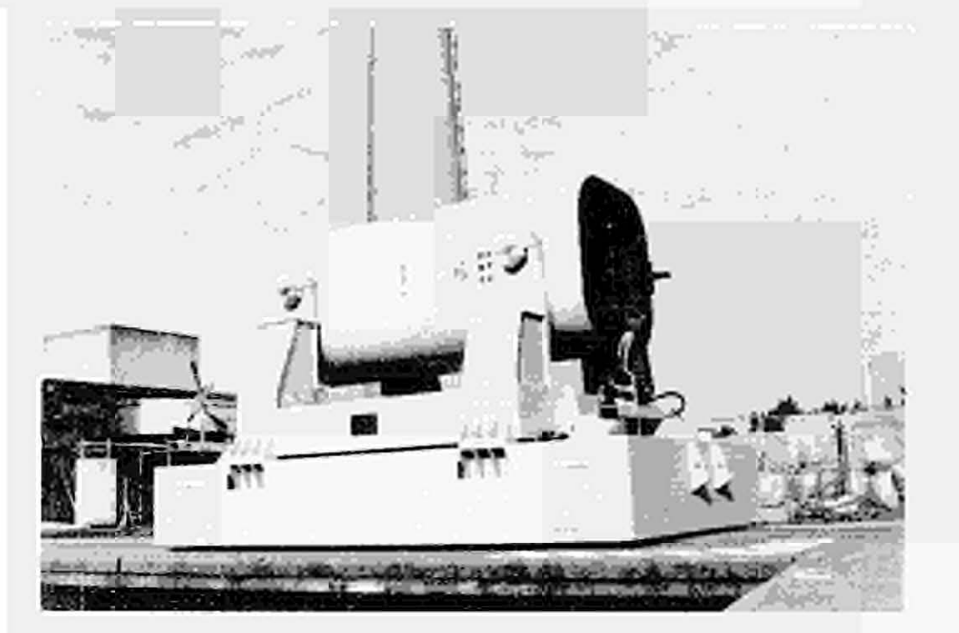

Photo 1: Shielded container for control rod

\subsection{Removal of reactor internals}

Radioactivity of the reactor internals close to the core is so high that remote underwater cutting is required for safety assurance of workers. The reactor internals have been dismantled with the following two types of plasma arc cutting devices developed in JAERI to demonstrate the operational performance of each device.

(1) Dismantling with robotic manipulator

Three reactor internals, namely, the core spray block, the feedwater sparger and the upper grid stabilizer, were detached from the inner wall of the RPV using an underwater plasma arc cutting device with a robotic manipulator. In the removal of these components, the support structure of the robotic manipulator was set up over the top of the RPV. An underwater plasma arc torch was installed at the top of the manipulator which has seven degrees of freedom and the whole assembly was enclosed in a plastic tent for local ventilation.

During the cutting work, the robotic manipulator was lowered into the RPV and then locked at any desired location in the RPV by a tripedal support mechanism having expandable legs. This manipulator was operated from a remote control room which was located about $100 \mathrm{~m}$ far from the $R / E$. Figure 4 shows a schematic view of the robotic manipulator type cutting system.

Prior to the actual cutting, key positions, a starting point and an ending point of each cutting path were manually determined using the master-slave mode of operation of the system. These data were then stored in the control computer. The torch positioning was carefully monitored by a TV camera system during this mode of operation. Figure 5 and Photo 2 show the RPV and the plasma arc torch with the slave arm of the robotic 


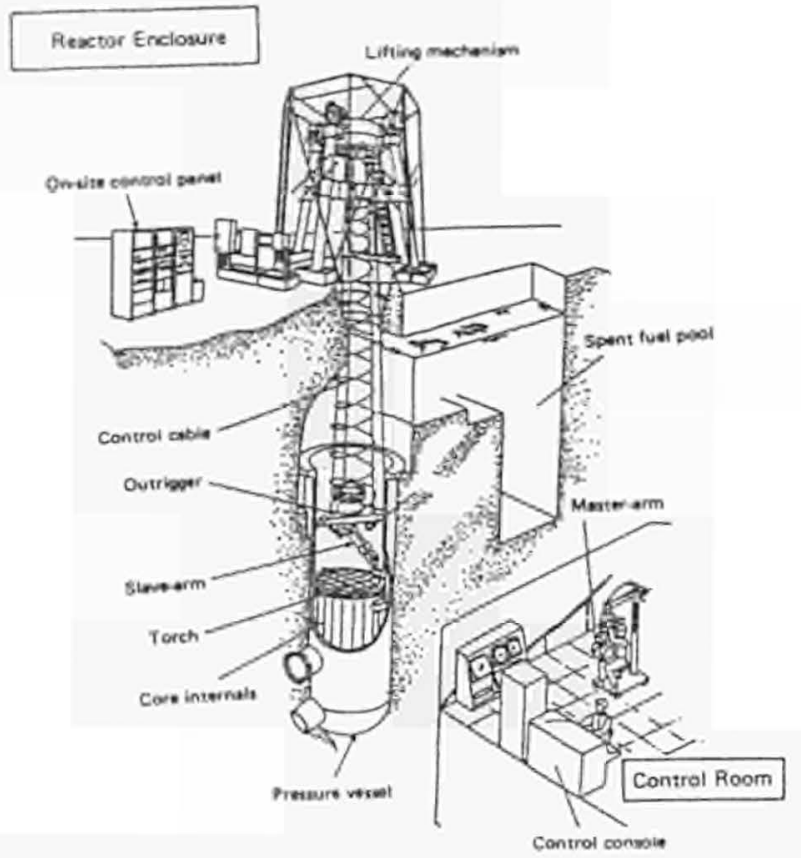

F1g, 4: Schematic view of robotic manipulator cutting system

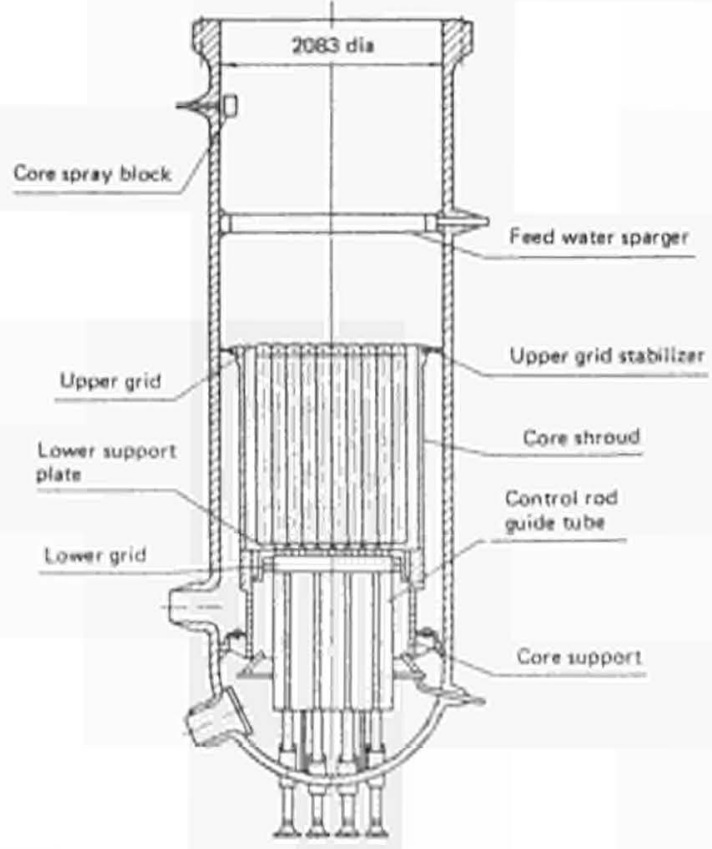

Fig, S: JPDR RPV and internals which have been cut

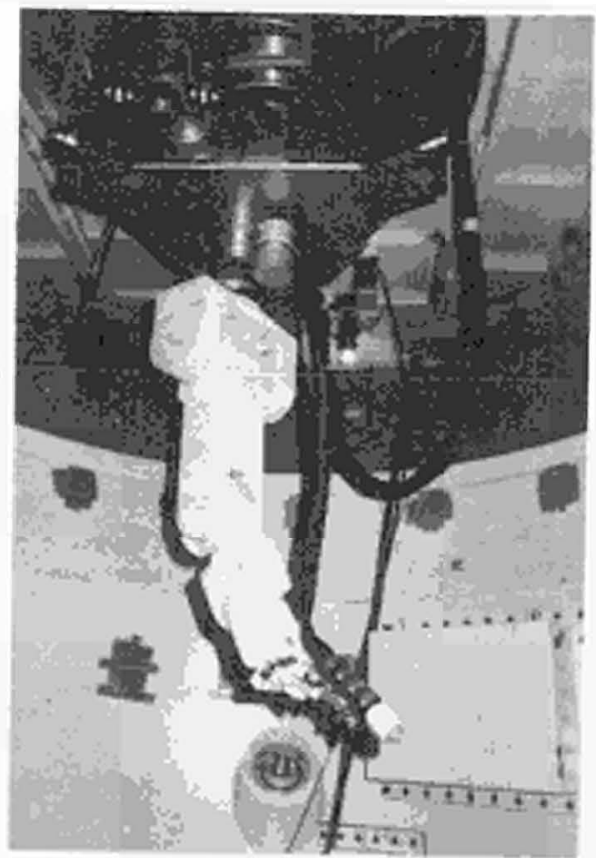

Photo 2: Plasma are torch with the slave arn of the robotic manipulator 
manipulator, respectively.

(2) Dismantling with mast-type manipulator

The activated reactor internals such as in-core monitor tubes, steam riser frame and the core shroud were removed using a plasma arc cutting system with a mast-type manipulator.

In the removal of the components in the spent fuel storage pool, the mast-type plasma arc cutting device was installed above the RPV and a secondary plasma arc cutting device was also set up above the pool. Figure 6 shows a basic concept of this dismantling.

The cutting process was divided into two steps to perform the cutting work effictently as shown in Fig. 6. First, the reactor internals in the RPV were roughly cut into pleces of proper size for the subsequent cutting work in the spent fuel storage pool (primary cutting). These pleces were then transferred to the pool underwater through the canal and were cut into smaller pieces to be put into shielded containers (secondary cutting).

Underwater monftoring cameras, a contamination control envelope and a gas collection system were installed before the dismantling work as shown in Fig. 6 .

Though the maximm surface radiation dose rate of the cut pleces was $3.7 \mathrm{~Sv} / \mathrm{h}(370 \mathrm{R} / \mathrm{h})$ for the core shroud, after the cut pieces were put into the shielded contalners, the maximum radiation dose rate on the surface of the contalners was $35 \mu \mathrm{Sv} / \mathrm{h}(3.5 \mathrm{mR} / \mathrm{h})$.

The dismantling work for the reactor internals using the plasma arc cutting device will continue unt1l August, 1989. After the removal of the reactor internals, pipes connected to the RPV will be cut using a shaped explosive cutting and a rotary disk knife cutting techniques.

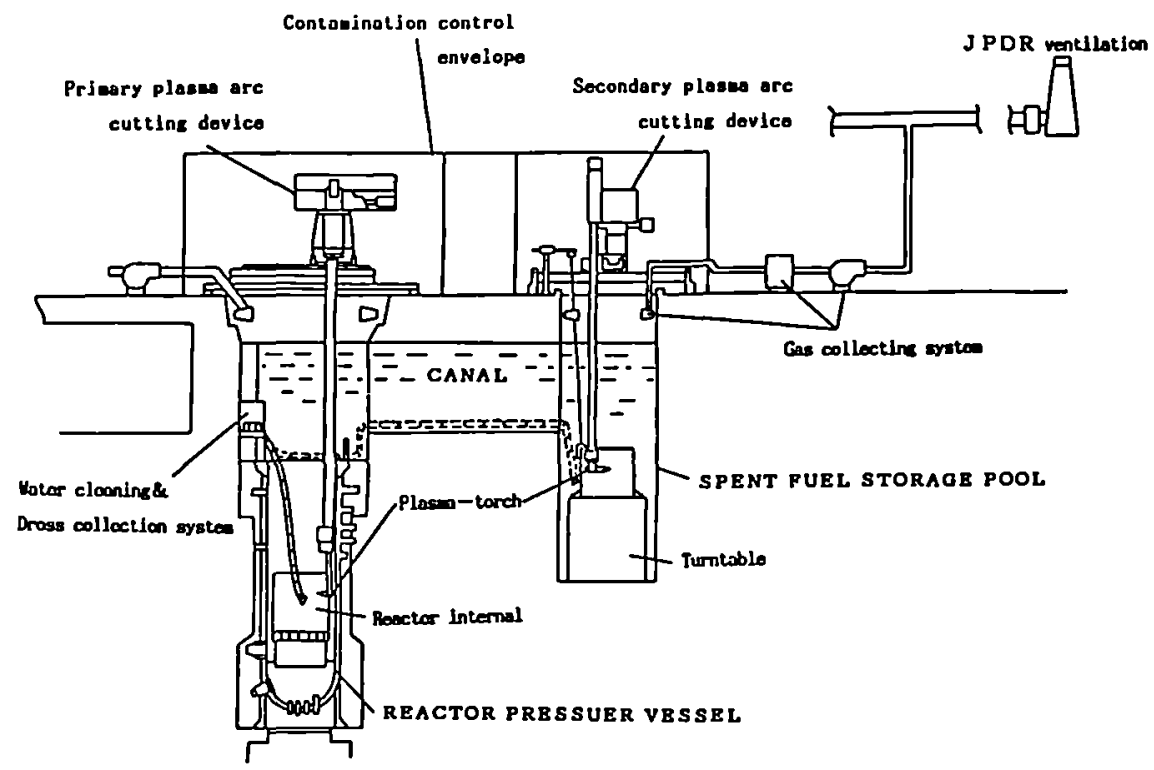

FIg. 6: Baslc concept of dismantling of reactor internals 


\section{EXPERIENCE OBTAINED THROUGH JPDR DISMANTLING}

The effectiveness of a part of dismantling techniques developed in JAERI has already been verifled through the dismantling work being so far performed.

\subsection{Performance of plasma arc cutting system}

Several types of plasma arc cutting systems such as a mast type and a robotic manipulator type systems have been properly used according to the content of the work. The plasma arc cutting work was mainly carried out underwater because of high-level radioactivity of the cutting objects. A typical underwater cutting system is composed of a cutting head, a cutting monitoring unit, a water cleaning unit, a contamination control envelope with local ventilation, etc.

(1) Cutting performance

Three kinds of plasma arc cutting techniques whose arc starting procedures are mainly different from each other were effectively applied to the dismantilng of the reactor internals. These cutting techniques were properly used according to the shape and the thickness of each cutting object to carry out the cutting efficlently. In the cutting of the core spray block, dross bridging produced in the kerf disturbed the separation of the cut pleces. A long striking rod had, therefore, to be used to separate the cut pleces. Furthermore, In some cases, re-cutting work was needed. Though dross bridging in the kerf of the feed water sparger also generated during its cutting, this problem was solved by decreasing the pre-planned cutting speed. In addition, the nozzle pieces were frequently exchanged to avold the adverse effect of the dross build-up which could make the plasma arc unstable.

When taking a measure to meet these problems, various experiences obtalned through the mock-up tests of the plasma arc cutting techniques have been very useful.

(2) Underwater TV camera

During the cutting work for the reactor internals, a few standard-size and a miniaturized TV cameras were used depending upon the cutting work. The minlaturized camera was found to be especially effective in the underwater cutting work because it could be installed in a narrow space in the RPV. In some cases, the camera had to be placed far away from the highly activated cutting object because the camera performance is generally disturbed by high-level radiation. However, when the camera had a zoom function, the cutting work was performed without a problem. Moreover, white spots were sometimes observed on the TV display when the camera was installed in the position with a radiation level of $2000 \mathrm{mSv} / \mathrm{h}(200 \mathrm{R} / \mathrm{h})$. It was also found that the camera function went out when the camera was placed in the field of $3000 \mathrm{mSv} / \mathrm{h}(300 \mathrm{R} / \mathrm{h})$.

In short, the experiences so far obtained from the cutting work using the underwater $T V$ camera have sufficlently proved the effectiveness of the camera.

(3) Radioactive contamination

Most contamination on the slave arm of the robotic manipulator could be easily removed after the cutting work for the reactor internals because the arm was coated with strippable paint before the cutting work to facilitate decontamination of the am. However, the holding mechanism could not be coated with strippable paint owing to 1ts complicated shape. Consequently, surface contamination of the holding mechanism was measured to be approximately $15 \mathrm{~Bq} / \mathrm{cm}^{2}\left(4.0 \times 10^{-4} \mathrm{C1} / \mathrm{cm}^{2}\right)$.

In addition to the strippable coating, a water cleaning and a local ventilation systems were also very effective in reducing a possibility of radioactive contamination. 
4.2 Management data on dismantling work

Various management data on the dismantling work have been accumulated for planning future commercial power reactor decomisissioning since the start of the JPDR dismantling as are listed in Table II. In addition, these management data have been extensively used to verify the code system for management of reactor decommissioning (COSMARD) developed in JAERI.

Table II: Management data (As of May, 1989)

\begin{tabular}{|c|c|c|c|c|c|c|}
\hline \multirow{2}{*}{ Removal Work elc. } & \multirow{2}{*}{$\begin{array}{l}\text { Working } \\
\text { Monpower } \\
\text { (mon·day) }\end{array}$} & \multirow{2}{*}{$\begin{array}{c}\text { Max. Personal } \\
\text { Exposure } \\
\text { (msv) }\end{array}$} & \multirow{2}{*}{$\begin{array}{l}\text { Cumulative } \\
\text { Exposure } \\
\text { (mon mssy) }\end{array}$} & \multicolumn{2}{|c|}{ Rodiooctive Woste } & \multirow{2}{*}{$\frac{\mid \text { ton })}{\text { Consequenlla }}$} \\
\hline & & & & Metal & Conerete & \\
\hline $\begin{array}{l}\text { Preporalory Work } \\
\text { (Includes Dump Con.) }\end{array}$ & 10,350 & 0.03 & 0.3 & 198 & 39 & 11 \\
\hline $\begin{array}{l}\text { Components } \\
\text { Around Reactor }\end{array}$ & 5,600 & 0.33 & 2.2 & 126 & 32 & 5 \\
\hline $\begin{array}{l}\text { Components in the Pool } \\
\text { Outside R/E }\end{array}$ & 1,190 & 0.03 & 0.1 & 6 & 0 & 4 \\
\hline $\begin{array}{l}\text { Components in the Pool } \\
\text { inside } R / E\end{array}$ & 1,770 & 2.11 & 17.1 & 13 & 0 & 2 \\
\hline $\begin{array}{l}\text { Reactor Internols } \\
\text { \& its preparatory work }\end{array}$ & 5,580 & 0.67 & 3.4 & 16 & 1 & 1 \\
\hline Tolol & 24,490 & 2.20 & 23.1 & 359 & 72 & 26 \\
\hline
\end{tabular}

(1) Manpower expenditure

The cumulative manpower expenditure from the start of the dismantling through May, 1989 was about 24,500 man-day. During the period, approximately 30 workers per day have been with the dismantling and 111 workers at the peak time of the dismantling. Moreover, the percentage of the workers for technical administration of nuclear reactor dismantling is found to be larger than that of the same kind of workers for dismantling of usual facilities. In the JPDR dismantling, the approximate percentage of workers in each kind of job is as follows: $40 \%$ for the technical administration, $10 \%$ for the supervising, $40 \%$ for the site work and $10 \%$ for the radiation control.

(2) Radiation exposure

The cumulative radiation exposure to workers and the maximum cumulative personal radiation exposure from the start of the JPDR dismanting through May, 1989 were about $22.7 \mathrm{man} \cdot \mathrm{mSv}(2.27 \mathrm{man} \cdot \mathrm{rem})$ and $2.2 \mathrm{mSv}$ (220 mrem), respectively.

The dismantling work accompanied with high-level radiation exposure was as follows: the decontamination of the spent fuel storage pool, the In-air and underwater plasma arc cuttings of the reactor internals and the removal of the pipes of the recirculation system.

Since the highly activated reactor internals were dismantled not only remotely but also underwater, the cumulative radiation exposure to workers during the underwater plasma arc cutting work for the reactor internals was found to be less than those for the decontamination of the spent fuel storage pool and for the in-air plasma arc cutting of the less activated reactor internals. 


\section{(3) Radloactive waste}

The cumlative amount of the solid radioactive waste from the start of the JPDR dismantling through May, 1989 was about 450 tons, most of wich is low-level radioactive. The waste is classified according to the specifications for the working area and the radioactivity level.

Containing work for the radioactive waste into shielded containers was started in May, 1988 and the total 6.1 tons of radioactive waste has already been put into 19 shielded containers. The weight of each shielded contalner 18 limlted to be less than 20 tons because of the maximm capac1ty of the used crane. By the end of the JPDR dismantling, total 36 shlelded contalners are expected to be used.

\section{CONCLUDING REMARKS}

The actual dismantling of JPDR is proceeding satisfactorily and has been producing varlous useful data and experience on decommissioning of nuclear reactors. The JPDR dismantling has been carried out almost on schedule and, up to now, there has been no serlous problem about safety, radiological and environmental matters. The wide variety of the results obtalned through the JPDR dismantling are expected to make a valuable contribution to decommissioning of commercial power reactors.

\section{ACKNOWL EDGMENT}

The authors are grateful for the support extended by Messrs. H. Ish1kawa and A. Toralsh1, Department of JPDR, in the preparation of this paper.

\section{REFERENCES}

[1] ISHIKAWA, M., et al., "Reactor Decommissioning In Japan - Philosophy and First Program - ", International Conference on Nuclear Power Performance and Safety, IAEA, Vienna, Sept. 28 - Oct. 2, 1987. 


\title{
COMPLETION OF THE SHIPPINGPORT REACTOR DECOMMISSIONING
}

\author{
SCHREIBER, JOHN J. \\ $U$. S. Department of Energy \\ Shippingport, Pennsylvania USA
}

\section{ABSTRACT}

Planning for the decommissioning of the Shippingport Atomic Power Plant began in 1979 and ended with publication of the Decommissioning Plan in 1983. The site was available for occupation by the Decommissioning Operations Contractor in September 1984 and physical work on decommissioning commenced in September 1985. This physical work was completed 3.75 years later, almost 6 months ahead of schedule. The total cost will be $\$ 92 M$ which is $\$ 6 M$ less than the $\$ 98 M$ estimated.

A breakdown of planned and actual statistics is presented for various aspects of the decommissioning work including: Cost, schedule, manpower, radiation exposures, waste arisings and shipments. Various aspects concerning contracts, decontamination, asbestos, safety, lessons learned and technology transfer are also presented.

\section{BRIEF HISTORY OF THE SHIPPINGPORT ATOMIC POWER STATION}

The Shippingport Atomic Power Station is located on the south bank of the Ohio River at Shippingport (Beaver County), Pennsylvania, on approximately seven acres of 1 and 1 eased from Duquesne Light Company (DLC) by the U. S. Atomic Energy Commission which was the predecessor agency to U. S. Department of Energy (DOE). This location is approximately $25 \mathrm{miles}$ northwest of Pittsburgh, Pennsylvania.

The Station was constructed during the mid-1950s as a joint project of the Federal Government and DLC. The purposes of the project were to develop and demonstrate pressurized water reactor (PWR) technology and to generate electricity. The reactor and steam generating portions of the station are owned by DOE, and the electrical generating portion is owned by DLC.

The Station achieved criticality in December 1957 and was operated by DLC under supervision of DOE-Naval Reactors (NR) until operations were terminated on October 1, 1982. End-of-life testing as well as reactor defueling were conducted in the following two years. The Station utilized three cores of reactor fuel. The first two cores were PWR cores, and the last core was a light water breeder reactor (LWBR) core. The LWBR core was installed in 1977 for the purpose of demonstrating the thermal breeding principle in a light water reactor. Responsibility for the Station was transferred from Naval Reactors to Richland, within DOE, on September 6, 1984, with General Electric (GE) replacing DLC as Operations Contractor at that time. Table I displays a summary of operational data and a chronological sequence of operations at Shippingport. 


\section{SHIPPINGPORI STALION DECOMMISSIONING PROJECT (SSOP)}

The mission for this Project was to decommission the government-owned portion of the Shippingport Atomic Power Plant and thereby:

a) demonstrate the safe and cost effective dismantlement of a large full-scale commercial nuclear plant

b) optimize the number of subcontractors to expand the technology base and experience

c) provide a technology transfer program (adequate records) for use in future decommissioning projects and to develop industry standards.

The technical baseline for the Decomissioning Plan required that:

1) all government-owned structures be removed to 3 feet below grade

2) all radwaste be removed from the site and buried at Hanford

3) the Reactor Pressure Vessel/Neutron Shield Tank (RPV/NST) be removed as a single unit

4) the site be returned to the owner, Duquesne Light Company, in a safe condition from a radiological standpoint.

The Decommissioning Plan was written for the project during the Phase I Engineering and a cost estimate was developed in support of $i t$. The Environmental Impact Statement (EIS) and Record of Decision were published in 1982. A Decommissioning Operations Contractor (DOC) was selected in March 1983. Site turnover from OLC (the plant operating contractor for Naval Reactors) was accomplished in September 1984. Table II provides a chronology of the major milestones during Phase II - Decommissioning.

The total estimated cost including planning was $598.3 \mathrm{M}$ with completion scheduled for April 1990. Final costs underran by $\$ 6.0 \mathrm{M}$ for a total of $\$ 92 \mathrm{M}$ with decommissioning operations being completed in September 1989. Actual physical decommissioning work occurred from September 1985 to July 1989 (46 months). A cost break-down by Phase and participants is shown in Table III.

Policy decisions made after start of work required the application of $\$ 4.4 M$ out of the original allowance of $\$ 10.8 \mathrm{M}$ for contingency. A further distribution of the $\$ 36$ Million spent just on Decommissioning work is shown in Figure 1 .

of the total 1,350,000 manhours applied to the job there were 334 lost work days due to accidents. There were no fatalities. The severity rate (i.e. Lost Work Days/100 manyears) of 49 for the project compares with 120 for the demolition industry in the United States.

Operational Readiness Reviews (ORR) were conducted at key points during the course of D\&D. These ORRs required a detailed evaluation of the ability of the contractors involved to safely complete their tasks based on availability and readiness of equipment, personnel and procedures. ORR's were conducted prior to: Takeover of the Plant; Start of physical decommissioning; 
Unrestricted Release of Materials; Lift and Load of the RPV/NST; and, Shipment of the RPV/NST.

The Decommissioning $\mathrm{Plan}$ estimated 1000 man-rem total radiation exposure for the work force during the project. The actual total personnel exposure accumulated was 155 manrem. Although the original estimate was conservative, dramatic reductions in exposures were effected by good planning and ALARA practices. Work on asbestos was performed at airborne concentration levels well below (one-tenth) the industry standards. At a later date, Occupational Safety \& Health Administration (OSHA) adopted standards comparable to those used at SSDP. There were no cases of personnel overexposure at the stricter standards.

The total work force averaged around 200 during the peak physical decommissioning years, of 1986 and 1987. Figure 2 shows the application of manpower during the course of physical decommissioning as compared to the acquisition of doses during the same period.

More than eighteen (18) subcontractors were utilized by the DOC (General Electric with M-K Ferguson as their fully integrated subcontractor) which accounted for an expenditure of $\$ 36 \mathrm{M}$ towards the basic decommissioning work. Eight (8) of these subcontractors performed $75 \%$ of the work, the DOC's Force Account performed another $8 \%$ with the balance accomplished using smaller subcontractors. An additional \$28M was spent for various support groups such as security, radcon, purchasing, transportation, plant maintenance and operations, etc. which were required to sustain progress. All subcontract work was competitively bid Fixed Price. Table IV shows the total distribution of manpower during the course of the project by major categories such as DOC Management, Operations/Support and Decommissioning.

The Decommissioning $\mathrm{P} I$ an and cost estimate was based on a recommended approach to maximize the application of subcontractors to work areas. To reduce the number of concurrent interfaces to be managed, the DOC was directed to optimize the number of subcontractors. Consequently, several of the 17 original Activity Specifications in the Plan were either split or combined to form more efficient work and bid packages. Additionally, the great majority of Asbestos removal was separated out in order to be accomplished first before removal of any components or piping rather than require simultaneous removal. Table $V$ provides a brief summary of the Asbestos activity.

One piece removal and burial of the Reactor Pressure Vessel/Neutron Shield Tank (RPV/NST) was a major feature of the Plan. The total cost to prepare, remove and bury the RPV/NST package was $\$ 10.3$ Million. This work included: replacing the non-fuel reactor internal components (which were originally planned to be shipped separately) into the RPV; filling the RPV/NST cavities with grout; writing the Safety Analys is Report Packaging (SARP); removing the reactor chamber; and lifting, loading, transporting and burying the package. Table VI provides a breakdown of costs by major contractor participating in this work and the percentages for the work compared to total costs.

All government owned structures were removed to at least 3 feet below grade and all radioactive waste was buried on DOE's Hanford reservation. The total volume of radwaste buried was $220,000 \mathrm{ft}^{3}$ (4200 tons) for a total cost of $\$ 2.25 \mathrm{M}$. Most shipments were by truck (200 loads). Eight (8) railcars were 
used for large unsegmented components such as: pumps, valves, heat exchangers, tanks, pressurizer, etc. An ocean-going barge was used for the shipment of the (RPV/NST) with its irradiated internal components. Other non-radioactive hazardous (chemical) and toxic (asbestos) wastes were disposed of through properly licensed and regulated vendors and burial grounds.

Release criteria established for the site was based on a dose of 100 $\mathrm{mrem} / \mathrm{yr}$ to the maximum exposed individual plus ALARA (to $10 \mathrm{mrem} / \mathrm{yr}$ ). Final projected doses for three key scenarios were: $2 \mathrm{mrem} /$ year for residential; 4 mrem/year for buried concrete pipechases and, $24 \mathrm{mrem} /$ year for deeply buried but potentially occupiable areas. A docket containing a description of the final site condition was assembled for public record. It is supported by a 75 volume package documenting radiation field surveys for 100 individual exposed areas which were then subjected to independent verification prior to backfilling.

A Technology Transfer program was initiated to provide annual progress reports as well as eight (8) different topical reports upon completion of the project. A final report, composed of an executive summary and a combination of nine (9) functional managers' reports, a 12 volume comparison report of how the work was actually performed compared to how it was originally planned and a compllation of DOC-issued manuals and project instructions was assembled for distribution.* Progress photos and video tape records were maintained and archived. Additionally, a foreign and domestic cooperative program was initiated for those who wished to participate during the course of the project. Information was further disseminated by numerous presentations to U.S. utflities and professional groups as well as open-houses for the community and media days.

\section{SUMMARY}

The objectives of the Project were accomplished with completion of the mission within the established technical baseline under cost and ahead of schedule. Some conclusions drawn are that with proper planning and prompt funding, the technology, equipment and skills exist, as regularly demonstrated in nuclear power plant outages, to decontaminate and decommission any size power plant without the need for huge sums of money nor overly extended application of manpower or effort.

Benefits were derived at SSDP from the low radiation levels of the plant and the low burial costs (at least at the start of the project) at the government burial ground. Utilities will need to do careful cost trade-off studies to evaluate decontamination and volume reduction versus burial costs. Reasonable criteria necessary to permit consideration of all options for decommissioning must be established early. Until then, the cost estimates associated with accrual of funds for Decontamination and Decommissioning (D\&D) are nebulous. Lacking is a complete set of reasonable and acceptable criteria which covers the release of materials (including deminimus quantities).

Realistic standards for shipping D\&D waste, especially oversize packages with large Curie contents, are needed. Physical D\&D work should not begin nor funds accrued until these are resolved.

*Available from National Technical Information Servis (NTIS) Alexandria, VA. and Remedial Action Program Information Center (RAPIC) Oak Ridge, IN. 


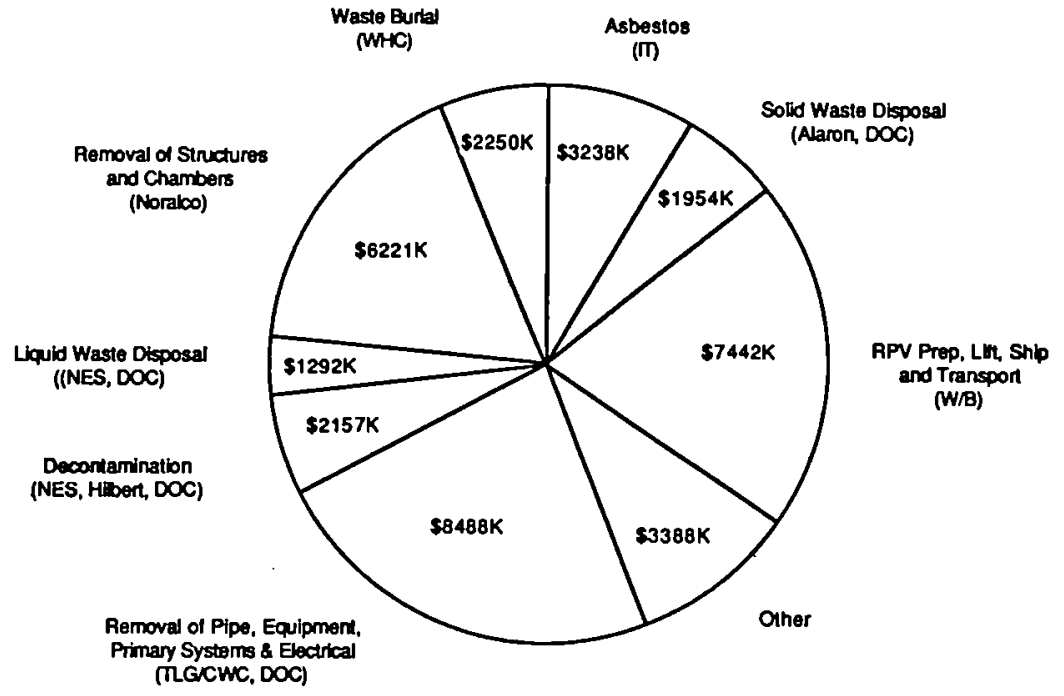

Figure 1 - Major Blocks of Decommlssioning Work at Shlpplngport

- Applied Manmonths \& Exposure

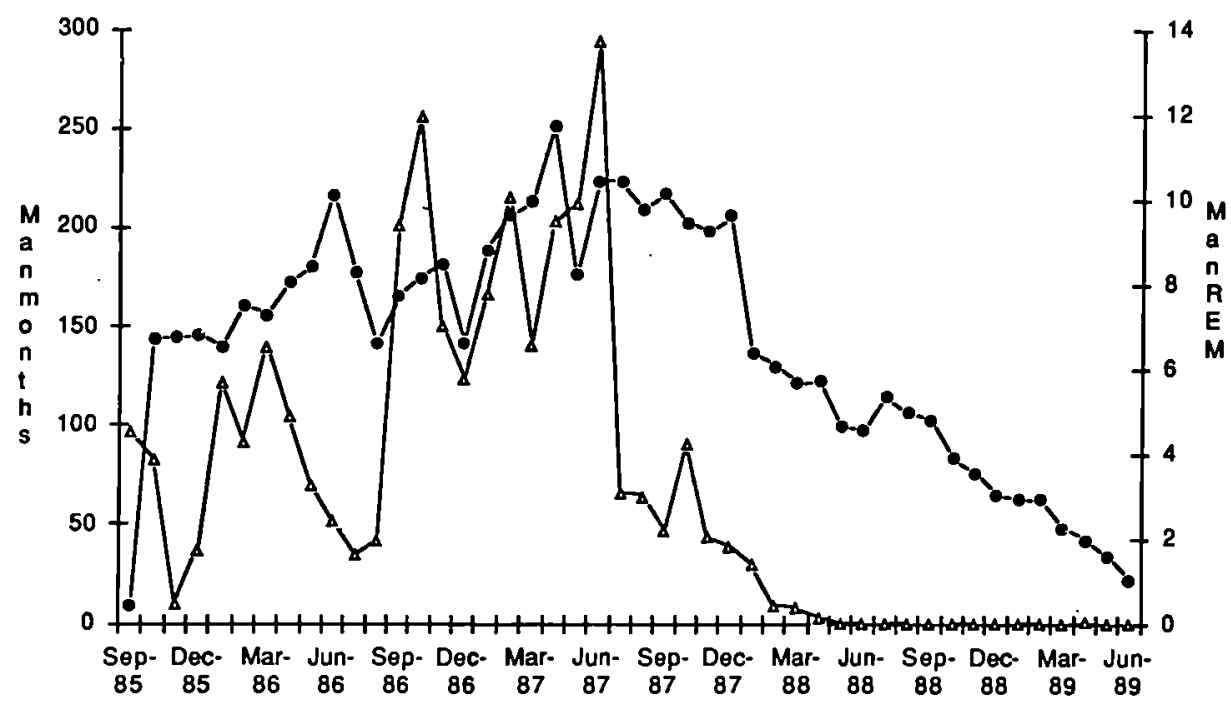

Figure 2 - DOC Manpower and Exposure vs. Time at Shippingport 
TABLE I: CHRONOLOGY AND SUMMARY OF OPERATIONAL DATA FOR SHIPPINGPORT

Pressurized Water Reactor Project Authorized

July 1953

Ground Broken

Construction Started

Initial Core 1 Criticality

Core 1 Operations Complete

Initial Core 2 Criticality

Core 2 Operations Complete

Initial Light Water Breeder Reactor Criticality

Light Water Breeder Reactor Operations Complete

Defueling and End-of-Lift Testing Complete

Turnover for Decommissioning

September 6, 1954

March 1955

December 2, 1957

February 9, 1964

April 9, 1965

February 4, 1974

August 26, 1977

October 1, 1982

September 6,1984

September 6, 1984

Total

Operation

Effective Full Power Hrs

Total Gross

Generation

(KW-HR)

$\begin{array}{ll}\text { Core } 1 & \text { (PWR } \\ \text { Core } 2 & \text { (PWR) } \\ \text { Core } 3 & \text { (LWBR) } \\ \text { Totals } & \end{array}$

$27,780.9$

$23,812.0$

$1,793,581,700$

$3,476,592,300$

$2,103,833,029$

Totals

$\frac{28,730.4}{80,323.3}$

$\frac{2,103,833,029}{7,374,007,029}$

TABLE II: CHRONOLOGY OF SHIPPINGPORT STATION DECOMMISSIONING PROJECT

$\begin{array}{cc}\text { Phase I - Engineering \& Planning } & 1979-1983 \\ \text { Phase II - Decommissioning } & 1983-1989 \\ \text { Award DOC Contract } & \text { Mar } 84 \\ \text { Heaquarters Approval to Start } & \text { Jun } 84 \\ \text { Site Turnover } & \text { Sep } 84 \\ \text { Start Decommissioning Operations } & \text { Jan } 85 \\ \text { Initiate Physical Decommissioning } & \text { Sep } 85 \\ \text { Irradiated Components Loaded into RPV } & \text { Mar } 86 \\ \text { Complete Removal of Asbestos } & \text { Jul } 86 \\ \text { A/C and B/D Chambers: } & \\ \text {-Removed Primary Components } & \text { Mar } 87 \\ \text {-Removed Pipe and Equipment } & \text { Mar } 88 \\ \text {-Removed Steel Chambers } & \text { May } 89 \\ \text { First Backfill } & \text { May } 88 \\ \text { Lift and Load RPV/NST } & \text { Dec } 88 \\ \text { Ship RPV/NST } & \text { Feb } 89 \\ \text { Complete Physical Decommissioning } & \text { Jul } 89 \\ \text { Stop Decommissioning Operations } & \text { Sep } 89 \\ \text { Headquarters Approval to Release Site } & \text { Nov } 89 \\ \text { Complete Archive Records } & \text { Dec } 89\end{array}$


TABLE III: SHIPPINGPORT PROJECT COST SUMMARY (\$ IN THOUSANDS)

Phase I Engineering

$$
\text { PLAN }
$$

ACTUAL

$A / E=B R I S C$

$\$ 4,669$
1,397
$\$ 6,066$

$\$ 4,669$

TSC $=$ UNC

Phase I Total

1,397

$\$ 6,066$

Phase II Decommissioning Operations

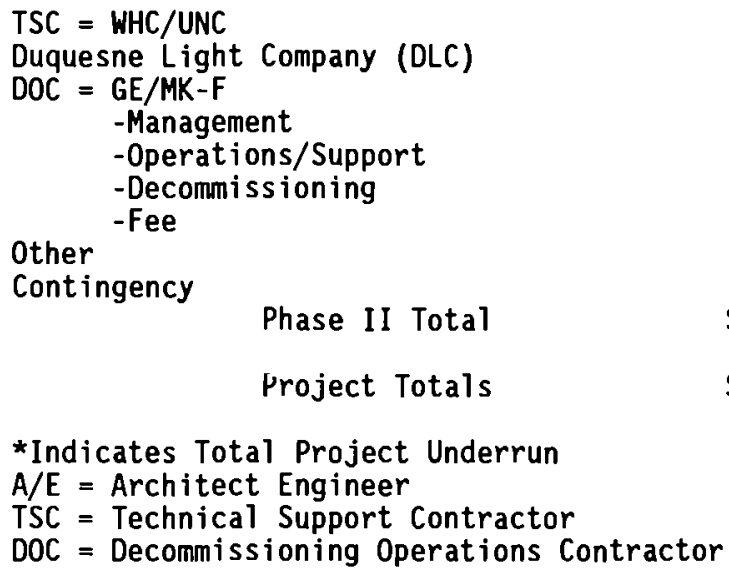

Contingency

Phase II Total

Project Totals

*Indicates Total Project Underrun

$\mathrm{A} / \mathrm{E}=$ Architect Engineer

TSC = Technical Support Contractor

DOC = Decommissioning Operations Contractor

$\$ 8,330$

1,000

$\$ 5,560$

1,000

6,348

25,535

35,016

5,975

27,895

5,225

36,373

6,153

2,925

10,780

6,353

$\$ 92,234$

$\$ 92,234$

$\$ 98,300$

$\$ 98,300$

TABLE IV: MANPOWER DISTRIBUTION AT SHIPPINGPORT

\begin{tabular}{|c|c|c|c|c|c|}
\hline YEAR & $\begin{array}{l}\text { DOC } \\
\text { MGMT }\end{array}$ & $\begin{array}{c}\text { OPNS/ } \\
\text { SUPPORT } \\
\end{array}$ & $\begin{array}{l}\text { DECOMM- } \\
\text { ISSIONING }\end{array}$ & TOTAL & $\begin{array}{l}\text { PERCENTAGE } \\
\text { PROGRESS } \\
\end{array}$ \\
\hline $\begin{array}{l}1984 \\
1985 \\
1986 \\
1987 \\
1988 \\
1989 \\
1990\end{array}$ & $\begin{array}{r}7 \\
16 \\
15 \\
13 \\
14 \\
2 \\
0\end{array}$ & $\begin{array}{r}39 \\
78 \\
70 \\
65 \\
34 \\
0 \\
0\end{array}$ & $\begin{array}{r}0 \\
69 \\
98 \\
160 \\
71 \\
0 \\
0\end{array}$ & $\begin{array}{c}46 \\
163 \\
183 \\
238^{\star} \\
119 \\
2 \\
0\end{array}$ & $\begin{array}{r}6 \\
13 \\
31 \\
55 \\
78 \\
98 \\
100\end{array}$ \\
\hline
\end{tabular}

HEAD COUNT TAKEN AS OF SEPTEMBER EACH YEAR.

*PEAK MANPOWER OF 250 OCCURRED IN APRIL 1987. 
TABLE V: SUMMARY OF ASBESTOS REMOVAL AT SHIPPINGPORT

$\begin{array}{lll}\text { Cost: } & 53.2 \text { Million } & \begin{array}{l}35 \% \text { of the Total Cost of P } \\ \text { and Equipment Removal }\end{array} \\ \text { Schedule: } & 1 \text { Year } & \begin{array}{l}35 \% \text { of Schedule for Pipe and } \\ \text { Equipment Removal }\end{array} \\ \begin{array}{lll}\text { Quantity: } \\ \text { (in-Situ) }\end{array} & 430 \mathrm{Cu} . \mathrm{Yd} . & \begin{array}{l}35,000 \text { Linear Ft. of Pipe } \\ 75 \% \text { in Radiologically } \\ \text { Controlled Areas }\end{array} \\ \begin{array}{l}\text { Waste Generated: } \\ \text { (Buried) }\end{array} & 1300 \mathrm{Cu} . \mathrm{Yd} . & \begin{array}{l}\text { Contaminated } \\ \text { Non-Contaminated }\end{array} \\ \text { Safety } & 400 \mathrm{Cu} . \mathrm{Yd} . & \text { NO CASES OF PERSONNEL OVEREXPOSURE }\end{array}$

TABLE VI: COSTS TO REMOVE RPV/NST AT SHIPPINGPORT (S IN THOUSANDS)

\begin{tabular}{|c|c|c|c|c|}
\hline ACTIVITY & CONTRACTOR & COSTS & $\begin{array}{l}\text { PERCENTAGE } \\
\text { RPV/NST }\end{array}$ & $\begin{array}{l}\text { TOTALS } \\
\text { PROJECT }\end{array}$ \\
\hline \multirow[t]{2}{*}{$\begin{array}{l}\text { Load internals } \\
\text { Install RPV head } \\
\text { Remove Rx Chamber* } \\
\text { Lift, load \& transport } \\
\text { Burlal (10,000 cf) } \\
\text { SARP }\end{array}$} & $\begin{array}{l}\text { ALARON } \\
\text { MK-F } \\
\text { PPB* } \\
\text { W-B } \\
\text { WHC } \\
\text { WHC-LLNL }\end{array}$ & $\begin{array}{r}\$ 566 \\
50 \\
1620 \\
5308 \\
165 \\
2626\end{array}$ & $\begin{array}{r}5.5 \\
0.5 \\
15.7 \\
51.4 \\
1.6 \\
25.4\end{array}$ & $\begin{array}{l}0.6 \\
0.1 \\
1.6 \\
5.4 \\
0.2 \\
2.7\end{array}$ \\
\hline & TOTAL & $\$ 10,335$ & 100.0 & 10.5 \\
\hline
\end{tabular}

*Included removal of components, piping and electrical equipment; manufacturing and installation of Lifting Beam and skirt; and, concrete fills of RPV, NST and LB\&S.

MK-F - MK-Ferguson

PPB - Proto Power Bisco

$W-B=W i l l i a m s-B r a g g$ Joint Venture

WHC = Westinghouse Hanford Company

LLNL - Lawrence Livermore National Laboratory 
DISCUSSION

Question: F MOTTE, SCK/CEN Mol - I would like to ask Mr Schreiber if he thinks that the Shippingport method will still be used in the future in the United States, even for larger reactor pressure vessels?

Answer: J J SCHREIBER, US DoE - A reactor pressure vessel of 1000 MWe size can be picked up in one piece if the utility desires it and has a clear transport route to burial. That is, transport by barge and/or railroad if road clearances are sufficient. A reactor vessel of Trojan or San Onofre size would be about 1 metre longer, slightly smaller in diameter (supposing a 6 inch steel shield instead of Shippingport's 1 metre neutron shield, which was filled with concrete as shielding) and weigh about $1200 \mathrm{t}$.

Question: D MacMAHON, Imperial College - What were the final measurements of radioactivity distribution which were made for the final site verification on which the dose rates presented were based?

Answer: J J SCHREIBER, US DoE - Standard instrumentation was used to perform and verify the measurements on the underground surfaces prior to backfilling. Since much fill material was required, initial soil was taken from the top metre at the site and used in the backfill operation. This meant that the top ' $1+m$ ' of surface soil all over the site was brought from offsite and had to meet specifications for absence of radioactivity. The actual description of the instrumentation and final readings are contained in the final release docket and other reports which are available from the agencies indicated in my paper.

Question: M NAKANO, JAERI - Some components were stored under low-level ground in Hanford. Is there no influence on the environment?

Answer: J J SCHREIBER, US DOE - All the boxes, drums and large components were of such low-level radiation as to cause no environmental insult at the Hanford burial ground. Even the reactor pressure vessel, which had almost all of the curies buried at hanford, had a radiation level of only $1 \mathrm{mrem} / \mathrm{h}$ at contact, over 998 of its surface. Radiation at the eight small nozzle locations ranged from 4 to $7 \mathrm{mrem} / \mathrm{h}$. Workmen can, and are expected to, work on the package in its burial trench in order to retrieve specimens of materials for laboratory studies. Some specimens ( 6 inch diameter disks) have already been removed (just prior to shipment, when the package was in its final configuration) without a large dose to the workmen.

Question: W STANG, KRB - Did you perform in situ decontamination of the primary circuit and/or auxiliary systems in order to reduce dose rates for the working personnel?

Answer: M YOKOTA, JAERI - We did perform in situ decontamination in the primary circuit, but not for reducing dose rates, as the circuit is only low contaminated. The purpose was the testing of decontamination for future decomissioning tasks.

Question; B W EMMERSON, Nuclear Installations Inspectorate - Assuming that the ALARA concept was applied when planning the decommissioning project, what were the main reasons for the very significant decreases in actual total dose, compared with the initial project estimates? 
Answer: J J SCHREIBER, US DOE - Careful attention to work procedures and discipline in requiring radiation controls (exposure time). Non-productive workers must leave the controlled area or go to a low radiation zone. I am not certain that ALARA was applied to planning estimates, and in some cases radioactivity may have been overestimated in the calculations.

\section{CONCLUSION}

I believe the time has now arrived to bring the meeting to a close, and that is one of the Session Chairman's duties. I must, however, confess to finding some difficulty in doing so. It is true, of course, that the papers presented to us concern important and successful demonstrations of decommissioning and dismantling operations and, on that score, we can be satisfied; more particularly, we can congratulate those who conducted those operations. Having said that, I also have to say that a 20 minute talk must leave most of us, technicians as we are, eager for more and I should think that even reading the reports set out in the Proceedings would prompt us to ask a number of questions. Moreover, when reflecting or attempting to draw a conclusion, I found myself on several occasions dwelling on another term: 'diversity in the field of decommissioning'. Diversity of installations of all types, which we shall have to manage in the future in order to decomission them; diversity of technical requirements, which relate to techniques as different as decontamination on the one hand and those used in cutting operations on the other, robotics, all the problems of waste management, and I would even say diversity of technical and economic problems or even diversity of regulatory problems. Diversity as well, of course, of the tools and resources existing today.

Be that as it may, an initial step seems to have been taken if we consider all the papers that have been presented, not only during this Session, but also in the others. Although we may feel satisfied, it is true that a lot of work still remains to be done, and even if there are grounds for satisfaction from a technological standpoint, savings can still be made. When I mention savings, I mean both financial savings and those which relate to man-rem. And if I were to be allowed a wish, it would be that we continue to work along the same lines so that the next meeting, to be held at the end of the next five-year programme, will at least exhibit the same quality and provide us with the same success coefficient as has this conference.

Thank you for having listened so attentively.

A CREgUT, CEA 
. 


\title{
PAKEL : DECOATISSIONING OF NOCLEAR INSTALIATIONS - ACHIEVEAENTS AND FUTURE TASKS
}

\author{
C D ANDRIESSE \\ Programmaleider Radioactief Afval, KEMA N.V., Arnhem, The Netherlands
}

\author{
A BERTINI \\ Responsabile del Programma Smantellamento degli Impianti Nucleari, ENEL, \\ Roma, Italy \\ S FINZI \\ Director of Nuclear Safety Research, Commission of the European Communities \\ L GILLON \\ Professeur Emérite a l'Universıté Catholique de Louvain, Belgium \\ $\mathrm{J}$ HOLLAND \\ Berkeley Nuclear Power Station Manager, CEGB (National Power Division), \\ Berkeley, UK \\ K H HUBENTHAL \\ Regierungsdırektor, Bundesministerium für Forschung und Technologie (BMFT), \\ Bonn, FRG

\section{A LOPEZ-GARCIA} \\ Director General de la Empresa Nacional de Residuos Radiactivos S.A., \\ Madrid, Spain \\ P TANGUY (Chairman) \\ Inspecteur Général pour la sûreté Nucléaire, EdF, Direction Générale, Paris, \\ France
}

\section{Int roduction: $P$ TANGUY}

The purpose of this Panel Discussion is to take stock of the success achieved and the results obtained and to present the future prospects of decommissioning and of the Community's programme in that field. Mr Contzen of the Commission was to have chaired this Panel but he has been called to an important meeting on the environment in Venice. However, I have discussed with him the subjects that should be raised at this session. It is suggested that the members of the Panel should endeavour to answer a serieg of questions covering two subject areas. The first one is the assessment of the last five-year programme on decommissioning from 1984 to 1988 , that is the results that have been presented at this Conference and the lessons to be drawn from them. Three particular questions arise in this subject area.

- Costs: do we know more about them now than we did five years ago?
- Radiation protection during dismantling operations, implications of the ALARA concept: is it possible to derive assurances from what has been achieved, bearing in mind the prospect which we all have in view - the very probable reduction of exposure, or at least the amendment in the sense of greater strictness of the radiation protection standards applicable to workers in the nuclear energy sector? 
- Has enough progress been achieved in relation to criteria for waste from decommissioning to be reused where the public might come into contact with it, or in more restricted areas in the nuclear field?

These are important questions. On leaving this Conference our aim must be to have as clear and precise an idea as possible of the advances made as a result of the comunity programme.

The second subject area is oriented more towards the future. The first question (and one which rightly occupies that position, I believe, after the meeting which we attended this morning) is: does decommissioning in the Community take sufficient account of what is being done in countries outside the Community, such as the activities described this morning in Japan and in the United States?

Secondly, what justification is there for a community programme for the future? Is it simply a question of money, because the Community is contributing 508 - an important justification for many community programmes? or is it rather the advantage to be gained from cooperative efforts between industries and research laboratories in different countries which would otherwise have continued work in isolation? Finally, is it the additional value which the EC contributes towards the ultimate establishment of European standards? Panel members should put forward their views on the advantages of and the approach to such European standards on decommissioning.

The last question is quite relevant, but perhaps more difficult: should the explicit and primary objective of the Commission, and of the programe that it supports in this field, be to increase public acceptance of nuclear energy in general and of the closing of the cycle with the decommissioning of installations?

Those are the six questions. I propose that each of the Panel members should make a preliminary contribution, identifying his own interest and highlighting the most important aspects, as he sees them, both in respect to what has been said during the week and to future prospects. We will then have a round table exchange of views and finally throw the discussion open to the floor.

\section{D ANDRIESSE}

I am speaking as coordinator of research on radioactive waste for the utilities in the Netherlands, but also as a university professor in physics, which gives me some freedom to speak about the political aspects of dismantling of nuclear reactors in Holland, since I am not in the world of politics itself.

At KEMA, we are finishing the dismantling of a $1 \mathrm{MW}$ nuclear reactor which was built in the sixties and which had a test period in the seventies. This particular reactor has not received a great deal of attention. It was constructed in such a way that the fuel, consisting of micron-size particles of thorium and uranium oxide, suspended in water, circulated through a loop with a pressure vessel and a heat exchanger. After testing for some 150 hours at full power, the reactor was shut down in 1977. We removed most of the fuel, sent it to Oak Ridge for study or, alternatively, for treatment and disposal, and we then started to take the systems apart. It took some 100 man years to complete the job. We had particular problems with the alpha contamination of the cooling circuit, in which about $1 \mathrm{~kg}$ of the fuel was left after we had removed its main part. We also had problems with the treatment of the pressure vessels, which had to be cut. To give you an example: the lid of the main vessel had a thickness of $25 \mathrm{~cm}$. All materials are packed in steel drums, and they are handed to COVRA, the Dutch 
organisation for storage and disposal. COVRA is building its main facilities close to the nuclear power station in Borssele. We have not looked for cooperation in this dismantling within the EC, as the lessons to be learned from it are quite specific. They refer to odd geometries and to a special alpha contamination. However, during 1990 we will publish a report on this operation which may be of interest to you.

Now, let me address the general questions posed by Mr Tanguy. There is no doubt of the great value of this meeting. We should not complain about its very technical nature, dismantling is feasible only by inventing the features towards all materials. We can follow many rules; in a sense our problem is not how to do it, but rather to find the way which is both cheap and safe. Of course, costs and radiation doses are mutual enemies. I have to say that ALARA or 'de minimis', as we have used it in the dismantling of our test reactor, can easily push costs to the extreme; just for the exercise this was not harmful, but for the operation of the dismantling of power reactors in Holland, it is. I fear that the costs, now around 100 million dollars for a reasonably sized nuclear power reactor, will increase by several factors if we aim at very low activities of the remaining materials. It has been suggested from the EC that we might set similar standards for the whole of Europe, for instance $1 \mathrm{~Bq} / \mathrm{g}$ for waste steel. If this suggestion is accepted, I fear that the costs will certainly increase above the amount I have predicted.

My question is: why should these standards be so low? Do we really have evidence that small doses are harmful, or do we recede under the pressure of public concern that it might be so? We have to stress scientific evidence. Furthermore, I believe that we cannot achieve public acceptance for nuclear energy by using scientific standards derived from mere opinion. However, in view of the considerable amount of public funds involved, there could be a case to study the real effect of low doses.

Finally, may $I$ congratulate the EC for providing us with a forum and some funds for the problem of dismantling. Although Europe certainly has its own context for dismantling; I believe that the world context is still more important. We should maintain close contact on these issues with the USSR, USA and Canada, and in particular Japan, a country which by its size, its population density and its nuclear programe, is certainly of great interest to us.

\section{K H HÜBENTHAL}

I am employed in the Federal Ministry for Research and Technology in Bonn and am therefore concerned with the R\&D projects undertaken in this sector by the Federal Government. In the past I have been a member of the Commission's advisory bodres involved in programme planning and allocation of projects.

I regard this meeting as a survey of the past five years of $R \& D$ in the Commission and would say that, from my standpoint, the results are very positive. This programe was divided into two parts: firstly RaD and secondly aspects of radiation protection and final disposal. R\&D has covered research projects on the most important points which are being discussed here today in connection with decomissioning: dismantling, decontamination and reuse - a very important subject, to which I shall return later. The second part of the programme is also very extensively systematised in this field, so that the individual results stand out in a clearly distinguishable manner, are more easily and more clearly available for the planning of real demonstration projects and can provide a basis for such projects.

Another chapter containing the Commission's participation in the actual application of the techniques developed in the last programe - 
essentially the papers presented this morning - has produced presentable results and provided proof that safe decommissioning is feasible: it must be possible to refute the accusation that ruins are created in this context. Although the EC has made only a very minor financial contribution in support of this work, the synoptic representation here is very impressive and also very important.

What can we learn from this assessment for application in the future? The results achieved in the R\&D area of the programme and those obtained with industrial-scale decommissioning have quite decisively improved the basis for the planning of future decommissioning operations in respect of cost, radiation exposure, quantities of waste, etc. However, and I was especially struck by this in the case of the paper concerning the decommissioning and decontamination of the vitrification plant in Marcoule, they also showed that planning must be reasonably flexible and the authorisations must also be of an appropriate type, so that, in the case of complex structures or decontamination operations in which the location of the contamination is never known precisely in advance, it is possible to react flexibly to the circumstances that arise as work progresses and to adapt planning to cope with such circumstances.

As regards the question of whether the EC takes too little account of results from outside and how much account should be taken of such results in the future, I would say that, at this Conference, a good overview has been provided of current projects in the EC, in the form of a report of activities over the past five years, and notice has certainly been taken of what is happening outside Europe's borders. In my view, however, the foral point of this meeting should be the survey of our own activities. There are problems in looking across our borders, and I should like to return briefly to that matter before I finish.

What can the commission do within the framework of the EC? It is certainly not its task, nor has it ever been its objective, to provide a major financial incentive here. The Commission's task, which it has also accomplished in the past, and accomplished very well in my view, is to coordinate the individual projects in the different countries, to harmonise them and to ensure that there is an exchange of information between the countries. Simultaneously, this common scientific basis serves as a foundation, in the run-up to European standards and directives, for preparatory work on the harmonisation of national regulations concerning exemption limits and other matters. One example is the EC Directive on exemption limits in the recycling of steel.

In conclusion, I would like to mention something else which, in my view, possibly somewhat restricted from the German angle, appears to be very important. What is important for the future is not so much an increase in R\&D results, and by that I do not mean that all questions have been answered and no future R\&D is necessary, but more important than technical barriers and problems, at least in my country, are administrative and legal questions relating to authorisations. For example, the questions of exemption limits and of authorisations which are flexible enough to be adapted to the results which emerge in the course of development work or during a dismantling operation, are much more important. A most crucial question which struck me during the talks on Gundremuingen and Shippingport, and which will have a decisive influence on decommissioning, is that of final disposal. In the Federal Republic, we at present have no reasonably acceptable final disposal facility, in fact we have nothing at all. All that we do is to condition material or decontaminate it for reuse. In the case of shippingport, very large components were removed as they stood for final disposal and carried away. This is of considerable consequence with regard to the questions of whether or not decontamination should be performed; whether or not 
dismantling should be carried out. This aspect is also crucial in respect to the radiation exposure of workers involved in the decomissioning operation. Finally, with regard to the costs, there is a dependence on the means of final disposal in the individual countries, also a certain limit to harmonisation and to learning from the experience of others.

\section{A LOPEZ GARCIA}

I am the Director-General of ENRESA, the National Company for Radioactive Waste, which is the public company responsible in spain for the management of radioactive waste, including that arising from the dismantling of major nuclear installations. First I have to say that since I have been unable to attend more than a small part of the meeting which has been in progress over the past few days, my view of the subjects dealt with here is somewhat limited. However, I will base my answers to the Chairman's questions on the experience I have acquired at meetings dealing with the various actions or activities included in the community's dismantling programme and by reading most of the papers presented at this meeting.

Generally speaking, our assessment of the community programme implemented over the past few years is a favourable one. The programme has represented an important effort to coordinate the various activities undex way in the different countries; it has certainly cut down on duplication and repetition of work and resulted in optimisation of resources. The Commission's coordination work has largely been responsible for this. From the Spanish point of view, there are perhaps a number of omissions from the Community programme, such as the dismantling of uranium mining and concentration installations.

As regards interest in this meeting, I think it is obvious that all the basic information available in the various European research centres has been concentrated in this single event, and its importance or interest can be gauged simply by observing all the professionals present in the Conference room. All the information presented here is also of use in defining the needs that still have to be met with regard to the industrial-scale dismantling of major installations, and it is evident that all this information should serve as a basis for programming future activities in this field.

Let us now come to specific subjects under the last programme implemented with Commssion coordination. I believe that we can assess very favourably the advances achieved in acquiring knowledge of the special technology used for dismantling and decontamination. Further development is st111 needed, basıcally in active installations and on an industrial scale, but it seems clear that the technological level acquired in developing these techniques is very high. However, I believe that there are several aspects still to be developed in respect of the dismantling strategy: principally the establishment of outline conditions and basic standards applıcable to programes for the dismantling of major installations.

One of the questions which the Chairman put to us concerned dismantling costs and whether we can now determine them more accurately. I believe that we have undoubtedly advanced considerably as regards knowledge of the costs of the individual techniques applied to dismantling and decontamination, the reason is that these types of techniques have been developed and applied and their costs are therefore known fairly accurately. However, we know very little about the cost of dismantling major installations, mainly because there is no adequate definition of the reference framework within which such dismantling operations should be carried out. I believe it is necessary to develop and clarify the subject of 'de minimis' criteria. Once a proper definition has been adopted of the 
criteria for determining what should be considered as radioactive waste and what is conventional waste, the management of dismantling operations will become more a matter of radioactive waste management. Other subjects which should be clarified are the availability of final disposal facilities for this type of waste and the acceptance criteria applicable to such disposal facilities both now and in the future. Only by defining these two aspects, that is to say, 'de minimis' standards and acceptance criteria for final disposal of radioactive waste from dismantling operations, will we be able to select the most suitable dismantling, decontamination and conditioning techniques from the standpoint of radiation protection and dose optimisation. Once the techniques have been selected, we shall be in a position to assess accurately the cost of industrial-scale dismantling of major installations. Only then will we have enough knowledge to decide when to decontaminate, when to reduce the volume, which conditioning process to apply, etc.

Another question referred to the criterion for reusing materials from dismantling, and perhaps I will give the same answer as I gave a moment ago, which is that only when we have a proper definition of the 'de minimis' criteria and the acceptance criteria for radioactive waste, and therefore sound knowledge of the cost, will we be in a position to assess the advantages of using some of the materials.

Spanish experience with the programme under review indicates that there has been satisfactory synergy, acceptable transmission of data and intensive exchange of experience between the different countries, and this is basically due to two factors: on the one hand, the spanish researchers have been well accepted and kindly received by their colleagues in the other Community countries and, on the other hand, the commission as an institution has been a most efficient coordinator.

As regards the future Community programne, there is likely to be intensified development of operations for the dismantling of old installations, in which the previously developed individual techniques will be applied. However, an adequate effort should be made to establish standards. A complete definition of the 'rules of the game' is what will be of greatest assistance to us in the time ahead, and it is therefore important for the European programme to intensify work on this aspect in future. It is evident that the budget allocated to the programme which has been initiated will probably be very small from the qualitative standpoint, especially if a comparison is made with the proportion of the investment costs required for development of the dismantling of major installations. I believe, however, that some fine results will be produced which will act as an incentive to the individual countries to work in this field and to give precedence to synergy, the transmission of data and the exchange of information between countries.

In conclusion, I would like to make a final reference to public acceptance; it should be remembered that this is a necessary condition for conducting any activity in a democratic country, so obviously it is a very important parameter to bear in mind in connection with the dismantling of nuclear installations. It is the responsibility of the governments in the different countries to explain to the public the activities which, in the nuclear field and more specifically with regard to dismantling, have been carried out and will be carried out in the future. In that connection, I believe that the Community Member states will always be happy to receive the support and assistance which can be provided by the commission and the European programme to the various countries. 
I am the Station Manager at Berkeley Power Station in the UR and I am a relative newcomer to the decommissioning scene. Just over 12 months ago I was the manager of an operating nuclear power station, when it was decided for economic reasons to announce the shutdown. The shutdown was completed on 31 March of this year, after 27 years of safe and successful operation. Over the past 12 months I have had to become familiar with the decommssioning scene and to lead the station in the stage 1 process. Being the first commercial nuclear power station in the UK to enter this process, this has been a completely novel task. It has meant considerable work to establish the procedural framework to satisfy the regulatory authorities in respect of decommissioning programmes, and the appropriate safety cases to enable us to operate the station in 1 ts new status.

Th1s is the first conference of this type I have ever attended. The first key point to strike me was a phrase which was used very early on, that decommissioning has arrived, and throughout the week we heard more and more of what is happening. In the UK, we are now beginning to recognise the significance of decommissioning, because we are facing this job now.

The second key point that came to me early in the week, was that it is likely that the way we deal with the decommissioning issue between us will probably set public reaction to nuclear power in its totality. So in many ways, although at the back end of the nuclear game, we are very much in the forefront of it being an acceptable process in the future.

I have gathered that the CEC R\&D programme over the past ten years has promoted useful R\&D, whlch will ald us in the task ahead. We have heard some of the successful results in the course of this morning. However, as has already been said this morning, the immediate concerns facing us are those of public acceptablitity of what we wish to do, particularly in regard to waste storage and the 'de minimis' level matter.

The value of the Conference to me has been that $I$ have gained an understanding of the range and depth of the work that has been undertaken and is continuing to be undertaken, and of some of the successes that have already been achieved. I have also had an opportunity to meet people from many countries involved in this significant topic. The experience will aid me in my task, particularly in explaining to the public that we are prepared for decommissioning. Certainly in the UK, in terms of public perception, I feel that we are subject to the accusations that we do not know how to do 1t, we do not know how much it is going to cost, and therefore we are on the end of a very doubtful business.

May I conclude by thanking the CEC for pursuing the policy of international collaboration in this field, and say that I have enjoyed this week very much.

\section{A BERTINI}

I am responsible for decommissioning the power reactors of ENEL, the Italian electricity authority: one shut down a few years ago, and the other one recently by government order, more or less unexpectedly. I have been working for 41 years in the field of power plants and for 32 years in the field of nuclear reactors. I started with design, then construction, commssioning and operation, and now decommissioning, ie from the obstetrician to the undertaker. My role here relates to the fact that I had the honour of serving in the groups of experts of the Community who met twice a year to follow the progress of the work made by the contractors in this programe. I cannot say that this Conference has brought to me personally something new, because I know, as do my colleagues in the group 
of experts, what the work was, how it was done and how it has progressed. Therefore, I shall not talk about this conference, which I think was extremely useful. Instead, I will try to answer some of the questions which have been put by the Chairman.

Do we know more or less about costs? What we know more about is the cost of individual actions which comprise the decommissioning complex. We have experience of costs with some projects, but as has been pointed out during this Conference, dismantling, that is stage 3, of two identical reactors located in two different countries might have completely different costs. This is not due to the decommissioning techniques; it is primarily due to factors which are outside the scope of the actual decomissioning and the research programme: essentially, the question of the waste management. I agree with my colleagues that the waste management problem is the problem. We can cut a reactor to pieces, but we must first know what to do with the pieces, where to put them, how to condition them, how much it will cost to condition them, how much alternative strategies will cost. Dealing with a few tons of material, mistakes wili cost little, but in dealing with many thousands of tons, one cannot afford to make mistakes, the cost is too high.

I can give you an example in relation to costs. A couple of years ago we held a national Energy Conference in Italy, and the Italian Electricity Authority submitted an example: "We need a new base-load plant of 2000 MWe. If we are going to build it, should it be fossil-fuelled or nuclear? What will be the cost of a kWh in each case?" In the case of the nuclear plant, the cost of decommissioning was assumed to be $30 \%$ of the construction costs, just to show how little its weight was on the cost of the $\mathrm{kWh}$, and therefore how insensitive the cost of end product - the kWh - is to the cost of decommissioning. Therefore, the decommissioning cost is not a problem in itself, although it is true that, in the final analysis, when money has to be made available for decommissioning, it is money, and we always try to postpone that expenditure if it is not absolutely necessary.

The Community has achieved a magnificent job with the three programmes. The division into five-year periods is purely administrative, the central issue is to have a common forum where technical people and people from all types of nuclear activities may meet, work together and exchange their opinions and experiences. It is not a question of money, it is purely a technical interest. The first priority must be to speak the same language, and in particular we do not speak the same language in terms of regulatory arrangements for the release of materials and for waste management. We discussed with a British colleague rumours of a 'de minimis' level being set at $0.1 \mathrm{~Bq} / \mathrm{g}$ instead of $1 \mathrm{~Bq} / \mathrm{g}$. If that happened the whole of the turbine house in a Magnox reactor, which was absolutely free from contamination, would be treated as radioactive waste. Why? Because of possible levels higher than $0.1 \mathrm{~Bq} / \mathrm{g}$ ? No. It is because the cost of demonstrating that everything is below $0.1 \mathrm{~Bq} / \mathrm{g}$ is enormous. So, we must also be practical.

Although the Community has done a splendid work with recommendation $\mathrm{Nr} .43$, about recycling materials from dismantling, there is an ambiguity. We know from this recommendation that we can recycle 10000 tons per year in the community, with a contamination of $1 \mathrm{~Bq} / \mathrm{g}$, and calculations have shown that this is within acceptable radiation dose limits. However, there is a Commity Directive stating that any materials containing not more than $100 \mathrm{~Bq} / \mathrm{g}$, or even not more than $500 \mathrm{~Bq} / \mathrm{g}$ in the case of solid natural radioactive materials, may be exempted from any authorisation. As an example, coal has an average radioactivity of about $0.04 \mathrm{~Bq} / \mathrm{g}$ radioactive thorium, which is much less than $1 \mathrm{~Bq} / \mathrm{g}$. Instead of 10000 tons of dismantled steel scrap, consider how many million tons of coal are used in the Community each year. A very conservative estimate of 10 million tons is 
equivalent in terms of radioactivity to 10000 tons at $40 \mathrm{~Bq} / \mathrm{g}$. It may be pointed out that the scenario for coal is different from the scenario for recycled materials; but are we sure that the scenarios chosen for those 10000 tons are realıstıc? It was a magnificent work, as a verification; but when we assume that a motor car is made with steel containing $1 \mathrm{~Bq} / \mathrm{g}$ and that this car is a taxi cab, and we consider the dose a taxi driver recelves, well I think that the assumptions are completely over realistic. It $1 \mathrm{~s}$ good to verify that our limits are safe, but we cannot take the limits with the spirit that, should they be exceeded, half of the Commity would be destroyed.

I believe that the Community should go ahead in making rational proposals and directives on this 'de minimis' problem. In addition, when we say $1 \mathrm{~Bq} / \mathrm{cm}^{2}$, or $0.4 \mathrm{~Bq} / \mathrm{cm}^{2}$, we must say clearly what we mean by that: is it every $\mathrm{cm}^{2}$, one in a hundred, one in a thousand? These are practical but fundamental points.

As for public acceptance, if the public is really honest in asking for good information, decommissioning will be a good demonstration. Up to now, we have demonstrated good operation and still they do not believe us. As long as the papers deal with the nuclear 'accidents', as they do now, that is, any time that a shift supervisor of a nuclear power plant falls down the stairs and breaks a leg, this is a 'nuclear accident', a 'near-chernobyl', as long as the press focuses on all the small inconveniences in nuclear power plants, and not the thousands of similar inconveniences which occur every day in conventional plants; people will think that only nuclear power plants have bad machines. We have spoiled the public, fighting rearguard battles, instead of vanguard battles. Because the public is spoiled, they neither believe our successful operation, nor will they believe in decomissioning whatever we do; we are and will be under the regime of which the American police say, "from now on, whatever you say will be used against you". Under such a regime, it is difficult to work.

I hope that the future may give some better experience on this point, but after so many years of experience, I am rather disappointed.

\section{GILLON}

I am Emeritus Professor at the University of Louvain and administrator of the Belgian Centre d'Etudes Nucléaires at Mol. I propose to put forward a number of suggestions, some of them critical in tone.

We have been asked to evaluate the cost aspect of the programe which has been completed, and when I refer to the papers presented, I would point out that there is obviously a two-fold aspect in relation to cost: the cost of the tool and of its specific use, and the cost of an overall project. It is absolutely certain that laser equipment costs far more than a plasma torch for cutting up the same type of sheet steel, but virtually none of the authors has put forward any figures in this regard. What a pity! The same is true of the abrasive water jet, for which the basic equipment is very expensive.

When speaking of the cost of installation dismantling, it is obviously necessary to distinguish between the types of installation. A figure quoted 1820 or 30 of the initial installation cost; this applies to certain types of installation, and it is absolutely certain that the relative dismantling cost of Shippingport is totally different from the complete cost of dismantling of West Valley, which is the most striking example of an extreme case, for the dismantling will cost several times the initial cost of the installation. Today, moreover, we have heard the dismantling cost for alpha installations, such as plutonium cells. 
As regard the actual tools dealt with under the programme over the past four years, there is sometimes regret that not enough importance has been attached to secondary waste produced during the use of these tools; I am thinking of aerosols. We finally obtained certain data, but I believe that the authors should set them out spontaneously in their reports. In this connection, international cooperation may be mentioned; it is extremely fortunate that the final session included the presentation of the Shippingport dismantling and the dismantling of the JPDR reactor by JAERI, but we have heard authors reporting on tools without any reference to what was being done - and sometimes done very well - outside the Community. I also believe that anyone participating in a community programme should be obliged to keep an eye on activities elsewhere.

Considerable emphasis has already been placed on the problem of standards, and on 'de minimis' standards as they have so far been called, and here I believe that the Community's role should be a fundamental one and that any steps to inform the governments of action in this area should be taken rapidly. As regards public cpinion, it is quite certain that its primary concern is the safety of nuclear power stations immediately followed by waste disposal. Public attention has been drawn to the dismantling of installations only by two factors, the first being the operators' remark, "Let us wait for 30 or 50 years", and this is to forget the importance of public opinion in decisions affecting the construction of future power stations. Although it is desirable to allow the installations to wait for several decades, it is essential to prove to the public that the dismantling of such installations is feasible, the second factor being that it is also illusory to imagine that, in 30 years, dismantling operations will cost mich less than now; obviously, the cobalt will perhaps have decayed considerably, but the safety standards will have become more stringent by an even greater factor and the cost of the operation as a whole will be much higher.

With the arrival of certain types of remote handling devices and the shielding facilities available to us, I believe that it will be accepted very soon that dismant].ing operations in the relatively near future will be preferable for society, even from the economic standpoint, to delaying dismantling until much later.

\section{S FINZI}

I am responsible for the Directorate for Nuclear Safety Research in the Directorate-General Science, Research and Development. I am certainly not the best person to give an unbiased judgement on the value of the programme. However, I want to say that we expected from this meeting essentially two things: encouragement for the work that we are accomplishing, and guidance for the future. In this sense I think we can be quite satisfied. My feeling is that the third programme, that we have just started, is moving in a direction corresponding to the main indications of this meeting, ie in particular to focus activities on the problems of dismantling industrial installations, leaving aside the particular problems of the multiplicity of small devices and plants of the beginning of the nuclear era, and passing from laboratory scale to field applications.

This indication, I remember, was given in particular by Mr Laverie, representing a licensing authority, during the discussion on Session $I$, that I chaired. In particular in the choice of the pilot projects, the effort was in the direction of selecting, within the limits of the availability, dismantling operations as representative as possible of the different types of industrial plants. Indications for strengthening certain aspects of research are very clear, and it must be recognised that they will require a special effort. First I mention the radiological impact of the dismantling 
operations, which has to be better evaluated; we have to pay a higher attention to this aspect, in particular in the implementation of the pilot projects. Cost evaluation 19 still affected by uncertainty; we have to take into account that the cost evaluation is essentially connected with the choice of dismantling strategy. There we have to make an effort towards a more global approach, trying to establish a correct methodology for the evaluation, and helping to rationalise the strategies.

A certain criticism has been expressed on the lack of attention to what is happening outside Europe, a criticism repeated just now by Mr Gillon. As a line of defence, I will explain that the purpose of the meeting was to report on the results of the work done within the framework of the Community programme, and this sometimes gave the impression of a certain isolation. Mr Hübenthal has noted this too. Nevertheless, we will take this criticism into account for future actions.

Now, what is the most important question asked by Mr Tanguy: what is the Community added value of this research programme? Certainly, the Community programme is not only a financing tool, having the obvious advantages of stimulating the actıvities and obliging in a sense cooperation between the different teams. I remember that in the last call for tenders, it was very clearly announced that a higher value will be given to the proposals put forward by multipartners. The commuity programme of research must contribute to the development of criteria for safe decommissioning. I am speaking about criteria in the most complete sense, and they include the aspects of industrial strategies, as well as the radiological constraints.

May I say that the creation of a consensus at a broad international level is certainly needed, both on these criteria and on the question of public acceptance. The community as a whole has the possibility and the weight to play a leading role in reaching this international consensus. In this sense, aiming at this goal, we can define the challenge of the Community R\&D programe and its added value.

\section{P TANGUY}

My thanks for those contributions. We now have time for an exchange of views between the Panel members themselves. There seems to have been a consensus in appreciation of the role and work of the commission but also certain interesting observations which probably came as a surprise to the Panel members.

Very little has been said about the technological aspects, perhaps because each technique is extremely specific in itself and requires specialists. However, one point of view has been expressed which I share: it 13 true that the EC contracts are awarded to undertakings within the Community, but this does not signify that the contractors are not expected to provide us with information on what is available at present on a worldwide scale. From the brief talks this morning we have seen that very efficlent techniques are being employed both at Shippingport and in Japan. Since I arrived only yesterday evening I have obviously missed quite a lot. In regard to Community decommissioning technology, I would like to know, are we in a leading position, somewhere in the middle, or not very good?

It has certainly been said on several occasions that the trend would definitely be towards increasingly strict requirements which would result in the use of robot devices, in particular, protective screens, a number of efficient techniques in respect of which attention will have been paid to nulsances, aerosols, secondary effluents, etc. One point is that it seems uncertain what conclusion will be reached after this Conference. Maybe Panel members will comment on this. 
There is also a second point which could be discussed: it was unanimously considered that the programme was truly justified for the future, and one of the main justifications was the creation of a comunity of viewpoints within the European Comunity which could be reflected in what was called the reference framework or the standards. Since dismantling as a whole is very heavily dependent on these reuse criteria, especially regarding reuse of materials where the public might come into contact with them, I thought I understood that the term 'de minimis' was no longer held in very high esteem and that, instead, the term to use was 'exemption from regulatory provisions', but, in the final analysis, everyone knows what is meant, and this is also linked, not only with the cost, but also with public acceptance of the decommissioning operations themselves.

I am saying this because I would also like to comment on what Professor Gillon said. It is true that saying, "I shall delay for 30 years, 50 years...". can have an unfortunate impact on the public. On the other hand, I agree with the view that it is necessary for the public to be convinced that if it has to be done, we know how to do it; hence we must demonstrate that we know how to do it. It would be far worse from the human standpoint in the public mind to undertake a dismantling operation lasting for years which ended with an accumulation of waste on the spot and a lack of any repository to accommodate it! If there is no authorised storage facility because we are still discussing the 1 or the $0.1 \mathrm{~Bq} / \mathrm{g}$ etc, public confidence is definitely going to be dissipated! It would be better to do nothing rather than adopt such approaches.

These are simply a few comments to point out both the considerable areas of convergence and also a number of points which appear to deserve discussion by the members. I have also noted an omission: at this conference no mention has been made of the problem of mining installations. If this is a real omission, I think it is a pity. I believe that the advantage of mining installations is that they involve natural radionuclides and, still within the context of both standards and public acceptance, natural radionuclides are of use in a reference framework and can provide a very useful basis for comprehension.

\section{GILLON}

In the early part of the Conference we had excellent talks on the results obtained with certain tools. It is a pity that each of those talks did not include a short comparison with similar tools used outside the Community, and also that the financial aspect of using such tools was often neglected; in that connection, progress still remains to be made. As regards your last comment, that it is necessary not only to dismantle, but also to package and dispose of the waste, we are at present engaged at Mol in work under a completely new Community contract concerning the dismantling of some of the parts of the $\mathrm{BR}-3$ reactor. We have hence added to this part of the programme at our own expense the conditioning of these parts in packagings which could suit final disposal, because we consider that this demonstration is incomplete unless it includes this aspect.

\section{S FINZI}

I would like to mention an aspect which I believe to be quite important. If there is one thing which the programme has certainly not adequately encompassed yet, it is the preparation of summary analyses of the different subjects; we have seen a few such sumary analyses appear, and immediately we realised that they were important and interesting. I therefore believe that it is necessary to insist in the near future on this 
type of exercise. Such a measure would also enable account to be taken in the most rational manner of what is being done outside the Community. I would also like to point out that the decommissioning programme is one of a set of programmes concerning nuclear safety: radioactive waste management and radiation protection are other closely related subject areas. The correlation between these programmes seems rather blurred in discussions between decommissioning specialists, but it is certain that the links between these programmes are very strong.

\section{A BERTINI}

I would like to clarify some of the points I made. On the question of costs, it is true the different contracts may give an indication of costs but the real costs can only be assessed on a real scale. However, since before selecting a particular technology you have to know where you are golng, I repeat that the question of the rules of the game with regard to waste management is of top priority. It is a matter completely outside the scope of this programme. But we cannot have, as in a certain legislation in a Member State, that you have some 'de minimis', let us call it 'limits', which are valid when you go uphill, but which are not valid when you go downhll; so that, if you do a certain activity, you can release materials contalning $3.7 \mathrm{~Bq} / \mathrm{g}$ of cobalt, but if you do other activities, you cannot! At this point, we do not know how to defend ourselves in front of the public.

\section{P TANGUY}

You touched upon a very important truth a short while ago, when you said that what may finally block an operation via a regulation is not so much the regulation itself, but the cost involved in carrying out the demonstration which has to be provided. We have quite recently had an example of this in France: EdF decided to anticipate the shutdown of one of its reactors; in a sense it was a safety-related decision. In fact, the power station was authorised to operate until April 1990. To gain the requested four-year extension the safety authorities told us, "The authorisation will be accorded, but you must first of all initiate a programme to demonstrate to us that the quality of the primary circuit plpework, after the inspections have been carried out, is in conformity with what we expect". When we attempted to assess the likely cost of that programme intended to demonstrate what we were already convinced of, ie that the installation was satisfactory from the safety standpoint, we discovered that we would at all events be forced to shut down the plant for a minimum of one year so that, of the four years of the extended authorisation, one would already be lost in advance. It was clear that the cost would be extremely high and the operation would also entall the usual type of discussions between the operators and the safety authorities. Ultimately, we preferred to abandon the ldea and to shut down the power station.

This 13 just one example; other countries could give more glaring examples. It shows that behind the safety criteria which, on the face of it, prompt one to say, "Oh, this is not unacceptable", there can be a perverse effect on the hidden cost of the consequences so that the whole operation is frustrated.

\section{H HÜBENTHAL}

The term 'acceptance' has been repeatedly used here, and I agree that It is absolutely crucial for us to demonstrate that decommissioning is 
feasible. I am personally convinced that we can do it as the Chairman has said, but we must also demonstrate it. We must bring this to a successful conclusion, there can be no giving up half-way or 908 of the way to our objective solely because we do not know what to do with the waste. There are two areas in connection with this demonstration in which the Commission can do something: one is the 'testing of new techniques under real conditions' or programme section $C$; the other is the establishment of reasonable 'de minimis' values, at least when the bases are being worked out. Another question, but one about which the Commission can certainly do nothing, is final disposal: a solution has to be found at national level.

I would like to make a further and somewhat provocative comment. The question of cost has repeatedly been addressed here. In my view, if we assume that acceptance is an essential prerequisite for the use of nuclear energy, then the question of the cost of decommissioning is almost irrelevant; Mr Bertini called the kWh a devisor, and there is no point in wishing to optimise the last 108 of the uncertainty that we have in respect of cost in the case of individual techniques if the prices vary by a factor of ten where final disposal is concerned, if the establishment of 'de minimis' values can increase or reduce the quantity of waste by almost the same order of magnitude, for these are open ends and it will be impossible for any R\&D programme to come up with solutions.

\section{A CREGUT}

The Panel seemed to consider that the reuse and release of decommissioning wastes had not been sufficiently dealt with. In fact, numerous studies concerning these topics have been performed within the framework of the EC decommissioning programme, and the Commission has issued recommendations concerning the 'de minimis' levels for metal wastes. May I also remind you that relevant papers on these topics have been presented during this Conference.

\section{P TANGUY}

Thank you for this additional information. I do not believe that it contradicts what has been said during the Panel's discussions, because proposals are not yet standards, particularly in the field of radiation protection. Going back to the discussions after Chernobyl, I have a personal recollection that what was finally published by the Commission had little in common with what the Commission's experts had advised. So I do believe, from that standpoint, that there is work still to be done. The subject is extremely important - and it seems to me that this has been firmly stated by the Commission - not so much from the standpoint of cost, but by virtue of the fact that dismantling operations cannot be properly organised on an industrial scale if there is lack of certainty regarding the problem of decommissioning. This can also be said of relations with the public; if we are not cautious, the public may finally reject nuclear energy as a solution for the future. The problems in getting rid of our installations may also result from poor understanding of the waste in question and the poor way in which it and its final storage are presented. The problem is a continuing one so the Commission programme covering joint work by the various countries and various bodies in order to attain a commuity in views which will finally enable European standards to be achieved, retains all its value. 
I represent the International Atomic Energy Agency in Vienna. Clearly, there is considerable convergence on a number of the issues that the Chairman put to the Panel, some of which are of particular interest to our organisation. I go along with the setting up of some common criteria or standards for radiation protection, in particular for unrestricted release, from decomissioned nuclear sites. On the question of public acceptance of waste management, including decomissioning, I would like to point out that at the IAEA we have set top priorities on these issues recently. If the Community comes up with a recommendation for any future work in this area it will be reflected positively in our work at the Agency. 



\section{CLOSING ADDRESS}

P TANGUY

Inspecteur Général pour la sareté Nucléalre Electricité de France

Directıon Générale, Paris, France

I will now bring the Conference to a close, since this is the last Session. At the preceding Conference, which was held in Luxembourg, the Final Panel was concluded with the following words: "Our research is interesting and must progress, but what has to be attained is credibility at industrial level and towards the safety authorities".

I believe that we have gone a long way towards attaining credibility at industrial level; as compared with my recollections of Luxembourg, I believe that we have indeed demonstrated the success of operations which are very significant from an industrial standpoint. Where the safety authorities and the safety regulations are concerned, I believe that there is obviously still something to be done. I was impressed this morning to hear talks which indicated that, before each operation, there had been discussions with the safety authorities. However, the objective for which everything lor almost everything) remains to be done is, I think, credibility in the eyes of the public.

If I take the situation in France, which is perhaps a special case, it must be said that developments in respect of nuclear installations, particularly power stations which have been shut down, do not concern the public to any great degree. It should be stressed that there is only a single nuclear operator, Electricite de France, which is a public operator, and that new nuclear installations have also been constructed and are in service on the same sites as the shut-down installations. This simplifies one of the problems of shutting installations down, which has nothing to do with the nuclear aspect, and that is the loss of revenue to the local population and, in particular, to the local administrations resulting from cessation of payment of a tax that we have in France, called the 'taxe professionnelle'. Money matters are not necessarily of no consequence from the public standpoint.

Thus, from the moment when the public understands that an installation which has been definitively shut down is much less dangerous than an operating power station, since the fuel has been removed and the operation to clean up radioactivity has considerably reduced its radioactive nuisance potential, it is not very concerned for the time being, whereas it is very concerned about radioactive waste. Mr Gillon said that the concerns were (1) the safety of nuclear power stations, and (2) radioactive waste; in France, it is the other way around: 87 of the French public, as has emerged from recent surveys, are worried about the storage of radioactive waste, while the figure in respect of the safety of power stations is less than 50. I therefore believe that the Commission has chosen the correct approach in its new 1989-93 programme. There has been general agreement that finance is not the essential point even though comunity financing is far from negligible. The essential point is really to work together to arrive at a consensus and to establish rules - let us, perhaps, not use the term 'standards', but the term 'reference frameworks' - within which everyone can work. I belleve that it has started well; I think that it is essential to achleve such regulatory credibility, at a later date, in the eyes of the public. 
On behalf of you all, I would like to thank the members of the Panel. since I am the last speaker, I would like to thank all those who organised this Conference, who participated in it, who presented papers and who chaired the sessions. I would like to thank you all for being so patient for such a long time. I now formally declare the Conference closed. 
AHLFÄNGER, $W ., 531$

ALARY, C., 139, 403

ALFILLE, J.P., 171

ALLIBERT, M. , 504

ANDERSSON, L., 497

ANTOINE, P., 554

AULER, I . 349

BACH, F-W., 229, 649, 680

BARRACLOUGH, I.M. , 395

BENAVIDES, E., 598

BENHAMOU, C., 107

BERTINI, A., 615

BEUKEIMANN, D., 51

BISHOP, A., 627

BOSANSKY, M., 43

BREGANI，F., 537

BRIGHTMAN, F.G. , 344

BRUNEL， G. , 579

BUCK, S., 798

CAILLOL, A., 379

CANDELIERI， T . , 149

CHAPUIS, A.M., 93, 755

COHEN, S., 107

COLQUHOUN, A., 798

CORNELISSEN, H.A.W., 731

COSTES, J.R., 356, 554, 738

CREGUT, A., 5

CROSSLEY, H. , 567

DA COSTA, D. , 356

DANCHEV, S., 43

DAVIS, J.P., 395

DAWSON, P. , 119

D'EER, A., 325

DEIPENAU, H. . 437

DELCHEVA, TS. , 43

de NORDWALL, H.J., 217

de SEROUX, N., 139

de TASSIGNY, C . 712, 738

DI FINO, M., 181

DRAULANS, J., 703

DREWS, P., 201

DUBOURG, M., 161

EBELING, $\boldsymbol{W}$. 659

ESSMANN, J., 20

ETTEMEYER, A. 482

FAJARDO, M., 598

FIELD， S.N. , 721

FINZI, S., 1
FISCHER, A., 258, 787

FLEISCHER, C.C., 119, 301

FOURNIE, J-L., 139

FREUND, H.U., 301

FUCHS, K., 201

GARBAY, H. , 755

GAROFALO, A., 537

GARREC, Ph., 171

GASC, B. , 191

GAUCHON, J.P. , 554

GAVRILOV, S. , 43

GERARDI , A., 149

GIBON, G., 504

GONNORD, J . , 171

GRAY, P. , 325

GREGORY, A.R., 5

HAAS, E.W. , 516

HAFERKAMP, H. , 279, 649

HARBECKE, $W ., 68$

HARKER, A.H., 291

HARRIS, W.K., 239

HARVEY, D.S . 473

HEBRANT, P. , 772

HELK, F. , 349

HERNBORG, G., 497

HERRMANNS, B., 321

HILLS, D.L . , 291

HLADKY, E., 43

HOFFMANN, R., 335

HOFMAN, M., 171

HOSHI, T., 818

HUBER, B. , 28

HUTH, R. , 51

IMBARD, G., 356

IN DER SCHMITTEN,., 386

JANBERG, K.G. , 765

JAOUEN, C . , 449

JEANJACQUES, M., 191

JOUAN, A., 808

JULL, S.P., 721

КОСН, С., 738

KOUTSOYANNOPOULOS, C., 325

KREMNEV, V., 43

KURKA, G., 504

LAVERIE, M., 13

LEAUTIER, R., 208, 666

LEIDENBERGER， B. , 335

LORIN, C . , 264 

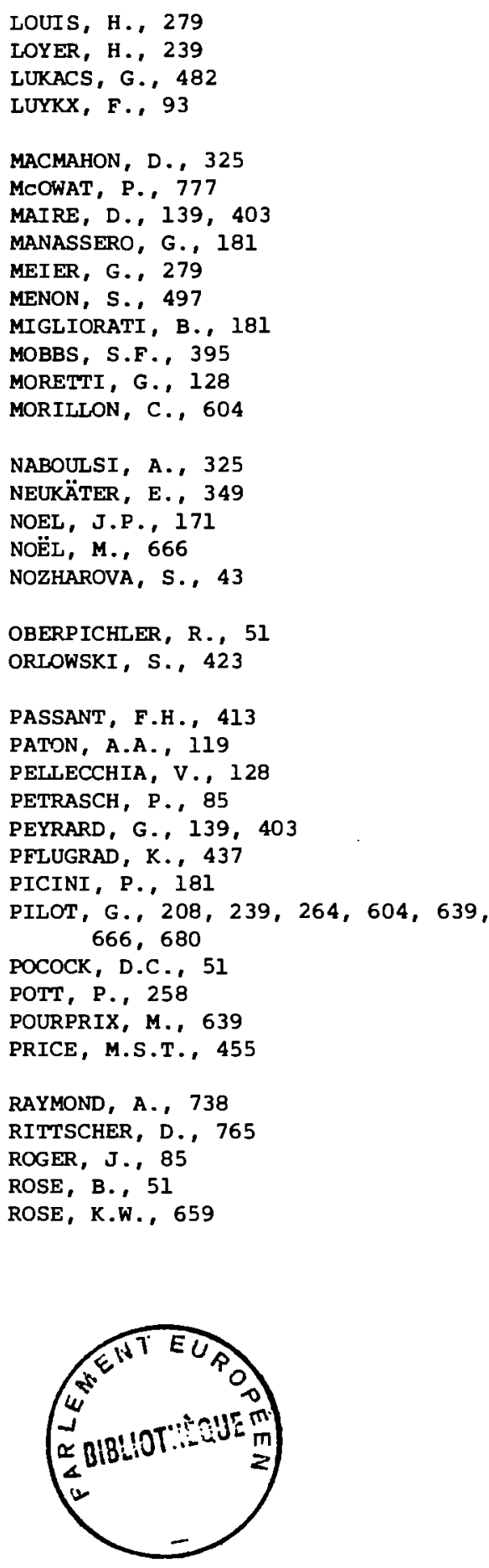

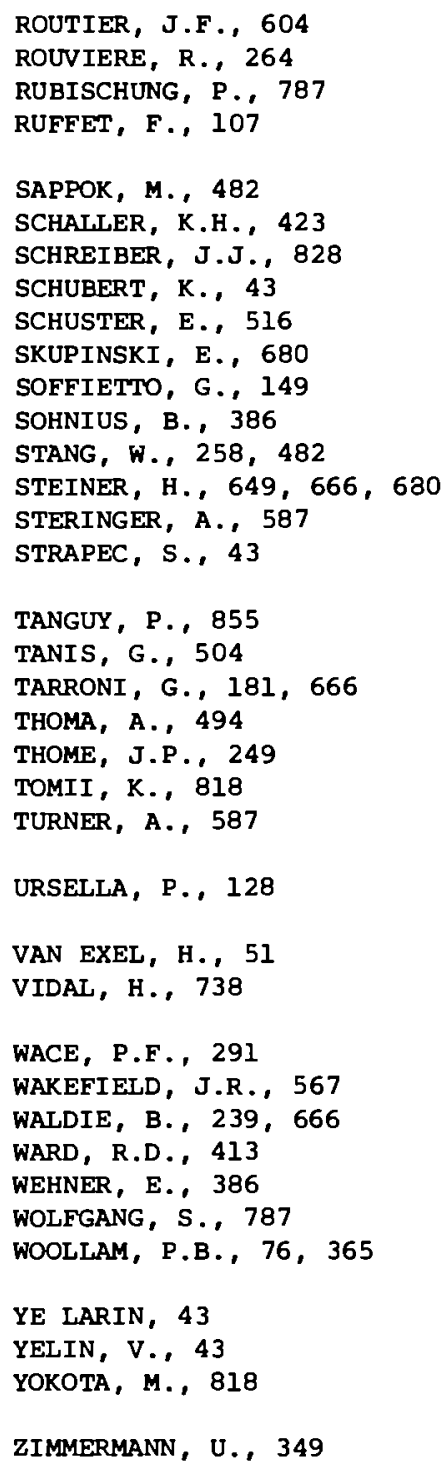



. 





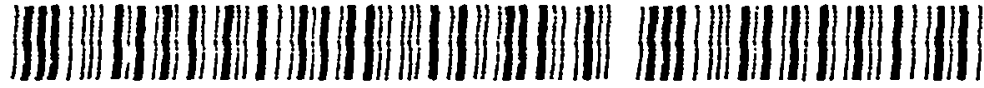


The European Community $(\mathrm{EC})$ is conducting research on the decommissioning of nuclear installations with the prime objective of developing effective techniques and procedures to ensure the protection of man and his environment against the potential hazards of niuclear installations that have been finally shut down.

This book contains the results of the 1984-1988 fiveyear programme of research on the decommissioning of nuclear power plants which were presented at the International Conference on the Decommissioning of Nuclear Installations, held at the Palais des Congrès, Brussels, Belgium, 24-27 October 1989. The programme extended to all types of installations of the nuclear fuel cycle and produced numerous scientific and technical achievements, some of which have already been tested on an industrial scale. Great progress has in particular been achieved in the reduction of metal waste arising from decommissioning, due to advances in areas such as aggressive decontamination procedures and techniques for melting and recycling low-level radioactive waste metal.

Decommissioning of Nuclear Installations will be of specific interest to those in the nuclear, reliability, safety, mechanical and structural engineering industries. 